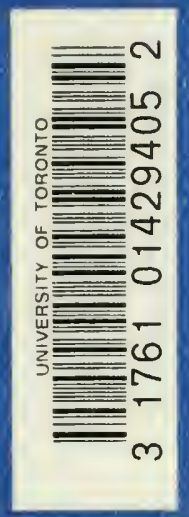

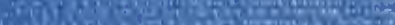

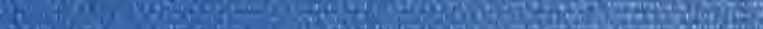
Q3.

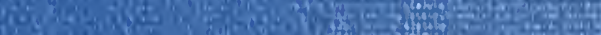

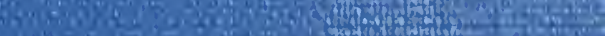
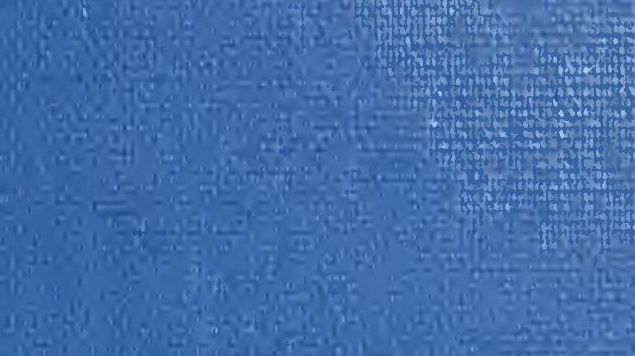
$$
\text { . }
$$ 
Digitized by the Internet Archive in 2008 with funding from Microsoft Corporation 
EUROPEAN THOLGHT IN THE NINETEETTH CENTURY 


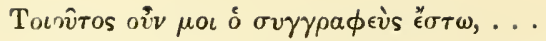

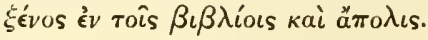

-Lucian. 


\title{
A HISTORY
}

\author{
OF
}

\section{E UROPEAN THOUGHT}

IN TIIE

\section{NINETEENTH CENTURY}

BY

JOHN THEOLORE MEL\%

VOL. II.

WILLAAM BLACKWOOD ANI) S(IN)

EIDXBURGH AND LONDUN

M C.MI I I 


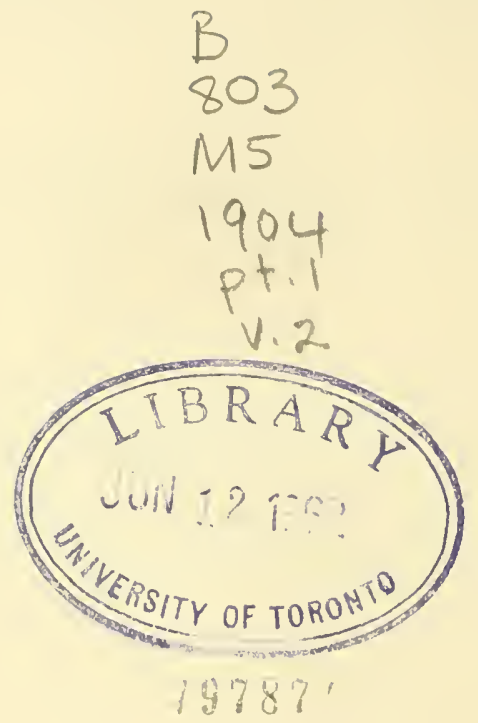




\section{PREFA CE.}

Is this second volume I have carried ont the programme which I put forward in the preface to the first volume, thus finishing the first portion of my undertaking-The Listory of Scientific Thought in the Nineteenth Century. The two volumes form a work complete in itself, and for this reason I have attached an alphabetical index.

In addition to the names I mentioned in the preface to the first volume, I have to add those of other friends who have been of great help to me in the course of my work. With Professor Sampson, F.R.S., of 1)urham University, I have had many helpful discussions on the subjects of this volume, notably on chapters viii. and xiii., which he read in proof. Mr Arthur Berry, M.... of King's College, Cambridge, has read over chapuer. xiii., and made valuable suggestions. Mr Archibald s. Tercival, M.B., of Cambridge, has read over chapters vi. and x. Professor F. G. Weiss, 1).Sc., of Victoria University, has read chapters viii. and ix. Mr. 'Thomas Whittaker has continued his revision, mueh to the lunetit of the book; and Dr Spence Watson has given the finishing 
touches to the last pages, in which I endeavour to secure in advance the interest of $m y$ readers for the subsequent portions of this work. To all these friends I wish to express my sense of obligation and my sincere thanks. I find it impossible to express how much this book owes to my beloved wife, my constant helpmate on the long course of this arduous enterprise.

It is unnecessary for me to lighten the work of $m y$ critics by pointing out the many defects of which I myself am painfully conscious; but, in the case of the last chapter on "The Development of Mathematical Thought," I wish to say that this is-so far as I know-the first attempt to give to this abstract region of thought a place in a general history of intellectual progress. I sincerely hope that it will be followed by other and more successful attempts to perform this very difficult task. It is now abundantly clear that mathematical thought will play an increasingly important part in the progress of science and culture, and it is no longer permissible to consider it merely an interesting specialty apart from the general course of intellectual development. A due appreciation of its importance and power will in future be expected, not only from the practical thinker who applies science, but likewise from the philosopher who assigns to science its place in the comprehensive scheme of human culture.

J. THEO. MERZ.

THE QUaRries,

Temcastle-cros-Trine, October 1903. 


\title{
CONTENTS OF 'THE SECOND TOL,UE.
}

\author{
CHAPTER VI. \\ ON THE KINETIC OR MECHAXICAL VIEW OF NATLRI:
}

The idea of motion in ancient philosophy; 3 ; Jescartes' development of the kinetie view, 6 ; Huygens and Yewton, 7 ; Revival of the kiueric virw in the nineteenth century, 7 ; Young aud Fresnel, 8 ; Undultwry and emission theories, 11 ; Both theories kinetic, 11 ; Indulntury thery prepared by acousties, 12 ; Newtmn's authority on the sille wi the enis in theory, 14; But also suggests the other theory, 15; bioh, lirwwin, and Laplace against the undulatory theory, 16 ; Euler the sucumor if Huygens, 16 ; Young, 16; His "general law of the inferierenc" if light," 18 ; Theory of the luminiferous ether, 18 ; Brougham's attack in Young, 19; Augustin Fresnel, 21 ; Diflieulties presented by 2 he lw $^{\text {th }}$, isation of light, 22; Fresnel's Memoir on Diflration, 25: linng and Fresnel introduce the eonception of transwerse vibrations, 24: Yhe I wh i. eal difference between light and sound, 30 ; The properties of the ether. 31 ; Other kinetie theories, 34; Kinetic theory of gases, 34: Vinte motion, 35 ; Faraday's researches, 35; Problems us to the nature if the ether, 36 ; The theory of elasticity, 10 ; The problem of the ether shy be treated mathematically, 11; or experinentally, H: New-if? at combining the two methods, 44 ; Spectrum analysin, 15: The tre furnisherl by the phenourena on which it depersds, 17 : sir 6 . sithe. 47 ; Gustav Kirehhofl, 48; Explanation of thumesonce, iz: : View of the

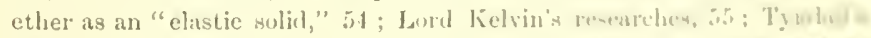

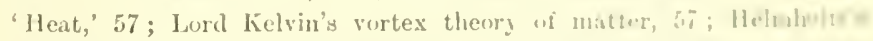
investigations, 58; barlier resenrehes on vorts motion, iil : Influem

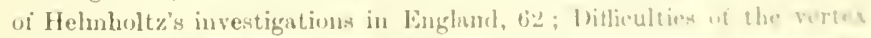
ring theory, 64; Hodern view of electrienal phemmens: liarday, it. 
"Lines of force," 68; Development of the conception by Lord Kelvin, 71 ; Clerk-Maxwell, 76; His series of works on the theory of electricity, 78 ; His conception of "tubes of force," 80 ; "Electrotonic state" of matter, 81 ; Correspondence between velocities of light and electricity, 84 ; "Elastic disturbances" of the same medium, 85 ; Consequences on the lines of the theory of Energy, 87; Destructive effect of the new theories on the astronomical view, 89 ; Lord Kelvin on the vibrations of the ether, 91 ; Indefiniteness of the electro-magnetic theory, 93.

\section{CHAPTER VII.}

\section{ON THE PHYSICAL VIEW OF NATURE.}

Recapitulation, 95; Insufficiency of the astronomical, atomic, and kinetic views, 96 ; The conception of energy, 96; The term first used by Young, 98 ; Watt introduces the term "power," 99; Poncelet introduces the term "mechanical work," 101 ; Black, Rumford, and Davy, 102 ; Correlation of forces, 105; Liebig, 105; Johannes Müller, 106; F. Mohr, 107 ; Mayer, 108 ; Joule, 110 ; Helmholtz, 112 ; "Work" and "energy" introduced by Clausius and Thomson, 115 ; Sadi Carnot, 117 ; Carnot introduces the idea of "availability," 119 ; Thomson introduces the idea of "dissipation," 119; Fourier, 120 ; His influence on Carnot, 122 ; Clapeyron's graphical method, 123 ; Perpetual motion impossible, 124 ; Application by William and James Thomson, 126; The two laws of thermodynamics, 128 ; Summary statement of Thomson (Lord Kelvin), 132 ; Rankine, Zeuner, and Hirn, 133 ; Revolutions brought about by idea of energy, 137; Helmholtz on "tension," 138; "Potential" and "actual" energy, 139; The Scotch school, 141; Thomson and Tait, 144 ; Clerk-Maxwell, 145; Faraday, 146 ; Helmholtz on electro-dynamics, 149; Ostwald's physical chemistry, 153; The factor of "cost" in industry, 155 ; Berthelot and Ostwald, 157 ; Arrhenius, 159 ; Graham and Andrews, 161; Dissociation, 163; Hittorf and Kohlrausch, 164; Victor Meyer on change of chemical views, 165 ; Ostwald's jourual, 166 ; Willard Gibbs, 167 ; Entropy, 169 ; Horstmann, 170; Helmholtz's "free energy," 173; Kelvin's "available energy," 174; Ostwald's 'Allgemeine Chemie,' 176 ; "Kinetics" and "energetics," 180 ; Criticism of mechanical view, 183; The outcome, 187 ; Recent triumphs of atomic view, 188; Modern electrical researches, 189; The term "electron," 193; Diffculties of Clerk-Maxwell's theory, 194; What are electric charges? 195; Dr Larmor's position, 195; Objections raised by atomists, 198 ; Artificial character of modern dynamical explanations, 199; The philosophic problem raised, 199. 


\section{CHAPTER VIII.}

\section{ON THE MORPHOLOGICAL VIEW OF NATCRE.}

The abstraet seiences, 200 ; Convenience and usefulness of the process of abstraction, 201; Interest opposed to the spirit of abstraction, 202: The deseriptive sciences, 203; The breaking down of oll lanrlwarks, 204 ; The spirit of exploration, 206 ; The merlieal interest, 207 ; l'hysical science applied to medicine, 208 ; Schwam, 209; Darwin, 209 ; 11 erbert Spencer, 210; Whewell's divisions abandoned, 210; Divisions of natural history, 211; Morphology and geneties, 213; Other aspects, 215; Life and mind, 216; Vitalistic and psycho-physieal aspects, 218 ; Morploblogy defined, 219 ; Artificial and natural systems, 220; Limous ancl Buffon, 221 ; Morphology of erystals, 222; Morphology on a large scale, 221; Humboldt, 225; Morphology on a minute seale, 227 ; Its improvement, 230 ; Morphology and elassification, 231; Study of separate organs, 233 ; Outdoor studies, 231; Jussieu, 235; Problem of orgunisation, 236 ; Cuvier, 237 ; "Types," 238 ; De Candılle, 239 ; Regularity and symmetry, 241 ; Goethe's metamorphosis, 243; 'The ideal type, 245; 1'alcontology, 247 ; Cuvier's catastrophism, 250 ; Study of analogies, 250 ; Geoffroy Saint-Hilaire, 253 ; Cuvier and Geoffroy, 255 : Richard Owen, 257 ; Study of homology, 258; The cellular theory, 260; Hugo von Moll, 262; Sehleiden and Schwann, 263; Transition to the study of development, 264; Affinity, 267; Insufficiency of the morphological view, 270; Herbert Spencer's "physiological units," 272; Change of scientific interests, 273 ; The morphological period, 274.

\section{CHAPTER IX.}

\section{ON THE GENETIC VIEW OF NATURE.}

Statics and dymamies of living forms, 276; "Evolution," 278 ; "Genesis," 279 ; Leibniz's 'Protogan,' 280 ; Kant's nebular theory, 252 ; Laplace, 281 ; "Cyelical" view, 286; Supplanted by genetic view, 290; Geology, 290 ; Hutton, 292 ; Lyell, 293 ; Embryology, 296 ; Epigenesis and evolution, 29s; C. F. Wolff, 298; Pander and K. E. von Baer, 299; V'on Baer's comprehensive views, 302 ; Von Baer's views in modern terms; 306 ; Phylotaxy and phylogenesis, 308; Lamarek, 309; The term "Biology," 312 ; "Environment," 314; The "Natur-philosophie," 315; Lamarck and Von Baer, 316; 'The 'Vestiges,' 31S; Popular influence, 320 ; Genetic view in Germany and Franee, 321 ; Apologetic literature in England, 324; Mansel and Darwin, 326; 'Triumph of the grenetic view, 328; Humboldt's 'Kosmos' and the 'Origin of Species,' 329; 
"Variation," 331 ; Malthus, 332 ; "Struggle for existence," 333 ; Outdoor studies, 334; "Natural selection" and "sexual selection," 336 ; Jeaning of natural classification, 336; Fertilisatiou of plants and "Mimicry," 338; The judicial methorl, 339; Darwin and Newton compared, 341: Unsolved problems, 343; Genetic view on a large scale, 345 ; Philosophical theories, 346 ; Herbert Spencer, 346 ; Haeckel, 347 ; Combines Darwin and Lamarck, 350 : Philosophical problems, 352 ; Problem of life, 352 ; Genetic view strengthened by physics and chemistry, 355; The lieat of the sun, 357 ; Spectrum Analysis, 359 ; Geuesis of the cosmos-Faye and Lockyer, 360; Palæontology and geophysics, 363; Dissipation of energy, 364; Mystery of the actual processes of Nature, 366.

\section{CHAPTER $X$.}

\section{ON THE VITALISTIC VIEW OF NATURE.}

The cosmical and the terrestrial riews, 369 ; Vagueness of biological theories, 370 ; Impossibility of prediction, 372; Oscillation of biological thought, 374; The unknown factor, 375 ; The purely scientific aspect, 377 ; Influence of medicine, 379; Practice urges the question: What is life? 381 ; Bichat, 381 ; His Vitalism, 383 ; His definition of life, 383 ; Vitalism and Darwiuism, 386; The extreme vitalism, 388; Attack from the side of clemistry, 389 ; Change in organic chemistry, 393 ; Influence of Liebig, 394; "Stoffwechsel" and "Kreislauf des Lebens," 395 ; "Autonomy of the Cell," 395; "Division of Physiological Labour," 396 ; Johannes Müller, 397 ; Influence of doctrine of energy, 399 ; Mechanism, 399 ; Lotze and Du Bois-Reymond, 401 ; Liebig's vitalism, 405; Darwin, 406 ; Lotze and Claude Bernard, 409 ; Darwinism and final causes, 411 ; "Natural result" against "purpose," 413; Organisation aud individuation, 415; Biology and economics, 415; The cellular theory, 417; Schwann, 419 ; Circulation of matter and energy, 420 ; "Netabolism," 422 ; Structural analysis of morphological elements, 423; Synthesis of organic substances, 425; The "physical" method, 428; Properties of the liring substance, 429 ; Environment, 430 ; The "internal medium," 432; Natural selection within the organism, 435; Mobility of living matter, 438; Anabolism and Catabolism, 442; Reproduction, 443; The protoplasmic theory, 444; Spencer's law of limit of growth, 445 ; Fusion of two elements, 446; New problems, 448; Weismaun on heredity, 450 ; Biogenesis, 451; The ubiquity of life, 452; The continuity of living forms, 453 ; "Pangenesis," 454 ; Germ-substance and body-substance, 457 ; Germ-plasma and body-plasma, 458; Differentiation of germplasma, 459 ; Weismann $v$. Lamarck, 460 ; Two aspects of the problem of life, 462 ; Transition to psycho-physics, 464. 


\section{CHAPTER XI.}

ON TIE I'SYCHO-PIYSICAL VIEW OF NATUIE.

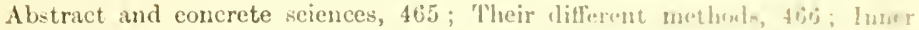
experience, 468; Psycho-physics, 469; C'absunis' simile, t70; l'repurel by Loeke and Haller, 471 ; Berkeley's 'Theory' wi Vi sum, 172; J'orn ubl

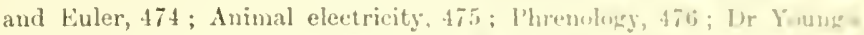

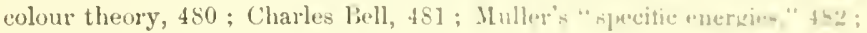

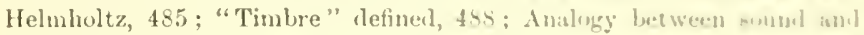
colour, 459; Helmholt\% and Kant, 491; The brother. Wiphr. 442: Fechner's Psyeho-physics, 193; Intluence of Herburt, 191; Hin atcuk on the "faculty-psychology," 495 ; Unity of mental life, 140 ; Marluematical psyehology, 498; Jotze's physiulogy of the soul, 500 ; Twu sicho of Irotze's doctrine, 502; 'l'he pisycho-pluysics of visiom, 501: Wherat stone's stereoseope, 505 ; Loealisation of sensations, 507: Latze's "Ix: 1

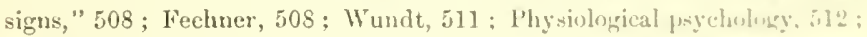
Wundt, Fechuer, and Lotze compared, 5l5; 'The unity of cmacin-men516; Doctrine of parallelisu, 518; Minsterberg, 521: Phenomemon if centralisation, 524; Externalisation and growth of minI, 525: Windin treatment of central problem, 525; Introspective methel, 527: The "objective miud," 529; Its study prepared by Herder, 5i31: Hz 'History of Mankind,' 534; Separation of natural and meutil -ciencm, 534; The problem of language, 536: 'The exact treatment, 535: Phonetics, 539; The dividing line between man and l,rute, 511: خummary, 543 ; The three facts impressed by 1sycho-phyrics, 545 ; 'Trums. tion to statistics, 546.

\section{CHAPTER X゙II.}

ON THE STATISTICAL VIEW OF NATLRF.

Life and Mind as liuiting conceptions, 5.48; Results of absatuct reience, 5.50 ; Uncertainty in the conerete, 552 : Sicientific spurit in busines, 55.3 ; 'The

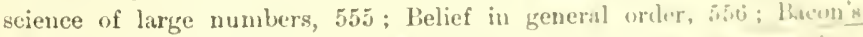
"Method of Instances," 557 ; Cieneral ulea underlying mumpration, 561 ; Doetrine of averages, 561 ; Statistics in livance, (iemmuny, mul

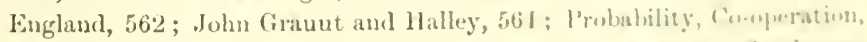

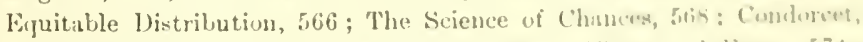
570 ; Laplace, 572: Fur applications, 57t; 'Thwory wi krow, 574:

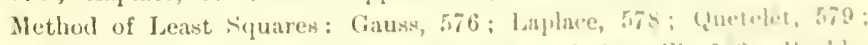

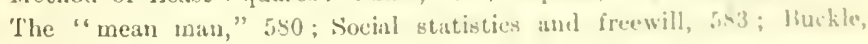


584; Criticism of preteusion of statistics, 586; Historical criticism, 588; Application in physics, 589; Clausius and Clerk- MIaxwell, 590; Mathematical representation of experimental laws, 592; Irreversibility of vatural processes, 593 ; Lord Kelvin, 594 ; "Availability" a theorem in probability, 597; "Selection" as conceived by Clerk-Maxwell, 598; Statistical knowledge of nature, 600; As opposed to historical and mechanical knowledge, 603; Sameness and variation, 607; Darwin, 608 ; Galtou, 609 ; "Pangenesis," 610; Lends itself to statistical treatment, 611; Problem of Heredity, 613; Mr Bateson's historical treatment, 615; "Particulate" descent, 615; Application of theory of error, 618; Difference in application to living and lifeless units, 620 ; Professor Pearson: The mathematical problem, 621; Statistical knowledge one-sided, 624; Critical methods, 626; The instrument of exact research, 626 .

\section{CHAPTER XIII.}

\section{ON THE DEVELOPHENT OF MATHEMATICAL THOUGHT DURING} THE NINETEENTH CENTURY.

History of thought, 627 ; Difference between thought and knowledge, 628 ; Popular prejudices regarding mathematics, 628 ; Use of mathematics, 630 ; Twofold interest in mathematies, 632; Origin of mathematicr, 634 ; Gauss, 636 ; Cauchy, 636 ; Process of generalisation, 638 ; Inverse operations, 639; Modern terms indicative of modern thought, 643; Complex quantities, 644; The continuous, 644; The infinite, 644; Doctrine of series: Gauss, 645; Cauchy's Analysis, 647 ; Revision of fundamentals, 649; Extension of conception of number, 650; The geometrical aud the logical problems, 651 ; Quaternions, 654 ; Foundations of geometry, 656; Descriptive geometry, 658; Poncelet, 659; Character of modern geometry, 662; Method of projection, 663; Law of continuity, 664; Ideal elements, 664; Priuciple of duality, 665; Reciprocity, 666; Steiner, 667; Mutual influence of metrical and projective geometry, 668; Plücker, Chasles, Cayley, 671; Historical and logical foundations, 671 ; Generalised co-ordinates, 673 ; Ideal elements, 674 ; Invariants, 676 ; Theory of forms, 678 ; Theory of numbers, 680 ; Symmetry, 681 ; Determinants, 682 ; Calculus of operations, 684 ; Principle of substitution, 686 ; General solution of equations, 687 ; Theory of groups, 689 ; Continuous and discontinuous groups, 691; Theory of functions, 693; Plyysical analogies, 696; The potential, 698; Riemann, 700 ; Weierstrass, 702 ; Riemann and Weierstrass compared, 707 ; Examination of foundations, 709; Non-Euclidean geometry, 712; Curva- 
ture of space, 715; Generalised conceptions, 717 ; Klein's expunition, 718; Sophus Lie, 719; 'Theory of numbers, 721; (iaus's thary of congruences, 723; Generalived conception of number, 720; Prucens of inversion, 727; Kummer's irleal numbers, 728; Holcrn algw bra, 731); Agebraical and transcendental numbers, 730 ; Counting and measuring, 732; Georg Cantor's theory of the transfinite, 735; Correspondene, 736 ; Arithuetising tendency in mathematics, 738.

\section{RETROSPECT AND PROSPECT.}

Order and Lnity, 742; Philosophical problems, 743; Individuality, 710; Practica! interests attaching to Order and Cuity, 7.18; The geografhical ceutre of philosophie thought, 750 .

IYDEX 



\section{E R R A T A.}

P.

47 ; text, 1. 4 from below

48 ; 2nd col. of notes, 1.8 from below I Read Miller insterd of Millar.

100 ; 2nd col. of notes, 1. 10 from below

101 ; 2nd col. of notes, 1.2 from below $\{$ Read Chasles instead of Charles.

361 ; 1st col. of notes, 1. 5 from above. Read Secchi instcad of Seechi,

407 ; 2nd col. of notes, last word.$\{$ Read C. Hauptmanu instead of

572 ; text, 1. 5 from above . . . . Read Stirling instead of Sterling. 



\section{CHAPTER VI.}

ON THE RINETIC OR MECHANICAL VIEW OF VATULE.

IT was a favourite illea with the philosophers of antiquity that everything is in motion, that rest is to he fommol mution in ancivent nowhere in nature, and that the entire process of life and philosopby: sensation in particular is lrought abont by the communication and transferenee of minute movements of a jurely mechanieal kind. Ont of the deep convietion that everything aromed us and in us is in a perpetual flux-il doetrine which is usually fathered upon Heraclitus of Eyhesus ${ }^{1}$ - two distinct problems resulted, and oecupied the thinkers of antiquity: the problem of explaining the aplarent rest and permaneney of many observable pheno-

1 The doctrine of Heraclitus (B.c. 500 ; is placed by Zeller ("Philosophie der Griechen,' vol. i.) in direct opposition to that of the Eleatic S'chool (Parmenicles, Zeno) and of Pythagoras. The Eleatics argued from the unity of all exist. ence to the impossibility of the multiplieity and the change of things. Heraclitus sets out from the conception that everything is in continual

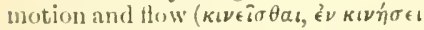
€lvas). Our knowledge of Heraclitus is derived mainly from references in the writings of l'lato and Aristotle. A very full account is given hy Zeller, and by E. Pfleiderer ("Die lhilosoplie des Heraklit von Ephesus,' Berlin, 1856), who sums uj) the fundamental idea in the beautiful verses of (ivethe (iedichte, "Eins und Alles" ") :-

"Und umzuschatten das Geschallie Danit sicls's nichet zum starèn watlue, Wirkt ewiges, lebendises 'Thun.

Und was niclit war, nun will es werden, Zul reimen Sonnen, farbigen Lirleu. In keinem Falle dart es rulun.

Es soll sicl regen, schatfend liandeln, Irst sich gestalten, dann verwarullen: Nur selieinlur stuht's Momente wtill. Dhts liwige regt sich fort in Allen: len Alles muss in Nichts zellallen, Wonn es im tein Jiclarren will." 
mena and properties of natural objects, and the higher ethical problem of fixing upon that which is lastingly real and important in the continuous change of sensation and opinion. The latter formed the central interest of that course of reasoning which began with Socrates and culminated in Plato and Aristotle: the former was the problem of natural philosophy of which Epicurus and Lucretius stand out as the great representatives. In a well-known passage of the second book of his great poem, Lucretius explains the apparent rest of natural things by the simile of a flock of lustily dancing sheep, which at a distance looks like a white spot on a green hillside. ${ }^{1}$ This tendency of philosophic reasoning to see motion where common-sense only sees rest, to reduce theoretically the apparently permanent properties of things to a play of intricate but imperceptible modes of motion, has governed still more markedly modern scientific thonght. I shall comprise all efforts to give more definite ${ }^{2}$ expression to this general idea under

1 'De Natura Rerum,' ii. 308-

"Illud in his rebus non est mirabile, quare,

Omnia cum rerum primordia sint in motu,

Sumna tamen summa videatur stare quiete,

Præterquam siquid proprio dat corpore motus.

Omuis enim louge nostris ab sensibus infra

Primorum natura jacet ; quapropter, nbi ipsa

Cernere jam nequeas, motus quoque surpere debent ;

Præsertim cum, quæ possimus cernere, celent

Sxpe tamen motus spatio diducta locorum.

Nam sæe in colli tondentes pabula læta

Lanigeræ reptant pecudes qno quamque vocantes

Invitarit herbæ gemmantes rore recenti,

Et satiati agni ludunt blandeque coruscant;
Omnia qua nobis longe confusa videntur Et velut in viridi candor consistere colli."

2 This more definite expression is entirely a question of mathematics. It is interesting to note how Le riage, in his 'Lucrèce Neutonien' (Berlin Acad.. 1782), "argues that if Enicurus had had but a part of the geometrical knowledge of his contemporary Euclid, and conceptions of cosmography the same as those of many then living, he might have discovered the laws of universal gravity, and not only the laws, but, what was the despair of Newton, its mechanical cause" (Munro, 'Lucretius,' vol. ii. p. 135). Lionardo da Vinei (1452-1519) says : 
the name of the kinetie theory ol vicew of matmles. It has frequently been placed in opposition to the atomic theory, and the history of the nitural pliblosmpliy of the arlier ages, down to Newton, lus in recent voals lecen written from this point of view. ${ }^{2}$ If crerything is motion, there must still be something that moves, and the yuestion arises, IVlat is it that moves? 'Mhe system of Fyiemus, and the great poem in which it lias found a classical expression, are really more ocenpied with describing the final elements of matter-the so-callerl nature of things - than with studying the different morles of their motion. In the atomic theory, in the conception of an infinite number of moving partieles, the kinetic tendency of thought repeatedly formel lontl in ancient

"There is no certainty in science where some mathematies are not applicable" (quoted by Lasswitz, 'Gesehiehte der Atomistik,' 1890, vol. ii. p. 11) ; and Leibniz, in a letter to Foucher rlated 1693, con. demns his arlier tract entitled "Ifypothesis Phy'ica 'as a " jusenile attempt of one who har not yet fathomed mathematies" (Gierhardt's edition of Leibniz's 'Philosophische 'schrilten,' vol. i. [1. 415).

1 The word "kinetie" seens to have beeu introrluced iuto scientific literature by Ampère, who uses the term "einématique" to denote that portion of mechanics where "les mouvements sont cousidérós en euxmênes, tels que nous les observons dans les corps qui nous environnent, et spécislement daus les appareils appelés machines" ("Essai sur la l'hilosophie des Seiences,' 18:34\% In Euglish text-bowks the term kinematies, following 'Thomson and 'T'ait (' Natural l'hilosophy', Preface), is used to denote whit Fencll writers call "cimématique pure," formerly ealled "phoronomie," the doctrine of the purely geometrical properties of motion, without reference to the cause of motion; the consideration of the latter being the special stucly of "kimetics," whieh, together with "staties," is comprised in the term "dynamies." The aceeptace "1 the word "kinetie" to denote the view that motion is at the bottom of all natural proesses dates probably from the writings of 'Thomson (Lord Kelvin), Tait, and Clerk Maxwell, who, uncler the intluence of Newton and the great linench schoul of Lagrange, Anprere, Poinsot, l'neelet, and others, have reformed English, and subsepuently also (iemman, thought and nomenclature in these subjects.

2 I refer to the highly interesting aml important work of l'rolessol Kmol Lasswit/, "(ieschichte der Atumistik mon Mitlelalter lis Newton,' 2 vols., Hamburg แnl Leipzig, I $\$ 90$. 
and modern times a convenient resting-place; but the repose which it afforded has never been long enjoyed; every new attempt to attach permanent, ultimate, or intrinsic properties to matter, or to its particles, has provoked the desire to explain these properties by going still farther back, and to see in them, through the dissecting microscope of the mind's eye, a still more hidden motion. Two of the most suggestive ideas by which physical science has benefited in the nineteenth century are the successful explanation of the dead pressure of gases by a rapid translational, and of the rigidity of solid bodies by a rapid rotational, motion of matter. The second of these suggestions is far from being exhausted in its capabilities; the working out of the ultimate problems which it suggests will be one of the principal tasks of the coming age.

Descartes' development of the kinetic view.

The kinetic view of nature, however useful and suggestive it may have shown itself to be in recent times, did not yield any fruits of real knowledge either in the hands of the ancients or even in those of the first great philosopher of modern times, in those of Descartes. Just like attraction and atomism, the linetic theory had to be worked out by the instruments of measurement and calculation, by the exact method, before it led to any actual results. The kinetic view of nature was made scientifically possible when Newton, in the First Book of the 'Principia,' laid down for all time the laws of motion. And yet we can hardly say that Newton himself developed this promising vein of exploration; for, even while opening out an endless vista of research, he also, in the enumciation of the so-called law of gravitation, afforded only 
one of those convenient resting-places, those preliminury or provisional bases of thought, from which definite pretrlens conld be attackerl and solved. His immediatt. intluence lay, therefore, rather in discomntenancing thr attempts towarils a kinetic view of natme, which helongred to the sehool of Descartes, and found an eminent exponent in Huygens as well as in others of his contemporaries ancl. rivals: ${ }^{1}$ in fact, he launched into existence what I lave 11 ingant. termed the astronomical view of nature, mnder the sway of which the promising beginnings of the kinetic view were for a long period almost forgotten, but which has the merit of having built up the most perfect of all physical seiences, namely, physical astronomy.

The sporadic beginnings of a gremuine kinetic view of natural phenomena, after having been cultivated with more or less suecess by Huygens and linler, ${ }^{2}$ and early Revival of the kinetic viens in the nimetwonth century.

1 Among these, of whom Lasswit\% gives an exhaustive account, must be mentioned specially Rubert Hooke (1635-1703). "In the history of the corpuscular theory Howke represents quite an originil iclea, which would have been of the most far-reaching importance if Hooke himself hat got beyond a mere sketch to an exhaustive theory, or if his conceptions harl, through Hurgens' principles of dynamics. been rlomiciled in science. The (leviation from kinetic theories caused by Newton's discoveries brusherl away, with mueh useless hypothetical rubbish, likewise Hooke's more valuable and legitimate suggestions. The doctrine owing to which we place Hooke between borelli and Huygens is his vibratury theory of matier. It is glven in varions writings, but most clearly in his lectures "] lo Potentia Restitutiva, or of spring explaining the Power of Springing Bulies, London, 167s" (op. cit., vol. ii. 1). $3298 \% \cdot 1$

2 Leonhard Euler (1707-s3), one of the greatest amalytical talents of all times, whose writings contain the beginnings of a very large portion of subsequent mathematical work in pure and applied science, was in pliysice a great opponent of Newtun's philosophy as it was then generally expounderl on the continent of Burope. There it was identified in mechanics with the theory of action at a distance, ancl, in optics, with the corpuscular theory of light. Ti, both Euler opposerl his eth"r theory, of which he gave a popular" accomnt in his celeloratel 'Lettres it une princesse d'Allemagne [l'rincess of Anhalt - Dessinu] sur quelyues sujets de physique et de phileso. plie ' (Peteriburg, 1763-7:2, 3 purts). He hal given a scientitic exposi- 
Young and in the nineteenth century by Rumford and Young, were united into a consistent physical theory by Augustin Fresnel, who has been termed the Newton of optics, and who consistently, and all but completely, worked out one great example of this kind of reasoning. He has the glory of having not only established the undulatory theory of light on a firm foundation, but still more of having impressed natural philosophers with the importance of studying the laws of regular vibratory motion and the phenomena of periodicity in the most general manner. His work was carried through, as was that of Newton, by a combination of observation, measurement, and calculation; of experimental skill with mathematical ability.

tion of the same twenty-five years before in his Berlin memoir, "Sur la lumière et les couleurs" (1745). Euler was as much opposed to Descartes' and Leibniz's views as he was to those of Newton, and though he almits having forerunners, he hardly refers to the principal one, viz., Huygens, whose well-known and useful principle he absolutely ignores. In fact, in spite of his great name and reputation, his ideas on the ether as continuously filling space, and his attempts to explain the plienomena of light, heat, magnetism, and even gravitation by meaus of this continuum remained isolated, and had hardly any influence on physical science. His great friend and correspondent, Daniel Bernoulli, remained a firm believer in action at a distance, andi thought Euler had put forward his hypotheses with too much assurance. It is, nevertheless, remarkable how closely the terms in which Euler, in his posthumous work 'Anleitung zur Naturlehre' (edited by the Petersburg Academy in the second volume of the "Opera posthuma . . anno 1844 detecta," 1862), describes his ether as continuously filling empty space and existing in a strained (gewaltsam) condition, agree with quite modern ideas on the subject. Accordiugly Euler's ether theory has in recent times been studied again by several writers abroad, of whom 1 will only mention E. Cherbuliez, 'Ueber einige plysikalische Arbeiten Eulers' (Bern, 1872) ; F. Rosenberger, "Die Geschichte der Physik' (vol. ii., 1884, p. 333 sqq.); C. Isenkrahe in 'Zeitschrift für Mathematik und Physik' (Hist. Lit. Abth., vol. xxvi.) and 'Abhandlungen zur Geschichte der Mathematik,' vi.; and E. Miething, 'L. Eulers Lelıre vom Aether' (Berlin, 1894). The first-mentioned author tries to answer the question why Euler's ideas remained so isolated. He says (p. 49): "If we combiue the results of Huygens' and Euler's investigations, we see that in the 'fifties of the eighteenth century the undulatory system formed a largely dereloped scientific doctrine. ... 
There is not, indeed, to be found in Fresnel's work any central and simple formula-like the gravitation formulis of Newton-out of which everything else flows with mathematical necessity. His work lay rather in combining a number of frutful surgrestions thown out hy contempolary or earlier writers into a consistent whole, correcting and enlarging them as was found necessary, and following them ont into their logrical consequences. Thus he was able to reveal in a special branch of physical science new phenomena which had remained mobserved or mexplained till that time. In meler to unlerstand low the kinetic view of nature has becone firmly established in the minds of physicists. it will be useful to enmm-

In a certain sense Euler earried further the work of Huygens, ... . but as he neglected the useful irlea of a wave-surface and anxiously avoided Huygens' principle, he male the theory which he wished to defend unfruitful. ... We think that Euler did more harm than good to the progress of that theory. … Euler's theory of light had no great number of followers." In England Euler's theory was known and senerally condemned. I'riestley, in his 'History of Opties' (1772), refers to it at some length. In the well-known attacks in which Lorl Brougham treated so unfairly and superficially the discoveries of Dr Young, it is suggested that the latter horrowed his icleas from Euler, whose natural philosophy is held in little esteem. The fact is thit Young really went back to Huygens and Newton, and that he well knew that his own opinion, as stated in the first Bakerian Lecture (1802), "was precisely the theory of Hooke and II uygens, with the anduntion of some suggentions made by Newton himself as not in themselves improbable" (Young's 'Miscellaneous W'orks,' ed. P'eacock, rol. i. P. 200). In spite of the great almiration which Young had for Euler as a mathematician, he admits that kuler "added no argunentative evidence whatever to the [undulatory] theory, but hiss done a real injury to the cause which he encleavoured to support" ("Leetures on Natural Philosophy, ed. Kelland, vol. i. 1) 3×0). A more recent and well-informed writer on this subject, M. Verdet, says of Euler: "Bien yu'il a dommé de la plupart des phénomènes eomus ile son temps les explications les plus inexactes, il ne mérite pas noins de conserver dans l'histoire de l'opt ique une place éminente pour avoir lit d'une manière expresse que les ondulations luminenses sont priviediques comme les vibrations sonures, et que la cause des diffircuces de culoration est au fond la mene, que lat cause des différencess de tumalité" ('anves de lirennel, rol. i. p. xix). 
erate shortly the different suggestions which Fresnel assimilated and worked up into his celebrated physical theory of light.

That light consisted in the motion of something was in the beginning of the nineteenth century a generally accepted notion among natural philosophers. It had been so ever since Olaus Römer ${ }^{1}$ in the seventeenth century, from the observation of the hitherto unexplained delay in the disappearance of Jupiter's satellites during eclipses, had inferred, and Bradley ${ }^{2}$ had later on con-

1 The moons of Jupiter, of which two are visible to the naked eye, were clearly seen and described as one of the first discoveries with his telescope by Galileo in 1610, and published in his 'Sidereus Nuncius.' Owing to their continual and rapid change of position and their frequent eclipses, they were very soon considered to furnish a valuable means of determining the longitude at sea, and were repeatedly and very minutely observed. In the course of sucl observations by Cassini and Römer at Paris, the latter found, in 1675 , that the period of occultation of the nearest moon varied. This variation he traced to the fact that the earth was moving towards or away from Jupiter. If light takes time to travel, the visibility of the phenomenon is necessarily thus anticipated or postponed. This was the first occasion on which data for the calculation of the velocity of light were forthcoming; the terrestrial experiments of Galileo having been inconclusive. Römer's explanation and calculation were accepterl by most astronomers; they were confirmed by

2 the phenomenon of aberration, discovered by Bradley. It is analogous to the observation we can make in a moxing railway train if it rains; the drops at the window, though they be descending perpendicularly, yet appearing in a slanting lirection, in proportion to the velocity of the train. Both phenomena involve the nur. tion of light itself and the motion of the observer, who receives the luminous impression and locates it in space and time. The principle involved in Kömer's discovery was later enunciated by Doppler, who maintained that the very short periods which belong to different colours of the spectrum, according to the undulatory theors, must suffer (like the longer periods in Rimer's occultations) by the motion of the luminous object or of the observer in the line of sight. Al. though this theory was adınitted in acoustics, it took some time before it was admitted in optics. Bolzano, Professor of Religious Philosophy and a colleague of Duppler at Prague, foretolit as early as 1842 the great utility of the principle, and wrote: "I foresee with con. firlence that use will be hereafter made of it in order to solve-by observing the changes which the colour of stars undergoes in time -the questions whether and in which direction and with what 
KINETIC OR MECHANICAL VIEW OF NATUHE. 11

firmed, that light takes time to travel from wne point in space to another. Wherever time is involver in is phenomenon, motion of something is suggested, anc] this something, as well as the nature of its motion, become subjeets of speculation. At the beriming of the mineteenth eentury two distinct theories existed arillisidis legrarding these matters. Both had succeerled in extheorify plaining and calculating satisfactorily a large number of the phenomena of light as exhibited hy mirms and lenses, as well as in optical instruments and crystals. One of these theories, the so-called emission, entuation, or corpuseular theory of light, helil that luminoms bodies send out minute particles which travel in straight lines, and, impinging moon the cye, create the sensation of light. The rival hypothesis, the undulatory or vibratory theory, held light to consist in the periodic wave-motion of a substance ealled ether, which was supposed to exist everywhere, filling all space and interpenetrating all ponderable matter. Both theories are kinetie or meehanical theories, and for their development require the analysis of certain modes of motion. Both had to formulate their respective notions as to the something that movel. lioth conlil point to analogies in other domains of natural seience. There existed at that time similar corpuscular explanations of the phenomena of heat, of electricity

velocity they move, how distant they are from us, and much else lesides," a prediction which, since the invention of spectrum analysis and various controversics connected with the subject, has been luilliantly verifierl hy the discoveries of sir
William Hogrins 1865 , Hux-'Tul. bot, aud wthers. That loppler's principle is really nene other than liomer's was remarkerl hy l'. li. 'Tait in "light" 2ut el., 1. 2200.

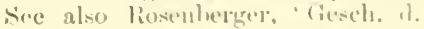
Physik, vol. iii. J. T08 NI\%. 
and of magnetism. On the other side there was the highly developed theory of sound, which had succeeded in explaining and analysing the properties of sounding bodies by studying experimentally and mathematically the vibrations of sounding strings, membranes and plates, and also of the air in organ-pipes and other 7. inusical instrmments. Acoustics, the branch of science

Undulatory theory prepared by aconstics.

which treats of these phenomena, was, next to physical astronomy, the furthest developed and best founded of the physical sciences. By following up the elementary and primitive experience, known already to the ancients, that sound is everywhere to be traced to the vibrations or the tremor of some body which has been struck or otherwise excited, a very complete theory, substantiated by many experiments, had been built up. Common-sense and everyday experience had originally suggested this line of inquiry and explanation. ${ }^{1}$ No other physical science was so early in possession of the right road of inquiry. In astronomy and optics the suggestion of common-sense, which regards the earth as stationary and light as an emission travelling in straight lines, had indeed allowed a certain amount of definite knowledge, based upon measurement and cal-

Acoustics is probably the only physical science where this has been the case; as is well remarked by Whewell in his 'History of the Inductive Sciences.' He there contrasts acoustics with as. tronomy and optics. He might have added dyuamics, where Galileo's principle of inertia similarly reversed the dicta of common-sense. Whewell says (vol. ii. p. 23\%) of acoustics: "Instead of having to travel gradually towards a great dis- covery, like universal gravitation, or luminiferous undulations, we take our stand upon acknowledged truths, the production and propagation of sound by the motion of horlies and of air; and we connect tliese with other truths, the laws of motion, and the known properties of bodies, as for instance their elasticity. Instead of epochs of discovery, we lave solutions of problems." 
ealation, to be acemmulated. A real physical theory, however, was inpossible until the notions surgesterl by common-sense were completely reverserl, aml an ideal eonstruction put in the place of a seemingly obvious theory. This was done in astronomy at one stroke by Coperniens; in optics only gradnally, tentitively, and hesitatingly. The purely geometrical relattions of straight lines, which light seemed to resemble: of peneils of rays, which were bent baek or altered in their direetion at the surface of plane or curved mirrors and of transparent bodies; seened to How quite easily and naturally when in the seventeenth eentury the simple law of refraction had heen added to that of reflexion, known already to the aneients. The scienees of catoptrics and dioptries, with their applieation to the telescope and microseope, were thus so complete and useful that to many it must have seemed difticult and unneeessary to plunge into a new theory: ${ }^{1}$ especially

It has always been the aim of "geometrical optics" to free itself from every hypothesis on the physi. eal nature of light, and to deduce propertics of light from a tew simple geometrical constructions. Precisely in the same way all geometrical and many physical properties of the stellar system can be deduced from the kinematical formula of attraction, without diseussing the nature of gravitation. 'This desideratum -81) far as uptics is concernedwas before the mind of Sir W. R. Ilamilon, when, rluring the year's 1821-33, he discovered and elaboratel the theory of the "character. intic function, by the help of which all optical problems, whother on the corpuscular or on the undulatory theory, are solved by one common process" (Tait, 'Light,' 2nd ed.. p. 160). Owing to the difficultiewhich have more and more jresented themselves in the fundanental conceptions of the wave-thenry and the vibrating ether, of which we shall leirn more in the seyuel wi this chapter, the desire to bring the phenomena of refraction under is purely geometrical formula, and (o) emancipate the optics of erverals from physical hypotheses, has ter come very pronounced. Huygens" geometical comstrution of the ordinay and extromblinary lays in uniaxial crystals answerel well. For hiaxial erystals frenel lial in. troduced the wave-surfice, to which eorresponds Homiltur's character. istic tunction. For dielactic purposes, and for the pratical applica 
as that theory failed for a long time to explain the apparently fundamental fact, viz., that light travels in straight lines, accompanied by well-marked shadows. The contrary view, according to which light is a tremor propagated like sound, was mable to explain the existence of clearly marked shadows. And so it came

s.

Newton's authority on the side of the emission theory, about that Newton, to whom both theories were quite familiar, and to whom we owe great discoveries telling severally in favour of each of these theories, in the end threw the weight of his authority into the scale of the corpuscular or emission theory. For many this was quite sufficient to suppress for a long time all claims which the tremor or wave theory put forward, the fact being forgotten or overlooked that Newton himself had pronounced the pure emission theory to be insufficient, and had modified and complicated it by

tion to crystallography, it became a desideratum to reach the geometrical conception of the wave-surface by purely geometrical methols. This has been done in an admirable treatise entitled 'The Optical Indicatrix,' by Mr L. Fletcher. He has shown that the construction of the ray, a conceptiou easily defined geometrically, gives an easier approach than the construction of the wave, which introduces physically doubtful definitions; and he demoustrates how "a simple generalisation, iuvolving no reference either to the constitution of the luminiferous ether or to the nature of the physical change involved in the transmission of light," will lead to the ray surface (p. 18). For his purpose he starts from a surface of reference, which in singly refractive substances is a sphere, in uniaxial crystals a spleroid, and by inference in biaxial crystals an ellipsoid with three unequal axes. This beautiful construction was arrived at, as the author tells us, before the detailed history of Fresnel's theory had come to his notice. It is now known through Verdet, one of the editors of Fresnel's 'Works' (1868), that Fresnel arrived at his wavesurface by a purely geometrical generalisation of Huygens' construction, and that the conception of the ether was subsequently fixed so as to allow the wave surface to be deduced therefrom (p. 24); surely an interesting case in the history of scientific thought. As to the insufficiency of purely geometrical optics for explaining the phenomena comnected with optical instruments, see Czapski, 'Theorie der optischen Instrumente,' Breslau, 1893, p. 2. 
suggesting that the rays of light were possesserl of fits of easy transmission and reflexion, i.e., of regulatr periodic changes which conld be measured and numbered. Tro this anplification of the simple geometrical emission theory Newton was driven by his own immortal researches, which revealed the wonderful regularly arranged colours of thin plates known as Newton's rings. In reading, after the lapse of nearly two centuries, the reflections of Newton on the nature of light, reflections which he never gathered up into a compact and exhaustive treatise, as he but also surerests did the theory of gravitation, ${ }^{1}$ we recognise that he had theory. clearly before his mind the two fundanental phenonena peculiar to light, namely, its property of travelling in straight lines, and its periodicity, as revealed by certain delicate experiments of his own. Which of the two theories should in the end prevail depended on the more intimate knowledge-to be gained hy experiment and calculation-of the two kinds of motion involved; of rectilinear motion of particles uncler the influence of contending forces, and of the more complicaterl periodic motion peeuliar to waves, trenors, or oscillations. The first kind of motion, heing more easily studied and also more nearly related to other prevailing studies, received earlier attention; the second-especially so

${ }^{1}$ It is now sufficiently known and recognised that Newton, both in the theory of gravitation and that of light, did not propose to do more than give a preliminary formulation which was applicable as a bisis for experiment and ealculation. His further speculations are contained mostly in the well-known 'Qurries' to the 'Opticks,' which were extendes in later edition, and among which, "to show lluat" le "did not take gravily for an esseutial property of trodies," he ander one question concerning its cause, choosing to propuse it hy way of a question, becallse "he was nut yet satisfied about it for want of experiments" (Alvertisement to second edition, $1 \pi 1 \%$ ). 
far as the mathematical side was concerned - was studied later. The former theory has been furthered more by the ingenuity of physical observers, the latter more by mathematical reasoning applied to the invention of crucial experiments which pure observation would probably never have suggested. Since the time of Newton, whose name has been used in a onesided way to discredit the vibratory theory, although, as already stated, his discoveries contributed equally to the formation of both views, the development of the corpuscular theory owes most to the experimental Biot,

Brewster, and Laplace against the undulatory theory.

11.

Euler the successor of Huygens. labours of Biot in France and Brewster in this country; whilst no doubt Laplace's great predilection for atomic and astronomical explanation of all natural phenomena gave it great support in the eyes of his many followers and admirers. The vibratory theory was first made the subject of detailed study by Huygens, Newton's contemporary; it was accepted on purely mathematical grounds by Euler; the lines of reasoning on which its ultimate success depended were elaborated by Lagrange's and d'Alembert's mathematical study of vibrations; but the first great step in advance, based upon experiment 12. and calculation alike, was taken by Dr Young, who Young. from 1793 onward studied the subject, and who in 1801 published his 'Principle of Interferences.' Young was led to his reflections on the phenomena of light by an inquiry into the nature of sound, ${ }^{1}$ a province where

I In his 'Reply to the Edinburgh Reviewers' (published as a pamphlet in 1801, see Works, ed. Peacock, vol. i. pp. 192-215), Young gives the following history of his speculations: "When I took a degree in physic at Göttingen, it was necessary, besides publishing a medical dissertation, to deliver a lecture upon some subject connected with medical studies, and I chose for this the Formation of the Human 
the theory of vilorations had alrealy achieved so much. He was thus more interested in the physical nature than in the geometrical properties of rays of light. He wats impressed by the analogies which exist between many phenomena of sound and light, and actuainted with the writings of the Continental mathematicians, anong whom Euler was conspicuons as favouring the undulatory or ether theory of Huygens. He noticed that in Newtun's writings were to be found the germs of both theories, also that the arguments by which Newton convinced himself that a theory of mululations could not explain the rectilinear propagation of light, were mitenable. ${ }^{1}$ On reHecting in May 1801 on Newton's beantiful experiments,

Voice. ... When I began the outline of an essay on the human voice, I found myself at a loss for a perfect conception of what suund was, and during the three years that I passed at Einmanuel College, Cam. bridge, I collected all the iniormation relating to it that 1 could procure from books, and I made a variety of original experimeuts on sounds of all kinds, and on the motions of tluids in general. In the course of these inquiries I learned to $m y^{\circ}$ surprise how much further our neighbours on the Continent were advanced in the iurestigation of the motions of sounding bolies and of elantic fluids than any of our countrymen ; and in making some experiments on the froduetion of sounds, I was so forcibly impressed with the resem. blance of the phenomena that I sitw to those of the colours of thin plates, with which I was already acquainted, that I began to suspect the existence of a closer analogy between them than I could before have eavily believed" (p. 199). This led to his 'Outlines of Experiments and Inquiries respecting sound and Light' (ibid., p. 64).

1 Works, vol. i. p. 200. "New. ton's arguments from experiment appear to me to have been sutti. ciently obviated by what Lambert has advanced in the "Mlemoirs of Berlin.' . . . The demoustration is attempted in the 'Principia': to me it appears to be defective.

The celebrated Laphec, in conparing the opinions respecting light, is contented to call the Newtonian doetrine a hypothesis, which, on account of the facility of its application to the phenomena, is extremely probable. If he harl considered the undulatory system as demonstrably absure, he would not have expressed himself in so undeciderl a manner. . . Much as I venerate the name of Newton, I am not therefore obliged to be. lieve that he was infallible. I sec ... with regret that he wiss liable to err, and that his anthority has, perhaps, sometimes even retarded the progress of science," sce, sc. 
he "discovered a law which appeared to account for a greater variety of interesting phenomena than any other optical principle that had yet been made known." ${ }^{1}$ This principle he familiarly illustrated by the well-known observation that two series of waves of water entering a channel reinforce or destroy each other according as their elevations coincide or alternate in time. He maintained that similar effects take place whenever two

His

"general law of the interference of light."
14.

Theory of the luminiferous ether. portions of light are thus mixed, and this he called "the general law of the interference of light." He showed " ${ }^{2}$ "that this law agrees most accurately with the measures recorded in Newton's 'Opticks,' relative to the colours of transparent substances, and with a great diversity of other experiments never before explained." 3 In three papers Ioung entered "minutely into the consequences of the law of the interference of light.' Especially in the case of the remarkable phenomena discovered by Grimaldi, where light seems to bend round the edge of screening surfaces, he showed how under certain conditions light added to light would create darkness, and, if removed, would leave light; and he boldly generalised the undulatory theory by maintaining that " a hminiferous ether pervades the universe, rare and elastic in a high degree," that the sensation of

I Works, rol. i. p. 202.

2 Ibid., p. 203.

3 "This, I assert, is a most powerful argument in favour of the theory which I had before reviced: there was nothing that could hare led to it in any author with whom I am acquainted, except some imperfect hints in those inexhaustible but neglected mines of nascent inventions, the works of the great Dr Robert Hooke, which had never occurred to me at the time that I discovered the law" (ibid., p. 203).

* The sentences in quotation marks are the headings of the different paragraphs in the "Bakerian Lecture " of November 12, 1 S01. Works, vol. i. p. 140 sqq. 
different colours depends on the different frequency of vibrations excited by light in the retina, and " that all material bodies have an attraction for the ethereal medium by means of which it is accummlated within their substanee." In all his conclusions, while differing from Newton's doctrines, he sees the strongest prontis uf the arminalile aceuracy of Newton's experiments, "lut scarcely any remaining hope to explain the affections of light by a comparison with the motions of projectiles." I Although Yomng thus established "a theory of the nature of light which satisfactorily removes almost every diflienlty that has hitherto attended the suljeet," his view was only tarlily accepted. Tollaston," with the hesitaney which also characterised his adhesion to the atomic thenry of Dalton, did not avowedly adopt Joung's views, though he fumished some capital experimental support for the viluratory theory of light."

Brougham, in the 'Edinburgh lieview' ricliculed Young's theories, and persuaded the public that they atrarknn stood in eontradietion with Newton's discoveries, on which they were really as much fommed as those of the opposite school. Through such disfavour, arising largely from a want of skill in grasping the intricate mathematical problems which were involved, the doctrine of the interference of light, the mainstay of the madula-

1 Works, vol. i, p. 169.

2 'Leetures,'ed. Kelland, Preface, p. ix.

3 "Whatever disposition Dr Wollaston may have felt to view this theory with favour, he was restrained from adopting its conclusions by the habitual eaution of his eharaeter, or rather by the want of that bold and enterprising spirit of speeulation which is more or less essential to those who make great revilutious in science" (Teacrock, 'Life of Young,' ए. 375 ). + Ibicl., 1. $37 \%$. 
tory theory was, like the atomic theory of Dalton, driven out of the country. Little was heard of it, or of Young's great contribution, till it was taken up abroad, and in the very place where the brilliant development by Laplace of one side of Newton's suggestions had given plausibility to that form of the "projectile theory of light according to which its material particles were supposed subject to attractive forces when they arrived in the neighbourhood of ponderable matter. Young had indeed shown that the introduction of such forces could easily be dispensed with as a basis of many of Laplace's calculations, and that the results could be - got withont making use of molecular attraction. He had emancipated himself from a belief in the infallibility of Laplace's methods. ${ }^{1}$ He was also one of the first to

1 On the 20th December 1804, Young presented to the Royal Society his important "Memoir on " the Coliesion of the Fluicls." It was printed in the 'Transactions' in 1805. In December 1805 Laplace read before the Institute of France, and subsequently published in a supplement to the "IIécanique céleste," his celelirated theory of capillary attraction. Young bases his investigation entirely on the existence of a surface tension, an observable and measurable property ; whereas Laplace falls back upon the hypothesis of all attraction of the smallest particles of matter, just as he had employed the idea of an attraction of matter on the smallest particles of light to explain atmospheric refraction according to the projectile theory arlopted by him. In the sequel this attraction is reduced to an action which is insensible at sensible distances. In a supplement to his memoir, which appeared anonymously in the first number of the 'Quarterly Review' (1809), Young, evidently annoyed that some of his results had been reproduced without acknowledgment (see Peacock, 'Life of Young, p. 205), reviewed the treatise of Laplace "with a severity which, though excessive, can hardly be considered unprovoked or unmerited" (ibid., p. 206). Inter alia he says: "The point on which M. Laplace seems to rest the most material part of his claim to originality is the deduction of all the phenomena of capillary action from the simple consideration of molecular attraction. To us it: does not appear that the fundamental principle from which he sets out is at all a necessary consequence of the established properties of matter; and we conceive that this mode of stating the question is but partially justified by the coincidence of the results derived from it with 
KINETIC OR MECHANICAL VIEW OF NATElE. ¿21

emaneipate himself from the astronomical view of phenomena. In Franee the mattrer stoonl ynite dillerently, amd nothing better proves the genius of Angustin firsmel than the faet that he ventured against the opposition of linemelo. great anthorities to go his own way, starting from the begimning and devising many ingenims appeals to nature herself-i.r, to experiment-iu order to establish a correct view. It is well known that his lahours harl to wait many years for their deserved appreciation. It is, however, only just to remark that Araso, an ahluirel of Laplace and an intimate friend of biot, the great supporter of the projectile theory of light, was the first to reeognise the importance of Fresnel's work, and that it was largely owing to his co-operation and influence that the undulatory theory of light trimmpled in the end. Fresnel's own lathours hegan with the study of the same phenomena which had led Young to the diseovery of "interference" - viz., the bands and colomed fringes observable round the shadows of snall sereening objects, or the images of small apertures through which ravs of light are allowed to enter: the phenomena of diffaction or infleetion of light. liut whilst Young still explained these phenomena as arising from the interference of direet "portions" of light and such as were reflected at the edge of the screening obstate, Fresnel showed that the principle of interference had a much wider applieation, that it was aderuate to explain why a periodic ware-motion, such as was coneeivel by Huygens, only sent ont lays of

experiment, since he las not deinsustrated that it similar coincielence might not be oblained by procecding on totally ditterent groumls" (") (narterly lieview,' Xo. 1, 1. 109).

I See the first volume of this work, 1\% 211 mute 2 . 
light in the direction which was in a straight line from the origin or centre of light; that the lateral or secondary waves destroyed each other almost entirely by interference or overlapping; and that the so-called inflection, bending, or lateral spreading of light, was occasioned by an incomplete coincidence or overlapping of these lateral undulations. It appears that about the year 1815 Fresuel had, through a study of the phenomena of diffraction, arrived at a conviction, entertained by Young fifteen years earlier, that the projectile theory of light could not explain them. He had also, by a more rigorous and minute study of Young's principle of interference, explained the

17. Difficuities presented by the polarisation of light. reason of the rectilinear propagation of light. Iet these results did not materially affect the adherents of the projectile theory, who had been during late years very active in studying another class of optical phenomena, those of polarisation-the power which light possesses of acquiring, either by refraction or reflexion, a difference not discernible merely by the eye. This difference consists in the fact that a ray of light very frequently - as Newton had already expressed it-possesses "sides," just as a Hat strip or narrow tape has sides if compared with an ordinary thread or wire, which has no sides; or as a wire drawn through a specially shaped die acquires sides or edges. This property was later termed polarity, ${ }^{1}$ a term which implies that the particles of light

1 The word " polarity" was illtroduced by Malus in 1810. It is unfortunate, as it suggests the corpuscular nature of light. Newton's conception of "sidedness" ("laterality," formed by analogy on Lord Kelvin's term "chirality" to describe right- or left - handedness, see vol. i. p. 432) is a better description of the pheumenon. It is contained in the 26 th query to the second edition of the 'Opticks' (1717). Huygens had long before, in his "Traité de la Lumière" (written in 1678, published in 1690), after having given a correct rule for 
KINETIC OR MECHANICAJ, VIEW OF NATL RE, 29

have unequal properties in different directions: anl $t_{1 .}$ process of revealing it was termed pulurisution. Huy, Hons had diseovered this property, which he foumd was grivell to rays of light if they passed throumh certain arylats, notably through Ieeland spar, which has the catproily of dividing the rays so that objects seen throngh them appear double. He could not explatin it on his hypothesis of undulations, though he hat inventerl at genmetrieal construetion of the double refraction which law led him to its discovery. Malus showed in 1808 that double refration was not a necessary accompaniment of polarisation, hut that ordinary retlexion was enomgh un give these sides to ays of light. Although the projectile. theory gave no eomplete explanation of this property, still the supposition that this one- or many-siledness was owing to certain geometrical shapes of the luojected particles suggested that double refraction migh be explained by the different attraction or repulsion which these particles suffered aceording to the aspect

determining the course of the ordinary and extraordinary ray's in leeland spar, described the phenomenon fully, adinitting at the sane time that he could not explain it. When Malus discovered that light might aequire this peculiar property by reflexion, loung wrote in a review ('Quarterly' Review,' Hay 1810): "The discovery... appears to us to be by far the most important aud interesting that has been made in Frauce, concerning the properties of light, at least since the time of Huygens; and it is so much the more deserving of notice, as it greatly influences the general balance of evidence in the com. parison of the undulatory and the projectile theories of the nature of light" Workis, rol. i. J. 217. Aml Malus himelf, in witing to lisuns as roreigu secretary of the linyal Society, by whom he himl burn awarded the Rumford Hedinl, any : "Je ne regarde pas la combaiminee de ces plúnomines comme plufavorable au systime de l'únis-n qu'à celui des omlukialions. 1ls ik. montrent également l'insuffi-ance des deux hypothises; en oflet connment expliquer dans l'une m dans l'autre pouryuoi un raym guharies peut thaverser sons une crraine inclinaison un en'les diaphane, en se dérolbant totalement is $1.4 \mathrm{r}$. Hexion partielle yui a lien it h sur. lace de ces corpos daus les cho wroli maires?" (quoted hy Peacork, "lale of Young," p. "2ts mute. 
which they presented when approaching ponderable or attracting substances. Nothing of this kind seemed imaginable on the undulatory theory, which, reasoning from the analogy of somnd, considered light to consist in a rapid to-and-fro motion of the ether in the direction of the rays of light. Sidedness or "laterality" seemed inconceivable. Rays of light possessing this property would (as Fresnel and Arago showed in 1816) eventually even lose their capability of interference, that main property discovered by Young, the principal argument for the vibratory theory. "Every day in that remarkable period - when so many great observers were endeavouring to outstrip each other in the career of discovery_was making known modifications and phenomena of polarised light which no existing theory was yet competent to explain. It was polarisation which still continued to cast a dark cloud over the hopes and fortunes of the undulating theory." 1 Thus it was natural that the representatives of the astronomical view of nature, who, headed by Laplace, had given so many real and some apparent explanations of complicated phenomena, and to whom the conceptions of the projectile theory of light seemed more promising, should think it time to attack the very stronghold of the vibratory theory, namely, the phenomena of interference, exhibited mainly in diffraction, and, by a minute experimental and mathematical analysis, show whether these phenomena conld not be brought within the pale of their fundamental conceptions. For the discoveries of Young and Fresnel had not shaken them. Accordingly the Paris Academy of

1 Peacock in 'Life of Young,' p. 383. 
Seienees in 1817 issued for the competition m the rmand mathematical prize for 1819 the suhjere of lobliention.

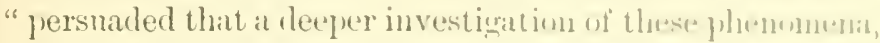
which seemed oplosed to their cherisherl inctrinn, would give occasion for new trimuphs." In this they wres doomed to disalppointment. It the repurst of dratern and Ampere, fosmel entered for this completitum, and his 'Mémone sur lia Jiffration' was ezownerl the following year. In it he viewed the subject from an much muse general point of view, examining the two rival systrensthat of emission ancl that of mululations-as to thrir capacity for explaining the fhenomena of diflastion. 'The result seemed decisive in favour of the latter thenry, and the impression prolnced was all the sreatur leranse Poisson, ${ }^{2}$ one of the jutges and a believer in the cmiscim theory, drew certain apparenty rery paradoxical couse-

1 Verdet in 'Aurres de Fresnel,' vol, i., l'reface, p. xxxv., \&c.

? The commission eomsisted of Biot, Arago, Laplace, Gay-Lussac; aut Poisson. Arago drew up the report, which is published in the first volume of the afurres de Fresnel,' No. 13. It closes with the following note: "MI. Joisson, depuis le rapport de la commission, ayant fait remarquer ì $\mathbf{M}$. Jiresncl que l'intégrale qui représente l'intensité de la lumic̀e diffractie peut aisément s'oltenir jour le ceutre de l'onbre d'un ćcran su l'une ouverture eireulaires, celui-ci fit le ealcul pour ce dernicr cas, et trouva que l'expression góućrale d'intensitó devenait alors semblable a celle de la luwière rélléchie clans le phénomène des ameaux colurés; que ses minima étaient tout ì fait nul et devaient présenter ainsi un noir à jeu près parfait clims mue humiere sensiblenumt homuginte ; du moins pour les l pois premiers orelres. où le défitut l'homogrinéité de la lumiere rouge employice ne se bisait pas encore trop sentir : c'ent a ussi ce que lexpérience a comfirmi ; en plarant le foyer de lis loupe du micromètre itux distances ealcules on appercevait comme une tache d'enere au centre de l'ouverture circulaire. . U U peut regarder cette expérience comme une viritication des formules de V. Fre-mel," sc. ('Eurres,' vol, i. [1. 24ii). see also the note which Fresum intached to his menuir (ihid., p. 365). The memoir was enwnerl in 1819 , but not published till I 26. An abstract of the first and an re. print of the secomt part lad been published in the $11 \mathrm{th} \mathrm{vul}$ of the 'Ammales de Chimio et de l'hy-iyue.' Fresne] sent I wo cupies to Young, 19th September 1s]!.
Fire 1 i He rit 1) 11 rescetinu 
quences from Fresnel's calculations: Fresnel was invited to prove by experiment these astonishing results, and he found them actually confirmed. So far as the phenomena of diffraction-erroneously termed inflection-are concerned, this work of Fresnel established the fact "that the theory of undulations foretells the phenomena as exactly as the theory of gravitation foretells the movements of the heavenly bodies." 1 It was, however, quite different if we consider that other larger class of phenomena ${ }^{2}$ which revealed the fact that rays of light

${ }^{1}$ See Schwerd, "Die Beugungserscheinnugen ausden Fundamentalgesetzen der Undulations - theorie analytisch entwickelt' (Nannheim, 1835), Preface, p. $\mathbf{x}$.

2 The history of the final establishment of the wave theory of light has been written by Whewell in the second volume of the 'History of the Inductive Sciences.' The main sources which existed at that time were the memoirs of Young and Fresnel, and the 'Life of Dr Young' by Peacock. This history has been written again with ampler materials by M. Verdet as an introduction to the edition of the complete works of Fresnel, published in 1866 . It is well to read both accounts, as some points which remain obscure in the earlier are fully explained in the later. There is no doubt that Young suggested that the phenomena of "sided. ness," which rays of light exhibit, lead to the conception of a lateral or transverse movement; he also hinted that in biaxial crystals the shape of the wave might be that of an almond or an amygdaloid (article "Chromatics," reprinted in Works, vol. i. pp. 317, 322), what we now call an ellipsoid; but $M$. Verdet is right in characterising Young's suggestions as vague, and vindicat. ing for Fresnel the full merit of having defined transverse vibrations and of having introduced the ellipsoid of elasticity as a geometrically perfect means of finding by construction the paths of rays in biaxial crystals. The method was quite independent of the theoretical views regarding light which were contained in the same memoir, the consideration of which was referred to a commission consisting of Ampère, Arago, Fourier, and Poisson. Of these Ampère had suggested transverse vibrations as a means of explaining the phenomena of polarisation ('Euvres de Fresnel,' vol. i. p. 394). Arago, though a great friend of Fresnel and a believer in the wave theory, never to the end of his life accepted the hypothesis of transverse vibrations (ibid., p. Iv.) Poisson, a supporier of Laplace's molecular theory, retired from the commission; and Alago, who composed the Report to the Academy, confined himself to promouncing on the experimental portion, which fully confirmed the general law of double refraction announced by the author; refraining from the expression of any opinion as to the theoretical portion, it being premature to do so (see 'Euvres de Fresnel,' vol. ii. p. 463). Im- 
have sides, the phenomenil of "Iatcrality" (min-lanlinely ealled polarisation). The believers in the emission thent? studied them with predilection, liint at their heanl. Ml. though to Young their explanations were monnvinding their results were so perplexing that he wrote to linwsted in september 1815 , "With respect to ny uwn fundumental hypotheses resprecting the nature of light, I lescome less and less fond of dwelling on them, ats I learn more and more facts like those which Mr Malus uliseovered: beeause, although they may not he incunpatille with these fitets, they certainly give us no assistance in explaining them." 1 When Toung wrote this, Firsnel had not yet presented his first memoir on Iniffraction tw the Institute; his own labours on that matter were more than ten years old; the phenomena of polarisation hal meantime absorbed the attention of opticians. In the summer of 1816 Arago and Gay-Lussac laid a visit (1)

mediately after the rearling of Arago's report, Laplace, "who had thought for a long time that his analysis had made the phenomena of double refraetion depend on his emission theory," proclaimed the great importance of the memoir, and declared that he placed these researches above anything that liad for a long time been communicated to the Academy ('CEurres de Fresuel', vol. i. p. lxxxvi., and vol. ii. p. 459). We are indebted to $M$. Yerdet for haviug shown that the discovery of this law by Fresuel is independent of the theoretical considerations by which he tried synthetically to prove it. (1) this point he says: "lin révélaut la série de généralisations et de con. jectures par lesquelles fresnel est arrivé peu ì peu ì la découverte des lois générales de la clouble ré. fraction, ils font disparaitre un. difticulté qui ne pouvait manquer he résulter de toute étude tant suit j".u approfondie de ses écrits imprimin. . . (n a vu au contraire que cette loi s'est manifesté ì Fresnel comue le résultat d'une généralisation tente semblable aus généralisations qui ont amené la plupart des grancles découvertes. Jorsqu'il a voulu eusuite se rendre compte de lit lin far une thécurie uécanique, il n'ent pas étommant qu'il ait, peut-itre it son insu, emoluit cetle théorie vers le but yu'il comnassait l'arance, et qu'il ait été léterminé, clans l"* choix des hypothères auxiliniren uoins far lour vraisemblance intrin. sique que par leur acomel aren ce qu'il était en droit de considerer comme la rerite" (il rid., vol. ii. p. 32.. (f. vol. i. p. Ixxiv.

1 Works, vol. i. p. 361. 
England and to Young, who learnt from them that, mainly owing to Fresnel's labours, his own researches had "attracted much more notice in Paris than in London,. . . leading to some very warm discussions among the members of the Institute on some public occasions." 1 It is likely that this visit, as well as the discovery of Arago that rays of light when polarised - i.e., possessed of laterality-lose under certain conditions their power of interference, induced Young to resume seriously the consideration of the subject. In

19. January 1817, long before Fresnel had made up his Young and Fresnel introduce the conception of transverse vibrations. mind to adopt a similar conclusion (suggested to him by Ampère), Young announced in a letter to Arago that in the assumption of transverse vibrations, after the manner of the vibrations of a stretched string, lay the possibility of explaining polarisation or "laterality," and the non-interference of rays whose sides are perpendicular to each other. By introducing this conception of a lateral or transverse movement into physical optics - a conception shortly afterwards adopted by Fresnelthe data were provided for a complete mechanical or kinetic explanation of all phenomena of homogeneous rays of light-i.e., of such rays as, on passing through refracting substances, are not divided into several colours.

Two great problems now presented themselves, one of which Fresnel attacked with great success. The other is hardly yet solved. Inasmuch as these two problems have largeily occupied physicists and mathematicians all through the century, and guided their reasonings in other

1 Peacock, 'Life of Young,' p. 389. 
KINETIC OR MECHANICAL VIEW OF NATLRE „2?

branches of research, it will lu useful (1) iletirn then more clearly.

Ever since Newton laid down the seoneral litwo of motion, it has heen seen with incleatsing clentluts an lu. the object of mathenatical physies on deseritw the a. ainting obscrvable or supposed forms of moninn in matme by having recourse to the fundautental laws of motion compled with the smatlest possible number uf atsimmptions as to the ultimate eonstitution of matter or of the moving substance. As soon as any definite assmmption was matle, it became necessary to follow it into all possible consequences, and not to make any new assmun]tions so long as the capalibities of the ohl ones were unexhausted, or so long as it was not shown cither that the new assumption was based upon observilul fitets, on aid not infolve latent contrarlictions with those alrealy adnitted. Newton had led the way by mitking one great assumption in aldition to laymg down the litws of motion. This was the property of gravitation. Heralless of Newton's waning that this atssmuption, thmenl proved by experiment, did involve certain seeminn absurdities which called for further exanination, philusophers like Boscovich, and mathematicians like laplinet. busied themselves with drawing all the consequences of the assumption, and they saw the most hopeful way of further progress in an extension of it into the realn of molecular physies. Young was probably ane wi the first to see the futility or the mere semblinues of truth in the astronomical view of nature. He alpproachenl both by experiment and mathematieally the great chass of phenomena of small, extremely rapuil, ferionlic more- 
ments; and he applied his results for the purpose of gaining a new basis for the theory of light. His speculations were, however, not confined to this. He had started by studying sound and had shown its analogy with light; but when he ultimately ventured on the bold assumption of a lateral to-and-fro tremor, he showed where the nature of light differed from that of sound.

20.

Mechanical difference between light and sound.

It was in this: that the tremor of sound was that of an elastic fluid such as air, or of any substance in which the movement is carried forward by alternate compression and expansion. But the phenomena of light seemed to require for their explanation two seemingly incompatible assumptions : first, a substance more sul,tle than air, incapable of impeding the motion of matter in it ; and, secondly, a substance having vibrations resembling the tremors of what we term solid bodies, e.g., stretched strings. Young is one of the founders of the theory of elasticity. ${ }^{1}$

1 The history of the theories of elasticity has been written by Isaac Todhunter and continued by Professor Karl Pearson. A perusal of the earlier portion of the work shows how imperfect were the irleas which existed at the time when Fresnel approacher the problem in the interest of the wave theory of light. The greatest mathematicians, like Euler, luad handled the subject, and had damaged their reputation, especially in this country, by serious errors or by conclusions which agreed ill with experience. Young was one of the earliest writers on elasticity in the nineteenth century ; having given considerable attention to the subject in his Lectures on Natural Philosophy (delivered in 1802, published in 1807). He there introduces the modulus of elasticity, a tern which, with some change of meaning, survives in modern treatises. His name, as well as that of Hooke ("Ut tensio sic vis"), appears accordingly at the portal of the science. Young, though Todlunter has a significant remark on his obscurity of style, stands out prominently, if compared with contemporary writers in this country, by his thorough knowledge of the labours of Contiuental mathematicians, among whom he assigns special merit to Coulomb. In general, Todhunter has little to say in praise of English science in this department during the earlier part of the century, and he considers the "perusal of Euglish text-books on practical mechanics published in the first half of the century a dispiriting task," in consequence of a "want of clear thinking, of scientific accuracy, and of knowledge of the work ac- 
He must have fully realiserl the dittieulty of inatrining at substance more subtle than air and yet emlowerl with $\left\{h_{1}\right.$. property of rigidity, known to us ouly in solid bodics. The elaboration of the theory of light pressed upon physieists and mathematicians a more careful sturly of the different states in which matter an "xist. "The different properties which this hypotheticil sulstance called ether must possess had to he mathematicially defined; and, further, it had to be shown whether it would be physieally possible for a burly, subject to the empirieal laws of motion, to possess certin of the properties of what we term solids, and yet to be in uther respeets the very opposite of a solid. The solution of the first problem was a purely mathematical performince, in which many eminent mathematicians, such as ciuchy, Neumann, Green, M'C'ullagh, and Stokes, ${ }^{1}$ have been

complished ahroad" (vol. i. p. 105). "It is difficult to picture the remarkable scientific ignorance of practical men in England in the first quarter of the century. One can only trust that there may be a closer union of practice and theory iu our own day" (p. 106). This passage was probably written in the soventies.

According to Tollhunter, the true theory of elastieity was founded in France between the years 18:0 and 1830 , by Navier, l'oissou, and Cauchy on the one side; by the experimental work of Savart on the other. It had been allied with theoretical acoustics since Euler's time. Chlarni in Germany fur. thered that branch of the subject in three celebrated works: "Theorie des Klanges' (178\%), 'Akustik' (1802), 'Peitriige zur Akustik' (1817). Chlarlni influenced the brothers Weber, whose "Wellenlehre auf Experimente gegriindę" ap. peared in 1525 . In it wave-motim, such as the theories of somml anil light had made sprecially interesting and important, was experimentally examined and illustrated. The theory of elasticity now received it new ally, viz., the rlastic theory of light or of the ethet. Though *uggested by Fresiel, its real founder was Cauchy.

1'The natural philosmuler to whon we are most indebted for lringing clearness and definiteness into cur ideas and our language in these very intriente subjects is sir tieorge Stokes. In two palners, published respectively in 18 fi and 149 (see "Nathematical and lyysical l'upers, vol. i. pe. $75-128$, and wol. ii. IP. 8.13), he hats done more than any other writer to tix for nearly hali a century the conceptions and the 
engaged. The solution of the latter problem involved experiment as well as calculation. The different states and properties of matter had to be studied from quite novel points of view: they had to be defined in terms of the different kinds of motion and of inertia, i.e., resistance to motion or capacity for motion. The popular conceptions of solidity, rigidity, fluidity, expansion, pressure, weight, required to be translated into the language of ordinary dynamics, that it might appear to what

vocabulary of physical optics. $\mathrm{He}$ has, however, whilst working independently, been careful to point out to what extent his views agree with or are anticipated by the important writings of Cauchy and Poisson in France. Up to his time the ether was universally spoken of as a fluid. Stokes led up to the "elastic solid" and the "jelly" theory of the ether. "Undoubtedly," he says, "it does riolence to the ideas that we should have been likely to form a priori of the nature of the ether to assert that it must be regarded as an elastic solid in treating of the vibrations of light. When, however, we consider . . . the difficulty of explaining these phenomena by any vibrations due to the condensation and rarefaction of an elastic fluid such as air, it seems reasonable to suspend our judgment and be content to learn from phenomena the existence of forces which we should not beforehand have expected. . . The following illustration is advanced, not so much as explaining the real nature of the ether, as for the sake of offering a plausible mode of conceiving how the apparently opposite properties of solidity and fluidity which we must attribute to the ether may be reconciled. Suppose a small quantity of glue dissolved in a little water so as to form a stiff jelly. This jelly forms, in fact, an elastic solid: it may be constrained . . . and return to its original form when the constraining force is removed, by virtue of its elasticity ; but if we constrain it too far it will break. Suppose now the quantity of water to be 'increased'... till we have a pint or a quart of glue-water. The jelly will then become thinner. . . . At last it will become so far fluid as to mend itself again as soon as it is dislocated. Yet there seems hardly sufficient reason for supposing that at a certain stage of the dilution the tangential force whereby it resists constraint ceases all of a sudden. In order that the medium . . . should have to be treated as an elastic solid, it is only necessary that the amount of constraint should be very small. The medium would, however, be what we should call a fluid as regards the motion of solid bodies through it. . . . Conceive now a medium having similar properties, but incomparably rarer than air, and we have a medium such as we may conceive the ether to be, a fluid as regards the motion of the earth and planets through it, an elastic solid as regards the small vibrations which constitute light" ('Papers,' vol. ii. p. 11 sqq.) 
extent these varions properties conlul exist sepitidtels ut were mutually dependent.

In the domatin of somed and light the early grote of the century was thus, as we have seen, witness of at useful interpretation of these variums numlitioutions ats merely different kinds of unotion: both were cousidereal to be vibrations, the trequeney of which nutherl the position of a note or a time in the musical or chromatio.

${ }^{1}$ That is to say, the number of indepentent constants had to be fixed which would permit isutropic or anisutropic boties (i.e., bodies which are either equal in all directions, or unequal in the three directions) to be mathematically defined, and in consequence their behaviour. studied, if subjected to strains and displacements. Over these definitions there arose the great controversies of those who believell in a small number of constants (one constant in isotropic and fifteen in anisotropic bolies against two and twenty-one respectively). A good account of these controversies and of their mathematical and physical significance will be found in the first volume of 'Todhunter's 'History of Elasticity,' by Professor Karl l'earson, p. $496 \mathrm{~s} q \mathrm{q}$. The former theory is termed the rari. (few) constant thenry, the latter the multi- (many) constant theory. The rari-constant theory is based upon the assumption that a body consists of molecules, and that the action between two molecules... is in the line joining them. It is an outcone of the atomic and action-at-a-distance theory in vogue on the Cuntinent, and is accordingly mainly represented by Navier, l'oisson, Cauchy, and others, notably SaintVenant. The other school, mainly represented by mathematical physicists in this country, starts not from a mathematical formula (which, after all, loses its precimion as the active forces are reduced to the vague statement that they act -en-ibly only at insensible distant....) lout from physical lata. It is an analogue to Young's theory if capillarity as against baplace free above, 1. 20, mute). "The romewhat unsatistactory nature of the results of those investigations furuduced, especially in thi-cuntry, a reaction in farvour of the unpurite method of treating bodies its if they were, so far at least as our experiments are concerned, truly continn. ous. This method, in the hamels of Green, Stokes, and uthers, hats ]cul to results the value wi which dues not at all depend on what theory we adoj, as to the uhtimate contstitution of bodies " (Clerk Maxwell, 'Scientific Papers,' vol. ii. p. 253). "After the French mathematiciums had attermited, with more or less ingenuity, to construet a theory of elastic solid. from the hypotheris that they consist of atoms in erpuilibrinm under the action of their mutual forces, stokes and others showed that all the results of this hypothesis, st far at leant as the! agreed with facts, uight be eleluceel from the postulite that elastive bodies exist, and from the liyputh. esis that the smallest portions intw which we ean divile them are sensibly homogeneous" (icl. ibid., 1. 449). 
Other kinetic theories.

scale, and the amplitude or height of the wave-motion 2. of which clecided its intensity. There was floating about the vague idea that heat also was to be interpreted as a mode of motion; still vaguer were the kinetic notions as to electricity and magnetism; whilst some early attempts to explain gravity, not as an inherent property of matter, but as a consequence of the motion of matter itself, which was possessed merely of inertia, had been half forgotten.

There is no doubt that the successful development of the undulatory theory of light induced many minds to dream of an ultimate kinetic explanation or interpretation of all natural phenomena, when in the course of the third quarter of the century this direction of thought received a great impetus through three independent branches of research of a purely theoretical kind. These have led to a very remarkable development of the kinetic view of nature; in fact it is mainly through them that this view has become possible not only in special departments, but on a universal scale. They have, each in its own way, led to a great extension of our experimental knowledge; one of them has likewise led to many practical applications. What most interests us here is the peculiar direction which they have given to a great volume of mathematical and physical thought of our day.

23.

Kinetic theory of gases.
The first of these lines of research was connected with, and grew out of, the atomic hypothesis. It culminated in the kinetic theory of gases, in which the names of Joule, Clausius, and Clerk Maxwell are prominent. Of this I have treated already in the fifth chapter. It rests on a study of the average effect produced by a 
KLNETIC OR MECHANICAL VIEW OF NATVRE. 35

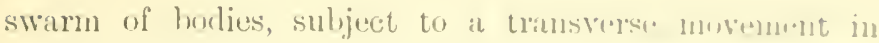
stratght lines like projectiles, and continntilly *monnuter-

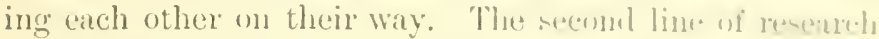

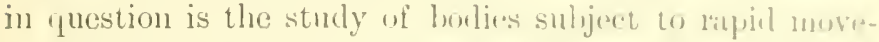
ment round an axis, lut immersed in a molium which is itself movable like wilter, but not in at lotin"l" lute merely in a flowing notions. The whole seleses at investigations which started hy letining surtex or whirling motion as distinct fonn transwerse, thowing, on projectile notion, and from viblatory to-and-fle motion, Wis initiated by Helmholts in 1857 in a pmoly matlumatical paper, and then applicel and greatly cotemoled by Sir Willan Thonson in the concention of the vortex atom. The thirel brancle of researeh hat its miorin in experimental investigations carriel on lor many years un peculiar lines, and guite independently, ly Fanality: it was put into mathenatical language by ('lelk Maxwell in his celelmated troatise on clectricity and magnetism which appeared in 187.2 . It will be ny ubject to show in how far these rlfferent investigations have confirmed and developed the kinetie view of natmal phemonesus. But before rloing this it will be well to realise what specific problems presented themselves to therenticisl physicists when once the undulatory ennception of linht had taken hold of their minds; what ]eculiar difticulties were involved; and into what distinct new lines of reasoning they were conducted.

We saw above that when the gravitational explanation of a large class of phenonnena had a century cinlier gradually gained ground, a great vallety of rescalledes was suggested by it, and new lines of reasming opened 
out, which in the course of the eighteenth century combined to establish what I termed the astronomical view of nature. The undulatory theory of light, established by Young and Fresnel during the first quarter of the nineteenth century, was a breaking away from what then seemed to many Continental philosophers a promising line of thought, a unifying principle in natural philosophy. As loug as light was thought to consist of particles, however minute, which were projected from luminous centres, the mechanical laws of impact, of attraction and repulsion, could be applied; and they went a considerable way in apparently explaining the ordinary phenomena of light, such as motion in straight lines, reflexion, and refraction. They failed indeed in the case of diffraction or inflection, and still more in those phenomena which were misleadingly grouped under the term polarisation. The new theory seemed specially adapted to these more recently discovered phenomena, but it had to be admitted that the explanation of reflexion and refraction of light at the surface of polished, transparent,

Problems as to the nature of the ether. or opaque bodies met with considerable difficulties. The new theory had introduced the conception of an allpervading, apparently imponderable substance, the ether. The reintroduction of this conception into physical science was repugnant to many thinkers of the then prevailing school, ${ }^{1}$ and it became more so when it hàd-

${ }^{1}$ One of the crucial tests for deciding between the corpuscular and the wave theory of light was the relative speed with which light travels in air and in water, i.c., in a refracting substance. Foucault, in 1850 , by a very ingenious method, improved since by Mitchelson, measured the speed of light in various media. He proved that light moves faster in air than in water, whereas on the corpuscular theory the speed of light in water must be to its speed in air as 4 to 3 approximately. "This finally disposed of the corpuscular theory" 
for the purpose of serving as tho carrier of at iletinite kiml of wave-motion-to he (andowed with most mys-

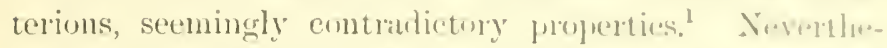
less the development of this eonception, the desim to define more minntely the properties of this fictitions substanee of whieh we have no linect freterption, canne

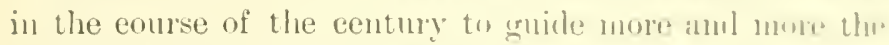
work of experimentalists as well as thanists. Wie mont with oljections in the hegiming, when the andeption wats tirst introduced, such as were meged hy many chemingl philosophers when l)alton reintrouheed amel formulited

(Tait, 'Light,' p. 192). Sir (i. ('. strkes tells us "that in a eourse of conversation with Sir David Brewster, who had just returued from France, where he witnessed the celebrated experiment by which Foucault had just proved experimentally that light travels faster in air than in water, he asked him what his objection was to the theory of undulations, and he found he was staggered by the idea in limine of filling space with some substance merely in order that 'that little twinkling star,' as he expressed himself, should be able to send his light to us" ('Burnett Lectures on Jight,' p. $15)$.

1 It is known that the two phis. asophers who in the nialdle of the century did more than any others to introrluce the positive or exaet spirit into general thinking and into philosophical literature, Auguate Comte and John Stuart Mill, were both opposed to the theory of an ether. Huxley, in speaking of Comte, exelains : "What is to be thought of the contemporary of Young and of Fresnel who never misses an opportunity of casting seorn upon the hypothesis of an ether - the fundanental basis not only of the nululatorg theory of light, but of so mueh elsie in molern physics, and whose contempt for the inlellects of some of the strongest men of his generation was such that he puts forward the mere existunce of night as a relut istion of the undulatory cheory " (see 'Philosophie l'onitive,' vul. ii. p. 440, amul Huxley, 'iay Sermoms, 1. 134.) The fourteenth eliapter of Mill's 'System of Logic,' written originally in the beginning of th. 'forties, but subserjuently' ammotated with reference to sime ui Whewell's criticisms, contains a lengthy discussion of the hypoth. esis of an ether. Mill sirys (vol. ii. 1. 21, seventh edition): "What has inost contributed to accredil the hypothesis of a physical meclium for the conveyance of light is thes certain fact that light travols, this its communication is not instan. taneous but reyuires time, aml that it is intercepted by intervening objects. "There ure anshurios between its phenomena and lluse wi the mechanical motion of a sulid os fluid substance. But we aro not entitleal to nsime that mechanioal motion is the only power in nature eapable of exhiliting these uteri. butes." 
the atomic view of matter. Similar uncertainties in the definitions exist in both theories all through the century, down to the most recent times. There are those who still look upon both conceptions as merely convenient symbolisms, as ideal instruments of thonght or scientific shorthand; and on the other side we have it as emphatically stated, that the question, What is ether? "is the question of the physical world at the present time," "that it is not unanswerable," in fact, "that it is not far from being answered," that "it is probably a simpler question" than the other question, What is matter ? ${ }^{1}$ The whole domain of physical science is even divided into two portions, the physics of matter and the physics of ether, ${ }^{2}$ and the older, more empirical, and common-sense divisions, treating separately of light, electricity, and magnetism, are assembled in one great doctrine, the "doctrine of the ether." It is, indeed, somewhat astounding, if not disheartening, to hear at the same time from an authority who has done more than any other living philosopher to enlighten us in these

1 Professor O. Lodge, in the Preface to the first edition of 'Modern Views of Electricity,' 1. xi. "It is simpler," he continues, "partly because ether is one, while matter is apparently many ; partly because the presence of matter so modifies the ether that no complete theory of the properties of matter can possibly be given without a preliminary and fairly complete knowledge of the properties and constitution of undisturbed ether in free space. When this has been attained, the resuitant and combined effect we call matter may begin to be understood."
2 See inter alia Professor Paul Drude's 'Physik des Aethers' (Stuttgart, 1894). In the Preface, p. vi, he speaks of the philosophical "desire of using the same fundamental conceptions for the physics of the acther as for the physics of matter, whereby it remains an open question whether it is more serviceable to reduce the equations in the physics of the xther to those ex. pressions which can be got from the observable phenomena in the physics of matter (the equations of dynamies), or whether the opposite road can be chosen with advantage." 
matters, that at the present moment he knum- at hulw as to the true natme of these agrencies m! suldstancen an lue did fifty yours ago.

Viewed from the position which we werups in this history of thought - i.r, in relition to thr invelupunent of icleas-the conception of an ether hats, lowwerer, like the atomie theory, hat the most matrenl inlluener on scientitic research and reasming. In ligrging for a hibliten treasure, in trying to describe the atoms or the whers. many practically useful conceptions, applicable to tancible phenomena, bave been discovered. The atomic; thenty led at once to an enommous increalse of our knowlenlere of difterent forms of matter, the knowledere of the elenents, and of their inmmerable possible connomuls. 'Thu' comception of the ether has led similaty to an enormm extension of knowledge of the diflerent possible forms of

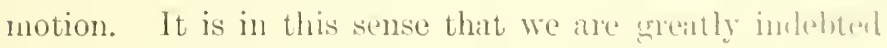
to these abstract eonceptions: hoth have guided on inleas in trying to understand and grasp the endless valriely of phenomena. Let us see how from the carly yetils of the undulatory theory of light om knowlerlese regarding the different forms of motion hats gromm, hum that theory has contributed to the kinetic view of nature.

1 Lord Kelvin, in referring to fifty years of scientific labour, sain (see the publication by Janes Iaclehose \& Sons of the proceedings at his jubilee in $1896, \eta .70): " 1$ know no more of electric and magnetic force, or of the relation between ether, electricity, and ponderable matter, or of chemical affinity, than 1 knew and trien to teach (1) my students of nutural philosopliy fifty years ago in $1 n y$ first session ats profe-sill. Ninue. thing of salness must comm of failure; lut . . What splemelisl compensition for philusiphlical liul. ures we have hat in the alunirath. discoveries by ubservition am ex. periment on the forpertics wi matter, and in the exquisitely beneticent applications of science in the use of nankind with whicls these tifty years have so il mumberl," 
It was recognised by Young, and still more clearly by Fresnel, that the medium which they supposed to be the carrier of light could not have the ordinary properties of either a solid, a liquid, or a gas. It offered apparently no resistance to the motion of the heavenly bodies, its waves were not like those which in air produced sound; it propagated its waves at a speed much wreater than any other velocity known at that time; at the same time the wave-motion was not that of a body possessing the properties of a gas - i.e., an elastic, compressible fluid: it was that of a body offering resistance to change of form rather than to change of bulk. It was evident that the different properties, which we see roughly assembled to constitute the three forms of ponderable matter with which we are practically acquainted, the solid, the liquid, and the gaseous, cannot be assembled in any similar manner in this imponderable substance, the ether. It was bound to

* have inertia-i.e., mass-otherwise the laws of motion could not be employed in dealing with it, and mathematical thinking about it would be impossible. A more perfect description of the elementary movements which constituted light evidently required a minute experimental study, and a closer mathematical definition of the different properties of matter, known popularly but not very clearly under the terms compressibility, rigidity, 27. mobility, elasticity, viscosity, \&c., and of the inter-deof elasticity. pendence of these clearly defined properties one on the other. Just about the time when the vibratory theory of light began to be seriously entertained by natural philosophers, a beginning had also been made in this study: the theory of elasticity had been founded in 
KINEIIC OR MFCHANICAL VIEW UN NAUURF, of 1

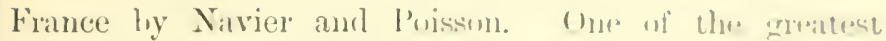
analysts of the century, Augustin l'unchy, hat likewise applied himself to it: aml when Flmsurs, in th"

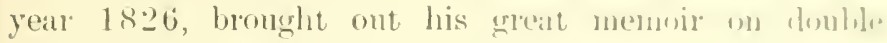
refration in erystals, in which he wats ohligerl to enter more elosely into the properties of the luminiferoms ether and its relation to ponderable natter, ('anchy was inducul to devote himself more specially to the mathemationd problems which presented themselves. Hedore his time the theory of elastieity had heen studied more as connected with questions of practical engineering, such ats the strengtle of materials, the stability of buildings, thes construetion of machines, or with the properties of musical and somuding holies. A new interest was ereaterl hy Fresnel's researches. 'The question arose, llow are we to describe the vibrations of an imponderable substance, endowed with mass (density) and rigridity, and what onnceptions can we form of the change of these vibrations if there is present likewise ponderable matter? Lridently upon the clearness and eorreetness of these notions depends the explanation of the phenomena olservable when rays of light fall upon the surfuces of transparent or opaque bodies. Wre have to ask: In what terms (viz., of different kinds of motion) eam we rlefine and describe, and accurdingly ealenlate the plemonena of reflexion, refraction, scattering (i.f., rlispersion), and absorption (i.f., extinetion) of light? A tolernbly rloar

I See Verdet in 'Gurres de Fresnel,' vol. i. p. lxxx: "I.es seuls écrits antérieurs ì Fresnel rù l'on trouve des notions justes sur les inégalités d'élasticité qui peuvent exister dans les eorps et sur leur répartition réguliore forr rapport it certains axes ou plans de symétrie sont ceux du grand mint. ralogiste allemand sammo] [ 'lıri-tiall Weis"(" Mém. de l'Acal. do berrlin," 1815). 
definition of the kind of motion constituting a pencil of homogeneous light in the free ether or in atmospheric air had been given by Fresnel. Experimentally the velocity of a wave motion of this kind was known; it was subsequently ascertained that this speed was not the same in air as in the free ether, the so-called vacumm. It was also known that this speed in an elastic medium, such as the ether was supposed to be, depends upon the density and the rigidity of the medium. But when rays of light-i.e, the wave-motions of the ether-arrive at the surface of liquid or solid bodies, various changes are known to take place. These changes had been to some extent described and brought into measurable terms by experiment, and it had been shown in a general way by Huygens, and more completely by Fresnel, how these observed changes of reflexion, refraction, and dispersion could be translated into the language of the vibratory theory. Complicated and yet very elegant geometrical constructions, at which Fresnel arrived by an intuitive or tentative process, ${ }^{1}$ enabled the course of rays inside transparent, doubly-refracting substances, such as crystals, to be calculated; a whole geometry of rays was developed out of these representations; new phenomena

1 The equation of the wave-sur. face was unt explicitly given by Fresnel himself. M. Verdet says ('CEuvres de Fresnel,' rol. i. p. lxxr): "F'resuel n'a pu lui-même venir à bout de ces difficultés et n'a su obtenir l'équation de la surface de l'onde qu'en la supposant a priori du quatrième degré, et calculant la valeur de ses coefficients de manière qu'ils satisfissent à certaines conditions faciles à déduire de la con- sidération des oudes planes normales aux trois plans de symétrie du milieu. Anipère est le premier qui ait effectué le calcul d'une manière rigoureuse." However, "the construction yields the wave-surface in such a way that its singularities are not obvious, and were only remarked by Sir W. R. Hamilton several year's after Fresnel's death" (Fletcher, 'The Optical Indicatrix,' 1. 31). 


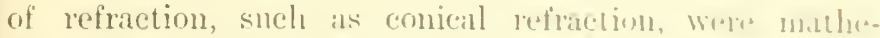

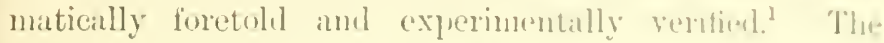
real physical ynestion, however, lemainml monswermel.

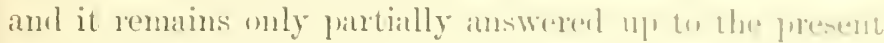
day. $^{2}$ How is it that the luminiferous other, whone oristing inside ponderable mattel, like air promenting it

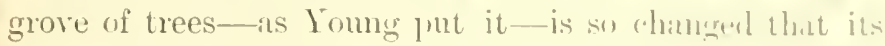
wares travel with variously altered specols, that in different directions the rays acquire diflerrent punperties, are diflerently maintained m partially extingruished (absorbed)? It was natural to suplust* that the particles of pondermble mattel must in smone way aftect the ether, elanging its density or its rigidity, and that they themselves are alfected by the mus'ment: of the ether which fills their interstices. 'l'he yuestion can only be exhanstively answred lis a complete know-

1 The subsequent sugrention of the phenomena of inner and outer conical refraction, experinentally verified by Humplirey Lloyil in 1833 (see his 'Mliscellaneous Pituer's,' No. 1, or Transactions, lioyal Irish Aeademy, vol, xvii.), was popularly. regarded as a complete proof of the correctness of the wave-surface, and of Fresnel's entire theory. But as to the first point, Sir (i. G. stokes showerl (Brit. Assoc. Report on Jouble Refraction, 1562, 1 . 270) that conical reiraction " must lee a property of the wave-surface resulting from any reasonable theory." Aiml as the wave-surface itself ean be geometrically constructed without any reterence (o) the mechanical theory of the ether (a.s Mr Fileteher has most exlaustively shown), the prediction of conieal refraction eamuot be re. garded as a proof of fresnel's theory. Todhunter- Pearsun =ilys : "but for Cituchy's marniticent inolecular researches, it might hirve been pusible for fresinel lo corn. pletely sacrilixe the infaut thenty of elasticity to that flimsy : stition, the mechanical dongma, on which he has exdeavoured to hrot his great disoveries in linht. Cinchy inspired Grenn, and fircen and his tollowers have doue sonis. thing. if not all, to reennile frow nels results wilh the nuw inlly developed theory of alasticity, the" growth of which his ilogunat at ant time seriously threntenel to check" "Hint. of Hasticity, wol. i. ]". 167 ).

" ln 1562 sir G. G. Stukm " *x. pressed his helief this the Iruo dynamical theory of double reliace tion lial get to be fouml" (lieport. 1. 268). 
ledge of the mechanism of the ether on the one side, of ponderable matter on the other. Two ways are open by which a solution of this ultimate or fundamental problem The problem can be solved. The one is purely mathematical. It of the ether may be treated mathematically,

means the analysis of all the possible modes of motion of a given mechanical system, and of the mutual influence which two interconnected mechanical systems, that of the ether and that of ponderable matter, exert on each other. This is a perfectly definite though a very intricate problem. It is a problem which can be compared withthongh it transcends in complexity - the analytical problem suggested by the gravitational view of physical astronony: to calculate mathematically the movements of any number of bodies attracting each other according

29. or experimentally. to Newton's formula. The other way is the experimental method - to observe how under methodically altered conditions rays of light are modified in colour (wave-frequency), in direction, in intensity (amplitude of wave-motion), in laterality (polarisation), and in other ways; and then to translate these conditions and alterations into the now fairly well-established language of the vibratory theory; gaining in this way indications as to the changes which the wave-motion is capable of, and inferring from these possible changes the original constitution (usually called the constants) of the primary substances - the ether and the ponderable matter which come into interaction.

30. Necessity of combining the two methods.

It may in general be stated that neither of these two methods has for any length of time been pursued alone, but that progress has nearly always depended upon an alternating employment or a combination of both. On 
KINETIC UR MECHANICAL VIEW WF NATCRE.

the one side we have a great volume of pumely analytical reasoning begun by canchy in liance, and punsment under varying assumptions by (ireen and Macculligh in Engtand, by F. Neumann and others in Germany. On the other side we have the purely experimental work beginning with Wollaston and Brewster in Englind, the refined methods for measuring the speenl of light inventul Jy Fizeau and Foneault, the beatutiful contrivances for experimental research and verification of Janin and many others. Ont of so many fruitul (onceptions which have resulted in an enomms acemumation of new knowledge of actual phenomeniz of light and watre-notion - the real and sole ent and aim of all theory- I will for the purpose of illustration single ont one which in the midale of the century opened out an entirely new tield of inquiry, forming almost a new seience ly itself. I refer to spectrum analysis.

The phenomena of dispersion (nanbow scattering) and absorption (partial or complete extinction) of light were among the earliest known, and had been among the longest studier, properties of hodies. Jieing, besides, connected with the physiological, subjective, and artistic effects of light, they have always commanderl speedal interest. And yet, so far as either the emission (1) the undulatory theory is eoncerned, they have always presented special difticulties. When the wave theory was first propounded, it was generally understmol on the analogy of the phenomenom of sound that differenses of colour depents upon difference of frequency, wh where the velocity of propagation (as in racuo or in itumsplutric air) is the same, on the length of the wares. The ditti- 
culty arose of explaining how in refracting substances, be they fluid, amorphous (singly refracting), or crystalline (including doubly refracting), these different rays, with different wave-lengths, come to travel with different velocities, and hence take different courses; how, further, some of these rays come to be extinguished or reflected (or both) in varying degrees.

Now, although the complete answer to this general question has not yet been given, a principle has been recognised which gives us a clue to the possible explanation of a large class of phenomena, and which is thus of remarkable fruitfulness. It was first laid down by Euler, ${ }^{1}$ a pure mathematician, whose physical reasoning was frequently suggestive but never particularly clear and definite: it was probably first applied to optical phenomena by Sir George Stokes: ${ }^{2}$ and it was later on used by him

In the last section of his treatise on light and colours ("Berlin Memoirs,' 1745 ; published in Latin, 1746), Euler treats of luminous. reflecting, refracting, and opaque bodies, and lie there mentions the analogy which exists with musical resonance. "The smallest particles [of opaque bodies] are similar to stretched strings, which are, as it were, specially receptive for certain vibrations, which they can assume without being struck, if only they are affected by the undulatory morement of the air." "In his expositions upou light ánd colours, Euler always starts with the analogy of sound and light; he follows it with absolute cousistency" (Cherbuliez, "Eulers physicalische Arbeiten,' p. 44). This analogy was exactly what was absent in the in. restigations of Brewster, who remained to the end an adherent of the projectile theory. Balfour Stewart came nearest to the true explanation in his memoir of 1858 ("Trans. of the Royal Society of Edinburgh,' 1861); but this referred to radiant heat and to Prévost's theory of exchanges. It contains the words: "The absorption of a plate equals its radiation, and that for every description of heat" (p. 13). Had this statement been distinctly applied to luminous rass, spectrum analysis would have been his discovery, although his theoretical proof might be regarded as insufficient (see Scheiner's treatise on Astronomical Spectroscopy, transl. by Frost, 1S94, p. 112; also Rosenberger's 'Geschichte der Physik,' vol. iii., 1890 , p. $482^{\prime} s q$.)

2 See the references gicen on p. 277 of the first volume of this history. 
RINETIC OR MECHAXICAL VIEW UF NATULE, \&7

in giving a mechanical explanation of the dark and liright lines of the spectrum, upon which Kirchlmti and limaten fommlerl spectrum analysis about the yeatl 1860.

Wollaston " had in 1802, on eximnining the stilin spectrum (the succession of rainhow colnums explatmber on a white screen placed behind a prisu uf white flans through which a nanew leam of smulight is maule (u pats?. noticed that with a sullicient enlargement lularke lines in great number conld be detected. Framhotir, in Munirh, mate a special study of them, named them by loters of the alphabet, and eompared the solar spectrum with the spectra of artificial terrestrial somces where limht is ereated by combustion or incinclescence. He fomnd ilutt these spectra differenl, the peculiar colsur exhibited hy various thames being defined in the spectrat ly special bright lines of different coloms. Thus motilly the two dark lines called by him $D$ in the solar spectrun were replaced in the spectrum of a Hame in which a volitile salt of sodium was present, by two hright lines: Hrewster found the same eoincidence of others of Frambliter's lines with the bright lines of a flame in which nitre Was volatilised. Very similar and rery accurate observations of A. Millar as to the identity of the dark lines I) in the solar speetrum with the two bright lines of the sudium Hame were explained by sir G. Stokes about the gear 1850 by the following theoretical reasoning: The stulimm sioke.s.

1 "A method of examining reiractive and dispersive powers by prismatic reflection" ("Traus. of the Royal Society,' 1802).

2 Fraunhofer, whose epitaph, "approximavit sidera," describes beautifully his life-work, was led to the discovery of the lines namerl after him in his investigations of the "refractive aml tispersive frowers of various kinds of glass" for the purpuse of improving the achromatic telescopre " lenkisluriften der Minchener Akiblemie, vol. i., $181+1-15)$, 
Hame which emits the two bright lines in its own spectrum destroys them (replacing them by two dark lines) in the spectrum of a ray of light which passes through the sollium flame. ${ }^{1} \quad$ Foncault had in 1849 already shown the direct reversal of the sodium line in the spectrum of the electric arc. These earlier auticipations remained partly umnoticed, partly unknown, or were looked upon 34. as isolated cases, and it was reserved for Gustav KirchGustav Kirchhoff. hoff to put this remarkable property of emission and absorption of special colours by coloured flames into practical language, and express it in a general way. $\mathrm{He}$ wrote in $1859::^{2}$ "I conclude that coloured flames in the spectra of which bright lines present themselves, so weaken rays of the colour of these lines, when such rays pass through them, that in place of the bright lines, dark ones appear as soom as there is brought behind the flame a source of light of sufficient intensity, in which these lines are otherwise wanting." And when he concluded further that the dark lines of the solar spectrum which are not evoked by the atmosphere of the earth, exist in consequence of the presence in the sun's atmosphere of those substances which in the spectrum of a flame produce bright lines at the same place, "he at once gave

I From this lie inferred that the presence of sodium vapour in the atmosphere of the sun would explain by absorption the two dark lines in the solar spectrum. Lord Kelvin reports that in consequence of this observation of Stokes he regularly taught his Glasgow students that sodium must be in the sun's atmosphere. See the reprint of the correspondence on this subject in the 'Gesammelte Abhandlungen' of
Kirchhoff, 1882, p. 639, where it will also be seen that Sir W. Crookes claimed a similar anticipa. tion for Millar in 1846. See also Sir W. Thomson's ninth Baltimore Lecture.

2 See the translations of Foucault's and Kirchhoff's memoirs sent by Sir G. Stokes to the 'Philosophical Magazine' of March 1860 , p. $194 s q q$. 
birth to two great applications of his forinciphto-the search, through the study of the spectrat of distant stellat somces of light, after the ingredients whirh ant frestent in those distant Imminaries, and the suanch, through the study of the flames of terrestrial substimers, for $110 \mathrm{~W}$ spectral lines ammouncing yet undisoovered olements." Whilst in these two independent directions an anormons amount of new knowledge has been acommulaterl, thes mechanical explanation through which sir (i. Stuhes anticipated these phenomena, am the further anplications of this principle by him, have dome much to confirm the conviction, that in looking upon light as a vibratory mentes of motion, we are on the road towarls an andequate deseription of these phenomena.

1 To this principle we owe the spectrum analysis of stellar atmoipheres and the discovery of new ehemical elements, of which no fewer than six have been iden. tified by this method, beginning with cesium and rubilium (found by Kirchhoff and Runsen in the waters of some mineral springs). The suggestion of Doppler, mentioned alove (p. 10, note), has only become fruitful through the invention of the spectroscope. Colour differenees originating through the change of the frequency of vibrations depending on cosinical velocities in the line of sight, could not be diseovered by the most. sensitive eye. In the spectrum, however, shown by the spectro. scope, "not only the colours of the briglit lines have been altered, but their position in the spectrum relatively to a fixed point if reference as well. . . . The ineasurement of the displacement of spectral lines in eousequence of the alterel refrangibility of the rays is the only

VOI. II. method yet know which ponensex sufficient accuracy for determining the motions of whjects in the line of sight. Thus far it has not been possible to produce in the laturatury velocities high enough to occasion a perceptible displacement of the lines" (Scheiner, loc. cit., 12. 115). And as Doppler's priuciple in acoustics was proved directly by Buys Ballot through the whistle on moving railway trains, so it has been proved directly in apties by observing the displacement in the lines of the solar spectrum, when this is lerived from the wuter rays of the sun's disc, the light-giving parts moving in the line of sight towarls or away from the chlserver in emserfuence of the rotation of the sun round its axis. "The re. sulting velocity of the surface of the sim is fouml to ngres vers. closely with the results of liment. ubservations of the revolution of the spots, thus practically furnishing a proof of the correcthess of Doppler's principle" "ihid., p. 14?. 
We have seen abore how the ribratory theory of light was arrived at-mainir in the hands of Young-through dwelling on the analogs of certain optical phenomena, notably those of interference, with the properties exhibited br sound. Among the latter none rere more remarkable than those knomn popularly as consonance and resonance. Sir George stokes, on the appearance of Kirchhofis memoir on the relation of emission and absorption of certain rars of light, gare the mechanical explanation in the following words: " "In describing the result of a prismatic analrsis of the roltaic arc formed between charcoal poles, M. Foucault found that the arc presents us with a medium which emits the rars $\mathrm{U}$ on its own account, and which at the same time absorbs them when ther come from another quarter.' . . . The remarkable phenomena discorered by Foucault, and rediscorered and extended by Kirchhoff, that a bodr mar he at the same time a source of light, giring out rars of a definite refrangibility, and an absorbing medium extinguishing rars of the same refrangibility which traverse it, seems readils to admit of a drnamical illustration borrowed from sound. We know that a stretched string which on being struck gives out a certain note. is caprable of being thrown into the same state of ribration br aerial ribrations corresponding to the same note. Suppose now a portion of space to contain a great number of such stretched strings, forming thus the analogue of a "medium. It is evident that such a medium, on being agitated, would give out the note abore mentioned, while on the other hand, if that note were sounded in air at a distance. the incident vitrations would : 'Phil. Mag.:' March 1860, pp. 194, 196. 
throw the strings intu viluattion, annl ennserfunthty woml I themselves be gradnally extingushed, since otherwin. there would be a creation of eis tim. The optical ilpllirattion of this illustration is too obvious to ment (onnunent,"

\section{Already ten years before kirchboll gatve to tho} researches into the speetrum their jupmlar celebrity and pratcieal importance, stokes ${ }^{1}$ hal matlo an extensive ex-

1 The memoir of Sir (i. Stokes "on the change of the refrangibility of light," in the "I'hilos. "Transactions" (May 1852), forms a landmark in optical science, ausd whilst dealing with the less obvious - though rery frequent aul general - phenomena of tluorescence anil phosploresceuce, reilly indicated the line of reasoning which liat become so fruitful and suggestive in his own lands and in those of other eminent natural philosipphers. On page 5.19 of that memoir he wrote: "All believers ii the uudulatory theory of light are agreed in regarding the production of light in the first instance as due to vibratory movements among the molecules of the seliluminous body. . . . Nothing then seems more natural than to suppose that the incident vibrations of the luminiferous etlier produce vibratory movements amoug the ultimate molecules of sensitive substances, and that the molecules in turn, swinging on their own account, produce vilirations in the luminiferous ether, and thus cause the sensation of linht. The periodic times of these vibrations depend upon the periuls in which the molecules are disposer to swing, not upon the periodic time of the incident vibrations." lieferring, then, to the dymamical difticultics which attach to such a view, he proceeds to point out "that we have no riglit t" regard the inolecular vibiutions as indetinitely small. The excurrsions of the atoms may be, and doubthins are, excesively small comparml with the linear dimensions of at complex molecule. It is well know that chemical changes take place under the inlluruce of light, expecially the more retrangible ribys, which would not otherwive hitpren. In such cases it is plain that the molecular disturbances must not he regarded as indetinitely small. but viluations maty very well take place which do not go to the length of complete lisiuption anl yet which ouglit hy no means to be regarded as indefinitely small.

Certainly we cannot affirm that in the disturbance communical el back again to the luminiferous ether none but periodic vibrations would be produced having the sime period as the incilent vibritions. Rather, it seems that a sort ui irresular motion must be producerl in the molecules, periolic only in the sense that the molecules retain the same mean state ; and that thdisturbance which the moleculen II turn communicate to the ether must be such as cammot l, by circular functions of it given periol, namely, that of the incirlont vibrations." Situkes then refers un the probable intermal vihration of the atoms in the eompunmel mole. cules, as " it is chictly ammg mandmic compounds. . having a eomplite caterl structure that intermal ilis. persion (thurescence) is inuml." 
amination into the question how vibrations of the luminiferous medium can be mechanically transferred to the compound molecules of a transparent body, and retransferred again to those of the ether itself-i.e., the question of the absorption and enission of light. He showed that vibrations of a certain period, corresponding to a definite tint of colour, could eventually give rise to vibrations of altered period in the emitted light; that this period, however, must always be longer--i.e., that the new colour must always be of a lower order in the scale of refrangibility. He was thus not only able to explain mechanically the peculiar lmminosity which he termed fluorescence, ${ }^{1}$ and which had been observed by Herschel and Brewster in certain minerals and solutions, and independently studied by E. Becquerel in France, but he also showed how, by means of such substances, rays of light which, owing to the frequency of their vibrations, transcend the perceptive powers of the human eye, can be made visible by giving rise to secondary waves of less frequency. The line of reason-

1 The term fluorescence was coined by Sir G. Stokes by analogy with opalescence as involving no theoretical suggestion, in place of the earlier names of "interual dispersion" or "epipolised light" used by Brewster and Herschel. $\mathrm{He}$, however, very soon favoured the term " degraded light," suggested by William Thomson (Lord Kelvin) (see the second memoir, 1853 , p. 387). The latter was at that time occupied with his celebrated and not less epoch-making researches referring to the dissipation or degradation of energy, of which more in the next chapter. If we remember that fifty years ago the term radiation was not yet generally used to embrace the invisible chemical (ultra-violet) and caloric (infra-red) rays; that photography, which more than any other process has familiarised us with chemical radiation, was a comparatively recent inrention; that the ideas of conservation, conversion, and degradation of energy were quite new; that the general term euergy had not even been invented, -we must indeed regard the words of Sir G. Stokes as containing a prophetic programme of the ideas and problems of the whole subsequent period down to quite recent times. 


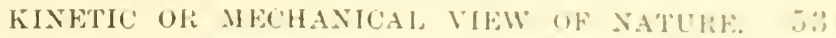

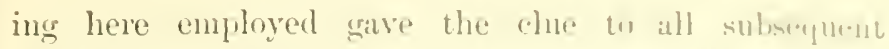
attempts to deal with the ditricule problen wi the incroaction of the ether and pomberalile matter: wi the pussible alteration of the density ar the rigrility culled the elastic constints) of the ether when filling the interstices of transparent hodies: of the nechanieal difforences which make some bodies transparent for some and "panple bol other rays of light. Many possible modifications were theoretically foreseen, giving rise to remarkitble unexpected phenomena, and these were irepuently varitied hy subsequent experience. The whole thency of light entered upon a new phase as it hecamme nore ambl more evident that the stuly of the vilnations of the elastic nedium was not suffieient, but that it must besupplemented by that of the interation of two viblating systems, the ether and the molecules of the pomderalil. substance, which givo rise to the phenomena of protial reflexion, refraction, dispersion, and jartial or conpleter ahsorption. This more complicater problen in the? theory of elasticity had already presented itself in its simpler form in the theory of the renchmm. Th the principle of optical consonance which had lecen employed to explain the phenomena of absorption of light was added, in order to explain the phenonenta of clispersion, the principle of the free and forced viluations of a vilurating system. ${ }^{1}$

I "If to the bob of a pendulum, exeeuting horizontal vibrations, another yendulum be attachei, executing vibrations of a slightly shorter period, the effect of the latter will be to inerease the period of the former and vice versi" (see

Anomalous dispersion such as was foreseen by sellmeiey und larit Kelvin ant diseovered ly Christiansen and kiumlt degends on the change of wave frepuency intepen. dent of the change ui wave length in refracting media. 
36.

View of the ether as an "elastic solid."

The latest discussion of this form of the elastic-solid theory of light, which was gradually developed from independent beginnings in the three countries, ${ }^{1}$ is to be

1 In France and Germany, where even in the middle of the century the labours of English natural philosophers like Green, M'Cullagh, Stokes, were only very imperfectly known, the necessity was equally felt of stuctying the interaction of the ether and ponderable matter. In France the school of the eminent "elastician," Barré de St Venant, produced in M. Boussinesq theauthor of the earliest published attempt to solve the difficulties which the older methods of Cauchy had not overcome. In a lucid review of the state of physical optics, Saint Tenant himself ("Ann. de Chimie et de Physique,' $4^{\text {me }}$ série, vol. 25, 1872) hails with delight the researches of M. Boussinesq from 1865 onward, where the iclea that the ether in the interstices of transparent bodies has different elastic constants is given $u p$, and the participation of the ponderable matter in the vibrations is introduced in its place. "En effet," he says, "il est bien difficile de concevoir, d'une part, que l'éther puisse être agité au sein d'un corps dont la densité est probablement bieu supérieure à la siemme, sans lui communiquer une fraction sensible de sa quantité cłe mourement, et d'autre part, que les ondes ne soient pas bientôt éteintes par cette participation de la matière pondérable au mouvement s'il n'y a pas concordance entre les oscillations inprimées à chaque molécule de cette matière et celles de l'éther qui l'environne." It was the problem of the contiuuity at the interface of reflecting and refracting substances and the problem of absorption which the older simple ether theories could not explain.
In Germany a similar impulse was given to the study of the interaction of elastic systems-as indeed to many problems of mathematical pliysics-by Frauz Neumaun, who was the centre of a numerous and influential school. He taught at Kïnigsberg together with Richelot and Bessel. His lectures have been edited by his pupils. Prof. Karl Pearson, in his continuation of Todhunter's 'History of the Theory of Elasticity,' does ample justice to the labours of Neumann, who, "in his investigations on ploto-elasticity and the elasticity of crystals, breaks almost uutrodden ground, which both physicists and mathematicians have hardly yet exhausted" (loc. cit., vol. ii. 2, p. 183). "Neumann was among the first (1841, "Ablı. der Berliner Akademie') to attribute dispersion to the influence of the ponderable particles on the particles of the ether" (ibict., p. 31). The most important original contributions of Neumann's pupils are the researches of Sellmeier, who had been led by theoretical considerations in 1866 to expect certain anomalies in the phenomena of dispersion, such as were in 1870 actually discovered by Cliristiansen, and fully investigated by Kundt. Surface coloration was shown to be intimately connected with the absorptive powers in substances showing these anomalous phenomena. A full report on these and other theories, based upon what has been termed abroad the "BesselSellmeier hypothesis" (see Ketteler, 'Theoretische Optik," 1885), will be found in Prof. Glazebrook's "Report on Optical Theories," Brit. Assoc. Reports, 1885. 
KINETIC OR MECHAXICAL VIEW UF NATLIR: Jj

found in Lord Kelvin's celehrated lialtimene lectures, where with mlinited resomeetulness the methoth of analogy, analysis, and experinent are employed to sulwe or to define the intricate problems of phisical eplich. Nor is it a merely fortuitums coincidence for the history of thomght that, whilst his mind mmst have been fillul with the many ilhstrations and nechanical devices, aml all the wealth of sugerestions container in the bialtinose Leetures, Lord Kelvin should have delivered the openinger arliress to the mathenatical section of the liritish Association, entitled, "Steps towards a Kinetic Theory w" Matter." Following-as did also Clerk Maxwell-on the lines indieated by stokes's earlier palpers, lue has done molh to change our fundanental conceptions as to the properties of matter, and this in two distinct ways. The first consisted in breaking down the rigid hatrins which popular definitions had set up hetween the lifferent forms of aggregation - the solid, hiquid, and grisents states of matter: whilst the second tencled to show how

1 The Baltimore Lectures were delivered by Lord Kelvin (then sir W. Thomson) after the meeting of the British Association at Hontreal in the mouth of Oetolver 18\$4, at the Johns Hopkins University, before a company of physicists. The final edition of these important and highly suggestive conterences is in the press as the fourtl volume of the colleeted mathematical amd plysical papers. The completion of this publication is eagerly expeeted, as containiug the most mature exposition of the elasticsolid theory of light, towards whieh the author has in the course of the last fifteen years male various valuable additions. Notably in a paper dated 1885, published in the ' l'hilosophical Magazine, he has, as it has been sail, "extricitenl the elastic theory trom the pusition wi deadlock, accorcling to which the ether must be buth conume-sible and incompressible," by showing that the ditticulty enu he met, "1, rovided we eithersuppore the medium to extend all through berumblex space, or give it a fixed éntaining vessel as its hounlary." l'ruf. Glazebrouk has further worked wut the consequences of this suggestiun. See vols. 26 and 27 of the 5 th seriess of the 'Phil. Mtag.,' alsu : Nature. vol. 40, 1859, 1. 32, and Fletcher, the 'Optical Inclieatrix,' p. o. \&c. 
the supposed static properties of matter could be explained by different modes of motion, translational, periodic, or rotational. The mathematical and experimental investigations comnected with the theory of radiations and vibrations had thus an influence ${ }^{1}$ on our general views of the nature of physical processes which far exceeded the aims for which they were originally undertaken. That a substance so attenuated as the ether should have the properties of a solid; that brittle substances like pitch should flow like liquicls, if only sulficient time were given; that towards very rapid impulses gases and liquids might behave as solids-all these observations resulted in a complete revolution of our scientific notions as well as of our vocabulary. The great turning-point, indeed, lay in the kinetic theory of gases, which about the middle of the century had introduced quite novel considerations by showing how the dead pressure of gases and vapours could be explained on the hypothesis of a very rapid but disorderly translational movement of the smallest particles in every possible direction. Pressure of gases having been explained by a very rapid motion of the minute particles of matter, heat was immediately conceived to be merely a "mode of motion." As no event did more to spread modern views in the theory of light, and to popularise modem scientifie methods, than Kirchhoff's

${ }^{1}$ It has been asserted that the theory of elasticity received a great impulse when Fresnel was forced to make assumptions as to the mode of vibrations of the ether which were quite incompatible with the then accepted laws of the vibrations of an elastic medium. Tothis view of the origin of the modern theory of elasticity Prof. Karl Pearson takes exception, as Navier's memoir of 1827 was not suggested by optical investigations (Todhunter-Pearson, vol. ii. 2, p. 5 ). 


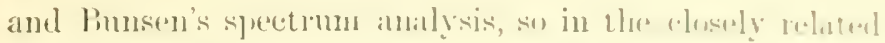
doctrine of heat, probalsly no publication dis nume w establish a general kinetic view of mattre amb of matmial phenomena than 'Tyndall's celebrated treatises, "Hout at it

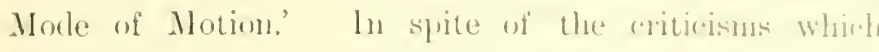
Thyeats $11+2 t$ have heen levelled agrinst this explession, ${ }^{1}$ the houk, which appeared in $1860 ;$, was to the populat miml it revelation; it was translated into namy foredgn lampruteres, ran through many editions, was recommnented hy thinkers of the first order, and the title coveted as "manifosting far and wide through the world one of the arratest discoveries of molern philosophy." 2 It is the pmplatr herald of the kinetie or mechanical view of matmre.

The same great anthority who las so generonsly referred to 'Tyudall's treatise-Lond lielvin-had been inspired from quite a different quarter to surgest tho most advanced conception, in this line of thoustht, of which the human mind has so far been calable: the

1 Notably by Prof. P. G. Trit; see his rolume on 'Heat,' ]. 350 , also his 'Recent Advances of Physical Science,' which contains as an appendix his lecture on "Force," delivered in Glasgow on the oceasion of the meeting of the British Association. He says there: "Heat and kinetic energy in general are no more modes of motion than potential energy of every kind is a mode of rest.' "Heat is not the mere motions, but the energy of these motions."

There is no loubt that the terms force and motion can be used in very different meanings, and that the carly expounders of the ne. chanical theory of heat have not been always eonsistent in the use of words; though their ideas, wher. ever they appeared in mathematical expressions, were letinite enough. A good deal of vigueness lias atccorrlingly crept into popular textbooks and into philosuplicil treat. ises, and criticisus such as throte of I'rof. Tait have been uselul in helping us towards clearer cons. ecplions. We shall cone ancoss uore of these instances in the $11 \times \mathrm{xt}$ chapter when dealing with the gradual evolution of the conceprim of energy.

" see Lord Kelvin's alstlitet of leeture, "Elasticity vicwed nis possiliy a Mode of Ilotion," $1 \leqslant 81$; 'Popular lectures,' \&e., vol. i. p. 142. "I have always alumirel it" (viz., Tyudall's title); "I lave lung coveted it for elasticity, and now; by kind permissiun of its Inventur, I lave borrowed it for this climcourse." 
vortex theory of matter. As this is one of the most remarkable instances of the fruitful reaction of abstract mathematical reasoning on the progress of physical research, it will be useful to consider for a moment by what gradual steps this novel idea was evolved or suggested. The immediate occasion which led to it was 40. the publication, in 1858 , by Fielmholtz of a purely Helnholtz's investigations.

mathematical investigation of some peculiar forms of Huid motion. ${ }^{1}$ About a hundred years before Helmholtz published his memoir, Euler had laid the foundation of theoretical hydrodynamics - i.e., of the theory of the motion of fluids. In doing so, it was necessary to define

${ }^{1}$ Helmholtz's inemoir, "Ueber Integrale der hydrodynamischen Gleichungen welche den Wirbelbewegungen entsprechen," appeared in the 55 th volume of Crelle s 'Journal für die reine und angewandte Mathematik.' It was trans. lated into English by Prof. Tait in the 'Philosophical Magazine' for 1867. Helmboltz's occupation with the subject had originated in the acoustical researches which he was carrying on at the time. These necessitated an analysis of the more complicated conditions which the motion of incompressible and elastic fluids presents in actual experience. The hydrodynamical equations had been solved under certain simplifying assumptions. Discontinuity of motion and interual friction had been left out of consideration. Helmholtz's re. searches led him to the study of these more complicated phenomena ; and he successfully applied the mathematical methods which liad proved useful in other branches of physical science for the solution of these problems. Notably in the paper on whirling motion, he came upon very remarkable and unexpected results, which ten years later led in this country to the novel speculations of Lord Kelvin. It is interesting to note how at that time researches in England or Germany could for many years remain unnoticed in the other country. The result was that the same problems were frequently taken up in ignorance of the fact that they had been treated before. See Hicks's "Report on Hydrodynamics," "Brit. Assoc. Reports,' 1881-82. Especially the labours of Stokes seem to have been little kuown to German writers, who usually started from the better-known French researches. Stokes had anticipated some of Helmholtz's results referring to whirling and discontinuous motion of fluids. About the middle of the century the periodical "Fortschritte der Physik" was started by the "Physikalische Gesellschaft" of Berlin. Helmholtz himself contributed several valuable reports on acoustical subjects. See the 'Wissenschaftliche Abhandlungen,' vol. i. passim. 


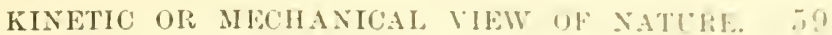

mathematically what is meant hy a lluirl. 'The m.livel property of a tluid, as eompaturl with at sulin lumly, in the perfect mobility of its parts, the alsenen of rierilits. Thus there were two possible kinds uf lluids thome which retained their lulk ol solume, whilst nlliding mu resistance to change of shape, and those whirh triml tu

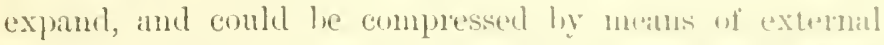
forces. These latter were ealled gatses. In teilling with the former, incompressibility hal to he trotimel mathr. matically, as also perfect mobility. These poundies constitute what is called a perfect thicl. simele prefint Huids do not exist in nature; lont the methonl of leasoning was to begin with an icleal, simplo case, and approach the explanation of natural phenonnonal ly at process of correction, introdneing nore amel mure rosnplications. The phenonena of the How of liquils, practically by far the most important, conld le studier to a sreat extent ly means of the simplest finne of the hydrodynamical conception, and up to the midelle wi the eentury such problems, as well as thrse of the propitgation of small displitcements muler the atcion of externat

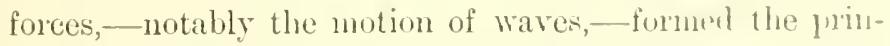
cipal problens which were treater mathematically. "I'se itea of the friction of Huids, also ealled viscosity, had been excluder in the definition of a tluil, inasmuch as finction opposed the notion of perfect nobility uf the jants, which was the mathematieal defintion of at fluid. Now it is at matter of experienee that in all liquids with which we are acquainted friction ean produce rotational motion, such as whirls and eddies; it was also fommet that other forces, such as magnetic forces, are, muder crotatin cuns- 
ditions, able to produce these rotations. It was therefore of interest to study the nature of rotational or whirling motion, if such could exist in a perfect liquid, and to see what would be likely to happen to these whirls. Though it might be difficult to understand how in a perfect liquid rotation of any portion could be produced, calculation might determine what would be the nature and fate of such whirls, if they did exist. The problem was a purely mathematical one. Can a rotational motion, a whirl, exist in a perfect fluid, as defined by the mathematical conception? If it can, what are the properties of such whirls, and what becomes of them? Helmholtz solved these questions in his now celebrated treatise, showing that whirls (called by English writers vortices) can exist, but only under certain conditions, such as can be experimentally represented by smoke-rings issuing from an orifice; that, if they existed in a perfect liquid, they would be indestructible and would possess a motion of their own, giving them a special individual character as to permanence and movement. The treatise, like the problem, was a purely mathematical one, ${ }^{1}$ and in the mind of the celebrated anthor was probably connected more with the problem of the formation of drops, and with that of the friction or viscosity of fluids, which he attacked subsequently, than with the nature of matter. In this country vortex motion had already been studied by natural philosophers with very different ends in view.

It was known that solid bodies which are in a rapid

1 It revealed incidentally the analogy of hydrodynamical and electrical phenomena. 
KINEIIC OR MECHAXI'AT, VIFU OF DATLEF, ¿I

lotaly nution acquire properties which they du nut

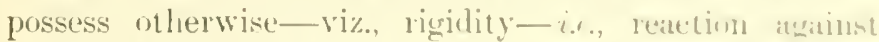
change of shape (the stifliness of a travelling rofe them off a pulley is a familiar illustration): stabilitt-i... re. action agranst cluange of position and motion, ats in at syjuning-top or a bicycle : elasticity-i.t. tendency to revert to

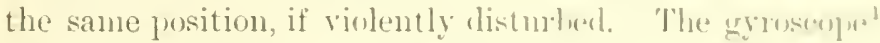
had been invented in 1852 hy Fincanlt, aml nsed lis him and other physicists in Funce and fienualy te illustrate the rotation of the eath. It wits lum shewit that poltions of a perfect thid-i.t, of a lmoly which possesses neitler rigidity, nur stallility, nol chativity -when in a state of lapjel rotational motion, acpuine these syostatic properties: that whirling portions annot lie natmally created, but that if once in existences they preserve their identity, being permanemtly dillerentiated from the surromeling lluid, which nuy be at lest or in the state of How. 'These differentiated jurtions wit the liquid were called hy Helumbltz rortex tilamests: le showed that in a liquid without a bumblaty they must rum back into tlenselves, fomming rings whinh might be knotted and linked together in many ways.

1 A muel older invention was that of Bohnenberger (1817), known by his name. The name "gyroseope" was iutroduced by Foueault ; and that of "gyrustal," as defining an apparatus which acquires stability through rotational (whirling or gyrating) motion, was uned first by Lord Kelvin. An extensive treatment of the subject is to be found in the first pirt of Thomsun and Tait's 'Naturil Ihilosoplyy' (2nd el.), pl. 311-\$15.). It is mainly through the intluence of this work, and through the inexhaustible wealth of experr. mental illustrations contained in many of loorl kelvinis adilresson (see" 'lopular Jectures and Ad.

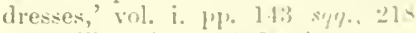
$8 q 7$. ; iii. 165 sq\%., 245, that syru. static and vortex mution ham becoume in this country a fitwourite study of mathenaticians and nalural phil. osoplers, and forms an impertant feature in almoat every recent attempt u describe the properties of matter aml ether. 
42.

Influence of Helmholtz's speculations in England.

It does not seem that Helmholtz's speculations were much taken up abroud; in this country, however, they fell on more fruitful soil : ${ }^{1}$ they led first of all to

1 It is a remarkable fact that the country which produced the great theory that finally destroyed the older vortex theory of Descartes, was the one in which, a century after Newton, the modern views on vortex-motion were first and almost exclusively developed. Notably the scientific atmosphere in which Thomson and Tait moved was, inter aliu, charged with the bold ideas and the suggestive nomenclature of Macquorn Rankine. He owes his permanent place in the history of science to being side by side with Lord Kelvin and Clausius, one of the three founders of theoretical thermodynamics. But he was in addition to this perhaps the earliest and purest representative of the kinetic or mechanical view of natural phenomena, and of the scientific tendency or habit-derived from his profession as an engineer-of constructing for every phenomenon to be explained a mechanical model. In a succession of memoirs beginuing in 1850 , Rankine put forward his theory of "molecular vortices," "which assumes that each atom of matter consists of a nucleus or central point enveloped by an elastic atmosphere" ("Scientific Papers of Macquorn Rankine,' ed. Miller, Londion, 1881, p. 17). Clerk Maxwell in $187 \mathrm{~S}$ wrote of Rankine's theory: "Whatever he imagined about molecular vortices was so clearly imaged in his mind's eye that he, as a practical engineer, could see how it would work. However intricate. therefore, the machinery might be which he imagined to exist in the minute parts of bodies, there was no danger of his going on to explain natural phenomena by any node of action of this machinery which was not consistent with the general laws of mechanism. Hence, though the construction and distribution of his vortices may seem to us as complicated and arbitrary as the Cartesian system, his fillal deductions are simple, necessary, and consistent with facts. Certain phenomenawere to be explained. Rankine set himself to imagine the mechanism by which they might be produced. Being an accomplished engineer, he succeeded in specifying a particular arrangement of mechanism competent to do the work." Maxwell goes on to say : "As long as the training of the naturalist enables lim to trace the action only of particular material systems, without giving him the power of dealing with the general properties of all such systems, he must proceed by the method so often described in histories of science - he must imagine model after model of hypothetical apparatus, till he finds one which will do the required work. . . The theory of molecular vortices was distinguished from other theories which attribute motion to bodies apparently at rest, by the further assumption that this motion is like that of very small vortices, each whirling about its own axis" (Clerk Ilaxwell in ' Nature,' 1878 ; 'Scientific Papers,' vol. ii. p. 662, \&c. ; and Prof. Tait's memoir of Rankine in the 'Collected Papers,' p.xxix). In the most recent attempt to reconcile the two fundamental ideas without which we do not seem to be able to proceed in a description of natural phenomena - viz., that space is a plenum, filled by a continuous something, and that matter 
KINETC OR MECHANILAL VIEW OF XैATTIR 63

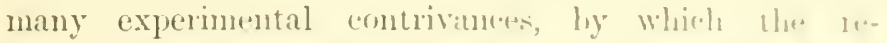
markable phenoment knumn ats "mgrustitir"

the stable properties of holies in rapoil rotar? muntions could he sturlied, as also to the rlevelupeneme wi the

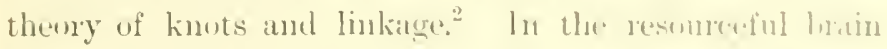

(and electricity) is atomic (disercte, graiued), 1)r Laruor has traced the molern rortex theory further back beyond Rankine to ,lanes Maccullagh, who in his "Emay towards a Dymanical Therry of Crystalliue lieflexion and Refraction ' (Trans. Irish Academy, 183!), "arrived at a type of elasticity (of the ether) which was wholly rotational, . . somewhat atter the manner that a spinning flywheel resists any angular deflection of it.s axis" (p. 26 of his Adans prize essay, 'Ether' and Matter,' 1900). "Rankine, never timid in lis specuJations, expounded AlacCullagli's analy tical scheme soundly and clearly, in full contrast with the elastic properties of matter, as representing a uniform medium or ylenum endowed with ordinary inertia, but with elasticity of purely rotatiomal type " ihid., 1. 77; cf. p. 73) ; but lie also remarks that "up to the period of Lord Kelvin's vortex atoms. . . the earlier theories... could only lave been hypothetical speculations" (p. 25 note!

1 Helmholtz himself did not give many practical illustrations of his remarkible theories. Such were first given by $\mathrm{II}$. B. Rogers ("Amer. Journ. "f Sieience' (2), vol. 26, 1). 246 ) in 1858 , without knowledge of Helmholti's theoretical investigintions. In this country such illustrittions have beeome quite fitvourite popular lecture experiments (see Sir Rob. S. Ball's memoir). Suokerings, solid aud linuid gyrostats, and a host of sinilar contrivances, have impressed on us the hidilen re. sources of whirling motion. Prot.

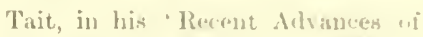

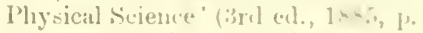
$29+5)$, states that experiment on smoke-ring* which lie performod, suggested to Lord hislvin the vortex theory of mattol. Tlus various gapers of the laterer have, so farr, nut beren collected his at innvenient form. The earliest is contained in the. 'l'roceedings of the Royal soeiety of Erlinlumgh,' Fel,ruary 1stiz. Then tolloweel as nemoir in the "liamsatetms' Ipril $1>67$ ) on vortex station (I'ruc, R. S. E., Decenber 1975: "Vilirations of at Colummet) Vintex" (l'rec., Mareh 1s-0). I'rut. Micke, and especially ['rof. J. I. 'Thlomand) (Trans. R. sive, 1h, 1; 1,-1), have contributed to the theory, and the. latter, in his drauss prize ensay for 108:, has further testerl the cincel" tion in its appliention to chemical stities. sere Hicks, liecent l'ru. gress in Hydrodynamies, (Brit. Assoe. liep., 1×81, J. 63, A(.), aml J. J. Thomson '(nn the Morion of Vurtex lings: (1853, p. 11 4, \&c.)

"The creator of this branch wi purely positional geometry is doube. less Johann lienelict Li-ting, who was led to his resenrelies liy some suggestions of Gauss. liauss refers tothe subject in eonnection with his unpublished reanelue intwelectrodynamice (1:3i3, posthumen-ly [n],lished in "Worke, vel. ve p. rives. Listing called this lranch wi geometry." Topulugice" let. l.intimf. "Vorstuilien zur. 'l'opulugie,' (int-

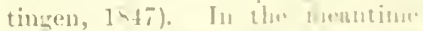

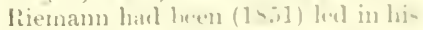
mathematical reprensution wi functions ofs the surfere allut 
of Lord Kelvin this theory led to the conception that in an all-pervading, boundless fluid, such as physicists imagined for the purposes of the theory of light, differentiated portions might exist in the form of whirling rings (vortex rings), which would possess most of the properties of ponderable matter-identity and permanence of quantity of substance, stability, rigidity, elasticity.

43. Difficulties of the vortex ring theory.

It was indeed soon found that although eminently suggestive in this way, and pointing in the direction of a general kinetic theory of natural phenomena, the vortex ring theory presented two fundamental difficulties. How does whirling matter acquire weight, and how does it acquire immensely increased inertia? In the explanation of these two properties the progress has been small, -if indeed any glimpse at all has as yet been got. ${ }^{1}$ But by suggesting numberless experiments through which our knowledge of things natural has been enormonsly increased, by placing before the minds of mathematicians a great number of problems of practical importance and physical interest, and generally by familiarising the minds of philosophers with an nltimate kinetic explanation of nature, ${ }^{2}$ the vortex-atom theory has marked an epoch in

after him, to distinguish between singly, doubly, triply, \&c., connected surfaces ('Werke,' 1876 , pp. 18, 88, 448). These studies, which for a long time were looked upon merely as curiosa or of purely abstract interest, were independently taken up in the practical interest of the vortex-atom theory by Prof. Tait in 1876 ("On Knots," Trans. Roy. Soc. Edinb., 1877, vol. 28 , p. 145 , \&c.), and continued iu 1884-85. To him we owe a convenient notation and vocabulary. For the history of the subject and further developments, see Dingeldey, 'Topologische Studien,' Leipzig, 1890.

] See Clerk Maxwell's article "Atom" in the 9th ed. of the 'Ency. Brit.,' reprinted in 'Scientific Papers,' rol. ii., and the account given there of Le Sage's theory.

2 See Dr Larmor's Address to Section A of the Brit. Assoc. at Bradford in 1890 (Report, p. 625): "The vortex-atom theory has been a main source of physical suggestion, because it presents, on a simple basis, a dynamical picture of an 
the history of thought. As the stuly of stathl. monion or dymanieal equilibrimm, it has joined hands with tho kinetie theory of gases-i.e., the stuly of the mution wi a swarm of bodies in reetilinear motion, anl with the mechanieal theory of lueat-i.f, of imeonlin infinitesimal motion of any kind: and it has certainly, throngh the; reminkable results gained by l'rofessor J. I. Thumbon, afforded a clue to the explanation of chemical linkinge, showing how it comes about that stability of elemeicat componnds is dependent on, and limited $4(1$, it sunal] number of eombinations or linkages. ${ }^{1}$ The nuthennticil difficulties in the way of progress are enormons, sufticient to tax the brams of many generations to come, lun as it

icleal material system, atomically constituted, which eould go on automatieally without extraneous support. The value of such a picture may be held to lie, not in any supposition that this is the mechanism of the aetual world laid bare, but in the vivid illustration it afforls of the fundamental postulate of physical science, that mechanical phenomena are not parts of a scheme too involved for us to explore, but rather present thenselves in definite and consistent correlations, which we are able to disentangle and apprehend with eontinually increasing preeision."

"See his essay on the "Notion of Vortex Rings": "Let us suppose that the atoms of the different chemieal elemeuts are made up of vortex rings all of the same strength, but that some of these elements consist of only one of these rings, others of two of the rings linked together, or else of a continuous curve with two loops, others of three, and so on. Our investigation shows that no element ean eomsist of more than six of these ringm ii they are arranged in the syumetrical way there describul "I. 119). "Wach vortex rimg in the atom would correspond to a unit of affinity in the ehemienl them of quantivalence. If we regard the vortex rings in those atoms consisting of more vortex rings than one as linked torgether in the most symmetrical way, then no element eould have an atom consistiug of more than six vortex rings at the most, so that no single atom wouhl be capable of unitimg with more than six atoms of mother eleuent so as to form a stable compunume?. This agrees with chenical lacts. as Lothar Heyer in his "Morlerme 'Theorien rler Chemie,' Ath wh. I'. 196 , states that no compound con. sisting of more than six atoms of one element comblned with unly one of another is known to exi-t in the gaseous state, and thit is gaseous eompound of tungutron, eonsisting of six atoms of chlorine unitert to one of tungsten, dons exist" (p. 120). 
has been remarked, "the glory of surmounting them would be unique." 1

The vortex-atom theory is the most advanced chapter in the kinetic theory of matter, the most exalted glimpse into the mechanical view of nature. Though suggested by Helmholtz, it has, as already stated, been limited almost exclusively to this country. If science still shows international differences and patriotic predilections, this affords one of the few remaining examples. Another step first taken in this country, the last and most important contribution to the science of physical motion, the greatest support of the kinetic or mechanical view of nature, has, in union with the undulatory theory of light, been now all but universally accepted in the 44. scientific world: I refer to the modern view of electric Modern view of electrical phenomena: phenomena, which for a long time was supported by the Faraday.

His great discoveries of magneto-electricity, of indnetion, of the electrification of light, to which I have had repeated occasion to refer, made his name familiar to the whole scientific world; but the processes of reasoning by which he arrived at them, or to which in his mind they gave rise, were ignored or not understood. ${ }^{2}$ Whilst

1 Tait, in 'Recent Advances of Physical Science,' p. 302, and Clerk Maxwell, in article "Atom" ("Ency. Brit.,' 9th ed., or 'Collected Scientific Papers,' vol. ii. p. $472)$.

2 See Helmholtz's 'Faraday Lecture,' delivered before the Chemical Society on April 5, 1881, reprinted in his ' Vorträge und Reden,' vol.ii. p. 275 , \&c. "Since the mathematical interpretation of Faraday's theorems by Clerk Maxwell has been given, we see indeed how sharply defined the conceptions are and how consistent the reasoning which lay concealed in Faraday's words, which to his contemporaries appeared so indefinite and obscure ; and it is in the highest degree remarkable to see how a large number of comprehensive theorems, the proof of which taxes the highest powers of mathematical analysis, were found by him without the use of a single mathematical formula, 


\section{Continental philosophers, following (ionlomb, trienl to put} into mathematical langnage the action at measmrable distances of magnetic masses and elements of electrical circuits, Fitruday fastened upon the peouliatl lines in which iron filings arranged thenselves in the neighloum-

by a kind of iutuition with instinctive eertinty. I would not depreciate Faraday's contemporarics because they did not sec this. I know myself too well how ofter I sat hopeless, gazing at one of his descriptions of lines of force with their numbers and tension, or looking for the meaning of statements where the galvanic eurrent is regarded as an axis of force and much the like" (p. 277). Rosenberger tells us that it may be in part attributed to the displeasure and annoy. ance with which foreign philosophers receiced F'araday's theoretical views, that I'oggendortt, who printerl Faraday's earlier memoirs in extenso in his 'Annalen,' only gave a short abstract of the later series. See Rosenberger, 'Die moderne lintwickelung der elektrischen Principien,' Leipzig, 1898, p. 105.

1 These researches, of which the fourth chapter of this work gave some account, and which culninated in Weber's well-known law of electrodynamic action of electrical particles at a distance, absorbed almost exclusively the attention of natural philosophers abroad. Mathematicians of the lighrest rank, such as Laplace, Gauss, and Riemann, worked at the subject. It is, however, interesting to note that Gauss, with that remarkable instinct for physical adaptation of mathenlatical ideas which characterised also the magnetic rescarches which he carried on between 1830 and 1840 , refrained from the development of a mathematical theory of electrodynamic action for reasons which he later explained to Weber: When the latter prejared for publication that elaborate serics of exact tueasurements which, irrespective of the theory attached to thom, finrued the foundation of modern electriat seience and of the correlation of the phenomena of magnetism, of electricity at rest and in motion, of induction and of dianagueti-n, Gauss wrote as follows uncler ilate 19th Mareh 1845: "The sulject belongs to those investigations which oceupied me very extensively about ten years ago (especially 1834-36).... I'erliaps I may le able to think myself again into these matters, which have now become so foreign to me. . . I should mo doubt have long agu [rublished my" researches; but at the time when I broke them otf, that was want. ing which I then considered to be the very keystone - nil acturn reputans si quicl supercsiset agendum-namely, the deduction of the additional forces (which have to be added on to the mutual action of particles of electricity at rest, it they are in relative motion) from aetion, not instantaneous, but (like that of light) propagated in time. With this I could not succeed at the moment, but so far as I can renember I let the subject not entirely without hope that this uright later be pussible; yet, if I remember aright, with the subjective eonviction that it would previously be neecssary to form for oneself a workable representation (cine construibure lorstellung) of the manner in which the propragation takes place" (Gauss, "Werke,' vol. v. 1. $62 \bar{\tau}$, sc.) 
hood of the poles of magnets $;^{1}$ inquired into the nature and condition of the region-afterwards termed the "field" - which surrounded magnetised and electrified bodies; invented the term "electrotonic state" and "dielectric" ${ }^{2}$ to describe the part which the surrounding medium played in the so-called actions at a distance; and conceived it to

45.

"Lines of force." be in a state of tension, which he further described by filling it with so-called "lines of force." The region or "field" 3 of magnetic and electric action, filled with these curved lines of force, possessing definite direction and frequency, gave him a clear mental representation of the direction and intensity of magnetic and electric forces at any point in space in the neighbourhood of magnets or of electric currents. For Faraday, the lines of force in the magnetic field, from being originally merely a convenient geometrical device, ${ }^{4}$ ac-

1 "By magnetic curves I mean the lines of magnetic forces, however modified by the juxtaposition of poles, which would be depicted by iron filings, or those to which a very small magnetic needle would form a tangent" (Faraday, "Experimental Researches on Electricity,' 1st series, November 1831, No. 114 note). "When an electrical current is passed through a wire, that wire is surrounded at every part by magnetic curves, diminishing in intensity according to their distance from the wire. . . These curves, although different in form, are perfectly analogous to those existing between two contrary maguetic poles opposed to each other " (ibid., 2nd series, January 1832, No. 232).

2 The term "electrotonic state" was introduced in 1831 to describe the condition of matter in the neighbourhood of electric bodies. "It is probable that what will affect a conductor will affect an insulator also, producing, perhaps, what may deserve the term of the electrotonic state" (ibid., No. 1661, 1838), "the intervening particles assuming for the time more or less of a peculiar condition, which (though with a very imperfect idea) I have several times expressed by the term electrotonic state" (ibid., No. 1729). "I use the word "dielectric' to express that substance through or across which the electric forces are acting " (December 1838, ibid., No. 1168 , note).

3 The term "magnetic field" seems to have been used for the first time in the year 1845 (see 'Exp. Res.,' No. 2252, vol. iii. p. 30).

4 November 1837: "I use the term line of inductive foree merely as a temporary conventional mode of expressing the direction of the power in cases of induction.... The power, instead of being like 


\section{quired gradually a physical ${ }^{l}$ signiticatuce, for lu luml} very early convinced hinself of the fiuct, known illutely

that of gravity, which eauses particles to act on each other through straight lines, . . . is nore analogous to that of a series of mag. netie neelles. . . So that in wlatever way I view it, and with great suspricion of the influence of fisvurite notions over myself, I camot perceive how the ordinary theory ... can be a correct refresentation of that great natural principle of electrical action" ("Exy). lies.,' No. 1231). "I have used the phrases lines of inductive force and curred lines of force in a general sense only. . . . All I am anxious about at present is, that a more particular meaning should not be attaehed to the ex. pressions used than I contemplate" (ibid., No. 1304). And after having referred to the agreement of his results with those of Poisson, arrived at by starting from "a very different uode of action," and with the experimental results of Snow Harris, he concludes by saying, "I put forth my particular view with doubt aud fear, lest it should not bear the test of general examination," \&c. (No. 1306).

1 It took more than ten years before the purely geometrical or conventional use of the term "lines of force" ripened into a physical conception. The latter is definitely expounded in a paper in the 'Philos. Magazine' for June 1852. We can compare this gradual development of a symbolical into a pliysical theory with the gradual develop)ment of the atomie theory; atoms and molecules becoming a physical necessity to chemist.s long after they had been used simply as a conveuient representation of the laws of equivalence and of the fixed proportions of combination (see vol. i, of this work, chap. v., p. 432 , \&e.) Faraday, during the years 1510 to 1850 , laknured at ewo great problesus: the on. lie molvel brilliantly and in the direction lae antieipated; the othor gendang is [moblem to this day. The liret refers to the atetion of magnets on the dieleetric. The dielectric, the sprace which Continental philis. sophers considered as a vacuum so far as magnetic and releetrical phomu. mena are concerned, haul been tilled by Yroung aud Fresnel with ilse luminiferous ether. Frambl muspected that this luminiferous ether cannot be insensible to nuinuetic action, ancl he sought in the e.s] x+ri mental proof of the action of unasnets on rays of light in the sur. rounding sjuce a sulpurt for his view of the part which the dielectric plays in the transmis.sion of electrie and magnetic action. After miny ineffectual attempts to prove this, he could at last (November 1\$\$5) announce his results to the linyal society as follows: "These ineffectual exertions... coulil not remove my strong persuanion derived from philosophical eomvislerat tions; and therefure I recontly resumed the incluiry by experiment in a most strict and searching manner, and have at last succeeded in magnetising and clectrifining at roy of light, and in illuminuting at maynetic line of force. . . Enploying a ray of light, we can tell, by the cyc, the direction of the magnetic lines through a buly : and by the alteration of the ray anl its uptical eflect on the eye, (an sec the course of the lines just as we can see the course of at threal of glass or any other transpurent sub. stance, rendered visible by the light" ("Kxp. Res.,' vol. iii., Sio. 21+5 and note). The serond froblens which Furaday atticked was to prove a similar "conmection he. 
to Cavendish, that in the case of electric attraction and repulsion, the nature of the intervening medium was of importance: it played a part in the electric phenomena in the same way as in the propagation of light and heat the intervening medium played a definite part. This part had been entirely overlooked by Continental philosophers, who worked on the hypothesis of an immediate action at a distance, based upon the analogy of gravitation. Their researches, carried on by methods similar to those invented by Laplace and his school for the calculation of the combined effect of gravitational forces at various points in space, entirely ignored the question how such effects were brought about. As time did not seem to enter as an appreciable factor, the investigation of the mechanism by which action at a distance was communicated was set aside as unnecessary or impossible: the astronomical view of the phenomena sufficed. For Faraday, the intervening medium, which-as in the communication of light and heat - took an active part, the question of its nature and mode of action was very important; he accordingly first of all gave it a name. As in optics the term luminiferous ether had been recently revived, and had become familiar through Young and Fresnel, so through Faraday were introduced the terms "dielectric" and "magnetic field," as the carriers of electric and magnetic action; and though for a long time used only by himself, they

tween gravity and electricity." On the failure of this attempt he fully reported in his Bakerian Lecture, November 1850 ('Exp. Res.,' vol. iii. p. 161). But the former results were sufficient to ripen gradually in his mind the idea of the physical nature of the lines of force, which he expounded with increasing precision from 1851 onward. (See 'Exp. Res.,' 28th series, vol. iii. p. 328 ; also pp. 402,438 .) 
KINETIC OR MECHANICAL VIFW OF NAlPLE 71

have been the means of kepping before the mincle wi natural philosopleas the question lonw therie aretion are mechanically eommunicaterl, a frolulem which liy outsicle of the astromomical view of the plicmonmat. 'To Faratay himself the analogy betwern the phonomenat of these actions menut also a real physicul rolation or even identity, a supposition which le followm up with unwearying patience and all the experintentil resonrees of his inventive mind, till he succeenled in showing by experiment that magnets in the neightourhood of transparent substanees which have a polarisin: effect on rays of light possessed the jurberty of alteriner the direction in which the polarised rays show their laterality. Faraday"s eonception of "lines of force filling all space and explanining electrie and mannetie action, radiation, and possibly also gravitation, was elaborated dming the years $18: 30$ to 1850 . An opinim then prevailed that his diseoveries stood in opposition to the views elaborated and experimentally verifial ly Continental philosophers. The first who showerl the analogy and threw out a hint how the two views eould be brought into harmony was Willian Thomson (Lomel Kelvin). As early as $1842,{ }^{1}$ when searcely eighteen

" "On the uniform motion of Ileat in homogeneous solid bodies, and its connexion with the mathematical theory of Electricity," "Cambridge Mathematical Jourmal,' February $1 \& 42$. 'The following note is attached to the reprint in the 'Philosophical Magrazine' of 1854: "The general conelusions established show that the laws of distribution of electric or mapnetic force in any case whatever must be identical with the laws of distribution of the lines of motion of heat in certain perfectly defined cireunstances. With developments and applications contained in a subsequent paper (1845), they cinstitute a full theory of the characteristics of limes of force, which have been so adusirably inve-tigated experimentally by Fombla, and complete the malogy with the theory of the compluction of hest, of which such terms as 'conduct. ing lower of lines of force (" lixp. Res.,' Nus. 27!7-2902) involve the iclea." 
years old, but already acquainted with English experimental and Fremch wathematical researches, he pointed out how phenomena of How-i.e., of motion-could be mathematically grasped by a formula quite similar to that of the distribution of masses at rest and apparently governed by attractive forces at a distance. For instance, the distribution of temperature at various distinct points in a space in which a flow of heat from an origin had brought about a stationary condition (the equilibrium being dynamical, not statical), was mathematically expressed by a formula identical with that which, according to Poisson aud others, gave the distribution of electrical or attracting masses. Now we know that in the former case the equilibrium is maintained by a flow across the intervening space, which takes time. This suggests, therefore, the possibility of explaining the so-called statical effects of attracting or repelling masses kinetically by a process of flow or motion going on in the intervening medium, a notion to which Faraday clung tenaciously. In 1845 Thomson reverted to this subject, and after harmonising the two views, concluded by stating that the latter "method of establishing the mathematical theory would be even more simple if possible than that of Coulomb." 1

1 "On the Mathematical Theory of Electricity in Equilibrium," 1845. See 'Reprint of Papers on Electrostatics and Magnetism,'2nd ed., p. 29. A study of these mathematical researches of Lord Kelviu, beginning early in the 'forties and extending over more than twenty years, is of special historical interest, as showing the gradual growth of a physical out of a purely mathematical theory : most of the conceptious which have since become general through Maxwell's electro-maguetic theory, as it has been developed and popularised by subsequent writers (notably Prof. Poyuting, Prof. Oliver Lodge, and Mr Oliver Heaviside), being already contained in Thomson's papers as mathematical notions. Thomson is throughout careful to 
'This suggestion was not carrien out for sronc tines, and then not hy Thomson himself, but, at lis instigation, by clerk Maxwell. In the nueantime, huwrever, Thomson added another step to the one alleatly taken, lyy bringing recent discoveries of Farulay, its well as his

point uut how the elementary experimental data referriug to electrical charges, as well as to mag. netic bodies, can be matlematically expressed equally well by the conceptions of Coulomb and Poisson and by those of conduction and llow, which are more in conformity with Faraday's pluysical ideas : neither of the mathematical analogies, of attraction at a distance or of con. duction through an intervening medium, being sufficient for a physical theory. 'These papers contain further the record of the gradual growth in the author's mind of the kinetic out of the statical view of natural phenomena. Thomson was the first (1851) to introduce the terms "field" and "lines of force" into mathematical literature, adopting them from Faraday. They have since hecome indispensable not only to the electrician but likewise to the mathema. tician ; forming, as it were, a unifying term for apparently distant regions of physical phenomena, and being introduced as fundamental notions at the begimning of dymamical treatises. See, for instance, the article by M. Abraham entitled "Geometrische Grundlegriffe," in the second part of the fourth volume of the 'Encyclopïdie der mathematischen Wissenschaften,' Leipzig, Teubner, 1901. Independently and quite unknown to laraday, or to each other, two eminent mathematicians, Sir W. R. Hamiltun at Dublin and Herrmann Grassmann at Stettin, were elaborating, between 1835 and 1845 , the geometrical conceptions and rocabulary which are required in the mere sentation of "Alrected" guantirisn. Their expositions lawe rince hreorne much simplitierl, and now form, under the title of "reetor analysis," an indispensable grometrical instrument. The gralual evolution of the kinetic view of physeicis phemonena (which here enserrim us most) in the uemoirs of Thumsen is most remarkable. Inter uliu, lie made a consunuication in 1.547 (c) the Britislı Association at ()xiorl, in which he dealt with the phe. nomena of terrestrial magnetinm, stating that "it becomes an interesting question whether mere electric eurrents could produce the actual phenumena observel. Anl. père's electro-magnet ie theory loudus to an aflirmative answer which must be regarded as merely thenr. etical ; for it is absolutely itupus-ible. to conceive of the currents which he describes round the molecules of matter as having a physical exi-t. ence" (Reprint, 2nd cil., 1. 469. On this passage he himseli remarkin 1572: " lrom twenty to twenty" five years ago, I hail no lellicf in the reality of this [Amgure's] theory; but 1 did not then know that inotion is the very essence of what has hitherto been called matter. At the 1847 mesting of the British Association in Oxforn I learned from Joule the dynamical theory of hent, nud was forwel to abauclon at onee many, ausl gradually from year (1) year all otluer, statical preconceptions regariling the ultimate enumes of splpurently statieal plienomena" (ilid., I), 423 note). 
unique conception of the communication of electric and magnetic phenomena, into connection with the mathematical theory which had been founded and worked out by Poisson and Green. Without attempting to give a physical explanation of Faraday's lines of force, he showed how they could be utilised in calculating the complicated action of magnetic push-and-pull forces; suggested that the newly discovered property called diamagnetism, in virtue of which bodies in the neighbourhood of powerful magnets appeared to be repelled, not attracted, could be explained as a differential ${ }^{1}$ effect of

${ }^{1}$ It was in the year 1845 that Faraday, after having discorered the "magnetisation of light," and made visible the "magnetic lines of force" ("Exp. Res.,' Nos. 21462242 ), entered upon that remarkable series of experiments and speculations which led him to the discovery of diamagnetism and to the assertion of the "magnetic condition of all matter" (ibid., Nos. 2243, \&cc.) In 1847 Thomson wrote: "According to Mr Faraday's recent researches it appears that there are a great many substances susceptible of magnetic induction, of such a kind that for them the value of the coefficient $i$ is negative. These he calls diamagnetic substances, and in describing the remarkable results to which his experiments conducted him with reference to induction in diamagnetic matter, he says, "All the phenomena resolve themselves into this, that a portion of such matter, when under inagnetic action, tends to move from stronger to weaker places or points of force.' This is entirely in accordance with the result obtained above; and it appears that the law of all the phenomena of induction discovered by Faraday with reference to diamagneties may be expressed in the same terms as in the case of ordinary magnetic induction, by merely supposing the coefficient $i$ to have a negative value" (Reprint, p. 502). In the Reprint (1854) of his early papers (1842) on the corresponding problems of magnetism and heat (Reprint, p. 18) he added a note to the effect that the "same demonstration is applicable to the influence of a piece of soft iron, or other paramagnetic, or to the rererse influence of a diamagnetic on the magnetic force in any locality near a magnet in which it can be placed, and shows that the lines of magnetic force will be altered by it precisely as the lines of motion of heat in corresponding thermal circumstances would be altered by introducing a body of greater or less conducting power of heat. Hence we see how strict is the foundation for an analogy on which the conducting power of a magnetic medium for lines of force may be spoken of, and we have a perfect explanation of the condensing action of a paramagnetic, and the repulsive effect of a diamagnetic upon the lines of force of a magnetic field, which have been described by Faraday" (Reprint, p. 33 note ; cf. Faraday, 'Exp. Res.,' Nos. 2807, 2808). 
KINETIC OR MECHANICAL VIEW OF NAILIE. 75

the magnetic actions which belong 10 all sulmtances introduced the term magnetic " permerthility" ats deseriptive of the degree in which varius substance: acquire magnetie properties and combluct the lines wi magnetic force in the neighlsourhood of powerful mat:nets; and finally demonstrated low, if these projnertim were considered as having different degrees in the dijferent axes of crystals, in analogy with the difierent elasticities which they exlibited, the consentucuce would be a turning effect which womld explain the chlamerel optical properties of crystals mnder the influcuce of magnetic action." In these investigntions the icleas of

1 This property was afterwards termed "permeability" by Thomson (Reprint, r. 489, 18\%2). The general rule of magnetic action ean then be expressed by saying that "by virtue of differential action a boly may behave paramagnetically or diamagnetically according as it is placed in a less or a more permeable merlium than itself " Chrystal in article "Magnetism," "Fincy. Brit.,' 9th ed., vol. xv. p. 248).

"2 "On the Theory of Magnetic Induction in Crystalline and Noncrystalline Substances" ("Philos. Nag.,' March 1857; also lieprint, 2nd ed., p. 471, \&c.) Poisson had already foreseen the mathematical possibility of what Faraclay termed magne- (correctly magneto-) crystallic action, but "ce cas singulier ne s'étant pas encore présenté à l'observation, nous l'exclurons de nos recherches" ("Mémoire sur la Thıéorie du Magnétisme," "Mém. de l'Institut, Paris, 1826,' quoted ly Thomson, lieprint, $\}$, 484). Stimulated by the discoveries of Faraday, Pliicker at Bonm, during the extraordinary interval whicls separated the second from the first perind of his original geometrical speculations (see vol. i. 1'. 242 of this work), de- voted himseli to the sludy of the electric and nagnetic pronnerties of gases and crystals, and in 1 s. 7 conmenced that remarkable teries of plyysical uemoirs through which he becane the fellow-worker, if nut the rival, of Faraday. One of his first discoveries was the action of magnets on crystals, publisleer in 1847 (Pogg. Anm., or Plucker's 'Physicalische Ablandlungen,' ed. Pockels, Leijzig, 1 $\rightarrow 96$, 1. 6, ke.), which supplied to Thomson "the rery eircumstance the observation of which was wanting (t) induee Poisson to enter upon a full treatment of the subject, and made the working out of a mathematical theory of magnetic induction... independently of any hypothesis . . upon a purdy experimental foundation ... important" ('Thennson, loc. rit. P. 471). l'licker was an uriginal thinker, and mainly a seli-taught genitus, imperfectly acquainted with the labours of his contempuraries or predectsurs. This has been noted ly his bingraphers as nuch in his gewnetrical as in his pliysical renearches fore the memoirs of Clebsels and of l'rof. libeke, prefixed to the two rolunus of the 'Gesaumelte. Abhandlungen'). 
Faraday are used merely for the sake of describing and calculating in the simplest manner phenomena which had been experimentally discovered: no attempt was made to explain physically how these actions come about. In fact, under the hands of Thomson the conceptions of Faraday were formulated as Dalton's atomic theory had been elaborated by chemists in the first half of the century, for the purpose of symbolically representing and calculating observed phenomena.

But the "lines of force" of Faraday were not to remain a mere symbolical representation, any more than Dalton's atoms were to remain merely counters of a chemical arithmetic. Both theories were to be raised to the rank of physical theories. What the kinetic theory of gases did for the atomic theory was done for Faraday's symbolism Clerk

47. by the researches of Clerk Maxwell. And as the fact \$axwell. that the molecules of matter could be really counted, and their distances and velocities measured, gave life and actual meaning to the atomic view of natural phenomena,

In his early geometrical researches he worked in ignorance of the remarkable 'Traité' of Poncelet, which had been published in 1822 (loc. cit., vol. i. p. 594, \&c.) : even the writings of lis countryman Möbius were unknown to him. Still more extraordinary was his comparative unacquaintance with the electrical measurements aud theories which dominated Gernian research when be commenced his physical labours, and which eman. ated from the school of Gauss and Weber. But he was equally ignorant of the purely mathematical theories of Poisson and Thomson, which, as he himself candidly confessed, might have saved him from important errors (loc. cit., vol. ii. p. 460), and which were later made more widely known in Germany by the excellent treatise of his pupil Beer ('Einleitung in die Elektrostatik,' \&c., Braunschweig, 1869), posthumously edited by Pliicker himself. The fact that Pluicker was uot influenced by the spirit of Weber's researches probably made him more appreciative of Faraday's purely physical methods. In such names as Beer, Clebsch, Klein, Fessel, Geissler, and Hittorf, Pliicker counts an illustrious array of pupils and fellow-workers. See Clebsch's characteristic of Plïcker, loc. cit., vol. i. p. xii, \&c 
so the rays of electric and mannetic force seen by farmlaty in the abstraction of his intuitive mind became a reality for every experimentalist when Hertz in 1888 actually showed the womlerful action of electric waves at at distance. Atoms and lines of force latve beconne a pratricil -shall I say a popular?- - reality, whereas they were unce only the eonvenient methor of a single original mind for gathering togrether and muifying in thought a hewilelerines mass of observed phenomenil, or at most calnable of hemg utilised for a mathematical description and calculation of actual effects.

For a quarter of a century after Faradiy had conceived the notion of looking upon electric and matgnetic phenomena as depending on a property belonging to all matter, and pervading all space, like radiation and gravity, the only natural philosopher who to any extont entered into his ideas was Thomson. Even Tyndall, who came more than any other prominent physicist umler Faraday's immediate and personal intluence, and contriliuted largely to our knowledge of the new phenomena diseovered by his great master, does not seem to have assimilated his scientific langllage and reasoning. It required a mathematical mind really to grasp and put into form Faraday's notions. Encomaged ly Thomson, and soon after the publieation of 'Thomson's mathematical theory of magnetism, clerk Maxwell devoterl himself to a theoretical study of electrieity and allied subjects, a field which Thomson had then almost monopolised in this comntry. 'The first of Maxwell's revoln-

a See Professor Glazebrook's little book on 'Jamnes Clerk Maxwell and Modern Pliysics,' published in the
"Century Science Series," 1901. Un page 12 a letter of Maxwell is quoted, in which he mrentis of 
48.

His series of works on the theory of electricity.

tionary series of works, 'On Faraday's Lines of Force,' was published in December 1855. The series was completed by the appearance in 1873 of his great work on 'Electricity and Magnetism,' which has formed the centre of a large literature to which all the scientific schools of Europe and America have contributed. Historically, Maxwell brought together two distinct and very fruitful lines of reasoning, due to Faraday and Thomson. ${ }^{1}$ He was impressed with the desideratum of every physical theory bearing on any large class of phenomena-viz., that it must be mathematical and physical at the same time. His own theory had to embrace and unite all the purely arithmetical and geometrical regularities which had been discovered, and which at that time were known to describe correctly the facts of electric, mag-

"poaching upon Thomson's electrical preserves." In the preface to the treatise on electricity and magnetism, he refers to the apparent discrepancy between the views of Faraday and the mathematicians, and he states that he had arrived at "the conviction that this discrepancy did not arise from either party being wrong. I was first convinced of this," he proceeds, "by Sir William Thomson, to whose advice and assistance, as well as to his published papers, I owe most of what I have learncd on the subject.

I In a different reference we may say that Maxwell's theory was prepared by three independent lines of research, starting respectively in France, Germany, and England: (1) The investigation of the actions at a distance of electrified and magnetised bodies, and of electric currents, which found mathematical expression in the formula of Coulomb and Ampère. The full significance and capabilities of the formulx of electrostatic and magnetic action had been clemonstrated by Thomson, who especially showed that these relations were not necessarily confined to the physical theory which had been elaborated on the Continent, but that, mutatis mutandis, they lent themselves equally well to the physical ideas of Faraday. (2) The exact measurements of magnetic, electro-dynamic, and galvanic action started by $\mathrm{Ohm}$ and Gauss in Germany, and much extended by Weber. (3) The idea of physical lines of force, filling space and representing action through contiguous particles, not at a distance, elaborated by Faraday. These three lines of research were brought together in the theory of IIaxwell, which in the beginuing professed to be only a mathematical but ended by being a physical theory. 
KINETIC OR IECHANICAL, VIEW OF JATLEK. T?

netie, and galvanie phonomena, such ats (imblomlis relectrostatic and magnetic laws, Amprode's electro-lymanic and electro-mangetic formulit, and Uhm's and Faralay's laws referring to galvanic cmrents, and many others. It had also to give an intelligible representation of th. elementary aetions of which these complicaterl phumbnena are mate 11 . In oreler to amive at the hatcer, the method usually employed is to lowk for andogres in other provinces of seience where the lesired unification has already been brought alout. The great matmal philosophers of the rrench sehool who had so suceessfully aceomplished the must extensive unitication yet attempted in any large branch of knowledge-the mijfication of physical astronomy under Newton's gravitattion formula-had tried to follow up this amalogy in other reahus of research, and harl dereloged what I called in a former chapter the astronomical view of natural phenomena. Anpère, and notably Veler, haul extended this analogy so as to emblate eleetric and magnetic jhenomena. 'There was, howrer, another analogy which was more familiar to the great experimentalists in this comtry, notally to findaty-namely, the analogy of those various phenomena which ilepent on processes of emanation, of a gradnal spreading ont, of a flow or conduction: those phenomenil where the factor of time comes in, and where an abpratently stiltionary eondition is brought about ly a mode wi mution, or what has been tement a "dynanic coniliturimu." 'Thomson, starting from Fomrer's mathenatical analysis of such processes, had been led to see how far-bardhing this analogy is, and had latterly (1850) cxtemdol it to 
embrace the processes of the flow of heat, of electricity, magnetic and diamaguetic, and of fluid motion. "He called attention to the remarkable resemblance which the diagrams of flow bore to those which Mr Faraday had recently shown at the Royal Institution to illustrate his views regarding the action of ferro-magnetics and diamagnetics in influencing the field of force in which they are placed, and justified and illustrated the expression 'conducting power for the lines of force' by referring to rigorous mathematical analogies presented by the theory of heat." 1

This view, which Thomson had merely shadowed forth, was more fully worked out by Maxwell in 1855 and 1861. His methods 2 were "generally those suggested by the processes of reasoning which are found in the researches of Faraday, and which, though they had been interpreted mathematically by Prof. Thomson and others, are very generally supposed to be of an indefinite and ummathematical character when compared with those employed by the professed mathematicians." The first addition which he introduced, by which he made Faraday's "lines of force" mathematically more definite, was

49.

His conception of "tubes of force." to change them into "tubes of force," which represented not only the direction of force at every point of space, but also-according to their sectional dimensions-the intensity of the force. These tubes were supposed to be

1 Abstracts of two communications to the British Association at Belfast in 1852, "On certain Magnetic Curves: with Applications to Problems in the Theories of Heat, Electricity, and Fluid Motion" (Reprint of Papers, \&c., p. 519, \&c.)
2 James Clerk Maxwell "On Faraday's Lines of Force," "Transactions of the Cambridge Philosophical Society,' 1855. See 'Collected Scientific Papers,' vol. i. p. $15 \%$. 
filled with a moving thit, and the velneity wi the thwinversely proportional to the sectional aneis of the mules -representerl the intensity of the fore at any juint in space. He also showed how very much simpler the andception lecomes, if the law of the acting forces is the experimentally established law of the inverse sifume of the distance.

This thonght of "referring to the purely seonetrical idea of the motion of an imaginary thuid" I was the beginning of the now miversally adopted view of at very large class of phenomena, and it was at the same time a great step) in the development of the kinetic or mechanical view of natural processes. These hines or tubes of force, with which all space survounding milnets

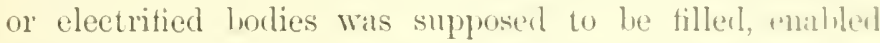
Maxwell further to give a definite representation of that peculiar state of matter of which Faralay lual very early formed an indefinite conception, and which lut called the "electrotonic stitte." Thomson harl alleally in $18 \pm 7^{3}$ shown how the irleas of Faraclay, who as carty

I How little Maxwell originally intended to give a physieal theory is seen from the concluding sen. tences of the introduction to his first paper (loc. cit., vol. i. p. 159): "By referring everything to the purely geometrieal iclea of the motion of an imaginary fluid, I hope to attain generality and pre. cision, and to avoid the dangers arising from a premature theory professing to explain the cause of the phenomena. If the results of mere speculation which I have collected are found to be of any use to experimental philosophers, in arranging and interpreting their results, they will have served their purpose, and a mature theury, in which physieal lacts will be physieally explained, will be formed by those who by interrogating Nature herself can obtalin the only true solution of the questions which the mathemittical theory sugrest..."

2 Faradity had already in 15.52 spoken of shells and tubes of force. and invented the term sphombluich to denote the portion of slrice enelosed between such shells of furce ('Exp. lies., vol. iii., No, 327l.

${ }^{3}$ In 18.7 "C'amlir. and lbuli. Math. Joumal, reprinted in ' Wath. and l'hys. l'ilpers,' vol. i. p. 76 Thomson wrole that fraralay's theory of electrostatic induction 
as 1831 conceived this peculiar condition of matter to be equivalent to a state of strain, could be represented by the mechanical analogy of the strains existing in an elastic solid. He had distinguished three distinct forms of this elastic strain, and had identified these three forms severally with electrostatic, magnetic, and galvanic forces. He had not given a physical explanation of the origin of these forces, but had merely used the "mathematical analogies of the two problems (the electrical and the elastic) to assist the imagination in the study of both." I Maxwell now took a further step and proceeded to give a physical or mechanical description of the nature of this state of stress, of the electrotonic state of matter. With this object in view he conceives of a medium which is capable of exerting force on material bodies by being itself strained, and exhibiting the

"suggests the idea that there may be a problem in the theory of elastic solids corresponding to every problem connected with the distribution of electricity on conductors, or with the forces of attraction and repulsion exercised by electrified bodies. The clue to a similar representation of magnetic and galvanic forces is afforded by $\mathrm{Mr}$ Faraday's recent discovery of the affection, with reference to polarised light, of transparent solids subjected to magnetic or electromagnetic forces.",

1 Quoted from Maxwell's paper "On Physical Lines of Force," in the 'Philos. Mag.,' 1861 (see 'Coll. Papers,' vol. i. p. 453), in which Haxwell applies Rankine's conception of molecular vortices to the representation of magnetic phenomena. He refers to his earlier paper (1855) on (geometrical) "liues of force" in which he had "shown the geometrical significance of the electrotonic state," and had used "mechanical illustrations to assist the imagination, but not to account for the phenomena." "I now," he says, "propose to examine magnetic phenomena from a mechanical point of view, and to determine what tensions in, or motions of, a medium are capable of producing the mechanical phenomena observed. If by the same hypothesis we can connect the phenomena of magnetic attraction with electro-magnetic phenomena, and with those of induced currents, we shall have found a theory which, if not true, can only be proved to be erroneous by experiments which will greatly enlarge our knowledge of this part of physics" (ibid., p. 452). 
phenomena of tension and pressure (magneatic alctions) as also of motion of its parts (electro-magnetic action). Now in a melium which is so constituted-i.'., which possesses elastic mobility of its parts-we know that by a whirling or vortex motion phenomena of pressure and tension can be produced in certain jurts, and the questions accordingly presented themselves to Maxwell, How ly such tension and pressure in certain parts of the medium can magnetic phenomena be represcnted ? and How can the vortices communicate motion (o), of receive motion from, the interlying morable particles of the medium? He succeeded in working out a very complete model of such a medium, representing by its nechanical motions both magnetic and electro-magnetic phenonena. Especially was he successful in visualising Faraclay's lines or tubes of force, and endowing then with mechanically measurable forces. Maxwell admits that "his conception . . may appear somewhat awkward. 1 do not," he says, "bring it forward as a mode of connection existing in nature. . . . It is, however, a mole of connection which is mechanically conceivable and easily investigated; . . so that I venture to say that any one who understands the provisional and temporary character of this hypothesis will find himself rather helped than hindered by it in his search after the true interpretation of the phenomena." I

1 'Collected Papers,' vul. i. p. 486. At the end of his paper on physical lines of force, Maxwell touches on the philosophieal question, "how much evidence the explanation of phenomena lends to the erelibility of a theory, or how lar we ought to regird a coineidence in the mathe. matical expressiou of two sets of phenomena as an indication that these plienomena are of the same find. We know that frartial co. incidences of this kind have lieen discoverel; and the fact that they 
The idea of a medium of extreme rarity, pervading all space and interpenetrating all matter, capable also of the elastic reactions of a solid body, was not repugnant to physicists at the time when Maxwell wrote. Though violently opposed forty years earlier when proposed by Fresnel and Young, it had gradually, through the development of optical theories, become a well-recognised instrument of scientific thought. In such a medium a disturbance or displacement is propagated with a certain velocity dependent on its elastic nature-the so-called constants of density and rigidity. Now, looking upon a charge of electricity not as a material something-an imponderable-but as a displacement of the medium, the question arose, Does the velocity with which such a displacement travels compare at all with the known velocities of other elastic disturbances, such as light is conceived to be? It was known to electricians that an amount or charge of electricity can be either stationary (called statical electricity) or in motion (called an electric current); and Weber and Kohlrausch had in 1856 actually measured the number of units of statical electricity which must flow through an electric circuit in order to produce the known mechanical effect of a unit

Corre. spondence between relocities of light and of electricity. of electric current. The quantity which they found, and which corresponded to a velocity, was of the same order as the velocity with which the elastic disturbance which we call light is known to travel. Maxwell was the first

are only partial is proved by the divergence of the laws of the two sets of phenomena in other respects. We may chance to find, in the higher parts of physics, instances of more complete coincidence which may require much investigation to detect their ultimate divergence" (p. 188). 
KINETIC OR MECHANICAL VIEW OF XATULF. S5̄

to see the physical significance of this correspmendence. "I have deduced the relation hetween the statical amil dynamical measures of electricity, and have shown by it comparison of the electro-mitgnetic experiments wi M.M. Kohlrausch and Weler with the velucity of light is formd by M. Fizean, that the elasticity of the mangrotic medium in air is the same as that of the luminiferoms merlium, if these two coexistent, coextensive, and equally elastic media are not rather one nediun." "2

After having pointed out this remarkable correspondence and other analogies between electrical and optical properties which could be verified by experinent, Maxwell seems to have felt satisfied that a dynamical or kinetic explanation of electric and magnetic phenonena based upon rotary and translational motions and elastic strains in the magnetic field was quite possille. The detailed descriptions given in his earlier pajers he looked upon merely as erude mechanical devices by which some of the known effects of magnets and currents could lex described. The valuable result was, that the electromagnetic field could be looked upon as a mechanical system; that the observed actions at a distance could be conceived as communicated through this mechanical system in definite measurable time; and that certain analogies had been pointed out as existing between

1 'Philos. Mag.,' Jauuary and l'eb. ruary, 1862 ; 'Coll. I'ajers,' p. 492 .

2 Cf. 'Coll. Papers,' vol. i. 1) 500 : "The velocity of transverse undula. tions in our hypothetical medium, calculated from the clectro-magnetic experiments of MM. Kohlmusch and
Weber, agrees so exactly with the velocity of light calculateil from the optical experiments of M. Fizenu, that we cau searcely ayoid the in. ference that light consists in the transverse undulations of the same medium which is the eause of electric and magnetic phenomenn."
32.

"Elaucicilizturlasticans" of 1 lan surstie metium. 
optical, electrical, and magnetic phenomena, which by carefully devised experiments might be verified and extended.

Through Maxwell, following on Faraday and Thomson, the treatment of electric and magnetic phenomena had thus entered on a similar stage to that which the treatment of optical phenomena had attained half a century earlier through Young and Fresnel. A kinetic or mechanical view, more or less precise and definite, had been propounded; a considerable number of facts had been bronght into comnection, into line and order; the direction which experimental research must take had been indicated; and finally a correspondence had been established between two great groups of phenomena, those of electricity and magnetism on the one side, those of light on the other. It might have been expected that Maxwell would now take the same course as that taken by Fresnel about the year 1820 , and perfect his views by giving his theory of molecular vortices greater precision and definiteness-i.e., by perfecting the electromagnetic model, as Fresnel and others perfected in their time the system of vibrations by which they visualised the processes of light. This is not the method which Maxwell adopted. ${ }^{1}$ In his later and more important

1 The progress of Maxwell's reason. ing is clearly marked in the three memoirs, belonging respectively to the years 1855,1861 , and 1864 , of which the last appeared in the 'Transactions' of the Royal Society, and which are reprinted in the first rolume of the "Collected Scientific Papers.' The first memoir on "Faraday"s Lines of Force" ad. heres strictly to the mathematical

formulation of Faraday's conception, much in the spirit of 'Thomson's many expositions. The second, on "Physical Lines of Force," follows Faraday in the attempt to take the original symbol in real earnest as a physical arrangement, and devises, or applies for that purpose, the theory of molecular vortices. The third memoir, which is by far the most important and original, 
writings he adopted a different and more general jucuces of reasoning. If electrical and magnetic as well as optical phenomena are produced by the notions of the parts of a medimm possessed of certain mochanical pruferties, this medium represents a mechanical system, and must therefore be subject to the general litws which regrulate all mechanical systems. These general laws are laid down in dynamies, where it is shown that a complete knowlerge of the behaviour of such a system can be redneed to the linowledge of the distribution in it of it quantity ealled Energy.

I intend in the next ehapter to trace historically the

drops this somewhat erucle device, as well as the older theory of particles acting at a distance, with forces which, according to Weber, depend on their velocities, and starts irom "the conception of a complicated mechanism capable of at vast variety of motion, but at the same time so connected that the motion of one part depends... on the motion of other parts, these motions heing communicated by forces arising from the relative dis. placement of the connected parts, in virtue of their elasticity" (Papers, vol. i. p. 533). He further says: "I have on a former occasion attempted to describe a particular kind of motion and a particular kind of strain, so arranged as to account for the phenomena. In the present paper I avoid any hypothesis of this kind; and in using such words as electric momentum and electric elasticity in reference to the known phenomena of the induction of currents and the polarisation of dielectrics, I wisl merely to direct the mind of the reader to mechanical phenomena which will assist him in understauding the electrical ones, AJl such phrases in the present paper are to hir considered as illustrative, not as explanatory. In speaking of the energy of the field, however, I wish to be understood literally. All energy is the same as mechinical energy, whether it exists in the form of motion or in that wi elas. ticity, or in any other form. The energy in electro-magnetic phenomena is mechanical energy". The only question is, Where docs it reside? On the old theories it resides in the electritied budics, conducting circniti, and magnets, in the form of an unknown quitity called potential energy, or the puwer of producing certilin effects at in distance. On our theory it resides in the electro-magnetic tiels, in 1 le space surrounding the electrifiect and magnetic bodics, as well us in those bodics themselve-, and is in two different forms, which may be deseribed without hyputhesis ns magnetic polarisation and electric folarisation, or, accurding to a very probable hypothesin, as the wotiun and the strain of one and the sane medium" (1).563).
Cotase. (Tur-Dere (ji) tlite Iinew if a tha wy of Ener:y. 
growth of this conception as applied not only to the energy of visible and measurable mechanical motion, but to all other forces of nature which have in the course of the century not only been measured in terms of this one quantity, but also represented with more or less success as dependent on the energy of specific forms of motion, be this rotatory or vibratory or translational motion, regular and periodic or irregular and disorderly motion. It is clear that such a general abstract view as Maxwell (first among natural philosophers) took of a special problem was only possible after it had been shown how all physical and chemical actions and effects can be reduced to a common measure. The influence of the development of these views on the kinetic view of nature has been very great. The first and most natural effect of measuring all forces of nature in terms of the energy of motion is to strengthen the kinetic view of natural phenomena. This, however, is not the only view which is possible, or which has been taken, as I shall endeavour to show more fully hereafter.

The influence of Maxwell's ideas on scientific-nay, even on popular-thought has been very considerable. The main conception around which research, both mathematical and experimental, has moved during the last twenty years is the conception of light as an electromagnetic phenomenon. This view has been much supported and extended by the experiments of Heinrich Hertz, who by ingenious contrivances succeeded in actually exhibiting electro-magnetic waves, and in showing how they differ from light waves merely in length and period, and agree with them so far as 
KINETIC OR MECHAYICAL VIEW OF NATLRE, 89

reflexion and refraction and other properties are concerned. Juminous waves ane mow comsidered hy many physicists to be merely clectro-magnetic: Wares of shent wave length and great frequency, such as the oryan wi vision is capalsle of perceiving in the form of light. The electric and magnetic medimn is identical with the luminiferous ether, postulated by Toung and liresnel, and rays of light are merely an electrie and mingnetic disturbance propagated as a periodic or wave motion.

These discoveries and theories have gone a long way to destroy the older astromomical view of natural phenomena, which explained nany effects by the action at a distance of partieles of ponderable or imponderalile matter. The firm conviction has taken hold of the modem seientific intellect or imagination that space is a plenum filled with a continuous medium, and that the undoubted atomic nature of pouderable matter maty be owing merely to a specific and mmoditiable form of motion with such properties as Lord Kelvin has shown to belong to vortex filanents. The difficulty still remains how to explain the phenomenon of gravitation as well as the increased amount of inertia or mass which belongs to all ponderable matter as compared with that material substance which we call ether.

The reason why Maxwell abandoned his carlier schemes, in which he tried to construct a mechnicil model of the electro-magnetie field, is not quite clun:? The idea has, however, been taken up by others, and elaborate deseriptions have been attempter, by which the

1 A suggestion regarding this is given by Dr J. Larmor in ". Hither nub Matter,' 1. 28. 
processes going on in the neighbourhood of electrically charged bodies, of electric currents, of magnets and diamagnets, can be visualised. ${ }^{1}$ For didactic purposes such elaborate models may prove to be of great value, though as a true mechanical basis of a physical theory of natural processes they have to be received with caution. None of those physicists who have expended their ingenuity in devising these contrivances seem to attach more than a symbolic or ideal value to them: they have, however, the desired effect of producing on the mind of the learner, of the practical inventor, or of a popular audience a strong conviction that all physical phenomena can be described as processes of motion, and that the ultimate solution of the problem of natural philosophy is to be found in a kinetic or mechanical view of phonomena. Physies and clemistry are, according to this

1 Such illustrations may be found in Dr. Oliver Lodge's 'Modern riews of Electricity,' a book which has had a large circulation and has helped to diffuse correct and practically useful ideas on electric and magnetic problems and phenomena. There is a danger of such mechanical illustrations becoming too rigid and of their being taken too literally ; still, for the purposes of practical application and handling it is indispensable to possess some mechanical mode of representation and construction by which actual problems can be readily solved. The success of Dr Lodge's attempt both in this country and on the Continent, especially in Germany, proves sufficiently that it meets a much-felt want. See inter alia Prof. Rosenberger's five lectures, 'Die moderne Entwickelung der elektrischen Principien,' Leipzig, 1898, p. 133. A great authority abroad, Prof. Ludwig Boltzmann, has made use of a peculiar kind of mechanical motion, investigated by Helmholtz, to illustrate electrical phenomena. The characteristic of such motion which is termed cyclic--is this, "that in the place of every particle which changes its position, an equal and equally moving particle enters, so that the condition of the system during the motion is nowise altered" ("Vorlesungeu über Maxwell's Theorie,' Leipzig, 1891 and 1893, vol. i. p. 14). Cycles can be " coupled," \&c. The general dynamical relations of such cyclic systems are investigated, and by introducing the necessary restrictions, based upon experimental facts, and suitable hypotheses facts and hypotheses being clearly distinguished - the general equations of Maxwell are arrived at. 
view, destined to become ultimately merely chatuters in dynamies as the doctrine of mechanical motion.

A similar reluctance to look upon the vibrations of the Iuminiferous ether merely as a convenient symbolism, its it crude method of visualising molecular processes, which in reality we cannot pieture to ourselves, dlues not secem in have troubled the minds of the greit propounders of the unchlatory theory of light-i.e., of the clastic solict theory, as it is now termed in contraclistinction to the electro-magnetic theory propounded by Maxwell. The greatest living exponent of the former view, Loml Kelvin, who in his Baltimore Lectures grappled with the diftieulties which still beset that view-falling back on the principle of optical consonance and resonance, sugrgested by Professor Sitokes to explain some of the interactions of the ether and ponderable matter; mpon the theory of free and forced vibrations, suggested by liessel and rellneier : and on his own fruitful suggestion of the vortex attom to explain some of the properties of ponderable atoms moving in the continum which fills all space-expresses himself very definitely on this point. "We must not listen to any suggestion that we may look upou the luibl helvin on the" vilurations luminiferous ether as an ideal way of putting the thing. A real matter between us and the remoter stars I believe there is, and that light consists of real motions of thit matter, motions just such as are deseribed by fresnel and Young, motions in the way of transverse vibrations. If I knew what the magnetie theory of light is, I might lee able to think of it in relation to the fundumental prineiples of the wave theory of light. lint it seems to me rather a backward stej from an absolutely definite 
mechanical notion that is put before us by Fresnel and his followers, to take up the so-called electro-magnetic theory of light in the way it has been taken up by several writers of late."

But whilst, no doubt, the train of reasoning started by Maxwell, and developed by his followers, has somewhat destroyed the simplicity and directness which the older vibratory theory of light and the kinetic theory of gases had brought into our mechanical views of natural phenomena, the subsequent experimental proof of the existence of electric waves by Hertz has done much popularly to strengthen that view. The discovery of other kinds of rays, by Lenard, Röntgen, and others, has likewise tended in the same direction, though their exact nature is still a subject of much conjecture.

Nor can it be denied that the practical usefulness also of these lately discovered forms of radiation has tended in the same direction; as has, all through the last thirty years, the enormous development of electrical industry in its many branches. Up to the beginning of the nineteenth century the principal electric and magnetic phenomena known were what we term statical; the study of these centred in the conception of electric and magnetic charges concentrated on or in conductors and acting at a distance. The practical interest was limited to mariners' compasses and lightning-conductors. The discovery of the galvanic current, and still more its applications by Davy to the decomposition of the most refractory chemical compounds, introduced an entirely new class of phenomena. Continental science, in Coulomb, Ampère, and Weber, first 
KINETIC OR MECHANICAL VIEW OF NATCRE. 93

developed the line of reasoning and resurall sumested by statical phenomena and applierl this to dymanical phenomena. Faraday, following lowy, approached the subjeet from the point of view of the chemist. It wat: soon suspected, and latterly proved by actual measurements, that the quantities which come into play in statieal charges, and even in a violent thmulerstom, are small compared with those of a steady electrical current. The phenomena of electricity in motion becante of infinitely nore practical importance than those of electrical equilibrimn or of statie tension. The views of Faraday, Thomson, and Maxwell, which Hehnloltz, edueated thongh he was in the continental methods, adopted and introdnced into German scientific literature, lent themselves, as he recogniserl, nore successfully aml directly to the solution of the problems which applied science foreed upon theorists.

something, indeed, has been lost by this fundamental change which las eome over modern reasoning in electrical matters. This luas been most clearly anl pointedly expressed by M. Poinearé, the eminent Freneh mathematician, who has done so much to illmuine physical and mechanical problems from the sicle of pure mathematies. "Maxwell," he says, " loes not give at meehanieal explanation of eleetricity and magnetism: he confines himself to the proof that sueh an explanation is possible." Aceorelingly, those who were brought up in thr traditions of the school of Laplace and ('anchy feel dismayed at the indefiniteness which allewes to the expusitions of Maxwell's latest and greatest work. "I great French philosopher", M. L'oncaré freveeds, "one wi these 
who have most completely fathomed Maxwell's work, said to me once, 'I understand everything in the book except what is meant by an electrically charged body." Professor Glazebrook tells us: "We cannot find in the 'Electricity' an answer to the question, What is an electric charge? Maxwell did not pretend to know, and the attempt to give too great definiteness to his views on this point is apt to lead to a misconception of what those views were. . . . Still, in order to grasp Maxwell's theory, this knowledge is not necessary."

Nevertheless, Maxwell's followers in this country and abroad are not satisfied to leave those points which are obscure or indefinite in his theory unilluminated. I have already referred to the valuable practical illustrations of Lodge. What has been done in a more systematic manner on the Continent and at home I shall briefly refer to at the end of the next chapter. We may call it a revival of the atomic view of electricity. 


\section{CHAP'TER VII.}

ON THE PHYSICAL VIEW OF MATURE.

I HAVE already remarked that none of the three great generalisations which we have so far reviewed have loeen Recapituls. ereations of the philosophers of the nineteenth century. Their first enumeiation belongs to antiquity, though they have only within the list three hundred years been expressed in sufficiently precise terms to permit of practical measurements and mathematical deductions. The first step towards a scientifically comprehensive employment of the familiar but vague terms of attraction, of atoms, and of undulations came, as we have seen, in each case from some solitary thinker of this comntry: from Newton, from Dalton, from Thomas Young. The systematic elaboration belongs to the combined scientific exertions of all the eivilised nations of the world. In bouks on astronomy, physics, and ehemistry, up to the mitlde of the century, we can hardly find any theoretical expositions which are not based upon one or more of these three ideas. Indeed they govern the entire science of inanimate nature during the first half of the century. None of these three prineiples, however, appeared suf- 
ficient to cover the whole field. The law of gravitation embraced cosmical and some molar phenomena, but led to vagueness when applied to molecular actions. The atomic theory led to a complete systematisation of chemical compounds, but afforded no clue to the mysteries of chemical affinity. And the kinetic or mechanical theories of light, of electricity, and magnetism, led rather to a new dualism, the division of science into sciences of matter and of the Insufficiency of the astronomical, atomic, and kinetic views. ether. The unification of scientific thought which was gained by any of these three views, the astronomical, the atomic, and the mechanical, was thus only partial. A more general term had to be found under which the different terms conld be comprised, which would give a still higher generalisation, a more complete unification of knowledge. One of the principal performances of the second half of the nineteenth century has been to find this more general term, and to trace its all-pervading existence on a cosmical, a molar, and a molecular scale. It will be the object of this chapter to complete the survey of those sciences which deal with lifeless nature by tracing the growth and development of this 3. greatest of all exact generalisations-the conception of The conception of energy. energy.

The complex of ileas and the manifold courses of reasoning which are centred in this conception form such an intricate network, the interests involved are so great, the suggestions which led up to it so numerous, the consequences which resulted for science and practice so far-reaching, that the historian has no little difficulty in laying bare the many lines of thought which apparently cross and re-cross each other. Accordingly the 
history of this subject has
points of view, and angry
"The histories are mostly in German. I give the titles of the more important. Foremost stand the writings of Prof. Erust Mach-viz, 'Die Geschichte und die Wurzel des Satzes von der Erhaltung der Arbeit' ('rag, 1872), incorporated in the author's 'P'opular Seientific Lectures,' translated by 'Thomas

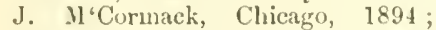
and the same author's 'Die Mechanik in ihrer Entwickelung, historisch-kritisch dargestellt' (Leipzig, 1883, 'nd ed., 1889, also translated by M'Cormack, London and Chicago, 1593). 'The philosophical faculty of the University of Giottingen has twice (in 1869 and in 1884) made the principles of clymanies the subject of a prize competition, presumably both times at the instigation of the late celebrated l'rofessor Wilhelm Weber. The first competition led to the publication of E. Dihring's ' Kritische Geschichte der allgemeinen Principien der Hechanik" (heipzig, 1872; republished, with much controversial matter, in 1876 and 1587 ); the second to the prublication of Prof. Max Planck's 'Das l'rincip' der Erhaltuug der Euergie' (1eipzig, 1887). In the same year as the last book there appeared 'Die Lehre von der Energie,' by Dr Georg Helm (Leipzig, 1587), and lately his very complete work, "Die Energetik, nach ihrer geschichtlichen Entwickelung' (Leipzig, 1898).

2 The controversy turned mainly on the question of the chaims of Dr Julius Robert Mayer of Ileilbrom. The experimental work of Joule in England and the theoretical work of Helmholtz in (iermany were published in ignorance of the writings of Mayer. Hen the earlier inportant papers of Willian Thom- been written from virions controversies ${ }^{2}$ as to priority

son (Lorrel Kelvin) ancl liurluly th Clausius appeared before the nante of Mayer was generally known. 'The question then arose (s) whist extent the publications of Maye-1 really anticipated the rlinuserien and theories of Joule, lteluboltz, Thomson, and Clausius. It cis1 hardly be held that they influsnces] them. The whole of the evilinen. as to the former print is con. tained in a very complete publication by Irof. Jacob J. Weyrauch, "Kleinere Selniften unl bri ‘fe von Robert Hayer" (Stuttgirt, 1592), which forms a supplement to the edition by the man author of Robert Mayer's 'Schriften,' en. titled "I Mie Mechanik der Wirme" (Stuttgart, 3rd ed., 1893). Both books contain very eareful and exhaustive notes. Whoever desires to settle the ruestion of Mayer's claims, which, however, will always depend much on individual opinion, will find all the documentary evidence collected in these interesting volumes. A further controver arose later as to the discovery auel enunciation of the second law of thernodynamics, the great dintrine of the "Dissipation of Fu. ergy." "This controversy aruse over the publication of the late l'rof. P. G. Tait's 'Sketch of Thermo. dynamics' in 1568, which is an amplification of $t$ wo articles ly the same author in the "North British Review' of 1864 . 'The (on)troversy, which referred mainly" w 1.. Clausins's share in the enueiation of the second law, can lie studied in 'Tait's little volume (1st ed., 1868; ; 2nd edi., 1577), in ruls. 43 and 4.1 of the 4 the series of the 'Phil. Mtug.,' in his 'Recont Advances in physical sience" (espreciatly the preface th the. 3 ril edlition, 1855, and in the 2und 
of discovery and as to the real points at issue have arisen. The history of thought only takes note of these in so far as they are indications of what was of real (not of personal) interest in the process, and are thus a measure of the value which was inherent in its development.

None of the different views or theories with which the earlier generations of philosophers during the century operated seemed sufficient to give an insight into the real essence, the $\phi v i \sigma s$, of natural phenomena. Neither the astronomical nor the atomic nor the kinetic view was all-embracing. On the Continent, both in France and in Germany, the sciences were rigidly marked off from one another, the connecting links were few and ill defined, and speculations as to the general forces and agencies of nature were left to metaphysicians and treated with suspicion. In England alone the name of natural philosophy still obtained, and in the absence of separate schools of science, such as existed abroad, suggester, at least to the self-taught amateur or to the practical man, the existence of a uniting bond between all natural studies. It is significant that the term under which we now comprise, and by which we measure, all natural agencies, the term Energy, was first distinctly used in this

4.

The term first used by Young. sense by Dr Thomas Young in his lectures on Natural Philosophy, ${ }^{1}$ a course which, be it noted, also embraced edition of the 2 nd vol. of Clausius, 'Die mechanische Wärmetheorie (Braunschweig, 1879), p. 324, \&c. In the labyrinth of these controversies I have found Helm a fair and conscientious guide.

1 Vol. i. p. 59 of the edition of Kelland. Young says: "The term
Energy may be applied, with great propriety, to the product of the mass or weight of a body into the square of the number expressing its velocity. . . This product has been denominated the living force (the vis viva), . . . and some have considered it as the true measure 


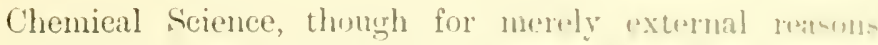
this was smmmarily handlert. It is explatly signifirant that the first valualle suggestions as to the connection of the various sciences, and the practical or common meatsme of the various agencies, cane from pratetical or profestional persons who took an outside and general view of physical and chemical processes and their application in arts and medicine. Joung himself was a medical man, as wert Robert Mayer and Hehnholtz after him. l'ravtical nuen such as Watt felt the necessity of measuring not so much forees (in the Newtonian sense) ats the action uf forces, and introduced the term power, and the yuantity calleal horse-power ${ }^{1}$ to measure the capacity of an enerine for doing work. Newton had alrearly measured this action" of the quantity of motion; but although this opinion has been very universally rejected, yet the force thus estinated well deserves a distinet leuomination." See alsu p. 172 .

1 The quantity ealled horsepower was introduced by Boulton and Watt to measure the power of the engines they built and sold at Soho towards the end of the eighteenth century. They eaused experiments to be made with thestrong horses used in the breweries in London, and from the result of these trials they assigned $33,000 \mathrm{lb}$, raiserl one foot per ininute, as the value of one horse-power. Dr Young in his 'Jectures' has the following statement: "A steam-engine of the best construction, with a 30 -inch eylinder, has the force of forty horses; and since it acts withuut intermission, will perforu the work of 120 horses or of 600 men, each square inch of the piston being uearly equiratent to a labourer" (rol. i. p. 103).

"See the Seholium to the "Ixio. mata sive Locges Motus," p, 25 of the first edition of the "P'rincipias, in which the "Agentis Actiu" i. measured "ex ejus vi it velocitate eonjunetim." Thumston and Tait ('Natural l'hilosophy,' lwh, gart i. p. 250 syq., and 'Tait, 'Dynamies,' 1895, p. 181 have drawn altention to the fact that this passare of the 'Principia' contains inplicitly the modern notion of energy, and the principle of the conservation of energy. The continental historians named above are inclined to give Huygens credit for hilving tirst made explieit une of the ithat of the conservation of the yuantily now termed energy, and they trace the further elucidation of it to the Bernoullis, especially Juhm ber. noulli, who repeatedly ifeaks of the " conservatio virium vivarum," ind "urges that where pis rum disappears, the fuwer to th work

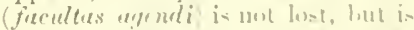
only changed intu smate other

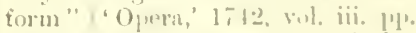
239 and 213 , quented liy l'lanck, lor. cit., 1. 111. 
of a force by the product of the force (itself measured by the velocity of a moving mass) and the velocity or space per unit of time through which it pushes or pulls a moving body, and Leibniz ${ }^{1}$ had suggested the term vis viva to distinguish it from the vis mortua, the force or pressure itself. But the first clear and consistent fixing of the terminology which has since been universally adopted is to be found-not in the 'Mécanique analytique' of Lagrange (that classical work on theoretical mechanics), but in the 'Mécanique industrielle' of Poncelet (1829). ${ }^{2}$ He introduced the term "mechanical

1 Leibniz's occupation with dynamies began with his publication of two theses in 1672, which he dedicated respectively to the Academy of Sciences in Paris and to the Royal Society. In distinction from the writings of Huygens and Newton, where precise definitions take the place of metaphysical discussions, Leibniz's tracts - except in the comparatively rare cases where he confines himself to mathematical formulæ-are vitiated, like those of Descartes, by philosophical speculations. Thus, though eminently suggestive, they contributed little to the clearing up of ideas. Influenced by Huygens and by Newton, he opposed in 1686 the ideas of Descartes on the measure of force, and has the merit of having introduced the term vis viva in 1695, and of having started the celebrated discussion on the measure of force which was carried on during fifty-seven years on the Continent, and only settled by D'Alembert in his "Traité de Dynamique' (1743) by stricter definitions. An excellent account of the questions involved, and of the gradual clearing up of ideas, will be found in Prof. Mach's historical treatise on dynamics referred to above. See the English translation by $M^{\prime}$ Cormack, p. 272 , \&c. It is there shown that one of the great defects of Descartes' and Leibniz's dynamical writings was the want of a clear definition of mass or inertia; also that this conception follows more simply from Newton's definition of force than from Huygens' conception of work (ibid., p. 251$)$.

2 By the side of, and sometimes in opposition to the purely analy tical school headed by Lagrange, Laplace, and later by Cauchy, there grew up in Paris the school of practical mathematicians which taught the application of theory to practice, to problems of artillery, engineering, and architecture. They created modern geometry, and to a great extent modern mechanics. Monge, Coulomb, the elder Carnot, Poncelet, Coriolis, were their leaders : Navier, Lamé, Charles, de Saint Venant, followed, and combined their more synthetic methods with the analytical methods of the former school. Through Monge, Carnot, Navier, and Poncelet, geometry and dynamics were led into those channels which liave since been so successfully followed in all applied work. To them 
work" for the definite quantity which hat lufure him been varionsly designated as power, effect, atction, di., and he distinetly states that the inertia of matter transforms work into vis vime and vis vive into work. He also measures this quintity "work" quite in the molern fashion-by the "kilogranmetre," which grives the simn" conception as the foot-pound, only in it difierent mestsure. Long before the terminology thus invented and fixed by Watt, Foung, and T'oncelet had heen accepted by scientific writers, a change in the current notions on the forees of nature had been grudually brought ibout from quite a different quarter. Uninfluenced ly thw theoretical views which were developed and firmly held

mathematics was not merely the science of magniturle, but quite as much that of position, of design and perspeetive, of mechanical work and effect. They introduced a whole series of new and practical ideas, drawn from their own appli. cations, and created a new rocabulary. They worked hand in hand with physicists and chemists, some of whom had little taste for the extrenely abstract and analytical methods of the school of Laplace and Cauchy. P'oncelet's origimal geometrical work, which will occupy us in a later chapter, led him into many coutroversies. It was, however, greatly appreciated in Germany and later in England. His inlluence on German applied mechanics has been quite as great as that on geometry ; and the great text-books of mechanics by Weissbach, Reditenbacher, Rilhlmam, and others, are as much indebter to Poncelet and other French models as the German text-bouks on mathematics, plyysics, and chemistry were for a long time to the well-known works of liot, l'ouillet, Cauchy,
Franceur, Lame, lisgnault, ansl others. The influence wi l'oncelet on practical mechanico, and especially in the fixiug of an alequate terminology, can therefire be studied equally well in French and in German historical witings. Among the former I may mention especially the "lixpoes de la Nitua. tion de la Mécanique applirgúe par Combes, Ihillips et Collignom, l'aris, 1567 , and among the latter, notably the above-nentioned writ. ings of Helm, who traces the growth of the conception wi mechanical work in Freuch writings, and its influence on (ierman thought ('Encrgetik,' p. 12, kc.) wee itlsi) Dïhring, loc. cit., y. \$71. Ec. I may also refer to Heun's lieport "Jahres. bericht der deutschen Matheniat. iker-Vereinigung,' vol. ix. pirt 2, 1901), where the sciences enmplianl in "Mechanies" are distimgnisherl according as they are astronomicul (1 aplace, f'oincaré), plysical timblish mathematical phisics, kirch. hotf, Helmholı, Hert\%. Lemmetrical (Poinsot, Chales, Bull, w lechni. cal (Wutt, l'oncelet, liankine.
Pos crip: introluces lie enru "simelisa coll w jok. 
by the school of which Laplace was the most distinguished representative, natural philosophers like Black, ${ }^{1}$ Rumford, and Davy had approached the study of those phenomena where heat and chemical change are the prominent features. The phenomena which they studied experimentally can be comprehended under the head of the disappearance and appearance of heat as measured by the thermometer, or as recognisable directly by our sensation of heat. Black accounted for the disappearance of heat by the doctrine of latent heat, and measured this by the capacity ${ }^{2}$ for heat, or the specific heat of different substances. Rumford made exact measurements of the heat generated by friction, and showed that Black's doctrine of latent

Black,

7. Rumford, and Davy. heat did not accomnt for it. Both Black and Rumford were led to science from the side of practical interests. Black, like Young after him, was a physician. Rumford was all through his life occupied with the

1 Joseph Black (172S-99), one of the founders of chemistry, and a prominent figure in that illustrious circle of philosophers who, during the second half of the eighteenth century, made the literature and science of Scotland renowned over the whole world, published very little, being mostly known through his teaching and his pupils. His name is, even to the present day, rarely to be found in French books; whereas in Germany, mainly owing to the historical writings of Herrmann Kopp, and quite recently of Prof. E. Mach, his great merit and originality have been fully recognised. See Kopp, 'Geschichte der Chemie,' vol. i. p. 226, \&c.; 'Die Entwickelung der Chemie,' 1873 , pp. 57 , \&c., 88, \&c. ; E. Mach, 'Die Principien der Wärmelehre,' 1896, p.
156, \&c. Black, who as early as 1755 had shown that carbonic acid gas could disappear as a gas and become "fixed," showed later that heat could disappear as tem. perature and become "latent." By himself, iudeed, the former important discovery was not interpreted against the then reigning phlogistic theory, nor was the latter used to upset the material theory of heat. Now, however, both discoveries are cornerstones in the history of science.

2 According to Dr Young ('Lectures,' new ed., p. 499), the term "capacity" is due to Dr Irvine, who, as well as Dr Crawford, was much influenced by Black's lectures. These were first published in 1802 by Robison, three years after the author's death. 
ON 'THE PHSSICAL VIFW UF NATUKF. 103

practical application of scientitic knowletge. Hiak's experiments and measmements combibuted latgely to fix the difference between tenperature and yuntity of heat; he demonstrated chearly that heat may disappear in the form of temprrature and exint as latent heat, that is, heat not liscoverable by the thermoneter. He, however, alliereal (n) the view that heat was a nuterial substance, which, thongh it might become latent, did uot disappear as smcl. Rimmforl ${ }^{1}$ was the tirst who definitely went a step further and suggested the comvertilility of lieat am mechanical work. It was not the disappearance of heat lut its appearance when mechanical work was performed which attraeted his attention. After elininating all the somees from which the heat produced inring the boring of cammon could have heen derived, he connes to the conchusion that "it apjears to be extrencly difticult, if not quite impossible, to forn any distinet idear w anything capable of being exciterl and communicaterl in the manner the heat was exeited and communicated in those experiments, excejt it be motion." liav, who, like Black, aplroached science in the interests of the nuedical man, connes to the conclusion in his first published papers, from experiments on the seneration

'Count Rumford's "Inquiry concerning the source of the Heat which is exeited by Friction" was fublished in a later edition of his 'Essays.' 'The experiments with the boring of cannon were cmried on at Junich in 1796 and 1797 : the substance of the essay was read before the Royal Sinciely in January 17:9. 'The 'Estays' were republished in Anseriod and tmaslated into several finteign lan. guages. Shee liumforils .lliurks, Lonklon, 1s76, vol. i. 1". 4*2. and rol. ii. p. 171 . lis $1-04$ Count humbrel published, in lis "Ménoires sur la Clatenor" l'aris, an. 1:3, a "Histuriat Roviosw of the Various Experiment क un Heat" "Works, vul. iii. !'p. 1:34 2 10 . 
of heat by friction and percussion, that heat is not matter, but "may be defined a peculiar" motion, probably a vibration, ${ }^{1}$ of the corpuscles of bodies tending to separate them. Rumford's and Davy's memoirs referred to belong to the last years of the eighteenth century. Dr Young, in his celebrated lectures on natural philosophy, discussing the experiments of Rumford and Davy came to the conclusion "that heat is a quality, and that this quality can only be motion." He refers to Newton's view "that heat consists in a minute vibratory motion of the particles of bodies," and to his own undulatory theory of light. This analogy with light seems to have for a long time served to unify the speculations ${ }^{2}$ of those who were inclined to

1 See his "Essay on Heat, Light, and the Combinations of Light," which appeared in Beddoes' 'Contributions to Physical and Medical Knowledge,' 1799. This essay Davy soon after condemned as "infant chemical speculations," from which he turned away to experimental work, remarking that chemical knowledge was yet too incomplete to allow of generalisations, and that the "first step will be the decomposition of those bodies which are at present undecompounded." This was written in 1799. In 1800 (30th March) Tolta's invention of the "pile" was communicated to the Royal Society, and on the 30th April of that year the first pile was constructed in this country. See the first and second rolumes of Davy's 'Collected Works,' London, 1839. Davy's first publication on voltaic electricity appeared in the September number of 'Nicholson's Journal.' Though the speculations of Davy on heat and light, in which heat is conceived to be motion and light (strangely) to be material, were discarded by him, they attracted the attention of Franklin and of Count Rumford. Davy states that his experiments on the generation of heat "were made long before the publication of Count Rumford's ingenious paper on the heat produced by friction" (loc. cit., vol. ii. p. 117). In spite of his own refusal to follow up the lines of thought suggested by them, they were probably the cause of Dayy's appointment as lecturer on chemistry at the Royal Institution : see vol. i. p. 83 ; also Memoir of Count Pumford ('Works,' vol. i. p. 417), and Paris's 'Life of Davy,' vol. i. p. 112, \&c. Tait, in 'Recent Advances,' gives a full account of Rumford's and of Davy's work.

'See 'Young's Lectures,' 51 and 52. In the second edition, published by Kelland forty years after the Lectures were delivered, the editor makes the following signifi. cant remark: "The theory of heat 
embraee a mechanical or kinetic view of the nature of heat. Joule, as staterl above, was the first who emancipated himself from it.

But whilst these suggestions that hat mat be lesgarded as sonehow eomected with motim remainem mostly vitgue and undeveloped, they tombed to inpress upon the seientific mind the interchangablility-or; as it was ealled, the correlation of the different forces of nature; and the illea seems to have foreed itself independently on many minds, throngh the study of very different groups of natural phenomena. In Gerniany we may look upon Liebig as the eentre of a great seientific movement which tried hy means of chemistry Liebig. to hring the realns of organie and animated existence under the treatment of exact methods. Not only were the methods of organic analysis perfacted by him and his school, and many eompounds investigated which appeared to be specially the bearers of the living proeess: but he was also among the first to study the economy of living orgunisms, the circulation of matter, and the play of the raried processes by which life is maintainel. Among these proeesses, the phenomenon of animal heat, its origin, and the part it plays in the living organism attracted special attention.

may be said to rest where it dicl at the time these Lectures were written. The facts which have just been mentioned clearly point out its unlulatory character" (p. 506). Between the years 1835 and 1845 theoretical ideas on the nature of heat were entirely dominated by the remarkable diseoveries of Melloni, Baden-l'owell, Forbes, and others referring to radiant heat, which was shown to have the satue properties of reflexion, refraction, and polarisation as light posisesed. The analogy of this form wi lieat with light threw into oblivion the beginnings of a more gensemal mechanical theory of heat, which -as we shall see further on-harl been laid ly sadi Carnot in 1524.

1 sice rol. i. of this work, I). 134. 
By his work on organic chemistry, by his many controversies, such as that on fermentation, by his popular letters on chemistry, and especially by his great influence as a teacher, Liebig himself did much to bring about an alliance of the separate sciences and a connection between practical pursuits and abstract research, and to draw attention to the interdependence of the various 10. forces of nature. Only second in influence was Johannes John Miiller.

Miiller of Berlin. Among the many expressions which took their origin in the circle of studies suggested by these influences, we may select three as giving increasingly clear emphasis to the point now under consideration-viz., the correlation of all the physical forces of nature. These expressions are those of the convertibility of forces, of the existence of a common measure of force, and of the conservation implying the perdurability of a certain quantity-now termed Energy - of which all phenomena are merely a partial exhibition. They are connected with the names of Karl Friedrich Mohr, Julius Robert Mayer, and Hermann Helmholtz.

Were it my object merely to write the history of science, I should probably follow the example of some historians ${ }^{1}$ and omit altogether the first of these names in the present connection. But as my object is to write the history of scientific thought, I feel bound to give a

1 Mach, in his recent very lucid and valuable work, 'Die Principien der Wärmelehre,' Leipzig, 1896, does not mention Mohr. On the other side, Helm ("Die Energetik,' 1898, 1. 9) mentions Moly' and likewise Planck ('Das Princip der Erhaltung der Energie,' 1857, p. 21). 'Tait's first edition of 'Recent Adrances,' 1874, does not contain Mohr's name. The third edition gives a full account of Mohr's early papers (pl). 51 and 60 , \&c.) See also the appreciative article on K. F. Mohr in the 'Ency. Brit.' 


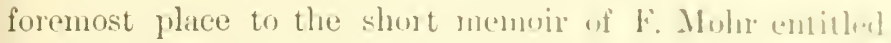
"On the Nature of Heat," which alpertrerl in ls:: an obsenre scientitic periodical publishen at Vienna. 'The publication of it remained unknown, aven to the anthor himself, and was certainly untpreciated hy the scinditio world for more than thinty years.

'The story of Molur's memoir is curious, not to siy romantic. His original paper, 'L'cuer die Nitur cler Wirme, was otfered to l'og. gendorf and refused, as were the later memoirs of Mayer and Heln. holtz. A dread of introducing speculative matter into the "An. nalen' prevented likewise - as I relaterl auove (p. 66, note 2)-the appreciation of mucl of fiaralay's later work. He then sent the MIs. to Baumgartner, in Vienna, whoalways interested in theoretical physics-printed it in a periudical ("Zeitschriit für Physik') of which he aud von Holger were jointeditor's. He did not inform the author of this. Hohr was a resmarkably original thinker, in whose mind important ideas rose at times to extraordinary elearness, but who: like many original thinkers, did not always appreciate his own ideas at their true value, and accordingly treated them with neglect, and did not consistently develop them. In the present instance he contented himself with inserting au abstract in the 'Annalen der l'hamacie" (rol. xxiv. p. 141), of which he was then joint-editor, together with Jiebig and Jerck. He made no further inquiries as to the ficte of his, larger memoir, and, in conversation with friencls up to the year 1860 , as also in his "Mechan. ische 'Theorie der chemischen Aflinitit' (Hrnumselweig, 1868, 1). 45), used to deplore the loss of a document which, more fully than the short payer in the "Amualen der l'harmacie.' would hate cotablished his priority in the clear enunciation of a remarkable principle which fifteen years later receivel general recognition. The matter would probably have rested there had it not been that Tyudall, in the year 1862 , in a celelrated lecture before the Royal lnstitution, ennnenced that long series of histurical and controversial pulplications in which many persons, including himkelf, Joule, Tait, Colding, Helmboltz, Akin, liohn, I)whing, \%ollner, and others touk part, and in which, ameng several claims frior to or contemprary with Mayer's, those also of Mohr received lue recognition. It secuns to have been especially lor Akin who drew attention to Moln's claims, and searched in the forgotten volumes of the Austrian periodical for the original memoir, which, unknown to the author himself, had been inscribel on 1 , 419 of the fifth volume. This discovery he ammouncel to Mohr himself after having already. in Novenber 1st.1 (Phil. Mag., 4 th series, vol. xxviii. 1'. 4i, given several extracts, anoug which is the one quoted hy me in the text. Mohr published, in lso?, a sequel to the above-nentined bouk, entitled "Allg'meine 'Vlıemie der' bewegung und Kraft, in which he refers to 1)r Akin's cliseovery, and reprints the miginal menoir in full. since that time his name has figured in many historical necrounts as one of the pinners in the development of the encrgy-concen- 
It forms, therefore, no link in the actual development of the energy-conception; but it is a significant evidence of the direction in which the ideas of natural philosophers were then moving, and of the high degree of clearness to which they rose in individual instances. When we read the following words: "Besides the known fifty-four chemical elements there exists in nature only one agent more, and this is called 'Kraft'; it ean under suitable conditions appear as motion, eohesion, elcetricity, light, heat, and magnetism," it seems difficult, even after the lapse of two generations, to alter anything in this clear and simple enunciation of the law of the conservation of energy. It has incleed been stated that "unless some still earlier author should be discovered, there ean be no doubt that Mohr is to be recognised as the first to enunciate in its generality what we now eall "conservation of energy.'" I At the same time, the ease shows how little, at the beginning of a scientific movement, purely abstract statements are capable of really guiding research into fruitful ehannels. There is with Mohr no attempt to establish or apply an actual measure $^{2}$ of the amount of energy appearing in the various instances which he mentioned. This further

12. step was taken five years later by J. R. Mayer, who can elaim to be the first $^{3}$ to have ventured on a

tion; his merit being varionsly appraised according to the purely scientific, the philosophical, or the more practical standpoint taken up by various critics. See, inter alia, P. G. Tait's 'Recent Advances,' 3rd ed., p. 60, \&c.; also the correspondence of Mohr and Mayer in the latter's 'Kleinere Schriften und
Briefe,' ed. Wayrauch, p. 407, \&c.

${ }^{1}$ See the article on K. F. Mohr in the 'Ency. Brit.,' 9th ed.

"See on this point Weyrauch, in Mayer's 'Kleinere Schriften,' p. 408.

3 Helm ('Energetik,'p. 34) begins the list of undoubted determinations of the heat-equivalent with 
numerical estimate as between mechanical tutring on the one side, and the amount of one wi the imponderables-i.c, heat as measured by the thermoneter-in the other. Although his methods were not free from objection, while his argunents were mixed up with

Maser, 1942. His determination is contained in his first paper, published, as was Mohr's, in Liebig's 'Annalen' (rol. xlii., May), with the title "Beuerkungen über die Krifte der unbelebten Natur." The experiments perfurmed by liuuford in 1793 were made the basis of a calculation of the heat equivalent, i.c., of the weight which can be lifted one foot if the heat required tw raise a pound of water $1^{\circ}$ be coll. verted into work agaiust gravitation, and the tigure turns out to be $1034 \mathrm{lb}$. as compared with 772 16. given by Joule himself 'Phil. Trans.,' 1850 ; 'Joule's Papers,' sol. i. p. 299!. The earlier computations of Séguin, based upon the work clone by the expan-ion of steam. were referred to by Joule, Tyndall, and Tait in 1862 and 1564 "Phil. Mag., t th series, vols. $x$ xiv. and $x x$ viii.), and shown to lead to figures iurther oft the mark than those of Hayer. In the course of this later controversy it became for the first time generally known that $\mathrm{A}$. Coldiug, an engineer in Copenhagen, had a little later than Mayer (1S13), and almost simultaneously with Joule, given a determination of the equiva. lent based upon friction of metals, which was lower than Mayer's. He accordingly now figures as second in Helm's list. One of Joule's earliest experiments with heat, "erolved by the passage of water through narrow tubes," gave the equivalent as 770 , very near the tigure. viz., 772 , finally settled on as correct in 1850 .

1 The reasuning of Ifayer is not completely contiined in his tirst paper, which subserguently, un a suggestion of Juule's, apleared in translation in the 'Phil, Mlag.' fth series, vol. xxiv. Pl. 123, and $3 i 1$ sq7.) The assumption called by Thomson in 1501 "Mayer's hypothesi-," -ee "Math. and l'hy: Papers', wil. i. [. 213 that " the work spent in the compression of a gas . . . is exactly the mechani. cal equivalent of the . . . heat evolved," which Joule dirl unt think it right to accept without atis fying himself by experiments see 'I'hil. Mar.,' tith serien, vol. xxiv. p. 122, was based by Mayer un an aluost forgotten experiuent of Gay Lu-sac's in the year $180 \%$, as is evident from his subsequent jalper, published in $1,4 j$ reprint in 'Mechanik der Warme, ed. Weyrauch, 1s93, p. 53), and still more from his correspondence with Baur previous to his first publication (ibid., p. 20, and 'Marer's Briefe,' p. 130 , September 1841 . The subject was exhaustively investigated by Thomson and Joule in a juintmemoir on "the thermal etfects of Huids in motion, " 1552 reprinted brith in Juule's and Lird Kelvin's Scientific Papers, when it was shown that for air Mayer's hypothesis was approximately, lut not absolutely, currect. sil long. theretore, as the history of Mayer' reasoning was not cumpletely known, it appeared as if he hail by a kind of accilent hit upon an approximately currect tigure. Sec Tait, 'Receut Allvances' Bril eal., p. 53 ; but also Helm, "Energetik, 1. 24, and Mach, 'Wartnelelire,' p. 249). 
philosophical speculations which tended to prevent their ready acceptance, it cannot be denied that, as a first approximation, "his equivalent" was sufficiently near the truth to be practically useful.

But neither the happy generalisation of Mohr, which was lost or forgotten, nor the numerical estimate of Mayer, which remained umnoticed, succeeded in impressing contemporary philosophers with the importance of the subject. This was done almost at the same date, though quite independently, by the persistent and perJoule.

13. severing experiments and measurements of James Prescott Joule, who laboured unnoticed and practically without support from 1841 to 1847 , when he had the good fortune of gaining the attention and friendship of William Thomson (Lord Kelvin). ${ }^{1}$

1 Joule not only defined more clearly the different data and conditions on which the correctness of the result must depend, but lad also at his command a much greater wealth of novel experimental facts, brought together by his own resourceful mind. Thus from 1843 to 1850 he published no fewer than ten series of experiments, approximating from widlely differing results to the true figure. See Helm's list ('Energetik,' p. 34). After he had laboured for more than five years his work was, in 1847 , at the meeting of the British Association in Oxford, still almost unknown. He himself reports as follows in 1885 ('Joint Scientific Papers,' 1887, p. 215): "It was in the year 1843 that I read a paper "On the Calorific Effects of Magneto-Electricity and the Mechanical Value of Heat "to the Chemical Section of the British Association at Cork. With the exception of some eminent men ... the subject did not excite much general attention; so that when I brought it forward again at the meeting in 1847 the chairman suggested that, as the business of the section pressed, I should not read any paper, but confine myself to a short verbal description of my experiments. This I endeavoured to do, and diseussion not being invited, the communication would have passed without comment if a young man had not risen in the section, and by his intelligent observations created a lively interest in the new theory. The young man was William Thomson, who had two years previously passed the University of Cambridge with the highest howour, and is now probably the foremost scientific authority of the age." See also Lord Kelvin's account of the meeting in 1847 in 'Popular Lectures and Addresses' (Londlon, 1894, vol. ii. p. 556, \&c.) 
A pupil of Dalton, Joule was daly drawn inte the circle of ideas and investigations which are containol in Faraday's experimental resenrehes. With nuteh anulls means, and possibly also with a greater love for aceoritt. guantitative measurements, than Furalay jussessul, he. grasped the great importance of the law of alectrolyti. equivalence as affording the means of accurately measuring chemical processes, and of giving definite expression to the vaguer illeas supported by Farulity and others that force was indestructible, and that the different forces of nature were mutually convertible. 'Jhes. ideas had received popular circulation and emrent rxpression in Grove's celebrated lectures on the " (orrelation of Physical Forces" in $18+2$ and $184 .$, .Joule, in whose mind they seem to have existed as axioms, set himself to devise acemate instruments and methoils by which the convertibility of difterent forces, their "mechanical duty," could be measured, and their eyuivalence put into figures. The first numbers which Joule found differed consilerably, ${ }^{1}$ so that the conchusion alrived at that the mechanical duty or "value" of a degree of heat is a constant quantity could only have been drawn by one who had a strung a priori2 con-

1 For details see Helm, Ener" getik,' 1\%. 34; atso vol. i. P. 265, note, of the present work. Joule's equiralent varied from $7+2$ to 890 foot-pouncls, and was finclly fixed at 772 in 1850 , this figure being correct to 1 jer cent (Joule's 'Scientific latuers,' p. 32s).

2 Philosophical considerations are mixed up with all the early enunciations of the prineiple of the indestructilility of force, or energy as it was later more clearly termed.
A predi-position to belirse that some quantily besicles matter could not be lost or created, but only preserved and trunshrmed, existeil in the minds of Mohr, séruir, Mayer, Colching, houle, Hirn, ans! has been traced rariously hark to the wrings of enrlier" lluinkers,

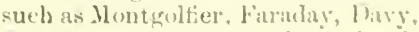
Deroted, Leilmiz, Ni. Prot. Math

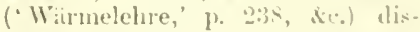
cusses this point fully. "The prin. (ij)le graduatly lrecame firmly 
viction in that direction. The experimental result did not satisfy Helmholtz, who, about the same time, was led to consider the origin of animal heat in living organisms, a problem with which Liebig ${ }^{I}$ had been greatly occupied for several years. Without himself devising or instituting new experiments, or attempting any determination of the equivalent as others-notably 14. Colding and Holtzmann - were doing, Helmholtz, in Helmholtz. 1847, undertook a theoretical investigation which has since become classical-a corner-stone in the philosophy of the subject. He first of all gave the principle involved a correct mathematical expression, showed how it conld be considered as an extension of the theorem known in abstract dynamics as the conservation of the vis viva of a mechanical system, attempted to define the nature of forces, in the Newtonian sense, which would be subject to the new principle, and brought it into logical connection with the axiom laid down and used by French philosophers, that perpetual motion is an impossibility. After clearing the ground so far as abstract dynamics is concerned and giving the necessary definitions, sharply distinguishing between acting (living) forces and mere tensions (dead forces), Helmholtz proceeds to draw all

established according as strict clefinitions, experimental proofs and figures, and mathematical formulæ took the place of vague speculations. Jonle did the experimental, Helmholtz the mathematical, part of the work; but it is interesting to see how little the latter without the former was able to impress contemporary German writers with the value of the principle which he established. $\mathrm{He}$ himself even did not for a long time develop the line of reasoning which he had begun.

1 See Helmholtz, 'Bericht über die Thenrie der physiologischen Wärmeerscheinungen,' 1845, reprinted in 'Wissenschaftliche $\mathrm{Ab}$ handlungen,' vol. i. No. 1, also on Joule's early experiments in 'Ueber die Erhaltung der Kraft,' ibid., vol. i. p. 33. 
other forees of natme into his consideration, showing, in the case of the phenomena of heat, electricity, matrinisin, and magnetic induction, how the different agencies can be brought into comparison with mechanical ones by measuring the work they perform; refers to the attempts to fix the mechanieal value of heat: anducles in each case that no observed phenomena- not even the processes in living organisms - stand in contraliction with the principle anmonnced, and ends with the words: "I think in the foregoing 1 have proved that the abovementioned law does not go against any hitherto known facts of natural seience, but is supported by a large number of then in a striking manner. I have tried to enumerate as completely as possible what consequences result from the combination of other known laws of nature, and how they require to be confirmed by further experiments. The aim of this investigation, and what must exense ne likewise for its lypothetical sections, was to explain to natural philosophers the theoretical, practical, and hemistic inportance of the law, the complete verification of which may well be looked upon as one of the main problems of physical science in the near future." l The reasons why this valuable docment attracted little attention at the time and was set asile, as were the eirlier contributions of Mohr and Mayer, by the centual organ of experimental physics abroad, are interesting from a historical point of view. The first and main reason seems to have been that none of the three original and independent expressions contained any new experincintal 1 'Gesammelte Abhandlungen,' vol. i. P. 67. 
facts, ${ }^{1}$ and that the then reigning school of natural philosophers in Germany discouraged theoretical deductions, as possibly leading back to the fatal "philosophy of nature," out of which they had only just escaped. Men of the intellectual eminence of Liebig, through whose labours an enormous mass of new facts had been accumulated, and who desired to see the more hidden processes of organic life subjected likewise to rigorous measurements, showed indeed a certain appreciation of the attempted definitions of Mohr and Mayer, struggling as he and they alike were under the still existing confusion in the fundamental conceptions. ${ }^{2}$ And these were not

1 See Mohr, 'Allgemeine Theorie der Bewegung und der Kraft,' $p$. 82, \&c. Poggendorf did not reply to Mayer's repeated communica. tions and did not return the MS.; the fact that he received it was first establisherl by Zöllner, who in 1877 recovered the MS. from Poggen. dorf's heirs (Mayer's 'Schriften und Briefe,' ed. Weyrauch, p. 100), and gave a facsimile of it in his 'Wissenschaftliche Alhandlungen' (Leipzig, vol. iv., 1881, p. 672). Helmboltz, who in 1847 had no knowledge of Mayer's writings, did full justice to his claims in his address, 'Ueber lie Wechselwirkung der Naturkriffte' (1854), and vindicated them against 'Tait's criticisms in a letter published by the latter in his 'Sketch of Thermodynamics" (Edinburgh, 1868); see Helmholtz, "Wissenschaftliche Abhandlungen,' vol. i. p. '1, \&c. Helmholtz closes his later comments on the subject ("Vortrïge und Reden,' vol. i., 3rd ed., 1884, p. 74) with the following significant remark: "The best ideas rum the risk of remaining barren, if not accompanied by that energy which lasts till the convincing proof of their correctuess has been given." This explains the neglect of Mohr and Mayer, and why in England the interest in the energy icleas only became general after Joule's, 'Thomson's, and Rankine's labours, as Helmholt\% himself remarks in 1854 ('Vortrage,' \&c., p. 39).

2 Helmholtz "Ueber Mayers Priorität," 'Torträge,' vol. i. p. 69) says: "That the [i.e. Mayer"s] dis. sertation contained really important ideas, that it did not belong to the wide-ranging literature of vague suggestions, such as are amnually served up by badly informed amateurs, could at best only be noticed by a reader who had already turned over in his mind similar reflections, and who could recognise them under the somewhat strange vocabu lary of the author. Liebig, who, in the same year in which Mayer's dissertation appeared, published his book on animal chemistry, in which he fully discussed the question as to the origin of animal heat, was perhaps such a reader, and was therefore willing to insert the article in his annals." The same remark would-refer equally to Mohr's earlier essay. It is now known 
sufliciently eleared up in Mohr's short aperese, which dous not attempt to distinguish between the two ditginnte meanings of the worel force, nor in the earlice pitynt's of Mayer, who, howerer, in later writings shows a clnal appreciation of the difticulty. In Heluhnlt\%'s monums the desired elearness was only attained by mathemationt reasoning, whieh in his age and comntry wats accessilil. to but few naturalists. The secomel and probably the fundamental obstate in the way of a just recangnition of the new truth lay in the fatal use of the term "foree" in two distmet meanings. I'opularly the dilliculty has only been removed hy the creation of a new vocabulary, and dates from the introduction of the term "work" by Clansius in 1850 , and of the tern "energy" by William Thomson, who adopted it from Young in the year 1852 . The eonfusion which had been kept up by "Wurk" and "erergy" introluced by Clisusius an! Thomsun. employing the worl "foree" to mean not mbly pressme or dead foree (in the Newtonian sense) but also acting foree (vis viva in the Leibnizian sense), and with this confusion the whole meaning of the great controversies which raged for many years between the Cantesians and Leilnizians on the eorreet measure of force, was then removed, and a crrmmatieal and logrical foumla-

from Mayer's published correspondence that some remarks of Lielig himself, which appeared early in 1842, induced him to send him his first pityer in order "not tu lose the right of priority" (letter to Griesinger, 5th.6th 1)ecember 184.2, in 'Sichriften und Brieie,' ed. Wey. rauch, p. 190). Hayer there says: "Liebig wote to me, inter alia: 'As to what force, cause, and effect are, there exist in geneml such confused notions that an easily understood explanation mu-t be considered to he uf reall value." One would accontingly think that he himalf consielers himselt quite above this general conlunion; that this is mol st), 1 could see sulliciently firom his "phenomentit of motion in the animal organism" liehig, "lie organische Chomice, de., 1.t2, I. 153, di.' 
tion secured on which a new generation could enter at once into the possession of correcter dynamical and physical views. It is now being recognised more and more that the word "force" applies only to a mathematical abstraction, whereas the word "energy" or "power to perform work" applies to a real quantity; and there are not wanting suggestions that the former should be altogether banished from scientific text-books, and that the latter denotes not merely a property of matter, but that it is after matter the only real thing or substance in the material world.'

This radical change in the fundamental notions which underlie all physical reasoning was not brought about, however, till the vaguer views expounded by Mayer in Germany, and the exact measurements of Joule in England, had been united by the independent labours of Thomson and Clausius, whose earliest researches (also carried on independently of each other) had been suggested by the

1 The late Prof. P. G. Tait has on various occasions expressed himself in this sense. See his lecture on "Force," delivered before the British Association, Glasgow, in 1876, and reprinted in 'Recent Advances,' 3rd ed., also the closing paragraphs of his article "Mechanics," in the 9th ed. of the 'Ency. Brit.' reprinted as 'Dynamics,' 1895 , where he says (p. 356): "The only other known thing in the physical universe, which is conserved in the same sense as matter is conserved, is energy. Hence we naturally consider energy as the other objective reality in the physical universe, and look to it for information as to the true nature of what we call force;" and (p. 361): "In all methods and systems which in. volve the idea of force, there is the leaven of artificiality. The true foundations of the subject, based entirely on experiments of the most extensive kind, are to be found in the inertia of matter, and the conservation and transformation of energy. With the belp of kinematical ideas, it is easy to base the whole science of dynamics on these principles; and there is no necessity for the introduction of the word 'force,' nor of the sensesuggested ideas on which it was originally based." We must, however, in that case extend the conception of matter to embrace also the ether (see Tait, "Properties of Matter,' p. 5, 2nd ed.) 
still earlier writings of Sadi Carnot and Clituryon in France. Thomson's interest in the sulject dates trom Sadi riarno: the middle of the 'forties. He was then occuniterl with finding a method for measuring heat on the absolute scale. Mohr, Mayer, and Helmholtz all approached the thermo-dynamieal problem in the merlical or physiolugiral interest. 'Trained in the sehool of Liebig and Johannes Miiller, they were led to study the ecomonics of ormaic processes and the mechanism of the physiological phenomena of animal heat, of motion, and of nutrition. Sadi Carnot, as after him Clapeyron in Fance and Joule in Manchester, approached the thermo-dynamical problem from the side of practical interests, created by the introduction and universal applieation of steam in the useful arts. The great ehange worked by the stemn-engine, especially in England, the utilisation of coal and ironstone, the foundation of England's growing industrial wealth, seemed to Sadi Cirnot to be concentrated in the problem of the motive power of heat; as to Liebig, the key which would unlack the mysteries of regetable growth, of animal mutrition, and of hunan labour, with their economic, industrial, and political aspeets, lay in the problem of combustion. As in the domain of electrieal science, so in that of thermotics, the first thing to do was to arrive at a correet method of measuring heat as distinguished from temperature. It was a problem of applied mathematies. About the same time Gamss hat established the system of absolnte measurement from at universal point of view, and he and Weber harl appliod it to magnetic and electrical phenomena. Thomson set himself to do the same thing in thermoties, and 
he found in the ideas expounded by Poncelet, Sadi Carnot, and Clapeyron, the means of accomplishing the object. We now see how there lay, in the fundamental problem of thermo-dynamics, the unifying idea of sciences hitherto far apart and working on independent lines and with independent standards of measurement, speaking, as it were, separate languages. And what was the new idea which lay concealed in Sadi Carnot's forgotten pamplnlet ? ${ }^{1}$ In Carnot's original memoir it appears as an axiom at the beginning of his reflections. "The production of motion," he says, " in steam-engines is always accompanied by a circumstance on which we must fix our attention. This circumstance is the re-establishment of equilibrium, or level, in the caloric_that is to say, its passage from one body where the temperature is more or less elevated,

1 The story of Sadi Carnot's memoir is not less curious than that of Mohr's first paper. It was first given by Lord Kelvin in his earliest article, "On an Absolute Thermometric Scale" (1848), reprinted in 'Math. and Phys. Papers,' vol. i. p. 100), aud "An Account of Car. not's Theory" (1849, ibid., p. 113). He had in 1845 searched in vain for the 'Puissance motrice du Feu' in all the bookshops of Paris. In 1848 he obtained a copy from Lewis Gordon in Glasgow. It was knowu to him before through Clapeyron's memoir in the $14 \mathrm{th}$ vol. of the 'Journal de l'Ecole polytechnique' (1834). Sarli Carnot published his memoir as a pamphlet in 1824. It has since been republished by his brother, Hippolyte Carnot ('Réflexions sur la Puissance motrice du Feu et sur les Machines propres à développer cette Puissance,' Paris, Gauthier-Villars, 1878), with important posthumous papers, from which, inter alia, it is evident that
Carnot, before lie died, had abaudoned the material theory of heat, and actually, by an unkuown process, calculated the mechanical equivalent of heat as 360 kilogrammètres. As in several other cases, so also in that of Sadi Carnot, the line of reasoning initiated by Laplace, and brilliantly developed by his school, militated agaiust the acceptance of the dynamical as opposed to the material conception of the phenomena of heat; and 1I. Bertiu, in his "Rapport sur le Progrès de la Thermodynamique en France" ("Recueil de Rapports,' \&c., p. 5) could write in 1867: "Il faut bien l'avouer, parceque c'est la vérité: nous sommes restés longtemps, je ne dis pas rebelles, mais étrangers aux nouvelles idées: elles nous sont restées trop longtemps inconnues, et encore aujourd'hui, on peut regretter qu'elles n'occupent pas une place plus considérable dans uotre euseignement scientifique." 
to another where it is lower. . . The prusluction of moving foree is therefore due in stean-engines, not $(1)$ at real consumption of caloric, lut to a transference from it hot body to a cold body." l

If it is the object of physical seience to rescribe the processes of nature completely and in the simplut language, we have here an instance of a description of a very general property in very simple language, and in terms which reduce it to a measurable quantity. Without this, progress is impossible. It is not likely; however, that Carnot saw the full significance of his simple statement, how in it he hat introduced into ploysical and mathematical science the great question of the availability of the forces of nature, as Mohr and Mayer in Germany, and Faraday and Grove in England, somewhat later, dwelt on the concelation or interchingeability of those forces. 'The two ideas were seprarately developed. When they came together in one mind, when Thomson fully realised the importance and meaning of both -as he undombtedly did earlier than any other natural philosopher-he at once established the great doctrine of the dissipation, also called degradation or depreciation, of energy. liut it required sone moditication of Carnot's enunciation of this general proprerty Thensin intrinduces the idlea of "dise before it could be jut into its modern form. This modification was preparing itself in C'arnot's own mind, as his papers, posthmously pulblished, have revealed to us. $^{2}$ What required to be modified was the word

1 Carnot, 'Puissance motrice,' ed. 1878, pl. 5 and 6 .

${ }^{2}$ His notebook contained the following entry ('Puissunce motrice," ed. 1875, p. 90): "Lorsyume hypothèse ne suftit plus ì l'explicastion des phénomènes, elle duit itre abaudontréc. C'ist le chri vil se 
caloric. Carnot was brought up under the influence of the school that looked upon heat as an imponderable substance which might hide itself-_might become latent -but conld not be created or destroyed. This was the view of Black, of Laplace, of Fourier; it was not the view of Cavendish, of Davy, of Rumford. The views of the former were embodied in great treatises, and consistently worked out with much collateral extension of physical and mathematical knowledge; the views of the latter were expressed in detached experiments and in

19. Fourier.

casual reflections. Fourier ${ }^{1}$ had just (1822) given to the world his epoch-making work, the 'Théorie analytique de la Chaleur,' in which he had stated that "the properties of heat form a special order of phenomena which are not to be explained by principles of motion and equilibrium;" 2 and again, "There exists a very

trouve l'hypothèse par laquelle on considère le calorique comme une matière, comme un fluide subtil." Again (p. 92): "La chaleur est le résultat d'un mouvement. Alors il est tout simplequ'elle puisse se produire par la consommation de puissance motrice et qu'elle puisse produire cette puissance. Tous les autres phénomènes . . p pourraient s'expliquer dans cette hypothèse : mais il serait difficile de dire pourquoi, dans le développement de la puissance motrice par la chaleur, un corps froid est nécessaire, pourquoi, en consommant la chaleur d'un corps écliauffé, on ne peut pas produire du mouvement." And (pp. 93 and 94) : "Lorsque l'on fait naître de la puissance motrice, par le passage de la chaleur du corps A au corps B, la quantité de cette chaleur qui arrive à $\mathrm{B}$, cette quantité est-elle la même, quel que soit le corps em- ployé à réaliser la puissance motrice? $Y$ aurait-il moyen de consommer plus de chaleur à la production de la puissance motrice et d'en faire arriver moins au corps B ? Pourraiton même la consommer tout entière sans en faire arriver au corps B? Si cela était possible, on pourrait créer de la puissauce motrice sans consommation de combustible et par simple destruction de la chaleur des corps." And (p. 94) : "La chaleur n'est autre chose que la puissance motrice, ou plutôt que le mouvement qui a changé de forme. C'est uu movement dans les particules des corps."

${ }^{1}$ On the tardy reception and recoguition of Fourier's work see vol. i. p. 241, note, of this work.

2 "Théorie analytique de la Chaleur,' 1822: 'Discours préliminaire,' p. iii. 
extensive class of phenomenar which are not produred by mechanical forces, hut which result solely from the presence and aecumulation of heat. This part of matural philosophy camnot be bromght under dynamical theories; it has principles peculiar to itself, ind is based upon a method similar to that of the other exact sciences. ${ }^{1}$ The dilatations, indeed, caused by the repulsive force of heat, the observation of which dilatations serves as a measure of temperature, are dynanical effects; but it is not these dilatations which we calculate when we investigate the laws of the propagation of heat." " He proceeds to build up this new science "upon a very small number of simple facts, of which the eauses are unknown, but whieh are gathered by observation and confimed by experiments," 3 and he thus arrives at eertain general relations, expressed in the form of equations, which are different from, though analogous to, and not less rigorous than, the general equations of dynanics.

One of the great experimental facts upon which Fomricr bases his theory of the propagation (i.e., the conduetion and radiation) of heat is this, that all motion of heat depends on differenees of temperature. He examines how differenees of temperature are equalised and deduces the law of the flow of heat. ${ }^{4}$ Although he llocs

'Fourier, 'Théorie analytique,' p. 13.

2 Ibid., p. 14.

3 Ibicl., pp. xi, 18, 39.

4 I cannot here omit to point out how elegantly Prof. Mach has trauslated into the language of common. sense the whole process of Fourier for establishing the funcumental equation of the theory. See his 'I'rincipien der Warmelehre'(Leip)- zig, 1896), pp. 78, sc., 116 sq7. Every student of physics shoukl real the chapters referring to this subject. The mathematical formule will thus becone living to hinı; but he will also see how necessary the abst ract mathematical expression of common-sense conceptions is in oriler to aroid false reasuning. 
not find it necessary to enter upon any theory of the nature of heat, the analogy with the flow of water from higher to lower levels wonld naturally present itself. For his purpose this analogy had no importance. For the purposes of Sadi Carnot, who noticed that upon the difference of temperature depended not only the flow of heat, but also the work it might eventually influ. do, the same analogy seemed all-important. " We may," he says, "justly compare the motive power of leat with that of a fall of water: both have a maximmm which camnot be exceeded. The motive power of a fall of water depends upon its height and the quantity of the liquid; the motive power of heat likewise depends on the quantity of caloric employed and on what we will take the liberty of calling the height of its drop-that is, the difference of temperature of the bodies between which the exchange of caloric has taken place." 1 In this analogy two further assumptions seem to be implied: First, that the work capable of being done is in direct proportion to the difference of levels of height or of temperature; secondly, that the quantities with which we operate, of water or of caloric, remain the same, before and after the fall. Neither of these inferences is necessary: neither is permissible. Carnot does not adopt the first inference, ${ }^{2}$ but he does adopt the second, ${ }^{3}$ though he significantly remarks that the

I 'Puissance motrice du feu,' ed. 1878, p. 15 .

2 "Daus la chute d'eau, la puissance motrice est rigoureusement proportionelle à la différence de niveau entre le réservoir supérieur et le réservoir inférieur. Dans la chute du calorique, la puissance motrice augmente sans doute avec la différence de température entre le corps chaud et le corps froid; mais nous ignorons si elle est proportiouelle à cette différence" (ibid., p. 15 ; compare also pp. $38,39)$.

3 " La production de la puissance 
foundations on which the theory of heat rests require careful exanination. ${ }^{1}$ Further thought evidently led him to doubt the eorrectness of the second assumption. It is the first point to which Thomson, more than twenty years after, directs his attention. He conceives the idea of measming temperatme by such a scale that for an equal drop in the scale-i.e, by letting down heat by an equal number of degrees on the new seale-equal amounts of work shall be done. ${ }^{2}$ The speculations of Sadi Carnot remained unnoticed for a long time. Ten years later Clapeyron ${ }^{3}$ reverted to the sulject, and put the ('la)w.yrus reflections of Cirnot into graphical form and intu mathematical langnage. He introdueed the conception, based on (arnot's theory, of the ratio of lieat transferred from a higher to a lower level of temperature to the maximum of work obtainable, - a quantity independent of the substance employed,- - and he eallerl this fixed ratio Carnot's function. It was through his paper that motrice est... due... non it use consommation réelle du cal. orique, nuxis à son transport l'un corps chaud ì un corps froid, c'està-dire à sun rétablissement d'équilibre" (ibid., p. 6).

1 "Au reste, pour le dire en passant, les principaux fondements sur lesquelles repose la théorie de la ehalour auraient besoin de l'examen le plus attentif. Plusieurs faits l'expérieuce paraissent ì peu près inexplieables dans l'état actuel de cette théorie" (ibicl., p. 20, note). "La loi fondamentale que nous avions en vue. . . est assise sur la théorie de la chaleur telle qu'on la conçoit aujourd'hui, ef il faut l'avouer, cette base ne nous parait pas d'une solidité inébran. litble" (1. 50). As stated above (1. 118, note), Carnot emancipated himself from the conventional or miterial view of the nature of heat. See the appendix to the edition of 1878 .

"See Cambridge Philowephical Society I'roecerlings,' June 184s; resprinted in Thomson's Lord Kelvin's) 'Math. and Phys, l'apers,' vol. i. P. 100.

${ }^{3}$ Benvit l'ierre Émile Clapeyron was an engineer. In 1834 he pub. lisherl, in the fourteenth ahier of the 'Journal de l'Éeole Polytechnique,' his "Mémoire sur lat P'uissance motrice de la Chaleur." It was through a translation of this paper in "Taylor's scientitic Memoirs' that 'Thomson hearl about Cirmot's earlier work, and through a translation in Poggendorf's "Annalen' (1843) that Holmholt\% becaure acquainterl with the subject. 
Helmholtz in Germany, and Thomson in England, heard about Sadi Carnot himself. Sadi Carnot, so much earlier and so unlike Mayer, had nevertheless one point in common with him. This point seems to have given a common anchorage to all those thinkers who, in the course of a generation, gradually lifted the theory of heat and energy out of twilight into clear thought. Sadi Carnot, Mayer, Joule, Helmholtz, Thomson, all express

22.

Perpetual motion impossible.

or imply the same idea_viz., the impossibility of a perpetual motion. ${ }^{1}$ In one form or other this seems

1 The conception of a "perpetual motion," or, as it is termed abroad, of a "perpetuum mobile," and that of its impossibility, have been changed and more clearly defined in the course of the hundred years which followed the decision of the Paris Academy of Sciences in 1775 not to receive in future any scheme of perpetual motion. Into the same class of axiomatic impossibilities were also thrown the "squaring of the circle" and the "trisection of the angle." Helmholtz (appendix to his Lecture on "Die Wechselwirkung der Naturkräfte,' 1853, dated 1883) remarks that the proof of the impossibility did not then exist, and that the resolution was therefore based merely on the experience of past failures. The doctrine of Energy, the arithmetical discoveries of Gauss, and the elegant researches of Hermite and Lindemann, have thrown much light on these celebrated problems. In the last chapter of this volume I shall revert to the two latter; as to the first, the "perpetual motion," what follows may tend to ciear the popular conceptions. Tait has correctly remarked that "perpetual motion is simply a statement of Newton's first law of Motion" ("Recent Advances,' 3rd ed., p. 74). $\mathrm{He}$ might have added that it took probably as much ingenuity on the part of Galileo to arrive at the principle of inertia-viz., that "all motion is perpetual until force interferes to alter and modify it " - as it took to formulate correctly the other principle that such a perpetual motion is of no use, because you cannot do any work with it, except by using it up or annihilating it. In the beginning of the nineteenth century the im. possibility of a mechanical device for the so-called perpetual motion was universally admitted, though -as Rosenberger ('Geschichte der Physik,' vol. iii. p. 229, note) remarks-this was not also extended to physical processes, it being taught that the processes of nature represented a "perpetual cycle which uninterruptedly renewed itself." In fact, the truth was beginuing to dawn that if motive power or energy conld not be obtained out of nothing neither conld it be destroyed. Carnot in 1824, and Mayer in 1842, botlı take it as an axiom that power cannot be created; Mohr in 1837, and Joule in 1843 and 1845 , are equally convinced that power cannot be 
to be an axion with then, but even this appanently simple article of faith in natural philosophy meant something different to different thinkers aceording to the greater or less elearness of their physical conceptions. Helmboltz, in his celebrated menoir of $18+7$, conceives all natural processes to he ultimately reducible to purely mechanical processes, and in doing so he sees that a well-known law in mechanies, the conservation of the vis viva, must have a meaning for all natural forees. This he proceeds to develop. Others, like Faraday, Mohr, Grove, have a silent conviction that besides ponderable matter there is some other quantity in nature which is indestructible and camnot be createrl, but only changed and transferred; they frequently call it foree, and thus entangle themselves or their readers in

destroyed. Ender the influence of Versted's philosophy colding expresses similar ideas in 1843 (see 'Phil. Mag.,' 4th series, vol. xxvii. p. 58). In fact, during the tifth decade of the century the three conceptions of the imposibility of ereating power, its indestructibility, and the convertibility of its different forms, were more and more clearly enunciated. They were at last expressed in the formula of the "conservation of energy." It was Thomson (Lord Kelvin) who then-in 1s52-first clearly recognised that the old phantom of a perpetual motion was turniag up again in a new form. (See his Essay on "I Dissipation of Energy" in the "Fortnightly Review,' March 1892, reprinted in 'I'opular Lectures and Adlresses,' vol. ii. p. 45\%.) Ever since Thom. son's essity of $185 \% 2$ naturalists and philosiphers may be said to be trying to tormulate in the simplest terms the great principle of nature, that though energy is never lost, it becomes - for our. practical purposes - unavilable. Prof. Ostwald has expressed thi. by reviving the terminolugy of the perpetual motion. "It is not generally recognised that the principle of perpetual motion has two sidles. On the one side... ferpetual motion could be realised it one eould create energy. . . . The expression of the imposibility of doing this is the first law oi Eirergeties. . . A perpetual motion could, however, on the other side be attained if it were posibible 10 induce the large store of energy at rest to enter intu transiormations. . . This might be termed a perpetual motion of the second kind." The impossibility of this Gatwalil terms the secoind principle of Einergetic ('Allgemeine ('hersule, vol. ii. part 1, 1. 172; if. Helm, 'Fnergetik,' 1'.304. 
that confusion which the indefinite use of the word had caused, especially among Continental writers. One of the first practical applications of this idea as referred to the motive power of heat in Carnot's sense was made 23. by William and James Thomson in 1849. They had Application and James Thomson.

both fully realised that lowering of temperature might be accompanied by the doing of work by heat, and that elevation of heat to a higher temperature meant expense of work. If, therefore, work could be done by heat without lowering the temperature, there was an apparent gain of motive power without corresponding expenditure. It was known that water at freezing temperature expanded in becoming ice: it was capable of doing work, frequently very destructive work, without a lowering of temperature. In order to convert water into ice of the same temperature, heat must be abstracted. Here, then, was a case of a possible transference of heat without fall of temperature, and the creation or gain of great power to do work; but, according to Carnot's principle, equality of temperature implied an absence of expenditure of work. So here was a case of gain without expenditure of power simply by a transference of heat at freezing-point. James Thomson ${ }^{1}$ saw the solution of the paradox. If water

1 The reasoning of James Thomson, based again upon the impossibility of a perpetual motion, is given in the following passage of his communication to the Royal Society of Edinburgh, dated January 2, 1849 (reprinted in his brother, Lord Kielvin's, 'Math. and Phys. Papers,' vol. i. p. 156) : "Some time ago my brother, Prof. William Thomson, pointed out to me a curious conclu- sion to which he had been led by reasoning on principles similar to those developed by Carnot with reference to the motive power of heat. It was that water at the freeziugpoint may be converted into ice by a process solely mechanical, and yet without the final expenditure of any mechanical work. This at first appeared to me to involve an impossi. bility, because water expands while 
in expanding by freezing is malle to do work, it orrel-

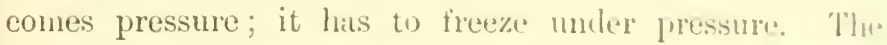
temperature of water freezing under pressum unust lu: lower than that of water sreezing moler orlinary cunditions. ${ }^{1}$ Knowing the mechanical dnty uf a degree of temperature and the work of the expansion of ice, he could calculate how much the freezing-point of water must be lowerel by pressure. In 1850 his brother William Thomson veritied this theoreticil prediction by actual experiment." It is well known how Helmholtz in 1865 made use of this theoretically predicted aml practically verified phenomenon in his celchrated glacier theory. ${ }^{3}$ Both James and Wrillian Thomson, when they drew the conchusions from Carnot's theory, still alliered to the loctrine of the entire conservation of heat. But Willim Thomson, who was eyually ac-

freezing; and therefore it seemed to follow that if a quantity of it were merely enclosed in a ressel with a movable piston and frozen, the motion of the piston consequent on the expansion leing resisted by yressure, urechanical work would be given out without any corresponding expenditure; or, in other words, a perpetual source of meehanical work, commonly called a perpetual motion, would be possible. . . 'l'o avoid the absurdity of supposing that mechanical work coukl be got out of nothing, it accurred to me that it is nece-sary further to conclude that the free\%ingpoint becones lower as the pressure to which the water is subjected is increased."

1 "The mechanieal pressure promotes-as is generally the ease witl the alternate aetiou of difierent forees in nature-such a change, viz, melting of ice, as is fuvourable to the effect of its own action " (Helmholtz, "Vortrïge und lieden," vol. i. p. 217).

' "I'roceedings of the liny. Soc. of Edinburgh,' January 1550 , reprinted in 'Math. ant l'hys. Papers,' vol. i. p. 165.

${ }^{3}$ Helmholtz, lor. cit., p. $2158 \% \%$, where also the phenumenom dis. covered and called "regrelation of ice," by laradily, is similarly explained.

+ It is important to motice this. as the formula with which we are now familiar, that the nuechanical work gained meant eonsumption of heat, was not avaihale at that time. This is significantly pointed out W. Hehn ('Energetik,' 1. 69). The reasoning was accorlingly more difticult and refined. . Taures T'homson, however, hal at the tine sime misgivings on the then prevalent view, and in a fontuole he refors $t)$ the "posibility wi the ahsulute for. 
quainted with Carnot's ideas and with Joule's work, increasingly felt the necessity of reconciling both views in one consistent view. So did Clausius independently at Ziirich. The result was the doctrine of the "conservation of energy," - not of heat, as Carnot had it, and the embodiment of the two correct ideas contained 24. independently in C'arnot's and Joule's work in the two

The two laws of thermodynamics. well-known laws of thermo-dynamics ${ }^{1}$ - viz., the conservation, equivalence, and convertibility of energy, as

matiou or destruction of heat as an equivalent for the destruction or formation of other agencies, such as mechanical work" "Math. and Phys. Papers,' vol. i. p. 161, note). The acceptance of the doctrine of the convertibility of heat and mechanical work - implying the consertation of energy in place of the conservation of heat, as Carnot had it-seems to have taken place in Lord Kelvin's mind immediately after his paper referred to above in consequence of a paper by Rankine "On the Mechanical Action of Heat" (Roy. Soc. Edinburgh, Feb. 1S50), as is shown by his letter to Joule, dated October 1850 (loc. cit., vol. i. p. 170). He there refers also to a memoir by Clausius in Poggendorf's 'Annalen' of April and May of the same year as adoptiug "Joule's axiom instead of Carnot's" (ibid., p. 173).

1 The reconciliation of Joule's dynamical theory of heat with Carnot's doctrine, and the necessary modification of the latter, is contained in Lord Kelvin's classical memoir, "On the Dynamical Theory of Heat," in the "Trans. of the Roy. Soc. of Edinburgh,' March 1851 "Math. and Phys. Papers,' vol. i. p. $173 s q q$.) In the introduction, Dary, Mayer, Joule, and notably Liebig, are mentioned as earlier supporters of the doctrine of the convertibility of heat into mechanical effect, Rankine and Clausius as the latest contributors ( $p$. 176). The first and celebrated enunciation of the second law by Thomson is given at the very beginning (p. 179), and in the sequel the denial of it is shown to mean the possibility of a perpetual motion. A little farther on Thomson refers to Clausius in the words: "The merit of first establishing the proposition upon correct principles is entirely due to Clausius, who published his demonstration of it in the month of May last year" (1850). It has on the other side been admitted by Clausius ("Die mechanische Wärmetheorie,' 2te Aufl., 1576, vol. i. p. 358) that Thomson's independent derelopment of the second law, though published later, is conducted from a more general point of view, whereas his own treatment was purely mathematical and confined to special cases. The most general and philosophical expression of the new principle was given by Thomson in his celebrated communication to the Royal Society of Edinburgh, April 19, 1852, "On a Universal Tendency in Nature to the Dissipation of "Nechanical Energy" (reprinted in 'Math. and Phys. Papers,' vol. i. p. 511). 
expressed in the first law, and the doetrint. of the availability of energy as expressed in the seeond litw. It was 'Thomson who first clearly' saw that the axion of the impossibility of a perpetual motion would be infringed if the first law of therno-dynamies-the indestructibility of energy-was accepted without the seconcl. For practieal use, for doing work, it is not sufficient that energy be not lost; it must be available-get-at-able. Energy may le in a condition in which it is useless-hidden away-and to bring it forth again may either be for us inpossible (if it he dissipated), or may require an expenditure of work-i.e., of enerey - to do so. The second law juts into mathematical language another very inportant and very striking property of the processes in nature. Lut us dwell on this a moment.

The doetrine of the preservation of energy, of the equivalence of the different forms of energy, tended to put all the forms of energy on the same level. If they be convertible, they appear to be of the same value. If in doing work, energy was not consumed but only changed, it stood to reason that it might be changed baek again, so that the work could be done over again. In other words, if all processes are purely mechanical processes-modes of motion-il supposition which very early foreed itself with nore or less clearness on the pioneers of the science of energy, they must be reversible: it must be possible to turn them romel again, to mulu what has been done, or to do what las been mndome. Now the common-sense view of nature tells us at once that this is impossible; but it does not seem to have struck the earlier propounders of the duetrine of the 
equivalence and correlation of forces, such as Faraday, Mohr, Mayer, Grove-not even Joule and Helmholtzthat if neither matter nor power is lost, the phenomena of loss and waste in nature and in human life remain unexplained. The only mind to whom this problem presented itself was Sadi Carnot, and it presented itself to him in an extreme form; for he started with the idea that even heat itself in doing work was not lost. or destroyed, but handed over from the hotter body (the boiler of the steam-engine) to the colder body (the condenser of the steam-engine). We now know that this view was not correct-that the whole heat is not handed over, but always only a portion of the heat. But, with this exaggerated view in his mind, he tried to explain the phenomena of loss and waste, and he conceived that the explanation lay in the lowering of the temperature. "It would be difficult to say why"-though he had assumed it as an axiom that-" in the development of motive power by heat, a cold body should be necessary, why in consuming the heat of a heated body we cannot produce motion." 1 Heat at high temperature is of more value for doing work than the same amount of heat at.

1 The words quoted are taken from one of the fragments published in the year 1878 by $\mathrm{H}$. Carnot from the posthumous MSS. of his brother, Sadi Carnot. In this fragment he approaches the modern conception that heat is the result of motion : he sees that all other phenomena can be explained by this hypothesis; but he pauses after having stated the difficulty quoted above in the text, and reverts, after some further queries, to the same diffi. culty in the words, "Can one consume the heat entirely without letting any arrive at the body $B$ [viz., from a body $A$ ]? If this were possible, one conld create motive power without consumption of fuel, and simply by the destruction of the heat of bodies" ("Puissance motrice, \&c.,' ed. 1878 , pp. 92 and 94). It is interesting to see how nearly these reflections approach to those made more than twenty years. later by Thomson. 
low temperature. Iy doing work, as also by conduction, and radiation with absorption, this inequality of temperatture is spent, i.e., lost. Clatusius and Thomsm alone seem to have grasped the value of this conceptim. The difficulty was to put it into mathematical languageinto ealculable terms. Each did this independently. Thomson, more than any other thinker, put the problem into common-sense linguage, brought the suhject home to the practical reason; at the same time he put it into mathematical language, allowing the conceptions of waste ${ }^{1}$ and of value and of availability (or usefulness) of energy to be scientifically-that is, measurably-defined. In 1851 he put the axiom upon which Carnot's reasoning is based (withont knowing the words of Carnot quoted above) into the following words: ${ }^{2}$ "It is impossible by means of inamimate material agency to derive nechanical effect from any portion of matter by cooling it leelow the temperature of the coldest of the surrounding objects." He saw at once, when adopting Joule's doctrine of the convertibility of heat and mechanical work, that, if all processes in the world be reduced to those of a perfect

1 The term "wasted," as distin. gui-hed from " aunihilated," is first introduced in Part 1 of the "Dynamical Theory of Heat," 1851, p; 189 of 'Math. and Phys. Papers.' vol. i.; and in the following year, in a paper read before the Royal Society of Edinburgh on the 19tli of April, entitled, "On a Universal Tendency in Nature to the Dissipation of Mechanical Euergy," the subject is brought home to the general understanding by a suceession of short theses referring to the dissipation and possible limited restoration of chergy ('Papers,' vol. i. 1. 511 , \&e.)

2 'Math. aud Phys. Papers,' vol. i. py. 179, 511. Helusholtz 'Vurtrïge und lieden,' vol. i. p. 43, said in 18.54: "In any cake we nust almire the acumen of Thomson, who could read between the letters of a mathematical equation, for some time known, which spoke only of heat, volume, and fluessure of bodies, eonelusions which threaten the aniverse, though inleed only in infinite tine, with eternal death." 
mechanism, they will have this property of a perfect machine, namely, that it can work backward as well as

25.
Summary statement of Thomson (Lord

Kelvin). forward. It is against all reason and common-sense to carry out this idea in its integrity and completeness. "The essence of Joule's discovery is the subjection of physical phenomena to dynamical law. If, then, the motion of every particle of matter in the universe were precisely reversed at any instant, the course of nature would be simply reversed for ever after. The bursting bubble of foam at the foot of a waterfall would reunite and descend into the water; the thermal motions would reconcentrate their energy and throw the mass up the fall in drops, re-forming into a close column of ascending water. Heat which had been generated by the friction of solids and dissipated by conduction and radiation with absorption, would come again to the place of contact and throw the moving body back against the force to which it had previously yielded. Boulders would recover from the mud the materials required to rebuild them into their previous jagged forms, and would become re-united to the mountain-peak from which they had formerly broken away. And also, if the materialistic hypothesis of life were true, living creatures would grow backwards with conscious knowledge of the future, but with no memory of the past, and would become again unborn. But the real phenomena of life infinitely transcend human science; and speculation regarding consequences of their imagined reversal is utterly unprofitable. Far otherwise, however, is it in respect to the reversal of the motions of matter uninfluenced by life, a very elementary consideration of which leads to the full explanation of 
the theory of clissipation of energy." 1 Whilst Clausius in Germany and Thumson in England were busy reonciling the truths contained in Carnot's oleler researches with the new conceptions firmly established by Jonle's classical measurements, putting both into mathematieal and into popular language, correcting our mathenitical formula' ats well as our voeabulary, other applications of the new ideas assisted in procuring for then general recognition and aceeptance. Rankine ${ }^{2}$ in kngland, Zeuner ${ }^{3}$ in (ier- Hirn.

1 Lord Kielvin, in a paper real before the Royal Soeiety of Ediuburgh, 2nd Feloruary 1874, on "The Kinetic Theory of the Dissipation of Energy" ('I'roecedings,' vol. viii. p. $32587 \%$ ) See also his article in the "Fortuightly Review' for March 1592 , reprinted in 'Popular Jeetures and Addresses,' vol. ii. p. $449 \mathrm{~s} q \%$.

2 The earliest formal treatise on thermo-dymamies was Maequor Rankine's article on "The Nlechanical Action of Heat" in Nichol's 'Cyelopadia' for the year 185.5 The part he took in the development of the new science was practical and at the same time highly speculative. His papers on temperature and elasticity of steam and other vapours, on the expansion of licuicls by heat, and on the meehanical action of heat, of dates 1849 and 1850 (see "Mliscellaneous Seientific Papers,' ed. Millar, 1851, ㄱ․ 1, 16, 234), entitle him to be eonsidered as one of the first-if not the first (see his claim to priority in a letter in l'oggendorf's 'Annalen,' p. 81, 15:0)-to reconcile Carnot's discovery with the mechanieal view. His investi. gations were peculiar, combining practical applieations of great value and inportant predictions (see 'Tait's memoir prefaeed to liankiue's 'l'apers, p. xxix) witl daring speculation: his dealuetions leing foumber on his theory of molecular vortices. 'T'loughl lie exirrted in this country a great influence (1n the early workers in thermu-dynanies, his theories were seareely relished in Fermany fer Helmholtzis eriticism of liankine methods in 155:3, quoted l,y Ilelı, 'Energetik, p. 114), where C'laumius's independent and simulamesus researelies on the same subject harl meanwhile usurped attention. liut Rankine's "Manual of' Apulied Hechanics' (18:7), his 'Manual of the Steam-engine and other l'rime Motors' (1859), were the lirst loroks of pactical application in which, through a hapy nomenclature and an extensive use of graplicial methods (Watt's imalicatol" lisgram aml Carnot's evele, the new iclous were introduced to a wider circle. See Helu's estimate of Rankine's work in "Energetik," p. 110 *n?.

${ }^{3}$ Somewhat later than liankime in this country, \%euner in switzerland and Germany, following upm Clausius's theoretical nemoirs, introducer the mechuniend treatment of practical locu-prolilems. His "Grumbinge der mochanische'll

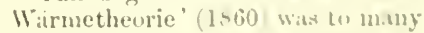
a revelation. Appering ateut the time when the German meclianical and elsemical induntries were start. ing upon a new deselopmens. 
many, and Hirn ${ }^{1}$ in France, studied the most important of all machines then in use, the steam-engine, in the light of the new discoveries. It became possible to define clearly what was meant by the efficiency of an engine, and to distinguish between those losses of the energy of heat or temperature which were dependent on the use of steam as the working substance, and therefore inherent and unavoidable, and those losses which depended upon the mechanism and upon the carrying out of the process employed. The older teachings contained in treatises written before a knowledge, or even an idea, of the

largely based upon the scientific training afforded in the excellent chemical laboratories and polytechnic schools of Germany, it assisted in giving to German industrial enterprise that scientific character which was at first ridiculed and has latterly been extolled in unbounded measure, and which-combined with the organising ability inherited from English ancestry-seems to be one of the distinctive features of the great industrial progress of America. First among writers on the Continent Zeuner gave such a counected exposition of the principles developed by Clausius, 'Thomson, and Rankine as met the requirements of practical engineers; attached to them applications referring to the steam-engine; criticised the views adopted by Watt and later writers, notably de Pambour, with reference to the behaviour of saturated vapour in the steam-cylinder during expansion and compression; and largely prepared the way for the great improvements in steam, air, and refrigerating engines which lave been brought out on the Continent by those trained in his school. 'Through Clausius, Zeuner, and others, Dingler's 'Polytechnic Journal' became the organ by which the many discussions on the new mechanical theory, and notably the second law of thermo-dynainics, gradually forced themselves upon the attention of practical men.

1 Equally important were the labours of Adolph Hirn (1815-90). $\mathrm{He}$ was a self-made man who had grown up in the midst of the important textile industry of Alsace. With a naturally iuquiring dis. position he combined the scientific and artistic accomplishments for the manifestation of which the chemical and mechanical products of that country lave long been renownel. He approached some of the great theoretical problems connected with practical engineering, such as those of heat, steam, lubrication, and superheating, by a long series of carefully planned experiments. A very interesting account by several authors is given in a publication by Faudel and Schwoerer ('G. A. Hirn, sa Vie, sa Famille, ses Travaux,' Paris, 1893). Hirn, like Rankine, was not only an engineer, but also an artist and a philosopher. 
mechanical value and the availalility of heat existed, had to be largely altered, and correcterl notjons laid down, frequently as a result of [rolonged isiscussion.. As an example, I may refer to the entroversy letwen Hirn and Zenner as to the cause of the sreat disereprancy between the theoretical and practical tigures referring to the work in the stean-cylinler, the so-called "Water or" Iron " controversy."

But whilst it must he almitted that the corrected views regarding the nature of heat - the preservation

3 The best account of the practical bearings of the mechanical theories of Rankine and Clausius is to be found in Prof. Inwin's "Forrest Lecture," delivered 2nd May 1895, before the Institute of Civil Engineers, and published in the 'Electrician,' vol. xxxv. p. 46 $s q q$. and $p .77 s q q$. He there refers to the great discrepancy hetween the "rational" and the "experimental" theories, and to Hirn's experiments and practical results, notably" with the "steam - jacket," and his introcluetion of "superheating" in $1855 . \quad \mathrm{No}$ drubt the rational theory altogether underrated the enormous ficility of heat-exchange, which arises out of the contact between a condueting cylinder-wall and a vapour in a condition of the greatest instability, and liable to condense or evaporate on the slightest change of thermal comlition" (p. 50). "The several con. troversies through which Clansius: detenderl and grarlually elucirlated the somewhat obscure statement which he gave of the so-ealler second law of thermo-dynamies may he studied with advantage in the 2nd erlition of his collected Memuirs ("Die mechanische W"irmetheorie, Braunschweig, vol. i., 1876), where lis replies to eriticisms of $\mathrm{Hol} \%$. minn, Deeher, Zeuner, Runkine, Wand, amel Tait are most inatruetive. A goral atecount is alsu given in Baynes's 'Lessons on 'Thermo. dynamien,' Oxforel, 1578, 1. 10:3 sri?.

See I'rof. [uwin, loc, rit., p. 79. "On the appearance of I-her" wood's researches in 1863 , the diserepancy between the rational theory and the results of experiment were reeognised by Rankine and others. But the conditions of the steam-cylimiler condensation are so complex that for a bong time the more theoretical writers prac. tically ignored both Hirn's and Isherwood's resulto. \%euner perhaps had pushed the rational theory to the furthest limit of detail, ancl with the greatest insight into prac. tical conditions. liut it was nut till 1881 that he begau to explicitly almit the largeness and importance of the comblensing notion of the eylinder. Zeuner then was disposed to attribute initial conclensation of the presence of a permanemt and not inconsidernble maxs of water in the clearance space of the engine. ... In oprening a liseussiun with Hirn in 1881 , \%euner wrote that if the presence of water in the elon. ance space was conseried, the Alsatian calculations would in 
and waste (degradation) of energy, have hardly resulted in those practical achievements and improvements ${ }^{1}$ which in other departments of applied science, notably in chemistry and electricity, have followed upon new discoveries, the influence of these new conceptions on scientific thought and method themselves has been enormous. Next to the conceptions introduced by Darwin into the descriptive sciences, no scientific ideas have reacted so powerfully on general thought as the ideas of energy. A new vocabulary had to be created; the older text-books, even where they dealt with known subjects in perfectly correct ways, had to be rewritten; well-known and approved theories had to be revised and restated in correcter terms, and problems which had lain dormant for ages to be attacked by newly invented methods. I propose in the rest of this chapter

greatly shaken. . . There thus arose a rather angry controversy which has been summed up in the question, 'Is it water or iron?' I do not know that this controversy has been as yet completely decided." See also Peabody, "Thermodynamics of the Steam-Engine,' 4 th ed., New York, 1900, p. 301 sqq.

1 This explains how it comes about that theoretical thermodynamics is still regarded with suspicion, not to say aversion, by many engineers of the old school, whose knowledge is principally based upon experience derived from the steam-engine. The first theoretical treatment of the steamengine by Rankine in England, and Zeuner in Germany, exhibited such enormous discrepancies between theory and practice; the simplifying assumptions which were introduced in order to make the behaviour of steam in the cyliuder at all calculable were so far wide of the mark, - that a general consemsus seems to prevail among theoretical engineers that progress depends less upon an immediate application of thermodynamic principles, than upon a careful analysis-guided by theory $\rightarrow$ of elaborate tests upon the various types of engines now in use. Such experiments are accordingly-following the example of Hirn - being carried out in many scientific establishments in. this country, on the Continent of Europe, and notably in the United States of America, and are elaborately recorded in many modern publications. See Peabody, "Thermo-dynamics of the Steam - engine,' 4 th ed., preface, and cliaps. xiii. and xiv.; Ewing, 'The Steam-Engine,' 1894, p. 31. 
to glance summarily at these revolutions in the demain of scientific thought which the physical viow, ly ngarding nature as the playgromel of the transformations of energy, has brought about. What I have just indicated will suflice to bring sone orter into the accomnt I propose to give. There are fon distinct directions in which we have to look. Firstly, there is the clearrer definition of the new ideas lail clown in the new voubulary of seientific and popular langugere dhring the second half of the century. Secondly, there is the revision and recasting of the whole lruly of plyysical and chemical knowledge in the light of the new insight which had been attained. Thirdly, there is the eriticism of existing theories from the new points of riew: anl lastly, there are the fresh clepartures which these nurel ideas have suggested.

The first definite use of the new conceptions of luwer and work, and of a scale of mechanical value, were contained in the writings of P'oncelet and Sadi Cirnot in France during the first puarter of the century. The first philosophical generalisations were given hy Muhr and Mayer; the first mathenatical treatment was griven by Helmholtz; the first satisfactory experimental veriticittion by Jonle, during the second yuarter of the century. The praetieal elaboration of the whole system following upon .Joule's and liegnault's experiments belongs, thromgh Thomson and lankine in this eomtry, and thromerh Clausins in Germany, to the third quarter of the century. students in onr age entering on the stucly of mechinicit, physical, elemical, and even physiological proxestes, lealp the benefit of these labours by at once erasping the 
underlying unity and correspondence of all natural phenomena, inasmuch as they all depend on the transformation of a quantity, termed energy, which is in many cases measurable in its best-known form-i.e., as energy of motion - and, where this is not possible, in the form of heat.

Helmholtz had already, in 1847 , summarily reviewed the whole field, begimning with a restatement of the fundamental formule of dynamics in the light of the new principle, and ending with a reference to the transformation of energy in living vegetable and animal organisms. The key to his explanations is to be found in the introduction of a term to denote what becomes of energy if it ceases to exist as energy of motion or as a velocity, when it is changed to energy of mere position. To this end he introduces the idea of stress or tension.

Helm.

holtz on "tension." The conception is already contained in older books on mechanics as latent force (Carnot), ${ }^{1}$ and the purely mathematical treatment of dynamies by Lagrange and Hamilton had prepared the ground by showing how all dynamical problems could be reduced to the knowledge of two quantities, the vis vira and the force function.

1 L. N. M. Carnot (1753-1823), usually termed the great Carnot, father of Sadi Carnot, nember of the Directory, War Minister, and one of the most celebrated geuerals of France, has a name in science through his 'Fssai sur les Machines en général' (Dijon, 1784), his 'Principes fondamentaux de l'Équilibre et du Mouvement' (Paris, 1803), as well as through his 'Reflexions sur la Métaphysique du Calcul infinitésimal' (Paris, 1797) and his 'Théorie des Transversales' (Paris, 1806), by which he became, to- gether with Monge, one of the founders of modern geometry, of which more in a subsequent chapter. He introduced the principle of the 'Corrélation des Figures de Géométrie' (Paris, 1801). His books were translated in Germany, where they had a great influence. Ou his connection with the history of the conception of energy, see Bohn in 'Phil. Mag.,' iv. 300, vol. xxix. ; also Helm, 'Euergetik,' p. 13 ; and the Eloge by Arago of the year 1837. 
The exposition of Helmholtz, however, does nor sin. (1) have been understood or aceepted. 'The general recoggnition of the relation of active and latent forces dates rather from Thomson's and Rankine's writings in 1851 and the following years. Thomson uses the term "meehanical energy" (later, from 1851, intrinsic energy, or sinply energy), and considers this (1umtity to be in ineasure of the store of power to do work which a material system possesses; ${ }^{1}$ and Rankine, early in 1853 , introduees and defines the terms actual (or sensible) energy and potential (or latent) energy; which are at once adopted by 'Thomson " in the place "lial" and of the terms dynamieal and statical energy, which he enersy.

I The memoir of Thomson in which he introduces the physical eonception of the quantity "energy" in the place of a merely mathema. tieal symbol used by Clausius, and inaugurates the terminology of modern physics, is contained in the "Transactions of the loyal Society of Edinburgh,' vul. xx., Part 3 (read lecember 15, 1851, and reprinted in 'Matl. and Phys. l'apers,' vol. i. p. 222), as an appendix to the great puper "On the Dynamical Theory of Heat, with Numerieal Results deduced from Mr Joule's Equivalent of a Thermal Unit, and M. Regnault's Observations on Steam" ('Trans. Ellinb. Soc., March 1851: reprinter in 'Phil. Mag.,' 1852, and 'Matl. and l'hys. 'Papers,' vol. i. p. 174 sq7. ; see especially p. 186, notej. The term energy had indeed been used by Thomson alrearly in 1849 as a synonym for mechanical eflect, but he liad not then accepted the dynamical theory. He merely puts the question in a foutnote to his exposition of Carnot's theory: "When thermal agency is . . . spent, what lecomes of the mechanical eflect which it might produee? Nuthing cin le loat in the operations of nature-ns energy ean be destroyed" ("l'apers,' vol. $i$. p. 118, 1549).

" In a pajer read before the l'hilosophical Soeiety of Glasgow, January 5, 19:3, reprinted in "Miscellaneous Scientitie l'apers," ed. Millar, p. 20:3 $s \%$. See also Rankine's note, dited litit, in the $2 s t h$ vol. of the th series of the 'Phil. Mag.,' p. 40 s.

3 see the Proceedings of the Glasgow Philos, Soc., January 1853 , reprinted with additions from Nichol's '( Yelopiedia' (1800) in "Mlath. and l'hys. P'apers, vol. i. p. 521. In this puper Thomson also introduces the term "electrital capacity" of a eomiluctor. 'Thom. son subsequently intruluced the word "kinctic" in place of "nctunl" (nergy. Sice also Thumson's Lecture before the linyal lnstitustion, Felruary 29, 1850, reprinted in 'Math. and l'hys. l'aperse, vol. ii. p. 182, and 'V'viular I,ectures,' vol. ii. $p .418$, cspecinlly the nole to $[$. 
had employed before. How little these ideas, which have now been introduced into elementary text-books as the very alphabet of physical knowledge, commended themselves in that age, except to a few intellects that had been occupied for many years trying to fix precise terms which should be capable of mathematical definition, and at the same time correspord to common-sense experience, is evident, inter multa alia, from the criticism by Sir John Herschel in 1866. ${ }^{1}$ Here it is maintained that the use of the term "potential energy" " is unfortunate, inasmuch as it goes to substitute a

425. A very complete and careful historical account of the gradual invention and crystallisation of the vocabulary of the energy conception is given by Helm, 'Die Lehre von der Energie,' Leipzig, 1887, p. $36 s q q$.

1 The passage quoted appears in an article "On the Origin of Force," by Sir John Herschel, in the first volume of the "Fortnightly Re. view,' 1865, p. 439 . The article is well worth reading for those who wish to realise the enormous benefit which has been rendered to science by banishing the indefinite use of the word force and by introducing the term energy, restricting the use of force to the meaning attached to it by Newton. Sir John Herschel still speaks of the "conservation of force" (as did likewise Helmholtz, who, however, very early introduces the term Arbeitskraft, power to do work, thus removing all ambiguity). Rankine replied to Herschel's criti. cism in a paper read before the Glasgow Philosophical Society, 23rd January 1867 (reprinted in 'Miscell. Scient. Papers,' p. 229 sqq.) He there states that the quantity itself occurs as a mathematical sym. bol in Newton's 'Principia' (prop. 39 , but till recently had received no appropriate name. He closes his remarks by the still more import. ant reflection: "One of the chief objects of mathematical physics is to ascertain, by the help of experiment and observation, what phy. sical quantities or functions are 'conserved.'" As such he enumerates mass, resultant momentum, resultant angular momentum, total energy, thermo-dynamic function. Whilst this physical problem was being defined by Rankine, Cayley, Sylvester, and Hermite were working at the corresponding problem in pure mathematics to decide what properties or quantities remain unaltered (i.e., in variant), if an arrangement of several algebraical symbols is sub. jected to algebraical operations. It is the modern doctrine of " in. variants." This doctrine has led to an enormous extension and simplification of the theory of mathematical forms or quantics. It is the key to all mathematical tactics, and prepares a useful instrument for the application of mathematics to physical problems. See Major MacMahon's Address to the Mathematical Section of the British Association, Glasgow, 1891. 
ON THE PHYSICAL VIEW OF XATURF, 141

truism for a great dymamical fact": an armision which would mean that it brings common-sense and precise mathematical expression into close proximity and harmony, or describes at very general phommments completely and in the simplest way.

In order to become generally recomised as the simple alphabet of scientifie languige, the new ideas had to be marle the foundation of the whole structure of physical and chemieal knowledge, theoretical as well as experimental: the elements and axions haul to be restated so as at once to express the new view and to open out the enlarged aspect which had heen prepoured. The different departments of mechanics, physics, and chemistry had to be elaborated and co-ordinated aecording to a miform design. Helmboltz hat indeed, as eurly as $18+7$, roughly sketched the plan of the work, but occupied as he was during the twenty following years mainly with another much-neglecterl fiehl, the analysis of the phenomena of sensation, he dir? not return to his original thesis till many years later, when he made an application of fundamental importance.

Meanwhile the important task of rebuilding the ellifice of the physical sciences, and establishing on a latge scale that which I term the physical riew of nature, fell almost exelusively into the hands of what we may call the Scotch school of matural philosophy-.Tanes and William Thomson, Macquorn Rankine, Jannes ('lerk schesesch Maxwell, P. G. Tait, and Balfour Stewart, in this conntr!: whilst Clausius abroad worked almost alone. liankine and James Thomson very early (185i) conceived the illea of a general science called "Energetios" or "the 
abstract theory of physical phenomena in general." I It is only in our day, after the lapse of a quarter of a century, that these ideas have been taken up by others, and that the plan begins to be realised. The reasons why at the time it was abandoned were manifold.

To begin with, it was soon found, notably by Joule, Helmholtz, and William Thomson, that the new principle of the conservation of energy, if applied to various other phenomena outside of the narrower field of thermotics, led to a co-ordination and comprehension of them which was then quite unexpected: opening out new aspects, disclosing unknown properties, and suggesting innumerable experiments. As instances I may refer to the thermo-elastic and thermo-electric phenomena of bodies, which very early occupied the attention of the founders of the theory of energy. The discharge of the Leyden-jar, the generation of electric currents in the voltaic cell, the heat of electrolysis, the actions of permanent magnets and those between

1 In a paper read before the Philosophical Society of Glasgow, Nay 1\$55, entitled "Outlines of the Science of Energetics," and reprinted in 'Miscellaneous Papers,' ed. Millar, p. $209 s q q$. See for the above definition $\mu$. 228. James Thomson's contribution is to be found in a paper on "Crystallization and Liquefaction," read before the Royal Society, December 5, ]861, in which he establishes and gives examples of the application of "a general physico-mechanical principle or axiom," which indicates when a "substance or system will pass into the changed state." As Helm says, it is a first attempt to find a general rule for the transformation of energy ("Lehre von der Energie,' 1887, p. 63). That such a general rule can in the present state of our knowledge be established on purely energetic principles is upheld by some (Ostwald, Helm) and disputed by others (see especially Planck, 'Thermodynamik,' 1897, p. 71 $s q q \cdot)$, who state their conviction that the "energy-principle clearly does not suffice for the definition of natural processes." The whole discussion merges into a philosophical question, of which more later on. 
ON THE PHYSICAL VIEW UE NATLRE. 143

electric currents and magnets, the phenomenda of diatmagnetism, Ampere's theory and Wober's bisis of electric measurement, seebeck's prolustion of elestric eurrents by heating in a non-homogenenss combluctor, the remarkable phenomena known by the nam. of Peltier, the electro-dymanic properties of metals, the thermo-elastic properties of matter, were all sudied in the light of the new principle, the conservation and transformation of energy. Another very important problem presented itself, viz, the introduction of the new ideas into the higher educational literature, the re-writing of the text-books of science on the basis of the principle of encrgy, and especially the development of the fundanental notions in mechanies in conformity with the more modern views. Here, then, it beeame evident that the physieal view of natural phenomena, aceording to which they are all instances of the transformation of energy, could he considered and expounded as a further development of the laws of motion as laid down in Newton's 'Principia.' It was especially the third law of motion, in which Newton stated the equality of aetion and reaction, that lent itself to such an interpretation as would at once lead to the wider grasp and ilepper insight into natural processes which the principle of energy afforded. Aceordingly about the year 1860 , when the new ideas on energy had, in the minds of the great pionerrs, aequired that importance which has enabled them to become the basis of a more and more comprehensive view-the physieal view-of natural phenomena, the necessity was experiencerl of 
bringing them into harmony and continuity with the older Newtonian ideas. These had been only imperfectly transmitted by the many commentaries and textbooks of the Cambridge school. The same was the case in the system of Lagrange, in which the whole of mechanics had been reduced to a mathematical expression, the physical and experimental foundations being pushed aside. The 'Principia' of Newton was again studied, and re-edited in the unabridged form, and an interpretation and amplification of the third law of Motion - so as to embrace the principle of energy - was made the key to the science of dynamics. Dynamies was not tanght after but before statics. Statics was treated as a special case of the theory of motion. To make the new position still more marked, it was proposed to make the term dynamics the general term which embraces kinetics and statics as subdivisions, and to rescrve the word "mechanics" for the science of machines. The change which then took place in the didactic methods can be seen by comparing the first and second editions of the well-known treatise by Tait and Steele on 'The Dynamics of a Particle.' The real compendium of the new doctrine is the treatise on Natural Philosophy by

31.

Thomson and Tait. Thomson and Tait, which has probably done more than any other book'in this country to lead the mathematical studies at the foremost universities and colleges into paths more useful for physical and experimental research. The greatest exponent of the new ideas was James Clerk Maxwell, to whom is also due the merit of having applied them for the purpose of testing and 
ON THE PHYSICAL, VIEW OF NATLIR 145

confirming the worth of the treasure which lay hidelen in the experimental researches of Farulay. Next (1) the handlook of Thomson and Tait, no writingse publully have done more-especially ontside of Einglinul, on the Continent and in America-than those of Mixwell (1) revolutionise the teaching of natural philosophy.

I must now revert to what I said in the last chalyter regarding Maxwell's attempt to put the illeas of Faraday on the communication of electric and magnetir. Maxwell. phenomena through space into mathenatical linguarei.e., into measmable terms. I there related low Maxwell's earliest treatment of the sulject was an ittempt to construet a mechanical model of the dielectric that would be capable of exhibiting and transmitting the properties of stress-i.c., of tension and jressure-which the experimental researches of Faraday had partly lemonstrated and partly suggested. In the sequel, as was said, he desisted from this attempt, which luas since been taken up and further elaborated by others, and resorted to a different train of reasoning. This line had been suggested by the introduction of the doctrine of energy into all physical research. Is the work of scientific chemists was for a long time exclusively governed by the application of the principle of the constancy of weight or conservation of matter, so, when once the mathematical expression of the various forms of energy latel been correctly establisherl, it lecane possible to arive at a multitude of relations of physical quantities merely by applying the principle of the constancy of the quantity of eneregy. ln this way the principle of energy is a kind of rengulative VOL. II. 
principle, one which allows us to deal with the grand total or outcome-mathematically called the integralof physical processes and changes without necessarily possessing a detailed knowledge of the minute elements or factors-mathematically called differentials_out of which they are compounded. Inasmuch as what we actually observe are always integral effects-i.e., summations or aggregates of great numbers of individual and unobservable processes - this line of reasoning is not infrequently very useful, and has been in many cases applied to arrive at important conclusions. In fact, it is the analogue in science of the method according to which practical men very often succeed in carrying on extensive business transactions, of which they possess a merely external though accurate knowledge; or of the balance-sheet of an industrial undertaking which exhibits and guarantees the correct result, though only the profit and loss account and the ledgers would show how this result has been arrived at.

33.

Faraday.

Faraday had taught us how to look upon any given portion of space in which electric, magnetic, chemical, and thermal changes were going on as a connected system, which he termed the electro-magnetic field. $\mathrm{He}$ and others-notably Oersted, Ohm, Weber, Lenz, and Joule - had shown how the different occurrences in such a system could be refluced to a common measure, and how they were observably connected. Maxwell brought all these phenomena together under the term "energy of the electro-magnetic field," and set himself to study the possible forms and changes of this quantity under the law of the conservation of energy-i.e., as the preser- 
vation of the sum-total of the energy. 'This anpley' could exist as notion (actual or kinetic energy), heiner either motion of electricity as in the current controbleml by the law of Ohn, or motion of ponderable matsses, sureh as magnets or electric conductors: or it might be dissipated energy-i.e, energy aplutrently lost in the form of heat-controlled by the law of Joule, or, to complete the smmmation, it might be stored-n]) energy-potential energy. Faraday's researehes hat sugrested where this store was: it was in the smrromeling space, which must be considered as capable of being strained or put into a condition of stress, as elastic hodies are calpablo of beime strained. Thomson and Tait had shortly before shown how to submit the properties of elastie systems to caleulation in the most general manner, by studying the modes in whieh energy, actmal and potential, was distributed in them, whether at rest or in motion. 'T'he way seemed then paved for Maxwell to consider with the greatest generality the properties of the eleetro-mannetic field, rencing them all to nechanieal measures. This be did by introdneing the generalised eonception of a displacement or strain which exists in the field, anl which is commmicated as a periodic or vibratory motion with a velocity dependent on the properties or so-called constants of the medimn. It is known how he snecrerled in identifying very eompletely all the various experimentally ascertained electric and magnetic phenomena, fixing their nature and quantities in conformity with exprerience. and arriving timally at the suggestion that the velueity of the transmission of the eleetro-magnetie displacentent in air must be the same as that of light, the latter beings. 
in fact, an electro-magnetic disturbance of very short wave length. I also mentioned above how this suggestion received a brilliant confirmation from Hertz when he succeeded in exhibiting electro-magnetic waves, which in travelling through space, though not luminous, showed all the properties peculiar to light waves, such as reflexion, refraction, polarisation, \&c.

Whilst in this country, during the period from 1850 to 1870 , the Scotch school of natural philosophy was thus occupied in rebuilding the whole edifice of physical science on the new basis afforded by the energy ideas, Clausius in Germany worked at the further elaboration of the dynamical theory of heat, and, as I stated above, at the kinetic theory of gases, without abandoning the astronomical view of natural phenomena, which, with its supposition of forces acting at a distance, still almost exclusively governed theoretical physics and chemistry abroad. No one did more to emphasise the difference between this and Faraday's views than Clerk Maxwell, who had welded the latter into a consistent scheme by means of the conception of energy. About the year 1870 Helmholtz again appeared as a leader of scientific thought in this domain, and placed himself at the head of a movement which by degrees almost completely swept away the older ideas. It was by him or at his suggestion that many of the more modern English works of science were translated ${ }^{1}$ and intro-

1 Notably Thomson and Tait's 'Natural Philosophy,' and several of Tyndall's well - known more popular works on 'Sound,' 'Heat,' and 'Fragments of Science.' Helmholtz was also one of the first natural philosophers of eminent rank abroad who broke with the older habit of exclusiveness which clung to academic teachers in Germany, and who followed the English example set by the "Addresses" of 
dueed in Germany, and that especially the ideats of Faraday and Maxwell were popularised, exponuded, and submitted to elaborate tests. These culninated in tho brilliant discoveries of Hertz already referred to.

As in his earlier researches into the connection of th. phenomena of heat and meehunical work, so in these later ones concerning the electro-dynamic litws, Helnholtz seems to have approached his subject prinatrily in the interest of physiologrical ${ }^{1}$ seience. At that time

34.

II.: Iflt jl:2 uin rlecer. 4) Jistuic. the British Association and the still older "lectures" of the linyal lustitution. Before his time there were only rare instinces - notalsly those of Bessel, liebig, and Humboldt-where scientific thinkers of the first rank condescended to intluence general opinion and polite literature by stepping down from the university chair into the arema of a popular audience. No other German seientific thinker has left a collection equal to Helmholtz's 'Vortrige und Reden,' not even Bessel, whose 'Populire Vorlesungen iiber wissensehattiehe Gegenstinde' (ed. Selumacher, Hamburs, 1848) are too little known. Du Bois-Reymond's ' lieden " are a mine of information on the history of science, and von later's 'Reden' (Braunschweig, 1886) contain some excellent and original diseourses.

1 Emil du bois - Reymond, in many passages of his remarkable addresses, and latterly in his :ppreciative lioge of Hetmlioliz (Leiprig, 1897), has preserved the historical data for a genetic hintury of Helmholtz's electrical researches, which, beginning in 1851, and culminating in Hert\%'s brilliant experiments on the "rays of elrctric energy" in 1888, completely changed the aspect of electrical science in Germany and to a less degree in France. The other view, based upon a mathematical development of the fumbarental concep. tion of Ampre and mainly asosciated with the brillint nante of Wilhelm Weber, wluse very ex. tensive and aceurate ueatsure. ments largely supplien the material for the moilen lhewry, is prac. tically unknown to electrician in this eountry. No English text-book contains even a relerence to a view which was once dominatrt aliruad, aud which for this reason firms a very interesting episule in the history of thought. In the fourth chapter I have reierred to this view as, hesile the thenry of Boseovich, presenting one wi the most remarkable applications of the as. tronomical view of nature, which originated in this country but wits maimly cultivated by the linench school. I must now brictly refier to the counter-movement. which in Ciernany is mainly illentitien with the name of Helunholtz. He may be said to have lelt the mark of his genius on the seientific history of his country as Iowrl Kelvin has done on that of England. His collected pitpers show ua -amd du bois-liegmomil tells u=how lleluboltis interest in elact. rical problens was connected with the remarkible fluenomena of animal electricity, to the exploration of which the inrmer devoled his 
there existed three different theories which aimed at finding a general formula or law that should embrace all known electro-dynamic phenomena. The two earlier ones were propounded independently and about the same

life. Du Bois-Reymond was a pupil of Johannes Miiller. One of the merits of Miuller's school was to have made the discoveries of phy. sics useful for physiology and medicine as the school of Liebig made those of chemistry. Helmholtz was trained in the school of Muiller, but he also came largely under the influence of Franz Neumann of Königsberg, the great teacher of mathematical physics, and of Gauss and Weber, the originators in Ger. inany of the system of absolute measurements. It is kuown that the interest in electrical phenomena received a great impetus through Galvani's and Volta's discoveries. But as du Bois-Reymond ('Reden,' vol. ii. p. 389) tells us, the galvanic pile constructed by Volta withdrew attention from the phenomena of animal electricity to the much more powerful actions of artificial arrangements of metals and solutions. The study of animal electricity was for a time continued only by Italian professors, and beyond the seas by Alexander von Humboldt in his observations on the torpedo; and had to wait till the school of Müller, and notably du BoisReymond, approached the subject methodically with the methods and ideas of modern science. This was in the fifth decade of the century. Modern science in Germany had, however, studied the properties of the galvanic current exhaustively only in linear (one dimensional) and in closed circuits or conductors. The phenomena of nervous and muscular electric currents demanded the study of sudden and repeated electrical impulses, and of the behaviour of currents in two and three dimensional conductors, and in unclosed conductors or circuits. Incited by du BoisReymond, Helmholtz undertook to deduce from the formula of Ampère, Neumann, and Weber the action of electric currents in these modified conditions. It was then found that these formulie gave indefinite results and required to be modified or amplified. After many years of thought and research Helmholtz arrived at a generalisation which comprehended all the different existing theories as special cases. He then-in addition to a masterly mathematical discussion - betook limself to devise special experiments to decide which of the three possible expressions of the general formula came nearest the truth. A perusal of the memoirs contained in the first volume of lis " W'issenschaftliche Abhandlungen' (pp. 429-820) shows how by gradual and strictly logical steps be convinced himself of the intrinsic correctness of Faraday's conception, which, in addition to the phenomena in linear conductors or wires, constantly took notice also of those of the surrounding medium or space - i.e., of the electromagnetic field. Looking back from our present position on the development of the ideas concerning electricity in motion, we can say that Continental thinkers tried to gain a correcter and more complete understanding by a mathematical, English science by a physical, extension of the then existing notions. Helmholtz in his Faraday Lecture (1881) showed how both courses, consistently pursued, lead to the same result. 
ON THE PHYSICAL, YIFM OF PATCRE, 151

time by Fanz Nenmann and Wilhelm Wober": the later. one was the theory of Maxwell hased upon the cotally different view which was maintained and eramlually unfolded in the experimental researehes of fabulaty. 'The two former looked to the effects of the action of electricity at measurable distances, and has heen callud the teleseopic view: the lattr.r reduced these to the aetion which takes place in enntignons portions of matier or of space, and has been called the microscopic view. Helmholt\% first of all, by an independent line of reasoning, brought the three mathematical formula in which these different views foumd expression mader one cummon formula, of which each apuears as a special case, and then proceeded by theory and experiment w dectile which of the three possible special forms is to be arlopted. As a theoretical test he applied the juinciple of the conservation of energy in a manner in which it hat at that time hardly been used ly continentit thinkers. His reasoning, which was largely disensserl and criticised by eminent philosophers, gave to this principle the prominence and injortance which it has erer since maintained in all continental treatises. It meant the introduetion of the physical view of natmral phenomena. ${ }^{1}$

1 In Fingland the publication of 'Thomson and Tait's ' Natural Phil. osophy' formed, as stated above (1. 1.4), an epoch in the teaching of the physical scienees, notally through the prominence riven to the prineiple of the eonservation of energy. A similar epoch was created in Germany, not so much hy Helmholiz's emunciation of the principle in 1847 as ly the wse he made of it, in one remarkable in. stance, in reviewing and criticising the existing and apparently eontlice. ing theories. As lavuinier inrrodueed the elomieal halance - hased upon the comsersation of matter as a test for the correctuesis chem. ical statements, so Helmholt\% userl the punciple of the entservition of energy in 1 wo dintince furm as as test of the valiblity of electrienl 
In the mean time this view had gained great support by the efforts of quite a different section of scientific workers, whose labours had opened out a new and promising field of research. The new field for a considerable period belonged almost as exclusively to foreign science as the energy-conception had for twenty years belonged to this country. Early and for the most part isolated labourers were Kopp and Hess in Germany, Regnault and Berthelot in France, Julius Thomsen in Copenhagen. ${ }^{1}$ They (with many younger men) can be

statements. These two forms were the impossibility of a perpetual motion and the equality of action and reaction. See his Faraday Lecture, 18s1. Both in the positions of Thomson and Tait and of Helmholtz the principle of energy is, however, like Iavoisier's principle, purely a regulative, not a constructive, principle of scientific research. It exerts a control and enables us to check the correctuess of results. Both in chemistry and physics other priuciples or methods are required for extending - not merely correcting-our knowledge. Such principles are in the abstract sciences the formula of gravitation, the atomic theory, the ether; in the natural sciences the morphological and genetic theories. The whole domain of physics and chemistry has been reviewed for teaching purposes from this point of riew by Hans Januschke, 'Das Princip der Erhaltung der Energie,' Leipzig, 1897. See p. 14 sqq.

1 Although the history of thought has more to do with theories than with the mere discovery of facts, and with the latter mainly when, as in exceptional instances, they change the scientific aspect of phenomena, I think it important to mention specially the great merit of Victor Regnault's experimental lesearches. How much the progress of physical and chemical theory is indebted to his elaborate and extremely accurate measurements of many physical constants may be seen by the perusal of Lord Kelvin's early memoirs on the dynamical theory of heat. The several (so-called) laws of Boyle, Dulong, and others were subjected by Regwault to exhaustive tests; the behaviour of steam in the steam. engine formed a subject of elaborate investigation; the proof that chlorine could be substituted for lydrogen in hydrocarbons supplied a prominent support to the chemical theories of Laurent. In general Regnault's work is a model of accuracy supported by great ingenuity in the construction of apparatus and the surmounting of difficulties. Like Liebig, he was the master of many pupils who subsequently became eminent. Besides being professor of ehemistry and physics in Paris, Regnault was actively counected with the celebrated porcelain works of Sèrres. Similar remarks might be made with reference to the labours of Hermamn Kopp, who was for many years probably the only professor of physical chemistry in Germany. 
consilered as the fommlers of the modrru science of physical chemistry, which has received an platwritte wxposition in the great work of Professur Ostwalel. 'This work is probably quite as epoch-making in the domatim wi chemistry as 'Thomson and 'Tait's 'Natural I'hilnsophy' has been in that of physics.

I have alrealy explained how in the development of chemistry the attention of its great representatives wats almost entirely absorbed in gaining a knowlodge of thro different substances with which they haul to deal, aum how through preoecupation with the natural history of matter, its decomposition, analysis and synthesis, aml appropriate classifieation, the other nore scientific questions regarding the physieal agencies which were at. work in chemical processes - constituting the iluctrinn" of chemical atrinity-were almost completely neglecterl. This I traced largely to the influence of that jowerful instrument of exact research, the atonic view, which had bcen introduced into chemical science through Lavoisier and Dalton. ${ }^{1}$ The pursuit of physical chem-

1 It is not an unusual experience to find that the change from one theory to another, though an aitvance from disproved to more correct views, is also accompanied by some loss either in definiteness or in actual knowledge of facts. The undulatory theory lost the definite notion of a rectilineay rity of light, which was only regained by prolonged and difficult analysis; the electro-magnetic theory of Maxwell has not as yet given a clear representation of those electrical charges which the older theory of Coulomb and Weber introduced in the form of stationary or moving electrical inasses. Something similar hap. pened when the ohler phlugisum theory was dispelled by the atomic theory and all attention wat concentrated upon change of wejght. The oller theory mintined that when a metal is caleined it luses somedhing - vi\%, phlugiston; the new theory had proved that it gatio something-i.c, weight in the form of coublines oxygen Jure recent knowledge has sluwil thit luth theories are right. It gitins weight and loses potential energy, or puwer to do work-i.s., to conlubine, giv. ing riss to molecular untion or

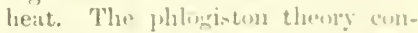
tainerl the correct idlea Itan hesicles matter there is something else- 
istry, the consideration of chemical as related to other physical forces, such as gravitation, heat, or electricity, though it very greatly occupied the pioneers of chemical science in the early years of the century, - notably Berthollet and Gay-Lussac in France, Dalton and Davy in England, Berzelius in Sweden,- fell gradually into popular disfavour; so much so that even Faraday's electrolytic law had hardly any influence on the development of chemistry. ${ }^{1} \quad$ This one-sided direction of chemical reasoning and observation was still further promoted by the great practical and technical results which followed from the atomic conception, the ease with which processes worked out in the laboratory could be imitated on a large scale in the factory and the workshop. It was the increased power over matter and its manifold transformations which followed immediately in the wake of atomic chemistry that gave it its interest, notably when through the study of the carbon compounds - incorrectly termed organic chemistry - new industries of undreamt-of magnitude and importance were created, and when through chemical knowledge the older methods of metallurgy were rapidly superseded. To the popular mind the result is always more interesting than the process of research or of reasoning which learls up to it; the possession of the product than the knowledge of the procedure. The

viz., energy. That the correct idea contained in the phlogistic conception was not at once given up, bnt only gradually lost sight of, is seen from the fact that Lavoisier's first table of elements contained 'caloric' as one of the simple bodies. See
Kopp, 'Entwickelung der Chemie,' ए. 209.

On the causes of this see Helmholtz's Faraday Lecture ("Wissenschaftliche Abhandlungen," vol. iii.) and Ostwald, 'Allgemeine Chemie,' 2nd ed., vol. ii. part 1, p. 530. 


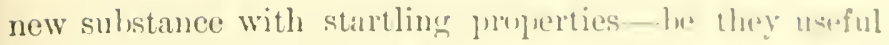
or only curions and rare-lats alunost immentiately it value, whereas the manifold transformations by which it was discovered, inventerl, or prolucenl esenpe generat notice, and are accordingly of secondary interest. This interest grows in proportion as another fuctor of equal conmercial importance gralually and slowly asserts itself, namely, the fitctor of enst of production, the property through which not only the material itself, but also the lahour bestowerl upon it, and the nust intricate transmutations and secret manipulations, gain a place and definite figure in the lestere of the accountant. Those of us who entered into prictical life about the hegriming of the last generation of the century know well by experience how then for the first time was being established the great system of statisties, of cost of production, which now governs every wellconcheted industry and manufactory, though in general this department is still but little unlerstuod. Now; in proportion as with progressing eivilisation we come more and more to use artificially prepared products in the place of natmral ones, the cost-figmres become more complex: there is not only the raw material and the labur of getting it, not only the general ecomony of arrangement and administration by which we sive linbour ind aroid waste-there is the whole aggregate of chamges and processes, manual, mechanical, and chenical, thromght which the raw material has to pass. These must all have a common measure by which they pussess at fignre of value in the ledger of the book-keeprer, otherwise the latter coukd not produce a statement of const. Watt, 
when supplanting manual labour on a large scale by the introduction of his perfected steam-engine, had suggested the term "horse-power" as the common measure of both; and the French mathematicians, who treated mechanics with a view to practical application, had introduced the term "work." In the general industries, however,-_outside of special branches, notably marine engineering,these measures were very crudely applied; they became unintelligible and meaningless where other agenciesnotably those of chemistry and electricity-had to be employed. It is only since the terms "power" and "work" have been enlarged and the more general conception of energy introduced that it has become possible to measure the new forces or agencies in terms applicable to all alike. Practically as well as theoretically the system of measurement remained imperfect so long as the energy of chemical combination could not be measured in the same way as Watt measured the energy of heat, and as Joule and others taught us how to measure the energy of an electric current. The tern "energy" has thus become as important a conception for practical as it has been long recognised to be for purely scientific purposes. If the only power we use is manual labour or steam power, there exists a crude way of measuring both by the liands employed and the weight of coal burnt; but electrical power is not so exclusively dependent on a personal or material item, and thus it can only be measured by a system in which the several items of cost are reduced to a common term. It is through the wholesale introduction of the electric current as a practical agent that the thing called 
"energy" has become a commercial connmolity as it hat before becone a scientific measure.

That ehemical reactions are comnected with nerchanieal, gravitational, optical, caloric, and electric phesumena has been known for a long tine. Each of these nunifestations has therefore been studied as affording at measure of the energy of chemieal reactions, and these have in turn been looked upon as results of attractions, or of mass actions, or of thermal conclitions, or of electrieal polarities. Wre have thus mechanical, thermo-ehenieal, electro-ehenical theories of aftinity. Valuable diseoveries and important sugrestions have also been arrived at by these special researches: we have the laws of mass-action suggested by lierthollet and revived in modern times by Guldberg and Watage: the all-important electrolytie law of Faraday and the so-ealled third law of berthelot in themo-chemistry: further, the important researches of Kopp and Hess. Bertherlot None of these discoveries, however, seemed really to grasp the whole subject of chemical reaction, and accordingly they remained for a long time unknown, or fell, after a short life, into oblivion and disrepute. It has been one of the greatest performanees of the last twenty years of the eentury to have approached the all-important question, "What is chenical aftinity, and how is it to be measured?" in a eomprehensive spirit, and to have brought it to the verge of solution. The merit of having done this belongs the more incontestably to Prof. Wilhelm Ustwald, ${ }^{1}$ becanse no one

'Prof. Ostwald's principal work is the 'Lebrbuch der allgemeinen
Chemie, of which the first edilion appeared in two volumes (leipligh, 
has taken such pains as he to gauge the value of many single and isolated steps that had been taken before him, and to combine them all through his own researches into a comprehensive doctrine. The practical importance of these labours-so long insufficiently understood-will doubtless in the near future be realised in proportion as the increasing competition of industry shall emphasise the necessity of studying the economies of production: this economy consisting not only in the absence of waste of matter, but likewise in the saving of work-i.e., in the absence of waste of energy. ${ }^{1}$

1885-87); the second edition, of which the first volume appeared in 1S91, is in progress, and will comprise three volumes. It is divided into three parts: Stöchiometrie, Chemische Energie, and $\mathrm{I}^{r} \mathrm{cr}$ wandtsehaftslehre. Nothing can give a better idea of the enormous development of chemical science in the nineteenth century than a glance at those two monuments of learning and research, Beilstein's 'Organische Chemie, (Leipzig, 1893-1900, 5 vols., 3rd ed.) and Ostwald's 'Allgemeine Chemie.' They form the basis for future development, as did Leopold Gmelin's 'Handbuch der Chemie' for the greater part of the past century. The first edition of Gmelin appeared in 1S17. See Kopp's 'Geschichte der Chemie" (vol. ii. p. 100). Since the publication of his great text-buok, Prof. Ostwald has done enormous service to science by the foundation jointly with Prof. van't Hoff of the 'Journal für physicalische Chemie,' iu 1889 , and still more by the opening of the first lahoratory specially designed for physical chemistry, in Leipzig, in the year 1857. But perhaps the most original and suggestive work of Ostwald is his work on the scientific foundations of Analytical Chemistry (Leipzig, 3rd ed., 1901. Transi. by (․ M'Gowas).

1 How recent is the systematic treatment and general recognition of physical, theoretical, or general chemistry can be seen from the historical sketches which had been published prior to Ostwald's great work. Kopp, in his excellent account of the developinent of chemistry, publisher in the Munich collection, and frequently referred to in the fifth chapter of this work (vol. i. pp. 382, \&c.), has hardly any occasion to refer to physical chemistry up to the year 1870 . This is the more remarkable as Kopp himself was a solitary ingenious worker in this isolated province. A goud account of his labours is contained in Thorpe's 'Essays in Historical Chemistry,' 1894, p. 299. A later and brilliant writer on the historical growth of chemical knowledge, Dr A. Ladenburg, in his "Vortrige über" die Entwicklungsgeschichte der Chemie' (2nd ed., Braunschweig, 1887), condenses all he has to say regarding this subject into a few pages in his last lecture. If German scieuce is destined to dis- 
The ileas through which unity and colnerence hats. been introduced into the many diflerent trains of reasuning which were hent upon unawolling the mysterien of chemical aftinity cime from an unexpected quarter. -from the comtry which, in the early jart of our century, hat become, through lierzelins, the centre if it great school of chenical research. I'rof. Ostwalil, in his recent historical sketch of the doctrines of chemieal athinity, dates the lattest period from the year $1886,{ }^{1}$ when svante Arrhenius pullished his thenly of the ehenical solutions deconprosed ly the gillinice Arrhelatur. current, the so-ealled electrolytes. That the reatcler may unclerstand what importance belongs to this littest development of physical ehemistry, I must go further

tinguish herself in the willer sphere of general or physical ehemistry as much as she has done in the past by the extreme and one-silled culture of ormanic or structural chemistry, it will be largely owing to the influence of the school of Ostwaht and thitt of the industrial factor mentioned in the text, which nowadiy: $\mathrm{cm}$. phasises as much the economical control of chemical reactions as it did formerly the diseovery and preparation of new compounds. The ultimate success in the in. dustrial preparation of artificial indigo, which was theoretically long known, is an example weil worth eareful attention.

${ }^{1}$ Prof. Ostwald had himself about the same time male in attempt in the seeond volume of the first edition of his great work to unite the disjectu mermbru of physical chemistry, notably of the theory of affinity, inte a systematic whole. This first aitempt may have contributed quite us much as the special labrurs of others, anumg whon he mentions specially Helinlsultz, Vin't Holl, lohem, l'lunck, and Arrhenius, to create an erat in chemintry. It may also be nuted that, like every other important step in chens. istry, this latest theoretical phase is characterised hy vistent contre. versies. Thene becane more pronounced as Prot. Untwald intro. duced into the sccond editisn of his work the idea of "energetics" as a general and sufticient basin for the whole of plyysien and chemintry ; making a rery empluatic frotest against the older pliysical theories, bascel upon atrations. atomism, or kinetice, which he stigmatines as mechanical. (1) this improtant controser-y I slatl have to rejurt at the enil ui the present chitpler, where ! Nhndl al-n give the full literature of the suld. ject. In the meintine, see also

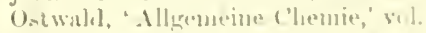
ii. part 1, preline, and part "2, 1 . $152 \times 17 \%$ 
back in the history of the subject and draw attention to the gradual change which the nineteenth century has brought about in our ideas regarding the different states in which matter is supposed to exist, be it in motion or in rest: the solid, the liquid, and the gaseous states.

Not very long ago the impressions of common-sense, according to which a fundamental difference separates solid from liquid and liquid from aeriform bodies, permeated scientific treatises also. Rigid demarcations were maintained between hydrostatics and pneumatics, and likewise between the doctrines of bodies at rest and such as are in a state of perceptible motion. One of the most marked changes which the century has witnessed, has been the breaking down of these older landmarks of science. The state of rest-once supposed actually to exist-has had to give way to a state of concealed yet measurable motion, as in the case of the kinetic theory of gases, which explains dead pressure by the bombardment of inmumerable particles darting about. The idea of dynamical equilibriumi.e., the maintenance of a state of uniform motion-has in many cases taken the place of static equilibrium or rest, as in the doctrine of the flow of heat, the theory of exchanges of radiation, and the conception that the rigidity of solids depends upon a peculiar form of whirling motion-the vortex. Similarly the intermediate or transition states which lie between the solid and fluid, the properties of viscosity and of colloidal substances, and of vapours as marking the transition between liquids and gases, have attracted more attention in pro- 
portion as experimental seience has taken the plume of that purely mathenatical treatment which oblitimed at the beginning of the century, notibly in the (i)ntinental schools, and which thought it combl exhatust the intinite variety of natural phenomena by a few easily ilefinterl properties measured by eonstants. The narrowness wi this view has been gradually orereome by the influenee of the great experinental philosophers in this comntry, and the independent development of chemical research abroad. Beside Faraday must be especially named Thonnas Graham $^{1}$ and Thomas Andrews, whose original experiments did so much to extend and deepen our knowledge $3 !$. Fraliam $3: 1$ of the less obvious properties of matter. Grahim carried on, between 18.5 and 1850 , extensive experiments on the diffusion of liquids and gases, on absorption, ant on the phenomena of osmosis or gradual filtering of substances through porous partitions, showing how in liquids motion and pressure exist similar to that which is now

1 Thomas Graham (1804-69), for many years professor at University College, London, then Master of the Mint, cultivated the unexplored regions of physics and cheusistry in an origiual spirit and yet with very simple apparatus, some of which is still used umder his mame. His ingenious labours attracted the attention of Liebig, through whose in tluence was brought about the translation of "The Elements of Chemistry' into German by Otto. This work in its subsequent cularged erlitions has formed for sixty years, next to Gmelin's 'Handbook,' a eornerstone of chemical literature in Germany, where Graham's naue is a household wold. The discoveries of Graban on the move- ment and "miscibility" of gases led to the well-knowi law, "that the diffusion rate of gases is inversely as the square rout of their density." From gases he arlvauced to the uore eomplicated sturly of liquids, divider bodies into two classes, "crystallokls" and "colloids," studied the "transpiration " of gases through fine tubes, ant their. "osmosis" or grmulual filtering through porous (aml many apparently non-purous) partitions. In many lirections lie anlicipatert later discoveries and collected in. valuable unterials for sulmeguent theories. Inter aliu, ho entablished the existence of "aleoholiater," compounds analogous to "hyilrates," and maintained the inctallic nature of hyclrogen. 
generally attributed to gases. Andrews ${ }^{1}$ in the 'sixties carried on his important experiments on the transition of bodies from the liquid to the gaseons state, and came to the conclusion "that the gaseous and liquid states are only remote stages of the same condition of matter, and are capable of passing into one another by a process of continuous change." 2 He also referred to the "possible continuity of the liquid and solid states of matter."

Another important step by which our conceptions of the nature of the liquid condition of matter were considerably enlarged and altered-motion being introduced where a former view had seen only rest-was taken by Clansins, who, following Joule and Krönig, had about the same time given its modern form to the kinetic theory of gases. What suggested this step was the phenomenon of electrolysis. The older view looked upon the action of the electric current, which, passing through substances in a state of fusion or solution, liberated the constituents out of which they were composed, as an exertion of a force contrary to the forces of chemical affinity, by which the chemical constituents were supposed to be held together. In this case energy wonld have to be spent in doing work against chemical forces. It was, however, very soon found that the decomposition, or-as Sainte Claire Deville first called it ${ }^{3}$ - the

I See vol. i. p. 316, note, of this History.

2 See 'The Scientific Papers of Thomas Andrews,' with a Memoir by Tait and Crum Brown, London, 1889 , p. 316.

S Sainte Claire Deville (1818-81) approached chemical research from the side of medicine, and after a series of original investigations, first in organic then in metallurgical chemistry, entered upon his remarkable work in thermal chemistry at the time when Clausius in Germany was being led from an entirely different point of view to the same subject. He introduced the term dissociation to denote the 


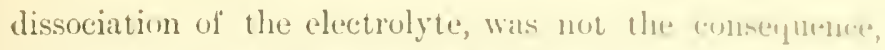
but the aceomurumying feature ar condition, of the exist - is a ence of an electric current in a solution. C'latusius first expressed this distinetly in 1857 , anl 11,lunholt\% repeated it in 1880. 'The conception was thus introduced that in certain (not in all) solutions of chemical compounds dissociation might exist independently of an electric current, and that the latter, if intruhuced, only direeted the already dissuebated and wandering molecules (ions), freemg them at the sime tinne of theil vectric charges. 'This conception, though at first violently'

lreaking-up of chemical compoumds not so much through the presence of other chemical agencies as through altered physical couditions, such, notably, ats heat, evaporation, and condensation. "Deville's observations on dissoeiation. . . have a very direet bearing on the kinetic theory of gases, and it is a fact of interest in the history of science that Deville did not recognise the validity of that theory. Our estimate of the ingenuity, skill, and patience shown in his experimental work, aud of the genius and sound judgment which directed his theoretical conclusions, is perhaps raised when we reeollect that he was neither led in the furst nor biassed in the seconel by ideas derived from the kinetie theory, and his hostile, or at least neutral, attitude towards it gives perhaps greater. value to the evidence that his work has eontributed to its soumduess" (A. Cruin lirown, "Ency. Brit.," 9 th ed., article "Sainte Claire Deville").

1 I have already mentioned (vol. i. p. 435 , note) that Clausius, when introducing his kinetic theory and distinguishing between molecules and atoms, could refer to several eminent chemists who har incle. pendently arrived int mimilar ideas by quite different trains of ressun. ing. Again, when introtucing, in $155 \pi$, his theory of dissuciation by solution, he embl refor tr similar anticipations. Willianson lam said alrealy, in 15,50 (Liebig's 'Anualen,' vol. Ixxvii. 1. 37), at the metetiug of the British Assuciation in Edinburgh: "We are led to the conclusion that in an aggregiate of uolecules of every compruncl there exists a continual exchange of the elements contained in it. Siupose, for instance, that a vessel with hydrochloric acid were filled with a great number of molecul's of the compound Cllt, then the visw at which we lave arrived would lead us to the supposition that every atom of liydrugen dues not re. main in quiet juxtaposition will an atom of chlorime, with which it is eombined, but that there is a contimual exchange of places with wther hydrogen atoms" "Clitusius, "Mo. chanische Warnethenic, vol. ii. p. 167 , Braunschweig, 1579. Fur an illustration of the therry of ('hu-ius modified to meet mone recent an reptions, see 0 . Iurlge's 'Muklern Views of Vlectricity,' 1\$92, I. \$3, \&ic. 
attacked by chemists, became gradually better understood and gained ground. The merit of having finally introduced into our modern notions the idea of the free mobility of the constituents of electrolytic compounds 41. belongs to W. Hittorf and F. Kohlrausch. The name

of the latter will be connected in the history of science with the phenomenon of the "migration of the ions," which he has expressed, after ten years of research (1869-79), in his well-known law. The question was put and answered, "What becomes of the energy of the electric current?" It was found that electrolytic conduction increased with dilution and temperature-two agents which would favour dissociation. The phenomena of dissociation had, moreover, been studied independently of the galvanic current. Following in the track of Graham and Andrews, a number of physicists abroad-notably van der Waals, Raoult, and Van't Hoff-had confirmed and extended the view that bodies in solution resembled gases, that the osmotic pressure of a liquid resembled ordinary gas pressure, that the law of Avogadro regarding the number of molecules in a gas could be transferred to matter in a state of solution, and that the magnitude of the osmotic pressure in a liquid could be used as a measure of the number of dissociated - wandering-molecules which are contained in a given volume of a solution, just as the pressure of a gas would increase if the number of molecules in a given space were increased through the splitting up of compounds. Apparent anomalies in the behaviour of gases approaching condensation were explained by the aggregation, and similar ones in dilute solutions by the dissociation, of molecules. 
The decisive step was taken in 1887 hy Arrhenins, who has the merit of having bunglat tugether the two independent courses of reseanch and reasoning, and nuade them fruitful for each other. He shows" "that the difference between active and inert nnolecules consists in this, that the former are split into their ions, the latter. not. Only the free ions take part in the conduction of electricity and in chemical reactions: this is the reasisun for the proportionality of the two (Faraday's law). The ions behave in solution like independent molecules: this is the reason of the deviation which electrolytic solutions show from the extended gaseous liaws (Vim't Hofl"s discovery)." "Whiat a change has come orer our conceptions," exelaims Victor Meyer, "if we have to alecustom ourselves to see in a dilute solution of common salt, no longer the undeeomposed molecules of a salt, but separate atoms of chlorine and sodium. For these revolutionary imnovations we are indebted to the labours of Vint Hoff, Arrhenius, Ostwald, Planck, Pfeffer, de lries, hut, so far as experiments go, notably to the splendid researches of liaoult, which for years have heen lreparing the way for this mighty theoretical arlvance."

The year 18s7, which brought together these two fruitful lines of reasoning and research, can also he considered as the epoch when the new science of physical chenistry was fairly lannched into existence. 'The year

I In a communication to the Acarlemy of Stockholm of Sth June and $9 \mathrm{tl}_{\mathrm{1}}$ November 1887.

2 Quoted from Ostwall's 'Allge. meine Chemie,' 2nd ed., vol. ii. part 1, p. 656 .

3 See the lighly interesting
Address by Victor Meyer before the German "Naturfurweherver. sammlung" at Heidelherg in 18s?, entitled "Chemische l'robleme der Gegonwart" (Heidelberg, 1890), 1. 32 .
Victor Meyer on chisuge of cliemical vie ws. 
1826 marks the revival of mathematical studies in Germany through the appearance of Crelle's journal; so

43. journal. the year 1887 saw the first number of Ostwald and Van't Hoff's 'Zeitschrift für physicalische Chemie.' From that period the physical properties of chemical substances, so long neglected, or only studied by isolated students, have received systematic, mathematical, and exact treatment, guaranteeing something like continuity and completeness, and leading on to the solution of the great remaining question, What is chemical affinity?

The eminent natural philosophers to whom is mainly dne the foundation of this modern science, claim also to be gradually realising the idea which was suggested by the early representatives of the theory of energynotably by Rankine and James Thomson-that of a general doctrine of energy, termed energetics; and they hold that this suggestion is only realisable by breaking with the conventional ideas which the older physical theories - the astronomical, atomistic, and kinetic viewshave imposed upon our reasoning. They further hold that the gradual development of chemistry into an exact science necessarily requires the introduction of this broader view which they embrace, and that the older views-nseful in their way-only suffice to comprehend certain restricted groups of natural phenomena, whereas in chemical changes, where all imaginable natural processes seem to come together, a larger and more inclependent theory is indispensable. It is interesting to note how very generally they trace this larger view to the long unnoticed labours of a natural philosopher in the New World, Professor Willard Gibbs of Yale. 
The train of thonght methodically and (mupretuen-

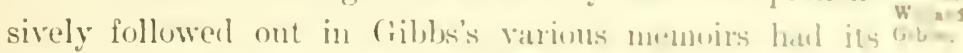
origin in the early speeulations of Willian 'Thomson (Lord Kelvin) and ('lausins, to which I referresl aluse. Thomson was the tirst whe, in atopting (after mu-h hesitation) the mechanical view of the phenemenal uf heit, the doctrine of the convertibility and equivalence of the different forms of energy, recognised that, in order w describe natural phenomena correctly, this view requirenl a qualification. The change of the different forms of energy into each other ean for the must part take place only in one direction: there is a general tendency in nature towards a degradation or dissipation of energy. Energy, though not lost, becomes less nseful, less available. The least available form of energy" is heat; anul it is in that form that in all natural changes a purtion of energy becomes lost, dissipated, or hicklen away. Thus we have to recognise the difference lietween available and mavailable, between useful and useless, energy. In the sequel Thomson showed in definite instances ${ }^{1}$ how to ealenlate the available and the $u n$ -

'See 'Math. and Pliys. Papers,' vol. i. No. IIX., 1852, “On a Universil Tendency in Nature to the Dissipation of Hechauical bnergy" : and Yo. L.XIII., 185.3, "( )n the Restoration of Meehanieal Energy from an unequally heated space." Iu Tait's 'Sketch of 'Thermotymamies' (1868), we read (p. 100): "1t is very desirable to have a worl to express the acrilubility for work of the heat in a given magazine, a term for that possession the waste of whieh is called Dissipution. I Infortunately the exeellent word cntropy, which Clausius his introdueed in this connection, is applied by him to the negative of the idea we inwit naturally wish to expresi. It would only confuse the student if we wore to endeavour to invent imother term for our purpose." the then proceels to use the term entruly" in an alterel sense, in which it measures the availatile insteral of the unavalable energy, creating for some time a preal confusion and some umnecessary irritation. See on this the early culitions of Clerk Jaxwell's excellent "Theory of Heat, and thes iminote to $j$. 159, sth ed., mal ('linsius, "Hie 
available energy : he introduced the word "motivity," the conception of a quantity of a "possession the waste of which is called dissipation." Whilst Thomson was thus putting into scientific language and calculating an important and obvious property of nature--namely this, that her processes mainly proceed in a certain definable direction-Rankine and Clausius were labouring independently at the mathematical wording, the analytical expression, of this remarkable discovery. Wherever a change in a system of various elements, factors, or quantities takes place mainly in a definite sense or direction, it is presumable that there exists a definite quantity which is always growing or always decreasing. This quantity may not be directly observable or measurable, as in mechanical motion velocity or distance is directly measurable; it may be hidden — we may have no special sense with which we can perceive it, as we possess a pressure sense, a heat sense, a sound and light sense; nevertheless, it may be indirectly discoverable, being made up (a function) of definite observable quantities and factors (such as heat, temperature, mass, volume, pressure, \&c.) Now Rankine and Clausius found that in all thermal changes

mechanische Wärmetheorie,' vol. i. p. 387 , and vol. ii. p. 324 sqq. A great deal of this confusion would have been avoided had Tait in 1868 introduced a really new term-viz., that suggested later (1876) by Thomson in a communication to the Royal Society of Edinburgh, and more fully explained in a paper in the 'Phil. Mag.,' May 1879 , the term "Thermo-dynamic Uotivity." We should then have two terms, inasmuch as the "con- sideration of the energy and motivity, as two functions of all the independent variables specifying the condition of a body completely in respect to temperature, elasticity, capillary attractiou, electricity, and magnetism, leads in the simplest and most direct way to demonstrations of the theorems regarding the thermo-dynamic properties of matter" (loc. cit., 'Papers,' vol. i. p. 459). 
or heat frocesses - and this practically means in all natural processes-there is such a yuintity which is always on the increase, and which thus measures in mathematical language the growing loss of atribible or useful energy in the wortd. limkine simply ablled it the "thermo-dynamic function": ('litusius thomght it important to give it a name which would co-ordinate it with energy, and he called it entropy: ${ }^{1}$ encrogy which is turned inside, beemues hidden or locked "up. Clansius thus gave a different wording of Thomson's loctrine of

1 Clausius had already in 1854 (Pogg. 'Ann.,' vol. xciii. p. 481) arrived at the principal eonsequences and the final enunciation of what he termed "the second law of thermo-dynamies," a law which refers to the transformation, as the first refers to the conservation, of energy. He there arrives at similar eonclusions to those put forth by Thomson two years earlier. The word entropy, however, was not introduced by him till 1865 (Pogg. 'Ann.,' vol. exxr. p. 390), when he introduced it with the following remarks: "I have intentionally formed the word entropy as much as possible on the model of that of energy, for the two quantities which are to be designated by these two words are in their physical meaning so intimately related that a similarity in the terms seeused to tne to be justified." As stated above(p. 167, note), Lord Kelvin, who worked simultaneously and indepremdently at the same subject, laid uore stress upon the direct state. uent, that in all transformations of energy we have to distinguish between the available and the total intrinsic energy, and introluced the terms energy and motivity as two functions of all the valiables specifying the conditions of a system. In his article on Heat, contributed to the 'buey. Brit.,' 9 th ed., he gives the mathenatical relation of motivity to entropy ("Papers,'vol.iii. p. 167). 'The terin motivity has not beeome current in thermo-dynanical treatises, but the need has heen vory genemally felt of reserving the worl energy in a restricted seuse for available ewergy, such energy as call l $x$ put to mechanieal use. Will, in a very interesting dissertation, 'Die Energie und ihre Entwerthung, (Leiprig, 1889), deplures (II). 43 and 4.) the fact that the worl energy has not been reserved (1) denote useful, avilable enery. "Had the worl energy," lu say, "been introduced before the discovery of the first law of thermudynamics, then certainly only mechanical energy would lave becu termed simply energy." In the use of the rorl hroft in sume writers, such as Milyer, llere geems occaxionally a confusion be. tween avalatile and total or intrinsic energy. See la Chatelier in 'Journal de l'hysinue,' 1 s) 
the universal tendency in nature towards a dissipation of energy, by saying, "The entropy of the world is always on the increase."

For about twenty years after these conceptions had been introduced into scientific language and reasoning, mathematicians and physicists were mainly occupied in defining more clearly this hidden quantity, and in defending what was called the second law of thermodynamics against misconceptions and attacks. In 1875 Lord Rayleigh could still say, "'The second law of thermodynamics and the theory of dissipation founded upon it has been for some years a favourite subject with mathematical physicists, but has not hitherto received full recognition from engineers and chemists, nor from the scientific public. And yet the question under what circumstances it is possible to obtain work from heat is of the first importance. Merely to know that when work is done by means of heat, a so-called equivalent of heat disappears, is a very small part of what it concerns us to recognise."

Whilst these words correctly describe the general attitude of the scientific public towards this important discovery, two men had already made a beginning in 46.

I 'Proceedings of the Royal In. stitution,' vol. vii. p. 3́s6.

2 Prof. Ostwald in the historical section of his "Verwandtschafts. lehre' ('Allg. Chemie,' 2nd ed., vol. ii. part 2, p. 111 , \&c.), Helm in 'Energetik' (p. 141, \&c.), and Duhem in his 'Traité de Mécanique chimique' (1897, vol. i. p. 84 , \&c.) all do full justice to the long-unrecognised labours of Horstmann, which began in the year 1869 and were continued in Liebig's 'Annalen' in various communications during the early 'seveuties, not without undergoing violent attacks from representatives of the older conceptions. Ever since James Thomson's celebrated prediction (see above, p. 126), physicists had recognised the importance of thermo-dynamical considerations, 
Willard Giblos ${ }^{1}$ in Anerica. They seren to have freen the lirst to approach the puestion of ehemical equilithium, the result of the action of varions conflieting (hrenical forces, termed affinities, from it geneml compuntusis. point of view; recognising that the thenry them (wnthmonly alopted on the Continent-the themo-cheminal thenry of affinity-was incorrect or incomplete. This thenry, which had been principally elaburated by .Julius Thomsen in Coprenhagen and ly lietrthelot in lirance, was supported ly the large amomit of riluable experimental research for which we are indehtenl to these two eminent men and their numeroms followers.

whilst chemists persisted in the exclusive use of atomistic conceptions, which, as Horstmann pointed out, are of no avail in problems of that nature (see Helm, 'Energetik,' 1). 143).

I More fuudamental than the latours of Hor-tmann were those of Gibbs, which began with the year $18 \pi 4$, and were for a long time burierl in the "Transactions of the Connecticut Acalemy.' They were known to Jaxwell, but remained generally unknown, partly owing to their abstract nature, partly to the fact that the majority of Continental chemists were not prepared to appreciate the mathcmatical forn in which his expontions were clothed. P'revious to the sturty of questions of chemical equilitrium, Gibbs had successfully developed an idea of James Thomsou's-viz, the graphical represontation of the different theruodynamic quantities in three insteras of merely in two dimension.. Thomson harl represented the properties of a body or system ly referring thern to volume, pressure, and temperature. Gibbs refers them to volume, energy, and entropy, the former quantities being alway - definable by the latter, but not vice versê. The arlvantages of this relreventation were demonstraterl to English students in Maswell:'Theory of Heat.' In Gernumy it was Prof. U-t wald who, hy collecting and translating the nemoirof Gibus, first mate them accessille to student. "Thermolynamirelue Sudten, von Willard Gibls, Leipiz. 1892). Subsequently both Ostwald aud Ilelm hatse done much to promote an understanding of Gibln's methods. See Ostwald, 'Allg. Chemie, rol. ii. part 2. 1. 11t, se.; Helm, 'Gruntzige dler' mathematischen Chemie (lappig, Irit. and 'Energetik, passim. Sulnequently Gibbs also introluced the very general and uselul term "phase" to denote the different states in which a substule ent exist. This term demeres ner mily such differences as wore formerly

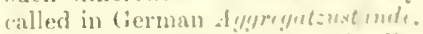
but likewise comblitims of atisociation, allotropice and immerie inorlifications. 
It measured chemical reactions by what is termed their heat-toning, i.e., by the amount of heat developed, and culminated in the colebrated third law of thermochemistry-viz., that such reactions take place as are accompanied by the greatest amount of energy liberated in the form of heat. Now, although this contains an adequate description of a very large number of reactions that take place at the temperatures at which we operate in our laboratories, the rule is by no means universal, and it required a great amount of ingenuity to explain away the many exceptions which presented themselves. The rule needed to be modified or amplified. The measurement of the energy of a chemical process by the heat-toning was not the only instance in which the thermal side of a phenomenon had been considered a sufficient means of measuring. In an allied department, that of electrolysis, Helmholtz had suggested, as early as 1847 , that the electro-motive force of a galvanic cell may be measured by the heat-toning of the chemical processes which produce the current, and for a long time this was considered to be a correct expression of facts. In consequence, however, of some discrepancies which had presented themselves, Helmholtz himself was induced, about 1881 , to examine the subject more thoroughly. He arrived at the conclusion that the heat-toning is not always a correct ineasure; and at the same time he introduced a more aclequate and generally applicable method of measurement. In fact, he arrived at the conception of available or useful energy for processes which take place at constant temperature. To this quantity, which decides in which direction a reaction takes place (tempera- 
ture remaining constant), he gave the mane of trese colergy. He showed that in a state of equilibrium the from an availalile energy must te a minimun. He also shumml the conneetion in which the arailable or free eneres stands to the quantity introcluced by limbine and Clausius, the entropy which measures the unavilable or hidklen energy. by making chemical changes deprent on the increatse or decrease of a ilefinite measuralile yuantity a parallel was established betwern chemical amel mechanical processes, the latter always taking place in the direction of a decrease of potential energy. Free energy" has thus been appropriately termed hy M. Inhen the thermo-dynamic potential.

Helmholtz did not apply this fonitul view to chenical processes on any extensive scale, but his explanations have done much to establish that correcter and nore comprehensive way of treating such questions which has since become general. Horstmann hat inteed led up to this riew, Willard Gibbs had applied it hefore, and Lord Rayleigh had suggestenl it. ${ }^{1}$ The concertion of

1 The general use of the concep. tion of useful or free energy must be dated from the remarkably lucid expositions of Helmholtz, though it is now recogniserl by all who have studied the history of this fertile coneeption that the physical notion of available energy gues back to 'Thomson (see Tait, 'Thermodynamics,' 1868 , p. 100) and Maxwell ('Heat,' p. 157, 8th ed. ; Duhem, 'Mécanique chimicjue,' vol. i. p. 92 ; Le Chatelier in 'Journal de Physique,' 1894, 1'. 291); that the mathematical formula were given by Massieu (quoted by Duliem, 'Le Potential Thermodynamique,' 1886, pl. $v$ and 11), and more definilely explained and applied to the physical phenomena of dissociation by Gibus ("Thermodynanisebe situilien,' ed. Ostwald, p. 66, sc.: 'Amer. Journ. of Sulences and Arts,' 1579); and that it is es. pecially owing to the labours of Juhem that the subject has received the attention of chemists. XI. Duhem, in the introduetion to the work of $1850^{\circ}$, gives a very valuable and lucil historienl ex. position, and subsequently in his large work in four volumes (" Mt'. canique chimique, $1597-1900)$ a vast number of applientions. Fin the history of thought the impere. 
48.

Kelvin's available energy.

available energy as distinguished from total energy had been introduced by Lord Kelvin and by Maxwell. This free energy is measured not ouly by the heat liberated, but depends on all the other factors, such as volume and pressure, the number of chemical substances engaged, and their physical conditions. The doctrine of energy and the conception of free energy pointed out a method of coordinating all these different factors and reducing them to a common measure. As Rankine, by the introduction of the term potential energy, did much to clear the ideas and guide the reasoning in dynamical science, so Helmholtz, by introducing the term free energy, did a great deal to introduce into chemical science the fruitful conceptions which had been elaborated and applied in physical research. The term free or available energy seems to describe more naturally the characteristic property of all energy which is useful for doing work, whilst the opposite term entropy - which measures the unavailable or hidden energy - refers to a quantity for which we have no immediate means of perception. ${ }^{1}$

auce of these somewhat abstruse expositions lies mainly in two directions: First, in the recognition of the fact that for the correct description of natural phenomena and changes the kuowledge of the total energy is as little sufficient as that of the total weight or mass, but that it is necessary to introduce the conception of use. ful energy, of energy which is free or available for doing work ; secondly, in the recognition that the course of chemical ahauges or reactions cannot be measured by attending to one special property, such as weight, or temperature, or eutropy, but that it requires the measurement of a quantity which comprises all the different agencies in nature, this quantity being the energy of the system or substances in question and its availability. A third point, which is of more or less importance according to the general view adopted, is this, that the ma. thematical formula involved have exhibited the analogy between chemical and mechanical processes, the latter being those which were earliest and are most easily grasped by the mind.

1 As Prof. Ostwald has remarked, it is to a great extent a matter of taste what particular form one adopts out of the many in which the 
It was about this time--after experinental resuted had heen carried on for many years hy Julius 'Thonsen and Berthelot, after Horstmitm hat made it hespinning of

second law of themo-dynamics can be expresserl ('Allg. C'liemie,' vol. ii. part 2, p. 150). In every case it is sinfily a question how most conveniently to express and apply the general prineifle that heat cannot of itself pass from a colder to a hotter borly, the prisciple on which fourier built his "Thérie de la Chaleur," and which revealed itself as the rationale of the expositions of Carnot when in the nuildle of the century their lididen truth euserged from the criticisus of William Thomson (Lord Kelvin) and Clausius. 'Thus aheady in the difierent treatment of the same subject there showed itself the twofold tendency which reasoning on plysical matters so frecuently exhibits - viz., towards physical directuess and mathematical elegance; the former leading to practical application, the latter to analytical refinement. Maxwell, in a review of 'Tait's 'Thermodynamics, written in 1877 ('Scientific Papers,' vol. ii. p. $666)$, contrasts the method of Clausius and 'Thomson, and Prof. Mach ('Warmelehre,' 1s96, 1. 300) has made similar renarks, of Thomson the former say"s, "that lie does not eren consecrate a symbol to denote the entrojy, but he was the first to clearly. define the intrinsic energy of a body, and to him alone are clue the ideas and the definitions of the available energy and the lissipation of energy. . . . He avoids the introduction of quantities which are not capable of experimental measuremeut." Since these criticisus a great deal has been written to make the sceond law of thermo-dynamics and the conception of "utropy mon inte llig. ible. The ubject here atain haheen twofold: first, lo luake the conceptions useful ier the partucal perpwese of perfectimg the leat en. gines (lamkine, Yeuner and his selool) and of insertigatiug the emolizions of chemical muilibrium ((Bib)s, Helmholt\%, Julı*ni) ; 110xt, to plince the secomrl law; which deals with the trau-fornation of energy, un an ejuslly tirun fuundistim with the first law, wlich deals with tlie conservation of en. ergy. There is no cloulst that the frinciple of the consisuation of energy owes a very large fatt of its intolligilility to the lact that for prely rueclatuical ry-iems it follows from such well-kuown dymamical axions as the lawe of notion. When leat was conceived to liate a mechanical equivalent in mechanical work, the more general priniple of the conservation of energy seemerl intelligible by mechanical conceptions. The second law, however, introduced a property oi natural procesies which is not so easily understood mechanieallyviz., that they are not reversible -and this projerty was shwn to he connecterl with a specinl phys. ical quantity, for which we have a sprecial sense-viz., temprerature. The problem of making the secont law mechanically intellicible thus coincicles with the froblem of griving a meelanieal defintion of temperature. It is not sutticient to call heat a mude (or, more cor. rectly, the energy) of motion; we nust express temperature, (n) the ditherence of which the urefulnes of heat depenrls, in sume way ly motion, we unut arive $a$ : a 
introducing thermo-dynamics into chemistry, after W. Gibbs had shown how to look at chemical energy as a sum of many forms of energy, and after Helmholtz had more clearly defined the useful conception of free or available energy as the measure of chemical reaction-

49.

Ostwald's 'Allgemeine Chemie.'

that Prof. Ostwald at length ventured after the lapse of eighty years to unite in a comprehensive doctrine the scattered fragments of our existing knowledge regarding chemical affinity. This he did as a restorer of the forgotten labours and fame of Berthollet. ${ }^{1}$ By the

kinetic definition of temperature. The two principal founders of thermo-dynamics, Clausius and Lord Kelvin, did not resort to kinetic conceptions when establishing the two laws which deal with the conservation and transformation of energy: Rankine, however, connected the subject with his theory of molecular vortices; and Clausius, who was one of the founders of the kinetic theory of gases, very early attempted to interpret the laws of the transference of heat by the help of that theory. So likewise did Maxwell, Helmholtz, Boltzmann, and many others. Mr Bryan, in a very valuable report on the "Researches relat. ing to the Comnection of the Second Law with Dynamical Princiules," has given a critical summary of these various attempts (see Brit. Assoc. Reports, 1891, p. 85). The three peculiar forms of motion referred to in our last chapter - periodic, rotational, and rapid translational (disorderly) motion-have been used to suggest manifold means of trans. lating thermo-dynamical processes into kinetic models, explaining, as Mr Bryan says, "the second law, about which we know some- thing, by meaus of molecules about which we know much less" (p. 121). It does not seem that much more has been gained than a general presumption that a mechanical illustration is possible. To the statistical ideas elaborated mainly by Maxwell and Boltzmann I shall revert when treating generally of the statistical view of nature.

1 Prof. Ostwald has himself, in the Inaugural Isecture which he delivered on the occasion of his accessiou to the chair of physical chemistry at Leipzig, 23rd November 1887, given a very lucid statement of the principles involved. He goes back to the two theories of chemical action represented at the beginning of the century by Bergmann on the one side and Berthollet on the other. In place of the conflict of chemical forces, in which the stronger ob. tains a complete victory (complete reactions) - the view of BergmannBerthollet introduces the "manifold play of forces acting to and fro, the result being that every one gets its due. The more powerful substance gets more, the weaker less. Only in cases where one of the possible compounds in consequence of its properties entirely leaves. 
publication of the second rolume of his 'Letrituch der' allgemeinen Chemie' a great impetus was given to physieal ehemistry. The large addition to our knowledgr in this branch, and the consolidation and eriticism of research which it brought about, and to which the second edition, now appearing, gives anple testimony, mark this publication as an epoch in molern scientific thumglit. 'T"s this derelopment is attached the growth of the special view of natural phenomena which Ostwald and some other C'ontinental thinkers embrace, and which they are inelined to place in opposition to the oller views as a more eomprehensive one. The older views they sonnewhat contemptuously term the materialistic views of nature - the views, in faet, which I lave presented under the healings astronomieal, atomic, and nechanical. As this most recent outcome of what I termed the physical view of nature refer's to fundanental conceptions and has furnished much matter for discussion

the field of contest, either by falling down as insoluble or esetiping as gas, can that complete decomposition take place which Bergmann held to be the normal result" ('Die Finergie und ihre Wand. lungen,' Leipzig, 1888, p. 20). 'That complete reactions were for a long time studied with predileetion was most natural, especially as they are the most useful for practical pur. poses; but the study of moring chernical equilibrium, depending on what is now termed mass action and iuvolving the question of the velocity of reactions, has in recent times again asserted itself. Ostwald dates the revival of this longneglected branch of research from the year 1867, when "two Nor. wegian chenists, Gullberg and
Watge, put the illeas of Berthollet into preeise inathematical form and subjeeted the resulting equations to the test of observation and veriliea. tion" (ibid., p. 21). Ostwald then shows furtleer how liergwann's theory was simultaneously revived in M. Berthelot's fanous third law derived from thermo-chemistry. This in turn had to viell to the correcter views which dite from Gibbs's studies "on the equilibria of heterogenenus sub. stances" (see "Thermolynmisehe Studien,' 1'. 6it, 1875 ; also () stwalil, 'Allg. Chemie, vol. ii. part :2, 1'。 $16: 3$, on the reconeilintion of berg. mann's and berthollet's views ; and further, Berthelot in 'Comptes Renclus,' 1894, 11.s). 
abroad, I will try to sum up finally the principal points in it which are of importance for the history of contemporary thought.

Ever since the conception of energy as a quantity which, like matter, is preserved in all natural processes, forced itself with more or less clearness upon natural philosophers, the question has been insistent as to the number of different forms in which this quantity can manifest itself; and some of the earliest propounders of the doctrine attempted an enumeration of the different forms, mechanical energy of motion and of attraction usually heading the list. When that form of energy which we call heat was subjected to examination, and the remarkable property formerly called latent heat defined in the new terminology, the want arose of bringing about some kind of connection between our ideas of motion and those of heat, which were shown to be mutually convertible quantities in nature. Before that time sound and light had already yielded to the kinetic view, and an enormons increase of our knowledge in acoustics and optics had followed. Thus we find some of the pioneers of the physical or energy view of nature-notably Rankine and Joule in this country, Redtenbacher and subsequently Clausius abroad-engaged in translating the properties of heat into mechanical analogies. ${ }^{1}$ It was not thought

1 Rosenberger, in his ' Geschichte der Physik' (vol. iii. p. 550, \&c.), gives a number of references to theories mostly forgotten which were published before and after the year 1850 . Clausius, who keeps his mechanical theory of heat quite separate from his kinetic theory of gases (see the three volumes on 'Die mechanische Wärmetheorie,' 2nd ed., 1876, \&c.), admits, nevertheless, in a paper published in 1857 (Pogg. 'Ann.,' vol. c., and 'Mechan. Wämetheor.,' vol. iii. p. 1, \&c.), that "from the beginning of his researches referring to heat he had attempted to account to himself for the internal 
essential, but it was found to he convenient - mainly for diclactic purposes- to elaborate such amalories, explatining or describing the less known ly that which is mom familiar. liegarding the value of such attempts there have always existed two opmions. I have hal occalsion to refer to them when explaining the atomic throry. 'There were those who looked upon that thenry merely" as a convenient symbolism, and there were those who looked upon atoms and molecules as really existing things. The latter view has gained force and inportance through the necessity of nore and nore elahorating the atomie hypothesis in order to represent not merely the chemical constitution of compoumes, hut likewise their manifold physical differences, some of which, in fact, could only be deseribed by geometrical enneptions. I need omly refer to what I said above on tho kinctic: theory of gases, and on the property temed chinulity manifested by some ehemical sulstances in solution, as well as on the phenomena of isomerism. In the last

state of motion of a hot body, and that he had arriver at a conception which he had already before his first publication (in 1550) used for various investigations and calcu. lations." He iurther states that hearing through. William Siemens that Joule had expressed a similar ilea (Manchester Phil. Soc., 1,48 and 1857), and more especially after the publication of Kronig (18.56), he resolver to publish his views. It is interesting for our present purpose to see how Clansius, like Maxwell in a different domain of research, was originally guiled by refinite mechaniea] representations. $\mathrm{lt}$ is equally noteworthy that $\mathrm{l}$, mol Kelvin's original researches on the subject of heat were quite iree from this element, though we owe to hin in other department: some of the most suggentive kinetic illustritions: and that lie has quite recently offeren sillunble criticisms on the attempted mo. chanical interpretation of the seenml law of thermo-dymanic (ser p. 11: of Bryan's Report, qumlest anwe. p. 176 , inte). Also the tirst Finglish treatice on thermonlynamics writ. ten for flilactic purjuse (Trit's sketch, 1804) contains nu roferouce to molecular lhenry, and Hirn, wne of the must wetive workers in the region of experimental prisits, kepu clear of it. 
chapter, while dealing specially with the kinetic view of natural phenomena, I had again occasion to refer to the opinion which has latterly crept into mechanical explanations-namely, that they are to be looked upon merely as symbolical, an opinion which did not enter the minds of the original propounders of the vibratory theory of sound and light, and which some eminent natural philosophers to-day strongly oppose. An opposite fate seems to have befallen the mechanical hypothesis in chemistry and in physies. Whilst Dalton's atoms were accepted with hesitation, the further elaboration of the atomic view has made it almost impossible to resist it as a physical reality; whereas the necessary complications introduced into Young's undulatory theory in order to make it cover electro-magnetic phenomena have given it the appearance of unnaturalness and artificiality - so much so that Maxwell himself abandoned the line of reasoning which led him originally to his fundamental formule, and contented himself with more general considerations derived from the conception of energy.

"Kinetics"

The conceptions which are expressive of the view dealt and "ener. getics." with in this chapter-the energy ideas-have had a similar fate. There have been those who have interpreted this view to mean that all phenomena in nature can be translated into the language of mechanics: they have accordingly been stimulated to invent all manner of kinetic contrivances by which light, heat, electricity, and chemical action can be represented. Others have interpreted the equivalence of all forms of energy to mean that kinetic energy is only one of the forms in 
which this quantity can appear : they hate thus exerted themselves to find such general properties as belong to all the forms in which energy presents itsulf to 115. They look mpon energy as it muel more general conception than motion, and they think it a mistake un try to narrow the conception so that it can only mean the energy of attraction and repulsion (the astronontical view), that between the ultimate particles of matter (the atomic view), or the energy of various furns of motion (the kinetic view).

On the purely scientific sille the mechanical view has much to say for itself, and can point to achicrements which recommend it as a fruitful methou of pronless amb research, and as even more fruitiul for the purposes of instruction. It can claim to give in many instances an apparently easy aceount of the common-sense ol obrious properties of bodies, and it gives this accomnt in terms which lend themselves to strict definition, to measurement, ealeulation, and predietion of phenomenas: it destroys all vagueness, and adopts, as it also stimulates, mathenatical, which is the most cogent kind of reasoning. The kinetic theory of gases and the viluatory theory of light are notable examples. 'The ideas of energy and the remarkable properties of the lowest form of energyi.e., of heat-becune gradually elearer and lost their strangeness as potential energy came to the defined as energy of position, available (or free) energy as the kimetic energy of regular or orderly, muvailalule (or bound) energy as that of irregular or disorderly notion, and when the strange quantity terned entropy, which Clansius and liankine strove in vain to luing honne to 
the general scientific intelligence, revealed itself as the measure of the disorder which prevails in the motion of the ultimate material elements of a system. ${ }^{1}$ Faraday's lines of force and the whole elaborate imagery invented and afterwards discarded by Maxwell to describe the interaction of magnets, electric currents, and charged bodies, have proved to be most valuable instruments of thought-a useful scientific shorthand-in the hands of the teacher, as in those of the practical electrician. And although the illustrious propounder of the vortex-atom theory of matter seems latterly to have discomraged the use of this kinetic contrivance as not likely to lead to any great revelations regarding the ultimate constitution of matter or the nature of the imponderables, ${ }^{2}$ the

1 Helmholtz, in his first memoir on the thermo-dynamics of chemical processes ('Sitzungsberichte der Akademie zu Berlin, 'nd February 1882), after having established the formulæ for the free energy in isothermal processes without reference to kinetic hypotheses, concludes his exposition with the following remarks: "We require, finally, an expression in order to be able to distinguish clearly what in theoretical mechanics is termed vis riva or actual energy from the work equivalents of heat, which are indeed mostly to be regarded likewise as vis vira of invisible molecular motion. I would suggest that the former should be called the ris vivu of orderly motion. I call orderly all motion in which the compounds of velocity of the moving masses are ditferentiable functions of the space co-ordinates. Disorderly motiou would then mean all motion in which the motion of each particle has no similarity to that of its neighbours. We have every reasou to believe that heatmotion is of the latter kind, and one might in this sense regard entropy as the measure of disorder. For our means, which compared with molecular structure are coarse, only orderly motion can be freely converted again into other forms of mechanical work" "Wissenschaftl. Abhandl.', vol. ii. p. 972).

2 "I am afraid it is not possible to explain all the properties of matter by the vortex-atom theory alone-that is to say, merely by motion of au incompressible fluid; and I have not found it helpful in respect to crystalline configurations, or electrical, chemical, or gravitational forces. . . We may expect that the time will come when we shall understand the nature of an atom. With great regret $I$ abandon the idea that a mere configuration of motion suffices" (Lord Kelvin, quoted by Prof. S. W. Holman in "Matter, Energ5, Force, and Work," New York, 1898, p. 226). 
foremost intellects are still busy in working this to them promising vein of reasoning.

The opponents of the kinetic, mechanical, ol matterial views of natural phenomena have always exinted: in the early years of the century they descrihed their virw ly the word "dynamic." It that time it was the atomic theory they principally objected to. Int their eriticisins, though not without use in exposing the liniturl nature of all meehanical explanations, failed to yielı any fruits, inasmuch as they moverl in vague expressims and dil not lend themselves to that jowerful methur by which alone the conquest of nature has been eflected, viz., mathematical reasoning, combined witlı observation.

The more recent critics of the mechanical interpuetation of physical phenomena, among whon I will only mention Prof. Ostwald of Leipzig, I'rof. C. Helm of Dresden, and Prof. Ernst Mach of Viemna," are fully

51. Critirism of nechunical view.
1 "With reference to the vortexatom theory, I do not know of any phenomenon which is manifestly iucapable of being explained by it; and persoually I generally endearour (often without success) to pieture to myself some kind of vortex-ring mechanism to account for the plienomenon with which I am dealing. . . . I regari the vortex-atom explanation as the goal at which to aim," \&c. (I'roi. J. J. Thonson, quoted ibid.)

2 Prof. Ernst Wach is the enrliest of these writers and had worked on quite independent lines before the other two names began to figure in scientilie literature. His critieisms refer botlı to metaphysical and meehanieal theories. His position is original and unique, and his writings, which are a splendid example of eritical and historical analysis, have been invaluable to me. His earliest important e...tys date from the vear 15i: "Wie Geschiclate und die Wurzel des Satzes von der Erhaltung den Arbeit,' and 'Die Gestallen der Fhissigkeiten,' Prays). 'They are now generally accensible, liaving been collecterl and translaterl (under the title 'Scientilic Lectures,' Chicago, 1-95i) by l'roi. T. J. Ml Cormaek. HIs 'sience ui Mechanies "translated ly the sane author from the seenuil Cierman edition, London and ('hicaten, l w9:3) has, ever since ils tirst aplesushed in 1583 , harl a great intluence in Germany ; ambl laterly alon in thieountry, as may he secin from such works as l'roi. liarl l'earsuli is 'Granumar of science' (lat idl., 1892, p. 357, and notably Irom l'rof. Love's 'prnanics' (p. sos). 
aware of the importance of mathematical presentation of their doctrine, and the two former have in fact done more than any one else to introduce mathematics into chemistry. But they maintain that their exact treatment is not arrived at by introducing hypothetical quantities such as the atomic and other theories are founded upon, but by contenting themselves with measuring such quantities as are presented directly in observation, such as energy, mass, pressure, volume, temperature, heat, electric potential, \&c., without reducing them to imaginary mechanical or kinetic quantities. ${ }^{1}$ To what extent they

A great many aspects of physical science which have been more prominently brought forward by the modern school of "Energetics" are to be found discussed in Mach's much earlier writings. To his valuable 'Principien der Wärmelehre' (Leipzig, 1896) I have frequently had occasion to refer in this chapter.

${ }^{1}$ In recent discussions and treatises two distinct tendencies must be distinguished. First we have the very useful effort to bring about a correlation of the different departments of physics and chemistry, including their applicatious in industry and in physiology, by the introduction of the conception of energy and the principles of its conservation and transformation. This dates practically from the publication of Thomson and Tait's 'Natural Philosophy.' 'The theoretical foundations of this undertaking have been very fully discussed, notably in Germany. I mention only the valuable series of writings of Prof. Max Planck, a list of which is contained at the end of his 'Thermodynamik' (Leipzig, 1897). They begin with his prize essay ('Das Princip der Erhaltung der Energie,' 1887) and his earlier dissertation (Munich, 1879) "On the Second Law." Out of this another endeavour has grown. The aim is to make the conception of energy the fundamental notion, and by following its physical appearance in its different forms, to arrive at certain fundamental relations expressed in equations, which are to serve as the basis for calculation, as in conventional physics the dynamical equations formed the starting-point for the various physical theories. In this more radical scheme the quantity "energy" was to play a part similar to that which the quantity "force" played in Newtonian dynamics. This method was probably suggested by the novel mode of treatment invented originally for heat-problems by Lord Kelvin and by Clausius, and most strictly adhered to by the former. The isolated character of this classical thermo-dynamics can be got over either by introducing a kinetic hypothesis on the nature of heat or by extending the method of thermo-dynamics to other physical provinces. The former was the most plausible view; it has its origin in the writings of Rankine 
ON TIE PHYSICAL VIEW OF NATURE, 185

may succeed in doing this consistently sorms at fresent uncertain. It has been maintained thith the very elements of all physical neasurenent, the independence of the three dinensions in space, necessitintes us to supplement the energy-conception - which by itself inclucles no more reference to direction than the conception of mass-by an assumption of a purely medlanieal nature such as the number of regrees of freerlom, and that the much-discussed eorrelation of all forms of energy, as it is suggested by W. (iiblss's formulic, camnot be usefully carried firther. This correlation' laxs been

and Clausius. The latter methol grew out of the gradual application of thermo-dynamies to ehemical phenomena, where the mechanical treatment had turned out to be powerless. This more ambitious scheme of remodelling the whole of physics, ehemistry, and meehanies on the model of the elassical thermo-dynamies dates from the year 18s7, when Prof. Georg Helm published his first treatise ('Die Lehre von der En. ergie,' Leipzig) and revived the word "energeties" invented by Rankine. Subsequently he published his application to ehemistry ("Grundziige der mathematischen Chemie,' Leipzig, 1894), very much under the influence of Willard Gibbs's studies of ehemical equilibria and Duhem's elaboration of Helmholtz's conception of free energy. His last work ('Die Energetik,' Leipzig, 1898) gives a history of the gradual purification of the energy conception from mechanical admixtures, into which all earlier writers on the sulject except Lord Kelvin are shown to have lapsed, and attempts a reconstruction of meehanies on "energetic" principles, sefending the author's position against various criticismm which had mentime been malle.

I The great generalisation of the science of energetics reforres to in the text was first explicitly put forth by Helm in his treative of 1887. He himself holls that he there finally brought together sug. gestions made in various ways by Yeuner (1866), IIach (1871), i iibus (1875), Mlaxwell (1575). Von Uettin. gen (1855), and Poppler (1854), aul expressed them in the form of a general principle. The two fincturs into which all energy can be sep. arated are called by various sul. sequent writers intensity, potential level on the on side; extensity, capacity, weight, on the others. In spite of further expesitions of Helm in 1890 the subject dis not attract much attention till l'rof. Ostwald introduced it in a slightly molified form in the second odition of his great work on physical chem. istry (1593), making it the foumlation of the deetrine of altinity. He had evidenty, hetwen the first and second erlitions, given ny the mochanical for the "energetic" treatment of the suljecet (sec, inter aliu, note :2, 1'. 114, of the 2nd edition: vil. ii. f. 12). At the meeting of the German 


\section{placed at the summit of the modern theory of energetics} by Helm and Ostwald, after earlier writers, such as Zeuner and Mach, had already used it or drawn atten-

"Naturforscherversammlung," held at Tienna in 1894 , a committee was appointed to report in 1595 at Libeck on the "actual position of energetics," and the introduction of the subject was put into the hands of Dr Helm. His address aurl the discussion which followed have been given in extract in the published 'Terhandlungen' (vol. ii. part 1, p. 2S. ic.), and since continued in 'Wiedemann's Annalen,' vols. lvii. et seqq. Simultaneously, however, the subject receired a much more fundamental or philosophical derelopment through Prof. Ostwald's general address at Liibeck with the somewliat polemical title "Die Ueberwindung des wissenschaftlichen Materialismus." From that moment the mechanical view of nature bore the stigma of materialism, to which the other side replied by attaching to the new or energetic view the stigma of "metaphysical" (see Planck, 'Wied. Ann.,' vol. Irii. p. Ti) as being scientifically rague and useless. It cannot be said that the whole matter has yet been fally discussed or fathomed. Prof. Boltzmann, Prof. Carl Nenmann, and Dr Helm have treated the questions at stake with much patience, and have made raluable approaches to a mutual understanding. The various contributions are most fully discussed in Helm's latest work, 'Die Energetik' (Leipzig, 1898). Some of those who originally assisted in introducing the energetic treatment have since refused to go the length of Helm's and Ostwald's final generalisations, though they prefer - for the purpose of the treatment of thermo-drnamical and chemical problems - the phenomenological method, admitting at the same time the usefulness of the atomic and mechanical hypotheses, though some do not look upon them as indispensable. This phenomenological view, which deals only with observable and measurable quantities, in contradistinction to the atomic and kinetic views, is largely represented by Prof. Nernst (see his "Theoretical Chemistry, translated by Palmer, London, 1895, p. 22), and by Prof. Planck (see his "Thermodynamik,' Leipzig, 1897), though the latter considers it merely provisional, a stepping-stone in the direction of a mechanical view (p. $\mathbf{x}$, preface). Prof. Boltzmann has summed up the position from a general point of view in his address at Munich in 1899. He there very lucidly defines the mechanical, energetic, and phenomenological positions, admitting the usefulness of all three, but also points out the fundamental difficulties into which a one-sided and exclusive derelopment of any of them unavoidably leads us. Having himself done so much in applying atomic theories, he concludes by saying that "the numerous conquests of the atomic doctrine eannot be won by phenomenology or energetics," and main. tains "that a theory which yields something that is independent and not to be got in any other way, for which, moreover, so many physical, chemical, and crystallographic facts speak, must not be combated but further developed"s. ("Verhandlungen der Versammlung zu J̈̈nchen,' 1899, p. 121). 
tion to it. It can be set out in the stitement that wherever energy shows itself it apperirs as compused wi two factors - the intensity and the eapacity farctens. These terms, borrowet from the older theries of heat and electricity, measure the quantity of energy as well as the direction in which changes of enelgy take place: the general law being that energy, in whatever form it may appear, tents to go from places of highter to places of lower potential or intensity.

The characteristic feature of this most recent onteome of the physical view of natural phemomena is that it come. takes in real earnest the suggestion at which many natural philosophers have indepentently arrivel, that energy is a substance quite as much as matter. This granted, it seems at least reasonahle to some thinkers to see how far they can get by employing the two (unceptions of matter and energy alone without atopting a third something, the ether, which was intrortuced at a time when the idea of the conservation of enerery had not yet been formulated.'

1 For an indieation of the further development of this point of view I must refer the reader to the chapter. on Plioto-chemintry in l'rol. Ust. wald's great work ('Allg. ('hemie,' 2nd ed., vol. ii. part 1, p. 1014, kc.) "In the interent," he says, " of a conception of nature which is free from hypotheses, we must ask whether the asumption of that medium, the ether, is unavoidable. To we it loes not seem to be so. If we ask for the eause of all displacements of eneryy in sprace which we can singly ubserve, we tind that it always consists in lifierences of intensity. . . Tle main point is that, having eonceived energy to be a real thing. indrevl the only real thing in the so-called outer world, there is no neeal to inpuire for a earrier of it when we find it anywhere. This enable: uto lusk upin radiant enery as in. dependently axisting in spat. We have found in the general lisw of intensity - i.f., in the empirical fact that energy temls to eryushline forced eluanges of its density in space - the prineiple accurcling tu which transmision of energy in space necessarily takes place when there appears anywhere an excess." From this amel athel prosuges of Prol. (), stwall's writinges it serems as if mass likewise was to he giren 
53.

Recent triumphs of atomic view.

But whilst the question as to the true method of physical research is still being ventilated abroad, as it has recently begun to be in this country also, the mechanical conceptions of atoms and ether have quietly gained new victories. At the end of the last chapter I related how, in the hands of Maxwell and his followers, the word "electricity" gradually lost its substantial meaning, so that there remained only the conception of a state of motion or stress in the electromagnetic field, it being difficult to assign a definite sense to the term, an electric charge. That those who were brought up under the ideas of Coulomb and Weber would naturally regard this as a defect has also been noted. Still more had the substantial nature of electricity been forced upon those who studied the electrolytic action of solutions and currents, the wandering of

up as a secondary phenomenon of energy. See Boltzmann, loc. cit., last note, p. 114, \&c. ; also, inter alia, Dr R. Pauli, 'Der erste und zweite Hauptsatz,' Berlin, 1896, preface.

1 The discussions which began in Germany in the year 1895 at the meeting at Lübeck, and have, after being continued at sulsequent meetings, and in the volumes of the 'Annalen der Physik und Chemie,' come to a kind of standstill by the exhaustive treatise of Helm on the one side and by Boltzmann's summing up ou the other, do not seem to lave attracted much attention in this country. Interest in the subject was, however, latterly aroused by two criticisms of the principles of scientific method coming from entirely different quarters. The first, which was of a purely philosophical character, was con. tained in Prof. James Ward's ' Gifford Lectures' (1896-98), published in two volumes with the title 'Naturali-m and Agnosticism.' The other was an Address delivered by M. Poincaré at the Congress of Plysicists in Paris in 1900. In consequence, the subject of the legitimacy of the various physical principles, such as action at a distance, atomism, kinetic and ether theories, the use of mechanical models, and many kindred questions, have been discussed in the Addresses of Poynting (1899), Larmor (1900), and Rucker (1901), before the British Association, with a very emphatic attestation of the usefulness and indispensableness of the atomistic theory regarding the constitution of matter, and the view that a continuous ether is the carrier of all physical actions through space. 
the ions, and how, during the process, wandering atums gave up or lost a detinite something — viz, their electrical charges. It seemed impossible in this case to do without an atomic or molecular view of electricity. Accordimgly, Helnholtz, in lis celebrated Faralay Lecture (1881), after having traced the gradial displacement of the Weberian theory of electrical particles auting at a distance by that of Faraday, feels himself exonstrained to say: "I see very well that the assumption of two imponderable fluids of opposite yualities is a rather complicated and artificial machinery, and that the mathematical langnage of ('lerk Maxwell's theory expresses the laws of the phenomena very simply and very truly; . . but I confess I should really be at a loss to explain... what he considers ats a quantity of electricity, and why such a quantity is constant, like that of a substance." And further on he silys: "If we accept the hypothesis that the elementary sulustances are eomposed of atoms, we cannot avoirl concluding that electricity also . . . is dirided into definite elementary portions, which behave like atoms of electrieity."

Besides the phenomena of chenical decomposition, there was another very large and imprortant class of phenomena which gradually led up to the conception of the substantial and atomic nature of electricity. This province of independent, and for it long time isolated, research was opened out ly the combined genius of Plicker and Geissler. It was in the rear 1857, two years before the annomeenent of the discovery of spectrum analysis, that Pliteker, with the 
aid of the now well-known vacuum tubes of Geissler ${ }^{1}$ of Bonn, began that long series of experiments on the discharge of electricity in rarefied gases, on the influence of magnets upon the course of the luminous rays, and on the spectra of incandescent gases, which subsequently, in the hands of Sir William Crookes ${ }^{2}$ in this country, of Hittorf, Goldstein, Elster and Geitel, and of Giese in Germany, and of a great number of other natural phil-

1 See the Memoir of Plucker in the "Annalen der Physik und Chemie' (1857); "Ueber die Einwirkung des Magueten auf die elektrischeu Entladungen in verdiinuten Gasen" (reprinted in 'Gesammelte wissenschaftliche Abhandlungen,' vol. ii. p. 475 , \&c.) Before Plïcker took up the iuvestigation with improved means of exhaustion (later perfected by the well-knowu Sprengel pump), several French experimentalists - notably Quet, Gassiot, and Abria-had independently marked the difference of the light near the positive and negative poles, mostly in ignorance of the observations recorded by Faraday in his early "Experi. mental Researches," as far back as 1838 , referring to the " dark discharge." Lord Kelvin, in his Presidential Address before the Royal Society (November 1893), refers to the researches of Faraday, and to a long list of entributions to the same subject contained in the Proceedings and Transactions of the Royal Society. Except those of Faraday, they are all later than Pliicker's earliest papers. Lord Kelviu himself says : "Fifty years ago it became strongly impressed on my mind that the differ. ence of quality between vitreous and resinous electricity, . . essentially ignored as it is in the mathematical theories . . . with which I was then much occupied (and in the whole science of magnetic waves as we have it now), must be studied if we are to learn anything of the nature of electricity and its place among the properties of matter." Cf. the words of Hit. torf (Pogg. 'Ann.,' vol. exxxvi. p. 1), quoted by Rosenberger, 'Geschichte der Physik,' vol. iii. p. 778.

2 The experiments and discoveries of Sir W. Crookes on "Radiant Matter," beginning with his paper in the 'Transactions' in December 1878 , and continued in many subsequent communications, as also in his Address before the Brit. Assoc. in 1879 , especially his theoretical explanations based upon conceptions taken from the kinetic theory of gases, made a great sensation and led to much discussion in this country and abroad. The term Radiant Matter was arlopted from Faraday (see Rosenberger, loc. cit., vol. iii. 1) 779). The corpuscular theory of light was not indeed revived; but in general, after much criticism, Crookes's views have to a large extent been adopted; and if not the corpuscular theory of light, certainly that of electricity has been greatly supported by these brilliant experiments. See J.J. Thomson in the Princeton Lectures (1898), p. 189 sqq., aud Prof. Kaufmann's Address, delivered at the Hamburg meeting in September 1901 (translated in the 'Electrician' of November 8, 1901). 
osophers, revealed a large array of strange and stirtling phenomena, which have batterly heen brought sonnew hat into line and order by the researches of Prof. I. J. Thomson, ${ }^{1}$ of Cambridge. A great sumy half-forgottent facts and experiments, which did not fit into the regulin programme of electrical science or pritctice as it harl heen elaborated by the older doetrine of Comlonls and Weber on the one side, or by the more mortern of Faralay and Maxwell on the other, were collecterl and shown to throw quite a new light on the processes of ruliation and electrification, and on the relations of the atoms of ponderable matter to the vacmum, now looked upon is filled with a continuous substance, viz, the ether: The older views of the two electricities, bronght hefore the eye by the celebrated figmres of Lichtenluerg: ? many isolated facts connected with the electric spark and statieal electricity, such as were collected by liiess seventy years ago, or demonstrated in the hydro-electric machine of Arnistrong; theories, many times abandoned

I Impressed with the importance which attaches to the phenomena in question for a further development of the theory of electricity founded by Faraday and Maxwell, Prof. J. J. Thomson, in his 'Researehes, published in 18.43 as a sequel to Maxwell's great treatise, devoted a long ehapter to "The J'assage of Electricity through (Aases." Hi.s own celebrated eontributions to this subject, after having been published in the "Philossmlieal Magazine, and brouglit before the Jover Ineeting of the Jritish Asfociation in 1599 , are now summariserl in his lectures on "The J)ischarge of Electricity through ( 'ases" (1895). A very intresting carlier summary of the resenrehes of others as well as of their own by Flster and (ieitel, will be fouml in the 'Annalen der P'iysik' (1sas), vol. xxxvii. 1) 31 s sq\%.

"Whilst the diflerences leswern the divelarges from the positive and negative temomals, ater having for a long time heon lookinl upm as isolated curiosities of electrical science, were being taken up aut studied in commertion with the subject here referreel to (son. J. J. 'Thomson, 'Researches, P. 17:2s\%\%.', loord Armstroug, during the paset ten years of his lont and reventinl life, earricl an a suljes of experiments on a large seralt, aml with very jwwerful ifecenlly elesigmer apparatum, on 'Electrient hinchage

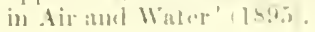


and as often revived, like that of Prout, ${ }^{1}$ on the constitution of matter; the fanciful speculations of Zöllner, based upon the views of Wilhelm Weber, - all these scattered fragments or glimpses of knowledge promise at the end of the century to come together into a consistent theory of the nature of electricity as an atomically-constituted substance which is associated with particles of ponderable matter, or may even be the ultimate constituent of such matter itself. When a large mass of experimental facts and many lines of special reasoning gradually converge towards a common view, two things are indispensable in order to weld them into a consistent whole, viz., a new name or rocabulary and an hypothesis as to the elementary processes which will allow of a simple construction and subsequent mathematical calculation of the more complicated phenomena of actual experience. In the case before us, both

1 See the concluding chapter of Prof. J. J. Thomson's 'Discharge of Electricity through Gases' (especially p. 197 , \&c.), where, after discussing Goldstein's "ether" theory and Crookes's "corpuscular" theory of the nature of the celebrated cathode rays, he, mainly on the strength of his own and Lenard's observations and calculations, inclines towards the latter theory, conclud. ing that the carriers of the negative charges of electricity "are small compared with ordinary atoms or molecules, . . this assumption being consistent with all we know about the behaviour of these rays." "It may," he continues, "appear at first sight a somewhat startling assumption in a state more sub. divided than the ordinary atom; but a hypothesis which would in. rolve somewhat similar assumptions -namely, that the so-called elements are compounds of some primordial element-has been put forward from time to time by various chemists. Thus Prout believed that the elements were all made up of the atoms of hydrogen, while Sir Norman Lockyer has ad. vanced weighty arguments founded on spectroscopic considerations in favour of the composite nature of the so-called elements. With reference to Prout's hypothesis, if we are to explain the cathode rays as due to the motion of small bodies, these bodies must be very small compared with an atom of hydrogen, so that on this view the primordial element cannot be hydrogen." See also Sir W. Crookes's protyle theory referred to, vol. i. p. 402 , note 2 . 
requisites were supplied before the cluse of the century. Here and abroad, the term electron, introduced by 1) $\mathrm{l}^{\circ}$ Johnstone Stoney ${ }^{1}$ about ten years ago, has been genc1"- "electra, ally aceepted to denote the ultinate parti-le of electricity, the atom of electricity-positive or negativeof Helmholtz. Mathenatical theories have been worked out independently abroad by Prof. H. A. Lorentz ${ }^{2}$ of Leyden, and in this country by Dl. Joseph Lamur ${ }^{3}$ of Cambriilge."

1 Sce 'British Arsociation Report.' 1891, p. 57t, "On the Cause of Double Lines in Spectra," by G. Johnstone Stoney: "The lines of the spectrum of a gas are due to some events whieh occur within the molecules, and which are able to affect the ether. These events may be Hertzian discharges between molecules that are differently electrified, or they may be the moving about of those irremovable electric charges, the supposition of which offers the simplest explanation of Faraday's law of electrolysis. . . Several considerations suggest that the source of the spectral lines is to be sought not in the Hertzian discharges, but in the carrying about of the fixed electric charges, which, for convenience, may be called the electrons."

"Prof. Lorentz's principal writings are the two memoirs, "La Théorie électromagnétique de Maxwell et son Application aux Corps mouvants" (Leyden, 189.2), and "Versuch einer Theorie der electrischen und optischen Erseheinungen in bewegten Korpern" (Leyden, 1895). His first labours, indecl, go back to the year 1550.

${ }^{3} \mathrm{Dr}$ Larmor's principal publi. cations are, "A Dynamical Theory of the Electric and Luminiferous Medium" ('I'hilos. 'T'ransactions,' 1894);
Part ii., "Theory of Electrons," 1895 ; Part iii., "Relations with Material Media," 1898; and his Adams Prize lissay, "Ather and Matter, a Development of the Dynamical Relations of the Ether to Material Systens on the lbasis of the Atomic Constitution of Matter" (Cambridge, 1900). Dr Larmor's several shorter pajer. and addresses, to which I shall refer, are very helpful as intro. ducing one into this novel domain of science.

4 A little later than Lorentz and Larmor, Dr Wiechert of Kinnigaberg began (in 1896) a series of publications on the same subject, with the aim of making the Max. wellian conceptions more definite. With him, also, the problem narrows itself down to a reconciliation of the continuity of the ether with the atomic nature of ponclerable matter, and of the electrical charges attached to it. His views, (1). gether with a historical analysis of the latrours of his great predecessors, Coulomb, Ampere, Biot and Savirt, Neumann, Faraday, Maxwell (incluiling the formal simplifications introuluced into Maxwell's scheme by (). Heaviside, Hertz, and l'oynting), Yon Helmholtz, anil II. A. Lorentz, are very concisely set out in a memorial essay entitled "Ciruml- 
56.

The theory of Maxwell had not only failed to give a Difficulties Difficulties
of Marwell's definite meaning to the conception of a charge of elec-
theory. tricity; it had also, in the general term "dielectric," somewhat obliterated the clear distinction between empty space and space filled with insulating matter, such as air. Empty space, i.e., space devoid of matter, was supposed to be filled with some continuous substance, the ether, which was the seat or bearer of electric and magnetic actions, the electro-magnetic field. When the only clearly known property of this ether, the fact that it was the carrier of radiation or the luminiferous medium, was identified with its electro-magnetic nature-light being conceived to be an electro-magnetic disturbancethe new theory had to attack the great question of the relation and interaction of ether and matter, in which all the remaining problems of physical optics seemed centred. ${ }^{1}$ How was the electro-magnetic theory of light,

lageu der Elektrodynamik,' published on the occasion of the unveiling at Göttingen, in 1899, of the monument erected in honour of Gauss and Wilhelm Weber. It is interesting to see how, from apparently quite independent beginnings, and in centres far removed from each other, the ideas of the atomic nature of electricity have almost sinultaneously become crystallised, and have united themselves with the great experimental labours emanating from Plücker and Crookes to give rise, at the end of the century, to the modern theory of electrons.

${ }^{1}$ Oue of the most important of these problems is the question to wliat extent the ether takes part in the motion of ponderable matter through it. Astronomical aberration, discovered by Bradley, and easily explained by the then current projectile theory of light (see above, chap. vi. p. 10, note), has caused great difficulty to the undulatory theory, and even Sir George Stokes, whose ideas on the subject have, been very generally quoted and accepted, would, in his Burnett Lectures on Light (1883), say no more than that "according to the theory of undulations ... it is not inexplicable" (ed. of 1887, p. 25). That the electro-dynamic view of the ether should take up the problem was most natural, and the discussion of it is accordingly placed at the opening of Lorentz's memoir of 1895 ; the effect of the motion of the earth on optical phenomena having already been treated by him in 1887. Dr Larmor treats very fully of this subject in the first section of his 
or the wave theory of electricity, to deal with the linulslem of ether and matter? In this combined schem. what and where were the electric charges or mnits! Whist are 1. le tric: clisiren

On the Continent the labours of l'rof. II. A. lorent\% of Leyden, and the almost simultaneons memoir of Von Helmholt\%, approached this subject from the side of certain optical problems, notably the vexerl question whether the luminiferous ether is stagnant, or participates in the movenents of ponderable matter through it, and the phenomena of dispersion. These writings have formed the begimning of a long series of therretical and experimental researches, which are by no means concluded. In this country we must chiefly consult the many and highly interesting witings of 1$)_{1}$ limmor for a fundanental discussion of the numerons problems involved. At the same time we find there at very thorough criticism, appreciation, and embodinent of the many scattered suggestions and eontributions of Finglish and Continental thinkers. 1)r Lamor starts from a begimung which is peculial to him. He finds amono In Laruor's the older theoretical discussions of the nature of the luminiferous ether one ${ }^{1}$ which will permit of such an

essay "On Lther and Matter," and IV. Wien has quite recently introduced it for discussion at the "Deutsche Naturforscherversammlung" (Duisselkorf, 1895, bericht i. p. 49). On the occasion of this discussion, Prof. Lorentz said : "Fither, pouclerable matter, and, we may say, electricity, are the builking stones out of which we compound the material world, and if we only knew whether matter, in its unotion, carries the ether with it or not, a way would have opened by which we could pen- etrate a little deeper into the nature of those building stones and their mutual action" "loc, cil., 1). 5 ).

The historical trulitions of $\mathrm{J} / \mathrm{r}$ Larmor's theory seem to lie in what may be called the loublin school of mathematical physics, with the great names of Rowan Hamilton (vector analysis, MacCullagl, and, in recent times, the much lamented G, F. loitygerald. "The form under which the atomic electric theory is introducen in $1 \%$ lammon intert exwit 
elaboration as admits on the one side the Maxwellian definitions of the propagation of electro-magnetic waves, and on the other the definition of electrons as permanent but movable states of twist or strain, which form the atoms of electricity, and possibly, in their aggregate, ponderable matter itself. The history of thought is mainly interested in this latest and most comprehensive "theory of the electric and luminiferous medium," because it is almost entirely based upon that great advance in physical theory which we owe to Helmholtz and Lord Kelvin, "the discovery of the types of permanent motion, which could combine and interact with each other without losing their individuality, though each of them pervaded the whole field." This has rendered possible an entirely new mode of treatment, ${ }^{1}$ and at least made thinkable the reconciliation of the two apparently contradictory notions of modern physics, the continuity and uniformity of the allpervading ether and the discontinuity of the embedded particles of matter and electricity. The history of thought also takes further note that these latest and yet unfinished theories revert, after the interval of thirty

originally presented itself . . . in the course of an inquiry into the competence of the æther devised by MacCullagh to serve for electrical purposes as well as optical ones" ("Ether and Matter,'p. vi.) "No attempt was made to ascertain whether MacCullagh's plenum could, in addition to its vibratory functions, take up such a state of permanent strain as would repre. sent the electrostatic actions between charged conductors, or such state of motion as would represent the electro-dynamic action between currents. The first hint on this sicle of the matter was Fitzgerald's passing remark in 1880 ('Phil. Trans.," "On the Electro-magnetic Theory of Light"), that MacCullagh's optical equations 'are identical with those of the electro-dynamical theory of optics developed by Maxwell" "(p. 78).

1 See Lar'mor's Address to the British Association at Bradford ('Report,' p. 624). 
years, to the older and apparently abandoned views comtained in the writings of Wilhelm Weber, who deale with electric particles and their actions at at distance. 'The chasm has been bridged ovel by such theories as those of Lorentz and Larmor, and the missing link supplied which prevented Gauss ' from accepting that theory when it was first communicated to him ly its author: 2

1 See above, p. 67, note, where Gauss's letterisquoted; also Larmor, loc. cit., aud '. Ether and Matter,' pp. 22, 72 ; 'Philos. Transactions,' vol. clxxxvi. (1895), p. 726 ; H. A. Lorentz, "La Théorie électromagnétique de Maxwell,' 1892, p. 71: "OOn voit donc que, daus la nouvelle forme, la théorie de Maxwell se rapproche des anciennes idces. On peut même, après avoir établi les formules assez simples . . . regarder ces formules comme exprimant une loi fondamentale comparable it celles de Weber et de Clausius. Cependant, ces équations conservent toujours lempreinte des principes de Maxwell." Further: Lorentz, 'Versuch einer Theorie,' \&c. (1895), p. S: "In general there lies in the assumptions which $I$ make in a certain sense a return to the older electric theory. The kernel of Maxwell's views is hereby not lost, but it cannot be denied that with the assumption of ions we are not very far removerl irom the electrical particles with which one operated formerly." Wiechert ("Grundlagen ier Flectrodynamik," 1. 108) expresses himself similarly. Lastly, I may refer to Prof. Kautimanis very interesting Address delivered at Hamburg, septemher 1891, translated in tlsc 'Elec. trician" November 1901, p. 95 sq7.) bo we may purhaps say that as Larmor attaches himself to the tratitions of the Inblin schors,
Lorentz and other continentisl representatives of the atomic view attich themselves to the schoul of Gauss and Weber. In prow that Weler's ileas never died out in the Guttingen school, see Riecke's liloge of Weber, Göttingen, 1597, 1. 27, and a very significant remark in the verdict of the philosophical faeulty on Planck's P'rize Essay ('1)ie Erhaltung ler Energie,' $1887, p .10)$.

$\approx$ it would be unjust to dismiss this subject, the overwhelming importance of which becomes erident if we glance at the many contributions which fill the third volume of the "Rapports présentés au Cungrès International de Physiffue' (Paris, 1900), without stating that the atomic theory of electricity mut only furnishes the very keystone which Gauss was looking fur sev. enty years ago, but that it lias also stood the test of experimental verification in the observation ly Keemanu of the effect of mangetisin on the rays of light, an eflect which Faradar sought for in vain about the time when Gaun was in search of the keysune of electrodymanics. A very concise and interesting account of \%eemann's phenomenon will be forme in .11 . A. Cotton's monograjh "le P'hen. omine le "eemann" "Scientia," l'hys. Mithem, l'aris, 15!9): "Comment II. Keemann a-t.il "u l'idée distulier swee un appareil de pularisution la lumière énise 
59. Objections raised by atomists.

The propounders of this atomic view of electricity very naturally look with little favour on those other theories which, under the name of energetics or phenomenology, would restrict the method of science to the use of only such quantities and data as can be actually seen and directly measured, and which condemn the introduction of such useful conceptions as the atom, the electron, and the ether, which cannot be directly seen and can only be measured by indirect processes; and there is no doubt that the century ends with a very emphatic assertion of the rights and the legitimacy of the atomic and mechanical views of nature, regarding the energy principle as a regulative but not, by itself, a constructive method of research and progress; for, as Dr Larmor says, "If a molecular constitution of matter is fundamental, energy camnot also be so." ${ }^{1}$ Nevertheless, though in many ways opposed, the two views of nature meet at least in one important point. Both theories have been

dans le champ magnétique? Ici encore, la théorie vint aider l'expérience; cette fois, c'est à $H$. A. Lorentz que l'ou est redevable du résultat obtenu. Il est juste de dire que d'autres considérations, par exemple celle de Lord Kelvin" (see Tait, Proc. Royal Soc., Edin. burgh, 1875-76, p. 118) " auraient pu, elles aussi, probablement conduire à cette découverte de la polarisation des raies. Mais en fait, cette découverte a été faite grâce à l'intervention de la théorie des 'ions' de H. A. Lorentz. Dans cette théorie, dit $M$. Zeemann, on admet qu'il existe dans tous les corps de petites masses électrisées, ou 'ions,' dont les mouvements constituent tous les phénomènes électriques; les vibrations lum. ineuses seraient des vibrations de ces ions. L'état de l'éther est déterminé entièrement par la charge, la position et le mouvement de ces ions. ... M. Lorentz fit remarquer que les bords des raies élargies devaient être polarisés. L'expérience permit à Zeemann de vérifier cette conclusion de Lorentz" (p. 37).

1 'Ather and Matter,' p. 286 : "One effect of admitting a molecular synthesis of dynamical principles... is to depose the conception of energy from the fundamental or absolute status that is sometimes assigned to it. . . We can know nothing about the aggregate or total energy of the molecules of a material system, except that its numerical value is diminished in a definite manner when the system does mechanical work or loses lieat. The definite amount of energy that plays so prominent a part iu mechanical 


\section{ON THE PHYSICAI, VIEW OF NATLLE, 199}

forced to consider anew the ultimate frinciples of all physical reasoning, notably the senge and validity of the Newtonian laws of motion and of the conceptrions of foree and action, of alsolute and relative motion, as defined or implied in the mechanical schenn. which is hased upon them. Also with their increasing connplexity ${ }^{1}$ modern lymanical explanations lave undoubledly, to every impartial observer, acquired it certain character of artifieiality which sugrgests the question to what extent all such meehanical sehemes are an explession of actual truths or merely useful illustrations. For the pursuit of scientific researeh this question is perhatps of little importance: a methol is a correct one if it leads to correct results verified by olservation. Pliilosophieally, as bearing upon the processes, pwwers, and limits of human reasoning, the question is all-important. We are thus led beyond the province of seientifie intu that of philosophie thought. In future elapters we shill The jlinilo. siphic prob. lem raised. frequently have oecasion to note this tendency of the purely seientifie thought of the eentury to leat up to philosophical problems. Wherever this is the caste at history of scientifie thought may legitinately elose me of its chiluters.

and physical theory is really the uechanieally arailable energy.

This energy is definite, but is not, like matter itself, an entity that is conserverl in unchanging amount. ... It may and usually does diminish, in the course of gralual physical changes."

i The three volumes of the 'Rapports,' ke., mentioned ahwe, have been significantly profiaced ly a diseourse of M. Poineare on the relutions of experimental and ma. thematical plysics, in which he inbists upm the unity and simplicity of nature as the two comlitions which make generalisations jussible and useful. With special relerence to undern eleetrical therries, such as those of Loreutz andl armur, which he hal alrealy criticined in his course on 'Electricitu' at () prtiejue' (2nd exl., 1901, 1. $57 \%, 80$, he discusses the prosibility of ultimate mechanical explanutions. of these, arconrling to his view, an "infinity" is alwavs pumaliles. Ho asks what is the aim we are inllow.

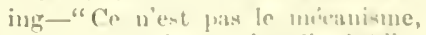
le vais, le reul int, cot l'unit:."
Arthos. clastaverer of unsderia ¿ynanices! "xplatua liuns. 


\section{CHAP'TER VIII.}

ON THE MORPHOLOGICAL VIEW OF NATURE.

1. THE different aspects of nature which I have reviewed The abstract sciences. $\quad$ in the foregoing chapters, and the various sciences which have been elaborated by their aid, comprise what may appropriately be termed the abstract study of natural objects and phenomena. Though all the methods of reasoning with which we have so far become acquainted originated primarily throngh observation and in the reflection over things natural, they have this in common, that they-for the purpose of examination-remove their objects out of the position and surroundings which nature has assigned to them: that they abstract them. This process of abstraction is either literally a process of removal from one place to another, from the great workand store-house of nature herself, to the small workroom, the laboratory of the experimenter; or-where such removal is not possible-the process is carried on merely in the realm of contemplation : one or two special properties are noted and described, whilst a number of collateral data are for the moment disregarded. In the former case, it is by a process of actnal or physical, in the latter by one 
ON THE MORPHOLOCIEAL VIEW OF NATURE. ¿OI

of purely mental, abstraction that our study Leugins and is prosecuted. One very powerful instrunum wi riseareh, where through size and listance-he they very great or very small-objects of nature are beyond our actual reach, is given us in the diagram and the modul. There we, for the sake of study, picture or initate on a relueed or an enlarged scale the movements of the heavenly bodies which are too large or of the atoms which are too small for our actual grip. Now and again the natural philosopher who thus uses the alstraet methods of experiment, registration, and calenlation, is forcibly reminded that he is in danger of dealing not with natural, lut with artificial, things. Instances are plentiful where, through the elaboration of faneiful theories, the connection with the real world has been lost and seientifie reasoning has been led astraty, to be recalled to a more fruitful path only by the effort of some original genius living in immediate communim with the aetual world.

There is, moreover, in addition to the aspect of convenience, one very powerful inducement for seientitic workers to persevere in their process of abstraction, in the study of such things and phenomena as can le handled in the laboratory and the workshop, and studied by diagram and by molel. This is the practical usefulness of such researehes in the arts and inchustries. In these we do actually abstract the possessions of nature from their proper hiding-platees: we drag the minerals from the bowels of the arth: we cut up the tiunture of exotic growth into artificial framents: we break up that natural eyuilibrimu in which electrical and 
chemical agencies have, for thousands of years, evaded our discovery and our regard. Having done so, we create an artificial world of our own making which ministers to our wants, comforts, pleasures, and supplies that most inestimable of all commodities of civilisation, varied and stimulating work for ready hands and active brains. The wants and creations of artificial life have thus proved the greatest incentives to that abstract and artificial treatment of natural objects and processes for which the chemical and electrical laboratories with the calculating room of the mathematician on the one side, and the workshop and factory on the other, have in the course of the century become so renowned. All this great activity is-as I have abundantly shown-more and more governed by the scientific, the exact, or the mathematical spirit.

Interest opposed to the spirit of abstraction.

There is, however, in the human mind an opposite interest which fortunately counteracts to a considerable extent the one-sided working of the spirit of abstraction in science and the growing tendency towards artificiality in our practical life. This is the genuine love of nature, the consciousness that we lose all power if, to any great extent, we sever or weaken that connection which ties us to the world as it is - to things real and natural: it finds its expression in the ancient legend of the mighty giant who derived all his strength from his mother earth and collapsed if severed from her. In its extreme and purest form this interest probably lies at the root of all poetry and all art, and it accordingly governs a great part of the literature and thought of the century. It will occupy us later on in our historical 
ON THE MORPHOLOGICAI. VIEW OF XATULF. $20:$

survey. At present it intrests us only ats fill as it asserts itself alsy in science. In the stuly wi natural oljects we neet with a class of students who inr attracted by things as they are: not so much by thuse which we artificially prepare in sur laboratories, as hy the infinite variety of real forms: not so unch ly the geometrical types which allow us to bring them together under some abstract formula, as hy the apparent disoriler and divine confusion in which real things are scattered about in the heavens and on our globe. It is nut the general equation which in its complete solution continims all real and many unreal instances merely as special cases that interests them, hut the individual exaluples themselves. The general laws of motion almit of an infinity of special cases which nay nevor oceur in mature: organic chemistry adds daily to the already enormums array of compounds which do not present themselves in living organisms. Clearly, besides the abstract sciences, which profess to introduce us to the general relations or laws which govern everything that is or can be real, there must be those sciences which study the actually existing forms as distinguished from the possible ones, the "here" and "there," the "where" and " huw", of things and processes: which look upon real things not as examples of the general and miversil, but its alone possessed of that mysterious something which listinguishes the real and aetual from the possilile and attificial. These sciences are the truly descriptive seiences, in opposition to the ithstract ones. "lhey are tivenenences. indeed older than the abstract scienees, and they hate. in the course of the period moler reviow in this work, 
made quite as much progress as the purely abstract sciences. In a manner, though perhaps hardly as powerful in their influence on practical pursuits, they are more popular; they occupy a larger number of students; and inasmuch as they also comprise the study of man himself, they have a very profound influence on our latent opinions, interests, and beliefs-i.e., on our inner life. It is the object of this and some of the following chapters to trace concisely the altered ways and means by which, in the course of the last hundred years, the study of the actual things and events of nature has been prosecuted. For those who wrote the history of the descriptive sciences in the middle of our century, the arrangement of this vast subject presented little difficulty. It had been in the main accomplished by the great naturalists who, during the seventeenth and eighteenth centuries, laboured to bring the large and ever increasing number of natural objects into some supposed system and some professed order, to enumerate them in catalogues or marshal them in museums. The familiar division of natural things into animals, vegetables, and minerals had received a general sanction. Separate sciences, with separate chairs at the universities, which still survive, attended to the separate treatment of these subjects. One of the greatest changes which the present age has witnessed has been 5. the breaking down of the old landmarks and of the ing down o old landmarks.

stereotyped divisions which existed in the beginning and all through the first lialf of the century.1

1 This change has also very much lessened the interest with which we now regard the solution of a problem which, down to recent times, was much discussed-the classification of the sciences. It will be seen that of the many principles of division which have been 
If we try to specify a little more alosely the argencies and interests that were at work in hringing alunt this very marked change, which, like every change of the kind, has been reflected by the altered vocalmblary of our languages, we come upon two distinet influences-

adopted, the present work unly retains that one principle which, in some form or other, appears in every attempt towarls classifieation-the difference between the abstract and the eonerete or actuil. The two original philosophical systews which France and England in the course of the century have produced, the positivist philosophy of Comte and the pliilosophy of evolution of Herbert Spencer, have both dealt elaborately with the problem of the clissification of the seiences. In this they betray their descent from the philosophy of Bacon and their practical tentencies. It is mainly in the interests of teaching that the division of the sciences is of importance; and so here it has proved to be indispentable, but also, not unfrequently, narrowing and harmful. German philosophers, who have generally been inore influenced by the traditions of Descartes, Spinoza, and Leibniz, lave attached less iumportance to the rigid divisions. The result has been that in Germany, more than in any other country, those modern seiences have grown up which eultivate the borterland that separates the existing wellmarked provinces which are artificially kejt up by the older chairs at the universities. Examples of this are the new sciences of physiological psycholngy and of plyyical chemistry, both brilliantly and for the first time representerl at the university of Leiprig. The two great conceptions, however, which have probably done more than any others to break down the old conventional landmarks that kejt the sciences asumcler, the concep. tion of energy and the inlea of ile. scent, were tirst prominently put forward in this country. The classical treatise on the division of the seiences in the widest sense is the 'De Augnentis Scientiarun' of Lord Bacon. An important and original work on the suljeet is André Marie Aupère's 'Fssai sul" lik Philosophie tes seiences, ou kx. position analy ticjue d'une Classifica. tion naturelle de toutes les Con. naissances liumaines' (1534). An analysis of the book is given in Whewell's 'Philosophy of the In. ductive Seiences,' vol. ii., liouk 12. Ampere's classifieation, on the model of that in botany, is symmetrical and tichotomous. Aug. Conte's elassifieation, contained in the second "Lecon" of the 'Cours de Philosophie pusitive' $(1530$, vol. i. ), is termet by its author "une échelle" or "une hiér. archie eneyclopétique." Mr. IIerbert Spencer, in an essay 'On the Genesis of Seience' (1854), rejul,lished with adclitions in the third volume of his 'Essays' (187.), criticised Comte's attempt to classify the seiences "serially." He more than any other thinker lias assisted in breaking down the older idea, which was very prominent iu many elassi. fications of the great lirench natur. alists, the irlei of the subordin. ation of things in nature, of the "échelle des itres," and the enresponding conception of an hiernechy of the seiences. In the place of this serial arrangenent, at genenlogical arrangenent, unter the specific term of evolutinn, was in. troduced, and the sorenes were co-orlinated according to their 
one of which has tended enormously to broaden our view of natural objects and events; the other to narrow it down and make it more definite, scientifically accurate, and precise. The former has tended to sweep away the older landmarks and divisions as inadequate to afford us a correct view of nature; the latter has tended to create new divisions and definitions, more in harmony with the lines on which the abstract sciences of physics and chemistry have been dereloped, and has thus brought the actual objects and erents of nature more within the grasp of those exact and mathematical 6. methods which those sciences have perfected. The former The spirit of exploration. has been carried on in the rast workshop of nature herself by those daring and far-seeing travellers who, with Alexander von Humboldt at their head, hare attempted to gain a view of nature on an extensive scale. For the sake of the increase of natural knowledge alone, they visited distant countries where the elemental forces of nature, undisturbed by the inroads of cirilisation, have battled and co-operated to produce the magnificent thoras and faunas of the tropics, or where, as in Siberia, the eternal cold has preserved intact the remains of brgone periods. Equipped with the instruments and methods of modern science, they recognised the necessity of studying the actual formation and stratification of rocks, the geographical distribution of organic life on the surface of the

genesis, the three great dirisions being the abstract, abstract-concrete, and concrete sciences. MI readers will readily see the similarities and the differences which exist between this classification and the more general dis- tinctions which I have adopted; and $I$ remind them again that I am not writing a history of Science but of Thought, and that all dirisions of this great subject are, more or less, arbitrary. 
ON THE MORPHOLOGICAL VIEW OF NATTMk. 2廿

globe, or in the depths of the vcean; of visiting the leal dwelling-places, the habitat of living beings: thus commteracting and enlarging the narrow and pedantiv: views which the older, purely systematic, and lifeless treatnent of natmal objeets was in danger of fosterims. We kmow how the germs of two of the gruatest generalisations of science were laid in the minds of Mayer and of lourwin during their visits to distant comntries, and how fertile in natural knowledge of all kinds have been the voyuge of the Challenger and many other similar expeditions, and with what interest and curiosity scientific and popular audiences listen to the narrative of such rlaring explorers as Fridjof Nansen.

The other and much more concentrated influester, which from the opposite side co-operater with the laburs of the great explorers in remolelling the descriptive sciences and infusing new life and vigum into them, has been not less marked. There has always existerl one great interest, in whieh nearly all the deseriptive branches of natural knowledge bave found a common rallying ground and a uniting purpose-namely, the art of healing, the alleviation of hmuan suffering and

the euring of disease. During long ages, when the purely seientific interest was ahmost dead, physical and chemical research was created or liept alive by the physicim, the alchemist, and the apotlecary; medical works like those of Celsus and Galenus in antiquity ${ }^{1}$ have leen the rncy-

1 It may also be pointed out that Aristotle was descended from a fanily of doctors, that-according to Zeller ("Philosophie der Griechen,' vol. ii., part 2) - the ussumption is warranted "that the medical art of his iutler Nicomaclus, who was the menlical adviser and friend of the Macedonian king, Anynlas, lual is prominent intluence on the mental developuent of liiv sum." 
clopedias of the existing knowledge of nature, and celebrities like Boerhaave, Linnæus, and Haller in more modern times have been the living centres of all the natural sciences. The same uniting bond has not been wanting in our century, when it has again, as many times before, manifested its powerful influence, has brought together researches which were on the point of falling asunder, and infused new life and interest into the driest of studies. As I have had occasion to remark above, the modern school of medicine originated in the attempt_-begun by Lavoisier in France, but carried out on the largest scale in the chemical and physiological laboratories of Germany-of making the new discoveries

Physical science applied to medicine. in physical science and chemistry fruitful for medical purposes and the treatment of pathological cases. The discovery of galvanism gave probably the earliest impetus, and was, to the discredit of an exacter treatment, largely misused in the earlier part of the century, till Du Bois Reymond, in the middle of the period, based his elaborate researches on more correct methods, and created nearly all the knowledge we now possess of the electrical currents in the nervous system. Somewhat earlier, Liebig led the study of the phenomena of animal heat and of the food relations of the animal and vegetable kingdom; the brothers Weber had introduced dynamies into the theory of the motion of the heart and the limbs; whilst Johannes Miiller and his numerous school about the same time laid the foundations of physiological and pathological acoustics and optics. Quite independently of these applications of the mechanical and physical sciences, which led some over-hastily to imagine that in the doctrine of the 
ON THL MUIPHOLOGICAL VIFW OF NATLRL. ¿U!?

organisul as a pult machine lay an answer to the gluat problems of life and conscjousness, 'Theoulor seluwamu proclaimerl about $18+0$, on the bisis uf minute mineroscopic observation, the essential irlontity of animal and vegetable-i.f., of all living-structure, thus tisking probably the zreatest step in miting researches which had so far been carried on in it diseonnectod tashions. Here is the beginming of the norleren theory of the. organic cell-of cellular pathology, and the atetual inaugnuation of nodern biology. 'Twenty years later, the appearance of Darwin's 'Origin ut Nipecies' Irecerl still further the sturly of the whole of oromic life firmu a comprchensive point of view. ln achlition it leal to at closer union with the scicnces of inmernic natur, an appeal being now marle to palirontulogical and goolongical records in prouf of the gratual clevelupment of all torns. of living as well as of inamimate reality. The sturlies of the geologist, which up to then had heen prosecutarl on independent lines, joined hankls not only with those of the zoologist and botanist, but likewise with the theory of cosmological genesis of the planetary systen, as proclaimed at the end of the former century ly Laplace in his ' Exposition du systeme du Monde', and fifty yrars earher by Kint in his "Natural llistury of the Heavens.' If in the course uf unt century, through the combincel influence of travel an the one side and medicine on the other, the history ul naturil objerts has been united in the langer conception ot hiolourg, this itself at the close of the century promises to he moited with geology and astro-physics (a science almost entirely foumbled on the invention and on the revalations of the VOI. II. 
spectroscope), into the still wider conception of a general science of evolution, as enunciated already forty years

11. ago in the writings of Herbert Spencer, and in a more Hepencer. shadowy form by Herder in the eighteenth century, and by Leibniz in the seventeenth.

Seeing, then, that the treatment of the descriptive sciences of nature has been so radically changed during the course of the century, and that the change has been accompanied by a complete revolution in our modes of thinking and reasoning on these subjects, the historian of Thought cannot be content with merely chronicling the progress of the methods in use in the separate sciences, such as mineralogy, geology, botany, and zoology, even with the addition of the more recent sciences of palæontology, physiology, and comparative anatomy. $\mathrm{He}$ might in doing so fairly grasp the history of the descriptive sciences up to the year 1850. It is exactly in this

12.

Whewell's divisions abandoned. mamer that Whewell, in his 'History of the Inductive Sciences,' treated this part of his subject. Beyond that period the old landmarks designated by those names have disappeared or become of secondary importance. On the other side, whilst a history of Evolution in Science might seize on the great characteristic feature of the more modern research which belongs to the second half of the century, it would hardly suffice to sum up the leading ideas of the descriptive branches of science as they were carried on on independent lines during the earlier years of our period. Evolution had then no definite meaning, and Biology was a disregarded term. We must thus look out for some more general aspects which belong alike to the earlier 
ON THE MORPHOLOGICAl, VIEW UE NATURE, 211

and later periorls, and which will cuable us to sere how that great ehange has gradually comese about.

All studies that deal with the actual things and events by which, on a large and on a mimnte scale, wo are surromuded in nature, are comprised miler the term Natural History. In opposition to Natmal Philosophy, which comprises our abstract knowledge of the possible forms of motion and the possible combinations of the elenents intu which we have so far heen able to decompose matter; Natural History deals mly with such forms ancl combinations as aetually exist around us, only with such processes of ehange as aetually take place in nature. Some of these forms and ehanges we may be able to collect in our musems or imitate in our laboratories, but the forms of nature eamnot in this way be exhausted, nor hel processes understood. Her forms or things do not exist in isolation, but always in a eertain enviromment, having a definite plan, a position in time and space. 'These surromuling features are as important as the things thenselves. Besides this, the proeesses of nature draw on the great factor of time with a much more liberal hand than we ean permit ourselves to do. Nevertheless, as in the abstrat sciences we deal with things at rest and with

things in motion, so we can appropriately divicle mu listury. study of the real and the actual into the attempt in give some aceount of the forms and things which actually exist and continually reeur, and the study of the changes which things metergen. In abstract science the terms staties and dymanics, the doetrines of rest and of notion, have been generally introluced, to distinguish the two great aims of sturly: some cur- 


\section{responding terms may appropriatels define the trofold} interest which we take in natural objects. The term morphologr $y^{1}$ was introduced early in the century by

${ }^{1}$ The term morphologt was in. troduced br Goethe to desne a series of researches and stuoiles to which he was led br his equal interest in art. nature, and human societr. Returning irom Italr. which he describes as "rich in forms." to Ger. many. which he term in contrast "gestaitlos," he reports that three distine: problems had presented themselres. "Wie die beg instigte griechishe Nation reriahren um die hüchste Kunst im eizenen Nationaltreise zu entrickeln. ... Tie die Natur zesetzlich zu Werke gehe. um lebendises Gebild, als Muster alles sinstlichen, herrorzubringen. . Wie aus dem Zusammentreffen ron Nothweydigkeit lind Milltir. ron Antrieb und Wollen, Toב Bewecung und Widerstand ein drittes hervorgeht . . . die mensch. liche Gesellschait." For the pur. pose of inding an answer to the second of these questions, Goethe collected and oteerred, read and speculated. and iormed the cunception of a reneral science of organised beings termed morphologr: which was not to treat merels of external fyure, but to comprise also Fhrsiologrand the sudy of derelop. ment. It is the frsi great attemp: to thint of nature as a whote and to break domn the rizid lines which dirided the sereral natural sciences. He thus inaugurated the molern view of na:ure by introdicing the seneral science of morpholozs. His trst literary attempt in this direction was the nom celebrated pamphlet on the "Metamorphosis of Plants, in which he represents the leat as the irpical formation from which the other parts of the plant can be derired. Whether this derivation is a real froces in the sense of modern erolution, or a merels ideal one in the sense of the earlier archetrpal riem, Goethe does not clearls say. This uncertaints Goethe share: with the whole school of the " "Saturu hilosophie, " as Julius Sachs points out in his "History of Botany German edition. 1575. p. $170^{\circ}$. This is not the point to which I want to draw sitention at present. More imfortant is the remark which Goethe mates in the further historical accoun: of the gradual derelopment of his morphological ideas. Wolt, the philologist, pointed out to him that his own nameasie, Caspar Friedrich Wolf. had anticipated Goethe in the attemp: to demonstrate the funda. mental idertity of the different narts of a plant. In the sequel of his most appresiative analrsis of Wolf" s espositions, Goethe characteristically notes that Tolf does not include in his conception the "metamorphasis of animals." or introduces it only as something en. tirely dit"eren:" Tha: Goethe sides of morphologr as a reneral science ot the forms and change of forms in nature is applicable likewise to in. animate forms-to geological. geomaphical, and manr other formations. nar. eren to rigid things like crsstals, and to such unstabie for. mations as the parts of speech and lanzuage-has in the cotrse of the century been abundantly renc: nised. It is known kow. guided by the same general interest. Goethe studied the formations and transformations of anima!s. rocks. and clouds. though. according to Zittel

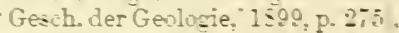
C. F. Yaumang trst used the eIpression, " mortholory of the surtace oi the earth." in 1550. Guethe"s 
one who loved above all things to watch the works wi nature in their proper alodes-who conthinel the puntcal with the scientific interest,_ly Gothe. The tomn grenesis 1 has long been employed to describe the froscesses hy which the actual worlel has conte to be what it is. To the statical and dynanical aspects of the abstract sciences correspond accordingly to sone textent the morphological and genetic aspects of the natural seiences. 'To some extent only, for' in nature, where

It. Morpholory atril seneties. everything is sulpject to contimual How, we never ante upon a realisation of absolute rest, a pure form, a rigid type. Rather would I put it in this way: In the perpetual variety of change the morphological view tries to define those recurring forms or types which present themselves again anil again, towarls which all changes seen to revert: tlums lminging some orilel intu

morphological writings have been for the first time completely edited and auuotated in the three volume. (6) to 8 ) of the second division of his works now being published by the Goethe-(iesellschaft at Weimar. The authority whom I approach nearest in the use I make of the term morphology is probubly Haeckel. See the first look of his "Generelle Morphologiecler Urganischen Wesen' (1866, vol. i. pp. 1-10s).

I Goethe's norphologieal sturlies were equally directed towards the iurmation and the transforulation of living things: morphology was to hin the science of "Bildunn und Cmbildumg." In the course of the century tlie terms norpholog: and morphological school have cone to mean more and more that cous. llex of comparative researches which historically preparen the genetic, develoymental, or evolutionist sehool of thought, but which were mainly dominated hy the conception of fixed types and forms, and, though searching for the law: of modification, dicl not rise to a clear enumciation of a theory of erolution and descent. Goethe him. selt hovered all his life loug between au artistic predilection for the perfect form or model and a decper philosophical conviction of the continual flow of things. See a remark of his ('Werke,' I1., vol. vi. 1'.304) in an apllorism on "genetic treat. ment" : "Erst bin ich greneigt mir gewisse stuien zu denken : weil aber die Satur keinen sprung macht, bin ich zuletzt genuthigt mix die Folge einer ununterbrochenen Thiitigkeit als ein Ganzes an\%usehauen, indem ich das Einzelne aufhebe, olsme den Eindruck zu zerstiren." See alsu a remark (n) Goethe's unlofinet prosition in Ciurus, 'Geschichte der 'ooulurie' (1572), 1). 590. 
what would otherwise be disorder and confusion. On the other side, the genetic view deals with the transition from one form to another in the course of time; takes more interest in movement and in the process and function; and seeks for their probable laws and regularities. Without wishing to limit these remarks to merely organic or living things, the difference between the morphological and genetic views can be brought home to the mind by referring to the different objects of anatomy and physiology. ${ }^{1}$ This twofold and very general aim-the desire to know what is, and how it has come to be-has existed at all times, though frequently obscured by artificial and temporary restrictions. From this point of view I propose to survey the mental attitude of the century towards the real things and events of nature, as distinguished from the artificial or mathematical forms and processes of our studies and our laboratories, our calculating and measuring rooms. The

${ }^{3}$ Genetic theories have everywhere been prepared and ushered in by morphological studies. So in Goethe's time; so later on, after Darwin had given a definite law of descent, and Herbert Spencer had fixed the vocabulary and ideas of evolution, this relation is manifested by two great works, the 'Generelle Morphologie der Organischen W' Wesen,' by Ernst Haeckel in Germany (1866), and Francis M. Balfour's 'Elements of Embryology' (1874) in England. It is characteristic that Prof. Haeckel, in the further development of his literary activity, dropped the term morphology, and published the desired new editions of his great work under two different titles, 'Natür. liche Schöpfungsgeschichte' (1868,
2 vols.), and 'Systematische Phylogenie ' (1896, 3 vols.) The division of the great modern biological doctrine into morphology and genetics is in conformity with Mr Herbert Spencer's treatment in the 'Prin. ciples of Biology,' vol. ii., published in 1865 , and with the two divisions of Haeckel's 'Generelle Morphologie,' which treated respectively of the "science of developed forms" and the "science of developing forms"i.e., of structure and process. I have chosen such expressions in the text as will permit of a coinprehension of inanimate as well as of animated nature. In 1875 there were founded simultaneously in Germany two periodicals, representing respectively the morphological and genetic sides of animal biology. 
ON THE MORPHOLOGICAL VIEW OF NATURE. 215

present chapter will deal with the morphohurical, the following with the genetic, views of nature. ${ }^{1}$

Were the real world only one out of many possible worlds whieh the mathenatical mind can inngine, though through its complication and intricacy it might still far surpass its powers of analysis: were the actual forms of nature only some of the infinitely possible states of equilibrimn, the events and changes surrounding us in space and time only a few of the comtless combinations of motion tanght in dynamies; were the actual eomse of things - as mathematicians since Laplace have fancifully put it-only one partienlar solution of the general differential equations of the world-motion, - then the two great domains of morphology and genesis would exhaust the subject and satisfy all the interests by which natural history has been ereated. Unfortunately for the pure mathematician, but fortmately for the rest of mankind, notably the poet and the artist, it is not so. An enormous gulf separates the ereations of nature from the most perfect maehine; and the fact that, with all the most delicate methorls at her command, her most perfect maehines, like the human eye, do not eome up to the demands of the optieian, ${ }^{2}$ shows us that other ageneies

I As in abstract mechanies, the sturly of the eonditions of equilibrium, i.e., staties, preceded in time the study of the phenomena of motion, i.e., dynawies, so in the study of mature the apparently finished or developed forms attracted attention before their genesis was infuired into; and as the key to staties has in the course of time been diseorered to lie in dynamies, so the key to an understanding of form and strueture has been found to lie in the dynamical theory of descent or evolution. In animal biology a separate intluence -the medieal interest-led, however, very early to a study of iunc. tion and of the processes in the living organism.

2 This refers to a well-known remark of Helmbolt\% in his populat lectures on the "Theory of light" (1868), where he emlarges on the remarkible inferiections of the eye as an optical instiument. His real 
and other interests are at work than we have as yet been able to grasp. So long as astronomy was content to observe the orbits and motions of the heavenly bodies from a distance, it indeed appeared possible to define that science as merely "une question d'analyse"; but in astronomy even, spectroscopy has brought distant objects near to us and opened out endless vistas into a purely descriptive branch of the science, a natural history of the heavens. Still more so is this the case when we fix our gaze on the world inmediately surrounding us-on the things and events in which we ourselves take an active part. Here two phenomena attract our attention

16.

Life and mind. - the problem of life, and the problem of consciousness or mind. The knowledge which we possess, or imagine we possess, of the latter, which is gained from a purely introspective point of view, the psychological aspect, I leave at present quite out of the question. As external observation through our senses would never have given it: as in the map of reality which we call nature, we have not even succeeder in accurately locating consciousness,-I relegate this large department of Thought to a different place in this work. At present we have to do only with the study of nature, the first condition of

object was to dispel the popular conception that the accuracy and variety of the performarices of the human eye could be explained by the precision and complexity of its structure, as if it were an optical instrument of a degree of perfection which could not be equalled by any optician. In the sequel Helmholtz shows how this admiration of a wrongly supposed mechanical perfection must make room for an admiration of a different kind, as "every work of the organic formative power of nature is for us inimitable" ; a remark which really supports the argument in the text ('Vorträge und Reden,' 3. Aufl. 1884 , vol. i. p. 240 , \&c.) It is also important to note how Helmholtz traces the imperfections of the eye to its genesis-i.e., its development in the embryo. The genetic supplements the purely structural examination (ibid., p. 255). 
ON THE MORPHOLOGICAL VIEW OF NATURL. „1T

which is that her phennnena have, or have at some time had, a definite place and position in space. Here, thrin, the phenomena of lower and higher life and the new creations of human culture, art and industry, open out it great department of reality which is accessible to external observation and study. Without committing omrselves to any theory on the subject, we have in this department to deal with the phenomena of apparent or real design and purpose. How has the century dealt with these phenomena? The answer to this question, the history of nineteenth century thought as directed towards the phenomena of life and of mint as natmral phenomena, will be dealt with in two further chapters, which will respectively deal with the vitalistic. and the psycho-

1 It would have been in some respeets preferable to use the word "biological" instead of ritalistic. In fact, in the original craft of this passage I used the former term. The reasons which made me ilter it are the following: The term biology was first used in 1 1801 by Lamarck in his ' Hyclrogéologie.' "Abont the sime time it oceurred to Treviranus that all those seiences which deal with living matter are essentially and funditnentally one, and ouglit to be treatesl as a whole: and in the year 1802 he published the first volume of what he also called 'Biologie.' Treviranus's great merit lies in this, that he workerl out his ifleat, and wrote the very remarkable book to which l refer. It eonsists of six volumes, and oceupied its author for twenty years - from 1802 to 1822. 'That is the origin of the term 'blology'; and that is how it hits come about that all elear thinkers and lovers of enn. sistent nomenclature have substituted for the old eonfusing name of 'natural history,' which has conveyed so many meanings, the term 'biology,' which denotes the whole of the sciences which rleal with living things, whether they be animals or whether they be plants." 'This extract from Huxley's "Leeture on the sturly of Biology" (South Kensington, Dec. 1876 , reprinter? in 'American Addresses,' \&c., 18s6, p. 129, se.), has inducer me to adolnt the term "vitalistic" to denote those duetrines and chapters in biology which deal sjecially with the principle and phenomena of life. A very large portion of biology deals with such phenomena of living things as can be studied without any reference to a doctrine or theory of life iu particular, they being either mere fitc $t$ s of distribu. tion or that very large and increasing elass of biological processes which admit of purely mechinical, physieal, or ehenical description and explanation. The very fact, low ever, that the question whether the principle of life is purely nechanical 
physical views of nature. Thus four distinct chapters, dealing severally with the morphological, the genetic,

17. Vitalistic and psychophysical aspects. the vitalistic, and the psycho-physical aspects of nature, will together attempt to describe the manifold and changing methods of reasoning by which our century has approached the actual things and events which surround us.

"Nature does not employ all figures, but only certain ones of those which are possible: and of these, the determination is not to be fetched from the brain, or proved a priori, but obtained by experiments and observations." These words, set down nearly two centuries ago by a now forgotten natural philosopher, ${ }^{1}$ express clearly the object of a study which, towards the end of the eighteenth century, had received definite expression in vari-

or not is not jet decided, makes it necessary to retain in a history of Thought a special term comprising all speculations which deal with the purely scientific solution of that problem. In fact, the question what is life is still unanswered. A fortiori, these remarks refer also to the question, What is mind or consciousness? But the two chapters referring to these problems will limit themselves to an historical exposition of what has been done to solve them by purely scientific, i.e., exact, methods. The full name of the author of the "Biologie" was Gottfried Reinhold Treviranus (1776-1837) of Bremeu. Though introducing the larger conception of biology, his own original labours were mainly in the domain of zoology. His brother, Ludolf Christian Treviranus (1779-1864), devoted himself mainly to botanical science, and was largely influenced by the doctrines of the "Natur. philosophie." On the former, see Carus, 'Geschichte der Zoologie' (Münchell, 1872), passim; on the latter, Sachs, 'Geschichte der Botanik' (ibid., 1875, p. 291).

1 They are quoted by Whewell ('Hist. Induc. Sciences,' 3rd ed., vol. iii. p. 165), from a work entitled 'Dissertatio de Salibus' (1707), by the Italian Professor at Padua, Dominico Gulielmini (1655. 1710). He was a practical plysician as well as a natural philosopher. He was the forerunner of Romé de Lisle and Haüy, inasmuch as he established the principle, not then sutficiently appreciated, that the constancy of the angles is characteristic of all crystals. See Kopp's 'Gesch. ichte der Chemie,' vol, ii. pp. 83 404. 
ous branches of natural science, and which can be best characterised by the term morphology. The word was first applied only to plants, then also to animals, and later still to erystals and minerals. The words quoted above refer to the forms of inamimate nature, to crystals. In all these cases we have to do with definite individual objects, which can be removed from their surromdings and examined in the laboratory. There is, however, 110 reason why a study of the actual forms of natme on a large scale, such as the physiognomy of landscape, the configuration of nomntains and valleys, the shapes of glaciers, the actual distribution of land and water on om globe, the stratification of roeks, the formation of clouds, and many other things, should not all be comprised under the term, the morphological view of nature. And conceived in this larger sense, the study of nature as a whole and in its separate parts had at the end of the eighteenth century already made very important progress. In fact, natural history had, in the course of that century, graclually emerged from the previous epoch, that of the purely systematic and classificatory attempts, which aimed at giving inventories, eollecting specimens, and classifying natural objects, naming, deseribing, and identifying them. The interest of the latter was a practical one, frequently

1 In the 'I eegons sur les Phénomènes de la lie communs aux Animaux et aux Végétaux,' is work which did so much to break down the older division of the scieuces which deal with animals and regetables separately, Clauile bernard says (p. 33:) of vol. i., 1855): "Dans un autre équilibre cosmique, la morploblogie vitule serait atutre. Je pense, en un mot, qu'il existe virtuellement dans lin nature un nombre infini de formes vivantes que nous ne connaissons pas. Ces lormes vivantes seraient en quelque sorte lormantes on expectantes. . . . II en est ninsi les corps nouvenux que forment les chimistes; ils ne les créent pas, ils étrient virtucllemsent posibles duns les lois de la nature." 
prompted by the needs of the medical profession, which studied animals as affording an insight into the analogons structure and functions of the human body; ${ }^{1}$ and plants, becanse they largely furnished the materials for the preparation of medicines. To this must further be added the practical interests of agriculture, of gardening, and of the artificial culture of flowers and exotic plants, and the breeding of domestic animals. All these interests, however stimulating they may have been and still are, introduce an element of artificiality into the study of nature. They have all a greater concern for natural objects, be they beautiful or useful, than they have for nature itself. From this artificial position the true sciences of nature had to emancipate themselves by slow degrees and with many efforts. Ever since the time of Limnens, through whose labours the systematic attempts received a kind of finality, and even in his own writings, great discnssions were carried on as to

19.

Artificial and natural systems. the difference between a natural and an artificial order of plants and animals. "The natural orders," says Limnæus, "teach us the nature of plants, the artificial orders enable us to recognise plants. The natural orders, without a key, do not constitute a method; the method ought to be available withont a master. . . . The habit of a plant must be secretly consulted. A practised botanist will

1 Referring to Albrecht von Haller, Victor Carus ("Gesch. d. 'Zoologie,' p. 567) says, "Through the leap which physiology took, thanks to his labours, zootomical researches developed in a direction which brought them into complete subjection to physiology, with a neglect of the independent importance which belongs to them.
It diverted attention from the $\mathrm{im}$ mediate object of zoology, the explanation of animal forms and their variety, to the more remote problem - the explanation of the phenomena of life.'

2 Quoted by Whewell ('Hist.,' vol. iii. p. 268) from the 'Genera Plantarum' (1764). 
ON THE MORPHOLOGICAY VIEW UF NATCRE, ¿21

distinguish at the first glance the plants of different quarters of the grolue, and yet will be at a loss to tell by what mark he detects them. There is, I know not what lonk-sinister, obscure, in African plants: supert, and elevated in the Asiatic: smonth and cheerful in the American: stmited and indurated in the Alpines." 1 The inventor of the sexmal system of plants, which prover to he such a good "finder" in the hands of the brotanist and herbalist, speaks of the difticulty of the task of discovering" the natural orders. "Yet," he says, "I, too, have labomed at this-have done something, have much still to do, and shall labour at the object as long as I live." -

Limneus's antificial systen met with little acceptance in France, where, moler the opluosite influence of Buffon, ${ }^{3}$ Binnitions aml

1 Quotel by Whewell ('Hist.,' vol. iii. p. 268) from the 'Philosophia Botanica? (1751).

2 Ibid., quoted from the 'Classes Plantarum² (1738). Julius Waehs, in his excellent ' History of liotiny' (Munich, 1875, transl. from the German by H. E. Garnsey, 1890), says of Linneus, that in his morpliologieal as well as in his systematic labours, there existed two unreconciled conceptions - a superticial one, meant only for praetical use, which found expression in lis artificial sexual system, and a deeper, scientifically valuable one. "For prictical purposes of descrijtion he elaborated his nomenclature of the parts which, however useful, appears nevertheless that and superficial, as any deeper foundation through a comparative study of forms is winting. But alongside of this, there aplears in various passages of his writings the desire for a more pro. found conception of plant-forms. What he had to sily on this subject he brought together under th. term 'metamorphosis plantarum '" (p. 110 of the German edition).

3 Buffion's great name has a place in the history of the genetie as well as of the morphological view of nature, inasmuch as he lookerl at the things of nature as inuch froun the side of their individual speciality as from that of their comnection and orderly arrangement in time and space. And inasmuch as he "does not only consider the form, but tries to maintain an interest in the general economy of the whole of nature by picturing (1) us the homes, the habits and customs, the instincts, \&c., of living things, sis he strove in general to represent the single phenomena of nature as existing in intimate connection" (Carus, 'Gesch. ler \%oologie,' p. 523). "As Buflon opposed the extrene systematisers, who seeured to think it the end of science, not so much to know about an object as to be able to name it, and fit it into their system, so Dauhenton (the collaborator of buthin in France) 
the great botanists, from Jussien to De Candolle, and the great zoologists, notably Cuvier, male an attempt towards a freer and more generons and more sympathetic conception of the objects as well as the totality of nature. These attempts were continued much on the same lines till well on into the nineteenth century. Buffon's comprehensive scheme was premature, but it had a very great and beneficial influence in popularising and enlivening the frequently dry and uninteresting pursuits of the collector and systematiser. Cook's voyages during the last third of the eighteenth, and Humboldt's travels at the turn of the two centuries, did much to further a comprehensive view; but the great task of the morphologist, like every other scientific work, had to be solved by special studies in separate departments. It grew from small beginnings and detached contributions.

One of the most notable of these, and one also which has all along exerted a great influence on all morphological studies, is the theory of crystals, both natural and artificial. I have already had occasion to refer to the labours of Haiiy ${ }^{1}$ and his successors. They have led to a complete mastery of the geometrical forms which minerals occasionally present in nature, and which substances assume if allowed to solidify out of the liquid 21. condition. The science of crystallography, now appropriately termed the "morphology of crystals," 2 has had

insisted on the study of each animal as an individual whole. . . . $\mathrm{He} \mathrm{oc-}$ cupied himself, therefore, with the production of a series of admirable monographs appended to the descriptions of Buffon in the 'Histoire Naturelle", (Huxley in the chapter on Owen's position, \&c., in 'Life of Richard Owen,' 1894, vol. ii. p. 280).

1 See vol. i. p. 116 , \&c., of this history.

2 See "The Morphology of Crys. tals,' by N. Story Maskelyne, 1895. 
ON THE MORPHOLOGICAL VIEW OF NATURE. 223

a peculiar faseination as forming the transition from the abstraet seience of geonetrical forms and statical equilibrium to the study of the actual forms of real thingss. Hele, if anywhere, it seemed as if we might discover the link that eonnects the theoretically calculable with the actually existing, the possible with the real. Accordingly, we find a very general and recurring tendeney to eary over the notions of crystallography into other seienees — into the norplology of plants and animals. The planes and axes of geonuctry, and the forees of attraction between particles of matter, have formed a theme which has been endlessly repeated and varied in explaining the elenents and the forns of living matter. bint whilst these faneiful analogies ${ }^{1}$ of organic erystals, of polar distribution, and the network of tissues, to which are also allied the spiral theories of leaves and branches in plants and other geometrieal arrangenents, have at times attraeted much attention, ${ }^{2}$ and have served to give at least the

1 "Ces complaraisons entre les formes minérales et les formes vivantes ne constituent certainement que des analogies fort loiutaines, et i] serait imprurleut de les exagérer. Il suffit de les signaler. Elles doivent simplement nous faire mieux concevoir la séparation théorique de ces deux temps de la création vitale: la eréation ou synthèse chimique, la eréation ou synthèse morphologique, qui en fait sont confondues par leur simultanéité, mais ‘jui n'en sont pass moins essentiellement distinctes dans leur nature" (Clauile Bernari, "Lerons sur les J'lı́nomènes de la Vie," \&c., vol. i. p. 296). See also on the extravagances of such search for analogies, Jul. Sachs, 'Gesch. d. Botanik,' p. 173, \&c.

"I shall revert to this subject when speaking of the elder De Candolle. Here only a passing remark on the "spiral theory," which was mainly developed by $\mathrm{K}$. F. Schimper and Alexancler braun, after the regular geometrical arrangement of leaves around their stalks had already been noticed in the eigliteenth century by Charles bonnet, following Cassalpinus. For about thinty years, from 1830 onward, the spiral theory was very popular in Germany. In France, the somewhat related theories of symmetry of te Camblle, of metiamorphosis of Goethe, and of spiral 
semblance $^{1}$ of an explanation of organic structures and forms, they have in reality done as little as Boscovich's centres of force and curves of attraction and repulsion in mathematical physics to establish a firm basis for actual research; for nowhere have they been capable of exact determination such as has been applied to the angles and figures of crystals.

Simultaneously with the science of crystallography there came into being the science of minerals on a

22. Morphology on a large scale. larger scale of study, through actual observation in definite localities of the formation and stratification of rocks; of the traces of the influence of the great

arrangements of Schimper, became known under the term "Morphologie végétale," through Auguste de Saint Hilaire in his "Leçons de Botanique' (1840). To the spiral theory, although strongly opposed in course of time by Wilhelm Hofmeister, one of the founders of the genetic conception of plant life, Sachs, the historian of botany, nevertheless assigns an important historical influence, "as through Schimper's theory the morphologically so important relative position of the plant organs was for the first time placed in the foreground of morphology" (loc. cit., p. 180). See, however, on this subject the paper by A. H. Church on "Phyllotaxis" in vol. i. p. 49 of "The New Phytologist,' 1902.

1 The early propounders of the cellular theory of organic structures adopted the view that cells were formed in a surrounding liquid in the manner of crystals in a motherliquor. When it was established that organic structures grow by intussusception, not by juxtaposition and accretion, like crystals, and that cells multiply by division, the discoveries of Graham, who divided bodies into crystalloids and colloids, were utilised for the purpose of explaining or illustrating organic processes. On this distinction is based the celebrated "micellar theory" of Nïgeli, who, in his "Mechanisch-physiologische Theorie der Abstammungslehre' (Miinchen und Leipzig, 1884), works out a complete mechanical doctrine of the constitution and formation of organic structures. The ideas contained in this elaborate treatise have been much used in Germany by various writers, but mostly only as convenient illustrations. See O. Hertwig, 'The Cell' (transl. by Campbell, 1895), p. 58, \&c. The micellar theory does not seem to have found much favour in France or in this country, where a general opinion prevails which is probably best represented in the words of Claude Bernard: "Les phéno. mènes physico-chimiques des êtres virants, quoique soumis aux lois de la physique et de la chimie générales, ont leurs conditions particulières qui ne sont réalisées que là, et dont la chimie pure ne peut offrir qu'une image plus ou moinsinexacte" ('Phén. de la Vie,' \&c., vol. ii. p.487). 
agencies of nature, - of water, atmosphere, and of ice and heat. last cane the study of the fossil remains of organic life as the neans of fixing the age and the order of succession of various geological formations. Werner $^{1}$ in Germany, Cuvier ${ }^{2}$ in France, Hutton ${ }^{3}$ in Seotland, William Smith ${ }^{4}$ in Fugland, led the way, from different points of view, towards an actual knowledge and a possible theory of the existing forms and structures in and on the crust of our glohe. The study of these subjects, morphology on the largest scale, necessitated distant travels, the examination of formations in situ and under diametrieally opposite conditions. Its greatest and mequalled representative was Alexander von Humboldt, ${ }^{5}$ who also brought the observations of geographical, geologieal, and mineralogical facts and details into comnection with the sturly of climate, of the weather, of the distribution of plants and animals."

I See supra, vol. i. p. 253.

- Ibid., 1. I25.

3 Ibid., p. 283.

4 Ibid., p. 291.

5 A good account of the gradual development of the plan of "Cospuos" will be found in Bruhns's 'Life of A. von Humboldt' (transl. by Lassell, 1873), vol. ii., pussim. It is chear that two great intluences co-operated to ripen in Humboldt's mind the conception of unrolling is great tableau of the physical worle in it.s purely material and in its ideal or poetical aspects: the influence of the great scientific movement then emauating from Paris, and the not less important influence of the ideal novement represented by the names of Herder, Goethe, and Schelliug, which emanated from the centre of Germany.
"But, however greatly Humboldt may be indebted to the inspiring influence of his contemporaries, the great merit of the work lies in what he alone has accomplishedthe attempt by means of a comprehensive collation of details, and the institution of the most searehing comparisous, to give a scientific foundation to the ideal cosmology of Herder, Foethe, Schelling, and their diseiples... In him may be said to be united the two schools of philosophy, so brilliantly. represented during the closing years of the former ceutury. On this account he was at the same time exposed to the censure of the representatives of either system " (vol. ii. p. 312).

6 'The third volume of the "life of Humboldt, in the original German edition, gives an account
23. II umboldt. 
He may be called the morphologist of nature on the largest scale: the representation of the grand aspect of things as exhibited in his 'Cosmos,' and in his earlier 'Ansichten der Natur,' was the leading idea of his life and work. Through him and his friend Karl Pitter " comparative geography received a treatment worthy of the subject, showing its connection with the history of the human race and the advancement of civilisation, inasmuch as the configuration of the earth is proved to have been an important element in the dispersion of nations." 1

But morphology, or the study of forms and structures, has to be carried on not only on the large, the gigantic scale, as by Humboldt; it is quite as important, and has probably been even more influential, when directed towards the minute, the imperceptibly small, which ordinarily quite escapes our notice. If

by various specialists of Humboldt's labours in the sciences of astronomy, geology, geography, the distribution of animal and plant life, meteorology, and other provinces of research, some of which largely owe their existence to his initiative. The study written by Ewald on his geological work, and that of Griesbach, on what is termed in German animal and plant geography, are specially interesting. Unfortunately this most' fascinating volume has not been brought out in the English edition. As illustrating the comprehensiveness of Humboldt's view it is well to note how, before beginning to put together his materials in the great tableau which the 'Kosmos' was istended to be, he drew two entirely different pictures of nature on our globe; first in the large work on the New Continent ("Voyage anx Régions équinoxiales du Nouveau Continent,' in six parts, published in Paris, 1805 to 1834) and then from an entirely opposite aspect in his works on Central Asia ('Asie Centrale : Recherches sur les Chaines et Montagnes et la Climatologie comparée," 3 vols., Paris, 1843). "To Humboldt the importance of the Asiatic expedition consisted in its elevating him above the one-sided effect of having contemplated nature exclusively in the New World, and leading him, so to speak, to feel experimentally that the earth, in common with every other object, is possessed of opposite sides" ("Life of Humboldt,' vol. ii. p. 212).

'See 'Kosmos,' vol. i. p. 60 (German edition, 1845). 


\section{ON THE MORPHOLOGICAL VIEW OF NATUIF. 227}

the great revolution of ideas which the seventernth century witnessed was nuch assisted by the invention of the telescope and founded upon its revelations, the on a mande change of thought during the nineteenth century hats been connected more with the revelations of the microscope. The great movement of irleas starterl hy Galileo, and contimed through Kepler, Newton, and Laplace, was accompanied ly the perfeetion of the teleseope. The invention of the inicroseope enabled Nehemiah Grew and Malpighi to begin half a century later their embryologieal studies, and to inamgurate a line of researeh which, in our days, through a long series of olservations ${ }^{1}$ from Anici to Strasburger on the pro-

1 These observations begin with the year 1830 , when Amici, to whom great improvements in the microscope are due, "traced the poilen grain from its lighting on the carpel tip down into the recesses of the ovule" (Geddes and Thomson, 'The Evolution of Sex,' p. 140), and removed all doubts and uncertainty by his observations on orehicls in 1845 and 1846 . "Here he demonstrated the whole scrics of processes, from the pollen dust on the stigma to the formation of the embryo" (Sachs, 'Gesch. d. Botanik,' p. 469). About the same time (1813) Martin Barry "observed the presence of the sperm within the ovum in the rabbit ovnu" (Geddes and Thomson, loc. cit., p. 142). It took, however, a quarter of a century, from the first diseovery of Amici, before the process of fertilisation described by him was accepterl by embryo. logists as typical for both plants and animals. Bischoff, the great authority in Germany, after confirming the entrance of the spermcell into the ovum, maintained by
Barry in 1S43, and by Newport (with flogs) in 1851 and 1853 , expresses his "infinitc astonishment," adding that "Dr Barry is certainly the first who has seen a spermatozoon in the interior of any crum, aud notably in the ovum of a nammal, and that to him belongs the glory of this discovery" (Theod. Bischott, "Bestiatigung de. son Dr Newport bei den Batrachicru und Dr larry bei den Kaninchen behaupteten Ein. driugens der Spermatozoiden in das Ei,' 1854, p. 9). For the history of scientific thought it is significant to see how little, cren in the middle of the century, discoveries referring to the phenom. ena of plant life or structure werc known or utilised by students of animal life. A mutually fructify. ing influence seems to dite like so many other advances from the publication, in 1859 , of the 'Origin of Speeies.' "The distinctively modern era in the history of fertilisation dates from about is75, when the brilliant researehes of Auerbaeh, Van Beneden, Biitschli, 
cess of fecundation in plants, and from Martin Barry to Hertwig and Fol on that in animals, has been brought to a temporary climax. The combination of telescope and microscope in the spectroscope has opened out a field of research in astronomy of which Laplace had no conception.

So much has depended, during our century, on the unravelling and disentangling of the imperceptibly small (once considered an unworthy occupation), that a short reference to the history of that optical instrument to which we are so greatly indebted may not be out of place.

25.

The Microscope.

The gradual perfection of the microscope is as much indebted to the problems and labours of anatomical workers during the seventeenth and the nineteenth centuries, as anatomy itself reciprocally has been indebted to the microscope. Robert Hooke, in 1660 , first gave a useful form to the compound instrument. Leuwenhoek perfected the simple microscope; and during the earlier part of our century no one did more than Amici in Modena and Lister in England ${ }^{1}$ to start that great suc-

Fol, O. Hertwig, and others, showed that one of the essential phenomena in fertilisation is the intimate and orderly association of the sperm-nucleus, of paternal origin, with the ovum-nucleus, of maternal origin, the result being the clearage or segmentationnucleus. The researches of Strasburger, De Bary, and others, established the same result in regard to plants" (J. A. Thomson, 'The Science of Life,' $p$. 127, 1899).

1 The improvements of Amici seem to go back to the year 1812, those of Lister to 1826 . The former is usually considered the in. ventor of the "immersion" system, -that of placing a drop of water between the object or its covering glass and the objectire lens. This system has lately been improved by Abbe, who discovered a liquid with the same refractive index as the glass of the objective possesses. According to Hogg ("The Microscope," 15th ed., 1898, p. 10), the immer. sion system was suggested by Pritchard in London before Amici hit upon it. The necessary modifications required where the immersion system is used, seem, howerer, to hare been first worked out by the celebrated Paris opticians, MII. Hartnack and Nachet. 
ON THE MORPHOLOGICAL VIEW UF NATURE. 229

cession of improvements by which errors the to colom and indistinctness - the chromatic and spherical aberrations-were removed. In the middle of the century the influence of some eminent hotanists, notably of Hugo von Mohl and Nägeli, in perfecting micrometric processes was considerable; whilst the last twenty years have witnessed quite a new departure in the theory of optical images, in that of microscopic vision, in the improvement of optical glass, and in the investigation of the possible limit of the magnifying powers. The most eminent physical anthorities-such as Stokes and Lord Rayleigh in Fngland, Helmholtz in Germany-have taken up one or more of these points; but the whole subject is associated with the name of Prof. Emst Abbe ${ }^{1}$ of Jena, who, through his comnection with the well-known firm of Carl Zeiss, has been able to put into actual practice many of the suggestions which resulted from his theoretical investigations. As the historians of zoology

1 The labours of Abbe go back to the year 1873. Simultaneously and independiently, Helmholtz attacked the theory of microscopical vision and the question of "resolution" i.e., of the possible limit to the resolving power of any optical arrangement. Airy had attacked the same subject on purely dioptrical lines. Helmholtz and Abbe went a step farther, taking into account the physical nature of light as a wavemotion, subject to interference phenomena, notably those caused by inflection, where objects with very fine markings are coucerned. Alibe's methouls were for a long time only imperfectly known. The lublication, hrwever, of lis theories by Crapski ("Theorie der optischen Instrumente naeh Albe,' Breslau, 1893) made the whole subject better known, and has been followed by two masterly papers by Lord lixyleigh and Prof. Johnstone Stoney in the 42nd vol, of the 'Philos. Mag.' (1896). The latter paper especially gives several interesting examples of the use of recent micruscopic appliances and the means of avolding errors in handling very delieate and minute objeets. It seems that the instrument cannot any longer be used without a theoretical knowledge of its optical construetion, which enables the observer not only to see, but also to critici-e and to interpret. 
and botany tell us, the use of the microscope had made little or no progress $^{1}$ during the eighteenth century: the study of structures and tissues had lost interest in comparison with the study of the physiological functions of the parts of plants and the organs of animals, which had been respectively furthered by 26. Hales in England and by Haller in Germany. ${ }^{2}$ Our Its improve. ment. century thus found the morphological studies of the imperceptibly small in a very backward state: it had to improve the instrument for its research pari passu with this research itself. ${ }^{3}$ But it has been truly remarked that the increased use of the microscope necessitated likewise a mental training in the interpretations and delineations of what was observed through it. "By fortifying the eye with the micro-

1 "So long as, in consequence of the imperfections of optical instruments, deceptive images existed, and, for instance, all microscopical structures appeared as composed of rows of beads, the explanation of what was seen stood under the influence of deceptions, which were only gradually recognised as such" (Carus, 'Gesch. d. Zool.,' p. 629). Compare also what Sachs says (Gesch. d. Bot.,' p. 241).

2 "The characteristic feature of that period lay in this, that the examination of the finer structure is always mixed up with reflections on the functions of elementary organs, so that anatomy and physiology always support each other, but also, in consequence of their imperfect state, do each other injury" (Sachs, loc. cit., p. 240). Similarly Carus (loc. cit., p. 567), "Through the progress which phy. siology made, thanks to Haller's activity, zootomical investigations took a direction which brought them into complete dependence on physiology, ... and retarded the progress of zoology by diverting attention from its primary objectthe exposition of animal forms and their differences."

3 As late as 1827 Aug. Pyrame de Candolle could still write ('Organographie végétale,' vol. i. p. 7), "De nos jours, MM. Mirbel, Link, Treviranus, Sprengel, Rudolphi, Kieser, Dutrochet, et Amici ont publié des recherches très délicates sur le tissu végétal, et les ont accompagnées de figures nombreuses et soignées ; mais la nécessité d'employer continuellement dans ces recherches un instrument aussi difficile à bien manier que l'est le microscope composé, fait que malgré l'habileté de ces observateurs, l'anat. omie délicate des végétaux est encore ... d'une incertitude désespérante pour les amis de la vérité." 
ON THE MORPHOLOGICAL VIEW OF NATURE. 231

scope, it became itself a scientific instrument which no longer hurried over its ohjects in tlighty motion, but is disciplined by the intellect of the observer and forced into methodical work." 1 Sinilarly, no doubt, the increasing devotion to the pastime of sketching from life and nature in our day's must have the effect of obliging the eyes of many persons to look stedfastly and carefully at the forms and outlines of things, and of thus training the artistic faculty.

It is, however, a remarkable fact that one of the greatest leaders in the morphological study of natural objects, Bichat, the great olserver of nembranes and tissues, despised the microseope, the instrument by which the sciences he founded were to benefit so enormously.

The object of morphology, as distinct from that of classification, can be defined as the attempt to describe, and classitiand if possible to comprehend and explain, the relative similarity as well as the graduated differences of form and structure which natural objects present to our gaze. Although the study can be conducted on a large as well as on a small scale, these sinilarities and differences sooner made themselves felt in the comparatively smaller objeets of living nature. These can, without apparent loss of their characteristic appearance and individuality, be collected and brought together, whereas a collection of minerals, with the exception of crystals and gems, always presents only fragnents, and forces upon us the conviction that they can really be studied only in their habitittion, in situ. 'The same conviction has indeed gradually'

1 Sachs, loc. cit., p. 237. 
made its way into botany; and last of all into zoology. The herbarium or coliection of dead plants was much sooner superseded by the "jardin des plantes" than the zoological museum with its skeletons, stuffed animals, and specimens in alcohol has been supplanted by any scientific collection of living animals. Marine stations, which study plant and animal life in situ, are quite a recent invention. ${ }^{1}$ The study of the forms of nature or morphology in the earlier or more limited sense, referred thus more exclu-

1 M. Yres Delage distinguishes four great periods in the study of living things. The first, cul. minating in Linnax and Buffon, studies living objects in the great outlines of their external forms, of the habits of plants and the cus. toms of animals. Detailed examination by dissection is resorted to, but only as a secondary method and in order to supplement the in tuitive discovery of natural affinities. Then comes the second period, that of Cuvier and his followers, relying mainly on anatomical dissection. The third period begins with the marine statious. "Je ne crains pas de dire que la fondation des laboratoires maritimes a marqué une troisième période et constitué une uouvelle méthode aussi importante que les précédentes. Si l'on songe que plus des trois quarts des types d'invertébrés appartiennent au monde de la mer, que le plus grand nombre ne pouvaient parrenir dans les centres scientifiques dans uı état convenable pour l'examen microscopique, si l'on songe que tout ce qui concerne leurs mours et leur embryogénie ne peut s' étudier loin de la mer, on comprend l'importance de ces créations. Faut-il rappeler que l'introduction de cette méthode est due it $\mathrm{H}$. de Lacaze-Duthiers? . . Aussi la fondation du labora- toire de Roscott a-t-elle été le signal de la création d'une multitude d'établissements plus ou moins similaires sur les côtes de tous les pays" ("L'Hérédité et les grands problèmes de la Biologie,' p. 3). The fourth period is marked by microscopic anatomy, and this according to M. Delage-has its home mainly in Germany. "The study of marine zoology has, since the publication of the 'Origin of species,' been found to require more complete arrangements in the form of laboratories and aquaria than the isolated vacation student could bring with him to the seaside. Seaside laboratories have come into existence: the first was founded in France by Coste (1859) at Concarneau (Brittany) with a practical end in view-riz., the study of food. fishes, with au aim to pisciculture. ... The largest and best-supported pecuniarily is that founded at Naples by Anton Dohrn iu 1872; others exist at Trieste, Villefranche, Cette, and at New Haven and Beaufort in the United States; whilst a large laboratory, on a seale to compare with that at Naples, has been (1 $\$ 88$ ) opened at Plymouth by the Mrarine Biological Association of the United Kingdom" (Ray Lankester, art. "Zoology " in 'Encyclop. Brit.,' vol. xxiv. p. 814). 
ON THE MORPHOLOGICAL VIFW OF NATURE. 233

sively to plants and animals, and here the term was first applied. In order to bring some kind of method into the perplexing study of living forms, two ways presented themselves; and they were consciously or unconsciously followed by morphologists with more or less success. As I mentioned above, one of the chief interests which led to zoological and also to botanical studies was the medical interest. Animals were dissected and observed, as affording by analogy an insight into the structure and processes of the human body. Physiology, the science which deals with the actions of the different parts of the aninal or human frame, termed from an early period the functions of the different organs, had made considerable progress during the eighteenth century. It was then found convenient to study the whole organism as an assemblage of different organs or machines, each of which performs a certain function. Thus we have the mechanism on which voluntary motion depends, the mechanism of respiration and of the circulation of the blood through the body, the mechanism of digestion, the mechanism of reproduction, and finally, the mechanism of the nervous system with its specified and localised optical, auditory, and other organs of sense. All these parts or organs conld to a great extent be separately Study of separate organs. studied and described in their mechanical, chemical, and electrical actions. These studies had, since the time of Harvey in England and Haller in Germany, made great progress. The application of chemistry to the processes of respiration and digestion, and finally, the discovery of the galvanic current by Galvani, had given a great impetus to the physiological study of the different 
organs in living beings, and their functions. In plants, these organs and functions seemed to be much simpler and more easily observed than in animals, and Linnæus had selected the sexual organs, since they were the most easily distinguishable, as a primary character for his classification of the vegetable kingdom. Somewhat later ${ }^{1}$ he classifies the animal kingdom according to the internal structure, and characterises animals for the purpose of division according to the heart and the blood. The celebrated dictum, that "minerals grow, plants grow and live, animals grow, live, and feel," which appeared in the last edition of the 'Systema Naturæ,' places a physiological distinction at the base of the classification. This conception, which has been somewhat modified since Linnæus's time to meet our altered views, is an obvious first step towards a description of natural objects. Yet this no more than the second step, which fastens upon the organs of reproduction in plants, on the heart and blood in animals, gives any clue to the comprehension of the great variety and apparent fixity of forms which the living world presents to our observation. In fact, purely morphological considerations were subordinated to physiological ones, and were brought in only to assist in the further subdivision of the two great kingdoms. Linnæus felt the artificiality of his classification-the arbitrariness of the characters he selected for the purpose of division. But a more natural system could only studies. be arrived at by an intimate knowledge of and intercourse with living nature, as well as by a careful comparison of its hidden forms and organisation-i.e., by a more de-

1 See Carus, 'Geschichte der Zoologie,' p. 503, \&c. 
ON THE MORPHOLOGICAL, VIEW OF NATURE. 235

tailed extemal and internal morphology. Both lines of study, with their respective methods of observation, research, and reasoning, were equally wanted. The former was nore easily attained with plants, the latter promised nore immediate fruit in lealing with animals. In following the former, Bernard de .Jussien heeane the founder of modern descriptive botany: in taking up the latter, in founding comprative anatomy, Georges Cuvier hecane for a long time the leader in zoology.

Hernard de Jussien was led to his natural system of 30. classification, not by any theoretical considerations, but by the practical task of arranging the plants in the garden of Trianon, confided to his eare by Lonis XV., who was a great lover of botany. He had with him as assistant his nephew, Ant. Laurent le Jussien, who in 1789 published his 'Genera I'lantarmu,' which is, so far as method goes, the work of his uncle. "This work prodnced a veritable revolution in botany, for only since its publication have plants been studied according to the relations which they exhibit and according to the totality of their organisation." I It was not one special eharater or side of their existence, arbitrarily selected by a first superficial observation, which servel as a means of description; their different parts or organs were conceived to be correlated-i.e., dependent on each other and united to form the totality of their organisation-their varjous characters were all taken into aeeount, and looked njon as subordinated one to the other. ${ }^{2}$ From the time of

1 See 'Histoire des Sciences Naturelles,' par Geo. Cuvier, com. plétée par T. M. de Saint Agy", Paris, 1845, vol. v. p. 298.
2 Aug. Hyrame de Caudolle ("Théorie élémentaire de la Botanique,' Paris, 1819, 2nd ed., P. 69 ) gives the following account of 
Jussieu we find introdnced into natural science, mainly for the purposes of classification, the ideas of the correlation of the different parts and the subordination of the various characters of a plant or an animal. Physiology and anatomy, hitherto mainly occupied with the study of the different organs, were henceforth to be occupied with 31. the problem of organisation, the problem of the unity of Problem of organisation. the various characters and organs. Inspired by Jussieu, De Blainville looked upon the whole development of the natural sciences as the history of our knowledge of organisation, ${ }^{1}$ and De Candolle, Jussieu's great successor in botany-the name that in systematic botany ruled the nineteenth century - -wrote an 'Organographie végétale,' a rational description of the organs of plants. ${ }^{2}$

the method of the two Jussieus: "Ce qui charactérise la méthode des Jussieu, c'est qu'elle est fondée sur la subordination des caractères. Sentant le vague des simples méthodes de tâtounement, l'ex. agération du principe de comparaison uniforme et générale des organes, ils ont les premiers remarqué avec soin, que tous les organes, tous les points de vue sous lesquels on pent les considérer, n'ont pas un égal degré d'importance, ni de permanence, que quelques-uns semblent, pour ainsi dire, dominer les autres; de sorte qu'en établissant la classification d'abord sur ces organes prédominans, puis les divisions secondaires sur cenx qui ont un moindre degré d'intérêt, on est conduit à imiter le jlus possible l'ordre de la nature dans celui de la classification. Ce principe simple et peu contestable a été fécond en conséquences importantes ; et c'est sous ce point de vue, que l'uu des hommes qui a le plus profondé- ment réfléchi sur la marche des sciences et sur le plau général de la nature, a proclamé, dans une occasion solennelle, le livre de M. de Jussieu, 'comme un ouvrage fondamental, qui fait, dans les sciences d'observation, une époque peut-être aussi importante que la chimie de Lavoisier dans les sciences d'expérience." (See Cuvier, 'Rapport historique sur les progrès des sciences naturelles,' Paris, 1810, p. 305.)

1 See the 'Étude sur la vie et les travaux de M. Ducrotay de Blainville,' par Pol. Nicard, Paris, 1890 , p. 157 sq.

2 See A. Pyr. de Candolle, 'Organographie végétale on Description raisonnée des Organes des Plantes,' Paris, 1827, 2 rols., especially vol. ii. p. 245 , \&c. "The classifications of the scientific taxonomist are of two kinds. Those of the one sort are merely handy reference catalogues. Such are the 'artificial' systems, useful in their day and for their particular pur- 
ON THE MORPHOLOGICAL VIEW OF NATURE. $2: 37$

The problem of organisation was much easier in dealing with plants than with animals. In the former there seems to be only one organ or system of organs definitely developed and nurked off-namely, the organs of fructification; and these had aceorlingly served Linnitus and his suceessors as the leading eharacter for their deseriptive elassifieation. In animals there are, or seem to be at least, four or five well-defined and separated systems of organs. The selection, for the purposes of classification and morphology, was much more difficult. Aecordingly we find Cuvier, who between the years 1795 and 1817 devoted himself to the morphological Cuvier. and anatomical study of the animal kingdom, hesitating in the selection of the leading character according to which he should classify and arrange it. As I have had occasion to remark above, ${ }^{1}$ he finally in 1812) settled on the nervons system as the leading charaeter governing the figure of an animal organism. ${ }^{2}$ Before

pose, but of no other value. The others, known as 'natural' classifications, are arrangements of objects aceording to the sum of their likenesses and unlikenesses, in respeet of certain characters ; in morphology, therefore, such classifications must have regard only to matters of form, external and in. ternal. And natural classification is of perennial importance, because the construction of it is the same thing as the aceurate generalisation of the facts of form, or the estab. lishment of the empirieal laws of the correlation of structure" (Huxley in 'Life of Owen,' vol. ii. p. 28:3).

${ }^{1}$ See vol. i. 1. 130 of this history.

2 Ou the gradual development of Cuvier's elassification see Carus, 'Geschichte der Zoologie,' 1'l. 602,
$612,614 . \quad$ "It dicl not escape Cuvier that the idea of subordina. tion is artifieial, and that the importance of an organ can only be fixed by experience - namely; through the proof of its constaney. Nevertheless he follows this principle, but naturally becomes racillating. Thus in 1795 he names the organs of reproduction, to the action of which the animal owes its existence, and the organs of eir. eulation, on which depends the individual preservation of the animal, as the most important, whilst in 1512, following the example of Virey, he declares the nervous system to be that system for the maintenance of which the other systems solely exist" (loc. cit., p. 602). 
that, he had already adopted from Lamarck, ${ }^{1}$ whose many-sided genius has made a lasting impress on the history of natural science in quite a different direction, the broad morphological division of the animal kingdom into animals with or without backbone, uniting under the former designation the four first classes of Linnæus. The more we follow Cuvier in the development of his classifying attempts, the more we find the form, the figure, the external and internal structure, urged as the aspect from which the organisation of living creatures is to be considered. To him fixity of form is the everrecurring character of organised beings as distinguished from inorganic structures which depend on fixity of matter. ${ }^{2}$ The clearer enunciation of this fixity of form is accompanied in Cuvier's view by the rejection of an idea which, before him, had very largely governed the speculations of naturalists. This idea, by which Charles Bonnet has been immortalised in natural history, is the conception of a graduated scale according to which living creatures can be arranged-viz., the celebrated Échelle des Etres, coupled with the axiom, "Natura non facit saltus." This idea Cuvier rejects as untenable, and introduces in the place of it the conception of distinct plans called "Types." later "types," 3 according to which living beings are

1 "An indirect inducement for a more pointed enunciation of the types of the various classes was given by Lamarck in 1797 when he placed the animals with white blood as 'invertebrates' in opposition to those with vertebræ, which expressions (à vertèbres and sans vertèbres) come from him" (ibid., p. 612).

2 See Cuvier's 'Éloge of Haüy'
(El. iii. p. 156, \&c.) and the extracts from it and from the 'Règne animal,' given in the first volume of this History, p. 129 and notes passim.

3 According to Carus ("Gesch. d. Zool.,' p. 615), the term "type," which became current later, was introduced by De Blainville, a philosophical naturalist who held a kind of middle position between 
ON THE MORPHOLOGICAL VIEW OF NATURE. 239

modelled, and which have always existed. These types or areheteetonic models are capable of certain molific: tions, which, however, do not affeet the main features of the plan. The different classes of these main types, called "embranchements," and designated as backboned, molluseous, articulate, and radiated amimals, stand near each other in independence and form no scale. ${ }^{1}$

The morphological view of nature took a somewhat different turn in De Candolle, the successor of Jussieu in botany, who, while greatly indebted to Cuvier, acknow-

34. De Candolle.
Cuvier and his opponent, Geoffroy St Hilaire. In 1816 Blainville gave the "principles of a new classification of the animal kingdom, in which, for the first time, the totality of structure of animals was used to characterise larger divisious." He divides animals first of all into three sub-kingdoms-srmmetrical, radiate, and those without regular form. De Blainville seems to have been an inspiring teacher, whose ideas became suggestive and fruitful in many other minds. Nearly the whole of the third volume of Comte's 'Philosophie Positive' is written under a sense of obligation to De Blainville, whose "Cours de physiologie générale et comparée' (1829-32) Comte considers "comme le type le plus parfait de l'état le plus avancé de la biologie actuelle" (vol. iii. p. 269, Paris, 1838). The 'Philusophie Positive' was dedicated to Fourier and De Blain. ville. How the latter also anticipated the modern conceptions of "Stoffwechsel" and "Mletabolism" sce Claude liernard, 'Phénomènes de la vie communs aux animanx et aux végétaux' (1885, vol. i. p. 36).

1 It is historically interesting to note that about the time when Cuvier was gradually definiug more rigidly his four elasses, Lamarek was working at his 'Histoire naturelle des Animaux sans vertèbres,' of which the 'Système,' \&.c. (I'uris, 1801), can be considered the first edition, the larger work appearing from 1816 to 1822 . With him there is no mention of a plan or a type. His classes form a progressive series, and he was the first to follow the jatl from the simple to the more complex. In opposition to Cuvier, he thus wrote: "La nature, dans toutes ses opérations, ne pouvant procéder que graduellement, n'a pu produire tons les animaux it la fois: elle n'a d'abord formé que les plus simples, et passant de ceux.ci jusques aux plus composés, elle a établi successivement en eux différents systèmes d'organes particuliers, les a multipliés, en a augmenté de plus en plus l'énergic, et les cumulant dans les plus parfaits, elle a fait exister tous les animaux connus, avec l'organisation et les facultés que nons leur oh)servons. Or, elle n'a ricn fait absolument, on elle a fait ainsi." ('Hist. des Animaux sans vertibres,' 2nd ed., par Deshayes et Milne Edwards, Bruxelles, 153i, vol. i. p. 42. Cf. alșo Carus, loc. cit., p. 615.) 
ledges yet another prominent influence in the formation of his ideas. Cuvier, the zoologist, contemplating the existing forms of nature from one of the two main points of view, was impressed with the contrast between the lifeless and the living, seeing in the latter stability of form, not of substance,-what we should now term dynamical equilibrium. To him the vortex is the symbol of life. De Candolle in studying plants is struck with the underlying regularity and symmetry of their formation. His views were formed after very extensive practical occupation with descriptive botany, which was followed by a lengthy residence in Paris, where, next to Cuvier, he came greatly under the inflnence of the Abbé Haiiy, the founder of crystallography. ${ }^{1}$ From the Jussieus he learnt the importance of looking at the "ensemble," the "port et aspect" (facies, habitus); ${ }^{2}$ from them and Cuvier the value of the principle of the subordination of characters, and the correlation of parts in the organisation of the whole. ${ }^{3}$ But he fastens mostly upon the underlying

1 De Candolle, 'Théorie élémentaire de la Botanique,' 2nd ed., Paris, 1819, p. 72 : "Je dois encore compter, au nombre des causes qui ont influé sur l'amélioration des méthodes botaniques, d'uu côté les perfectionnemens importans que la classification zoologique a reçus, principalement par les travaux philosophiques de M. Cuvier, travaux qui ont réagi sur quelques parties de la Botanique elle-même, et dont je m'honore d'avoir profité; de l'autre, les importans travaux de M. Haiiy sur les lois de la crystallisa. tion, et notamment sur les décrois. semens des rangées de molécules des cristaux, lois par lesquelles j'ai été conduit à quelques-unes des idées que j'exposerai dans le livre suivant." Cf. also 'Organographie végétale,' Paris, 1827, vol. ii. p. 237 .

2 'Théorie élémentaire,' p. 89 ; also, p. 216.

3 This principle is stated very clearly by Cuvier iu mauy placese.g., in the celebrated "Discours" prefaced to the 'Recherches sur les Ossemens Fossiles' (3rd ed., 4to, 1825, vol. i. p. 47): "Tout être organisé forme un ensemble, un système unique et clos, dont les parties se correspondent mutuelle. ment, et concourent à la même action definitive par une réaction 
U. THE MORPHOLUGICAL VIFIV UF NATUlis. ¿ 41

regularity and symmetry, and studies the causes which in the actual visible siveciness of plant life veil and cover up this symmetry : ats Haiiy had taught us in erystallography to reconnise the primitive forms which appear chinged by the phenomena of clecrescence." De Candolle accorlingly enters rery fully into the theory of abortive, degenerate, and coalesced forms, recurring again and again to the statement that the "nsomble" of mature tends to make one think "that all orgunised beings are regular in their nost intimate structure, and 35. Regularity and that various and differently combined abortive efforts symutinetry. prouluee all the irregulatities which strike our glance and embarlass our comblinations." 3 fud the norpho-

réciproyue. Aucune le ces parties ne peut changer saus que les autres changent aussi ; et par conséquent cliacune d'elles, prise sépirément, indique et donne toutes les autres."

'Cf. 'Théor. élem.,' p. 116, where he draws a parallel between the two wethods in crystallography represented by Romé de l'Isle and Haiiy and similar methods in botany. He reverts to this irequently - e.\%., 'Organographic,' vol. ii. p. $\$ 37$, where he says: "Le premier rai. sominait comme ceux des butanistes qui voyaient une feuille ou une corolle comme un tout unifue, entaillé sur ses horls par une cause ineonnue; le second in'a servi de guide lorsque j'ai tenté de montrer que les découpures diverses les organes végétaux terraient esientiellement itux modes variés et aux degr'és divers de leur agrégation."

¿'Théorie élémentaire,' p. 186: "Les avortenens, les soudures des purtien, leurs dégénérescences, ne sont pas plus des suppositions de désordre ou d'imperfeetion dans les étres organisés, que les déerois. semens des molécules ne sont des désortres dans la eristallisation."
3 'Théorie élémentaire,' p. 97, \&c.; also p. 236 : "La vraie seience de l'histoire naturelle générale consiste dans l'útude de la symétrie propre it elaque famille, et des rapports de ces familles entr'elles; toute la reste n'est qu'un echafaurage plus ou moins industrieux your" parvenir it ce but." And 'Organographlie végétale, rol. i. p. x. : "L'organographie est la bave eommune de toutes les partie- de la scieuce des êtres organisés: evnsidérée en ce qui tient à la symétrie des etres, elle est le foulement de toute la théorie des classifications, sc." And again, ibid., vol. ii. 239: "Plus le nombre des etres connus: a augmenté, plus on les a cituriés avee som, plus ou sest emraineu de ce principe que j'ai été le premier, ou l'un des preniers ì énoncer dans si grínéralité, qu’il est p'esque certain que les ères organisés sunt syux́triques ou régulier's lor q qu'on les eonsidere dans leur type, et que les irrugularités apparentes des végétaux tiennent à des pliénouines constans entre certaines limites, et susceptibles l'exister, soit séparément, soit reunis, tels

VOL. II. 
logical view is still more clearly expressed in the further analysis of their regularity and symmetry. The character of the structure is to be found in the existence or absence, in the relative or absolute position, number, size, and shape of the different organs, ${ }^{1}$ whereas the use or functions of the organs, as well as their other sensible properties, ${ }^{2}$ are considered to be, not the cause, but the consequence, of their structure, and hence of little importance in the anatomy, and of none in the classification, of plants, whatever may be their value from a physiological point of view. "But symmetry supposes a primitive plan or archetype, and the proofs of symmetry are those of a general order." 3 "The natural classification of organised beings consists in appreciating the modifying circumstances, and in abstracting them so as to discover the real symmetrical type of each group." ${ }^{4}$ Here again De Candolle refers ${ }^{5}$ to the examples of the crystallographer and the astronomer, who both make abstraction of the disturbing secondary influences in order to arrive at the primitive form and

que l'avortement ou la dégénérescence de certains organes, leur soudures entre eux ou avec d'autres, et leur multiplication d'après des lois régulières."

1 'Théorie élém.,' p. 147: "La symétrie organique se compose d'un certain nombre d'élémens dont les principaux sont: l'existence; la position relative ou absolue; le nombre relatif ou absolu; la grandeur relative ou absolue: la forme; l'usage ; la durée ; . . . les qualités sensibles," \&c.

"Ibid., p. 170: "L'usage des organes est une conséquence de leur structure, et n'en est nullement la cause, comme certains écrivains irréfléchis semblent l'indiquer; l'usage, quelle que soit son importance dans l'étude physiologique des êtres, n'a donc eu luimême qu'une médiocre importance dans l'anatomie, et ne peut en avoir aucune daus la taxonomie." ... "Ce que je viens de dire de l'usage des organes, s'applique ì bien plus forte raison encore ì leurs qualités sensibles, qui ne sont que des conséquences plus on moins directes de leur structure," \&c.

" Ibid., p. $185 . \quad{ }^{4}$ Ibid., p. 188.

${ }^{5}$ See especially the chapter "De la Symétrie végétale" at the end of the 'Organographie,' vol. ii. p. $236 s q q$. 
ON THE MORPHOLOGICAL VIEW OF NATURE. 243

the true orbit. It follows that "we must study the different species as constant things," I and that this is a more "dignitied" occupation for a "naturalist than the accumulation of doubtful cases in farour of the nonpermanence of species." - He agrees with Cuvier in rejecting the older idea of the "échelle des êtres," 3 and he praises the sagaeity of Linneus, who suggests that the regetable kingdom resembles a geosraphical chart, -an idea which, in the hands of several French and German botanists, has become a fruitful conception.

In De Candolle we neet with a repeated accentuation of the reeurring symmetry of form, of the existence of definite prinitive types, in the regetable kinglom. Simultaneously with him there was labouring another thinker and keen observer of nature, who was primarily struck by the resemblance exhibited in the different parts or orgatns of one and the same plant, and searched for the type or plan on which they were modelled. He introduced into the vocabulary of scientific language the expression "metamorphosis of plants." It was Goethe the poet who, in 1790 , published under this title his first contribution to morphological science. In subsequent publications and essays, covering the last forty

1 "Théorie élémentaire," p. 195.

2 Ibid. $\quad 3$ lbid., 1). 230.

" "Linné a le premier, avee sa sagacité ordinaire, comparé le règne végétal à une carte géographique; cette métaphore, indiquée dans son livre par un seul not, a été dé. veloppée ensuite par Giseke, Batseh, Bernardin de Saint-Pierre, L'Héritier, l'etit - 'Thouars, \&e. Et quoi qu'on ne loive la prendre que pour une simple inage, cette image est tellement juste, tellement foconde en conséquences utiles, qu'il est peut-être convenable d'entrer dans quelques détails ultérieurs. Je suppose pour un moment cette earte exécutće; les clisses répondent aux parties du monde, les fimilles aux royaumes, les tribus anx provinces, les gemes aux cantons et les espéces aux villes ou villages," \&c. (Théor. élém., 1. 231). 
years of his extraordinary life, he again and again reverts to the subject, which with him is only one chapter in the extensive science of morphology, of which he was indeed the first to form a general conception. Goethe's ideas hardly influenced the course of science, but in the history of thought they form a remarkable anticipation of later views, and have accordingly been frequently referred to by contemporary writers, notably by Haeckel and Huxley in their important works on Morphology and Evolution. Of the foremost scientific writers, De Candolle was almost the only one ${ }^{1}$ who, during Goethe's lifetime, referred to his views with approbation; seeing in his theory of the metamorphosis of the leaf a truly admirable divination ${ }^{2}$ of vegetable organisation. Saint-Hilaire's honourable mention of Goethe's morphological contributions to zoology came only just in time to be seen by Goethe himself. ${ }^{3}$

'See 'Organographie,' vol. i. p. 551: "Les parties de chaque rangée ou de chaque verticille sont susceptibles de se transformer dans la uature de la rangée qui la touche immédiatement. Ainsi l'on trouve des sépales changés en nature pétaloide (Primula calcycanthema), des pétales changés en étamines (Capsella Bursa-pastoris), des étamines changées en carpelles (Magnolia fuscata), ou bien l'inverse, savoir : des carpelles ehangées ell étamines (Euphorbir palustris), des étamines changées en pétales (toutes les fleurs doubles), ou les pétales transformés en nature de calice (Ranunculus abortivus). M. Goethe a très-heureusement désigné la première de ces séries de trans. formations sous le nom de Metanor. phose ascendunte ou directe, et la seconde sous celle de Métumorphose dcscendante ou inverse."

2 Ibid., rol. ii. p. 243 : "C'est ainsi qu'en rosant la mauière véritablement admirable dont $\mathbf{M}$. Goethe, quoiqu' habituellement occupé d'idées si différentes, a comme deviné l'organisation végé. tale, on est bien tenté de croire qu'il l'a moins inrenté qu'il n'a généralisé avec génie quelques faits partiels heureusement choisis." This was written in $152 \bar{i}$.

3 See Goetle's 'Werke' (Weimar edition, Abth. II. Bd. vii.), the review of "Prineipes de Philosoplie Zoologique. Discutés en Mars $1 S 30$ au sein de l'académie royale des sciences par M. Geoffroy Saint-Hilaire, Paris, 1830," especially p. $1 S 1$, and dated Sept. 1830. In 1831 Geoffroy says of the uuity of organisation : "Elle est présentement acquise au domaine de l'esprit humain ; et l'honneur d'un succès aussi mémorable appartient à Goethe." Quoted by Huxley in 'Life of Owen,' vol. ii. p. 291. 
ON THE MORPHOLOR:AL VIEW OF NATIIRE 245

What did great harm to (ivethe's correct anticipations was the faret that in optics he had unsnecessfully cunbated the generally accepted Newtonian therory of colours, and that his morphological glimpses were taken up by schelling and his school and incorpurated in the fantistic speculations of the philosophy of nature. They sharel the fate of this and passed into temporary oblivion.

The irlea of the fixity of certain forms in nature, of the archetectonic modelling of her oljects according to certain archetypes, which Cuvier hat put forth as the result of extensive observation and inductive examination of living and fossil forms, which in t)e ('andolle was connected with the conception of geometrical order, recularity, and symmetry, fomd in Goethe's minel an artistic sanction. "It is," as the historian of botany type. has remarked, "the illealistic conception of nature which looks upon the organic forms as continually recuring

1 A full discussion of Goethe's theory of colours will be found in two addresses of Helmlioltz: the first, from the year 1853, was reprinted in the first volume of his often-quoted 'Vorträge und lieden'; the second was delivered nearly torty years later at the meeting of the Goethe Society at Wcimas, in June 1×9.2. In the latter Helmholtz significantly refers to the great revolution which in the interval had come over scien. tific thought through the general recognition of the prineiples of energy and of evolution. By the light of these we are better able to understand the shadowy hut nevertheless truthful antieipations contained in Goethe's poetical and scientific writings. Helmholt: traces the errors of Guethe's colour-theory largely to the fact that he worked with imperfect apjaratus and in. wre colours; that "he never had before his eyes perfectly purified homogeneous-coloured light, and hence would not believe in its existence. On this diffienlty," Helmholtz continues, "of complete purification of the simple spectral colours, a man like sir I). Brewster tounclered, who was much more experienced and clever in optical experimenting than Goethe, aud wis equiphed with the best instruments" (Goethe's "Vorahnung kommender naturwissenshaftlicher Ideen,' by H. rom Helmholtz, Perlin, 1s92, p. 30). Cf. also Helmholtz's Memoir on lirewster's Analysis of sunlight, 15\%2. Reprinted in Wisseuschatt. Abhandl., vol. ii. 
imitations of eternal ideas in the sense of Plato, and which confounds these abstractions of the mind with the objective nature of real things." I Nevertheless, we must recognise that through the vague and poetical expositions of Goethe's writings there is to be seen the fruitful idea of the change, the instability, of forms, as an equally important side of reality. ${ }^{2}$ In fact, Goethe oscillates in his half-formed theories between the ideal archetypes of Plato and the more recent conceptions of Darwin and Spencer, as is proved by the vivid, even passionate, interest which he took in the celebrated controversy of Cuvier and Saint-Hilaire in the French Academy of Sciences in the year 1830,-an incident which carries us into the midst of the ideas with which the following chapter will be occupied.

Before we take up those entirely different lines of observation and reasoning, we must note a great expansion and development of the study of the form of natural objects - of morphology - in two independent directions. One of these carried the study of forms into the larger dimensions of time and space, the past

'Sachs, 'Geschichte der Botanik,' p. 181.

${ }^{2}$ Of Goethe Huxley says ("Life of Owen," rol. ii. p. 290): "On the face of the matter it is not obrious that the brilliant poet liad less chance of doing good service in natural science than the dullest of dissectors and nomenclators. Indeed there was considerable reason, a hundred years ago, for thinking that an infusion of the artistic way of looking at things might tend to revivify the some. what mummified body of technical zoology and botany. Great ideas were floating about; the artistic apprehension was needed to give these airy nothings a local habitation and a name; to convert rague suppositions into definite hrpotheses. And I apprehend that it was just this service which Goethe reudered by writing his essays on the intermaxillary bone, on osteology generally, and on the metamorphosis of plants." A rery full appreciation of Goethe's merit will be found in all the principal writings of Ernst Haeckel, notably in the fourtl chapter of the first volume of the 'Natürliche Schöpfungsgeschichte,' 9th ed., Berlin, 1898 . 
ON THE MORPHOLOGICAL VIEW OF NATURE. 247

of history and the morphologieal changes of the carth; the other carried it into those small dimensions where the mulderl eye sees only sameness and repetition, but where the microscope reveals the hidden structure, the internal and minute forms, of which living matter is made ul).

I have alrealy pointed out how the great travellers of the second half of the eighteenth century-banks, Pallas, and Humbolit - carried the study of nature beyond the narrow limits of the musem and the workroom into the larger area of nature, of the present and the past world. Camper in Holland, Hunter and Momro in this country, Blumenbach and Soemmering in Germany, Saussure in Geneva, towards the end of the cighteenth and the besimming of the nineteenth century had begum to unite these scattered discoveries and records into something like order and system. It was again the great merit of Cuvier ${ }^{1}$ to publish a monumental Palaon.

1 Of the labours of other naturalists who precederl Cuvier, a very full account will be found iu a posthumous work of Ducrotay de Plainville, edited by M. P'ol Nicard and entitled 'Cuvier et Geoffroy SaintHilaire' (1890). The author, as is well known, was for some time a colleague and eollaborator of $\mathrm{Cu}$. vier, with whom he fell out, partly from personal reasons, partly owing to the whole bent of his scientific researches, which was inuch more philosophical than that of Curier. $\mathrm{He}$ had a very great appreciation of Lamarck at a time when that speculative naturalist was unknown or treated with neglect, not to say with ridicule. The criticisms of De Blainville on Cuvier must be taken with caution; nevertheless his works and lectures had a great influence on the developmeut of the more philosoplical side of natural science in France, as many allusions of Auguste Comte, Flourens, Claude Bernard, \&c., sufficiently prove. In the chapter on Palieontology in the work on Cuvier ( $p$. 380 , \&c.), De Blainville does full justice to Camper, Iilumenbach, Soemmering, and other Continental naturalists, with whose labours Cuvier, through his German education, was better acquainted than his French colleagues. There is also a significant remark of his on the fact that Cuvier was essen. tially a collector and dissector, a nuan of the museum and the library, not an outdoor maturalist (p. 241). 
work on the subject and to found the science of palrontology. His researches in this subject were based upon the collection of fossil remains which had been begun by Daubenton for the natural history of Buffon, and which he arranged and largely increased; on the collection which Camper had made at Amsterdam; on descriptions which he procured from all the collectors of Europe, notably from Blumenbach; on his excavations together with Brogniart in the environs of Paris. As early as 1798 he announced his intention of collecting everything that was known on fossil remains in a great tableau--a plan which was not realised till 1812, when his many separate publications were united in the great work on the "Ossements fossiles," and was only completed by the greatly revised and augmented edition of 1821 . This work is important in morphological science, not only because it contains many accurate and still highly valned descriptions of "extinct species," but also because, in its celebrated introduction ${ }^{1}$ on the revolutions on the surface of our globe, it takes a comprehensive view of the changing aspects which succeeding ages, divided by great catastrophes characterised by distinet geological formations

1 In this introduction (p. 52 of vol. i.) there is also to be found the celebrated passage in which Cuvier says that by the application of his principle of the "correlation of parts" he could, if he ouly possessed one well-preserved fragment of a bone, determiue everything as certainly as if he possessed the whole animal-a statement on which De Blainville (loc. cit., p. 417) has some very pertinent remarks: " $\mathrm{Ce}$ ne sont pas des auatomistes véritables comme l'étaient Hunter, Camper,
Pallas, Vicq-d'Azyr, Blumenbach, Soemmering et Meckel qui se seraient ainsi avancés, et II. G. Cuvier aurait été bien embarassé lui-même, si on l'avait pris au mot, et cependant c'est cette assertion qui restera formulée dans la bouche des ignorants," \&c. Cuvier by this method determined and classed more than 150 mammals (loc. cit., p. 53). A more favourable view of Cuvier's work on fossil remains is taken by Huxley, 'Life of Owen,' vol. ii. p. 297. 
ON TIF MORPHOLOGICAL, VIEW OF NATURE. $2 \pm 9$

and by the fossil remains of extinct organic cleations, presented on the surface of sur carth. "What is certain," says Cuvier at the close ${ }^{1}$ of this celelnated liscourse, "is that we are now at least in the midille of a founth succession of terrestrial animals, and that after the age of reptiles, after that of the palientheria, after that of the mastodons, the megatheria, there has conse the age when the human race, supported by some domestic animals, peaceably rules and enltivates the earth, and that it is only in the conntries formed sinee this epoch in the recent alluvial deposits, peat-bogs, and concretions, that we find in a fossil condition those lnomes which helong to animals known and now living." such is the resume of the ideas which had followed-nay, even tornuented 2-Cinvier during his reseatches into fossil lemanins, and which led him to the conclusion" "that it required great events to bring about the important differences whieh he recognised"__differences which the slow "influenee of weather, or of climate, or of domestication," could not explain, but which required the violent aetion of sudden "catastrophes," 4 which frequently " disturbed the life on this planet by frightful events," "broke off the thread of operations," " "none of the present agencies of nature sufticing to produce her lygone works."

1 "Diseours sur les révolutions de la surface du globe et sur les changemens qu'elles ont produit: dans le rigne aniulal," reprinterl in the $3 r d$ ed. of the "Recherchen sur les ussemens fossiles,' 1825, vol i. P. 172 .

2 "Ces idies m'ont proursuivi, je dirai presque tourmenté, lendant que j'ai fait les recherches sur les os fossiles, dont j'ai donné depuis yeu au public la collection, recherches qui n'embrassent qu'une si petite partie de ces phénomènes de l'avant. dernier âge de la terre, et qui cepeudant se lient à tous les autres d'une manière intine" ('Discours,' \&e., 1. 140).

$\begin{array}{ll}\text { "Ibid., 1. } 3 . & \text { Ibid., 1. } 8 . \\ \text { s Ibid., 1. 9. } & \text { Ibid., 1. 14. }\end{array}$

7 "Ainsi, nous le réprétons, e'est en vain que l'on eherehe, dans les 
39.

Cuvier's catastrophism.

These words, which embody a conception since appropriately termed "catastrophism," and which picture to the mind's eye a succession of morphological changes of the entire aspect of our globe, were written at a time when, in this country especially, through the labours of Hutton, an entirely opposite view was gradually preparing. With this we shall deal in another chapter. The Cuvierian conception of epochs in geology harmonised with that of distinct types of organic creation. These exhibit in space, as those do in time, certain definite and distinct morphological characters-i.e., certain typical forms and structures on a vast or a small scale, around which the features of events and individuals seem to oscillate, and which permit us scientifically to classify, describe, and comprehend them. This conception gave the tone to a long line of researches on the Continent and in this country in geology as well as in natural history.

In the study of these typical forms and structures in which nature repeats herself, reverting again and again to them, but in every single case departing more or less from them; in the study of this order without monotony, this change withont confusion, this variety of forms in

40. Study of analogies. which leading features are always recognisable,- the discovery of analogies played a very prominent part. Goethe's metamorphosis of plants is based upon the analogy of their different organs: before he published

forces qui agissent maintenant ì la surface de la terre, des causes suf. fisantes pour produire les révolutions et les catastrophes dont son enveloppe nous montre les traces; et si l'on veut recourir aux forces extérieures constantes connues jusqu'à présent, l'on n'y trouve pas plus de ressources" (ibid., p. 20). 
ON THE MORPHOLOGICAL VIPW OF NATURE. 251

this first morphological fragnent he had alrearly-lect by analogy-discovered the intermaxillary bone in the upper human jaw. Later he and Uken independently traced the analogy between the skull and the vertebral column in vertelirate animals, a view which was taken up by eminent anatomists, such as Meekel, Spix, and Geoffroy Saint-Hilaire. 'The tendeney which lay in these attempts, of which the metanorphosis of plants and the vertebral theory of the skull are only prominent examples, is one which was naturally provolied by the opposite tendeney which anatomieal stulies had received through Linneus and Cuvier. Goethe himself gives a clear explanation of its origin. In a remarkable passage in the history ${ }^{2}$ of his botanical studies, he mentions Shakespeare, Spinoza, and Linneus as the three masters who had led him to refleet on the great problems of art, of life, and of nature. Now, he says, the influence of Linniens lay principally in the opposition which he provoked.

1 A grood account of the part which the vertebral theory of the skull played in comparative an* atomy will be found in Whewell's History, rol. iii. p. 369 , \&c. But see against this Huxley' in 'Life of Owen" (vol. ii. p. 304): "The lyypo. thesis that the skull consists of modified vertebrx, advocated by Goethe and Oken, and the subject of many elaborale works, was so little reconcilable with the mode of its development that, as early as 1842, Vogt threw well-founded doubts upon it. "All efforts to in. terpret the skull in this way, said he, 'are vain.'

See the Weimar edition of his Scientific Works, vol. ii. The passage given in the text is from an earlier account contained in two numbers of the "Horploologisclie
Hefte' (1817), reprinted loc. cit., p. 389 , \&c. How Goethe continually hovered between the theory of types and that of development is seen in the following passage (1831, W. W., vol. vi. p. 120): "Das Wechselhafte der Pflanzengestalten, dem ich läugst auf seinem eigenthümlichen Gange gefolgt, erweckte nun bei mir immermehr die Vorstellung: die uns umgebendeu Pflanzenformen seien nicht ursprünglich determinirt und festgestellt, ilmen sei viehmehr, bei einer eigensinnigen, generiscleu und specifischen Hartnäckigkeit, eine glickliche Mobilitit und Biegsamkeit verliehen, um in so vicle Bedingungen, die iber dem Erdkreis auf sie einwirken, sich zu fiigen und darnoch bilden und umbilden zu kinnen." 
"For as I tried to take up his sharp and suggestive distinctions, his expressive, useful, but frequently arbitrary laws, there arose in me an inner conflict: what he tried forcibly to hold asunder, tended according to the innermost demands of my nature to be united." And as the process of dividing, classifying, and keeping apart went on among the successors of Linneus, so it must have produced in many genuine observers of nature a tendency similar to that which Goethe describes. They would emphasise the resemblances and analogies of natural objects and their organs in proportion as the classifiers had separated and distinguished them. And it was just as likely that the artistic mind of Goethe might succeed in "lifting the veil of nature," as Humboldt ${ }^{1}$ put it, when he transmitted to Goethe his suggestive work on the geography of plants, and as Huxley ${ }^{2}$ repeated in 1894 . Indeed it was the former who, on the largest scale, had traced those analogies and correspondences in nature which are so much dearer

1 See Goethe's own account (in Werke, 2 Abth., vol. vi. p. 163): "Sollte jedoch meine Eitelkeit einigermassen gekränkt sein, dass man weder bei Blumen, Minern, noch Kuöchelchen meiner weiter gedenken mag, so kann ich mich an der wohlthatigen Theilnahme eines höchst geschätzten Freundes genugsam erholen. Die deutsche Uebersetzung seiner Ideen zu einer Geographie der Pflanzen nebst einem Naturgemälde der Tropen. länder seudet mir Alexander von Humboldt mit einem schmeichelhaften Bilde, wodurch er andeutet, dass es der Poesie wohl auch gelingen kömne den Schleier der Natur aufzuheben; und wenn er es zugesteht, wer wird es leugneu?"
2 See quotation supru, p. 246 note; also ('Life of Owen, vol. ii. p. 288) : "The cultivator of botany, who went beyond the classification of 'hay,' became familiar with facts of the same order. Indeed, flowering plants fairly thrust morpliological ideas upon the observer. Flowers are the primers of the morphologist; those who run may read in them uniformity of type amidst endless diversity, singleness of plan with complex multiplicity of detail. As a musician might say, every natural group of flowering plants is a sort of visible fugue wandering about a central theme which is never forsaken, however it may, momentarily, cease to be apparent." 
ON THE MORPHOLOGICAL VIFW OF NATURE. 253

to the poetical mind of Goethe, and all other artists, than the separations and classitications of the nen of science. "It is one of Humboldt's uncontesterl merits that he, in order to prove the muity which rules in the formation of the earth, searcherl for analogies in the geological constitution of distant countries. Is we see him pointing ont ummerons novel coincidences between the formations of Mexico and Hungary, so likewise we owe to him suggestive hints for other similar comparisons." I But the man in whose labours the tendency of thought which was uncritically followed by Grethe, and magnificently represented in Hmmboldt, fomd the clearest scientifie expression, so far as amimated natme is eoneerned, was Étienne Geoffroy caint-Hilaire, the friend and colleagne and then the sreat rival of Cuvier." No one recognised more elearly the deeper significance of the great outburst of the two eonflicting ways of viewing natme in the P'aris Acadeny of Feiences in 18:30 than Groethe hinself, who in the eighty-first year. of his life was deeply stirred by seeing his favourite ideas espoused by a scientific anthority of the first order."

1 See Julius Ewalı in the third volume of the "Jueben Hum. boldt's' by Bruhns (German eclition), p. 154 .

2 See Huxley in 'Life of Owen.' vol. ii. 1), 29:3.

3 Eckermann in the 'Conversal. tions with Guethe" gives the follow. ing remarkable account, under tate 2nd August 1830: "The news of the outbreak of the French lievolu. tion arrived to-clay, and created excitement everywhere. In the course of the aftemosu I went to Guethe. 'Well,' he called out to ne, "what do you think of this great event? The volcano has come to an eruption, everything is in Hames, and it is no longer a diseussion witl closed dooss.' 'A Arealful affair,' I replied. 'But what else could one expect uniler the well-known cireumstances and with such a ministry, but that it would end with the expulsion of the Royal Fimily?" "We do not seen to understand each other. my friend,' retorter Goethe. 'I am in nowise speaking of those penple: I an coneerned with quite difierent thiugs. 1 speak of that nust im. portant confliet which has come
41.

Geolliroy

SaintHilaire. 
Similarly the aged Gauss, twenty-four years later, listened with emotion when Riemann, in his celebrated dissertation, touched a string that had been vibrating in the master's soul for fifty years, unheard or unheeded by any other thinker. ${ }^{1}$ We can best understand the two ways of reasoning in natural objects, which found an expression in the controversy between Cuvier and SaintHilaire, if we read the account which Goethe himself subsequently published in a Berlin periodical: "Cuvier labours untiringly as a distinguisher, describing accurately what lies before him, and thus attains a command over a great breadth of facts. Geoffroy Saint-Hilaire, on the contrary, is silently exercised about the analogies of living creatures and their mysterious relations." 2 The two men had worked as colleagues for thirty-eight years, Cuvier continuing and defining more clearly the classifying work of Linnæus, who, for example, had thrown all non-vertebrate animals into one class. This led him

to pass in the Academy between Cuvier and Geoffroy Saint-Hilaire, and which is of such importance to science.' This utterance of Goethe was so unexpected to me that I did not know what to say, and that for some minutes I experienced a complete cessation of my thoughts. "The matter is of the greatest importance,' continued Goethe, 'and you have no idea what I feel coucerning the news of the 19th July. We now have a mighty ally permanently in Geoffroy. But I also see from it how great is the interest of the scientific world in France in this matter, as, in spite of the frightful political excitement, the meeting took place in a crowded house. What is best is, that the synthetic treatment of nature, introduced $\mathrm{by}$
Geoffroy in France, cannot again go back. . . . I have for fifty years laboured in this cause ; first alone, then supported, aud at last, to my great delight, excelled by congenial minds. . . . This event is for me of incredible value, and I rejoice rightly over the ultimate general victory of the cause to which I have dedicated my life, and which also is essentially my own."

1 On this incident see the prefatory notice in Riemann's 'Mathematische Werke,' ed. Weber, Leipzig, $1875,1.517$; also the 13th chapter of this volume.

2 Goethe in the 'Berliner Jahrbücher für Wissenschaftliche Kritik,' vol. ii., 1830, September, reprinted in Werke II. vol. vii. p. 167 $s q q$. 
ON THE MORPHOLOGICAL VIFW UF NATURE. 255

finally in 1817 to establish the four great classes- the vertebrate, the molluscons, the articulate, and radiated types-in the animal kinglom. His colleagne harl contributed much to Cuvier's work, but had been increasingly struck by what he termed the "unity of organic composition," which he evernore looked upon as a key ${ }^{1}$ to the comprehension of nature: he searched for one plan or type where Cuvier saw four types. In 1818 he published his principle in a celebrated work with the title, 'Théorie des Analogies, on de I'hilosophie Anatomique.' ' It has been correctly stated that he only rives more precise expression to a truth known to Aristotle and proclained by Buffon, that the mystery" of organisation consists in " unity of plan comlined with variety of composition." Cuviel emphasised and studied the latter, his colleague the former. For an intinate knowledge and description of natural objects the work of distinguishing is all important; for a comprehension of nature the connection of things, the unity of plan, the filiation and relations of beings, the mutability of species, will ever be the more important and fascinating. The former was a pmely scientific, the latter a philo-

1 See Goethe's detailed lieport, loc. cit., Werke II. vol. vii. p. 173 . A very full aecount of this celebrated controversy is also giveu in the posthumous work of Duerutay de Blainville, 'Cuvier et Geoffroy' Saint-Hilaire, Biographies scientifiques,' ed. Nicard, Jaris, 1890 , pu. $357-375$, which is specially interesting, because Geoffroy's ideas were there traced to Lamarck (p). 351 ), of whow Goethe takes no notice.

"See the "Elloge Ilistorinue d'Etienue (ieoffroy Saint-Hilaire," par $P$. Flourens, in the third volume of lis 'Recueil des Filoges,' \&e., Paris, 1862, pr. 229-281. He quotes, inter alia, a passage from Vieqd'Azyr : "La nature semble opérer" toujours d'ajoès un molle primitif et général dont elle ne s'écarte qu' it regret, et lont on rencontre partout des traces. . . . On observe partout ces deux characteres que la nature semble avoir imprimés ì tous les êtres, celui cle la constance dans le type et celui de la variété dans les morlifications," \&c. (1). 270). 
sophical, task. Both thinkers were right, but only partially right, as Huxley has clearly shown; ${ }^{1}$ but it was natural that Cuvier's position should for a long time be regarded as the stronger; since he had shown how, by detailed research, to increase enormously the stock of actual knowledge about the things of nature: whereas the uncritical and only half practical suggestions of Goethe had undergone in the wild speculations of Schelling, Steffens, and Oken a development that frightened off men of exact thought. Cuvier saw the necessity of crying halt to these vague dreams which he had the merit of opposing, for the lasting benefit of true science, with the full force of his great authority. ${ }^{2}$

As in France and Germany so also in England, the tendency to distinguish minutely, to describe, to classify, and in doing so to fill the museums with new specimens,

1 'Life of Owen,' vol. ii. p. 296 : "The irony of history is nowhere more apparent than in science. Here we see the men over whose minds the coming events of the world of biology cast their shadows. doing their best to spoil their case in stating it; while the man who represented sound scientific method is doing his best to stay the inevitable progress of thought and bolster up antiquated traditions. The progress of knowledge during the last seventy years enables us, to see that weither Geoffroy nor Cuvier was altogether right nor altogether wrong; and that they were meant to hunt in couples instead of pulling against one another."

2 As to Cuvier's own wavering on the great question of the fixity of species, see Huxley, loc. cit., p. 294 : "During the earlier part of his career, I doubt if Cuvier would have categorically denied any of
Geoffroy's fundamental theses. And even iu his later years Sir Charles Lyell, many years ago, gave me reasons for the opinion that Cuvier was by no means confident about the fixity of species. There was never any lack of the scientific im. agination about the great anatomist; and the cliarge of indifference to general ideas, sometimes brought against him, is stupidly unjust." And further, p. 295: "In later life, however, Cuvier seems to have become so much disgusted by the vagaries of the Naturphilosophic school, and to have been so strongly impressed by the evil which was accruing to science from their example, that he was provoked into forsaking his former wise and judicious critical attitude; and in his turn he advocated hypotheses which were none the better than those of his opponents." 


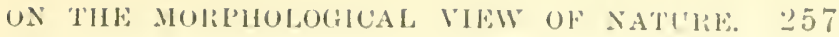

and to discover and arrange systenatically unknown and extinet species, got the upper hand for a long time. No one has done better work in this large field than Richard Owen, who has been terned with some propricty the british Cuvier. lint in following lischard the lines and filling un, the sehedules which ('uvien had prepared, Owen and other ${ }^{\mathrm{I}}$ contemporary workers in the same field have also had the great merit of hringing the Cuvierian view to the point where it elearly leads on to another and more comprehensive view of nature. In the first place, it happened that in finding and describing the remains of extinct aninals. increasing diftienlty was experienced ${ }^{2}$ in deciding to which of the great existing groups of anjmals they should be assigned. There arose the necessity of interpolating species between groups which we now look upon as widely separated. The necessity arose of forming the conception of what is now termed the "inter-

${ }^{1}$ Huxley, loc. rit., p. 310 : "Un. less it be in the 'Ossements fossiles,' I do not know where one is to look for contributions to palieontology more varienl, more numerous, and, on the whole, more accurate, than those which Owen poured forth in rapid succession between $18: 37$ and 1888. Yet there was no lack of strong contemporaries at work in the same field. De Blainville's 'Ostéographie'; louis Agassiz's monumental work on fossil fishes, achieved under the pressure of great obstacles and full of brilliant suggesticns; Von Meyer's long series of wonderfully aceurate memoirs, with their aclmirable illustritions executerl by his own hankls, all belong to Owen's generition."

2 See on this Carus, 'fieschichte VOL. II. ler \%oologie,' p. 618, and Huxley, loc. cit., p. 309 , where referenee is made to Owen's memoir "on an exlinet mammal discovered in south Auerica by Darwin in 1833, which Hwen named Trxodon Platensis. It is worthy of notice that in the title of this memoir there follow, atter the name of the species, the works "referalile by its dentition to the Rodentia, but with aftinities lo the l'achydermata and the herbivorous C'etacea'; indicating the inportance in the mind of the writer of the fact that, like Cuvier's Anoplotherium and l'uleotherium, Taxodon oceupied a position be. tween groups which, in existing nature, are now wilely separated. The existence of onl" more" "inter" ealary' 'ype was establisherl." 
calary type." Especially through palæontological finds, the landmarks were gradually removed which separated the distinct species and groups of organised beings. It had happened to Cuvier only in single instances that he had to record resemblances between widely separated groups. Such resemblances became more and more frequent and perplexing. In the second place, Owen had the great merit of giving more definite ex44. pression to the conception of analogies, as developed Study of homology. principally by the school which Cuvier opposed. In fact, he revised and brought into general use the term "homology," which had already been used by French and German anatomists before him." This term signified

1 Great importance has been attached to the term "homology," wlich, to a reader uninitiated in the complicated and changing vocabulary of the uatural sciences, presents not a little difficulty. It is a good example of the classical saying of Goethe, "dass wo Begriffe fehlen, da stellt ein Wort zu guter Zeit sich ein." In the attempt to define the current term "homology," in seeking for numerous examples of homologies as distinguished from analogies, naturalists were led to the recognition of real, not only of verbal or logical distinctions. In this respect it is most instructive to read Owen's treatise 'On the Archetype and Homologies of the Vertebrate Skeleton' (1848), the enlarged reprint of a Report to the British Association in 1846. In it he gives a pretty full history of the term homology, which in the first half of the nineteenth century became current with special meanings in three independent sciences. With the precision of the usage, both in geometry and chemistry, the vague- ness of the term as used by nat. uralists stands in characteristic contrast. "The corresponding parts," Sir R. Owen there says (p. 5), "in different animals being made namesakes, are called technically 'homologues.' The term is used by logicians as synonymous with 'homonyms,' and by geometricians as signifying 'the sides of similar figures which are opposite to equal and corresponding angles,' or to parts having the same propor. tions: it appears to have been first applied in anatomy by the philosophical cultivators of that science in Germany. Geoffroy Saint-Hilaire says, "Les organes des sens sont homologues, comme s'exprimerait la philosophie Allemande; c'est-à-dire qu'ils sont analogues dans leur mode de développement, s'il existe véritablement en eux un même principe de formation, une tendance uniforme à se répéter, à se reproduire de la même façon." After remarking on the looseness of this definition, Owen proceeds to give his own, taken from the "Glossary" ap- 
comespondence of parts ol olgans bised not so lunch on external likeness as on similarity of origin. by aclmitting the latter conception, the irlea of origin, the rigidity of the purely structural classification was lost. Morphology became the seience, not of fixed, lut of tlowing forms and structures. It is remarkable that Owen, in following up this line of reasoning, was pre-eninently attracted to the oracular writings of Oken, whose influence his great forerumner C'uvier had combater with all his

pencled to the tirst volume of his 'Hunterian Leetures,' as follows: " Analogue'-A part or organ in one aninal which has the same function as another part or organ in a different animal." " "Homologue'-The same organ in diferent animals under every variety of form and function." "He then gues on to distinguish "special," "general," and "serial" homology. Fin a history of thought the imfor. tint point in all these divensions is that, besides the similarity of structure and the sameness of function, relations and points of comparison of a different kind were introduced; that these were, with more or less elearness, traced to developnent; and that throush this the genetic view, the doctrine of descent, was Irepareal by those who, like Owen, were least ready to accept it when it appeared in a definite form. In the light of this new view, of which the next chapter will treat, the whole vocahulary of the older morphologists required recasting. These olles views, which traced homology to the existence of definite types, models, or patterns possessing a purely ideal existence, have heen termerl Platonic, inasmucl 22.8 in the philosophy of Plato the exist. ence of a world of ideal forms or archetypes served to explain whatever of order is found in the real world of separate things. "The term 'homology,'" say's Prof. Kay Lankester, "belongs to the l'latonic school, but is nevertheless used without hesitation by those who reject the views of that school. prof. Owen . . would understand by 'homologue' the same organ in different animals under every variety of form and lunetion. . . . But how can the sameness of an organ under every variety of form and function be establislied or investigated? This is, and always has been, the stumbling-block in the study of homologies without the light of Evolutionisu ; for, to settle this question of sameness, an icleal 'ty'ue' of a group of organisms under study liad to be evolved from the human mind, after study of the component nembers of the group ; and then it could be asserterl that organs might be said to be the "simes" in two animals which had a common representation in the ideal type" ("Amnals and Mag. of Natural History,' $4 \mathrm{th}$ series, vol. vi., 1870, p. 34, ke.) See also Huxley in 'Life of Owen,' vol. ii. p. 303 , \&c.; and J. Artlur 'Thom. son, 'The Seience of Life,' D. 32 (1899). 
might, and who "provided him with the subject-matter of his severest as well as of his most justifiable sarcasms." 1

The great extension of the morphological or structural view of nature into distant time and space-into palæontology by Cuvier and Owen, into geography by Humboldt, Ritter, and others-i.e., morphology on an extensive scale-led to an appreciation of the labours of a different class of students of nature, namely, those who-also on a large or a smaller scale-investigated the agencies which bring about and the laws which govern the change of forms. I have now to mention the last great contribution to the purely morphological The cellular view, I mean the cellular theory, which tended ultimately

in a similar direction.

The earlier researches into the minute microscopic structure of organised beings-such as those of Malpighi and Grew in the seventeenth century-were conducted by persons who took an equal interest in animal and plant life. ${ }^{2}$ But this class of research soon fell into the hands of specialists, with the result that anatomy, the science of animal structure, and phytotomy, that of vegetable structure, were conducted on different lines

'Huxley, 'Life of Owen,' vol. ii. p. 315 .

2 Carus ('Gesch, der Zoologie,' p. 395) mentions especially Malpighi (1628-1694) as an exception, inasmuch as he conducted his researches from a purely scientific interest, keeping them free from extraneous practical considerations. "In his anatomy of plants there are laid, moreover, the first foundations, more firmly established by all sub- sequent researches, of the doctrine of the composition of all organised bodies out of cells, which has given to the whole conception of the living creation a definite startingpoint, and in the sequel a firm basis for the genetic view." See also on the same subject, and on the relation of structural and physiological researches in the seventeenth and eighteenth centuries, Sachs, 'Gesch. d. Botanik,' p. 351, \&c. 
ON THE MORPHOLOCICAL VEW OF X゙A'TRE. உG

and for different pmposes. The fate that the organisittion of the higher amimals, which, for medical reasons, is more interesting, can he ronghly divided into a variety of separate organs or systems of organs, each of which can be, to some extent, studied by itself as we sturly the parts and workings of a machine, and that for the physician greater interest attuches to the funetions of these organs, placel anatomy for a long time under the influence of physiology, which is the science of the performanee, not of the strncture, of the parts of living cleatures. Phytotony, on the other side, was for a long time neglected, awating the greater perfection of the mieroscope. Thus it came about that down to nearly the middle of the century the morphological study of amimals and that of plants were pursued withont mueh mutual benefit or regard. The phytotomists of the seventeenth century laad established the fact that plants are built up of minute parts called variously utrieles, hladder's, vesicles, but mostly eells, and which were compared with the structure of the foam of beer or the cells of a honeycomb. I) Ifferent forms were assigned to these cavities,

1 Aug. l'yx. de c'andalle begins lis 'Urganographice' 1527) with the worls: "La mature intine des vegritaux, vue aux plus forts microscoues, offre peu de diversités. I,es plantes les pilus disparates mar leurs formes extérieures, se resisublent al l'intérieur it un legré v'rainent extraordinaire," \&c.: and after going back to the observations of Malpighi and Grew, and relerring to the recent mes of birliel, link, Treviranus, siprengel, Rudolphi Kieser, Introcliet, aml Anici, men. tions Kieser's " llémoire sur l'Organ- isation des P'lanter' (Harlen, 1\$12) as the only Freneh book which eon. tains an aceount of the plivtotomic researches curried on by the (iermatus, who, after the larise of a century, were the first to take ul, these studies again. In the secomil chatpter" he Camblle says: "Le tirsu cellulaire, considéré en masie. est un tissu membraneux formé par min grand nombre de cellules ou de cirvités eloses de tontes parts; l'écnue de la lic̀re ou un rayou de miel en doment me idée grossièe mais assey exacte" (p), 1]). 
and it was also recognised that they were frequently elongated into tubes or joined so as to form larger vessels. In all these researches and descriptions paramount importance was attached to the form and composition of the framework of this cellular arrangement, and only little to its contents. In fact, the historian of botany ${ }^{1}$ characterises the period from 1800 to 1840 as that of the study of the cellular framework of plants. The skeleton, as it were, of plant structure received primarily the greater attention. In the course of these researches, which, with a few important exceptions, were all carried out in Germany, one point was permanently settled, namely, that "the cell is the one fundamental

46. element of all vegetable structure." 2 No one did more Hugo von Sohl. to establish this important fact than Hugo ron Mohl, whose name has been somewhat cast into the shade by the more attractive writings of Schleiden. It was Schleiden who first brought the new cellular theory into popular recognition, not without an admixture of errors, which had to be gradually eliminated in the various controversies with which his name is connected.

1 See Sachs, loc. cit., p. 276, \&c. This period finds its consummation in the researches of Hugo von Mohl. It begins with those of Brisseau Mirbel, the first French author who took up this line. His labours were continued and criticised by a long list of German naturalists. Sachs also refers to the erroneous habit these earlier phytotomists had of getting their diagrams of what they saw by the microscope made by other persons who were supposed to be impartial - a custom fortunately abandoned by Mohl, who in his drawings did not give "undigested copies of the objects but his own impressions of them" (j. 281).

2 Sachs assigns the final establishment of this principle to the year 1831 , and considers it as one of Mohl's achierements, since, although it had been already aunounced by Sprengel and Mirbel, it had not been sufficiently supported by observations. Even the curious but antiquated idea, according to which the spiral fibre formed a fundamental part of plant structure, survived up to 1830 (p. 323). 
But the highest value for a history of Thought attaches to this point for a different reason. In it the longrseparated lines ${ }^{1}$ of botanical and zoological sturly net again. Inmediately after the alpearance of Schleiden's epoch-making publieation - and partly in consequence of rehleiden it-Theodor schwann was induced to collect, in $18: 59$, all the known olservations, coming principally from the school of Johannes Miiller, which referred to the existence and formation of animal cells, and to utilise them in the enunciation of his great generalisation, "that there is one universal prineiple of development for the elementary parts of organisms however lifferent, and that this prineiple is the formation of cells." 2

I The fourth decade of the century was alsin the period in which plyysical and chemical methorts and icleas were-notably in France and Germany-marle useful for anatomical and physiological research in zoology and botany. Sachs, however, sisnificantly warns us against the view, which has siuce been frequently put forwarl in an exaggerated form, that the physiology of plants eonsists in nothing but applier plysics and clemistry (loc. cit., p. 393, \&c.) That Schwann himself attached the greatest importance to this point ean be seen from the preface to his principal work. This appeared in 1-39, and was translated into Juglish by Henry Smith, and puhlisherl by the Sylenham Society in 1547 with the significant title, "Microscopical Re. searches into the Accoldance in the structure and Growth of Animals and Plants.' 'The tranklator has also attaches a remlering of Schleisten's 'Contribution to Phytogenesis,' which appeared first in Part II. of Miiller's 'Arcliv fir Anatomie umb l'hysiologie' in 1838, and wis. also translated in 'Taylor's Scientific Memoirs,' vol. ii. jart 6.

2 schwam, loc, cit., 1. 165. A little iarther on he arlis the following generalisition, which it is well t) read in the light of more recent researches: "A structureless substance is present in the first instance, which lies either around or in the interior of cells already existing: aud cells are formed in it in accord. ance with certain laws, which cells hecome developed in various ways into the elementary jitrts of organisus." It is clear that the discovery of what nay be ealled the morphological element or unit of orginisent structures in this view meant the end of pure morphology. The problem of the explanation of existing forms was hambel over to the student of development, to the genetic view and conception of nature. The cellular theory, thus rumeiuterl in its greatest generality by Solnwam, has formed a kind of provisional resting-place in the sturly of the forms and ehanges of living nuture; as Newton's gravita. tion formula has served as a provi- and

vil iwann. 
Morphologically the microscopic examination of animal and vegetable tissues had thus led not to a clearer definition of the great differences which exist in the forms and structures of the larger and the full-grown organisms, but rather to a conviction of their intrinsic and essential sameness. These differences conld not be explained in the purely morphological manner in which Haiiy had shown how to trace the difference of crystalline forms to the shapes and configuration of the "molécules intégrantes." The diversity of forms had to be traced to processes of growth or development-i.e., the purely Transition
to the study morphological examination led on to the developmental
of development. or genetic study of organic forms. And this was made still more evident when the microscopic examination revealed yet other and more important elements in the composition of organic structures, elements which were seemingly quite shapeless or amorphous. The skeleton, which had so long seemed to contain the key to the understanding of organic forms, the framework of the plant structure, the cell-walls and partitions, with all their geometric figures and arrangements, turned ont to be of quite secondary importance compared with the cell contents, the substance called in animals by Dujardin sarcode, and in vegetables by Von Mohl protoplasm, and with the nuclens or cell-kernel, which had been discovered by Robert Brown. ${ }^{1}$ Accordingly great interest attached

sional basis for physical astronomy. Both generalisations involve unsolved problems, with the difference that the formulation of the cellular theory is not as precise as that of gravitation.

${ }^{1}$ Both the discovery of the nucleus by Robert Brown and that of the cell contents by Dujardin preceded the enunciation of the cellular theory. Brown's discovery was referred to both by Schleiden and Schwann. In fact, Brown's researches were much better known and followed up in Germany than in England. His papers were trans- 


\section{to these anorphous ${ }^{1}$ constituents, and chemical investi-} gations as to their eomposition were added to the previous microscopic dissection. The purely morphological view

lated into (ierman by" a number of botanists, and erlited in tive volumes between 1425, and 143.1 by Nees von Esisenbeck. He dirl not collect his original ieleats into any great work or propound a new system of classitication as dill Jussieu and the Cinclulle, whom be eyuals in seien tific inportance; his valuable generalisations were given oceasionally in his numerous monographs, Suchs considers him more advanced than the two great rivals just named, inasmuch as he had an appreciation of yuestions of development which they liteked ("Fickeh. d. Botanik,' ए. i21). Humboldt called him "botanicorum facile princeps," and succeeded in procuring for him, through his intluence with sir Robert Peel, a pension of ¿200 per ammum.

1 The detinition of a cell--i.e., of the morphologrical or form-element of organised matter, as consinting of a membrane, a cell content, a nucleus, and a nucleolus-stood in contrast with Felix J)ujardin's de:cription, in 1835, of a living substance which he net with in his researches in lower animal life, and which he had eilled "sareode." In the place of this name-the observation of Dujatrdin being little notieed - Von Mohl, after having for a time acepted the erroneous theory of schleiden and Schwom as to cell. formation, introduced the term "protoplasma," which has been retained in science as the name of the elementary constituent of all liviug inatter with very varying detini. tisns, according to the different observations of animal or vegetable organisms and the increasing postr's of the mieroseope; this having revealed structures where before only iuruless, amorphous sulsistance hat becen observed. "l'he history is these fluctuations of opinions and definitions can be real luth in the older histories (Sitchs, Carus) amel the more recent accounts. Anomg there numerous exposilions, see especially Yves Delage, "L'lléréditú et les grauds problèmes de la Biolugie,' 1595, 1. 19, ac.; 0. Ilertwig, 'The Cell,' translated firm the German by H. J. Cimplell, 1895; and the mont recent work by lor Val. Hacker, "Praxis und Theorie iler Zellen und liefruchtungslehre, . Jena, 1599, 1. 10, de. 'The cellular theory has gained enormously in importance and in popular esteen, as has also the stucly of all mieroorganisuns, through its application (6) medicine and luygiene. [n 1847 kudolph Virchow founded his celebrated "cellular pathology," eom. bining the many beginnings of the cellular theory which had been laid by others, in his famous axiom "omnis cellula e cellula." He gave up the theory of the free formation of cells, proclaimed the duetrine of the genesis of cells-even patholugical ones-by cell-division, and arlopted Goodsir's theory of the uninterrupted filiation of the ele. ments of all living matter, of the autonomous cells. As in general biology, so also in cellular patholugy, the last tifty years have witnessed gleat controversies and many special theories, one of the chief difficulties laving leen to connbine the doetrine of the automomy (1) inclividuality of the cells with a correct view of their tiliation and commecterl life. In spite of these many ehanges and modifications, the nime of Schwam still stands at the opening of every treatise on fumbla- 
had exhansted itself. The fundamental unity of the organisation of living beings had been proved; how was their actual diversity to be explained? This evidently required considerations of a very different kind. What they were we shall see in the next chapter. The position of the morphologist in the middle of the century had thus become one of considerable perplexity. It may be compared to that of the organic chemist about the same time. The older ideas, around which, under the great influence of Cuvier and De Candolle in zoology and botany, of Werner and Humboldt in geology, the morphological classification and description of natural objects had clustered on the Continent, had become obsolete. The doctrine of definite types, of architectonic models, or of distinct ages of creation, separated by catastrophic changes, was becoming untenable; floras and faunas of entirely different appearance had been revealed in other countries and climates in the distant past, ${ }^{2}$ or in the great newly-discovered realm of living

mental biology, aud that of Virchow at the origin of modern pathology, as the greatest practical application of the cellular theory. An exceedingly good record of the different and changing views referring to the cell will be found in the chapter on "Cell and Protoplasm" in J. A. Thomson's 'Scieuce, of Life,' pp. 101-117.

" $\mathrm{On}$ comprend aisément le découragrement de Robin renonçant à édifier son 'Traité d'Anatonie générale,' après avoir tenté inutilement, dans *a 'Chimie anatomique,' de pénétrer le mécanisme des phénomènes moléculaires s'accomplissant dans les corps organisés. La moruhologie, pourtant, n'avait pas dit son dernier mot, et la barrière bio-chimique était moins rapprochée que le ne croyaient les disciples de Comte et de De Blainville" (Herrmann, article "Cellule" in "La Grande Encyclopédie,' vol. ix. p. 1060).

2 Owen, in the very instructive "General Conclusions" to the third volume of the 'Anatoing of Verte. brates' (1868), clearly points out how the position of Cuvier has been made untenable by these discoveries: "As my observations and comparisons accumulated, with pari passu tests of observed phenomenit of osteogeny, they enforced a reconsideration of Cuvier's conclusions to which I har previously yielded assent" (p. 188). "Accurdingly, these results of extensive, 
forms only aecessible to the mieroseope. 'The metamorphosis of the different organs in the plant had been suggested by Wolf, and more fully demonstrated by Goethe. Unity of organisation had been proelitined by saintHilaire and De Blainville, and the ultimate identity of the elementary strueture of animals and plants had been demonstrated by Schleiden and Schwann. How was the evident relationship of the different types of living beings to be explained? It is interesting to note low the very terms whieh were then used implied the explanation, though this was only apparent to one or two natural philosophers who were then secretly at work. 'The word "aftinity," which in chemistry has for ages been used to denote, without explaining, the mystery of eombinations and separations of different substances, had been imported into philosophieal anatomy to denote the deeper struetural likeness hetween animals which at the first glanee appeared to helong to different elasses. This word ordinarily intplies blood-relationship, and might have

patient, and unbiasserl inductive rerearch-or, if there were a bian, it was towarl cuvier-swarel with we in rejecting the principle of direct or miraculous ereation, and in reegnising a "natural law or secomiary cause as operative in the production of speeies in omlerly succession and progression' $(1+19)^{2}$ (p. 789)... "Wach successive parcel of geological truth has tencled to rissipate the belief in the un. usually sudden and violent nature of the changes reeognisalile in the earth's suriace. In specially directing my attention to this moot point, whilst engaged in investigations of fossi] renains, and in the reconstruction of the species to which they lelonged, I was at length ledi to recoguise one eaune (i) extinction as being rlue to defeat "in the eontest which, as a living organised whole, the indiviclual of each species harl tor maintain against the surrounding asencies which might militate "rainst its existence". ( $p .797$ ). 'Though this passage, quoted ly Uwen irom the pretice (1s60) of the same work, a controversy arose. it being taken Iry a reviewer to prove the arlmission of the Dar. winian theory. There followed an explantion by Owen, rejecting matural selection and the admitted contest as explanations of the origin of speeies. 
suggested the theory of descent: it was used by those who most strongly repudiated such a doctrine. ${ }^{1}$

In the absence of any satisfactory explanation of the continual recurrence of certain definite forms in nature, and the presence of an evident relationship and a clear indication of metamorphosis in single instances, it was natural that morphologists of the first order, such as Owen, and other authorities in science, such as Whewell in England and Alexander Bram in Germany, should have recourse to older views and vague philosophical theories. Owen in 1848 spoke of a specific organising principle which "moulds in subserviency to the exigencies of the resulting specific forms," argues that the knowledge of such a being as man must " have existed before man appeared, for the divine mind which planned the archetype also forcknew all its modifications," and conclucles that we learn from the past history of our globe that "nature has advanced with slow and stately steps, guided by the archetypal light, amidst the wreck of worlds, from the first embodiment of the vertebrate illea under its old ichthyic vestment until it became arrayed in the glorious garly of the human form." 2

1 Huxley in 'Life of R. Owen,' vol. ii. p. 302 .

"See Owen's treatise 'On the Nature of Limls,' 1849 , pp' 85, 86. In the essay "On the Archetype and Homologies of the Vertebrate Skeleton,' he concludes with the following remarks: "Now, besides the $i \delta \epsilon ́ \alpha$, organising principle, vital property, or force, which produces the diversity of form belonging to living loodies of the same materials, which diversity canuot he explained by any known pro- perties of matter, there appear: also to be in counter-operation during the building up of such bodies the polarising force pervad. ing all space, and to the operation of which force, or mode of force, the similarity of forms, the repetition of parts, the signs of the unity of organisation may be mainly ascribed. The Platonic i $\delta \epsilon \alpha$ or specific organising principle or force would seem to be iu antagonism with the general polar. ising force, and to subdue and 
ON THE MORPHULURICAL VIEW OF NATLRE. 269

Whewell, in various passages of his 'History' and of his 'Philosophy of the Inductive Sciences,' argues that the explanation of organic forms is to be found in the study of the functions which each organ is destined to perform, and brings morphology back under the guidance of physiology, from which be Candolle and others had only recently liberated it." Alexander Bram, the great German botanist, wrote about the same time: "Although the organism in its growth is sulject to physical conditions, the real causes of its morphological and biological speciality lie, nevertheless, not in these conditions: its laws belong to a higher gralle of development of reality, to a sphere in which the capacity for spontaneous self-determination becomes evident." 2 Even Johamnes Miiller,

mould it in subserviency to the exigencies of the resulting specitic form" (1) 172). Huxley attributes these theoretical views of Owen $t o$ the intluence of Lorenz Oken, the urincipal scientific representative of the sehool of the "Naturphilusuphie." In this re-ject Owen left the direction oi study initiated and so successfully followed by Cuvier. In fact, though opposed to Darwinism, ()wen di,l not, like Cuvier, believe in special creation, ats is clearly shown in a pasinge frequently quoted, taken from the conclusion to the third volume of wen's great work 'In the An. atomy of Vertebrates' (1865), 1). s07: "So, being unable to accept the rolitional hypothesic, or that of impulse from within, or the selective force exerted ly outwarl circumstances, 1 deem an innate tendency th deviate from parental type, operating through periols of allequate duration, to be the mont probalble nature, or way of operation, of the secomlary law, whereby species have teen derivel one from another."

1 De Candolle is very clear on this point; he salys ("Throric élémentaire,' p. 170): “. L'usage de. organes est une conséquence de leur structure, et n'en est nullenent la cause, comme certains éerivains inéHéchis semblent l'indiquer; l'usage. quelque soit son importance dins. l'étude physiologique des tres, n's donc en lui-même qu'une médiocre importance dans l'anatouie, et ne peut en avoir aucune dans la taxonomie; quelquefois seulement on peut s'en servir comue d'un indice de certitines structures it nous "nesre inconnues ; ainsi lorsque je sois la surface unie d'un pétale suinter une liqueur, j'en conclus que cetse partie est glandulaire, et je l'assimile aux neetaires; mais cette assimilation, bien que reconnue par l'identité de l'usage, est ríellement établie sur l'identité prisumée de lia structure."

2 Quoterl by Sachs (Gesch. d. lotanik,' p. 158). 
who did more than any other naturalist to base zoology, anatomy, and physiology on the foumdation of the exact sciences, physics and chemistry, "assumed the existence of a vital force which, differing from physical and chemical forces, enters into conflict with them, and which in organisms acts the part of a supreme regulator of all phenomena according to a definite plan." 1

50.

Insutficiency of the morphological view.

The insufficiency of a purely morphological description of living beings, the unsuccessful search for the morphological elements out of which organisins are built up, as crystals are formed out of the molecules integrantes of Haiiy, led thinkers (up to the middle of the century) to have recourse to older and vaguer conceptions, which, under the name of archetypes, formative influences, vital forces, \&c., were destined to help where the purely mechanical view would not suffice. This dilemma was appropriately described somewhat later by one who had-earlier, perhaps, than any other thinker-emancipated himself from the influence of these fanciful conceptions. Herbert Spencer in his 'Principles of Biology, published in 1863, expresses it in the following words: ${ }^{2}$

"If we accept the word 'polarity' as a name for the force by which inorganic units are aggregated into

1 See Du Bois-Reymond, "Gelächtuissrede auf Johannes Mäller" ('Reden,' vol. ii. p. 217).

2 The 'Principles of Biology,' from which this extract is quoted, appeared in successive instalments, beginning in January 1863 . It is well to note that this was before the appearance of Haeckel's 'Generelle Morphologie,' which bears the date 1866. It does not appear tliat
Spencer has had any influence on German science, though no doubt many of the conceptions put forward in the numerous treatises of German biologists are anticipated in Spencer's 'Biology,' notably in his conception of the physiological anits as intermediate between compound chemical molecules and erystals on the one side, and cells on the other. In the exhaustive 
ON THE MORPHOLOGICAL VIEW OF NATLRE. 271

a form peeuliar to them, we may apply this word to the analogous force displayed by organie units. liut polarity is but a name for something of which we are ignorant. Nevertheless, in default of another word we must employ this. . . It will be well to ask what these units are which possess the property of arranging

review of these theories, given by II. Yves Delage, a very prouninent position is accordingly issigned to Herbert spencer's biological writings. In fict, he sayss ('L'Hérédité,' p. 424 note): "lei"-i.e., in the 'I'rinciples of Biology" - "est montrée, prour la première tois et avec une lueidité parfaite, l'utilité de concevoir des particules spéciales, féments primitifs de la substance vivante, intermérliarjes aux inolécules et atux cellules. Les tris nombreux auteurs qui ont utilisé la même iclúce n'en ont créé que des variantes. Spencer est le rrai pìre de la conception initiale, si fécounde comme ou le verra." And again (ibid., 1. $\left.\$ 36^{\circ}\right)$ : "Brusquement, arec H. Spencer, on tombe en plein molerne. Ici plus de thécries vieilluttes, plus de procédés surannés. . . Les phénomènes sont décomposés en leurs éléments avec une puissance d'abstraction qu'iducun philosople n'a dépassée, des principes généraux sont déduits qui servent à leur tour à juger, ì interpréter les phénomènes, ì les ramener à leurs causes vraies. Comme résultat de ses méditations, spencer nous offre les 'Unités pliysiologiques,' particules matérielles toutes idlentiques dans uue méme espèce d'etres avec lesquelles il croit que l'organisme doit pouvoir se construire le lui-même, par le seu] jeu de leurs forces moléculaires. ..1l a... ouvert uue voie: sa théorie est un des bras principaux du Delta de ce fleure qui nous scrvait de terme de comnparaison." The other great arm of the Delta is Darwin's theory of Pangenesis, on which see infin, chapter xii. of this volume. OI others, such as Ellswerg, 1laeckel, His, Haticke, It. Delager sayss: " 1/s ont ríussi seulement it montrer. qu'en sulstituant aux forces polaires des 'I'nités phy'siologiques,' des formes de mouvement ou des proprités gémenetriques, on n'arrive pas à un meilleur résultat." l'rof. Haeckel in his "Generelle Morphologie' (1866) has interpolated a special investigation, as it were, between the morphology of living things and the corresponding science of iuorganic or purely physical (such as erystalline and chemieal) structures and arrangement under the name "l'romorphology," investigating with much ingeuuity all manner of symmetrical, axial, rulial, se., configurations. J. Arthur Thomson ('Science of Life,' p. 34) remarks that little attention lati been paid to this subject since, but, as stated above (p. 223 note), the systematic treatment of crystallography has all through the century appeared to biologists as an enticing and seductive nodel, and N. Y'ves Delage's great work gives many examples of this tendency-see, e.y., his remarks on the theories of Hatacke, Cope, Niigeli, Erlsberg, and many others, 1p. $304,315,424,441,451,459,475$, $495,502,593,743, \& \mathrm{c}$. 
themselves into the special structures of the organism to which they belong. . . . On the one hand, it cannot be in these proximate chemical componnds composing organic bodies that this specific polarity dwells;... the occurrence of such endlessly varied forms would be inexplicable. On the other hand, this property cannot reside in what may be roughly distinguished as the morphological units. The germ of every organism is a microscopic cell, or a structureless blastema which nevertheless exhibits vital activities. . . . If, then, this organic polarity can be possessed neither by the chemical

Herbert Spencer's "physiological units." units nor the morphological units, we must conceive it as possessed by certain intermediate units which we may term physiological. . . . We must conclude that in each case some slight difference of composition in these units ... produces a difference in the form which the aggregate of them assumes."

Now, there are only two ways open to the purely scientific thinker by which he can reach these intermediate structures lying between the mathematical forms of crystals or the molecular arrangement of atoms, and the visible but apparently structureless forms of cells and protoplasm. One of these is the still more advanced analysis of these microscopic structures by still greater powers of magnifying instruments; the other is the mathematical method of calculating from simple beginnings the complex forms of equilibrium which atoms or molecules are capable of assuming under the action of known forces. It appears unlikely that the powers of the microscope can be much further extended; and the mathematical calculation of even the simplest configur- 
U. THE MORPHOLORICAL VIEW OF SATLRE. ¿ $7:$

ations of attracting and repelling centres, or of linker vortex rings, is already so formidable that much cammot be expected in that direetion. These intermediatr mits, vastly more complex than the most complex chemical molecules, and vastly more minute than the smallest visible grain of protoplasm, must therefore for a lomg time to cone lie in the region of hypothesis, mattainable for the eye or the ealenhs: an indication rather than a real guide for our scientific researches. Seeing, then, that the study of forms - the morphological view of natural ohjeets in the case of organic hemgs, where to the naïve eontemplation of things these forms seemed full of so much significance, indicative of so much meaning, possessed of so mueh beauty and striking suggestiveness -has led to no comprehension of the essence of vital phenomena, and hardly eren afforded a safe criterion for classifieation, it is intelligible how the scientific interest has moved away from the consideration of the fixed forms and structures to that of the variation and continued change of these forms. This alteration in the scientific way of lowking at the aetual forms of nature, goes hand in hand with the tendency we had occasion to notice when dealing with the abstract sciences. Many things which once seened at rest, or possessed of very simple reetilinear motion, have revealed themselves to the mind's eye as complex states of motion. Coloms are exceedingly minute and rapid but well defined vibrations; the deal pressure of gises is the impact of numberless quicklymoving particles; and the wonderful properties of the whirling vortex ring lave made us familiar whith what lias been termed the dymanical or moving equilibrimn, the VOL. II. 
semblance of apparent rest produced by very rapid rotary motion. Rest and fixity of form seem ouly to exist apparently or for transient moments in the history of natural events; and even the finished and recurring structures of living beings, which appear to our eyes to be possessed of so much finality and sometimes of so much finish, owe these qualities only to the comparatively short space of time during which we are permitted to gaze at them, and to our ignorance of the slow but endless changes to which they are nevertheless subject.

53. The morpho. logical period.

The period from 1800 to 1860 can be termed the morphological period of natural science. It succeeded the period of the simpler natural history, which had been mainly occupied with classification and description of specimens. During the morphological period the knowledge of the existing things and forms of nature was not only largely extended by excursions into distant lands and periods of history, but forms were also studied in situ, and the living things visited in their habitats. A deeper knowledge of the connection and interdependence of natural things and events was thus gained, and the relations and resemblances, the analogies and homologies, of the various forms were impressed on the observer. Besides all this, the microscope revealed the innermost composition and the ultimate structural sameness of living matter, adding moreover the knowledge of an enormous creation which remains hidden to the unarmed eye of the ordinary observer. The morphological view also took note of the relatedness and apparent recurrence of definite forms called types, of the so-called fixity of species and the succeeding characteristic periods of creation, and 
ON THE MORPHOLOGICAL, VIEW OF NATURE. 275

sought to explain these morphologrically: ief, it sought in the abstract sturly of forms-sometines geometrical, sometimes artistic-the key to an understanding of the recurrence as well as the continned variation of definit. types. 'The relationship was mostly looked "lpon as icleal, not real. How a gradual change came over this view of nature, how the study of development led on to the modern pluase of natural science which is governed by the grenctic view, I shall try to show in the next chapter. 


\section{CHAP'TER IX.}

ON THE GENETIC VIEW OF NATURE.

1. statics and dynamics of liv. ing forms.

Whilst the great influence of such leaders in scientific thought as Cuvier, De Candolle, and Humboldt on the Continent, and of Richard Owen in this country, was mainly exerted in spreading the morphological view of nature, describing on a large scale or in minuter detail the typical recurring forms which natural objects or natural scenery present to the eye of the mbiassed observer, another school of naturalists was secretly busy in following up the changes to which all the things of nature seem continually subjected. They were as much impressed with this restless movement of everything as the others were with the continual recurrence of certain definite forms - be they geometrical or artistic. The general ideas which underlay their researches were not new, - they were probably older and more familiar ${ }^{1}$ than

1 Cosmogonies of all sorts abound in almost every literature, ancient or molern, whereas Cosmography, accurate, painstaking, and reliable, is of comparatively recent date. The first attempt to give a purely descriptive picture of nature as a whole, beginning with the larger features of the universe and ascend- ing through terrestrial, inanimate and animate, phenomena to the central and crowning phenomenon of human life, was $A$. von Humboldt's 'Kosmos': and it is interesting to note how averse the autlior was to introducegenetic expositions. In fact, it has been truly remarked that Humboldt's influence went to 
the types and epochs of the other and dominant schoul; hut they were difticult to grasp, being not unfrequently fantastic compromises between the legents of religious trarlition and the heginnings of seientific thought. For a long time they evaded the endeavour to put them into

encourage purely morphological ancl to discourare genetic tonsilerations. Accorlingly the many herinnings of a scientific ateount of the origin and listorical develop"ment of the thimes around us, it which lyell gave the tir:t faily aceurate summary ill the first volume of his "Principles of Geology' (1st ed., 1830), were harrlly noticed in the "liosmos" (vol. i., 1S4i, vol. ii., 1847). Nune of the celelmaterl cosmoronical hypotheses, which we shall real with in this chapter,-meither the "Protogiva" of Leihriz nor the 'Ejoupes de la Vature of Buffon, neitler Kint's uor lsaplace's nebular theory, nor "ven the brilliant introtuetion to the 'Ossemens fosiles' of C'uvier, though the latter, anl still more Laplice, must have liad a great personal influence on him, - re. ceive any adeguate attention in the pages of 'Kosmos.' 'They are ritrely reterred to, and then ouly as works of imaginative value, for which the true scientific ground. mork, extenive observation, and especially the experiences aud results of travel, are wanting. Munboldt, whose mind was storerl with these riches in an aloundance and variety unequalled before or since, limited limnelf to a jor. traiture, to a panoramie and mor. phological, to a structural ancl architectonic view of things, with which he combinerl a deep sense of the reaction which the ecntemplation of nature nunst liave on the artistie faculty. (See the Intro. sluction to the second, the most brilliant, volume of 'Kosmos.') (icuetic theorices were to his minct prenature and foreign to his pur. pose. "The mysterious and unsulverl problems of alevelopment ils not belong to the empirical serion of ohjective observation, to the description of the developed, the actual state of our planet. The lescription of tles miverse, soberly contined to reality, rematis averno to the olscume lecrimuings of a history of organic life, not from modesty, but from the nature of its object and its linits" ("Lusmos,' vol. i. 1) :367). "The world of forms, 1 repert, ean in the enum. eration of space relations only be pictured as something actual, at something existing in nature ; jot as a subjeet of an intellectual poress of reasuning on already known causal connections. . . They are faets of mature, resulting from the conflict of many, to us, unknown eonlitions of active prosh-and pull forees. With unsatistied curisity we ap. proach here the dirk reginn of development. We have here to do, in the proper sense of the frequently misused worl, with world-events, witl cosmical processes of iumeasurable periods. . . "The present form of things and the precise numerieal determination of relations has not hitherto succeeded in learing us to a knowledge of states traversed, to a elear insight into the ensulitions under which they originated. These emmlitions are not therefore to le termed aecilental, as man calls everything that he camnot explain genetiolly" (vol. iii. 1' 431). 
exact language. It is only in the second half of the nineteenth century that the many independent lines of reasoning, the fragments of the great doctrine of development, have been united together, that the search after the principles or laws which govern the restless change has been rewarded by a certain number of definite results, and that what was once vague, fanciful, and legendary has become a leading idea in all the natural sciences. As in other instances which we have had occasion to notice, so also in this case, the appearance of clearer and more definite ideas has been heralded and helped by a novel mode of expression, by a new vocabulary. The word "evolution" has in this country done much to tion." popularise this way of regarding natural objects and events: abroad, the word has not met with the same popular acceptance. It was known there and used in science and literature when it was yet unknown in this country, and has in consequence not been monopolised in the same way as in the English language, to denote the continuous and orderly development of states and forms of existence. ${ }^{1}$ Moreover, it has been identified in this

1 On the older and uorder'n use of the word "evolutiou" in the English language see Huxley's article in the 9 th ed. of the 'Ency. Brit.' It is reprinted in his collected essay's with the title "Evolution in Biology." According to Huxley, the term "evolution "was introduced in the former half of the eighteenth century in opposition to "epigenesis." The two terms denoted the two theories of the generation of living things, by development of pre-formed germs (pre-formation) or by successive differentiation of a relatively homo. geneous rudiment (after-formation). Harvey, the expounder of the latter theory against Malpighi, who em. braced the former, calls the first "metaınorphosis." Leibniz, Bonnet, and latterly Haller, were "evolu. tionists" in the older sense of the word; Harvey, C. F. Wolf, and the modern school of embryologists, with von Baer as its most eminent representative, were adherents of the originally Aristotelian theory of "epigenesis." "Nevertheless," as Huxley says, "though the conceptions originally denoted by 'evolution' and 'development' were 
comntry with a special philosophical teaching, that of Mr Ilerbert śpencer, which, whilst, in many points coineiding with scirntific views of development, has some special and peculiar features which will occupy us further on in our survey of thought. Having sought therefore for a term which is to comprise all the contributions to seientific thought which deal with the change and development of natmal objects and events, I propose to use the older worl "genesis," and to call this view "the genetic view of natme" : it is, in generul, the view which secks to give answer to the futestion,

shown to be untenable, the worcts retained their apslication to the process by which the embryos of living beings gradually make their appearance: and the terms 'development,' 'Entwickelung,' amel 'evolutio' are now indiscriminately used for the series of genetic changes exhilited by living beings, by writers who would emplatically deny that "development" or "Entwickelung' or 'evolutio,' in the seuse in which these words were usually employed by bomet or by Haller, ever occurs." The woril evolution has, however, acquirel in the English language, mainly through the influence of $\mathrm{Mr}$ syencer's writings, a much wider sense than evolution in biology implies: in fact, it takes the place of the German "Werden," a word much used in the philosophical writings inlluenced by the Hegeliau loctrine, which indeed taught a logical or dialectic developument of things, as Herbert sipencer and his sehool teach a mechituical ilovelup. ment. 'There seem to be griven to us by observation only two elementary processes of change, or of

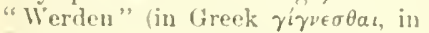
French "devenir," in linglish "be- coming, "in Latin "tier., "in lien mutn also the synonym "geschelien" . lhese ire, on the one himd, the process of mechanical motion, and on the other ham the proces of logical thought: the one being the movement of extermal things, ultimately of atoms, the other the spontaneous murement of whit IIune called isleas. When the thinking mind fixes its attention on the "fieri" rather than the "esse" of things there are accordingly two clues available, the mental or the physieal, the logieal or the nechanical. Mamy times takes up in earlier ages, buth have been consistently applied only in the nineteenth century, the latter by Herbert spencer, the former tilty years earlier by Hegrel, whose philosoplyy is fundamentally as mueh a logical as the former is a mechanical system oi evolution. The natrower meanine of evolution m biology is usually gives 111 lrench by the word "transiorm. isme," in Ferman hy "lintwick. elungslehe" or " l)arwinismus." Siee on the general subject l'rof. James Sully's able article on "livolution" in the 9ll erl. ol the 'Bney. Brit.' 
How have things come to be what they are? What is their history ${ }^{1}$ in time?

The first great philosopher of modern times who seems to have approached the question of the genesis of the objects of nature in the modern scientific spirit was 4. Leibniz, who, in composing his local history of the

'Protog*a.' origin of the Guelphs and the antiquities of Brunswick, pushed his researches into prehistoric times and made use of the geological and mineralogical data supplied in the Harz forest and mountains to arrive at conjectures as to the past history of the earth. His ideas, based upon local facts and observations on stratification and fossil remains, were collected in a famous tract entitled 'Protogrea,' which during his lifetime was only known in abstract, ${ }^{2}$ and was published in 1749 , many

1 Although the word "genesis," through its use in the Scriptures, has acquired the meaning of a narrative of the origin or beginning of things, this meaning is not necessarily implied in the word $\gamma^{\prime} \boldsymbol{\gamma} \nu \in \sigma$. $\theta a$, and the genetic view of nature, or things in general, may limit itself to the study of observable, actual change, renouncing altogether the question of origins. The German words, "werden" and "geschehen," are in this respect less ambiguous and less ambitious, and many philosophers may accordingly prefer "evolution" to "genesis.

2 On the connection of Leibniz's genetic studies with his History of Brunswick, which expanded under his hands into the 'Annales imperii occidentis Brunsvicenses' (edited by Pertz in the first three volumes of 'Leibnizens Gesam. melte Werke,' Hannover, 1843-47, 4 vols.), see the introduction by Scheidt to his complete edition of the 'Protogrea,' Göttingen, 1749 (reprinted in the second volume of Dutens' 'Leibnitii Opera Omnia,' 1768) ; the words of Leibniz himself in the 'Plan' of his History (quoted by Pertz, vol. i. p. xxiii): "Premittetur his annalibus quadam dissertatio de antiquissimo harum regionum statu qui ante historicos ex nature vestigiis haberi potest" ; the address of Ehrenberg, 'Ueber Leibnitzens Methode' (Ber. lin, 1845); the account in Guhr. auer's 'Life of Leibniz' (1846, vol. i. p. 205, and an interesting note in the appendix). Fontenelle, who knew of the 'Protogaa' only by the abstract (ed. 1693) in the Leipsic 'Acta,' and from correspondence with Eckhardt, Leibniz's executor, says in his 'Eloge de Leibniz': "1l la [viz., the History] faisait précéder par une dissertation sur l'état de l'Allemagne, tel qu'il était avant toutes les histoires et qu'on pouvait le conjecturer par les monuments naturels qui en étaient restés; des coquillages pétrifiés dans les terres, 
years after his death. He conceived that louth fire and water ${ }^{1}$ had lieen at work in forming the surfuce of the earth, and suggested that similar examinations of other localities ${ }^{2}$ would be repuired in order to arrive at general conclusions. Finch were subsennently supplied hy Werner, de Saussure, Pallas, Hutton, Cuvier, and Willian Sinith, before the systenatic exploration of the whole globe lucane in the nineteenth century one of the tasks of geological science. A few years after the publication of Leibniz's speculations, which pointed to an acemmlation of loeal observations as the means of arriving at a history

des pierres vì se trouvent des tulpreintes de poissons ou de plantes yui ne sont point du pays, médailles incontestibles du déluge," \&c., \&c. How very much Leihniz was-in this as in many other irleas - in ad. vance of his age can be seen liom his correspondence with the swiss naturalist suheuchzer of Zuiriels: "Merentur Alpes vestric, si quis aliu= Europie lucu-, lane eru. diti inguilini curam et cicteros montes utili exemplo preibunt, quem admoxlum mannitudine vinc unt. . . liermanorun nos. trorum non ea est diligentia quam vellem: itaque Historias legionum naturales labemus nullas, cmm Angli Seotique nobis egregiis exemplis priciverint" (quoted by Guluauer in the note referred to). An interesting reference is male in $\$$ xvii. uf the 'P'rotogrua' to the use of the microscope, then only recently invented, and largely used by Leuwenhoek in comnection with the examination of the formation and crystals of the celebrater "Baumann cave": "lit relim mieruscopia ad inquisitionem ad. hiberi, quibus tantum prestitit sagax Leuwenhoekii diligentia, ut sicpe indiguer lumanie igmavic, quie aperire oculos, et in paratam seientia posse-sionen ingredi non dignatur." A very fair aeconut of the contents of the 'l'rotogien' is given in IV. 1). Convleare' "lie. port on the l'rugress . . of licologieal sicience in the tirst volume of brit. Assoe, Riepurts, p. $360^{\circ}$ se.

1 'P’otogien," siv: "l)onec quiescentibus caunis atyue ispuilihratis eomsistentior energeret statux rerum. I nole jam duplex origo intelligitur firmorum corporum : nui, cum at, ignis fusione refrigescerent, altera cum reconcrescerent ex solutione aquarum. Neque igitur putandum est lapides ex solat esie iusione. Id enim polissimum de prina tantum nasial ac terre basi aceipio."

"Ihid, s r.: "IItec vero utcum. que eum plitusu forte rici possint de incunalilis nostri orlis, seminapue contineant seientie nove, quim (ieographian naturalem apjelles. . Et licet conspirent vestigtit veteris mumli in priesenti facie rerum, tamen rectius ommia definient posteri, ubi euriositas mortalium es processerit, ut per regiones procurrentia soli genern et strata descrilunt," 
of the earth, another philosopher of the highest rank took an important step in the direction of the study of the genesis of things natural, on the largest scale. It

Kant's nebular theory.

was Immantuel Kant, the philosopher of Königsberg, who, stimulated by the perusal of the cosmical theories of Thomas Wright of Durham, ${ }^{1}$ applied the principles of the Newtonian philosophy in a first attempt to trace out the great stages in the formation of a planetary system.

1 The work of Wright is not so rare as it is represented to be by foreign writers, as I picked up two copies from a secund-hand catalogue several rears ago. It is chiefly interesting as having induced Kant to venture on his genetic speculations, which appeared anonymously at Königsberg in 1855, and for a long time remained unknown. About the same time as Kant, the celebrated mathematician J. H. Lambert published his 'Cosmological Letters on the Structure of the Universe" (Augsburg, 1761), many ideas in which coincide with the later expositions of Herschel and Laplace, which were based on quite litferent considerations. The specu. lations of Wright, Lambert, and Herschel were what we may call morphological, whereas it is the merit of Kant and Laplace to have built upon the ideas as to the architecture of the universe a plausible theory of its genesis. A full account of Wright's suggestions, which were accompanied by very beautiful mezzotint engravings executed by himself, is given by Prof. R. A. Sampson of Durham in the 'Proceedings of the Society of Antiquaries' of Newcastle-upon-Tyne, vol. vii. p. 99.

Kant's theory has been dealt with by Helmholtz in his Königsberg address (1854), "Ueber die Wechselwirkung der Naturkräfte" ("Vorträge and Reden,' vol. i.), by Faye
('Sur l'Origine du Monde,' Paris, 1885,2 nd ed.), by C. Wolf ("Les Hypothèses Cosmogoniques,' Paris, 1886, which contains a translation of Kant's work), and by G. F. Becker (Amer. Journal of Science, 1898). It is, however, to be noted that recent writers on Astronony are inclined to speak of the genetic theories of the aniverse very much in the same way as Humboldt treated them in his 'Kosmos,' which professedly excluded the historical aspect in favour of a purely descriptive treatment, recognising the many difficulties which stand in the way of a consistent elaboration of the "nebular hypothesis." See A. Berry's ' History of Astronomy' (1898), p. 409 ; R. Wolf, 'Handbuch der Astronomie' (vol. i., 1890), p. 594 ; G. H. Darwin, 'The Ticies' (1898), p. 302 ; also J. Scheiner, 'Der Bau des Weltalls' (Leipzig, 1901). On the adcitional great support which has been given to a genetic conception in general in the second half of the nineteenth century by Thermodynamics and Spectrum Analysis I shall speak later on. The writings of M. Faye in France, and of Sir Norman Lockyer in this country, utilise to the fullest extent the arguments derivable from these sources, and mark a great contrast to the manner in which cosmological questions were treated by $A$. von Humboldt. 
The speculations of Wright had been purely geometrical. He had drawn attention to the apparent mity of organisation in the stellar system, as establisherl by the accumulation of stars in a certain belt, popularly ealled "the milky way." He also sugrested that the whole system was moving in a certain direction. Kant pointed out the analogy with the solar systen, in which, viewerl from the eentre, the plinetary masses would likewise appear sitnated in a narrow belt, moving all in the sane direction. From these lata he proeeds to show how, taking for granted an initial movement and the action of gravitation, the formation of rings, like those of satum, caln be explained; further, how these might be broken up and concentrated in satellites. In fact, he recosnised how, under the influence of gravitation, the solar system might have been gradually formed out of matter which was previously seattered through the whole of that space which the system still oceupies. Kant also descended somewhat further into detail, and proceeded to discuss the possible retardation of the earth's rotation through tidal friction. ${ }^{1}$

1 The mint in which lint develops his views on this subject wh oceasioned by a prize offered by the Berlin Aculemy in 1754 for an answer to the question whether the time of revolution of the earth hal sullered any retarlation, and if so, through whit causes? Kant dicl not compete for the prize, deeming his reHections not capable of being suttieientiy periected to deserve to lue submitted. So he simply published theu in a local Konigsbers paper, irom which they were litur reprinterl in the collected works, forming one of the first of Kint's publications. At the end of this tract he announces his "Cosmogonie, which appeared the following year with the title 'Natural History of the Heavens,' \&e. Kant harl the satishetion of seeing many of his speculations veritied by the subsequent discoserics of inductive rescurch, notably through Sir Willian Hersehel's ubservations of nebulie; and the (ienman edition of Herschel's great memoir 'Un the Construction of the lleavens' ("Phil. 'Trans,' 1784), which appeared in Konigsberg in 1791, by sommer, contains an extract from Kant is 
The two lines of speculation, originated by Leibniz and Kant as to the genesis of things on this earth and in the universe, mark two distinct ways of approaching the genetic problem. They were both isolated, and it was not till well on in the course of our century that they were again taken up and independently developed - the one by geologists, the other by physical astronomers. They remained for a long time without mutual influence: till, within the last generation, they were brought together, their different results deduced, and a reconciliation attempted. To this I shall revert later on. Forty years after Kant, Laplace put forward his so-called nebular hypothesis at the end of the popular exposition which he gave of his mechanical theory of the heavens. He apparently knew nothing of Kant's attempt, and his views differ materially from those of Kant, in so much as he assumes in the rotating nebular mass an attracting nucleus from which, in the course of condensation through attraction, the planetary rings and bodies were thrown off as the centrifugal velocity balanced the attracting forces. For a long time this sketch of a possible genesis of the planetary system was paraded in popular

work. The merits of Kant have ouly been tardily recognised; they were unknown to Laplace, and only imperfectly known to more recent authorities, such as Helmholtz and Lord Kelvin, who were fully prepared to do him justice. Lord Kelvin, in his Rede Lecture of 1866, refers to Kant as the first to publish " any definite estimate of the possible annount of the diminution of rotatory velocity experienced by the earth through ticlal friction" ("Pop. Lects. and Addr.,' vol. ii. p. 65), and ऐin the controversy which took place between him and Huxley on "Geological time" the theories of Kant were frequently referred to. See his lecture on "Geological 'Time," 1868 (loc. cit., p. 10, \&c.) ; Huxley on "Geological Reform," 1869 (reprinted in 'Lay Sermons,' No. XI.) The best account in the English language of Kant's contributions to cosmogony will be found in an article by G. F. Becker in the 5 th vol., 4th series, of the "American Journal of Science,' 1898. 
works on astronomy as an established theory, whereas Iaplace himseli had put it forwall with great reserve, and only as a likely suggestion." "There is, howerer, no clombt that it powerfully influeneed the mints of many students of nature in the direction of a genetic view of plienonnenil.

'The attempts referred to so far cin be describerl as belouging to the lionnance of seience. I now conne to the more solid contributions - to a real genetic theory of the things of nature. 'Tluese are not mueh older than (mir century. 'They belong to two entirely independent lines of researeh which were followerl up in Fingland and on the Continent resjectively-the former in paliontology, the latter in anbryology. Mlthough they were carried on quite independently of each other, they had this in common, that they hoth resorted to a sturly of life_as preserved in geological strata or as now existing around us-for a suide in comprehending the genesis of 'Things on a laroger scale.

It nay be well to remark here that the contemplation of the phenomena, the forms ancl the frocesses exhibited in the living portion of ereation, has not always, and even not generally, in the conse of history led to those theorios which ont asce is elaborating, and which will in future times possilny be looked upon as one of its chatr-

1 Laplace himself says: "Je présente cette origine du sy-lème planétaire avec la définnee que doit inspirer tout ee qui n'est puint un résultat de l'observation et dn calcul." The elaborate exposition of the architecture and system of the universe eontained in A. von Humboldt's 'Kosnuss,' which was professedly inspired by Laplace (see
'Kosmos,' vol. vi. ए. S). gives us little, if anything, abuut the liston:y of the universe, frofessing to be only a "Weltgremilde" and not a " Welterklitrun." 'The time for genetic theories had mol yel come. and both Kant's aud Laplace's cosmogonies are only easually referred to. 
acteristic achievements - the genetic view. There is another view which a superficial glance at organic life, with its well known phases of birth, culmination, and decay, has frequently impressed upon the observer; there seemed another lesson to learn than that which our age is trying to master.

7. "Cyclical" view. view of things, the doctrine that every thing runs in a cycle ${ }^{1}$ and repeats itself, that all change is periodic and recurrent, that there is nothing new under the sum. ${ }^{2}$

$1 \mathrm{Mr}$ Thomas Whittaker has given ne various references to the writings of ancient philosophers which bear on this subject. He finds the cyclical or recurreut aspect of the world-process prominently put forward by the Stoics. Zeller ('Philosophie der Griechen,' vol. iii. I. p. 136, \&c., 2nd ed.) says iu his account of the stoical philosophy : " Out of the original substance the separate thiugs are developed accordiug to an inner law. For iuasmuch as the first principle, according to its definition, is the creative and formative power, the whole universe must grow out of it with the same necessity as the animal or the plant from the seed. The original fire-according to the Stoics and Heraclitus-first changes to 'air' or vapour, then to water; out of this a portiou is precipitated as earth, another remains water, a third evaporates as atmospheric air, which again kindles the fire, and out of the changing mixture of these four elements there is formed -from the earth as centre-the world. . . Through this separation of the elements there arises the contrast of the active and the passive principle: the soul of the world and its body. . . . But as this contrast came in time, so it is also destiued to cease ; the original substance gradually consumes the matter, which it segregated out of itself as its body, till at the end of this world-period a universal worldconflagration brings every thing back again to the primaval condition. ... But when everything has thus returued to the original unity, and the great world-year has run out, the fornuation of a new world legins again, which is so exactly like the former one that in it all siugle things, yersons, and phenomeua return exactly as before; and in this wise the history of the world and the deity . . moves in an endless cycle through the same stages." Zeller, in a note to this passage, remarks that "the conception of changing world-periods is frequent in the oldest Greek philosophy; the Stroics found it first in Heraclitus. The further statement, however, that the succeeding worlds resemble one another down to the minutest detail, is to be found, to my knowledge, before Zeno only in the Pythagorean school ... and is connected with the doctrine of metempsychosis and the wor]d-year."

2 Mr Whittaker quotes a pass. age from Aristotle's 'Metaphysics," towards the end of the 12th book (Berlin ed., p. 1074, b. 10-12):

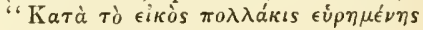

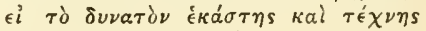

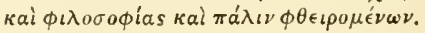


Poets and philosophers have repeated this theme in enclless variations, probably withont improving upon the classical and perfeet expression which it has fomml in ancient ${ }^{1}$ poetry and in the sacred writings. History las been written with the professed object of gaining, by analogy, an insight into the drift of nodern or future events, and econonic and political theories have been based upon the likelihood of a recurrence of what has happened before. Especially has the teaching been impressed upon us that the universal fate of all development is to lead to leath and decay, and to make room for the endless repetition of the same recuming phases

Every art and every kind of philosophy having probably been found out many times up to the limits of what is pos-ible and again destroyed;" and remarks, "This notion of eycles refers to liuman civilisation, not to the universe, which is one eternal system with a fixed central mass, and with its outer part in a moving equilibrium. Empertocles unfloubtedly had a theory of recurrent cyeles in the universe. The four ele. wents, - which he first brought to. gether as elements of the whole, early thinkers having taken one or other of them as a first principle from which the rest are evolved, - accorling to limperloeles, are necessarily aggregated and segregated by the predominance of principles which he calls love ( $\phi i \lambda i ́ a)$ and hate (veikos). 'The four periouls are: 1. Predominant love (the $\sigma \phi a i p o s)$, a state of (complete aggregation; 2. decreasing luve and increasing hate or strife; 3 . pre-

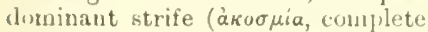
separation of the elements): 4 . recreasing strife and increasing love. These are cosinic periods. It hats been supposed-\%eller takes this view-that we are living in the fomrth ensmic period, the period of inereasing he."

1 The best known passage is that from the celebrated fourth eelorue of Virgil, where, after describing the return of the gulden Saturnian age, the poet continues $(\% \%, 31-36):-$

"l'utuca tamen suberuut prisca vestigia fraudis,

Quat trintare Thetim ratibus, gut eingere muris

oppicta, qua jubeant telluri infimelere suleos.

Alter erit tum Tiploys, et altera ipue velat Argo

Delectos heroats : erunt etiam altera bella, Atyue iterum ad 'rojum matgums mittetur Achilles."

Dugald stewart ("l'hilos. Works," vol. iii. 1. 167) refers to this with the following quotation from Clavius's 'Commentary on the Treatise on the siphere,' by .Joannes sacro Boseo: "Hoc intervallo, fuilam volunt, omnia quitemmque in mundo sunt, eodem ordine esse reditura, (juo nune cernuntur," and he also attributes this theory of recurrence to an extreme application of the mathematical spirit (rol. iv. 1. 207). Huw this ides of reeurlent cycles faseinaled and hauntel Fr. Nictsiche sec seth's article, 'Conten. liev., vol. 73, p. 734. 
of existence. ${ }^{1}$ This view was considerably strengthened
by the popular interpretation of the teaching of modern astronomy, which laid great stress on the periodicity of the planetary movements, and the stability and inherent readjustment of the solar system. Also the insight gained by the first application of chemical knowledge to

I The idea of recurrent, periodic repetition seems opposed to the modern idea of progress and development as taught by Leibniz aud Herder abroad, by Spencer in this country; still it seems almost impossible in a purely mechanical system to avoid introducing the conception of an ultimate recurrence, so long as one deals with finite space, time, or number, however great they may be. The only escape seems to be in assuming an infinite process or an immaterial primeiple which is not subject to mathematical treatment, the latter being inherently one of repetition. It is interesting to note how Herbert Spencer at the eurl of 'First Principles' relapses into the eyclical conception: "Thus we are led to the corrclusion that the entire process of things, as dis. played in the aggregate of the visible universe, is analogous to the entire process of things as displayed in the smallest aggregates. Motion as well as matter being fixed in quantity, it would seem that the change in the distribution of matter which motion effects, coming to a limit in whicherer direction it is carried, the indestruetible motion thereupon necessitates a reverse distribution. Apparently, the universally coexistent forces of attraction and repulsion, which necessitate rhythm in all minor changes throughout the universe, also necessitate rhythm in the totality of changes-altermate eras of evolution and dissolution. And thus there is suggested the conception of a past during which there have been successive evolutions analogous to that which is now going on ; and a future during which successive other such evolu. tions may go on-ever the same in principle but never the same in concrete result" ("First Principles,' 1st ed., p. 536). The other great system of modern philosophy, which aims at a reconciliation of the mechanical and spiritual aspects -the philosophy of Lotze-though it lwells less than Spencer's system on the renctic problem, gives a different view of cosmic development. "The series of cosmic periods cannot be a number of pliases, in each of which tlie one purpose of the universe does in fact maintain itself : it must rather be a chain, each link of which is bound together with every other in the unity of one plan. The One can manifest itself in various forms only when such variety of forms is necessary for the expression of its meaning-in a rlefinite order of succession only when this order corresponds to a eraving for development in its nature. As we required that each section of the world's history should present a harmony of the elements firmly knit throughout, so we must now require that the successive order of these sections shall compose the unity of an onward advancing melody" ("Mierocosmus,' Eng. trans]. by Hamilton and Jones, Book IV. chap. 3). 
physiology and agrictulture in the schonl of Iichige and the first chapters of meteorolong, seened to favonr the idea that the elenents and forees of nature were engigenl in eyclic movements which return again and agrin in the same fashion. To the same cyclical view the doctrine of the fixity of species, as well as that of the repetition of varions ereations, lent further support: hence it contimued up to the midille of our century ${ }^{1}$ to be fre-

I In Germany Mfoleschott's 'Lireislauf des Lebens,' a popular exposi. tion of the conceptions developed iu the second quarter of the century through chemistry and embryology, represented ademuately the cyclic conception of life and development in a catching phrase. Nuch later we find - incer muler ulin - in Michael Foster's "Text-book of Physiology' at concise description of the process in nature which has always served its a type for the cyclic cunception: "When the animal kingdom is surveyed from a broad standpoint it beeones obvioles that the ovum, or its correlative the spermatozoon, is the goal of an individual existence; that life is a cycle beginning in an orum and coming round to an ovum again. ... The animal borly is in reality a vehicle for oxa ; and after the life of the pareut has become potentially renewed in the off-pring, the body. remains as a cast-otf envelope whose future is but to die." Another example may be found in Moly's 'Geschichte ier Wrde,' where the circulation of different elements in nature is considered. The concention of periodic cycles has fomd pretical expression in Rickert's beautiful poen, "Chidher," which is evidently the pontical render. ing of an Arabian legend quoted by Lyell ('Principles,' vol. i. p. 3i) :-
"Chilher, the ever youthitul, spake:

I passel a eity on my way,

A man in a garden truit did break, 1 asked llow long the fown here lay?

IIe spoke, and broke on as before,

"The town stamis ever on this shore,

And will thus stand for evermore.'

And when tive humlred yours wero gone

I eamp. lise salne poill as anblt,

Then not a mark of the lown I met.

A shepluer on the fluce dial jolity,

The cattle leaf and foliage ate.

1 askel loow long is the tuwn itway?

11. spetie, and pijeel on as betore,

"One plant is green when the other's 0 'cr, This is my pasture for everumore.'

And when tive humblred years were gono

I came the same roal as anom,

'llen diul I find witl wases a lake,

A nan the net cast in the bay,

And when he proused from his heary take, I isked since when the lake here lisy?

He spake, and langlued ny question o'er,

'As Inng as the waves break as ot' yore

One tishes and tishes on this sluore."

And when tive hundred years were gont

I eame the same way as anon.

A woorted place 1 thin did see,

And a liermit in a cell did staty;

He felled with an axe a nighty tree.

I askel sinee whin the woul here lay?

lle spake: "The wood's a slielter for evolinore,

I ever livent ufm this ther,

And the trees will grow on as before."

And when tive hundred years were gone

I came the same way as inom,

But then 1 foumul a city lillerl

With markets' clumour shrill and gay.

I asked how loner is the city built,

Where's wood and seat and shepleril's play?

They ponfered not uy 'puestion o'er

But erient: "So was it long before,

And will go on for everumere.

And when five humbrol rears are gone

I'll go the same way as dinon." 
quently put forward and popularly accepted. It is useful then to note that in the course of the second half of the century we were more and more growing out of the cyclical and realising the meaning of 8. the genetic ${ }^{1}$ view of things natural. We have been

Supplanted hy genetic view.

taught in astronomy to inquire into the origin of our solar or any similar system and the conditions of its duration, to ask concerning the central heat of the sun whence it came and how long it will last-a question unknown to Laplace,- - to consider the effects of tidal friction, to learn that all the movements in nature are irreversible as distinguished from completely reversible ones, which only exist in abstraction; and, finally, we are met with the doctrine of the immortality of the germplasma, an idea, the meaning and significance of which I shall have to explain later on. All these novel theories and views combine to impress upon us the general significance of the terms "genesis, evolution, development," the fact that everything in and around us, in spite of the seeming recurrence of smaller movements and phenomena, and of the periodicity of the minuter and elementary changes, is slowly, continuously, and inevitably tending in a definite direction, which is certainly not that of a cyclical recurrence.

9. Geology.

Leaving aside for a moment these more general views, which have been clarified in the course of our century, it is interesting to note how they gradually emerged in

Perhaps it would be more correct to say that we were learning to consider the chauges within the larger cycles, confining ourselves to the study of one branch only of the periodic or cyclical movement of things around us, that branch which we are pleased to call the ascending or progressive branch. 
the teachings of the several natural philosophers who initiated the genetic conception of natural phemomemat. Une of the earliest who broke with the older and introduced the modern methorls was Inumes IIntton, who towards the end of the preceding centmry lecl that school in geology which is called after him, and which violently' opposed the ideas introdnced from the Continent. The controversy enhunated in the wangle of the Neptunists and Vulcanists, those who lookerl to the agency of wates and those who upheld that of fire as the principal camse of geologieal ehange. 'This difference, whieh at the time inpressed the popular mind, is hastly that by which, in a history of scientific thonght, ${ }^{1}$ this controversy has become important. Hutton's position is marked rather hy his opposition to catastrophism, and ly his doetrine that geological chimges, such as the deeay and reproduction of rocks, were going on with the ntmost uniformity, being always in progress. This he opposed to the Wernerian view, which believed in the existence of certain "fundanental rocks," which were "triumphantly

I The great merits of James Hutton, his extensive aud original geological sturlics, his opposition to catastrophism, were overlooked through the theoretical hiscussions and the unfortunate title of lis book. The world harl grown tired of 'Theories of the Earth' and the discussion of fundamental problems. A spirit of observation had oet in ; the (ieological Suciety was former, and theories were for the time discountenanced. (See vol. i. p. 290, note 1 , of this 'History.') The attacks also of hirwan and De Luc, which turnel upon the stale argument that Hutton's irleas were opposerl to the scriptural reeorls, had thein effect in eircles in which everything commected with the revolution against Church and state was distasteful. As Huxley has told us, Hutton carne before his time. 'To him belongs the merit of laving initiated the line of researeh and reasoning which, through the brilliant labours of Charles Iyell a generation later, swept away the older geology, and prepared tlie way for the genetic study of natme on in large scale. (See the "Historical sketch" in the firm volume of Lyell's ' ['rinciples of rieolowr," and Huxley's adriress on "Geological leform,"1869.) 
appealed to if anybody ventured to doubt the possibility of our being able to carry back our researches to the creation of the present order of things." 1 Hutton destroyed these characters, which were considered by many as sacred, and declared that in the economy of the world he could find "no traces of a beginning nor signs of an end." And yet, as Lyell has shown, his principles were only imperfectly carried through, for though he maintained that "the strata which now compose our" continents have once been beneath the sea, and were formed out of the waste of pre-existing continents," ${ }^{2}$ he imagined that when the decay of old continents had furnished the material for new ones these were upheaved by violent and paroxysmal convulsions. He therefore required "alternate periods of general disturbance and repose, and such he believed had been and would for ever be the courses of nature." 3 A strange mixture of the genetic and cyclical views of natural phenomena! Professor Huxley ${ }^{4}$ has explained these seeming inconsistencies in the theory of Hutton, whom, together with Sir Charles Lyell, he has described as having founded the "uniformitarian" school of geology, by the influence which the discoveries of physical astronomy, brought out at that time by Laplace and his contemporaries, had upon Hutton. Thus Hutton writes: "From seeing revolutions of the planets, it is conchuded that there is a system by which they are intended to continue those revolutions. But if the succession of worlds

' See Lyell, 'Principles,' 3rd ed., vol. i. pp. $90,91$.

2 Ibid., p. 89.

4 Huxley, on "Geological Re- form," quotes largely from Hutton's

"Theory of the Earth' (1758) and Playfair's 'Ilustrations of the Hut. tonian Theory' (1802). 
is established in the system of nature, it is in vain to look for anything higher in the origrin of the earth. 'The result, therefore, of this physical inquiry is, that we find no vestige of a begimning, no prospeet of an end." The heginnings of the genetic view of geological phenomena, which in Hutton were still mingled with eatastrophism, were further developer ly sir charles Lyell in his celebrated 'l'rinciples of reology.' When he entered upon his reological resenches, which were conducted during his very extensive travels all over Europe, a new element had already been introduced into scienee, of which neither Hutton nor Wrerner had been able to avail themselves extensively. This was the identification of geological strata according to the fossil remains which were entaned in then,--a realisation of the plan of work alrealy dimly foreshadowed in Leibniz's 'P'rotogian,' hut nevertheless aceepted even by Humboldt as only at dombtful indication. ${ }^{1}$ This valumble branch of geological seience had been stated hy William Smith in his 'Tabular View of the British strata' in 1790 , and further elaborater in lis geologieal may' of England (1815), which was the fruit of his own unaided iabours, "for he hat explored the whole commtry"

I The Wernerian achool are gen. erally aceused of having negleeted the historical record afforded by fossil remains, and Humbuldt, iu his 'Essay' on the Superposition of Roeks in hoth Hemispheres' (1823), says (Eng. transl., p. 52): " $\mathrm{m}$ the present age naturalist. are no longer satistied with vitgue and uncertain notions, and they have sagaciously observer that the greatent number of those fosils, huried in lifferent formations, are not mecifically the same; that many species which they have been enabler to examine with preeision vary with the superposed rocks. . . . (Jught we to eoncluale from this asiemblage of tacts that all the furmations are characterisel hy particular species? that the fosil shells of the chalk, of the muschelkalk, of the Jura linestone, amcl of the Alpine limestonc, all ditfer from cateh other? This would he, in my ofminion, to carry the induction much tow far." 
on foot without the guidance of previous observers or the aid of fellow-labourers," I and "had thus singly effected for the whole of England what many celebrated mineralogists had only accomplished for a small part of Germany in the course of half a century." 2 simultaneously with Smith in England, Cuvier and Brongniart were exploring the Paris basin. Thus the three different nations of Europe with whom I am mainly concerned in this work furthered independently the main divisions of geological inquiry. "The systematic study of what may be called mineralogical geology had its origin in Germany, where Werner first described with precision the mineral character of rocks; the classification of the secondary formations belongs to England, where the labours of smith were steadily directed to these objects; the foundation of the third branch, that relating to the tertiary formation, was laid in France by the splendid work of Cuvier and Prongniart." 3 To these words of Lyell we can now add that the theoretical explanations were first suggested, and the correct line of reasoning on this accumulated evidence initiated, by Sir Charles Lyell himself.

The key to the doctrines of Lyell was the study of existing canses - the attempt to show how the slow agencies which we now see at work in nature around us are sufficient to explain the successive changes ${ }^{4}$

1 Lyell, 'Principles,' vol. i. p. 101.

2 An expression of d'Aubuisson, quoted by Dr Fitton, 'Phil. Mag.,' vols. i. and ii., also 'Edin. Rev.', Feb. 1818.

3 See Lyell, loc, cit., p. 103.

${ }^{4}$ Id. ibirl., vol. iii. p. 273 : "It is only by carefully considering the combined action of all the causes of change now in operation, whether in the animate or inanimate world, that we can hope to explain such complicated appearances as are exhibited in the general arrangement of mineral masses." 
which the recognisable strata of the earth's crust with their fossil remains indicate as having ocemred in former ages. It was an attempt to "reconcile the former and the present state of nature." 1 This wis to break with the idea of great and general convulsions, to which the Continental school resorted in their explanations, and it also meant upsetting the vague notions whieh set a linit to the time ${ }^{2}$ which should be allowed for the operations of natmal causes. It is possible to adnit that in both directions, in their uniformitarian explamation and in their geologieal time-reckoning, the new school frequently went too far, the inclications of aetual catastrophes and paroxysmal convulsions being to many observers quite unmistakable. On the other side, the arguments based upon pliysical astronomy, mechanics, and thermodymanics, which afford an indepeudent basis for geological time-reckoning, were not yet elaborated," or were deemed too crucle ${ }^{4}$ to be of ralue: and for a good while geologists were permitted

1 Lyell, vol. i. p. 114.

2 Id. ibicl., p. 241 : "When diffi. culties arise in interpreting the wonuments of the past, I deem it more consistent with philosophical eaution to refer them to our present ignorance of all the existing ageuts, or all their possible effeets in an inclefinite lapse of time, than to causes formerly in operation but which have ceased to act."

3 See Lyell, vol. i. p. 154, \&e., also vol. ii. 1. 274: "It has long been a favourite enjecture that the whole of our planet was originally in a state of igmeous fusion, and that the central parts stil] retain a grent portion of their primitive heat. Some have inagined with the late Sir W. Hersehel that the elementary matter of the earth may hare been first in a ganeous state, resembling those nebulie which we hehold in the heavens, and which are of dimensions so vast that some of them would fill the orbits of the remotest plinet: of our system. . . Without dwelling on such speculations which ean never have any lircel bearing on geology," \&c.

t See Iyell, vol. i. p. 206, where he refers to "astromomical cau=c" of thetuations in climate," and to the ealculations of sir J. Herseluel aul the fact that "this matter is still under discussion," and that "M.M. Fourier and Herschel hav" arrived at very ditlerent opinions. " 
to draw indefinitely on the great bank of time, ${ }^{1}$ just as in former ages they had been quickly brought to book by existing prejudices. ${ }^{2}$

Whilst these contributions to the genetic view of nature on the large scale were being independently worked out, the sciences which deal with the minute and hidden phenomena of organic growth had made great progress in the same direction. Here a definite scheme of development was quite evident to the most casual observer. In these sciences indeed we have to do with what is called in the German language "the history of development "par excellence, a term which is inadequately

12. Embryology. rendered by "Embryology" in French and English. For it is an error which has frequently and for long periods obscured the correcter view to assume that the changes and processes which characterise the development of embryonic or germ life are essentially different from those which exist in the larger and more complex adult organism. The abolition of the fundamental distinction between the processes of embryonic and of adult or full-

I Lyell, vol. iii. p. 358 : "Confined notions in regard to the quantity of past time have tended more than any other prepossessions to retard the progress of geology, . . and until we hąbituate ourselves to contemplate the possibility of an indefinite lapse of ages having been comprised within each of the more modern periods of the earth's history, we shall be in danger of forming most erroneous views in geology.",

2 One of the first to attack the uniformitarian doctrine in geology and to apply the principles of modern physical science to geolog- ical and cosmical questions in this country was Lord Kelvin. His influence belongs, however, mainly to the post-Darwinian perior, and begins with his celebrated memoir 'On the Secular Cooling of the Earth' (Edin. Trans., 1862, reprinted in the 3rd vol. of 'Math. and Phys. Papers,' p. 295). See also the 2nd vol. of his 'Popular Lectures and Addresses.' Accorling to the introductory statement in the former paper his doubts regarding the uniformitarian teaching begau as early as 1844. I shall refer to these speculations at the end of this chapter. 
grown life, the unification of thrught m these matters, is quite as important in the history of science as the abolition of the supposed fundanental difference lutween animat and regetable growth or between normal and ahommal (or pathological) development. The reduction of all these seemingly so different chatuges to the one great problern of eellular structure, cellular growth, and cellular division marks one of the greatest atehevements of om contmy. "Onr position with regard to the cell is similar to that of investigators towards the whole animit or vergetable body a hundred yoars ago, befote the discovery of the cell theory." ?

Inticipations of this genemalisation, of the eondensation of the whole moblem of animal and regetable embryology, of generation, growth, and organic developnent in the formula, "ommis cellulat ex cellula," lave indeed existerl since the time of Harvey, who, in aldition to the great discovery of the circulation of the blood, laid down the thesis, "omme vivum ex ovo." " The further correct

1 See (1. Hertwig, "Tl" C'ell," - ()utlines of General Anatomy and P'lysiology.' Transl, by C'anublel, $1895, \% .11$.

2 One of the best expositions of Harvey's ideas is to be found in Huxley's article on "Evolution in Biolugy" in the ninth elition of the 'Encychnsedia Lritamica,' He there also refers to Aristotle's opinims. "One of Harvey's prine objerts is to defend and extablish, on the hasis of direct observation, the opinion already held by Aristotle, that in the ligher animals at any rate the formation of the new organisul by the process of generation takes place, not sud. denly by" simultaneous accretion of rudiments of all, or of the must important of the organs of the arlult, nor by sudden mretanor. phosis of a formative substance into a miniature of the whole, which subsequently grows, but by epigenesis, or suceessive differentiation of a relatively lomogeneou: rudinent into the parts and struetures which are characteristic of the adult." In the sequel of his exposition, after maintaining epigenesis or after-formation against evolution in the older sense or preformation, Huxloy, however, makes a passing remark l hat "though the luctrine of eprigenesis, as understool by Harvey, hats definitely trimmphed sver the doetrine of evolution, . . . it is not impossible that, when the amalyois of the process of alevelop. 
13.

Epigenesis and evolution.

generalisation which he ventured to put forward, that growth and development of the germ or embryo consisted in the addition or formation of new parts and structures through division or differentiation, was, however, obscured and cast into the shade by the opposite doctrine, termed evolution, according to which every form or particle of organisation was minutely pre-formed in an invisible germ, and growth consisted merely in a process of enlargement, as a particle of "dry gelatine may be swelled up by the intussusception of water." The supporters of this doctrine, to which the celebrated names of Leibniz, Boerhaave, Haller, and Bonnet belonged, seemed unable to conceive of any force in nature which was capable of producing organisation, and were thus compelled to accept in some form or other the doctrine of the pre-existence of germs, a theory which has in modern times been revived under an altered form.

The real foundation of scientific embryology, of the study of the genesis of vegetable and animal organisms,

C. F. Wolff. is now pretty unanimously ${ }^{1}$ traced to Caspar Friedrich Wolff, whose 'Theoria generationis' appeared in 1759 . His observations refer alike to plant and to animal life, and his distinct object was to refnte the theory of evolu-

meut is carried still further, and the origin of the molecular components of the physically gross, though sensibly minute, bodies which we term germs is traced, the theory of development will approach more nearly to metamorphosis than to epigenesis. . . The process, which in its superficial aspect is epigenesis, appears in essence to be evolution in the morlified sense adopted in Bonnet's later writings; and development is merely the expansion of a potential organism or original pre-formation according to fixed laws."

1 See J. A. Thomson, loc. cit., p. 121. Yves Delage, 'L'Hérédité,' p. $35 \%$, note; and especiallly 0 . Hertwig, "The Biological Problem of To-day,' transl. by P. C. Mitchell (Heinemann's Scientific Handbooks, 1896), p. 4, \&c. 
tion and replace it by the correcter doctrine of eprigenesis -i.e, of repeated or after-formation. Haller' thomght very highly of this attack on his own view, hut wis not convineed by it: and although in botany Wolfl's views on the cellular structure of plants were adopited in France by Mirbel, and those on nuetamorphosis were unknowingly reproduced by foethe, his inthence on enbryology dates actually only from the year 1812, when Meckel translited one of his treatises and thus drew attention to his great merits. Wroll tried to refute the theory of evolution or pre-formation, supplanting it hy that of epigenesis or after-formation, through aetual nhservations of the development of germs in plants and aninals in definite instances. In botany his views, after lying dormant for a long period, led nltimately to the famous cellular theory of chehleiden and Mohl. In zonlogy, shortly after Meckel's republieation of his treatise in 1812 , there were pulished the rosearches of Pancler, who, in his treatise on the development of the chick, "gave a fuller and more exact view of the phenomena less elearly indicated by $\mathrm{Wolft}$, and laid the fommation of the views of all subsequent embryologists." 2

I'ander was a Russian by lirth, and so was his greater' 15. l'ander and li. E. von contemporary and friend, Karl Ernst von Baer, ‘ man Bace.

1 As lrof. I. Arthur 'T'homaton says ('Seience of Life,' p. 120), "A wingle scentence, "Es sibt kein' Werden - theve is no Becoming? sufficiently indieates Haller's position."

". A. Thomson in article "Embryology" ("Eney. Brit.,' 9th erl, 1. 1651$)$.

3 The work of von bier (17921876) remained for a long time un. kuown and unreconnised outside of Ciemany. Huxley made him know'n in this (r)untry by translating extracts from his principal writings for 'Taylor's 'Acientitic Memoirs in 1853, nearly thirty vears after von Buer had liegun the brilliant series of his reseaches. It can be sail of him that he, evon more than his forerumners, l'ancler and bölinger, withdrew natural 
who occupies a unique position in the history of natural science. He introduced the principle and aspect of development into the midst of those studies which, under the important but one-sided influence of Cuvier and his school, were in danger of being confined within the limits of morphology and comparative anatomy. Through a long series of most important embryological investigations, conducted during the years 1819-1837, he demon-

science from the spell under which it was kept for a long time in the West of Europe by the great authority of Cuvier, Geographically also, von Baer's activity was centered in Königsberg (where he was one of a brilliant company who male the University celebrated) and st Petersburg. Though a great admirer of Curier, whose biography he wrote, and au adherent of the doctrine of animal types, which he independently arrived at, he intro. duced three distinct lines of research into his scientific labours, to all three of which Cuvier was either foreign or distinctly averse-viz., microseopic research, study of embryological development, and the philosophical spirit of the "Naturphilosophie." He was not dazzled by the latter; but whilst avoiding its extravagances and premature generalisations which then flooded German science, he always apureciated the search for the connection and nnity of all the things of nature which was characteristic of that school. Baer stood, historically and philosophically, in the middle between the extreme morphological and genetic views represented respectively by Cuvier before and by Darwin after him. Alrealy in 1815, when studying under Döllinger at Wiirzburg, he was guided by the iclea that "nature follows in her creations certain geveral themes (types), and that sle raries these in the different species." Von Baer also combined the geographical and anthropological interest, so largely represented by Humboldt and litter, with his morphological and genetic studies. In fact, it is doubtful whether in any naturalist of the very first order the different interests which the nineteenth century inherited and created were inore equally and impartially balanced than in him. The embryological researches of von Baer. stimulated many ardent students in (iermany, such as Purkinje, Rathtke, Bischoff, and it is maiuly through them that this branch of science was cultivated and made generally known. The name of the distant originator thus becane somewhat forgotten, so that in French science we do not find von Baer as frequently and appreciatively mentioned as he deserves. Ample information on von Baer's scientific and personal character can be found in later publications: foremost in his 'Autobiography,' published in 1865; in his 'Life,' by Stieda (187 7 ) ; and in an elaborate work by Professor $R$. stölzle, entitled 'K. E. von Baer und seine Weltanschauung' (Rcgensburg, 1897). This work contains very ample and useful references and extracts from Baer's writings and correspondence. Very important are also vou Baer's miscellaneous writings and essays, which were published by Vieweg in lirunswick, in three parts (2nd ed., 1886). 
strated in the completest mamer the truth of epigenesis. In fact, he had recognised development as th" "sole basis of zoological classification; while in France ('uvier and Geolfroy st Hilaire were embittering each other's lives with endless merely anatomical discussions and replications, and while in Germany the cautious study of nature was given "y for the spiming of Natur-philosophies and other hypothetical cobwebs." I

The position which Karl Erust von liaer ocenpies in the history of seience and thought is in many respects interesting and unique. He lived early enough in the century to experience the full influence of ('uvier's anthority, and lived long enough to witness the great change which Darwin's writings bronght on in all the natural seicnces: whereas his great contemporary, Johamnes Miiller, passed awa before the name of larwin was known ontside of his own country. In unison with Mïller, and yet in an independent mamer, he effeetually liberated Cieman science from the undne influence of the speculative school. And he has, probably more than any other great naturalist, recognised the importance of the three aspeets which a contemplation of natural ofjects forees upon us: the apprarent or real fixity of certain forms (the morphologieal view), the continued and orderly change ${ }^{2}$ of these forms (the genetic view), and the apparent or real existence of a

\footnotetext{
1 Huxley in 'Tuylor's - Ścientific Memoirs,' New Series, p. 176.

" Very important in this respeet is a lecture delivered by vou Bacr in 1s:31, with the title "Dis all. gremeinste Geset\% ler Natur in aller Entwickelung" (reprinted in the Brunswick erlition, vol. i. p. 39 s77.) "We must conelurle that, sis
}

fir as observations now give material for inferences, a transf mmation of certain original forms of animals in the succession of generations is very probible, but only to a limited extent" (1) 60), a view which von Baer maintained to the end against extreme Darwinism (see [1. 37). 
design in this process of change (the teleological view). Though his own researches did so much to give prominence to the genetic view, to the conception of development, he retained and elaborated the doctrine of types; and though he effectually handled the modern methods of the mechanical or exact sciences, he realised the full importance of studying the things and processes of nature in their actual and living connection, ${ }^{1}$ and not merely in the artificial isolation of the laboratory or the dissecting-room. And he never became an adherent of the doctrine so prevalent with many of the followers of Darwin, that the apparent purpose of forms and processes in organic nature could be mechanically explained. During the period of his greatest scientific activity he was little known outside of Russia and Germany; in England; Carpenter and Huxley alone drew attention to his embryological and genetic studies; but since the tide of Darwinism has somewhat subsided, or has ceased to be all-absorbing, it is to the writings of Baer that many naturalists revert. In fact they belong to the few books of this class written during the pre-Darwinian age that bear to be read and re-read with profit by those who take a philosophical and not merely a historical interest in the development of

16. Von Baer's comprehensive views. natural science. Perhaps the fact that von Baer was as great in relation to the morphological as he was in relation to the genetic and the teleological conceptions of natural phenomena prevented him from producing that revolutionary impression on the minds

I See the introduction to the geschichte der Thiere' (Königsberg second part of his 'Entwickelungs. ( 1837). 
of his eontemporaries which l)arwin did, and for which he indeed largely prepared the way. Instearl of opposing the genetic change and development of the forms of natural objects to their apparent fixity, he rather reconciled both views with each other ly maintaining "that in order to obtain a just insight into the mutual afinities of amimals it is hefore all things necessary to distinguish the diflerent types of organisation from the different grades of Arrolopment." He consillered that" "the idea of amimal organisation does not vary at equal intervals, but is realised in certain principal forms which again lreak up into variations of a lower grade": and he "arrived at the four principal divisions of the animal kingdon established by cuvier:" In 1828, in his work on the "Development of Animals,' he discusses " "the prevalent notion that the embryo of higher animals passes through the permanent forms of the lower animals" - i.e., "the doetrine of the agreenent of individual metamorphosis with the ideal metanorphosis of the whole animal kingdon." Ton Baer had himself added greatly ${ }^{5}$ to

I See Huxley's translation, loc. cit., p. 178 .

2 Ibikl., 1). 142.

3 Ibid., p. 183.

4 See K. li. von Baer's 'Letver Fintwickelungigeschichte der 'Thiere Beobachtung und Reflexion,' K̈önigsherg, 1828. 'The above extructs are taken from the fifth scholion: "Ueber das Verhilutuiss der Formen, die das lndividuum in den verschie. denen Stufen seiner Entwickelung anuinunt." See also Huxley's Translation, loe. cit., p). 186, 159.

5 Prof. J. A. Thomson summarises as follow's von Baer's own results: "It was von biaer who first elearly discriminated the great erents in a life-history: (a) the primary process of egrg-eleavage, and the establishment of the germinal layers: $(b)$ the gradual differentiation of the tiseues (histogenesis); and (c) the blocking out of the organs (organogenesis), and the shape-taking of the entire organism (morphogenesis) ("Scienee of Life,' 1) 123). The elassical work of von Baer is dedicated to his friend P'ander, from whom and Dollinger he acklowledges having received the first impulses towards 
the existing knowledge of the early development of the germs of animals by discovering the ovum in the body of the mammalia before fructification, and by this and other discoveries secured his claim to be considered the greatest embryologist of his own age, and perhaps of all time. He goes on to examine to what extent the morphological differences which the animal kingdom exhibits in its various members can be taken as a guide to the genetic differences in the growth and development of the higher organisms. He, in fact, tried to ascertain how far the facts of classification throw a light on the facts of development, how far the changing embryo of the higher animal gradually passes through the permanent forms of the lower animals. He combats the idea that the classification or morphological arrangement can be uni-serial-i.e., brought into one continuous line or order.

his researches. He wishes to distinguish carefully between facts and theory, and is very cautious as to the latter, a trait which runs through all his writings. It is also very interesting to see how in his biography of Cuvier (posthumously published by Stieda) he consider's it a merit of that great naturalist not to have indulged in genetic theories. "It is evident that Cuvier in his youtl had also a genetic system in view, such as Oken afterwards followed up, but that he must soon have found out that this task was unattainable for hirr. He abandoned it, and sought rather to draw from the manifoldness of the formed product inferences regarding the conditions of its genesis. Thus he arrived at the teleological concep. tions which he developed on vari. ous occasions. German naturalists drew from all this, especially in the age of Schelling's 'Natur-philosophie,' the conclusion that Cuvier. was not a philosophical mind. To me it seems that we recognise in it Cuvier's desire for chearness. $\mathrm{He}$ dropped the higher task because he found that it would not lead him to clear views" ("Lebensgeschichte Cuvier's von K. E. von Baer,' ed. Stieda, 1897, p. 72). English readers, to whom the genetic view has only become familiar since Darwin or perhaps Lyell, will find with astonishment how in the writings of Baer, before Lyell and even before the appearance of Cuvier's final system, genetic ideas were thought to be prevalent, and were criticised elaborately and received with the utmost caution even by the great propounders of the doctrine of development. 
Animals differ according to the type of organisation to which they belong. 'Thus the "embryo of the vertemate animal is from the very first a vertelorate animal, and at no time agrees with an invertebrate aninal." H Haing, however, once fixed the existence of special organic forms, he asks whether within the limits of such form no law can he disenvered to formulate the development of the individual. He believes there ean," and he proceerls to explain it in terms which for the most part might appear maltered in the most molem work on evolution. He states that the more special type is developed from the more general, "and that the more different two animal forms are, so much the further hack must theil. development be traced to find them similar." Indeed he thinks it probable that "in the condition of the actual germ all embryos which are developed from true ova agree," and he anticipates the cellular theory of Schwann, established by olservation ten years later, by suggesting that the simple vesicle is the common fundanental form "from which all animals are developed, not only ideally. bist actually and historically." 3 In further examining the process of development, von bier introduces the very suggestive tem * diffirentiation. "The higher and lower development of the animal coineides perfectly with that histological and morphologieal differentiation which gradually arises in the course of the development of the individual." 5 bevelopment, in fact, is the estab-

Loer, cit., p. 220; transl., p. 210 .

2 Ibill., p. 221.

3 Loc. cit., 1. 224 ; transl., 1). 213. (1) this anticipation see, however, ron bacr's later explanation in 'Reden, \&c.,' vol. ii. 1. 250.

VOL. II.
4 The German term is "Smderung," which Huxley reuders by the English term "Diflerentiation."

5 Loc. cit., 1. 229, 230; transl. 1. 219. 
lishing of differences, and in reality "the embryo never passes through the form of any other animal, but only through the condition of indifference between its own form and others." And he sums up his reflections by stating that the "development of an individual of a certain animal form is determined by two conditions: first, by a progressive development of the animal by increasing histological and morphological differentiation; secondly, by the metamorphosis of a more general form into a more special one."

In order better to understand the difference which separates these various reflections, though breathing so

17. Von Baer's views in modern terms. much the air of the more modern theory of evolution, from later views, and to prepare for a real comprehension of the great step taken by Darwin, it will be helpful to resort to modern nomenclature. None of the terms of that vocabulary which was invented by Darwin and his followers to bring home to the popular mind the main points of his revolutionary doctrine are to be found in the earlier writings of von Baer. Nevertheless they are useful in defining the views of the great naturalists who preceded Darwin. Since we have become familiar with the idea of the origin and the transmutation of the different animal and vegetable species, we are accustomed to apply the gerietic view not only to the growth and development of individual living things in nature, but to everything else. When von Baer speaks of development, when he tells us that "the history of development is the true source of light for the investigation of organiser bodies," he means development in the narrower sense,

${ }^{1}$ Loc. cit., p. 231 ; transl., p. 220. 
that which Haeckel has termel "Ontogenesis," the genesis of the individual being. Fom this Hackel distingnishes "I'hylngenesis," the genesis of the phyla, the genera, and species. Now, in discussing the relation of the orler which prevalils in the natural systems of animals to the stages of development of individual emloryos, von biter does not seem to have hat hefore his mind the genesis of one species ont of another, a view which he in fact ridicules ${ }^{1}$ after a very moctern fishion. He lookerl

1 Loc. rit., p. 200; tratust., p. 157 (142S): "This iclea-vi\%, that the higher forms of animals in the single stages of the develoment of the individual, from its first origin to its completer development, answer to the permanent forms of the animal series- . . could nut fail to be wjdely arepted, since it was suyfrorted by a multitude of special demonstrations. (ertain of its artveates were so zealons that they no longer spoke of similarity but of perfect ielentity, and assunsed that the correspondence hat lieen demonstrated in all cases and to the minutest details. . . By degrees it became the custom to look upon the different forms of animals as developerl out of wre another, and then many appeared to forget that this metamoryhosis was after all only a morle of conceiving the facts. . At lengtle, in solier serious. ness, and with all due particularitý, we were informed exactly how they arose from one another. Nothing could be easier. A fish, swimming towards the shore, desires to take a walk, but fincls his fins useless. 'Tley diminish in brealth for want of $u$ se, and at the sime time elougitte. This goes on with children and grandehifelen for a few my riark of years, and at latst, who can be astonished that the lins beconne feet? It is still more matural that the fish in the meadow, finding an water, sluuld gape atter air, therely, in a like periml of time, develup. ing lungs ; the only difficulty leing that in the neanwhile a few generations unust manage to do without breathing at all. 'The long neck of the heron arose from a lialit its. ancestor's aequired of stretching ont their necks for the purpose of catcliing fisl. . . An immediate conseyuence of the assumption of this idea as a natural law was that it view which hat once been very general, lut bad subsequently leen fretty generally given nu, -- that of the universal progression of the different forms of animals, - gradu. ally got footing again. . . . It must he confessed that the matural law being assumed, logical conse. quence required the almission of the view in question. There was then only one road of metanolphosis, that of further develupment, either attained in one in. diviclual (individual metamory hosis) or through the different animal forms (the metamorphosis of the animal kinglom); and disease was (1) he eomsidered as a retrugressive metammphosis, herause universil metamomplosis. like a milroad, allow's motion hackwards or for. wards, but not to one sirle." 
upon this order as systematic only, and ideal ${ }^{1}$ he thinks merely of arrangement or "taxonomy." TVe may say that he deals with phylotaxy (called at that time taxonomy), not with phylogenesis. He conceives that ontogenesis, the historical development of the individual thing, throws light on the "mutual relations of organised bodies": ${ }^{2}$ he wishes to make ontogenesis helpful in taxonomy or in phylotaxy. This term did not then exist, but it is useful in order to enable us to understand the change which eame over natural science when

18. Phylotaxy and phylogent'sis. the attempts at phylotaxy were succeeded by the schemes of phylogenesis, when reasons were established for taking in real earnest the idea then fancifully ${ }^{3}$ put forward that the natural order of living beings represented the order in which they had developed ont of each other in time. These reasons did not at that time exist.

A suggestion in this direction had indeed been thrown ont, and an elaborate theory had been publisher abont

${ }^{1}$ In his later writings von Baer notes especially the difference between a purely ideal and a genetic or genealogical relationship. See 'lieden, \&c.,' vol. ii. p. 386 (2nd erl.)

2 'Entwickelungsgeschichte' (1828), p. 2:31 ; transl., p. 221.

${ }^{3}$ In a later publication of von Baer's (see 'Reden, \&c.,' 2 Theil, No. V., "Leher Darwin's Lehre") the aged author tries to define more exactly the part which his early writings played in the gradual establishment of a genetic conception of nature. If Haller arrived ultimately at the dictum "es gibt kein Werden," we may say that ron Baer as emphatically asserted the opposite, that "es gibt kein Sein." In Baer we hare progressed from the study of the "esse" (fixed forms) to that of the "fieri" (processes of change and ilevelopment). See the expositions in the introduction to the article on Darwin. He there also mentions Meckel and Oken as the two principal exponents of the extreme view them put forward anct opposed by himself, that the humau being in its development passes through the different higher forms of the animal creation, and he maintains that Johamnes Müller, who had in the first edition of his 'Physiology' accepted this view, struck it ont in the second. He also refers to a passage in a Memoir of 1859 , published just before the appearance of the 'Origin of Species,' in which he maintains his belief "that formerly organic forms were less rigirl." 
ten yeurs hefore ron Bier ${ }^{1}$ took up " the sulject, which then presented itself as the richest which an anatomist eould take "1], the history of development," and twenty" years before his first larerer publication on this sulject. Lamarck's" "l'hilosophie Zoologique' appeared in 1809. Though known to von Baer, it does not seem to have ever leen much appreciated by him, hut it was the first serious attempt to deal with jhylogenesis, as ron Baer's researches were the first ronsistent studies in ontogenesis.

It is of interest to inquire into the reasons which indueed limarek to form opinions so entirely different from those which, through the influence and the anthority of C'uvier, were then prevalent among naturalists, amd tu oppose the idea of variability and of rescent to that of

1 Von liaer himseli describesusing these words-how in the year 181 ! the play of accirlent or good fortune "threw this subject into his hanrls." stieda, p. $6 \%$.

2 fince the intere-t in the speculations of .I. Baytiste le lamarck $(1744-1829)$ has heen revived through the writings of ('harles Darwin, the historicial antecerlents of his irters have also been studier?. and his as well as Geoffroy's theories have been brousht into eonnection with the views containerl in Buffon's 'Epoques le lir Niture.' See especially the interesting analysis in Filmond Perier's "la Philosophie \%oologinue avant Darwin,' 1854. "Ainsi surgissent, posés par liutlon, ce part isan d'aborr si résolu de la fixité des espèces, tous les problèmes dont la solution sura été sans aucun dloute la pensée dominante de la seconde moitić de ce sitcle. . . Et toutes ces grandes irlies que bullion devine en quelipue sorte, vers lesquelles il est iuvineiblement entrainé par la puissante et rigoureuse logique de son génie, sont précisément celle's yui commencent a jourd'hui, appusets sur un ensemble imposint de recherches, a triompher de tous les serupules" ( $p$ 68). "Trois grants hommes y vont poursuive, far des voies diverses, locurre de Buffon: latmarek, Geoffroy sit llilaire, et Cuvier" (1). 72). For the historical commections of Lamarck's ideasee also lluxley"s article in the 9 th el. of the 'Eney. Brit.,' in which he' points to a great change which took place in latmarek's riews between 179t and 1809. In fact, the theories which have given to Latmatrck so distinguisherl a position in the his. tory of the genetic view of nature belong to the latter half of his long life. I know of nu other recent example of ro late a development of quite original irleas except perhajs the critical philosophy of liant.
19. Istmate. 
the fixity and independence of species. And it is equally interesting to mark the causes which militated against the more general acceptance of his views, and which cast the 'Philosophie Zoologique' into oblivion. To the first question Lamarck has himself, in the introduction ${ }^{1}$ to his great work, furnished us with the means of replying. He there tells us that when the real study of natural history began, and each of the different kingdoms of nature received the dne attention of naturalists, animals with a backbone-viz., mammalia, birds, reptiles, and fishes-received the greater attention. ${ }^{2}$ Being in general larger, with parts more developed and more easily determinable, they, as it were, obtruded themselves on the attention of man, for whom they are both more useful and more formidable. The other large group of animals, classed together first by Lannarck himself as "Invertebrates," are mostly very small, with organs and faculties less developed, and thus much further removed from man and his interests. Of this by far more numerous elass of beings, those called insects had alone at the end of the former century received considerable attention, whereas all the others, classed together by Linneus as "worms," formed a kind of chaos, an unknown land.

1 Lamarck"s later genetic views are contained in the "Philosophie Zoologique,' which appeared in 1809, and was republished with a biographical notice by Charles Martin in 1873. I quote from this edition. His principal ideas are also summarised in the introduction to his great work, 'Histoire des Animaux sans Vertèbres' (1816), which in fact he represents as con- taining the "pieces justificatives de ce que j'ai publié dans ma Philosophie Zoologique." This great work was republished in 1837 by Deshayes and Milne-Edwards. I quote from this edition, which is in three volumes.

'See 'Philosophie Zoologique,' Discours préliminaire, rol. i. p. 29 ; also 'Animaux sans Vertèbres, Introduction, vol. i. p. 11. 
It was to some extent accidental ${ }^{1}$ that Lanalck, ifter having devoted himself for many years to the exclusive study of plants, should on the occision of the foundation of the different chairs for the natural sciences at the "Musemu" suggrested hy Lakanal, have allotted to him the cultivation of this departnent, unknown to himself as it was to others, and where even the systematising genius of Linneus had abstained from trying to make order. Thus it came about that Lamarck brought to the study of the animal world a mind trained in a very different region of science, ${ }^{2}$ and that he approached this study

1 See the "Introduetion liograplique," hy Martins, "Pluilos. Zool.,' I. xiii. "La Convention gouvernait la France, ('armot organisait la victuire. Lakanal entreprit d'organiser les seiences naturelles : sur sa proposition, le Muséum d'histoire naturelle fut crée. (1) avait yu nommer des professeurs i toutes les chaires, sauf pour la zoolngie; mais dans ces temps d'enthousiasme la france trouvait des hommes de guerre et des hommes de science partout ou elle en avait besoin. Étienne Geoffroy Saliut-Hilaire était îgé de vingt-et. un ans, il s'oceupait de minéralogie sous la lirection d'Haiiy. Daubenton lui dit: 'he prends sur moi la responsabilité de votre inexpérience; j'ai sur vous l'aut rrité d'un père; osez entreprentre l'enseigner la zoolugie, et un jour ou puisse dire que vous en arez fait une seience franyaise.' Geoffroy accepte, et se charge des animaux superieurs. Lakanal avait compris qu'un seul professeur ne prourait suflire à la tìche de ranger daus les collections le règne aninal tout entier. Geoffroy devant cla-ser les vertébrés seulement, restrient les invertélurés, ì savoir les insectes, les mollusques, les vers, les zoophytes, c'est-à-dire le chaos, l'incoinnu. Lamarck, dit II. Michelet, accepti l'inconnu .. . il avit tout ì ap. prentre, tout à créer dans ce monde inexploré, ou Linné avait pour ainsi dire renoncé à introluire l'orilre méthodique qu'il avait su si bien ¿tablir parmi les animaux supér. ieurs." Lamarck was accorlingly about fifty when he nudertook this novel study, which, as Huxley pointed out, wits to work such a change in his views (loc. cit.)

2 He harl written in six months his 'Flore francaise,' which was prefaced by his 'Clé dichotomique.' 'This was in 1778. "loussetu avait mis la botanique it la mode; les gens du monde, les dames sen oceupaient. Buffun fit imprimer les trois volumes de la 'Flore francaise' à l'imprimerio' royale" (loc. cit. p. 11). Lamarck hail also qualified as in naturalist by extensive travels in many lisur. pean countries as a companion to Bulfon's son. 
from that side which at the time was the least known, and probably the least promising: he approached it, as it were, from below. But this had the consequence of giving to his original mind in two ways a special direction. First of all, it enabled him to look at natural objects from a more general point of view, not as a zoologist or as a botanist, but as a naturalist and a biologist-i.e., from the more general view of the phenumena of Life. ${ }^{1}$ Indeed he himself seems to have been

20.

The term "Biology. the first, if not to use, at least to introduce in his published writings, the term "biology." 2 And secondly,

1 'Philos. Zool.,' Discours prélim., p. 31 : "Le vrai moyen de parvenir à bien connaître un objet, même dans ses plus petits détails, c'est de commencer par l'envisager daus son entier; par examiner l'abord, soit sa masse, soit son étendue, soit l'ensemble des parties qui le composent; par rechercher quelle est sa uature et son origine, quelles sont ses rapports avec les autres objets connus; en un mot, par le cousidérer sous tous les points de vue qui peurent nous éclairer sur toutes les géuéralités qui le concerment." P. 32: "La nécessité reconnue de bien observer les objets particuliers a fait naitre l'habitude de se borner à la considération de ces objets et de leurs plus petits détails, de manière qu'ils sont devenus, pour la plupart des naturalistes, le sujet principal de l'étude. Ce ne serait cependant pas une cause réelle de retard pour les sciences naturelles, si l'on s'obstinait à ne voir dans les objets observés que leur forme, leur dimension, leur parties externes, mêmes les plus petites, leur couleur, \&c., et si ceux qui se livrent à une pareille étude dédaignaient de s'élever à des con. sidérations supérieures, comme de chercher quelle est la nature des objets dont ils s'occupent quelles sout les causes des modifications ou des variations auxquelles ces objets sont tous assujettis, quels sont les rapports de ces mêmes objets entre eux, et avec tous les autres que l'on connait," \&c.

2 Lamarek in his "Hydrogéologie,' in an appendix (p. 188) which seems to be a rehearsal of his opening lecture of 1801 , a11nounces a work, 'Biologie,' as a sequel, being the third and last part of the Terrestrial Physics. This work was not published, but was probably comprised in his 'Philosophie Zoologique.' See Prof. A. S. Packard's excellent work on Lamarck, "The Founder of Evolution, lis Life and Work,' London aud New York, 1901. As Lamarck's writings are very scarce and his teaching only imperfectly understood, frequently misrepresented, even by competent authorities, and in popular opinion surrounded by mystery and sometimes treated with ridicule, the work of Prof. Packard is most welcome. It contains copious extracts-unfortunately all translated - from the earlier biological writings and lectures, which are otherwise al- 
it introduced him to the sturly of amimal life from that sile where organisation, the phenumena and the organs of life were the simplest, Judimentary ats it were, inm unformed. Here the great diflerences of form, the morphological differences which the observation of the higher and more developed creatures force upon onr attention, disappear; not the marked lifferences, but the mumerous relations, the endless varieties and resemblances, seem to command our ecmsideration. These seem to be much more likely to "make us understand the begimnings of all organisation as well as the cantse of its complexity and of its development." 1 Now in descending in the scale of the living objects of nature, Lamarek was struck by the fitet that many of the phenomena of life which in the higher animals seened to originate within were in the lower creatmes producer

most inacessible. Aceording to Huxley (Lecture "On the situdy of Biology," 18\%6, and "Evolution iu Biology," 'Eucy. l'rit.,'9tl ed.), there were simultaneously three iudependent attempts to treat the phenomena of organic life as a whole and in connection, emanating from lichat and I Lamarck in France, and from G. li. Treviranus in Germany. 'The great but uufinished work of the latter, with the title "Biologie oler Philosophie des lebunden Natur, was begun in 1796, when the autloor was only twenty, lut the first volume was not publisher till 1:0?, one year after Lamurch's 'Hydrogéolugie.' Haeckel in his 'Natiir. liche Schöpfungs goschichte' gives some account of 'Treviranus' illeas (Band 1. Vorlesung 4). Although so much has been written about "Biology," the delinition of the neience is still uncertain. Prof.
Gocbel sitys: "The worrl liology is one of those cunceptions of moleru times which liave not yet arrived at a generally accepted limitation. Some understand by it the whole science of living things, others only the doctrine of the phenouneua of life in contrast to tlie purely descriptive branches". ("Pflanzenbiolomiclos Śchilderungen,' Marburg, 1859, vol. i. p. 1). With Lamarek biology was only one division of a general science of nature, for he says ("Hỹdrogéologie,' p. 8): "Toutes ces consiclérations jartagent natur. ellement la physique terrustre m trois parties essentielles, dont la première doit compresulye la théoric de l'atmosphere, la Néléorolugie, la secoule celle de la croute exterue in globe, l'tlydrogéologie; la truisième enfin, celle des corps vivant -, la Biologic.."

'Philos. \%ool., vol. i. 1. 30. 
or excited from outside, and he was thus led to the conception that nature herself, through the environment, did a great deal for the lower creatures which in the gradual development of the higher ones she knew how to make them do for themselves. ${ }^{1}$ In fact, the idea is worked out in the 'Philosophie Zoologique,' that if we commence the study of living creatures from below, and from the side of vegetable life, we are inevitably led to the conviction that the surrounding conditions and 21. influences, the environment, are gradually and slowly "Environ. ment." modifying the elementary organisms, and through habit and inheritance ${ }^{2}$ developing the higher ones, endowing them with more specialised organs and more complex powers and activities.

Lamarck is aware that these ideas sound strange and novel, and he is quite prepared to admit in the reception of them by his readers the same inevitable force of habit which, as it only permits gradual modification of the forms

'Philos. Zool., 'Avertissement,' p. 13: "Ayant remarqué que les mouvements des auimaux ne sont jamais communiqués, mais qu'ils sont toujours excités, je reconnus que la nature, obligée d'abord d'emprunter des milieux environnants la puissance excitatrice des nouvements vitaux et des actions des animaux imparfaits, sut, en composant de plus en plus l'organisation animale, transporter cette puissance dans l'intérieur même de ces êtres et qu'à la fin elle parviut ¿̀ mettre cette même puissance ì la disposition de l'individu." P. 12 : "Ayaut considéré que sans les excitations de l'intérieur, la vie n'existerait point et ne saurait se maintenir en activité dans les végétaux, je reconnus bientôt qu' un grand nombre d'animaux devaient se trouver dans le mêrne cas; et comme j'avais eu bien des occasions de remarquer que, pour arriver au même but, la nature variait ses moyens, lorsque cela était nécessaire, je n'eus plus de doute à cet égard."

2 Ibid., p. 13: "Je pus saisir le fil qui lie entre elles les causes nombreuses des phénomènes que nous offre l'orgauisation animale dans ses développernents et sa diversité, et bientôt j'aperçus l'importance de ce moyen de la nature, qui consiste à conserver dans les nouveaux individus reproduits tout ce que les suites de la vie et des circonstances influeutes avait fait acquérir dans l'organisation de ceux qui leur ont transmis l'existence." 


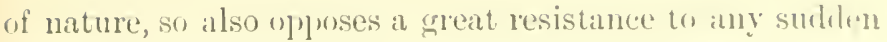
change of opinion. " "But it is better," he sals, " that a truth once perceived should struggle a loug time to obtain nerited attention than that everything that the ardent imagination of man produces should be easily accepted." I Whereby it may appear to us worthy of note that Lamarck did not stop to reflect on the existence of those sudelen changes by whieh sueh powers as the "ardent imagination of man" are continually breaking through the slow aetion of labit. 'The cloctrine of the mutability and rariability of species, of the intluenee of the envinonment on the liabits, and through them and inheritance on the forms of living ereatures, was thus opposed to the prevalent doctrine of the fixity of species and the permanenee and recurence of types. Through these generalisations, and through the larger view whieh Lamilek took of the phenomena of nature and of life, lie stepped outside of that school of natural studies which was then doninant in his conntry, and approached the teachings of the German philosophers of nature, such as Schelling, Oken, and Steffens, with whom Goethe is frequently ussoeicted, who, rather than limit themselves to the patient study of detail, indulged in fanciful theories on the origin of life, the genesis and netamorphosis of forms, and the ideal significance of natural phenomena and proeesses. A wide gap seprarated the speculations of the anthor of the 'Flore française, the 'Histoire des Animanx sams Vertèbres,' and the 'Mémoires sur les Coquilles fossiles des environs de Paris' from those of the Cielman school, yet it eannot be denied that in 
many passages of the 'Hydrogéologie,' where be speculated on matters of chemistry, geology, and meteorology without the necessary foundation of facts, such as he possessed in botany and zoology, he laid himself open to the criticism and ridicule ${ }^{1}$ of his more cautious opponents. Thus it happened that the most original contributions to science were forgotten or disregarded for more than half a century, after which time Lamarckism became a familiar term in speculative science, denoting one of the great ideas with which the genetic view of nature operates - viz., the influence of environment, adaptation, acquired habits, in the development of living organisms.

23.

I.amarck and von Baer.

In the history of the genetic view of nature, the position of Lamarck nay be regarded as, in a certain sense, complementary to that of vom Baer. Both brought the study of living forms back to that of their origins -Lamarck to the study of the lowest forms of animal creation, the great variety and abundance of which he was the first to attempt to put into some order: von Bacr to the study of the embryonic hegimmings of the higher organisms, on which important subject he was one of the first to thrmw some light. Though widely

' See, inter aliu, what Cuvier wrote in his 'Eloge de Lamarck,' which was read posthumously in the Academy by Silvestre, 26th November 1832 ("Mem. de l'Acad. des Sciences,' rol. xiii. p. $\mathrm{xx}$ ), with omissions to tone down its severity : "Quelque intérêt que ces ourrages excitassent par leurs parties positives, persome ne crut leur partie systématique assez dangrereuse pour mériter d'être attaquée; on la laissa dans la même paix que la théorie chimique" ; and farther on he touches on one of the weakest points of all genetic speculations (p. xxii): "Le temps sans horne qui joue un si grand rôle dans la religion des mages, n'en joue pas un moius grand dans toute cette physique de M. de Lamarck, et c'était sur lui qu'il se reposait pour calmer ses propres doutes et pour répondre à toutes les objections de ses lecteurs." 
sifferent in their mental attitude, the two men agreed in Iooking for the alvancement of natural scionce in an understmuling of the simpler, mspecified, and nudifferentiated forms or stiges of existence out of which they conceived the more complex to have srown or developed by a process of specialisation or differentiation. Many other natmalists and philosophers contributed, partly independently, partly through the influence of Lannark's systematic and ron Baer's embryological labours, to elaborate the same view and strengthen the simue tendeney of thought and reseirch. Sor were there wanting suggestions as to the ultimate philosophical drift of the line of reasoning. It is cloubtful whether these speculations, like those of Oken in his 'Physio-philosophyy, did not retard rather than promote the accejtance of the nenetic riew ly scientitic thiukers: ${ }^{1}$

1 ()n the porition of fivethe and ()ken in the history of the genetic: riew, see Carus, '(iesthichte der' Zoologie, P. $72: 3$; von Barr, - Rerlen mul wissenschattiche A\}. latndlungen, Bd. II. 1). 2.8s, \&c. Both consicler Limarek ats the real origisator of a seicentific theory of Descent. Vun Batr gives all amuxing account of the "xtent to which, as early as 1 1829 , actual genealogrical trees were given in Jacol, Kaup's 'skizzirte Entwickelungrigeschichte und naturliches siysem dor Eur. opreischen 'Thirerwelt.' Von biser sums up his historical account in the folluwing work (j). 2(it) : "In general I believe that at that lime, when the succession of tifferent animals and plants in the history of the earll-and generally from im. preffect (1) une perfect organisms - occupied the thoughts of naturalists, and whon, at the same time, the sturly of development of single organisus hat taken a new start. the notion of their l'ransformation was pretty generally accepted." The view expressed here by von baer would probably have to be linited to German naturalists at that clate. It monst, however, be ad. mitted that the fairest exposition and eriticism of the arguments of Latharck at that eary date is prob. ably to be found in lyectl's ' Jrinciples of (ieologrl (vol. ii. Bk. IIl. chal). i. to iv.) He there also considers the arguments derivel from enturylogr an contained in the re. searclies of Thiedemann, contirmerl by Sierres ("Amatomie Comparíe du Cerveau, 18:4), and comes timally to the result that-1. "There is at capacity in all species 10 aceommadate themselvos." 2. "That the mutations thus superindncerl are governel hy constant laws." 8. That "some aecpuired peeuliarilie: of form, structure, and instinct are 
they belong, therefore, more to the history of philosophical than to that of scientific thought. There is, however, one instance of which it is necessary to take a passing notice.

In the year 1844 a book appeared which in nine The

24. years, up to 1853 , ran through nine large editions. It 'Vestiges.'

\section{was anonymous, ${ }^{1}$ and bore}

transmissible to the offepring." 4. That "indefinite divergence" from the original type is " prerented." 5 . That "the intermisture of distinct species is guarded against by the aversion of the individuals com. posing them to sexual uniou." 6 . That "it appears that species have a real existence in nature, and that each was endowed, at the time of its creation, with the attributes and organisation by which it is now distinguished." The reviewers of Lyell's work-such as Whewell ('Quarterly,' vol. xlvii. p. 113)treat Lamarck with much less gravity than Lyell himself, who evidently' had studied the 'Philosophie Zoologique' carefully and with much interest: which, I am afraid, was not the case with many otbers who then and long after only quoted certain extreme passages and exauples which liad been spread in general literature in a garbled fashion. Coutrast in this respect what Lyell wrote to G. Mantell in 1827 ('Life of Lyell,' vol. i. p. 168), where he admits having "devourerl Lamarck witl pleasure," and though disagreeing with him, admits that it is impossible to say "what changes species may really underg(," with the remarks of Charles Darwin-otherwise so careful and morlerate-when he talks of " I Lamarck nonsense" ('Darwin's Life and Letters,' 1. 23) and his "veritable rubbish" (p. 29), and attributes to him statements which such a careful student of his writings as
Prof. Packarl has been unable to trace (see his work on 'Lamarck,' 1901 , p. 74). One would be inclined to agree with Darwin that such absurdities have done the subject more harm than good, but to attribute them rather to garbled paraphrases and quotations by Lamarck'scritics (see Darwin to Hooker, 1853, 'Life,' vol. ii. p. 39) than to Lamarck himself. More than thirty years after the publication of the ' 'Principles,' when, in consequence of the appearance of the 'Origin of Species,' the subject of Transmutation was much discussed, Lyell wrote to Darwin that he had reread Lamarck, and admitted that, "remembering when his book was written, he felt he had done him [Lamarck] injustice" ("Life, \&c., of Sir Charles Lyell,' 1881, vol. ii. p. 365). In the same letter Lyell states that forty years ago (1823) Prérost, a pupil of Cuvier's, told him his conviction "that Cuvier" thought species not real, but that seience could not advance without assuming that they were so."

1 The anonymity of the work was long maintained, and though, after various guesses as to the authorship_attributing it, e.g., to Lyell or Darwin--had been made, it was generally believed that Robert Chambers (1802-1871) was the author, this was not publicly admitted till Alex. Ireland - the last survivor of the few friends to whom the secret was committed-publislied (1884) the twelfth edition of the book, 


\section{Natural History of Creation.' 'This hook contained a very} clear and popularly intelligible statenent of the genetic or development hypothesis as applial to cosmic, geological, and organic phenoment. 'The innportance of the book did not lie in its own original contributions, but in the great controversy which it oceasioned. In this controversy most of the arounents fol and against the

with au introluction, in which he "toll for the first time" the "stury of the authorship." It is ot interest, atter the lapse of half a century, to read the various-mostly hostilecriticisms of the book in the review and magazines of the lay. The attack: canc froul two distinct siles: from seientific authorities, who-- each in his own specilic branch-challenged the correctnces of single facts, unosty willont inquiring whether, in spite of many misstatements. sufficient evirleuce was not after all adrluced to prove the main thesis; and, secondly, from both scientifie and penular writers, who used the well-known arguments, that the teaching of the: book was unorthodox, buth in is religious and scientific -ense. In iact, they displayed in a great degree scientific and religious dor matism and intolerance, and in sumb. cases consiclerable temprr. To thilarger section of the eritical attack. belonged the reviews in all the leading perivelicals of the dis, heacled by the "Elinburgh heview" (Adam Sedgwick), the "North british" (Sir David lirewster), the 'Evlectic, the 'North Aunerican' (Bowen and $\mathbf{A s}$ (iray), the " Brit. ish Quarterly.' 'Tolerance and appreciation were, however, shown by some of those more reeent re. views which were pofesserlly the organs of freechm, ("nlighteminent, and progres, notably the 'l'ros. pective" (F. W. Newman) and the 'Westminster' in two articles, in the first of which the genctic view of the 'Vestiges' is suggestively contrated with the purely descrip. tive of the 'Kosmos.' Looking at the whole controversy, the "Westminster leview" (xliii. 130) neems, in the light of history, justified in maintaining that, after" "having attentively considered the oljections which have been urged in numerous able criticisns to the theory and the aroments of the author," after moting that "learned men have discovered that lie jo less fumiliar than they with the pedauty of science," that "they have triumphed in the detection of slips of the pen, mistalies in teelnicatities, and some inaceuracies of fact," the conclusinn is nevertheless jurti. fiel that "these detract but little from the merit of a work which may be farily characterised as the most skilful generalisation that has yet (1845) appeared of the results of sreological, atronomical, and plissiological researches made to hear. upon the history of the first and most momentous of all problemsthe order and plin of creation." It is known tlat solne scientific men of tirst rank, such as Palcu l'owell of Oxiord, and the physiologist 11 . B. Carpenter (whi, according to Huxley, was the only authority in this enunty aequanted with the "Entwickelumgsgeschichte" of von baer), di-tinctly suppwrted the ductrine of the 'Vestiges' : aml Darwin hinself, who had studied the 'Vestiges' with evilent cure 
genetic aspect, which have since become familiar, were very ably stated by scientific as well as by popular writers. Earlier anticipations of the genetic view were recalled, the historical sketch given in Lyell's 'Principles' was supplemented by reference to many great and many forgotten anthorities, who in more or less distinct terms had given expression to their belief in a gradual development of the existing forms and phenomena of nature out of simpler beginnings, which they described with more or less precision. It cannot be denied that the enomous literature which accumulated during the ten years following the publication of this book unsettled

25.

Popular influence. the popular mind in this country, and prepared it for a really able, dispassionate, and exhaustive exposition of the whole subject, and especially of the crucial problem to which it was narrowed down, the question regarding the fixity or variability, the historical origin and development or the sudden creation and persistence, of animal and vegetable sprecies. The genesis of the cosmos as suggested by Laplace, the geological history of our earth as worked ont by Lyell, the fact of organic growth and development as given by embryology, seemed clear

(see 'Life of Darwin, wol. i. p. 338, gave probably the fairest verdict on the book in the historical preface to the later editions of his own great work, where he says: "The work, from its pwerful and brilliant style, though displaying in the earlier editions little accurate know ledge and a great want of scientific caution, immediately had a very wirle circulation. In my opinion, it has done excellent service in this country in calling attention to the subject, in removing prejudice, and in thus preparing the ground for the reception of analogous riews" ('Origin of Species,' 'thl ed., 1872 p. xvii). In a history of European thought it is well to mention that the "Vestiges' had no influence on the Continent, for reasons partially stated in the text. A little later, however, a similar "scandale" (as the 'Grande Encyclopédie' has itart. "R. Chambers and L. Biichner") arose in Germany on the publication of ' Kraft und stoff.' 
and plausible enough, but there remained the last stromghold of the older view, the existence of definite forms of animal and vegetable life. Were these to be merely tassified and redueed to separate types, as the morphologital riew was eontenter to reduee them, or was the growing evidence of variability to be interpreted in favour of a gradual development of the higher out of the lower and simpler forms of life? Above all, how was. the highest type of all, man himself, to be regarded in such a comprehensive scheme of development? In Gemany many great naturalists ${ }^{1}$ were quite prepared for a eonsistent genetie or developnental view of nature: in Frunce at that time the question was not agitated at all, the suggestive writings of Lamarek and St Hilaire having heen

1 This does not refer to the earlier writings of Goethe, Uken, Treviranus, and others, whose merits, sinee the appearance of the 'Origin of speeies,' have been variously estimated by Huxley in England and by Haeckel in tiermany: their speculations had, with the generalisations of the "Naturphilosophie,' been swept away by the inductive sehool represented in botany at that time by von Nohl, Nägeli, and Hofmeister; in zonlogy by the embryological sehool with von Baer at its head. Of W. Hofmeister (1824-1877), whose labours begin about ten years before the appearance of Darwin's great work, Julius Sachs says: "The results of his 'Comparative Researches' (1519 and 1851) were magnificent beyoud all that has been achieved befure or since in the domain of deseriptive botany, . . . the eonception of what was meant by the development of a plant was completely changed, . . the reader was presented with

VOL. II. a picture of the genetic comnection between eryptogams and phanerogams which could not be reconeiled with the then reigning belief in the constancy of species. . . When, eight years after Hofmeister" 'Comparative Researehes,' Darwin's theory of descent appeared, the affinities of the large divisions of the plant-world lay so openly, so deeply founded, and so elearly before the eyes of students of nature, that that theory had only to recoguise what had been macle evident in this line by genetic morplology " ('Geseh. d. Botanik,' p. 215, \&e.) In another direction Nigeli, by his mechanical theory of "the growth and internal structure of organisms," which he reduces to "physical, chemical, and mechanieal l"veesses" (1860), fell in with Darwin's attempt to "reduce the earlier purely formal cousideration of organic struetures to a eausal (genetic) view" (ibidl, p. 373).
20. Gentic view in Civruany and France. 
entirely overruled by the authority of Cuvier. ${ }^{1}$ In England, where geology and natural history were always popular pursuits, the question was one of more than scientific interest: it was one which had been appropriated by general literature, ${ }^{2}$ and the larger bearings of

1 Huxley describes the position of France and Germany to the doctrine of descent as follows: "In France the influence of Elie de Beaumont and of Flourens, to say nothing of the ill-will of other powerful members of the Institute, produced for a long time the effect of a conspiracy of silence. . . . Germany took time to consider; Bronn produced a ... translation of the "Origin' ... ; but I do not call to mind that any scientitic notability declared himself publicly in 1860 . None of us dreamed that in the course of a few years the strengtl (and perliaps, I inay add, the weakness) of 'Darwinismus' would have its most extensive and most brilliant illustrations in the land of learning. If a foreigner may presume to speculate on the cause of this curious interval of silence, I fancy it was that one moiety of the German biolugists were orthodox at any price and the other moiety as distinctly heterodox. The latter were erolutionists à priori already," sc. ("Life of Darwin,' vol. ii. p. 186). The two men abroad to whose opinion English biologists of that day would probably attach the greatest value were Karl Ernst von Baer and MilneEdwards. 'The former "wrote to Huxley in August 1860, expressing his general assent to evolutionist views" (loc. cit., p. 186, note). It was von Baer from whom Huxley admits to Leuckart that he learn' the "value of development as the criterion of morphological views" ('Life of Huxley,'vol. i. p. 163). Vou Baer later on qualified his adher- ence, admitting development only within the regions of the different types which he had establisherl (see the second volume of his collected papers). The opinions of the great contemporary French zoologist, Henri Milne-Edwards (1800-1855), are fully given in the last chapter of his very interesting 'Rapport sur les progrès récents de: Sciences zoologiques en France' (186i), where he also refers to the writings of Isidore Geoffroy Saint-Hilaire, who in France continued to some extent the line of researcl and reasoning which, through his father, Etienne Geoffroy, and Lamarck, dates back to Buffon, Bonnet, and other philosophical naturalists, of whom, under the name of "Transformistes," MI. Edmond Périer lias given a connected account in his very valuable historical work, 'La Philosophie zoologique avant Darwin" (1884). Milne-Edwards remained to the end unconvinced by the arguments of Darwin. He had already in 1853 set forth his ideas referring to the general problems of zoology, and he repeated them in 1867 (loc. cit., p. 432 sqq.) It is, however, well to note that ever since 1827 (loc. cit., p. 453 , note) he had contributed largely to the furtherance of the genetic view by his principle that progress in nature depends on division of labour. In his subsequent writings he dwells with much success on this principle of the "division of physiological labour." (See Spencer, 'Biology,' vol. i. p. 160.)

2 About ten years after the con. troversy about the 'Vestiges' had 
which had been fully demonstrated to the elucited and reading public. There has alwatys existed in this combry a class of literature which is alnost entirely wanting, or has died out, on the Continent. The value of this class of literature has heen differently ganger, but it never-

filled the columns of the foremont british periodicals, we find in Germany a similar agitation originating through the publication of several works which liave since been generally considered as the purest expression of Materialism. The controversy begins in 1852 with the publication of Rudolf Wagner's 'Ploysiological Letters,' Woleschott's 'Kreislauf des Le. beus, and Carl Vogt's 'Bilder aus dem Thierleben'; it cane to its height after the appertraute (in 1855) ol' $\mathrm{L}$. Buichner's 'liraft und Stoff,' and oceupied the meeting of scientific and medical men which was held in Göttingeu in 1854 . 'The subjeet belongs esseutially to the history of philosophical thought, and can be sturlied in the very tair and exhaustive 'Histury of Hitcrialism ' Written by F'. A. Lange, with a distinctly idealistic tendeney (English trauslation, three vols., by 'llomas, 1880). I mention the sulf. ject in tlis counection, because in Germany and Fugland attempt were made about the same time to found a general philossplyy of life upon the teachings of seience. This liad been done about two generations earlier in France by the "Sensualistes" and the "Idéologues." For a French public neither the Fuglish nor the German entroversy jre. sented any essentially new feature, or disclosed any novel argument. 'The older orthoilox conceptions hiul been abaudoned very largely in France in the eigliteenth ceutury, and at once replaced by conceptious derived from science. In Germany a similar movement look place, likewise during the eightcontl century; lut, insteal of exact science, it wis the prevailing ilealistic jhilosiphy which was appealed to lor the purpose of raining new foundation., and science only cume in when the speculative re-turation was gener. ally comsilered to have failed. In England, which had really supplied the beginuings both for the lirench sensualistic philosuly through locke, and for German eriticism thioush lacke and Hume, the older orthorlox foundations wre not materially sliaken before the milllle of the nineteenth cen. tury. The athor of the "Vestiges' distinctly appeals to science, thoughi in a religions spirit, desiring to make it helpful for a general philosophical, and not merely an industrial, purpose. Again, the English movenent, which really culminated in Herbert Spencer; differs from the German, being more influenced by biological conceptions, whereas in Germany the extreme system of liuchner took jurely meehanical. though ill-rlefined, idleas-force and matter -as the slibbuletl. It is siguificant, as showing the great general importance of Darwinism, that through it both the controversy over the 'Vestiges' in Eugland aurl that over 'Materialismus' in Germany were soon east into oblivion, though they hat both to some extent prepared the way (see Iange, 'Gesch. des Mat.', p. 570, Ausg. 1867; and Haeckel, 'Schïp)fungsgeschichte,' vol. i. 1. 98, 9 Autl.) 
theless forms an important feature in the development of English thought, if not also of English science. It is 27. the apologetic literature, those works which deal with Apologetic literature in what have been termed the "Evidences." In the absence of any scientific theology based upon accurate historical research and philosophical criticism, such as has existed with many good and some evil results since the end of the eighteenth century in Germany, the need was felt for defending or interpreting those answers to the great problems of Nature, Man, and Life, which seemed bound up with the Christian belief, or suggested by the sacred writings. The teaching of science had not become, as in France, a purely secular occupation; instruction was not separated from education; apologetics had not become doubtful through the bad faith and duplicities of eynics. like Voltaire, nor ridiculous through the puerilities of shallow writers such as Campe in Germany. Many serious minds were occupied with the growing discrepancies between scientific and popular religious teaching, and believing they could discern the drift of the former, they made various more or less successful attempts to effect a reconciliation between the moving and developing conceptions of scientific thought and the fixed and unalterable ideals of religious belief. Such attempts must be doomed to failure, or at best they offer an individual solution, interesting only if it happens to be the inspiration of a poet or if it represents the creed of one of the few great and soaring intellects which appear once or twice in a century. The conviction is gradually gaining ground that scientific and religious thought emanate from two separate centres, 
that althongh they inevitably cone into frequent (.ontact, the study of their independent origin and history' and their different psyehological method is more valuable than a temporary and merely ephemeral empronise of their respeetive doctrines. Mappily this eombry has produced many great and a few thinkers of the first order, in whom the greatest that scientific thomght has achieved was in hamony with a truly religions spirit. In eontemplating these illustrious examples, and bowing before their greatuess, the popular nind will probably find its conviction of the possibility of an ultimate reconciliation of both aspeets more strengthened than by leaning on the doubthul support of a voluminous apologetic literature, which proposes to give general proofs where only individual faith ean decide.

I deemed it appropriate to ofler these few remarks on the whole of the roluminous literature ${ }^{1}$ from Butler

1 The largest and best known type of publication in this class of literature, which is mactically unknown on the Continent, but which belongs to our period, is found in the Bridgewater Treatises "On the Power, Wistom, and Goudness of God, as manilested in the Creation." The circumstance's under which this series was published are sot forth in the peliminary notice to the first treatise. The liarl of Bridgewater, heir to the title and fortune of Francis figerton, third Farl of Briclgewater, who construeted from the plans of James Brindley, and in accordanee with the idea of lis father, Ior Clamcellor Egerton, the first of the large camals in Englanel, from his coal mines at Worsley to Manchester and liver. pool, leit in his will to the hisyal Society the sum of $\$ \$ 000$, which, with its accruing interest, was to be pritcl to the person or persons sclected by the President and apprinted to write and publish one thousiml copies of a work with the above title, _ "illustrating sueh work by all reasonable arguments. ats, for instance, the variety and iormation of God's ereatures in the animal, vegetable, aml mineral kingaloms; the effect of ligestion, and thereby of conversion; the construction of the hand of man, and an infinite variety of other aguments; as also by discoveries, ancient and modem, in it ts, seiences, and the whole extent of literature." 'The series contained works by such foremost men of science as sin Charles bell, Willian Whewell, Willinm l'ront. and Willian Buck: land. 
to Drummond whilst I was dealing with the 'Vestiges,' because the latter is probably the last example of that class of books in which purely scientific thinkers took any great interest. Similar publications which have since appeared have made no impression on the course of scientific thought, though they may have won a place in the popular literature of their day. To bring about that complete separation and independence of the scientific and the religious arguments in this country which has been recognised during the whole of the nineteenth century on the Continent, two books have probably contributed more than any others: Dean 28. Mansel's Lectures, ' On the Limits of Religious Thought,' through its unanswerable logic: and Darwin's 'Origin of Species,' through treating fearlessly a scientific argnment which was hased upon observation and expanded by legitimate inference without any reference to the ulterior consequences which might be drawn from it. It required some courage to attack a jroblem leset with snch difficulties and which had become hackneyed

1 It is a remarkable coincidence, showing the general tendencies of English thought about the middle of the century, that Dean Mansel's "Bampton Lectures" appeared just a year before the "Origin of Species." The argument of the Lectures "On the Limits of lieligious Thought" was that which was elaborated by Sir William Hamilton on the lines of Kant's 'Critique of Pure Reason' in his celebrated article in the "Edinburgh Review" on the "Philosoplry of the Unconditioned." A further appreciation of this line of reasoning, which had its beginniug in Hume's sceptical writings a hundred years previously, belong to a different section of this 'History.' We shall there see that in the negative portion of this analysis lie also the germs of the ideas put forward by Herbert Spencer and Huxley under the well - known terms of the "Unknowable" and "Agnosticism," and there is no doubt that both Hamilton and Mansel had a considerable influence in forming Huxley's attitude in this respect. He says, in 1863 ('Life,' vol. i. p. 242): "I believe in Hamilton, Mansel, and Herbert Spencer so long as they are destructive, and I laugh at their beards as soun as they try to spin their own cobwebs.' 
through periodical and popular literatme. Others who. before Inrwin, treated sinilar controversial subjects, such as Whewell, Babbage, Herschel, Lyell, Baten I'owell, and the author of the 'Vestiges,' had always taken into accomnt the possible inferences which might be drawn from their scientitic statements, and had oftentimes toned them down so as not to offend existing opinions. ${ }^{1}$ Darwin thought it mure modest and more beconing for an independent scientific thinker to state his side of the question completely and simply, without presuming to attack or to support i view of things which lay ontside of the dominion and the powers of science. And this is not the least of the many reasons why his work has created an era, especially in this

1 The position arlopted by several of the eminent forerumners of I)ar. win is interestingly analysed by Huxley in the chapler on the "lie. ception of the "(T)igin of Species "." eontributed to the second volume of the "Life and Letters of Charles Darwin.' ()i Lyell, who had eorne nearest to the ductrine of unbroken descent of species, Huxley says (vol. ii. p. 193) : "I ree no reason to doubt that if sir Charles Lrell could have avoided the inevitable corollary of the pitheerid origin of man-for which to the end of his lile he entertained a profound antipathy - he would have adroeated the efficiency of catuses now in operation to bring about the condition of the organic world, as stoutly as he championed that doctrine in reference to inorganic nature." And lyell himself wrote to Darwin in 1863 ('Life of Lyell,' vol. ii. p. 3tis): "I remenber that it was the conciusion he [Lanmrek] eame to abust mas that fortified me thirty years ago against the great inpression which his argu- ments at first made on my mind." Treviranus, the author of the 'Biologie,' the contemporiry of lamarck, was quite consistent in his riews of descent and mutabil. ity, for he declures against catas. trophism, believes in the evolution of higher species from the zoophyte. and even in that of a higher species than man (see 'Biologie,' rol. ii. p. 22.25 , ke.) Neither in Germany nor in France, at the beginning of the century, dicl those prejurlices exist which in 1859 preventel even Darwin from developing to the full the consequences of his main thesis. This was done in his later works. See his letter to A. R. Wallace. 22ud Dee. 1857 ('Life,' vol. ii. P. 109): "You ask whether I shall discuss 'man, I think I shall avoid the whole subject, as so surromeled with prejudices; though I fully aduit that it is the highest and most interesting problem for the naturalist. My work, on which I have now been at work more or less for twenty years, will not tix or settle anything." 
country, not only in the region of scientific, but quite as much in that of philosophical, thought.

29.

Triumph of the genetic view.

So far as the purely scientific aspect is concerned, the 'Origin of Species' firmly established the genetic or developmental in the place of the morphological view, or the earlier purely systematic and classificatory treatment of the objects and processes of nature; and it is interesting to note how the period from the publication of the 'Vestiges' to that of the 'Origin of Species,' the fifteen years from 1844 to 1859 , was also the period during which Humboldt published his 'Kosmos' - the résumé of the labours of a lifetime. This was the consummation of that aspect of nature which I have termed the purely morphological one, and which in his mind was expanded to the panoramic view: the attempt to unroll before his readers a picture or panorama of the whole world as the scientific mind was then able to see it. Nature appeared mapped out in bold and characteristic lines and colours, without allowing the questions of past history or future development, — the origin, life, and fate of the cosmos, - to present itself at all. The fact that this latter question was professedly excluded as foreign, or premature, is probably the reason why the book attracted so little attention in this country, where a new manner of treating all the problems of natural science was being inangurated; but it is interesting to learn from Darwin that his whole life was influenced ${ }^{1}$

1 See 'Life and Letters of Charles Darwin,' vol. i. p. 25: "During my last year at Cambrilge I read with care and profound interest Hum. boldt's 'Personal Narrative.' This work, and Sir J. Herschel's 'Intro- duction to the Study of Natural Philosophy,' stirred up in me a burning zeal to add even the most humble contribution to the noble structure of natural science. No one or a dozen other books influ- 
and his studies direeted by reading and re-reading Humboldt's 'Personal Narrative.' The 'Kosmos' of Humboldt elosed the older, the 'Origin of Species' 'Humsmoldt" of Dirwin opened the new, epoch of natural science: "sryum of the former was retrospective, the latter mospective. Both works owe their origin to a visit to the sane portion of the globe, to a study of the subtropical scenery and life of South Anerica - Humboldt having visited the inland, Darwin specially the maritime and island seenery. ${ }^{1} \quad$ It is further of interest to note how the

enced me nearly so much is these two. I copied out from Humboldt long passages about Teneriffe," \&c. Also vol. i. p. 337 : "I never forget that my whole course of lite is due to having read and re-read as a youth Humboldt's 'l'ersonal Narrative."

1 Besides Darwin and Lyell, to whom, of British naturalist as reprosenting the genetic view in the middle of the eentury, I have so far confined my remurks, there were at that time two other eminent nen working in the same direction. The views of these two were likewise much influenced by travel and by the study of plant and animal life in distant countries. I refer to sir J. D. Hooker and $\mathrm{Mr}$ A. Russel Wallace. The inportant part which these inen blayed in the gralual conception and birth of the ideas which were for the first tine com. prehensively set forth in the 'Grigin of Species' is lucialy and impartially told by Huxley in the well. known chipter which he contributer to the second volume of the "I,ife and Lcturs of Charles Darwin,'edited by his son, l'rufessol' Franeis Darwin, in 158\%. lew episoles in the history of thought have been treated with greiter mastery. Few botanists have possessed a greater personal know. ledge of different and greatly varying Horas thay sir J. D. Honker, who suceeeded to the position and labour's of his father, sir 15 . J. Hooker, at Kew. After laving aceompanied Captain Ross on his Antarctic expedition for the ais. covery of the south magnetic pole, he became best known by his 'Himalayan Journal' (1s5). It was in constant correspondence and intercourse with Hooker that Dar. win, from 1844 to 1859 , wrote his tirst great work. The inmortant original contributions of $\mathrm{Mr} \mathrm{Wa}_{\mathrm{a}}$. lace are well known, and the story low his paper, "Un the Tendency" of Varieties to depart indefinitely from the Original 'Type," reached Darwin when he hal got halt through the larger work which he was then writing, how this coincirence hastened the publication of the two pupers by Wallace and 1)arwin, which "eontained exactly" the same theory," in the "Journal of the limniean Society" (Zoology, vol. iii. 1. 45), has been told by l,yell and Howter (ibiol, letter w the secretary), and by lowwin himselt' (Autobiography, in 'Life,' Se., vol. i. p. 81). No mystery lies upon the history of the first enmm. ciation of the doctrine of natural 
same year which witnessed the appearance of the work of Darwin was also that of the invention of Spectrum Analysis, that great instrument by which astronomy, doomed by the purely mathematical treatment to become simply "une question d'analyse," was once more enrolled among the natural sciences: the means being supplied for that natural history of the heavens which is now one of the most progressive and fascinating branches of science. The reader who has realised from the foregoing exposition how the genetic view of nature was anticipated by earlier writers on cosmology, such as Leibniz and Laplace, how it obtained in geology through Hutton and Lyell, how it became dominant in embryology through von Baer, and how the morphological treatment broke down through the recognition of the variability of species and the impossibility of defining clearly the landmarks of zoological and botanical classification, will readily understand the importance and timeliness $^{1}$ of Darwin's work, which proposed to deal

selection, no national or yersonal jealousies obscure the issues which were then at stake; neither of the two great naturalists has ever put forward any complaint that the other has not fairly and generously dealt with his own merit. Since the deatl of Darwin IIr Wallace has written the well-known book which, under the title of 'Darwinism' (London, 1859), gave to many readers the first comprehensive account of the celebrated theory which is generously identified with the sole name of only one of its original propounders.

1 Both propounders of the theory of natural selection have in their subsequent witings referred to those who prepared the way be- fore them, and Mr Wallace has taken special pains to explain why a doctrine which was so well prepared, and even anticipated, had not been more distinctly accepted before the appearance of the "Origin of species' ("Darwinism," chap. i.): "Notwithstanding the vast knowledge and ingenious reasoning of Lamarck, and the more general exposition of the subject by the author of the "Testiges of Creation,' the first step had not been taken towards a satisfactory explanation of the derivation of any one species from any other. Such eminent naturalists as Geoffroy St Hilaire, Dean Herbert, Professor Grant, von Buch, and some others, had expressed their belief that species 
specially with the actual fact and the function of variation in the domain of living beings. Ho pmshed the tions." problem of variation and variability into the foregromed, and discussed one of its main features-riz., its possible effect and results. Since his time the eye of every botanist, every zonlogist, and every emlnyologist has been directed tuwarls the ratiability, transition, and genesis of forms, to their history rather than to their portraiture, whereas hefore him it was mostly attracted by their seeming fixity and recurrence. Tariations have been studied on the large and on the minute scale in geologieal strata at home amb abroal, and the rexed question has been raised as to theil eanses and laws,Darwin having been mainly ocenpied with their existence and operation, the results which they brought alout, the gradual alterations of the forms of living things. Un this side he tells us that he fomnd an inportant elue throngl realing a look which had appeared at the rery encl of the eighteenth century, Malthus's 'Essay on the P'rinciple of P'opulation.' 1

arose as simple vimieties, and that the species of each genus were all descended from atommon incestor : but none of them gave a clue as to the law or the method by which the ehange had been eflecterl. This was still "the great urstery" (p). 6). "Darwin, by his discovery of the law of natural selection and his demonstration of the great principle of the preservation of uselul variations in the struggle for life, liats not ouly thrown a tlood of light on the process of development of the whole organic workl, but also estallisherl is firm foumbation for all future study of nature" (p.9).

1 This essay appeared first in
1798 , and in the cnlarged and much improved form in which it is now known in 1.503. J)arwin seems to lave come upon it accislentally. In his dutobiography ('Life,' vol. i. 1. 8.3) he writes: "In October 1838 - that is, fifteen months after I had becrun ny systematic inquiry-1 happened to real for anusement 'Malthus on Population,' and being well prepared to apprecinte the strugrgle for existence which everywhere gnes on, from hnur-continued obervation of the habits of animals ind pliants, it at once struck the that under these cireumstances fitrourable viriations would tend to be preserver, and unfarourable 
The ideas and reflections contained in this celebrated essay, which has played a prominent part in the philosophical literature of economics, conld not have occurred to any one who had studied human society or nature merely in individual specimens or isolated cases; for they referred not so much to the natural history of a single being, as to the peculiar relations and complications which arise in a community or society of beings, some of these being applicable quite as much to animal and plant life as to the life of men. In fact, it was a chapter in the science of bionomics. Malthus, Darwin, and Wallace were not "laboratory naturalists, to whom the peculiarities and distinction of species, as such, their distribution and their affinities, have little interest as compared with the problems of histology and embryology, of physiology and morphology." 1 The problem of population, whether it refers to man or other living creatures, is one that will force itself upon those who study nature and mankind on the large, on the outdoor, scale, not as does the collector or dissector of specimens. How has the face of the earth been peopled by plants, animals, and human beings? What are the forces which

ones to be ilestroyed. The result of this woull be the formation of new species. Here, then, I had at last got a theory by which to work," \&e. Prof. Haeckel, in his 'History of Creation,' lıas dwelt exhaustively on this eomnection of Darwin with Malthus, quoting a letter of Darwin's to him, dated 8th October 1864, in which he says that for years be could not comprehend how any form should be so eminently ardapted to its special conditions of life, but that when through good fortune Malthus's book on Population came into his hands, the idea of natural selection came into his mind ("Schöpfungsgesch.,' chap. vi.) In the first paper which Darwin published in the "Jourual of the Linmean Society" ("Letter to Asa Gray," vol. iii. p. 51), he uses the term "Natural Selection," and refers in the abstract which he there gives to Malthus; whereas Wallace (ibid., p. 56) in troduces the term "Struggle for Existence."

1 Quoted from Wallace, "Darwinisu,' preface, p. vi. 
ensure the multiplication, what are those which check the increase, of population? As all living things aro dependent on each other, forming the great household or eeonomy of natme or the smaller one of human society, a eertain adjustment must exist by which a definite place and part are allotted to arery indivitual and to every class of individuals. Malthus hat stutied the problem from a politieal point of view. Here it was felt to he of human and social importance, but his principle was applicable to all living creatures. For everywhere, even in the remotest and only recently discovered eountries, we see at work the luxuriant and produetive powers of nature on the one side, on the other side the many difficulties and obstacles by which they are forcibly and automatically kept in cheek, resulting in the ever-reeurring spectacle of a "struggle for existence." The more we penetrate into the hidclen and remoter provinees of "Struggle nature, into the luxuriant "famma and Hora" of tropical ence." regions, or realise the enormons population among the lower forms of life, the more the eonviction forees itself upon us that the apparent equilibrim is only maintained by the phenomenon of "crowling out" on a scale compared with which the spectacle unfolded by Malthus in his special application to hmuan societies is quite a miniature display. This proeess of "crowding ont" must have been at work during the untold ages which modern geology has made known to us, and the effects of it must indeed have been extraordinary, and well worthy of study. 'That living beings, if left to their natural instincts, multiply at an enormons rate, and would, except for certain automatic cheeks, in a very short time 
people the whole habitable portion of the globe, is a fact which has only been realised since Malthus, and, on a much larger and more general scale, Darwin and Wallace have drawn attention to it. ${ }^{1}$ This being generally admitted, the questions arise: What are these automatic checks, and what results do they produce? It is evidently quite a new line of reasoning, unknown to former naturalists, or only sporadically and fragmentarily pursued by them; but it introduces us at once into nature itself, away from the class-room and the museum, where we hear of the forces and laws of nature in their abstract mathematical development, or where we behold specimens arranged peacefully and lifelessly side by side. We are face to face with the fierce and continuous conflict which is unceasingly going on around us, and realise the endless changes which it wust be producing.

Among the many influences which the Darwinian view has had in opposite directions on the thonght of our age, none is greater or more fundamental than this, that whereas before Darwin naturalists stepped

$1 \mathrm{On}$ the publication of the 'Origin of Species,' Darwin received many letters pointing out earlier anticipations of his views. The more important of these-bearing upon descent and change-have been referred to in the present chapter. The special principle of natural selection seems to have been already foreseen by Dr Wells in 1813, and published in his famous 'Two Essays upon Dew and Single Vision' in 1818. "In this paper he distinctly recognises the principle of natural selection, and this is the first recognition which has been indicated" ("Origin of
Species,' historical sketch to later editions). Another anticipation was that of Patrick Matthew in 1831, in his work on 'Naval Timber and Arboriculture:" "Unfortunately the view was giren very briefly in scattered passages in an appendix to a work on a different subject, so that it remained unnoticed until Mr Matthew himself drew atten. tion to it in the 'Gardeners' Chronicle' on Apri] 7, 1860.... He clearly saw the full force of the principle of natural selection" (loc. cit., p. xvi). Neither of these writings was known to Darwin in 1859. 
out of doors only from curiosity, and in search of new speeimens, prompted by the love of travel and adventure, or as eompanions to commercial and colonising expeditions, they are now foreed to do so, becanse one of the greatest agencies in nature- "the strugrgle for existenee"-can only he studied in nature herself. Before Darwin the sturly of nature was antificial; through his influence it has hecone natmal. From the point of view of the history of thought, this is surely a much greater result than any of the several theories or special arguments which are connected with his name. These are indeed nmmerous, each making, as it were, at distinctly new departure in scientific reasoning, characterised by that mmmistakable sign ${ }^{I}$ of all that is really. novel in the realm of thought, the creation of a new vocabulary of distinet terms and phrases. Varieties were known to botanists before Darwin, but who studied "variation" and "variability" ! or who spoke of the "divergence of character"? breorlers of stock and pigeon-fanciers knew what "selection" neant, but the

1 The late Hewett Cottrell Watson, author of the 'Cybele Hritamica :-one of a must valuable series of works on the topography and geographical distribution of the plants of the British Islandswrote to Darwin shortly after the publication of the "Urigin of 'species,' 21st Novenuer 1559: "I aun tempted to write you the first inpressions, not doubtiug that they will, in the main, be the peruanent impressions. Your leading idea will assuredly become recognised as an established truth in science-i.c., 'Natural Selection.' It has the eharacteristics of all great natural truths, clarifying what was obscure, simplifying what was intricate, adding greatly to previous knowledge. You are the greatest revolntionist in natural listory of this century, if not of all centuries. . . Now these novel views are brought fairly be. fore the scientific public, it scems truly remarkable liow so many of them could have failed to see their right road sooner. How could sir C. Iyell, for instance, for thirty years read, write, and think on the subject of species and their succession, and yet constantly look down the wrong road?" ("Life of Dirr. win, vol. i. 1. 352 , and vol. ii. p. 226.) 
35.

"Natural selection" and "sexual selection."

terms "natural selection" and "sexual selection" appeared for the first time in Darwin's writings. The "struggle for existence," and the resulting "survival of the fittest " individuals, represent definite processes always going on conscionsly or unconsciously in nature and in human society; nor is it less significant that many other phrases have been coined, by which the same idea has been made useful in other domains of research. "Hybrids," "mongrels," "rudimentary organs," and "monstrous" developments, which in earlier times were subjects of mere curiosity, have been raised to scientific importance as indicative of the concealed and mysterious agencies by which natural forms are altered or maintained, and natural processes encouraged or checked. "Environment" and "adaptation" open out great vistas of inquiry, whilst nearly all those different lines of search and of reasoning have latterly become eentred in the great problem of "heredity" - the central question of biological science. In addition to these, the older terms of the naturalists and anatomists have received new interpretations. It has been shown by Darwin himself how the vague endeavours of system-makers, since Linnæus, after a "natural" as distinguished from Meaning of natural classification. a merely "artificial system of classification" of living beings, implied "something more" than mere resemblance, and that this something more is "propinquity of descent-the only known cause of the similarity of organic beings - it being the bond, hidden by various degrees of modification, which is partially revealed to us by our classifications." 1 In the light afforded by 1 ' Origin of Species,' 1st ed., p. 413. 
this idea, the whole work of elassification has since Darwin's time been taken up anew; and thongh it is probably premature to fix upon any elaborate scheme as likely to afford a correct view of the main lines of descent in the two sreat realms of animal and plant life, single pedigrees, such as those of the rhinoceros and the horse, have, with the assistance of the geologricul record, been suecessfully worked out, the missing links having mexpectedly turned 11$)^{1}$

In addition to this sreat service of directing the glance of the naturalist ontside, and of helping to overcome the bewillering effects which the aspect of nature must produce on every one who is not prepared for research by some definite aim and a distinet habit of reasoming, the Ditrinim spirit lats further froved its usefulness by the great intrease of our knowledge of the things and phenomena of mature which has taken

1 "It is certiain that, berore the therory of descent wits accenterl or eren discussed, geneilogical trees were userl to represent posibible relatimshipe among lumun races, or possible atfintie's among animals. It wat uned as a 'graphic' way of expressing classification, and was true just in proportion as the elassification was true. The naturalist traveller, Peter l'allats, wa: one of the first to use it to express affinities anong animals, thrueh it is possible he saw it fleeper meaning in his symbol. but when the theory of descent took hulk on men's minds, the genealogical tree hecame more thin a graphic register of atfinities, - it was used to express the supposed fiacts of rescent. T" Ernst Haeekel belumgs the ererlit, or, as some critics woulil sity, the respousilitity, of

VOLL. H. introlucing the use of genealogical trees intu youlogy and botany. In his "Generelle Morphologie (1860) and in his 'sichijpfungs. gerchichte' (1865, 9th ed. 1 $159 \bar{i}$ ), he displayed numerous genealogical trees designed to show the descent of various stocks and types of animals and plants. There can be no doubt that in so doing lie focussed the illea of descent into vividness, and, hy the very definite. ness of the notation, forced natural. ists $t o$ a criticism of the reality of the supposerl lines of descent. Prof. I. von (iratf' says of Haeckel's 'Stammbiume,' 'There is the to them the immortal erealit of having given the tirst impetus to the grimd revolution in the amimal morphology of the last ileciules," (J) A. Thomsm, "The science of Lite,' 1899, J. 15). 
place since the publication of Darwin's works, by the industry of friend and foe, with the object of proving or of disproving and modifying Darwin's theories. Whole chapters, such as those referring to the fer37. tilisation of plants through insects, to the part which Fertilisation

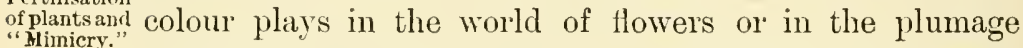
of birds and in the wings of butterflies and moths, have been added to our handbooks of natural history $;^{1}$

1 Two remarkable instances may be mentioned. It was known to Christ. Conrad Sprengel that many Howers are "dichogamous" - i.e., that though the organs for selffertilisation exist in the same flower, nevertheless, because of a want of timekeeping or for other reasons, polliuation is done by crossing, wherein the visits of insects are instrumental through elaborate exist. ing arrangements. "Variously coloured spots serve as honey-guides and pathfinder's to the exploring insects, hairs protect the nectar from rain and yet offer no obstacle to de-irable visitors, other arrangements secure that the insects are dusted with pollen" (J. A. T'homson, 'The Science of Life,' p. 192). sprengel published his observations in a remarkable book (1793) with the title "The Secret of Nature discovered in the Structure and Fertilisation of Flowers.' Such was the enthusiasm of this true naturalist, that he, "after being ejected from the rectorate of Spandau for neglecting his flock in favour of flowers, settled down to a frugal life in Berlin, and gave lessons in languages and botany. The commonest plant became new by what he had to say about it; a bair, a spot, gave him opportunity for questions, ideas, investigations" (ibid., p. 191). Sachs ('Gesch.,' p. 449) considers Sprengel's little work to contain "the first attempt to explain the genesis of organic forms out of definite relations to their environment." For sixty years this bionomical classic was forgotten. Darwin in 1841 heart of it through Rolvert Brown, who, according to Dr Gray ("Nature," 1874, p. 80), "in con1mon with the rest of the world, looked on Sprengel's ideas as fantastic." The book impressed Darwin, who in 1837 had written in his notebook: "Do not plants which have male and female organs together, yet receive influence from other plants?" as being "full of truth." (See 'Life of Darwin,' vol. i. p. 90 ; vol. iii. p. 257 .) 'The uther important research which has been much stimulater by the two great propounders of Darwinism, is the study of the meaning of colours in plants and animals and the allied subject of "Mimicry." "It is the wonderful individuality of the colours of auimals and plants that attracts our attention - the fact that the colours are localised in definite patterns, sometimes in accordance with structural characters, sometimes altogether independent of them, while often differing in the most striking and fantastic manner in allied species. We are thus compelled to look upon colour not merely as a physical but also as a biological characteristic, which bas been differentiated and specialised by 
the older division of zoology imel botany having to a large extent been remover by a study of the interdependence of the many forns of living things and their eonnection with peculiarities of climate and soil. The Darwiniau attitule to the stuly of natural objects has also introdnced into the natnral seiences the exact spirit of reseurch, - accurate measurements, together with elaborate eountings, being resorted to in order to rlecide the range of variability of species, the rate of inerease in numbers, and the proportion of the surviving to the lost or wasted specimens. A larese amomut of statistical information ${ }^{1}$ has thus been acemulated, and natmal history is hecoming to some extent an exact science. That it will ever be so to a very large extent is doubtful: it is one of the great merits of Darwin that he has introduced a special method into the sciences of naturethe methol of a jurlicious balancing of evidence. He was fully "aware that scurcely a single point was dis- Mnethol. chssed in his works on which facts eamnot be adluced, often aprarenty leading to conchusions direetly opposite to those at which he arrived, and that a fair result cam be obtainerl only by fully stating and balancing the facts

matural seleetion, and must, therefore, fiml its explanation in the principle of adaptation or utility" (Wallace, 'Darwinism,' 1). 159). The term "Mimicry" was first introduced by H. W. Bates in his. paper on "Mimetic Butterflies," read before the linnaan Sioe., Nor. 1861, and hailed by 1)arwin ('Tife,' vol. ii. p. 392) as "one of the nost remarkable and aluirable papers" he ever reat. The subject hat been passed over in the first editions of the 'Origin,' hut was introtured in later ellitions, and las always served as one of the most valuable illustrations and proots of the theory of natural selection. The whole matter is admirably ex. pounded by Mr Wallace in his long artiele in the "Westminster" Review,' July 1567 , reprintel in his "Contribulims to the Theory" of Natural selectiou' (1570. pp. 45 129), and again in 'Darwinism."

1 On the development of statis. tical methods in the service of the theory of evolution, see chap. xii. below: 
and arguments on both sides of each question." I It is quite a different process of investigation and method of thought from that which the abstract sciences use, where every agency is first considered in its isolated action and mathematically calculated, and a complex effect is rightly looked upon as merely the resultant of specific, welldefined forces, compounded according to rigid dynamical formulie. That the whole of natme, as well as all observable phenomena, are in reality only the result of such a composition of definite simple actions, and can be studied as such, may be quite correct; but that this method, however useful in isolated cases, and especially however fruitful in the application to artificial mechanisms, will never lead to a just comprehension of any large cluster of phenomena, or to an appreciation of the totality of things which surround us, must be erident to any one who at once appreciates the rigidity and universality of mathematical calculations, and sees how soon they fail to become of practical use when we attempt to attack any complex problem through them. Now, all processes in nature herself, as distinguished from the laboratory, are eminently complex, and far transcend the powers and grasp of the mathematical calculus, so far as the human mind is able to employ it. In fact, the outdoor naturalist must attack the problem of nature and life by quite a different method: he must, like a judge, confront and appreciate the evidence of many witnesses who are speaking on all sides to him, and he must, with an open and unbiassed mind, judiciously combine such evidence in the sentences which he passes or the 1 'Origin of Species,' 1st ed., p. 2. 
generalisations which he attempts. Alssolute mathematical certainty is almost mnknown in such calses: they can only he male out with more or less clearness and probalility.

It seems to me that the new phase into which scientific thought las entered, mainly through the inthence of 1)arwill :t1, Darwin, has not heen sufficiently appreciated by those of Sivtain his critics who have compared his methods with those of earlier philosophers and naturalists. Darwin has been called by some the Newton of the natural sciences, ${ }^{1}$ and again by others his method has leen unfarourably contrasted with that of Newton and cuvier:" Some of these

1 It is in many instances only a furon de purler. Maxwell similarly ealled Ampere the Newton of Eleetrodrnamics: and Young has been ealled the Newton of Optics. Mr Wallace says ('Darwinism,' p. 9): "We claim for Darwin that he is the Newton of natural history, and that, just so surely as that the diseovery and demonstration by Newton of the law of gravitation extablished order in place of chaos, and laid a sure foundation for all future sturly of the stary" lieavens, so surely has Darwin, by his discovery of the law of natural selec. tion and his demonstration of the great principle of the preservation of useful variations in the struggle for life, not only thrown a tlood of light on the process of development of the whole organic world, but also established a firm founclation for all future sturly of nature."

2 The most important publica. tion of this kind is the late l'rofessor Albert Wiganl's work, in three volumes, 'Der Darwinismus und die Naturforschung Newton's und Cuvier's' (Braunschweig, 1974. 1877). The author significantly clitsses Humboldt also among those who belong to that period and school of research which has-unfortunately, in his opinion-been superseded by the modern genetic treatment (see vol, iii. p. 14). It is not likely that a perusal of these volumes will, in the mind of the reader, change the current of thought which is now, even more than twenty-five years ago, ruming in genetic lines, nor will it do anything towards diminishing the sense of importance which attaches to this modern movement. Nevertheless, the book is valuable as giving a very complete résumé of what was said "pro and eon" lar. winism during the first fifteen years: of its existence. It is interesting to see what a small part French seientific opinion played lluring that period as to the theories of dexcent and mutability of species, which hat both their origin and their first great exponents in france. The book does not appear to have had much intluence in its time, but more recently the criticisms of Wigand, von Baer, and other writers seem to receive greater attention since the central biological problems have been pushed into the foreground. Of 
comparisons refer to the law of "natural selection," which is placed in parallel with Newton's law of " universal gravity." Now, although "natural selection," the automatic process which ensures the survival of the fittest and the extinction of the less adaptive members in a crowd of living beings, is a definite formula which allows us to understand and clearly define one of the many factors which are at work in the development, in the genesis and growth, of living beings, it is only one. It is not a prime mover or force, like the force of gravity; it is a check upon the overluxuriance of other existing forces of production and development. These are only very imperfectly known; whereas Newton not only discovered the "law of gravitation," but also the correct expression for the general and all-pervading laws of motion which obtain, even where gravitation or any similar force ceases to be a valid conception. Again, Newton's greatness does not rest on the "law of gravitation" alone, but much more on the general foundations of dynamics and natural philosophy which he has laid. So also Darwin's greatness is not limited to the formula of "natural selection," but depends on the novel conception which he has introduced into the study of nature on the large scale and as a whole, viewing it as a scene of conflict and ceaseless development. From this time dates the study of nature as a whole ${ }^{1}$ in contradistinction to that of natural

this I shall treat in the next chapter. See also the various writings of Hans Driesch, such as 'Analytische Theorie der organischen Entwicklung' (Leipzig, 1894): 'Die Biologie als selbständige Grund- wissenschaft (1893), especially p. 7 of the latter.

1 Though this was prepared, as Darwin himself points out, by $A$. von Humboldt. 
objects and processes. The general laws which obtain in this great fichl, and which would correspond to Newton's laws of notion-the laws of variation and of heredity-have not yet been discovered; lut it is again Darwin more than any other naturalist who has caller? attention to these prine movers in the living miverse. He has pushed into the foregromul the two great problems of "variation" and "heredity." I

40 Unsolved jrobleins.
1 Darwin in his subsequent writings urged another important prob. lem, to which he had already in his first and greatest work drawn yassing attention. This is the agency of "sexual selection." It oeculies by far the larger portion of live third great work, which apleared in 187 I with the title 'The Descent of Man and selection in Relation to Sex.' In the introduction he says, "During wany years it has seemed to me highly probable that sexual selection has played an important part in diflerentiating the races of man; but in my 'Origin of speeies' I contented myself by merely alluding to this belief. When I came (o) apply this view to man, I fonnd it indispensable to treat the whole subject in full detail. Professor Hacekel is the sole author who, since the publication of the '()rigin,' has diseussed in his various works, in a very able nammer, the subject of sexual selection, and has seen its full importance." 'The probleur of "sexual selection" is introlucerl in the "Origin" (p. 8i) in the following words: "Inasmueh as peculiarities oiten appear under domestication in one sex, and beeome hereditarily ittached to that sex, the same fact probably oceurs under nature; and if so, natural selection will be able to modify one sex in its functional relations to the other sex, or in relation to wholly different habits of life in the two sexes, as is some- times the case with inseets. And this leals me to say in few words. on what l call Sexual Selection. This depends not on a struggle for existence, but on a struggle hetween the males for possession of the females: the result is not death to the unsuccessful competitor, but few or no offspring. Sexual seleetion is thus less rigor. ous than nutural selection." A great deal has been written about sexual selectiou, and in general it may be said that the question belongs to quite a diflerent eategory from that of natural selection. Some of the foremost champions of the latter doctrine, notably $\mathrm{MI}_{\mathrm{I}}$ Wallace, rejert sexual selection as unnecessary in the whole scheme. 'The characteristic feature of natural selection is this, that it is at purely automatic process, dependent on overerowling, whereas in sexual selection it becomes much more ditficult to see low the process works automatically. Nowadays the question of natural selection is hardly any longer doubtful; it is a fact. As to sexual seleetion, the statistical proofs that there is a superabundance from which to choose are still wanting. To understand sexual selection, or even to define it, we need to form some conception of the reason and origin of sexual differ. entiation, and this cannot be ar. rived at without a theory of life 
Ancl, besides this, it is well to remember that Newton was condemned by some of his contemporaries on the hasis of the philosophy of Bacon; Fresnel and Young were condemned on the ground of Bacon and Newton combined. In like manner the novel line of reasoning adopted or largely cultivated by Darwin has been attacked as being opposed to Bacon, Newton, and other great thinkers before him. In all these cases it is the results, and not the theory, of the process of reasoning which have justified its continued employment. Without attempting to elaborate the parallel too minutely, we may say that as Newton created Natural Philosophy and took one brilliant step in fixing for all time one of the great laws of the material universe, so Darwin has founded the study of nature as distinguished from that of the objects and processes of nature, and has enunciated one of the great factors which obtain in the living portion of nature: through him a history of nature, the genetic view of nature on a large scale as distinguished from the older natural history, has for the first time become conceivable. The word history indeed suggests other analogies. Political history, what we ordinarily term history proper, has in the course of our century undergone changes and developments similar to those in the history of nature. Confined once to a casual, unmethodical, uncritical, and incomplete record of isolated

which rests on something more than the two purely statistical or numerical facts of overcrowding and of variation-i.e., the fact that no two individuals are absolutely alike. The importance of the phenomenon of sex in the economy of living nature has been studied, and given rise to many theories. A very good account of these will be found in P. Geddes and J. A. Thomson, 'The Evolution of Sex, 1889. In the following chapter, where I deal with the various attempts to define "Life," I shall revert to this subject. 
events or liographies, it has been gradually uniterl and organised as a whole, largely thromgh the same julicial sifting of manifold evidence and elaboration of critical methods of research. Of this I hope to treat in it different portion of this work: here I only wish to draw attention to the enlarged aspect, which in hoth instances has, thromgh the same process of development, come wrer our sturlies. When ance we rise from the Genctic view contemplation and exannination of cletails and single faets, on a large scale. and glasp the connection and econony of the whole as a subject worthy of special attention, we involuntarily introduce two new elements into onr research-the element of conjecture and the element of speculation. The former is needed to fill up the many gatps which we find in the actual records when we wish $u$ string then together into a united and intelligible whole: the latter is the inquiry into the general principles which underlie any and every development of the kint we have in view. The creation by Darwin of the seience and history of nature, as distinguished from the science and history of natural ohjects and single processes, has been aecompanich and strengthened by the alpearance of conjeetmal and speenlative attempts; just as the enltivation of the science of general history las grone hand in land with, and has been supported by, the brilliant results of philologieal conjecture and the philosophy of history. ${ }^{1}$ Of

1 lu an elougent passage Professor Parker eompares the work of the naturalist of to-day with that of the philolegist. 'This pasiage occur's in his Memoir on the Fow? (1868), and is yurted in his book 'On the Morplology of the Skull' (by P'arker and Bettany, London, 1877, p. 362):
"Whilst at work 1 seemed to myself to have been endearouring to decipluer a palimpsest, and one not erased and written upon again just once but five or six times over. Having erasel, as it were, the characters of the culninating type -those of the gaudy Indian birt 
these I shall treat elsewhere. It may be a question capable of very opposite answers whether the philosophy of history, such as it has been offered in the brilliant 42. generalisations of Kant, Herder, Hegel, and Buckle, has cal theories. really aided the science of history proper; whereas no question can arise as to the indispensable service that has been rendered to historians by the criticism and conjectural emendation of texts and other monuments of antiquity. With Darwinism the matter stands differently: no person who peruses the great and increasing literature of the subject can deny the enormous assistance which the philosophical ideas of evolution have rendered to the cause of Darwinism-how the latter, when it appeared, found ready made, though then only slightly appreciated, the philosophical canons and terms which were so well fitted to its systematic enmoiation

43.

Herbert Spencer. and literary mise en scène. This was the independent work of $\mathrm{Mr}$ Herbert Spencer. ${ }^{1}$ The other well-known

-I seemed to be among the sombre grouse; and then, towards incubation, the characters of the sandgronse and hemipod stood out before me. Rubbing these away in my dowuward work, the form of the tinamou looked me in the face; then the aberrant ostrich seemed to be described in large archaic characters; a little while and these faded into what could just be read off as pertaining to the sea-turtle; whilst underlying the whole the fish in its simplest myxinoid form could be traced in morphological hieroglyphics."

I The part and position which belongs to Mr Herbert Spencer in the history of evolution as a scientific doctrine has not yet received due attention or adequate recogni- tion. There is, however, no duabt that the principal features of the genetic view of natural phenomena were clearly before his mind as early as 1852 , when he wrote his short essay on "The Derelopment Hypothesis " in "The Leader,' republished in the first volume of his 'Collected Essays.' It has been pointed out by Romaues ('Darwin and After Darwin,' vol. i. p. 257) that though the attempts towards a genetic conception of organic nature were numerous, if not abundant, before Darwin, yet this view only broke through and became dominant on the appearance of the theory of natural selection. He says: "If we may estimate the importance of an idea by the change of thought which it effects, this 
name which is so frequently associated with Jarwin, especially in Germany, is that of I'rofessor Haeckel, whose 'Generelle Morphologie' and ' History of Creation' have done much to introduce the spirit of Darwinism into German literature. These works also represent the"

idea of natural selection is uncpuestionably the most injurtant irlea that has ever been conceived by the mind of man. Yet the wonder is that it should not have been lit upon long betore; " and after referring to the forgutten anticipations of Wells and Matthew, liominnes proceerls: "Still more remarkable is the fact that $\mathrm{H}_{\mathrm{H}}$ Herbert Spencer - notwithstanding his great powers of abstract thought and his great devotion of those powers to the theory of evolution, when as yet this theory was scorned by scitnee - should have missed what now appears so oly. vious an idea." In this eonnection it is intererting to note how those general canons of evolutionary thought which were established ly Spencer heinre the publication of the 'Origin' were brought into general recognition by scientific men only when the definite mathe. matical or statistical formula of natural selection was announced, and that, after the lapse of a whole generation, it is not tlis precise formula but the general conception of evolution which, accorling to many of the foremost naturalists, will obtain; the part which natural selection plays being uncertain and variously estimated by the many adherents of the theory of evolution. See, inter alia, the article on "Evolution in Biology" by Huxley in the 'Ency. Brit.,' 9th ecl., vol. viii. p. 751: "How far llatural seleetion suffices for the production of species remains to be seen. lew ean doulst that, if not the whole cause, it is a very important factor in that operation. . . The importance of matural selection will not be impaired even if iurther inquiries should prove that variability is definite and is determined in certain clirections rather than in others by conditions inherent in that which varies." See also the Aderess of Lurd Salisbury at the meeting of the lrit. Assuc. at $O x$ ford in 1594 , and the subrexuent remarks of Huxley in seconding the rote of thank: ("Life of Huxley," vol. ii, p. 37s): "The esseuce of this great work (the "Origin of species') may be stated summarily thus: it affirms the mutability of species and the descent of living forms, separated $h y$ ditferences of more than varietal value. from one strock. . And yet it is also true that if all the conceptions promul. gated in the "Origin of Snecies. which are peculiarly Darwinian were swept away, the theory of the evolution of animals and plants would not be in the slightest dlegree shaken." In fact, the general prin. ciples of mechanical evolution, as first systematised by Mr Spencer, received recognition only through is definite formula, but may, after all, survive that special doctriue. It is further very evident how the parallel with Newton's formula of gravitation entirely breaks dowu if we look at matters in this light: every subseunent discovery having only tended to confirm that suecial matheunatical relation, and prover the all-important port it plays in nature. 
first brilliant attempt to fill up conjecturally the broken lines of development and descent as the Darwinian conception of living nature postulates them. ${ }^{1}$ As a first and daring approximation, they deserve to have assigned to them a prominent place in the history of the scientific thought of our age. In elaborating his pedigrees, Professor Haeckel has taken up and more clearly defined the analogy between the development of the embryo in the higher organisms and the supposed transition from lower to higher forms which is found in the classification of the genera or species of animals and plants. He has termed this analogy the great law of biogenesis, of the development of life in the individual

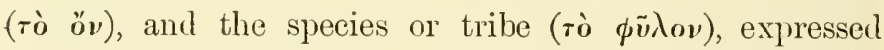
also as the parallelism of ontogenesis and phylogenesis. Long before Darwin and the appearance of the theory of descent this analogy ${ }^{2}$ was pointed out in a restricted

1 The later editions of the "Urigin of Species' contain the following reference to Haeckel (6th ed., p. 381): "Prof. Haeckel, in his 'Generelle Morphologie,' and in other warks, has brought his great knowledge and abilities to bear on what he calls pliylogeny, or the lines of descent of all organic beings. In drawing up the several series he trusts chiefly to embryological characters, but receives aid from homo. logous and rudimentary organs, as well as from the successive periods at which the various forms of life are believed to have first appeared in our geological formations. $\mathrm{He}$ has thus boldly made a great beginniug, and shows us how classification will in the future be treated." And Huxley (art. "Evolution," p. 752) says: "Whatever hesitation may not unfrequently be felt by less daring winds in following Haeckel in many of his speculations, his attempt to systematise the doctrine of evolution, and to exhibit its influence as the central thought of modern biology, cannot fail to have a far-reaching influence on the progress of science."

${ }^{2}$ As to the early anticipations of this so-called "law of biogenesis," they are given with more or less completeness by many modern writers, such as Huxley in his article on Evolution (1878, 'Ency. Brit.'), P. Geddes (ibid., art. "Reproduction "), Yves Delage ("L'Hérédité,' \&c., p. 159), J. A. 'Thomson ('The Science of Life,' p. 133, \&c.) The most important earlier statement is that quoted by Huxley from Meckel's 'Entwurf einer Darstellung der zwischen dem Embryo- 
sense by Meckel, ron liater, and serres. It hats smurtimes leen termed von baer's law, though von liater very carefully gramderl himself agaiust many populan versions of the analugy, alplying it only within the limits of the fom great gromps or plans of organisation into which he divided the animal kingrom. ${ }^{1}$ In his

zustande der hoheren Thiere und dem permanenten der niederen stattfindenden Parallele' (1S11): "There is no goml physiologist who has not been struck by the observation that the original form of all organisuns is one ambl the same, and that out of this one form all, the lowest at well as the highest, are developed in such a mamer that the latter pass through the permanent forms of the former as transitory stages. Aristotle, Haller, Harvey, Kielmeyes, Autenrieth, and many uthers, have either male this obvervation incilentally, or, especially the latter, have irawn particular attention to it, and clrawn therefrom results of permanent importance for plyysiology." Louis Agasiz, in lis celebrated "Essay on Classitication" (1559), though rejecting the doctrine of descent, "insisted, nevertheless, on the corresponflence between stiges in embryonic development and the grades of differentiation expressed in the clasifieation of living and extinct animals" ('Thomson, "The Science of Life, 1). 134).

I "A careful eximination of vou Baer's 'law's' slow's that he dirl not accept the recapitulation without many saving clauses. He believer in it much less than many a modern embryologist, such as 1. M. Balfour or $\mathrm{A}$. Milnes Marshall " (Thomson, p. 133). Dielore the publication of Haeckel's. Generelle Morphologie' the naturalist who seems to have most elearly expressed the recapitulation theory was Fit\% Huller, who in $1560-1$ publisherl his tamrus latet 'Fur Darwin,' which appearenl in 1866 in an Euglislı trasiation ly liallas. with the title "Facts ancl Argu. ments for lourwin.' 'The work of bitz Mnller, who for many year, lived in the Prazils, iscolated and recluded, and deroted L seitutifie observation, was welconed by lharwin as one of the first and greatest supports to his doctrine: the author was singled out hy him athe "prince of ubservers," and frequently referred to in the later elitions of the 'Orizin of Sipecies. Delage considers him to have first expressed the fundamental bio. genetic litw ('L'Hérédité,' J\}. 159, 469), and this is in agreement witl Haeckel's own declaration in the 13th elatiter of the "History' w' creation.' It is, however, well to mention that the recapitulation theory has found litule favour with botanists; that Haeckel himself admits that the parallelism between ontugenesis and phylogenesis is general and not exact; that there is a tendency to abhreviation; that recent alaptations (called by lim "kainogenetie") may mask more ancient ("palingenetic") features. se. See J. A. 'Thomson, "The Seience of Life,' p. 13\%. 'Ziegler, in his recent excellent review of the "I'resent Position of the lowetrine of Descent ' (Jena, 1!02, p. 12), aflmits that the theory of paral. lelism has "perhaps nut realised all the expectations" which were cherished thilly years age. 
time also no attempt was made to bring phytogenesis - the genesis of plant-life - into line and order with zoogenesis, the genetic arrangement of animals. It is Haeckel's undoubted merit to have attempted for the first time to carry out this general scheme on a large scale, and by means of detailed pedigrees, beginning with the undefined organisms in which as yet the peculiar characters of animal- and plant-life do not appear to be differentiated, and ascending in two great trunks into the vegetable and animal kingdom, and thence through many ramifications into the several classes, families, genera, species, and varieties of living things, to construct the supposed real natural system for which systematists had been unconscionsly searching since the age of Ray and Linnæus. For the purpose of elaborating this great scheme he employs not only the great law of heredity, according to which ancestral characters are reproduced in development, but also the older law of adaptation to the existing enviromment, as

45. pointed out by Lamarck. Haeckel, in fact, combines the Combines Darwin and Lamarek.

views of Darwin and Lamarck, which other naturalists are more or less inclined to keep apart, whence has arisen the well-known division into the two great schools of. the neo-Darwinians and neo-Lamarckians. ${ }^{2}$ Thongh

I Natural selection being an admitted fact among living things, like gravitation in the physical universe, three distinct problems arise: First, how far does it reach? the scope of the principle. The subsequent writings of Darwin were mainly occupied with this question, though-as we shall see later-he also ventured upon an importint suggestion as to the underlying problem of inheritance. Secoudly, the fact or principle itself requires to be traced to deeper-lying causes. We may say natural selection is a rera causa, but not a prima causa : it is a true but not a prime cituse. The investigations regarding "variation" and "heredity" work along this line of research, and form the 


\section{Hacekel's work is, as he himself adnits, highly con-} jectural, ${ }^{1}$ it has done much to extemel and popularise the

whole domain oi molern postDarwinian biology. The problem is far from being solved, though it is perhajs nearer a solution than the question as to the cause of gravitation. Thirlly, there is the anbitious attempt to construct a general philosophy of life by uncans of the new principle, or some moditication or amplitcation of it. After Newton had discovered universal gravitation, the attempt was made by Buscovich and the French school of mathematical physics in use the illea of attraction at a distance as a general plyyical theory. of those who, before or after Darwin, at tempited the more anbitious task, we may take Herhert spencer, Eru-t Haeckel, and Nigeli as three distinct representatives. They, however, agree in one joint-vi\%, in considering natural selection to be insulficient, and in admitting wher agencies, which are largoly drawn from the suggestive writings of Lamarck. The section of these philosophical witers who consider Lamarek's prineiples to be more fundamental than l)arwin's, and who are largely represented hy American naturalists (notably k. D. Cupe and A. Hyatt), are called neo-Lamarckians. The best account of their riews will he found in the last chajter of l'rofesor l'ackard's hook, 'Lamarck, the founder of Evolution' (1901). The following passage quoterl there (1. 391) from a much earlier nemoir (1577) gives a very clear account of the reason. ing of this school: "Darwin's plirane, 'natural selection,' or Her. bert Spencer's term, 'knrvival of the fittest,' expresses simply the final result, while the process of the origination of the new forms which have survised, of berell selected by nature, is to be ex. plained by the action of the phyrical enviromments of the animals, coupled with inheritance-force. The phranes yuoted have been uninused to state the cause, when they simply express the result of the action of a chain of causes which we uay, with Herbert sjencer, call the 'envirument' of the organism undergoing morlitication : and therefore a form of lamarck. iani-m, greatly morlitied by recent scientitic discuveries, seems to neet most of the chifticulties which arise in accounting for the origination of species and higher groujs of organisms." lt is also well to note that Mr Wallace, though not a Lamarckian, considers the principle of natural selection insufticient especially to explain the higher develol. ments of mental life. (tiee 1)ar. winism, p. 463, \&..)

1 "It is evilent that our "phyl. ogeny" is anl remains an edifice of lyjotheses in the same way as her sister, historical geolngy. For' We tries to gain a comnected view of the course and causes of events long past, the direct investigation of which is inpossible. Neither observation nor experiment can give us direct information regarding the entless processes of change through which the existiug animaland rlant-forms have encrged out of lengtlyy ancestral stages. . . . The empirical documents of our history of descent will always remain largely incomplete, however much through continued diseoveries our region of knowledge of indivil. ual things may increase." (Haeckel, 'Systematisclse l'hylogenie,' 1894, vol. i. preface, p. vi.) 
genetic view of nature, drawing likewise into this circle of ideas the great departments of anthropology and geography; in fact, it amounts to rewriting the 'Kosmos' of Humboldt on genetic instead of on purely descriptive lines. Bnt in perusing these and similar writings of modern times, we feel on the one side that we are grarlnally getting ont of the depths of science, not only into the domain of conjectme, withont which a knowledge of the past cannot be gained, but also into the

46. ical problems.
Philosoph-

regions of philosophical thonght, which proceeds on other lines than those prescribed to science, and which will clain on attention in a special portion of this work. On the other side, in using so confidently the ideas of descent and adaptation, we feel that we are appealing to two great empirical facts, the facts of heredity and of variation of living things, on which the genetic view of nature, when applied to the living portion of creation, rests, but which are scarcely even clefined in clear terms, mnch less explained. In fact, we are face to face with the problem and definition of life itself. Neither the morphological nor the genetic view of nature is limited to the living world, althongh both views originated there, and were from thence extended to the larger domain of inorganic and cosmical phenomena. Into these larger views which try to grasp the foms of nature in their apparent rest or in their endless change and history, the phenomena of life have been fitted by the help of three definite con47. ceptions - the conception of the cell as the morphoProblem of life. logical basis or unit of all life, and the two conceptions of inheritance and variation, by which living 
forms are partially maintained and contintumsly altered. ${ }^{1}$ These three enceptions deserve and have received special attention by a class of students who, since the berinning of the nineteenth century, have termed themselves biologists. On what lines of reasoning their studies have been conducted, and to what general results they have led, I propose to discuss in the following chapter, which might he appropriately entitled the "IBological view of Nature" in the narrower sense of the term. In order to distingnish the studies which I shall have to deal with in that chapter from those which have ocempied us in this and the last chapter, which deal largely but not exchusively with living things, I have preferred to give to it the tille, "On the Vitalistic"

1 To these - aceorling to some naturalists - might be added the factor of adaptation, so prominently put forward by Lamarek and his followers. But adaptation is one of the causes of variation, as natural selection is a consequence. The latter is a plyssical necessity wherever overcrowding exjsts; whereas the seope of arlaptation, which is an undeniable fact so fir as intivicluals are concerned, is, so far as it regarks inlleritanee-i.e., the development of the racea much controverterl question. It comes under the larger problem of the influence of enviromment, and will occupy us again in later chapters. Among the most valuable contributions to this subject are Mr Herbert sipencer's articles on the "Fatetors of Urganic Evolu. tion," publisherl in the "Nineteenth Century' in 1986, and separately, with additions, in 1887. In these essays he also shows how barwin himself in his later writings includes the influence of environment as all important fuetor in VOL. II. development. (See 1). 29 sir. of the reprint.)

" As the two terms "biological" and "vitalistic" might, aecorrling to their etymology, mean the same thing, it may he appropriate to ofler sone explanation of the reasons which have indueed me to adopt the latter term for the purpose inclicated in the text. Biology means the science of life. This can ouly be studied in living things. Iiviug things, however, are formed entirely of the same elementary substances as we find in inorganic or not living things, and are very largely formed through the sane chemical and physical pocesses as we find anoug the latter. And as our seientifie-i.r., exict. aceurate, and useful-knowledge lias all begun with the sturly of inorganic pluenomena, it is natural that biologists should have attacked the problems of living nature from the side of the similarity or same. ness which they presented when compared with lifeless nature. The main progress in physiology 
view of Nature." Clearly both the morphological and the genetic views of nature remain incomplete unless they embrace the forms and the processes of life. It is the problem from which both started and to which both lead. They, as it were, presuppose its possible solution. Let us see what has been done in the course of our century to effect it.

Before we do this it is well to draw attention to the great strengthening which the genetic or developmental view of nature has received, since the time of Darwin, from other quarters - notably from that of general physics and chemistry in their application to geology and astrophysies. ${ }^{1}$

and medicine during the last hundred years has come from that quarter. This large class of studies can be earried on without facing the problem of life at all ; and thus it happens that we may have a very large biological literature in which the word life liardly occurs, and in which we seek in vain for a definition of life. We inust, therefore, have a term which singles out from the enormous mass of bio. logical literature that smaller portion which professedly deals with those properties and phenomena which are peculiar to the living as distinguished from the lifeless creation. I have chosen for this purpose the term vitalistic; but I may note that in using it I do not limit inyself to that class of thinkers who are usually termed "Vitalists," because they are led to, or start with the assumption of, a special vital principle. Even those who, in studying the phenomeua of life, arrive at or start from the denial of such a principle are included under the vitalistic view, just as Kant is rightly termed a metaphysician although the outcome of his philosophy may be considered to be the destruction of metaphysics in the sense which was current in his age.

1 A general scheme of evolution, or of development as it was more frequently termed, which would embrace equally cosmical and terrestrial processes, the lifeless and living world, was clearly before the mind of Schelling and his followers, notably Oken and Steffeus. The vagueness aud extravagancies of this school brought the idea into discredit, and the remedy applied by Hegel, to put a logical process in the place of fantastic suggestions, ruined it utterly in the eyes of the cultivators of exact research. Only very few of the great students of organic development, but among them the greatest, von Baer, retained a just appreciation of the great aims of Schelling. The study of development abroad was almost entirely limited to embryology. In other sciences the "statical " aspect ruled supreme. In the face of this somewhat retrograde movement 
In the second chapter of this volune, which treated of the physical view of nature, and developed the various ideas which cluster around the term "energy," I showed (if nu.tic vic:w how, in the midale of the century, through the introduction of these irleas, a new che was gained wherewith to penetrate the comection of natural phenomena in time and space. Before that time the conservation of matter, the rule that matter can neither be lost nor created, gnided research by trying to account for the apparent loss or gain of matter whenerer and wherever clanges take place in the material world. The science of ehemistry with its instrument the halance was huilt on the foundation of this axiom. When, through the labours of Mayer, Helmholtz, and Joule, the further axiom becane established that, besides matter, there exists in the material mniverse a second quantity (or substance) termed "energy," which, like matter, can be changel, but which, like matter, ean neither be ereated nor amihilated, the questions began to be asked, "If we

abroad, the merit of Mr Spencer in urging the "dynamical " aspect long before the 'Origin of Species' put forward a definite mechanical agency is so much greater, and he himself says ("Faetor's of Organic Evolution," p. 5): "Of the few . . . who, espousing the belief in a continuous evolution, hacl to ac. count for this evolution, it must be said that though the eause assigned (viz, the morlification of structures resulting from molification of funetions) was a true cau $*$ e, . . . it left unexplained the greater part of the facts. Having been myself one of these fow, I look back with surprise at the way in which the facts which were congruous with the esposused vicw monopolised con. seiousness and kept out the finets which were incousruous with itcon-picuous though many of them were." Mr. Spencer was also probably the first who defined in mechanical terus, applicable to cosmical, lifeless, and living phenomena alike, the process of (levelopment, alopting the term evolution. This fitting of the proeess of organic development into the general formula of evolution, aud the suls. sequent anouncenent by Darwin of the mechanical ageney of over. erowling and selection, has had the effect of strengthening immensely the genelic view of nature, but also of obscuring and pushing into the background the special problem of life. (if.mictic vich (*11+1) by physics and c.lu.mistry. 
receive energy, where does it come from? if we lose energy, where does it go to?" It was recognised that the great store of energy on which we at present depend is the heat of the sum, which is partly used or wasted by daily radiation, partly stored in the separated energies of chemical substances, such as were produced by the agency of solar heat in bygone ages; the deposits of coal in the bowels of the earth being a prominent and important example. Where does the heat of the sun come from, and how is it maintained? These were some of the questions which began to be asked. The genesis of the cosmos, as suggested by Laplace and fancifully elaborated by popular writers, had taken note only of the matter in the sun and in the planetary system, and had disregarded the heat ${ }^{1}$ or energy which the sun supplied, and on which the historical changes on the surface of our globe have almost entirely depended. "But physical laws are for our mental vision," as Helmholtz says, "like telescopes which penetrate into the farthest night of the past and the future." 2 Shortly before the pioneers of the mechanical theory of heat published their

1 "When Play fair (in his' Illustrations of the Huttonian Theory') spoke of the planetary bodies as being perpetual in their motion, did it not oceur to him to ask, What about the sun's heat? Is the suu a miraculous boly ordered to give out heat and to shine for ever?" (Lord Kelvin in 1868, "On Geological Time," "Popular Lectures and Addresses,' vol. ii. p. 45.)

"The old nebnlar hypothesis supposes the solar system and other similar systems through the universe which we see at a listance as stars to have originated in the con- densation of fiery nelulous matter. This hypothesis was invented before the discovery of thermodynamics, or the nebule wonld not have been supposed to be fiery; and the idea seems never to have occurred to any of its inventors or early snpporters that the matter, the coudensation of which they supposed to constitute the sun and stars, could have been other than fiery in the beginning" (id., 1871, ibid., vol. i. p. 184).

'See 'Vortrige und Reden,' 3 Aufl., vol. i. p. 57. 
first theoretical and experimental essays, experinents laud already leen mate by sir John Hersehel at the C'ape, and independently by Ponillet in France, with the object of measuring the ammal expenditure of heat by the

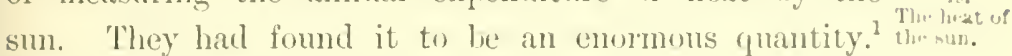
They represented it popularly by the thickness of a crust of ice on the surface of the earth, which the heat racliated annualy by the sum would be able to melt, and they found this to be ahout 30 metres or 100 feet. Mayer was the first who seems to have put the question definitely: How is this enomoms expenditme of heat defrayed, which would, if not in some way complensated, have resulted, even in historical times, in a great lowering of the temperature of the smi, and hence also of that on the surface of our globe, such as is contracticted by all historical evilence? The answer which Mayer gave to this question was based upon an application of his conception of the equivalence of heat and the energy of mechanieal notion. As the smu, aceording to the cosmogonic hypothesis ${ }^{2}$ of Laplace, was originally formed by

1 These measurements wer male in 1.837, and very nearly angeed. The resulting figmes cam, of eourse, only be considered as rough approximations: they have been considerably increased hy muse recent ohservations. See $A$. Berry, 'A Short History of Astronomy, p. 397.

$\because$ It does not appear that llayer brought his "meteoric" hypothesis of the greneration and maintenance of the heat of the sun into connection with the nebular hypothesis of kant and Laplace. In fact, in his first mention of it in his eom. munication to the Paris Acarleny. in 1846 he says simply : "lon eon- sidérant le grand nombre que nous voyons, comme bolicles ou étoiles tombantes, nous ne prourwns pas doubter qu'it tout moment des myriades d'antéroides semblables it une grêle épatisse se jettent clans tous les sens sur le soleil où ils perdent lit force vive de leur mouvement" (Mayer's "Schriften und Briele, J. 264); and $H$. Faye remarks that the fact that Uayer's ideas are opposed to Laplace's theory of the origin of the sular system explains low it came about that his theories were never reported on or explieitly mentioned. Leverrier also seens to have ridiculed the meteorie hypothesis, aecorling to 
the gathering up of cosmical matter which, under the force of gravitation, was in rapid motion-so the heat of the sun originated through the conversion of the energy of this arrested motion into heat. This process of gathering up of cosmical or meteoric matter is still going on, and it makes up for the loss or expenditure of solar heat through radiation. Helmholtz, in the sequel of his investigation into the conservation of energy, likewise takes up this problem, and while admitting to some extent Mayer's theory, ${ }^{1}$ shows that even without the accession of cosmical matter, the mere contraction through gravitation of the gaseous substances of the sun would result in a continual production of heat. His calculations show that the amount of this contraction, resulting in a diminution of the sun's apparent diameter, would not be great enough to be perceptible during historic ages. The theory of Helmholtz has in general been accepted as

which the sun's heat was kept up by breakfasting and dining on meteorites. (See Wolf, 'Hanilbuch der Astronounie,' vol. ii. p. 433.) It is on the other side equally interesting to see how Herbert Spencer, for whom the nebular hypothesis was a principal example of cosmic evolution, failed to avail himself of the strengthening support it received through thermody namics (see 'Essays,' vol. i., "On the Nebular Hypothesis," 1858). Had Mayer" brought his ideas into connection with Iaplace's cosmogrony, he probably would have hit upon the correcter version, the contraction theory, which it was reserved for Helmholtz to propound in 1554 .

1 The subject was about the same time taken up by William Thomson (Lord Kelvin), first in a paper "On the Mechanical Energies of the Solar System" (Trans. Edin. Roy. Soc., 1854), and continued in a series of papers and addresses, reprinted in his mathematical, \&c., papers (vol. ii.) in the 1st volume of his 'Popular Addresses,' and in an appendix to Thomson and Tait's 'Natural Philosophy.' He shows that the form of the meteoric theory propounded by Mayer, and independently by Waterston (Brit. Assoc, 1853), is as little able to explain the maintenance of the sun's heat through known historic ages as the chemical theory of com. bustion, which was alleady abandoned by Mayer in 1846, and finally adopts Helmholtz's form of the meteoric theory as the most likely. ('Pop. Lect.,' rol. i. p. 365, \&c.; p. 373, sc.) 
a valid explanation of the maintenance of solar heat. In fact, "as to the sun, we can now go both backwards and forwards in his history upon the principles of Newton and Joule." 1

But further means for testing the eorrectness of these 50. theories were afforeled ly the invention, in 1859, of Artibsis spectrum Analysis. It was fomel that the composition of the light of luminoms boclies, as revealed by prismatic scattering in the spectrum, enabled us to tell a good deal about the nature of the borly itself from which the light emanated. We can tell whether the body is shining with its own or with reflected light, what are the constituents of the incanlescent body, whether it is an incandescent solid or an ineandescent gas: also whether the body is in motion or not. The nebular hypothesis supposed that the planetary system owed its origin to incandescent, perhaps gascous, matter, which, throngh the force of attraction, was collected in different eentres: the discoveries of thermorlynamies and of spectroscopy have enabled us to expand and correct some of the assumptions of this theory, and to add new features to its minuter elaboration. It is not necessary that the matter which was oricrinally seattered through space and was gathered into attracting centres should be itself incindescent or gaseons; it may have been cold and solid like dust; rising in temperature and becoming ineandescent only through the conversion of arrested motion into hent, which again was maintained for some time throngh aceession of new matter or progressive shrinkage, but which must in a calculable time be radiated away, leaving a

1 Lorl Kelvin, loc. cit., vol. ii. 1. 131. 
cold, heavy, lifeless, and lightless body behind. ${ }^{1}$ The action of attractive power would sometimes reveal the existence of cold bodies, with specific gravity much in excess of our earth, as in the case of the satellite of Sirius, and the spectroscope would reveal clusters of stars or nebulx in the various stages of development, such as the nebular hypothesis suggested as making up the genetic process of our planetary system. Much uncertainty and much conjecture must of course exist in these chapters of science, which those who are in full possession of the accumulated and yet very imperfect facts may venture to elaborate in a more or less plausible or fanciful manner. Such attempts to

51.

Genesis of the cosmos - Faye and Lockyer.

write the history of the universe have been made in an original fashion by M. Faye in France ${ }^{2}$ and Sir Norman Lockyer ${ }^{3}$ in this country. They have tried

1 See Helmholtz, "Vortrïge und Rerlen,' vol. ii., 3rd ed., p. 88, \&c.

". Sur l'Origine du Monde,' 2nd ed., Paris, 1885. The author, finding the celebrated cosmogonic hypothesis of Laplace in "full contradiction" with the actual state of science, takes up an original theory of Descartes, that of vortices, in order to characterise not the actual, but the initial, stage of the solar system (see Preface) : "Autrefois, je veux dire il y a ne vingt. aine d'années, on avait les condées franches pour imaginer un système cosmogonique: il suffisait de l'accommoder aux notions contemporaines d'Astronomie solaire et de mécanique céleste. Il n'en est plus de mềme aujourd'hui, car la thermodynamique assigne ì notre Soleil une provision limitée de chaleur, l'Analyse spectrale nous révéle la constitution intime des astres les plus éloignés, et la palé- ontologie nous fait remouter à des époques où il n'y avait, sur notre globe, ni saisons, ni climats."

3 Whereas M. Faye has ingeniously modified the original and older nebular hypothesis so as to account for the anomalies in the movement of some of the nembers of our planetary system, which were unknown or unexplained in Laplace's time, and has tried to account for the phenomena of loss and supply of heat which thermodynamical theory and paleontological records reveal, Sir Norman Lockyer has during more than thirty years been occupied with the elaboration of a special theory which tries to liarmonise the revelations of the spectroscope as to the chemical constitution of the sun and other stars with the more recent developments of the atomic theory as suggested by chemical and electrical plenomena observed in our labora- 
to do what P'rofessor Haeckel has done in the more restricted field of the history of the living creation. Whilst these attempts are by many scientitic authorities con-

tories. His speculations, based upon his own ofservations as well as those of many other Eurojeat and American authorities, such as Seechi, 1)uuas, Kayser and Runge, Rutherforl, Rowlani, Young, and, above all, of Sir W. Crookes and the late Professor l'reston,-all of which, as well as many otlers, lue generously quotes, -were given in three wurks "The Chemistry of the Sun' (1S57), 'The Meteoritic Hy. pothesis" (1890), and "The sun's Place in Nature' (1.97). He las latterly collected the whole evidence in a brilliant and fascinating volume entitled 'Inorganic Fvolution as studied by Sipeetrun Anulysis' (1900). The central iclea contiined in these books, and elaborated with increasing detail and clearness, was suggested ats early as 1873 , when sir X. latelyer pointed wut "that many of the rlifticulties would rauish if it were concederl that the "atoms' of the eluemist were broken up or dissociated into finer forms by the ligh temperatures employed in the new method of investigation" ("Inorg. Hvol.," ). 73). This "dissociation" hypothesis has been wuch eritieised, and can only be firmly established by patient and prolonged research in that borderland which unites ehemistry and astronomy. As the author says: "I'he chemrist las little interest in in appeal to celestial phenomena, and astronouners do not generally coneen thenselves with elienistry. The region investigated by the eliemist is a low temperature region, cominated by monatomic and polyatomic molecules. The region I have chiefly investigated is a high temperature region, in which ner- cury gives us the sane phenomenit as manginese. In short, the cluanges with which spectrum analysis lass to clo take place at a far higher temperature level than that employed in ordinary cliemieal work." It is well to note that during and since the time when the clissociation hypothesis was first yomiuently put forward researche. condueted on entirely different lines have lert to similar viewsi.t., to a further alaberation of the atomic hypothexis. M. Hertlic. lot wrote in 1880 : "l'étude approfondie des propriétés physiques et chimiques des masses élónen. taires, qui constituent 110 s corps simples actuels, tend chaque joum d'avantage à les assiniler, nom is des atounes indivisibles, homogenes et susceptibles d'ćprouver seule. went des mouvements d'eusemble . . il est difficile d'innaginer un mot et une notion plus contraives ì l'observation ; matis à des ćlitices fort complexes, doućs d'une architecture spécitique et aniurés de mouvenents intestins tròs viriés" (quoter in 'Inorg. Evol., 1. 28). The first elemical eonfirmation of the dissociation hypothesis came in 1883 through the "beautiful researches on the rare earth Ittria, contained in sir Wn. Crookes's Bakerian lecture to the lioyal Society. "In the lectures he gave a sketch of the train of reasoming by which he had heen led to the opinion that . . this stable molecular group had been (by a process termed 'fractionation') split uj, into its constituents" (ilid., p. 116); and already, in 1879. Sir Wn. Crookes had frovisionally accepted the "dissociation" hypothesis (1).74). Anomalies also in the periodic 


\section{sidered to be premature, ${ }^{1}$ they have contributed much to} impress on the thought of our age the genetic or developmental view on a large as well as on a minute scale.

law of Mendeléef were explaiued by utilising this hypothesis (p. 165), and in the sequel other authorities, such as Brodie and Rydberg, expressed themselves in the same sense (p. 164). These, and quite recently the electrical researches of Prof. J. J. Thomson (referred to supra, p. 192), support the view, originally suggested in a cruder form by Prout, that what we call elements are really compounds or aggregations or complexes, built up "from similar particles associated with the presence of electricity" ('Inorg. Evol.,' pp. 167, 190 ; also J. J. Thomson, 'Discharge of Electricity through Gases,'p. 198 sqq.)

1 It would be unfair not to state that many works on astronomy are still written in which all genetic hypotheses are left out, the "statical" view being still the predominant one. Especially in Germany, it seems as if "inorganic evolution" is not very popular; though a large amount of the best work in spectrum analysis of the stars has been done there by H. C. Vogel, Kayser and Ruuge, Scheiner, and many others. Dr. Scheiner, in his valuable work (translated with the title 'A Treatise on Astronomical Spectroscopy,' by Prof. Frost of Dartmouth College, U.S.A., 1894), has some important criticisms ou hypotheses and solar theories (see Preface, and the discussion of the Meteoritic Hypothesis in the German edition, Part II. chap. i.) In his 'Bau des Weltalls' (Leipzig, 1901) genetic views are not discussed. The older very valuable works of $R$. Wolf ('Gesch. d. Astronomie,' 1877, 'Handbuch der Astrouomie, 2 vols., 1890-92) give only slight attention to "genetics," and consider even the "statics" of the universe though a possible yet a difficult problem (see the last-named work, $\S \S 298,299$ ). The latest and excellent 'History of Astronomy,' by $\mathrm{Mr}$ A. Berry (1898), is likewise reticent about the evolution of the universe, admitting only a general, fairly wellfounded presumption in favour of a modified nebular hypothesis (p. 409). It would, therefore, be doubtful whether a history of science should, at the end of the nineteenth century, give much room to these modern genetic theories in astronomy. It is different with a history of scientific thought. However premature and renturesome it may appear to purists in science to elaborate such hypotheses, there is no doubt that the genetic arguments and lines of reasoning have got a firm hold of mauy great thinkers in the physics of the universe as well as in biology, and that the genetic view of nature in general has received very strong support from the several traius of reasoning and the rapidly increasing revelations of spectrum analysis of cosmical and terrestrial objects, as set forth in Sir $N$. Lockyer's interesting volumes. Already thirty years ago Lord Kelvin said of the spectroscope: "It is not merely the chemistry of sun and stars, as first suggested, that is subjected to analysis by the spectroscope. Their whole laws of being are now subjects of direct investigation ; and already we have glimpses of their evolutional history through the stupendous power of this most subtle and delicate test. 
It is intelligible that these different lines in the genetie view of nature-the diflerent trains of reasoning which, in the comse of our contury, have started imlepentently in astronony; in geology, and in natmal history-should, as they develop and expand, cone into contact, and in the event either snpport or invalidate each other. 'The former was the case when the geolugrical reeord, the discoveries of palinontology, were hought in to throw light on the history and development of speeies; the stories of nature, as written from the point of viow of the embryologist, the systematic zoologist and botanist, and the palcontologist, seemen more and more to eonfirm ant support each other. The same cannot be sail if we write the history of om earth from the point of view of the geological recort on the one side and from that of the purely physical data afforded by thermodymamies on the other: Lord Kelvin has shown ${ }^{1}$ that the nutold

We har only solar and stellar chenuintry : we now have solar and stellar pliysiology" (Presid. Adelress, Brit. Arsoe, 15:1. See "Popular Lectures and Adrlresses, vol. ii. p. 1si)).

1 'The literature of the subject begrins with Lord Kelvin's Adelress to the fieolngical soeiety of Glas(gow, february 27, 1568, which harl been preceled by a pajur read before the liogal Society of Edinhurgh in 1865 , liriefly refuting the "I heetrine of Lniformity in Geology." The address began with the worls: "A great reform in geological speeulation seens now to have becone necessary," and in the soruel stated: "It is quite certinin that a great mistake has been marle-tluat British popular geology at the present time is in direct opposition to the prineiples of natural philo- soluly:" There palper"s are reprinter in the zurl vol. of "Popular Lecetures and Adllesses' (see l'p, 10 ant 4t). The attack was taken up hy Huxley in his Adlress to the Geologieal society for 1869, reprinted in 'Lay Sermons.' \&e., 1891, p. 19s. In a rejoinder to this, delivered in the same vear at Glasgow (Ior cit., p. 73), loord kelvin shows how the enrent genlogy was in the hal,it of lonk. ing upon geolugical time as "an alement to which we can set no bounds in the past any more than we know of its limits in the future " (quoted from l'age's 'Text-buok "), that Darwin's arguments themselves involve an almost unlinited clura. tion of the conditions aslmitting of the operation of natural selection, since, in his view, "in all probability a far longer periol than 300 million
52. Palitentoto. logry and geolly sies. 
ages with which geologists, since the time of Lyell, have been accustomed to reckon, are not supported by our present knowledge of the periods during which the socalled secular cooling of the earth has been going forward - the period which has elapsed since the "consistentior status" of Leibniz sêt in. He has thus put before natural philosophers a problem-the reconciliation of the geological and the thermophysical recordin which the genetic view of nature must be greatly interested. But even more important than all this is

53.

Dissipation of energy.

the doctrine of the dissipation of energy, referred to in the second chapter of this volume-a doctrine of which

years lias elapsed since the latter part of the secondary period" ('Origin of Species,' 1st ed., p. 287). He shows that Hutton and the uniformitarians were misled by a belief in the so-called stability of the solar system, which took no notice of the effect of tidal friction, nor of the phenomena of radiation and cooling in the past, still less of the law of dissipation of energy, and maintains that the modern ideas of evolution are in a sense a return to the older conceptions of Leibniz, Newton, and wher more recent geologists (7oc. cit., p. 111). Since the subject was thus brought prominently torward, astronomers, physicists, and geologists have not only-as Huxley expected them to do (see 'American Addresses,' 1886, p. 93)-ardduced arguments in order to arrive at an approximate idea how loug the earth may have been able to maintain organic life, but biologists have been induced to revise the postulates of the extreme -almost infinite-slowness, and of the uniform continuity of organic changes, originally contained in the Darwinian theory. The influence of these researches upm biological and genetic reasoning has been to emphasise the sudden changes, the ruptures in the continuity of development. In England the great work of $\mathrm{Mr}_{\mathrm{r}}$ William Batesun ("Materials for the Study of Variations,' 1894) has familiarised us with the idea of "Discontinuity" in the origin of species. On the Continent the rapid or even sud. den appearance of variations is not a new idea, though the original suggestion of Maupertuis (174s), which was takeu up and elaborated by Geoffroy St Hilaire (see Yves Delage, 'L'Hérédité, p. 291), wits forgotten. In quite recent years the reconciliation of the "persistence of species" with their "variability," and of the "geological" with the "biological" reeords. has been much furthered by the theors of "Mutation" of the celebrated Dutch botanist de Vries. IIis view is that "every species has its beginning and its end; it behaves in this way like an individual." He refers to the experiments on heredity and erossing of butterflies of standfuss, who has been led to maintain the existence of sudden or " explosive" transformations; and he 
the mechanical and cosmical inportance was clearly foreseen by Lord Kelvin in 185., but which is hardly assimilated yet by scientific, much less by popular, thought.

The two doctrines of the conservation of matter and of energy would lead to the irlea that nature is a kind of perpetuum mobile, nothing in the way of natter or energy being lost; and that such a reversal of her processes is possible as we are aceustomed to deal with in purely mechanical eontrivances. But a closer exanination of the processes of nature, as distinguished from those of artificial machines, revealed the fact that,

s.12:ak of "periuxls of mutation"i.e., of rapid clange of speeies, of which he gives various instanees. He concludes that "as many steps" as the organisation has taken since the beciming, so many periods of "mutation' must have existed." He considers the vitil processes to be built up out of "units." "Of such units there are probably in the higher plants several thousands, aucl their ancestors nust have run through as many periods of mutatation." He concluites with the following words: "Althougis such ealculation: are naturally exposed tu much criticism, they nevertheloss lent on very different roads to identicul results. Lord Kelvin, who a few years ago colleeted and examined eritically the various data referring to this subject, arrises at the eonelusion that provisionally, ancl with all reservations, the duration of life on the earth ean be placed at 24 millions of years. We aceorlingly tike this tigure for our biochronic equation. And as we ean with great probability estimate the number of elementary properties in one of the higher plauts at some thousands, it follows that the interval of time between two periods of mutation must have lasted several thousanils of years." (See de Tries's Aldress to the fierman Assoc. of Scienee at Ilamburg in 1891, 'Verhandelungen,' \&c., !) 202, \&c.; also Lord Kelriu (l'hil. Mag. (5.) 47, p. 66). Mr Mallace las, from an entirely diflerent point of view, been led to the conclusion that "eertin definite portions of man's intellectual anei moral nature could not liave been developert by rariation and natural selection alonc, and that, therefore, some other in. tluenec, law, or agency is repuired to account for them." "l'his would account for an apparent, though perhates not an actual, brak in the contimuity of all natural processes, which, in the dietum ruture non fiecit saltum, has reeeivel a very gencral expresion and aceeptance. This dictum - supported by tho authority of Leibmiz-is, however. ly some molern thinkers de nouncerl as a selnolastic and anti. quated aphorism. (See lves 1)elage, 'L'Hérédité,' Ee., p. 260.) 
thongh matter and energy be indestructible, the succession of phenomena, the changes and processes which we call the genesis or history of things, are dependent on the condition in which energy exists; it being a general tendency for energy not to be lost, but to become unavailable; change and action, the life of things everywhere, depending on an equalisation of existing differences, say of level or temperature, or quicker and slower motions. This great property of natural, as distinguished from purely mechanical, processes, explains the fact that the processes of nature are irreversible, that the clock cannot be turned back, that everything moves in a certain direction. Various attempts have been made to explain mechanically this remarkable property of all natural processes, which seems to lead us to the conception of a definite beginning and to shadow forth a possible end-the interval, which contains the life or history of nature, being occupied with the slow but inevitalule ruming down or degradation of the great store of energy from an active to an inactive or unavailable condition.

54. Mystery of the actual processes of nature.
This doctrine of the degradation or dissipation of energy leads us one step farther towards an understanding, or at least a description, of the processes of nature, but also of their mystery. It has been urged that, as we always only deal with a small portion of existing things, we have no right to apply conceptions which are based upon a restricted observation to the totality of things in the miverse. For instance, we know nothing of what becomes of the energy radiated away into empty space. This is a reflection we should always bear in 
mind. We have alsu been reminded that the theories of the so-called stability of the planctiry system which were propounded in the earlier years of onr rentury, and which lave found their way into popular treatises (n) astronomy, are only approximations. (1) the wther sirle, we have daily before om eyes the ever-recurring instances of the building "up and rmming down of natmal forces in smaller systems. These we term organisms, the living things of natme. It is from and throngh them that we first learnt to dook upon the whole of nature as having a history and a life. hupereptibly we have been led to stmly life, the genesis of things, on the latge scale and in the abstract, and in loing so have lost sight of the life which goes on aromul and near ns. lioth the morphological and genetic views of nature starterl with a liological interest, hut have gradually lost sight of it. It is time to come back to it and to see what real frogress has been made during our century in the study uf life itself-the truly biological view of nature. 'This will be the olject of the next chapter. 


\section{CHAPTER X.}

ON The VITAlistic VIEW OF NATURE.

IN the foregoing chapters, where $I$ have treated of the several distinct aspects of nature which have become helpful in science, I have always used the word nature in its widest sense as comprising everything which is revealed to us by our external senses, directly or indirectly.

The title of the present chapter may suggest to some of my readers that I am now narrowing down the meaning of the word, - the vitalistic view of nature being possible only where life is present. The astronomer might say, Life is only known to exist in an infinitesimally small portion of the universe, on the surface of our planet. This infinitesimal area has nevertheless for us the greatest importance, inasmuch as all that we know of the larger outlying world is only won by inference from observations made in this restricted portion. Independently of this, the conception of life itself has always fluctuated between the two extremes of considering it as a universal property of all matter, or on the other hand as quite a casual and accidental occurrence attached to conditions which, from a wider point of 
view, are extrenely rare and exceptional. Jetween these two views, the cosmical and the terrestrial, the wider The cusini. and the narrower views of life, biological theories have eal and tho terreatrial fluctuated even in our century, and are still fluctuating. views.

1 One of the forenust upholders of the wider conception of animation as a universal property of all matter is the celebrated firman naturalist, l'rot. Finst Hacekel of Jena. See, inter ulia, his Address "Ueber die heutige Entwickelunsslelre im Verhiltnisse zur Gesimmt wissenseluaft," 1570 , reprinted in 'Gesammelte populire Vortrige,' \&e., part ii., lionu, 1879 , 1. 119 : "The recent coutloversies l'ogard. ing the properties of the dtoms, which we must aecopt in some form or other as the uhimate elementary factors of all phy-ical amd cliemical processes, seem io be most eavily settled by the assumption that these smallest particles of mass, as centres of force. jossess a per. manent soul, that every atom is endowed with sensition and mo. tion," tc., p. 109: "Alriviug at this extreme psychological consequence of our monistic doetrine of development, we attach ourselve: to tho:e ancient conceptions as to the animation of all matter which, in the plilosophy of Denoeritus, Spinoza, Bruno, leibniz, silnopenhauer, have alyeady found varied expression." The cosmieal origin of life has also been put torward by such authorities as 1 lolinlioltz and Lorel Kelvin, as long ago as 1571 . (See Helmholtz's lecture "Ou the Origin of the l'lanetary System," 'Popul. Tortrige,' \&e., vol. ii. p. 11, and Lord Kielvin's celehrated adidress to the Iirit. Assoc. at Eilinburgh in 1871, reprinted in 'Pol. Leets.,' \&e., vol. ii. p. 199, \&c.) 'This theory of "I'mspermia," of the cosmical or ubiquitous nature of the germs of life, has also been pro. posed by biologists such as 11. E.

VOI. II. lichter (1\$65), and has besm more fully elisborated Wy Prot. W. Preyer since the year 1850 : it has received turther support in the genetic theorices of the chemical elements and compounds put forwarl by lim in 1591 (") bie orymisehen Elemente uml ilne Stellung in System,' Wiesbarlen), and in 1893 (")is genetische Sistem ler chennischen Eilemente,' Berlin). Uf the fourteen elements which are common to organic substanees, he says ( 1.49$)$ "that they belong to the oldest clemrnts" ; that "they inluit of more varied relations," and "arree with the assumption that, before being conclensed as at present on the surface of the enth, they formed at higher temperatures more stable protoplasus which might he in other places the earriers of life" ; and he has no loubt "thiat there existed before the present terrentrial phyt oplasma and zooplasmi another plisma, which ultimately came from the sun" (I'. 50). In fact, l'rot. l'reycr asks whether, justead of living heing evolved from dead matter, the latter is not rather a product of the former. Siee also the reforence to organic evolution us a cosmical process in sir N. luckyer's 'Inorganie Fvolution' (1900, p). 165). In many of the witings of the celebrated German plyyicist and pliblosopher, Gustav 'Iheod. liechner, the fact is emplatsi-ed that we never see the organic aleveloperl out of the inorganic, but that everywhere the living generates not inly the living but nore frepuntly the inaniunte. Siee basswit\%, 'G. T. Fechner,' Stuttgart, 1896, p. 130, ke. 
No theory of the nature and origin of life has gained universal acceptance: the very alphabet of biology, or the science of life, has still to be written. We fancy we possess some knowledge of certain forms or processes which are conmon to all living matter, but the description of these has to be kept in the most general, not to say the vagnest, terms: quite unlike the rudiments of other scientific theories which deal with mathematically defined conceptions expressed in distinct language and formulæ.

2. For instance, if we take one of the best founded of Vagueness of biological modern biological theories - the cellular theory ${ }^{1}$ of living matter - we notice that the pretty definite description which the early supporters of this theorySchleiden and Schwann-gave of this morphological unit of vegetable and animal structure has been displaced by much vaguer descriptions. Schleiden and

1 The history of the cellular theory has been written from various points of view in all the three languages. I give the titles of a few out of the great abundance of excellent treatises. Foremost stands the work of Prof. Oscar Hertwig of Perlin, 'The Cell : Outlines of General Anatomy and Physiology.' English transl. by Camplell (1895). Then there is the more recent book by Prof. Valentin Hiicker of Freiburg, 'Praxis und Theorie der Zellen- und Befruchtungslehre' (Jena, 1899). In the French language we have the great compendium of biological theories by M. Yves Delage, 'La Structure du Proto. plasma et les Théories sur l'Hérédité,' \&c. (Paris, 1895). In English we have the valuable treatise of Prof. E. B. Wilson, "The Cell in Development and Inheritance' (1896), and the excellent little work of Prof. James Arthur 'Thomson, 'The Science of Life' (1899). Of high importance are also the older works of the great master and brilliant expositor in biological science, Claude Bernard, notably his celebrated lectures entitled "Leçons sur les Phénomènes de la vie communs aux animaux et aux végétaux" (1878 and 1879), which every philosophical student of biology should read, as wcll as his excellent posthumously published little work, "La science experimeutale,' 1890 . Of him M. Dumas says that he has "épuisé ses forces à l'étude du grand mystère de la vie, saus prétendre à pénétrer toutefois son origine et son essence" ("Sci. Exper.,'p. 6). 
Schwamn defined the cell its "a small vesicle with it firm membrane enclosing fluid content." I but the cellular theory was gradually replaced by the protoplasmic theory of Max sichultze, the distinet menbrane was found to be frequently absent, and there only remained "at small mass of protoplasm endowed with the attributes of life." The cell, which hat once been compared to a crystal, became a rexy complicated and indefinite thing: it hecanc, in the conception of biologists, an "organism." 2 Futher, the nucleus or kernel to which schleiden attached great importance in his cellnlar theory was, for a while, quite lost sight of - it being for a long time held that there exist nonmucleated cells. Elihorate theories, such as that of Hateckel, ${ }^{3}$ were founded upon this view, till in more

1 1). Hertwig, "The Cell,' P. 5 n.

- Treatises on the subject now usually begin with an alology, the worl cell being considered mislearl. ing. Thus Hertwig says loc. eit., p. s), "It is evident that the tern "cell' is incorrect. 'l'liat, it hats, nevertheless, been retained may be partly ascribed to a kimd of loyialty to the vigorous eombatants who conquered the whole fiels? of histology under the bamer of the cell-theory, and partly to the cir. eumstance that the discoveries which brought about zlse new reform were only unade ly clegrees, and were not generally aceepted at a time when, in consequence of its having been used for several decarles, the word cell lial taken firm root in the literature of the subject."

3 "Since, in eonsequence of the inadequacy of former methods, no nucle had been discovered in many of the lower organisms, the exist. ence of two kinds of elementary cells was assumed - nore simple ches, cunsisting only of a mass if protuplasm, and more couplex unc., which hat developed in their in. terior a special organ, the nucleus. 'The former were called cytocles by Hitecke] (1866), to the simplest solitary forms of which he gave the name of Monera; the latter he called cellulir, or cytes. but since then the aspect of the question has been considerably changen. Thanks to the improvements in optical instruments and in staining methorls, the existence of oryanisuls without nuclei is now much yues. tioned." (Hertwig, 'The cell,' I. 54. See also Hicker, p. 239.) On the wther side $I I$. 1)elage says ("L'Hérédité,' ". 37), "Apres awoir déeouvert un noyau che\% la plupart des monères et des cytodes et mêue clie\% les Bactéries, on a, jar me induction a mon sens un peu lattive, nic l'existence d'organismes saus noyau." 
recent times, owing to improvements in the microscope, the existence of organisms without nuclei has become doubtful. To complicate matters still more, to the nucleus have been added the nucleolus, the vacnoles, the central or pole corpuscles of the cell, \&c. It is quite ericlent from this short reference to the changes which the definition of the morphological mnit of living matter has undergone, that no complete and accurate description lending itself to measurement and calculation conld be based upon it. The conception, nseful as it may be, has therefore not permitted of predictions, such as mechanical, physical, and even chemical science, abound Impossi-

3. in. "Has one ever," says Delage, "in a single instance Impossi-
bitityon.
of the microscope has unveiled? Has one divined the transverse striation of muscles, the cilia of vibratile epithelia, the prolongations of nerve-cells, the action of the retina or the arcades of Corti, the chromosomes of the nucleus, the centrosome of the cytoplasma?" I Or, to take an example not from the morphology but from the physiology of organic cellular bodies. It is a very general and a very useful property of cells that they readily absorb substances; in fact, this property is one of the most valuable aids in microscopic exam-

1 'L'Hérédité, \&c., P. 746. Prof. Weismann, in lis celebrater 'Essays upon Heredity' (Engl. transt. by Puulton, \&c., p. 255), claims for the theory of descent that "it has rendered possible the prediction of facts, not indeed with the absolute certainty of calculation, but still with a high degree of probability. It has been predicterl that man, who, in the adult state, only possesses twelve pairs of ribs, would be found to have thirteen or fourteen in the embryonic state; it has been predicted that, at this early period of bis existence, he would possess the insignificant remmant of a very small bone in the wrist, the so-called os centrale, which must have existed in the arlult condition of his extremely remote ancestors." 
ination, insomuch as the different behaviom of different parts of the cellular boly towarls organic staining solutions reveals to the olserver clifferences of structure otherwise indistinguishable. Tet T'rofessor T'fefter, ${ }^{1}$ whw has studied the absorbing powers of cellular substances with much eare, states that these camnot in the least be foretold, hut ean only be determined empirically; nor is the fact that cells require some substances for their life, while others are harmful, sufficient to enable us to predict that either will he alsorhed or rejected. Again, hybridisation has been much studier by gardeners and loreders, and also, since the time of Ditrwin, by naturalists: nevertheless, the result of cross-fertilisation of individuals belonging "to diffeient families or species, or even only to different varieties," cannot he theoretically foretold, but "can only he discovered by means of experiment." 2

This ignorance in which we are still placed as to the forms as well as functions of living matter, has been a subject of much comment by biologists all through the

'See W. P'ieffer, 'V'eber Aufnalnue von Anilinfarben in lebende Zellen.' Lntersuchungen aus dem botanischen Institut zu 'Tilingen. Quoted by Hertwig, 'The Cell,' p. 136.

' Hertwig, 'The Cell.' p. 310. Ansther point, strongly urged by Claucle Bemard, is, that it knowledge of structure in living beings-i.e., anatonical knowledge-in no wise suffices to explain the functions, does uot lead to physiological knowledge. See 'La Science Expérimentale,' p. 105, "L'impuissance de l'anatomie it nous apprendre les fonctions organiques devient surtout évidente daus les cas particuliers où elle est récluite à elle-même. l'our leorganes sur les usages denquels la physiologie expérimentale n'it eneore rien dit, l'anatomie rote absolument muette. C'est ce yui a lieu par exemple pour la rate, les capsules surrénales, le conps thyroide, \&ce, tous orranes dont nous commaisons parfaitement lit texture anatomique, mais dont nous ignorons complètement les fonctions. We mène, quand sur un animal on déconve un tissu nonveau et sins analogue dans d'autres organismes, l'anatomie est incaprible d'en dévoiler les pwpriétés vitales." 
century, nor can it be stated that uniformity of opinion exists even yet as to the cause of this ignorance. The enormous progress which has been made in our knowledge of the different properties of living things has had an effect on the minds of those searchers to whom we are mostly indebted for it, similar to that produced on a wanderer who ascends an unexplored and distant peak. Ever and anon, after scaling the eminence just before him, he beholds a new and greater one rising into view, which he contemplates with mixed feelings of discouragement and of eager desire for advance. But whereas our wanderer must know that the very greatest height or distance is none the less a measurable and attainable quantity, what hope has the biologist to encourage him on his way? No other-as it appears to some-than the assurance that he is all the time exploring an unknown country, whereas the final achievement is impossible to him through the inaccessibility of the position or the limitation of his own powers. Others, indeed, from time to time have not taken this despondent view, but, elated by the trimmphs which every new step has afforded them, have persistently maintained that some day the last step will be taken and the central peak really gained.

4. Oscillation of biological thought.
The history of biological thought, as distinguished from biological knowledge, presents us with the spectacle of a repeated oscillation between these two extreme views: on the one side the continually recurring conviction that the problem of life is insoluble, and, on the other, the assertion that it is soluble, though 
ON THE VITALISTIC VIEW OF NATULE. 375

it is anmittedly as yet unsolved. Biological knowledge itself has progressed on the same lines as chenical, physical, and nechanical knowlenge; it registers the progressive conquest of new regions of phenomena exhibited by living matter through the methods which have been diseovered in the abstract sciences: but it has generally been felt that this knowledge does not exhaust the subject; that there is some prineiple involved which we know not; and that we eamnot think about the living portion of creation withont conseiously or unconseiously admitting the existence of this principle. The unknown-nay, possibly, the unknowable-clement or factor must be admitted to exist, and it involuntarily governs our reflections on that which we know. To show the differenee between reflections on biological and on other phenomena, which, though equally unknown, yet do not contain an admittedly unknown factor, it may be useful to refer to the scientific way of dealing with meteorological phenomena. The science of meteorology is probably as young as that of biology, if not younger. Prediction of the weather is probably even more uncertain than the prognosis of a physician at the bedside of a patient suffering from a malignant disease. Yet no one would suggest that there is a special meteorological principle involved, as in the ease of the phenomena of life and death there is a special biologieal principle. We are quite satisfied that purely mechanical and physical and possibly chemical processes make up the whole of the weather problem, and that the difficulty of the latter is simply one of 
complexity and intricacy. A similar ${ }^{1}$ attitude has in the course of our century frequently been taken up with regard to the problem of life, but it has always been abandoned again." We are still told that "in

1 See, for instance, what Huxlej, who, in his earlier writings, might be termed a vitalist (cf. his address "On the Educational Value of the Natural History Sciences," 1554 , and his own criticism thereof in the preface, dd. 1870, in 'Lay Sermons and Addresses'), says in his article "Biology," 1875 , in the 'Ency. Brit.,'vol. iii. p. 681 : "A mass of living protoplasm is simply a molecular machine of great complexity, the total results of the working of which, or its vital phenomena, depend-on the one hand, upon its construction, and on the other, upon the energy supplied to it; and to speak of 'ritality' as auything but the vame of a series of operations, is as if one should talk of the "horologity" of a clock." Similarly Claude Bernard, in his 'Leçons sur' les phénomènes de la vie, \&c., vol. i. p. 379, says: "Eu un mot, le phémomène rital est pré-établi dans sa forme, non dans son apparition. . . La nature est in. tentionelle dans son but, mais aveugle dans l'éxecution." Both Huxley's comparison of au organism with a elock and the quotation from Claude Beruard suggest a parallel between the dictum of Archimedes: " $\delta o ́ s ~ \mu o b ~ \pi o \hat{v} \sigma \tau \hat{\omega} \mathrm{kal}$ $\tau \delta \nu \kappa o ́ \sigma \mu o \nu \kappa \iota \nu \eta \dot{\sigma} \omega$," and a possible one of a biologist: "Give me an organism, and I will explain its action mechanically." In another place Claude Bermard says (loc. cit., ii. p. 524): "L'élément ultime du phénomène est physique ; l'arrangement est vital."

2 Examples of this could be multiplied indefinitely. I take one from an entirely different field. Prof. Kerner von Marilaum, the celebrated botanist, says ("The Natural History of Plants,' transl. by Dr Oliver, 1894, vol. i. p. 52): "In former times a special force was assumed-the force of life. More recently, when many phenomena of plant life had been successfully reduced to simple chemical and mechanical processes, this vital force was derided and effaced from the list of natural agencies. But by what name shall we now desig. nate that force in nature which is liable to perish whilst the protoplasm suffers no physical alteration, and in the absence of any extrinsic cause; and which yet, so long as it is not extinct, causes the protoplasm to more, to inclose it:elf, to assimilate certain kinds of fresh matter coming within the sphere of its activity and to reject others, and which, when in full action, makes the protoplasm adapt its novements under external stimulation to existing conditions in the manner which is most expedient? This force in nature is not electricity nor magnetism; it is not identical with any other natural force, for it manifests a series of characteristic effects which differ from those of all other forms of energy. Therefore I do not hesitate again to designate as rital force this natural agency, not to be identified with any other, whose immediate instrument is the protoplasm, and whose peculiar effect we call life." Another example is that of Prof. Virchow, to whom we are indebted for the great revolution which the application of the norel conceptions of the cellular theory has worked in the 
accepting a mechanical conception," we must not "fall into the very common mistake of trying to explain vital processes as heing the directly to meehmical eanses." It has been quite as impossible to banish the word life from the biological vocalmlary as it has been to banish the word "onght" from the ethical. Liologrical knowledge has become purely chenical, physical, and mechanical, but not so biological thought. The yuestion "What is life?" still hamnts us. Let us see what position the foremost representatives of molern biological research have taken "y, to this question. We find that they can be divided into two classes.

First, there are those who have stutied the phenomena of living natter solely by the means which the The purely screntilic aspect. advancing sciences of dynanics, phẹsice, and chemistry have placed at their command. To them liohngy is an applied science. The question "What is life?" is, according to their view of methorl, only to be solved by degrees, by lringing the forms and processes manifested in the living workd more and more under the sway of observation, measurement, and possibly ealculation. The central problem as to the essence of life and the

field of pathology. After having assisted in banishing the older vitalism, he, to the dismay of many of his own school, reintroluced the conception of a vital pinciple in a well-kuown review entitled "Old and New Yitalism," in his own jourmal (rol. ix. p. 20). "Indeed, the living borly consists, so fir as we know, of substances of the same kind as we find in 'lifeless nature,' and these sulsstances have not only no other properties and powers in the living body, but they do not eren lose any of them. . . Nevertheless, we eanmot see how the phenmena of life can be under. stood simply as an assemblage of the natural forces inherent in those substances : rather do 1 consider it necessary to distinguish as an ossential factor of life $\mathrm{m}$ in derived force in addition to the molecular forees. I see no (b). jection to designating this foree ly the old name of vital force." 
consensus of many mechanical, physical, and chemical processes in the living organism does exist, but it can only be answered by attacking it from all sides and reducing it to ever narrower issues. The stronghold in which life is intrenched is to be conquered by surrounding it on all sides by the attacking forces of dynamics, physics, and chemistry. It will have to yield some day, though that day may be far off. The number of those who treat biology in this way has increased very much ever since Descartes, ${ }^{1}$ and still more Lavoisier, applied

1 The claims of Descartes to be considered as one of the founders of modern physiology are put forward by Huxley in several of his addresses, notably in that of 'On Descartes' Discours,' \&c., 1870 ('Lay Sermons,' \&e., p. 279); and in that on 'The Connection of the Biological Sciences with Medicine,' 1881 ('Science and Culture,' p. 325). In the latter address he says : "Now the essence of modern, as constrasted with ancient, physiological science, appears to me to lie in its antagonism to animistic hypotheses and animistic phraseology. It offers physical explanations of vital phenomena, or frankly confesses that it has none to offer. And, so far as I know, the first person who gave expression to this modern view of physiology, who was bold enough to enunciate the proposition that vital phenomena, like all the other phenomena of the physical world, are, in ultimate analysis, resolvable into matter and motion, was René Descartes.... And as the course of his speculations led him to establish an absolute distinction of nature between the material and the mental worlds, he was logically compelled to seek for the explanation of the phenomena of the material world within itself " (p. 335). It is interesting to contrast with this announcement of the banishment of the animistic aspect from modern physiology what Prof. Bunge says in the introductory chapter to his well-known 'Text-book on Physiological and Pathological Chemistry' (Engl. transl. by Woolridge, 1890) : "The mystery of life lies hidden in activity. But the idea of action has come to us, not as the result of sensory perception, but from selfobservation, from the obserration of the will as it occurs in our consciousness, and as it manifests itself to our intermal sense" (p. 7). "Physiological inquiry must com. mence with the study of the most complicated organism, that of man. Apart from the requirements of practical medicine, this is justified by the following reason, which leads us back to the starting-point of our remarks: that in researches upon the human organism we are not limited to our physical senses, but also possess the advantage afforded by the "internal sense" or selfobservation" (p. 11). "The essence of vitalism does not lie in being content with a term and abandon. ing reflection, but in adopting the only right path of obtaining knowledge, which is possible, in starting 
the purely seientific or exact nethor to the sunly of the organism.

But biology is not only a sulject of purely scientific interest. There is a second and larger class of students $\overline{1}$ Influence of medieist. -those who study hiology as the hasis of the alt of healing, the medical profession. To them the question of life and teath, of the nommal or abmormal co-operation of many processes in the preservation of health or the phenomena of discase, is of prime interest: the knowledge of the mechanical, physical, and chenicul properties and reactions of living matter, of the construetion of the organs and their functions, is only the means to an end. Before the time of Lavoisier, with the solitary exception of Deseartes, biology was stulied only by medical men; indeed to them both the existence and the progress of the science were entirely due. For them the paramount questions must always he, "What is life? What is its origin? What is death? What are its causes? What is disease?" To this elass of stuclents we are inclebter for again and again hringing forward and trying to answer these fundamental, these central questions.'

By the other, the smaller yet inereasing class of purely scientifie biologists, we are being continually told that these questions are premature or metaphysical, ${ }^{2}$ and

from what we know, the internal world, to explain what we do not know, the external world" (1) 12).

i See, for example, the two very interesting and suggestive addresses by Prof. lid. yon lindfleisch of Würzburg, "Arztliclee Philosophie' (Wirzburg, 1888), and 'Neo'Vitalismus' (Verhandl, il. Ges. deutscher Naturforseher und Arrte zu Liileck, 189", vol. i. p. 111 .
2 See Claucle Bernard, 'La Science Expérimentale,' 3mu ell., 1). 211 : "Lit vie est l'idée directrice ou la force ivolutive de l'itre : . . mais l'erreur serait de croire que cette force métaphysique est active ì la façon d'une force physigue. . . La force métaphysique érolutive prar laquelle nous pourons caractériser la vie est immtile à la science, f'urce 'qu'ctant en lehors des forces 
that the answer which we may give to them is of no scientific importance and of no scientific value. The question, "What is electricity? What is the ether?" cannot yet be answered; nevertheless the sciences which cleal with the properties of the ether or of electrical bodies are advancing daily. So also-we are tolddoes the science of biology progress, even though we leave the question "What is life?" manswered. This would be a tenable position if the living organism were like an electrical or an optical apparatus, constructed by man himself with the modicum of knowledge which he possesses. But the living organism, the eye that can see or the nervous system that is in action, or even the smallest "autonomous" cell, visible only with the microscope, are each an apparatus constructed by nature with the employment of all the intricate agencies which are at her command. In dealing with such an apparatus, we are again and again tempted to ask, "What is life? On what does the normal and healthy co-operation of all parts in the living organism depend? In what does it consist?" Fragmentary knowledge may be well enough so far as it goes, but every medical practitioner must painfully feel it to be altogether insufficient. Where practical interests are involved we cannot indefinitely postpone our answers. Science can wait and

physiques elle ne peut exercer aucune influence sur elles. Il faut donc ici séparer le monde métaphysique du monde physique phénoménal qui lui sert de base, mais yui n'a rien ì lui emprunter. . . . En résumé, si nous pourons définir la vie à l'aide d'une conception métaphysique spéciale, il n'en reste pas moins vrai que les forces mécaniques, physiques, et chimiques, sont seules les agents effectifs de l'organisme vivant, et que la physiologiste ne peut avoir a tenir compte que de leur action. Nous dirons avec Descartes: on pense métaphysiquement, mais on vit et on agit physiquement." 
content itself with the known and the knowable. l'rac- pracese tice is placed face to fice with the nuknown and the urges lue unknowalle. Thus the gnestion will arain aud areain What is be asked, "What is life?" And for the benefit or injury of mankind thenries will rxist which jofess to handle this delicate problem successfully, even as weather-prophets will always exist though the necessary knowledge for accurate prediction is still wanting.

One of the first in time and eminence in the comse of the nineteenth exntury to whom we are indebted, not

?. Bicliat.

1 See what 'Theod. Bischutt, one of the first and foremost (ierman amatomists of the new school, silys in his Éloge of Liebig (Ilinchen, $1 \rightarrow 74, p .60$. "Inorganic science is not any way induced and is mueh less obligerl to forsake the road from the known to the unknown. But what would have bern the result, what would still be the result, if, in all sur researches into organised nature, and yet more in all our actions which have refer. ence to our state of health or illheilth, we haul proceded, or were now to proceed, only from ditia firmly established as to cause and (onnection! ('oulil we then st) much as take a morsel into our mouths or treat a cold utherwise than with fear and trembling? l'hysiologists and doctors have surely always been ready to proceed acerirding (1) the methods of exact science so far as this was developerl. Jut so long as this gave but a stone instearl of breat, aeceptance could not be throught of ; necessity compelled us to make some attempt towards the solution of questions, to invent some languitge in order to gain an understanding; and through this frequently an eroneous procelure has arisen which outlives the means for its correction." "Physiology," says thu Job-Reymond (Floge of Joh. Miiller, 'Reden,' vol. ii. p. 14:9). "is the only science in which one is obliged to speak about things which one toes not know. C'hem. istry neal not treat of unknown eompoumls, nor physies of undis. eswerel forces: botany and zoology (1) not mind what kind of animals may -till move about unknown among nuknown regetation in unexplored regions. But in physi. olugy, even if we confine ourselves to wan, a definite number of things is given which must be dralt with. The spleer, the thyroil gland, the thymus, the suprarenal capsules; many garts of the brain, ganclia, nerves, the labyrinth of the ear-all these are there, and must, according to the customary view, be there for something. Manifolel suppositions as to the innetions of these parts, seemingly supported or invaliclated by pathological experience, have put in the place of absolute darkness a twilight which is richer in delu-ions thungh not in certainty. The expounder of our seience is obliged to leat his pupils through this twilight on an anxious path, and then meet in return with that discouragement which really is "wing to the sulject itwolf." 
indeed for the name, but for the modem science and direction of biology, was Xavier Bichat, who during the short period of his remarkable career (1771 to 1802) remodelled biological studies. He approached the subject from the sicle of medicine and in a philosophical spirit. In 1800 there appeared two treatises, one on the membranes and tissues, and another entitled "Recherches physiologiques sur la vie et la mort." These by their titles already reveal the twofold aspect of biological science which drew the attention of Bichat and his school. First, the attempt to reform biological and medical knowledge by a close anatomical examination of organic tissues in their normal and diseased states, for the purpose of which he, within a very short time, examined six hundred corpses. The fuller account of his researches is given in the four volumes of the "Anatomie Générale' (1801) and in the posthumous five volumes of the 'Anatomie Descriptive,' completed by some of his numerous pupils and followers after his death. In these works Bichat created the science of histology without resorting to the microscope, which was to do such good service in the hands of those who came after him, and without that application of physical and chemical principles which during his time (notably by Lavoisier and his school) had been applied with much suceess in the theory of animal combustion and in the foundation of another new science-that of organic chemistry. The reasons which inclined Bichat to distrust the microscope were the delusive nature of the revelations of the imperfect instruments then in use. They disappeared when, in the course of the next thirty 
ON 'THE VITALISTIC VIEW UF NATURE, :38:3

years, the instrument was gradually improved. The reasons which preventen bichat from treating biology as an application of physics and chemistry lay deeper, and were rooted in the second great inlea which governed him and his sehool-his "Vitalism." As stated above, those who have studied the phenomena of life can le vitalisn. divided into two classes. There are those who have been struck by the resemblance of the processes and phenomena in living matter with those in dead or unorganised matter: their attention has been directed more and nore to establishing a parallelism between organic and inorganic nature, and they have frequently ended in the conviction that their parallelism warrants us in asserting their ultimate identity. There have been others who have leen inpressed with the essential and fundanental difference between organic and inorganie proeesses and phenomena. To them, all attempts to recluce the living process to a mechanism seem to have failed, and however much they have appreciated the insight gained by the other class of students, they have deemed it equally important to emphasise the essential clifference-the independence, originality, and incommensuralility of the phenomena of life. The latter can be called Vitalists in the broalest sense of the term. Bichat belonged to them. Is the former elass of students have frequently arrived at the thesis that organic and inorganic processes are nitimately identical, so the latter have frequently arrived at the thesis that they are fundamentally opposer and antagonistic. Bichat gives expression to this view in his celebrated definition of life, as the totality of those tion or life. 
functions which resist death. He adopts, on the one side, the method of looking for the explanation of the phenomena of matter in the properties of matter. In the introduction to the 'Anatomie Générale,' he says: ${ }^{1}$ "The connection of the properties as causes with the phenomena as effects is an axiom which has become almost tiresome to repeat nowadays in physics and chemistry: if my book establishes an analogous axiom in the physiological sciences, it will have fulfilled its purpose." But being convinced of the essential difference of the object with which the physiologist is concemed,

1 Claude Bernard (1813-78), from whose various writings the passages of Bichat are mostly taken, has very fully analysed the theoretical views of his eminent predecessor. The following books belong to the best, in substance and notably in style, that have been written on the subject: 'La Science Expérimentale,' $3^{\text {me }}$ ed., 1890 ; especially: 'Definition de la vie,' p. 149, \&c. ; 'Lecons sur les Phénonnènes de la vie com. muns aux auimaux et aux végétaux,' 1sis, especially vol. i. p. 57, \&c. ; 'Rajport sur les progrès et la marche de la Physiologie générale en France,' 1867. Introduction. Although Bichat was a vitalist, he took a first and important step in the direction of getting out of the vitalistic conceptions which be in. herited from Haller, and which had assumed a special form in the Montpellier school. Through his foundation of physiological research upon an anatomical study of tissues, he localised the problem of physiology. Had he proceeded further on the lines be himself started, he would have thrown off, like his successors, notably Magendie, the hypothetical distinction between physical, chemical, and vital properties, and become a pure ex- perimentalist. The founder of this purely experimental school in France was Magendie (1783-1855). It is interesting to note that prior to Magendie in France, Cliarles Bell in London had led up to experimental physiology in England by his famous distinction between sensory and motor nerves (1811). But, according to Claude Bernard, this anatomical distinction required experimental verification in a living animal. Magendie furnished this in 1822, and, together with this corner-stone of modern physiology, laid the foundations of the art of vivisection, with all its wonderful discoveries and its disfavour in certain quarters. There is no doubt that for many years Paris became, through this innovation, the centre of medical teaching on the Continent. As to the listinctive merits of Bell and Magendie, see Claude Bernard's exhaustive examination ("Physiol. gén.,' p. 11, \&c.), but also Du Boislieymond's Eloge of Johannes Miüller ('Reden,' vol. ii. p. 176 , sc.) According to him the "Thesis" of Bell was not generally considered to be proved till after Miiller's experiments in 1831. 
he does not adrance to the position that the same method will lead to parallel results. "There are," ho says, "in natme two elasses of things, two classes of properties, two classes of sciences. Beings (things) are organic or inorganic, their properties are vital or nonvital, the sciences are physical or physiological." He did not anticipate that a faithful examination of the properties of organised matter, of membranes and tissues -which should not be limited to lifeless corpses-would more and more reveal that their properties, the forces aeting on and in them, conld he analysed into the same forces as those we find in the inorganic world. ${ }^{1}$

1 According to Claude Bernard ('Physiol. gén.,' p. 5, \&c.), three things were wanting at the beginning of the nineteenth century to place physiology ou a satistactory basis. The first-anatomieal know: ledge of the strueture of living matter-was brilliantly establisled by Bichat. But Bichat was not a physiologist: he neglected the second requisite, the study of the continual confliet between the living organism and the mechanical influences of the "milieux," the environment. "Il faudra"-says Bermard-"tenir compte de deux ordres de conditions: $1^{\circ}$, des conditims anatomiques de la matiere organisée qui doment la nature ou la forme des phénomines physiologiques ; $2^{\circ}$, des conditions physico-elimiques ambiantes qui cléterminent et reglent les manifestations vitules." A third iul. julse was wanted in physiology: "il fallait la ramener définitivement ì la méthode des sciences expérimentales; il fallait la pousser avec vigueur dans la direction des expériences sur les organismes vivants, afin de la détourner de la

VOL. II. roie des hypothèses et des explications prénaturies dans latpuelle elle s'était si souvent égarée. Un grand plyysiologiste franciais, Magendie, mon maître, est venu, au eommencement de ce siècle, exercel cette action générale sur la scienee plyysiologique, en méme temps qu'il l'enrichissait par ses propres dicouvertes. Magenclie fut élevé dans l'écule anatomique de Paris, mais il n'était point disposé à suivre les suecesseurs de Bichat dans leurs explieations hypothétiques. Dorté d'un esprit précis et pénétrant, sceptique et indépendant, il fut lic: le bonne heure avec Laplace, qui le patronna. Par eette influence il se trouva encore iortifié dans son antipathie innée pour les explications phỵsiologiques dans lesquelles on ne se payait que de mots. l'uis, par une tendance spontance de reaction qui, i cette époque, fut très utile it la physiologic, if s'arrêta à l'expérimentation em. pirique, cest-ì-dire au résultat brut de l'expérience consilléríe en dehors de turte interprétation et de tout raisomnement." 
Bichat, as Claude Bernard has told us, ${ }^{1}$ thus clearly and eloquently found the expression or "formula for the fleeting ideas of his age. All the ideas of his contemporaries regarding life, all their attempts to define it, are, in a way, only the echo and paraphrase of his doctrine." We find it repeated by surgeons like Pelletan, who practised in the Hôtel Dien, and by great naturalists like Cuvier, who founded comparative anatomy. To both of these life was a contest, a struggle, as it is at the end of the century to the Darwinians; but it was a struggle of the living forces against the dead, whereas nowadays it is the struggle of the living for supremacy amongst each other or a process of adaptation to external condi12. tions. Whilst there is this great difference between Vitalism and handeme

these two views characterising respectively the beginning and the end of our century, they have one point in common - they both emphasise the unrest, the continued change, the extreme mobility which distinguishes living matter. But even this distinction has ceased during the course of the century to impress us so much as it did Bichat; since the stability of the solar system proclaimed by Laplace has ceased to charm astronomers, and the dictum of ancient science has been refuted: "materiam cœli esse inalterabilem." 2

1 'La Science Expérimentale,' p. 164 .

2 Claude Bernard (loc. cit., p. 172, \&c.) dwells on this point with great eloquence. "Aujourd'hui l'esprit des astronomes est familiarisé avec l'idée d'une nobilité et d'une évolution continuelle du monde sidéral. Les astres n'ont pas toujours existé, dit M. Faye ; ils ont eu une période de for- mation; ils auront pareillement une période de déclin, suivie d'ume extinction fiuale. . . Les astronomes, avant de connaitre les lois des mouvements des corps célestes, avaient imagiué de ipuis. sances, des forces sidérales, comme les physiologistes reconnaissaient des forces et des puissances vitales. Kepler lui-même admettait un esprit recteur sidéral par l'influence 
After the age of Bichat, and langely through his influence, - i.c., through the cultivation of anatomical researches, - the pentulum swung in the direction of proving more and more the parallelism of organic amel inorganic processes. It reached its maximum swing in that direction about the second thind of the century. Since then it appears to have again returned in the opposite direetion. let us follow this movement somewhat more elosely, and see how the stronghold in which the innermost secret of life is intrencherl hats been attacked from all sides by all the processes and methods of the mechanieal, physical, and chemieal sciences, and how it has prersistently refused to sulrender. There was a time when the leading repre-

kiuguel les planites suivent dans l'espace des courber silvantes sans heurter les astres qui fournissunt l'autres carrièes, sills troubler. l'harmonie réglée par le divin géometre." Another jroperty which was once thought peculiar to aml cliarateristic of living organisms, that of regeneration after mutilistion, of "redinterration," is now known to exist also in lifeless structures: " M. Pasteur a signalé desfaits le cicatrisation, le rédintécration cristalline, qui méritent toute notre attention. . . C'os faits . . se rapplochent complitement de coux quc présentent les itres vivints lorsqu'on leur fait une plaie plus ou noins profomile" (ibid., 1. 17:3).

1 lischoff, in his Éloge of Liebig, who remained all his life a vitalist, suys (p. $5 \bar{\gamma})$ : "We must, incleed, as in the exact sciences, guard against letting a mere word step in as an explanation, wherever our insiglit into the conditioning eauses has been insuthieint, as was indeed rejeaterlly dome formerly, when a word was considered to be a sufli- cient reason. We must eonsider it to be the continual iluty of onganic science to wage, an it were, at constint war against thi- organic force, ancl to dispute its territury wheresoever posible. If, for example, a talent like his suceeels in derlucing many norphologrical traits of tle higher animal organisms from the mechanical conditions of growth in the embryo, \&e., we shall matefully acrept the lnow : lnat we must all the while not forget to ank the further question. by whon these meehanical eonditions have bern brought together. If it be iurther true that the eells of the ambryo perform the most extraordinasy wamlerings, in order to arrange themselves into the vitious: tissues and organs of the animal boxly, we shall welcome this as a very interesting and remarkible phenomenon in the obscure region of revelopment; but we have receivel no light on the question whos acts as guide to the wanlering (a)lls. Similarly, if ehenistry should some day succeed in forming allmunco ar- 
13. sentatives of the medical profession considered it vitalism. unworthy and degrading to treat the human frame as a mechanism, and to approach it by the methods used in other sciences. "For the vitalist physician," says Helmholtz," "the essential part of the vital processes did not depend on natural forces which act according to fixed laws. What these could do appeared of secondary importance, and a study of them hardly worth the trouble. He thought to be face to face with something soul-like," - the anima of Stahl, the vital force of the vitalists,_- "which had to be met by a thinker, a philosopher, a man of spirit. . . . Auscultation and percussion were practised in the hospitals, $^{2}$ but I have heard it said that these were crude

tificially, we shall probably be able to date from that day an entirely new period in natural science, but this artificial production of albumen will never be feasible through the simple affinities of the elements, but only by producing a new arrangement in organic substances already formed by the plant. We shall gratefully receive all such increase of our knowledge: we do not require wonders and belief in miracles for the vital force, but only a name for the effects of which we do not know the causes. . . Neither the ancient primaval ooze nor the moderm Bathybius, neither the remote monads nor the recent monera, neither protoplasm, nor nucleus and cell and their development, confessedly so simple and easily understood up to self-conscious man, give us the smallest clue to the forces at work and their origin. This induces us to ascribe them to a force, regarding the essence of which we indeed know no more than we know of any cause that cannot be further analysed. But we admit in doing so the imperfection of our knowledge, and do not deceive others by suggesting that mechanical science could solve the secret of organised nature."

I 'Tortrïge und Reden,' vol. ii. p. 179 .

2 Chr. Fried. Nasse (1778-1851), since 1822 professor at Bonn, where, together with Walther, Jol. Müller, and others, he cultivated the physiological method in medicine, "was, as it seems, the first German doctor in whose clinical institute physical diagnosis was iutroduced. From 1820 onward percussion was practised; since 1821 the stethoscope was regarded as an indispensable instrument" (Haeser, "Geschichte der Medizin,' 3rd ed., Jena, 1881, p. 912). "The thermometer was first used extensively at the bedside by James Currie (1756-1805). His 'Medical Reports on the effect 
mechanieal devices which a physician with a clear mental vision did not require: moreover, the patient would thereby be degraded and treated as a machine. Feeling of the pulse was the most direct nethod of ascertaining the reactive power of the vital forces, and was delicately praetised as the nost important process. Elderly praetitioners considered comnting with a secondwatch as hardly good taste: taking the temperature was not thought of. As to the eye-mirror, a highly celebrated surgieal colleague told me he would never use the instrument, it being dangerons to throw brilliant light into suffering eyes: another declared the mirror might do well for oculists with poor sight; he himself possessed rery good eyes and did not need it. . . . A celebrated professor of physiology had an argument with his colleagne in physics regarding the inages in the eye. The professor of physies invited him of physiology to come and see the experiment. This was indignantly refused: a physiologist should have nothing to do with experiments, which might do well enough for a physicist."

The first great attack upon the organie system of forces, upon the citadel of life, was made by chemistry, the side of and was led by Laroisier and the great school of chemists which continued his work. It consisted in the application of the theory of eombustion, in which oxygen played such an important part, to the processes of respiration,

of water, cold and wirm, as a remedy in fever and other di-eanes,' London, 1797, "contains olserva. rions on the variations of the body-temperature. . . . liut these atteinpts had little success. Sot till the middle of the nineteenth century was the importance of medical thermometry recognised, tirst througl the clasical wurk of von Birensjrung (1851), then through that of Traube, but mainly through Wunderlich" (ibicl., p. 930). 
nutrition, and the generation of animal heat. ${ }^{1} \quad$ Already in 178:3 Lavoisier and Laplace had presented a memoir to the Paris Academy of Sciences, in which they attributed the generation of animal heat mainly to a process of combustion which took place by the conversion of oxygen into fixed air during the process of respiration. Lavoisier continued his researches on these and other similar physiological processes, such as perspiration, along with Séguin. They presented a joint memoir on the subject in 1790 . It is also known, through the posthumous publication of Lavoisier's scientific papers in 1S62, long after Liebig hal brought out his series of researches on this matter, that the former had entertained very correct views on the economy of organic life as it exists in the balance of the animal and vegetable creations. After Lavoisier, the application of the new science of chemistry to ruestions of the individual and collective life of organisms was extended in a series

i The two great discoreries of oxygen and of the electric eurrent at the close of the eighteenth century were not long in being applied to the reform of medical doctrine. In both instances exaggerated theories were not wanting. Fourcroy, himself a inedical student by profession and one of the most ardent followers and promoters of the new chemistry, who, moreover, edited a journal with the title "La médecine éclairúe par les sciences physiques' (1790-92), found it nevertheless necessary to give warning against the premature introduction into medical teaching of the new ideas of chemistry. Of this many instances existed, both in France and Germany, such as the 'Essai d'un système chimingue de la science de l'homme' (1798), by J. P. T. Baumes of Montpellier, against which Fourcroy aimed his eriticisms in a letter to Humbolclt. On these extravagances see Haeser, 'Geschichte der Medicin,' vol, ii. p. 737, \&c.; also Ior A. Hirsch, 'Gesch. 1. medicin. Wissenschaften in Deutschland' (Miinchen, 1893, p. 567 ). There is no doubt that opposition to this one-sided application of some chemical or physical theory, or of some special therapeutic method, which might be valuable to a limited and restricted degree, jastly accounted for the fact that the more thinking members of the profession clung to the notion of a vital force or principle, as yet undefined but nevertheless existent. 
of very valuable but unconnected researches in all the different countries where elounistry was cultivated. Priestley, in England, hat noticed the purifying ellect of plants on air: De Samssure, in a series of rematkable experiments, carried on in the last years of the eighteenth century at Geneva, estahlished the fact that in sunlight plants increase the quantity of carbon and other constituents in their tissmes. lngenhonsz in Holland and Senebier in France had shown that in the presence of sunlight lubbles of oxygen gas are given off by plants when plunged muler water, and had traced this oxygen to its somee, the carhonic acid in the atmosphere. Sir. Humphry bavy had appliel chemistry to agrieulture: and, much later, German physiologists like Tiedemann and Johannes Miiller hatd recognised the necessity of explaining the processes in the living body ehemieally. All these lahours, however, were detached, and their value was little known. It was therefore a very timely proposal which issued from the British Association in 1839 , that a report on the present state of organic chemistry should be drawn up. For this task no less a person than .Justus Liebig was selected." The erent

1 The sources of information on Liebig"s great work in revolutionising the science of life through his application of organic chemistry to agriculture and physiology are numerous. In parlicular there are two arluesses by logel and von IBischott; delivered in the Munich Aeademy in 1871, Hof omaun's "Faraday" lecture, delivered in the liogal Institution in 1875, unt a very able summary, draw mainly from these sources by $\mathrm{Mr}$ W. A. Shenstone, in C'issell's 'Century sience" Serie. (1895), entitled "Justus von liebig, his Life and Work." Bin. choft"s adciress contains a very full discussion of Liebigr's vitalistic sympathies. His great intluence was established as much hy his special scientific discoveries as by lis method of teaching,--by his early attempts to popularise science anil make it an edueational power through his well-known "Fandian" Letters.' He was ju this respeel a pionrer, as after him Heluholuzand Du Bois-keymond were pioneers in sprenting scientific idlens by mens of popular lectures and addresses. 
marks an epoch equally in the science of organic chemistry proper and in the life-work of Liebig. The necessity of collecting and systematising the scattered labours of chemists and physiologists in this department was simultaneously felt in France, where Liebig's friend and rival, Dumas, published his 'Essai de Statique chimique des Etres organisés' as a conclusion to his course of

Liebig broke through the barriers which in his age separated science in Germany from general culture, and the university professor from the man of the world. From France he learnt the merit of a clear style, and from England the higher art of popularisation. His fame did not grow slowly and surely like that of Helmholtz, spreading almost imperceptibly from narrower into ever wider circles: he took the world by surprise, and stirred up everywhere inquiry, opposition, and controversy. He ventured on great and sweeping generalisations and on daring experiments and prophecies, with the result that in the final establishment of truth his opponents had frequently as great a share as himself. Notable instances are his so-called "mineral theory" of manuring and his theory of fermentation. Through the former the great division which separated the processes in the living from those which obtained in the imanimate (mineral) world was broken down; and through the latter the modern notions of the ubiquity and continuity of life were to a large extent establisher, as will be seen in the sequel of this chapter. The correct notions which he entertained as to the necessity of the mineral ingredients (phosphoric acid, lime, potash, \&c.) in plantmanures, which he started in opposition to the older "humus" or "vegetable mould" theory, was on the point of being refuted by his insistence on making his chemical fertilisers insoluble, ignorant as he then was of the absorbing and retaining function of mould; but, a generation after, the prevailing predilection for soluble manures was again much modified by the introduction of the "Thomas slag," and the enormous improvements in the process of extreme pulverisation. Prof. Togel in his above-mentioned arldress gires many extracts from Liebig's writings, referring to the final and corrected expression of the chemical theory of fertilisation. These are so characteristic of Liebig's habit of thought and his whole mental attitude, that I transcribe them: "When I knew the reason why my fertilisers would not act, I felt like a man who had received a new life, for through this all processes of agriculture were explained, and now that the law is known and lies clearly before our eyes, there remains only the wonder that we did not see it long ago: but the human mind is a queer thing, - what does not fit into the circle of ideas once given, does not exist for it. . . . I had sinned against the wisdom of the Creator, and for this had received merited punishment. I wanted to improve His work, and in my blindness I thought that in the wonderfu] chain of laws which bind life to the surface of the earth, one link was missing which I, a helpless worm, could supply" (loc. cit., p. 34). 
chemistry at the Medical School of I'aris in $18+1$. With him was associated Bonssinganl, the man who, next to Liebig, did most for the elaboration of the true principles of agrieultural chemistry.

To Liebig, organic chenistry did not mean the chemistry of the carbon compounds as it is defined nowarlays, and has largely becone since Jumas himself introduced into science the fruitful method and idea of substitution. This idea extended the facilities of the laboratory chenist enormonsly, but also marks the altered view which has since taken hold of organie chemistry, the alliance with arts and industries rather than with an understanding of the economy and the phenomena of living organisms. From the moment of that alliance dates the division of organie chemistry into the two great branches of the ehemistry of earbon compounds and the chemistry

${ }^{1}$ It is well known that organic chemistry during Liebig's lifetime outgrew the canons and the circle of ideas in which he moved, and that he complained of not heing able to understand the papers in his own periodical, the 'Annaten,' \&c. liebig originally olposed limmas' ideas on substitution, but in the eml admitted himself deferted, when, through Hofmann, he became convinced "that the character of a chemical substance does not ilepend so much as he had supposed on the nature of its constituent atoms, and depends very largely also on the manner in which these atoms are arranged. Some years afterwards, at a dinner given by the French chemists to chemical visitors to the Exhibition of 1867 , Lielig made his defeat on this oecasion the source of a haply retort to Dumas, who had asked him why of late years lie had devoted hinself exclusively to agri. cultural ehemistry. "I have withdrawn from organie chemistry," said Lielsig, "for with the theory of sulstitution as a foundation, the edifice of chemieal seience may le built up by workmen : masters are no longer needed" (Shenstone, 'J. von Liebig,' 1895, p. 61). Alrearly, in 1838, Liebig and Wohler, in their investigation on uric acid and its derivatives, prophetically sugrested the twofold develoument which organic chemistry was destined to take: "From these researches the philosophy of ehemistry must draw the conclusion that the synthesis of all organic compounds which are not organiscd must be looked upon nut merely as probable, lut as certain of ultimate achievement" ('Annalen,' \&c., vol. xxvi. 1. 242). In fact, we have now a ehennistry of organie and one of organised substances.
15. Cliange in orcanic eliemistry. 
of organised nature. From this organic chemistry of the modern school Liebig turned away-continuing to lead research in the older and less fashionable direction. This choice is explained by the peculiarity of his great mind, which, while investigating details, never lost sight of the organic whole of natural processes, and which allowed itself many a flight of imagination into unexplored regions. In fact, if we review the 16. work of Liebig from the side of the history of thought Liebig. of rather than from that of science, we must assign to it a very great and lasting influence. He was probably the first man of science who conceived the twofold meaning which belongs to the words, life and organism, a meaning which was known and appreciated by practical men, but which had, at that time, hardly received scientific recognition. ${ }^{2} \quad$ Life is not only defined, as Bichat put it, by the contrast with cleath; it is just as much defined by the idea of co-operation or solidarity : life is not only the property of individual beings, but also of the collection or society of several individuals in a larger organism. As such, political economy had conceived it long before Liebig's time, but Liebig was probably the first seientific thinker who studied the economy of nature, who fully realised the interdependence of animal and plant life, and tried to reduce this larger life of living things to scientific data and laws. Through him and his school two terms have become current in scientific and popular literature which, especially in the

1 The idea of the dependence of living things on the environment, on the "milieu," was indeed fully recognised and emphasised by
Lamarck (see p. 314 supra) : but the philosophical ideas of that great thinker were then unknown and disregarded. 
(ierman tongue, have characterised the new irleas then introdnced into science, and have bronght them lome to the intelligence of the aducated chasses. These two terns have only heen inalequately rendered ${ }^{1}$ in any other modern language: they are the works "Stoftwechsel" and "Kieistanf tes Lebens." The forner denotes the continual change of matter comecterl with in. weclisel" and threis. latif di:xi maintenance of form in all living things: the latter denotes the continual interchange which exists hetween the separate members and the lifferent provinces of the living ereation, the eirculation of living matter and living processes. Liebig lookert upon natme on the large and on the small seale as an economy, as a homsehold, and he applied himself to stuly the comblitions of its existence, of its nomal and almormal states. Throngh Liebig clemistry entered into cluse alliance with political economy, or, as it is temed almotel, mational economics.

We shall see immerlately how the progress of science has, in the further conses of the century, tenderl to emphasise this twofold aspeet and lefine it more elealy: how the individual organism, the hearer of life, has been traced to smaller and smaller dimensioms ant units, amel how, correspondingly, life as we see it on the larger stalte has more and more revaled itself as consisting in cooperation, in the collective action of societies mate up of individuals. Wre have on the one side the doetrine of the "Autonomy of the Cell," so elounently prochamed by Professor Virehow: on the other site the doctrine of of the Cull."

1 We shall sec farther on huw the worr "Metabolism," with its two subordinate terus" "Anabol- ism" and "Calabulism," is even nure expresive than the German term "strutivechinel." 

"Division of the "Physiological Division of Labour," the happy excal Labour."

pression invented by the great French zoologist, Henri Milne-Edwards.

Whilst Liebig was working at the great problems of the economy of life, and making chemistry subservient to the interests of agriculture, physiology, and pathology, another influence was exerted-mainly in Germany-on the study of the processes which take place in the living organism. This influence had its source in an application of the principles of dynamics and the more modern teachings of physics. ${ }^{1} \quad$ It emanated from two distinct centresfrom Leipzig, where the brothers Weber $^{2}$ tanght how to

${ }^{1}$ In many passages of his interesting and brilliant "Addresses" Du Bois-Reymond has dwelt on the great revolution which came over physiological studies about the middle of the century, characterising it as a special German achieve. ment. Claude Bernard has given us an interesting account of a corresponding, but not identical, change of ideas in the great medical schools of Paris. Quite recently Sir Michael Foster has created in this country an interest in the history of medicine, notably of physiology, and has on various occasions given us masterly summaries of the results of his historical research. I may refer specially to his very lucid and fascinating monograph on Claucle Bernard (London, 1599, in Fisher Unwin's 'Masters of Medicine' Series). Another authority in modern physiology, Prof. M'lien. drick of Glasgow, has treated in a companion volume of Helmlioltz, dwelling mainly on his physiological labours, based upon his brilliant application of physics and mathematics. The two monographs exhibit very clearly two distiuct in. fluences which have been at work in remodelling the science of physiology and the conceptions of the phenomena of life.

? Regarding the position and in. fluence of the three brothers Weber, I may refer to former passages of this history (vol. i. p. 196 ; vol.ii. chap.vi. prossim). The greatest of the three - Ermst Heinrich Weber (1795-1878) -occupies a unique position in the development of the "science of life" in Germany. He seems never to have come under the influence of the then prevalent "philosophy of nature," and he had accordingly, unlike Liebig and Johannes Miller, nothing to unlearn. See on this point Iu Bois-Reymond's Éloge of Mïller in 'Rerlen' (vol. ii. p. 216), also Ludwig's Éloge of Weber (Leipzig, 1878, p. 10). Weber represents in the purest form the influence which physics, based upon experiment and measurement, had upon the development of the study of organic form and function, as Liebig represents in the purest form the influence of chemical research and reasoning. In this respect Liebig was more nearly related to the Paris school, Weber to the Berlin school, which he greatly influenced. 
apply strict experimental research, combined with actual measmements, to physical, orgunic, and psychical phenomena, which had so far esciped all exact treatmont; and from Berlin, where in the person, and still more in the school, of Johannes Miiller, the great and complex phenomenon of life in the higher organisms was analysed into various mechanical and physical processes, each connected with some well-defined organ which was more and more recognised as possessing the properties of a physical apparatus. A great deal of the work of the numerous members of this school consisted in muravelling with the microscope the structure of such organic apparatus, and sturlying its action by physical measurements and experiments. As examples and models of this kind of work we have bu bois-Reymond's 'Tiesearches in Animal Electricity' (1StS), and Helmholtz's 'Physiological Optics' (1867, second edition, much enlarged, 1896), and 'Physiological Acoustics' (186.). In the course of these labours it was fom that the older ideas of "stoftwechsel," and the conception of the circulation of matter as it was taught in the sehool of Liebig, required to be correeted and extenderl. I have referred in an earlier chapter ${ }^{2}$ to the interesting circmustances under which our modem notions of the conservation of energy first dawned independently upon Mayer and Helmholtz whilst studying the phenomena of heat in the animal organism. In the school of Liebig we meet with an occasional attempt to extend the idea of "Stoffwechsel," the exchange of material or of elementary matter in the living body of animals and 
plants, so as to embrace likewise the imponderablesheat, light, electricity, \&c. We find Mohr treating of heat and animal energy as substances which must be counted among the elements or prime materials known to ehemists - just as the French chemists of Lavoisier's school enumerated the imponderable along with the ponderable elements of nature: even Liebig's first edition of the '('hemical Letters' is not quite averse to such an interpretation. The ideas on this matter were, however, vague, and needed lefining. When Mayer attempted a first step in this direction, Liebig did not see the value of it. The subject was only cleared up when Helmholtz, in 1847 , showed that all so-called living forces were the different manifestations of a certain quantity of power to do work-later termed energy - and that this power could show itself in actual change and motion, or be stored up in tensions in the system, later called "potential energy." After this, "Stoffwechsel" appeared not only as an exchange of material, but also as a change in the form of energy, whereby potential or latent energy could be accumulated in the organism and let loose, as the latent power of an explosive substance is let loose by the pulling of a trigger.

One of the immediate consequences of these varied researches - all tending to show how the conception formerly established in chemistry, physies, and dynamics could be utilised in the description of the phenomena of living matter, how the complex phenomenon of life could be split up into a number of separate chemical and physical processes, which could be imitated in 
the laboratory, and how the living mganism could be analysed into a complex of separate apparatus or machines, acting on intelligible mechanical and physical principles-was a rarlical change of the conception of vital force and the vital principle. It eeasenl in the opinion of many to be opposed to other non-living forces, Influesice of doctrine of as it wis with lichat; according to others it wats nonexistent, or at all events useless: others again reelnced it to a purely regulative function, or even a mere idea. A popular philosophy fomded upon the mknown principle of matter, and the equally nuknown and even less clear principle of force, promulgated the notion that seienee had suceeder in banishing all spiritual entities, and was able to explain ererything on purely mechanical principles. Vitalism and animism were at an end; there only remained mechanism and materialism. It is well to note that none of the great men to whon we are inlebted for the real extension of om knowledge of biological phemonena favomed (ז embraced this view. The reasons which kept them from drawing what seemed to some the inevitible consequences of their discoveries were manifold.

As I stated before, there are two ways of approaching the problens of nature, and two interests by which om researches can be gruided. The one is the abstract mathematical methol, which begins with the simplest definable and measmable elementary processes, and tries to imitate the eomplicated phenomena of natme by more and more intrieate combinations of these elenentary processes. The other is the more concrete method inspired by praetical interests. The mechanical, physieal, and 
chemical methods of analysis and synthesis follow the former way, and they generally arrive at satisfactory explanations of isolated parts of the actually existing phenomena, or of special and simple cases. Notably, they create the artificial world of manufactured things, such as instruments, machines, chemical and mechanical compounds. They may at times make it appear as if this process of putting together, continued indefinitely, would ultimately reach the real things which we behold in inorganic, organised, and even in animated nature. At all events no other way, it might seem, is open to science, and the only thing that delays our progress is the bewildering intricacy and complexity of things natural. At the beginning of our century, when, through Laplace and his school, many seemingly complicated phenomena of nature, notably those of physical astronomy, yielded to the processes of analysis just described, there seemed for the moment a possibility of building up a complete philosophy of nature on such a groundwork. Laplace himself indulged in a frequently quoted prophetic vision of this kind. When, in the middle of the century, some molecular phenomena, notably those of light, had likewise yielded to the calculus, and when correcter views as to the nature of forces had further brought another and different world of phenomena into a calculable form, it seemed likely that even the mysterious processes of living organisms might be subjected to similar reasoning. It seemed time to abandon the familiar conception of a special vital force, and to hand over physiological problems likewise to the physicist, the chemist, and the microscopist. A regular 
crusade was accordingly started in Germany by philosophers, as well as hy naturalists and biologists, against the vitalists-those who believed in a special principle of life : and an impression was created in the minds of thinking outsiders that a purely mechanieal explanation of life and mind was finally decided on, and within possible reach. Among those who assisted in bringing about this inpression, I need only single ont two names-those of Du Bois: Hermann Lotze, ${ }^{1}$ the philosopher of Götingen, and of

I The position which lotze occupies in the history of the conceptions of life or of vitalism is peculiar. If we read works dealing speeially with the history of medieine, such as those of Haeser or Hirsch, we do not come across the name of Lotze at all, and it is only in quite recent times, fifty years after the appearance of Lotze's writings dealing with vitalism, that experts in physiology have reverted to his discussion of the subject. See notably the following : 1. Rauber, "Formbildung und Formstiorung in der Entwickelung ron Wirbelthieren" ("Morphol. Jahrbueh,' Band vi.), Isso. '2. Wilhelus Roux, "Einleitung zu den Beitrigen zur Entwickelungsmecluanik des Embryo," 1885 (reprinted in "Gesammelte Abhand. lungen,' vol. ii. p. 11, Leipzig, 1895). 3. O, Hertwig, 'Zeit uncl Streitfragen zur Liologie' (Heft 2, Jena, 1s97), pp. 23-29. 4. Carl Hauptmann, 'Die Metaphysik in der modernen I'hysiologie' (Jena, 1894), p. 3. These and many other reeent references go back to Lotze's article, "Leben und Lebenskraft," in Rurl. Wagner's 'Handwörterbuch der Physiologie,' 1842; and to his larger publications, 'Allgemeine I'athologie und Therapie als meehanische Naturwissensehaften' (Leipzig, 1812), anıl'Allgemeine P'lysi.

VOL. II. ologie des körperlichen Lebens' (Leiprig, 1867). The reasons why lotze's expositions were so little regarled at the time were prob. ably twofold. He tauglit that the phenomena of life constituted a nechanical problem. This was enough to disuriss in the eyes of many empirical naturatists the further, but not easily con. prehended, statement of Lotze that life was not merely a meehanical problem. The definition and solu. tion of the second part of the problem was much more difficult, and Lotze delayed his exposition. on this side of the question for ten years, when he published his 'Meclicinisehe Psychologie oder' Physiologie der Seele' (1852), which container a metaphysieal introcluction apparently little in harmony with the supposed purely mechanical or even materialistic standpoint of his earlier writings. In the meantime several important works had apjeared which earried out in wider or narrower regions the purely mechanieal or inductive and experimental treatment, and quite revolutionised plysiologieal and medieal studies. I need only mention such works as Jacol, Henle's 'Allgemeine Anatomie' (1840), and his 'Hanclbuch der rationellen lathologie" (1546-53). Henle, as ron liulliker 


\section{Du Bois-Reymond, the eminent physiologist of Berlin.} The former owed much of his scientific training to the school of Emst Heinrich Weber in Leipzig, the latter to that of Johannes Miiller in Berlin. Both agreed in denouncing the conception of a vital force - as it was then called-as illogical, and moreover as scientifically useless. But whilst Lotze distinctly stated that his criticisms on this subject were only addressed to scientific thinkers, and promised a further philosophical

says, "correctly saw that the work of Bichat had to be remodelled on the foundations laid by Schleiden and Schwann," an undertaking in which ron Kölliker himself laboured with the greatest success. But above all must be mentioned the appearance of Rud. Virchow's 'Cellular Pathology' (1858, Engl. transl. by Chance, 1860), "in which he himself explains that he does not give a system but a general biological principle," and in so doing lays the foundation for the entire exact treatment of pathological cases. It is, however, well to note that Virchow does not regard life as a purely mechanical problem. The works of such autborities as Henle and Virchow give as much or as little philosophy and riscussion of general principles as physiologists of the exact school required for about thirty years. Those masters, indeed, had themselves grappled with the plilosophical problem, and had arrived at a formulation which sufficed to lead research into fruitful paths for a new generation of experts who themselves were not philosophically educated. The term vital force disappeared, and in the specialist medical literature of a lengthy period even life itself was hardly any longer discussed. Thus a firm basis was laid on which mechanics, physics, and chemistry could be usefully applied. A similar silence as to general problems reigns in the great school which for two centuries built on the principles laid down by Newton in natural philosophy. Similarly in chemistry, the foundations laid by the atomic theory sufficed for the greater portion of the century following its enunciation. We have seen in earlier chapters of this work how, even in these much more firmly established mechanical sciences, our century has witnessed before its end discussions again arising as to fundamental questions and leading principles. A similar fate has come over biological science, and with it a renewed interest in the writings which stand at the entrance of that epoch which was so rich in the unravelling of definite and special problems. Authorities like Prof. 0. Hertwig warn us now of that "other extreme which sees in vital processes nothing but chemico-plyssical and mechanical problems, and thinks it finds the true science of nature only in so far as it is possible to rerluce phenomena to the motions of attracting and repelling atoms, and to submit them to calculation" ('Die Lehre vom Organismus,' an Address, Jena, 1899, p. 8). 
investigation of the question, 1) lo lois-lieymond ${ }^{1}$ ginve the impression, in his earliest deliverance, that the

1 Du bois-lieymumls position in the vitulistic enntrupersy is inter. esting and instructive, inasmuch ats he eonsiblerably moditied his oppinions in course of time. IIis lirst deliverance on the subject is to be found in the preface to his celebrated "Lntersuchungen iiber' 'l'hierische Elektritith' (Alareh 18.15). This thiscussion of the subject followed son after the deliverances of men like liermelius (1639), Sichwann (1s39), sichleiden (1842), Lotze 1412), on tlue same subject, which are stated to lave been "ineffectual." After the litpie of twenty.tour rears bu lois-liegmond appuroneled the subject again in lis celebrated aldress at the fierman Association of Sciences at Leipzig, Is:2, entitled "Yeluer die Grenzen des Naturerkemens." This deliverance rreated a great sensation: the pamphlet appeared in many editions and trasslations, and only in this country lailed to get arlequately noticed. A iurther explanation of the views expounderl in it was given ly the author $(1850)$ in an oration at the meeting held amually in honour of leibniz in the lierlin Aerrleny on the sth of July. It hears the (haracteristic tille "Wie sieben Weltrithsel." These locuments together eontain the author"s "philosophieal ereer," which ends in "Pyrrhonism," ont of which there secus no escales except through "supernaturalistu," which, however, hegins where science ends. (Nee note 1 to the listmentioned address.) All three docunents are reprinted in the two volumes of 'Rerlen' (Leipsie, $1896-87$ ), from which I quote. In the interval of a quarter of a eentury which lity between the trrst and second theliverance great thanges hat come over scientific thought. 'The mechanical view, which hith been put forwarl in an extreme form in 15.4, when it was prophersied that " physiology, giving up its particularistic interest, would disappeatr in the great unitud estate of niatural philusoplyy, mould be entirely dissolved in organic plysics and chemistry" (vol. ii. p. 23), hael lad time and (p) portunity to show its power and jis limits. It hiul gained through grater facility of application (such as Luclwig's antomatic curve. plotting), through the larger conception of "stollwechsel" as denoting "netabolism" of matter and energy. The atuthor limself had introfluced a new definition of lite as a "dynamieal mujlibrium" in the place of older descriptions (vol. ii. 1. 25); and, ahore all, linwin had shown the posibibility of a mechanical explanation of so-called "final causes" in nature. The autlor himself wis one of that great schosh, emanating from Jolumes Miiller, but now represented is the still greater Helmholtz, which had pusthed the mechnuical or exat treatment to its furthest limits. to the analysis of the phenomena of the nervous system in $\mathrm{its}$ higr 1 est activity, those of sensation and perception. It is therefore highly signifieast that. insteal of eonfirming the earlice dictum, that the exact treatment would lialt only at the nost advanced pointviz, the manifestation of "free will,"- the athor is now forced to almit that not only is the "origin" of all motion yuite obscure, but likewise the lowest fortus of animation or conscionsuess are not to be explained mechanienlly; 
question was definitely settled and the road quite clear for research. To those-and they comprised the second class of thinker's referred to above-who were unwilling or unable to follow Lotze and Du BoisReymond into the details of their criticism of the illogical conception of force as employed in the term "vital force," but who looked at the great facts of economy, design, and recurrent order which are exhibited in the living creation, these criticisms had little that was convincing. If the term "vital force" was illogical, some other term such as "vital principle" might be substituted. The enormous difference between the phenomena of living and of dead matter remained and impressed itself on them. Liebig, and many naturalists in France and Germany, had approached the study of nature from the practical side. Their methods were not mathematical but rather experimental, and very frequently not limited to the laboratory and dissecting-room, but carried out in the workshop of nature itself. In spite of his successful attempts to establish clearer views regarding the economic processes of living nature and the application of chemical analysis, Liebig ${ }^{1}$ to the end

the mystery which attaches to all beginnings as well as to the great transitions in the ascending scale of natural phenomena being further emphasised and forcibly driven home in the last-named address, which, as bas been said, bears the title "The Seven Enigmas." The three deliverances of $\mathrm{Du}$ Bois-Reymond, together with the copious notes and references which he gives in the latest reprint, serve as a very good and lucid exposition of the inherent difficulties of the problem, and should be studied by every one who desires to be at home in the ancient and modern literature of the subject. The position of the author has been many times criticised. See, inter aliu, Kaufmann, 'Die Meta. physik in der modernen Biologie' (Jena 1594), pussim.

1 Lord lielvin in his essay "On the Dissipation of Energy" (reprinted in 'Popular Lectures,' \&c., vol. iii. p. 464) has the following interesting note: "The influence of animal or vegetable life on matter is infinitely beyond the range of any scientific 
of his life never satistied himself that the phenomenal of 23. life can be mechanically explained: he remainel, in the vimlism. face of much eriticism, a Vitalist. So clicl Wöhler in Germany-so dicl most of the eninent physiologists in France and in England. The crusade against Vitalism, which was started in Germany, seems to have harl little influence on them. In 1S5t, six years after I)u buislieymond's essay on Vital Force, and twelve year's after that of Lotze, Huxley ${ }^{1}$ could still, in the first of his "Lay semons" "On the edncational valne of the natural history sciences," express opinions on the difference between living and not-living bodies which were distinctly vitalistic, maintaining, much in the same way as Iiebig did in the later elitions of his chemical letter's, that "the phenomena of life are dependent neither on physical nor" on chemical, but on vital forces"; and if, in 1870 , he conlel himself state that he had long since grown out of this view, it is interesting to discover what were the argunents which brought about this remarliable change. I will at once state what seems to me to be the sreat influence which comblated Vitalism in this country, which greatly strengthened the anti-vitalistic or nechanical views in Germany, but which, as little as the mathenatical and philosophical criticism of Lotze and Du hois-heymond, ever took real hold of biological thought

inquiry hitherto entered on. About twenty-tive years ago 1 asked Liebic if he believed that a leaf or it thwer could be formed or coukl grow by chemical forces. He answered, I would more readily believe that a book on chemistry or on hotany could grow out oi deal matter by chemical processes."

1 The uldress referred to was re- printed in 1870 in the well-knwm volume, entitled 'Lay" bermons, Addresses, and leview's, with i "prefatory letter" to Tymlall, in which the tollowing passage wecurs: "The oldest essay wi the whole contains a view of the nature of the ditterences hetween living and not-living hoolies, out of which I have long since grown." 


\section{in France, where a modified kind of vitalism still pre-}

24. vails. ${ }^{1}$ It is the far-reaching influence of the reasoning which sprang out of Darwin's theory of descent.

${ }^{1}$ The older ideas of vital forces have in all the three countries been combated by authorities of the very first order, but, characteristically, in a very different manner - the phenomena of living bodies laving been attacked from different sides. In Germany the mechanico-physical school was for a time the dominant one. In France tlie dominant school was the so-called experimental, also termed the vivisectional, school, founded by Magendie. Between these two extreme positions, both equally opposed to the older vitalism, there stood in the middle, with a less strongly pronounced autagonism to earlier conceptions, thuse who, like Liebig in Germany, Dumas and Boussingault in France, approached the phenomena of life mainly by the methods and reasoning of the new science of chemistry. This school had a profoundly modifying influence on the extremeviews of the experimental school in France. It made itself felt mainly through Claude Bernard. In Germany this influence was felt later, after that of Dar'winism had somewhat subsided. In England it was the doctrine of descent pure and simple which combated the older vitelism: the question beçame one of origins, and vitalism, as such, could be temporarily ignored. The facts of variation, overcrowding, natural selection, and inheritance, presented such a mass of material, waiting to be sifted and arranged by exact methods, that the problem of the essence of life and its beginuings was set aside. Accordingly, the attempts both of Darwin and Huxley to grapple with the central and final problem of vitalism are very few; the latter only repeating what had been said long before him by thinkers of a very different school. The question was not answered, because, for the progress of the sciences and for their successful application in medicine, it did not require to be answered. It became a purely philosophical question, and the only English writer of authority who seriously grappled with it was Mr Herbert Spencer in his 'Principles of Biology.' Darwin in 1863 wrote to Hooker ('Life,' vol. iii. p. 18) : "It is mere rubbish thinking at present of the origin of life; one might as well think of the origin of matter." Huxley, in a letter from the year 1884 ('Life,' vol. ii. p. 67), compares life with a whirlpool, a favourite simile of Cuvier's (see supra, vol. i. p. 129), but is doubtful as to comparing it with a machine. M. Delage names Chevreul ('Considérations générales sur l'analyse organique et ses applications," 1824): "Il a eu le mérite d'écrire que la Force vitale n'explique rien, qu'elle aurait besoin elle-même d'être expliquée avant de prétendre expliquer autre chose, et que les phénomènes de la vie ont leur cause directe dans les principes immédiats constitutifs de la matière organisće. Il n'établit cependant sur cette donnée une théorie de la vie, car il conclut, au contraire, que, eût-on ramené les phénomènes ritaux ì leurs causes prochaines et aux forces qui régissent la matière inorganique, on ne serait pas encore en état de comprendre comment l'être organisé en se reproduisant répète avec une constance si remarquable les caractères de son espèce." Even François Magendie, the great founder of the purely experimental school of physiology, says of Bichat's celebrated 'Recher- 
In order to enable ny readers to comprehend clearly the great change which has come over biological thought through Darwin's writings and reasonings, I nunst now introduce an idea which I have so far intentionally avoided in cliscussing the various scientitic views of nature. This is the idea of final causes, the apparent existence of a purpose (in German Zuvect), or an end (in German Zicl) in all processes of nature, but preeminently in those of the living portion of ereation. In all writings prior to l)arwin a great deal is made of final causes in nature, of the teleology of living processes. The phenomena of life seemed safely intrenched in the citadel of final causes: no mechanism could explain them away. The very fact that organisms were compared with machines, admitted the existence of a definite end and purpose; for it is the peculiarity of every humanly construeted machine or instrument that it serves a definite purpose which, in the mind of the inventor or maker, suggested the peenliar arrangement or organisation which we behold. The criticisms of Lotze ${ }^{1}$

ches,' \&c: : "Les esprits sévères et anis les progrès des seiences... ont regretté que l'auteur opposit sins cesse la vie aux lois physicyues, comme si les êtres vivans n'étitient pas de corps, avant d'étre cles végétaux ou des animaux" ("avertisement" to the Ith ed. of Bichat's 'Reeherches' \&c., 15:2).

1 'The lengthy discussions of Lotze contrined in the writings quoted above are not easy to understand, and it is not surprising thas, beyond the elimination of the eonception of vital iorce as useless to the yurely scientifie student, his real meaning was at the tine not grasped at all. In fact, we may say that Lotze, though ceasing to be a vitalist, remained an animist. I isearding vital foree, he retained the conception of a soul in a manner which drew upon him the ridienle of those whow, like Carl Vogt, he hal convertel to pure materialism. 'This hats hal the consequenee, that in more recent times his whole philosophy hits been stigmatised as dualistic, and that he has lieen accused of having halted halfwity. His real meaning can be gatherel more easily from his later and more mature writings: for lis enntemporaries it must have remained to a great extent enigmatieal. See Kíaui- 


\section{and Du Bois-Reymond ${ }^{1}$ did not do away with this very evident property of living things, but only maintained}

mann ('Die Metaphysik in der Physiologie," 1894, p. 7): "However convincingly Lotze destroyed the conception of a vital force, he had no desire to criticise in a sim. ilarly destructive manner the principle of a soul, though both have grown up in the same climate, in the fertile country where sub. stances blossom, \&c. . . . And although he emphatically, and in many ways, urged that all organism is a deninite form and arrangement of mechanism, he nevertheless accorcled to the principle of inherent disturbances (soul, will) a partial control over the functions of the animal body," \&c. Accordingly this view set only the physiology of plant-life quite free for a purely mechanical treatment, which it received - after the suggestive beginnings made by Schleidenmainly at the liands of Julius Sachs, from whose 'Lectures on Plant Physiology' (1887) Kaufmaun gives the following very characteristic extract: "The organism is only a machine put together out of different parts; . . . in a machine, even if only made by human hands, there lies the result of deepest and most careful thought, and of high intelligence, so far as its structure is concermed," \&c. (p. $623)$.

1 The two great facts which stare every unbiassed student of nature in the widest sense in the face, and which always upset a purely mechanical view, are Purpose and Will. Lotze recognises both, and in all his writings nerer forgets or iguores them. Naturalists, who for the nonce are deeply interested and fully absorbed in the analysis of some definite organ, or some special chemical power in the organism, may usefully ignore these two facts, of which the first only intrudes itself if we rise to a general, a comprehensive aspect; the second is a result of individual experience. Nor did Du BoisReymond ignore these facts. It is interesting to see how he deals with them in his earlier and later writings. In the earlier period he eliminates the problem of free will as not a scientific problem at all, and gets over the question of purpose by a reference to the evident existence of purpose in inanimate nature also, - an idea which really comes ultimately back to an assumption of a general animation of the whole of nature, such as has been maintained by many philosophers and naturalists in very various forms. See, for instance, the further remarks of Julius Sachs in the passage quoted ahove. But there is no doubt that this method of viewing the teleology of nature did not really satisfy Du Bois-Reymond, for in the reprint of his paper on vital force he refer's to it as superficial ('Reden,' vol. ii. p. 26), having in the meantime adopted the explanation of Darwin, whose "highest title to glory" will, "so long as philosophy of nature exists," be this, that he to "some extent allayed the agony of the intellect that pouders over the problems of existence" ('Reden,' vol. i. p. 216). In 1887 he holds that what he wrote as late as 1859 , before the appearance of the "Origin of Species', - for instance his celebrated Éloge of Johannes Miilleris antiquated, though it still gives a valuable picture of the "tormenting confusion of those who could not free themselves from the embarrassing fetters of the fixity of species, the incompleteness of the palieontological records, and, more than all, 
that this end or furpose was attained by furely mechanical processes, that no new foree, called vital force, need be assmmed to exist, that it was the aderuate and sole olject of science to discluse the mechanism ly which the varions ends of life were attained. The very' idea of life, the vitalistie element or factor, was chased away beyond the region of the knowable, and remainen nerely an idea in the reahn of thought, as it was for Jeseartes and Leibniz, and as it has remained, up to reeent times, for von Baer and for Clande Bermard, and for all those who do not accept the 1)awinian explana- Lotze and tion. For Lotze, Du Bois-Reymond, and Clande Fernard ${ }^{1}{ }_{\text {Cende }}^{\text {Cland. }}$

of tinal causes; in one word, of all jne-Darwinian Darwinians" (vol. ii. 1. 299).

'Du Bois-Reymond ('Rerlen,' rol. ii. 1. 557 ) claims that the greater part of the progress in modem physi. ology belougs to Germany, in spite of the great talent and originality of Claude Bernard. He thus describes the different position of the three countries: "One branch of physiology especially emanated from Germany - general physics of muscle and uerves. Whereas in England experimental physiology lay fallow, while it moved in france in vivisection and zoochemistry, being helil down in both eountries by vitalism, German science was the first to advance to the inrestigation of the surviving organs, especially of the frog, looking upon them as apparatus built up by nature, extremely complicated, yet conceivably only machines." This was spoken in 1890 . since that tine a certain change has come over physiological reasoning, notably even in the very centre of the physieo-chemical sehool at Lerlin. In 1599 l'rof. O. Hertwig warns us of the othel extreme, opposerl to the olcler vitilism, "which would learl us to a one. sided and equally inadequate conception of the rital process... whieh would see in it merely a chemico-physical and nechanical moblem, and would recognise the genuine seience of nature only so far as it is possible to reduce phenomena to motions, . . and to subject them to mathematical calculation" ("Die Lehre vom ()rganismus, an Aclilress, Jena, 1. 8). How far Du Bois-Reymond in later years modified his earlier notions, we cau to solne extent see from his published arldresses. Wie know that the French sehool, witl Claude Bernard as its nost illustrious representative, never iell into the mistake of looking at the living organism as a physico-ehemi. cal machine, and we may be inclined to attribute this to a large extent to those experiments on the living orgauism which were first instituted by Magendie, which, under the hands of Claude Beruard, lecl to the dixcovery of the action oi the pancreatic juice, of the glyeogenic iunction of the liver, of varo-motor nerves, and of the ellects of poisons: 
purpose exists in nature, notably in living nature; it is its very characteristic, its definition-the very "quid proprium " of life, ${ }^{1}$ but it is useless as a scientific conception. It remains a problem for the philosopher, but the

all of them epoch-making discoveries which revolutionised physiological science, and which it is difficult to conceive of as having been made without vivisectional methork. We have also a remark from the pen of the late Prof. Georg Wiedewann, that Helmholtz himself, that greatest master in the line of mechanico-physical reasoning on the processes and organs of the higher senses and the nervous system, foresaw the necessity of resorting for further progress to vivisectional research, to which he had a personal dislike. (See Wiedemann's Introduction to the thiri volume of Helmholtz's 'Wissenschaftliche Abhandlungen,' p. xxiv.)

I In many passages of his later writings Claude Bernard has dealt with the definition of life : most fully in the posthumously published volume entitled 'La Science Expérimentale' (3rd ed., 1890). $\mathrm{He}$ there arrives at the final statements (p. 207): "Je pense, quant à moi ... que les phénomènes chimiques dans l'organisme sont exécutés par des agents on des procédés spéciaux; mais cela ne change rien à la nature purement chimique des phénomènes, \&c. .. I Ies agents des phénomènes chimiques dans les corps vivants ne se bornent pas ì produire des synthèses chimiques, . . . mais ils les organisent. . . Parmi ces agents ... le plus pnissant et le plus merveilleux est sans contredit l'cuf, la cellule primordiale qui contient le germe, principe organisateur de tout le corps. Nous n'assistons pas à la création de l'ouf ex nitilo, il vient des parents, et l'origine de sa virtualité évolutive nous est cachée. . . . Il y a comme un dessin vital qui trace le plan de chaque être et de chaque organe; . . . ils semblent dirigés par quelque condition invisible dans la route qu'ils suivent, dans l'ordre qui les enchaîne. ... C'est cette puissance ou propriété évolutive que nous nous bornons à énoncer ici qui seule constituerait le quid proprium de la vie, car il est clair que cette propriété évolutive de l'œuf, qui produira un mammifère, un oiseau ou un poisson, n'est ni de la physique, ni de la chimie... En disant que la vie est l'idée directrice ou la force évolutive de l'être, nous exprimons simplement l'idée d'une unité dāns la succession de tous les changements morphologiques et chimiques accomplis par le germe depuis l'origine jusqu'it la fin de la vie. . . . La force métaphysique évolutive par laquelle nous pouvons caractériser la vie est inutile à la science, parce qu'étant en dehors des forces physiques elle ne peut exercer aucune influence sur elles. Il faut donc ici séparer le monde métaphysique du monde physique phénoménal qui lui sert de base mais qui n'a rien à lui emprunter. Leibniz a exprimé cette délimitation dans les paroles: 'Le corps se développe mécaniquement, et les lois mécaniques ne sont jamais violées dans les mouvements naturels; tout se fait dans les âmes comme s'il n'y avait pas de corps, et tout se fait dans le corps, comme s'il n'y avait pas d'âmes.' . . . Nous dirons avec Descartes: on pense metaphysiquement mais on vit et on agit pleysiquement." 
naturalist may neglect it, or at best can only use it as an "heuristie" help, as an indication where to look for the special mechanical contrivances which he is trying $\omega^{\prime}$ unravel. It seems to me that the position which such thinkers take up towards the objects or indivicluals of living nature is similar to that of a mathematical student who elearly comprehends the solution of an algelmaical problen, but who himself would be mable to find it. He may all his life remain in this attitude withont being ahle to find any solution himself: he has got eomplete hold of the mechanism, but not of the idea, of mathematical reasoning. The student of nature could thus hope eventually to understand the mechanisn of life, but the idlea is beyond his comprehension. This can be expressed ly saying: the mechamism of life is ultimately comprehensible, though highly intricate; the ilea of life is transeendental, incomprehensible. let us not troulsle ourselves about the manner in which life first originater, but let us study the mechanical proeesses by which it is maintained, by which its various ends are aceomplisherl. Let us study the mechanism of the clock, though this may not tell us the story of its maker nor the process of its manufacture. Those who cling to the conception of a vital force or principle wonld probably not even acluit as much as this. It is coubtful whether Liebiy to the end, whether Huxley in his earlier period, and I) lois-lieymond in his later writings, would have admitted even this position.

We are now prepared to understand the novel position which the Darwinian conception of natural processes introduced so far as the teleology of matme is concerned, 
- how it dealt with final causes, with the apparent existence of a purpose, an end in the processes of nature, notably of the living organism.

It must here be remembered that the question how living things come to exhibit traces of design and purpose has really nothing to do with the nature and processes of life: it is not necessarily a biological question. Every machine shows the same marks of design, but is not therefore alive. The influence of Darwin's principle of natural selection, of overerowding and consequent struggle for existence and survival of the fittest specimens, has therefore not been in the direction of explaining any of the vital processes which are at work in the individual organism. It is at best merely a statistical relation, a peculiar phenomenon oceurring only in a large or congested group of living and self-multiplying beings: it presupposes the facts of reproduction, heredity, and variation; it does not explain them. Hence I dealt with Darwin's ideas in the last chapter, and did not introduce them under the present heading of Biological Thought. As we shall see later on, Darwin did recognise the necessity of attempting also a biological explanation.

The possibility of explaining the marks of design as merely apparent depends on the conception of the genetic process acting on a large, a gigantic scale: individual things put forth ever new developments by which they eventually overtop their neighbours, ultimately advancing to such a degree of excellence and individual perfection that to an outside beholder the few surviring specimens give the impression of having been origin- 
ally designed. In fact, they only exist becanse thos: numberless individuals which eouhl not grow in a sutticient degree perished in the struggle. Only those indivilual specimens survived in whom, in one or a few directions, something specially excellent was producert at the expense of development in other directions. In the nass, the crowd are sacrificed-ir, antomatieally erusherl, in favour of the few: in the individual, one special growth is antomatically pusued at the expense of a general but less encluing-i.r, self-assertive-development. The end - the seeming propose-is producerl in the process of production, it being nerely sonething more enduring - i.t., something better. It conveys the impression to an ontside beholder of having been consciously set at the term of the process of development; in reality it was promeel simmlameonsly. The momntain peak which towers above its neighbours, and grives a distinetive romding off and finish to a landscape, may be concerved as haring been built up ly the selective action of the natural artist who brought together the lest materials and placed them in their most enduring positions: in reality it owes its existence only to one ont of the numberless throes of natme which happened to take place with stronger materials and in more stable forms of arrangenent and gromping, or it is lue to the denudition of the strata surrounding it. The end and purpose of any natural development is that which it ean itself "xatural result automatically produce and endow with nost distinctive against and endming characters, for this only survives at the expense of weaker productions: there is a natmal result in development, but there need not he a purpose. The 
contemplation of the result may permit us to trace backward the process by which it was brought about; but we are not warranted in assuming that it existed independently, like the plan of a building or the purpose of an instrument. In the place of a growth according to a prearranged plan, Darwin put the conception of an automatic adjustment called "natural selection"; in the place of a conscious end or purpose he put the conception of a mere result, a product, the "surviving fittest." I

The development and proof of Darwin's ideas gave a new impetus to biological research, as it did also to the science of the history and economy of nature. The fact that the phenomenon of selection, or rather of automatic crowding out, presupposes intimate relations and contact of every living thing with numberless other similar and dissmilar beings, led naturalists into the open air, to

1 A very full appreciation of the great ehange that has come over the sciences of nature through the influence of Darwin will be foumd in the various writings and addresses of l'rof. Haeckel, notably in his address to the German Assoeiation in 1877 at Inuieh, "Ueber" Entwiekelungslehre" (reprinted in 'Gesammelte populäre Vortrige,' vol. ii. p. 97). A more eritical examination, referring specially to the central biologieal problem, is the address by lou Bois-Reymond, delivered in 1876 in the Berhin Acaremy, and reprinted in 'Rerlen,' rol. i. 1. 211 , with valuable literary notes. He there discusses how tar the principle of natural selection, in addition to the general doctrine of descent, has been adopted or opposed, and refers to the outstanding difficulties. "One of the greatest difficulties," he rays (1.226), "presents itself in physiology in the so-called regenerative power, andwhat is allied to it - the natural fower of healing: this may now be seen in the healing of wounds, in the delimitation and compensation of norbid processes, or, at the farthest end of the series, in the re-foruation of an eutire fres.l. water polyp out of one of the two halves into which it harl been divided. This artifice could surely not have been learnt by natural selection, and here it appears impossible to aroid the assumption of formative laws acting for a purpuse. They do not becoure more intelligible by the fact that the regeneration of mutilated crystals, observed by l'asteur and others, points to similar processes in inanimate nature. Also the ability of organisms to prerfect themselves by exereise has not found sufticient appreciation with regard to natural selection." 
ontroor research, into the arena of real life. On this I dwelt in the last chapter. Ideas of a cognate kind had alrealy emanated from other schools, such as that of liebig,-- the circulation of life in the different provinces of nature, the interdependence of different species of living things. Isolated investigations, like those of Gïrtner and Sprengel, of Huber and Lubbuck, on insect life, or of baeteriologists like Pistem and boussinganlt on fermentation and fertilisation, received a fitting place as important chapters in the economics of nature. The problem of life becane twofold - the life of the eomOr.ranisation and individ. munity and the life of the individnal: organisation and indiviluation. T'wo great questions presenter thenselves: What is an indivichal? what is a socicty of individuals? l'hysiologists were from of old acenstomed to ask the former; eeonomists like Ronssean and Adam Smith had asked the latter question. both now becane questions for the biologist. Physiology and economies joinerl hands. In isolated instances, as in those of Lieling and von Baer, these two interests had aheady been united. The real meaning and reason of this mion now becane clear to every one: it revealed itself as fomnded on the two characteristic features of life-individuality and cooperation. With the exception of the strong emphasis put hy Liebig on the latter sicle of natural, notably Biology and organic processes, biologists hefore I arwin had mainly studied the phenomena of individual life. In two special directions-in embryolugy and in the cellular theorythey had made great progress. I have alrealy treated of these advances in their bearing upon morphology, the study of forms, and unom genesis, the study of ehange 
and development. Let us see how they affected biology proper-the study of life.

The early propounders of the cellular theory were evidently much influenced by the then existing theories which explained the constitution of inorganic chemical substances by atoms and by the processes of crystallisation. The progress of science, however, was in the direction of showing more and more that these borrowed conceptions are quite inadequate. Reasoning or thinking on organised matter is quite different from that which refers to unorganised substance. Chemists and physicists deal with atoms as imaginary units, which form the ideal groundwork for constant arithmetical proportions or for the action of calculable mechanical forces measured by observable movements. Biologists, whether dealing with plants or animals, approach the cells which they regard as the units of living matter with the microscope-an instrument which, till quite recently, has only been sparingly used in chemical research. The units of the chemist far transcend our powers of vision; the units of the biologist are to some extent accessible to our senses. All organisms have been found to be analysable by the aid of the microscope into similar morphological constituents called cells, which present very similar forms and functions. This has had the advantage of permitting the phenomena of life to be analysed into a few fundamental processes common to all living things; the great diversity of the larger organisms, and the more conspicuous phenomena of life, being conceived as put together in various ways out of these elementary units, which exhibit in varying degrees 
of intensity the living processes common to all. Just so a state or human society is madr up of a large number of individuals, all having the sinne human nature, who earry on the different functions peculiar to each with varying degrees of efticiency. The conception of the cell as the unit or typer of all living the cellutar tion of the eell as the unit or type of all living theory. matter, and the further discovery that there exist unicellular beings whieh are not essentially different from the constituent living elements of the most eomplicated organisms, has brought physiological researeh to a focus. The diflieulties in the study of biological phenomena have vanished as those of the organie chemist did on the introduction of the eonception of valeney, of the saturating powers of chemieal substances. Accordingly, if we compare a text-book of these subjeets written in the middle of the eentury with one belonging to the latter part of it, we find an enormous difference of treatment. It is instructive to contrast the introduction given in Johamnes Miiller's 'Elements of l'hysiology' and that of Professor Michael Foster's 'Text-book.' The former represents the nost adraneed knowledge obtainable at the end of the thirties-the latter that of a generation later. The former contains a lengthy introduction on general physiology-the latter a short one on the physiological properties of a living amoba, ${ }^{1}$ a

I Already, in 1835 , k. k. von Baer pointed out how tlse study of one small animal can revolution. ise our entire reasoning. "Ninety" years ago a naturalist diseovers the hyxlropolyp, an insignificant slimy animal, not larger than a peppereorn, and how, without heal, sense-organs, muscles, nerves, blood, and sexual organs it never-

VOI. II. theless is nourisherl, grows, feels, noves, and multiplies,-how it can even be diviled, each part formiug a whole: he obrerves it with much wonder for nine years with untiring perseverance. It that time many would, no doubt, emssider such an ocempation childish and unworlhy, yet these diligent observations have slowly but ma- 
unicellular organism which is taken as a type, a model of all the phenomena of life. The former consists of philosophical and abstract generalisations, gathered from many sources; it treats of life in general, of the vital force, of the difference between animal and plant life, Sc.: the latter sums up the whole matter of the treatise uncler a few heads, taken from the life of the simplest living thing. The generalisation has become an actual observable example. This transition from the abstract to the concrete, from the idea to the thing itself, is owing mainly to those definite conceptions which in Miiller's time were being slowly elaborated : these were the cellular theory, the larger conception of "Stoffwechsel" as contained in the term "metabolism," and the conception of "differentiation of tissue" connected with division of labour. The two former are already very clearly foreshadowed in Theodor Schwann's microscopical researches; the latter takes us back to K. E. von Baer's embryological researches, to which the Darwinian idea of a struggle for existence, and the consequent tendency to one-sided development of form and function, have given an additional importance. Of the first and third of these definite modern conceptions I have treated above. The cell is the morphological unit of living matter. The process of differentiation was recognised

terially influenced physiology, the basis of mediciue, and lience also the latter; and it is incalculable what many of those here present have gained through such intluence in days of sickness or may still gain. Whoever carefully studies the derelopment of physiology, will be convinced that it is mainly Trembly's observations of the hydro- polyp that have changed the former aspect of things, and that the transformation of the general views of life has altered the theory of sensation, circulation, \&c., very materially, and is still active" ("Blicke auf die Entwickelung der Wissenschaft," an address, reprinted in 'Reden,' vol. i. p. 109). 
in the exanination of deal emliryos in varions stages of development, and the idea of the division of labour is one flowing from the premises of the Darwinian theory-the facts of variability and overcrowling. 'The second conception, that of "metabolism," touches inmediately upon the processes of life, and demands special treatment in the jresent chapter which deals with liological Thonght.

The conception of a contimnous exchange or cirenlation of matter and of energy in every living organism, and the study of this elementary typical form of the living process in the morphological muit of all living organisms, in the cell, seens to have originated with Theodor schwann," and is laid down in his 'Microscopical liesearches,' pullished in $18: 39$. (1) it is lased Schwain the whole simplification and mification of biological thought which distinguishes the second from the first half of our century. The study of the cell - its

1 on the change which came over general physiulogy about 1510 , and the part he himselt playerl, Theodor Śchwann has expressed himself in a letter addresserl to Du Buis-Reymond, which is given in the notes to the latter's liloge of Miiller, reprinted in the secomil volume of his 'Reden,' 1']' 113-334. It forms one of the most im. portant historieid doeunents. The libge itself should be read together with Claude liernard's "liaplort," Sc., mentioned above ( $[$. 351 n.), which gives the history of the great change from a more exclusively French point of view. In the letter nentioned above, from which also the quotations given in the text are taken, Seluwam chaims that the first instance in which an "evidently vital plienomenon was submitted to mathematical, numerical" rule, was his measurement of the carying power of a muscle in relation to its con. traction in 1836. The purely physieal view of vital phenornena cxhibited in this example was not arlopted by Miiller. nor yet the "Iuickly following genera] principle of the cellubar theory. Sichwamn refers to the thircl section of his 'Mieruscopical Researches,' in which he discarls "vitalism," but aclmits in man ("on acemont of his freerlum") an immaterial prin(ij)le, and elaims that this assmup)iion divicles him distinctly from the malerialists. 
formation, growth, division, and maintenance of form amidst change of matter and alternation of functionconstitutes the "prolegomena" of physiology, and a comparison of Prof. O. Hertwig's recent publication on the "cell" with the introduction to Johannes Miiller's 'Physiology' marks well the change of ideas which half a century has produced. And we must so much the more admire the clear anticipation of Schwann, as he was not in possession of the full conception of energy in its two interchangeable forms of kinetic and potential energy, which was developed in the course of the two decades following his publication. Schwann not only conceived the cell to be the morphological unit of all living matter, but he also saw that "cell formation must be the general principle of organic development, and that there can be only one such principle." In the third section of his 'Microscopical Researches' he founds on this "his theory of organisms, and rejects distinctly therein all teleological explanations based upon a vital force acting according to final purposes." $\mathrm{He}$ thus showed "that the only essential property of all living matter-viz., growth - is not inaccessible to a physical explanation," and he did this at a time "when Liebig had not yet taught physiologists the chemical changes which take place in living tissues." These ideas were only partially adopted by Johannes Miiller and other leading physiologists of the day. Schwann's view could only be consistently elaborated in proportion as to the older conception of a "Stoffwechsel" (a chemical process) there was added that of a "Kraft"- or 
Energie-wechsel" 1 (a physical process). had to be supplemented by bio-physics. anticipation of the correcter and fuller view, Schwann introdnced the Greek term "metabole." It is the merit of Prof. Michael Foster to have domiciled this useful and all-comprising technical term in English physiological

1 Du Buis-Reymond ('Reden,' vol. ii. p. 220) mentions this as the third injortant gain which phys. iological science latd to register since the appearance of Miller's book: the first and second being the cellular theory and the mechanico-plysical method, both largely owing to Sehwann. This was written just before the great influence of Darwin began to be felt. In the ideas introduced by Heluhloltz, which clarified the eon. cepition of force, he sees the "key which opens a eumprehension of the 'Stotfwech-el' in plants and animals." The term "stotfweehsel," also "Stoffumsatz," or simply "Cmsatz," has beeu quite familiar in German physiolngieal literature luring the whole of tlye century. I eaunot find any generally aecepted term in English literature before the introduction of Sclıwann's term "metabolie plienomena," which, I believe, was first adopterl by Sir M. Foster, and is now quite domiciled in English text-busis and translations. The passage in Schwann's 'Vicroseop. ical Researches' is as follows ('Sylenham Society's Translation,' p. 193): "The phenomena attend. jug the formation of eells may be arranged in two natural groups: first, those which relate to the combination of the moleeules to form a cell, aml whieh may be denominated the plastic phenom. ena of the cells; secondly, those which result from chemical changes, either in the compronent particles of the cell itself or in the surrounding cytoblastema, and which may be called metubolic plienomena

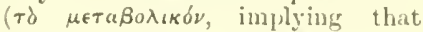
which is liable to occasion or to suffer chamge)." It will be seen later on that the term metabolism is a peculiarly hapuy one, is it lends itself by a slight ehange in the prefix to denote the twofold unocess of building up and of running or falling down, which eon. stitutes the changes peculiar to protoplasm as the coustituent element of all organised sulustance. It is, aceorlingly, somewhat surprising that the term has found so little favour abroad. In France, where this twofold movement has long ago been recognised as one of the eharacters of the living process, the terms "composition et déconuposition" (de Blainville), "organisation et désorginnisation" (Clatude liernarl), "assimilation et désassimilation," have been variously adopted (nee Claurle Beruari, 'Phérsomènes de lin vie,' vol. i. p. 36, \&e.) I. I'ves Delage ('L 'Hérédité," 1. 53) says : "Les Anglais ont substitué ì ces expressions si signifieatives: nutrition, assimilation, désassimilation, une terminologie qui a dû leur paraitre bien belle, car ils l'ont tous arloptée avee un empressement remarouable ; e'est celle de métabolisme," \&c. 
literature, to have placed it at the entrance of his textbook of physiology, and thus to have given the student a somewhat more detailed description of the elementary functions of living matter than was afforded by the older term "vortex," employed by Cuvier.

33. "Metabol. ism."

These merits of Schwann, which attach more to the conception of "metabolism" than to that of the cell, are not reduced by our having to state that the latter conception has been entirely changed since his time. The cell of to-day is not the cell as Schwann conceived it. Of the pretty clearly defined structure or organisation of that biologist, with its wall (membrane), its kernel (nucleus), and its fluid contents (cell sap), nothing has remained but the cell contents, termed protoplasm by von Mohl; and the living process can no longer be considered as the function of a well-defined organ or machine. It is rather the fundamental property of an almost homogeneous substance, the mass of protoplasm, in which the kernel is the only recognisable differentiated portion. The immediate effect of this clestructive analysis of the early conception of the cell was to destroy the idea that the living processes carried on in any special cell or organ are a result of its organisation, as the function of an apparatus is dependent upon the arrangement and combination of its parts. It has promoted the view that - for our understanding at leastthe first thing to learn is the nature of the processes themselves. We have to look upon the visible structure of special cells and organs merely as "mechanical contrivances, serving only to modify in special ways the results of the exercise of these fundamental activities, 
and in no sense determining their initial rlevelupment." 1

It seems, then, that we can late lack to Schwimm's 'Researches' the origin of two distinct comses of 'Thomuth which in the second half of our century obtain in biologieal seience. The first we nay call the norphological or structural school of hirology. It is liased on the theory of the cell or some modified eonception, and attempts to explain the fundamental processes which go on in living organisms from the strueture of the elementary parts. Is the most minute particles of

1 See sir Michael Foster's excel. lent article on "Generall'hysiology" in the 19 th vol. of the 'Lucy. brit.,' 9 th ed., p. 12. In this eomnection a pasage from an early review of Huxley"s, "On the Cell Theory," has been frequently quotel, according to which cells may be "ni) inore the prolucers of the vital phenomena than the shell. seattered in orlerty lines almong the sea beach are the instruments by which the gravitative force of the moon acts upon the scean. Like these the cells mark only where the vital tides have heen and how they have atcterl" (1858, in the "Brit. and lor. Med. Chirurg. heriew, reprinter in the first volume of 'Sicientific Mensuirs, p. 27\%. Aceording to this view, which has been further developed in more recent times, the cells would be "imlieations," not instruments, of the vital phenomena, which "are not necessarily precelled by organisation, nor are in any way the result or etlect of formed parts, the faculty of manifesting them residing in the matter of which living hodies are composerl, as such-or, to use the lauguage of the day, the 'vital forces' are molecular' forces." It is interesting to yuote together with this passage from Huxley, what was sail forty years later by an (mment living jhysio. logist, l'rof. Max Verworn of Jena : "The fact has heen ontalblisherl that a tuntamental eontrist between living orranisms ancl inorganic bulies does not exist. In rontradi-tinction to all imsronic nature, however, ofganinns are chatacter. ised solely by the prisession of certain highly complex chemical compunds, especially poteids" ("General l'hysiology, transl. by F. s. Lee, 1s99, 1) 126). "We can summarise our consirlerations and grive simple expression to the problem of all pliy -islogr. The life. proress consists in the metuluolism of proteils. It this be true. all physiological research is an experiment in this field: it emmsists in following the metabulism of provesils in to its details, and recognising the virious vital plemenena as an ex. pres-ion of this netabolism which must result from it with the same inevitable necessity as the phomo. mena of inorganic mature result from the ehemical and physical chauges of inorganic bodie's" (ibill, 1. 136). 
living matter, revealed by the most powerful microscope aided by all the elaborate processes of staining, still appear to be endowed with the fundamental properties of life, such as irritability, contractility, and metabolism, i.e., change in form and chemical constitution, the object of this line of research, viz., the investigation of the initial structure of the elements of living matter, can only be reached by indirect means or by conjectmre. Structural chemistry and stereo-chemistry proceed by similar methods of investigation, and have succeeded by means of the atomic, molecular, and kinetic theories of matter in bringing order and unity into a very large portion of our knowledge of chemical combinations. The morphological or structural biologist pictures to himself very much more complicated arrangements of molecules than the carbon tetrahedron of van 't Hoff or the benzine ring of Kekulé, yet formed on similar principles; and by continuing in his mind these combinations which, as they become more complex, also become more unstable, he arrives ultimately at a very complex and continually changing chemical structure, which he imagines might be the begimning of the living process, the element of organisation. This conception, so far as I can find, was first introduced into biological literature by Herbert Spencer. He has termed this element of living matter "the physiological mit." The conception has been varied in endless ways by many subsequent biologists, all of whom have invented special names for these elementary units of life out of which they hope to put together the many observable protoplasmic and cellular tissues of the plant and animal 
organism as Haiiy attempted to build up erystals ont of his "molécules intégrantes." The most elaborate analysis of this conception is put forward in the 'Micellat 'Theory' of the celebrated hotanist Niigeli, which in Ciemany has found farour with many eminent hiolngists as a provisional progranme of the various problems involved. It is clear that the conception of the physiologieal unit opens out two distinct lines of research. We can approach it on the one side hy artificially prolucing in the chenieal laboratory more and more of those chemically stable compounds which we find in the living organism. After Wöhler had produced urea artificially in 18.8 , the number of Synthesis of organic these artificial syntheses greatly increased, and we are specially indebted to MI. Berthelot for having shown how all the simpler chenical compounds contained in the organism ean be put together by inorganic processes. Some of the more complex substances have likewise subsequently yielded to this synthetic method. "It is possible," we are told, "that after a time our knowledge of chemistry may have advanced suffieiently to enable us to produce albuminous bodies artificially by synthesis." " We are aheady able artificially to build u', atom for atom, out of their elements a series of organic compounds, some of a very complicaterl character. We no longer doubt that all the rest, even the most complex, will be thus produced; it is only a question of time." lint the ways in which the

16.

1 See 0. Hertwig, 'The Ceil,' I.

2 See G. Hunge, 'Physiological
Chemistry,' transl. by Woullyidge, p. 313. 


\section{chemist puts together these substances in the laboratory} are rarely the methods adopted by nature in the living organism, and in many cases the product itself, though apparently the same, is yet essentially different. ${ }^{1}$

1 This touches on a rery important point, which is much emphasised in all the best modern treatises on the subject. Claude Beruard in all his writings insisted on the fundamental difference between the processes going on in the organism and those that go on in the laboratory of the organic chemist, though the two produce frequently the same apparent result. "Si les forces que l'être vivant met en jeu dans ses manifestations vitales ne lui appartiennent pas et rentrent toutes dans les lois ile la physicoclimie générale, les instruments et les procédés à l'aide rlesquels il les fait apparaître lui sont certainement spéciaux. En effet, l'organisme manifeste ses phénomènes physicochimiques ou mécaniques à l'aicle des éléments histologiques cellulaires, épithéliaux, musculaires, nerveux, \&c. Il emploie donc de procérlés, éest-ì-dire des outils organiques qui n'appartiennent qu'ì lui. C'est pourquoi le climiste, qui peut refaire, dans son laboratoire, les prorluits de la nature vivante, ne saurait jamais imiter ses procédés, parce qui il ne peut pas créer les instruments organiques élémentaires qui les exécutent. Cela revient it dire que tous les appareils des êtres organisés ont une morphologie qui leur est propre" ('Rapport,' \&c., 1567 , p. 135). Quite recently Bunge (loc. cit., p. 313) has said, "All our artificial syntheses can only be achieved by the application of forces and agents which can never play a part in vital processes, such as extreme pressure, high temperature, concentrated mineral acids, free chlorine-factors which are immediately fatal to the living cell. ... It follows that the animal body has command of ways and means of a totally different character, by which the same object is gained." A very interesting speculation, referring specially to this point, was put forward by the eminent physiologist, Prof. E. Pfliger of Bonn, in the year 1875 . lt is fully discussed in Terworn's frequently quoted work on General Pliysiology (pp. 304, 311, 482). The theory is based upon the semarkable part which the compound radicle cyanogen seems to play in the organism. Pfluger start from the fundamental characteristics of the substance called proteid, with which life is inseparably connected. Proteid is known to exist in a stable form in food-stuffs. for instance in egg albumen. But this is not the same as the proteid contained in living matter. In the latter it is not stable, but is being continually decomposed. The decomposition was found to be due to the oxygen that occurs in the living proteid molecule. This oxygen, which is intramolecular, being continually received from outsile by respiration, transforms the more stable molecule into an unstable labile molecule. In further following the clue afforded by this property, and comparing the decomposition products of living proteid with those obtained by artificial oxidation of read proteid, Pflitger is led to the conclusion that the presence of the radicle cyanogen in the living proteid will explain the difference. "In the formation of cell-substance-i.e., of living proteid -out of food proteid, a change of the latter takes place, the atoms of 
Another way of inquiry is to analyse the existing organic tissues still further ly mieroscopic and chentical methods, in orter to find out how they are brilt up. As the result of such inquiries we have a framewrork theory of protoplasm, a foam theory, a filanrent theory, a granular theory: and the attempt has been mate to define living protoplasm as a colony of still smaller structural units termed "bioblasts." liy this twofold method-by synthesis and by analysis - the hiologist nay attempt to approach the physiological unit, the seat and stronghold of the rital process. ${ }^{1}$

nitrogen entering into a cyanogenlike relation with the atoms of carbon, mobably with the absorption of considerable heat." Cyanogen being a raticle possesing a great quantity of internal enerry, the arlelition of it to the livine molecule "introduces into the living matter energetic internal motion." The interest which attaches to the theory lies in this, that it allows uto furm some conception how living matter origrinater. This problem is idontified with the problem, How does cyanogen arise! This we know is formed at an incandescent heat. AAceorlingly, nothing is clearer than the posilibility of the formation of cyanogen compounch when the earth was wholly or par. tially in a tiery or heated state. . . . If, now, we eomsicler the immeasurably long time during which the cooling of the earth's surface dragged slowly along, eyanogen, and the compounds that contain cyanogen and hydrocarbon substimees, hat time and ofportun. ity to indulge extenvively their great temleney towarls transior. mation,. . . and to pasis over, with the aid of oxygen, and later of water aud salts, into that selflestructive jroteis, living matter.
The tirst proteid to arise was living matter, embowed in all its raclicles with the prolerty of vigorously attracting sinilar constituents, arlding them ehemically to its molecule, aml thus growing mel infinitum." This theory is interesting, as it is, so far as $1 \mathrm{know}$, the only attempt to reconeile the exintence of living untter with the fact of the high temperature which once existert on the earth.

I A lescription of these several theories on the structure of protoplasm, among which the micellar lheory of Xitgeli, the foam therry of Biitschli, and the "bioblasts" of Altmanu, have been elaborately develuped, will be found in I'rot. O. Hertwig's work on 'The Cell" (Engl. trans., p. 19, de.), as also in M. Yves lelage's great work, - L'Hérédité' (11). 294-310). Verworn (loce cit., 1. Si draws special attention to the "alveolar" or "foan" theory, which, l,uilt upm investigations of l'rof. Tuincke, has "completely elaritied mur isleas upon the real nature of the protoplasmic structures so much whserved. . . As a result of these reeent investigations the following picture can le tormed of the finer inorplological structure of joto. 
There is, however, a second way open to the student of the phenomena of life, and this may be termed The 36. the "physical method," as opposed to the "structural." "physical" Thus chemists and physicists first establish the general
method. laws of motion and change in dynamics and energetics, and subsequently apply them to special problems, such as those of physical astronomy or the chemistry of electrolysis and solution. Similarly the physiologist may study the processes common to all living matter, and look upon the action of a definite cell, tissue, or organ merely as an application of these general processes. From this point of view structural biology, like structural chemistry, only furnishes illustrations, not an explanation, of the vital processes: the special structure or organ is a result of the process or functionnot its cause. As Prof. Michael Foster says, "We may throw overboard altogether all conceptions of life as the outcome of organisation, as the mechanical result of structural conditions, and attempt to put physiology on the same footing as physics and chemistry, and regard all vital phenomena as the complex products of certain fundamental properties exhibited by matter, which, either from its intrinsic nature or from

plasm. Protoplasm consists of a ground mass in many cases completely homogeneous, in most cases very finely foam-like or honeycomb. like, in which lies embedded a greater or less quantity of rery various solid elements or granules. In the foam-like protoplasm the granules always lie at the comers and angles where the foam-vacuoles come together, nerer in the liquid of the bubbles themselves." Some physiologists think that none of the descriptions of protoplasmic architecture help us much, and "hold to the fundamental priuciple that living matter acts by virtue of its structure, provided the term structure be used in a sense which carries it beyond the limits of anatomical investigation-i.e., beyond the knowledge which can be attained either by the scalpel or the microscope" (Burdon Sanderson, 'Address,' Brit. Assoc., 1889, p. 607 ). 
its existing in peculiar conditions, is known as living matter." 1

Thus, instead of trying to penctrate to the physiologieal units amel construet them through a process of Properties imagination, this latter class of biological thinkers confine themselves to the task of describing in the simplest manner and as completely as possible the varions properties of the living substance-i.e, its functions." And

1 'Mncy. Brit.,' article "I'hy:iology," vol. xix. 1". 12. Siee alsu an aldress delivered by Proî. Burdon sanderson at the meeting of the lirit. Assoc. at Neweastle in 1S\&9 ("Tieport," p. 601) : " During the last ten or fiteen years histology has carried her methorls of resench to such a clegree of perfection that further improvenent scarcely seems possible. As comparel with these subtle refinements, the 'minute anatomy' of thirty year's ago seens. coarse-the skill fur which we once took credit seens but clumsiness. Notwithstanding, the problems of the future from their very nature lie as completely out of reach of the one as the other. It is by difierent methods of investigation that our better-e(puipped successors must gain insight of those vital processes of which even the ultinate results of microscopical analysis will ever be as they are $11, w$, only the outward and visilble signs" (j). 608).

2 As Prof. Burbion Sauderson puts it in his 'Arldress, it is a reversion to a position which is not new in the history of physiology. "The departure from the traditions of our seienee which this change of direction seems to imply is indeed more apparent than real. In tracing the history of some of the greatest adrances, we find that the recognition of function has preeeder the knowledge of structure. Haller's discovery of irritability was known and bore fruit long before any thing was known of the structure of muscle" (1) 607). ".. . In much more recent times the investigation of the function of gland-cells, which hats been carriet on with such re. markable results by l'rof. Heidenhain in Germany, and with equal success hy Mr langley in this country, has led to the discovery of the silucturil changes which they unclergo in passing from the state of repose to that of activity; nor could I mention a better example than that afrorded by 1 r Gaskell's recent and very inportint discovery of the anatomical ditference between cerebro-minal nerves of ditlerent functions" (ibid.) Wlat has to a great extent worked this im portant change in the methods and reasoning in physiology is the re cognition of "plurality of Iunction with unity of structure," a minci]le urged strongly by the experimental school of medicine, with Claucle Bernard as its greatest rejresentative. Notably this was the eflect of his "demonstration that the liver had other things to do in the aninal economy besides secreting bile. This, at one blow, destroyed the then dominant coneeption that the animal body was to be regarcled as a bundle of organs, each with it. appropriate function - a eonception which dicl much to narrow inquiry, since when a suitalle function hal once been assigned to an organ 
38

Environinent.

here we meet first of all with the great fact that a living thing cannot be conceived to exist alone: it is dependent upon its enviromment, and mpon other living things of similar, never quite identical, and mostly very different nature. As a consequence of the conception which guided Lamarck in contemplating the living worldespecially the crowd of living things which before him had remained unobserved - the influence of environment plays a greater and greater part in the study of every form of life. The further fundamental property of all living matter-that it absorbs through intussusception other matter which surrounds it, that it grows and multiplies by division, casting off some portions of its own substance as useful secretions or cumbrous and useless excretions-has the twofold result that every living thing modifies its own surroundings and that it creates a society of its like which, through an antomatic process of crowding-out, exercises a kind of selection among its members, they being forced to accommodate themselves to circumstances and to each other. ${ }^{1}$ The process suggested by Darwin as the rationale

there seemed no need for further investigation. Physiology, expounded as it often was at that time in the light of such a conception, was apt to leave in the mind of the hearer the riew that what remained to be done consisted chiefly in determining the use of organs such as the spleen, to which as yet no definite function had been allotted. The discovery of the glycogenic function of the liver struck a heavy blow at the whole theory of functions." (Sir M. Foster in 'Claude Bernard,' p. 90.) On the necessary condition of the experimental as distinguished from the ana tomical method, namely, that it deals with the organism whilst it is alive, see the conclud. ing remarks in Sir M. Foster's article on "General Physiology" in the 'Ency. Brit.,' vol. xix.

1 The relations of living things to each other and to their environment admit of being contemplated in two ways, which may be best distinguished by a reference to human society, exhibiting as it does the two phenomena of co-operation and of competition. The former 


\section{of variation and development is more and mone conning} to be recognised as an incritable property of all growing and multiplying living things. So far as the intluence on the enviromment, the medium in which it lives, is concerned, we owe to the great French biologist, c'lande Bernard, the helpful conception of the immer medimn, as

is batserl upun harmony, the latter upon contlict. l'lue former aspect is more particularly emphasised by the lirench school of Lamarck, te Blainville, and c'laude Bernard; the latter none by the English sehoul of Malthus and Darwiu; eatch starting allurently without any referenee to the other. Claude Bernarel in particular sars " "Phéno. mènes le la vie, vol. i. 1.67): "Pour nous la vie rúsulte d'un contlit, liune relation étrojte et harunon. ique entre les eonlitions ex térieures et la eonstitution pré-établie le l'organime. Ce nest point par une lutte contre les conditions cosmiques que l'organisule se dé. velopye et se maintient; c'est, tont au contraire, lar une adaptation, un accord avec celles-ci. . . . L'être vivant ne eonstitue pas une exception ì la grande harmonie naturelle yui fail que les choses s'alaptent les unes aux autres; il ne rompt aucuu accord; il n'est en contradiction ni en lutte avec les forces eosniquets générales; bien loin de lit, il tait partie tu coneert universel fles choses, et la vie de l'animal, par exemple, n'est qu'un lragment de la vie totale de l'univers."

1 Although the biology of Claude bernard does not contain the principle of descent and evolution which so powerfully influenced the contemporary writings of linglish and German naturalists, one is nevertheless reminder of the irleas of Lannarck in reating the secont of his lectures on the Phenomena of life (vol. i. 1'p. 65-124). Lamarek lad expressol the idea that in the grarluaterl scale of living things we recognise an in. creasing indejendence with regitril to the externat environment. ree supre, rhats. vii. 1. 315.) Claude bermart says (p) 6i) : "Le morle des relations entre l'ctre vivant et les comlitionss eosmiques imbiantes noun permet fle comsinlérer trois formes de lat vie, suivant qu'elle est dans une dépendance tout ì fait étroite de exmolitions extérieurer. dans une dépendance moindre, ou dans une inrlépenklance relative. C'es trois formes de la vie sont: $1^{\circ}, 1$ a rie letente; vie non manifestée. $22^{\circ}$. la vic osrillante; vie ì manifestations variables et fépendantes du uilieu extérieur. $3^{\circ}$, la vic comstante; vie it manifestations lilues et inclépentantes du milieu extérieur." Examples of the "vie latente" are to be fouml in the vegetable and animal creation alike. (irains of seed, desiecated animals, germs, eggs, ferments, yeast, de., are examples. All vegretables lelong to the elass of the vie oscilliente, also anong animals all inverfebrates, and anong the vertebrals those with cold bloml. 'These depend on cosntic conditions, the cold of winter, and the reviving heat of summer, \&c. 'The highej' animils: with warm howel whose temperature is constant are not in the sane way subject to the influence of the external modimm. They 
it were the inner atmosphere which any large assembly of living units must necessarily create for itself. All larger organisms are complex societies of living units which depend not only on the external but also on the internal medium which bathes them. It was one of Claude Bernard's happiest generalisations to look upon the blood, not as a living tissue but as a means of communication of the living tissues of the organism, as an internal medium which bears the same relation to the constituent tissues that the external medium, the atmosphere, does to the whole body.

One of the principal functions of this artificial medium or atmosphere which the larger organisms possess, create and maintain for themselves during their life, is to enable a particular elementary substance to get access to every living cell or tissue of the organism. This substance is oxygen, without which the continuance of life in the higher organisms seems impossible. That life is a process of combustion is accordingly a

possess "un milieu intéricur perfectionne " (p. 104). But they begin their existence as beings with an oscillating life when they are in the form of eggs. Of the vic constante ou libre Claude Bernard says: "Je crois aroir le premier insisté sur cette idce qu'il y a pour l'animal réellement deux milieux; un milieu cxtéricur dans lequel est placé l'organisme, et un milicu intericur dans lequel viveut les éléments des tissus. L'existence de l'être se passe, non pas dans le milieu extérieur, air atmosphérique pour l'être aérien, eau douce ou salée pour les animaux aquatiques, mais dans le milieu liquide in. térieur formé par le liquide organique circulant qui entoure et baigne tous les éléments anatomiques des tissus; c'est la lymphe ou le plasma, la partie liquide du sang qui chez les animaux supérieurs, pénètre les tissus et constitue l'ensemble de tous les liquides interstitials, expression de toutes les nutritions locales, source et confluent de tous les échanges élémentaires. Un organisme complexe doit être considéré comme une réuuion d'êtres simples qui sout les éléments anatomiques et qui vivent dans le milieu liquide intérieur. La fixité du milieu intérieur est la condition de la vie libre indépcndante" (p. 113). 
definition which has been put forth in varions ways ever since Lavoisier's time, when he and Laplace trient to explain the existence of animal heat in this manner. The progress of seience in the comse of the century which followed Lavoisier has more and more confinned the importance of the rôle which oxygen plays, but has also shown how very emplex are the products of oxygenation in the living organism, - how the living processes are incleed chemical processes, but are quite different from those of the ehemieal laboratory. As Claude Bernard says, "The chemistry of the laboratory is carried on by means of reagents and ajparatus which the chemist las prepared, and the chemistry of the living being is earried on by means of reagents and apparatus which the organism has prepared." One of the great performanees of living matter is the production, another is the storing up and distribution, of oxygen. But though we know that the chlorophyll - containing cells of green plants, under the influence of sunlight, are able to decompose that very inert borly, carbonic acid, breathed out by both animals and plants, into free oxygen and carbon, allowing the carbon to be retained or ntilised in the form of more or less eomplex carbohydrates, and though

1 See especially the extensive explanations in the "Rinport sur les progrès de la Physiol. gin.' (18tit, p. 133 sq\%): "Les phénomènes phyrieo-chimignes yui se prisent diuns les corns vivants sont exacte. ment les mênex, quant ì leur uature, quant aux lois qui les régisent et quant it leurs proluits, que ceux qui se passent ditus les enrys loruts; ce qui differe, ce sont seulement les

VOL. II. procédés et les apprareils à l'airle desqueli ils sont manifestés. . . Il est déjà prouré qu'un grand nombre de phénomènes qui s'itecumplissent dans les eorps vivants preuvent ètre reproduits artificiellement, en dehors de l'orgmisme, dans le monde minéral. Ifitis ce qque lion ne queut pas reproduire, ce sont les procétés et les outils sprócianx de l'organisme vivant" (1). 2"2.2. 
we also know that the red blood corpuscles in vertebrate animals convey oxygen in a concentrated form ${ }^{1}$ through all the organs, giving it up wherever it may be wanted, the real chemical process concerned in the action of chlorophyll is not cleared up; ${ }^{2}$ and "no one has been able hitherto to explain, by a reference to pliysical laws, the active functions of the heart and muscular wall," by which the circulation of the blood is effected. ${ }^{3}$

In the explanation of many physiological phenomena no idea has proved more fruitful than the conception of natural selection, introduced by Darwin to explain the growing diversity and the purposefulness of organisms. Coupled with the cellular theory, which looks upon every living organism as a society of self-accommodating individual units or cells, forced by circumstances into differentiation of form and into divided labour or function, it relieved biologists of that spectre of vitalism which still survived after Lotze and Du Bois-Reymond had placed the creative and formative influence outside of the mechanism-as the watchmaker lives ontside of the watch, which exhibits only mechanical contrivances. That which puzzles the spectator of the watch, as it does the spectator of every

1 See Bunge, 'Plysiological Chemistry,' p. $2 \overline{7} 5$.

2 "Iron plays au important part in vegetable life: we know that chlorophyll granules cannot be formed without it. If plants are allowed to grow in nutritive solutions free from iron, the leaves are colourless, but become green as soou as au iron salt is added to the fluid in which the roots are immersed. It is even sufficient merely to brush the surface of the colourless leaf with a solution of $3 n$ iron salt to cause the appearance of the green colour in the part thus painted. Chlorophyll itself contaius no iron, and we du not know in what way the iron is concerned in its production" (Bunge, loc. cit., p. 25). See also Hertwig, 'The Cell,' p. 153.

3 Bunge, P. 7 ; cf. also p. 275. 
organism, is the apparent design and purpose, withon which neither conld be conceived to have heen formenl.' Here, then, the illea that it was a process of matural choice, of antomatic aljustment, which producerl the aplarent end and purpose at the monent when the structure itself was prodnced, cane as a great relief." It explained how it comes about that nature, even with mloaded lice, so often-yet not always-throws doublets. It permitted naturalists and physiologists to use purpose and final cause, not as an explanation, but as an indication where to look for causalthat is, for mechanical-comnections. Accorlingly the first systematic attempt to use natural selection in the explanation of the adjustment of the internal parts of an oroanism, which is due to Prof. Wilheln within the 1) reatisis.

s "The main problem which the organie world offers for ouy solu. tion is the purposelulness seen in organisms. 'Tluat species are from time to time transformed into new ones might perhaps be understoud by means of an intemal trans. forming force, but that they are so chumged as to become better arlapled to the new conclitions under whieh they liave to live is left entirely unintelligible" (Weisnamm on Nigreli's "MechanisehPhysiologiselıe Theorje der Abstammungslehre" in "E-says mpon Hererlity,' Engl. trans]., 1. 257).

2 siee Du Bois-Reymond's Address, "I)arwin versus (ialium" ("Rexlen,' vol. i. f) 211, s(.) : "Here is the kuot, liere tlie great dithiculty that tortures the intellect which would understand the world. Whorer loes not place all activity wholestle under the sway of Epicurean ehance, whocver gives only liis little finger to teleology, will inevitably arrive at l'aley's dis- carcled ' Tatural 'Theology, aud so much the more necessarily, the more clearly he thinks and the more in. devendent his jurlgneut. . . The physiologist may define his science is the doetrine of the changes which take place in organisms from juterual cumses. . . No suoner has he, so to speak, turned lik lack on liminelf than he discovers himieli talking again of functions, performances, actions, and lumpores of the organs. The posibility, ever so distunt, of banishing from nature its seeming purpose, and putting a blind necessity everywhere in the place of final causex, alyear's therefore as one of the greatent advanees in the world of thought, from which a new era will be clated in the treatment of these problens. 'lo have sonewliat eased the torture of the intelleet which ponders over the world-problem will, as long as philosophical naturalists exist, he Clharles Darwin's greatest title to glory" (1. 216). 
Ponx in his work on the "Struggle of the Parts in the Organism,' was hailed by Darwin as "the most important book on development that has appeared for some time." 1 In modern books on physiology the process of selection is a familiar conception; but if in natural history, in the life of plants and insects, there still remain many extraordinary instances of selection

1 The work appeared in 1880 , and is referred to by Darwin in a letter to Romanes ("Life and Letters,' vol. iii. p. 244 ; 16th April 1881), where he suggests also a similar consideration of plant life and structure. It has been republished in Roux's 'Gesammelte Abhandlungen zur Entwickelungsmechanik der Organismen ' (Leipzig, 1895, 2 rols.), with an interesting preface (vol. i. $p$. 139 , sc.), and many bistorical and critical digressions. It originally emanated from the earliest school of Darwinism in Germany, represented by Haeckel, Gegenbaur, and Preyer, at Jena. It has been found very suggestive, and has been the beginning of a rery large controversial literature in Germany, in which the funda. mental problems of biology have been discussed, and have receired new formulations. The idea of the struggle of individuals for survival, suggested by Darwin, is applied by Roux to the different parts and organs within the dereloping organism. Du Bois-Reymond almost contemporaneously jublished his brilliant and celebrated address on "Exercise" ("Ueber die Cebung," 'Reden,' vol. ii. p. 404). Iu Englaud Roux's suggestive treatise does not seem to have been much noticed, and Prof. Roux himself attributes this to the inadequate notice of the book by Romanes in 'Nature' (rol. xxiv. p. 505), in which his doctrine was erroneously compared with Spencer's ideas of "direct equilibration." Prof. J. A. Thomson, in 'The Science of Life,' refers to the importance of Roux's work (pp. 135, 229), and of his 'Archiv für Entwickelungsmechanik.' Roux has been classed by some of his eritics among the "organicists," a school represented in France chiefly by Claude Bernard. The main thesis of this view seems to be that the phenomena of life consist in the play of two facturs-the organisation and the environment of the living thing. Roux applies the process of natural selection and consequent adaptation, which Darwin sees at work in a crowd of living things, to the organisation of the individuals themselves, each of which is a microcosm, a society of autonomous units, say of cells. $\mathrm{He}$ has accordingly gone a step farther back than the older "organicists," studying the development, the genesis of the organisn on Darwinian lines. MI. Delage accordingly dates from him a new scliool of "organicism." "L'organicisme commence, à mon sens, avec Descartes (1642), se continue arec Bichat, Claude Bernard, et arrive avec Roux (1881) à une théorie si profondément modifiée, bien qu'elłe dérive du même principe, qu'elle peut être considérée comme toute moderue" ("L'Hérédité, p. 408). 
for which no teleological nechanism has been invented, still more are we baflled by the apparent "autonony of the living cell," in consequence of which it is, (\%), "alble to seleet its food, retaining what is useful and rejecting what is harmful." I And what shall we say of the so-ealled "wandering cells, which are actually sent ont by the orcanism in orcler to absorb in the alimentary canal food-stuffs, notably fat, returning with it into the blood, or to receive into themselves malignant baeteria, making them imoenous by a lrocess of digestion?"2 No nuechanical physico-chemical explanation of this process is imaginable, and the worl "selection," with which Darwin clanmed away so many inysteries, has revealed new ones in their place. ${ }^{3}$

I see the very interesting aud fresuently quoted address by Prof. (i. E. Rindtleisch (Wirzburg, 1s-8). entitled 'Arztliche Philosophie, 1. 13.

2 Rinlteisch, loc. cit., p. 15.

${ }^{3}$ In thiseonnection it is interesting to refer to a discusion which was raised by the suggestive address of I'rot. F. R. Jayp, entitled, "Stereochemistry and Vitalism" ("Brit. Asure. Report,' Is98, 1) 813 '. It reter's to the diseovery by Patseur of "ehirality" in solutions of certain crystallised organic salts, on which 1 reported in rol. i. p. 450. "Pasteur regarded the formation of asymmetric organic compounds as the special prerogative of the living organism. Most of the substances of which the animal and vegetable tisisues are built up-the proteids, cell. ulose - are asymuetric organic compounds." Now, in his experiment: on fermentation Pasteur found that "the asymmetric living organism relected for its nutri. ment that particular arymuetric form" ont of a mixture of two enantionorphous compounds held in solution - "which suited its neets-and leit the opposite form either wholly or, for the most lart, untouched" (p. 817 ). Prof. Japly proceeds to consider the opinion then formed by Pasteur, "that compounds exhibiting optical activity have never been obtained without the intervention of life" (1) 81s). This view, to which Pasteur adhered, and which he defended against emineut opponents, has been frequently challenged, and seemed definitely set aside by the explanation of Prof. Emil Fischer of Berlin, and by Jungfleiseh's synthesis of raceriic acid and its resolution into dextro- and lievo-tartarie acids. ... "Consequently, the overwhelming majority of chemists hold that the foregoing synthesis and separ. ation of optically active compounds have been etrected without the intervention of life, either directly 
41.

Mobility of living matter.

Another property of all living matter which has been seized upon to furnish a definition of life is its extreme mobility. It has been stated that the great difference between living and non-living matter is this-that the former is in a state of movable or dynamical equilibrium, whereas the latter tends always to a condition of rest or of statical equilibrium. This was especially urged by the late celebrated Du Bois-Reymond of Berlin, to whom we owe the greater part of our knowledge of the physical and chemical changes exhibited in the active nervous system. In comparison with this property of a dynamical equilibrium, explained by the analogy of a fountain of water or a vortex which change their substance whilst maintaining their form, other older distinctions which had been drawn between organised and unorganised bodies sank into insignificance. ${ }^{1}$

or inclirectly." (1. 824). Prof. Japp and Prof. Crum Brown of Edinburgh are of the opposite opinion, inasmuch as in the view of the former" "the action of life, which has been excluded during the previous stages of the process, is introduced the moment the operator begins to pick out the two enantiomorphs," as was done by Jungfleisch.

1 Among the older discussions of the best way of defining life which belong to the second third of the century, we have in Germany the various writings of Du Bois - Reymond ('Reden,' notably vol. ii. p. 25); in France those of Claude Bernard ("Phéno. mènes de la vie,' notably vol. i. p. 21, \&c.) ; in England the 'Biology' of Mr Herbert Spencer. The two last-named authors examine with some care the definitions of earlier writers. All three should be read and re-read by any one who desires to arrive at a clear understanding of the subject. Du Bois-Reymond's definition shows the preponderating influence of the ideas which governed the Berlin school of physiology, and which centred in Helmholtz's tract on the Conservation of Energy. Claude Bernard defines life by the words "La vie, c'est la création." Organisation and disorganisation are the two sides of this process, organisation and environment the two factors. The doctrine of evolution goes a step farther back, and attempts to analyse "organisation." The process of creation is to $\mathrm{Mr}$ Herbert Spencer a process of development. The word creation in the older sense ceases to have a meaning. Of more recent rlate are the discussions of the subject in the very interesting work of Carl Hauptmann, "Die Metaphysik in der modernen Physio- 
It is true that not all parts of a higher oromisism ale subject to this continued change, but those that are not - suel as the skeleton of an animal or the trunk of a tree-are automatically deposited by the living organism for the purpose of external or internal smpport, potection, or communieation. They are the permanent nuechanisu by which the economy and administration of the soeiety of living mits or cells are kept up. These it has been possible, in many instanees, to analyse into stable chemical compounds, whieh have been reproduced in

logie' (Jena, 1s.t, neue Aufl.), esinecially the last ehapter. Still nore recent is the very careful analysis contaned in the new edition of $\mathrm{Mr}$. Spencer's 'l Biolerey,' notably vol. i. p. $111 \mathrm{sq}$. The tinal conclusion arrived at by these two latest philosophers has much in eommon. Both strive after a dynamic conception of lite; both confess that such is at present unattinable $-\mathbf{a}$ desideratum, not an achievement. Hauptmann kays (p. 356): "The most primitive life, from which alone the living world on this earth can have sprung, eau only be assumed to be a species the nembers of which variect in manifold ways and propagated themselves. Here we have to do alrearly with an eninently complex interaction of elementary jrocesnes. . . Westill alsolutely lack every conception of such a dynamical system.

Likewise the origin of the simplest living substance is mechanieally quite unknown and uneomprehended. . . . The indiviriual furms of life stand in the mirlet of a yet unintelligible higher order of the inaterial workl." Similarly $\mathrm{Mr}$ Spencer (loc. cit., P. 120): "We are olliged to cuntess that life in its essence cannot be eonceived in physico-chemical terms. The required principle of activity, whieh we found cammot be repre. sentel is an independent vital principle, we now tind cannot les represented as a prineiple inherent in living matter. If, by asiunning it.s inherence, we think the fact: are atceomuted for, we do but cheat oursolves with preudo-illeas.

lt needs lout to obnerve how even simple forms of existence are in their ultimate nature incompre. liensible, to see that this most complex form of existence is in a sense doubly ineomprehensible. . . While the phenomena (of life) are accessible to thought, the inplied noumenom is inacessillie, . . . only the manifestations come within the range of our intellizence, while that which is manifesterl lies heyour it" (p. 122). There seems ample evidence that unler litferent forms of words Claude Bermard aml Du Bois-Reymond, in lis later writiugs, arrived at similar conclusions. See 'I I t seience Exprérimentale," p. 2210, and "I)ie sieben Weltrithicel" "lieden," vol. i. p. 381). "The nystery is the more profound the more it in brought into contrast with the exact knowled ge we posiess of sulrounding conditions." Prol. Burdon Sanderson, 'Brit. Aswoe, Report,' 1589, [. 614). 
the chemical laboratory by processes which were like or unlike those going on in the organism itself. But such stable compounds are not the bearers, they are merely the collateral products, the accompaniments, of the living process. The artificial production of organic compounds, beginning with Wöhler's production of urea, and ending with the production of albumen, do not approach the problem of the production of living matter. Could the chemist produce protoplasm, it would not be living; or were he fortunate enough to lit upon one of its many metamorphoses, it would die the next moment, not having the imner structure or the external and internal enviromment necessary for its self-conservation and activity. Nor do we seem to get any nearer the real secret by analysing more closely the chemical and physical changes, the metabolism, the rhythmical processes which constitute this activity. We call it nutrition or respiration, assimilation and disassimilation, oxidation and reduction - storing up and letting loose of energy. We picture to ourselves the building up of more and more complicated chemical molecules, containing thousands of atoms, in a temporary and easily disturbed equilibrium, and the subsequent breaking down again of these complex structures by gralual decomposition or by sudden explosions due to external stimuli, or by the still more mysterious directive action of conscious will: we liken them to the pulling of a trigger, or the gathering up and letting loose of a destructive avalanche by the motion of a flake of snow on the top of a peak. We see how this metabolism, this "Stoff- und Kraft-wechsel," goes on in the smallest amœba in rhythmical movements, and how, in higher 
organisms, it is divider into many stages, allocated to special cells or to puite distinct classes of lueings, sonne of which, like plants, take mpon themselves the finst important steps of the anabolism, so that others-the animals-may carry it a stage higher, preparing a liselarge, or catabolism, which becomes more and nore effective, till it reaches the unique nervous function which aceompanies the highest phenomenom of animal activity - the mental process. Claude lieruard ${ }^{1}$ has put into classical words the rationale of this process. "If, in the language of a mechanic, the vital phenomena - nanely, the construction and destruction of organic substance-may be compared to the rise and fall of a weight, then we may say llat the rise and fill are accomplished in all cells, both plant and animal, lut with this differenee, that the animal element finds its weiglit ${ }^{2}$ already raised $" 1$, to a certain level, and that luence it las to be raised less than it subsequently falls.

1 'Phénomènes de la rie, \&c., vol. ii. 1) 513. It is one of Claturle bernard's greatest merits to have corrected the earlier formula in which the circulation of matter hat heen expressed. Dumas and Boussingault hat sairl: "J.'oxygène enlevé jar les animaux est restitué par les régélaux. Les premiers consomment de l'oxygine; les seeonds prorluisent de lixygène. Les premiers brûlent du carbone; les secomls produisent du carbone. Les premiers exhalent de l'acile carbonique; les seconds fixent de lacide carbonique." On this pansagre Claucle Bernard his the following emmment: "Celte loi qui sous lit forme précélente exprine avec vérité le mécanisme d'une des plus grandes harmonies de la nature est une loi cosmique et non une loi physiologique. Appliquée en physiologie, elle n'explique pas les phénomènes inlividuels: elle exprime eomment l'ensemble des animaux et l'ensemble des plantes se comportent en définitive jar rapport au milieu anbiant. Ia bi étiblit la balance entre lit somme die tous les phénonènes de la vie animale et de la vie régétale: elle n'est point l'expression do ce qui se passe en particulier dans un animal ou une plante dommís" (p). 512). This false direction, which had been introdueed into fhysiology a generation eurlier, Clinude Bernard eorrected by the view that the circulation of matter takes place not only between the two kingdoms of nature but in every elementary organism.

Or its potential. 
The reverse occurs in the green plant cells. In a word, of the two movements, that of descent is preponderant in the animal, that of ascent in the vegetable." No one has done greater service to the fixing of our ideas on this subject than Dr Gaskell when he analysed the whole process, called "Metabolism" by Professor Michael Foster after Schwann, into the two complementary pro-

Anabolism and Catabolism.

cesses of Anabolism the upward, and Catabolism the downward, movement - the winding up and running down of the clock, the preparation and loading of the explosive and the discharge of the gmm. ${ }^{1}$

1 The introduction of these terms is, however, connected with it special view - differing somewhat from that suggested by the formula of Claude Bernard-which is now very generally adopted in textbooks of plysiology. Prof. Burdon Sanderson has given a lucid statement of this difference in his Address, entitled "Elementary Problems of Physiology," before the Brit. Assoc. in 1859 ('Report,' p. 613). He there says: "A characteristic of living process ... is that it is a constantly recurring alternation of opposite and complementary states, that of activity or discharge, that of rest or restitution. Is it so or is it not? In the minds of most physiologists the distinction between the phenomena of discharge and the phenomena of restitution (Erholung) is fundamental, but beyond this unanimity ceases. Two distinguisherl menProf. Hering and Dr Gaskellhave taken, upon independent grounds, a different view to the one above suggested, according to which life consists not of alterna. tions between rest and activity, charge and discharge, loading and exploding, but between two kinds of activity, two kinds of explosion, which differ only in the direction in which they act, in the eircumstance that they are antagonistic to each other. Now, when we compare the two processes of rest... and discharge ... with each other, they may further be distinguished in this respect, that whereas restitution is autonomic, the other is occasional-i.e., takes place only at the suggestion of external influences. . . . It is in accordance with the analogy between the alternation of waking and sleeping of the whole organism, and the corresponding alternation of restitution and discharge, of every kind of living substance, that physiologists by common consent use the word stimulus (Reiz), meaning thereby nothing more than that it is by external disturbing or interfering influence of some kind that energies stored in living material are discharged. Now, if I were to main. tain that restitution is not auto. nomic, but determined, as waking is, by an external stimulus, that it differed from waking only in the direction in which the stimulus acts-i.e., in the tendency towards construction on the one hand, towards destruction on the otherI should fairly and as clearly as. 
ON THE VITALISTIC VIEW UF NATCLIS $4 \notin 3$

The modern theories of the cell, of nutabolism, and selection, have also greatly influencerl and molifierl on conceptions concerning the last and most imjurtant property of all hiving matter-riz, that it is self-reproductive. Older text-hooks on physiology treated of the sreat mannice problem of generation-i.e, the origin of a new individual tion. -as a phenomenon of organised life which stood quite isolaterl; and although the sexual difference in plants and animals had early led to certain analogies, to similar terminology, and to vague inferences, the mysterious phenomena of generation, and especially of sexual generation, were not brought into line with the general properties of all living matter till abont fifty vears ago. Even Johamnes Müller in his great text - look on Physiology, which takes a mueh wirler view of the sulject than any work before it, treats of the reproduction of tissues and of generation in quite separate, seemingly discomneeted, parts of his work. Into this uncertainty only little light was thrown by the original propomulers of the Cellular theory, who, misled by the supposerl analogy of eells and erystals, imagined that cells originated out of the surromuling cell sap, is crystals solidify ont of the solution or mother liquns. Conecter views were gradually elaborated by botanists. Mohl emphasised the important part which protoplasm plays in the formation of eells. Nïgeli established the proeess of intussusception as against external aeeretion : anatomists like Max Schulze and linieke joined hands,

possible express the doetrine which 1)r (raskell and l'rof. Hering have embolied in words which have now become faniliar to every student. The words in question - 'anabolixn,' which, being interpretel, tnean: winding-up, and 'catabolism,' run. ning duwn - are the creation of $1 y_{r}$ Gaskell." 
and the year 1863 is usually given as that in which

44. The protoplasinic theory.

the protoplasmic theory was established. According to this view protoplasm is the element or unit of all living substance: it grows throngh assimilation (intussusception and excretion), and multiplies (i.e., gives rise to other living units) by subsequent division. This process was found to be fundamental: it describes the growth of the simplest and the most complicated organisms as beginning alike with a unit cell, which may or may not grow by division; it is the formula of growth, restitution, and generation (whether sexual or asexual); and, what is equally important, it prevails also in pathological cases - i.e., in the formation of diseased tissues. In fact, the great generalisation which followed Harvey's celebrated dictum, "omne vivum ex ovo," was put forth by the late Professor Rudolf Virchow, the eminent fomder of cellular pathology, in his formula, "ommis cellula e cellula." The formula has in more recent times been further elaborated on the same lines of thought in proportion as the importance of the nuclens or cell kernel has been recognised, or as the granular structure of protoplasm has been maintained; leading to analogous formulie, stch as "omnis nucleus e nucleo," "omme granulum e granulo." These formule ${ }^{1}$ are the

1 See Roux ('Gesammelte Abhandlungen,' vol. i. 1. 393): “ $\mathrm{Cn}$ interrupted durability is the indispensable condition of all that is organic, although this does not involve a distiuction from inorganic processes. This fact is expressed by the fundameutal theses: Omne vivum ex ovo (Harvey), Omnis cellula e cellula (Virchow), Omnis nucleus e nucleo (Flemming)."
Hauptmann ('Die Metaphysik,' \&c., p. 334) says: "Altmann formulates for limself in analogy with these biological principles the further principle, 'Onne granulum e granulo." On Altmann's theory of the "bioblasts" as elementary organisms, see Yves Delage, 'L'Hérédité,' p. 498, \&c., Hertwig, 'The Cell,' p. 24. 
expression of anatonical observations and theories reporesenting an enornous anomnt of research, lalour, and ingenuity, but they involve 110 new line of reasoning, and they belong, aceordingly, more to the history of Sicience than to that of Thonght.

The first to attempt a mechanical explanation of the 4 Sipencer's process of ecllular division was Mr Herbert vipencer, 1 law ol limit who, in his 'Prineiples of Biology' (1S6:3), printed out that there exists a limit of growth thromgh assinilation or intussuseeption, inasmueh as volume and mass increase at a greater rate than the surrounding surface through which communication with the enviromment is afforcled. A resultant tension brings about an increase of surface through rupture, and restores the balance lesween the contained mass and the surface. In lis analysis of this process of readjustment, spencer luas given mechanical

1 The prineiple liere referrel to sometimes goes unler the name of the Leuckart-spencer prineiple, it having heen suggested independently by liulolf Leuckart, Herbert Spencer, and Alexander James. It requires, of course, a great many qualifications. See the 'Prineiples of Biology,' vol. i. part 2, ehap. i. But "it follows from these eonsiclerations that the cell can never surpass a certain size; for if the disturbance of metabolism that arises because of the increaving disproportion between the more superficial and the deeper layers has reached a certain extent, the cell can no longer continue living in its existing form. Thus the remarkable faet is explained very simply, that no cells of constant form are known that are larger than a few millimetres in liameter, and thus we are made to understand why the development of large organisms is only possible by the arrangenent of the living substance into an aggregate of small cells instear of into a single cell, for example, of the size of a man... If, therefore, the living substance of such a cell is not to perish ly growth, at sume period in its growth a correction of this disproportion between mass and sur. face and of the disturbance of metabolism conditioned by it must come in: sueh a correction is realised in the reproduction of the cell hy division. The reprouluction of the cell by division is accordingly to be eonsiclered merely as a result of growth, and the morphologists for a long time have rightly termed reproduction a continution of growth, "a growth beyond the measure of the indivirluall " (Ver. worn, 'General l'hysiology,' Engl. transl., p. 530, se.) 
biologists a formula which, like his physiological units, has helped to give precision and direction to reasoning on these subjects. But as growth has a natural limit and leads to division, so reproduction through division appears to have a limit also. "Only the very lowest organisms, such as fission fungi, appear to be able to multiply indefinitely by repeated divisions: for the greater part of the animal and vegetable kingdoms the general law may be laid down that, after a period of increase of mass throngh cell division, a time arrives

when two cells of different origin must fuse together, producing by their coalescence an elementary organism which affords the starting-point for a new series of multiplications by division." 1 Fertilisation is now known to be a cellular problem. As such it has been studied in favourable cases which permitted of direct observation, and what has been ascertained in those cases -exhibiting in general the same common features and phases of development-has by inference under the great generalisations of the cellular theory been extended to all living things in which sexual differentiation exists, be they animals or plants. ${ }^{2}$ The male and the female

1 Hertwig, 'The Cell,' 1. 252. The process may be looked at as an instance of the cyclical order of change. "The multiplication of the elementary organism, and with it life itself, resolves itself into a cyclic process. . . . Such cycles are termed generation cycles. They occur in the whole organic kingdom in the most various furms." Similarly Sir M. Foster ("Text-book of Physiology,' 5th ed., p. 1555), as quoted, supra, p. 289. We may add that from a still broader standpoint, which we may call that of bionomics - in distinction from biology - the cycle never repeats itself, but, owing to overcrowding and selection, something different, more complex-i.e.. externally or internally better eudowed-is produced. Philosophically we call this progress.

2 There exists no more remarkable instance of the extension of natural knowledge by a process of very incomplete induction than the gradual firm establishment of the now universally adopted doctrine of fertilisation, no more brilliant refu- 
elements concerned have both been recomised to be cells, hoth lave been found to molergo, before what is termed the stage of matmrity, similar preparatory changes. 'The changes represent, as it were, the last stages of their' independent existence as living cells. After these changes have taken place they can only enter into a new eycle of existence, exhibiting new powers of growth and division by a process of fusion where each supplies what in the other is wanting to start on a new cycle of life-i.e, of differentiation and development.

Thus the vague theories of former times, which reach far into the nineteentl century, the speculations of the Spermatists and the Urists, have during the last thirty years, hegimning with l'ringshein's observation in 1869 of the pairing of the swarn-spores of certain alge,

tation of the purely enumerative, or all-cine method. 'I'he number' of instances in which the process of fertilisation, witl its various preparatory stages and its conse. (fuences, can be actually ubserved is infintesimally small compared to the number of rifferent species and varieties in which it is endlessly repeated on lines which no biolurist doubts to be essentially the sanue. M. Yves Helage says: " ('est une chose remaryuable com. bien certitius ctres, par cles particularités en aplarence sans intérét ont facilité la solution de certains problimes presque insolubles en lehors l'eux. l'Ascuris meraloceplectu the round-worm of the horne, first observed ly wan licneden in 1833], par le petit nounbre de ses chromosones, les Echinudermes [sea urchins, \&c.] far la facilité arec larpuclle ils acceptent la fécondation artifielele, ont fait faire, en dix ans, plus de progris aux yuctions relatives à la fécunelation cpe n'ont lait avant ou depuis tuus les autres animaux réunis. 1)ins l'Ascaride, le testicule forme un long tube et les diverses pliases de lat spermatogéncise s'accoumplissent dans les régions dillérentes de l'urgane: il $y$ a une zune it spermatogonies, une zone il spermato('Vtes en voie d'accroissment, une rone où se font les divisions: récluctrices et mue entin où les slier. matiles se transforment en spermatozoïdes" (" J:Hérédité." p. 133). see on the variety of object: which liave lont thenselves to the grudual unravelling of the processes of cell division, nuclear division, fuxion of nuclei, clearage and embryonic de. velopnont, notably the volume of Prot. Val. Hatecker, " l'raxis und 'l'leorie der" Wellen- und betru-lut. ungslelure" (Jena, 189!). A rery lucid sumnary is contained in s. A. 'Thomsun's 'The sicince of life" (184!). 
and centring in van Beneden's discovery, ${ }^{1}$ been replaced by definite conceptions capable of typical description. This typical process consists in the fusion of certain parts of the male and female cells, - the nuclei or kernels playing an important if not the essential part. Many biologists of the foremost rank, notably in Germany and France, have contributed to make clearer the varions lines in this typical picture of the most mysterious process in the physical organism, whilst every new discovery has brought with it new and manswered questions or given a novel aspect to older problems.

4i. Of these problems, those of heredity and variation problems. are at present by far the most important. Both the cellular theory of living matter and the theory of natural selection, including the principles of differentiation and of the division of physiological labour', converge upon these two great facts of modern biology. The theory of natural selection pre-

I See last note. "Since the female parent; and that, regarded researches of 0 . Hertwig and as a mass of molecules, the entire others in 1875, it hat been clear organism may be compared to a that each parent contributes a web, of which the warp is derived single germ-cell to the formation of the offspring; but the masterly researches of E. vau Beneden (1883) showed that every nucleus of the offspring may contain nuclear substance derived from each of the parents, a conclusion which is visibly demonstrable for a few of the first steps in cleavage. In fact, van Beneden to some extent proved what Huxley had foreseen when he said, in 1878, 'It is conceivable, and indeed probable, that every part of the adult contains molecules, derived both from the male and from the from the female, and the woof from the male" "(J. Arth. Thomson, 'The Science of Life,' $p$. 129). Another theoretical anticipation is, according to Haecher (loc. cit., p. 133), the "Idioplasma" of Nägeli: "The heritable sub. stance, organised, possessing a com. plex structure, transmitted from one generation to another," which was "about the same time identified by Strassburger, O. Hertwig, vou Kölliker, and Weismann, with the chromatin substance of the nucleus." 
supposes the fact of herelity-that is, the trusmission of characters peculiar to the parents (he they acquirert by them or not), and the fact of variation, lut it loes not explain them. It does not give any intelligible description of the means which nature uses to secure that continuity of change which is marked on the one sicle by a faithfuhess to certain typical forms, and on the other by a gradual development. The cellular theory permits us to comprise, unler the general categories of cell-growth, cell-division, and cell-fusion, the great facts of the history of all living natter, but it loes not explain how that apparent sameness of structure which the ultimate morphological unit, the cell, presents to our view, develops into that variety of recurrent forms which make up the wealth and the order in the work of natural objects. The older' naturalists were divided into two distinct schools: one believed in pre-formation with development-the older meaning of "evolution": the other in after-formation, or "epigenesis." The former foundered on the difficulty of explaining or making plansible how all the germs of hundreds of succeeding generations conld be eontained in the first ancestor; the latter failed to explain how nature was able to huild up by mechanical forces out of unorganised matter a structure resembling the parent structures. The suggestion of a "nisus formativus," which we owe to the celebrated Blumenbach, is only a definition of the difficulty, not an explanation.

The three distinct ideas represented by these historic terms oceur again in morlem biology, thongh altered to suit the vast extension of actual knowledge of facts, anit 
the three great generalisations mentioned above. Out of the three ideas of pre-formation, after-formation, and the directive principle, the three generalisations, namely, the cellular theory, natural selection, and metabolism, and the enormous number of facts collected by microscopists and naturalists of all kinds, many more or less ingenious theories of life have been put together. None of them has obtained, though some have had a very marked influence on biological science, and even on popular thought. Of these Prof. Weismann's theories of heredity are probably the best known. Without entering upon the enormous array of biological facts which have been marshalled by supporters and opponents alike, it will be of interest to point out the norel aspects and lines of reasoning which have come into prominence through the voluminous discussion belonging to this subject. They were prepared before the appearance of Weismann's writings by the changed and enlarged conceptions which the discoveries of the middle of the century introduced concerning the general phenomena of Life, Death, and Disease. Three distinct convictions regarding these three main aspects of the living portion of creation have been forced upon the scientific and popular mind. First, we have the modern doctrine of the ubiquity of organisms and germs, at least so far as our planet is concerned: beyond this sphere we can say that we know no more of the existence of living matter than past generations. Secondly, we have the generally recognised doctrine that spontaneous generation of living out of not-living matter is unknown and inconceivable under such conditions as 
we ean realise or imagine. And thirdly, hand in haml with the conviction of this mique but ubiquitous character of life, the impression of the mutual interdependence of living ereatures has gained gromnd, and has especially influenced our ideas of the cause and treatment of disease.

In one of those lmminous addresses in which he has rivalled the combination of literary with scientific clearness characteristic of the French genius, the late I'rof. Huxley has written the history of Biogenesis ${ }^{1}$ -i.e., of the theories of the origin of life from the time of the Italian Redi down to Pasteur, showing how experiment and theory alternately supported and contradicted the doetrine that living matter could be formed ont of not-living matter, till the great French biologist, by his refined experiments, entirely banished from the provinees of seience and practice the once arlmitted fact that, after exclusion or destruetion of all living germs, phenomena peculiar to life, such as fermentation and putrefaction, could be generated. Those great departments of medical practice, the antiseptic and aseptic treatment, with their enormous derelopment of prophylactie and antitoxic methods, form the daily and ever-growing argmment against abiogenesis

1 In his presidential address to the British Association in 1870, reprinted in 'Critiques and Aildresses,' p. 218 siq. A very readable and much earlier deliver. auce on "The Diffusion of Life" is that by K. E. von Baer, before the Aeademy of St Petersburg in 1838 , reprinted in the first rolume of his 'Rerlen,' \&e., p. 161 sq . In the preface of 1864 to this reprint, the illustrious author tells u.s that between 1810 and 1830 there were probably few naturalist. who "did uot cousider the gener. ation without parents of inferior organisins as proved, or at least as highly probable," and lie him. self would not at that time (183S) "deelare it to be nou-existent" (1) 173). In 1564 he describes the theory as having almost vanished, leaving the problem of the first beginnings of life in the number. less varieties, even ufter Darwin's hypothesis, unsolved (1). 177) 
-i.e., the generation of living out of dead or not-living matter.

But in proportion as abiogenesis or spontaneous generation has disappeared from our scientific textbooks, life being recognised as a phenomenon between which and dead matter there exists no intelligible and no practical transition except that of destruction, 50. the ubiquity of life has forced itself more and more Theubiquity
of life. the adherents of spontaneous generation urged as an argument on their side that if biogenesis be true, innumerable facts and experiments prove "that the air must be thick with germs; and they regarded this as the height of absurdity. But nature," as Huxley continues, "occasionally is exceedingly unreasonable, and Professor Tyndall has proved that ordinary air is no better than a sort of stirabout of excessively minute solid particles." It is now, after a generation has passed, hardly necessary to refer to any special experiments of Tyndall or of others, when the daily press brings us records of the number of billions of germs contained in a cubic inch of the atmosphere of large cities, precisely as it does of the mortality of their population. The cellular theory of disease has been succeeded and amplified by the bacillar theory, and no modern scientific fact has fastened on the popular mind with a stronger hold than the ubiquity of the micro-organisms, which, with beneficent or fatal results, assist everywhere-chiefly in the larger organisms-in the struggle for existence.

It is, moreover, only a logical inference that if living 1 'Critiques and Addresses,' p. 233. 
matter is not being continually formed out of not-living matter, while it is an uncleniable fact that living matter is continually and everywhere passing out of existence, the preservation of life is dependent upon an enormous self-overproduction which, combined with the process of natural selection, seemes its permanence and the development of the highest forms of which it is capable. The continuity-i.e, the interdependence-of all living forms in time and space gutrantees the non-exThe con tinuity of tinction of this phenomenom, which, for all that we know, is of a unique character. The modem seientific and popular. view of life is that it is a mique phenomenon, that it is a ubiquitous phenonenon, at least within the area of what we eall "our" world, and that it is a continuous phenomenon. The mique charaeter or singularity of life has been directly demonstrated by the sameness of the ultimate units of all living matter, the cells, indirectly by the refutation of the older theory of spontancous gencration; and has been enormously strengthened by the doetrine of descent, the phenomena of overcrowding, and the possibility of natural selection. The ubiquity of lifewithin certain limits - has been revealed directly by the microscope, and indirectly by the modem theories of disease, and of many forms of growth. ${ }^{2}$ The continuity of

I There is a striking yassage in Nansen's 'Farthest North,' vol. i. p. 445, showing the ubiquity of organic germs: "When the sun's rays had gained power on the surface of the ice, and melted the snow, so that pools were formed, there were soon to be seen at the buttom of these pools small yellowish lorown spots, so small that at first one hardly noticed them. I by by day they increased in size, and absorbing, like all dark substances, the heat of the sun's rays, they gradually melted the underlying ice and formed round cavities often several inches deep. These brown spots were . . alga and diatoms. . . I actually found bacteria, even these regions are not free fiom then." 
life has - as an inevitable corollary-come more and more into prominence. It has been the subject of much discussion, as a phenomenon which is felt to require a mechanical explanation.

The problem of the continuity in time of the forms and properties of living matter forced itself on the great propounder of the modern theory of Descent, on Darwin. He looked upon the principle of "Reversion ${ }^{1}$ - this power" of calling back to life long-lost characters-as the most wonderful of all the attributes of inheritance."

At the end of his second great work, ten years after the appearance of the 'Origin of Species,' he ventured on a hypothetical explanation, his theory of "Pangenesis," "which implies that the whole organisation, in the sense of every atom or nnit, reprodnces itself ; hence ovules and pollen-grains, the fertilised seed or egg, as well as birds, include and consist of a multitude of germs thrown off from each separate atom of the organism." 2 This idea, as the author himself admitted, and as has since frequently been pointed out, was not fundamentally new : it had been anticipated by Buffon in his celebrated "organic molecules," and since Darwin it has been restated and adapted in various modified forms. It is hardly an explanation, but it is a statement which emphasises the great fact of modern biology, - the fact lrought out by the cellular theory, that the units of life are not the large visible organisms which were formerly studied by preference, but the inmumerable, infinitesimal living beings

1 'Animals and Plants under Domestication,' vol. ii. p. 372.

2 'Animals and Plants under
Domestication,' chap. 27, vol. ii. p. 358. 
called cells which, through growth and reprouluction by division and fusion, naintain lifo as a continuous unique phenonenom.

Into this view, which mucler the special form of pangenesis has not found much favour, lut which, nevertheless, in some form or other, forees itself more and more on our attention, l'rofessor Weismann has imported a further distinctive feature, not prominently brought out by Darwin, though it also dates farther lack ${ }^{1}$ than the present generation.

1 The history of the knowledge and theory of sex and heredity las. been switten in Euglish by I'rots. l'atrick (iekles and J. Arthur 'Thomson, in a book entitled 'The Evolution of 'sex' (1st ed. 1989); in French by $\mathrm{M}$. Yves Delage, in his much-quoted work, "La structure du Protoplasua et les Théories sur l'Iérédité et les grands problènes de la Biologie' (1895). 'The latter work contains elaborate criticisms, and finally inclines towards a theory of life termed in France "Organi. cisme," the main idea of which is the assumption of two distinctive factors in all the phenomena of living matter-viz., "Organisation and Environment." This view, according to the author, has not yet gained sufhicient strength to furm a definite current of thought like the three earlier views defined by the terms "Animisume," "Evolutionisme," "Micromérıme." The first of these centres in the irlea of vital force, the second in the older school of evolution; the last hegins with buffon, and comprises the modern theory of Evolution with spencer, Darwin, Hacckel, Weismann. Of the last II. belage rays: "Ce demier est, jour le moment, l'ouvrage le plus jarfait eréé pour expliquer l'Hérédité et l'livolution. Nous croyons avoir montré qu'il est bâti l'hypothères fragiles, invraisenblables, et, tout en rendant justice au talent de son anchitecte, nous conseillons de l'admirer de loin et de cemstruire ailleurs" ( 1.837$)$. " ()rganicisme" is represented by $W$. Roux, 1)riesch, and 0 . Hertwig, and is historically traced back to Discartes (p. sus), and to von liaer and claude liemard (1). 720). To the theories of the others, "les Organicistes opyosent le concours d'une détermination unculéré et des forces ambiantes toujours agissantes, toujours nécessaires, non comme sinple condition d'activité, mais comme élément essentiel de la détermination finale" (1. 720). As in this account the mames of lioux, Driesch, and 0 . Hertwig are placed together, it is well ts remark that since that time the two last-named authorities have in virious polemical publications signified the divergence of their fundinnental conclusions from the later attitude which l'rof. Roux has assumed. For those of my realers who desire to get some insight into the drift of this most recent and adranced controversy, in which questions of principle, of reientific and philosophical method, alternate with discussions of minute 
Growth by intussusception and assimilation has long been recognised as the characteristic property of all living matter, of every living cell. Mechanical causes suffice to explain the further process of division as a necessary consequence of continued growth, the formation of new cells out of existing ones, the process of reproduction. Only in the lower organisms, however, does reproduction exist simply as multiplication by division. In all higher organisms at least, reproduction by division seems connected with the phenomenon of death of a portion of the dividing organisms: a differentiation seems to set in between the new cells, some gradually losing their power of self-multiplication by division, and thus being doomed sooner or later to arrive at the end of their organic existence; while others retain this power or regain it by uniting with others - the process of fusion of male and female elements - and seem thus to be specially endowed with the work of reproduction-i.e., the preservation of the continuity of life. The great morphologist Richard Owen, about the middle of the century, in a tract on Parthenogenesis, remarked that "not all the progeny of the primary impregnated germ-cell are required for the formation of the body in all animals : certain of the derivative germcells may remain unchanged and become included in

embryological derelopment, assisted or disturbed by experiments carried on in microscopic dimensions, I recommend, besides the larger works of Hertwig and Roux already referred to, the highly suggestive writings of Hans Driesch, notably lis 'Analytische Theorie der organischen Entwickelung' (1894), and 'Die Biologie als selbständige Grundwissenschaft' (1893). As a very helpful introduction to the original views of this writer, English readers will welcome the concluding chapter of Prof. E. B. Wilson's book, 'The Cell in Development and Inheritance' (1896). 
that body, . . . so inchuled, any derivative gemm-cell or the muclens of snch maty commence and repeat the same proeesses of growth by imbibition, and of propagation ly. spontaneous fission as those to which itself owed its origin." 1 We have here the first enunciation of that idea of a differentiation between the gem-substance and Gerlin-si+ll. stanice and boxly-sub: the body-substance, between that portion of living stalice. matter which is destined to prescrve the contimuity of life, and that other portion which, destined to differentiate more and more into the aggregate of living cells, each bearing a special form and earrying ont a special function in the econony of the higher organisms, is at the same time doomed to death, gradually losing, as it does, its power of assimilation, growth, and division-i.e, of self-preservation. Prof. Haeckel in 1866 , and $\mathrm{Dr}^{*}$ Jiger in 1877 , elaborated the illea further, pointing out that the "germinal" element or substance was that portion which in the process of division is reserved for the preservation of the species (the $\phi \tilde{v} \lambda$ ov, hence termed the phylogenetic portion), whereas the "personal" element or substance goes to form the body or individual (the oै $v$, henee terned the ontogenetic portion). ${ }^{2}$

I Jarwin quotes this passage in a lisistorical note to his theory of "l'angenesis" in the ennclurling ehapter" of his "Animals and Plants unrler Domestication' (rol. ii. p. $375)$. He alds further, "By the ageuey of these germ-cells Prof. Owen accounts for parthenogenesis, for propagation by self-division rluring successive generations, and for the repairs of injuries. His view agrees with mine in the assumed transmission and multiplieation of his germ-cells, but differs fundancentally from mine in the helief that the primary germ. cell was formerl within the ovarium of the female, and was fertilised by the male. My genmules are sup). posed to be formed, yuite intepend. ently of sexual concourse, by each seprarate cell or unit throughout the body, and to be merely aggregated within the reproductive organs."

"Complete references to the rarlier statements of this theory, which, through the various writings of Prof. Weisurann (since 1881, when he ract a paper, "On the luration of life," before the 
This provisional statement, which emphasises the now generally recognised difference between the germ-substance and the body-substance, requires, however, two further qualifications in order to embrace the great characteristic facts of life and death as modern embryology and the phenomenon of descent have unfolded them.

Only in rare instances can we observe the contimuity of cells-i.e., of those organisms which, so far as our knowledge goes, form the ultimate units of living matter. Weismann recognised, as did the great botanist Nägeli, and long before both of these the philosopher Herbert Spencer, that though in the cell, with its nucleus and protoplasm, we may have arrived at the last microscopically visible independent units of life, we must-with the atomic theory in chemistry - assume the existence of much smaller units in all living matter, compared with which even the nucleus of the cell is a very complex aggregate. If the continuity of life is dependent upon that of an underlying living substance, this substance must be only an infinitesimal portion of any visible cell Germplasma and body. plasma. or nucleus. The conception of a continuons germinal substance has thus taken refuge in the more refined conception of a germ-plasma, as distinguished from the body or somatic plasma: the former is immortal within the limits of the conditions of organic life, the latter is

Naturforscher - versammlung at Salzburg, reprinted in 'Essays upon Heredity,' tran*l. by Poulton and others, Oxford 1889; see also the 'Studies in the Theory of Descent,' transl. by Meldola, 2 vols., 1882, and the earlier essays of Weismann mentioned in the preface, p. viii.), has become both scientifically and popularly recognised and debated, are given in Gedrles and Thomson, 'The Evolution of Sex,' p. 93 ; also in M. Delage's great work, p. 349, \&c., and in Wilson, 'The Cell,' p. $295, \& c$. 
perishable, mortal, doomerl, after temporarily serving the purposes of individual development, to disappeal from the category of living matter.

And secombly, it apjear's that the gerninal substance or germ-plasina, when once differentiated from the tionot germ. personal substance or body-plasma, cannot, as a rule, perform maided the function of continuous preservation of the species or phylum. In all the higher animals the germ-substance ajpears in two distinct seemingly complenentary forms, and only by the fusion of these does the development of the germ-substance become possible.

The great difticulties which stand in the way of applying these conceptions (which have found an exhaustive exposition in l'rof. Weismann's ' Essays on Deseent and Heredity') to the vegetable kingdom have been pointed out, and have prevented their general adoption by biologists ${ }^{1}$ nor have the elaborate moditications introduced in Prof. Weismann's later writings tended to make them more aeceptable; the idea, nevertheless, of a fundamental differentiation of the elements of living matter into germinal and personal has got hold of the scientific mind at the present day, and cannot be

In the objections of Prof. Strasburger, who pints to the fact that in the cisse of begonias the frag. ment of a leaf planted in inoist sand can reprouluce the whole plant; of Prof. Vines, who show that whole group) of champigums, which propagato annually, are nevertheless rich in genera and species, which have evidently descencied from one an. other, sro. Yves l telage, 'L'Hérédite, 1. 526, \&e.; ' Nature.' vol. x. 1\% 621; aler, $U$. Hertwig, The Isiological
Problen of 'To-day,' tramsl. hy P. C. Mitchell (1596). \}. 40, \&e. On the discovery of Weismann " that in parthenogenetic ova ouly ane polar globule is formed, while there are always two in ovia which are impregnated," and the "numentary" presumption in farour of his theory which it afforied, see. "Finsays on Heredity,' 1'. 3:3:3, \&c.: Gedeles and 'Thomson, " Evolution of sicx," 1. 180, sec. : and l belage, 'L'Héré(3ité, 1. 151. 
passed over in a history of Thought. Moreover, it has made itself felt by giving rise to two separate views of the cause of variation-i.e., of that phenomenon in the living creation on which the entire modern theory of descent is founded.

If it be true that the preservation of the species, the continuity of living forms, is dependent on the germplasma, whereas the somatic plasma, from this point of view, only serves individual ends and is a receptacle or temporary dwelling-place for the germs which it transmits but does not create, the experiences of the body, its changes and development, can have little or no influence on the hidden germs and their further history. Thus 56. Weismann is led to a denial of the influence of enWeismann $v$. Lamarck. vironment, of habit and acquired characters, except in those cases where, as in the lower organisms, no differentiation has set in between the germinal and the personal substance. This amounts to a negation of those modifying influences which Lamarck emphasised, and which play such a great part in the theories elaborated by Darwin, Haeckel, and especially by Herbert Spencer. On the other side, it has led Weismann to lay a much greater weight upon sexual selection and the effects of crossing in the process of descent and the phenomena of heredity. But for sexual selection, and the endless combinations of different germ-plasmas, there would, according to Weismanu, be no variation, and hence no development of the higher forms of life. The controversy turns mainly upon the inheritance of acquired characters, of which indeed no genuine and authenti- 
cated ease seems to have licen established. ${ }^{1}$ On the other side the influence of crossing, of the repeated division and fusion of different germ-plasmas, to which Darwin in his later writings attached more and more importance, and on which Weismamn relies exclusively for an explanation of variation and natural selection, is denied by some biologists to tend in the direction of the gradual growth of definite characters: they point rather to the obliterating and diluting influence of such promiscuous fusion, and they maintain that the presence of an environment which always acts in a constant manner ${ }^{2}$ is indispensable.

If we now look lack for a moment on the fundamental change of ideas which the century has bronght about in the biological aspect of nature, we are bound truly to halt in astonishment. In $n$ o department of thought have comparatively small beginnings and detailed discoveries, referring to infinitesimally small phenomena, led to such revolutionary ideas concerning those phenomena which most intimately affect our personal interests - the problems of life and death, of conduct and of health. The whole of this change has been brought about by introducing and extending those

1 It is needless to give special references, as all the recent works on the subject, which have been largely quoted in this chajter, deal with this point. See, however, Y'ves I)elage, 'L']lérédité, p. 196, for a very complete biblingraplyy. He concludes as folluws: "Il n'est pats démontré que les modifications acquises sous l'influence des con‘litions de vie soient généralement héréditaires, mais il parait bien certain qu'elles le sont quelquefois. Cela dépend rans doute de leur nature. H'ailleurs on ne sait jas quelle est dans ce résultat la part de la transmission des modifiations somatiques anx eellules germinales et celle de laction direete des conditions ambiantes sur colles-ci" (1). 221 ).

"Hertwigr, 'The Cell,' 1’ 319. 
methods of investigation and reasoning which have been learnt in the mechanical, physical, and chemical sciences: the processes of observation, measurement, and calculation. And yet it may be asked, have we come nearer an answer to the question, What is Life? At one time, for a generation which is passing away, we apparently had. But a closer scrutiny has convinced most of us that we have not. The study of life has indeed been transferred from the higher and more complex forms to the lower, the minuter, and the simpler; and now lingers by preference among cells, germs, and primitive organisms, ont of which we have learnt to consider the higher ones as put together on the principles of co-operation, division of labour, and mutual 57. accommodation. The problem "What is Life?" has Two aspects of the problem of life.

in all this gained a twofold aspect. Wherein consists the peculiarity of the smallest unit of living as compared with not-living matter? In organisation we are told, in growth through intussusception, in metabolism; but we are far from being able mechanically to describe these phenomena or processes. The spectre of a vital principle still luxks behind all our terms. ${ }^{1}$ On the other

1 If we broadly summarise the properties peculiar to living things which the nineteenth century has dwelt on in an original manner under the three conceptions of adaptation (fitness), selection (natural or sexual), and organisation (order or harmony), the question presents itself, Is any of these much-used terms intelligible or definable without reference to something which is extraneous to the object we treat of, this reference existing in our own thinking or contemplating mind, and, if actually present in natural objects themselves, then also indicative of the existence of some immaterial principle? Though this is manifested in mechanical contrivances which it has left behind with its signature npon them, it is nevertheless vaguely analogous to the selective, purposeful, or orderly performances of a human intellect The exclusive study of detail on the one side, the aspect of the whole on the other, will always induce opposite answers to this question. In addition to the literature given in the notes to this chapter, I may refer 
side, the union or co-operation of many essentially sinnilar units in a complieated organism brings out nore and more, as we aseend in the seale of living things, a new phenomenon, a new kind of unity, that which we term "individuality," the wealth of an inner self-conscions life, to which the older school of biologists attached primary importance. Life accordingly has now for us two sides -first, the life of the smallest, the most primitive unit of living matter, say the cell, the amaba, or, if you will, the idioblast, the gemmule, the germ-plasma, the physiological mit. Secondly, the life of the eomplex soeiety of eells, the higher organism in which the inner world with all its mental phenumena has beeome manifest. How is the unity of this higher complex possible? In what does it eonsist? What tan we know of it? Neither the physiological nor the psychological nnity is intelligible to us. An eminent biologist, to whon we owe the ereation of an entire new seience, the late Professor Virehow, the founder of Cellular Pathology, has told us recently ${ }^{1}$ that only since biologists have ceased to try to understand the unity of life in the higher organisms, the psychological unity, and have realised the fact that the unity of life is in the autonomous eell, has biology in theory and practice made much progress. Be it so. It seems likely that the progress of biology depends entirely on the enltivation of the mechanical view; but from another and

to the following tracts which deal specially with the problems of mechanism and vitalism. Hans Driesch,'I)ie mathematisch-mechanische lietrachtung morphulogischer. Probleme rler Biologice' (Jena, 1s91):
O. Iïtschli, 'Meehnnismus unel Vitalismus' (Leipzig, 1901): Lugen! Albrecht, "Vorfragen der Biologie (Wiesbade11, 1599).

1 In the II uxley Leeture of 1 s 95. 
equally legitimate aspect, the unity of the complex as the bearer of all the phenomena of higher or inner life is equally important. In many ways it is a counterpart of the other, showing a peculiar continuity of its own, that continuity which I have made the special subject of this work. In proportion as the biological view of nature has become the science of the cell, another science has grown up which sets itself to study this higher phenomenon of living matter, the phenomenon of mind, directly by the methods of the exact

58.

Transition to psychophysies. sciences. This is the modern Science of Psycho-physics. Even the microscopist and biologist of the most modern type are occasionally startled by phenomena akin to those which commonly are only visible in the highest organisms. Psychical existence, an inner side to the external phenomena of motion, has accordingly been attributed by eminent representatives of the mechanical view of biological phenomena to the lowest, the most primitive, unit of living matter. Another school of science has set itself to study this inner side of living organisms in its more perfect, as it were fullgrown, manifestations, and by appealing in addition to the facts only known by introspection or self-consciousness. With the history of this movement, so far as it belongs to exact science, I propose to deal in the next chapter under the general title of the Psycho-physical View of Nature. 


\section{CHAP'TER XI.}

ON THE PSYCHO-PHYSICAL VIEW OF NATURE.

Is the three foregoing chapter's I have attempted to trace 1. Ix the thice for and conerete the development of the different aspects mider which our sciences. knowledge of the real things which surround us, and of natme as a whole, has been extended in recent times. I have brought these different aspects which respectively consider things natmal according to their forms, their genesis, or their life and purpose, under the general name of the hiological as distingnished from the abstract view, with which I dealt in the four previous chapters. The abstract view tries to arrive at the general properties of all things, which it has snceeded in om times in smnming up under the great generalisations of Attraction, Atomism, Kinetics, and the doctrine of Energy. The biologieal view is interested not so much in general properties as in real specimens - the things, beings, and phenomena in which we see the general properties exemplifier and beeme real and in their actual mion or totality which we call natme. The abstract sciences started on their modern career with mathematics, and progressed through the derelopment and application of VOI. II. 
the mathematical methods to the data furnished by observation and experiment; the biological or concrete sciences began with a study of living things, and have progressed immensely in our times by viewing these not in isolation, but in their relations to each other and to the surrounding lifeless world-the so-called environment. An exact treatment, that to which the term "scientific" has been pre-eminently applied, seems here also to depend largely, if not exclusively, on the degree to which the mathematical processes of numbering and measuring can be applied, and on the utilisation of the general results arrived at in the abstract sciences.

Their

different methods.

The method of the abstract sciences is that of building up from small beginnings, by the process of summation or integration, intricate complexes which not infrequently are found to correspond to phenomena of actual experience. It has at its command the unlimited resolving powers of the calculus, and the well-established assumption that things natural are made up of numberless particles entering into innumerable combinations. The whole is thus for the mathematical view the sum of its parts. The concrete or natural sciences, on the other hand, start with the ready-made things or creatures of nature, or on a larger scale with the great order and economy of our world or the universe, and only descend into the minutice of the observatory, the dissecting-room, or the laboratory, with the hope of better understanding the great and complicated objects of their study. The greatest progress in the abstract sciences has been made by those minds that could concentrate their attention on special points, not infrequently expressed in 
mathematieal formule, and expond their view through applieations: the greatest progress in the natural seiences has been made hy those who started with a large and comprehensive view of things natural, and gradually descended into detail. Newton, Lagrange, Fresnel, and Helmholtz are good examples of the former; Humboldt, von Baer, Claude Bernard, and Darwin of the latter.

Now, it is a frequent experience that in the study of things natural, through the unavoidable process of dissection and analysis, the subsequent synthesis or summing up has not carried the student back to the real thing from which he started, but to some artificial produet differing essentially from the natural object. The real essenee of the thing seemed lost when its parts were examined by themselves or in their apparent aggregation. A prominent example of this kind is to be found in the living organisu. Theories have aceordingly been formulated which looked upon life as a speeial principle to be superadded to any coneervable agrgregation of mechanieal proeesses, in order to raise then from the lifeless into the living order of things. The last ehapter' dealt with the various biologieal hypotheses, of which three are conspicuous: the purely meehanical, aceorling to which the living organism is metely a very complieated ehemical molecule; the vitalistic, which establishes an essential difference between the action and constitution of a living and a lifeless mit of matter; and an intermediate view, which looks mon organisms as manufactured nuchines built up according to some plan, design, or irlea, the nature of which ean be further inquired into, but which does not try to throw any additional 
light on the mechanism itself, the working of which, like that of a clock, can be described on purely mechanical lines and without reference to the idea which preceded its construction.

According to many prominent naturalists, the evident design and purpose which characterise so many phenomena of living matter are explained on purely mechanical lines by the inherent or forced teleology of living things, which through over-production have to submit to an automatic process of selection or survival. To others this automatic process does not seem to suffice, and they assume a principle of progress which acts in a regulative manner. This vitalistic view is further supported by taking into account an extensive class of phenomena which I have, so far, hardly noticedthe marvellous properties of the higher creations of the animal world which exhibit the phenomena of 3. consciousness or of an inner experience. That these experience. phenomena belong to the realm of natural science as much as any other properties of living things cannot nowadays be doubted. The division into natural and mental science can no longer be upheld, or only with a very different meaning from that which it had for a bygone age.

It will be my object in this chapter to give an account of the various and changing aspects which this great phenomenon of an inner or conscious life has presented to naturalists - i.e., to those who have approached the phenomena of Mind from the side of nature, and of the different lines of research and reasoning along which they have dealt with it. I shall comprise the whole of 
this section of scientific thought under the general term of I'sycho-physics. ${ }^{1}$ It refer's to the borterland or ${ }^{4}$ common ground where physical and mental or psychical inysic. phenomena meet or interact.

Although the term psycho-physics is quite modern, the iclea of a special science dealing with the relations of mind and body, or of the physical and mental hife of the human organism, has been prominently before the scientific world ever since Cabanis published his celebrated 'Rapports du I'hysique et du Moral de l'Homme,' in which the well-known passage occurs which has been frequently repeated, modified, and quoted with varying approval or reproach ${ }^{2}$ "In order to arrive at a correct

1 The term was first used by G. T. Fechner in the well-known work bearing this title, of which I shall have more to say in the course of the chapter. 'This work, dealing mainly with a certain numerieal relation, narrowed the term down to a special investigation, whereas the larger problem, the study of the interaction of mind aud body by the methorls of the exaet sciences, wis variously designated as physiological psychology, mental physiology, psycho-physiology or physiolugy of the soul. As there is a teudeney to regard physiology more and nore as the physics of the living organism, it is evident that physies is the larger terun; and in dealing with the relations of the physical and the pryehical in the widest senke, the term psycho. physics seems the more approyriate.

¿ 'Eurres eompletes' de Cabanis (1834), vol. iii. p. 159. The simile hits attained a sort of historieal celebrity through the drastic version which was given to it by liarl Vogt in his 'Physiologische Briefe' (1847), p. 206, where, with a distiuet inteution of rousing an isthetic disapproval, he comparethe function of the brain with the secretion of bile by the liver and of urine by the kidneys. This dictum, which he repeated in his eontroversy with liurlolf Wagner, led in the midalle of the century, as Du Bois-lieymond lells us, to a kind of systematic ehampionship of the soul, the eomparison with the kidneys being lookerl on as a degrating offence. "Physiology, however, has no knowledge of such grades of dignity. As a scientific problem the secretion of the kidneys is to her of the same dignity as the investigation of the eye or the heart or any other socalled noble organ." Tourt used the simile as an illustration of his purely materialistic view. Lange ('Hist. of Materialism,' vol. ii. 1. 242) shows that with Cabunis the dietum is by no means bound up with such a view, as he really was a puntheist. The mistake, say's Du lisois-Reymond, dues not lie in the comparison, but in the implied suggestion, that psychical 
idea of those operations from which thought arises, we

Cabanis' simile.

must consider the brain as a particular organ, destined specially to produce it in the same way as the stomach and the intestines are there to perform digestion, the liver to filter the bile, the parotid, maxillary, and sublingual glands to prepare the salivary juice."

The argument which led Cabanis to draw this parallel between the functions of the brain and those of other organs of the human body was based upon the philosophy of Locke, which had been domiciled in France by Condillac and Helvetius. This philosophy, in its popular version, taught that all our thoughts and ideas were ultimately made up of sensations. ${ }^{1}$ On the other side,

activity could be "explained through the structure of the brain, as secretion can be explained from the structure of a gland " ('Reden,' vol. i. p. 129).

${ }^{i}$ Cabanis (1757-1808), in the preface to the 'Rapports,' \&c., p. 11, gives a list of contemporary French writers who, following in the line of Locke, to whom "philosopliy is indebted for the greatest and the most useful impulse," have taken up different sides of the doctrme. Of their writings a very clear and exlraustive analysis will be found in II. Picaret's 'Les Idéologues, Essai sur l'histoire des idées et des théories scientifiques, philosophiques, religieuses, \&c., en France depuis 1789' (Paris, 1891). Cabanis's own position is very clearly lefined (p. 16) when he says that "Les opérations de l'intelligence et de la volonté se trouveraient confondues à leur urigine avec les autres mouvements vitaux : le principe des sciences morales, et par conséquence ces sciences ellesmêmes rentreraient dans le domaine de la physique; elles ne seraient plus qu'une branche de l'histoire naturelle de l'homme: l'art d'y vérifier les observations, d'y tenter les expériences, et d'en tirer tous les résultats certains qu'elles peuvent fournir, ne différeraient en rien des moyens qui sont journelle. ment employés avec la plus entière et la plus juste confiance dans les sciences pratiques dont la certitude est le moins contestée." This was written in 1502. M. Picavet says of Cabanis witl much truth: "Le continuateur d'Hippocrate, de Descartes et des philosophes du XVII [ [ ${ }^{\text {me }}$ siècle, a été un précurseur de Lewes et de Preyer, de Schopenhaver et de Hartmann, comme de Lamarck, de Darwin et de bien d'autres penseurs qui appartiennent aux écoles les plus différentes, et ne soupconuent quelquefois même pas que les idées dont ils sont partis leurs sont venues in. directement, mais par des intermédiaires authentiques, de l'auteur des 'Rapports du physique et du inoral " " ('Les Idéologues,' p. 264). M. Picaret also gives valuable explanations how it came about that 
the physiologists of the eighteenth century, notably Haller, had demonstrated that the properties of the physieal organism enlminated in those of the nerrous l,ocke and system-irritability and sensibility. The phenomenon of sensibility, of producing and combining - as it were digesting - sensations, was thus the function of the brain, or the central organ of the nervons system, as other processes were the functions of other organs or physiological apparatus. Cahanis was led on from medical ${ }^{1}$ studies, as Locke had been hefore him, to the study of mental and moral subjeets, and he former the conception of a science of Man, or Anthropology," divided into P'hysiology, the Analysis of Ideas, and Morals, which would ultimately be of as much nse for the practieal purposes of edneation and government as the exact study of other natural phenomena then eultivated in France for the purposes of medicine, industry, and material eivilisation. Although it may be admitted that Cabanis created ${ }^{3}$ physiological psychology, and that he east far-reaching glances into the neighbouring departments of animal,

the line of philosophical thought so clearly indicated by Cabanis was not more systematically developed in France at the time, and, like many other lines of research whicl origrinated in that country, had to be re-discovered fifty years later in other countries. The question is important, and may occupy us later on. See, however, regarding the disfavour into which the "moral" suiences fell owing to political reasons, vol. i. p. 149 of this work.

${ }^{1}$ Cabanis blames in Condillac and Helvetius that they knew nothing of physiology. "s"ils eussent mieux comnu l'économie animale, le premier aurait-il pu soutenir le sy'stème de l'égalité des esprits? le second n'aurait-il pas senti que l'ime, telle yu'il l'euvisalge, est uue faculté, mais non pas un ètre; et que, si c'est un être, ì ce tilre elle ne saurait aroir plusieurs des qualités qu'il lui attribue" (ibid., p. 66 ).

" "C'est ce que les Allemands appelleut l'anthropolngie; et sous ce titre ils comprennent en effet les trois objets principand dont nous farkns" (Cabanis, "Luvres," vol. iii. p. 40).

" Picavet, loc. cit., 1). 292. 
embryological, and morbid psychology, from which he expected much assistance, his ideas remained vague, as did those of the contemporary school of the "Idéologues," among whom Destutt de Tracy $^{1}$ deserves honourable mention as having conceived the plan of a psychological treatment of grammar. Their merit lay more in drawing the plans of the new science of psychology as a natural science in its largest sense, and of urging its scientific and exact treatment, than in making a real and fruitful beginning on special lines.

It is a remarkable fact that the first attempt to analyse in detail one of the special instances of psychophysical interaction came about a hundred years earlier from that successor of Locke who has always been counted as the extreme idealistic development of English 7 . speculation. Bishop Berkeley's 'Essay towards a New Theory of Vision' (1709) has been called "the veritable historical starting-point of psycho-physical investigation." 2 Although averse to any exact theory of the universe, deeming it "beneath the dignity of the mind to affect exactness," 3 and at war with the mathema-

1 Picavet (p. 398) says of Destutt de Tracy (1754-1836): "Venu par les sciences à la philusophie, D. de Tracy a domné à l'idéologie un nom et un caractère positif. S'il a cru, à tort, qu'il pouvait la constituer de toutes pièces, il a fort bien vu que, pour devenir une science indépendante et complète, elle devait s'appuyer sur la physiologie et la pathologie, sur l'étude des enfants, sur celle des fous et sur celle des animaux. Il l'a unie intimement à la grammaire et à la logique, à la morale et à l'économie politique, à la législation et à la politique."
2 Dr Fdmund Montgomery, in his very interesting and valuable critical analysis of 'Space and Touch,' three memoirs contained in the tenth volume of the first series of 'Mind' (1885), p. 385.

${ }^{3}$ See 'A Treatise concerning the Principles of Human Knowledge,' \$ 109: "As in readiug other books, a wise man will choose to fix his thoughts on the sense and apply it to use, rather thau lay them out in grammatical remarks on the language; so in perusing the rolume of nature it seems beneath the dignity of the mind to affect au exactuess in reduc- 
ticians, ${ }^{1}$ as Hobles had been before him, lierkeley hatd at clear conception of the follwwing definite problem: By what succession of physical and mental expreriences, by" what "organic and vital rlata," to we becone aware of space and of body or matter? His answer, which makes taetile sensations the hatse, has been adrocated and quoted by English psychologists of the Assoeiation school up (1) the present day, and forms the text for their various explanations.

The genesis of space perception was much discussed in the cirele of Locke's friends, Molynenx proposing the celebrated query ${ }^{2}$ named after him, and Cheselden describing at length, in the Philosophical Transaetions, the experiences of an adult blind patient who had received his sight by eouching. 'The eighteenth century brought other isolated researches of an experimental or mathematieal nature, which nray be regarded as the heginnings of an exaet treatment of the relation of psy-

ing each particular phenomenon to gencral rules, or slowing how it follows from lhem. We should propose to ourselves nohler views, such as to recreate and exalt the nind," de. In the following paragraph Berkeley refers to the "Principial" as "the best grammar of the kind" he was speaking of.

1 A very full account of this controversy will be iomel in a paper by Prof. Geo. A. Gibson in the 'Proceedings of the Edin. Math. Soc.,' vol. xiii.

2 The yuery is griven in Locke's "Wssay, liook 11. eh. ix. \$ 8, as follows: "Suppose it man born blind, and now adult, and taught by his toueh to distinguish between a cube and a spliere of the same metal and niglily of the same biguess, so as to tell whoth he felt one and the other, which is the eube and which the sphere. Sup. pose, then, the cube ant sphere placed on a table, and the blind man made to see: Query, whether by his sight, before lie touthed them, he could now distinguish, and tell, which is the globe, which is the cube? 'To which the acute and juclicious proposer answers, No." For a full aualysis of actual cases, such as that of Cheselden, and more recent ones, see lliudt, 'Physiologische l'sychologie,' vol. ii. 1. 233. 'That berkeley was, however, neither a psycho-physicist nor a physiological psychologist in the moleru sense, is well remarked by Camplell Fraser in his exily on Berkeley (1)lackwood"s " Philos. ('lassicy," "Berkeley,' p. 45, \&c.) 
chical with physical phenomena. Fechner, the founder of psycho-physics as an independent doctrine, refers notably to two ${ }^{1}$ such instances. They were contributed $\delta$. by two great mathematicians, Daniel Bernoulli and

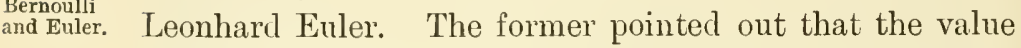
which we attach morally to the addition to any material possession is not measured by the actual magnitude of such addition, but by the relation it bears to that which we already possess. The first sovereign earned by a poor and starving labourer has an almost infinite value compared with what it has for a person already possessed of a million. Laplace and Poisson referred to this statement of Bernonlli, and introduced the terms "fortune physique," "fortme morale," showing that they stand in a simple mathematical relation. The same relation was shown by Euler to exist between our estimate of musical intervals in the harmonic scale and the difference of the number of vibrations of the strings which produce the two notes. It was above a century before Fechner correlated these isolated remarks with observations of modem psycho-physics in his celebrated law, of which more anon.

On the whole, little progress was made during the eighteenth century in the department of research I am now dealing with; but the end of the eighteenth and the beginning of the following century brought several important discoveries, some of which were at the time much over-estimated, whilst others were for a long time forgotten or overlooked.

The first is the accidental discovery by Galvani in. 1 'Psychophysik,' 1860, vol. ii. p. 548, \&c. 
1786, follower, fifteen years after, hy Volta's greater. invention. The late eminent Prof. Du Bois-Reynond, "lectricity. in various passages ${ }^{1}$ of his scientific and literary writings, has told us of the recurrent faseination which the futa moryana of Electricity has exercised over those interested in the explanation of the phenomena of innervation; how this seductive clue has been, in the

1 See vol. ii. 1'l'. '212, 356, 229 of Du l;ois-Reymond's 'Reden,' also lis "Lntersuchungen iiber' thier. ixche Electricitit? (1545). vol. i. 1'p. $30-128$. Une of the fir:t tu take up in the interests of nervons physiology the elue which Galvani's diseovery atforled was A. voll lfumboldt. who published in 1797. three years befine Volta's discovery, his valuable "Versuche iiber" die gereizte IIuskel- und Nervuntaser, nebst Vermuthungen iber den ehemiseluen Process des Lebens" in der Thier- und Pflanzenwelt.' A lucir aceount of Humbolelt's work is given by Prof. Wundt in the thirl volume of the German editions of Brubns' 'Jife of Humboldt,' ए. $301 \mathrm{sq} \%$. "It is clifficult," lie silys, "to picture to oneself nowalays the exeitement which the olservations of Galvani producerl in the scientific world. - . Sueh experiments had alnost become a general subject of entertaiument in cultured eircles. . . . It almost alpeared is if what at that time wis louked upon as the most general property of living matter, irritalility, were by the experiment of Gilvaui to be fol the first time unveiled in its real essence. . . At the time when Humboldt male his experiments the contest was still going on between the followers of (ialvani and Volta." This referred to a physiological or purely physical explanation of the phenomenon.
" Barely three years after the publication of Humboldt's work the discovery of Volta's pile put au abrupt end to all theories which were lawed upon the physiological origrin of gatranic phenonena. The brilliant development of physical galvanisu irom that mument yshed the plysiological aspect of electricity for a long time into the lackground. . . Humlsolelt's work was forgotten " (1). 310). Tn the meantime Hunbolit had travelled in South America, where he had - inter mlia observed the "natural eleetromotors which stand in such extraorlinary comnection with the nervous system" of the electrical eel (Ciymnotus arctricus), giving a thrilling (tescription of a battle between the horses and the eels which he witnessed in the waters of Calabozo. (See Humboldt's - l'ersomal Narrative,' vol. iv. p. 345 ‘rq. ; also 'Ansiehten der Natur,' vol. i. 1. 33.) Interest in the subject of animal electricity was again revived by Italian physiologints atrut the year 1\$35. Nobili, Marianiri, Sinti-Linari, Matteucci repeated and enlarged the experiments of ralvani, and through the intluence of Humboldt and Johamnes Miiller. the study of the whole subject was eompreliensively taken up at Berlin by lou liois-Jieynond about 1810, and exhaustively treated in his great work on the subject (vol. i. 1848, vol. ii. 1860). 
course of more than a century, alternately taken up with enthusiasm, and abandoned as misleading. At the turn of the centuries the mania for animal electricity was at its height. Men like A. von Humboldt took up the study with eagerness, and sovereigns like Napoleon offered special prizes, in the hope that here at last the secret of life and consciousness would be revealed. The school of the "Naturphilosophie" in Germany seized upon the suggestion of polarity and polar forces contained in the phenomena of galvanic action, and, supported by the still more mystical processes of the so-called animal magnetism which had been exhibited by Mesmer twenty years earlier, worked up these vague indications into fanciful theories of vitalism and animism. This brought the whole line of thought into discredit, drove away the soberer, more scientific students of nature, and retarded real progress in the knowledge of the electric phenomena of the muscular and nervous system for fully a generation. At length in the school of Johannes Miiller the subject was again approached and was put on a firm scientific basis by Helmholtz, and notably by Du Bois-Reymond. It is now known that, as in inorganic, so also in organic systems, the energy proper to them can appear under the different forms of mechanical, thermal, electric or chemical energy, but also that in none of these can be found pre-eminently the principle of life, still less that of consciousness.

10. Phrenology.

Another important line of research which has had an equally fluctuating development, being sometimes enormously exaggerated, to the damage of sound pro- 
gress, sometimes repudiated and treated with wholesale contempt, was that started by Gall, who from the year 1805 onward, and latterly in conjunction with Spurzheim, ${ }^{1}$ started on an anatomical description of the brain as the centre of nervous and conscious mental

I The two most prominent teachers of phrenology were Franz Joseph ciall (1758-1525) of Pfor\%heim, and Joh. Christ. Spurzheim (1776-1834) of Trier, the former. in excellent doctor, the latter a skilled anatomist. 'Their influence was ceutred in Vienna and l'aris. In England and America phrenulogy dates its popularity from George Combe (1785-1858). The term pluenology was suggented by George Forster about 1815, ten years after fall had started his 'Schiulellehre' or 'Craniulogy.' Of eminent nerlical anthorities, the great Broussais in France $(1772$. 1838) and C. G. Citrus (1749-1869) in (iermany were both phren. ologists, the latter attenpting to give the doctrine a more scientific foundation. Thongh phrenology was never popular in France, where the Academy of sciences from the beginning assumed a very sceptical attitude (sce above, vol. i. 1. 136 note), the opponents of (iall have always given him full credit for his alility, and for the great im. pulse he gave to anatomical science of the brain. Flourens, one of the most formidalle eritics of the doctrine of the special faculties, and consequently of the separate phren. ological organs and their location, nevertheless says: "(iall fut un observateur profond, qui nous a ouvert, avec génie, l'éturle de l'anatomic et rle la physiologie du eerveau. . . Je nouhlierai jamais l'impression que j'cprouvai la première fois que je vis rall disséquer un cerveau; il me semblait que je n'avais pas encore ru cet or- gane" ('[uot. by Langlois, 'Grande Encyclop., vol. xxif.p. 801). Some. what earlier than phrenology the science or art of physiognomici, which was known already and practised by the ancients, had a representative in Caspar Lavater of Zürich, who, from 1772 onwari, published his 'Physiognomische Fragmente, a work which, acconpanied by engravings by Chodowiechi, created a great sensation in philosophical, literary, and artistic circles, the whole of Europe being divided into followers and erities of Lavater. Among the latter was the celebrated Lichtenberg of Götingen. Among scientific men were Camper in Holland, and later Charles bell in England; the former putting forwast the well-known theory of the "facial angle" as an external measure of intelligence, the latter publishing his 'Essay" on the Anatomy of Expression" (1806). In more recent times no less an anthority than Challes Darwin took up the subject in his work (1) the "Expression of Emotions' (1872). Shortly hefore l'h. Piderit published his "Wissenschat tiches System der Mimik und Physiognomik' (1867) ; Duchesne (1862) his 'Mécanisme de la physionomie hu. maine'; and more recently the Ital. ian Mantegazza his "l'hysionomie et l'expression des sentinents' (French transl., 1585). A very readable essiy on the subject will be found anong Prof. Wundt's 'Eisiays' (1855). Shee also his 'Physiologische l'sychologie' (rol. ii. 1. $598, \&$ c., 4 tlı ed.) 
action. The scholastic notion of the older psychologists which divided the mental life into different powers or faculties as the body was dissected into parts and organs, lent itself to the idea of a localisation of these faculties or powers in different spheres of the brain, which Gall by a hasty generalisation maintained to be distinguishable on the external surface of the skull. Though these popular and practical applications, which form the basis of phrenology, were speedily and easily refuted, having always been regarded with suspicion by the medical profession, the anatomical labours of Gall were taken up and continued by others. Opinions fluctuated between the different views of Flourens, who insisted upon the unity of the central organ, as did Herbart in psychology on the unity of the mind; of G. H. Lewes, who assigns to the spinal cord together with the brain an important and initiatory rôle in conscious life; and of Hermann Munk and Friedrich Goltz, who by carefully devised experiments on living animals, by electrical irritation, and by systematic removal of parts of the brain, have to some extent succeeded in delimiting the special "spheres in which the various sensory nerves deliver their messages, and where the latter are transformed into conceptions and mentally stored." 1 Paul Broca had already, about forty years ago, succeeded in localising the powers of speech.

1 Du Bois-Reymond, 'Reden,' vol. ii. p. 558: "Though there is, in principle, no hope that the causal connection between material processes in the brain and consciousness will ever become clear to us, this does not hinder our penetrating deeply into a knowledge of those processes, or prevent such knowledge being of the greatest importance and of fascinating interest. As a first step in this direction there presents itself naturally to our understanding the localisation of the different faculties into which we natarally and systematically 
Whilst animal electricity and the eximnination of the brain were taken up with ardour, over-valued by poptularisers, and developed into fanciful theories which postponerl for a long time the sober inquiries of science, another very fruitful vein of reasoning and research was struck early in the century, but left mexplored for fifty years. Since then it has been followed with suecess and profit.

divide mental activity. Out of the desire for such localisation there sprang up the fundamental illea of the phrenological follies; but, as so often, here also scientifie superstition eontained a kernel of truth. In the same eortex of the brain in which (iall and spurzheim located their batly. cliosen thirty-five usental faculties, Nunk now describes the spheres in which the various sensory nerves deliver their mesagges, and where the latter are transformed into coneeptions and stored. 'Thus, for the first time in the domain of seusation aud intellection, a local basis of mental atctivity has been denonstrated, as had been done before by laul Broea in the domain of volition, in the localisation of the ficulty of ipeech." Most moclern pisclio-plyysicists woukl probably accept this statement with slight modifications; it is therefore well to note that one of the foremost and most original workers in this. field of research, l'rof. Fr. Goltz, takes a different riew of the result of the experiments of himself and others. He does not consiler Munk's teachings as the foundation of a physiology of the lrain, but lroks upon them as a system of error, and "lioper to see the day" when all the beatifully elaborated modern hypotheses of eircumseribed centres of the cortex will be laikl in the same grave in which Gall's phirenology rests" (quoted from
Goltz's nemoirs, 'C̈ber die Terrichtungen des Grosshirns,' in Ptluger's Arehiv, by Carl Hauptuann, 'Dje Metaphysik in der modernen Biologie" (1804), p. 2t0). Prof. Ferrier, whese "Functions of the Brain' (2nd ed.) is a standarl work in the English language, takes up a less negative position; yet lie rays (1. 23): "We are still on the threshold of the inquiry, and it nay be questioned whether the time has even ret arriver for an attempt to explain the meehanism of the brain and its functions. To thoughtful minds the time may seen as far off as ever." P'rof. Williau James of Harvard, in his excellent 'Principles of Psychology' (2 vols., 1891), gives, in his first chapter, a suceinct acount of the "Jocalisation-question," which, he thinks, "stands firm in its main outline" (rol. i. 1) 162). The standard work in the German language is l'rof. Wunlt's 'Physinlogische l'sychologie' (2 vols., 4th ell., 1s93), which gives in the first division (chaps. 4 , 5) a very exhaustive account of the experimental and theorelieal work on localisation. l'rof. Wunlt himself takes up a position lying between the doctrine of shay delimitation and that of a denial of local distinctions (rol. i. p. 15)(t), but aclunits that the whole yuestion is still highly contro. versial, though latterly the apparent clitlerences of opinion have been umach toned down (vol. i, p. 210). 
11. Dr Young's colour theory.

The beginnings of this line of reasoning are to be found in the writings of Thomas Young, who here, as in several other directions, "marched far in advance of his age." 1 During the last decade of the eighteenth century Young had been occupied with the study of the phenomena of Light and Colours; and, being a student of medicine, he had given equal attention to the physical phenomena and the physiological sensations of Light, going back to the beginnings laid in Newton's writings on these two important branches of Optics. ${ }^{2}$ I have treated of his epoch-making discoveries in physical optics in an earlier chapter. As to the physiological problem of colour sensations, he likewise reviewed Newton's work, and especially took up the remarkable fact noted by Newton, that it appears possible to refer the great variety of colour sensations to three primary elements, out of which the whole wealth of the colomr scale-varying in intensity, tint, and saturation-can be made up. In two distinct points he made a definite

1 Note, in many passages of Helmholtz's 'Physiologische Optik' (2ud ed., Braunschweig, 1896), and his often-quoted "Vortrïge und Reden,' the high esteem in which he held the work of Young.

2 A very succinct and exhaustive account of how Young arrived at his colour theory is given in a paper by $A$. M. Mayer, of New Jersey, in the 'Phil. Magazine' for $1876^{\circ}$ (5th series, vol. i. p. 111). Young first selected reil, yellow, and blue as the three simple colour. sensatious, but later modified his view in consequence of the experimeuts of Wollaston between the years 1802 and 1807. How little Young's theory was thought of may be seen from the worrls of Helm. holtz, quoted by Mayer (p. 114): "The theory of colour, with all these marvellous and complicated relations, was a riddle which Goethe in vain attempted to solve; nor were we physicists and physiologists more successful. I include myself in the number; for I long toiled at the task without getting auy nearer my object, until at last $I$ found that a wonderfully simple solution had been discovered at the beginning of this century, and had been in print ever since for any one to read who chose. This solution was found out and published by the same Thomas Young who first showed the right method of arriving at the interpretation of Egyptian hieroglyphics." 
ON THE PSYCHO-PHYSICAl, VIEW OF NATUli: 481

advance upon Newton. For the three prinary colonts of the ohler unticiuns he substituterl resl, streen, and violet; and for the remarkable fact that the simple colours of the rainbow can be eomponnterl ont of these three, he suggested a physiological reason-riz, that the eye possesses three distinct colom-sensations or three distinct senses in relation to light, elependent upon sone peculiarity of nervous structure or function. Young cliel not elithorate his ideas, but it is elear that in the short passages in his "Lectures on Natmal l'hilosophy" ancl earlier papers, there were contained a rariety of definite problems and hints which were destined to learl research for a long time after.

The next great step in arlvance, which has revolutionised and permanently fixed om ideas on the action of the nervons system, was taken ahout the year 1810 by Charles bell, who discovered the anatomical difference between the anterior and posterior roots of the nerves of the spine, and also went a long way towards showing their different functions. The point as regards functions was established by means of experiments on living animals ly Magendie, and independently hy Johannes Müller. Epon the combined labours of these three masters of anatomy and experimental physiology is based the distinction between sensory and motor nerves-namely, that the anterior nerves of the spine are employed to earry the nervous stimulus ontwarl to the different organs (efferent or motor nerves), the posterior and better protected nerves serving to earry

1 On the respective merits of Charles Bell, Magendie, aml Johames Miiller, ree the writing of

VOI. II.
Clatule liemard and In Bois-lieymond, referred to sumre, 1).38t of this volume. 
the peripheral stimuli of the senses inward to the nervous centres (sensory or afferent nerves).

13.

Miiller's "specific energies."

About the same time Johames Muiller, under the influence of Goethe's observations on the subjective colour-sensations and of Kant's doctrine of the imnate forms of perception, ${ }^{1}$ introduced another important distinction into the theory of the action of the sensory nervous apparatus. This doctrine is known by the name of the "specific energies." It has for a long time governed all physiological reasoning on the subject of our sense perceptions. In the words of Helmholtz, who more than any other has lent the great weight of his authority to an elucidation of this theory, "physiological experience has found that by the stimulus of any single sensible nerve-fibre, only such sensations can be pro-

1 The ductrine of the "specific energies " of the sensory nerves. one of Joh. Müller's earliest speculations, which has governed a large section of psycho-physical research, at least in Germany, has grown out of the philosuphical discussions in the 'Kritik der reinen Vemunft,' and the asthetic treatment in Goethe's 'Farbenlehre,' both of which deal with the subjectire element in our sense-perceptions. In this regard the reform of physiology in Germany contrasts with the contemporaneous reform by Magendie in France, whose extreme experimentalism Miiller even ridiculed. See on the historical origin of Miiller's psychophysics, Du Bois-Reymond's excellent "Eloge of Müller" ('Reden,' vol. ii. p. 159), also Helmholtz's lecture on "Goethe's Naturwissenschaftliche Arbeiten" ("Vorträge und Reden,' vol. i. No. 1, 1853), and his address hefore the Goethe Society in 1892. Helmholtz finds the cause which misled Goethe in his optical experiments to be the same which misled Brewster-viz., the difficulty of obtaining really pure homogeneous light of any special tint. He worked with impure light and dull media. Helmholtz experienced great difficulties in obtaining the necessary purity in his own labours. Goethe, however, was not alone in studying with predilection the subjective colour-sensations. Du BoisRermond mentions Erasmus and Robert W. Darwin in England, and Purkinje in Germany, as working in the same field (loc. cit., p. 160). Miiller's work is contained principally in the treatise, "Zur vergleich. enden Physiologie des Gesichtsinnes des Yenschen und der Thiere nebst einem Versuche iiber die Bewegungen der Augen und iiber den inenschlichen Blick' (1826), and in his larger work on Physiology. See also on Goethe's merits Helmholtz, 'Physiologische Optik,' p. 249. 
dneed as belong to the pualitative-or order-regrion of one definite sense, and that every stimulus which can it all aflect this nerve fibre poduces only sensations belonging to this lefinite orler." 1 This means that, for' instance, any effective stimulus of the optic nerve appanatus produces only and always the sensation of light, whereas the same stimulus would in the anditory nerve apparatus, if effective, prodnce the sensation of somel. "The same vilurations of the ether which the eye perceives as light, the nerves of the slin perceive as heat. The sane vibrations of air which the latter perceive as a tremor, the ear perceives as a musicil somel." The quality of our sensations does not lepend on the stimulus but on the nervous apparatus.

Helmholtz has saicl ${ }^{3}$ that the law of the specific energies forms the most important anvance which the physiolugy of the senses has marle in reeent times, and has even eompared it with the discovery of the law of gravitation." As we shall see immediately, he has him-

1 see Helmholtz, 'Handbuch der' I'hysiulogischen Oprik,' 'tte Auth., $1896,1, \cdot 2: 33$.

: Heluholtz, "Vortrige und Re. den,' vol. ii. p. 22.24; ilso - Physiologische (Optik," p. 2t9: "Nüller's law of the specitic energies markis an arlvance of the grealest importance, for the entire doctrine of the sense. perceptions has since lrecone the scientific toundation of this doctrine, and is, in a cortain sense, the emipirical expessition of the theoretical discussion of Kant on the nature of the intellectual process of the human mind." Cf. also 1. 5st.

" 'Vortrige und lieden," vol. i. p). 378 ; vol. ii. 1. 181.

'This excesive appreciation of Miiller's theory is, however, very much limited to Germany, and there also almost entirely to what may be ealled II uller's school, in which Helmholu is the central figure. In England the doctrine was subjected to a full criticism by George Henry Lewes, an important thinker, whose writings contain many original views, which have in some instances since been independently jut forward by other authorities. Siee his 'I'hysio ology of Common Life" 1.60, elnit). s) ; "Problems of life and Mind" (rol. i. p. 135, 1574); "Rerue Lhilo. soplinge (I'aris, 1s76, No. 2) ; "T'he Physical Basis of Mind' (1877. 1.15.1). Withoutknowing of Lewes": criticisms, Prof. Wunctt was led to a eriticism of the doctrine from the physiulogical side in the first 
self made a very important application of it, by bringing it into connection with Young's colour theory. But before I refer to this, it will be well to note the clifferent lines of research which were opened out by Muiller's formula, and how they have led in many ways to very fruitful expansion of natural knowledge. In this respect it is indeed permissible to compare Miiller's formula with that of gravitation, which, as we saw above, through the different ideas which it introduced, helped to guide research for fully a century. Miiller in the original statement of his riews had made use of the term "specific energy," and had applied this term to the process or sense of sight: he spoke of the seeing substance or apparatus of sight. Now this apparatus is a complicated one, consisting mainly of three parts-the external or

edition of his great work on Physiological Psychology in 18:2. See the note on p. 332, rol. i., of the 4th German edition (1893). Wundt says (p. 331): "Historically, the doctrine . . . is to be traced to the fact that the philosophical fouudation of modern science, and especially of the science of sensation, rests on Kant. In fact, that doctrine is nothing else thau a physiological reflexion of Kant's attempt to find the conditions of knowledge which are given a priori, or, what was mostly considered to be the same, subjectively. This is very evident in the case of the foremost representative of that doctrine--viz., Johannes Miiller." In opposition to Miiller and bis school, Lewes and Wundt put forward a riew which has been termed the doctrine of indifference of the function of the nervous elements. The difference between the two views is very clearly stated in an excellent paper by E.
Montgomery in the fifth rolume of "Mind' (1880): "According to the ductrine of functional indifference, the various qualities-i.e., our wellknown seusations-are merely due to differences in the stimulating rhythu, to differences, therefore, of motion communicated from outside to the chemically uniform nervesubstance, and the whole complex make-up of our consciousness is, consequeutly, thought to result from the coexistence and subsequent combination of such stion. ulated motions. According to the doctrine of specific energies, the varieties of sensation are due to preexisting differences in the substratum in which they respectively arise, and all their manifold combinations to ligher products are believed to be realised in materially ligher - i.e., specifically pre-endowed - ranges of nervous substratum" (p, 4). 
terminul organ, the connecting fibre or nerve, and the cuntral or percipient organ situated somewhere in the hruin. How are these different prarts of the combined apparatus anatomically constituted, and what are their respective physiological functions-in particular, where does the specitic enery resirle? 'The answer to these questions as regards not only the process of seeing, but likewise that going on in other sense organs, involved an enormous anount of detailed anatomical and physiologieal, analysing and experimenting work. With this work many great names are connecterl-first of all, Heluholtz, who in his two great treatises on 'Physiological Optics' and 'Physiologieal Aconstics,' 1 has lail

14. Ilehnioltz. the fomdation of those two psycho-physical seienees whieh bring us nearest to an molerstanding of the interaction of mind and boly. Like Young before him, for whom he expresses the greatest admiration, Helmboltz had approacherl the study of nature from the side of medicine: from this he was, by the peculiarity of his genius, driven to mathematieo-physieal studies on the one sicle, to psychologieal on the other. The exact methods of the mathematical, the experimental methocks of the medieal seienees; the mental analysis of Kant and Fichte, as well as the logical methouls of J. . Mill, were equally faniliar to him. Inventions of his own, like that of the eye-min'or, or of others, like

1 "Wie Lehre von den Tompmpfindungen: Plysiologische Grund? lage fur die 'Theorie der Musik,' list ed., 186:3. "Hamlluch der physiolugischen Optik,' 1str, 2nd el, much enlarged. I succinct and very lucirl exposition of the prineipal contents of those two great treatises, by an authority in the same fomain of science, will he found in chanss. x. tor xii. of Prof. J. (4. II'Kenulrick's volume in the "Mister's of Medicine" Series on H. von Helmholtz, 1599 . 
the stereoscope of Wheatstone; pathological cases, like those of colour-blindness; a host of ingenionsly devised experiments, as well as the gift of an exceptionally musical ear,- -all these factors, and innumerable others, contributed to the production of these two monumental works, which form an epoch in the history of science as well as of philosophy and psychology. They form the first magnificent examples of the comprehensive application of exact methods to phenomena which had before been treated only fragmentarily, and where the influences of taste, fancy, and belief, the vagneness of metaphysics and the difficulties of nomenclature, had created a confusion which to many must have appeared hopeless. This confusion of language and of terms, of objective observations and subjective fancies, of the data of experience and the prejudices of theory, Helmholtz has done more than any other thinker to unravel.

In his two great treatises on the psycho-physics of the Eye and the Ear, of Vision and of Music, he has drawn two elaborate and detailed charts, which for a long time to come will have to be consulted by those who, in the interests of physics, philosophy, or esthetics, enter into these mysterions domains. Many celebrated theories or definite aspects and lines of reasoning invented by others, his forermuners or contemporaries, were adopted, but mostly with important modifications. It may be of use to enmmerate briefly the principal ones, beginning with the most mathematical and exact and ending with the more general and metaphysical. In the begimning of the century Fourier had shown how any forces of motion in 
two dimensions-liowever complicaterl or irregular that motion might appear to be-conld be mathematically represented or calculated by the superposition or addition of a larger or smaller number of simple periodic motions; as it were analysed and dissected into these simple movements, just as any number can be looked upon as made up by the addition of others-say of prime numbers. Now, it was also known that sounds were produced by wave-like tremors of the air set going by the vibrations of strings or other sounding musical instruments; furtler; that definite musieal notes were absorbed or transmitted by neighbouring sounding bodies according as these were in or out of tune with the vibrating source of somnd. This is the well-known phenomenon of resonance. Ohm ${ }^{1}$ had applied Fomier's mathematieal analysis to the explanation of the partial notes, the gromul tone and the hamonic overtones (or uper partial tones), of which musieal ${ }^{2}$ sounds are made up. Hehnholtz invented a

I Geo. S. Ohm, the same to whom we are indelsted for the well-known law which obtains in electric currents, published in 1843 a paper in Poggendort's 'Ammalen' (deprinted in (Gesammelte $A$ h. handlungen," 1892, p. 575), "(On the definition of a tone and the theory of the siren," in which lie apulied the mathematical methods introluced by fourier in his 'Théorie analytique de la Chaleur' (15.22) : as he harl alrearly dome in his earlier work on the galvanic current (1827). In fact, ohm was one of the first to recognise the value of lourier's conceftions in contradistinetion from Iaplitce's, which were bound up with certain hypothetical notions as to the inrlecular constitution of bodies.
See the introduction to his treatise on the galvanic eurrent ("ies. Werke,' p. 63).

"Cagniard de la Tour har in. vented (1819) and Seebeck the younger had improvel (1St1) the first mechanical counter for the frequencies of musical sounds. the siren; and the latter as well as Duhamel had studied the composition of such sounds out of their elements or simple notes. A sug. gestion had been thrown out as to the part played by the upper partial tones which accompunied the ground tone. Helinlioltz treats first of this snbject in a lecture (185i), reprinted in 'Vortrige und lierlen, vol. i. p. 79 , dealing with "the psychological causes of musi. cal harmony." 
series of simple but ingenious apparatus by which these partial notes conld be analysed, isolated, and made specially audible, or by which the ground tone could be purified, and thus led up to his conception of the human ear-the different parts of which he analysed anatomically and acoustically — as a most delicate resonator which separately absorbed the different elementary periodic movements that constitute musical sounds, the different nerve-fibres carrying them separately to the central

15. "Timbre" defined. organ of perception. ${ }^{1}$ On the bases of these distinctions, Helmholtz succeeded in giving an accurate definition ${ }^{2}$ of that property of musical notes termed "timbre" by the French, "Klangfarbe" by the Germans - that peculiar colouring or texture which characterises the same note ${ }^{3}$ if produced by different instruments. $\mathrm{He}$

1 See 'Die Lehre von den 'Tonempfindungen,' 1st ed., 1863, pp. 92, 95, 97. "The main result of our description of the ear can be thus stated, that we have found that everywhere the ends of the auditory nerve are comected with special auxiliary apparatus, partly elastic, partly solid, which uuder the influence of external vibrations are made to vibrate correspondingly and then probably affect and agitate the nerve-substance" (p. 212).

2 Helmholtz was the first to give a positive definition of "timbre." As he himself says (p. 114), before him it meant all the peculiarities of a musical sound which are not defined by its intensity or its position in the scale--i.e., its "pitch." Of these he eliminates all such as are comnected with the beginning, rising, and dying away of sounds, and deals only with sounds which are uniformly maintained (p. 116).

3 The terminology of acoustics and of music has been considerably changed, especially in this country, through scientific literature, in which the work of Helmholtz forms a kind of epoch. According to Lord Rayleigh ('Sound," vol. i. \$22, 1st ed.), the word "toue" in the English language has been adopted by Tyndall to denote a musical sound which cannot be further resolved. The word was used before, but in a general sense, not limited only to sounds, and where now "tone" is used in works on acoustics, the word "note" was more usually employed. Sir John Herschel ('Encyclop. Metrop.', article "Sound," 1845) does not consistently use the word "tone" as an equivalent for the German "Ton," but niakes use of "sound" or "note" or "tone" promiscuously. Still more uncertain was the terminology by which to express the quality of a musical sound other than lourlness and 
entered into an analysis of the processes by which rocil somnds and notes are producel, and showed their inportance in musieal and linguistie theories. ('ombined with all these deductions and applications, which started from Fomrier's nathematical analysis of eomponnd novements, Helnholtz's anatomical dissection of the organ of hearing leads him to the conclusion that there "must exist in the ear diflerent parts which are set in vibration by notes of different pitch, and which have thus a sensation of these notes." I And here he takes up a different line of reasoning-that suggested by Johannes Miiller's theory of the specitie sense energies. In his studies in physiological opties he had alrealy accepted Young's hypothesis that there exist in the eye three distinct kinds of nerve - fibres, to which belong distinct modes of colour-sensation. Something analogous exists in the ear:" "The differences in notes - namely, pitch and colour [or character]-are reduced to differences of the sensitive nerve-fibres, and for each nerve-fibre there exists sound and only the difference of the intensity of the stimulus."

This hrings the action of the sensory nerves into line with that of motur nerves: everywere the nerve itself is

pitch, and, to the present day, the English tongue has no equiv. alent tor the Fench "limbre" or the German "Klangfarbe." Everett used the word (haracter, and so dues Lord Rityleigh. I) Young, in his "Essay on Music" (1800, 'Mirecll. Works,' vol. i. No. 5), speaks of the yuality of sound, sometimes called its lone, reginter, colour, or timbre (1). 11s). In the most recent scientitic work on sound in the English language (Poynting and Thomson's "lext-
Book of P'lyyices' Sound, 1'. 69) we read, "It is comvenient to use the term note ior an ordinury compound sound to which a lefinite pitch may be asigned, and the term tone for each simple larmonic constitnent which goes to form il." There is an importint note on the terminolugy by' Alex. 'T'. Ellis, the' lemed transhator of helmlolt\%: 'Sensations of 'T'one' (1875. 1) 36).

1 "Tomempfindungen, 1". 215.

"Ibid., 1'1. 220, 221. 
indifferent to the stimmlus, which it carries in or out like a telegraph wire; which, whilst acting in every case in the same way, may, according to its terminal connection, ${ }^{1}$ " deliver messages, ring a bell, explode a mine, decompose water, create or move magnets, prodnce light, \&c. The same with the nerves. The state of irritation is, so far as the isolated nerve-fibre is concemed, everywhere the same, but in accordance with the nature of different parts, be it of the brain or of the external portions of the body, it produces motion, secretion, increase or decrease of blood, of heat in different organs, or lastly, sensations of light, somnd," Ee.

The physiology of hearing had its brilliant application in a clearer understanding of the elements of language, of the formation of the vowel sounds, and in the study of the development of music_that art which, more than any other, seems founder on definite rules. ${ }^{2}$ In analysing

1 'Tonempfindungen,' p. 222.

2 "From the time when Pythagoras is said to have discovered the arrangement of tones in an octave, by observing that the sounds of the blacksmith's hammer in the forge produce a fourth, a fifth, and an octave, and was then led to obtain harmonic proportion between the strings of the heptachord, all who investigate musical tones know that, although these are fleeting sensations, they depend physically on numerical relations between various kinds of movements; but it was Helmholtz, more than any other philosopher, who examined the whole range of the phenomena, physical as well as physiological, and whose work will for generations remain an enduring monument to his genius" (Prof. M'Kendrick in the Helmholtz volume of the
"Masters of Medicine" Series, p. 168).

Since the appearance of the last edition of Helmholtz's great work, of which there exists an excellent English edition with valuable notes, many of the points first investigated by Helmholtz have been taken up by other experimentalists as well as by psychologists. The invention of the phonograph by Edison in 1877 gave a great impetus to exact research in the problems of audition, and rarious facts and theories have been advanced confirming or modifying the views put forward by Helinholtz. On these see the last chapter of Lord Rayleigh's 'Treatise on Sound,' 2nd ed., 1894. On the psychological sicle see the 2nd volume of Prof. Wuudt's 'Physiologische Psychologie,' Pp. $47-96$. 
these Helmholt\% is led into atsthetical aud poycloolonieal disenssions, elearly distinguishing between such principles as are inherent in natmal, physical, and physinlogical relations, and such others as tepend on the inventions of grenius and the gradual changes hrought about by external requirenents and inglaned by habit and edncation.

The pliysinlogy of seeing had yet more remarkable eonsequences for the history of Thonght. We may say that through Helnholt\%'s analysis of the formation of our space perceptions hy the eye in comnection with the tactile and muscular senses, psychology aml motaphysics were bronght into immediate contact with plyysics and physiology. It is here that Helmholtz takes up an eutively lifferent, aud, previously isolaterl line of ueuson- Helmholtz ing, which centres in Kant's theory of space and time as immate forms of pereeption--the so-called subjectivity or ideality of time and space. The studies of this sulject harl been somewhat prepared by the writings of Ierlart and Lotze. The teachings of Kant have had an influence in the direction indicated through two distinet elannels, -through Johames Miiller's Physiology and through Herbart's I'sychology: the latter seems to have had

I See the elosing works of the 13th chapter of Hehnholty's work: "As the fundamental principle for the developenent of the European tonal system, we shall sisume that the whole mass of tones mul the comnection of harmonies must stand in a ciose and always rlistinetly perceptible relationship to some albitrarily kelected tonie, and that the mass of tone which forms the whole composition must be ile. veloped from this tonic, and must finally return to it. The ancient world developed this principle in homophonic musie, the modern world in harmonic music. But it is evident that this is merely an icsthetical pineiple, not a natural law. The correctuess of this prin. ciple cammot be extablished a priori. It must be tested by its results. The origin of such itsthetical priuciples should not be ascribed to a natural necessity. 'They are the insentions of genins, as we pre. viously endearoured to illustrate by a reference to the principles of architectural style." 
little influence over the Berlin school of physiology, but it has had a considerable influence on several members of the Leipzig school. In this school Lotze was educated.

Locke had tanght, and his followers had accepted, the doctrine that the so-called secondary qualities of sensible things, such as colour, sound, hardness, \&c., were subjective. Speculative physics had prepared this view by translating such properties into special forms of aggregation or periodic motion, leaving only extension and resistance as the primary properties inherent in things. Kant had gone a step further, and maintained that space and time were likewise only subjective forms of our perceiving sense apparatus. Two problems grew out of this view, which are not clearly stated in Kant's writings. First, How does the perceiving mind arrive at the elaborate and systematic space conception which is peculiar to us human beings ? - i.e., out of what perceptive elements, and by what psychical processes, is it gradually built up? Secondly-What is it that locates our sensations at definite places in space? There is a third question which Kant put and answered, that referring to the nature and validity of the geometrical axioms. According to his view the axioms of geometry are innate, expressive of the inborn nature of our space conceptions; in fact, the truths of geometry formed in his view the only instance of knowledge gained not by experience but a priori-before or outside of experience.

18. The brothers Weber.
An entirely independent series of psycho-physical investigations was started even before Johannes Muiller, by Ernst Heinrich Weber of Leipzig, who, with his two brothers, Wilhelm and Eduard, may be considered as 
the centre of the Leipzig school of Anatony, l'hysiolony, and Physics. After having been anome the first to import the exact methods of researeh into physiology, and having carried on a variety of investigations referring to physiological opties and acousties, ${ }^{2}$ he approacher the subjective phenomena of sensation: recording, for example, with what degree of aceuncy different parts of the surface of the skin on face, arm, leg, \&c., pelceive the distance between two points which tonch the skin - saly the two points of at pair of compasses: recording also the relation of the smallest increase of any given sensation to the corresponding increase of stimulus. In the latter series of experiments, he

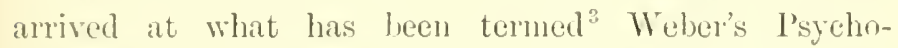
physical law. He diel not call it so himself; he simply showed by experiment that in a variety of cases the stimulus had to increase in proportion to its own initial intensity in order to prounce a just perceptible increase of sensation. These experiments did not attract much attention till Gmstar Theodor Fechner took them up, building upon then his celebrated "Principles of I'sychophysics." Before referring more in detail to these, I must mention a third line of reasoning which, as stated above, had a consiclerable influence on the Leipzig school of Psycho-physies, though probably it hate as little

IOn the labour's of the brothers Weber, see the references given above, vol. i. p. 196 , also the present volume, p. 31, note.

"F. H. Weber published in 1517, 'Anatomia comparata nervi synpathici;' in 1820, 'We aure et auditu hominis et animalium :' from 1.827 onward, 'Annotationes anatomicre et physiologice, in which, in 1831, there appeared his celebrated trottise "Tasiximn und Gemeingefuihl." Joh. Mliller's 'Vergleichente Anatomie des (Gesicht. simes' appreared in 1820.

3 Iiy Fechnel" in his "Elemente ier l'sychophysik' ('2 rols., Leipzig. $1860)$. 
influence on E. H. Weber as the earlier philosophy of nature, to which it formed a pronounced opposition.

20.

Influence of Herbart.

Herbart was not an experimental philosopher; nevertheless a place in a history of scientific Thought belongs to him. Indeed, his philosophy, like that of Kant, and, in quite a different way, of Schelling, has had a marked influence on many thinkers and men of science who have prepared the ground for an exact treatment of the phenomena of Life and Mind. Among exact psychologists I need only name Volkmann, Drobisch, Lotze, and in our time Professor Wundt ${ }^{1}$ of Leipzig. It is therefore of interest to mark the precise point where Herluart's inHuence comes in.

Although an exact school of psychology might aim at studying psychical and psycho-physical phenomena without reference to any general theory of the soul as the supposed centre and substance of these phenomena, the existing ideas and theories as to soul and mind have nevertheless always played a great part in these researches, just as it has been found impossible to free biological research altogether from some theory of life. Older psychologists were conseiously or unconsciously governed by the conception of a number of distinct mental faculties. Even Kant's philosophy is still embarrassed by this view, whieh reigned supreme in the teaching of his predecessor Wolf. The attempt of

1 This is not the place to speak about the Herbartian school, which is almost entirely confined to Germany. I have referred to Prof. Wundt because, in spite of a running eriticism, in the 'Physiologische Psychologie,' of Herbart's special doctrines, the author of that important and comprehensive work himself declares (Preface to the 1st ed., 1874) that for the formation of his own views be is, next to Kant, most indebted to Herbart. 
Herlart, therefore, to overthrow the so-called fincultypsychology, and to insist on the essential mnity and 21 II s articck

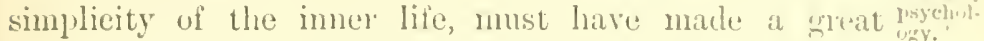
impression on all who cante under the inthence of his philosophy. It did this in two ways. ${ }^{1}$ It first of

1 Besides Herbart (1776-1811), whose joycholugical writings date from 1513 to 1525 , another German psychologist is usually mentioned as having helped to over hrow the older lacuity-posyehology. lieneke (1795. $1554)$, a younger contemporay of Herbart, eonceived of psychology as a natural science. His principal work, 'Lehrbuch der l'sycholorie als Saturwisensehaft, appeared in 1533 , and hits been several times republished, the fourth edition apyearing in $15 \%$. Beneke worked in opposition to Hegel at Berlin, his histurical forerunners being the German philosophers, Jacobi, Hries, and schleiermacher, as well as the English philusophy of the so-called Association-school. An account of his plilosophy does not belong to a chapter on psycho-physies except in as much as he introrluced into the study of the inner life not indeerl the facts and data of physical -i.c., fluysiological-science, but the physical methorl. He was the purest representative of the psyeholugy of the "imner sense." Whilst Herbart based his psycloology alike on experience, metaplyyics, and mathematics, Bencke alecepted only the first, aud discarded the latter. Standing thus outside the allyowerful school of Hegel and the increasing influence of llerbart, Bencke laal during his lifetime ouly a limited audience, and received due attention in a wiler circle, first and principally through Ueberweg, who was greatly inpresmed by him. In fact, his influence was felt in Germany about the sime time as that of the English aturl ficotti-h philo. sophers. Ueberweag, in his well known 'Hintury of Philosephy,' vol. ii. p). 281-292. (Engl. transl. by Morris, 1874), gives it full account of beneke. l'rof. Errluann gives a very full account also in his excellent " irundriss der tiesehichte der Philsophie' ("3te Autl., 1578 , vol. ii. (1). $62-4-(541)$. The fact that Beneke's nuetherl is introspective, brings him not only into contact with the English schure, but also with French thought, which has always been characterised by subtle pischolugical athalysis. This explains the fact that II. Marion (in the 'Gramble Eucyclo. pédie ") calls Beneke "un ches juincipaux philosophes Allemands du sièele,"-a designation which would harlly be echoet either ju Gernumy or in England. The best aceount of Beneke's positiou in the levelopment of psychology extant in the English language is that of $\mathrm{D}_{\mathrm{r}}$ G. F. Stuut, in his article "Herbart comparerl with English l'sychologists ind with beucke," in the 1tth volume of the lot series of 'Mind' (1569). M. Ribot, in his well-known brok on Mndem ('erman l'sychology' Engl. transl. by Baldwin, 1s!99), does not say much absut Bencke, but his account of Herbart aml his school, and their position in pycho-physical thought, is concise and much to the point. lor situnt's articlex on Herbart in 'Miud' (vols. 13, 14) are also much to be recommented. 
all liberated them from the trammels of an antiquated and misleading terminology; and secondly, it impressed them with the necessity of giving an answer to the question how the multiplicity of sensations or the flow of ideas was held together in the unity of an imner existence. Thus it is a characteristic of all psychophysical writers who have come under the influence of Herbart, that however much they may be occupied with detailed description of physiological processes, with the analysis of sensations or the dissection of the data of experience, they never lose sight of the underlying mental mity which is the central phenomenon of psychology and of psycho-physics, just as it must be the central problem of biology to arrive at some definition of life. Had the investigations of psycho-physical phenomena remained where Weber or even Helmholtz left them, we should have brilliant chapters on the phenomena of touch, of seeing, hearing, and other processes where the outer and inner worlds come into contact, but no attempt to sum up these brilliant contributions in a connected view of the inner and higher life-the most 22. remarkable and unique phenomenon in nature. It seems mental life. to me that, in Germany at least, it is through Herbart, more than through any other thinker, that we have been preserved from a threatening disintegration of psychological research. It is the more necessary to recognise this, as most of those writers who at one time came greatly under Herbart's influence have found it necessary, after having become thoroughly saturated with this one great truth in his philosophy, to abandon almost the whole of the more detailed expositions con- 
tained in his works. Herbart was quite as correct in his ideal of what jesyehology should he, as he was unfortmute in the particular manner in which he elaboraterl it.

P'sychology was to he founded on experiunce, nuetiphysics, and mathenaties. Kant had sturlied the inner activity of the mind as it is compounded of sensation, pereeption, and apperception; of understanding, julgnuent, and reasoning. In opposition to this Herbart went back to the position taken "1, by Locke and Hume, looking at the inner life of a eomscions mental being or soml, not as a complex of mental faculties, but as a flow of icleas or perceptions. How is the unity and simplieity of this mental being preserved in the midst of this contimuous How of ideas? how is it regained as often as it is in danger of being lost? His investigations start at the point where the inquiries of the assoeiation sehool of psychologists started in Hugland. Having, however, the meehanies and dymanics of physical forces more promin-

1 Dr Stout has given an account of the Herbartian school in the 1tth volume of 'Mind,' 1 . 353 s/ $\%$. He confines bimself to Drobisch, Wait\%, aud Volkmamn, the psycholegists proper. M. liibot (loc. cit.) hats dwelt more on the derelopment of the Herbartian school in the direction of anthropology and ethuology; he mentions specially Waitz, us well as Iazarus and steintlial. $\mathrm{He}$ contrasts their work and their positions with those of the great anthropologists of the English sehool, such as Tylor, Lublock, and Herbert sivencer, and notes, in the German school, the absence of barwinian jeleas. It is inportant to observe that both in the ease

VUI. II. of Prof. Wiundt of Leipsic and of $\mathrm{Mr}$ Spencer in lingland-that is, in the ease of the latest outerme of the Kant-Herbartian philosophy on the one side and of the Association phil. osoplyy in England on the otherand in eacli ease under the iufluence of the exact and biological sciences, philosophy ends in elaborate treatises on Antluropolugy, which with sipeneer is enceived under the name of Sociology. Similarly, the sehool of Hegel ended in elaborate historical treatises. Hume turned from abstract philosophy to political economy and history, and Herler-as we shall see later on - anticipated mueh of all this movement in his Ilistory of Minkind. 
ently before his mind than they had, he was tempted to try how far the conceptions of equilibrium of motion and of the composition of forces could be applied to the inner play of ideas which chase, oppose, and displace each other, preserving all the time a kind of dynamical equilibrium. His elaborate mathematical calculations in the first part of his greater work on psychology do not specially refer to the purely intellectual process; ${ }^{1}$ they refer rather to all inner processes which oppose each other, which come into conflict, restraining each other in proportion to their contrast, creating a tendency towarls reversion to former conditions. Such a play of opposing forces is to be found likewise in the larger field of human society; this is accordingly quite as much a case for the application of those psychical mechanics which Herbart aimed at establishing.

In a history of scientific Thonght, which aims at showing by what gradual steps the rarious provinces of phenomena have been bronght under the methods of exact treatment, the psychology of Herbart has an important as well as a unique and isolated position. It

1 Herbart himself says of his mathematical chapter, that the results therein given "do not follow immediately from the conception of a thinking being; but they refer to the mutual arrangements of any things, in so far as they are opposed and as they collide, restrictiug each other in proportion to their contrast, tending to revert to the previous condition, the unrestricted portions being fused into complex forces. The forces which are active in society are doubtless originally psychological forces. They meet in so far as they appear in language and in actions in a common sensual world. In the latter they restrict each other; this is the universal spectacle of conflicting interests and social frictions. Also the fusion no doubt exists. . . We therefore assume that among men living together the same conditions appear which exist, according to our view, among the ideas in one and the same consciousness. We examine the result of their mutual restrictire action" ("Psychologie als Wissenschaft," 'Werke,' ed. Hartenstein, vol. vi. p. 31 , \&e.) 
led psychologists to consider more closely the conditions under which a mathematical treatment is at all possible, and to recognise that exact and accmate measmenents must precerle all application of an alsstract calculus. Herbat's icleal was that of a psychical mechanies; he opposed ${ }^{1}$ the idea of a mion of plyysiology and lisychology. And yet this was just the direction in

In a very interesting note at the end of the introduction to the second part of his larerer work on psychology, Herbart explains his porition with regancl to physiological y) yehology, It refers to certain extraets which he makes from liuclolph's 'Grumbliss ler l'hysiologie, in which that eminent physiologist refereded to Herbarr's 'leelirbuch der l'sychologie." "It is not only a melaphysieal but also a losical error to confound psychological and physiological research. lsychological phenomena are not in space, but space itself, with all that appears in it, is a psychologjeal phenomenon, and, indeed. one of the tirst and most ditlicult facts for psychology, which, in the treatnent of it, would behave very im. properly if it began In discussing the forces in the nerves; for the question is not, where sensations come from, but how sensations acpuire the form of space. Now, I maintain further, that the lillerence hrotween lifeless and living matter-that is, between physies and physiology-cannot be uniterstood until we know mind ly means of psychology, fur in all the countles: elements of the organised borly -in plants as well as in animalsthere is an analogue of mental be. velomment which cammot possibly be found on the surfaes of phenomena. We observe internally a tragment of our ou u mental existence. This trument is developurl into scientific knowledge through speculative psychology based on metaphysics. 'Plis knowledge meets inctler equally metaplyy. sical science, natural philos(s) hyy, with its conception of matterthat is, of such matter as we know through elsemistry and dynamics. Then only can the question be put, low such matter must be constituted, so that its sejarate elements are deternined, not only through their original guality, but also through a developnent imalogous to the mental one," se. The section closes with the following characteristic passage: "Those who favour empiricism can learn Irom the present state of plysioloury how wuch, or rather how little, mere experience can do. Physiology, as an empinical doetrine, has attained a heiglit which noborly can lespise. Moreover, it proceeds in the light of modern physies. Novertheless, it has eagerly sucked up, as the sponge sucks up water, that philosophy of nature which kinow: nothing, because it began by construing the universe e priori. Towarls this error no science las proved so weak, so little capuble of resist. ance, as physiolocr. The ralk about life has become the 1)eat Sea in which all spirit of phitosuphical researeh is clrowned, so that, if a resurrection is at all to he hoyerl for, it must be born anew in quite unbiassed miuds" ("Wcrke," vol, vi. p. $65,8 \mathrm{e}$. 
which an exact or scientific treatment of mental phenomena could meet with any success at all. It was in the schools of physiology, in those of Johamnes Müller and of Weber, that philosophers had to learn how to attack the borderland of bodily and mental phenomena.

24. Lotze's Physiology of the soul.

The first who approached the subject from this point of view was Hermann Lotze. He was a disciple of E. H. Weber, and had been led to psychological researches from two independent starting-points: first from the study of the medical sciences which, under the hands of his great master, had largely benefited by the application of the exact methods of the physical, the measuring, and calculating sciences, but also from an entirely opposite quarter." "A lively interest in poetry and art had led him to philosophy." He was attracted by that great body of ideas which, through the systems of Fichte, Schelling, and Hegel, had become permanently domiciled in German culture. In this great realm he could move "with some freedom," for it had not become crystallised into a definite system of doctrine: exact studies har, moreover, easily convinced him "how absolutely untenable was the form into which Hegel had cast that valuable possession."

1 The quotations in the text are taken from Lotze's polemical pamphlet, 'Streitschriften' (Leipzig, 1857), pp. 6, 7. As already mentioned (supra, p. 407 note), Lotze had been misunderstood by his critics, of whom some represented him as a materialist, others as a follower of Herbart. In refuting the latter charge he explains his position towards the idealistic systems of the first half of the nineteenth century.
He acknowledges two great personal influences, that of C. H. Weisse, which, as it were, touches the kernel of his convictions, and that of the sturly of medicine, which, in his case, was intimately con. nected with that of the plyysical sciences. He admits, as did Herbart, having passed through the maguificent portal of Leibniz's Monadology to a general arrange. ment of his plilusophical opinions. 
We must bear in mind this twofold sonree of Lotze's reflections if we want to estimate correctly the value of his eurly eriticisms regarding the then prevalent treatment of such questions as life and mind in the nedieal sciences. On the one sille he had the object of clearing the way for purely mechanieal explanations. We learnt in an earlier chapter how he was one of those who suceessfully chased out of biology the vague irlea of a vital force. And when he approached the problem of mind and body, we tind him insisting on the presence of a psycho-physical mechanism which rules ${ }^{1}$ the inter-

1 The opinion of totze regarding the relation of soul and body, or rather of psychical ind pliysical phe. nomena, has been stated by him, variously, as parallelism, occasionalism, pre-established liarmony, and was ultimately erystallised in the term psycho-physical mechanism. The question is fully discussed in the articles, "Leben unt Lebenskraft," "Instinct," "Seele und Fieeleulehen," which he eontributed to R. Wagner's 'Handworterbuch der Physiologie.' They are reprinted in Lotze's 'Klemerindenten, ed. D. l'eipers, 4 rols. (Leiprig, 1s85-91). He there silys, "The ronception of a paycho-physical nochanism ean be stated as follows: As irleas, volitions, and other mental states cannot be compared with the quantitative and special properties of matter, but as, nevertheless, the latter seen to follow upon the former, it is evident that two essentially ditlerent, totally disparate, series of procesies, me bodily and one mental, run par. allel to each other. In the intensive quality of a mental process, the extensivedefiniteness of the miterial process can never he found; but if the one is to eall forth the other, the proportionality between them must be secured through a comneetion which appears to be extrinsic to both. There must exist general laws, which ensure that with a morlification "f of the mental substance a modifieation $b$ of the bodily substance shall be comnected, and it is only in consequence of this independent rule, and not through its own power or impulse, that a change in the sou! produees a conesponding one in the body" (vol. i. p. 193). Lotze destroyed the illea of vital force, but lie only ehased the conception of the soul heyond the limit of the paycho-physical mechanism, and he maintains that natural and medical science have no interest in pursuing the question leyond that limit, "however interesting the further discussion of this subject may be to speeulative prchology" (vol. i. p). 197 - - "for it is quite indiflerent to medicine, wherein the mysterions union of body and soul consists, as this is the constant event which lies equally at the bottom of all phenomena. liut it is of the grealest interest to medicine to know what atlections of the soul are comected in that mysterious 
action of external and internal phenomena, of stimulus and sensation.

25.

Two sides of

There existed indeed another side-that which we doctrine. may call the philosophical; it does not at present enter into the course of our narrative, which deals only with the extension of scientific or exact thought, and with mental phenomena and the inner life in so far as they form a province-perhaps a very restricted province — of the whole of nature. This province Lotze was among the first to proclaim distinctly to be one which natural science had to conquer and to cultivate. He is careful to explain that it does not cover the whole ground of psychology, and at the end of his long discomse on the "soul and its life," which formed an important contribution to the great physiological encyclopredia published in the middle of the century, he clearly marks out "physiology of the soul as an exposition of the physical and mechanical conditions to which, according to our ohservation, the life of the soul is attached," ${ }^{1}$ as one of the several problems of psychology. It formed a counterpart to the physiology of the body, of the physical side of our existence, and was, like it, to become a natural -i.e., a mechanical-science. Subsequently he collected the whole of his reflections belonging to these two departments in two treatises on the 'General Physiology of Bodily Life' (1851), and on 'Medical Psychology' or 'The Physiology of the Soul' (1852).

As little as it now enters into our programme to

manner with what affections of the body. Unfortunately; medical science has only too often lost sight of this its proper problem over fruit- less speculations referring to that connection itself" (p. 197). Cf. also 'Medicinische Psychologie,' p. 78. 1 'Kleine Werke,' vol. ii. p. 204. 
follow up the philosophical reasonings of Lotze heyonil the limit of the psycho-physical mechanism, so little were these at the time of their appearanee heederl hy many of his readers, some of whom he seems to have converted to or confirmed in a purely materialistic eonception of the phemomena of the inner or mental workl. Lot\%e haul banished "vital forces" from liology: why not follow him, and banish all other higher principles, and revive

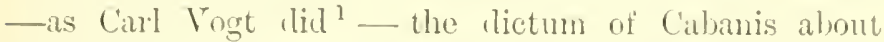
the analugy between the functions of the brain and the kicheys? Why should the "anima" of stahl not have the same fate as the "rital force" of Borden and Bichat?

This was a misconception of what Lotze had intencled. He had, indeed, banisher ${ }^{2}$ the principle of life as a factor useless in physiologieal explanations; but not the prineiple of organisation, which must have presiled over the begiming of all organic forms. This might be neglected hy physiologists, who had nothing to do with origins but only with existing relations. It was quite different with mental phenonena, which, manifesting themselves alongside of plysical processes, required to be dealt with and reeognised as actually existing and concurrent events. ${ }^{3}$ Herbart's psychical mechamism might

1 On this, see the aecount given in Lange's 'History of Materialism ' (Engl. transl., vol. ii. p. 2๖5) and Lot\%e's reference to it in 'Med. Psychol.,' p. 4:3.

is "lhere is no doubt that a legitimate attack upon 'vital force' has marked in our ditys that line of reasuning, which luas by the law of inertia carried many of our contemporaries far beyond the correct limit on to a negation of the exist. enee of a soul" (ibil., 1. 41).

"These various points are very fully discussed in Lotze's earliest philosoyhical work, 'Metaphysik' (Leiprig, 1841), pp. 251, 255, 259: and again in the 'Mel. Psychologie' (1852), p. 75. Referring to the last clapter, in which I dealt with the development of the theories of life and organisation, two points 
be an unrealisable ideal in that it dealt with inner phenomena as unconnected with onter ones: a psychophysical mechanism was a nearer approach to a true description of reality, and could not be narrowed down to a purely physical occurrence; moreover, the unity of mental life was a special property which had to be recognised and defined.

26.

The psycho physics of vision.

Lotze himself, after formulating the conception of a psycho-physical mechanism, and ntilising the elaborate and fundamental experiments and observations of Weber as illustrations of what was meant, made an important contribution towards an analysis of a compound physicopsychical process. He took up the problem which Berkeley had attacked, of the formation of our space perception. It had been introduced into German psychology mainly through Herbart with reference to the Kantian doctrine that space is a subjective form. Through Lotze, and subsequently through Helmholtz, it has been shown to have not only a psychological but likewise a physiological importance: it is a problem of psycho-physics.

There exists a peculiar difficulty in bringing home to the popular mind the fact that a special problem is in-

may be noted. First, it is clear that Lotze was an "organicist" before Claude Bernard and other more recent thinkers mentioned above. Secondly, it is very evident that Lotze belongs to the pre-Darwinian school of thought. In fact, he does not rehish the genetic aspect. The historical beginnings of ideas are for him no indication of their value and correctuess. He says on this point: "The genesis of a conception is no argument for its validity; in the ever indistinct manner in which language operates in forming its words, it may form the correctest conceptions in just as incorrect a manner as the most erroneous ones. What is important is whether the conception, formed anyhow, cau justify itself" ( Med. Psychol.,' p. 41). I shall on another occasion have to refer more fully to this marked absence of the historical sense in Lotze. 
OX THE PSYCHO-PHYSICAL VIEW OF NATURE. う0

volver in the manner in which ont senses of sight and tonch combine and arange simple sensations int, the whole of a well-ordered pereption of spuce; for we do not become able to appreciate the fact of the show and gradual growth of this pereeption, which takes place in the early rlays of our infancy, till long after we have actually gained full possession of it. simething similar exists with regard to langmage and thought: we only liear of grammar and logic long after the main difficulties of speech ant thinking have been unconscionsly mastered, and if it were not for the existence of other languages than om own, and of an erroneous logic as exemplified in errors of calculation and of measurement, it is doubtful whether grammar and logic would have leen so early tereloped. As it is, the physiological problem of the formation of our space perception was actually first forcerl upon naturalists by the observation of pathological cases, such as the acquisition of sight in later life through eouching, the existence of colonr blindness, and a variety of optical delusions which still serve as indispensalule test cases for the varions theories that have been propomeled. Only when something turus out to be palpally wong do we begin to inquire what constitutes the right sicle of many things.

Thus the cases of Cheselelen and Wiurlyop and the colom blinclness of Dalton set physiologists thinking about the genesis of our spaee and colom pereeptions. I very great impetus-perhaps the most valuable of all -was given by Wheatstone's invention of the stereoWheatscope in 18:38; an instrument which, as it were throngh stene's stereuserpe. 
a kind of deception, gave to perfectly flat surfaces the vivid appearance of depth and distance. And here we may note, in passing, how it was almost entirely left to foreign thinkers to utilise this remarkable invention for the benefit of the theory of vision and the science of psycho-physics; ${ }^{1}$ Whewell having characteristically omitted this epoch-making fact, as in his well-known history he onitted to notice many other contemporary British contributions to science.

Philosophers, who are accustomed to find hidden problems where ordinary persons only see common-sense, had already approached the question of the genesis of our space perception from two definite points of view, which we may, for the sake of convenience, identify with the names of Kant and Herbart. The genetic riew associated by the physiologists with the name of Kant, and supposed to have been prepared by Locke, Berkeley, and Hume, was this, that what we know of external things depends upon the peculiarities of our own perceiving

${ }^{1}$ Sir Charles Wheatstone (1802$1875)$, to whom several inventions of equal scientific and practical interest are due, inventert the mirror-stereoscope in 1833 . A notice of it was given in Mayo's 'Ontlines of Human Physiology,' but neither its theoretical nor its practical importance was recognised till Wheatstone published his paper in the 'Phil. Traus.' in 1838. He there refers to Leonardo da Vinci as having been the only one before him to notice the difference of binocular and monocular vision. Since Wheatstone's invention became known and was perfected by Brewster, Moser, and others, and especially since Helmholtz entered the field with his extensive and original researches in opties, it has been found that ancient as well as more recent philosophers had approached the subject very closely; and many references are given in the new edition of the "Physiologische Optik ' (1896), p. 840. The invention of photography about the same time (1835, by Daguerre, after extensive and prolonged experiments by himself and Niepce, published in 1839 by Arago), which was of great importance to optical theory, was also for some time singularly little appreciated by theorists. See Rosenberger, 'Gesch. d. Physik,' vol. iii. p. 316. See also Helmholtz's lecture "Ueber das Sehen des Menschen" (1855). 
and thinking self, on sensations, ancl on their arrangement or orilerly presentition. The sensations themselves are the substance, the spatial arrangenent I.ocalinati,n if :ello, aof them the form, of onr perception of external things. The question was gratually put more and more clearly, 11 w we come to localise certain of ou sensations at definite places in the totality of a spatial arrangenent? Herbart adeded another important reflection, which really dated from Leibniz. Impressed with the unity of all mental existence, and claming this as the characteristic property of our inner life, he asked the question, How can the oncuess or simplicity of this inner existence, as it were, expand itself withont losing its unity, into the orderly variety of a spatial contemplation? For the purpose of an inswer to this question he fixed on the phenomenon of notion. The conception of an orderly arrangement of sensations or things in space is gained in great measure hy the aid of definite movements of the sensitive organs, which are accompanied by definite sensations of motion-c\%, hy muscular sensations.

The first of these two questions may be expressed in the words, Given the subjective form of a space perception, either complete in its geometrical arrangement (the nativistic hypothesis) or gradually aernired in the arly monents of our conscions life (the muric hypothesis), who do we nake ourselres faniliar with, and at home in, this form of perception? And secondly, ly what special properties or loeal sigus do we localise or place each single sensation in its right and orderly position? The first is the problem of space construction, the secomel 
that of localisation of things in space. Lotze was one of the first to attempt detailed answers to these questions.

Lotze's "local bigns."

30. Eechner.

29. In particnlar he propounded the theory of "local signs," which with certain modifications has been adopted by subsequent writers on the subject. The combination of physiological, optical, and psychological investigations in Helmholtz's great work on 'Physiological Optics' has brought definiteness and mathematical precision into many of the questions suggested by philosophers and naturalists before him. Throngh it and its great companion, the 'Physiological Acoustics,' psycho-physics has to a large extent become an exact science.

A great step in the direction of drawing psychical phenomena into the circle of the exact sciences was taken independently by Gustav Theodor Fechner $;^{1}$ in fact, it is

${ }^{3}$ G. T. Fechner (1S01.1887) was a unique figure in German literature, science, and philosophy. Beyond his own country he is only very imperfectly known and appreciated. He was self-taught, and liviug all his life somewhat outside the conventional categories of German academic activity, he made a position for himself which has only become intelligible to a larger public through the issue - after his death-of Prof. Wundt's oration, Prof. Kuntze's (his wepbew's) charming biography (1892), and Prof. Lasswitz's monngraph on Fechuer (Stuttgart, 1896), in which for the first time a coherent exposition of his philo. sophical teaching is attempted. I'rof. Wundt has also, in many passages of his work on psychology, and through the second edition of the 'Psychophysik,' contributed largely to a better under. standing of Fechner's views and merits. $\mathrm{He}$ descended on both sides from ancestors whose position was that of highly esteemed Protestant pastors; he studied medicine like Lotze, and was the friend and colleague of Lotze's teachers, Weber and Weisse. In his autobiographical record, communicated by Kuntze, he confesses having become almost an atheist under the influence of his medical studies, until he became acquainted with the philosophy of Schelling, Oken, and Steffens, which dazzled him, toucherl the poetical and inystical side of his'nature, and, though he hardly understood it, had a lasting influence on lim. The simultaneous occupation with the best scientific literature of the day (he translated French text-books such as those of Biot and Thénard, and verified Ohm's law experimentally), however, forced upon him the sceptical reflection whether, "of all the beautiful orderly connection of optical phenomena, so clearly expounded by Biot, anything could 
to him that we are indeloted for the term l'sycho-physics, which in the present elapter I hase nsed in a more general sense. Fechner workerl indequendently of latze and Hehmoltz on the lines of $k$. H. Welver. He dres not seem to have been much intluenced by either Kant or Herbart. In 1860 he published his 'Elemente der Psyehophysik,' which was to be an exact treatise on the relations of "mind and horly," fomded upon a measmement of psyehieal quantities.

Herbart's attempt to submit psychieal phenomena to the exact methorls of ealculation had failed through the want of a measure for psychieal pruntities. Lotze hal suggested the idea of a psycho-physieal mechanismi.e., a constant and definite eomneetion between inmer and onter phenomena, between semsation and stimulus. E. H. Weber in his inportant reseanches on "Tonch and Bodily Feeling" had made a variety of measurements of sensations, and shown that in many eases stimuli must be augmented in proportion to their own original intensity in order to produee equal increments of sensation. 'These olservations lent themselves to an easy mathematical generalisation. Fechner was the first to draw

lave been found out ly Uken. schelling's method?" This mixture or alternation of exact seience and speeulation, of faithifulness and loyalty to facts as: well as to theory, runs through all Fechner's life, work, and writings. Much of his poetry, of his famciful and paradoxical eftusions, is meant seriously, ancl is really mone eolierent than it aplenterl to his reallers, some of whom knew him only under his jmeudonym of lor Mines. He liverl, thought, and worked truly on the burderland of nature and iniml, of this world and another, of science and puetry, of reality and fietion. like I.otze, he wanted the genuinely historieal sense. Like lotze, too, he received from others only sug. gestions which he elaborated in. repemlently in his own original fanhion. As little as lotze does lie serm ever to have attempted to realise amb understamel any other philesophical system than his own. To boll, the ultimate poblem was eaprable mly of a suhjective solu. tion. Ci. vol. i. p. 200. 
the attention of philosophers to the existence of this relation in a variety of instances, and collected a large number of facts to prove its general correctness. $\mathrm{He}$ conceived the idea of measuring sensations by their accompanying stimuli, a mode of measurement based upon that relation which, under the name of Weber's law or formula, he introduced as a general psychophysical proposition. The intervals in the numerical scale, the differences in the magnitude of stars, the facts established by Weber relating to our estimate of differences of touch, of weight, and of temperature; lastly, the relation of "fortune physique" and "fortme morale," known to Euler and Lagrange, could all be utilised towards proving the general aceuracy, within certain limits, of the psycho-physical formula. The work gave rise to many discussions ${ }^{1}$ as to the meaning of the term quantity applied to psychical phenomena, as to methods of measurement, and as to the signiticance to be attached to the new branch of research

I In addition to the 'Elemente der Psychophysik' (1860), of which a second edition appeared in 1890 , the author enlarged, discusserl, and defended his special ideas and theories in three further publications. The year 1877 producel ' In Sachen der Psychophysik,' the year 1882 the 'Revision der Hauptpunkte der Psychophysik,' and shortly before his death (1887) there appeared, in the "Philosophische Studien' of Prof. Wundt, his last contribution, "Ueber die psychischen Maasprincipien und das Webersche Gesetz," which Prof. Wundt declares to be "the clearest and most complete exposition of the problem which he gave in the course of the forty years during which he was occupied with it." (See the obituary oration, reprinted in Kuntze's 'Biography', p. 360.) The attacks on Fechner came from many quarter's. In the polemical treatise of 1877 he notices how the views of his critics Helmholtz, Aubert, Mach, Bernstein, Plateau, Delbouf, Brentano, Hering, Langer - agree as little among themselves as with his own. He sums up with fine humour: "The tower of Babel was not finished, because the builders could not agree how to build it; my psycho-physical structure may remain standing, because the workmen canuot agree how to pull it down " ("In Sachen,' \&c., p. 215). 
as well as to the interpretation of the Irober-Fechner law of psycho-physical dependence.

We are indebted to l'rot. Wundt of leipzig for a 31 . complete and exhatustive examination of the new province of exact science. ${ }^{1}$ He enlatged its lumnlaries,

I The psychological achool, of which Prot. Wumlt ean be con. sidered the heat or centre, hits been contristed by M. Ribot, in his: 'Psychologie Allemande Contemporaine" (Ist el., 1s79), with the Einglish echool, and, in the exposition in the text, I have taken a similar view. It would, however, be unjust not to note that in Finglancl, prior to the publication of Prof. Wuncit's principal wreings, a development of psychology in the mitne direction had alrearly begun. 'The juncipal representative of this development is Prof. Alexander bain (born 181S), whose two great works, The senses and the intel. lect' (1855) and 'The Eumotions aud the Will' (1859), a y,eared ercn before Fechner's 'Psychophyik, and were charaeterised by J. s. Mill as "an exposition which deserves to take runk as the foremost of its elass, and as marking the most advanced point which the $a$ posteriori piycholog! his reached," being "the most genuinely scientific analytical exponsition of the human mind which the a posteriori psyeloology has up till this time produced" ('Elinb. Rev.,' Uctolier 1559 , reprinted in '1)issertations ant Discussions,' vol. iii. 1p. 99, 100). Bain earried ont what had been ealled by 'Thomas Hrown "the physical iuvestigation of the mind," and was probably the first Euglish psyehologist who enriched the older assuciational juychology by an ex. tensive use of the teachings of physi. ology ; the germ of his theory being contained in a pasisage cited by him froun Jolnannes Hiller: in fact, he alpreciated the well-known dictum of the latter, "psycholoyus nemos nisi physiologfus." "Shortly after the appearance of Prof. Bain's works, the overmastering intluence of the evolutionist school in Englancl, healed ly $\mathrm{Mr}$ sifuncer and sup. proted hy hatwin, and the pro. nounced ofposition with which the joycho-physical schoul starterl in Germany, cast somewhat into the sladie the stearly develonment, in this eumtry of the exact seienee of fingehology lig those who former the clirect succession to the older, purely. introspective, scluool of sicottisil thinkers. As $I$ an not, in the pres. ent chapter, treating of lisychology and philusoplyy, but of the attempit to gain, by the inethods of the exact sciences, a conception of the phenomena of animation and consciousness, 1 leave for another occasion the inpreciation of the English school of juschology. The members of this school considered physiology as an aid to prycholongical research, whereas most of the representatives of the modern German school were, to hegin with, physiologints or physicists, and only became subseyuently prycloblogists or philosophers. Characteristic of this seliool are two points: the opposition they macle from the start to the existing nethoris, ant their prominent use, not only of ob. servation, but of experinent. 'The less ostentatious development of English thought would, no doulit, late led in the end, hut for the reasons given above, to like results. An opposition similar to that so marked in Germuny was, however, 
taking in the ground covered by Lotze's medical psychology as well as by Helmholtz's physiology of hearing and seeing; alded a large number of measurements of his own, some of them quite original, such as those referring to the time-sense, many of them in confirmation and extension of Fechner's collection of facts; invented new methods and new apparatus; brought the whole subject into connection with general physiology, as also with the more exclusively introspective psychology of the older, notably the English and Scottish, schools; and pointed to the necessary completion which these investigations demand from the several neighbouring fields

of research. Through his labours "physiological psyeho$\operatorname{logy}$ " as an independent science has for the first time become possible. The influence of his great work on this subject, as also of his teaching and demonstrations, has been very stimulating. With its place in the history of philosophical thought I shall have to deal in a later portion of this history. At present I will merely refer to the leading ideas and contributions it contains to our scientific reasoning on the psycho-physical problem.

Wundt approached psychological research from the side of physiology $;^{1}$ his earlier writings referred to the

taken up in England in single in. stances-e.\%., by G. H. Lewes and Dr H. Maudsley, the former in favour of Positivism, the latter on the foundation of his 'Physiology and Pathology of Mind' (1st ed., 1867 ).

1 The researches of Wundt and the earlier work of Fechner remainer practically unknown in this country up to the time of the appearance of the periodical 'Mind,' edited by Prof. Croom
Robertson, in 1876, under the generous patronage of Prof. Bain. Even Lotze and Herbart were hardly known in this conntry. A similar disregard of English psychology existed in Germany. The foremost witers on the his. tory of molern philosophy, such as Erdmann and Ueberweg, wrote as if modern philosophic - including psychological - thought cxisted only in Germany. Even the singularly impartial and unbiassed 
physiology of the senses, to physiology proper, and to such phenomena of psychieal or inner life as can be traced, not only in man, hut also in the hrute creation. He thus seems to have approached psychology with the true instinct and methods of an exaet student of nature. In the comse of years his psycho-physical studies took more and more the character of an experimental psychology, and in the latest edition of his great work he describes it as such, maintaining that the designation of physiologieal psychology has rather a historical meaning. ${ }^{\prime}$

author of the 'History of Materialism,' Albert Lange, dues only scaut justice to the labours of the English school, J. \$. Mill being, in fact, the only English philosophical writer of the middle of the century who was aprreciater in Germany. 'The last twenty-fire years have entirely altered this state of things. French and American writers, such as $\mathrm{Xl}$. Ribot, Prof. $\mathrm{M}^{\circ} \mathrm{Cosh}$, and more recently Prof. James, treat inpartially of the rival elaims of German and English thinkers. 'Mind' has preserved its fair'ness in admitting contributions from opposite sides; and latterly there has been starterl by the publishing house of Frommann of Stuttgart, under the editorship of Prof. Falckenberg, a series of very useful monographs on recent thinkers, whose voluminous or scattered writings make it difficult to arrive at a comprehehsive and just appreciation of the main drift of their doctrine. Ever since some provinces of philosophy were conquered by exact research, unity of plan has been to a great extent sacrificed; the natural science of mind is becoming split up into fragments like that of life. Prof. Lasswitz has given us for the first time a coherent account of

VOL. II.
Fechner's philosophy, and althourh Prof. Wundt had aheady put forth in bis 'System der Philosophie' (1st ed., 1890) a statement of his systematic views, the monograph by Erlmund König (1901) is very helpful in fixing the historical position of Wundt and the grenesis of his doctrine. I refer to these volumes for a bibliography of the thinkers discussed.

I In the introluction to the 'Phrsiologische Psychologie' (1te Autl., vol. i. p. 9) Prof. Wundt says, "The conception of experimental psychology has been expanded beyond its original limits, as we now comprehend under it not only those parts of psychology which are directly accessible to experiment, but the whole of psychology ; as it makes a direct use of the experimental method wherever this is possible, and an indirect use in all other instances through applying the results gained in the former, and through rendering internal observation more acute. . . The designation of physiological psychology, which originater in the peculiar historical antecedents of our science, is one-sided. ... The centre of gravity of the experimental method lies in this, that it alone makes reliable iuner observation possible." 
Whilst his methorls are exact and definite, his aim is, nerertheless, wide and comprehensive; for not only is the animal creation studied as a valuable field for enlarged psycho-physical research, but also the psychology of infancy and of human societies (ethnical psychology) are drawn into the circle of a scientific psychology. At the same time his exposition is directed towards the totality 1 of the phenomena of life and mind, it being his ultimate olject to arrive at some appropriate conception of the whole of human existence. In this respect his scientific labours form a comnterpart to those of naturalists like Humboldt and Darwin, who did so much to direet the attention of natural science to the whole of nature, her history and economy. It seems to me that Prof. Wundt has similarly introduced into the psycho-physical study of nature the prominent consideration of the mental side of life in its totality, starting, as Darwin and Humboldt did, from a large aceumulation of detailed observations.

This regard for the whole problem distinguishes Wundt's writings from those of other eminent psychophysieists, such as Helmholtz, who deals brilliantly and exhaustively with certain speeial problems, or Fechner, who relegated the discussion of the fundamental questions to a series of half-poetical treatises, which are full of suggestion rather than close scientific reasoning. But

1 'Physiologische P'sychologie' (4te Aufl., rol. i. [. 2): "Our science has accordingly the task, first, to investigate those rital phenomena which, lying in the middle between outer and imner experience, requice the simultaneous application of both methods of observation, outer and iuner; and secondly, to throw light from the points thus gained on the totality of the phenomena of life, and, if possible, to gain in this way a comprehensive conception of human existence." See also his essay "Philosoplie und Wissen. schaft" in a volume of 'Essays' (Leipzig, 1885), p. 1; also 'Dic Aufgibes der experimentellen Psychologie,' ibirl, p. 127, \&c. 
Wundt differs quite as much from Lotze, who also strove to arrive at a view of the totality of human life and its significanee. Lotze belonged, in spite of the original eumpared. and independent view which he took of the psychophysical problem, to the older school of philosophers. Wundt belongs quite to the modern school. ${ }^{\text {W Fechner }}$ forms the transition. Lotze begins his psyehology, and even his physiology of the soul, with a lengthy dissertation on the unity of the sonl as a special leing, just as Herbart begins his psyehology with metaphysies. This metaphysical introluetion, these lefinitions relating to the essence of the sonl, its mity, and its loeation, are absent in the modern psychology. Instead of fomcling psychology on experience, metaphysics, and mathematies, Wunct founds it on experience (including experiment), physiology, and mathematics. In consequence of this altered foundation a new problem has arisen, preeisely as a new problem arose for loiologists when they discarded vital force as a meaningless and useless encumbrance. For the older biologists life was the exhibition

1 See the preface to the second edition of the 'System der' Philosophie' (Leipzig, 1897), p. ix : "I have always tried to co-operate in the endeavour to secure for psycho$\log y$ an independent position as an empirical science outsicle of philosophy, and to see that she should not lack the support of the scientific method in so far as this could be transferred to her. . . . As I started from natural science and then came to philosophy through occupation with empirical psychology, it would have appeared to me impossible to philosophise in any otlier way than in corre. spondence with this sequence of the problems. But I quite well ununderstand that the position may be different for him who begins with philosophy and then makes occasional exeursions into the regions of science or psychology." Compare with this what Lotze says in the Introduction to his "streitschriften' (1857), or the following passage from one of his last essays ('Contemp. Rev.' January 1880), "Except in rare cases, a prolonged philosophical labour is nothing else but the attempt to justify, scientifically, a fundamental view of things whieh has been adinted in early life." 
of vital force. This laving been dropped, the question arose for modern biology, What is life? We thus find thinking hiologists of the modern, exact school aiming at a mechanical clefinition of life. Many answers have been attempted, such as that it is the action of a very complex chemical molecule, of dynamical equilibrium, of metabolism, of a special form or organisation, \&c. Similarly, when the worl soul dropped out of psychology in its older metaphysical meaning as a separate being or entity, when it was used to mean only the sum-total of the imer or psychical phenomena, a new problem arose for the psyeho-physieist or experimental psychologist. The problem now was to give some definition of the unity and unified totality of all inner or mental phenomena. The older metaphysical psychology, as also for the most part the so-called empirical psychology, answered this question by placing the conception of an independent entity, the soul, person, or self, at the opening of their cliscussions. Modem exact psychology camnot do this. For it the unity of the inner life and its unified totality has become a problem. This problem Prof. Wundt faces 34. fully and fairly. He asks himself the question, Wherein The unity of
conscious.
ness.

of all mental life, individual and collective? Armed with the methods of exact research, he tries to extract from the whole array of mental phenomena an idea of their essence as distinguished from external or natural phenomena, and of their collective meaning and significanee. In so doing he enters the domain of philosophy, and his results belong to the realm of philosophical thought. When dealing with that large section of $m y$ 
ON THE PSYCHO-PHYSICAL VIEW OF NATURE. 517

subject I shall have to take up Wundt's theories where I now leave them.

Through the efforts and widespread influence of Prof. Wundt, the imer or psychical phenomena have been drawn into the circle of exact research; a large portion of psychology has become natural science. It is quite consistent with this that some of the diseiples of the modern school should have assumed towards the new branch of natural seience the attitude which has become habitual among those who eultivate other natural sciences. All these sciences are based upon observation, aided if possible by experiment: none of them, however, has sncceeded in rising to the rank of an exact seience withont the aid of some generalisation which admitter of elear expression in a few definite conceptions, being the more valuable in the clegree that it lent itself to a clothing of mathematical language. In the course of the last centuries, notably the nineteenth, several of these fundamental prineiples - such as the laws of motion, gravitation, atomism, viluratory motion, the conception of energy, natural selection, metabolism-have attained in varions degrees, some almost perfectly, to this state of definiteness, and the sciences built up by their aicl have accordingly acquired the character of certainty. Psycho-physics having through Weber, Lotze, Fechner, and Wundt gradually evolved the notion of a partial parallelism of physical and psychical phenomena, the conception of a mathematical dependence or of function could be introduced between the measurable external processes and the hidden internal events which we term mental; the whole of the latter being 
looked upon as concomitant occurrences, as "Begleiterscheinungen " or "Epi-phenomena" of the more accessible though very complex phenomena of the nervous system and its centres; whereby it had to be noted, that whilst the external visible processes exhibit that contimuity in time and space which is characteristic of all physical phenomena, the epi-phenomena were subject to discontinuous appearance and disappearance, to sudden growth and collapse. Having got hold of this partial formula, which in some cases admits even of a rigorous mathematical expression, psycho-physics had no pressing need of investigating its meaning any further, or of inquiring into the supposed independent existence or significance of the "epi-phenomena" as such; similar general inquiries into the origin of gravitation, of atoms, of the essence of energy or inertia, having proved to be of little or no use in furthering astronony, chemistry, thermodynamics. It cannot be denied that this is a perfectly tenable scientific attitude. Such an attitude has notably been taken up by Dr Hugo Miinsterberg, and by what we may term the Freiburg school of psycho-physics. Also there is no doubt that through a series of very cleverly contrived experiments-particularly those referring to the muscular sense and the time sense-a good deal of light has been thrown upon such mental processes as association of ideas, attention, apperception, and voluntary effort, which have thus been brought into closer correspondence with changes taking place in 35. the nervous system. In fact, a parallelism of neurosis

and of psychosis has been more and more established. This doctrine of psycho-physical parallelism, also 
called the conscions antomaton theory, is the central eonceptions in jsychulogy as a matural science, or, ؛s I have trumed it, of the psicho-physical view of nature. It was prepared ${ }^{1}$ hy earlicr thinkers, such as Descartes, and, in a different form, ly spinoza," and hy Leibniz's doctrine of pre-estahlished harmony.3. It has been strengthened by the physiological theory of retlex action, and, inclependently, by psychephysics in the natrower sense of the word, as founded ly Weber and Fechner: lint the possibilities of the autonaton theory were not scientifically tester till towards the end of the nincteonth century. In this country, two thinkers

1 The doctrine of psicho-physical parallelism and its historical genesis is given by Huxley in his addrens before the British Association Veeting at Belfist in $187+$, "On the Hypothesis that Animals are Automata, and its History," in which he goes back to Deseartes and ("harles Bonnet. A gool aceount of the theory is also given by l'rof. Win. James in the jth chapter of his 'Principles of Psychology' ; ancl it is fully discussed by l'rof. Janes Ward in his (ittiors lectures, 'Naturalism and Agmosticism,' vol. ii. pt. iii.

'The passage from Spinoza which is constintly yluoted, anch, as l'rof. Ward says, usually in ignorance of the context, is in 'Fthica,' part ii. prop. $i$ : "Ordo et connexio ide. arum idem est ac ordo et connexio rerum."

${ }^{3}$ Leibnix, as hluxley (lor. cit.) tells us, also invented the term "automate spirituel" and applplien it 10 man.

+ Du Bois-Reymomol, in his "F́loge" of Johannes Miiller, has shown that the principle of rellex action dates batck to Jescartes, whe also introduced the term re. flex. Next in time cane Willis ('De motu musculari,' Amsterlam, 1652). The subject seems to have heen overloxkel to such an extent, that l'rochaska (1751) got ior a long time the credit of having established the notion of refles action, and even his work hat to be rediscuvered by linluarl $1 \mathrm{Heber}$ (18t6), after the prineiple of the transition of a reaction from the aflerent to the efterent nerves in the central urgums had heen forminently put forward by Legallois (1811), IIarshall Hall (1835), ancl Johanes Miiller (1835). In more recent times, l'rof. l'Higger's "Laws of Reflex Action," and his aml li. II. Lewes's theory of the presence of consciounass in the spinal ent. hive formed the subject of much discussion and much experiurntal work. A good historical aceount will be fomm in the 13th Leron of M. Ch. Richet' os "l'hysiologie des Museles et des Nerfs" (Paris, $1582)$, and a tiscussion of the whole subjeet in l'roi. Wumlt's 'Physiologische P'syclublugie,' ch. xix., where especially the difference between aucmatic and reflex movement is lnomght out. 
of eminence, Huxley and Clifford, ${ }^{1}$ have made the theory accessible to the popular understanding, withont, however, taking a comprehensive view of the study of mental phenomena, inasmuch as they approached the subject from the side of natural science-the former more from that of physiology, the latter from that of the inechanical sciences. Prof. Wundt treats the subject exhaustively in many passages of his works, notably in the last chapter of his great work on 'Physiological Psychology, in which he broadly defines "the psycho-physical view as that view which starts from the empirically wellestablished thesis, that nothing takes place in our consciousness which does not find its foundation in definite physical processes. The simple sensation, the connection

I Although neither Huxley nor Clifford added anything new to the conception of parallelism as contained in the writings of many earlier Continental philosophers, the fact that they were driven from their purely scientific positions to discuss the subject, and were not psychologists and metaphysicians by profession, gave their expositions, which are otherwise as fresh as they are immature, a peculiar charm. Being both masters in style, they at once enricher the vocabulary with new terms which liave since become classic. The word "epi-phenomenon," an equivalent for the German 'Begleiterscheinung,' which is of independent origin but expresses Huxley's view, is a real enrichment of thought. It is also the direct way to bring home the absurdity of the whole theory. The things of nature being first considered as "phenomena" - i.c., as "appearing" to some one,-the some one is next looked upon as a secondary phenomenon, an epi- phemomenon. Clifford actually in his psychological atomism goes the length of saying, "Reason, intelligence, and volition are properties of a complex which is made up of elements, themselves not rational, not intelligent, not conscions" (see 'Mind,' vol. iii. p. 67). In the physical theory of atoms it has been truly said that you cannot get anything out of the atoms that you have not, to begin with, put into them. Clifford's dictum reminds one of Carlyle's definition of the object of political economy, which has to solve the problem, "Given a community consisting of fools and knaves, how to produce efficiency and honesty by their combined action?" Clifford's solution of the psychologicaldeadlock is the "Mindstuff" theory, the theory that all matter is the phenomenal correlate of the elements of mind. Clifford's essay "On the Nature of Things in themselves" is reprinted in 'Lectures and Essays' (1879), vol. ii. p. 71 sqq. 
of sensations and perceptions, their assuciations, finally, the processes of apperception and volition, are acempanied by physiological nerve-prucesses. Other borlily processes, such as the simple and complex reflex actions, do not enter directly into conscionsness, but they form inportant anxiliary processes of the phenomena of consciousness." 1 It is, accordingly, quite consistent, from a purely scientific point of view, to test this central conception of exact psychology, and to refrain from introducing any purely psychical conceptions su long as the possibilities of the conception, that mental phenomena are only conconitant ocenrences of chances which take place in the nervous system and centres, have not been exhansted. Investigations, with or without this ilefinite purpose, have been very largely prosecuted in the course of the nineteenth century, and have been in part purely anatonical, in part plysiological, the latter again either referring to pathological or to nomal cases. Systematic comses of experiments have been begum at Leipzig and taken up, according to a well-defined special programme, by J) Miinsterberg at Freilume, who in the researches of his lahoratory has, berg. more distinetly than any other philosopher, adopted the theory as a working hypothesis."

I 'Physiologixehe P'sychologie' (4 Aufl.), vol. ii. 1. 644.

2 The principal writings of $\mathrm{Dr}$ Miinsterberg, in whieh his psyeho. physical researches are contained, are: 1, 'Jie Willenshandlung,' Freiburg, 1588; 2, 'l’eitrige zur' Experimentellen Psychologie,' 4 parts, 1859.92; 3, 'l"eber Autgaben! und Methoden der Psyehologie,' being part 2 of the 'Schriften der
Gesellschaft fiir Psychologische Forschung,' 1891. 'These writings, although starting from the position prepared by the Leipzig school of jischo-physical research, are largely polemical, and directed against some of Prof. Irundt's principal theories. They have received at eonsiderable amount of attention in Germany and America and in this country, and also a gool deal 
It can hardly be saicl that this course of study has done more than make a start, and even those who are inclined to consider it a rery one-sided attempt are bound to ackmit that it has a promising future. Thus Prof. Wm. James, whose 'Principles of Psychology' treat of the subject from many and very different points of view, refers to these experiments in a characteristic passage as follows: "Within a few years, what one may call a microscopic psychology has arisen in Germany, carried on by experimental methods, asking of course every moment for introspective data, but eliminating their uncertainty by operating on a large scale and taking statistical means. . . Their success has brought into the field an array of experimental psychologists, bent on studying the elements of mental life, dissecting them ont from the gross results in which they are embedkled, and, as far as possible, reducing them to quantitative scales. . . . The mind must submit to a regular siege, in which minute advantages, gained night and day by the

of opposition. The late editor of 'Mind,' lrof. Croom Robertson, reported pretty fully upon $\mathbf{M}$ iinsterberg's work in the 15 th volume of the first series of 'Mlind,' and drew especial attention to the confirmation which certain views contained in the writings of the British Associationist school have received through Dr Münsterberg's expositions. Prof. E. B. Titchener criticised Dr Münsterberg's experiments and theories somewhat severely in the 16 th volune of the first series of 'Mind,' p. 521 sqq. As the subject is still under discussion, and as in more recent writings of Dr Mïnsterberg, who is now professor at Harvard University, his studies have shown quite a different side from that exhibited by the above-named earlier writings, it is impossible in this history to do more than refer to them as marking a distinct phase in modem psycho-physical thought. It does not appear that Prof. Wunclt agrees with much of the outcome of the important movement lie originated; see his article in 'Philosophische Studien,' rol. vi. p. 382, and a rery valuable paper by Prof. J. Ward ('Mind,' 2nd series, vol. ii. p. $54 s q q$.$) , entitled "MLodern$ Psychology : a Reflexion." As these discussions refer more to the philosophical value than to the purely scientific aspect of psycho-physics, they would lead us beyond the regions of purely scientific thought. 
forces that hen her in, resolve thenselves at last intw her overthow. There is little of the grand style abut these new prism, penululum, and chronograph phitosophers. They mean husiness, not chivalyy. What generons divination and that superionity in virtue which was thought by Cicero to gire a man the hest insight into nature have failed to do, their syying and scraping, their deadly tenaeity and almost diabolical cumning, will douhtless some day hing about. . . . The experiunental method has yuite ehanged the fince of the scitence, so far as the latter is a record of the mere work lone."

It is, however, only fair to remark that it has never heen the oliject of any science, and ean, therefore, no more be the olject of exict psychology, to deal with everything at once, and that psycho-physical science las quite as mueh right to pustpune the question, What is mind ? ${ }^{1}$ as hiolugical science has had to postpone, or even to eliminate, the question, What is life? But this comparison revals also the essential difference between the exact science of life aml the rat science of minct. of life we know only through the observation of living beings, but of mind we lave not only the apparent knowledge of its unity, which introspection forees upon

1 "Sensation, lielentiveness, As. sociation by Contiguity, - these are to be our ultimate and sufficient psychological conceptions: the facts of feeling amul conalion are resolved into facts of sensation; and all mind-processes held to be not merely conditioned, but explained by brain-processes, which they accompany as epi-plienomena or 'Degleit-erseheinungen.' It is not so long since the worthl was shocked at Lange's mot about a psychology without a soul, but the 'mortern' psychology is a piscluology without even consciuusuess. 'Content of consciousness' as much as you like, but conscionsuess it-elf, consciutnosess as activity, is nut our affair; we leave that to metaphy. sics, saly our 'molern' teachers." (Prof. J. Ward, nn "Molern l'y. clulugy," "Mind,' 2nd series, vol. ii. 1. (1)). 
us, but we have also a large array of external facts which have been appropriately defined by the term "the objective mind." There are, in fact, two properties with which we are familiar through common-sense and ordinary reflection as belonging specially to the phenomena of our inner self-conscions life, to the so-called "epiphenomena" of the higher organic or nervous systems, and these properties seem to lie quite beyond the sphere and the possibilities of the ordinary methods of exact

37. research. The first of these properties is the peculiar' Phenomenon
of centralisa. unity exhibited by the higher forms of organic existence, tion. and still more evident in the phenomena of mental or inner life. Instead of unity, it might perhaps be better to call it centralisation. Now, the more we apply mathematical methods, the more we become aware of the impossibility of ever arriving at a comprehensive mity by adding units or elements together. The sum of atoms or molecules, however artfully put together, never exhibits to our reasoning that appearance of concentration which the higher organisms or our conscious self seem to exhibit. In this circumstance lies the clifficulty of ever arriving at any really satisfactory definition of life-which definition eminent physiologists have, as we have seen, felt compelled ultimately to relegate to the realm of the idea. In the last chapter I showed how modern research into the phenomena of life has impressed upon our thoughts the ubiquity, the continuity, and the unique character or singularity of life, without being able to fix upon any one satisfactory mechanical definition of life. But as we ascend in the scale of living things we become aware of another property: they are centred-i.e., they exhibit a 
speeial kind of mity which cannot be defmed, a mity which, even when apparently lost in the periors of $11 n$ conscionsuess, is able to re-establish itself by the wonderful and indefinable property called "nemory" - a centre which can only be very imperfectly localised - a togethro which is more than a mathematical sum; in fact, we rise to the eonception of inclivisluality-- that which eammot be divided and put together again out of its parts.

The seconcl property is still more remarkable. The world of the "epi-phenonena," of the inner processes which accompany the highest forms of nelvons developments in human beings, is capable of mlinited growth: and it is eapable of this ly a process of becoming external: it becomes external, and, as it were, perpetuates itself in language, literature, science and art, legislation, society, and the like. We hare no analogue of this in physical natme, where matter and energy are constant yuantities, and where the growth and multiplication of living matter is merely a conversion of existing matter and energy into special altered forms witlont increase or deerease in quantity. lint the quantity of the inner thing is eontinually on the inerease; in fitet, this increase is the only thing of interest in the whole world.

Now, no exact scientific treatment of the phenomena of mind and boly, no psycho-physical view of nature, is complete or satisfactory which passes by and leaves undefined these two remarkahle properties of the inner life, of the epi-phenomena of nervons action, of conscionsness. And it seems to me that l'rof. Wrudt is the unly psyehophysicist who, starting from science and trying to pene- 
world, has treated the subject comprehensively, and fairly and fully tried to grapple with these two facts peculiar to the inner world--its centralised unity and its eapacity of unlimited growth throngh a process of externalisation. He has done so by his philosophical theory of "apperception and will," and of the "growth of mental values," two conceptions which lead us into the realm of philosophical thought. ${ }^{1}$

But, before closing this chapter, which deals with the study of the phenomena of an inner life and the interaction of body and mind by the methods of exact research, it is well to note that long before psychology existed as a natural science, a large amount of knowledge had been accumulated by a different method. Especially in this country-ever since the time of Locke-there has existed a very large and influential school of thinkers who studied the imner phenomena by what has been appropriately termed the inner sense; every observer recording his own imner experience and leaving it to others, by doing the same, to confirm or correct his statements. Psychology, carried on throngh self-observation or by the

I It would serve no good purpose to string together a list of quotations from Prof. Wundt's volumiursus writings in which these two central ideas of his philosoplyy find expression, especially as there is no one passage to be found in which his highest abstractions and final conclusions find an adequate expression, still less one which could be conveniently rendered in the Euglish lauguage. König has, it seems to me, dove much to make Wundt's view more easily understood, and I must content myself at present with referring to his little volume, notably to the extracts given on pp. 134, 141, and 167, which explain more clearly the theory of apperception and will. On the theory of the "growth of mental values," see especially Wundt, 'System der Philosophie' (2 Aufl., pp. 307, 596), "Nental life is, extensively and intensively, gorerned by a law of growth of values: extensively, inasunuch as the multiplicity of mental developments is always on the increase ; intensively, inasmuch as the ralues which appear in these developments increase in degree" (p. 304). 
introspective methor, hat grown to large dinemsions in 40. I tranln.c.

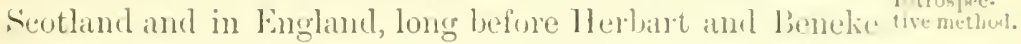
in Germany gave it a sinilar direction. In fact, most of the wrings of the introspective school in Ciernimy, which dates from the milule of the century, is concerned with the material accummlated by Ritish psychologists. And even the psycho-physical methor itself would carry us only a little way if its results and olsservations conld not continually be checked, supplementerl, and interpreted by what we alrealy know by introspection. One of the foremost representatives of the English school of psychology has siriel, and many will agree with him," "In om desire to know omselves-to frame some conception of the flow of our feelings and thoughts - we work at first ly introspection purely: and if at a later stage we find means of extending and improving our knowledge, introspection is still our main resort-the Alpha and Unega of fisychological inquiry : it is alone supreme, everything else sulsidiary. Its complass is ten times all the other methods put together, and fifty times the utmost range of psycho-pliysics alone."

A history of Thonght must accordingly contain some account of the view which om century has taken of the introspective method and the valne of the inner sense as a means of enlarging our knowledge. 'This discussion

1 See Prol. Jain's ensay in 'Mlind,' ancl series, vol. ii. p. 42: "The respective Spheres and mutual Helps of Introspection and T'sy. chophysical Experiment in P'sy. chology."

2 Une result of the modern pycho. physical view, or of the doctrine ol parallelism of physical and mental states, has been not ony to develup a clearer view of physiological psy. chology, but also to define nore clearly the object of psycholugy proper - that is, of the science which deals with the facts revealed by introspection. When, in the middle of the century, the physinl. ngy of the senses attracterl the 
will, in a future volume, form one of the appropriate links which join science to philosophy - which lead us on from exact to speculative thought. At present I have to refer to another and very extensive field of research, into which the natural as well as the speculative philosopher have been led from opposite sides, and which especially affords a hopeful prospect for an enlargement of the psycho-physical view of nature. If the natural philosopher cannot consistently and fairly enter into the mysteries of an inner consciousness from which his opponent-the speculative philosopher-starts, he may perhaps do so by a roundabout way or a side-door.

As I stated above, the inner world, the psychosis, which intermittently accompanies the neurosis, the epi-

attention of psychologists in all the three countries, it became custum. ary to introduce purely psychological treatises by an exposition of the psycho-physical relations, in. troducing in to psychology chapters from physiology. The consequence of this has been that modern works on psychology have grown to inordinate length, and frequently exhibit a dual aspect and method. Quite recently it has therefore been insisted on that psychology can be written either from the physiological or from the purely psychological point of view. A good example of the latter is Prof. G. F. Stout's 'Analytic Psychology' (2 vols., 1896). "Physiological results," he says (vol. i. p. 37), "are likely to be valuable only in proportion as they are controlled and criticised by psychological analysis. This holds good apart from consideration of such metaphysical questions as whether the brainprocess is the sole real agency, and consciousness a mere function, or consequence, or epi-plienomenon ; or whether consciousness is the reality of which the correlated brain-process is a phenomenon, or whether they are two aspects of the same fact. Whatever may be our attitude to such questions, the psychologist has still his own work to do on his own lines; and for the sake of plyysiology itself, so far as it entertains the hope of throwing light on the mechanism of brainprocesses, he must attempt to do it. It is idle to require psychology to wait for the progress of physiology. Such a demand is logically parallel to a demand that history or biography, or the prac. tical estimate of character and anticipation of men's actions in ordinary life, shall come to a standstill until they have a sufficient physiological basis. On this view, Carlyle should liave abstained from writing his 'French Revolution,' because he did not know what precise configuration and motion of brain particles determined the actions of the mob who stormed the Bastille." 
phenonenon which lies on the other sicle of the phenomenon, is not only characterised by a peculiar mity or centrel connectedness which we look for in vain in the external and physical world; it has also beeme external or objective, it has detached itself from the subjective live min." and hidklen somee from which it sprang, and can be studied as such in the great creations of langmage, literitture, society, science, art, and religion. Why not study its nature and its life in these sreat and undeniable manifestations, and instear of hegimming at the hidden source, the unknown and indefinable centre, try to reach this by heginning at the periphery, measuring out the great circle and learning what it contains?

Ancient philosophy, which found its consummation in the writings of Aristotle, had ahrealy begun this work, and, in establishing the rules of grammar and logic, bad furnished the material for many modern speculations. What the ancients had only begun, modern thinkers of the most opposite schools have been induced to continue on more methorlical lines, and with the more or less distinet olject of learning something lefinite regarding that mental life and mity which they have, with little suecess, tried long enough to reach by various direet roads, such as introspection, speculation, physiological and psycho-physical experiment. Aceordingly we find springing up ahmost simulaneously in the three commtries, erer since the latter part of the cighteenth century, the study of mankind or of hmman eulture in all its historical forms. Hume and Adam Smith, Montesquien, and the French physiocrats, studied society and the great fabric of industry and commerce; ('abanis and the "Idéo- 
logues" pointed to the importance of the philosophical study of language and grammar; the idealistic school in Germany ended by leading to the study of the objective mind in history, art, and philosophy; the school of Herbart in Waitz, Lazarus, and Steinthal led into "Völkerpsychologie" and "Sprachwissenschaft"; and it is well known how in our days the synthetic philosophy of $\mathrm{Mr}$ Herbert Spencer in England has entered on the study of sociology on the large scale. We hear on all sides of natural histories of mankind, of society, of religion, \&c., and they appear either in the modest attire of the other and older natural histories which we have been accustomed to, preparing the ground by patient and nubiassed collection of facts, or they attach themselves to certain philosophical theories, such as are furnished by the dialectics of Hegel, or by the evolutionary doctrine of Darwin and Spencer, in commection with which we shall meet them in a future section of this work. For it has been found here, as it had been in the older natural histories, that the accmmulation of facts and materials was of little use unless some leading idlea was at hand by which it became possible to regulate and arrange them.

Thus we see how the psycho-physical problem-the question of the interaction of mind and body, of soul and nature, of the inner and the outer worlds-is being attacked from two entirely different sides,- - from the side of the individual and from that of the collective life of the human being: the mental principle is being studied in its imner and hidden existence as the unifying and centralising factor of individual life, or in its ex- 
ternal manifestations in history, socioty, science, alt, industry, and religion,-in fact, in the history of culture and civilisation. If Bishop, Perkeley has, with some fropriety, heen caller "the historical starting-poind" of psycho-physical investigation of the first kind, the insportance of that of the second and wider kind is nowhere nore clearly and definitely expressed thanwer a centuly ago-in the writings of Johann Gottfriel Herder.' His inthence in this direction was very

42, Its study

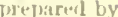
ilerder.
1 The intluence of Herder (174t. is03) on German literature and thought was fully acknowledgerl by his contemporaries, as is testitied hy the frequent referenees to him in the biographies of nearly all the eninent nen who lived at the end of the eighteent land the begimning of the nineteenth centuries, as also in the voluminous correspondence which he carriel on with many eminent contemporaries. Hat it not been for the overpowering and one-sided influence which the critical, and, later, the transcenclental, schools of thought gained, notably at the German universities, Herder's icleas would liave been more generally acknowlerlged as iormine, to a very great extent, the starting-point of many lines of research which were not exclusively eontrolled by the ruling philosophies, and which gradually: and imperceptibly united at a later. diate to form the mure molern current of German thought. Herder was much more illied with the histrrical sturlies referring alike to nuture, literuture, and culture, than witl the eritienl and metaphysical systems, being alss, well acquainted with contemporary linglish thought, as, inter relie, with the curious writinges of Lord Monborlelo, Through Mislaure de Starel, who was in. timate with Herder, his writings were early known in france, whereas Carlyle's studies in German liternture, though most valuable and original in their way, do not give that prominence to Herder's writings which they deserve. In more recent limes, atter the indefatigable Düntzer, through the prubliention of lis eorrespondence, had clone much to revive the interest in $\mathrm{Her}$ des, full justice has been tlone to his great inerit by liudolf Haym, whose great work, "llerder nach seinem leben und seinen Werken' (2 vols., Berlin. 1585), is a perfect mine of information. 'The side of Herder's influ. ence which is not sufficiently dwelt on by Haym, lut which interests us most at present, - what we may call his anthropological riew, - had already been exlaust. ively dealt with by $D_{1}$. lfeinrich loehmer in his little-known 'Geschichte der Entwickelung der' Naturwisenschatlichen Weltanschaumug in l)eutschland ' Gotha, 1572, who especially draws attention to the prycho-physical inleas of Herder, It hias been truly sainl that there is harlly any molern idea which has found widespreal application that cammot he traces in the writings of Herler: but Herder last no methot, having 
great, and would have been greater had he not lived at a time when the study of the human mind by the purely introspective or speculative methods had absorbed all philosophical interest in England and Germany. His opposition to the (abstract) subjective philosophy of Kant and Fichte made him umpopular; he was only half understood at the time; and only towards the end of our century have his ideas been recognised as containing the clear conception of psycho-physics on the large scale-i.c., of the natural history of humanity, the genesis and evolution of the objective mind.

Herder was a pupil of Kant during his pre-critical period. He was still more influenced by great naturalists like Haller, Buffon, Camper, Sömmering, Forster, and Blumenbach, who through physiology, comparative anatomy, and ethnology, attempted to bring the study of the human race and its mental development into comnection with that of the brute creation, of the surrounding plant-life, of the characteristics of climate and soil, and of the great natural features of sky and landscape. He did not believe that we could study the great forces of nature and mind from inside or in the abstract-he desired to follow Haller's physiology, to complete and continue it into psychology. Irritaloility,

characteristically maintained that method is frequently only a convention, and he was deficient in critical acumen. The German mind had to go through the severe discipline of the school of mathematieal and critical thought, and to amass an enormous volume of $\mathrm{ex}$. perimental and historical knowledge, before the brilliant conception of Herder in his great work 'Irleen zur Geschichte der Menschlieit' (4 pts., 1784-87) could be partially realised by A. von Humboldt in his 'Kosmos' (1841-59), and by Lotze in his 'Microcosmus' (1856-64). See especially the preface to the latter.

1 See above, p. 471, on a similar development of Haller's teaching through Cabanis in France somewhat later in time. 
the highest physical phenomenom of matter, was to he the starting-point of this psychology. In an carly essay on melerstanding and sensation (1778) he wote: "According to my thinking there is no psychology" possible which is not at every step definite physiology. Haller's physiologieal work once raised to psyclology, and, like Pygmalion's statuc, enlivened with mind, we shall be able to say something about 'Thouglit and Sensation." 1

lint this psycho-physiological view was not limited to the study of the individual: it widened ont and enbraced the whole of mankind; nature on a large seale harl to be observed; historical records had to be collecterl on all sides; origins had to be studied and the elementary forces followed иp in the beginnings of poetry, art, and religion. Materials were gathered everywhere from historians, chronielers, travellers, prinitive records, and the "voices of the peoples." All this was to furnish the materials for a "History of Mankind." "In many"

I "Vom Erkennen und limpfinden der menschlichen sicele", (17\%8), in the 9 th vol. of the Works of Herder ('Abtheilung zur Philosophie und Geschichte, 1828). 'To give an idea of Herder's inticipation of moders views, see 1) 10: "We cammot penetrate deeper into the genesis of sensiation than to the renarkable phenomenon called by Haller 'Jejy.' The irritaterl fibre (ontracts and expauls agitin ; perliaps a "stamen.' the first glowing sparklet of sensiltion, towards which deat matter has purified itself ly many steps and stages of meehanism and an. ganisation." Many pissages could be quoted from Herder's 'lileen,' \&c, and otlıer writings, anticipating modern Inawinian ideas, such as those of the struggle for existence, andeven of automatie selection. See l'rof. J. Sully's apureciative article on Hercer in the 'Bneye. Brit.' (9th ed.), and notably Fr. von birenbach, "Herder als" Vorginger Darwin's' (Berlin, 18т). I Laym ('Herler,' vol. ii. 1. 209) ohjects $t$ (t) this extreme view of Hoder as a forerumer of liarwin on the ground that, according to the former, no animal in its development ever for. sook that aljustment of organie forces peculias to it, nature hiving kept each being within the linit:of its type. Aceorlingly, lferder"s evolutionism would he more akin to that of K. F. von liater than (1) that of 1)arwin and Haeckel. 
43. parts," he says," "my book shows that one camnot as of Mankind.' yet write a philosophy of human history, but that perhaps one may write it at the end of our century or of our chiliad."

And indeed the whole of our own century has been busy in carrying out this prophetic programme of Herder's, conscionsly as planned by him in Germanyunconscionsly and independently in other countries. As a comterpart to the introspective labours of Kant and their followers, a large array of naturalists, historians, philologists, and ethnologists have in the spirit of Herder ransacked every corner of the globe and every monument of history with the distinct object of tracing there the physical basis and the workings of that inner and hidden principle which we call the human mind. In doing this, they or their numerous followers, who belonged to a generation which knew not Herder, have strayed far away from the common starting-point, and have frequently lost themselves in the bewildering details of special research.

44.
Separation of natural and mental sciences.
Above all, in the country to which Herder belonged, a separation set in early in the century hetween what have been termed the natural and the mental sciences. The former came more and more under the sway of the mathematical spirit, which, as I showed in an earlier chapter, turned the eyes of its rotaries away from their own national scientific literature to that of their neighbours - first to France, latterly to England. The mental sciences, on the other hand,-history, philology, the social sciences, - came under the influence of exactly those philosophical idleas which Herder never understood nor assimi-

1 See the preface to the first part of the 'Ideen,' 1784. 
lated: ${ }^{1}$ the eritical spirit of Kint, and the constructire canous of his snceessors, each of these distinet and separate movements, supplied exactly what was wanting in the prophetic, not to say dithyrambie, utterances of Iferder'; they smpllied enlerence and method. Earlier chapters of this book have shown how the mathematical spirit has perneated and revolutionised the natural sciences, and latterly how it has, in the science of psycho-physics, led philosophers hack to the problem which Herder had adumbrated at the end of the previous century. A second large department of $1 n y$ task will consist in showing how what in Germany are called the mental sciences have been developed independently of the natural sciences, how the study of the mind as such-

I During the latter part of his life Herder was occupied to a grent extent with those publications in which lie gave expression to the opposition which he consistently maintained to the eritical writings of his master liant. His two principal works referring to this are "Fine Jetakritik zur Kritik der Reinen Vernunft' (2 parts, 1799) and 'Kalligone' (1800). Kant had reviewerl the first volume of Herler's greatest work, the 'Ideen,' auonymously, eriticising the absence of logical acumen and clear lefintions, and also the attempt towards a genetic as opposed to a eritical treatment of the intellect, the former being an enterprise " which transeends the powers of inuman reason, whether the latter gropes with physiology as a lealer, or attempts to soar with metaphysics." In the secont part of the 'Illeen' Herder had taken up a polemical attiturle to Kant's teachings, and Kant hacl again reviewed it, dwelling upon the uneritical manner in which Herder had built up his hypotheses on unsiftel material gathererl from all sides. In the "Metithritik" Herier, irritated by what be eonsiflered the arrogance of the Kantian sehool, umlertook to put into systematic for'm his criticism of Kant's principal work, following to a great exteut the suggestions: thrown out by a mutual friencl of himself and Kaut, Johann Georg Hamamn (1730-80), and falling back upon the earlier philosophics of spinoza and Leibniz on the one side, and upon the common-sense philosophy of the Scottish sehool on the other, seeking for a solution of the problems raised by both, not in abstract reasoning, but in the realism of the concrete and the historieal seienees. In the 'Kalligone,' Herder similarly attarki Kant's asthetical philostphy ('Kritik der Urtheilskraft,' 1790), which hat been enthusiastically received in Herler's immediate neighbour. hood by Schiller. A full aceount of these controversies will be found in the '2mil vol. of Haym's work. 
in its individual and collective existence-has proceeded when separated from that of nature. This survey will start with exactly that movement of thought which was so distasteful to Herder, the critical inquiry of Kant, and it will follow this up to the point when in our days a junction has again been attempted, not unlike in spirit to that dreamt of by Herder, though very much more accurate and precise in method. There is, moreover, one special problem where this has been markedly the case; one phenomenon stands out pre-eminently; it belongs equally to the realm of nature and of mind. After being independently attacked by philosophers, naturalists, travellers, philologists, and latterly by physicists, it has revealed itself as the psycho-physical problem par excellence; and it is exactly that which Herder himself 45. treated with special attention. This phenomenon is that The problem of language. of human speech - the problem of language. ${ }^{1}$

1 The problem of language and the question of its origin inde. pendently occupied thinkers in the three countries in the latter half of the eighteenth century. In France the followers of Locke, notably Condillac ("Essai sur l'origine des connaissances humaines,' vol. ii.), wrote on the subject, while Rousseau opposed them ('Sur l'inégalité parmi les hommes,' 1754). In Germany the Pastor Siissmilch, of whom I shall have more to say in the next chapter, wrote an elaborate work to prove the divine origin of language ('Beweis dass der Ursprung der Menschlichen Sprache Göttlich sei,' Berlin, 1776). In order to settle the question the Academy of Berlin offered, in the year 1769 , a prize in the following terms: "En supposant les hommes abandonnés à leurs facultés natu- relles, sont-ils en état d'inventer le langage? et par quels moyens parviendront-ils d'eux-mêmes àcet te invention?" a problem which Her. der characterised as a "truly philosophical one, and one eminently suited for me." He had alreadyfollowing Hamann-thought much about the subject, and he proposes, in his prize essay, which was subsequently crowued by the Academy, "to prove the necessary genesis of language as a firm philosophical truth." A short time after Herder had written his essay (1771), there appeared in England, by James Burnett, Lord Mouboddo, a work 'On the Origin and Progress of Language' (1773), in which he refers to the ideas of James Harris in his work 'Hermes; or a Philosophical Enquiry concerning Language and Universal Grammar' 
In no department of knowlerlge has the scientific spirit worked a greater change than in the science of language. With the exception of snggestions by lecihniz, who clearly saw the neeessity of founding the theny of language on a lnouler hasis than the small number of classical and modern tomgues then current aflorded, and of some glimpses of a correcter view such as those contained in the much ridicnled witings of Lord Monbodklo, we find, "u, to the end of the eighteenth century, hardly any attempt towards a methorlical treatment of the great problem. I'hilosophical theories and ragne etymologies, anominting frequently to little nore than punning with works, bronght the sulyect into ridicule. Herder las the great merit of having urced the importance of the sturly of langnage and literatme in primitive forms ${ }^{1}$ as the great gateway into anthropolony

(1751). The question attracted considerable attention, partly through the eccentricities of Lorrl Mon. bollo, of which it has been well said that they appeared more vidiculous to his own than they would to the present age, partly through the controvers which arose shortly after on the publication of Horne Touke's celebrated "Е $\mathrm{E} \epsilon a \quad \pi \tau \epsilon \rho \sigma \in \nu \tau a$, (1) the Diversion: of Purley' (17,6). Herler was aequainted with Moubnddo's work, laving ocensioned a translation of it to be male and written a jrefice (1757); but he does not seem to have taken any notice of Horne Tooke (1736-1SI2), who, as the historian of the seience of language (Theodor lienfey, 'Geschichte 'ler Sprachwissensehaft,' Mimchen, 1869) says, would, for his novel ideas and method, descrve to be wut at the entrance of the modern linguistic epoch, had lie been able to avail himself of a knowledge of Sanskrit.

I This refers to the second greatest work of Herder, his collection of popular songs, published under the significant title of "Voices of the Peoples" ("Stimmen ler Vouker in Liedern, 1775), is work which had the greatest influence on German literature a: well as on modern philological studies. See lienley, loc. cit., l. 316. \&c. That the publication of the 'I'ercy Ballads' (176\%), of Mac. pherson's 'Ossian.' and of l.owth's - I,ectures on Hebrew Pretry' (1753), formed a great stimulus to Herder in his historical and poetical studies is shown by Haym in nany" extracts and passages, also in the prefaces of llerder himself and of his editor, Joh. von Miiller (Herder's ' Werke,' 18:28, ' Kur' schonen Liter. atur und liunst,' vols. vii. and viii.) 
and the science of hmmanity. Through his writings there rose two distinct views both fruitful for thought, the philosophico-historical and the strictly scientific. His immediate successors, or rather those who unconscionsly inbibed the spirit of his writings, took up the former line. The great development of classical philology in the school of Wolf, the discovery of Sanskrit and the new field of oriental philology, for a time threw the purely scientific aspect into the background. Yet at the same time with Wilhelm von Humboldt and his philosophical interests in comparative philology, we find his brother Alexander giving a large share of his attention to the unknown languages of the New World, of which he has been called "the scientific discoverer."

But the real beginnings of an exact treatment of the problem of speech were laid by one who did not come under the conscions influence of Herder, thongh he came under that of Goethe. By Johamnes Miiller it was carried further, and it was completed by some of his most illustrious pupils and followers-Donders, Bricke, Helmholtz, and Czermak of Vienna. Throngh the anatomical and pliysiological labours of these and other naturalists, joined to the physical analysis of musical notes and sounds contained in the great work of Helmholtz on Acoustics, aided by such instruments as the laryngoscope or throat-mirror, and the wonderful inventions of the phonograph and phonantograph, the organ of speech is now known to be a complicated wind instrment by which pure notes and an almost infinite variety of nasal, labial, dental, palatal, guttural, and other sounds can be produced which form the phonetic ele- 
ments of speech. Simultanemusly the discovery ly bincui, in 1S61, of the speech centre in the lrain markex an epoch on the plyysiological side. I new science, calleal Phonetics or P'lonology, has sprung up, ant is now miversally admitted to have ereated the modern science of language. In addition to this physiologieal and physieal basis, the sunerstructure of the science of

1 This localisation places the speech centue in "a very" cireun. scribel fortion of the cereloral licmispheres, and more especially. of the leit. This portion is situate (n) the ulper erlge of the sylvian Fissure, opposite the island of Reil, and occupics the posterior hali, probably only the pusterior third, of the third fromal convolution" (Broca, "Bulletins de la Société anatomiurue,' 1561). The discovery resulted from the examination of the brain of patients who had been aftlieted with "aph. asia," whieh is accompanied with "a lesion of the posterior half of the third, left or right, frontal convolution, nearly always-nineteen times out of twenty-of the left convolution." The phenomenon of aphasia has ever since been one of the great psycho-physical jroblems bringing together the most refinel and intricate physiological, psychologieal, and linguis. tic analyses. To begin with, we lave to distinguish motor aphasia and sensory aphasia. "Our knowleige of this disease lıas had three stages: we may titl of the period of Broca, the perion of Wernicke, and the period of Chareot. Wernicke (1874) was the first to cliscrininate those cases in which the patient cunnot men unlerstund speech from thrse in which he can unclerstand, only not talk and to ascribe the former conclition to lesion of the temporal libe. The condition in question is remeldenf. ness, aud the disease is auditory uphasia... The minuter analysis of the facts in the light of individual differences constitute: Chireot's contribution towardelearing up the subject" (Jame-, "Principles of Psychology", vol. i. 1. 5.1.

"In the modern science of language we have one among the many cases where a historical or philosophical seience is becoming an exact seience 以 attaching itselt to plysics and physiolugy. On the other sile we have the great morement initiated by I)arwin in the purely natural sciences, which. as was shown above, relies on the historical collection of facts and the juciicious critical sifting of evi. dence. "It is phonology," says l'rof. Sayce ("Introduction to the Science of hanguage,' 2 rols. . 1 sso. chitp. iv.), "which has createrl the" modem science of language, and phomology may therefore be forgiven if it has elaimed more than rightfully belongs to it or forgot ten that it is lut one side and one branch of the master science itself. . . . It is when we pass from the out. ward vesture of speech to the meaning which it clothes, that the seience of language becomes a historical one. The inner neaning of speech is the retfection of the human mind, and the development of the lumman mind must be stuctied listorically."
4 i lhoneties 
language has likewise been stated to be no longer a historical or a philosophical, but to have become a physical, science. It is true that, as with other natural sciences, so also in this case, the morphological, genetic, and liological aspects can be specially studied; also analogies can be drawn between geology and glossology as to their mode of inductive reasoning. The great anthority who first took up this novel position was the late Prof. Angust Schleicher of Jena, and the same has to a great extent been simultaneously adopted by Max Miiller in his celebrated 'Lectures on the Science of Langnage.' It is interesting to note that Schleicher wrote on the 'Morphology of Language' in the same year in which the 'Origin of Species' appeared, and that he recognised very early the importance of Darwin's work for the science of language. ${ }^{1}$ This became still more evident on the publication, twelve years later, of the 'Descent of Man,' and of 'The Expression of the

1 On August Schleicher (1821$68)$ see a very valuable article in the 'Allgemeine Dentsche Biographie' (vol. xxxi. p. 402 sqq.) by Johannes Schmidt. Very different eurrents of modern thought, such as we shall in the sequel frequently have to represent as opposed to each other, the study of the classical and of the modern languages, of critical and comparative philology, the historical and the exact spirit, Hegelianism and Darwinism-i.e., logical and mechanical evolution - the inflnence of Grimm, Ritschl, and Bopp, of botany and grammar, combined to generate in this remarkable man the conception of linguistic as a natural science in contradistinction from philology as a historical science. The principal works in which he developed his original view were: 'Die deutsche Sprache' (1860); 'Compendium der vergleichenden Grammatik der indogermanischen Sprachen' (1861); 'Die Darwin'sche Theorie und die Sprach wissenschaft' (1863); and 'Ueber die Bedleutung der sprache für die Naturgeschichte des Menschen '(1865). Schleicher's ideas have been taken up in France, notably by Abel Hovelacque ('La Linguistique,' 4 ène ed., 1857), who says of him that "he had com. pletely liberated himself from metaphysical aspirations" (p. 6). On the one-sidedness of the purely physical theory of language see Sayce, "Introd. to the Science of Lauguage' (1880), vol. i. p. 76, \&c. 
Emotions in Man and Animals' a year after: 'These writings did more than any others to inpress upon philosophers the genetic or historical riew, the existence of an mubroken chain or transition from the lower to the higher and the lighest forms of animal structures, and culminated in the well-known expression of Inwwin, that 'in a series of forms graduating insensiluly from some ape-like creature to man as he now exists, it would be impossible to fix at any definite point when the term "man' onght to be useel." 1 This dictum has been the theme on which endless variations have been played down to the present day-l'rof. Ernest Haeckel's address to the Congress of \%oology at Cambridge in 1898 heing the latest summary of the physical aspect of the proliem. But the problem has also a psycho-physical side, and this aspect is concentrated in the prollem of language. Even those philologists who, like August Sehleicher and Max Miiller, look upon the science of langnage as a natural science, bring in at this point the acemulated and weighty evidence of the historical, jsyehological, and philosophical researches into the growth and development of human speech and human thought, as absolutely negativing the possibility of a gradual transition from the brute to the human creation. To the latter, language, The dividing line letween which he considers to be the mion of definite concepts man anil with definite nanes, is the limbicon which camnot be crossed, ${ }^{2}$ the chasm which divides that portion of the

2 'Deseent of Man,' 1st ed., rol.

"See Max Miiller, "The Science of Thought,' pussim, notally chap. iv. $\mathrm{p}, 177$, where he quotes and uaintains his diclum of 1 s61 ('Lee- tures on the Seience of Lamguage, vol. i. 1. 403): "Language is our liubieon, and no brute will dare to cross it." Relerring to s.hleicher, he say, (1) 164): "I'rofessor Sehleicher, though an enthusiastic 
living creation which is capable of an unlimited development and an external realisation of its inner life from that which has no mental history or development: it is the point of discontinuity in the physical development. The study of language in its physical and mental aspects -i.e., in phonetics and in sematology-affords, according to this view, the only means of penetrating from outsicle into the inner world of thought: it is the psycho-physical problem par excellence-the "Science of Thought."

Inasmuch as in this latest development of psychophysics the whole of the accumulated material and most of the arguments have been drawn from the historical and philological researches of such thinkers as Schlegel, W. von Humboldt, Bopp, Grimm, and their followers, who were without exception trained, not in the mathematical but in the philosophical schools of Thought which ruled in the earlier part of our century, the further consideration of their ideas belongs properly to that portion of this work which will deal specially with philosophical thought and its application in such separate branches as are presented, inter alia, by the historical sciences.

admirer of Darwin, oluserved once jokingly, but not without a deep irony, "If a pig were ever to say to me, "I am a pig," it would ipso facto cease to be a pig.' 'This shows how strongly he felt that language was out of the reach of any animal, and constituted the exclusive or specific property of man. I do not wonder that Darwin and other philosophers belonging to his school should not feel the difficulty of language as it was felt by Prof. Schleicher, who, though a Darwinian, was also one of our best students of the science of language. But those who know best what language is, and still more, what it presupposes, cannot, however Darwinian they may be on other points, ignore the veto which, as yet, that science enters against the last step in Darwin's philosophy.' 
ON THE PSYCHO-PHYSICAL VIEV OF NATULE.

It now only remains for me to smu up in a few works 42. the learling eonceptions which the psyeho-physical view of Sinnmary. nature has forced upon us. In the last chit]ter I showed how the sturly of life has in the course of om century more and more bromght ont the conviction that life is a continuous, a ubiquitons, and a mique jhenomenon; an exhaustive or even a working defintion of life being so far harlly possible. In this chitpter we have learnt, by following the psyeho-physieal lines of researeh, to distinguish another and peenliar sile of the lighler forms of living matter, that which is commonly called the mental, inner, "r self-conseions side. This alpearerl, when viewed externally, as a liscontimuous epi-phenomenon-"eine begleiterscheinmo" - of some rury complex physiological pueesses and anatomical arrangements of living matter, and as such it exhibits a property with which we are otherwise not faniliar in the visible phenomena of nature-nanely, discontinnity. Viewed externally, the inner phenomena, which we comprise under the term "mind," appear and disaplear, their contimuity being preserved in association with the permanence of the external substratum or basis to which they are attacherl, and intemally regained by the indefinable property of menory. But inasmuch as we have not only an external hut also an internal linowledge of at least sone of these epi-phenomena, we have lat forced upom us an entirely different view of this imer life, uf nind. 'To the inner view there exists in selt-conscions heings a centre of relatedness - a special kind of unity which we call individuality on personality ; and this imner mity is capable of being extermalised or mate objective in the 
mental life of mankind, language being the great instrument by which this is accomplished. In this external or objective existence-which, however, is only intelligible to beings which form a part of it-that continuity is regained which in the existence of every individual is continually being interrupted and in danger of being lost. Psycho-physical research reveals to us the existence of a unity different from that visible in merely external or physical nature,-a centred unity which is something else than the sum of parts in a mathematical whole. Through this process of centralisation and externalisation there has been formed in the physical world, or in nature, a new worldthe world of mind, which is continually growing in contrast to the former, which only changes without increasing or losing its two constitnents, matter and energy.

This new world within the old one, this creation of man, forms indeed a portion of nature-it is the microcosm in the macrocosm. It might be investigated by the usual methods of exact research; and the science of anthropology, with its many branches, proposes to study it in the same way as natural history in modern times has studied the social life of certain animals, such as bees, ants, and beavers. Inasmuch, however, as the exact methods do not lead very far, and have continually to appeal to the interpretations of psychology, gained by personal experience and introspective methods, ${ }^{1}$ it scems

1 Prof. E. Hering ("Ueber das Gedächtniss als eine allgemeine Funktion der organischen Materie, Vienna, 1870) says: "So long as the physiologist is only a physicist he stands in a one-sided position to the organic world. This onesidedness is extreme but quite 
more practical to range the whole of these researches within that great realus of thought which starts with a distinet recognition of conseions individual life as its source and centre. As such, in fact, these researches have been till quite reeently carrien on, and the main lines of their recent development belong acoordingly to philosophic as distinguished from scientific or exact thought.

The three great facts, howerer, which even the exact treatment of mental phenomena lias impressed mpon us The three facts int. presinil by - namely, the existence of centralised nuterial systens, juycho. termerl "individuals," the disenntinuity of their inner life as viewed from outside, and the phenomenon of its growing external manifestation_llave cliven natural philosophers to form sone explanation, or at least to venture upon a definition of this hirkten mineiple, which shows itself in the highest forms of living matter, and which, though discontinuous to the extemal observer, acquires in the aggregate of human society a continuous and ever growing reality and development. Two dis-

legitimate. As the crystal to the mineralogist, the vibrating string to the student of acoustics, so also the animal, and even man, i.s to the physicist only a piece of matter. That the animal experiences pleisure and pain-that with the material lile of the human frame are connected the joys and sorrows of a soul and the vivicl intellectual life of a consciousness; this cannot change the animal and human bocly for the physical stuclent into anything other than it is-a material complex subject tu the unalterable laws which govern also the stone and the sub-tance of the plant, a material

VOL. II, complex whose external and internal movements are causally as rigidly connected amongst each other, and with the movement: of the environment, as the work. ing of a machine is with the revolution of it wheels (p. 4). . . . Thus the phyojologist as physici-t. But be stanls behind the scene, and while lie painfully examines the mechanism and the busy loings of the actors behind the drop scenes, he misses the sense of the whole which the spectator easily recoguises from the front. Cosuli the phy-iologint not, for once, change his position?" (1\%. i.) 
tinct views have been evolved by modern science on this matter.

The one emphasises the fact of the discontinuity of mental-i.e., conscious - life, regards it as an ultimate fact, as a mystery beyond which we camnot travel. This idea presents itself in various forms, and has been notably insisted on-with very varying philosophical inferences-by Du Bois-Reymond in Germany, by $\mathrm{Mr}$ A. R. Wallace, and quite recently by the late Prof. St George Mivart in England.

The other takes refuge in the hypothesis of unconscious or subconscious mental life, and again with very different philosophical inferences assumes that all physical existence has an inner side which only under certain favourable conditions rises into the light of selfknowledge or consciousness. The late W. K. Clifford's "mind-stuff" theory, as also the speculations of Fechner and of Prof. Haeckel, are types of this view, which has been consistently and comnectedly elaborated in Hartmann's 'Philosophy of the Unconscious.'

These speculations can be summed up under the title "The Creed of Science," and as such will occupy us later on in one of the chapters on the Philosophical Thought of the century.

By many natural philosophers it is felt that the time has not yet come to arrive scientifically at any definite 51. conclusions on these last questions. Sufficient facts have to statistics. not been collected; or even if collected, they have not yet been classified and tabulated. This is especially the case with the vast materials referring to the collective life of mankind. Leibniz had in his time foretold the 
ON THE PSYCHO-PHYSICAL VIEW OF NATClE. 547

necessity of extensive statistical information before builling theories. In one instance, that of language, lis advice was followed with signal success.

but even some of the purely physical sciences, like meteorology, are still almost entirely limiter to statistical information.

Statisties have thus become a very important department of knowledge, and hefore taking leave of the exact lines of thought, it will be well to note more precisely the jart which these have played in our age, as also the methorls by which they proceed. This will be the wheet of the next chapter, which will aceordingly deal with the Statistical View of Nature. 


\section{CHAPTER XII.}

\section{ON THE STATISTICAL VIEW OF NATURE.}

I HAVE now treated of the several grand and general aspects under which the objects of nature can be scientifically regarded, and have tried to show how these aspects, not unknown to former ages, have nevertheless, in the course of the nineteenth century, become more definite, and accordingly more useful, as means for describing, measuring, and, in many cases, predicting phenomena. It is true that the two last chapters, which dealt with the phenomena of Life and Mind, had to take notice of a principle or of principles which have hardly yet received any scientific definition at all, and which in the progress of the sciences which deal with them have played rather a negative part. It has been mainly by eliminating the conceptions of life and of mind as special agencies, factors, or entities that the scientific study of living and conscious beings has progressed; by showing more and more how an accurate and useful knowledge of much of their nature and behaviour can be gained with the aid of the methods adopted in other scientific inquiries, which we may call mechanical. 
Seientific inquiry in biology and psycho-physics has thus advanced on the lines indicated in the earlier. chapters, where it was shown how several positive scientifie conceptions have been gained, defined, and alpplied. These conceptions are all generalisations based upon definite observable ficts of nature, such as attraction, atomic constitution, notion (rectilinear, periodic, and rotational), energy, form, and change of form, ${ }^{1}$ and they have given rise to great lranches of science, containing special methods of thought and reasoning. They have all shown themselves accessible, in a greater or less degree, to mathenatical treatment, and have consequently been the means of introducing the exact scientific spirit into large fields of research, into ever

1 The statement in the text is not strictly correet; for of the six definite conceptions mentioned we really, even in single cases, only see two exemplified-viz., motion and form. Neither attrietion, nor the atom, nor energy, nor development is, even in single eases, observable, though, with the exception of energy, they are very early and very familiar abstraetions. This remark may suggest that motion and form are, at least for the present, the simplest and most obvious coneeptions into which we ean analyse or resolve all external ubservations, and that conseruently kineties and mor. phology may be the fundamental sciences, the first in natural phil. osophy, the latter in natural his. tory or biology in the widest sense. That a kinetie view will gradually supervene in natural philosophy is, I think, generally adinitted. It neems less generally conceded that morploblogy will supervene in biology ; especially as all the rage is just now for evolution and development. But as development must start from something, it is likely that it will lead back to morphology. As tending in this direction I rearl the expositions of Lotze, Claude Beruarl, and the "Urganicists." Urganisation must mean a certain arrangement, and arrangement is ultimately the same as order, strueture, or form. It may mean something nore-viz., unity or centredness; but this is a eonception not capable of a purely mechanieal or geometrical defini. tion; we know of it only through introspection. A great deal has been written on Morphology and Morphogenesis by that very suggestive author, Hans Driesch ; see a list of his writings, supra, p. $450^{\circ}$ note. 1 here only refer to them; tor, heing myself unahle elearly to al'prehend his main drift, I hesitate to quote him as confirming the argunent of this note. The reader must jurlge for himselt. 
widening circles of phenomena and events. This has been most decidedly the case with the sciences in which the law or formula of gravitation has become the leading principle. As we advanced on the other lines of thought, marked by the conceptions of atomism, of the various forms of motion and of energy, this subjection to precise formule became less perfect, more complicated and hypothetical, whilst the study of the typical forms of natural objects, and even more of their genesis and developments, opened out a field for much conjecture and fanciful reasoning, amid which little more than the general outlines of a definite theory could be established. Lastly, in applying these various conceptions to the phenomena of the living and selfconscious creation, we have struck upon the limiting ideas of life and mind, of which, from a purely external point of riew, little more can be said than that they indicate to us the existence among natural objects of a unity of a different kind from that which we can understand mechanically as the sum of many parts. In the higher forms this unity revealed itself to us through the analogy of our own inner life as a peculiar kind of centralisation, discontinuous when viewed from outside, but possessing, when viewed from another side, a continuity, connectedness, and capacity of unlimited growth of its own which is the special object of the psychological and historical sciences. These characteristics belong to the great realun of philosophical as distinguished from exact scientific thought.

2.

Results of abstract science.
Before entering on this other great branch of our subject, we may well pause for a moment and cast 
a general and unbiassed glance at the world outsile, leaving our study, our observatory, our laboratory, our dissecting- or our measuring-room, and ask ourselves the simple question, By the work carried on in these various secluded places, in the "sapientum templa serena," how much of the world outside have we really learnt to comprehend, or even only to describe and pieture to ourselves correctly and completely? The answer is hardly cncomaging. The first thing we notice in stepping out of our door is a phenomenon still as incalculable as it has erer been, and yet bound up with the enjoyment of our lives and the success of our work as much as ever-the weather. What do we know of it which is praetically reliable and useful? The reply must be, "Next to nothing." Some greneral astronomical and some more detailed physical and chemical relations permit us to deseribe a few general meteorological and a few recurring seasonable events, but scarcely with more practical detail and certainty than the unseientific ancients or the untanght children of nature of to-day. We know in general the cause of storms, of changes of temperature, of the seasons, of rain, hail, drought, and cold, but we do not know much more of the exact when and where of these various changes than did our forefathers. The natmal atmosphere and climate which surround us are still elements of conjecture and uncertainty.

Assume, however, that we go a step further, and having accustomed ourselves to take the weather, good or bad, as it is, enter into the artificial atmosphere and surroundings of practical life, of industry, trade, and 
commerce, of politics and society, in which most of us have to spend the larger portion of the working hours of omr existence. We can again put the question, What do we know with certainty of the changes and vicissitudes of this artificial atmosphere which surrounds us; what of the chances of a fall or rise in prices, of increased or lessened demand, of impending labour troubles, of the risks even of famine, fire, shipwreck, disease, or war? Again we may say that in general we know the proximate causes, natural or artificial, which may bring them about, but the exact when and where of their occurrence is so slightly known to us that such knowlerlge is of little, if of any, practical valne, and proceeds, moreover, where it exists, more from general good sense and practical experience than from the discoveries of science. Indeed, the latter have, through the wonderful applications in the inventions of arts and crafts, tended to make our artificial atmosphere more complex, liable to more rapid and more drastic changes, and accordingly its features less permanent and less calculable and reliable.

3.

Uncertainty in the concrete.

Thus, in spite of the wonderful increase of scientific knowledge and the general diffusion of scientific thonght in the course of the century, uncertainty is still the main and dominant characteristic of our life in nature and society; the atmosphere and climate of each are as fickle and changeable, as incalculable and unreliable, as ever. Neither the great law of gravitation nor the fixed proportions of chemistry, neither the intricate doctrine of undulations nor the conception of energy, neither the knowledge of typical forms of nature nor that of their orderly evolution, has, in the hands of those who 
govern, regulate, and fashion the practical work of lift and society, becone an instrument of personal use and daily importance. Statesmen, legislators, organisers of men, captains of industry, contractors, practical engineers, colonisers, pioneers, and leaters of all kinds are still mostly ignorant of these scientific ideas. They regard them from a distance, themselves relying mainly on common-sense, on personal experience, or on the innate but indefinable impulses of individual genius; professional, scientifie knowlenge is only one, and hardly the most important, of the many agencies with whieh they deal and which they lave to take into account.

And yet, in spite of this fact that the ordinary routine of life is a very different process from the ways of Sicientific science, we must admit that the seientific spirit very largely pervarles the business of to-day. You camnot enter any commercial, shipping, or general trading office withont being struck with the number of carefully prepared charts, tables, and statistical registers of all kinds of eurves showing the rise and fall of prices, the production and consumption, the stocks and ralues of metals, coal, grain, chemicals, cotton, and produce of every kind: and in quite recent years, not only material things of all sorts, but the intangible thing ealled energy - after supplanting the older term horse-power--llas become the subject of elaborate tabular and graphical registration. The streets of even the smaller towns in every civilised country show, besides the sign-loards of shops, oflices, and banks, an increasing array of insuranee firms, whose whole business depends on elaborate caleulations, based on long tables of births, deaths, marriages, shipwrecks, 
and other casualties. The daily newspapers bring us weather charts with isothermic, isobaric, and other lines, on which they found weather predictions or storm warnings. Surely, if counting, measuring, and calculating are the elementary processes of the scientific method, it must be admitted that the latter has permeated our practical life to an enormous extent. Thus the question can be asked, If the calculating spirit is so general, how does it come about that in its application to life and commerce it has led to so much grasp but to so little certainty; whereas in science itself it has led to so much actual and reliable knowledge? How does its application in practice differ from that in theory? The answer to this question is not far to seek, and it will introduce us to a special branch of science, to a special form of scientific thonght which again is, if not a creation of the nineteenth century, yet one of its characteristic developments.

That which everywhere oppresses the practical man is the great number of things and events which pass ceaselessly before him, and the flow of which he cannot arrest. What he requires is the grasp of large numbers. The successful scientific explorer has always been the man who could single out some special thing for minute and detailed investigation, who could retire with one definite object, with one fixed problem into his study or laboratory and there fathom and unravel its intricacies, rising by induction or divination to some rapid generalisation which allowed him to establish what is terned a law or general aspect from which he could view the whole or a large part of nature. The scientific genius can "stay the moment fleeting"; he can say to the object 
of his choice, "Ah, linger still, thou art so fail"; he can fix and keep the star in the foeus of his telescop ${ }^{*}$, or protect the delicate fibre and nerve of a decaying organism from sucemuling to the rapid disinteglation of organic ehange. The praetical man cannot do this: he is always and everywhere met by the crowd of facts, by the relentlessly hurrying stream of erents. What he requires is grasp of numbers, leaving to the professional man the knowledge of detail. Thus has arisen the science of large numbers or statistics, ${ }^{1}$ and the many methods of which it is possessed. It will form the subject of the present ehapter.

1 Gottfried Achenwall (1719. $1772)$ is eommonly termed the "father" of statistics. 'This, however, is hardly eorrect, either in relation to teaching $\omega^{*}$ to the practical part of the subject, or even so far as the name is concerned. In connection with adwinistration statisties existed in antiyuity. They were taught by the celebrated professor, Conring, the elder contemporary and rival of leibniz, and the name occurs in the seventeenth eentury in the 'Microscopium statisticum, quo status imperii lomano-(iermaniei reprosentatur auct. Heleno Politano' (1672). By Achenwall and his successor, Ludwig August Sichlozzer (173\%-1509), statistics were treated in connection with listory. The latter says, "Statistics are history" stauding still, and listory is statistics put in mution." "See on this subject, Wegele, "(ieschichte der deutschen Hi-toriographie' (Minchen, 1885), p. 793; also lioscher, 'Geschichte der NationalOekououtik' (ibid., 1874), p. 466. $A$ very valuable and exhinustive account of the etymology and gradual change of meaning of the worls "statist" and statistics will be found in Dr Y. John, 'Geschichte der Statistik,' 1. 'Theil. (Stuttgart, 1881), pl. 3-11. He divides the history of the subject down to (quetelet into that of the "German Lniversity Statistics," following in the lines of Conring, Achenwall, and Schlizer, also called the "Göttingen Schorl," and that of statistics as an exact, an enumerative science, which he calls the modern science of statistics. It appears that in English also the two meanings of the word are exemplified in the older use of the term "statist" by Shakespeare ("Hamlet," v. 2.; "Cymbeline," ii. 4.) and Webster, in which sense it meant simply "statewnn"; and the modern title 'Statist,' for' a statio. tieal and fonameial periolical. Nor must we forget that Eugland has in her 'Liber judiciarius seu censualis Willehmi 1., regis Anglie,' callew 'Domeslay-book' (1053-56), ito Ditvid Hume says, "the most valuable piece of antiyuity powsessed by any nation" ("List. of Englund,' chap. is.)
5. Thic scinnce of large numbers. 
The grasp of large numbers, the methodical array of figures and the registration of events, would in itself be of little use were it not for a fundamental assumption which appeals to common-sense and has been confirmed by science, though it is hardly anywhere expressly stated -namely, the belief in a general order, in a recurrent regularity or a slow but continuous change and orderly development of the things and events of the world. Science, in the different aspects which we have so far passed in review, tries to give a definite expression to this general Order, to this all-pervading rule and regularity. Statistics and the practical use of them limit themselves to the bare fact that such order and regularity do exist, though the formula or reason for them may be unknown or unknowable. It may also be well to note that this belief in a general order is common to all schools of thought, be they ancient or modern, pagan or Christian, religious or scientific, optimist or pessimist.

Belief in general order. The dictum, "est modus in rebus," is the fundamental axiom of all thought and all practice; and the statistical view of nature, which merely puts into form and figure this general axiom or truism, has accordingly been appealed to as much by those who uphold a divine order of things as by others who insist on a natural or mechanical one. In the school of Quetelet, through whose influence statistical knowledge has been so greatly furthered in the course of our century, the regular recurrence of events and the stability of large numbers has been sometimes nsed as the basis for a fatalistic and pessimistic view, whereas nearly a hundred years before Quetelet, statistics had been elaborated by 
the Pastor Sïssmilch in Prussia, in a celebrated brok bearing the title 'On the Divine Order,' with a tendency' towards optimisn, and as a proof of an orerruling Providence.

Althongh it is generally admitted by witers on statistics that in the narrower sense of the word they have existed ever since the existence of govermments which required to know the number of their population, the natural resources of the country, and its means of subsistence or defence, there is a general npinion current that what we now eall the statistical methods in science and in practice were introduced, or at least expressly reconnmended, by Lord Bacon under the name of the "Method of Instances." This method, which consisted in a kind of tabulating of numbers of facts referring to any special subject under investigation, has been eriticised

The difference seems to narrow itself down to this, that one class of writers refers everything to a physical, the other to a moral, order. M. Maurice Block, an eminent writer on statistics, discunses this question, palssing a number of morlern authors under review in the fifth chaliter, $\$ 3$, of his excellent 'Traité thiorique et pratique de Statistique,' (2me éd., Paris, 1.856). Ileferring to the theological statistician, $A$. ron Oettingen, and comparing him with Quetelet, he says (1. 146): "Sous certains ripports, i'opinion de II. le professeur de théologie Alex. andre d'Cttingen, pourra paraitre l'opposée de celle de quetelet, mais elle nous semble en diffírer beaucoup moins 'que le savant proiesseur ne le croil. . . Nons purons caractériser en peu de mots ce que MIS. d'(Ettingen et Quetelet ont de commun et com. ment ils different: ils ont de commun les fond de la sience; il. constatent l'un et l'autre la ré. gularité du nouvement des fait: ; ils ne diflèrent yue par l'interprétation: Quetelet roit des lois naturelles lì où $\mathrm{M}$. le professeur d'Gitingen woit des lois momale: institutées par Dieu. Aussi l'un nolnme-t-il son live Physique sociale, et l'autre Éthique sociale. M. d'Ettingen est un croyant yui aine it s'appuyer sur lic seience. 11 dit, page j: de la premiere édition: "Lans les sciences comme' dans la religion, ce que l'bomme invente ne peut itre yue faux, tandis que les réritéx yu'il al:courre, sont uniquement des faitou des lois yui rayonneut du Createur.'" The reconciliation of either physical or moral orler with the existence of freewill is not a statintical but a philosophical problem. 
by writers like Whewell, von Liebig, Stanley Jevons, and many others, and shown to be of very doubtful value; the example given by Bacon himself-the research into the nature of heat-being especially unfortunate and badly chosen. In spite of this, it is noteworthy that, up to quite recent times, the Baconian method is continually referred to, mainly by writers who are desirous of introducing what they call the exact methods of research into other sciences than those of external nature. A good example of this kind is given by Walter Bagehot, and as it serves to make an important point more intelligible than a general statement would, I will here give it in full. $\mathrm{He}$ speaks of the Enumerative, or, as he calls it, the "Allcase method," and then continnes: "A very able German writer ${ }^{1}$ has said of a great economical topicbanking-' I venture to suggest that there is but one way of arriving at such knowledge and truth, namely, a thorough investigation of the facts of the case: by the facts I mean not merely such facts as present themselves to so-called practical men in the common routine of business, but the facts which a complete historical and statistical inquiry would develop. When such a work shall have been accomplished, German economists may boast of having restored the principle of banking - that is to say, of German banking, but not even then of banking in general. To set forth principles of bauking in general, it will be necessary to master in the same way the facts of English, Scottish, French, and American banking - in short, of every

1 Prof. Cohn in 'Fortnightly Review,' Sept. 1873. 
country where hanking exists. . . The only, but let us add also the safe, ground of hope for political ecomony, is following Bacon's exhortation to recommence afresh the whole work of economie inquiry. In what conclition would chemistry, physies, geology, zoology be, and other branches of natural seience which have yielded such prodicrious results, if their students had been linked to their chains of deduction from the assumptions and speculations of the last century?" "To this bagehot replies: "The method which Mr Cohn suggests was tried in physical science and failed. And it is very remarkalle that he should not have remembered it as he speaks of Lord Bacon, for the method which he suggests is exactly that which Lord Bacon himsclf followed, and owing to the mistaken nature of which he discovered nothing. The investigation into the mature of heat in the 'Novum Organum' is exactly such a collection of facts as Mr Cohn suggests, but nothing comes of it. As Mr Jevons well says, Lord Bacon's notion of scientific method was that of a kind of scientific book-keeping. Facts were to he indiserininately gathered from every somrce and posted in a kind of ledger, from which would emerge in time a clcar balance of truth. It is difficult to imagine a less likely way of arriving at discoveries." I

1 'The I'ustulates of English Political Economy' (1585), \%. 17, \&c. He further remarks: "If we wait to reason till the 'facts' are complete, we shall wait till the human race has expired. I think that Mr Cohn, and those who think with him, are too 'bookish' in this watter. They mean by lraving all the 'facts' before them, having all the grinted facts, all the statistical tables. But what has been said of nature is true of commerce. 'Nature,' says Sir Charles Lyell, 'has made it no part ol her concern to provide a record of her operations for the use of men'; nor does trade either-only the 
In fact, the eight chapters of this work which have dealt with the various abstract views from which natural phenomena have been considered in recent times, form an elaborate refutation of the so-called Baconian, of the enumerative or "all case," method. It was the light of the idea which brought life and order into the "rudis indigestaque moles" of badly collected facts, and in many cases even led for the first time to their useful and intelligent enumeration. But now we come to a further important question. Allowing that in certain large but nevertheless secluded spheres of science a few general ideas have been found to apply and work wonders of calculation, prediction, and useful application, how about those complicated phenomena which form our natural and social environment, and where so far no scientific formula has proved powerful or comprehensive enough? Are all these elaborate enumerations and graphical representations in meteorology, in sociology, commerce, industry, and finance, to which we have instinctively and increasingly had recourse during the whole of the century, of no value? Is no useful

smallest of fractions of actual transactions is set down so that investigation can use it. Literature has been called the 'fragment of fragments,' and in the same way statistics are the 'scrap of scraps.' In real life scarcely any one knows more than a small part of what his neighbour is doing, and he scarcely makes public any of that little, or of what he does himself. A complete record of commercial facts, or evell of one kind of such facts, is the completest of dreams. You might as well hope for an entire record of human conversation."
Stanley Jerons ('Principles of Science,' Preface, p. vii), says : "Within the last century a reaction has been setting in against the purely empirical procedure of Francis Bacon, and physicists have learnt to advocate the use of hypotheses. I take the extreme view of holding that Francis Bacon, although he correctly insisted upon constant reference to experience, had no correct notions as to the logical method by which, from particular facts, we educe laws of nature." 
result to spring from them? Had they been conducterl under the influence of no useful general idea, our answer would indeed have to be in the negative. Isut if, as practice shows, they have been of use, if, in fact, they prove to be in many cases quite indispensable, we may General idea underlying artumerat ask, What is the idea, the alstract thought, which dominates them? I will give the answer at once and then fix the aspect with which the present chapter has to deal. It is the eonception and doctrine of averages.

Although to the general reader nothing may seem to averages.

9 be simpler than a process of counting and of registration, the seience of statisties, the systematie eollection of large numbers, and the fixing of averages, is comparatively young: it dates from the beginning of the serenteenth century, when Sully in France, followed by Richelieu and Colbert, had organised what may be ealled the first statistieal buream. It emanated from the same spirit which ealled into existence the Paris Aeademy of Seiences. Charaeteristically for the two other nations with which we are mainly eoneerned in this history, the

1 II. Block (loc. eit., p. 25) says : "En France Sully avait déjà $O \mathrm{l}^{\circ}$ ganise, rers 1602 , un cubinet complet de politique ct de finunces, qui jeut itre consilléré comme le premier bureau de statistique. Les rapports que Sully demaudait embrassaient l'armée, la mariue, les finances et un grand nombre de branches de l'arlministration, et le résultat de ses investigations se trouve exposé dans l'ouvrige qui a été souvent réimprimé sous le titre de 'Mémoires de sully:' kiclielieu et Colbert se sont égale. went fait adresser des rapports, auxquels on a puiné, dans ces

VOL. II. derniers temps, bien des élément. utiles it l'histoire et que lia statistique pourrait également utiliser." The Liomans, who in antipuity may be regarled as the forerumners of the French in administrative ability and business-like conduct of state atiairs, seem also to have developel an extensive system of registration. The yuestion has been fully treated hy the late l'rof. Hillebram of Jena in the "Jalrrbuch fiur Notionale 'Thonomie und statistik' (1566), in an article eutitled "IVie Antliche lievölkerungs-statistik in alteu Rom." 
10. labour of statistics was taken up in Germany by the

Statistics in many, and? England.

Universities, whereas in England it fell to the lot chiefly of a single person-the celebrated Sir William Petty, the creator of the term "Political Arithmetic." Thus, as in science generally, so in statistics, France marched ahead with her systematic and administrative genius; Germany followed in the person of Professor Conring, who introduced the matter as a subject of miversity teaching; whilst Sir William Petty ${ }^{2}$ wrote his essay with the practical object of disproving an opinion then much current in England, and which has periodically cropped up in the writings of journalists at home and abroad - the threatened decline of the English nation.

1 Hermann Conring (1606-81) Professor of Medicine and Philosophy at Helmstält, lectured on "Staatskunde, Notitia Rerum Publicaruu," from about 1660.

2 About the same time when lectures on "The Science of the State" were begun in Germany by Conring, Sir William Petty (162:38i) in England, one of the founders of the Royal Society, occupied him. self for practical reasons with similar subjects, collecting his view's in a tract called 'Political Arithmetic' about the year $167 \%$, besides onn. tributing various papers to the 'Philosophical Transactions' and publishing several 'Essays' (168186). The 'Political Arithmetic' would have been printed, but for the French policy of Charles II., to whom it was presenterl in nanu. script. It was not published till 1690, after the author's death, on a permission "given at the Court of Whiteliall on the seventh day of Norember," by Lord Shelburne, the son of the author. In the preface, he characteristic- ally says: "I have thought fit to examine the following Persuasions; which I find too current in the world, and too much to have affected the minds of some, to the prejudice of all-viz., That the rents of lands are generally fallen; that therefore, and for many other reasons, the whole kingdom grows every day poorer and poorer. That formerly it abounded with gold; but now, there is a great scarcity, both of gold and silver. That there is no trude, nor employment for the people; and yet that the land is under-peopled. That taxes have been many and great. That Ireland and the Pluntutions in Ameriea, and other additions to the Crown, are a busden to England. That Seotland is of no aclvantage. That trade, in general, doth lamentubly deeay. That the Hollanders are at our heels, in the race for naval power; the Freneh grow too fast npon both: and appear so rich and potent, that it is but their elcmency that they do not devour their neighbours." 
And as in science, so also in statistics, Germany in time followed the example wi France by introulucing oreranisations similar to that oi the "(abinet complet de politinue et de finances" oi silly. It was notably during the reign of Frederick the Great that the population statistics were recrularly and systematically collected in l'ussia, this enterprise being rreatly stimulated by the publication of .J. I'. sissmilch's' "Treatise on the lovine Urder.' In England_-with a notable exception to he mentioned imnediately - the line of research opened out ly :ir William Petty was not followed uy, and Macc'ulloch, when publishing, at the lecrinnin: of our cen-

1 Juhann Peter Aismilch 11;07. 67 rubli-herl, in the rear 1711 , a book with the iullowing title: "Die guttliche Ordnung in den Veriuderungeu des wenschlichen Geschlechts: au - der Geburt, dem Tode und der Fortptanzung dessellen erwiesen vop Johamn Peter Suissmilch, Prediger berm hachlüblichen Kulcksteini-chen Piegiment. Nebst einer Vorrede Herrn Christian Wolffeus: The brorik, as well as the autlor, was for a long time but little appreciated : for although the iormer wa. dedicater to Frederick the Great, and must presumably, tu jurde from the several editions wlich apveared, have leen made u-e rif in the statistical labours of the Prusian administration, the author, ne: having been connecterl with any univer-itr, lıad, for a long time, little induence on the so-called "unirer-ity school" of stati-tic: In the cour-e of the la-t fifty years, all yrominent writers on thatistics, such as Wappius, Rocher, ion Jettinten, Knapp, and $\%$. John, in Germant. M. Block and others in France, d- also Italian writers on stati-tic-, have taken increa-ced iuterest in the book. IIs V. Juhn
'Geschichte der statistik.' rol. i. p. 241, \&c. gives an exluaustive analysis of the work. He calls the author "the first statistician in the modern sense," the precursor of Quetelet, and sars, moreorer, "It is easils exylainerl how the philosopher vïssmilch would ranish in to the background as soon as the conception of the encrelopichi-t . that only matter in unution exists and no mind, came to le senerally accented, and that the politician sits:milch should utterls di-appear in the turmoil oi the French Rerclution." Von Oettingen, who, on the other side. arrees in accepting with Sussmilch the existence uf a Divine or moral order sars of the latter, that "he has become, through lis magnificent labour-, the iounder of the science which we now call moral stati-tics," inasmuch as lie. "for the firt time, recogni-erl the intrin-ic regularity in the apyarently no-t arcidental human phenomena and actions, and trietl ti e-tatli-li it by incluctive methorl=" ("Moralstatistik." 3rul ed., 1sㄴ. p. 21! That he was known to Herder and appreciated br hin, we saw sur ro, I. "3.30 note. 
tury, his 'Statistical Account of the British Empire,' had hardly any similar work to refer to during the whole of the eighteenth century.

The exception just referred to was "The Tables of Mortality," which date back to the middle of the sixteenth century, and in a more regular form to 1603 . 11. They were analysed by John Graunt, captain, in 1661, John Graunt and Halley. in a tract with the title "Natural and Political Observations upon the Bills of Mortality.' ${ }^{1}$ Of Graunt's ${ }^{2}$ work, M. Maurice Block says that the difficulties of preparing such a table at that time were so great that it might wellnigh be considered a performance of genius. The invention once made, improvement

1 The tract was presented to the Royal Society in 1662, and printed by order of the latter in 1665 , the author becoming a fellow at the request of the king. $V$. Joln gires a full account of the book, and as much of the author as he could collect from the scauty records of him which exist (loc. cit., pp. 161 . 178). He was born in 1620 , was a man of business, and latterly became connected with the Gresham College and with sundry matters pertaining to the administration of the City. He died in 1674 . In 1676 a new, sixth, edition of the tract was published by Sir W. Petty, whom both Halley and Evelyn erroneously referred to as the author.

2 'Statistique,' p. 194. Süssmilch, a century after Graunt, says that the material for the determiuation of the 'Divine Order' existed in the parish registers since the time of the Reformation. "But who," he exclaims, "made use of it for this purpose before Graunt? The dis. covery was just as easy as that of America, but the Columbus was lacking" (quoted by V. John, loc. cit., p. 177). The author, however, who suggested to Siissmilch the researches which led to the celebrated 'Divine Order,' was not John Graunt, but Dr William Derham $(1657-1735)$, an eminent divine and natural philosopher, who publisher in 1713 his 'Pliysico-Theology ; or a Demonstration of the Being and Attributes of God from His Works of Creation,' a book which ran through six editions in ten years, being trauslated into Freuch and several times into German. This book contained, as Siissmilch himself says, besides uumerous notes, a collection of the observations of other English authors on the lists of births, deaths, and marriages. On following up the clue given by it he arrived ultimately at Graunt aud Petty, of whom the former had, as he says, broken the ice, whereas Petty had mainly discussed the influence of the changes of population in politics ( $V$. Johu, 'Statistik,' p. 243). 
was easy; the invention was the difficulty. The next great name connected with this subject was the astronomer and mathematician Edmund Halley, who had before him, in addition to .John Graunt's work, the figures of birth and mortality during the five years 1686 to 1691 collected by Kaspar Neumann for the city of Hreslau, eapital of the province of Silesia. Tables of mortality, based upon several thousands of life ammuties, were prepared in Holland by order of the Grand Pensioner, John de Witt, and nsed in 1671 as the hasis for a loan in the form of annuities. ${ }^{2}$ The growing practice of life insuranee, as is well known, attaches a great interest to these tables of mortality, which have been slowly perfected in the course of the last hundred and fifty years; it having been reserved for the labours

1 For a long time it was not known how Halley came into possession of Kaspar Neumaun's mortality-tables; but, in recent times, mainly through examination of the lucal records of the eity of Breslau by Bergius and others, and notably by the aid of S. Gritzer ('Edmund Halley und Faspar Neumann,' Jireslau, 1883), it has become almost certain that Neuwann's registers were communicated to the Royal Society by no less a person than Leibniz, who corresponded with Neuuran on the one side as we!l as with the secretaries of the Royal Suciety ou the other. Some of the uriginal documents have been traced in the archives of the Society by Dr Bond and Prof. Burdon Sanderson. It is well known that Leibniz him. self attached great importance to aceurate statistical knowledge of all kinds, and considererl the collection of such to be one of the main cluties of the various aeademies which he plamed or founded.

" "Le grind pensionnaire de Hollande, Jean de Witt, se fondant sur les ealeuls de probabilités enreignés par Chrétien Huygens, se servit, comme éléments d'olserva. tion, des résultats constatés sur quelques milliers de rentiers via. gers. Il frésenta sa table aux états géuéraux le 25 avil 1671, jour servir de hase à un emprunt fiait sous la forme dianuités viagères. Cette table citée par M. de Baumliauer, re trouve dans les registres des itats de Hollande, annce 1671" (Block, loc. cit., ). 190). A translation of this document appeared in 'Contributions to the History of Insurance' lyy $\mathrm{F}$, Hendriks, 'Ak. Matg., 'vol. ii., 1552. 
of quite recent writers ${ }^{1}$ to place the whole matter upon a thoroughly scientific lasis. But it is not these necessary technical refinements that interest us most at present; rather let us take note how the needs of governments, as well as the uncertainty and risks of life, have automatically led to the definition and study of three distinct statistical conceptions, which in our age govern a very large part of all our practical 12. enterprises. These three conceptions are the probaProbability, Co-opera. tion, Equitable Distribution. bility of future events based upon long series of past experiences, the idea of reducing or areraging risks by "amicable" co-operation, and the "equitable" distribution of the burdens of such co-operation according to the individual units who co-operate. ${ }^{2}$ It will at

1 It is generally admitted that Prof. G. F. Knapp created a kind of era in the more rigorous mathematical treatment of the subject by his various publications, dating from the year 1868 with his tract 'Ueber die Ermittelung der Sterb. lichkeit aus den Aufzeichnungen der Bevölkerungs-statistik.' M. Block (loc. cit., p. 232) says: "Ce livre a fait une véritable sensation parmi les hommes spéciaux; non que l'auteur ait apporté beaucoup de nouvelles pierres ì l'édifice, mais il a donné à ces pierres une ordonnance, une disposition qui les constituent un monument." In the year 1874 he published his "Theorie des Bevölkerungswechsels.' Many other writers have followed in the new track, among whom I will only mention Becker, Zeuner, and Lexis. The graphical method is largely employed by these authors, amongst whom Zeuner resorts to a representation in three dimensions with some very elegant results. See his 'Abhandlungen zur mathematischen
Statistik' (Leilrig, 1869). A historical and critical review of these and older writings is given in the last-named work of Knapp, p. 53, \&c. See also Prof. Lexis's 'Einleitung in die Theorie der Beviilkerungs-statistik' (Strasburg, $1875)$.

2 This is not the place to discuss the social and moral aspects of co-operation, which by future historians will possibly be looked upon as one of the very few novel political ideas which our century has evolved or at least elaborated in a practical form; the older cooperative attempts, such as were made under the influence of the ideals of the great Revolution by Fourier, Saint Simon, and Babeuf in France, and by Robert Owen in this country, not having contained the elements of permanent success. These elements seem to belong almost exclusively to the line of development started by the "Rochdale Pioneers." 
once be seen how all arrangenents which are hiteed upon these three conceptions - viz, probability, (u)operation, and equitable distribution - lead us away from the study of individual cases to that of totils and averages; how they merge the interests of single persons and the peculiarities of single cases in those of the aggregate of a liarge number and the properties of the average event or the "mean" man. Their" value and success depend on the consideration and participation of large numbers, and they have accordingly only arisen during the latter diys which have witnessed the steady growth of modern populations and the bewildering complieation of molem business. The moral or social aspect which has simultaneously been evolved during onr period does not for the moment concern us. We are concerned at present only with the fact that statistics as the science of large numbers and of averages has heen increasingly drawn into use. In fact, we might call our century -in distinction from former centuries - the statistical century.

The necessity of having recourse to elaborate comntings, to registrations of lirths, deaths, and marriages, to lists of exports and imports, to recorls of eonsumption and production of food-stuffs and many other items, forced upon those who were entruster with the gathering and using of these data the observation that all such knowledge is incomplete and inacenrate. Owing to the variability, within certain limits, of recurring events and the errors of comting and registration, we have to eontent ourselves always with approximation insteal of certainty. Error bullis 
very largely in all statistics, and vitiates them; and as regards coming events, our minds are in a state of expectation rather than of assurance. But events can be more or less probable, errors can be greater or smaller, cumulative or compensatory, and our expectations may be well- or ill-founded. And so there has arisen the 13. science of Probabilities and of Chances, and the Theory The Science of Chances. of Error, two subjects intimately interwoven. The former arose in the seventeenth century out of the frivolous or vicious practice of betting and gambling, ${ }^{1}$ whilst the latter was founded when astronomical observations accumulated, and the question presented itself how to combine them so as to arrive at the most reliable result. The greatest mathematicians and philosophers, such as Pascal, Huygens, and Leibniz, the Bernoullis, De Moivre, Laplace, Gauss and Poisson, have bestowed much thought on the subject, ${ }^{2}$ which has nevertheless been very differently judged-praised beyond measure by some, and ridiculed by others; sometimes pronounced to be merely common-sense put in figures, and then again wrapped up

1 See supra, vol. i. p. 120 sqq.

2 In addition to the references given in vol. i., the following are of importance. The history of the Theory of Probabilities, as stated above, has been written by Isaac Todhunter. This history brings the subject down to the writings of Laplace, whose two works mentioned in the text still remain the two standard works on the science. In quite recent times the history has been written and brought up to date by Prof. Emanuel Czuber in his 'Entwickelung der Wahrscheinlichkeits. Theorie und ihre Anwendungen,' contained in the seventh volume of the 'Jahresbericht der Deutschen Mathematiker Vereinigung' (Leipzig, 1899). The latter work is written on a different principle from that of Todhunter. Whereas Todhunter deals in separate chapters with the work of the foremost mathematicians on this subject, Prof. Czuber gives an independent historical and critical analysis of the different developments of the theory and its applications. Quite recently the same author has published an independent treatise on the subject (Leipzig, 1902). 
in appalling mystery. 'There is, however, no doubt thitt the Theory of Probability inereasingly pervades seientific as well as statistical work in om age, and that in the

1 In spite of the eneornium on the theory of probabilities quoted in vol. i. p. 123, sir Joln Herschel gave only a qualified adherence to one of its principal applications (see 'Brit. Assoc. Rep),' vol. i. p. 165). The two formost adverse erities of the theory were Auguste Counte in France and John Stuart Mill in Eugland. In the second volume of the 'Philosophie J'ositive' (1st ed., 1835, p. 371) the former explains why he omitted to deal with so important a subject in his mathematical philosophy. "Le calcul des probabilités ne me semble aroir été ríellement, your ses illustres inventeur's, qu'un texte commode à d'ingéuieux et difficiles problèses numériques, qui n’en conservent pas moins toute leur valeur abstraite, comme les théories analytiques lont il a été ensuite l'oecasion, ou, si l'on veut, l'origine. Quant it la coneeption philoso. phique sur laquelle repose une telle doetrine, je la erois raclicalement fausse et suseeptible de conduire aux plus absurdes conséquences. Je ne parle pas seulement de l'application évidemment illusoire cu'on a souvent tenté d'en faire au prótendu perfectionnment des sciences sueiales: ces estais, néces. sairement chimćriques, seront caractérisés dans la dernière partie de eet ourrage" : and in the fourth volume (1S:39, p. 512), "La seule aberration de ce gense . . e'est la vaiue prétention d'un grand nombre de gćomìtres a rendre positives les études sociales d'ayrès une subordination chincrique ì l'illusoire théorie mathématique des cluances. . . Quelyue grossière yue soit évidemment une telle illusion, elle étitit néanunoins essentiellement exeusable, (juind] l'esprit innemunent philosoplique de l'illustre Jacques bersoulli concut, le prenier, cette pensée gésćrale, dont la production, ì une telle eporpue, constituait riellement le précieux et irrécusable symptóne du besoin prématuré pour ce temps, mais qui n'y pouvait être éprouvé même ainsi que par une intelligence vraiment sujérieure." John Stuart Mill, in the second volume of his 'Logie,' has devoted a whole chapter to the subject, in which he eorrect. a statement made by lim in the first edition of his book, attributing a "fundamental fallacy" to the arguments of Laplace and otlier mathematicians, but nevertheless takes an unfavourable view of the usefulness of the calculus. In nore recent tines the subject las becu exluastively treated from a logical point of view by Mr John Vern in lis work, "The Logie of Chance' (3rd ed., London, 1858), and by stanley Jevons in "The Prineiples of Sicience' (rol. i. cli. x.) The doubts with which Mill, and still more Coute, regarded the subject, seem to have been dispelled in works on Logic; and the increasing use to which the methods for the correction of error have been put in many branclses of science have convineed mathematicians of its ajplicability. T'lue nintl erlition of the 'Ency". Brit.' contains an excellent artiele on "Probabilities" by M. II. I rofton. Among the clearest and safest guiles in this intricate subject must be counted the late l'rof. Augustus de Morgan, whuse profound treative in the "Ency. Metrol.' (vol. ii.), as well as his "Esiay on Probubilities' (London, 
course of the last hundred years much has been done to make it more easily understood.

James Bernoulli had already in his celebrated book which bears the title, 'De arte conjectandi,' promised to show the application of the mathematical doctrine of probability to political, moral, and economical subjects, ${ }^{1}$ but the fourth and last part of the book which was to give this, remained unfinished. It was left to his successors, notably to Daniel Bernoulli, to take up this sicle of the question. But the first practical states-

11.

Condorcet. man who-as we are told by Condorcet ${ }^{2}$-held the

1838), still rank witl the best that has been written. Stanley Jevons sums up his opinion in the words : "This theory appears to me the noblest creation of the human intellect, and it passes my concep. tion how two men possessing such high intelligence as Auguste Comte and J. S. Mill could have been found depreciating it, or even vainly attempting to question its validity. To eulogise the theory is as needless as to eulogise reason itself " ("Principles of Science,' vol. i. p. 227).

1 James Bernoulli (1654.1705) was the eldest of the celebrater? family of mathematicians. Daniel, his nephew, lived half a century later (1700-82). The "Ars Conjectandi' was published posthum. ously in 1713 by Nicholas, another nephew of the author. In a letter to Leibniz the author says : "Ab. solvi jam maximam libri partem, sed deest adhuc priecipua, qua artis conjectandi principia etiam ar civilia, moralia, et oconomica applicare doceo." Daniel Bernoulli, as we saw above (vol. i., chap. v. p. 434), was the father of the kinetic theory of gaves, of which more hereafter.' He was also the first to make a distinction between mathematical and moral expectation, - a difference which led Laplace to distinguish between "fortune pliysique" and "fortune" morale," to which reference was made in connection with Fechner's psycho-physical measurements.

"Essai sur l'application de l'Analyse à la Probabilité des Décisions, Rendues à la pluralité des voix" (Paris, 179:): "Uu grand homme, dont je regretterai toujours les leçons, les exemples, et surtout l'amitié, était persuadé que les vérités des sciences morales et politiques, sont susceptibles de la unême certitude que celles qui forment le système des sciences physiques, et même que les blanches de ces sciences qui, comme l'astronomie, paroissent approcher de la certitude mathématique. Cette opinion lui était chère, parce qu'elle conduit ì l'esjérance consolante que l'espèce humaine fera nécessairement des proglès vers le bunheur et la perfection, comme elle en a fait dans la connoissance de la vérité." It is evilent from this extract that Condorcet (1713-94) thought that his friend Turgot shared his own well-known opinions as to the unlinited perfectibility of the human race. 
view that morals and politics might derive the same benefit from the science of calculation as the physical sciences hal alrealy experiencerl, seems to have heen Turgot. To show the importance of this riew, Condorcet wrote his much quoted lut little read essay on the application of analysis to decisions based on the plurality of rotes. In his Introuluction the author laments that his friend, on whose suggestions he had commenced his work, did not live to see it finished. ${ }^{1}$ It would have been interesting to know whether so eninent a practical philosopher as Turgot is considered to have been, would have heen encouraged by his friend's specimen of political algebra, or whether he would have held the opinion of Mill, who saw in these "applications of the calculus of probalibities... the real opprobrium of mathematics." 2

1 (Loc. cit., p. i.) "sii l'humanité n'ent pas eu le malheur, longtemps irréparable, de le perdie trop tót, cet ourrage eût été moins imparfait : éclairé par ses conseils, j'aurois vu mieux ou plus loin, et j'aurois avalué avec plus de eonfiance des prineipes qui auroient été less siens. Privé d'un tel gruide, il ne me reste qu"ì fairè à sa mémoire l'hommage de mon travail, en faisant tous mes efforts pour le rendre moins indigne de l'amitić dont il m'honoroit."

2 There is no doubt that the writings of Condoreet, through the useless accunulation of formulie with very little substance behind them, contributed to bring the whole theory into discredit. An. other still more eminent emutem. purary mathematician, 1)'Alenlsert, after having oecupied himselt at considerable length with problems in probabilities, former an unfavourable opinion of the usefulness of the caleulus. (rouraud (yuoted by Tollhunter, p. 293) says: "(quant an reste des malhématicien, ce ne tut que par le silence ou le détlain yu'il répondit aux doutes que d'Aleubert s'était permis d'úmettre. Mépris injuste et ualluabile vù tout le monde avait ì perdre et qu'une po-térité moius prévenue ne levait point sanctionner." It is interesting to note that Laplace, in hilintorichl aceount at the end of his 'Esisai Philosophique,' does not refer either to Comborcet or to l'Alembert. J. S. Mill ("Logic, vol, ii. 1,66 ) says: "It is olvious, too, that even when the probabilities are derived from olservation ant experiment, a very slimt improvement in the data, by better olsaervitions, or by takinge inte fuller consilleration the special cireumstanees of the case, is ol mome unt than the morst elaburate appli. cation of the calculus to probabil. 

cerned, it was left to Laplace to place it on the foundation upon which it has ever since rested. He brought together the ideas of his predecessors, notably of De Moivre, the two Bernoullis, Sterling, Bayes, and Lagrange, as well as his own extensive researches, in his great analytical theory of Probability, which appeared in 1812, and, with several additions and an elaborate introduction, in two subsequent editions during his lifetime. This work has been justly considered a monument of human renius, and stands worthily beside the great 'Mécanique Céleste' of its author. The

ities founded on the data in their previous state of inferiority. The neglect of this obvious reflection has given rise to misapplications of the calculus of probabilities which have marke it the real opprobrium of mathematics. It is sufficient to refer to the applications made of it to the credibility of wituesses, and to the correctness of the verdicts of juries." I have already referred to the position which Comte took up. De Morgan, with his usual clearness and wisdom, at the end of his "Theory of Probabilities" ("Ency. Metrop.' vol. ii. p. 470), whilst reducing to a very uarrow province these applications of the calculus of probabilities, says: "There are circumstances connected with the mathemathical theory of independ. ent evidence which it may be useful to examine. In this, as in several other preceding investigations, it is not so much our wish to deduce and impose results, as to inquire whether these results really coincide with the methods of judging which our reason, nnassisted by exact comparison, has already made us adopt. The use of the process is, that both our theory and our pre- conceptions thus either assist or destroy each other: in the former case we feel able to trust this science for further directions; in the latter, a useful new inquiry is opened. For when we consider the very imposing character of the first principles of the science of probabilities, and the mathematical necessity which connects those simple first principles with their results, we feel convinced that, even on the supposition that the main couclusions of the present treatise are altogether fallacious, there must arise a necessity for investigating the reason why a mothodical treatment of certain notions should lead to results in. consistent with the vague application of them on which we are accustomed to rely. For it must not be imagined that opposition to the principles laid down in this treatise is always conducted on other principles : on the contrary, it frequently happens that it is only a result of themselves obtained without calculation, which is arrayed against arithmetical deduction." 
labours of mathematicians since Laplace in the field of probabilities have consisted mainly in commentaries on and simplifieations of his expositions, and in a sreat improvement in the formal methods, due mostly to English workers. ${ }^{1}$ At present we are not interested in the purely mathematical side of the subject, which for some minds has a great fiscination, but rather in the question: To what extent have the anticipations of such men as Condorcet, Turgot, and Laplace, as to the practical value of these researches, been realised? in how far have they proved to he "the happiest supplement to the ignorance and weakness of the human mind"? " This idea, though ridiculed by some, has as often cropped

1 The problems suggented ly the calculus of probabilities gave rise, collaterally, to several important mathematieal developments, notably the combinatorial analysir, the calculus of finite differences, and, in the hauls of Laplace, the theory of generating function and the recurrent series. A large part of Laplace's great work is taken ul, with this purely mathematical device. It has in more recent times been supplanted, especially under the hands of English mathematicians, by the ealeulus of oper. ations, of which the germ is to be found, according to Laplace, in a suggention of Leibniz (ree 'Essail Philosophique sur les Probabili. tis, 1. 65).

"La théorie des probabilités n'est, au fond, que le bon sems réduit au calcul : elle fait ilplécier avec exactitude ce que les esprits justes sentent par une sorte d'in. stinet, sans cqu'ils puissent souvent s'en remlre eompte. Elle ne laisos rien l'arbitraire dans le choix des opinions et des partis à prendes, toutes les fois que l'un preut, à son moyen, determiner le ehoix le plus avantageux. Par lin, elle devient le supplénent le plus heureux à l'ignorance et it la faiblesse de lesprit humain. Si l'on considere les méthodes analytiques auxquelles cette théorie a donné naisoance, la vérité des principes qui lui servent de base, la logique tine et délicate qu'exige leur emploi dans la solution des problèmes, les établissemens d'utilité publique qui s'ippuient sur elle, et lextension qu'elle a reçue et quelle peut recevoir eneore, par son application aux questions les plus importantes de la Philosophie naturelle et desciences nurales; si l'on observe ensuite yue dans les choses memes qui ne peuvent ctre soumises au ealcul, elle dome les aperçus les plus sûrs qui puirsent nous guiler dans uos jugemens, et qu'elle apprent ì se garantir des illusions qui souvent nous égarent, on verra qu'il n'est point de seience plus digne de nos mélitations, et qu'il soit plus utile le faire entrer danx le systime de l'instruction publique " (loc. cil., p. $273 \mathrm{et}$ seq.) 
up again in the course of the century, and is at present occupying the attention of distinguished thinkers. It will be interesting to give some account of these practical applications.

Four ap.

Of these, four notably attract our attention. First, plications. the theory of error, prominently associated with the name of Ganss. Secondly, the writings of Adolphe Quetelet, and the great impetus given by him to statistical research. Thirdly, the peculiar development of the Atomic theory known as the Kinetic theory of gases, which gave to many scientific investigations what Clerk-Maxwell termed the statistical, in opposition to the historical or descriptive, character. Lastly, the Darwinian ideas which deal with the great and increasing numbers of living things, and the changes inherent in their growth and development. These have led to statistical enmerations and registrations which, begiming with $\mathrm{Mr}$ Francis Galton's researches into the phenomena of heredity, are at the present moment being continued on special lines by Prof. Karl Pearson.

17. Theory of Error.

That Error is subject to law, or, to express it mathematically, to regularity, is a reflection which forced itself upon the attention of thinkers who occupied themselves with the doctrine of chances, and of statisticians who collected registers of large numbers of events. Let special known sources of error be eliminated or allowed for in every instance, there still remains a very large, practically an infinite, number of nuknown sources of error which - where we have to do with simple magnitude-may increase or reduce our result by mutually 
ON THE STATISTICAL VIEW OF NATURE. 575

destroying or angmenting each other. The repeated measurement of a physical quantity, of the position of a fixed star; the arrangenent of the bullet marks on it target; the grouping of the inpressions made on the sand by a stone let fall rertically from the sane point at a considerable height: even the comtings ly a large number of skilled persons of the same munber or the estimates of the sane distance or height of an object, of the weight of a heap of materials: all these statements will show a certain regularity aromd the nean number which we consider to be the most probable or correct one. Small errors will be more frequent than large ones: very large ones will be practically alsent: and the mean will be the result of a mutual destruction or compensation of many small sourees of error acting hoth ways. Mathematicians, from the time of Lagrange and liernoulli, have tried to put into a mathematical formula this resularity in the distribution of error; and, since Laplace and Cianss approached the subject from different points of view, they have arrived at a rlefinite analytical expression ${ }^{l}$ for the distribution of errors of inereasing magnitude around a fictitious centre or mean which is considered in every instance to lie the most probable quantity. Practical trials on a very large scale have been made by bessel, Encke, (qnetelet, Faye, and others, and they have in every case yielded a satisfaetory approximation to the figme given ly the theoretical formula; so that at present little doult as to its usefulness exists in the mincls of those who eruploy it for the purposes of

1 This is the well-known "curve of Error." 
elaborate calculations in astronomy, geodesy, and in various physical and statistical researches.

18.

Method of Least Squares. Gauss.

Bound up with the theory of Error is the celebrated method of least Squares, first used by Gauss in 1795, published by Legendre in 1805 in his memoir 'On a New Method of Determining the Orbit of a Comet,' and elaborately discussed by Laplace, Gauss, and many subsequent writers to this day. ${ }^{1}$ It may be looked upon as an extension or generalisation of the common-sense

1 In addition to the references given in the notes to pp. 120 and 183 of vol. i., I can now recommend two excellent summary accounts of the history and theory of the method of least squares-the one in Prof. Czuber's 'Bericht,' quoted above (pp. 150 to 224); the other in Prof. Edgeworth's article on "The Law of Error" in the Sup. plement to the last edition of the 'Ency. Brit.' (vol. xxviii., 1902, p. 280, \&c.) Prof. Cleveland Abbe, in a "historical note on the method of least squares" ("American Journal of Mathematics,' 1871), has drawn attention to the fact, that already in 1808 Prof. R. Adrain of New Bruuswick had arrived at an expression for the law of error identical with the formula now generally accepted, without knowing of Gauss's and Legendre's researches. See a paper by Prof. Glaisher in the 39th vol., p. 75, of the 'Transactions of the Royal Astronomical Society.' The logical and mathematical assumptions upon which the method is based have been submitted to repeated and very searching criticisms, many rigid proofs having been attempted, and every sub. sequent writer having, seemingly, succeeded in discovering flaws in the logic of his predecessors. In connection with another subject,
I may have occasion to point out how nearly all complicated logical arguments have shown similar weakness, and how, in many cases, the conviction of the correctuess or usefulness of the argument comes back to the self-evidence of some common-sense assumption, which cannot be proved, though it may be universally accepted. Many analysts have tried to prove the correctness of the every day process of taking the arithmetical mean, but have failed. Prof. Czuber says, inter alia (loc. cit., p. 159): "The fact that Gauss, in his first demonstration of the method of least squares, conceded to the arithmeti. cal mean a definite theoretical value, has been the occasion for a long series of investigations concerning the subject, which frequently showed the great acumen of their authors. The purpose aimed atviz., to show that the arithmetical mean is the only result which ought to be selected as possessing cogent necessity, liereby giving a firm support to the intended proofs, has not been attained, because it cannot be attained. Nevertheless, these investigations have their worth because they afford clear insight into the nature of all arerage values and into the position which the arithmetical average occupies among them." 
method of taking the arithmetical nean in determining what figure to accept in a number of slightly cliffering computations. Where more than one quantity is to be determined-for instance, where from a series of olservations dotted on a chart the continuous enrve which marks the course of a planet or comet is to be deduced - the simple method of averaging cimnot he applied. Every set of three complete observations suffices, as Gauss has shown, to determine the elements or constants of an elliptical orbit. Put astronomers try to gret as many observations as possible, and none of these is a repetition of the sime observation-as, for instance, are the repeated weighings of a substance in chemistry, of the measurings of a length in surveying, or the counting of a number in statistics: on the contrary, each is the independent ascertainment of definite positions in a moving object. It is clear that the method of averaging must be more general than the common-sense method of taking the arithmetical mean, but must - where the latter is applicable - coincile with it. It has been shown that the following rule answers this purpose. Fix the average constants or elements so that the sum of the squares of the differences between the observed and calculated positions is a minimmm. In mathematical language this results in the algebraical determination of the constants in an equation.

Whereas the labours of Gauss and the sehool of astronomers which he headed in Germany were mostly oecupied in the mathematical proof of this rule, and in its applications in astronomical and georletic computations, the doctrine of probabilities acquired a larger VOL. II. 
meaning and attracted much popular attention in France

and Belgium through the dominating influence of Laplace. He har not only collected in his abstract and very difficult 'Analytical Theory of Probabilities' all that himself and others had dowe in this line of research, but he had in a similar manner to that adopted in his 'Celestial Mechanics' tried to bring the substance of the theory home to the non-mathematical student in his 'Essai Philosophique sur les Probabilités.'

The analytical formulie of probabilities can, he maintained, "be regarded as the necessary complement of the sciences which are founded on a mass of observations which are subject to error. They are indeed indispensable for solving a large number of questions in the natural and moral sciences. The regular causes of events are mostly either unknown or too complicated to be submitted to calculation: frequently also their effect is disturbed by accidental and irregular causes, but it always remains impressed on the events produced by all these causes, and it brings about changes which a long series of observations can determine. The analysis of probabilities shows these modifications: it assigns the probability of their causes, and it indicates the means of increasing their probability more and more." 1 Then, referring to the phenomena of the weather, Laplace proceeds: "Moreover, the succession of historical events similarly shows us the constant action of the great moral principles in the midst of the diverse passions and interests which agitate society in every direction. It is remarkable how a science 
which began with the consideration of play has risen to the most important objects of human knowledge." In 1523 , soon after the appearance of the works of 20. Laplace and other French writers, this application of Quetriet. the theory of probabilities was taken up by Adolphe Quetelet, who collected his researches in his celebrated work, 'Sur l'Homne et le Développenent de ses Facultés, on Essai de P'hysique sociale.' 1 Qnetelet

1 In ardition to this work, which wiss published at Brussels in 1s35 in two small volumes, and which (quetelet $(1796-1874)$ describes as a "résumé de tous mes travaux antérieurs sur la statistique,' he published, besides a great number of nemoirs, a series of 'lettres sur la Thénie cles I'robabilités' (begun in 1837, pub. 18.45 , Eug. trans. by O. G. Downes, 1549), and as a continuation of the former work in 1S4s, 'Du Système social et des Lois qui le régissent.' Less known than those of Quetelet, but about the same time, and independently, there ap. peared in France the writings of A. M. Guery, beginning with the publication in 1829-in collaboration with A. Balli-of 'Statistique comparée, et l'état de l'iustruetion et du nombre des erimes,' and in 1833, 'Essai sur la sta. tistique morale de la France.' The term "moral statisties" appears here for the first time. Quetelet was the inventor of the term "Social Physies." Guerry employed graphieal methods, and published in 1864 "statistique morale de l'Angleterre comparée avec la statistique morale de lik France.' M. Block ('Statistique,' P. 43) attributes to Guerry and Charles Dupin the general intro. duetion of the graphical metlond in statistics; geometrieal represent. ations having been adopted at the end of the eighteenth century by Wun. Playfair in Fuglind, and, hetore hith, by Crome, professor at Giessen, in 1782, and tabular syuoptical statements going back to the Danish writer J. l'. Anchersen, in his 'Descriptio Statuun Cnltiorum in 'Tabulis' (Copenhagen and Leipzig, 1741); see $V$. John, 'Geselichte der statistik, 1\% ss. Referring to Guerry, V. John (p. 367) say's: "Quetelet is incontestably to be regarded as the founder of the new seience (viz., moral statisties), for the rival works of the French lawyer Guerry appeared only partly before ('uetelet's, and are excelled by the latter in the use male of the material. Independently of this formal difference, the two authors have quite different eonceptions of the new seience. (iuerry regards its object as consisting mainly in collecting data in order to gain an opinion of the moral status of a country. 'Plus he looked upon moral statistics as auxiliary to the history of civilisation. Guetelet went beyond this, inasmuch as he was the first to inquire into the cause of the moral level of a population, and in as muels as iu his criminal statisties of belgium, 1833, lie had alrealy given expression to the fundamentat iden, "Sineiety lears the germs of erime in itself.', 
was astronomer-royal of Belgium and the founder of the Observatory at Brussels. Having opened his career by some memoirs on geometrical subjects, he directed his attention to questions of meteorology and statistics, which he was probably the first to extend into the region not only of the physical but also of the moral attributes of man, studying the phenomena of crime, suicide, and disease as revealed by the criminal courts in France, the Netherlands, and other countries.

Subsequently it was mainly through his influence that a series of international statistical congresses was held in the principal cities of Europe, and a greater uniformity in the methods of research and registration attempted and partially attained.

21.

The "mean man.'

Quetelet's statistical inquiries centre in the conception of the average or mean man who, in a very geometrical fashion, is looked upon as an analogue of the centre of gravity $^{1}$ of a body, being the mean around which the social elements oscillate. "If one tries," he says, "to

1 Quetelet defines the object of his work as follows ('Sur l'Homme,' vol. i. p. 21): "L'objet de cet ouvrage est d'étudier, dans leurs effets, les causes, soit naturelles, soit perturbatrices qui agissent sur le développement de l'homme; de chercher à mesurer l'influence de ces causes, et le mode d'après lequel elles se modifient mutuellement. Je n'ai point en vue de faire une théorie de l'homme, mais seulement de constater les faits et les phénom. ènes qui le concernent, et d'essayer de saisir, par l'observation, les lois qui lient ces phénomènes ensemble. L'homme que je considère ici est, dans la société, l'analogue du centre de gravité dans les corps; il est la moyenue autour de laquelle oscillent les élémens sociaux : ce sera, si l'on veut, un être fictif pour qui toutes les choses se passeront conformément aux résultats moyens obteuus pour la société. Si l'on cherche à établir, en quelque sorte, les bases d'une physique sociale, c'est lui qu'on doit considérer, sans s'arrêter aux cas particuliers ni aux anomalies, et sans rechercher si tel in. dividu peut prendre un développement plus ou moins grand dans l'une de ses facultés.' 
establish in some way the foundation of Social Physics, it is the mean man whom one must consider without stopping at particular and anomalous cases and without investigating whether sone individual can take a development more or less great in one of his faculties. - After having considered man at different epochs and among different peoples, after having suceessively determined the different elements of his physical and moral condition, . . We shall be able to fix the laws to which he has been subjeeted in different nations since their birth-that is to say, we shall be able to follow the course of the centres of gravity of every part of the system." In an astronomical fashion Quetelet speaks of the perturbing forces and variations, and of the "stability of the social system," 3 and eompares the new seience of society to the mechanies of the Heavens." The influence of Laplace and his school is evident in every pacre of Quetelet's work. Whilst speaking of the "variability of the human type and the mean man among different peoples and in different eenturies," he

1 'Sur l'Homme,' vol. i. p. 22.

2 Ibid., p. 23.

3 Iluid., p. 26.

+ Vol. ii. p. 338. Quetelet syeaks of the annual and diurnal periods, and continues: "Les caluses régulières et périodiques, qui dévendent ou de la période annuelle ou de la période diurne, exercent sur la société des effets jlus prouoncés et qui varient dans des limites jlus larges, que les effets coumbinés non périodiques, produits annuellement par le concours de toutes les autres causes qui agissent sur la société; en d'autres termes, le systène social, dans sa manière d'itre, parait ittre flus dissemblable à lui-mine pendant le cours d'une année ou mêne pendant l'espace d'un jour, que pendant deux mmés consécutives, si lon a igard it l'accroisisement de la populatiuu. La période diurne semble exercer une influence un peu plus prononée que la période annuelle, du moins en ce yui concerne les naissances. La périole annuelle produit des effets jlus sensibles dans les campagnes que dans les rilles, et il parait en être de nême des causes en général qui tendent à modifier les faits relatilis at l'honme." 
anticipates discussions which came fifty years later. ${ }^{1}$ His aim is to arrive at a precise knowledge of things hitherto vaguely known and merely sketched by artists and literary persons; but he evidently looks beyond the study of the average man to that of individual departures, as of special interest to the physician, ${ }^{2}$ for instance, in the case of disease, and he significantly recommends what he calls the "study of maxima." 3 He regards the " mean man in the circumstances in which he is placed as the type of all that is beautiful and all that is

${ }^{1}$ Vol. ii. p. 270: "Les anciens ont représenté avec un art infini l'homme pliysique et moral, tel qu'il existaic alors; et la plupart des modernes, frappés de la perfection de leurs ouvrages, ont cru qu'ils n'avaient rien de mieux ì faire que de les imiter servilement; ils n'ont pas compris que le type avait changé ; et que, tout en les initant pour la perfection de l'art, ils avaient une autre nature ì étudier. De lì, ce cri universel, 'Qui nous délivrera des Grecs et des Romains!' De là cette scission violente entre les classiques et les romantiques; de là enfin, le besoin d'avoir une littérature qui fût véritablement l'expression cle lie société. Cette grande révolution s'est accomplie, et elle fournit la preuve la plus irrécusable de la variabilité du type humain ou de l'homme moyen chez les différens peuples et dans les différens siècles." It is interesting to see from this quotation that the opposition to a one-sided clasisical education emanated at that time from the romantic move. ment, whereas in our days it is the scientific movement which forms the opposition.

"Vol. ii. p. 281: "Comme dans le plus grand nombre de cas, le malade ne peut présenter aucune observation satisfaisante faite sur sa propre persomne, ni aucune des élémens qui lui sont particuliers, le médecin se trouve forcé de la ramener à l'échelle commune, et de l'assiniler à l'homme moyen; ce qui au fond semble présenter le moins de difficultés et d'inconvéniens; mais peut causer aussi de graver méprises dans quelques circonstances; car c'est encore le cas de faire observer ici que les lois générales relatives aux nıasses sont essentiellement fausses étant appliquées à des individus: ce qui ne veut pas dire cependant qu'on ne peut les consulter avec fruit: et les écarts sont toujours considérables."

3 Vol. ii. p. 284 : "Il ne faut pas confonlre les lois de développement de l'homme moyen à telle ou telle époque, avec les lois de développe. ment de l'humanité. Elles n'ont en général que peu de rapport entre elles: ainsi je serais très disposé à croire que les lois de développement de l'homme moyen restent à peu près les mêmes aux différens siècles, et qu'elles ne varient que par la grandeur des maxima. Or, ce sont justement ces maxima, relatifs ì l'homme développé, qui donnent, dans cliaque siècle, la mesure du développement de l'huuanité." 
good." I And further, "one of the principal things accomplished by civilisation is to draw closer and closer the limits within which the different elements oscillate which are characteristic of man." "

There was, however, another idea besides that of 22. Social stat. the mean man which followed in the course of this isties and mathematical or astronomical treatment of social statistics-namely, the seeming negation of the scupe of freewill and of moral responsibility, which seened inconsistent with the regularity of the statistical reeords. In his treatise, 'Sur l'Homme, Quetelet had drawn attention to the regular recurrence of crime - of the tendency to crime - as one of the most remarkable features in society; which, through its physical and moral constitution, "prepares erime, the guilty being only the instrument which earries it

1 Vol. ii. 1. 297 : "Jai dit précédemnent que l'homme moyen de chaque époque représente le tyire du développement de l'humanité pour cette éporue; j'ai dit eneore yue l'homme moyen était toujours tel que le comportaient et qu'exigeaient les temps et les lieux; que ses yualités se développaient danun juste équilibre, dans une parfaite harmonie, également éloignée des excís et des défectuosités de toute esivece; de sorte yue, dans les circonstances où il se trouve, on doit le considérer comme le type de tout ce qui ext beitu, de tout ce qui est bien." P. "2\$9: "[ " qui résumerait en lui-même, à une époque donnée, toutes les qualités de l'houme moyen, représenterait it la fois tout ee qu'il y a de grand, de beau et de bien."

2 Vol. ii. ") 342: " $\mathrm{Un}$ des prin. cipaux faits de la eivilisation est de resserrer, de plus en plus, les limites dans lesquelles oscillent les différens élémens relatifs ì l'homme. Plus les lumières se répandent, plus les écurts de la moyenne vout en diminuaut; plus, par conséquent, nous tendons it nous rapprocher de ee yui est beau et de ce qui est bieu. La perfeetibilité de l'espèce humaine résulte eomme une consé. quence nécessaire de toutes nos recherches. Les défectuosités, les monstruosités disparaissent de plus en plus au pliysique; la fréquence et la gravité des maladies se trouvent combattues avee plus d'arantage par les progrès des sciences médicales; les qualités moriles de l'homme n'éprouvent pas de perfectiounemens moins sensibles; et plus nous avanceron:, moins le, gramis bouleversemens politinues et les guerres, ces tléaux de l'lumanité, seront it crainclre dans leurs effet.s et dans leurs conséyuences." 
out"; society, as it were, exacting a certain proportion of crime, as it does of suicide, poverty, physical and mental disease, for the maintenance of its equilibrium and as an "alarming" 2 tribute to its stability. The extreme consequences which seemed to flow from this doctrine were not drawn by Quetelet, who believed in a gradual though slow development of human society, and in moral as well as physical causes and influences. They were drawn, however, by what we may term the mathematical school of social philosophers, who relied greatly upon the figures collected by Qnetelet and confirmed by others. In this country the statistical labours of Quetelet were made known by Sir John Herschel in a brilliant article ${ }^{3}$ in the 'Edinburgh Review' on the "Translation of Quetelet's Letters to Prince Albert on the Theory of Probabilities." They do not seem to have been regarded as detrimental to the moral aspect of human history till Henry Thomas Buckle, in his celebrated 'History of Civilisation,' ${ }^{4}$ made use of Quetelet's statistics in sup-

1 'Sur l'Homme,' vol. ii. p. 241.

2 Cf. vol. ii. p. 262 ; also 'Système Social' (1848), p. 95, and the 'Mémoire sur la Statistique Morale' (1848).

3 Vol. xcii. p. 18.

4 The 'History of Civilisation,' vol. i., appeared in 1857 , and was very soon translated in Germany, running in a short time through five editions. There the statistical theories of Quetelet had not made that impression which they made in some other countries. This is explained by the fact that the philosophy of Kant, to which Buckle himself referred in a long passage in his "Introduction," had long before Quetelet accustomed thinkers to abandon the popular conception of freewill, which sees in it merely the absence of causal determinateness, in favour of the causal connection of so-called free actions with the motives and the moral character. The subject has been very fully discussed by F. A. Lange in his well-known 'History of Materialism' (Eng. trans. by Thomas, vol. iii. p. 196, \&c.) Lange refers to a remark of the well-known political economist, Prof. Adolph Wagner, who, in his work 'Die Gesetzmässigkeit in den scheinbar willkührlichen mensch. lichen Handlungen' (Hamburg, 1864 , p. xiii, \&c.), mentions the fart that Quetelet's writings had 
port of one of his favomrite theses-vi\%, that the comrse of historical progress depends on the combined action of the external plysical surromdings and of the intellectual side of lumm natme. Apart from intellectual modifications the moral sicle is a constant. In the course of the discussions following the appearance of Buckle's History, especially in Germany, it was conchusively shown that statistical figures prove neither one view nor the other: indeed, one of the most complete and exhaustive treatises on moral statistics comes from the orthodox pen of Alexander von Oettingen, a Professor of Theology, just as we saw that the first great work on political arithmetic in Germany cane from the pastor Sissmilch a century earlier. Philosophical writers like Lotze ${ }^{1}$

not receiced the attention melited : "This reproach does not quite hit the right point. . . IIagner might, in tact, have been led by Buckle... to see that German philosophy in the doctrine of the freedom of the will las for once an advantage which permits it to regard these new studies with equanimity ; for buckle supports hirnself above all upon kint, addueing his testimuny for the empirical necessity of hunan actions, and leaving aside the transcendental theory of freedom. Although all that inaterialism can draw from moral statistics. . for the practical value of a materialistic tendency of the agre as against idealism has thus becn conceded by kant, it is by no means indifferent whether moral statistics, and, as we may put it, the whole of statistics, is placed in the foreground of anthropological study or not; for moral statistics direct the view outwards upon the real measurable facts of life, while the German philosophy, despite its clearness as to the nullity of the old doctrine of freewill, still always prefers to direct its view inwards upon the iacts of consciousness."

'Lotze's deliverances on this subject will be found in the third chapter of the seventh book of the 'Microcosmus' (Eng. trans. by Hamilton and Jones, vol. ii. p. 200, \&c.), and also in the 'Logits' of 1874 (Book II. chap. 8). In the former jassage he says: "The dis. like with which we hear of laws of psychic life, whilst we to not hesitate to regard bodily life as subordinate to its own laws, arises partly because we require too inuch from our own freetom of will, jartly beeause we let ourselves be too much imposed npon by those laws. If we do not find ourselves involved in the declared struggle between freedom and necessity, we are by no means averse to regarding the actions of 
and Drobisch ${ }^{1}$ have long ago reduced to their proper

measure the pretensions of statistics, and it is now generally admitted that in the sciences dealing with human nature and society, as in those which investigate purely physical phenomena, observations, figures, and measurements rarely if ever suffice to establish a valid generalisation; but that, if such be suggested by other processes of thought, notably through attentive reflection on, and analysis of, single and accessible cases, statistics supply the indispensable material by which

men as determined by circum. stances: in fact, all expectation of good from education and all the work of history are based upon the conviction that the will may be influenced by growth of insight, by ennoblement of feeling, and by improvement of the external con. ditions of life. On the other side, a consideration of freedom itself would teach us that the very notion is repugnant to common. seuse if it does not include sus. ceptibility to the worth of motives, and that the freedon of willing can by no means signify absolute capacity of carrying out what is willed." And, further, he remarks on "the extreme overhastiness with which the statistical myth has been built up from deductions which cannot be relied upon. We have yet to obtain from exacter investigations the true material for more trustworthy conclusions -material which should take the place of the statistical myth above referred to."

1 Before Lotze, aud as early as 1849 , M. W. Drobisch, the Herbartian, had reviewed Quetelet's Memoir, 'Sur la Statistique morale,' \&c. : and later (1867), after the publication of A. Waguer's work, he came back to the subject in an im. portant tract, 'Die moralische Statistik und die menschliche Willensfreiheit,' which should be read by every one who desires to form just views on the subject. "In all such facts," says Drobisch, "there are reflected not natural laws pure and simple, to which man must submit as to destiny, but at the same time the moral conditions of society, which are determined by the inighty influences of family life, of the school, the Church, of legislation, and are, therefore, quite capable of improvement by the will of man" (Zeitsch. für exacte Philos.' vol. iv. p. 329). After all that has been said by Quetelet, Buckle, and others, the words of Schiller ('Wallenstein's Tod,' ii. 3) still remain the best statement of the problem :-

"Des Mensclien Thaten und Gedanken, wisit!

Sind nicht wic Meeres blind bewegte Wellen.

Die innre Welt, sein Microcosmus, ist

Der tiefe Schacht, aus dem sie ewig quellen.

Sie sind nothwendig, wie des Baumes Frucht;

Sie kann der Zufall gaukelnd nicht verwandeln,

Hab'ich des Menschen Kern erst untersucht,

So weiss ich auch sein Wollen und sein Handeln." 
these generalisations can he tested, elevater to the rank of leading canons of thought and research, and in rare cases to that of the expression of a law of nature. So far, therefore, as the complicated phenomena presenter in meteorology, agriculture, and economics are concerned, the suggestions leading to so-ealled laws have in every case been got elsewhere-from astronomy, chemistry, psychology, history, dc.: and the work of seience has subsequently consisted largely in gathering the necessary statistical materials by which to prove, amplify, curtail, or refute then. In many cases it has been fouml that even elaborate series of observations hat not been performed in such a mamner ${ }^{1}$ as would permit of the necessary inferences being drawn from them. Similarly biologists after Darwin have had to rearrange the collections male by those who came before the epoch marked by that great name.

I This refers as much to statist. ical figures as to the knowledge accumulated in many of the natural sciences. Especially it refers to the statistical material upon which Quetelet based his startling and eporh-naking assertions : the earlier erities had, as V. John observes ('Geschichte der Statistik,' p. 364), realt with the deductions which Quetelet had drawn, without dealing with the empirical material itxelf. It was therefore of great inportance that Prof. Rehuisch of Gristingen for the first time sub. ruitter the figures thenselves to a searching analysis. He did this in the years $1875-76$, in his articles in the "Zeitschrift für I'hilo:ophie und Philosophische Kritik,' through which it became evident that the inferences were, as Lotze had alrealy suggented, to say the lea-t, premature. "In the memoir 'sur le Penchant au (rime' (1531), only. four years, and in the work 'Sur l'Houme,' ouly six years (1\$20-31) of the 'compte général,' furnished the data upon which the astound. ing regularity will which eriue repents itself was maintained" ( $V$. John, p. 3t5). Rehnisch adds many other examples of the extreme iucompleteness of the records upon which the theory of quetelet is built up. Iore recent labours have therefore been to a large extent directed towarks gathering unere complete statistical data, ats well as towarls improving the mathematical methols themselves to which not only these but also the population and mortality statisties have been sulmitted, for the purpose of arriving at average figures. 
With the scientific treatment of the phenomena of human society, the name of Adolphe Quetelet will always be associated; yet the mathematical or exact school was not the only one which in the course of the first half of the century had approached the subject. 25. Notably in Germany, under the ruling influence of criticism. philosophical, historical, and critical studies, a school of research had grown up calling itself the historical. If the centre of gravity of the mathematical view lies in the conception of a certain uniformity and stability of social phenomena, the other school looked more to historical changes and developments, opposing the doctrine of the movement or of the dynamics to that of the statics of society. Its inspiration came from a different quarter, and will occupy us in a later portion of this work. For the moment it suffices to remark how here also, in the study of economics and social phenomena, the developmental or genetic view has gradually dispelled the earlier search for recurrent forms and regularities, which we may term the morphological aspect: the physiology has succeeded the anatomy of society.

But statistical methods, with the accompanying doctrines of probability and averages and the theory of error, have not only been extensively and usefully employed where large numbers of similar facts and events crowd in upon our observation, and, as it were, overwhelm us by their multitudes, as in astronomy, meteorology, economics, and political arithmetic: they have also shown themselves applicable by what we may term the inverse method. Quetelet, when deal- 
ing with long eolumns of human statistics, felt it relief in studying the average or mean man. Is it not possible that in many instances what nature and experience show us is only the average itself-our senses and our intellect being too coarse to penetrate to the numberless individual cases out of which the sum or the average is made up? May not even the simplest phenomenon or thing in nature be in fact an aggregate, a total, and its apparent behaviour and in phlysics. properties merely a collective effect? Both the kinetic and the atomic view of matural objects and phenomena seem to favour this way of regarding things, - the former showing us in many eases motion and mrest where at the first glance we saw only rest, and the latter dissolving apparently continuous and homogeneous struetures into erowds or assemblages of many particles.

Thus the apparently stealy pressure of gases is now known to be in reality the violent hombardment of the wall of the containing vessel by their molecules; and the most homogeneous and transparent crystal is revealed, by its optical properties, as an assemblage of very minute particles, held together hy forces which may be overcome by mechanical or chemieal agencies. Regarded from this point of view, our knowledge of natural objects is merely statistical: it deals with aggregates; it is a collectire knowledge. And if we further consider that the simeness of the numberless constitnent particles is by no means proved, this collective knowledge turns out to he merely concerned with arerages: it is stutistieal, not individual, 
information that we seem to possess; it resembles the knowledge which an economist may possess of the statistics of a society or of the properties of the "mean" man. If such be the case, the theory of large numbers and the calculus of probabilities must be applicable and useful in dealing with those phenomena which, through their minuteness and great number, elude our detailed examination.

The first to introduce this conception of treating a very large assemblage of moving things by the method of averages was Joule, ${ }^{1}$ who, adopting Daniel Bernoulli's conception, calculated the average velocity which a particle of hydrogen gas must possess in order to explain the total effect which shows itself as a definite gas pressure at a definite temperature. His result was that this average speed must be 6055 feet per second in order to be equal to the pressure of one atmosphere at the zero temperature of the Centigrade scale. The speed of the particles, however, cannot be assumed to be equal, owing to continual encounters: and we are indebted to Clausius and

2i. Clerk-Maxwell for introducing the more refined statistical methods of the theory of probabilities. They calculated the mean free path, and showed that former calculations of the average speed were in the main correct. The kinetic theory of gases afforded an opportunity of brilliantly applying the conceptions of averages or means and of the differences of frequencies as the measure of the probability of certain occurrences. In this case-as was first shown by Joule's figures-we

1 See supro, vol. i. p. 434, and vol. ii. p. 110. 
have to do with hillions and trillions of particles, moving with velocities varying from zero to many thousands of miles per second: we have therefore to do with numbers which practically mean infinity-that is to say, we have to do with that condition of things where alone the laws of probahility lecome strictly correet. $^{1}$

In this case, any deductions which can lye made as to the average condition or collective behaviour of an infinitely large assemblage of particles, whose individual members move about with infinitely varying velocities at infinitely varying speeds in infinitely varving directions, must be realised in the well-known laws of gaseous bodies referring to pressure, volume, expansion, inolecular structure, and heat, assuming the latter to be merely the sensible effect on our nerves of very numerous inpingements of infinitesimally small particles. It is one of the greatest trimphs of the mathematical methods applied in one of the most difficult instances, that the average behaviour and collective properties of

1 P. G. Tait ('Heat,' 18\&4, ]). 355) says: "It is to Clausius that we are indebted for the earliest approach to an adequate treatment of this question. He was the first to take into account the collixions between the particles, and to show that these did not alter the pre. viously obtained results. He has also the great eredit of introducing the statiotical methods of the theory of probabilities, and of thus giving at least approxinate ideas as to the probable length of the man frce path-i.c., the average di-tance travelled over by a paiticle hefore it inpinges on another, and thus lias its course changed. He thus explains also the slownes of difiu. sion of gases, and their very small conduetivity of heat. Clerk-MIaxwell shortly afterwards inmoved the theory by introducing, also from the statistical point of view, the consideration of the variety of speed at which the different particles are moving : Clausius having expressly limited his investigations by assuning for simplieity that all move witl equal speed. Clerk. Maxwell explained gaseous friction, and gave a more definite determination of the length of the mean free patl." 
such moving crowds turn out to be exactly those laws 28. which Boyle, Charles, Gay-Lussac, Dalton, and Avogadro Mathematical representation of experimental laws.

had found out by direct experiments with gaseous bodies. James Clerk-Maxwell was the first to recognise the great importance of the statistical methods, and to apply them in an exhaustive manner. ${ }^{1}$ And we witness here the same spectacle which presented itself in the history of the theory of probabilities. Problems which are to be solved by the mere application of a few rules dictated by common-sense and an exercise of common logic, present in their complexity such a multitude of traps, snares, and pitfalls, that it required the successive application of the highest intellects to free the reasoning from insidious errors, and put the results on

1 The manner in which Joule dealt with the problem of a large crowd of moving particles in his memoir of 1851 was not strictly statistical, inasmuch as he dealt with an average velocity of the molecules, and assumed that all the molecules of a gas moved with the same velocity. Clausius, in his memoir of 1857 , made use of assumptions which were more in conformity with nature: he had, accordingly, to employ the calculus of probabilities. Clerk - Maxwell's occupation with the subject dates from the year 1859 , when he read his paper, "Illustrations of the Dynamic Theory of Gases," Part I. (published in the 'Phil. Mag.,' 4th series, vol. xix. p. 19, reprinted in 'Scientific Papers,' vol. i.) He showed that "the velocities are distributed among the particles according to the same law as errors are distributed among the observations in the theory of the method of least squares. The velocities range from 0 to $\infty$, but the number of those having great relocities is comparatively small." If we leave out Joule's imperfect attempt to employ the statistical method, one of the first applications of the method of averages to a physical problem is to be found in Sir G. G. Stokes's paper "On the Composition of Streams of Polarised Light from different Sources" ('Camb. Phil. Trans.,' 1853), where he shows "what will be the average effect of a very great number of special sources of light: thus giving one of the earliest illustrations of the use, in physics, of the statistical methods of probabilities. . . From this point of view the uniformity of optical phenomena becomes quite analogous to the statistical species of uniformity, which is now found to account for the behariour of the practically infinite group of particles forming a cubic inch of gas" (P. G. Tait, 'Light,' 2nd ed., 1\$89, p. $237)$. 
undisputed and indisputable bases. ${ }^{1}$ In proportion as this has been done the calculated results have proved to be in eloser and closer accord with observert facts. I will here mention only one of the latest achievements in this line of research and reasoning. Assuning - as the atomic and kinetic theories do-that all external phenomena of bodies can be reduced to the collective or mean effect of a practically infinite variety of turbulent movements of a very large number of particles, it must be possible to give a mechanical explanation of that remarkable property of all phenomena of nature, first noticed by Lord Kelvin, that they are essentially Irreversinatural irreversible - i.e., that, with very rare exeeptions, they lrucesses. take place in a certain direction which we may lefine as an equalisation of existing lifferenees of level, temperature, electrie pressure, and similar inequalities. In order to fix this remarkable property of all natural phenomena, physicists found themselves obliged to introduce, alongside of energy and mass (which are both assumed to conserve or maintain their total quantity), a third something which is the measure of the degree in which an existing distribution of mass and energy can be considered to be capable of external, visible, finite activity

1 Those who are interested in seeing how diffieult it is to link together the common-sense arguments of the theory of probabilities in a consistent chain of unimpeachable logic, should read the report on the various attempts to prove Clerk-Jaxwell's law (nentionerl in the foregoing note) contained in Prof. O. E. Meyer's 'Kinetische Theorie der Gase' ('2nd ed., lireslau, 1599), espeeially [. 16, kc., and

VOL. II.
'Mathematical Appeudix,' J. 17 ; and the great number of nemoirs referred to on p. 60 of that book. Nevertheles. 'l'ait speaks of the still reminining difficulties in the kinetic theory of gases as having been "greatly enhanced by au apparently" unwarranted applieation of the theory of probabilities on which the strtistical method is baserl." ('Properties of Mlatter,' and ed., 1890, p. 291.) 
-i.e., of its availability to do work. ${ }^{1}$ The infinitesimally small motions of an immense crowd may be exerted in such a way as to total up to a finite movement perceptible to our senses and accessible to our handling, or they may so mutually annul each other as to present in their finite sum and aggregate the appearance of rest and inaction, however turbulent their behaviour might appear to an observer gifted with powers of perception millions of times more delicate than ours. Lord Kelvin introduced the conception of the availability of energy, ${ }^{2}$ Clausius that of entropy (or energy which is hidden away), to measure this condition of any natural system. Has the statistical view any conception to put at the base of this remarkable property of natural phenomena? It has, and we must assign to Clerk-Maxwell ${ }^{3}$ the \&c.

1 See supra, chap. rii. p. 128 ,

"Or of "motivity" (i.e., " energy for motive power"), this being "the possession, the waste of which is called dissipation." See supra, chap. sii., p. 168; also Thomson (Lord Kelvin), 'Popular Addresses,' vol. i. p. 141 .

3 The contributions of Clerk. Maxwell to this topic are notably two, independently of the larger view which he took of statistical, as compared with historical, knowledge, of which I treat farther on in this chapter. First, in the con. cluding remarks of his treatise on the "Theory of Heat" ("On the Limitation of the Second Law of Thermodynamics") he introduced his famous conception of a "sorting demon," the meaning of which fanciful device was, to impress upon the student of the dynamical theory of heat, first the fact that the loss of availability of the energy of molecular motion is owing to the coarseness of our senses ; and second, that the restoration of differences of temperature, or of availability of energy, is simply a matter of arrangement or order, not of an increase of the intrinsic energy of the system. The subject has been frequently referred to, notably by Lord Kelvin, who says " On the Sorting Demon of Clerk-Maxwell," Royal Institution, February 1879. Reprinted in 'Popular Lectures and Addresses,' vol. i. p. 137, \&c.): "Dissipation of energy follows in nature from the fortuitous concourse of atoms. The lost motivity is essentially not restorable otherwise than by an agency dealing with individual atoms; and the mode of dealing with the atoms to restore motivity is essentially a process of assortment, sending this way all of one kind or class, that way all of another kind or class" 
credit of having first indicated, and to l'rof. Boltzmann ${ }^{1}$ -aided by many other eminent natmal philosophers - that of having definitely established, this lighly suggestive explanation or illustration. The doetrine of chances, to which artifice the statistical view of

(p. 139). "The eonception of tle 'surting demon' is merely' mechanical, and is of great value in purely physical science. It was not inveuted to help, us to deal with questions regarding the influence of life and mind on the motions of matter, questions esientially be. yond the range of nere dyuanics" (p. 141). The other eontribution through which Clerk - Maxwell's name has become celebrated in this eonnection is to be found in the so-called Maxwell-lboltzmann law of the distribution of kinetic energy in a mass of moving particles. The discussion of the subject dates irom the first memoir of Clerk-Maxwell, quoted above ; and, after Prof. Boltzmann had treated of the same sulject in 1868, and Mr Watson in 1876, ClerkMaxwell returned to it in a paper "Un Energy in a system of Material Points" ("Camb. Mhil. Soc.,' vol. xii.) In the year 1894 Prof. Bryan presented the 2nd part of his Report on "Our Knowledge of Thermolymamies" ('Brit. Assoc. Rep.', 1894, p. 61, Se.), in which he gives an aceount of all the different investigations referring to this subject, up to that date. This was followed by a loug diseusion of the subject in the pages of 'Nature' (vol. li.), in which Messrs bryan, Boltzmanu, Burbury, Culverwell, Lamnor, and H. W. Watson took jart, and which gave I'rof. lioltzmann the opportunity of giving a final expression of his opinion $(\mu, 415)$.

1 Prof. Holtzmann's investigations connected with the second law of thermorlynamies and the kinetic theury of gaves cover the last thirty-five years. He laks suceeded in putting the whole problem more and more into a strictly accurate, as also into a popularly intelligible, form. Un. fortunately his very numerous contributions are seattered in various periodical publications, and lave not yet appeared in a collected edition. Most of them appeared in the Proceediugs and Transactions of the Viemna Academy, anong which the Adliress deliverel on the 29 th May $1886^{\circ}$ ean be specially recommended. Siuce theu, and after the eorrespondence in 'Nature' referred to in the last note, Ine has publinlied lis lectures "Vorlesungen iiber Gas. Theorie' (2 vols., Leiprig, 1896-98). He there (rol. ii. 1\%. 260 , note) gives a list of the most important literature on the subject. and also a general sunmary regarding the application of the theory of prob. abilities to the distribution of the kinetic energy of a crowd of moving frartieles. In this eonneetion lie also deals with the consequences of the atomic hypothesis, the irreversibility of all natural processes, and the application of the second law to the listory of the univerie. He these says (p. 253): "The fact that the closed system of a linite number of molecules, if it had originally an orderly condition, and las then lipsed into a disorderly one, must finally, after the lajse of an inconceivably long period, assume again orderly eonditions, is 
phenomena reduces us, distinguishes between probable and improbable events or arrangements of a crowd of elements-i.e., between such as are of an average and such as are of an exceptional character. Any highly improbable arrangement-though possible-will be followed by a gradual settling down to more probable or average arrangements. And as in nature you are forced to introduce the conception of availability, so in the calculus of chances you can introduce a certain mathematical quantity which is the measure of the probability. The more improbable, i.e., exceptional, the begin-

not a refutation, but a confirmation, of our theory. But one must not consider the matter thus: as if two gases ... which were initially unmixed, then became mixed, after a few days again unmixed, then again mixed, \&c. We find, rather, that . . only after a period which, even compared with $1010^{10}$ years, is enormously great, a perceptible unmixing would take place. That this is practically equivalent to never, we see, if we consider that in this period there would be, according to the laws of prob. ability, many years in which, by mere chance, all the inhabitants of a large city would, on the same day, commit suicide, or fire break out in all its buildings; whereas the insurance companies are in so good an agreement with facts that they do not consirler such cases at all. If even a much smaller improbability were not practically identical with impossibility, nobody could rely upon the present day being followed by night and the latter again by day." And further (p. 255): "If we, therefore, represent the world under the figure of an enormously large mechanical system, composed of enormously numerous atoms, which started from a very perfectly ordered condition, and exist still mainly in all orderly condition, we arrive at consequences which actually stand in perfect harmony with observed facts"; and (p. 258), "That in nature the transition from a probable to an improbable condition does not happen as frequently as the reverse, can be explained by the assumption of a very improbable initial state of the whole surrounding universe, in consequence of which any arbitrary system of interacting bodies is, in general, in an improbable condition to begin with. But one night say, that here and there the transition from probable to improbable conditions must, after all, be observable. . . From the numbers regarding the inconceivably great rarity of a transition from probable to improbable conditions, happening in observable dimensions and during an observable period, it is explained how such a process within what we, cosunologically, eall a single world, or, specially, our world, is so extremely rare that any experience of it is excluded." 
ning you choose, the greater your distance from the average or most probable condition into which, in the long-lum, things must settle down; the more play for the equalising and levelling down of eoming events. The world-or at least that part of the world accessible to our observation, and the playgromul of om activityshows a large amount of available energy, or, expressed in a purely statistical manner, it started from a lighly improbible condition, and it is descending or rumning down into a more probable or average condition. The doctrine of availability or of its reverse, of entropy "Avail. atility" a -i.e, of the loss of availability-turns out to be a probability. theorem of probabilities; and the refined mathematical researehes of Prof. Boltzinam and others show that these two conceptions ean be made to cover each other. Moreover, we can bring home to the popular mderstanding the difference between the exeeptional condition, with its large amomt of available energy, and the average condition, with its large amount of selfdestructive and wasted energy (or entropy), by the simile of order and disorder. For every arrangement of a erowd of things or beings which is orlerly, there are innmmerable arrangements which are disorderly; every one knows how easily the orderly arrangement lapses into disorder, and noborly expects by mere hiphazard or chance movenents to produce order out of disorder. There are thonsands of ways by which a stone can fall from the peak of a momtain to the lower levels, but only one direction which would take it up again to the top. A tree has been surgesesterl as the picture of the course that natural movenents take: for the one position 
in the trunk, where all branches and all roots meet, there are in both directions numberless ways of ramification or dissipation into the twigs or the root-fibres. The statistical view measures the chances of an orderly arrangement compared with disorder, of a commanding unique position compared with the average or mean position, by saying the odds are infinity to one against it. The orderly exceptional position and arrangement of a crowd does not possess more actual energy, but its energy is directed, arranged, it has become availableget-at-able.

32.

"Selection" as conceived by Maxwell.

And what is it that changes disorder into order? It is a process of selection. Maxwell imagined a sorting demon endowed with powers of perceiving and dividing the immeasurably small movements of a gaseous bodyi.c., of a crowd of particles in turbulent to and fro movement. Such a being could, by mere selection and separation of the slow and fast moving particles, bring order into disorder, converting the unavailable energy into available energy. It would be a process of mere sifting and arranging, such as is apparently carried out in the living creation and by organic structures. ${ }^{1}$ And Maxwell went a step further, and conceived the idea

1 See supra, cliap. x. p. 437, note, where the selective action of certain organisms is referred to in connec. tion with Prof. Japp's Address to the Brit. Assoc. in 1898. Lord Kel. vin says ("On the Dissipation of Energy," 1892, 'Popular Lectures and Addresses,' vol. ji. p. 463, \&c.): "It is conceivable that animal life might have the attribute of using the heat of surrounding matter, at its natural temperature, as a source of energy for mechanical effect. . . .
The influence of animal or vegetable life on matter is infinitely beyond the range of any scientific inquiry hitherto entered on. Its power of directing the motions of moving particles, in the demonstrated daily miracle of our human free-will, and in the growth of generation after generation of plants from a single seed, are infinitely different from any possible result of the fortuitous concourse of atoms." 
that, after all, the whole of our knowledge of natural phenomena and natural things may be only statistical, not historical or individual. "In dealing," he says," "with masses of matter, while we do not perceive the indivilual moleeules, we are compelled to adopt the statistical method of calculation, and to abunlon the strict dynamieal method in which we follow every motion by the ealculus. It would be interesting to inquire how far those ideas about the nature and the methods of science which have been derived from examples of scientific investigation in which the dynamieal method is followed, are applicable to our actual knowledge of conerete things, which, as we have seen, is of an essentially statistical nature, beeause no one has yet discovered any praetical methor of tracing the path of a molecule, or of identifying it at different times." And elsewhere ${ }^{2}$ he says: "The statistical method of investigating soeial questions has Iaplace for its most scientific and Buckle for its most popular 329.

1 'Theory of Heat,' Sth exl., p.

"Life of Clerk - Maxwell by Camphell and Garnett.' Chap. xiv. continins a paper with the title, "Dies the progress of lhysical Science tend to give any arlvantage to the opinion of recessity (or Leterminism) over that of the Contingency of Events and the Freedom of the Will?" In it (1). 435) there oceurs the following passage: "The doctrine of the conservation of energy, when applied to living beings, leals to the conclusion that the soul of an animal is not, like the mainspring of a watch, the motive power of the body, but that its function is rather that of a steerman of a vesisel - not to produce, but to regulate and direct, the animal powers." He then speak of the "powerful effect on the world of thought" which the developments of molecular science are likely to have, considering the "most inportant effect on our way of thinking to be that it forces on our attention the distinction between two kinds of knowledge, which we may eall for comvenience the Dynamical and Statistical." The paper from which the extracts in the text are taken is dated 1873 . Clerk-Maxwell was then forty-one years of age. 
expounder. Persons are grouped according to some characteristic, and the number of persons forming the group is set down under that characteristic. This is the raw material from which the statist endeavours to deduce general theorems in sociology. Other students of human nature proceed on a different plan. They observe individual men, ascertain their history, analyse their motives, and compare their expectation of what they will do with their actual conduct. . . However imperfect this study of man may be in practice, it is evidently the only perfect method in principle. . . . If we betake ourselves to the statistical method, we do so confessing that we are unable to follow the details of each individual case, and expecting that the effects of widespread causes, though very different in each individual, will produce an average result on the whole nation, from the study of which we may estimate the character and propensities of an imaginary being called the Mean Man. Now, if the molecular theory of the constitution of bodies is true, all our

33.

Statistical knowledge of nature. knowledge of matter is of a statistical kind. A constituent molecule of a body has properties very different from those of the body to which it belongs. The smallest portion of a body which we can discern consists of a vast number of molecules, and all we can learn about the group of molecules is statistical information. . . Hence those uniformities which we observe in our experiments with quantities of matter containing millions of millions of molecules are uniformities of the same kind as those explained by Laplace and wondered at by Buckle, arising from the slumping to- 
gether of multitudes of cases, each of which is by no means uniforn with the others. . . Much light nay be thrown on some of these questions by the consideration of stalility and instability. When the state of things is such that an infinitely small variation of the present state will alter only by an infinitely small quantity the state at sume future time, the comlition of the system, whether at rest or in motion, is said to be stable; but when an infinitely small variation in the present state may bring about a finite lifference in the state of the system in a finite time, the condition of the system is said to he unstable. It is manifest that the existence of unstable conditions renders impossible the prediction of future events, if our knowledge of the presentsstate is only allyroximate and not aceurate. It has been well pointed ont by l'rof. Balfour Stewart that physieal stability is the characteristie of those systems from the eontemplation of which determinists draw their arguments, and physieal instability that of those living bodies, and moral instability ${ }^{1}$ that of those developable souls which furnish to conseiousness the conviction of free-will." 2

1 There is an awkward minprint in the first edition of 'The life,' which is corrected in the second edition.

2 Clerk - Maxwell irequently reverts to this subject. In an article on "Holecules," contributed to the ninth edition of the "Eney. Brit.' (reprinted in 'Scientific I'aners,' vol. ii.), he contrasts hiscorical and statistical knowlerlge as follows (p. 373): "The modern atomists lave adopted a methosl which is, I believe, new in the dejartment of mathematical physics, though it has long been in use in the section of statistics. When the working nembers of section $F$ (of the Brit. Assoc.) get hold of a report of the census, or auy other document containing the numerical data of economic and social science, they begin by distributing the whole population into groups aceorling to age, income-tax, ellucation, religious beliei, or criuninal convictions. 'The number of inclividuals is far too great to allow of their traeing the 
The conceptions involved in the atomic and kinetic views of natural processes, and the statistical manner of dealing with these crowds of moving particles, have thus introduced into natural philosophy two distinct and novel considerations not known to former ages: first, the consideration that our knowledge of things and phenomena in nature is not historical, but that it is that of the mean or average and of the total effects produced by an immensely large number of singly imperceptible events upon our senses which are too coarse to receive or deal with individual occurrences; secondly, the consideration that our knowledge is not purely mechanical, inasmuch

history of each separately, so that, in order to reduce their labour within human limits, they coucen. trate their attention on a small number of artificial groups. The varying number of individnals in each group, and not the varying state of each individual, is the primary datum from which they work. This, of course, is not the only metlod of studying human nature. We may observe the conduct of individual men and compare it with that conduct which their previous character and their present circumstances, according to the best existing theory, would lead us to expect. Those who practise this method endeavour to improve their knowledge of the elements of human nature in much the same way as an astrononer corrects the elements of a planet by comparing its actual position with that deluced from the received elements. The study of human nature by parents and schoolmasters, by historians and statesmen, is, therefore, to be distinguished from that carried on by registrars and tabulators, and by those statesmeu who put their faith in figures. The one may be called the historical and the other the statistical method. The equations of dynamics completely express the laws of the historical method as applied to matter, but the application of these equations inplies a perfect know. ledge of all the data. But the smallest portion of matter which we call subject to experiment consists of millions of molecules, not one of which ever becomes sensible to us. We cannot, therefore, ascertain the actual motion of any one of these molecules; so that we are obliged to abandon the strict historical method of dealing with large groups of molecules. The data of the statistical method, as applied to molecular science, are the sums of large numbers of molecular quantities. In studying the relations between quantities of this kind, we meet with a new kind of regularity, the regularity of averages, which we can depend upon quite suffi. ciently for all practical purposes, but which can make no claim to that character of absolute precision which belongs to the laws of abstract dynamics." 
as besides the purely mechanical movements and their summation, it must contain a reference to the nature of our own faculties - a principle which imlicates to what extent the elementary movements come under our control or escape it. There must be a principle which meatsures the arailability and usefulness - for om powers-of naturil processes, marking ofl what is orderly for om senses and accessible to wur powers, from what is disorderly and inaccessible. This principle the founters of the scicuce of Thermodynamics-Tiankine, Clausius, and Thomson-had empirically established: Thomson having foreseen its far-reaching importance in the economy of nature and the applications of industry. The statistical view of natural phenomena forcel upon us by atomism and As olposeri to histrorical and mechan. kinetics has shown us that it is not a purely me- ieal knowchanical ${ }^{1}$ principle. It is one belonging to the theory of arerages and probability. The seientific riew of nature is thus, as Clerk-Maxwell says, neither purely historical nor purely mechanical-it is statistical."

'To this view of the scientifie treatment of natural phenomena Clerk-Marwell has attached a further con-

1 Clerk-Maxwell, in a review of Tait's "Thermolynamics" ("Scien. tific Pajers,' vol. ii. p. 670) : "The truth of the secoul law is thereiore a statistical, not a mathenutical, truth, for it depenuls on the fact that the bodies we leal with consist of millions of moleeules, and tlint we never can get loold of single molecules."

2 Any one who has had occasion to observe the internal work of any large iulustrial or manufaeturing organisation, will have noticed the twofolil way in which important occurrences are looked at by the commercial and the technieal chiefs. As regularity is in many instancer the eondition of success, any break of its routine is carefully eximined and eriticised. In such cases the technical man will look to the proximate meehanical causes for an explanation, whereas the commercial man, unable to reflect on the teehnical and mechanical conditions of the special case, will alway refer to his statistics of the past as a guile in juclging the innediate ditficulty thit is before him. 
sideration, which is interesting inasmuch as it shows that that which I called above the inverse method of statistics does not involve ideas identical with those which the direct method - as applied in ordinary economic and social statistics-involves. In the direct processes of statistics, which we may class under the all-case or enumerative method, we rise, from a large number of individual facts and data which are all different, to the conception of certain uniform averages, to recurring, or continuously and slowly changing, totals, such as we handle daily in sciences like meteorology, in moral, economic, and industrial statistics. The averages are nowhere represented by the individuals, and the regularity of the totals does not appear in dealing with single instances, or with such restricted numbers as come under the personal control of any of us; hence the general uselessness of statistics in handling individual cases or predicting special occurrences. But the statistical view of natural phenomena, as applied to the atomic constitution of bodies, leads us ultimately to the conception that the smallest constituents of matter, the atoms, exhibit a regularity and recurrent uniformity of structure which reminded Sir John Herschel of manufactured articles. The attempt to reduce the somewhat numerons types of these ultimate elements to purely geometrical configurations of the homogeneous elements of one substance has indeed failed, though it is being continually revived. But allowing that there exist some sixty or seventy distinct forms of matter or atomic structures, these structures seem to be alike and stable wherever we meet with 
them; our observations ranging over very large distances in space and time, from the particles inmediately before us in artificial flames to the viluations of atoms of distant stars, which must have taken millions of years to reach us. "I do not think," says Clerk-Maxwell, " that the perfect identity which we observe between different portions of the same kind of matter can be explained on the statistical principle of the stability of the averages of large numbers of quantities, each of which may differ from the mean. . . For if the molecules of some substance, such as hydrogen, were of sensibly greater mass than others, we have the means of producing a separation hetween molecnles of different masses, and in this way we should be able to produce two kinds of hydrogen, one of which would be somewhat denser than the other. As this camot be done, we must admit that the equality which we assert to exist between the molecules of hyctro-

1 'Theory of Heat,' p. 329, \&c. Cf. also many pasiages in the articles on "Ators," "Molecule," "Constitution of Bollies," \&c., reprinted in the second volume of 'Scientific l'apers'; inter aliu, p. 453: "Jiut the equality of the constants of the molecules is a fact of a very different order. It arises from a particular distribution of uratter, a collocution, to use the expression of Dr Chalmers, of things: which we have no difficulty in imagining to have been arrangel otherwise. But many of the ordinary instances of collocation are adjustments of eonstants, which are not only arbitrary in their own nature, but in which variations actually occur; and when it is pointed out that these adjustments are beneficial to living beings, and are therefore instances of benevolent design, it is replied that those variations which are not conducive to the growth and multiplication of living beings tend to their destruc. tion, and to the removal thereby of the evidence of any adjustment not beneficial. The constitution of an atom, however, is such as to render it, so far as we ean judge, independ. ent of all the dangers arising frou the struggle for existence. Plausible reasons may, no doubt, be ansigned for believing that if the cunstants had varied from atom to atom through any sensible range, the borlies formed by aggregates of sueh atoms would not have been so well fitted for the construction of the world as the bodies which actually exist. Hut as we have no experience of bodies formed of such variable atoms, this must remain a bare conjecture." 
gen applies to each individual molecule, and not merely to the average of groups of millions of molecules." And Clerk-Maxwell goes on to show how the fact that the molecules ${ }^{1}$ "all fall into a limited number of classes or species with no intermediate links . . . to connect one species with another by uniform gradation, produces that kind of speculation with which we have become so familiar under the name of theories of evolution, it being quite inapplicable to the case of the molecules. The individuals of each species ${ }^{2}$ of molecules are like tuningforks all tuned to concert pitch, or like watches regulated to solar time." 3

1 'Theory of Heat,' p. 330.

2 Ibid., p. 331.

3 'The passages quoted from ClerkMaxwell's writings, and the inferences drawn by him, were criticised by Clifford in a lecture delivered in 1874 with the title, "The First and the Last Catastrophe. A Criticism of some recent Speculations about the Duration of the Universe" (reprinted in 'Lectures and Essays,' vol. i. p. 191 sqq.) ; and, quite recently, Prof. Ward has, in his Gifford lectures, reviewed both Maxwell's and Clifford's arguments ('Naturalism and Agnosticism,' vol. i. p. 99, \&c.) As Prof. Ward says, the ideas of Herschel and ClerkMaxwell "are far more due to theological zeal than to the bare logic of the facts." It is, therefore, out of place to discuss here the philosophical consequences of the ideas of the immutability or of the gradual evolution of the ultimate elements of matter. In a former chapter (see pp. 360 sqq. and 369 , note, of this volume) I referred to the theories of the evolution of the different chemical elements as they have been put forward by various scientific authorities. The interest which attaches to the passages quoted from Clerk-Maxwell is, that in them, for the first time, an instance was given of the application of statistical methods in the domain of abstract science. The reader may gather from a perusal of the writings mentioned above, as also of the present and foregoing chapters of this history, that there is an inherent contradiction (or as kant would say, antinomy) between the logical methods and the highest objects of scientific reasoning. The methods all tend in the direction of reducing existing differences in the things and phenomena of nature to a small number of data which are easily grasped and calculated, whereas the observation of things natural forces increasingly upon us the existeuce of ever greater differences, changes, and varieties. The question presents itself, Is it likely that a process the principle of which is unification and simplification, will ever lead to a comprehension of that which increasingly reveals itself to be infinitely complex and varying? Dr Larmor has some remarks which bear on this subject 
The jugress of morlern science has, however, given 35. Sameness a great impetus to the development of statistical or and vars. enumerative methods, and notably to the graphical registration of these results, through the importance which the phenomena of variation attained in all theories of evolution, and chiefly in those based upon natural selection. Quetelet had already pointer to the study of the maxima of the possille deviations from the mean and average, as of special interest and value. Nevertheless, the centre of gravity of the aspect unfolded in the writings of (ynetelet and his followers was the idea of uniformity and average sameness. The enception of ehange and development did not fit naturally and logically into their scheme. ${ }^{1}$ It was not till after the

('Ether and Matter,' p. 28s): "The processes by which our eonception of the unifornity of Nature is obtained essentially involve averaging of effects, and lose their efticacy long before the individual moleeule is reached. Mechanical determinateness thus need not involve moleeular leterminateness; then why should either of them inrolve determination in the entirely distinct province of vital activity ? . . Every vital process may conceivably be correlated with a mechanical process, as to its progress, just to that extent to which it is possible experimentally to follow it, without lending any countenance to a theory that would place it: initiation under the eont rol of any such system of mechanical relations. In otler terms, there is room for complete mechanical eoordination of all the functions of an urganism, treated as an existing material system, without requiring any arluission that similas prineiples are suj,reme in the more remote and infinitely eomplex phenomena concerned in growth and decay of strueture."

1 A fate overtook the theories and writings of Quetelet and Buckle similar to that which I hacl oceasion to notice above in referring to the great work of A. von Humboldt. Through the influeuce of the evolu. tionist movement, prepared by Lamarck, von Baer, Speneer, and others, centring in Darwin, the statical or morphological view had in every department of science to give way to the kinetic or grenetic view. This explains why some names, once celebrated, like Humboldt and l3uckle, sank rapidly into oblivion. Grant Allen, in his somewhat one-sicled but spiriterl monograph on Darwin ("English Worthies,' 1SS8), has drawn attention to this. I give liere the striking passage, reserving for the sequel of this work the liberty to differ in detail from much in it that is too dratically expressed : "There is no dejartment of human 
36. publication of the 'Origin of Species' that the phenomena of variation-i.e., of deviation from the existing type or average-forced themselves upon naturalists and statisticians as requiring to be specially observed, described, and accounted for. Since that time a new branch of science has sprung up, unknown before even by name-the study of variation in nature. This, as we have seen in a former chapter, is one of the great and important aspects of nature brought prominently before the thinking naturalist by Darwin's and Wallace's discoveries, and strongly urged forward by the independent arguments of $\mathrm{Mr}$ Herbert Spencer. It involves the great problems of Inheritance and Adaptation. What are the facts, and what the causes of variation, of the moving and propelling principle in natural selection and evolution? The latter is a physiological problem-the former is one of statistics.

thought or hnman action which evolutionism leaves exactly where it stood before the adrent of the Darwinian conception. In nothing is this fact more conspicuously seen than in the inmmediate obsolescence (so to speak) of all the statical pre-Darwinian plilosoplies which ignored development, as soon as ever the new progressive evolutionary theories had fairly burst upon an astonished world. Dogmatic Comte was left forthwith to his little band of devoted adherents ; shadowy Hegel was relegated with a bow to the cool shades of the common-rooms of Oxford; Buckle was exploded like an inflated windbag ; even Mill himself,-magnum et venerabile nomen,-with all his mighty steam-hammer force of logical directness, was felt instinctively to be lacking in full appreci- ation of the dynamic and kinetic element in universal nature. Spencer and Hartmann, Haeckel and Clifford, had the field to themselves for the establishment of their essentially evolutionary systems. Great thinkers of the elder generation, like Bain and Lyell, felt bound to remodel their earlier conceptions by the light of the new Darwinian hypotheses. Those who failed by congenital constitution to do so, like Carlyle and Carpenter, were, philosophically speaking, left hopelessly behind and utterly extinguished. Those who only half succeeded in thus reading themselves into the new ideas, like Lewes and Max Müller, lost ground immediately before the eager onslaught of their younger competitors" (loc. cit., p. 197). 
The first who secms to have fully grasped the Darwinian problem from this point of view is $M_{1}$ Francis Galton, who in a series of papers, and notally in his 3 . well-known works on 'Hereditary Cienius' (1869) and on 'Inheritance' (18S9), made a beginning in the statistical treatment of the phenomena of Variation. The novel point of riew which was thus introdnced into natural science was perhaps somewhit obscured by its inmediate applieation to a most diflicult and mique problem, which can harlly le discussed withont inporting what may be ealled a sentimental bias. This was the question of the connection through rescent of those rare occurrences in human nature which we term genius. Mental phenomena had been almost entirely passed over" hy Darwin. The results which Mr Galton arrives at, so far as the phenomena of genius are concerned, are of minor importance compared with the general methods which he introduced or suggested for dealing with statistics of heredity. In these he combined the ideas of Quetelet with that renarkable

1 Mr Francis Galton (horn 1822, a grandson of Erotsmus Darwin) had, like his celebrated cousin, legun his career as a medical student, and then become a well. known traveller and explorer. Subsequently he levoted himself to ineteorulogy, where he drew attention to the existence ant theory of antieyclones. His first publieation, referring not to physieal but to lumun statistics, a 1 . peared in 'Maenillan's Magazine' in 1865, in the shape of two articles on "Herellitary Talent and Characler." Here he intro. duced the "theory of hereditary" genius," which was "usually seonted." He rightly elains "to be the first to treat the sulject in a statistical mamer, to arrive at numerical results, and to introduce the "law of deviation from an average' into discussions on heredity" (P'reface to "Hereditary" Genius,' published one year after Darwin's great work in which wis: put forwarl the hypothesis of l'angenesis).

2 As stated by Darwin himself. see "Animals and Plants under Domestieation' (1568), vol. ii. P. 353. 
speculation of Darwin's which he put forward at the end of his work on 'The Variation of Animals and Plants under Domestication' (1868)-the theory of organisation, in the sense of every separate atom or unit, reproduces itself. Hence ovules and pollen grains, the fertilised seed or egg as well as buds, include and consist of a multitude of germs thrown off from each separate atom of the organism." 1 These germs he calls gemmules, and admits that they agree to some extent with Buffon's organic molecules, only that neither in these nor in Spencer's physiological units does it seem clear that each "independent or autonomous" organic umit, say each cell, throws off or contributes its free gemmule (or gemmules), which is capable of reproducing a similar cell. ${ }^{2}$

The theory of Pangenesis has not found much favour with biologists. ${ }^{3} \quad$ For their purposes it would be neces-

1 Loc. cit., vol. ii. p. 358.

2 "Physiologists agree that the whole organism consists of a multitude of elemental parts, which are to a great extent independent of each other" (loc. cit., vol. ii. p. 368). Darwin then quotes Claude Berward (1866) and Virchow (1860) on the doctrine of the "autonomy" of cells: "I assume that the gem. mules in their dormant state have a mutual affinity for each other, leading to their aggregation either into buds or into the sexual elements" (p. 374). "Physiologists maintain, as we have seen, that each cell, though to a large extent dependent on others, is likewise, to a certain exteut, independent or autonomous. I go one small step farther, and assume that each cell casts off a free gemmule, which is capable of reproducing a similar cell" (p. 377). "As each unit, or group of similar units throughout the body, casts off its gemmules, and as all are contained within the smallest egg or seed, and within each spermatozoon or pollen-grain, their number and minuteness must be something inconceivable" (p. 378).

3 Grant Allen dismisses the whole speculation in the fol. lowing words: "The volume on the variation of animals and plants contained also Darwin's one solitary contribution to the pure speculative philosophy of life-his 'Provisional Hypothesis of Pangenesis,' by wlich he strove to account, on philosophical principles, 
sary to define somewhat more clearly what those units or gemmules are. This has accorlingly been attempted in several other liypotheses put forwarl about the same time or somewhat later; each thinker having elaborated, when so inelined, his own fanciful picture, following eonscionsly or mennseionsly in the line of Speneer's physiologieal units. We lave in Germany Nïgeli's micellar theory, Haeekel's kinetic hypothesis, Prof. Weismann's idioplasma theory, and Prof. Pthitger's theory of the compound organie moleenle. All these theories attempt to bring biological phenomena into closer eomection with the firmly established conceptions eurrent in physies and chemistry, where atomism and kineties have been so suceessfully used in analysing and, to a smaller extent, in jutting together the eomplex proeesses of nature. Of this I treater in former ehapters. But the hypothesis of Darwin is eapalile of another treatment. Wherever we have to deal with a large, an immense number of single elements or units, which in their totality form eertain phenomenk, there

for the general facts of physical and mental heredity. Not to mince matters, it was his one conspicuons failure, and is now pretty universally admitted as such. Let not tlie love of the biographer deceive us; Darwin was here attempting a task ultra vires. As alrearly observed, his mind, vist as it was, leaned rather to tlie concrete than to the ahstract side: lis lacked the distinctively inetuphysical and speculative twist. Strange to say, ton, his abortive theory appeased soune years later thau Herbert Sirencer's magnificent all-siderl con. ception of 'l'lysiological l'nits,' jut forth expressly to meet the self-sane difliculty. liut while Darwin's hypothesis is ruclely materialistic, Herbert Suencer's is built up by an acute and subtle analytical jerception of all the analogous faets in universal nature. It is a singular instance of a crude and exsentially uuphilosophic conception endeavour ing to replace a finished and delicate philosouhical irlea " (loc. cit., 1. 120). Sice also many references to the unfavouralile criticisms of l'angenesis in the thirr) volume of the "life of Clarles l)arwin.' 
is room for the statistical treatment. This treatment entirely ignores the definite nature of the component mits, and merely investigates those properties which depend upon aggregation in large numbers, the average or mean results, and the chances of deviations or variations. Now, if organic beings are supposed to be made up of immeasurably large numbers of units transmitted to them by inheritance, and capable of self-multiplication, they must be subject to certain regularities, to regular deriations or recurrent changes: and, under the influence of selection, be it artificial or automatic, to certain developments which can be studied without a precise knowledge of the biological, chemical, or physical nature of these units themselves, or of the mechanism of their movements. Economics, meteorology, the kinetic theory of gases, deal in this way with complex phenomena, the exact individual history of which they are quite incapable of narrating. As in the case of the kinetic theory of gases we had to translate into statistical language the phenomena of pressure, temperature, volume, available or hidden energy, dc., so in dealing statistically with biological phenomena, such as inheritance, on the basis of the theory of Pangenesis, we have to translate into statistical language such phenomena as. "types, sports of nature, stability, variation and indivichality." "The word man," as Mr Galton says, "when rightly understood, becomes a noun of multitude, because he is composed of millions, perhaps billions, of cells, each of which possesses in some sort an independent life, and is parent of other cells. He is a conscious

1 'Hereditary Genius' (1892), pp. 349, 350. 
ON THE STATSIICAL VIEW UF NATURE. 613

whole, formed hy the joint ageneies of a host of what appear to us to be uneonscions or barely eonscions elements. . . The doctrine of Pangrenesis gives excellont materials for mathematieal formulits, the eomstints of which might he supplied through averages of facts." 1 $M{ }^{\prime}$ Galton does "not see any serions diffienly in the way of mathematieians in framing a compact formula, based on the theory of Pangenesis, to express the composition of organie beings in terms of their inherited and individnal peenliarities, and to give us, after eertain comstants had been deternined, the means of foretelling the arerage distribution of eharacteristies anong a large multitude of offspring whose parentage was known." . . In short, the theory of P'ingenesis brings all the influences that bear on heredity into a form that is appropriate for the gras] of mathematieal analysis."

Evidently in the mind of Mr Galton the problem of heredity divides itself into two distinet problems: and Ireredity. he has himself labouren at the solntion of both. We may call the one the "historical" or the "mechanical" problem, the other the "statistical" problen, following the distinction whieh Maxwell drew when dealing with the kinetics of gases. The historical problem would involve a more detailed aecount of the natme of those organic mits which the theory of Pangenesis, in common with other similar theories, like those of Bufton and Niigeli, assmmes, and of the meehanism by which they unite and are transmitted. If this is impossible, or at all events highly hypothetical, the actual following up-by observation and experinent-of the phenomena of 1 'Hereditary Genius' (1892), 1. 356. 
variation in special instances would at least allow us to accumulate many interesting life-histories of families of living creatures, and might some day lead to important generalisations. Mr Galton has himself made an attempt to modify and further elaborate the hypothesis of Pangenesis; ${ }^{1}$ and $\mathrm{Mr}$ William Bateson has given us,

1 Mr Galton in 1871 advanced certain objections to the theory of Pangenesis, based upon experiments made with the transfusion of blood, and tending to show that blood cannot be the carrier of the germs or gemmules. See a paper read before the Royal Society, March 30, 1871. Darwin did not think Pangenesis had "received its deathblow, though from presenting so many vulnerable points, its life is always in jeopardy" ("Life of Darwin,' vol. iii. p. 195). In $1875 \mathrm{Mr}$ Galton published an article in the 'Contemporary Review,' vol, xxvii. p. 80, entitled "A Theory of Heredity," in which he put what may be termed the atomic theory of life and its propagation into a form in which it might serve as a working formula for statistical research. It is a mistake to look upon any such theory as a biological, mechanical, or historical explana. tion. For statistical purposes only the scantiest data need be borrowed from biology. There is, however, one very important biological conception which Galton introduced, which is not contained in Darwin's "provisional hypothesis," and which somewhat later became celebrated mainly through the writings of Prof. Weismann. This is the distinction between the germ-plasma and the body-plasma, the former preserving the continuity of life and inheritance, whereas the latter forms the character of the individual, and is probably sterile. In fact, Galton, from a purely statis- tical point of view, anticipated-as several other naturalists did, from various other aspects-the theory of the differentiation of the germinal from the personal portions or aggregates of life units in the "stirp" or sum-total of organic units of some kind which are to be found in the newly fertilised ovum. Prof. J. A. Thomson ("The Science of Life,' p. 147) gives the following succinct statement of the conception of "stirps": "First. Only some of the germs within the stirp attain development in the cells of the 'body.' It is the dominant germs which so develop. Second. The residual germs and their progeny form the sexual elements or buds. The part of the stirp developed into the 'body' is almost sterile. . . The continuity is kept up by the undeveloped residual portion. Third. The direct descent is not between body and body, but between stirp and stirp. The stirp of the child may be considered to have descended directly from a part of the stirps of each of its parents; but then the personal structure of the child is no more than an imperfect representation of his own stirp, and the personal structure of each of the parents is no more than an imperfect representation of each of their own stirps. This is a definite expression of the notion that the germinal cells of the offspring are in direct continuity with those of the parents. The antithesis between the 'soma' and the chain of sex-cells is emphasised." 
in his 'Materials for the Study of Variation,' a remarkable specimen of the historical treitment of the problen. Mr Buteson's liswrica! But the aspect we are at present specially interested in is the other one which, in the course of Mr Cialton's studies, has presented itself to him with increasing clearness, nanely, the bearing which the general laws of averages and statisties have on the facts of inheritance. Thus, in his seeond main contribution to the subject, which anpeared in $18 S 9$, twenty years after the earlier work, the statistical problem comes ont much nore clearly, and quite separated from the mechanical or the historical one. The hypothesis of Pangenesis is retained only as a general scheme which suggested "the idea though not the phrase of particulate inheritance." It was felt to be $n$ o longer necessary, for the purpose of the problem, "to embarrass ourselves with any details of theories of heredity beyond the fact that descent either was particulate or acted as if it were so." 1 And what "Particulis meant by "particulate" (i.e., "bit by bit") is illustrated in the following expressive manner:" "Many of the mortern buildings in Italy are historically known to have been built out of the pillaged structures of older days. Here we may observe a columm or a lintel serving the same purpose for a second time, and perhaps bearing an inscription that testifies to its origin; while as to the other stones, though the mason may have ehipped them here and there and altered their shape a little, few if any eame direct from the quarry." "This simile gives a rude though true idea of the exact meaning of l'articulate Inheritance-namely, that each piece of the new structure 
is derived from a corresponding piece of some older one, as a lintel was derived from a lintel, a column from a column, a piece of wall from a piece of wall. . . We appear to be severally built up out of a host of minute particles of whose nature we know nothing, any one of which may be derived from any one progenitor, but which are usually transmitted in aggregates, considerable groups being derived from the same progenitor. It would seem that while the embryo is developing itself, the particles more or less qualified for each new post wait, as it were, in competition to obtain it. Also that the particle that succeeds must owe its success partly to accident of position and partly to being better qualified than any equally well-placed competitor to gain a lodgment. Thus the step-by-step development of the embryo cannot fail to be influenced by an incalculable number of small and mostly unknown circumstances." 1

Now, wherever we have to do with a very large number of unknown elements which combine to produce a result, we are introduced to those conditions with which the theory of averages and probability deals. The curve of error discovered by Laplace and Gauss to picture the distribution of a large number of observations around the average or mean position, which is taken as the most probable or correct one, comes in as a valuable aid, not in studying the errors of natural growth, but as the graphical illustration of the deviations or rariations which cluster around what we call the normal, or with Quetelet the mean, figure. Only the interest is now attached not so much to specifying and defining the 1 'Natural Inheritance,' p. 9. 
homme moyen as to studying the leviations from this ideal standard. "How little," says Mr Galton, " is conveyed lyy the bald statement that the average income of

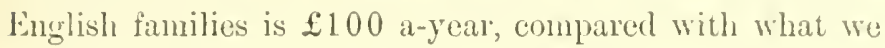
should learn if we were told how English incomes were distributed." $A$ crowel of data furnish for the astronomer the material out of which he has to chonse the most probable, the eorreet figure: a crowd of olsservations furnish for the naturalist the material from which he has to learn how nature deviates from her types and exhibits rariations which are the factors of change and development. Thus, under the hands of Mr Galton, the Law of Error becomes a Law of Distribution, and the whole machinery of the doctrine of probabilities, "exeogitated for the use of astronomers and others who are coneerned with extreme accuraey of measurement, and without the slightest idea, until the time of Quetelet, that they might be applieable to human measures, ${ }^{2}$ become the only tools by which an opening can he eut throngh the formidable thicket of difficulties that bars the path of those who pursue "the science of man.."

Hence while most people regard statisties as ilull, they become for the naturalist and student of human nature "full of beauty and interest" ${ }^{3}$ there is searcely" anything so apt to impress the imagination as the wonderful form of cosmic order expressed by the "law of frequency of error." "It would have heen personified by the Greeks, and deified if they had known of it." *

1 'Natural Inheritance,' p. 35.

2 Ibid., pl. 55, 62.

3 lbid., p. 62.

4 Ibid., p. 66. 
43. Application of theory of error.

Every mathematical instrument, when applied to a novel purpose for which it was not originally invented, "derives as much benefit in its development as it confers through being made use of." Thus $\mathrm{Mr}$ Galton's application of the theory of error to the facts of distribution and variation not only enabled him to bring method and order into such questions raised by the Darwinian theory ${ }^{l}$ as natural selection,

1 It is perhaps premature to speak with great confidence of the actual results which have been gained by this novel branch of scientific inquiry, or of the practical importance which these results may have in the future with regard to some of the great social questions. Still, in a history of thought it is of importance to note how, through Mr Galton's writings, the problem of Inheritance has acquired quite a new aspect. This finds expression in his famous so-called "law of filial regression," which goes against "the current belief that the child tends to resemble its pareuts" (p. 104). In fact, all opinions and theories which har been propounded before Galton, either popularly or scientifically, were based upon a one-sided regard to the more visible portion of the ancestry - viz., the parents; whereas, if any general theory like that of "pangenesis," or of "stirps," or of the "differentiation of the germ-plasma and the body-plasma" be made the basis of discussion, the whole ancestral tree must be considered to contribute to the formation of the characters of auy individual. In fact, we have before us not one pair, but an endless line of pairs which are, as the terms of a series, connected by the powers of the number two; and it is then easily seen, without going into refinemeuts (which, how ever, in the further elaboration of the problem, may become very important), that the first term of the series, which represents the parents, contributes only one-half of the whole, that is, each parent one quarter. It is also evident, if each parent only contributes on the average one quarter, that an exceptional bias in any direction communicated by them would be balanced in the long-run by the opposite action of the remaining ancestry, and that, coutrary to ordinary belief, inheritance would operate in the direction of bringing each individual back to the average of the whole lineage. Mr Galton first observed this law of regression to the average by definite countings with seeds and "a comparatively small number of observations of human stature" ; and he remarks that if it was only by these experiments and observations that the law of regression had been established, it could not have beeu expected that the truth of the apparent paradox would be recognised. When, however, the rule was once expressed, it was "easily shown that we ought to expect filial regression, . . . two different reasons for its occurrence" existing- "the one connected with our notions of stability of type, the other as follows : the child iuherits 
regression, leversion to ancestral types, extinction of families, effect of biats in marriage, mixtme of inheritance, latent elements, and generally to prepare the rrotund for the combined labours of the naturalist and the statistician: he was also able to put novel problens to the mathenatician.

'o understand this latter point we nust realise the

partly from his parents, partly from his ancestry. In every pol. ulation that intermaries ireely, when the genealogy of any man is traced liar backwards, his ancestry will be found to consist of such varien elements that they are inclistinguishable from a sample taken at hapliazard from the general population." As to the uathematical problem referred to, it was suburitted by MIr Galton in a detinite form to $\mathrm{Mr}$ I. D. H. 1)ieksor, whose solution is given in the appendix to "Natural In. leritance? On this solution $\mathrm{Mr}$ Galton remarks: "The problem may not be diffieult to an accomplished mathematician, but I certainly never felt such a glow of loyalty and respect towarls the sovereignty and wide sway of mathematical analysis as when his answer arrived, confiruning, by pure mathematical reasoning, my various and laborions statistical conclusions with far more minuteness than I hal dared to hope, because the data ran somewhat roughly, and I hasl to snooth them with tender eaution. . . . It is obvious from this elose accord of ealculation with observation, that the law of bror holds throughout with sufticient precision to be of real service, and that the various results of $m y$ statisties are not easual and disconnected rleterminations, lut strictly interdependent" (p. 202). Another pastage indieating low much the inferences from the law of regression run contrary to popular opinions on inheritance is the following: "The law of Regression tells heavily against the full hereditary transmission of any gift. Only in few out of many children would be likely to differ from mediocrity so widely as their mill-parent, and still fewer would ditfer as widely as the nore excep. tional of the two jarents. The more bountifully the parent is gitted by nature, the wore rare will be his good fortune if he begets a son who is as richly endowed as himself, and still more $s 0$ if he las a son who is endowed yet more largely. But the law is evenhanded ; it levies an equal succession - tax on the transmisisis of badness as of gooduess. If it dircourages the extravagant loppes of a gifted parent that his children will inherit all his powers, it no less discountenances extravigant fears that they will inherit all his weakness and disense" (1. 106). I'rof. Karl Pearsou ("The ('ranmar" of seience,' 2nd el., p. 479) says of the law of ancestral inheritance : "If Darwinism be the true view of evolution-i.c., if we are to deseribe evolution l, natural selection combined with heredity - then the law which gives us lefinitely and concisely the type of the off: spring in terms of the ancestral peculiarilies, is at once the foumdation-stone of biology and the basis upon which heredity hecomes an exact branch of seience." 
44. great difference which exists between dealing with a Difference in
tolivingand
vast number of lifeless and of living units. This lifeless units. difference becomes evident if we consider that in the former case the number of mits is unalterable and the units are indestructible; in the latter the elements or units are subject to enormous increase and corresponding destruction, generally with a preponderance of the first. In the kinetic theory of gases we have to consider, in every finite system, the conservation or persistence of mass and motion, the two units we deal with. To these two properties of an immensely large crowd we have to reduce the various phenomena of pressure, temperature, volume, available or unavailable energy. In the vast crowd of gemmules which build up a new organism or regenerate an existing one, we have to deal with a continual influx or creation of new units and a continual extinction and ejection of old or dead ones. Without venturing on any theory as to how this state of things has come abont, we may see that the mathematics and statistics of such crowds must be different from those referring to stable, lifeless assemblages. The twofold task arises of formulating the new problems and solving them. To the extent that this is possible we shall be able to deal mathematically with the great problem of variability; and for the practical application of these mathematical formule we shall have to collect long series of facts and data of measurements-the material which has to be statistically arranged and sifted, and which is to confirm the conclusions and test the results which calculation has brought ont. 
Mr Galton found ready, or instituted himself, vallons comntings of lange numbers, which formerl valuable material for his mathematical schemes, anrl which confirmed them in at smprising degree. Some very elaborate series of measmenents of the varying dinensions of individual members in latge crowds of animals were published by Prot. Weldon, whose monograth on C'rabs will always remain an historical docmment. ${ }^{1}$ It was noticed about the sane time that the attempt to bring the neasured deviations from the arerage into a symmetrical arrangement on the sides of more or less was impossible, and the fuct had to be realised and mathematically expressed that special influences tending towards ehange on the intermixing of different varieties produced an asymunetrical distribution or frequency: ${ }^{2}$ in fact, nature works with loaded dice, prodncing a bias in certain directions: this is the farour which, aecording to Darwin, Wallace, and Lanarek's ideas, must meet the better fitted inclividuals and exact from them a smaller tribute in the inevitable process of destruction and removal.

We owe it to I'rof. Karl Pearson to have first grasped clearly and comprehensively the mathenatical problem Prof. Pearson. The natlematiinvolved, and to have solved it in a mammer useful for cal problem.

1 See the "Proceerlings of the Royal Society' since 1890, notabiy vol. Ivii., 1895, p. 360 sq ?.

2 "An asyminetrical frequency curve nay arise from two quite distinct classes of causes. In the lirst place the inaterial measured may be heterogeneous, and may consist of a mixture of two or inore homogeneous materials. ..
The second class of frequency curves arises in the case of homogeneous material when the tendency to deviation on one sille of the mean is unequal to the tend. ency to deviation on the other sicle" (Karl Pearson, "On the Mathematical "Theory of Wrolution," 'Truns. Roy. Soc.,' 1895, 1. 314). 


\section{biological research. ${ }^{1}$ He has thus put into the hands of} naturalists an instrument wherewith to describe graphically the observed facts of variation and other allied

1 A consirlerable literature has already accumulated in this novel branch of exact inquiry. The complete list of it is given in a pamplilet by Georg Duncker, entitled 'Die Methode der Variationsstatistik' (Leipzig, 1899). From this list (p. 60) it will be seen that one of the earliest workers in the field of biological statistics was the botanist F. Ludwig, whose 'Abschnitte der Mathematischen Botanik' have appeared in various periodicals abroad since the year 1883. The philosopher, however, to whom we are most indebted for the mathematical foundations of the whole theory, is, as noted above, Prof. Karl Pearson, whose "Contributions to the Mathematical Theory of Evolution" have been appearing since the year 1893 in the Trans. of the Royal Society. Very helpful abstracts of these contributions, covering a large field of matlematical theory, and containing elaborate discussions of many of the terms recently introduced into biological science, such as regression, reversion, inheritance, panmixia, selection, \&c., will be found in the Proceedings of the Royal Society (1893, onwards). Also in his collected essays, "The Chances of Death and other Studies in Evolution' (2 vols., 1897); and, lastly, in the later chapters of the second edition of his 'Grammar of Science' (1890). From the latter it will be seen what far-reachiug inferences may eventually be drawn from the quautitative treatment aud mathematical discussion of biological data; notably the results so far gained "lead us to consider variation as a permanent attribute of living forms, which ean hardly have been substantially modified since the beginnings of life. In the same manner we find heredity intimately associated with variation in the individual, and not differing very substantially as we pass from one character to a second, or from one to another form of life. We conclude that variation and inheritance rather precede than follow evolution; they are, at present, one fundamental mystery of the vital unit" (p. 502). Prof. Pearson, whose training was that of a mathematician and a lawyer, approached the problems of biology from the exact point of view, and it is interesting to see how, in many ways, he comes to results similar to those arrived at by oue of the other great representatives of modern biological research, $\mathrm{Mr} \mathrm{Wm}$. Batesoll. See his "Materials for the Study of Variation, treated with especial regard to the discontinuity in the Origin of Species' (1894). If I understand him rightly, his researches have led him to the con. clusion that variation cannot be the work of natural selection, since he has given "such eridence as to certain selected forms of variations" as to afford "a presumption that the discontinuity of which species is an expression has its origin, not in the environment, nor in any phenomenon of adaptation, but in the intrinsic nature of organisms themselves, manifested in the original discontinuity of variations" (p. 567). This "disposes, once and for all, of the attempt to interpret all perfection and definiteness of form as the work of selection. . . . It suggests, in brief, that the discontinuity of species results from the discontinu- 
phenomena, such as eorrelation, heredity, regression and pammixia, and he has shown how to andyse these graphical tracings so as to indicate the several possible elements out of which they are eompoumled, representing separate agencies which are at work in nature. The mathematical inventions of Fourier had similarly enabled physieists to analyse the complicated periodicity of tidal curves into their elements, and, mnder the hands of Olnn and Helmholtz, to resolve the harmonies of musie.

We have here arrived at the last stage of the development of the statistical view of natme. It has been varionsly judged by biologists according to the speeial views they take of their problems, and also according

ity of variation" (p. 560s). Mr liate. son expects great assistance from the statistical methods. "There is," he says, "no eommon shell or butterfly of whose variations some. thing would not be learnt, were some huudreds of the same species collected from a few places and statistically examined in respeet of some varying charieter. Any we can take part in this class of work, though few do" (n. 5T.1). Notwithstanding the general resem. blance noted above between the ideas of Mi. Bateson and of Prof. Pearson, they ditter so much in detail as to be led to confess that they do not understand one anotlıer's languages. Cf. W. liate. son, "Heredily, Differentiation, and other Conceptions of biology," 'Roy. Sioc. Proe., vol. lxix. I'l. 193-205; K. P'earson, "On the Funclanental Conceptions of Biology," "Binmetrika,' vol. i. pl. 320. 34. Prof. l'earsm's view is that, for the working out of the theory of evolution, "l,iolorical eonceptions can be aceurately detined, and so defined measured with quantita. tive exactness" (loc. rit., l). 32t). Mr bateson, on the other hand, regrurls them as to some extent out of the reach of mathematieal definition and measurement. "T)iseontinuous variation "' in Mr l3azeson's special sense-by" which we may perhaps understand great as distinguished from small l,ut num. erous deviations from the average - Prof. l'earson regards ass "statistically megligible for the pupose of vital statistics" ( 1$) .333,334)$. He, in tact, liolds elo-er to hitrwinism as understood by 1) awin, who never looked with much favour on Huxley's view, for ex. ample, tlat "sports," as clistinguished from the sum of small liflerences in inclivituals, might furdish an apprecialle part of the materials for natural selection. Mr Bateson's view found favour with Huxley, as may be observen in the 'Life aml Letters.' On the novelty and ralue of l'yot. Pearson's methols see also the Adilress by l'rof. Wellon to the Zoological Section of the British Association ii) 1898 . 
to the degree in which they appreciate and are able to grasp mathematical methods. The subject is still under discussion, and will belong to the History of Thought of a coming age. It is enough to have indicated the latest lines of reasoning which our century has marked out, and to notice how they form a new and remarkable instance of the growth and diffusion of the exact or mathematical spirit in a department of research hitherto almost untonched by it, prepared though it has been for such treatment by one among whose great endowments a grasp of mathematical reasoning hardly formed a distinctive feature. In former chapters I have had occasion to show how Charles Darwin introduced into the science of nature two novel points of view - the genetic view and the process of judicial sifting of evidence. We may now add that he has indirectly, more than directly, furthered quite as much the statistical view of natural phenomena through which we have learned to find and trace law and order in great realms of phenomena and events usually supposed to be governed by what is termed blind chance. The study of this blind chance in theory and practice is one of the greatest scientific performances of the nimeteenth century.

46.

Statistical knowledge one-sided.
But whilst acknowledging the great importance which the statistical treatment of phenomena has acquired in our age, and the value of the statistical view of many large departments of natural processes which escape almost every other mode of dealing with them, we must not forget that it is essentially one-sided.

Clerk-Maxwell has suggestively opposed it alike to the mechanical and the historical views, of which the former 
tries to deseribe the general meehanism under which, the latter the individual steps and incidents by which, special events or phenomena proceed and are characterised. Earlier ehapters of this narrative attenpted to give atu aecomt of the former, whilst the essentially historical treatment belongs to another portion of the work. The word history has generally been reserved for reeords which deal with those erents in which human consciousness has played a large, if not an overwhelming, part, and has been able to assist the observer by its own aceounts and representations. What should we know of human life and human interests without them, and how helpless-in spite of minutest observation-do we still appear to le in understanding the life of the brute and mute ereation, even of the donestic animals, on daily friends and eompanions? But if history, as opposed to statisties, really seems only possible where the living voiee or the surviving narrative of those who liave departed helps us to a true understanding of its incidents and its meaning, it also imposes upon us the task of sifting its value and trustworthiness critically. Mathematies, logic, and statisties may do something to exelude the actually impossible or the highly improbable from a vast mass of material; but more delieate eriteria are required in dealing with the acemulated testimony of bygone ages. With an merring instinet of what, in addition to mathenatical measurements, may be required in order to accomplish this task, the nineteenth century las not only nursed the seientifie spirit and eultivated its methods, but with equal diligence and originality those other methods which lie at the foumdation of VOL. II. 
47. all recent philosophical thought - the methods of methods. criticism.

And yet, before taking leave of science and entering on a comprehensive appreciation of the workings of the Critical Spirit with which all our thought seems to be permeated, I owe to my readers the attempt to answer one remaining question. If it be true, as the foregoing narrative has abundantly insisted, that through the increasing application of mathematical methods of measuring and calculating, our thought has become truly scientific and our knowledge accurate and useful for describing and predicting phenomena, as also for manifold practical applications, we may be curious to know whether the refined instrument, mathematical thought itself, has been subject to such change and development as has been undergone by the various branches of science to which it has been applied. In fact, we have to ask the question, How has mathe48. matical thought itself fared in the course of the ninement of exact re. search. teenth century? The concluding chapter of the present volume will try to give a reply to this question. 


\section{CHAP'TER XIII.}

ON TIE DEVELOPMENT OF MATHEMATICAL THOLGHT DULIXG TIE NINETEENTH CENTUIY.

Ir venturing upon the last and most abstract portion of the great domain of Scientific Thought of the century, it thought. may be well to remind the reader that it is not a history of science but a history of thought that I am writing. When dealing in the foregoing chapters with manifold discoveries, drawn promiscuously from the various natural sciences, I have done so only to show how the scientifie mind has, in the eomse of the period, come to regard the things of nature from different points of view, and to think and reason on them differently. Such changes have frequently been brought about by the discovery of novel facts, but this alone has not generally sufficed to mark also a change in the manner of reasoning on and thinking about them. The increase in the number of natmral species, of the chemical elements or of the smaller planets, has not necessarily marle us think differently about these things in themselves: the theory and point of view nnay ehange withont any change in the object towards which they are directed, 
for they mark more the attitude of the beholder than the things which he regards. It is true that a very small addition to our actual knowledge of facts, like the sudden appearance of some characteristic feature in a landscape, may sometimes entirely alter the whole aspect, induce us to abandon our accustomed views, and call up suddenly an unforeseen train of ideas; in such a ease, perhaps, this insignificant discovery becomes historically interesting, although it is mainly by the altered trains of thought which it has evoked that it has become important to us.

2. The difference of scientific knowledge and scientific between thonght is thus owing to the two factors which are involved - the facts of science or nature on the one side and the scientifically thinking mind on the other. Now it might appear as if this difference vanished when we approach the abstract science of mathematics, or at least that of number; for in numbering and counting we have really only to do with a process of thought, and it would seem as if the science of number were itself the science of thought, or at least a portion of it. In fact, the question arises, Is there any difference between mathematical science and mathematical thought? Some considerations might induce us to think that there is not. On the other side, I shall try to show in this chapter that there is, and that the development of mathematics during our period has brought this out very clearly and prominently.

3. prejudices regarding mathematics.
There is an opinion current among many thinking persons who have not occupied themselves with mathematical science, though they may be very efficient in 
calculating and measming, that there is really nothing new in mathematics, that two and two always make four, that the smm of the angles in a triangle alwalys make two right angles, and that all progress in mathematies is merely a question of intrieacy, a never-enting process of inereased complication by which you can puzzle even the eleverest calculator. To them the history of mathematics would he something analogous to the history of games like whist or chess, the resources and complications of which seem to be inexhanstible. So they think ${ }^{1}$ that the intricaeies and refinements of elementary and higher mathematies will supply endless material for training the ninds of schoolboys or trying the ingenuity

1 "Some people have been fouml to regard all mathematics, after the tith proposition of Euclid, as a sort of morlid secretion, to be compared only with the pearl sair to be grenerated in the discated oyster, or, as I have heard it described, 'une excroissance maladive de l"esprit humain.' (others find its justification, its ruison d'être, in its being either the torch-bearer lealing the way, or the handmaiden loolding up the train of Physical Selence; and at very elever writer in is recent magazine article expresses his donlyts whether it is, in itseli, a nore serious pursuit, or more worthy of interesting an in. tellectual human being, than the study of chess problems or Chinese puzzles. What is it to un, they say, if the three angles of a triangle are equal to two right angles, or if every even number is, or may be, the sum of two primes, or if every equation of an odd degree nust have a real root? How dull, stale, flit, and unprofitable are such and such like ammouncements! Much more interesting to read an account of a marriage in high life, or the details of an international boatrace. But this is like judging of architecture from being shown some bricks and mortar, or even a quarried stone of a public building, or of frinting from the colours mixed on the palette, or of music by listening to the thin and screech sounds produced by a bow prasied haphazitld over the strings of a violin. The world of ideas which it discloses or illuminates, the contemplation of divine beauty and order whicls it induces, the harmonious connexion of its parts, the infinite hierarehy and absolute evidence of the rutlis with which it is concerned, lhese, and such like, are the surest grounds of the title of mathematics to human regard, and would remain unimpeached and unimpiaised were the plan of the universe unrolled like a map at our feet, and the mind of milu qualified to take in the whole schene of creation at a glance" (Jrof. J. J. Nylvester, Address hefore 13rit. Assoc., ree 'Reprost,' 1869, p. 7). 


\section{of senate-house examiners and examinees, withont for a} moment considering the question whether mathematical thought as distinguished from mathematical problems is capable of and has undergone any radical and fundamental change or development.

Use of mathematies.
Closely allied with this is the further question as to the use of mathematics. Two extreme views have always existed on this point. ${ }^{1}$ To some, mathematics is only a measuring and calculating instrument, ${ }^{2}$ and their interest

1 Of the two greatest mathematiciaus of modern times, Newton and Gauss, the former can be considered as a representative of the first, the latter of the second class; neither of them was exclusively so, and Newton's inventions in the pure science of mathematics were probably equal to Gauss's work in applied mathematics. Newton's reluctance to publish the method of fluxions inrented and used by him may perhaps be attributed to the fact that he was not satisfied with the logical foundations of the calculus; and Gauss is known to have abandoned his electro-dynamic speculations, as he could not find a satisfactory physical basis (see supra, p. 67). Others who were not troubled by similar logical or practical scruples stepped in and did the work, to the great benefit of scientific progress. Newton's greatest work, the 'Principia,' laid the foundation of mathematical physics; Gauss's greatest work, the 'Disquisitiones Arithmetice,' that of higher arithmetic as distinguished from algebra. Both works, written in the synthetic style of the ancients, are difficult, if not deterrent, in their form, neither of them leading the reader by easy steps to the results. It took twenty or more years before either of these works received due recognicion; neither found favour at once before that great tribunal of mathematical thought, the Paris Academy of Sciences. Newton's early reputation was established by other researches and inventions, notably in optics; Gauss became known through his theoretical rediscovery of Ceres, the first of the minor planets (see above, vol. i. p. 182). The country of Newton is still preeminent for its culture of mathematical physies, that of Gauss for the most abstract work in mathematics. Not to speak of living authorities, I need only mention Stokes and Clerk-Maxwell on the one side, Grassmamn, Weierstrass, and Georg Cantor on the other.

2 Huxley said: "Mathematics may be compared to a mill of exquisite workmanship which grinds you stuff of any degree of fineness: but, nevertheless, what you get out depends on what you put in ; and as the grandest mill in the world will not extract wheat.flour from peas-cods, so pages of formule will not get a definite result out of loose data"; and on another occasion he said that mathematics "is that study which knows nothing of observation, nothing of induction, nothing of experiment, nothing of causation." The former statement was endorsed by Lord Kelvin ('Pop. Lectures,' \&c., vol. ii. p. 
ceases as soon as discussions arise which cannot luenefit those who use the instrument for the purpuses of application in mechanics, astronomy, physics, statistics, and other sciences. It the other extreme we have those who are animated exclusively by the love of jure science. To them pure mathematics, with the theory of numbers ${ }^{1}$ at the head, is the one real and genuine science, and the applications have only an interest in so far as they contain or suggest problems in pure mathematics. 'They are mainly ocempiced with cxamining and strengthening the foundations of mathematical reasoning and purifying its methods, inventing rigorons proofs, and testing the validity and range of applicability of current conceptions. We may say that the former are led by juactical, the latter hy philosophical, interests, and these latter nay be either logical or ontological,"

102); the latter was energetieally repudiated by sylvester in his famous Arldress to the first section of the Britisl! Assoe. at lixeter. (1869, 'Report,' \&e., 1. 1. \&c.)

1 Gauss eonsidered inathenaties to be "the Queen of the sciences, and arithmetic the Queen of Mithematics. She frequently coudeseends to do service for istronomy and other natural sciences, but to her belongs, under all cireumstanees, the foremost place" (see 'Gauss zum Gerlichtniss,' by Sartorius von Waltershausen, Leiprig, 1856, p. 79). Cayley's presidential Address to the British Asiociation, 1883, has been frerpently quoted: "Nathematies connect themnelves on one side with common life and the physical seiences; on the other side with philosophy in regard to our notions of suace and time and the questions which have arisen as to the universality and neeessity of the trutlis of mathematics. and the foundation of our knowledge of them. I would remirk here that the connection (if it exists) of arithmetic and algebra with the notion of time is far less obvious: than that of geonetry with the notion of space" ("Mathematical Papers,' vol. xi. p. 130). In addition to founding higher arithnetie, Gauss oceupied himself with the foundations of geosuetry, and, as he expected much from the development of the theory of numbers, so he placed "great hopes on the cultisation of the gormetrin situs, in which he saw large uncleveloped tracts which could not be confuered by the existing ealculus " (Sirtorius, loc. cit., p'. 85).

"T'o this might be arlderl the psychologieal interest which at. taches to mathematical concep. tions. The late l'rof. P'aul Du lois - Reyurond occupied himself 


\section{inasmuch as number and form are considered to be}

5.

Twofold interest in mathematics.

\section{the highest categories of human thought, or likewise as} the ultimate elements of all reality. These two interests existed already in antiquity, ${ }^{1}$ as the word "geometry"

much with the question. See the following works: 'Die Allgemeine Functionentheorie,' part i., Tiib. ingen, 1882 ; 'Ueber die Grundlagen der Erkenntuiss in den exacten Wissenschaften,' Tiibingen, 1590 ; and his paper "Ueber die Paradoxien des Infiuitïrcalciils" ('Mathematische Annalen,' vol. ix. p. 149). In addition to the two main interests which attach to mathematical research, and which I distinguish as the practical and the philosophical, a third point of view has sprung up in modern times which can be called the purely logical. It proposes to treat any special derelopment of mathematical research with the aid of a definite, logically con. nected complex of ideas, and not to be satisfied to solve definite problems with the help of any methods which may casually present themselves, however ingenious they may be. In this way the great geometriciau, Jacob Steiner, e.g., refused the assistance of ana. lysis in the solution of geometrical problems, ennceiving geometry as a complete organism which should solve its problems by its own means. This view has been much strengthened by the development in modern times of the theory of Groups ; a group of operations being.defined as a sequence of such operations as always lead back again to operations of the same kind. Mathematical rigorists in this sense would look upon the use of mixed methods or operations not belonging to the same group with that kind of disfavour with which we should regard an essayist who could not express his ideas in pure English, but was obliged to import foreign words and expressions. It is interesting to see that the country which has offended most by the importation of foreign words - namely, Germany-is that in which this purism in mathematical taste has found the most definite expression. (See, inter aliu, Prof. Friedrich Engel's Inaugural Lecture, "Der Geschmack in der neueren Mathematik," Leipzig, 1890, as also Prof. F. Klein's suggestive tract, 'Vergleichende Betrachtungen ïber neuere Geometrische Forschungen,' Erlangen, 1872.)

1 The literature of this subject is considerable. I confine myself to two works. The late eminent mathematician, Hermann Hankel, of whom more in the sequel of this chapter, besides showing much originality in the higher branches of the science, took great interest in its philosophical foundations and historical beginnings. In 1870 he published a small but highly interesting volume, 'Zur Geschichte der Mathematik in Alter. thum und Mittelalter' (Leipzig, Teubner). We have, besides, the great work of Prof. Moritz Cantor, 'Vorlesungen iuber Geschichte der Mathematik,' in three large voluwes (Leipzig, Teubner). It brings the history down to 1758. Referring to the two interests which led to mathematical in restigations, Hankel says (p. 88): "From the moment that Greek philosophers begin to attract our attention through their mathematical researches, the aspect which mathematics present 
and the well-known references to mathematical irleas in the schools of Pythagoras and l'lato indicate. An ancient fragnent ${ }^{1}$ which enumerates briefly the (irecian mathenaticians, says of P'ythagoras, "He changed the oecupation with this branch of knowledge into a real science, inasmuch as he contemplated its foundation from a higher point of view, and investigated the theorems less materially and more intellectually;" 2 and of I'lato it says that "He filled his writings with mathematieal discussions, showing everywhere how much of geometry attaches itself to philosophy." 3

'This twofold connection of mathematical with other' pursuits has, after the lapse of many centuries, come prominently forward again in the nineteenth century. We have aheady had to record a powerful stimulus to mathematical thought in almost every thapter in which we dealt with the fruitful ideas which governed scientific work, and we have now no less to draw attention to the philosophical treatment which has been bestowed mpon the foundations of seience and the inroml of mathenati-

changes radically. Whilst among the earlier civilised nations we only mect with routine and practice, with empirical rules which served practical purposes in an isolated manner, the Greeian mind on the other side recognised, from the first moment when it became aeguainted with this matter, that it contained sonething which trm. scended all those practieal ends, but which was worthy of special attention, and which could be expresised in a general form, being, in fact, an object of seience. This is the high merit of the Greek mathematicims; nor need one fear that this merit should be diminished by admitting that they borrowed the new material from the ancient Egyptian civilisation."

1 'l'he fraguent referred to is preserved hy Proclus. and is given in iull in ('intor's work (vol. i. p. 12t sr\%.) He ealls it an ancient catalogue of mathematicians. It is generally attributed to Eulemus of Kliodes, who belonged to the peripatetic sehool of philosopliy, and was the author of several historical treatises on geometry and astrunomy (C'antor, vol. i. p. 108).

'Cintor, vol. i. 1. 137.

It Ibil., p. 213. 
cal into philosophical thought; ${ }^{1}$ so much so that this closing chapter on the development of mathematical thought forms a fitting link with the next great department of our subject - the Philosophy of the Century.

6.

Origin of mathematics.

We are told that mathematics among the Greeks had its origin in the Geometry invented by the ancient Egyptians for practical surveying purposes. The first mathematical problems arose in the practice of mensuration. Modern mathematical thought received in an analogous manner its greatest stimulus through the Uranometry of Kepler, Newton, and Laplace: through the mechanics and the survey of the heavens new methods for solving astronomical problems were invented in the seventeenth and eighteenth centuries, and the nineteenth century can be said to have attempted to perform towards this new body of doctrine the same task that Euclid, three hundred years before the Christian era, performed towards the then existing mathematics. As Proclus tells us, "putting together the elements, arranging much from Eudoxus, furnishing much from Theretetus, he, moreover, subjected to rigorous proofs what had been negligently demonstrated by his predecessors." 2 What one man, so far as we know, did for the Grecian science, a number of great thinkers in

1 Thus, for instance, the recent investigations and theories of the "manifold," as they have been set fortl by Prof. Georg Cantor of Halle, constitute, as it were, a new chapter in mathematical science, whereas they were formerly a subject merely of philosophical interest. See a remark to this effect by B. Kerry at the end of his very interesting article on
Cantor's doctrine in the 9th vol. of Avenarius's 'Zeitschrift für wissenschaftliche Philosophie' (1885), p. 231, where he refers to Kant's comparison of philosophy to a Hecuba "tot generis natisque potens."

2 Quoted by Cantor, vol. i. p. 247. See also Hankel, loc. cit., p. 381 sqq. 
our century, among whom I omly mention (iauss, Ciunchy, and Weierstrass, attempted to (l) for the new science which was created dming the two preceding centuries. As Prof. Klein says, "We are living in it critical period, similar to that of Euclicl." 1

I See "The Evanston Colloguium, Lectures on Mathematics delivered in August and september 18.43, 'by Felix Klein, notably 1,eeture vi. In this lecture Prof, Klein explains his view (to which he had griven utterance in his address before the Congress of Mathematics at Chicago: 'Papers published by the American Mathematical Society,' vol. i. 1'. 133. New York, IS96) on the relation of pure mathematics to applied science. This view is basert upon the distinction between what he calls the "naive and the refinerl intuitiou." . . " It is the latter that we find in Euclid; he carefully develoys his system on the basis of well-formulated axioms, is fully conscious of the necessity of exact 1roofs, elearly distinguishes between the commensurable and the incommensurable, and so forth. . . . The naive intuition, on the other hand, was especially active during the period of the genesis of the differential and integral calculus. Thus we see that Newton assumes without hesitatiou the existence, in every case, of a velocity in a mov. ing point, without troubling himself with the inguiry whether there might not be continuous functions having no lerivative."

In the upinion of Prof. Klein "the root of the matter lies in the fact that the naive intuition is not exact, while the refined intuition is not properly intuition at a!l, but arises through the logical development from axions considered as perfectly exact."

In the sequel Prof. Klein shows that the nave intuition iuports into the elementary conceptions elements which are left out in the purely lugical development, and that this again learls to couclusions which are not capable of being verified by intuition, no mental inage being pussible. 'Thus, for instance, the abstract geometry of Lobateheriby and liemann led Beltrami to the logical conception of the preutosphere of which we cannot form any mental image. Similar view, tu thuse of Prof. Klein have been latterly expressed by H. Poincaré in his suggestive volume 'la science et "llypothère' (l'aris, 1893). He there says (p. 90): ". . liexpérience joue un role indi-pensible dans la genise de la géométric; mais ce serait une erreur d'en conclure que la géométrie est une science experimentale, mêtue en partie. . . La géométrie ne serait que l'étude de: mouvements des solides: mais elle ne s'uceupe pás en réalité des solides naturels, elle a pour objet cortain: solides idéaux, absolument invari. ables, qui n'en sont qu'une image simplifice et bien lointaine. . . . C e qui est l'objet de la géométrie c'est l'étude d'un 'groupe' particulier: mais le concejt général de grouje préexiste dans notre esurit au moins en puissance. . . Seulement, yarmi tous les groupes possibles, il faut choisir celui qui sera pour ainsi dire l'étalon auquel nous rapporterons les phénomines naturels." This distinetion between the mathematics of intuition and the mathenatics of logie liats also been forced upon us from quite a diflerent quirter. The complica- 
7.

It is right to place the name of Gauss at the head, for his investigations regarding several fundamental and critical questions in arithmetic and geometry date from the last years of the eighteenth century, long before Cauchy's influence made itself felt. This is now abundantly clear through the publication of Gauss's works, and from much of his correspondence with personal friends, notably with the astronomer Bessel. We can now understand how those who knew him regarded him as a kind of mathematical oracle to whom "nothing in theory existed that he had not looked at from all sides," I and who anticipated in his own mind the development which mathematical thought was to take for a long time after him. And yet it was not to him primarily that the great change was due which came over mathematical reasoning during the first half of the century. Gauss was not a great teacher. In fact, there existed in the first quarter of the period only one great training school in advanced mathematics, and that was Paris. Cauchy. There it was that Augustin Cauchy-first as lecturer,

tion of modern mathematics and the refinement of the moderu theories have brought about the desire "to create an abridged system of wathematics adapted to the needs of the applied sciences, without passing through the whole realm of abstract mathematics" (Klein, loc. cit., p. 48). In this country Prof. Perry has made a beginning by publishing his wellknown work, Calculus for Engineers,' which has been welcomed by Prof. Klein in Germany, and which has led to an extensive correspondence in the pages of 'Nature'; it being recognised by many that a quicker road must be made from the elements to the higher applications of mathematics in the natural sciences than the present school system, beginning with Euclid, admits of. The separation of the logical and prac. tical treatment of any science, as likewise the indepeudent development in Germany of the polytechnic school alongside of the university, has, however, its dangers, as is recognised by Prof. Klein ('Chicago Mathematical Papers,' p. 136).

1 See Bessel's letter to Gauss, 27 th December 1810, in 'Briefwechsel zwischen G. and B., Leipzig, 1880 , p. 132. 
then as professor-exerted his great influence in the famous ferole Polytechnique, in the sorbonme, in the Collége de France. In contrast with (ianss-who was self-contained, proud, and mapproachable, whose tinished and perfect mathematical tracts were, even to those who worshipped him, an abonination," owing to their unintelligible and novel enunciation, who hated lecturing -Canchy possessed the enthusiasm and patience of the teacher, ${ }^{3}$ spent hours with his pupils, and published his leetures on the foundations of the Calculus for the benefit of the rising mathematieal generation. Thus he has the merit of having creater a new school of mathematical thought-not only in France but also ahroad, where the greatest intellects, such as that of Abel, expressed themselves indebted to him for haring pointed out the only right road of progress. It will be useful to define somewhat more closely wherein this new sehool differed from that preceding it, which culminated in the great names of Euler, Lagrange, and Laplace.

The great development of modern as eompared with ancient nathematies may be stated as eonsisting in the in-

1 See Talison, "La Vie et les Travaux du Baron Cituchy,' Paris, 186s, vol. i. p. $60 \mathrm{sq7}$.

2 "()n disait que sa manirre dexposer était mauvai-e, ou eneore qu'il fitiait comme le renard, qui eftace avec sa queue les traces de ses pas sur le sable. Crelle dit, selon Atiel, que tout ce (qu'écrit fiauss n'est qu'alomination (Griuel), car c'est si obscur qu'il est presque impossible d'y rion compreutre" (Bjerkues, 'Niels Heurik Abel,' Trad. francaise, Paris, 1885, p. 92). 3 "C'est que Cauchy alliait su génie des liuler, les Lagrange, des Laplace, des Giauss, des Jucobi, l'anour de l'enseignement porté jusqu'ì l'enthousiatsue, une rare twité, une simplicite, une chalenr de crur qu'il a conservées jusqu'i la fin de sa vie" (Combes, quuted by Valson, vol. i. p. i3).

" Siee Bjerknes, 'N. H. Abel,']" 48 sq7. ; p. 300. Caucliy's 'C'ours ('Aualyse' appreared in 1S21: the 'Résumé des lerons sur le ealcul infinitésinal,' to which Aluel reiers iir a letter to Holmboe, lated 1526 , appeared in 182:3. 
troduction of algebra or general arithmetic, in the application of this to geometry and dynamies, and in the invention of the infinitesimal methods, through which the rigorous theorems of the older geometricians which referred to the simpler figures-such as straight lines, circles, spheres, cones, \&c.-became applicable to the infinite variety of curves and surfaces in whieh the objects and phenomena of nature present themselves to our olsservation. Logically speaking, it was a grand process of generalisation, based mostly on inference and induction, sometimes

9.

Process of generalisa. tion. merely on intuition. ${ }^{1}$ Such a process of generalisation has a twofold effect on the progress of science.

The first and more prominent result was the greatly increased power of dealing with special problems which the generalised method affords, and the largely increased field of research which it opened out. We may say that the century which followed the inventions of Descartes, Newton, and Leibniz, was mainly occupied in exploring the new field which had been disclosed, in formulating and solving the numberless problems which presented themselves on all sides; also, where complete and rigorous solutions seemed unattainable, in inventing methods of approximation which were useful for practical purposes. In this direction so much had to be done, so mueh work lay ready to hand, that the second and apparently less practical effect of the new generalisations reeeded for a time into the background. We may term

] "On se reportait inconsciemment au modèle qui nous est fourni par les fonctions considérées en mécauique et on rejetait tout ce qui s'écartait de ce modèle ; on n'était pas guidé par une définition claire et rigoureuse, mais par une sorte d'intuition et d'obscur in. stinct" (Poincaré, "L'weuvre math. de Weierstrass," "Acta Mathema. tica,' vol. xxii. p. 4). 
this seeond and more hidden line of research the logical side of the new development. It corresponds to the work which Enclid performed in ancient geonetry, the framing of clear definitions and of unambignous axioms; proceeding from these by rigorous reasoning to the theorems of the new seience. $\quad$ But the translation of eneonetrical and mechanical eneeptions into those of generalised arithmetic or algebra brought with it a logical problem of quite a novel kind which has given to modem mathematics quite a new aspect. This new problem is the retranslation of algebraical-i.e., of general-formule into geometrical conceptions - the geometrical construction of algebraical expressions. It is the inverse operation of the former. In this inversion of any given operation lies the soul and principle of all mathematical progress, both in theory and in application. ${ }^{2}$ The invention of

1 Referring specially to the definition of "it "function" or mathenatical dependence, a conception introducerl by buler, but not rigurously defined by him, II. Poincaré kays, loc. cit.: "Au commencement du siècle, l'itée de fonction était une uotion is la fois trop restreinte et trop) vague. . . Cette défnition, il fallait la clonner: cal l'analyve ne pouvait qu"is ce prix aequérir la pariaite rigueur." In itsgenerality this takk was performer in the lnst third of the century by Weierstrass, but the neces-ity of this criticism of the formulie in. vented by morlern inathematies dates from the aplearance of Cauchy's 'Mémoire sur lí thérrie des intégrales definien' of 1814 , which legendre reported on in this sense, but which was nut publisher till $182 \%$.
2 The operations referres to are generally of two kiuls: first, there is the operation of tranulating geometrical relations, intuitively given, ints algrebraieal relations; and, secondly, the operation of extending algetwaical relations by going forward or backwarl in the order of numbers, usually given by indices. In each che the new relations arrived at require to be interputed, and this interpretation leads nearly always to an extension of knowledge or to novel conceptions. A vimule example of the first kind presents itself in the gennetrical construction of the higher powers of ynuntity. Having agreenl to define by a the length of a line, by $u^{2}$ an area, what is the meaning of $a^{3} a^{4}$... an? Can auy geometrienl meaning be attached to these symbols? An example of the
10. Inverse operations. 


\section{the seventeenth century afforded two grand occasions} for such progress, and the creation through it of novel mathematical ideas. The translation of geometrical con-

second class is the following : having defined the symbols

$$
\frac{d y}{d x}, \frac{d^{2} y}{d x^{2}} \cdots \frac{d^{n} y}{d x^{n}},
$$

an operation suggests itself in the inverse order, the indices or their reciprocals (inversions) being taken negatively. Can any meaning be attached to these latter symbols? Further, if the operation denoted by going on from one of these symbols to the next is known and feasible, how can tlie inverse operation be carried out? In the first class of problems we proceed from an intuitively given order to a purely logical order, and have in the sequel to go back from the purely logical order to an intuitive order of ideas. In the second case, having followed a certain logical order, we desire to know what the inversion of this order will produce and how it can be carried out. The view that the direct and indirect processes of thought form the basis of all mathematical reasoning, and an alternation of the two the principle of progress, has been for the first time consistently expounded by Hermainn Hankel in lis 'Theorie der Com. plexen 'Zahlen-Systeme,' Leipzig, 1867. But it had already heen insisted on by George Peacock in his "Report," \&c., contained in the 3rd vol. of the "leports of the Brit. Assoc.,' 1833, where he says (p. 223): "There are two distinct processes in Algebra, the direct and the inverse, presenting generally very different degrees of difficulty. In the first case, we proceed from defined operations, and by various processes of demonstrative reasoning we arrive at results which are general in form though particular in value, and which are subsequently generalised in value likewise; in the second, we commence from the general result, and we are either required to discover from its form and composition some equivalent result, or, if defiued operations have produced it, to discover the primitive quantity from which those operations have commenced. Of all these processes we have already given examples, and nearly the whole business of analysis will consist in their discussion and development, under the infinitely varied forms in which they will present themselves."

It is extraordinary how little in. fluence this very interesting, com. prehensive, and up-to-date report on Continental mathematics, including the works of Gauss, Cauchy, and Abel, seems to have had on the development of English mathematics. But the latter have through an iudependent movement -viz., the invention of the Calculus of Operations - led on to the radical change which has taken place in recent mathematical thouglit. This change, which can be explained by saying that the science of Magnitude must be preceded by the doctrine of Forms or Relations, and that the science of Magnitude is only a special applicatiou of the science of Forms, was indepeudently prepared by Hermann Grassmann, of whom Hankel says (loc. cit., p. 16): "The idea of a doctrine of Forms which should precede a doctrine of Magnitude, and of considering the latter from the point of view of the former, . . . remained of little value for the development 
ceptions into algebraical langmage suggested the inverse operation of interpreting algebraical terms hy geometrical conceptions, and led to an enomons extension of gerometrieal knowledge. ${ }^{1}$ Further, the infinitesinal nethorls through which curves and cmved surfaces were conceiver as being made up of an infinite number of infinitesinally small, straight-i.e., measurable-lines, led to the inverse problem; given any algebraical operations which obtain only in infinitesinally small dimensions-i.e, at the limit-how do they sum ш) to finite quantities and

of mathematics, so long as it was only used to prove theorems which besides being already known, were sufticiently though merely empirically proved. lt was $H$. Grassmann who took up this idea for the tirst time in a truly philosoplical spirit and treaterl it from a comprehensive point of view," Hankel also refer: to Peacock as well as to De Morgan, wlose writings, however, he was insufficiently acfuainter] with (ibid., p. 15). In quite recent times Mr A. N. Whitehead has conceived "mathematics in the widest signification to be the development of all types of formal. necessury, deductive reasoning," and has given a first instalment of this development in his "Treatise on Universal Algebra' (rol. i., Cambridge, 1\$.\$S). Shee the preface to this work (1). 6, 7).

1 A good example of the use of the altermating employment of the intuitive (inductive) and the log. ical (decluetive) methods is to be found in the modern doctrine of curves. The invention of Descartes, by which a curve was represented by an equation, lerl to the intro. duction of the conception of the "degree" or "orler" of a curve and its greometrical equivalent ;

VOL, II. whereas the geometrical conception of the tangent to a eurve led to the distinction of eurves according to their "class," which was not immediately evident from the equation of the curve but which lest to other analytical methors of representation where the tangential properties of curves became more evident. A third methool of studying curves was introduced by Plicker (1832), who started from "the singularities" which eurves present, defined them, and established his wellknown equations. A further study of these "singularities" led to the notion of the "genus" or "deficiency" (Cayley) of a curve. The grarlual development of these and further ideas relating to curves is concisely given in an article by Cayley on "Curve" in the 6th vol. of the 'Eneyeloyserlia Britannica,' reprinted in Ciryley's collected papers, vol. xi. This artiele furnishes also a good example of the historical treatment of a purely nathematical subject by showing, not so much the progress of mathematieal knowledge of special things, as the development of the manner in which such things are looked at -i.c., of mathematical thought. 
figures? What are the properties of these finite figures as inferred from the properties of their infinitesimally small parts? The infinitesimal methods evidently corresponcled with the atomistic view of natural objects, according to which the great variety of observable phenomena, the endlessly complicated properties of natural objects, could be reduced to a small number of conceivable properties and relations of their smallest parts, and could then be made intelligible and calculable.

The general reader who is unacquainted with the numberless problems and intricate operations of higher mathematics can scarcely realise how in these few words lie really hidden the great questions of all the modern sciences of number and measurement; the trained mathematical student will recognise in a process of inversion not only the rationale of such extensive doctrines as the integral calculus, the calculus of variations, the doctrine of series, the methods of approximation and interpolation, but also the application of analysis to geometry, the theory of curves of higher order, the solution of equations, \&c. All these various branches were diligently cultivated by the great mathematicians of the eighteenth century, mostly, however, with the object of solving definite problems which were suggested by the applied sciences, ${ }^{1}$

I In general it ean be stated that the impetus given to mathematical research by the problems set by the applied sciences has been im. niea-urably greater than that which can be traced to the abstract treatment of auy purely mathematical subject. We have a good example of this at the beginning of the nineteenth century in the great work of Laplace as summed up, for the most part, in the 'Mécanique Celeste' and the 'Théorie des Probabilités,' which contain the beginnings and the development of a great number of purely mathematical theories suggested by problems in astronomy, physics, and statistics. On the other side we have at the same time the socalled "Combinational School" in Germany, whose members and 
notably astronomy-not infrequently also as objects of mere curiosity without any pratical furpose whatever. In the latter part of the eighteenth century the need was felt of putting the new science into a comprehensive system. The attempts to to this-notalsy the great text-books of Leonhard Euler in Ciermany and of Lacroix in Franee-revealed how uneertain were the foundations and how paradoxieal some of the apparent conelusions of the reasoning which, in the hands of the great inventors and masters, hal leit to sneh remarkable results.

Is in other eases which we dealt with in former chapters of this work, so also in the present instance we may find a guide through the labyrinth of modern mathematical thonght in the terms of language around which cluster the more recent doctrines. Two terms present themselves which were rare or altogether absent in older treatises: these terms are the "complex quantity" and tho 11. teruns in. dicative of modern the "continuous." To these we can adel a thirl term which we meet with on every page of the writings of mathematieians since Newton and Leibniz, but which has only very reeently been subjected to careful analysis and rigorous definition,- - the term "infinite." Aecordingly we may say that the range of mathematical thought during

their lalours are almost forgotten, although in their claborate treat. ises there are to be found many formula which hat to be redis. covered when, fifty years later, the general theory of forms ind substitution bowan to le systematically develngerl, ind proved (1) be an indispensable instrument in dealing with many advanced mathenatical problems. Siee in the latter subject an articte by Major Macllahon on "Combinational Antysis" "l'roe, lomblom Yath. Soc. ' vol. xxviii. 1. 5, sc.), as also the chapters on this subject and on "Deteruminants" in the first vol. of the "Encyelopridie de'" Mathematischen Wissenschaften' (Leiprig, 1898). Also, inter ulin, a note l,y J. Mur in 'Nature,' vol. lxvii., 1903, 1'.512. 
the last hundred years has grown in proportion to the methodical study and stricter definition of the notions of the complex quantity, of the continuous, and of the infinite. And these conceptions indicate three important logical developments which characterise modern mathematical

12. reasoning. The conception of the complex quantity or Complex quantities. of our system of counting and measuring, retaining or modifying, the fundamental rules on which it is based.

13. The conception of the continuous and its opposite, the The continuous. discontinuous, introduces us to the difference of numbers and quantity, numbers forming a discontinuous series, whilst we conceive all natural changes to be made up of gradual-i.e., of imperceptibly small - changes, called by Newton fluxions. The discussion, therefore, of the continuous leads us ultimately to the question how our system of counting can be made useful for dealing with continuously variable quantities - the processes of nature. 14. The conception of the infinite underlies not only the infinitesimal methods properly so called, but also all the methods of approximation by which-in the absence of rigorous methods-mathematical, notably astronomical, calculations are carried out.

Problems involving one or more of these conceptions presented themselves in large number to the analysts of the eighteenth century: there were notably two great doctrines in which they continually occurthe general solution of equations, ${ }^{1}$ and the theory of

1 As it may not be immediately evident how the ideas of continuity have to do with the general solution of equations, I refer to the first publication by Gauss, in 1799 , containing a proof of the fundamental theorem of algebra, and its republication fifty years later (see Gauss, 
infinite series. 'The solution of an exuation being called finding its roots, it was for a long time assumed that every equation has as many roots as are indieated by its degree. I proof of this fundamental theorem of algebra was repeatedly attempted, but was only completed by Gauss in three remarkable memoirs, which prove to us how much inportance he attached to rigorous proofs and to solid gromelwork of science. The second great doctrine in which the eonceptions of the continuous and the intinite presenter thenselves was the expansion of mathematical expressions into series. In anithnetic, decimal frietions ${ }^{1}$ taken to any number of terms were quite familiar; the infinite series presented itself as a generalisation of this deviee. I very general formula

'Werke, vol. iii. yp. 1 and 71). A very good summary of this prowi is given by Hankel ('Complexe /alilem-systeme, j. 87 ). A purely algebraical clemonstration of the same theorem, not involving consiclerations of continuity and approximations, was also given by Gauss in the year 1816 , and reproducerl by others, including George Peacock, in lis 'Report,' quoterl above, 1. 29\%. Mankel (loc. cit., 1\%. 97) shows to what extent Gauss's proot supplemented the similar proofs given ly others before and after.

1 Decimal fructions seem to have been introsluced in the sixteenth century. Sieries of other numbers, formed not according to the lecinal but to the ilyadic, iluodecimal, or other systems, were known to the ancients, and continued in uses to the middle ages. The dyadic rystem was much faroured by Leilmiz. It was also known that every rational fraction could be developed into a periorlical decimal fraction. Prominent in the recommendation of the use of decimal fractions was the celebrated simon stevin, who, in a tract eutitled 'La Disme' attached to his 'Arithuétique' (1590, translated into Hnglish, 1608), deseribed the decinal $x y$ stem as "enseignant facilement expécier par nombres entiers sans rompus tous comples se reneontrans aux affines des hommes." Prof. Cantor ("iresch. der Hath.,' vol. ii. 1. 616) says, " 11 e know to-day that this pre. diction could really he ventured on-that indeed decimal fraction. jerform what Sitevin promised." At the end of his traet he cloubt: the suecdy adoution of this device, comnecting with it the suggestion of the universal atoption of the decimal syitem. The lisst account of the gratual introduction of decimal fractions is still to be found in Feorge l'eaeock's 'History of Arithmetic' ('Hncy. Metrop., 'vol. i. 1'. 1:39, \&e.) 
of this kind was given by Brook Taylor, and somewhat modified by Maclaurin. It embraced all then known and many new series, and was employed without hesitation by Euler and other great analysts. In the beginning of the century, Poisson, Gauss, and Abel drew attention to the necessity of investigating systematically what is termed the convergency ${ }^{1}$ of a series. As a specimen of this kind of research, Gauss published, in 1812, an investigation of a series of very great generality and importance. $^{2}$ We can say that through these two isolated memoirs of Gauss, the first of the three on equations, published in 1799 , and the memoir on the series of 1812 , a new and more rigorous treatment of the infinite and the continuous as mathematical conceptions was introduced into analysis, and that in both he showed the necessity of extending the system of numbering and measuring by the conception of the complex quantity. But it cannot be maintained that Gauss succeeded in impressing the new line of thought upon the science of

1 A rery good account of the gradual erolution of the idea of the convergency of a series will be found in Dr R. Reiff': 'Geschichte der unendlichen Reihen' (Tibiugen, 1899, p. 118, \&c.) Also in the preface to Joseph Bertrand's 'Traité de Calcul Différentiel' (Paris, 1864. p. xxix, \&c.) According to the latter Leibniz seems to have been the first to demand definite rules for the convergency of Infinite Series, for lie wrote to Hermann in 1705 as follows: "Je ne demande pas que l'on trouve la valeur d'une série quel. conque sous forme finie; un tel probleme surpa-serait les forces des géomètres. Je roudrais seulement que l'on trouxât moyen de décider si la raleur exprimée par une série est possible, c'est-ì-dire convergente, et cela sans connaitre l'origine de la série. Il est néces. saire, pour qu'une série indéfinie représente une quantité finie, que l'ou puisse démontrer sa conrergence, et que l'on s'assure qu'en la prolongeant suffisamment l'erreur devieut aussi petite que l'on reut." In spite of this, Leibniz, through his treatment of the series of Grandi, 1-1+1-1, kc., the sum of which he declared to be $\frac{1}{2}$, seems to have exerted a baneful influence on his successors, including Euler (See Reiff, loc. cit., pp. 118, 158).

2 The nemoir on the Hspergeometrical series. 
mathematies in general. 'This was done ahout fifteen ir' twenty years after Gauss had begun to pullish his isolated memoirs, in a comprehensive treatment of the subjeet ly Cauchy, who, before 1820 , delivered lectures on Inalysis at the Ecole Polytechnique and in other colleges, and commenced their pullieation in 1821. In Analysis. this eourse of lectures the discussion of the notions of the infinite, of the continuous, of the convergence of series, and of the extension of our conception of quantity beyond the ordinary or real quantities of algebra, is put in the foreground, and the illicit habit of using the generalisations of algebra without delining the eonclitions of their validity severely criticised. ${ }^{1}$ It is also evident, from the extensive notes which C'anchy added to the "cours" of 1821 , that he felt the necessity of a revision of the fundamental notions of algehra. The publicution of 1821 was followed by others on the Calenlus, and it is through these treatises mainly that a new spinit was infused into general mathematical literature, first in

I The earlient habours of Cauchy were geometrical, and he evidently acquired through them an insight into the contrast between the rigour of the oliter geometrical and the losseness of the molern algebraical wethods. In this re. garrl he says: "J'ai cherché à leur lonner toute la rigueur qu'on exige en géometrie, le manière it ne janais reeourir aux raisons tirées de Ja gónéralité de l'algèbre. L.es raisms de cutte expéce, quoinge assez communcuent mulires, sur. tout dans le passago des séries convergentes aux sérits divergentes, et les quantités réelles aux expressions inaginaires ne peuvent itre consiclérés, ce line semble, que comme des inductions popes it fare pressentir prelyue fois la vérité, mais qui s'accordent peu avec l'cxitctituile si vantée des seiences mathénatiques. On doit mêne observer qu'elles tendent is fitire attribuer aux formules al. gébriques une étendue indéfinie, tandis que, dans la realité, la plupart de ces formules subsistent milyuement sous eertaines condi. tions, et jour cortaines valeurs des yuantitis qu'elles renlerment. Iin déterminant ces conditions et ten valeurs, et en fixmt llune nuniè précise le scus des notations dont je me sers, je fitis disparaitre toute incertitucle" ('Cour's il'Analyse,' 1821, Introd., p. ii). 
France, somewhat later also in England and Germany. In the latter country, the highly original writings of Abel, and the independent labours of Jacobi, opened out an entirely new branch of higher mathematics, beginning with the discovery of the property of double periodicity of certain functions. ${ }^{1}$ This extensive and fruitful prorince of analysis for a time retarded the revision and extension of the gromdwork of mathematical reasoning which Canchy had begun, and upon which Gauss evidently desired to make the extension of higher mathematics proceed. ${ }^{2}$

1 Before the discovery of the functions with a double period, functions with one period were known: the circular and exponential functions - the former possessing a real, the latter an imaginary, period. The elliptic functions turned out to "share simultaneously the properties of the circular functions and exponential functions, and whilst the former were periodical only for real, the latter only for imaginary, values of the argument, the elliptic functions possessed both kinds of periodicity." This great step became clear when it occurred to Abel and Jacobi independently to form functions by inversion of Legrendre's elliptic integral of the first kind. The two fundamental principles involved in this new departure were thus the process of inversion aud the use of the imaginary, as a necessary complement to the real, scale of numbers. The share which belongs independently to Abel and Jacobi has been clearly determined since the publication of the correspondence of Jacobi with Legendre during the years 1827-32 (reprinted in Jacobi's 'Gesammelte Werke,' ed. Borchardt, vol. i., Berlin, 1881), and of the complete documents referring to Abel, which are now accessible in the memorial volume published in 1902 . A very lucid account is contained in a pampllet by Prof. Königsberger, entitled 'Zur Geschichte der Theorie der Elliptischen Transcendenten in den Jahren 1826-29' (Leipzig, 1879).

2 Of the four great mathematicians who for sixty years did the principal work in connection with elliptic functions - viz., Legendre (1752-1833), Gauss (1777-1855), Abel (1802-29), and Jacobi (180451), each oceupied an independent position with regard to the subject, - suggested originally by Euler, and important for the practical applications which it promised. Legendre luring forty years, from 1786 onward, worked almost alone: he brought the theory of elliptic integrals, which had occurred originally in connection with the computation of an are of the ellipse, into a system, and to a point beyond which the then existing methods seemed to promise no further ad. vance. This advance was, however, secured by the labours of Jacobi through the introduction of the novel principles referred to in the last note. Two years before Jacobi's publication commenced, Abel had already approached the subject from an entirely different and much more 
That such a revision had hecome necessary was seen, 17. slowly if in many quarters, lut it disl not becone gener- of fund ally recognised till late in the century, when thinkiors of

general point of view. "Abel," As Monsieur L. Sylow says ("Mémorial des études d'Abel,' [" 14), "('tait avant tout algébriste. Il at dit luimême que lit théorie des épuations étaitson sujet favori, ce quid'ailleurs apparaît clairement dians ses couvres. Dans ses travaux sur les fonctions elliptiques, le traitement des diverses équations algélriques dont cette théorie abonde est mis fortement en évilence, et dans le prenier de ces travaux, la résolution le ces équations est même indliquée comme ćtant le sujet principal. Qui plus est, la théorie des épuations était entre ses mains linstrument le plus éfficace. (ie fut ainsi sans aucun doute la résolution de l'śpuation de division des fonctions elliptiques qui tout d'abord le couduisit à la théorie de la transformation. Elle joue eucore un rôle capitale dans sa démonstration du théorène dit théorème d'Abel, et clans les recherches générales sur les in tégrales des rliflér. entielles algébriques qui se trouvent dans son demier ménoire le 'Précis d'une Théorie des fonctions elliptiques." " But whilst Abel certainly took a much more general view than either hegendre or Jacobi, both of whom canne to a kind of cleadlock on the roals they harl chosen (Jacoli, when lie atteinpted to extend the theory of the periodicity of functions), it is now quite clear that Gauss viewed the whole subject almost thirty years before Abel and Jacobi entered the field from a still more general point of view. Alrearly, in 1798, when he was only twenty-one, he must lave recognised the necessity of enlarging and defining the fundamental conceptions of algebra and of functionality or math. ematical dependence; and it is very likely that the magnitude of the undertaking, for which his astron. omical libours left him no time, debarred him from publishing the important results which lie had already attained, and which covered to a great extent the field cultivated in the meantime by Abel and Jacobi, leaving only the celebrated theorem of the former (referring to the algebraical comparison of the higher non-algebraieal functions) and the discovery of a new function on the jart of Jaeobi (his Theta function) as the two great additions which we owe to them in this line of research (see lionigrberger, loc. rit., p. 104). In this recognition of the funda. mental change which mathematical science demanded, and its bearing upon these special problems here referrel to, Gauss must have for a long time stood alone; for his great rival Ciluchy, to whom we are mainly inclebted for taking the first steps in this direction, did not for many years apply his iunlauental and novel ideas to the theory of elliptic functions, which up to the year 1841, when Hermite entered the fielı, were almost exclusively cultivated by German and Scandinavian writers (see li. L. lillis, "Report on the recent Progress of Aualysis," Brit. Assoc., 18t6; reprinted in "Mathematical and other Writings,' p. 311). Nor could it otherwise be explained how Cauchy could keep the manuscript of Abel's great memoir without ever wecupying himself with it, and thus delay its publication for fifteen years after it liad been presented to the Acarlemy. (See the above-mentioned correspoudence between Legendre and Jacobi, 1829; aleo Sylow, [1. $31)$. 
the highest rank, who for some time had lived apart in the secluded regions of sublime analysis, descended again into the region of elementary science, both pure and applied, where they speedily remodelled the entire mode of teaching. England possessed very early a writer of great eminence who represented this tendency, and whose merits were only partially recognised in his dayAugustus de Morgan.

18.

Extension of conception

It will now be necessary to explain more definitely of number.

what is meant by the extension of our conception of number and quantity through the introduction of complex numbers or complex quantities. This extension first forced itself on analysts in the theory of equations, then in the algebraical treatment of trigonometrical quantities - i.e., in the measurement of angles, or, as it is now called, of direction in geometry. The first extension of the conception of number lay in the introduction of negative numbers. These admitted of comparatively easy representation arithmetically by counting backward as well as forward from a given datum; practically in the conception of negative possessions, such as debts, geometrically by the two opposite directions of any line in space. In algebra, where the simple operations on quantities are usually preserved in the result and not lost in the simple numerical value of the result as in arithmetic, compound quantities were looked upon as generated by the processes of addition, resulting in the binomial (of which the polynomial was an easy extension), and further by the multiplication with each other of different binomials or polynomials, through which process expressions of higher order or 
degree were arrived at. The forward or direct process was casy enough, though even here assmuptions or arbitrary rules were inchuded which escaped notice for a long time: lout the real labour of the analysts only began with the inverse problem-viz, given any compound quantity, similar in structure to those lirectly produced by multiplication of himomials, to find the factors or binomials out of which it can he componnded. Now it was found that as in the arithnetieal process of division, the invention of fractional quantities; ats in that of extraction of roots, the irrational quantities had to be introdnced: so in the analysis of compound algel,raical expressions into binomial faetors, a new quantity or algebraical conception presented itself. It was easily seen that this analysis could be carried ont in every case only by the introduction of a new mit, algebraically expressed by the square root of the negative unity. There was no difficulty in algebraically indicating the new quantity as we indicate fractions and irrational quantities; the difliculty lay in its interpretation as a number. Since the time of I)escartes geometrical representations of algebraical formule hat become the custom, and it was therefore natural when once the new, or so-called inaginary, unit was formally admitted, that a geometrical meaning should be attached to it.

Out of the scattered heginnings of these researches two definite problems grahlually crystallised: the one, metrical and a purely formal or mechanical one - riz, the geothe logicat metrical representation of the extended conception of quantity, of the complex quantity; the other, a logical 
or philosophical one-viz., the clearer definition of the assumptions or principles which underlie arithmetical and algebraical reasoning. And if algebraical, then also geometrical reasoning. Both problems seem to have presented themselves to the youthful mind of Gauss, as is evident from his correspondence with Bessel ${ }^{1}$ and Schumacher, and from his direct influence on Bolyai, ${ }^{2}$ Möbius, and Von Standt, perhaps also indirectly on Lobatchersky. ${ }^{3}$ It does not, however, appear as if he

1 See especially the letters of Gauss to Bessel, dated November and December 1811 and May 1812 ('Briefwechsel,' Leipzig, 1880, p. 151 sqq.)

2 Bolyai, the elder (1775-1856), was a student friend of Gauss in the years 1797 to 1799 , and kept up a correspondence with him dur. ing half a century. This correspondence has now been published by F. Schmidt and P.Stiickel, Leipzig, 1899 , with a supplement containing some information about this extraordinary man. His son, Johann Bolyai (1802-60), is the author of the celebrated "Appendix, scientiam spatii absolute veram exhibens," which was attached to his father's 'Tentamen, juventutenn ... in elementa matheseos puræ . . . introducendi,' 1832. The tract seems to have been written in 1823. A trauslation, with introduction, has been published by Dr G. Bruce Halsted ('Neomonic Series,' rol. iii. 4th ed., Austin, Texas, 1896). When the elder Bolyai sent to Gauss in the year 1831 to 1832 a copy of his son's tract and of his own work on Geometry, Gauss expressed great surprise at the contents of the former. (See his letter of March 6, 1832.) His remarks that the jounger Bolyai had anticipated some of his own idleas on the subject, remind one of a similar remark which he made, May 30 , 1828 , to Schumacher with reference to Abel's "Memoir on Elliptic Functions" in vol. ii. of Crelle's 'Journal' (see Gauss, 'Werke,' vol. iii. p. 495). In both cases he felt himself relieved from the necessity of publishing his own results, though, so far as those referring to the foundations of geometry are concerned, it does not appear that his ideas had arrived at that state of maturity which the publication of his posthumous papers has proved to liare been attained in his treatment of the higher fumctions. Indeed little or nothing of prime importance has been found among his papers referring to the principles of geometry; and he stated to Bolyai that though he had intended to commit his views to paper, so that they should not be lost, he had not intended to publish anything during his lifetime.

3 It is doubtful whether Gauss's speculations had any influence on the younger Bolyai's theory, and still more so as regards Lobatchersky, whose first tract appeared in the 'Kazan Messenyer,' 1829 to 1830 , but dates back probably to 1826. Inasmuch, however, as the younger Bolyai must have become acquainted 
hal arriverl at any tinality in his speculations, and, beyond oceasional hints which have only sulsequently beeome intelligible, the love of finish exhibited in all his published writings prevented hin from giving to the world the suggestive illeas which evillently formed the gromulwork of his mathematical labours. There is no doubt that-like Goethe in a very different sphereGauss anticipated individually the developments in the sphere of mathematieal thought down to the end of the eentury. The interpretation of the complex quantity had been given by Wessel, linéc, and Argand $^{1}$ in the early years of the century; but it remained umoticed till it received the sanction of Ganss in a celelorated menoir referring to the theory of munhers, and until in

through his father with the speculations of the youthful Gaus:, and as Lobatehevsky was a pupil of another student friend of Gauss in the person of Prof. Bartels, it is, not unlikely that the interest which these thinkers took in the subject can be originally traeeri to the same source. (See Dr Halsted's anddress on Lobatehersky, 'Neomonic Series,' vol. i., 1894). A complete bibliography of the earlier papers, referring to the so-called "nonEuclidean" literature down to 1878 , is given by Dr Halsted in the first two vols. of the "Amerjetil Journal of slathematics': the most recent publications are those of the Hon. B. A. W. Rus.ell in his work, 'The f'oundations of Geometry' (1897) and his excellent article on "Non-Wuelidean Geometry" in the 2Sth vol. of the 'Eney. Brit.' See also lijein's lithographed lectures on 'Nicht-Fuklidische Geometrie,' Göttingeu, 1893.

1 The first somewhat exhaustive historical statement as to the geumetrieal representation of the complex or inaginary quantity was given by Hankel in the above. inentioned work (see above, note, p. 645), p. 82. He there says, after discussing the elaims of others, notably of Gauss, - that Argand in his 'Essai' of the year 1806 (reedited by Hoilel, 1874) "had so fully treated of the whole theory that later nothing essentially new was added, and that, except a publication of still earlier date were found, Argand must be consillered the true founder of the representation of eomplex quantities in the plaue." Such an ear.]ier publication has indeer been met with in a tract by Caspar Wesiel, which was presented to the Danish Aeademy in 1797 , and publisherl in 1799. Having been overlooked, like Argand's 'Essai,' it has now been republished at. Copenlagen, 1897, with the title 'Esssai sur la représentation de la direetion' (see 'Encyk. Math. Wissenschafteu,' vol. i. p. 155). 
this country the labours of De Morgan and of Sir William Rowan Hamilton gave the matter a further and very important extension. ${ }^{1}$ It was also in this country that the second problem, the critical examination of the principles which underlie the process of legitimate generalisation of algebra, received distinct attention. To George Peacock, and to the school of algebraists which followed him, is due the merit of having brought out clearly the three fundamental laws of symbolical reasoning now generally admitted in text-books on the subjectthe associative, distributive, and commutative principles. That these principles were to a great extent conventional, or empirically adopted from ordinary arithmetic, and in consequence not necessarily indispensable for a consistent system of symbolical reasoning, has been generally ad20. mitted ever since Sir William Rowan Hamilton, after Quaternions. ten years of labour, succeeded in establishing a new calculus - the method of quaternions, in which the commutative principle of multiplication is dropped. This

\begin{abstract}
1 Far more important than the suggestions or artifices mentioned in the foregoing note, and which since the time of Argand and Gauss have been variously mortified, is the conception that our common numbers do not form a complete system without the addition of the imaginary unit, but that with the introduction of a second unit "numbers form a universe complete in itself, such that, starting in it, we are never led out of it. There may very well be, and perhaps are, numbers in a more general sense of the term; but in order to have to do with such numbers (if any) we must start with them" (Cayley in art. "Equation," 'Ency. Brit.'; 'Coll.
\end{abstract}

Works,' vol. xi. p. 503). There seems little doubt that this conception was first clearly established in the mind of Gauss, and that none of the contemporary writers can be shown to have had a similarly clear insight. Since this has become generally recognisedand we owe this recognition probubly to the independent labours of Grassmann and Riemann-the discussion of the whole subject has been raised to a much higher level, as may be seen by comparing the Report of Peacock, quoted above, with the discussion of Hankel (loc. cit.), and still more with the exhaustive article by Prof. E. Study in vol. i., 'Encyk. Math. Wiss,' ple. 147-184. 
ealeulus was shown to be of special nse in viplescing the relations of spherical trigronometry. 'Jwo ter'us expressing definite notions special to geometry, lyy which science has been enriched and practical application greatly simplified, are an ontcone of this line of research. 'These are the terms "vector", to express the nution of direeted magnitude-i.e., of direction and magnitule combined as distingruished from magnitude and position alone; and the notion of an "operator" which elanges direction and magnitude as an ordinary multiplier changes magnitude only. It was shown by Argand and others that the

1 These two notions, which lave their origin in the writings of Hamilton on the one side and the Calculus of Operations on the other, belong to this country aml to a period during which mathematical researches were carried on in a fray. mentary manner, and much out of contact with the contemporary mathematics of the Continent. Buth the Calculus of Quaternions: of Hanilton and the C'alculus of Operations were looked upon for it long lime as cmriosities (as was alsu the Barycentric Caleulus of Mobju. in Germany). Gradually, lowever, the valuable ideas which were contained in then became recognised as mucl frour the practical as from the theoretical point of view. In the former interest the application of Vector Amalysis or the Algebra of Directed Quantities received a great inpetus when the need was felt of havine an "algebra of "plyysieal quantitie.." This found expression in the writings of clerk. Ilaxwell. (See lis "Treatiwe on Electricity and liagnetimn,' vol. i. p. 5, 2nd ed., as also his pajer on "l'he Hathematical Classifiertion of Plyysical Quantities," 18il. "Coll. I'apers,' vol. ii. 1. 257.) In the prattical application of electrical theories theve notions hive since become indispensable, and the subject has re. ceived increasing attention, notably in Anerica, which holds a foremost platee in the development of electrical seience and its application. Mathematicians of the first order, such as J. Willard Gibus, have published text-books on the subject, whilst other electricians of eninence, such as Mr Otiver Heavisicle, lave elaborated special forms of the Directional Calculus to serve their purposes. In Dynamics the 1)ublin School, representert after the death of Ifamilton by sir liobert s. Ball (in his 'Theory of Serews,' 1876), has had an important influence in the introduction of novel and more appropriate methods which hitve graclually permeated the greneral treatment of the subject. Whilst there is no roubt that for a long time the Calculus of Quateruions was the only methodical elaboration of these novel and useiul ideits, it was overlooked that simultaneously and quite independently H. Grass. mann of stettin (see above, vol. $i$. 1. 213) had worked out a much more comprehensive and lundanenta! calenlus, of which the metlusel of quateruions and all the diflerent forms of Vector Analysis can be 
arithmetic based upon two units instead of one-i.e., the arithmetic of couples or complex quantities-could be completely and consistently represented by choosing as axes whereon the separate units were counted, the two perpendicular axes of Cartesian geometry. An attempt to extend this geometrical representation into space led Hamilton to the invention of his method, Gauss having very early satisfied himself that within the limits of ordinary algebra no further extension was necessary or possible.

The examination into fundamental principles was not limited in the mind of Gauss to those of algebra: he early applied himself likewise to those of geometry and of dynamics. The great French mathematicians, such

21. as Legendre and Lagrange, were also occupied with such Foundations
of geometry. speculations. They luave been carried on all through the century, but have only towards the end of the period been brought into connection and shown to be of importance for the general progress of mathematics. The secluded, and for a long time unappreciated, labours of isolated but highly original thinkers have accordingly

considered as merely special instances. This has now been abundantly proved through the writings of mathematicians in all countries, among whom I will only mention Hankel and Dr V. Schlegel in Ger. many, Clifford, Prof. Henrici, and latterly Mr Whitehead in England, Prof. Peano in Italy, and M. Burali Forti in France. See on the whole subject, on the fate of Grassmann and of his great work, Y. Schlegel, 'Die Grassmann'sche Ausdehnungslehre,' Leipzig, 1896 ; also, by the same author, a short biography of Grassmann (Leipzig, Brockhaus, 1878). A complete edition of
Grassmann's works is being published by Teubner. 'Those who are interested in seeing how the notions underlying the directional calculus are gradually becoming clarified, and the terminology and notation settled, may read with profit the controversy carried on in the pages of 'Nature,' vols. xlvii. and xlviii., between Prof. Macfarlane, Willard Gibbs, Mr O. Heaviside, Mr A. I'Aulay, and $\mathrm{Dr}$ Knott; also Dr Larmor's review of Hayward's 'Algebra of Coplanar Vectors' (vol. xlvii. p. 266), and Sir R. S. Ball's reference to the 'Ausdehnungslehre' of Grassmann (rol. xlviii. p. 391, 1893). 
received tardy reeognition. Such speculations can be carried on either as fiscinating exercises of mere ingenuity, or for practical jurposes to improve the refined instruments of mathematical calculation, or in the philosophieal interest of arriving at the fundanental processes of human thought and intuition. Many persons think that only the second of these thee in-

1 Already Euler lial remarked on the differentinterests that prompted mathematieal research. Referring to the writings of Count Fagnano, he says in the introduction to the first of his memoins on Elliptic Integrals (1761, quoted by Brill \& Nöther' in 'Bericht der Deutsehen Mathematiker-Verenigung,' vol. iii. p. 206): "If one looks at mathenatical speculations from the point of view of utility, they can be divided into two elasses: first, those which are of advantage to ordinary life and other sciences, and the value of which is accordingly neasured by the amount of that advantage. The other class comprises speculations which, without any direet advantage, are nevertheless valuable beeatuse they tend to enlarge the boundaries of analysis and to exereise the powers of the mind. Inasmuch as many researches which promise to be of great use have to be griven up owing to the inadequacy of anilysis, those speculations are of no little value which promise to extend the province of analysis. Such seems to be the nature of observations which are usually made or found a postriori, but which have little or no ehance of being discovered e priori. Having once been establisherl as correct, nethods more easily present themselves which lead up to them, and there is no doubt that through the senreh for such methods the domain of analysis may be considerably ex-

VOL. II. tended." The school of mathematicians headed by $\Delta$ bel and Jacobi pursued mathematic from purely scientific interest, and was criti. cised on this grounl by eminent contemporary mathematiciass in France: see a letter of Jacobi to Legendre, dated July 2, 1830, in which he refers to a lieport of Poisson on his great work, but adds: "Il. P'oisson n'auratic pats dû reproduire dans son ribport une phrase peu adroite de feu M. Fourier où ce dernier nous fait des reproches, it Abel et à moi, de ne pas nous être oceulés de préférence du mouvenent de la chaleur. Il est vrai que II. Fourier avait l'opinion que le but principal des mathématiques était l'utilité publique et l'explication des phénomènes naturels; mais un philosophe comme lui aurait dû savoir que le but unique de la seience, e'est l'homneur de l'esprit humain et que sous ce titre, une question de nombres vaut autant qu'une yuestion diu systène du monde." In the seyuel he adds: "Je crois entrevoir que toutes ces transcenlantes" (i.e., the elliptic and Abelian functions) "jouissent des propricités almirables et inattendues auxipuelles on leut itre combluit par le théorène d'Abel. . . J Jai rétléchi aussi de temps en temps sur une méthode uouvelle de traiter les perturbations célestes, méthode dins laquelle doivent entrer les théuries nouvelles des fonctions elliptiques." 
ducements is likely to prove fruitful for the progress of science; they look upon the first as an amusing pastime, and upon the third as empty and not devoid of danger. In recognition of the partial correctness of this view, I will follow up the practical stimulus in its fruitful influence upon the derelopment of the lines of mathematical research.

This stimulus came in the closing years of the preceding century through the lectures of Gaspard Monge at the École Normale, and has become popularly known 22. through his invention of Deseriptive Geometry, the first

modern systematic application of purely graphical methods in the solution of mathematical problems. As Cauchy was the founder of the modern sehool of analysts, so Monge, together with Carnot, founded the modern school of geometricians; Dupin, Poncelet, and Chasles being among his most illustrious pupils. The aim of this school was to give to geometrical methods, such as had been practised by the ancients, ${ }^{1}$ the same generality and systematic unity which characterised the analytical methods introduced by Descartes.

Not long after the introduction of the latter, Leibniz

1 These methods had been largely used in this country by Newton, Robert Simson, and Stewart. They were systematised by L. N. M. Carnot. Chasles ("Discours d'inauguration, \&c.," 1846, 'Géométrie Supérieure,' p. lxxvii) says: "Dans le siècle dernier, R. Simson et Stewart donnaient, ̀̀ l'instar des Anciens, autant de démonstrations d'une proposition, que la figure à laquelle elle se rapportait présentait de formes différentes, à raison des positions relatives de ses diverses parties. Carnot s'attacha à prouver qu'une seule démonstration appliquée ̀̀ un état assez général de la figure devait suftire pour tous les autres cas; et il montre comment, par des changements de signes de termes, dans les formules démontrées par une figure, ces formules s'appliquaient à une autre figure ne différant de la première, commes nous l'avons dit, que par les positions relatives de certaiues parties. C'est ce qu'il appela le 'Principe de corrélation des figures." 
had foretold ${ }^{1}$ the possibility and necessity of such an independent development of pure geometry, in which the relations of position in space, as opposed to those of measure, magnitude, or quantity, would be placed in the foreground. Projection, as practised in the drawing of maps, and perspective, as practised in the fine and descriptive arts, had alrearly revealed a number of remarkable properties of figures in the plane and in space. liy continuous motion of points or lines, by artifices like throwing of shadows, by sections of solids with lines and surfaces, a vast number of problems had been solved and isolated theorems established. The method here practised was that of construction, as in analysis the method was that of calculation with subsequent interpretation. All this purely constructive work was to be brought together and systematically comlined in a whole. It was evidently a distinct line of researeh, based upon intellectual processes other than the purely analytical method - a line which, as it seemed to its followers, had been unduly neglected and pushed into the background. Although Monge became the founder of this purely descriptive or eonstructive branch of geometry, he was himself equally great as an analyst; in fact, the fusion in his mind of the two methods was the origin of much of his greatest work. In attempting to carry out more thoroughly the separation or independent developunent of the constructive or descriptive method, his great pupil, J. V. Poncelet-whilst cleprived of all literary resourees Poncelet.

1 See the quotations from his letters to Huygens and others given above, vol. i. p. 103 note. 
in the prisons of Russia-meditated on the real cause of the power which algebraical analysis possessed, on the reason why geometry proper was deprived of it, and what might be done to give it a similar generality. In pursuing this line of thought he was led to discover the cause of the existing limitation of purely geometrical reasoning in its rigidity, inasmuch as it was arrested as soon as its objects ceased to have a positive or absolute, that is a physical, existence. ${ }^{1}$ Opposed to this limitation was the freedom of the analytical method, which, operating with indeterminate symbols, could, by letting them change gradually, include not only what was explicitly given, but also that which was merely implied; not only the finite, but likewise the infinite; not only the real, but likewise the fictitious or imaginary. In order to gain a similar generality in purely geometrical or descriptive science, a similar flexibility would have to be introduced. Poncelet was thus led to the enunciation of his celebrated and much-criticised "principle or law of continuity." 2

1 See the "Introduction" to the 1st volume of the "Traité des Propriétés projectives des figures,' $p p$. $x i$, xii. I quote from the 2nd edi. tion of 1865 . The 1st was published in 1822 . The researches date from 1813, the year of Poncelet's im. prisonment. See "Préface de la première édition."

2 Ibid., Introduction, p. xiv. On the priuciple of continuity in geometry, see an article in vol. xxviii. 'Ency. Brit.' by the Rev. Charles Taylor, and the references given therein; also Prof. E. Kötter's Report on the "Development of Synthetic Geometry" in vol. v. of the 'Jahresbericht der Deutschen Mathematiker Vereinigung,' p.
122, \&e.: "Originally the expositions referring to the principle of continuity were intended to occupy much greater space. . . . In consequence of correspondence with Terquem, Servois, and Brianchon, Poncelet desisted from the publication of it. . . However cautiously Poncelet advanced his principle" -in the "Essai sur les propriétés projectives des sections coniques' (presented to the Academy in 1S20) - " it nevertheless aroused the doubts of Cauchy, who in his report on Poncelet's paper warns against the too hasty application of the principle. Gergonne accompanied the reprint of this report with notes, in which he characterised 
Analytical geometry, by substituting an algebraical $\mathrm{cx}$ pression for a geometrical figure - say a curve,-could apply to it all the artifices of abstract analysis. By varying the co-ordinates you can proceed along the whole extent of the curve and examine its behaviour as it vanishes into infinity, or discover its singular points at which there occurs a break of continuity: you can vary its constants or parameters, and gradually proceed from one curve to another belonging to the same family, as is done in grouping together all curves of the second order, or-as was done in the calculus of variation, invented by Euler and Lagrange-you can vary the form of the equation, proceeding from one class of curve to another. Now clearly all this operating on equations and symbolic expressions was originally abstracted from geometry, including the mechanical conception of motion; in particular the ideas which underlie the method of fluxions were suggested by the motion of a point in space. The conception of continuous motion in space-

the principle as a valuable instrument for the discovery of new truths, which nevertheless did not make stringent proofs superfluous." Cauchy's report seems to have aroused Poncelet's indignation. Hankel ('Elemente der Projectivischen Geometrie,' 1875, p. 9) says: "This principle, which was termed by Poncelet the 'Priuciple of Contiuuity,' iuasmuch as it brings the various conerete cases into connection, could not be geometrically proved, because the imaginary could not be represented. It was rather a present which pure geometry received from analysis, where imaginary quantities behave in all calculations like real ones. Only the habit of considering real aud imaginary quantities as equally legitimate led to that principle which, without aualytical geometry, could never have been discovered. Thus pure geometry was compensated for the fact that analysis had for a long time absorbed the exclusive interest of mathematicians; iudeed it was perhaps an advantage that genmetry, for a time, had to lie fallow." Kötter continues: "Vou Staudt was the first who succeeded in subjecting the imaginary elemeuts to the fuudamental theorem of projective geometry, thus returning to aualytical geometry the present which, in the hauds of geometricians, had led to the most beautiful results." 
of motion of points, lines, planes-corresponded accordingly to the notion of variability in analysis. The introduction of motion, gradual and continuous, would give to purely geometrical or descriptive reasoning the same flexibility which analysis had acquired in the calculus of fluxions and of variations. Figures would lose their rigidity and isolation and limited nature and become movable, related to each other, filling the whole of space

24.

Character of modern geometry. instead of a restricted and confined area or region. It is the peculiarity of the modern as opposed to the older geometry, never to let figures become motionless or rigid, ${ }^{1}$ never to consider them in their isolation, but always in their mutual relations; never to have regard only to a finite portion of a line or surface, but to conceive of it in its infinite extension. By a reaction of analysis and geometry on each other, freedom and generality have been gradnally acquired.

But this moving about of figures in space in order to learn their properties and mutual relations must be according to some method; otherwise it will not lead to scientific and exact knowledge. Poncelet, in considering how the two successful methods in geometry - the Cartesian and the Descriptive-had attained to their perfection, discovers a general principle which underlies their proceedings, and which is capable of great extension: this is the principle of projection. ${ }^{2}$

1 See, inter alia, what Geiser says of Jacob Steiner's method in his pauphlet 'Zur Erinnerung an Jacob Steiner,' Schaffhausen, 1874, p. 27 .

2 'Traité des Propriétés projectives,' vol. i. p. xviii : “Fn réfléchissant attentivement à ce qui fait le principal arantage de la Géométrie descriptive et de la méthode des coordonnées, à ce qui fait que ces branches des Mathématiques off'rent le caractère d'une véritable doctrine, dont les principes, peu nombreux, sont liés et enchaînés d'une manière nécessaire 
Of this principle of projection, which Poncelet at once 25. introduces in the more general form as conical or central projection. projection, two signal applications existed in the treatises on Conic Sections handed down from antiquity, and in the practical methods and Rules of Perspective invented by Lionardo da Vinci and further developed by various geometricians. The results, which lay scattered in many books and memoirs, Poncelet collected in a systematic form, bringing them, by the application of the law of continuity, under a fow general and eminently useful points of view or principles. By the nethod of projection or perspective he "transformed figures which are very general into others which are particular, and vice versa." He established the principle of "homology" in figures, and by showing how figures apparently very different could be described by the process of projection from the same original figure, he showed that there existed a peculiar relation among figures-viz., their "reciprocity." 1

et par une marche uniforme, on ne tarcle pas à reconnaitre que cela tient uniquement à l'usage qu'elles font de la projection."

1 The properties of figures, callert by Poncelet "homology" and "reciprocity," refer to the correspondence of certain elements of one figure to those of another figure. In the case of "homology," we have to do with corresponding points or corresponding lines-i.e., with the corresponflence of the same elements. In the case of "reciprocity," we have to do with correspondence of points or lines in the one figure, with lines or points in the other-i.e., with the correspondence of different elements. The idea of placing figures in an lonulogous relation was got by the device of making two planes, which contained figures in perspective, fall together into one plane; upon which the section of the two original planes became the "axis," and the eye-point the "centre" of homology-all situated in one and the same plane. Poncelet had alrearly conceivert of the possibility of reducing the two planes in Monge's 'Descriptive Geometry,' which represent the plan and ele. vation of a figure in one plane, on which the elevations were marked by what are now caller "contour lines." The idea of the correspondence of figures by what is called "reciprocity" was sug- 
26. By the law of continuity he showed how in pure continuity. geometry it became necessary to introduce the consideration of points and lines which vanish into infinity or which become imaginary, establishing by their invisible elements the continuous transition from one geometric form to another; just as in algebra these conceptions had forced themselves on the attention of analysts. Ideal elements were thus made use of to lead to the discovery of real properties.

The consideration of lines and points which vanish or lie at infinity was familiar to students of perspective from the conception of the "vanishing line"; but the inclusion of ideal points and lines was, as Hankel says, a gift which pure geometry received from analysis, where imaginary (i.e., ideal or complex) quantities behave

27. in the same way as real ones. Without the inclusion of elements. these ideal or invisible elements the generality or contimuity of purely geometrical reasoning was impossible.

The geometrical reasoning of Monge, Carnot, and Poncelet was thus largely admixed with algebraical or analytic elements. It is true that Monge's descriptive geometry was a purely graphical method, and that

gested to Poncelet by the property, known already to De la Hire ("Sectiones Conicx," 1685). that in the plane of a conic section every point corresponds to a straight line called its "polar," that to every straight line corresponds a point called its "pole," that the "polars" corresponding to all the points of a straight line meet in one and the same point, and vicc rersa that the "poles" corresponding to all lines going through one and the same point lie on a straight line; the line and point in question standing in both cases in the relation of pole and polar to each other. Poncelet uses "this transformation of one figure into its reciprocal polar systematically as a method for finding new theorems: to every theorem of geometry there corresponds in this way another one which is its 'polar,' and the whole of geometry was thus split up into a series of truths which run parallel and frequently overlap each other" (Hankel, loc. cit., p. 20). 
Poncelet's method of central projection attacked geometrical problems from a purely constructive point of view. Nevertheless the frequently expressed object of the later writings of Monge, as well as those of Carnot and Poncelet, was to introduce into geometrical reasoning the generality and contimuity which analysis possessed, and this was largely attained by the interpretation of notions taken over from analysis. Their endeavours were, however, in the sequel crowned by the discovery of a purely geometrical property, the understanding of which has ever since formed the basis of what may be termed modern geometry.

This remarkable property, which may be regarded as revealing the very essence of extension in space or of the "space-manifold," - inasmuch as it brings the different elements of space into mutual relation,- -is the so-called principle of "duality" or' of "reciprocity." The principle of duality is now nsually defined to mean that duality. in geometry on the plane or in space, "figures coexist in pairs, two such coexisting figures having the same genesis and only differing from one another in the nature of the generating element." ${ }^{1}$ The elements of plane geometry are the point and the line; the elements of solid geometry are the point and the plane. By interchanging these correlative terms, correlative propositions may be written down referring to plane and to space geometry. In projective geometry there are two processes which are correlative or complementary to each other-the process of projection and the process of section. We can project

1 Cremona, 'Elements of Projective Geometry,' transl. by Leudesdorf. Oxford, 1885 , p. 26. 
from a point drawing lines or rays on the plane and in space, and we can cut these by lines in a plane or by planes in space. And it can be shown that "if one geometric form has been derived from another by means of one of these operations, we can conversely, by means of the complementary operation, derive the second from the first." 1

The projective geometry of Poncelet contains the twofold origin of the principle of duality in his method of projection and section, and in his theory of the reciprocity of certain points and lines in the doctrine of conic sections,

29. Reciprocity. called the theory of reciprocal polars. But the mathematician who first expressed the principle of duality in a general - thongh not in the most general - form was Gergonne, who also recognised that it was not a mere geometrical device but a general philosoplical principle, destined to impart to geometrical reasoning a great simplification. He sees in its enunication the dawn of a new era in geometry. ${ }^{2}$

1 Cremona, loc. cit., p. 33.

2 The principle of Duality seems to have been first put forward in its full generality by Gergonne, inspired probably by the theory of Reciprocal Polars (see note, p. 663) enunciated by Poncelet, who many years afterwards earried on a vol. uminous polemic as to the priority of the discovery. "Gergonne saw" that the parallelism (referred to above) is not an accidental consequence of the property of conic sections, but that it constitutes a fundamental principle which he termed the 'principle of duality.' The genmetry which is usually taught, and in which a line is con. sidered to be generated by the motion of a point, is opposed by another geometry equally legitimate in which a point is generated by the rotation of a line. Whereas in the first case the line is the locus of the moving point, in the latter case the point is the geometrical intersection of the rotating line. In this gemerality the principle of duality has been in. corporated into modern geometry" (Hankel, loc. cit., p. 21). Gergonne says of the new priuciple (1827, see Supplement to vol. ii. 2nd ed. of Poncelet's 'Traité,' p. 390): "Il ne s'agit pas moins que de commencer jour la géométrie, mal connue depuis près de deux mille ans qu'on s'en occupe, une ère tout - a - fait nouvelle; il s'agit d'en mettre tous les ancieus traités ì peu près au 
It must, however, in all fairness be stated that about the period from 1S22 to $18: 30$ this great simplification and unification of geometric science was as it were in the air - that it had presented itself to various great thinkers independently, being suggested from different points of view. The beginnings can no doubt be traced in the beantiful theorems of older French mathematicians, such as Paseal and De la Hire, and more generally in the suggestive methods of Monge and Poncelet; its first formal enmeiation is in the menoirs of Gergome: but the eomprehensive use of it-the rewriting of geometry from this point of view--was the illea of Jaeob Stciner, who, in his great but unfinished work on the "Systematic

Development of the Dependenee of Geometrie Forms" (18:30), set himself the great task " of uncovering the organism by which the most different forms in the world of space are connected with eaeh other." "There are," he says, "a small number of very simple fundamental relations in whieh the scheme reveals itself, by which the whole body of theorems ean be logically and easily developed." "Through it we come, as it were, into possession of the elements which Nature employs with the greatest economy and in the simplest manner in order to invest figures with an infinite array of properties." 1

rebut, de leur substituer des traités d'ume forme tout à fait différente, des traités vraiment philosophiques qui nous montrent eufin cette téten. due, réceptacle universel de tout ce qui existe, sous sa véritable physiunomie, que la mauvaise méthode d'enseignement adoptée jusqu'à ce jour ne nous avait pas permis de remarquer; il s'agit, en un mot, d'opérer dans la science une révolu- tion aussi inpérieusement nécessaire qu'elle a été jusqu'ici peu prévue."

1 See the Preface to the 'Systematische Entwickelung, \&c.,' in Jacob Steiuer's 'Gesammelte Werke' (erl. Weierstrass), vol. i. p. 229. "In the beautiful theorem that a conic section can be generated by the intersection of two projeetive rencils (and the dually 
The labours of Poncelet and Steiner introduced into geometry a twofold aspect, and accordingly, about the middle of the century, we read a good deal of the two kinds of geometry which for some time seemed to develop independently of each other. The difference has been defined by the terms "analytic or syuthetic," "calculative or constructive," "metrical or projective." The one operated with formula, the other with figures; the one studied the properties of quantity (size, magnitude), distances, and angles, the other those of position.

The projective method seemed to alter the magnitude of lines and angles and retain only some of those of position and mutual relation, such as contact and intersection. The calculating or algebraical method seemed to isolate figures and hide their properties of mutual interdependence and relation.

31.

Mutual influence of metrical and projective geometry.

These apparent defects stimulated the representatives of the two methods to investigate more minutely their hidden causes and to perfect both. The algebraical formula had to be made more pliable, to express more naturally and easily geometrical relations; the geometrical method had to show itself capable of dealing with quantitative problems and of interpreting geometrically those modern notions of the infinite and the complex which the analytic aspect had put promi-

correlated theorem referring to projected ranges), Steiner recognised the fundamental principle out of which the innumerable properties of these remarkable curves follow, as it were, automatically with playful ease. Nothing is wanted but the combination of the simplest theorems and a vivid? geometrical imagination capable of looking at the same figure from the most different sides in order to multiply the number of properties of these curves indef initely" (Hankel, loc. cit., p. 26 ; see also Cremona, 'Projective Geometry,' p. 119). 
nently into the foreground. The latter was clone by the geometrie genius of Von Standt, who succeeded in giving a purely geometrical interpretation of the imaginary or invisible elements ${ }^{1}$ which algebra had introduced, whilst Steiner astonished the mathematical world by the fertility of the methods by which he solved the socalled isoperimetrical problems-i.e., problems referring to largest or smallest contents contained in a given perimeter or vice versa, problems for which Euler and Lagrange had invented a special calculns. ${ }^{2}$ In spite of

1 The geometrical interpretation of the imaginary elements is given by Von Staudt in a sequel to his 'Geometrie der Lage' (1847), entitled 'Beitrïge zur Geometrie der Lage' (1856-60); and after having been looked upon for a long time as a curiosity or a "hairsplitting abstraction," it has latterly, through the labours of Prof. Reye ('Geometrie der Lage,' 1866-68) and Prof. Liiroth ('Nath. Annalen,' vol. xiii. y. 145), become more accessible, and is systematically introduced into many excellent text-books published abroad. The simplest exposition $I$ am acquainted with is to be found in the later editions of Dr Fiedler's German edition of Salmon's 'Conic Sections ' (6th Aufl., vol. i. p. 23, \&c., and p. 176 , \&c.) In 1875 , before the great change which has brought unity and connection into many isolated and fragmentary contribu. tions had been recognised, Hankel wrote witl regard to Von Staurt's work, and in comparison with that of Chasles, as follows: "The work of Von Staudt, classical in its originality, is one of those attempts to force the manifoldness of nature with its thousand threads running hither and thither into an abstract scheme and an artificial system : an attempt such as is only possible in our Fatherland, a country of strict scholastic method, and, we may add, of scientific pedantry. The French certainly do as much in the exact sciences as the Germans, but they take the instruments wherever they find them, do not sacrifice intuitive evilence to a love of system nor the facility of method to its purity. In the quiet town of Erlangen, Von staudt might well develop for himself in seclusion his scientific system, which he would only now and then explain at his desk to one or two pupils. In Paris, in vivid intercourse with colleagues and numerous pupils, the elaboration of the system would have been impossible" (loc. cit., p. 30).

2 See the lecture delivered by Steiner in the Berlin Academy, December 1, 1836, and the two memoirs on 'Maximum and Minimum' (1841), reprinted in 'Gesammelte WVerke,' vol. ii. p. 75 s.q., and 177 sqq., especially the interesting Introductions to both, in wlich be refers to his forerumner Lhuilier (1782), deploring that others had needlessly forsaken the simple synthetical methods adopted by him. Some of Steiner's expositions in these matters were apparently so easy that non-mathematical listeners 
these marvellous works of genius, science is probably indebted for its greatest advances to those mathematicians who, like Pliicker in Germany, Chasles in France, and Cayley in England, employed the analytic and constructive methods alternately and with equal mastery.

It is impossible - and it is not ny object - to allot to each of these original thinkers the special ideas introduced by him into modern science; but for the purpose

like Johannes Müller could not understand low such simple things could be brought before the Academy of sciences, whereas the great mathematician Dirichlet was full of praise of the ingenuity of the method by which problems were solved which the Calculus of Variations attacked long after Steiner, and then only in ways which the synthetical method had indicated (see Geiser, 'Zur Eriunerung an Jacob Steiner,' p. 28). It must not be supposed, however, that Steiner was an extreme purist so far as geometrical methods were concerned, for he says himself "that of the two methods neither is entitled to exclude the other; rather both of them will, for a long time, have plenty to do in order to master the subject to some extent, and then only can an opinion as to their respective merits be formed " ('Ges. Werke,' vol. ii. p. 180). An instance of a celebrated problem being treated alteruately by synthetic and analytic methods is that of the Attraction of Ellipsoids, in which the Theorem of Maclaurin had created quite a sensation. In spite of the admiration which it evoked, both Legendre and Poisson expressed the opinion that the resources of the synthetic method are easily exhausted. The latter, whilst admitting "que la synthèse ait d'aboril devancé l'analyse," never- theless concludes that "la question n'a été enfin résolue complètement que par des trallsformations ana. lytiques . . . auxquelles la synthèse n'aurait pu suppléer." 'This expression of opinion was falsified when Chasles preseuted to the Academy, in the year 1837, a memoir in which, through the study of confocal surfaces, the Theory of Maclaurin was synthetically proved in its full generality. Poinsot, who reported on this memoir, attached the following remarks: "Ce mémoire remarquable nous offre un nouvel exemple de l'élégance et de la clarté que la géométrie peut répandre sur les questions les plus obscures et les plus difticiles. . . . Il est certain qu'on ne doit négliger ni l'une ni lautre; elles sont au fond presque toujours unies dans nos ouvrages, et forment ensemble comme l'instrument le plus complet de l'esprit humain. Car notre esprit ne marche guère qu'à l'aide des signes et des images; et quand il cherche à pénétrer pour la première fois dans les questions difficiles, il n'a pas trop de ces deux moyens et de cette force particulière qu'il ne tire souveut que de leur concours. C'est ce que tout le monde peut sentir, et ce qu'on peut reconnaître dans le Mémoire même." (Chasles, 'Rapport sur les progrès de la géometrie,' 1870, p. 105, \&c.) 
of bringing some order into the tangled web of mathematical speculation, mainly represented by these, I shall identify the name of Pliicker with the great advance which has taken place in geometry through the change in our ideas as to the elements of space construction and the generalisation of our ideas of co-ordinates: with Chasles I shall specially comnect the modern habit in geometry of combining figures in finite space with their infinitely distant elements, and with Cayley the application to geometrical science of the novel and comprehensive methods of modern algebra. Let us dwell for a moment on each of these three great departures.

The elements of any science are a very different thing from the elements of the special object with which that science is concerned. The elements of chemistry are not the chemical elements. The latter are, we suppose, something existing in nature, something fixed and un- and logical alterable, which science aims at finding out; the former are certain conceptions from which we find it convenient to start in teaching, expounding, and lunilding up the science of chemistry. The latter are artificial, the former are natural. The same remark obtains in geometrical science. The elements of geometry have an historical, a practical beginning: the elements of space form a conseption which gradually emerges in the progress of geometrical science. In every science there is a tendency to replace the casual and artificial elements by the natural or real elements, and to build up the historical raditional body of doctrine anew, using the very lements which Nature herself, as it were, employs in roducing her actual forms and objects. As the pass- 
age quoted above shows, such an idea must have been before the mind of Jacob Steiner when he wrote the 'Systematische Entwickelung.' Through Enclid geometricians had learnt to begin with the straight line of definite-not indefinite-length, the triangle, the circle, advancing to more complicated figures; practice had made geometry a science of mensuration, involving number; the convenience of practice in astronomy, geodesy, and geography had introduced the artifice of referring points and figures in space to certain arbitrarily chosen data-points and lines. The terms "right ascension" and "declination," "altitude" and "azimuth," "latitude" and "longitude," led to the coordinates of Descartes and to analytical geometry. In this older and modern geometry, the beginnings were arbitrary, and many conceptions were introduced which were foreign to the object of research. It was through a slow process that in quite recent times-notably during the nineteenth century - mathematicians became aware how artificial were their methods, and with how many foreign elements they had encumbered the objects of their study. To replace the artificial by natural conceptions, and to open the eyes of geometricians to the advantage of not confining themselves to the point (its motion and distances) as the element in their space construction, no one did more than Julius Plicker of Bonn. We have now not only a point-geometry, but likewise a line-geometry - i.e., we have a geometry in which the line is the primary element, the point being the secondary element, defined by the intersection of two lines. This conception, which 
can be applied also to geometry in space, the point being conceived as generating a plane by its motion, or three planes defining a point by their intersection, leals us to the same idea of dual correspondence or reciprocity which Poncelet and Gergonne had arrived at by entirely different consiclerations. Pliicker's was an analytical mind, and with him the principle of duality at once assumes an analytical form. He saw that the same equation lent itself to a twofold interpretation, accordingly, as we adopt point co-ordinates or line co-ordinates -i.e., according as we refer our geometrical figure to the point or the line as the moving and generating space element. Through this step the idea of co-ordinates was generalised, and the dualistic conception of figures

34. Generalised co-ordin. ates. in space received an analytical expression. It was the junction of analytical and descriptive methods on a higher level, from which an entirely novel and fertile development of geometry became possible.

Whilst the labours of Pliicker lay in the direction of making analytical formula more natural, better adapted to the expression of geometrical forms and relations, and of reading out of these remodelled formule novel geometrical properties, the French school, with Michel Chasles ${ }^{1}$

1 In addition to numerous valuable memoirs, Chasles published, among others, two works of paramount importance, inasmuch as they for a long time dominated purely geometrical research, not only in France but also in Germany and England,- - the 'Apercu historique sur l'origine et le développement des méthodes en géométrie' (1837), and the 'Traité de géométrie supérieure' (1852). These works, through their bril- liant style, not only threw into the shade for a time the labours of contemporary German mathematiciaus, such as Möbius, Steiner, Pliicker, and Von Staudt, but also obscured some of the single discoveries of the author himself. The 'Apercu' was early translated into German; whereas in this country it was the Dublin school, rotab!y Townsend and $\mathrm{Dr}^{\text {r }}$ Salmou, who spread a knowledge of Chasles's work.

VOL. II. 
as its leader and centre, laboured at the introduction into pure geometry of those ideas which were peculiar to the analytical method, and which gave to that method its unity, generality, and comprehensiveness. Two ideas presented themselves as requiring to be geometrically dealt with: the infinite and the imaginaryi.e., the elements of a figure which lie at infinity and those which are ideal or invisible, which cannot be construed. It is usually supposed that the consideration in geometry of imaginary or invisible elements in connection with real figures in space or on the plane has been imported from algebra; but the necessity of dealing with them must have presented itself when constructive geometry ceased to consider isolated figures rigidly fixed, when it adopted the method of referring figures to each other, of looking at systems of lines and surfaces, and of moving figures about or changing them by the processes of projection and perspective. The analytical manipulations applied to an equation, which according to some system or other expressed a geometrical figure, found its counterpart in projective geometry, where, by perspective methods,changing the centre or plane of projection,-certain elements were made to move away into infinity, or when a line that cut a circle moved away outside of it, seemingly losing its connection with it. By such devices, implying continuous motion in space, Poncelet introduced and defined points, lines, and other space elements at infinity, and brought in the geometrical conception of elements. ideal and imaginary elements. "Such definitions," he says, "have the advantage of applying themselves at once to all points, lines, and surfaces whatsoever; they 
are, besides, neither indifferent nor useless, they help to shorten the text and to extend the object of geometrical conceptions; lastly, they establish a point of contact, if not always real, at least imaginary, between figures which appear-prima vista - to have $n$ mutual relation, and enable us to discover without trouble relations and properties which are common to them." I It was the principle of geometrical continuity which led Poncelet to the consideration of infinite and imaginary elements.

As we saw above, the projective methods of Poncelet had introduced into geometrical reasoning a renarkable distiuction among the properties of figures. In general it was recognised that, in the methods of central and parallel projection or in drawing in perspective, certain properties or relations of the parts of a figme remain maltered, whereas others change, become contorted or out of shape. Poncelet called the former projective or descriptive, the latter metrical, properties. This distinction introduced into all geometry since his time several most important and fundamental points of view; it divided geometrical research into two branches, which we may term positional and metrical geometry-the geometry of position and that of measurement. We know that ancient geometry started from problems of mensuration: modern geometry started, with Monge, from problems of representation or graphical description. It has thus becone a habit to call ancient geometry metrical, modern geometry projective. This habit has led to an mnecessary separation of views, but in the further course of development also 
to a mification on a higher level. But the distinction mentioned above led to another most remarkable line of thought and research which tends more and more to govern mathematical doctrine. The methods of projection are based upon the motion or upon the transformation of figures. Under such a process some relations remain nualtered or invariant, others change. As analytical methods in the hands of Pliicker and others began to accommodate themselves more closely to geometrical forms, as an intimate correspondence was introduced between the figure and the formula, it became natural to study the unalterable properties of the figmre 36. in the invariant elements of the formula. This is the Invariants. origin and meaning of the doctrine of Invariants. ${ }^{1}$ It is the great merit of the English school of mathematicians, headed by Boole, Cayley, and Sylvester, both to have first conceived the idea of a doctrine of invariant

1 "In any subject of inquiry there are certain entities, the mutual relations of which, under various conditions, it is desirable to ascertain. A certain combination of these entities may be found to have an unalterahle value when the entities are submitted to certain processes or are made the subjects of certain operations. The theory of invariants in its widest scientific meaning determines these combinations, elucidates their properties, and expresses results when possible in terms of them. Many of the general principles of political science and economics can be expressed by means of invariantive relations connecting the factors which enter as entities into the special problens. The great principle of chemical science which asserts that when elementary or compound bodies combine with one another the total weight of the materials is unchanged, is another case in point. Again, in physies, a given mass of gas under the operation of varying pressure and temperature has the well-known invariant, pressure multiplied by volume and divided by absolute temperature. Examples might be multiplied. In mathematics the entities under examination may be arithmetical, algebraical, or geometrical; the processes to which they are sub. jected may be any of those which are met with in mathematical work. It is the principle which is valuable. It is the idea of invariance that pervades to-day all branches of mathematics." (Major P. A. MacMahon, Address, Brit. Assoc., 1901, p. 526.) 
forms, and to have foreseen its importance and corresponding significance when applied to a great variety of scientific problems, notably to the projective processes in geometry. These were known to them mainly through the classical treatises of Poncelct and Chasles, the leading ideas of which had been introduced to British students by the labours of the Dublin school. ${ }^{1}$

The investigations referred to mark the junction of two important lines of mathenatical research, which had been carried on independently in earlier times, or only united for special purposes or for the solution of special problems. The history of the progress of geometry during the nineteenth century has already shown us the use and interest which belong to two different aspects of the common object, of which the one relies mainly on processes of measurement, inchuling number, the other mainly on processes of description, in-

1 The history of the doctrine of invariants has been written by $\mathrm{Dr}$ Franz Meyer, and is publisher in the first volume of the 'Jaliresbericht der Deutschen Mathematiker Vereinigung' (p. 79 sqq.) The fact that this formed the first of the several Reports which the German IIathematical Society has undertaken to publish, testifies to the great im. portance which belongs to this doctrine in the history of recent mathematies. A concise summary with copious references is given by the same author in the first volume of the 'Encyklopiidie der Math. Wissenschaften,' p. 320 sqq. How necessary the form and perfection of algebraic operations was for the development of the geometrical conceptions which are laid down, e.g., in the works of Plicker, can be seen in the work of Otto Hesse, who introduced ele- gance and conciseness into many of the expositions which, for want of this formal development, ap. year cumbrous in the writiugs of Pliicker. "The analytical form in which Pluicker's Researches present themselves is frequently wanting in that elegant form to which we have become accustomed, specially through Hesse. Pliicker's calculations frequently bear the stamp of mere aids for representing geometrical relations. That algebraical connections possess an interest in themselves, and require an adequate representation, was realised only by a generation which habitually employed methods that had been largely devised by Plitcker himself" (A. Clebsch, "Zum Gedächtniss an Julius Plicker,' 1872, p. 8. See also Gustav Bauer, 'Gedichtnissrede auf Otto Hesse,' Mïnchen, 1882). 
cluding arrangement. The same difference of views can be established with regard to many other things which form the objects of other sciences. In geometry this difference obtrudes itself, as it were, in its naked form. Thus in all the natural, and even the social, sciences we have become accustomed to look first at the constitnent elements or parts of things, to count and measure them, then afterwards to look at their possible arrangement, or existence together in the actual world of nature or society. Astronomy, crystallography, chemistry, geology, the natural history sciences, economics and statistics, the doctrine of chances,-all furnish, especially in their systematic development during the last hundred or humdred and fifty year's, examples of the twofold aspect just referred to. The progress of these sciences, as we have abundantly seen, has depended largely upon the application of mathematical methods. As the analysis into elements or parts, and the possible synthesis of such elements in complicated strnctures, has become everywhere the order of stndy, so there must exist in the abstract science of mathematics - i.e., in the framework of our scientific reasoning -not only the theory of measurement and number, but also that of combination, form or arrangement, and order.

37. Theory of forms.
The doctrine of forms in the well-known problems of permutations and combinations begins with modern mathematics in the seventeenth century, and received scientific recognition mainly in connection with the doctrine of chances at the hands of James Bernoulli abroad, and of De Moivre in this country. The process of multiplication of binomials and polynomials leads to the formation of combinations, and 
where the factors are the same, as in Newton's linomial theorem, to combinations with permutation; and eonsequently the doctrine of chances and of arrangements in triangular, pyramidal, or other figures is closely connected with the doctrine of series and algebraical expressions. In this eountry the interest in the subject has been stimulated and kept alive by isolated problems and puzzles in older popular periodicals, such as the 'Gentleman's Magazine' and the 'Ladies' Diary '; in Germany - as we noticed before--a school of mathematicians arose who attempted a systematic treatment of the whole subject, which, owing to its barrenness in practical results, bronght this line of research somewhat into disrepute. What was wanted was a problem of real scientific interest and a method of abbreviation and condensation. Both were supplied from mexpected ${ }^{1}$

1 The theory of arrangement or of order, also called the "Ars Combinatoria," has exerted a great fascination on some master minds, as it has also given endless opportunities for the practical ingenuity of smaller taleuts; among the former we must count in the first place Leibniz, and in recent times J. J. Sylvester, who conceived the "sole proper business of mathe. matics to be the development of the three germinal ideas-of which continuity is one, and order and number the other two" ("Philosophical 'Trausactions,' vol. clix. p. 613). This idea has been dwelt on by Major MacMahon in his adrlress (Brit. Assoc., 1901, p. 526), who says : "The combinatorial analysis may be described as occupying an extensive region between the algebras of discontinuous and continuous quantity. It is to a certain extent a science of enumeration, of mea- surement by means of integers as opposed to measurement of quantities which vary by infinitesimal increments. It is also concerned with arrangements in which differences of quality and relative position in one, two, or three dimeusions are factors. Its chief problem is the formation of connecting roads between the sciences of discontinuous and continuous quantity. To euable, on the one hand, the treatment of quantities which vary per saltum, either in magnitude or position, by the methods of the science of coutinuously varying quantity and position, and, on the other hand, to reduce problems of continuity to the resources available for the management of discontinuity. These two roads of research should be regarded as penetrating deeply into the domains which they connect." 
quarters - the one purely theoretical, the other practical. Accordingly the doctrine of forms and arrangements has during the last century been developed by mathematicians in two distinct interests, which only quite lately seem to approach and assist each other.

38. Theory of numbers.

The purely abstract or theoretical interest came from the side of the theory of numbers, a branch of research which was revived by Legendre in France and by the youthful genius of Gauss in Germany; the more practical one came from the theory of equations, notably in its application to problems of geometry. The methods by which these subjects were treated had in the early part of the nineteenth century undergone a great change. The older inductive method in both branches-namely, in the solution of equations and in the investigation of the properties of numbers-relied mainly on ingenions devices which were mostly of special, not of general, value. Theorems were found by induction, and had afterwards to be proved by rigorous logical deduction. Success depended on the degree of care with which the mind operated with mathematical symbols, and rested frequently on the intuition, if not the inspiration, of genius. Two of the greatest mathematical mindsFermat ${ }^{1}$ in France and Newton ${ }^{2}$ in England — stood

1 Pierre Fermat (1601-65) prepared an edition of the Treatise of Diophantus, and his marginal notes contain many theorems referring to the properties of numbers which have been the subject of much comment and examination by mathematicians of the first rank down to the present day. In letters to contemporaries he referred to many of these discoveries, and to his proofs, which he did not communicate. Some of these proofs seem not to liave satisfied him, being deficient in rigour. In spite of the labours of Euler, Lagrange, Cauchy, Dirichlet, Kummer, and others, one of these theorems still awaits proof. A full account of Fermat's theorems is given in Cantor's 'Geschichte der Mathematik,' vol. ii. 2nd ed., p. 773 sqq. Also in W. Rouse Ball's 'History of Mathematics,' p. $260 s q q$.

"Newton, in his 'Universal 
foremost in having with unrivalled fertility propounded theorems which were as difficult to prove as the mamer in which they had been arrived at was mysterions. The great analytical genins of Euler, who possessed nnequalled resources in the solution of single problems, spent much time and power in umravelling the riddles of Fermat. In the theory of equations the gencral solution beyond the fourth degree baftled the greatest thinkers. The time had come when in both branches a systematic study of the properties had to be attempted. This was done for the theory of numbers by Gauss, for that of equations by Abel. Every great step in advance of this kind in mathematics is accompanied by, and dependent on, skilful abbreviations, and an easy algorithm or mathematical language. An assemblage of elements held together by the simplest operations or signs of arithmetic - namely, those of addition and multiplication - is much easier to deal with if it can be arranged with some regularity, and accordingly methods were invented by which algebraical expressions or forms were made symmetrical and homo- 39. geneous $;^{1}$ the latter property signifying that each term

Arithmetic,' gave an interesting theorem by which the number of imaginary roots of an equation can be determined; he left no proof, and the theorem was discussed by Euler and many other writers, till at last Sylvester in 1866 found the proof of it in a more general heorem. In more recent times Jacob Steiner published a great 1umber of theorems referring to lgebraical curves (see Crelle's Journal,' vol. xlvii.) which have veen compared by Hesse with the "riddles of Fermat." Luigi Crenona succeeded at last in proving them by a general synthetical method.

1 The introduction of homogene. ous expressions marks a great formal advance in algebra and analytical geometry. The first instance of homogeneous co-ordinates is to be found in Möbius's "Barycentric Calculus" (1826), in which he defined the position of any point in a plane by reference to three fundamental points, considering each poiut as the centre of gravity of those points when weighted. "The idea of co-ordinates appears here for the first time in a new 
contained the same number of factors. Such forms could be written down on the pattern or model of one of their terms by simple methods of exchange or permutation of the elements. It would then not be necessary to write down all the terms but only to indicate them by their elements, these also being abbreviated by the use of indices. Rows and columns or arrangements in squares suggested themselves as easy and otherwise well-known artifices by which great masses of statistics and figures are marshalled and controlled. Ont of these manifold but simple devices there grew an algebra of algebra, a symbol for denoting in a very general way symmetrical and homogeneous algebraical expressions. ${ }^{1}$

40. Determinants.

Gauss termed such expressions Determinants: they turned up in his 'Disquisitiones Arithmetice' as they had done half a century before in Cramer's 'Analyse des lignes courbes algébriques.' Just as common fractions can be

garb, which soon led to a more general conception. The Barycentric co-ordinates were the first instance of homogeneous eo-ordinates, . . . and already with Möbius the advantages become evident through the symmetry and elegance of his formule" (Hankel, 'Project. Geom.' p. 22).

1 Determinants were first used by Leibniz for the purpose of elimination, and described by him in a letter to the Marquis de l'Hospital (1693). The importance of his remarks was not recognised and the mattel was forgotten, to be rediscovered by Cramer in the above-named work (1750, $p$. $65 \%$ ). It is interesting to note that the same difficulty of the process of elimination induced Pliicker to resort to geometrical interpretation of analytical expressions, and that whilst he "saw the main advantage of his method in avoiding algebraical elimination through a geometrical consideration, Hesse showed how, through the use of Determinants, algebraical operations could receive that pliabil. ity the absence of which was the reason for Pliicker to discard it." (See the account of Clebsch's work in 'Math. Ann.,' vol. vii. p. 13.) 'Through this invention the combinatorial analysis, which, in the hands of the school in Germany, had led into a desert, was raised again into importance. It has become still more important since the general theory of forms and of groups began to play an increasing part in modern analysis. 
dealt with as if they were special things having special properties, though the latter depend only on the properties of the numbers they are made up of and their mode of connection; as powers and surds are separately examined; so the arrangements called determinants can be subjected to a special treatment, their properties ascertained, and themselves subjected to the ordinary operations of arithmetic. This doctrine, which constitutes the beginning and centre of the theory of algebraical forms or "quantics" and of algebraical operations or "tactics," was pretty fully worked out and first introduced into the comse of teaching by Cauchy in France; then largely adopted by Jacobi in Germany, where Otto Hesse, trained in the ideas of Plicker, first showed its usefulness in his elegant applications to geometry. In lrance it was further developed by Hermite, who, together with Cayley and Sylvester in England, proclaimed the great importance of it as an instrument and as a line of mathematical thought. ${ }^{1}$ In the latter country the idea of abbreviating and summarising algebraical operations had become quite familiar through another device which has not found equal favour abroad - namely, the Calculus of

1 "For what is the theory of determinants! It is an algebra upon algebra; a calculus which enables us to combine and foretell the results of algebraical operations, in the same way as algebra enables us to dispense with the performance of the special operafions of arithmetic. All analysis nust ultimately clothe itself under his form." In this conuection Sylvester ('Plil. Mag.,' 1851, Apl.,
1. 301) refers to Otto Hesse's "problem of reducing a eubic function of three letters to another consisting only of four terms by linear substitutions - a problem which appears to set at defiance all the processes and artifices of common algebra," as "perhaps the most remarkable indirect question to which the method of determinants has been hitherto applied." 
41.

Calculus of Operations.

Operations, the idea of treating algebraical operations and their symbols as quantities, and of subjecting them to arithmetical treatment separately from the material operated on. The genius of Arthur Cayley was specially fertile in this direction, as was that of Sylvester in the nomenclature or language of the doctrine of forms. ${ }^{1}$ The merit, however, of having brought together the new ideas which emanated from the schools of Poncelet and Chasles in France, of Cayley and Sylvester in England, into a connected doctrine, and of having given the impetus to the fundamental re-

1 The theory of invariants was gradually evolved from many inde. pendent beginnings. In 1864 Sylvester wrote ('Phil. Trans.," p. $579)$, "As all roads are said to lead to Rome, so I find, in my own case at least, that all algebraical in. quiries, sooner or later, end at the Capitol of Moderu Algebra, over whose shining portal is inscribed the Theory of Invariants." About the same time (1863) Arouhold developed the principal ideas which lay at the foundation of the theory in organic comnection and in complete generality, hereby domiciling in Germany the doctrine which had previously owed its development mainly to Euglish, French, and Italian mathematicians (see Meyer, 'Bericht,' \&c., p. 95). The different roads which Sylvester refers to can be traced, first, in the love of symbolic reasoning of Boole, who was "one of the most eminent of those who perceived that the sym. bols of operation could be separated from those of quantity and treated as distinct objects of calculation, his principal characteristic being perfect confidence in any result nbtained by the treatment of sym. bols in accordance with their primary laws and conditions, and an almost unrivalled skill and power in tracing out these results" (Stanley Jerous in article "Boole," 'Ency. Brit.'); secondly, in the independent geometrical labours of Hesse in Germany (whose mathematical training combined Pliicker's and Jacobi's teaching) and Dr Salmon in Dublin (who, after having transplanted Poncelet and Chasles to British soil, recognised the importance of Cayley's and Sylvester's work; and in. troduced in the later editions of his text-book modern algebraical methods) ; thirdly, in the independent investigations belonging to the theory of numbers of Eisenstein in Germany and Hermite in France. In full generality the subject was taken up and worked out by Sylvester in the 'Cambridge and Dublin Mathematical Journal' (1851-54), and by Cayley in the first seven memoirs upon Quantics (1854-61), which " in their manysidedness, together with the ex. haustive treatment of single cases, remain to the present day, for the algebraist as well as for the geometrician, a rich source of discovery" (Meyer, loc. cit., p. 90). 
modelling of the text-books and school-books of algebra and geometry in this country and in Germany, belongs undeniably to Dr. Salmon of Dublin. ${ }^{1}$ The conception of a form-be this geometrical or algebraic-suggests the investigation of the change, the recurrence of forms. How dlo forms under the process of geometrical or algebraical manipulation alter or preserve their varions properties? The processes of projection practised by Monge, Poncelet, and Chasles in France had alrearly led to a distinction between descriptive and metrical properties of geometrical figures. A corresponding examination of algebraical forms, which are all capable of geometrical representation or interpretation, would leal to the extensive and fundamental doctrine of the invariants of these forms-i.e., of such arrangements of the elements as remain absolutely or proportionally unaltered during the processes of change and combination. Notably instead of the geometrical process of projection by central perspective we may employ in our algebraic formulice a corresponding process, that which is known as linear substitution. And at the time when it was recognised that geometrical transformation had its

1 Of Dr' Salmon, whose 'Lessous introductory to the Modern Higher Algebra' appeared in 1859 4 th ed., 1855 ; 1st German ed. by Fiedler, 1863), Meyer says: "Reognising how the special results n this domain gradually acquired i cousiderable bulk, we must the nore gratefully acknowledge the vork of Salmon-who had already, $\mathrm{n}$ the direction of algebra as well as f geometry, furnished valuable conributions of his own-in underaking the labour of collecting the widely-scattered material in a concise monograph. For the promulgation in Germany we have to thank Fiedler both for his edition of Salmon, and for having already given an independent introduction to the subject, in which especially he made Cayley's applications to projective geometry generally accessible. About the same time (1862) there appeared likewise an edition by Brioschi, which gained many adherents for the theory of Invariants in Italy." 
counterpart in the transformation of algebraical forms 42. by the processes of substitution, these latter had Principle of
substitu-
tion. the theory of algebraical equations, which in the first quarter of the century had undergone a great development under the hands of two brilliant mathematical talents both lost to science at an early age - the Norwegian Abel and the Frenchman Évariste Galois. Like all algebraical expressions, those termed equations were originally invented and commanded attention

1 Évariste Galois is held to have been one of the greatest mathematical geniuses of modern times, who, if he had lived, might have been a rival of Abel: he was born in 1811, aud died before he was twenty-oue, in consequence of a duel. For a loug time his writings remained un. published and unknown, till Lion. ville published them in the 11 th vol. of his 'Jourual' (1846). Liouville was also the first to recognise the importance and absolute correctness of Galois's method, which, when sub. mitted to the Academy in the year 1831, and reported on by Lacroix and Poisson, had appeared almost unintelligible. On the eve of his death Galois addressed a letter to his friend Auguste Chevalier, which is a unique document in mathema. tical literature, forming a kind of mathematical testament. $\mathrm{He}$ desires this letter to be published in the 'Revue Encyclopédique,' referring publicly the "importance," not the "correctness," of his discoveries to the judgment of Jacobi and Gauss, and expressing the hope that some persons would be found who would take the trouble to unravel his hieroglyphics. The first attempt to make Galois's ideas generally accessible is to be found in Serret's 'Algèbre Supérieure' (3rd ed., 1866), but it was not till after the publication of Camille Jordan's 'Théorie des Substitutions' (1870) that the short papers of Galois were recog. uised as containing the germs and beginnings of an entirely novel and comprehensive mathematical theory -viz., the "Theory of Groups." The relation between the writings of Abel and Galois is exhaustively treated iu Prof. Sylow's Paper on Abel's work, contained in the 'Me. morial Volume,' 1892, p. 24 . He there says: "Le mérite de Galois ne consiste pas essentiellement dans ses propositions, mais daus la généralité de la méthode qu'il appliqua. C'est son admirable théorème fondamental qui a douné à la théorie des équatious sa forme définitive, et d'où est sortie, en outre, la théorie des groupes généralisée, qui est d'une si grande importance, on peut le dire, pour toutes les branches des mathématiques, et qui déjà, entre les mains de Jordan, de Klein, de Lie, de Poincaré et d'autres, a en. richi la science d'une longue suitr de découvertes importantes." The memoirs of Abel aud Galois re ferring to the Theory of Equation: have been couveniently edited, in : German trauslation, by $\mathrm{H}$. Maser 1889. See also Cayley's article or "Equation" in the "Ency. Brit., $\S 32$. 
as instruments or deviees for the solution of definite problems in arithmetie, geometry, and mechanics. The solution of the equation-i.e., the expression of the $1 \mathrm{m-}$ known quantity in terms of the known quantitiesserved a praetieal end. Gradually as such solutions became more and more difficult, owing to the complexity of the formule, the doctrine divided itself into two distinct branches, serving two distinct interests. The first, and practically the more important one, was to devise methods by which in every single ease the equations which presented themselves could be solved with sufficient accuracy or approximation; this is the doctrine of the numerical solution of equations. The other more scientifie branch looked upon equations as algebraical arrangements of quantities and operations which possessed definite properties, and proposed to investigate these properties for their own sake. The question arose, How many solutions or roots an equation wonld admit of, and whether the expression of the mknown quantity in terms of the known quantities was or was not possible by using merely such operations as were indicated by the equation itself - i.e., the common operations and the ordinary numbers of arithmetic? This doctrine of the general properties of equations received increasing attention as it became empirically known that equations beyond the fourth degree could not he solved in the most general form. ${ }^{1}$ Why could they not be solved,

a Since the researches regarding the solubility of Equations have led on, through Galois and the French analysts, to the same line of reasoning as other researches mentioned before - viz., toward the development of the theory of groups - the history of the whole subject has aroused special interest. The earlier beginnings and the labours of forgotten analysts have been un- 
and what were the conditions-i.e., the special properties-of an equation which rendered it soluble? These were some of the questions which the great mathematicians, such as Gauss, Abel, and Galois, placed before themselves during the earlier part of the century. There are other unsolved problems which the nineteenth century inherited from preceding ones, where the same line of reasoning was adopted-i.e., where the question was similarly reversed. Instead of trying to solve problems as ret unsolved, it was proposed to prove their general insolubility, and to show the reason of this: also to define the conditions which make a solution possible.

earthed and placed in their correct historical perspective. Prof. Burkhardt of Guttingen, to whom we also owe the chapter on this subject in the first rolume of the 'Encrklopädie,' \&c., contributed in the rear 1892 a most interesting historical paper, "Die Anfänge der Gruppentheorie und Paolo Ruffini" ('Abhand]. zur Gesch. der Math.,' 6 Heft). In this paper he also goes back to other earlier analrsts, among them Prof. Waring of Cambridge, who during his lifetime used. to complain that he knew of no one who read his mathematical tracts. It appears that during nearly the last thirty rears oi the eighteenth century nothing had been added regarding the general theory of equations, and that Puffini was the first to begin a new epoch in the rear 1799. with the distinct assertion that a general sulution of algebraic equations berond the fourth degree, bs means of radicals, was impossible, aud with an attempt to prore this. His researches were therefore contemporaneous with those of Gauss, who published his "Dissertation" (see note p. 611) in the same sear, and his great arithmetical work in 1801. Although Gauss seems to have arrired at the same conclusion, and perhaps eren to hare anticipated much later attempts to solre the general equation of the fifth degree by other than algebraical operations (see Srlow, loc. cit., p. 16), his publi-hed researches rather took the line of the studr of a definite class of soluble equations which were connected with the celebrated problem of the dirision of the circle; a satisfactory proof of Ruffini s statement being withheld till Abel published his celebrated memoir in the year 1825 in the first rolume of Crelle's 'Journal.' With this memoir the theors of equations entered a new phase, towards which the labours of Puffini were preparatory. As in 80 many other cases, so also in this, the solu. tion of the problem depended upon stricter definitions of what was meant br the solution of an equation, and by "algebraical" and other ("transcendental ") function and operations. We know that both Abel and Galois began theix research br futile altempts to fino a solution of the general equatior of the fifth degree. 
In following this altered course of investigation, an enormous amount of mathematieal knowledge was gained, and problems were solved which had previously never been thonght of. Espeeially through the theory of equations the abstraet doetrine of algebraical forms was ereated and greatly advaneed long before it was generally reeognised that it had peenliar importance through the correspondenee or parallelism whieh existed between algebraieal expressions and geometrieal eonfigurations.

Ont of these earlier algebraical and later eonbined algebraieal and geometrical investigations, a novel and very groups.

44. Theory of useful point of view has been gradually gained which represents the most general conception of nuathematical tactics. This eentres in the notion of a group of elements. These elements may be quantities or operations, so that the theory of Groups embraees not only the doetrines whieh deal with quantities but also those which deal with arrangements and their possible ehanges. The older eombinatorial analysis dealt mainly with assemblages of a quantity of separate clements, their number, their variety: the modern theory of groups deals rather with the proeesses and operations by which different arrangements can be transforned one into the other. It is an algebra of operations. The methorls of transformation whieh presented themselves first of all were the methods known in algebra as substitution. Accordingly the first eomprehensive treatise on the theory was the 'Treatise on Substitutions,' publisherl in 1870 by M. Camille Jordan. This book forms a landmark in modern mathematics; it brought into a system VOL. II. 
the beginnings of the new and comprehensive calculus of operations which were contained in the writings of Lagrange, Abel, Cauchy, and Galois, and established the terminology and the algorithm. A group of substitutions is defined as having the property that each two or more operations belonging to it and sucessively applied can be replaced by another single operation contained in the same group. Succeeding operations are symbolically represented by the product of two or more letters. This product has certain algebraical properties, and in analogy with common products it has factors, a degree, an index; the substitution may be cyclical and symmetric, and may have many other remarkable properties which the theory ${ }^{1}$

1 'The "Theory of Groups" has now grown into a very extensive doctrine which, according to the late Prof. Marius Sophus Lie (1842-99), is destined to occupy a leading and central position in the mathematical science of the future. "The conception of Group and Invariant was for him not only a methodical aspect from which he intended to review the entire older region of mathematics, but also the element which was destined to permeate and unify the whole of mathematical science" (II. Nöther, "Nath. Ann.,'vol. liii. p. 39). But though it is an undoubted fact that the largest systematic works on the subject emanate from that great Norwegian mathematician, and that his ideas have won gradual recognition, especially on the part of prominent French mathematicians, notably M. Picard ('Traité d'Analyse," 1896, vol. iii.) and M. Poincarć, the epoch - making tract which pushed the novel conception into the foreground was Prof. F. Klein's 'Erlangen Programme' (1872), entitled "Vergleichende
Betrachtungen iiber neuere geometrische Forschungen." To those who read and re-read this short but weighty treatise, it must indeed have been like a revelation, opening out entirely new avenues of thought into which mathematical research has been more and more guided during the last generation. The tract, which has now been translated into all the important modern languages, renuained for a long time comparatively unnoticed, and, twenty years after its publication, was reprinted by the author in the $43 \mathrm{rd}$ volume of the "Math. Annalen,' with some introductory remarks which indicate the changes that had taken place in the iuterval as regards the scope of the idea. The main result of the dissertation is this: That, primarily, for all geometrical investigations, the characteristic propertics of any manifold (or arrangement) is not the element out of which it is composed, but the group, the transformations of which reveal its invariantive properties. There are, accordingly, as many different ways of 
of groups investigates. Its immediate application, and the purpose for which it was elaborated, was the theory of Equations. Every equation constitutes an arrangement in which a finite number of independent elements, ealled constants or coefficients, is presented under a certain algebraical form. The solution of the equation means the finding of such an arrangement as when substituted in the equation for the mknown quantity, will satisfy the equation.

The conception of a group of operations standing in the defined relations is, however, capable of a great and fundamental extension into that region of mathematies which deals, not with fixed or constant, but with variable or flowing quantities; not with elements which are discomnected or discontinuous, but with such as are Continuous and discontinuous. To understand the development of modern continuous mathematical thought, it is accordingly neeessary to go back somewhat and review the progress which the

studying any manifold (c.g., such as projective geometry, liue geometry, geometry of reciprocal radii, Lie's sphere geometry, analysis situs, \&c.) as there are continuous groups of transformations that can be established ; and there are as many invariant theories (see 'Ency. Math. Wiss.,'vol.ii. p. 402 ; Nöther, loc. cit., p. 22$)$. From that date onward the different kinds of groups have been defined and systematically studied, notably by Klein and Lie and their pupils. In this country, although many of the relevant ideas were contained in the writings notably of Cayley and of Sylvester, the systematic treatment of the subject was little attended to before the publication (1897) of Prof. Burn- side's 'Theory of Groups of Fiuite Order,' and latterly of his article on the whole Theory of Groups in the 29 th volume of the 'Ency. Brit.' It has been remarked by those who have studied most profoundly the development of the two great branches of mathematical tactics -viz., "The Theory of Invariants" and the "Theory of Groups" - that the progress of science would have been more rapid if the English school had taken more notice of the general comprehensive treatment by Lie, and if Lie himself had not refrained from entering more fully into the special theories of that school (see Dr F. Meyer, 'Bericht,' \&e., 1. 231). 
conception of the variable ${ }^{1}$ has undergone in the course of the last hundred years. Here we come upon a term which was introduced into mathematical language mainly through the writings of Euler - the term function. It is used to denote the mathematical dependence of two or more variable quantities on each

1 To the theory of equations in algebra there corresponds the theory of differential equations in analysis; and as the theory of algebraical equations had gradually emerged in a complete form out of investigations of special equations, or sets of equations, so likewise in analysis a general theory of differential equations is gradually being evolved ont of the scattered and very extensive investigations of special differential equations which presented themselves notably in the application of analysis to astronomical and physical problems. It is claimed by those who have grasped the abstract ideas of Sophus Lie, that he has taken a great step forward in the direction of a general theory of differential equations, by applying methods which suggested themselves to him through the general theory of algebraic forms and its connection with geometry. Accordingly, the theories of Lie can be termed an algebraical theory of differential equations, depending upon transformations analogous to those which liad been established in the general theory of forms or quantities of which I treated above. Prof. Engel, in his obituary notice of Sophus Lie ('Deutsche Math. Ver.,' vol. viii. p. 35), tells us that in the year 1869-70, when Lie met Prof. Klein in Berlin, the former was occupied with certain partial differential equations which exhibited, under certain transformations, in: variantive properties, and that Klein then pointed out "that his procedure had a certain analogy with the methods of Abel. The suggestion of this analogy became important for Lie, as he was generally intent upon following up more closely the analogies with the theory of algebraical equations." Dr H. F. Baker, in his recent article on Differential Equations in the 'Ency. Brit.' (rol. xxvii. p. 448), roughly distinguishes two methods of studying differential equations, which he names respectively "transformation theories" and "function theories," "the former concerned to reduce the algebraical relation to the fewest and simplest forms, eventually with the hope of obtaining explicit expressions of the dependent in terms of the independent variables; the latter concerned to determine what general descriptive relations among the quantities are involved by the differential equations, with as little use of algebraical calculations as may be possible." For the history of thought and connection of ideas, it is interesting to learn, through Prof. Engel, that it was not purely algebraical work,-such as is represented by Galois and Jordan, to which Lie was early intro. duced by Prof. Sylow,-but the study of Poncelet's and Pliicker's methods which led Lie to his original conceptions, and that he was fond of calling himself a pupil of Pliicker, whom he had never seen (Engel, loc. cit., p 34). 
other. The question arises, What are we to understand under this term? What is a mathematical function or dependence? The question was approached by the great analysts of the second half of the eighteenth century. A preliminary answer which served the requirements of a very wide field of practical application was given by Fourier at the beginning of the nineteenth century. Since that time the question has been independently treated by two schools of Continental mathematicians. Of these the first was founded by Canchy in France, and is mainly represented by Bernhard Riemann and his numerous pupils in Germany; the other centres in the Berlin school, hearled by Weierstrass, and goes back to the work of Lagrange.

The interests which have led to this modern branch of mathematical research ${ }^{1}$ are various, but we can

1 The literature suitable for intro. ducing the student of mathematics to the modern theory of functions - which plays in analysis, i.e., the doctrine of variable quantity, a part of similar importance to that which the theory of forms plays in algebra-is so enormous, the subject being approached from so many sides by different writers, that it seems worth while to refer to two expositions which may be read with profit, and which do not require extensive mathematical knowledge. First and foremost I would recommend Cayley's article on "Functions" in vol. ix. of the 'Ency. Brit.' Then there is the chapter on "Foundations of the General Theory of Fnnctions," contained in the 2nd volume of the German 'Mathematical Encyclopedia,' written by Prof. Prings- beim. Cayley's article introduces the general theory after giving a short summary of the more important "known" functions, including those which presented themselves in the first half of the nineteenth century, and which I referred to in dealing with the work of Abel and Gauss (see note, p. 648). The treatment of these latter functions, which had been brought to a certain degree of perfection by Jacobi, had made it evident that more general aspects had to be gained and broader foundations laid. But ever since the middle of the eighteenth century another development of mathematical ideas had been going on which started from the solution of a problem in mathematical physics-namely, that of vibrating strings, which led in the sequel to 
distinguish two which are very prominent, and are roughly represented by the two schools just referred to. In the first place, a function can be formally defined as an assemblage of mathematical symbols, each of which denotes a definite operation on one or more quantities. These operations are partly direct, like addition, multiplication, \&c.; partly indirect or inverse, like subtraction, division, \&c. Now, so far as the latter are concerned, they are not generally and necessarily practicable, and the question arises, When are they practicable, and if they are not, what meaning can we connect with the mathematical symbol? In this way we arrive at definitions for mathematical functions which cannot immediately be reduced to the primary operations of arithmetic, but which form special expressions that become objects of research as to their properties and as to the relation they bear to those fundamental operations upon which all our methods of calculation depend. The inverse operations, represented by negative, irrational, and imaginary quantities ; further, the operations of integration in its definition as the in-

a certain finality when Fourier introduced his well-known series and integrals, by which any kind of functionality or mathematical dependence, such as physical processes seem to indicate, could be expressed. The work of Fourier, which thus gave, as it were, a sort of preliminary specification under which a large number of problems in physical mathematics could be attacked and practically solved, together with the stricter defini. tions introduced by Lejeune Dirichlet, settled for a time and for practical purposes the lengthy dis. cussions which had begun witl
Euler, Daniel Bernoulli, d'Alem. bert, and Lagrange. The abovenamed cliapter, written by Prof. Pringsheim, gives an introduction to the subject showing the historical genesis of the conception of function and the various changes it was subjected to, and theu proceeds to expositions and definitions mostly taken from the lectures of Weierstrass (see p. 8), whereas Cayley's article introduces us to the elements of the general theory of functions as they were first laid down by Riemann in the manner now commonly accepted. 
verse of differentiation,-- - led early to investigations of the kind just mentioned. The experience that ordinary fractions might be expressed by decimal fractions-i.e., by finite or infinite series-led to the inverse problem of finding the smm of such series and many other answerable and apparently unanswerable problems. The older method of research consisted in treating these problems when and as they arose: new chapters were accordingly added to the existing chapters of the text-books, dealing with special functions or mathematical expressions. It was only towards the end of the eighteenth century, and at the beginning of the nineteenth, that Lagrange, Gauss, and Canchy felt and proclaimed the necessity of attacking the question generally and systematically; the labours of Euler having accumulated an enormous mass of analytical knowledge, a great array of useful formulie, and amongst them not a few paradoxes which demanded special attention. I have already had occasion to refer to the problem of the general solution of equations as an instance where, in the hands of Abel, the tentative and highly ingenions attempts of earlier analysts were replaced by a methodical and general treatment of the whole question. Another chapter of higher mathematics, the investigation of expressions which presented themselves in the problems of finding the length of the are of an ellipse, and which opened the view into the large province of the so-called higher transcendents, gave Abel further occasion of laying new foundations and of creating a general theory of equations or of forms.

But yet another interest operated powerfully in the 
direction of promoting these seemingly abstract researches. Nature herself exhibits to us measurable and observable quantities in definite mathematical de47. pendence; ${ }^{1}$ the conception of a function is suggested by Physical analogies. all the processes of nature where we observe natural phenomena varying according to distance or to time.

1 Nearly all the "known" functions have presented themselres in the attempt to solve geometrical, mechanical, or physical problems, such as finding the length of the arc of the ellipse (elliptic functions); or answering questions in the theory of attraction (the potential function and other functions, such as the functions of Legendre, Laplace, and Bessel, all comprised under the general term of "har. monic functions"). These functions, being of special importance in mathematical physics, were treated independently before a general theory of functions was thought of. Many important properties were established, and methods for the numerical evalu. ation were devised. In the course of these researches other functions occurred, such as Euler's "Gamma" function and Jacobi's "Theta" function, which possessed interesting analytical properties. These functions, suggested directly or indirectly by applications of analysis, did not always present themselves in a form which indicated definite analytical processes, such as processes of integration or the summation of series. Very frequently they presented themselves, not in an "explicit" but in an "implicit" form; their properties being expressed by certain conditions which they had to fulfil. It then remained a question whether a definite symbol, indicating a set of analytical operations, could be found. This arises from the fact that the solution of most problems in mechanics and physics starts from the assumption that, though the finite observable phenomena of nature are extremely intricate, they are, nevertheless, compounded out of comparatively simple elementary processes, which take place between the discrete atoms, or the elementary but con. tinuous portions of matter. Mlathematically expressed, this means that the relations in question present themselves in the form of differen. tial equations, and that the solution of them consists in finding functions of finite (observable) quantities which satisfy the special conditions. A comparatively small number of differential equations has thus been found empirically to embrace very large and apparently widely separated classes of physical phenomena, suggesting physical relations between those phenomena which might otherwise have remained unnoticed. The physicist or astronomer thus liands over his problems to the mathematician, who has either to integrate the differential equations, or, where this is not possible, at least to infer the properties of the functions which would satisfy them - in fact, the differential equation becomes a definition of the function or mathematical relation. In consequence of this the theory of differential equations is, as Sophus Lie has said, by far the most im. portant branch of mathematics. 
The attraction of the heavenly bodies varies with the distance, the velocity of a falling stone or the cooling of a hot body varies with the interval of time which has lapsed or flown. We are now so much accustomed to represent such dependence by curves drawn on paper, that we hardly realise the great step in advance towards definiteness and intelligibility that this device marks in all natural sciences and in many practical pursuits. But the representation of the natural connections of varying quantities by curves also forms the connecting link with the other class of researches just mentioned. Descartes had showu how to represent algebraical formula by curves in the plane and in space; and at the begimning of the nineteenth century this method was modified by Gauss and Cauchy so as to deal also with the extended conception of number which embraced the imaginary unit. Two questions arise, Is it possible to represent every arbitrary dependence such as we meet with in the graphical description of natural phenomena by a mathematical formulai.e., by a formula denoting several specified mathematical operations in well-rlefined comnections? and the inverse question, Is it possible to represent every well-defined arrangement of symbols clenoting special mathematical operations graphically by curves in the plane or in space? The former question is one of vital importance in the progress of astronomy, physies, chemistry, and many other sciences, and has accordingly occupied many eminent analysts ever since Fourier gave the first approximative answer in his well-known series: the latter question can only be answered by much stricter defini- 
tions of all the more advanced and of some even of the elementary operations which analysts had become aceustomed to use without a previous knowledge of the range of their validity. All applications of mathematics consist in extending the cmpirical knowledge which we possess of a limited number or region of aecessible phenomena into the region of the unknown and inaccessible; and much of the progress of pure analysis consists in inventing definite conceptions, marked by symbols, of complicated operations; in ascertaining their properties as independent objects of research ; and in extending their meaning beyond the limits they were originally invented for,- - thus opening out new and larger regions of thought.

The

A brilliant and most suggestive example of this kind of potential. reasoning was afforded by a novel mode of treating a large elass of physical problems by means of the introduction of a special mathematical function, termed by George Green, and later by Gauss, the "Potential" or "Potential function." 1 All the problems of Newtonian attraction were concentrated in the study of this formula: and when the experiments of Coulomb and Ampère showed the analogy that existed between electric and magnetic forces on the

${ }^{1}$ See vol. i. p. 231 of this work. The history of the subject has been written by Tollhunter ("History of the Theories of Attraction and the Figure of the Earth,' 2 vols., 1873) for the earlier period down to 1832 . For the later period see Bacharach's 'Abriss der Geschichte der Potentialtheorie,' Göttingen, 1883 ; for the connection of the theory with Riemanu's mathematical methods, especially Prof. F. Klein's tract, 'Ueber Riemann's Theorie der algebraischen Functionen' (Leipzig, 1882, trans. by F. Hardcastle, Cambridge, 1893) ; Prof. Carl Neumann's 'Untersuchungen über das Logarithmische und Newtonische Potential' (Leipzig, 1877); Dr Burkhardt's 'Memorial Lecture on Riemann' (Göttingen, 1892); and juintly with Dr Franz Meyer, the same author's chapter on "Potentialtheorie" in the 2nd volume (p. 464) of the 'Encyclopidie der Math. Wiss.,' 1900. 
one side, and Newtonian forees on the other; still more when Fourier, Lamé, and Thomson (Lord Kelvin) pointed to the further analogy which existed between the distribution of temperature in the stationary thow of heat and that of statical electricity on a conductor, and extended the analogy to hychostaties and hydrodynamics, -it became evident that nature herself pointed here to a mathematical dependence of the highest interest and value. Many eminent thinkers devoted themselves to the study of this subject, but it was reserved for Bernhard Riemann to generalise the mode of reasoning peculiar to these researches into a fundamentally novel method for the explanation and definition of mathematical function or dependence. ${ }^{\mathrm{I}}$

1 Although Riemann's original method of dealing in a general way with algebraical functions is here introduced as a generalisation of certain ideas suggested by mathematical physics, it was not in this way that they were introduced to the mathematical world. This was done in his very abstract and difficult memoir, 'Theorie der Abel'schen Functionen' (published in 1857 in vol. liv. of Crelle's 'Jourual'). In this memoir the counection which existed with mathematical physics was not patent, and it took a long time before his methods, which seemed to be a development of Cauchy's earlier researches, were understood and fully appreciaterl. It was only after he had lectured repeatedly on the subject, and initiated a nutaber of younger mathematicians, who now occupy many of the chairs at the German universities, that the discoveries and inventions of Riemann received their deserved appreciation. Even in his own lectures on mathematical physics- notably on partial differential equations (including harmonics) and the theory of the potentialhe did not learl up to the fundamental ideas which he developed in his lectures on the theory of the Abelian functions. Some light is thrown on the subject of the genesis of liemann's ideas by his dissertation written in the year 1851, though even the biographical notice attached to the 1st edition of his works (1876) did not deal with the origins of his theory. It seems, therefore, correct to date the adequate recognition of Piemann's work in wider circles from the publication in 1852 of Prof. F. Klein's tract mentioned above. Like several other short treatises of this eminent living mathematician, it must have thrown quite a new light upon the subject; and, like several of his other writings, it revealed connections between regions of thought which to many students must have appeared isolated. "Through the treatment initiated l,y Klein, the theory of 
49.

Riemann.

The peculiarity of such dependence, as exemplified in the phenomena of the steady flow of heat or of electric distribution, consisted in this, that if at certain points or in certain regions of space the thermal or electrical conclitions were defined and known by actual observation, then the whole distribution in other points and regions was completely determined. Those boundary conditions could therefore be regarded as the necessary and sufficient definition of the whole existing distribution. Translated into mathematical language, this means that functions exist which are completely defined by boundary values and singularities - i.e., values at single points. Nature herself had shown the way to define and calculate measured relations when through their intricacy they evaded the grasp of the ordinary operations of algebra. ${ }^{1}$ Pliicker had already in geometry (following in the lines of Newton), when attacking the problem of the infinite variety of higher curves, suggested the method of classifying them according to their characteristic properties or singularities. What had been done by geometers and physicists in isolated cases with the expenditure of much ingenuity and skill, Riemann and his school elevated to the rank of a general method and doctrine.

functions acquires a great degree of clearness and connectedness, which is mainly gained by conceptions derived from the (physical) theory of the potential, and thus exhibits the intimate relationship of these theories" (Bacharach, 'Geschichte der Potentialtheorie,' Göttingen, 1883, p. 71).

I On this subject see Burkhardt's 'Memorial Lecture on Riemann' (Göttingen, 1892), p. 5, \&c.; Bacharach (loc. cit.), p. 30, \&c. The latter especially with reference to the theorem called by Clerk-Maxwell "Thomson's theorem " "Cambridge and Dublin Mathematical Journal,' 1848 , or 'Reprint of Paper's on Electro-statics,' \&c., p. 139); and abroad 'Dirichlet's Principle,' after' Riemann (1857). Further, Brill and Nöther's "Bericht" ("Math. Ver.', vol. iii. p. 247); and lastly, a very suggestive address by Prof. Klein ("On Riemann's Influence on Modern Mathematics") to the meeting of the German Association in Vienna in 1894 ('Report,' p. 61). 
It is a process of generalisation and simplification. Moreover, Riemann's manner of proceeding brought with it the gain that he could at once make the various theorems of the doctrine of the potential useful for purely mathematical purposes: the equation which defined the potential in physics became the definition of a function in mathematics. ${ }^{1}$

1 "One may define Riemann's developments briefly thus: that, beginning with certain differential equations which the functions of the complex rariable satisfy, he is enabled to apply the principles of the potential theory. His starting-point, accordingly, lies in the province of mathematical physics" (Klein, 'Vienna Report,' loc. cit., p. 60). By starting with physical analogies I'rof. Kilein evades certain difficulties which the purely mathematical treatment had to encounter. In the preface to his tract of the year 1882, quoted above,-in introducing his method of explaining Riemann's theory,-he say's: "I lave not hesitated to make exactly these physical conceptions the starting-point of my exposition. Instead of them, Riemann, as is well known, makes use in his writ. ings of Dirichlet's principle. But I camnot doubt that he started from those physical problems, and only afterwards substituted Dirichlet's principle in orcler to support the physical evidence by mathe. matical reasoning. Whoever understands clearly the surroundings among which Riemann worked at Gottingen, whoever follows up Riemaun's speculations as they have been handed down to us, partly in fragments, will, I think, share my opinion." And elsewhere he says: "We regard as a specific performance of Riemann in this connection the tendency to give to the theory of the potential a fundamental importance for the whole of mathematics, and further a series of geometrical constructions or, as I would rather say, of geometrical inventions" ("Vienna lieport,' p. 61). K'lein then refers to the representation on the socalled "Riemann surface," which is historically connecterl, as Rienanu hinself points out, with the problem which Gauss first attacked in a general way-viz., the representation of one surface on another in such a manner that the smallest portions of the one surface are similar to those of the other: a problem which is of importance in the drawing of maps, and of which we possess two well-known examples in the stereographic projection of Ptolemy and the projection of Mercator. This method of representation was called by Gauss the "Conformal Image or Representation." His investigations on this mattel were suggested by the Geodetic Survey of the kingdion of Hanover, with which he was occupied cluring the years 1818 to 1830 . (See Gauss, 'Werke,' vol. iv., also his correspondence with Schumacher and Bessel.) A vely complete treatise on this aspect of Riemann's inventions is that by Dr J. Holtzmiiller, "Theorie der Isogonalen Verwandschaften' (Leipzig, 1882). On the historical antecedents of Riemann's conception, which for a long time appeared somewhat strange, not to say artificial, see Brill and Nöther's frequently quoted "Report" ("Bericht der Math. Verein.,' vol. iii.), p. 256 sqq. 
In the investigation of those higher functions which the purely analytical methods of Abel and his followers had forced upon the attention of mathematicians, the methods of Riemann proved to be eminently useful and suggestive. But these novel methods themselves had been imported into the pure science from the side of its application in physics. The value of such ideas has always been questioned by another class of thinkers who aim at building up the edifice of the science by rigorous logic, without making use of practical devices which could only be legitimately employed when once their validity had been thoronghly proved and its limits defined. The merit of having done this in the whole domain of those conceptions which, since the age of Descartes, Newton, and Leibniz, had been introduced as it were from the outside into analysis, belongs to the school of mathematicians headed in Germany by Karl Weierstrass.

Riemann had grown up in the traditions of the school of mathematical thought which was inspired by Gauss and Weber in Göttingen. Geometrical representation and physical application, including the immerliate evidence of the senses, formed a large and important factor in the body of arguments by which scientific discovery and invention was carried on in that school; though Gauss himself made logical rigour the final test of maturity in all his published writings, abstaining in many cases from communicating his results when they had not satisfactorily passed that test in his own mind. Through this self-imposed restriction he had permitted important discoveries, which led to large increase of mathematical knowledge, to be anticipated by others. 


\section{The cases of Canchy, Abel, and Jacolsi are the best-} known instances. Through their labours an entirely new field had been prospected and partially cultivated. It was to this that Weierstrass, the other great leader in modern theory, was attracted. He made the clear definition and logical coherence of the novel conceptions which it involved his principal ain. Ganss had laboured without assistance at similar problems, making many beginnings which even his colossal intellect could not adequately develop. Weierstrass early gathered around him a circle of ardent and receptive pupils and admirers, ${ }^{1}$ to whose care and detailed elaboration he

1 The researches of Weierstrass. (1815 to 1897 ) began somewhat earlier than those of Riemann, but only became generally known and appreciated in their fundamental originality throngh his pupils-his academic influence dating from the year 1861. Some account of Weierstrass's activity is given by Emil Lampe in the 6ith rolume (1899) of the 'Bericht der Nath. Verein.,' p. 27, \&e. The genesis of his ideas is traced by Brill and Nöther in the Report quoted in the last note, and by M. Poincaré in 'Acta Math.,' vol. xxii. The former divides his Researches roughly into two periods, during the first of which $(1848-56)$ he dealt with what Cayley would call "known" functions; progress during this period depending not so much upon fundamentally new ideas as upon an investigation of special problems and great analytical skill. The second period berins in the year 1869, and is devoted to nothing less than the building up of the entire structure of mathematical thought from the very beginning upon altered definitions, through which the dilemmas and paradoxes would be obviated that had shown themselves ever since the middle of the eighteenth century in consequence of a too confident application and extension of conventional ideas suggested mainly by practical problems. The elements of this grand edifice are now largely accepted, not only in Germany, but also in France, Italy, and England. In Germany Prof. O. Stolz, through his works on General Arithmetic, 2 vols. (1855 and 1886), and the Calculus, 3 vols. (1893 to 1899), has probably done more than any other academic teacher to utilise the new system of mathematical thought for the elementary course of teaching. It seems of importance to state, however, that outside of the circle of Weierstrass's influence, and quite within the precincts of Riemann's school, the necessity was felt of strengthening the fonndations on which research in higher mathematics was carried on, by going back to the fundamental ideas of arithmetic. The principal representative of this line of research was Hermann Hankel (1839-73), a pupil of Riemam's, who, in the 
confided many separate and lengthy investigations. It was through one of these that a test-case, in which existing mathematical definitions broke down, was published in 1872. It forms a kind of era in the history of

middle of the sixties, delivered lectures at the University of Leipsic upon "Complex numbers and their functions," starting in a characteristic manner with that extended algebra which Cauchy and Riemaun had used to such good purpose. The first part of these lectures was published in $\mathbf{1 8 6 7}$. In the preface Hankel says: "In the natural sciences we witness in recent times the distinct tendency to ascend from the world of empirical detail to the great priuciples which govern every thing special and comnect it into a whole-i.e., the desire for a philosoplyy of nature, not forced upon us from outside, but naturally evolved out of the subject itself. Also in the domain of mathematies a similar want seems to make itself generally felt -a want which has always been alive in England." Had the author not been prematurely taken away, there is no doubt that he would have still more largely contributed to the rerolution of mathematical ideas now in progress. As it is, he made one further important contribution, of which more hereafter. In Italy Prof. Ulisse Dini began to lecture in the year 1871 to 1872 on the theory of functions, and published his lectures in 1878. A translation was brought out in German (1592) by Prof. Lüroth and $\mathrm{Mr}$ A. Schepp, in which many of the modern developments are utilised. In France we owe to M. Jules Tannery a valuable introduction to the theory of functions of one variable, based upon a series of lectures delivered in the Ecole Normale in 1883, in which, as he says
(Preface, p. vii), he collected the labours of Cauchy, Abel, Lejeune Dirichlet, Riemann, Ossian Bonnet, Heine, Weierstrass, and others; after which he considers that nothing essential need be added in the way of elucidation of the foundations of the theory. II. Émil Borel published in 1898 'Lectures on the Theory of Functions,' the first of a series of text-books dealiug with various aspects of the theory of functions, in which he largely refers to the labours of Weierstrass. Before Weierstrass's theory had become knowu, however, M. Méray had already entered upon an exposition of the foundations of analysis on lines which had much analogy with those adopted by Weierstrass. In England the late Prof. Clifford had occupied himself in various memoirs with the theories of Rienann; but we owe the first comprehensive treatise, embraciug the work of Riemann as well as that of Weierstrass, to Prof. Forsyth ("Theory of Functions of a Complex Variable,' Cambridge, 1893). Almost simultaneously Professors Harkness and Morley published a "Treatise on the Theory of Functions,' and in 1898 an 'Introduction to the 'Theory of Analytic Functions,' in which they in the main adopterl the point of view of Weierstrass. A very original thinker, whose independent researches reach back to the year 1872 , and who played an important part in the investigation of many obscure points, was the late Prof. Paul Du Bois-Reymond, who published in 1882 the first part of his 'Allgemeine Func. tionentheorie,' containing the 
mathematical thought. Up to that time "one would have said that a continuous function is essentially capable of being represented by a curve, and that a curve has always a tangent. Such reasoning has no mathematical value whatever; it is founded on intuition, or rather on a visible representation. But such representation is crude and misleading. We think we can figure to ourselves a curve without thickness; but we only figure a stroke of small thickness. In like manner we see the tangent as a straight band of small thickness, and when we say that it touches the curve, we wish merely to say that these two bands coincide without crossing. If that is what we call a curve and a tangent, it is clear that every curve has a tangent; but this has nothing to do with the theory of functions. We see to what error we are led by a foolish confidence in what we take to be visual evidence. By the discovery of this striking example Weierstrass has accordingly given us a useful reminder, and has taught us better to appreciate the faultless and purely arithmetical methods with which he more than any one has emriched our science." 1

"metaphysics and theory of the fundameutal conceptions in mathematics : quantity, limit, argument, and function" (Tiibingen). This work touches the borderland of mathematics and philosophy, as does the same author's posthumons work 'Über die Grundlagen der Erkenntniss in den exacten Wissenschaften' (Tiibingen, 1890), and will occupy us in another place.

1 II. Poincaré iu the 'Acta Mathematica,'vol. xxii., "L'œuvre mathématique de Weierstrass," p. 5. The "test-case" referred to in the text consisted in the publica.

VOL. II. tion by Weierstrass (in the year 1872, 'Trans. Berlin Academy,' reprinted in Weierstrass's 'Math. Werke,' vol. ii. p. 71) of the proof of the existence of a continuous function which uowhere possessed a definite (finite or infinite) differential coefficient. This example cleared up a point brought into prominence by Riemann in his posthumously (1867) published Inaugural Dissertatiou of 1854 ('Werke,' p. 213). The question had already, following on Riemann's suggestions, been dis. cussed by Hermann Hankel in a 
Before Weierstrass, Cauchy and Riemann had attempted to define the vague term "function" or mathematical dependence. Both clung to the graphical representation so common and so helpful in analysis since Descartes invented it. We have, of course, in abstract science, a right to begin with any definition we choose. Only the definition must be such that it

remarkable tract on "Oscillating functions," in which he drew attention to the existence of functions which admit of an integral, but where the existence of a differential coefficient remains doubtful. In fact, it appears that the question as to the latter had never been raised; the only attempt in this direction being that of Ampère in 1806, which failed (Hankel, p. 7). Hankel in his original investigation showed that a continuous eurve might be supposed to be generated by the motion of a point which oscillated to and fro, these oscillations at the limit becoming infinitely numerous and infinitely small: a curve thus generated would present what he called "a coudensation of singularities" at every point, but would possess no definite direction, hence also no differential coefficient. The arguments and illustrations of Hankel have been criticised and found fault with. He nevertheless deserves the credit of having among the first attempted "to gain a firm footing on a slippery road which had only been rarely trodden" (p. 8). In this tract (which is reprinted in 'Math. Ann.' vol. xx.), as well as in his valuable article on "Limit" (Ersch und Gruber, 'Encyk.,' rol. xc. p. 185 , art. "Grenze"), Hankel did much to establish clearly the essential point on which depends the entire modern revolution in our ideas regarding the foundations of the so-called infinitesimal cal. culus; reverting to the idea of a "limit," both in the definition of the derived function (limit of a ratio) and of the integral (limit of a sum) as contained in the writings both of Newton and Leibniz, but obscured by the method of "Fluxions" of the former and the method of "Infinitesimals" of the latter. Lagrange and Cauchy had begun this revolution, but it was not consistently and generally carried through till the researches of Riemaun, Hankel, Weierstrass, and others made rigorous definitions necessary and generally accepted. It is, however, well to note that in this country $A$. de Morgan very early expressed clear views on this subject. Prof. Voss, in his excellent chapter on the Differential and Integral Calculus ("Encyk. Math. Wiss.,' vol. ii. i. p. 54 , \&c.), calls the later period the period of the purely arithmetical examination of infinitesimal conceptious, and says (p. 60), "The purely arithmetical definition of the infinitesimal operations which is characteristic of the present critical period of mathematics has shown that most of the theorems established by older researches, which aimed at a formal extension of metliod, only possess a validity limited by very definite assumptions." Such assumptions were tacitly made by earlier writers, but not explicitly stated. 
corresponds with conditions which we neet with in reality, say in geometry and physies, otherwise our science becomes useless: further, our definitions must be consistent, and follow logically from the fundamental principles of axithmetic, otherwise we run the risk of sooner or later committing mistakes and encountering paradoxes. We have two interests to serve: the extension of our knowledge of functions and the rigorous proof of our theorems. The methods of Riemamn and of Weierstrass are complementary. "By the instrument Riemann of Riemann we see at a glance the general aspect of compared. things-like a traveller who is examining from the peak of a mountain the topography of the plain which he is going to visit, and is finding his bearings. By the instruments of Weierstrass analysis will, in due course, throw light into every corner, and make absolute clearness shine forth." ${ }^{1}$. The complementary character of

1 Poincaré, loc. cit., p. 7. Similarly Prof. Klein (loc. cit., "Viema Report,' p. 60): "'The founder of the theory [viz., of functions] is the great French mathematician Cauchy, but only in Ger. nuany has it received that modern stamp through which it has, so to speak, beeu pushed into the centre of our mathematical con. victions. This is the result of the simultaneous exertions of two workers-Riemann on the one side and Weierstrass on the other. Although directed to the same end, the methods of these two mathe. maticians are in detail as different as possible: they almost seem to contradict each other, which contradiction, viewed from a higher aspect, naturally leads to this-that they mutually supplement each other. nVeierstrass defines the functions of a complex variable analytically by a conmon formula - viz., the 'Iufinite Power Series'; in the sequel he avoids geometrical means as much as possible, and sees his specific aim in the rigour of proof. Riemann, on the other side, begius with certain differential equations. The subject then immediately acquires a physical aspect. . . His starting-point lies in the region of mathematical physics." We now know from the biographical notice of Riemann, attached to his collected works (1st ed., p. 520), that he was pressed (iu 1856) by his mathematical friends to publish a résumé of his Researches on Abelian functions-"be it ever so crude." The reason was that Weierstrass was already at work on the same subject. In consequence of Riemann's 
the labours of the two great analysts is nowhere better shown than in the special manner in which Weierstrass succeeded in strengthening the foundations ${ }^{1}$ on which much of Riemann's work rests.

The labours of the great analysts-Gauss, Cauchy, Riemann, and Weierstrass-all tended to increase our

publication Weierstrass withdrew from the press an extensive memoir wlich he had presented in the year 1857 to the Berlin Academy, because, as he himself says (Weierstrass, 'Math. Werke,' vol. iv. p. 10): "Riemann published a memoir on the same problem which rested on entirely different foundations from mine, and did not immediately reveal that in its results it agreed completely with my own. The proot of this required insestigations which were not quite easy, and took much time; after this difficulty had been removed a radical remod. elling of my dissertation seemed necessary," \&c., \&c. The mutual influence of Riemann's and Weierstrass's work is also referred to by Weierstrass in a letter to Prof. Schwarz, dated 1875 , in which he utters what he calls his confession of faith: "The more I ponder over the principles of the theory of functions - and I do this incessantly - the stronger grows my conviction that it must be built up on the foundation of algebraical truths, and that, therefore, to employ for the proof of simple and fundamental algebraical theorems the 'transcendental,' if I may say so, is not the correct way, however enticing prima vista the considerations may be by which Riemann bas discovered many of the most important properties of algebraical functions. It is a matter of course that every road must be open to the searcher as long as he seeks; it is only a question of the systematic demonstration" (Weierstrass, 'Werke,' vol. ii. p. $235)$.

1 This refers mainly to Weierstrass's investigation of the principle called by Riemann "Dirichlet's principle," but which had been stated already with great generality by Thomson (Lord Kelvin) in the year 1847. The validity of this method depended on a certain minimum theorem. Weierstrass has shown that the existence of such a minimum is not evident, and that the argument used is not conclusive. He laid before the Berlin Academy, in the year 1870 , a communication giving a test-case to prove that Dirichlet's method was not generally valid ('Werke,' vol. ii. p. 49). "Through this," Prof. Klein says (loc. cit., p. 67), "a great part of Riemann's developments become invalidated. Nevertheless the far-reaching results. which Riemann bases upon the prineiple are all correct, as was shown later on exhaustively and with all rigour by Carl Neumann and H. A. Schwarz. Indeed we must come to the conclusion that Riemann himself arrived at these theorems by a physical intuition, and only afterwards resorted to the principle referred to in order to have a consistent mathematical line of reasoning " (loc. cit., p. 67). See on this also Poincaré (loc. cit., pp. 10 and 15), who gives other instances where the work of Weierstrass supported that of Riemann. 
knowledge of the higher mathematical relations, but also to reveal the uncertainty and absence of rigorous definition of the foundations of arithmetic and of geometry. Accordingly we find these great thinkers continually interrupting their more advanced researches by examinations of the principles. This feeling of uncertainty harl led, ever since the end of the eighteenth Examina. tion of forudations. century, to many isolated attacks and half-philosophical discussions by various writers in this country and abroal. Many of them remained long unrecognised; such were the suggestive writings of Hamilton, De Morgan, Peacock in England, Bolzano ${ }^{1}$ in Bohemia,

1 The merits of Beruhard Bolzano (1781-1848) as one of the earliest representatives of the critical period of mathematics were recognised after a long interval of neglect by Hankel in his article on "Limit" mentioned above. This philosophical mathematician published many years before Cauchy a tract on the Binomial Theorem (Prague, 1816), in which he gives, in Hankel's opinion, the first rigid deduction of various algebraical series. "Bolzano's notions as to convergency of series are eminently clear and correct, and no fault can be found with his development of those series for a real argument (which he everywhere presupposes); in the preface he gives a pertinent criticism of earlier developments of the Binomial Theorem, and of the un. restricted use of infinite series, which was then common. In fact, he has everything that can place him in this respect on the same level with Cauchy, only not the art peculiar to the French of refining their ideas and communicating them in the most appropriate and taking manner. So it came about that Bolzano remained unknown and was soon forgotten; Cauchy was the happy one who was praised as a reformer of the science, and whose elegant writings were soon widely circulated." (Hankel, loc. cit., p. 210.) Following on this statement of Hankel and a remark of Prof. H. A. Schwarz, who looks upon Bolzano as the inventor of a line of reason. ing further developed by Weierstrass ('Journal fiir Mathematik,' vol. Ixxiv. p. 22, 1872), Prof. O. Stolz published in 1881 ("Math. Ann.,' vol. xviii. p. 255 ) an account of the several writings of Bolzano, beginning in the year 1810 , in so far as they referred to the principles of the Calculus. "All these writings are remarkable inasunch as they start with an unbiassed and acute criticism of the contributions of the older literature" (loc. cit., p. 257). A posthumous tract by Bolzano, 'Paradoxieen des Unendlichen,' was republished in 1889 in 'Wis. senschaftliche Classiker,' vol. ii., Berlin (Meyer and Miiller). As stated above, Hankel was also one of the first to draw attentiou to the originality and importance of Hermann Grassmann's work. 
Bolyai in Hungary, Lobatchevski in Kasan, Grassmann in Stettin. Most of these were unknown to each other. However, near the beginning of the last third of the century three distinct publications created a great stir in the mathematical world, brought many scattered but cognate lines of reasoning together, and made them mutually fertile and suggestive. These three were-first, the publication in 1860 of Gauss's correspondence with Schumacher, in which two letters of the former, dated May and July 1831, ${ }^{1}$ became known, where he referred to his extensive but unwritten and unfinished speculations on the foundations of geometry and the theorem which refer's to the sum of the angles in a triangle. The second was the publication in 1867 of the first and only part of Hermann Hankel's "Lectures on the Complex Numbers and their Functions." ${ }^{2}$ The third was the posthumous publication in the same year of Riemann's paper, dated $1854,{ }^{3}$ " On the Hypotheses which lie at the Foundation of Geometry." Almost simultaneously there appeared the first of Helmholtz's two important papers ${ }^{4}$ on the

1 See 'Briefwechsel zwischen Gauss und Schumacher,'ed. Peters, 1860, vol. ii. pp. 260, 268.

2 The small volume contains so much original and historical matter that I have on several occasions refered to it. See above, pp. 645 , 653.

3 Riemann, 'Math. Werke,' 1st ed., p. 254 sqq.

4 The first publication of Helmholtz was a lecture on "the actual foundations of geometry," which he delivered on the 22nd May 1868 to the Medical Society at Heidel. berg. This communication, which referred to investigations carried on for many years, - notably in connection with the theory of the colour-manifold, - was occasioned by the publication of Riemann's paper in the 'Transactions' of the Göttingen Society. He had heard of this through schering, to whom he wrote onl the 21st April 1868 before having seen Riemann's paper: "I have myself beell occupied with the same subject during the last two years, in connection with my researches in physiological optics. . . I I now see, from the few hints which you give as to the 
same subject, through which it became more widely known and attracted the attention of other than purely mathematical writers. The small but eminently suggestive volume of Hankel showed the necessity of a revision and extension of the fundamental principles and definitions ${ }^{1}$ of general arithmetic and algebra as

result of the investigation, that Riemann has arrived at exactly the same results. My startingpoint was the question, How must a magniturle of several dimensions be constituted, if solid bodies are to move in it everywhere continuously, monodromically, and as freely as bodies move in real space?" On receiving from Schering a reply with a copy of Riemann's paper, Helmholtz wrote (18th May), "I enclose a short exposition of that which in my researches on the same subject is not covererl by Riemann's work." A fuller paper, with the title "On the Facts which lie at the foundation of Geometry," appeared in the 'Göttinger Nachrichten,' June 3, 1868. See Helmholtz, 'Wiss. Abhandl.,' vol. ii. pp. 610 and 618 , \&c. ; also 'H. von Helmholtz,' by Leo Koenigsberger (1903), vol. ii. p. 138, \&e. In another lecture, "On the origin and meaning of the Axioms of Geometry" (1870, reprinted in abstract in 'The Acardemy,' vol. i.), as well as in an article in vol. $i$. of 'Mind' (p. 301), he discussed "the philosophical bearing of recent inquiries concerning geometrical axioms and the possibility of working out analytically other systems of geometry with other axioms than Euclid's" (reprinted in vol. ii. of 'Vorträge und Reden').

I In this treatise Hankel introduced into German literature the three terms "distributive," "asso. ciative," and "commutative" to define the three principles which govern the elementary operations of arithmetic, and introducer further what he calls the principle of the permanence of formal rules in the following statement: "If two forms, expressed in the general terms of universal arithnetic, are equal to each other, they are to remain equal if the symbols cease to denote simple quantities; hence also if the operations receive a different meaning." Hankel seems to have been led to his definitions by a study of French and English writers, among whom he mentions Servois ('Gergomne's Ann.,' v. p. 93, 1814) as having introduced the terms "distributive" and "eommutative," and Sir IV. R. Hamilton as having introduced the term "associative." He further say's (p. 15): "In England, where investigations into the funclamental principles of mathematics have always been treated with favour, and where even the greatest mathematicians have not shunned the treatment of them in learned dissertations, we must name George Peacock of Cambridge as the one who first recognised emphatically the need of formal mathematics. In his interesting report on certain branches of analysis, the principle of permanence is laid down, though too narrowly, and also without the necessary foundation." Other writings, of what he terms Peacock's Cambridge school, such as those of De Morgan, Hankel states that he had not inspected ; mention- 
an introduction to the advanced theories of Gauss and Riemann; and for this purpose he went back to the umnoticed labours of Grassmann in Germany, to the writings of Peacock and De Morgan in England, and incidentally introduced into Germany the elaborate algebra of quaternions, invented and practised by Hamilton twenty years before that time. The papers of liemann and Helmholtz similarly showed the necessity of a thorough investigation of the principles and foundations of ordinary or Euclidean geometry, and showed how consistent systems of geometry could be elaborated on other than Euclidean axioms. Only

Non-

Euclidean geometry. from that moment, in fact, did it become generally recognised that already, a generation before, two independent treatises on elementary geometry had been published in which the axiom of parallel lines was dispensed with and consistent geometrical systems developed. These were contained - as already stated - in the 'Kasan Messenger,' under date 1829 and

ing only a short paper by $\mathrm{Dr}$ F. Gregory on Symbolical Algebra in the Edinburgh 'Transactions.' Whilst Hankel was delivering lectures on these fundamentals, Weierstrass in Berlin was likewise in the habit of introducing his lectures on the Theory of Analytic Functions by a discussion of the theory of Complex Numbers. This introduction was published, with Weierstrass's permission, in the year 1872 by Dr E. Kossak (in a programme of the Friedrichs-Werder Gymnasium), after lectures delivered by Weierstrass in 1865-66. To what extent Hankel may have been influenced by Weierstrass's lectures, which he seems to have attended after leaving Göttingen, is uncertain, for in spite of his very extensive references he does not mention Weierstrass. In Kossak's 'Elemente der Arithmetik' the term "permanence of formal rules" is not used, but the treatment of the extended arithmetic is carried on along the same lines-i.e., not by an attempt to represent the complex quantities, but on the ground of maintaining the rules which govern the arithmetic of ordinary numbers. Great importance is also attached to the principle of inversion as having shown itself of value in the theory of elliptic functions, and being not less valuable in arithmetic. As stated above (p. 640 , note), this principle is also insisted on by Peacock. 
1830 , the author being Lobatchevski; and in the appendix to an Introduction to Geometry, published by Wolfgang Bolyai at Maros Vasarheli, a town of Transylvania, the appendix being by the author's son, Johann Bolyai. The elder Bolyai having been a friend and correspondent of Gauss, and his speenlations evidently of the same nature as those indicated by the latter in the above-mentioned correspondence, conjectures have been made as to which of the two originated the whole train of thought. ${ }^{1}$ The independent investigations of Riemann and Helmholtz started from a differ-

1 See above, p. 652, note. What is important from our point of view in the investigations of both Riemann and Heluholtz lies in the following points: First, Neither Riemaun nor Hehnholtz refers to the non-Euclidean geometry of Lobatchevski or Bolyai. This is not surprising in the case of Helmholtz, whose interest was originally not purely mathematical ; in fact, we may incidentally remark how, in spite of his profound mathematical ability, he on various occasions came into close contact with mathematical researches of great originality and importance without recognising them - e.g., the researches of Grassmam and Plïcker. As regards Riemann, his paper was read before Ganss, who certainly knew all about Bolyai, and latterly also about Lobatchevski, of whom he thought so highly that he proposed him as a foreign nember of the Göttingen Suciety. Gauss could therefore easily have pointed out to Riemann the relations of his speculations with his own and those of the other mathematicians named. Since the publication of the latest volume of Gauss's works, it has become evident that Gauss corresponded a good deal, and more than one would have supposed from reading Sartorius's obituary menoir, on the subject of non-Euchidean (astral or imag. inary) geometry, notably with Gerling; and that several contemporary mathematicians, such as Scliweikart, came very near to Gauss's own position. Second, although Riemann, and subsequently also Helmholtz, made use of the term "manifold" (Mannigfaltig. keit), it does not appear in the course of their discussion that they cousidered the space-manifold from any other than a metrical point of view. In fact, the manifold becomes in their treatment a magni. tude (Grössc). It is true that Riemann does refer to certain geometrical relations not con. nected with magnitude but only with position, as being of great importance. These two points through which the researches of Riemamn and Helmholtz stand in relation to other, and at the time isolated, researches, were dwelt on, the first by Beltrami, and the second by Cayley and Prof. Klein. 
ent origin: both made use of the more general conception of an extended magnitude, introduced the notion of the curvature of space by analogy with Gauss's measure of curvature of a surface, and tried to express in algebraical formule the general and necessary properties of a magnitude which should form the foundation of a geometry. The relation of these algebraical results to those arrived at by the critical and purely geometrical methods of Lobatchevski and Bolyai were set ont by Beltrami, who showed clearly that three geometries of two dimensions are possiblethe Enclidean, that of Lobatchevski, where the three angles of a triangle are less than two right angles, and a third where they are more. He showed the analogy of the third with geometry on the sphere, and suggested the pseudo-sphere as a surface on which the second could be similarly represented. At the same time he indicated the generalisation through the algebraical formula of the conception of dimensions, and introduced the symbolical term geometry of four or more dimensions, as Grassmamn and Cayley had done before him. ${ }^{1}$ Through all these investigations a habit

1 The geometry of non-Euclidean space, as well as the geometry of four or more dimensions (both usually comprised under the term "non-Eucliclean geometry"), can now boast of an enormous literature, the enumeration of which alone would fill many pages. A complete bibliography up to the year 1878 is given in vols, i. and ii. of the American 'Journal of Mathematics' by Prof. Bruce Halsted, who has done much to make known to English readers the original writings of the pioneers in this subject. Later publications are referred to in Dr Victor Schlegel's papers ('Leopoldina,' xxii., 1886, Nos. 9.18): "Ueber Entwickelung und Stand der n-dimensionalen Geometrie," \&c., \&c. In France Houell published (beginning with the year 1866) translations of memoirs referring to this subject; in fact, he was almost the first to draw attention to this important modern departure. But it is almost exclusively owing to the various writings of Prof. Felix Klein that 
has been introduced into mathematical writings which has not a little puzzled outsiders, and even cxposed the logically rigorous deductions of mathematicians to the ridicule-not to say the contempt-of eminent philosophical authorities. The complete parallelism or correspondence of geometrical with algebraical notions - the possibility of expressing the former with perfect accuracy by the latter, and of retranslating the latter into the former, and this in more than one way, according to the choice of the space element (point, line, sphere), led to the habit of using purely geometrical presentable ideas as names for algebraical relations which had been generalised by the addition of more than a limited number of variables. Thus the conception of curvature, easily defined for a plane curve, and extended by Ganss to surfaces, was, by adding a third of space. variable in the algebraic formula, applied to space. We are then told that it is necessary to understand what is meant by the curvature of space, this being a purely algebraical relation, not really presentable, but only formed by analogy from the geometrically presentable relations of geometry on a surface. In a similar

the differcnt points of origin of this most recent mathematical specula. tion, which are to be found in the mathematical literature of all the principal nations, have been put in the true light and bronght into connection. In fact, here, as in several other subjects, his publications, including his litbograpled lectures on non-Euclidean geometry (delivered at Götingen, 1893-94), serve as the best guide through the labyrinth and controversies of this intricate subject. See especially his article "Ueber die so-genannte nicht-Euclidische Geometrie" in vol. iv., 'Math. Ann.,' 1871. In this paper he connects the independent researches of Cayley (following Laguerre, 'Nouv. Ann. de Math.,' 1853), who in his sixth memoir on Quantics showed how metrical geometry can be included in projective geumetry by referring figures to a fundamental fixed figure in space called by him the "Absolute," with the independent researches of Lobatchevski, Bolyai, Riemann, and Beltrami. 
way the idea of the dimensions of space was extended, and four and more dimensions freely spoken of when really only a limited number is geometrically presentable. In the hands of mathematicians these terms are useful, and we may discard the criticism of philosopher's and laymen as based on misunderstanding. ${ }^{1}$ The introduction, however, into geonetrical work of conceptions such as the infinite, the imaginary, and the relations of hyperspace, none of which can be directly imaged, has a psychological significance well worthy of examination. ${ }^{2}$ It gives a deep insight into the resources and working of the mind. We arrive at the borderland of mathematics and philosophy.

1 The most important philosophical criticism of the non-Euclidean geometry is that of Lotze, contained in the second book, chap. ii., of the 'Metaphysik' (1879, p. 249 , \&c.) It must not be forgotteu that Lotze wrote at a time when the novel and startling conceptions put forward by popular writers ou the subject had been employed in the interest of a spiritualistic philosophy, to the delusions of which some even of Lotze's friends had fallen a prey. This explains the severity of Lotze's criticisms, which are of the very same nature as those he pronounced many years earlier on similar aberrations (see 'Kleine Schriften,' vol. iii. p. 329). 'Those who are interested in following up the subject should refer tol the writings of Friedr. Zöllner as collected in the four vols. of his 'Wissenschaftliche Abhandlungeo' (Leipzig, 1878-81). They belong to the curiosities of the philosophical and scientific literature of that age, but can hardly claim a place in the bistory of thought.

2 See the remark of Cayley in his Presidential Address ('Coll. Works,'

vol. xi. p. 434): "The notion, which is really the fundamental one (and I cannot too strongly emphasise the assertion), underlying and pervading the whole of modern analysis and geometry, is that of imaginary magnitude in analysis and of imaginary space for space as a locus in quo of imaginary points and figures) in genmetry. I use in each case the word imaginary as including real. This has not been, so far as I am aware, a subject of philosophical discussion or inquiry. As regards the older metaphysical writers, this would be quite accounted for by saying that they knew uothing, and were not bound to kuow any thing, about it; but at present, and considering the prominent position which the notion occupies-say even that the conclusion were that the notion belongs to mere technical mathematics or has reference to nonentities, in regard to which no science is possible-still it seems to me that (as a subject of philosophical discussion) the notion ought not to be thus ignored ; it should at least be shown that there is a right to ignore it." 
'There exists, moreover, an analogy between the manner in which these novel and extended ideas have been historically introduced and the mode of reasoning which led Sir W. R. Hamilton to the invention of a new and extended algebra-the algebra of quaternions. This analogy becomes evident if we study the small volume of Hermann Hankel, which appeared about the same time as Riemann's and Beltrami's fundamental geometrical dissertations.

The extension of Hamilton was only possible by dropping one of the fundamental principles of general arith. Generalised metic, the commutative principle of multiplication, which is symbolically expressed by saying that $a \times b$ is equal to $b \times a$. By assuming that $a \times b$ is equal to $-b \times a$, Hamilton founded a new general arithmetic on an apparently paradoxical principle. Similarly Lobatcherski and Bolyai constructed new geometries by dropping the axiom of parallel lines. Hankel made clear the significance of the new algebra, Riemann and Beltrami that of the new geometry. The practical performance anticipated and led up to the theoretical or philosophical exposition of the underlying principles. But there was a third instance in which a new science had been created by abandoning the conventional way of looking at things. This was the formation of a consistent borly of geometrical teaching by disregarding the metrical properties and studying only the positional or projective properties, following Monge and Poncelet. The two great minds who worked out this geometry independently of the conception of number or measurement, giving a purely geometrical definition of distance and number, were Cayley in Eng- 
land and Von Staudt in Germany. It was reserved for 56. Prof. Felix Klein of Göttingen to show how the generKlein's exposition. alised notions of distance introdnced into geometry by Cayley and Von Standt opened out an understanding of the three geometries of Euclid, of Lobatchevski, and of Riemann. ${ }^{1}$ We have to go back to the purely projective properties of space to understand these different possibilities. Lobatchevski attacked the problem practically, Riemamn analytically, Klein geometrically. Through the labours of Klein the subject has arrived at a certain finality. And what was still wanting after he had written his eelebrated memoir (which was approved and

1 See the note on p. 714, above; also 'Math. Ann.', vol. iv. p. 573, and vol. vi. p. 112. Prof. Klein -following a usage in mathematical language - distinguishes three different geometries, the hyperbolic, the elliptic, and the parabolic geometry, corresponding to the possession by the straight line at infinity of two real or two imaginary (that is, none) or two coincident points. The whole matter turns upon the fact that, although metrical relations of figures are in general changed by projection, there is one metrical relation-known in geometry as the "anharmonic ratio" (in German Doppelverhältniss)-which in all projective transformations remains unchanged. As this anharmonic ratio of points or lines can be geometrically constructed without reference to measurement (Vou Staudt, 'Geometrie der Lage,' 1847 and 1857), a method is thus found by which, starting from a purely descriptive property or relation, distance and angles-i.e., metrical quantitiescan be defined. Some doubts have been expressed whether, starting from the purely projective properties of space and building up geometry in this way (arriving at the metrical properties by the construction suggested by Von Staudt), the ordinary idea of distance and number is not tacitly introduced from the beginning. This may be of philosophical, but is not of mathematical, importance, as the main object in the mathematical treatment is to gain a starting - point from which the several possible con. sistent systems of geometry can be deduced and taken into view together. See on this point, inter alia, Cayley's remarks in the appendix to vol. ii. of ' Collected Works' (p. 604 sqq), also Sir R. S. Ball's paper (quoted there), and more recently the discussion on the subject in $\mathrm{Mr}$ Bertrand Russell's 'Essay on the Foundations of Geometry' (1897, p. 31, \&c.; p. 117, \&c.) See also the same author's article on non-Euclidean Geometry in the supplement of the 'Ency. Brit.,' vol. xxviii. 
commented on by Cayley) was later on supplied in consequence of a suggestion of his. The researches of Riemann, and still more those of Helmholtz, had not merely a mathematical, they had also a logical and a psychological, meaning. Space was conceiverl to be a threefold-extended manifold. There are other manifolds besides space--such, for instance, as the threefoldextended manifold of colours. Helmholtz canre from the study of this manifold to that of space. Now the question arises as to the conditions or data which are necessary and sufficient for the foundations of a science like geometry. We have seen that the axiom of parallel lines is not required; we have also seen that the notion of distance and number can be generalised. What other data remain which cannot be dispensed with? Helmholtz had attempted to answer this question. But neither he nor Riemam had considered the possibility of a purely projective geometry. Now it is the merit of Prof. Klein to have seen that there exists a purely algebraical method by which this problem can be attacked. This is the method of groups referred to above, and applied by Sophus Lie to assemblages of continuously Sophis Lie. variable quantities. Klein was one of the first to recognise the power of this new instrument. He saw that the space problem was a problem of transformations, the possible motions in space forming a group with definite elements (the different freedoms of motion) which were continuously variable-i.e, in infinitesinal quantitiesand which returned into themselves under certain welldefined conditions. They possessed, moreover, in the maintenance of distance the algebraic property of in- 
variance. He also expressed some doubt regarding the logical consistency of the assumptions of Helmholtz. Sophus Lie undertook this investigation, and thus brought the logical side of the labours of Riemann and Helmholtz to a final conclusion. ${ }^{1}$ This is one of the celebrated instances where the rigorons algebraical methods have detected flaws in the more intuitional or purely geometrical process, and extended our knowledge of hidden possibilities.

But there is yet another branch of the great science of number, form, and interdependence, the principles and foundations of which had been handed down from earlier ages, where the critical and sifting process of the nineteenth century has led to an expansion and revolution of our fundamental ideas. Here also, as in so many other directions, the movement begins with Ganss. Hitherto I have spoken mainly of algebra or general arithmetic, of geometry, of the connections of both in the

1 "Lie was early made aware by Klein and his "program" that the space problem belonged to the theory of groups.... Ever since 1880 he had been pondering over these questions; he published his views first in 1886 on the occasion of the Berlin meeting of natural philosophers. Helmholtz's conception was itself unconsciously (but remarkably so, iuasmuch as it dates from 1868) one belonging to the theory of groups, trying, as it did, to characterise the groups of the sixfold infinite motions in space, which led to the three geometries, in comparison with all other groups. He did this by fixing on the free mobility of rigid bodies-i.e., on the existence of an invariaut between two points as the oniy essential invariant. When Lie took up this problem in principle, as one belonging to the theory of groups, he recognised that for our space that part of the axiom of monodromy was unnecessary which added periodicity to the free mobility round a fixed axis. . . The value of these investigations lies mainly in this, that they permit of our fixing for every kind of geometry the most appropriate system of axioms. . . . And they justly received in the year 1897 the first Lobatcherski prize awarded by the Society of Kasan" (M. Nöther, 'Math. Ann.,' vol. liii. p. 38). A lucid exposition of Lie's work will be found in Mr B. Russell's 'Essay,' \&c., p. $47 s q q$. 
theory of forms and functions: there remains the science of numbers-of number in the abstract and also of the named numbers of ordinary arithmetic. Gauss's earliest numbers. labours were comnected with this branch. Superseding the work of Fermat, Euler, and Legendre, he produced that great book with seven seals, the 'Disquisitiones Arithmetice.' The seals were only gradually broken. Lejeune Dirichlet did much in this way: others followed, notably Prof. Dedekind, who published the lectures of Dirichlet and added much of his own. The question may be asked, Have we gained any new icleas about numbers?

In this abstract inquiry we can again facilitate our survey by distinguishing between the practical and the purely theoretical interests which stimulated it. Looking at the matter as well as the formal treatment by which it was rendered accessible, we may say Ganss not only taught us some very remarkable new properties of numbers-he also invented a new instrument or calculus for their investigation. Let us consider his work and that of his follower's from these different points of view.

First, then, there were certain definite problems connected with the properties of numbers which had been handed down from antiquity. Such were the division of the circle into equal parts by a ready geometrical construction, the duplication of the cube, and the quadrature of the circle or the geometrical construction of the number $\pi .^{1}$ To the latter may be attached the

1 See above, vol. i. p. 181, note. The student will find much interesting matter referring to these problems in Prof. Klein's little

VOL. II. volume entitled 'Famous Problems in Elementary Geometry,' transl. by Beman and Smith, Boston and London, 1879. In it is also given
58. 
properties of the number $e$, the basis of the Napierian or natural logarithms, this number having been shown by Euler to stand in a remarkable arithmetical relation to the number $\pi$-a relation which could be very simply expressed if one had the courage to make use of the imaginary unit. As in the instance referred to above, when I dealt with the problem of the solution of the higher order of equations, so also in the case of the three celebrated problems now under review, the reasoning of the mathematicians of the nineteenth century lay largely in proving why these problems were insoluble or in defining those special cases in which they were soluble. Moreover, the labours of Gauss and the class of matheInaticians who followed or read him were directed towards the defining and fixing of general conceptions, the study and elaboration of which embraced these single problems as special cases. Prime numbers had always been the object of special attention. Division and par-

au account of several mechanical contrivances for the solution of transcendental problems, or of those where the use of the compass and the ruler do not suffice. Although accurate constructions with a ruler and compass, or with either alone, were known to the ancients only in comparatively small numbers, approximations, and sometimes very close ones, seem to have been known. A very interesting example is Röher's construction of the regular heptagon, of which we read in the correspondence of Sir W. R. Hamilton with De Morgan (Life of Hamilton, by Graves, vol, iii. pp. $141,534)$, and which was described by him in the 'Phil. Mag.,' February 1864 . The approximation to the correctly calculated figure of the true septisection of the circle was so close that he could not discover, up to the 7 th decimal, whether the error was in the direc. tion of more or less. On carrying the calculation further, he found the approximation to be such that a heptagon stepped round a circle equal in size to the equator would reach the starting-point within 50 feet. The inventor or discoverer of this method-Röber, an architect of Dresden-supposed that it was known to the ancient Egy ptians, and in some form or other cun. nected with the plans of the temple at Edfu, but on this point I have obtained no information. The ques. tion is not referred to in Prof. Cantor's 'History of Mathematics.' 
tition of numbers had been studied, and many interesting formulie had been found by induction, and subsequently proved-or not proved-by a multitude of ingenions devices. As in so many other directions of research so also here, the genius of Gauss gave a great impetus to progress by the invention of a definite calculus and an algorithm. This invention referred to the solution of what used to be known as indeterminate equations: to find two or more numbers-notably integers, which obey a certain algebraical relation. For one large class of these problems (which already occupied the ancient geometers), viz., those of the divisibility of one number by another (called the modulus) with or without residue, Gauss invented the conception and notation of a congruence. Two numbers are congruent if when divided by a certain number they leave the same remainder. "It will be seen," says Henry Smith, "that the definition of a congruence involves only one of the most elementary arithmetical conceptions - that of the divisibility of one number by another. Int it expresses that conception in a form so suggestive of analysis, so easily available in calculation and so fertile in new results, that its introduction into arithmetic has proved a most important contribution to the progress of the science." ${ }^{1}$ Notably the analogy with ordinary algebraic equations and the possibility of transferring the properties and treatment of these was at once evident. It became a subject of

I See Henry J. S. Smith in his most valuable 'Report on the Theory of Numbers' (Brit. Assoc., 1859-65, six parts. Reprinted in 'Collected Math. Papers,' vol. i.
59. Gauss's theory of congrt ences. 
interest to determine the residues of the powers of numbers. A number is said to be a quadratic, cubic, or biquadratic residue of another (prime) number (the modulus) if it is possible to find a square, cube, or biquadratic number which is congruent with the first number. The theory of congruences was a new calculus: as such it was, like the theory of determinants or of invariants or the general theory of forms, a tactical device for bringing order and simplicity into a vast region of very complicated relations. Gauss himself wrote about it late in life to Schumacher." "In general the position as regards all such new calculi is this-that one cannot attain by them anything that could not be done without them : the advantage, however, is, that if such a calculus corresponds to the innermost nature of frequent wants, every one who assimilates it thoroughly is ablewithont the unconscious inspiration of genius which no one can command-to solve the respective problems, yes, even to solve them mechanically in complicated cases where genius itself becomes impotent. So it is with the invention of algebra generally, so with the differential calculus, so also-though in more restricted regions - with Lagrange's calculns of variations, with my calculıs of congruences, and with Möbins's calculns. Through such conceptions countless problems which otherwise would remain isolated and require every time (larger or smaller) efforts of inventive genius, are, as it were, united into an organic whole." But a new calculus frequently does more than this. In the course of its

1 See 'Briefwechsel,' \&c., vol. iv. p. 147 ; also Gauss's 'Werke,' vol. viii. p. 298 . 
application it may lead to a widening of ideas, to an enlargement of views, to a removing of artificial and conventional barriers of thonght. As I stated early in this chapter, the attempts of Gauss to prove the fundamental theorem of algebra, that every equation has a root, suggested to him the necessity of introducing complex numbers; the development of the theory of congruences and of residues-notably of the higher residues-confirmed this necessity. In the year 18:31, in his memoir on biquadratic residues, he announces it as a matter of fundamental importance. In the earlier memoir he had treated this extension of the field of higher arithmetic as possible, but had reserved the full exposition. And before he redeemed this promise the necessity of doing so had been proved by Abel and Jacobi, who had created the theory of elliptic functions, showing that the conception of a periodic function (such as the circular or harmonic function) could be usefully extended into that theory, if a double period-a real and an imaginary one-were introduced. A simplification similar to that which this bold step led to in the symbolic representation of those higher transcendents, had been discovered by Gauss to exist in the symbolical representation of the theory of biquadratic residues which only by the simmltaneous use of the imaginary and the real unit "presented itself in its true simplicity and beauty." In this theory it was necessary to introduce not only a positive and negative, but likewise a lateral system of counting-i.e., to count not only in a line backwards and forwards, but also sideways in two directions, as Ganss showed very plainly in the now familiax mamer. At the 
60. same time a metaphysical question presented itself--viz., Generalised conception of number.

Can such an extension into more than two dimensions be consistently and profitably carried out? Gauss had satisfied himself that it could not; ${ }^{1}$ but the proof of this was only given in more recent times by Weierstrass, who definitely founder the whole discussion of the subject on the logical principle "that the legitimacy of introducing a number into arithmetic depends solely on the definition of such number." And this leads me to another extension in the region of number suggested by Gauss's treatment, which has also become fundamental, and, in the hands of Dirichlet, Kummer, Liouville, Dedekind, and others, has remodelled the entire science of higher arithmetic. It is based on the logical process of the

1 A concise history of this subject is given by Kossak in the Program referred to above, p. 712, note. Gauss had promised to answer the question, "Why the relations between things which have a manifoldness of more than two dimensions would not admit of other" (than the ordinary complex numbers introduced by him) "fundamental quantities being introduced into general arithmetic?" $\mathrm{He}$ never redeemed his promise. In consequence of this, several eminent mathematicians, notably Hankel, Weierstrass, and Prof. Dedekind, have attempted to reply to this question, and to establish the correctness of the implied thesis according to which any system of higher complex numbers becomes superfluous and useless. Prof. Stolz, in the first chapter of the second volume of his 'Allgemeine Arithmetik,' gives an account of these several views, which do not exactly coincide. In general, however, the proof given by Weierstrass, and first published by Kossak, has been adopted. This proof is based upon the condition that the product of several factors cannot disappear except one of its factors is equal to zero. "We must, therefore, exclude from general arithmetic com. plex numbers eonsisting of three. fundamental elements. This is, however, not necessary if the use of them be limited" by sone special conditions (Kossak, loc. cit., p. 27). In the course of the further development of this matter Weierstrass arrives at the fundamental thesis "that the domain of the elementary operations in arithmetic is exhausted by addition and multi. plication, including the inverse. operations of subtraction and division." "There are," says Weierstrass, "no other fundamental operations - at least it is certain that no example is known in analysis where, if an analytical connection exists at all, this cannot be analysed into and reduced to those elementary operations" ( $p$. 29). 
inversion of operations in the most general manner. In the direct process we build up algebraical formuliecalled equations or forms-by a combination of addition and multiplication. TVe can omit subtraction and division, as through the use of negative quantities and fractions these are reduced to the former. Now, given the most general algebraical equation or form, we can search ont and define the simple factors or forms into which it can be split up, and these factors and their products we can take to serve as the definition of numbers. The question then arises, What are the properties of numbers thus inversely defined? and, secondly, Do these inversion. numbers cxhaust or cover the whole extent of number as it is defined by the uses of practical life? The answer to the former question led to the introduction of complex and subsequently of ideal numbers; the discovery hy Liouville that the latter is not the case has led to the conception of transcendental, i.e., non-algebraic, numbers.

The idea of generalising the conception of number, by arguing backward from the most general forms into which ordinary numbers can be cast by the processes of addition and multiplication, has led to a generalised theory of numbers. Here, again, the principal object is the question of the divisibility of such generalised algebraical numbers and the generalised notion of prime numbers-i.e., of prime factors into which such numbers can be divided. Before the general theory was attempted by Prof. Dedekind, Kronecker, and others, the necessity of some extension in this direction had already been discovered by the late Prof. Kummer of 
62.

Kummer's

ideal numbers.

Berlin when dealing with a special problem. This was no other than the celebrated problem of the division of the circle into equal parts, which had been reduced by Gauss to an arithmetical question. Gauss had shown that the accurate geometrical solution of this problem depended on the solution of certain simple binomial forms or equations. The study of such forms accordingly became of special interest: it necessitated the employment of the extended notion of number called by Gauss that of complex numbers. Now it is one of the fundamental laws in the theory of ordinary numbers that every integer can be divided only in one way into prime numbers. This law was found to break down at a certain point if complex numbers were admitted. Kummer, however, suggested that the anomaly disappeared if we introduced along with the numbers he was dealing with other numbers, which he termed ideal numbersi.e., if we considered these complex factors to be divisible into other prime factors. The law of divisibility was thus again restored to its supreme position. These abstract researches led to the introduction of a rery useful conception - the conception not only of generalised numbers, but also of a system (body, corpus, or region) of numbers; ${ }^{1}$ comprising all numbers which, by the

1 The idea of a closed system or domain of generalised numbers has revolutionised the theory of num. bers. Originally the theory of numbers meant only the theory of the common integers, excluding complex numbers. Gauss, in the introduction to the 'Disquisitiones,' limits the doctrine in this way. $\mathrm{He}$ excludes also the arithmetical theories which are implied in cyclotomy-i.c., the theory of the division of the circle; stating at the same time that the principles of the latter depend on theories of higher arithmetic. This con. nection of algebraical problems with the theory of numbers became still more evident in the labours of Gauss's successorsJacobi and Lejeune Dirichlet, and was surprising to them. "The 


\section{ordinary operations of arithmetic, can be formed ont of} the units or elements we start with. Thus all rational integers form a system; we can compound then, but also resolve them into their elements. Where we introduce new elements or units we only arrive at correct laws if we are careful to cover the whole field or system which is measured by the application of the fundamental operations of arithmetic. Throughout all our abstraet reasoning it is the fundamental operations which remain permanent and maltered,-a rule whieh,

reason for this connection is now completely eleared up. The theory of algrebraical numbers and Galois's 'theory of equations' have their common root in the general theory of algebraical systems; especially the theory of the system of algebraical numbers has become at the same time the most important province of the theory of numbers. The merit of having laid down the first beginnings of this theory belongs again to Gauss. He introduced complex numbers, he formulated and solved the problem of transferring the theorems of the ordinary theory of numbers, above all, the properties of divisibility and the relation of congruence, to these complex numbers. Through the systematic and general development of this idea,-based upon the far-reaching ideas of liummer,Dedekind and Kronecker succeeded in establishing the modern theory of the system of algebraical numbers" (Prof. Hilbert in the preface to his "Theorie der Algebraischen Zahlkörper, " Bericht der Math. Ver.', vol. iv. p. 3). In the further course of his remarks Prof. Hilbert refers to the intimate connection in which this general or analytical theory of numbers stands with other regions of modern mathematical science, notably the theory of functions. "We thus see," he says, "how arithmetic, the queen of mathematical science, has conquered large domains and has assumed the leadership. That this was not done earlier and more completely, seems to une to depend on the fact that the theory of numbers has only in quite recent times arrived at maturity." He mentions the spasmodic character which even under the hands of Gauss the progress of the science exhibited, and says that this was characteristic of the infancy of the science, which has only in recent times entered on a certain and continuous development through the systematic construction of the theory in question. This systematic treatment was given for the first time in the last supplement to Dedekind's edition of Dirichlet's lectures (1894, 4 th ed., p. 134). A very clear acconnt will also be found in Prof. H. Weber's 'Lehrbuch der Algebra" (vol. ii., 1896, p. 487, \&c.) $\mathrm{He}$ refers (p. 494) to the different treatment which the subject has received at the hands of its two principal representatives - Prof. Dedekind ( 1871 onwards) and Kronecker (1882) - and tries to show the connection of the two methods. 
as we saw above, was vaguely foreshadowed by Peacock, and expressly placed at the head of all mathematical reasoning by Hermann Hankel. In passing it may also be observed how the notion of a system of algebraical numbers, which belong together as generated in certain defined ways, prepares us for the introduction of that general theory of groups which is destined to bring order and unity into a very large section of scattered mathematical reasoning. The great importance of this aspect is clearly and comprehensively brought out in Prof. $H$.

63. algebra. and transcendental numbers. Weber's Algebra. Nothing could better convince us of the great change which has come over mathematical thought in the latter half of the nineteenth century than a comparison of Prof. Weber's Algebra with standard works on this subject published a generation earlier.

I have shown how the definition of algebraical numbers has led to an extension and generalisation of the conception of number. Another question simultaneously presented itself, Does this extension cover the whole field of numbers as we practically use them in ordinary life? The reply is in the negative. Practice

64. is richer than theory. Nor is it difficult to assign the reason of this. Numbering is a process carried on in practical life for two distinct purposes, which we distinguish by the terms counting and measuring. Numbering must be made subservient to the purpose of measuring. Thus difficulties arising out of this use of numbers for measuring purposes presented themselves early in the development of geometry in what are called the incommensurable quantities: taking the side of a square as ten, what is the number which measures the 
diagonal? Assume that we prolong the side of the square indefinitely, we have a clear conception of the position of the numbers $15,20,30$, \&c.; but what is the exact number corresponcling to the length of the diagonal? This led to the invention of irrational numbers: it became evident that by introducing the square root of the number 2 we could accurately express the desired number by an algebraical operation. But there are other definite measurements in practical geometry which do not present themselves in the form of straight lines, such as the circumference of a circle with a given radins. Can they, like irrational quantities, be expressed by definite algebraical operations? l'ractice hack early invented methods for finding such numbers by enclosing them within narrower and narrower limits; and an arithmetical algorithm, the decimal fraction, was invented which expressed the process in a compact and easily intelligible form. Among these decimal fractions there were those which were infinite-the first instances of infinite series-progressing by a clearly defined rule of succession of terms; others there were which did not show a rule of succession that could be easily grasped. Much time was spent in devising methods for calculating and writing down, e.g., the decimals of the numbers $\pi$ and $e^{1}$

It will be seen from this very cursory reference to the practical elements of mathematical thonght how the idcas or mental factors which we deal with and

1 The transcendent nature of the numbers $e$ and $\pi$ was first proved by Hermite and Prof. Lindemann. The proofs have been gradually simplified. A lucid statement will be found in Klein's 'Famous Problems,' p. 49 sqq. 
string together in mathematical reasoning are derived from varions and heterogeneous sources. We begin 65. with counting, then we introduce measuring; in both and cases we have definite elements or units which may serve to express order or quantity or both, and we have definite conventional operations; then we have symbols which may denote order or quantity or operation. With these devices we perform on paper certain changes, and we get accustomed to use indiscriminately these heterogeneous conceptions, arithmetical, geometrical, algebraical--nay, even dynamical, as when Newton introduced the conception of a flow or fluxion. As mathematics is an instrument for the purpose of solving practical problems, skill in alternately and promiscuously using these incongruous methods goes a very long way. Geometrical, mechanical evidence helps frequently where pure logic comes to a standstill, and pure logic must help and correct where apparent evidence might deceive us. Mathematics and science generally have always progressed by this alternate use of heterogeneous devices, and will probably always do so. The straight line of pure logic has but very meagre resources, and resourcefulness is the sonl of all progress. But though this may be so in practice, there are two other interests which govern scientific reasoning. There is the love of consistency and accuracy, and of clean and transparent, as distinguished from muddled and scamped, work. The latter leads inevitably into serious errors and paradoxes, as the great mathematicians, Gauss, Cauchy, Abel, pointed out early in the century. Mathematics then frequently 
exhibited the slovenliness of a man who talks at the same time in more than one language, because he is too negligent to arrange his thoughts clearly. Then there come in the demands of the teacher who has to introduce abstract and difficult subjects in a clear, consistent, and simple mamner, taking heed that with the elements he does not introluce the sources of future error. The same interest that led in ancient times to the composition of the Elements of Euclid has led, in the higher education of the nineteenth century, begimning with the École Polytechnique and ending with Weierstrass's famous courses of lectures at Berlin, to a revision and recasting of the whole elementary framework of mathematics. In the mean time the resourcefulness in applied mathematical thought which ever since the age of Newton has characterised the individual research of this country, has opened ont new vistas and afforded much material for critical siftings and strict definitions. Both qualities were united in the great mind of Gauss with a regrettable absence of the love of teaching and the communicative faculty. Like Newton's 'Principia,' his greatest works will always remain great storehouses of thought; while his unpublished remains might he compared to the Queries appended to the 'Opticks' and to the 'Portsmouth Papers.'

Several eminent mathematicians in France, Germany, and Italy have been for many years ${ }^{1}$ working at the

1 The literature of this subject has been rapidly increasing since the year 1872 , - the approximate date of the following publications, which created an epoch : R. Dedekind, 'Stetigkeit und irrationale Zahlen' (Braunschweig, 1872); E. Heine, "Die 
clearcr enunciation of the fundamental conceptions of the science, and though the ways in which they approach the subject are different, a general consensus seems to be within view as to the elementary definitions. The main difficulty lies in the introduction into pure arithmetic of the ideas which are forced upon us when

Elemente der Functionenlehre" ('Journal für Mathematik,' vol. lxxiv. p. 172, 1872). This paper refers both to Weierstrass's and Cantor's theories; H. Kossak, in the pamphlet referred to above (p. 712 , note). This contains the principles of Weierstrass's theory ; C. H. Méray, 'Nouveau Précis d'Analyse infinitésimale' (Paris, 1872). The first comprehensive publication of Georg Cantor belongs to the year 1883, 'Grundlagen einer allgemeinen Manuigfaltigkeitslehre' (Leipzig, Teubner). It was preceded by various articles in the 'Journal fur Mathematik,' vol. lxxvii. p. 257, vol. lxxxiv. p. 82, aud" 'Math. Aun.,' vol. xr. p. 1, in which he had introduced and defined several of the terms and conceptions that have since become generally accepted in writings on this subject. These earlier publications, by - or referring to-the pioneers in this new province of mathematical thought, were followed by a number of further expositions by Cantor, Dedekind, and Weierstrass. The principal writings of Cantor have been republished in the 'Acta Mathematica,' vol. ii. Prof. Dedekind published in the year 1858 an important pamphlet, "Was sind und was sollen die Zahleu,' and has incorporated many of the results of his researches in his later editions of Dirichlet's 'Lectures '; whilst the lines of reasoning peculiar to Weier- strass have become better known through the writings of his pupils and the collected edition of his mathematical works which is now in progress. A complete biblio. graphy is given in three important articles in vol. i. of the German 'Math. Encyc.' by Profs. Schubert (p. 1, \&c.), Pringsheim (p. 48, \&c.), and Schönflies (p. 184, \&c.) Important works, giving a summary and analysis of these various researches, now exist in the mathematical and philosophical literature of France, Germany, Italy, and England. Like the nonEuclidean geometry, the subject has attracted considerable attention also outside purely mathematical circles. Notably Cantor's writings have been exhaustively dealt with from a philosophical point of view - in Germany by Walter Brix (Wundt's 'Philosophische Studien,' vol. v. p. 632, vol. vi. p. 104 and 261), and by B. Kerry, 'System einer Theorie der Grenz-begriffe' (Leipzig und Wien, 1890); in France by M. Louis Couturat, 'De l'Infini ma. thématique' (Paris, 1896); and latterly in this country by $\mathrm{Mr}$ Bertrand Russell, 'The Principles of Mathematics,' vol. i. (Cambridge, 1903). Italian mathematicians have also dealt largely with the subject, notably G. Peauo, who published an important work, 'Arithmetices principia nova methodo exposita' (Turin, 1889). 
we apply the counting process to the nceds of geometry and physics. We are here confronted with notions which require to be arithmetically defined - the infinite and the continuous. The same notions at the beginning of the century attracted the attention of eminent analysts like Canchy. It is now clear, thanks to the labours of Prof. Georg Cantor of Halle, that for mathematical purposes we must distinguish between the indefinitely great and the actually infinite in the Georg. Can. tor's theory
of the sense of the transfinite. To deal with the actually infinite, as distinguished from the immeasurably or indefinitely great, we have to introdnce new notions and a new vocabulary. For instance, in dealing with infinite aggregates, the proposition that the part is always less than the whole is not true. Infinities, indeed, differ, but not according to the idea of greater and smaller, of more or less, but according to their order, grade, or power (in German Mächtigkeit). Two infinities are equal, or of the same power, if we can bring them into a one-to-one correspondence. Prof. Cantor has shown that the extended range of numbers termed algebraic have the same power as the series of ordinary integersone, two, three, \&c.-because we can establish a one-toone correspondence between the two series-i.e., we can count them. He has further shown that if we suppose all numbers arranged in a straight line, then in any portion of this line, however small, there is an infinite number of points which do not belong to a countable or enumerable multitude. Thus the continum of numerical values is not countable-it belongs to a different 
grade of infinity; it has a higher, perhaps the second, power. ${ }^{1}$

In all these, and in many similar investigations, a conception has gradually emerged which was foreign to older mathematics, but which plays a great and useful part in modern mathematical thought. Older mathematics, ever since the introduction of general arithmetic or algebra, centred in the conception of equality and in the solution of equations. Everything was reduced to magnitude. But there are other relations besides those of magnitude, of more or less. Often in practical pursuits, if we cannot find a counterpart or write down an exact numerical equation, we can gain information

6i. by a correspondence. This conception of correspondence Correspond. ence.

plays a great part in modern mathematics. It is the fundamental notion in the seience of order as distinguished from the science of magnitude. If older mathematics were mostly dominated by the needs of mensuration, modern mathematics are dominated by the conception of order and arrangement. It may be that this tendency of thought or direction of reasoning goes hand in hand with the modern discovery in physics, that the changes in nature depend not only or not so much on the quantity of mass and energy as on their distribution or arrangement.

With these reflections we touch the limits of mathe-

1 A summary of Prof. Cantor's work is given by Prof. Schönflies in the 'Fncyklop. Math. Wiss., vol. i. p. 184 sqq. The importance of accurate definitions and distinctions regarding the infinite and the continuous is dwelt on and the different recent theories set forth in a very lucid address to the London Math. Society by Prof. Hobson, "On the Infinite and Infinitesimal in Mathematical Analysis," November 1902. 
matical thonght and enter the region of metaphysics. Like other lines of reasoning which have occupied us in former chapters, the exact and rigid definitions and deductions of arithmetic and geometry lead us up to that other large department of our subject-philosophic thought. Many eminent mathematicians of recent years have noticed this tendency, and have urged the mutnal help which arithmetic and geometry on this side, logic and psychology on that, may derive from each other. The names of Helmholtz, Georg Cantor, and Dedekind in Germany; of M. Tannery and M. Poincaré in France; of Peano and Veronese in Italy, stand prominently forward abroad; while England can boast of having cultivated, much earlier, by the hands of De Morgan and Boole, a portion at least of this borderland, and of having in recent years taken up the subject again in an original and independent manner. ${ }^{1}$ Cayley, in his address to the British Association in 1883, has said: "Mathematics connect themselves on the one side with common life and the physical sciences: on the other

1 I refer to the important but unfinished works of $\mathrm{Mr}_{\mathrm{r}}$. Whitehead on 'Universal Algebra' (vol. i., 1898), and of $\mathrm{Mr}$ Bertrand Russell on 'The Principles of Mathematics' (vol. i., 1903). I must defer a more detailed appreciation of these and other writings of this class, such as those of the late Prof. Ernst Schrüder ("Algebra der Logik,' 3 vols., 1890-95) and of Prof. Gottlob Frege (see an account of his writings in the appendix to Mr Russell's 'Principles'). They belong largely to a department of philosophical thought which may be termed

VOL. II. "the Philosophy of the Exact Sciences." This deals with two great questions-the logical foundations of scientific reasoning, and the general outcome and importance of scientific thought, not for technical purposes, but in the great edifice of human thought which we may term Philosophy. It deals with what has been called "the Creed of Science" and its value. Stanley Jevons and Prof. Karl Pearson in this country, Prof. Mach in Germany, and M. Poincaré in France, have treated the philosophy of science in one or both of these aspects.

$3 \mathrm{~A}$ 
sicle with philosophy in regard to our notions of space and time, and in the questions which have arisen as to the universality and necessity of the truths of mathematics and the foundation of our knowledge of them": and he subsequently refers specially to the "notion which is really the fundamental one underlying and pervading the whole of modern analysis and geometry," meaning the complex magnitude, as deserving to be specially discussed by philosophers. Begimnings of the philosophical treatment of this and other questions indeed exist. The questions are still sub judice, and the historian can merely refer to their existence and importance.

There is, however, one controversy which has arisen out of these and similar speculations, and out of the desire to bring unity and consistency into the fundamental notions of elementary as well as higher mathematics, which deserves to be specially mentioned, because it occupies a prominent place in foreign literature, having given rise to a special term, and thus commanding more general attention. Prof. Klein of Göttingen, under whose master-hand many abstract and obscure subjects have become plain and transparent, has prominently brought the subject before the scientific public in a Arithmetising tendency in nuathe recent address. ${ }^{1}$ I refer to the tendency represented matics.

in its extreme form by the late Prof. Kronecker of Berlin, to reduce all mathematical conceptions to the fundamental arithmetical operations with integral numbers, banishing not only all geometrical and dynamical conceptions, such as those of continuity and flow, but

1 'Ueber Arithmetisirung der Mathematik' (Göttingen, 1895). 
also such apparently algebraical notions as those of irrational and complex quantities. This attempt is an outcome of the school of Weierstrass, which lias done so wuch to banish vagueness and introduce precision into modern text-books.

Opposed to this so-called arithmetising ${ }^{1}$ tendency is the equally emphatic view, strongly urged by the late Prof. Paul Du Bois-Reymond in his general theory of Functions, that the separation of the operations of counting and measuring is impossible, and, if it were possible (as, since the publication of his work, the fuller expositions of Kroneeker and his followers have tried to show that it is), would degrade mathematics to a mere play with symbols. ${ }^{2}$ He tries to show that such is philosophically impossible, and finds a support for his view in the historical genesis of the idea of irrational numbers in the incommensurable magnitudes of Euclid and ancient geometry. Prof. Klein in his address favours the arithmetical tendency as destined to introduce logical

1 The term seems to have beeu coined by Kronecker. See Prof. Pringsheim in the 'Encyklop. Matl. Wiss.,' vol. i. p. 58, note 40 . Kronecker's position is set forth in Journal fuir Math., vol. ci. pp. $337.355,1887$.

2 "The separation of the conception of number and of the analytical symbols from the conception of magnitude would reduce analysis to a mere formal and literal skeleton. It would degrade this science, which in truth is a natural science, although it only admits the most general properties of what we perceive into the domain of its researches ultimately to the rank of a mere play with symbols, wherein arbitrary meanings would be attached to the signs as if they were the figures on the chessboard or on playing-cards. However amus. ing such a play might be, nay, however useful for analytical purposes the solution would be of the problem,--to follow up the rules of the signs which emanated from the conception of magnitude into their last formal consequences, - such a literal mathematics would soon exhaust itself in fruitless efforts; whereas the science which Gauss called with so much truth the science of magnitude possesses an inexhaustible source of new material in the ever-increasing field of actual perceptions," \&c., \&c. ("Allgemeine Functionen-Theorie,' 1882, p. 54.) 
precision and consistency into the foundations of matheInatics, and everywhere to further the very necessary process of critical sifting; but he denies that pure logic can do all, and points to the valuable assistance and suggestive power of geometrical construction and representation. ${ }^{1}$ Most of my readers will no doubt agree with this view. Indeed the perusal of the foregoing chapters must have produced on their minds the conviction that, so far as the advance of science and also of mathematics is concerned, it largely depends upon the introduction of different aspects leading to different courses of reasoning. The unification of all of these into one consistent and uncontradictory scheme, though it remains a pious hope and far-off ideal, has not been the prominent work of the nineteenth century. Rather, wherever it has been attempted it has had a narrowing effect, and has resulted in a distinct curtailment of the great and increasing resources of Scientific Thought.

1 Prof. Klein summarises the opinion which he holds as to the present task of mathematical science as follows: "Whilst I everywhere demand the fullest logical elaboration, I at the same time emplasise that pari passu with it the intuitive representation of the subject should be furthered in every possible manner. Mathematical developments which have their origin in iutuition eannot count as a firm possession of science unless they have been reduced to a strict logical form. On the other side, the abstract statement of logical relations cannot satisfy us until their importance for every form of representation has been clearly demonstrated, so that we recognise the manifold connections in which the logical scheme stands to other departments of knowledge according to the field of application which we select. I compare mathematical science to a tree which stretches its roots ever deeper into the soil, and at the same time expands its branches freely upwards. Are we to consider the root or the branclies as the more important part? The botauist will tell us that the question is wrongly put, and that the life of an organism consists in the interaction of its various parts" (loc. cit., p. 91). 


\section{RETROSPECT AND PROSPECT.}

IN the foregoing chapters I have attempted to set forth the chief conceptions which are contained in the scientific literature of the nineteenth century. Upon these the scientific work of that period has been founded or they are the results to which its scientific reasoning has led. The most important outcome of the scientific work of the century does not lie in the region of thought, but rather in that of practical application; and this I have only incidentally referred to. Only in so far as it has reacted upon scientific thought, suggesting or modifying scientific ideas, has it been necessary to allude to it.

My readers who have so far accompanied me may be struck by one feature which indeed is characteristic of scientific thought. Our survey has presented such thought as broken up into a series of different aspects; and although certain connections between these aspects have been occasionally pointed out, no attempt has been made to combine them into one comprehensive or united view. The reason for this is to be found in the nature of scientific thought itself, which, proceeding by a definite method, starts from the great variety of phenomena which surround us in time and space; the only assump- 
tion which science is obliged to make being the inevitable one that Nature is intelligible to the human mind, which

1. Order and Unity. is the same as saying that we must assume the existence of some kind of Order.

There exists, indeed, in the human mind a further demand, which may be defined by saying that the conception of order in Nature or of its intelligibility should not be held merely as a formal iteration, but should be expressed as a highest Unity by some term which conveys to our minds something more than the idea of an empty form. From this demand there have further arisen at all times varions attempts to give expression to the ideas of unity, of simplicity, and of the significance of the whole scheme of existence which we call Nature. Such attempts do not form part of purely scientific thought. They are speculations for which those principles of science that are capable of exact enunciation do not suffice. They have, indeed, frequently appeared in the literature of the nineteenth century. But although there are isolated cases where scientific authorities of the first order have indulged in them, such authorities have, as a rule, shown an increasing reluctance to deal with fundamental questions or with principles which extend beyond the limits of scientific thought. We have no examples in the nineteenth century of such intellects as those of Leibniz or Newton. However different these two great thinkers of an earlier age may have been, they had this in common, that for them the scientific and the religious aspects were not only equally important, but equally occupied their attention. The characteristic difference was that Leibniz apparently strove after a 
unification of scientific and religious leasoning, frequently to the disadvantage of both, whereas Newton kept them so distinctly apart that his immortal scientific works can be studied without any reference whatever to his theological writings.

The two positions represented by these two great men-namely, the attempt on the one side to unify or combine the scientific and the religious aspects, and on the other to keep them apart or contrast themhave, indeed, been adopted by many thinkers in the course of our period; but an attempt to do justice to such problems has been more usually considered the duty of philosophy par excellence. In the rare instances in which scientific authorities of the first order have ventured upon a solution of these problems, they have stepped outside of the limits of scientific reasoning; having, as it were, attempted to occupy the more impartial if not more elevated position of judges who assign to scientific reasoning its position and its value in the connected whole of human thought and interests. ${ }^{1}$

Consistently with the division of thought which underlies the present history, and which has been explained in the third part of the Introduction, I relegate the exposition of such theories to the second part of this work, which deals with philosophical thought. The fact that in the course of the nineteenth century there have still appeared scientific thinkers who have not only attacked special scientific problems, but also the great universal world-problem, may well be

1 Examples of this will be found in the writings of André Marie Ampère, of Emil Du Bois-Rey-

mond, and of Gustar Theodor Fechner. 
noted as a connection, a bond of union, between those two great realms of systematic thought which, for the sake of convenience, I have kept apart in this historical survey.

There are other features in the scientific thought of the period, as it has become known to us, which naturally lead up to a different treatment from that which is peculiar to science. In almost every instance, in following up the various aspects of scientific thought, I have had to show how they have brought us to problems which cannot be solved by the means which we call scientific or exact; and in many instances I have shown how the foremost scientific thinkers themselves have been led up to inquiries which they have variously termed philosophical, metaphysical, logical, or psychological. Such has notably been the case with the ultimate conceptions of the atomic theory, of the doctrine of energy, and, still more, with the conceptions which underlie the scientific treatment of the phenomena of life and consciousness. The further we have advanced from the simple mechanical conceptions of motion and inertia or mass, into the phenomena of the actual world of natural objects which exhibit order, development, purpose, and consciousness, the more we have been obliged to make use of terms not capable of being defined by the simple categories of exact or mathematical thought; and with whatever zeal some of the foremost thinkers have in the course of the century attempted to express these more indefinite conceptions in terms of mechanical science, they have only partially succeeded, and have certainly failed in 
banishing them from the scientific vocabulary. Such conceptions have always crept in again, proving that they are indispensable even to the purely scientific comprehension or description of natural objects, or of nature as a whole.

It is not surprising, therefore, that an independent examination of the ultimate conceptions which science makes use of, or which it evolves, should have been a task which has occupied some of the greatest intellects of our period, and that the problem arising from this should form a fitting transition from the purely scientific to the philosophical portion of this history.

Now, if we try to characterise in the briefest possible manner the general problems which scientific thought as a whole has definitely formulated and placed before the philosophical thinker, there are two words which stand out prominently as indicating the two grand and complementary conceptions which either underlie all scientific inquiry or result from it. The first of these has already been stated. We saw that exact or scientific thought assumes that there exists in Nature an intelligible Order. The closer definition of this order in the so-called laws of the cosmos has to be ascertained by experience, and has been the subject of the foregoing narrative. The subject which remains for philosophical discussion is not any special form of order, but the fact that any kind of order exists at all, and that it is accessible to the himan intellect. Clearly this is a question which affects Nature, the object, as much as the human Intellect, the subject.

But if the idea of Order underlies all scientific thonght, 
standing as it were at the entrance of scientific reasoning, there is another idea which stands at the end of all 3. scientific thought. This is the idea of UNITY in its most impressive form as Individuality. It remains over as an ultimate empirical fact to which scientific reasoning advances, of equal importance with order.

These two conceptions of Order and Individuality likewise govern the two great divisions under which scientific thought has been studied by us-Physics and Biology. After reviewing in the first three chapters the characteristic attitudes taken up by the three leading nations in scientific thought, I entered upon the four abstract conceptions - namely, Attraction, Atomism, Kinetics, and Energy - which are capable of strict mathematical definition, and which form the skeleton or framework around or in which the sciences of Astronomy, Dynamics, Physics, and Chemistry have arranged their various doctrines. They serve together to define more precisely the conception of the general order of things, appropriately termed the Cosmos. In the four chapters following upon these I dealt with the different conceptions under which a comprehension, not so much of the general order as of the special events and things of our world, has been gained. These conceptions, referring to the actual forms, the history, the life and soul of things natural, have been likewise dealt with in four chapters. On them the physics of the universe and of our earth, the sciences dealing with the organised and animated creations, have been built up. Beginning with a special kind of ordernamely, that indicated by external figure-these sciences 
have advanced through the study of the changes of figure to an increasing appreciation of an underlying unity. In many of the organs of living creatures the unity seems to lie outsicle the organs themselves, as the unity of a machine which exists in the design of the maker adapting it to a certain purpose; whereas in the animated world it seems to be inside the objects of Nature. The sciences of life have accordingly forced upon us more and more the conception not only of orderly arrangement, but also of a unifying principle - that is, Individuality.

These two conceptions of Order and Individuality are as little new as are the various conceptions of purely scientific thought, most of which, as has been shown, have been handed down to us from earlier times. They have accordingly been defined and studied by philosophers from antiquity. The varions positions which thinkers have taken up with regard to them during the nineteenth century have, however, been characteristic of the age, and have been very largely influenced by the conceptions of Order and Unity which science itself has elaborated. In this connection it is of importance to note that the idea of Order or arrangement has only within the nineteenth century met with a comprehensive mathematical treatment; and, so far as that of Unity is concerned, it can also be said that the mathematical sciences have in the course of the nineteenth century for the first time approached the analysis of the allied idea of Continuity, which indeed plays an increasingly important part in many scientific theories. It may even be held that the 
scientific mind advances from the idea of Order or arrangement to that of Unity through the idea of Continuity.

If, however, these highest conceptions had been introduced to us by scientific thought in the form only of limiting ideas or highest abstractions, it is doubtful whether the special discussion of them would have attracted so much attention or occupied so many minds as has actually been the case. In many instances we found it to be quite sufficient for the purposes of science that fundamental principles should be dogmatically asserted, and that their usefulness should be the only proof of their correctness. If no other interest attached to the conceptions of order and unity than attaches, for instance, to the ultimate principles of dynamies, to atomism, or to the axioms of geometry, the number of persons who take up these refined studies would probably be exceedingly small. The reason why the conceptions of order, unity, and individuality have received so much attention lies in this, that they have not only a logical meaning as instruments of thought, but also, as the words them-

Practical interests attaching to Order and Unity. selves indicate, a practical meaning, being bound up with the highest ethical and resthetical, as well as with our social and religions, interests. The word order means something more than arrangement when we speak of the social or moral order; the word unity is more than an arithmetical conception when we speak of the unity of action or of purpose, or the unity of design in art; the word individuality acquires a higher meaning in the term personality. Those thinkers who in the nine- 
teenth century, as well as in former ages, have dealt exhaustively with these the most abstract and highest conceptions of which human thought is capable, have not been, or have only very rarely been, led to their inquiries from the side of purely scientific interests; they have approached them with a full appreciation of the great moral and religions interests which lie hidden in the deeper significance which we attach to the words. In starting, therefore, on the survey of philosophical thought, it would be quite inadequate to take scientific ideas as a suitable introduction. Whatever future ages may bring, the philosophy of the nineteenth century has certainly not been exclusively, or even pre-eminently, scientific or exact. If philosophy has assumed the name of a science, it has done so in that larger sense of the word which, as we have seen, is peculiar to the German language. In this comnection scientific treatment means simply methodical treatment, whereas there is an increasing tendency in many circles to identify the word science with exact mathematical or positive treatment. The exact treatment of philosophical problems, such as has been attempted but only very partially carried out in the systems of Auguste Conite in France and of Herbert Spencer in England, belongs almost entirely to a later part of that century, and forms, even then, only one side of its large philosophical literature. Philosophical thought had a brilliant history in the earlier part of the century before the ideas of Positivism or of modern Evolution were much thought of. It will therefore be necessary in any account of philosophical thought to ascertain and clearly define the positions 
occupied by the great thinkers who governed and revolutionised the thought of earlier generations before the great generalisations of science, notably those connected with the ideas of energy and the theory of descent, could have had any influence whatever. Though the latter have acquired in recent times a great, perhaps an undue, importance, it will only be after becoming aequainted with an earlier and different phase of philosophic thought that we shall have once more to return to those conceptions and trains of reasoning which must be uppermost in the mind of the writer as well as of the reader of the foregoing chapters.

The geographical centre of philosophic thought.

But in starting on the historical account of an entirely different realm of thought, I shall not only have to ask my readers to enter into a new circle of ideas, which for a long time during the course of the nineteenth century lay entirely outside of that circle of ideas with which we have become acquainted so far; we shall be assisted also by finding an entirely different geographical centre from which these ideas emanated. It has been repeatedly pointed ont that the great volume of scientific thought with which we have hitherto been occupied, emanated in the latter part of the eighteenth century from the French capital; and in the course of narration I have had to go back almost in every single instance to the foundations laid in French scientific literature. I shall now have to invite my readers to give their attention to the peculiar features which were characteristic not of French but of German literature at the end of the eighteenth and the beginning of the nineteenth century. 
The centre of philosophical thought during the first half of the nineteenth century lay as much in Germany as the centre of scientific thought lay, somewhat earlier, in France. It is true that in both cases, if we trace the movement a little further back, we come upon the powerful influences of English thought. Newton can be considered as marking the beginning of the modern era of scientific thought; Locke can be looked upon as having infused into philosophic thought much of its modem spirit. But though this must be conceded to a large extent, it must also be admitted that the scientific thought of the nineteenth century for a long time received its special colouring through the influence of the French mathematicians and naturalists, with Laplace and Cuvier as their most illustrious representatives; while philosophical thought for a long time received its specific colouring from the idealistic movement which began with Kant and culminated in Hegel. And although it was again the specific influence of English thought which in the latter part of the nineteenth century diverted alike scientific and philosophical thought from the channels in which they ran during the first half of the century, we have only very partially emancipated ourselves from the overwhelming influence which the conceptions of the idealistic school of German philosophy have had upon the deeper philosophical thought of all three nations alike. The features peculiar to that period are still strongly marked on the philosophical countenance of the age: neither the lights nor the shadows thrown by the great lumin- 
aries which appeared on the philosophical horizon of Germany a century ago have as yet died away.

It will be the object of the second part of this work to trace in more detail this powerful influence, to define more clearly wherein it cousisted, and to discover to what extent it still survives or is mingled with other influences, among which that which we have studied exchusively in the first part of this history will prove to have been one of the most important. 


\section{IN D EX.}

Abbe, Ernst, improvements in the microscope, ii. $22 \$, 229$.

Abbe, Prof. Cleveland, method of least squares, ii. 576.

Abel N. H., memoir by Bjerknes cited, i. 184; investigations of, 185; and Crelle, 186; on Gauss, ii. 637; his 'Life' by Bjerknes, ib.; on Cauchy, 637 ; on convergency, 646 ; his pioneering work, 648; his relation to Jacobi and Legendre, $i t$.; Sylow's memorial of, 649 ; his addition theorem, $649 ; 657$; theory of equations, $681,686,690,692,693,695,704,732$. Abélard, i. 74 .

Abraham, MI., 'Geometrische Grundbegriffe,' ii. 73 .

Abria, experiments with vacumm tubes, ii. 190.

Absolute, the, Cayley on, ii. 715 .

Abstraction, process of, ii. 201.

Academic culture in France, i. 134.

Académie de Chirurgie, i. 107.

Acalémie des Sciences, i. 107.

Académie des Sciences morales et pol. itiques, i. 145.

Academies, provincial, in France, i. 107.

Academy of Saxony founded, i. 100.

Academy of St Petersburg founded, i. 100 .

Academy of Vienna founded, i. 100.

Academy, Paris, organisation and cooperation of members of, i. 99.

Achenbach, i. 165.

Achenwall, Gottfried, the "father" of statistics, ji. 555 .

Acland, Sir Thomas Dyke, 'Chemistry of Farming,' i. 284.

Acoustics, ii. 12, 485 .

VOL, II,
Adams discovers Neptune, i. 277 ; lunar theory, 329.

Adare, Count, i. 106.

Airain, law of error, ii. 576.

Etiology, Huxley's definition of, i. 194.

Affinity, chemical, neglect of the study of, i. 420 ; chemical, ii. 157, 267.

Agassiz on fossil tishes, ii. 257; "Essay on Classification," 349 .

Agnosticism, ii. 326 .

Airy and Herschel, article in 'Encyclopædia Metropolitana,' i. 236.

Airy, Sir George Biddell, worked in harmony with the Analytical Society, i. 271; the discovery of Neptume, 277 ; measurement of an arc of parallel, 322 ; calculus of probabilities, 325 ; Tides, 330.

Akin, ii. 107.

Albrecht, Eugen, 'Vorfragen der Biologie,' ii. 463.

Alexander the Great, Napoleon com. pared with, i. 153.

Alexander VI., Pope, and the University of Aberdeen, i. 268.

Alison, W. P., i. $27 \%$.

Allen, Grant, monograph on Darwin quoted, ii. 607; on "pangenesis," 610.

Altmanu, theory of "bioblasts," ii. 427, 444.

America, influence of, only touched upon, i. 14; declaration of Independence, 79 .

Amici, enıbryological studies, ii. 227; improvements in microscope, 228 ; $230,261$.

Ampère, A. M., on electro-magnetism, i. 92 ; "mechanical theory of gases," 310 ; 313 ; electric currents, 347,367 ;

$3 \mathrm{~B}$ 
develops astronomical view of nature, 366 ; $368,370,371$; importance of his discoveries, 372 ; chentical discovery of, 408; Avogadro's hypothesis, 427 ; 'Essai sur la Philosophie des Sciences,' ii. 5, 205; requested Fresnel to write his 'Memoire sur la Diffraction,' 25 ; suggested transverse vibrations to explain polarisation of light, 26 ; equation of wave surface, 42; Lord Kelvin on electro-nagnetic theory of, 73 ; referred to, 78 ; electrical formula of, 79 ; researches of, 92 ; theory of, 143 ; 193,695 ; on oscillating functious, 706,742 .

Amyntas, King of Macedonia, ii. 207.

Anabolism, ii. 395, 442.

Analogies, studies of, ii. 250 ; physical, Klein on, 701.

Analytical Society of Cambridge, i. 271.

Anchersen, J. P., statistics, ii. 579.

Andrews, Thomas, "critical temperature" of gases, i. 316 ; experimental work of, ii. $16 \mathrm{l}$; 'Scientific Papers' of, $162 ; 164$.

Angle, trisection of the, ii. 124.

Angström, spectrum analysis, ii. 278.

Anhalt-Dessan, Princess of, letters from Euler to, ii. 7.

Anharmonic ratio, ii. 718 .

Anilin colours, discovery of, i. 92.

'Annales de Chimie et de Physique,' i. 236 , ii. 25,54 .

Anthropology, ii. 497.

Apologetic literature in England, ii. 324.

Appelt, i. 209.

Arago, letter from Young to, i. 230; 'Annales de Chimie et de Physique,' 236 ; and Fresnel, 241; éloges of, 279 ; his appreciation of the labours of Fresnel, ii. 21 ; views on "sidedness" of rays of light, 24 ; requested Fresnel to write his 'Mémoire sur la Diffraction,' 25 ; never accepted theory of transverse vibrations, 26 ; visit to England, 27, property of polarised light, 28; Éloge on Carnot the elder, $138 ; 506$.

"Arbeitskraft," term used by Helmboltz, ii. 140 .

Archinedes quoted, ii. 376.

Arfvedson, chemist, i. 188.

Argand, geometrical representation of imaginary quantities, i. 184 ; on imaginaries, ii. 653 .

Argon discovered, i. 423.

Aristotle, constructive system of, i. 75 ; his works models of scientific research, $95 ; 120$; philosophy in English universities represented by, 254 ; views of Heraclitus, ii. $3 ; 4$, 207 ; analogies of nature, 255, 349; grammar and logic, 529.

Arithmetic, fundamental laws of, ii. $654 ; 703$.

Arithmetising tendency, Klein and $\mathrm{P}$. Du Bois-Pieymond on, ii. 738 et seq. Armstrong, Lord, hydro-electric machine: electrical discharge, ii. 191.

Arnold, Matthew, introduced new words into English, i. 22 ; on German culture, 225 ; ' Literary Influence of Academies,' 298.

Aronhold on invariants, ii. 654 .

Arrhenius, Svante, theory of electrolytes, ii. 159, 165.

Art, German, not patronised by royalty, i. 157 .

Arundel collection of antiquities, i. 295. Ascherson, 'Deutscher' Universitäts-Kalender, i. 161.

Association, British, founded, i. 42.

Astronomical view of nature: cosmical, molar, and molecular phenomena, i. 348; developed by Ampère and Weber, 366 ; opposition to, 381 ; insufficiency of, ii. 96.

'Athenæum' of Schlegel, i. 84.

Athens under Pericles, i. 67; the schools of, 74 .

Atom and molecule, i. 432 ; size of, 437.

Atomic theory (see Dalton), i. 385 ; two aspects of, 415 ; developnient of, 431 ; accepted, 437 ; crystallographic laws, amalogy between, 444 ; linkage, 449 ; defects and insufficiency of, 451; ii. 574.

Atonic view of nature, i. 382 ; criticisms of, 455 ; insufficiency of, ii. 96 ; recent trinmphs of, 188.

Atomism, ii. 465 .

Atoms, geometrical arrangement of, i. 441.

Attraction, ii. 465.

Attraction and repulsion, i. 342.

Attraction of ellipsoids, ii. 670 .

Alubuisson, d', ii. 294.

Aucoc, Léon, 'L'Institut de France,' i. $90,127,148,149$.

Auerbach, modern era in history of fertilisation, ii. 227.

Autenrieth, ii. 349.

"Availability," idea of, introduced by Carnot, ii.119 ; 597. See also Kelvin, Lord. 
Averages, doctrine of, i. 440 ; ii. 561.

Avogatro, "mechanical theory of gases," i. 310 ; 313 ; law of, 415 , ii. 165,592 ; hypothesis of, i. $427 ; 428$; hypothesis of, revived by Canniz. zaro, 445 .

Babbage, Charles, i. 18: 'Pecline of Science in England,' 127; history of his calculating engine, 248; educational movenient begun lyy, 261; formed the Analytical Society, 271: criticisms of science in Britain, 233; 236 ; Prof. Moll's reply to, ib.; English replies to, 238 ; not a university man, 239; ii. 3ㄱ.

Babeuf, co-operation, ii. 566.

Bacharach, llistory of Potential Theory, ii. 698 ; on Klein's Tract, 699.

Bacon, Lord, his intuence on the Encyclopædists, i. 34 ; his interpretation of the word "science," 90 ; unseientific, 93; his philosophical status, 94, 311; and Newton compared, 96 ; influence in new University of Halle, $160 ; 215$; schemes of', realised by the 'Encyclopédie,'\&c., 250; appreciated educational work of the "Order of Jesus," 256 ; Harvey, and Napier, 282 ; on the study of natural phenomena, 285; 311 ; his philosopliy, 385 ; system of philosophy, ii. 205 , 344; "method of instances," 557.

Bacon, Roger, i. 249, 403.

Baconian philosophy, decay of, i. 306.

Baden-Powell, radiant heat, ii. 105 ; apologetic writings, 327.

Baer, Karl Erust von, his opinion on the Naturphilosophie, i. 207 ; embryologist, ii. 278 ; his labours, 299 ; quoted, 307, 417; Lamarck and, 316 et seq.; Huxley on, 322; genetic view in embryology, 330 ; 341 ; law of biogenesis, 349; and Schelling, 354; irlea of life, 409 ; embryological researches, 418; on "diflusion of life," 451 ; " organicism," 455; 467, 533, 607.

Bagehot, Walter, quoted, ii. 558.

Bailie, Matthew, English medical science, i. 208.

Bailly guillotimed, i. 147.

Baily on Greenwich Observatory and the Rev. J. Flamsteed, i. 98.

Bain, 'The Senses and the Intellect,'ii. 511; 512: on psychology, 527 ; 608 .

Baker, H. F., on differential equations, ii. 692 .
Balbi, ii. 579.

Balfour, Francis M., organic morphology, ii. $214 ; 319$.

Ball, Sir R. S., 'Gravitation,' i. 320 ; memoir of Helmholtz, ii. 63; geometrical mechanics, 101; his theory of screws, 655; on Grassmann, 656 ; on generalised notion of distance, 718 .

Ball, IV. Rouse, 'A History of the Stuily of Mathenaties at Cambridge,' i. 275, 321; history of mathematics, ii. 680 .

Banks, Sir Joseph, i. 83, 155 ; travels of, ii. 247.

Bärenbach, 'Herder als Vorgänger Darwins,' ii. 533 .

Bärensprung, von, medical thermonetry, ii. 359 .

Barere, foundation of Écoles normales proposed, \&c., i. 112.

Barlow, not member of any university, i. 239 .

Barry, Martin, enıryological observations, ii. $227,228$.

Bartels, friend of Gauss, ii. 653.

Barthez, vitalist, i. 126.

Barycentric Calculus of Mübius, ii. b55, 681.

Basedtow, "philanthropinism," i. 166 ; educational work of, 256 ; 257 ; was inspired by Rousseau, 259.

Bates, H. W., "nimiery," ii. 339.

Bateson, William, 'Materials for the Study of Variations,' ii. 364 ; study of variation, $614 ; 622$; and Karl Pearson, 6ะ3; agrees with Huxley against Darwin, 623 .

Bathybius, ii. 388.

Bauer, G., on Otto Hesse, ii. 677.

Baumes, J. P. T., 'Essai d'un système chimique de la science de l'homme,' ii. 390 .

Baumgartner, i. 44; printed Mohr's 'Ueber die Natur der Wärme,'ii. 107.

Baumhaner, ii. 565.

Baur, ii. 109.

Bavaria, Elector of, and Count Rum. ford, i. 248.

Bayes, ii. 572.

Bayle, value of work of, i. 93 ; followed Newton, 96 ; French medical science, 208.

Bayne, Peter, 'Life and Letters of Hugh Miller,'i. 2 ss.

Beaumont, Elie de, doctrine of descent, ii. 322 .

Becker, G. F., on Kant's theory, ii. $282 ; 284$. 
Becker on mortality statistics, ii. 566.

Becquerel, E., phenomenon of fluorescence, ii. 52.

Bedson, Prof., 'Memorial Lecture' on Lothar Meyer, i. 427.

Beer, plyysics, i. 44; 'Einleitung in die Elektrostatik,' ii. 76.

Bell, Henry, built the "Comet," i. 303.

Bell, John, i. 293.

Bell, Sir Charles, discovery of the two kinds of nerves, i. 193, 292, 293 ; ii. 481 ; physiological discovery of, 230 ; and German universities, i. 251; of Edinburgh University, 272; Bridgewater Treatise, ii. 325 ; experimental physiology, 384; 'Anatomy of Expression," $47 \%$.

Bell, Sir Lowthian, phosphorus as fertiliser, i. 93.

Beltrami, the pseudosphere, ii. 635 ; supplements Riemann's work, 713 ; 717 .

Bence Jones, 'Life and Letters of Faraday,' i. 246 ; Royal Institution, 246 , 248.

Beneden, Van, on fertilisation, ii. 227 ; discovery of, 448.

Beneke, psychologist, influenced by school of Fries, i. 209; "facultypsychology," ii. 495 ; introspective nethod, 527.

Benfey, Theodor, 'Geschichte der Sprach wissenschaft,' ii. $245,537$.

Bentham, Jeremy, school of, i. 84.

Bentley, Richard, i. 169; intluence of, on German thought and literature, 212 ; services to classical learning and criticism, 222; his theories, 251 ; Newton's philosophy and atheism, 337 ; Newton's letter to, 340.

Bergmaun, i. 117 ; forerunner of Berzelius, 391; doctrine of chemical affinities, 392 ; theory of chemical aftinity, 452 ; chemical theory of, ii. 176.

Berkeley, and Hume, i. 47 ; "Theory of Vision,' ii. 472; space perception, 504; genetic view, 506; psychophysical view, 531 .

Berlin Academy, language, ii. 536.

Berlin, foundation of University of, $i$. 38.

Berlin school of mathematicians, ii. 693.

Bernard, Claude, "Association Francaise," i. 298; on identity of Animal and Vegetable Morphology, ii. 219; quoted, 2223, 410 ; 'Phénomènes de la Vie' quoted, 224, 239, 370, 438; De Blainville, 217; 'La Science Expéri- mentale' quoted, 373, 376, 379, 384, 385,386 ; change of ideas in medical schools of Paris, 396 ; 406, 409; 'Rapport,' 419 ; " organisation et désorganisation," 421 ; 'Rapport' quoted, 426 ; 429 ; school of, 431 ; the "internal medium," 432 ; chemistry of the living being, 433 ; school of "organicists," 436 ; rationale of the mental process, 441 ; 442 ; "organicisme," 455, 467, 481, 504, 549; quoted by Darwin, 610 .

Bernard, Thomas, associated with Rum. ford's philanthropic schemes, i. 249.

Bernoulli, Daniel, the theory of probabilities, i. 120 , ii. 570 ; i. 135 ; hypothesis of, 314; on gravitation, quoted, 351 ; 'Hydrodynamica' (the kinetic theory of gases), 433 ; motion of particles of gaseous matter, 434 ; on Euler's theory of the continuity of the ether, ii. 8; psychophysics, 474; $572,590,694$.

Bernoulli, James, took up the calculus, i. 101 ; the theory of probabilities, 120 ; ii. 569 ; 'De Arte conjectandi,' $570 ; 572$; theory of error, 575 ; doctrine of chances, 678 .

Bernoulli, John, took up the calculus, i. 101 ; the conservation of euergy, ii. 99 .

Bernstorff, Minister von, i. 158.

Berry, A., ' History of Astronomy,' ii. $282,357,362$.

Berthelot quoted on crystallography, i. 117; 'La Synthèse chimique,' 418 ; 'Chimie organique fondée sur la Syn. thèse,' 454; 'La Synthèse chimique' quoted, 455,457 ; a founder of physical chemistry, ii. 152; third law in thermo-chemistry, 157; chemical affinity, 171, 177; quoted, 361 ; chemistry of organic compounds, 425 . Berthollet issued 'Annales de Chimie,' i. 41 ; 'Essai de Statique chimique,' 83,116 ; chemistry at the Ecole nor. male, 112; practical discoveries of, 147 ; gunpowder, iron, steel, 148 ; 152, 200 ; chemical saturation, 347 ; influenced by Laplace, 380 ; chemical equilibrium, 392; quoted, 416 ; heat a material substance, 433 ; theory of chemical affinity, 452 ; ii. 154 ; law of mass-action, 157; (see Ostwald), 176 .

Bertholon quoted, i. 327.

Bertin, M., 'Rapport sur le Progrès de la 'Thermodynamique en France,' ii. 118 . 
Bertrand, Joseph, quoted, i. 121, 134 ; 'Calcul des Probabilités' 324; his 'Calcul différentiel' referred to, ii. 646.

Berzelius, Reports, i. 42 ; chemistry, 44 ; discoveries published, 83 ; services to chemistry of, 188 ; biographical, 189 ; 'Jahresbericht,' 190 ; organic analy. sis, 190 ; 191; influence on German science, 208 ; mechanical view in biology, 219 ; 220, 238; experimentally proved Dalton's atomic theory, 245; and Faraday, 365; electrical action in chemical processes, 366 ; chemical combinations, 396; elaborated Dalton's theory, $399 ; 400$; disproves Prout's hypothesis, 402 ; 403 ; electrochemical theory, 404; organic chenistry, 407 ; 409 ; "radicle" theory, 411 ; death of the binary theory, 412 ; 413,414 ; atomic theory, 416, 417 ; 426 ; characteristic of bydrogen atoms, 430 ; theories of chemical affinity, 452 ; ii. 154 ; chemical research, 159, 403.

Bessel, Friedlr. Wilh., services to astrononiy of, i. 177; correspondence with Gauss, 185, ii. 652 ; i. 199 ; measurements of, 322; taught at Königsberg, with Neumann and Richelot, ii. 54; popular work of, 149 ; on Gauss, 636 ; functions of, 696.

Bessel-Sellmeier hypothesis, ii. 54.

Beuth founded industrial schools in Prussia, i. 166.

Beverwijck, i. 282.

Bewick, wood engraver, 'British Birds,' i. 289.

Bichat, works of, i. 83: not among the academicians, 126; biological labours of, 194 , ii. 313 ; i. 195,200 ; morphological study of natural objects, ii. 231 ; the science of biology, 381; "Vitalism," 383, 384 ; 386, 387 ; on life, 394; doctrine of energy, 399 ; 402 ; quoted, 406 ; school of "organi. cism," 436 ; vital force, 503.

Billroth, Prof., 'Lehren und Lernen der medicinischen Wissenschaften,'i. 197; 198; infuence of English science on medical studies in Germany, 208; quoted on services of Kant to German science, 219.

Biogenesis, ii. 451.

Biology a German science, i. 193 ; grew out of science and philosophy com. bined, 216 ; essential unity of sciences of, not yet recognised in Germany, 220 ; British contributions to, 232 ; ii.
208,312 ; vagueness of theories of, 370 ; oscillation of thought, 374 ; 415.

Biot, experimental physies, i. 44, 200; fall of stones at l'Aigle, 328 ; his discovery, 431 ; opposed to undulatory theory of light, ii. 16,21 ; nember of Commission of Paris Academy of Sciences competition, 1819, 25 ; "laterality," 27 ; inftuenced German thought, $101 ; 193,508$.

Biran, Maine de, 'Mémoire sur l'habitude,' i. 83.

Bischoff, Theod., embryology, ii. 227 ; 300 ; quoted, 381, 387; address on Liebig, 391.

Bjerknes, A., on Abel, i. 184, 185, ii. 637 .

Black, Joseph, discovered carbonic aciıl, i. 115 ; on latent heat, 229, 399, ii. 102 ; Scottish university professor, i. 272 ; and Lavoisier, 386, 387; 391, 400 ; formule of, 436 ; biographical, ii. 102 ; attitule to science that of a medical man, 103 .

'Blackwood's Ellinburgh Magazine' publisherl, i. 273.

Blair, Hugh, i. 273.

Blennerhasset, Lady, on De Stael, i. 17.

Block, statisties, ii. 557, 563; quoted, 561, 566 ; 'Statistique morale,' 579.

Blonistrand, 'Die Chemie der Jetztzeit,' i. 430 .

Blumenbacb of Göttingen University, i. 165,194, ii. 247 ; fossil collections, 248 ; influences Herder, 532.

Böckh, science for its own sake, i. 211; 212 ; classical learning of, 222 ; 'Logos epitaphios' on Wilhelm von Humboldt quoted, 263.

Bode's law, i. 422.

Bodenhausen, i. 104.

Bodenstedt, 'Mirza Schaffy,' i. 213.

Boehmer, Dr Heinrich, 'Gesch. d. Entwick. d. Naturwissenschaftlichen Weltanschaunng in Deutschland,' ii. 531.

Boerhaave, i. 144, 175; and the medicat schools of Germany, 208; 268; atoms and massule, 398 ; epigenesis, ii. 298 .

Böhmer, "libertas docendi," i. 164.

Bohn, ii. 107.

Bohnenberger's gyroscopic instrument, ii. 61 .

Boileau referred to by Voltaire, i. 105.

Boltzmann, Ludwig, lectures on Maxwell's theories, i. 251 ; quoted, ii. 90 ; $176,186,188,595$; "availability," 597. 
Bolyai, i. 161 ; a pupil of Gauss, 181 ; father and son, and Gauss, ii. 652; 710,713 .

Bolzano, Bernhard, on undulatory theory of light, ii. 10 ; on the infiuite and convergency, 709 ; and Cauchy compared, $i b$.; Stolz on, $i$.

Bomare, Valmont de, first course of natural history at Paris, i. 106.

Bonald, De, on origin of language, i. 23.

Boud, Dr, ii. 565.

Bonnet, Charles, regular arrangement of leaves, ii. 223; 'Echelle des êtres," 238; " "evolutionist," 278 ; 279 ; epigenesis, $298 ; 322,519$.

Bounet, Ossian, ii. 701 .

Boole, George, neglect of, in England, i. $247 ; 272 ;$ and moderu school of mathematics, ii. 676 ; Stanley Jevous on, 684 .

Bopp, language, ii. 540, 542.

Borda, i. $113,148$.

Bordeu, vitalist, i. 126 ; vital force, ii. 503.

Borel, Émil, his lectures, ii. 704.

Borelli, medicine in alliance with physies, i. 126.

Boscovich, Roger, theories of molecular attraction and repulsion, i. 357 ; metaphysical theorist, 371 ; 416 ; on the nature of matter, 419 ; application of theory of gravitation to molecular physies, ii. 28 ; gravitation as a general physical theory, 351.

Bossut, i. 107.

Bougainville, pupil of the Ecole normale, i. $112 ; 113$.

Bouillier, M., quoter, i, 107,108 ; 'Eloges de Foutenelle,' 135.

Boulton, use of the term "horsepower," ii. 99.

Boussinesq quoted ou transmission of vibrations of ether to ponderable bodies, ii. 54 .

Boussingault, agricultural chemistry, ii. 393 ; 406 ; bacteriological work, 415 ; quoted, 441.

Bowen, criticism of 'Vestiges,' ii. 319.

Boyle Lectures, Beutley's, i. 169.

Boyle, Hon. Robert, Newton to, i. 342 ; and Lavoisier, 386 ; atoms aud massuloe, 398 ; law of pressures, 425; 427 ; law of, 429 ; ji. 592.

Boys, Prof., determiuation of force of gravitation, i. 320 .

Bradley, i. 158; observations of, utilised by Bessel, 177; 238; aberration of light, ii. 10 ; astronomical aberration, 194.
Brandt, Sebastian, i. 163.

Braun, Alex., spiral theory, ii. 223; 268; quoted, 269.

Bravais, 'Etudes crystallographiques,' i. 443.

Bréal, educationalist, on Rousseau, i. $259 ; 260$.

Brewster, Sir D., 'Life of Newton,' i. $98,321,342$; experiments of, 230 ; quoted ou toundation of suggested "British Association," 238; never adopted theories of Young, 244; Scottish university professor, 272; opposed to undulatory theory of light, ii. 16 ; letter from Young, 27 ; theory of undulations, 37 ; experimental work of, 45 ; adherence to projectile theory, 46 ; observed the phenomenon of tluorescence, $52 ; 245$; criticism of 'Vestiges'' 319 ; 482 ; stereoscope, 506.

Brianchou, ii. 660 .

Bridgewater Treatises, ii. 324.

Briggs, Hewry, 'Logarithmorum Chilias prima,'i. 269.

Bright, i. $27 \%$.

Brill and Nöther, 'Theory of Functions,' i. 308: 'Bericht' quoted, ii. 657; $700,701$.

Briosehi and imvariants, ii. 685 .

Brisseau, a pioneer of the cellular theory, ii. 262.

British Association, i. 42, 236 ; founded, 89, 238; suggested by Brewster, ib. ; successful work of, 239; Sir Charles Lyell on, 240 ; reports, ii. $54 ; 55,58$, 73 ; meeting, 163.

'British Quarterly Review' quoted on the two older universities, i. 254.

Brix, Walter, ii. 734 .

Broca, speech, ii. 478, 479, 539.

Brockhaus, 'Conversatious-Lexicon,' i. 273.

Brodie, ii. 362 .

Brongniart (see Cuvier), associated with Cuvier in paleontological work, i. 139 ; excavations, ii. 248 ; exploration of Paris basin, 294.

Bronn, translation of 'Origin of Species,' ii. 322.

Brougham, Lord, unfair criticism of Young, i. 244; 'Edinburgh Review,' 273 ; on Dr Young, ii. 9, 19.

Broussais, French medical science, i. 208; phrenology, ii. 477.

Brown, Crum, and Tait, Memoir of Thomas Andrews, ii. 162; ou Sainte Claire Deville and "dissociation," $163 ; 438$. 
Brown, John, i. 126.

Brown, Robert, nsed the term "cell," i. 195; scientitic publications of, 230 ; not member of any university, 238; discovery of the cell mucleus, ii. 264; 339.

Brown, Thomas, 'Cause and Effect,' i. 84 ; ii. 511.

Browning, maturer thought of, i. 76.

Bruicke, i. 198 ; protoplasmic theory, ii. 443 ; language, 538.

Bruhus, 'Life of A. von Humboldt,' i. 238 , ii. $225,253,475$.

Bruno, animation of all matter, ii. 369.

Brunswick, history of, ii. 250.

Bryan, Prot., secoull law of thermodynamics, ii. $176 ; 595$.

Bryce, James, quotel on German universities, i. 159.

Buache, geography at the École normale, i. 112; 113 .

Buch, von, ou descent, ii. 330.

Bïchner, L., materialism, i. 60 ; ' Kraft und Stoff,' ii. 320 ; 32:3.

Buckland, Wm., i. 106 ; palrontological work of, 139 ; ii. 325.

Buckle quoted, i. IIt; statistical method, 124; philosophy of, ii. 346 ; statistics, 584, 599; 607, 605 .

Buée on imaginaries, ii. 653.

Buffon, importance in Freuch literature of, i. $105 ; 283$; influence of, on the study of nature, 106; at the Jatdin des Plantes, 107; philosophical infinence of, 111; 113; discouraged views of Linuæus in France, 117; 119,131 ; natural history of, 126 ; 137, 142; 'Théorie de la Terre,' 144 ; $2 S S$; agaiust Clairault's attempt to correct gravitation formula, 334; classification of natural objects, ii. 221 ; 232; analogies of nature, 255 ; 'Époques de la Niature,' 277, 309 ; 322 ; "organic molecules,' 454, 610 ; 455 ; influences Herder, 532 ; 613.

Bunge, 'Plysiological Chenistry' quoted, ii. $378,425,426,434$.

Bunsen, Baron von, relative merits of Young and Cliampollion, i. 244 ; 'Egypt's Place in Universal History,' 245 .

Bunsen, R. W. vou, i. 412 ; cresium and rubidium, ii. 49 ; spectrum analysis, 57.

Burali Forti, ii. 656.

Burbury, ii. 595.

Burckharilt, J. K., calculates orbit of Ceres, i. IS2; lunar theory, 329.
Burkhardt, H., on Ruffini, ii. 685 ; on Riemann, 698, 700 .

Buruet, Thomas, i. 283.

Burnett, James. See Lorl Monborldo. Burns, healthy spirit of, i. $78 ; 212$, 285.

Burnside, his 'Theory of Groups,' ii. 691.

Butler, philosophy in English universities represented by, i. 2.54; apologetic writings of, ii. 325 .

Bitschli, on fertilisation, ii. 227 ; foam theory, 427; "Nechanismus und Vitalismus,' 463.

Buys Ballot and Boscovich's theory, i. 359 ; Doppler's principle proved in acoustics, ii. 49.

Byrou, revolutionary spirit of, i. 78 .

Cabanis, alliance with medicine, i. 126 ; 127; 'Révolutions de la Médecine,' 135; 152; 'Rapyorts du Physique et iu Moral de l'Homme,' ii. 469; his simile, 470,503 ; science of man, 471 ; language anil grammar, 530; 532.

Caesalpinus, arrangement of leaves of plants, ii. 223.

Cæsar, Napoleon compared with, i. 153.

Casium found by Kirchhoff and Bunseu, ii. 49.

Cailletet, conclensation of permanent gases, i. 316.

Caloric, ii. 154.

Calvin, direct influence of, on Scotland, i. 253 ; educational work of, 255 .

'Cambridge Iathematical Journal,' i. 41.

Campell and Garnett, "Life of ClerkMlaxwell,' ii. 599.

Campbell, H. I., translation of Hertwig's 'The Cell,' ii. 265.

Campe, edition of 'Robinson Crusoe,' i. 256 ; ii. 324 .

Camper, ii. 247 ; collection of fossils, 248; physioguomy, 477; influences Heriler, 5:32.

Camnizzaro showed the value of Avogadro's hypothesis, i. 427, 445.

Canton, M., history of mathematics, ii. 632 ; quoted, $633 ; 634$, 650 .

Cantor, $G$., on theory of probabilities, i. 122 ; ii. 630 ; a new chapter iu mathematics, 634 ; 734 ; on the transfinite, 735,737 .

Capillary action, i. 356.

Carbon tetraherlron, the, i. 450.

Carlyle, intuence of, on English style and language, i. 22 ; first to give 
specific meaning to the word Thought, 26; 'Life of Schiller,' 134; 171; quoted, ii. $520 ; 528,531,608$.

Carnot, Hippolyte, Sarli Carnot's 'Puissance Motrice,' ii. 118; referred to, 130.

Carnot, L. N. M., on correlation, ii. $100,138,658$; Chasles on, ib.

Carnot, Sadi, valuable researches utilised by Helmholtz, Thomson, and Joule, i. 201 ; absolute scale of temperature, 315 ; the steam-engine, 331 ; mechanical theory of heat, ii. 105 ; practical claracter of his labours, 117 ; 'Puissance Motrice' quoted, 118, 122; analogy between flow of water and of heat, 122; heat theories, 123 ; perpetual motion, 124, 126 ; and Joule, 128 ; dissipation of energy, 130 ; first definite use of new conceptions of power and work, 137 ; his theory referred to, 139 ; second law of thermo-dynamies, 175 .

Carocher, i. 113.

Carpenter, labours of von Baer, ii. 302 ; 608.

Carruthers quoted on Hugh Miller, i. 288.

Cartesian physical philosophy, i. 433.

Carus, C. J., phrenology, ii. 477.

Carus, Victor, 'Geschichte der Zoologie,' i. 130 , ii. 213 ; comparative anatomist, and the Naturphilosophie, i. 207; 'Geschichte der Zoologie' quoted, ii. $220,221,230,234,237,239,260$, 265 ; Goethe, Oken, and the genetic view, 317 .

Cassini, i. 107, 113; astronomical constants, 322 ; the motion of light, ii. 10.

Catabolism, ii. $395,442$.

Cauchy, Augustin, mathematics and physics, i. $45 ; 188$; theories of elastic forces in solid bodies, 360 ; properties of ether, ii. 31, 33; theory of elasticity, 31,41 ; molecular researches of, 43 ; analytical method of, 45 ; referred to, 54 ; school of, referred to, 93, 100 ; inflnenced German thought, 101; his reforming influence, \&c., 636 ; and Gauss, 637 ; Abel on, ib.; Combes on, $i b$.; his memoir on definite integrals, 639 ; Legendre on, ib.; 640 ; his 'Cours d'Analyse' quoted, 647; on Poncelet's principle, $660 ; 680,683$, 690; and Riemamn, 693, 695, 697, 704,$706 ; 707,732$.

Cavendish, discovered hydrogen, i. 115 ; 155 ; scientific discoveries of, 229 ; not nember of any university, 238 ; important papers of, lost, 277 ; measurement of gravitation, 320 ; measurements of, 343 ; founded exact science of electricity, 347 ; discoveries of, 354 ; researches of, 363 ; and Lavoisier, 386, 387 ; 391, 393 ; chemical equivalents, 418 ; ii. 70 .

Cavendish Society, i. 43.

Cayley, Arthur, and Pliicker, i. 242 ; developed theories of Boole, 247; doctrine of "invariants," ii. 140 ; on mathematics, 631 ; on "Curve," 'Encyclopædia Britannica,' 641 ; on "deficiency," $i b . ;$ on extended system of numbers, $654 ; 670$; geometry and modern algebra, $671 ; 676,684$; his great memoirs on Quantics, 684, 686,691 ; on functions, 693 ; on non-metrical relations, 713 ; on the "Absolute," 715; on the "Imaginary," 716.

Cell, autonomy of, ii. 395.

Cellular theory, i. 194; ii. 260, 417 ; pathology, i. 195.

Celsus, metlical works of, ii. 207.

Centralisation, ii. 524 .

Century does not inherit all of the past, i. 56 ; nineteenth, the scientific century, 89.

Ceres, discovery and rediscovery of, $i$. 54,82 ; discovery of, 423.

Challis and the discovery of Neptune, i. 277 .

Chambers, Robert, authorship of 'Vestiges,' ii. 318 ; 320 .

Chambers, Robert and William, publish their Journal, i. 273.

Chambers's Encyclopædia, "Education," i. 257 ; first published, 273.

Champollion, "hieroglyphics," 1. 244.

Chances, science of, ii. 568 .

Chaptal, practical discoveries of, i. 147. Charcot, language, ii. 539.

Charles, and Gay.Lussac's law of temperatures, i. 425, 429.

Charles, Duke of Wuirtemberg, i. 133.

Charles II. built Greenwich Observatory, i. 98 ; ii. 562.

Chasles, Michel, quoted on Monge, $i$. 114 ; synthetic method of, ii. 100 ; geometrical mechanics, 101; his 'Géométrie supérieure' quoted, 592, 658 ; 670 ; infinitely distant elements, 671 ; brilliant writings of, 673 ; eclipses German mathematicians, $673 ; 684$, 685.

Châtelet, du, Madame, explained Newton to Voltaire, i. 106. 
Chemical laboratories established, i. 188.

Chemical symbolism, i. 417 ; affinity, neglect of the study of, 420 ; theory, Kopp on, 421 ; and physical reasoning contrasted, 424; aftinity, theories of, 452 ; affinity, ii. 157 .

'Chemie, Gehlen's Allgemeines Journal für,' i. 41.

'Chemische Annalen,' Crell's, i. 41.

Chemistry, a French science, i. 114; equivalents, 399 ; organic, 407 ; Liebig's definition of, 409 ; substitution, $i b$. ; "type" theory, 411 ; uncertainty about theory in midlle of century, 413 ; periodic law, 422 ; structural and stereo-chemistry, 447 ; change in definition of, 454 ; ii. 389 ; change in organic, 393.

Chénier, Marie-Joseph, Report on French literature, i. 149.

Cherbuliez, E., 'Ueber' einige physilsalische Arbeiten Eulers, ii. 8; quoted, 46.

Cheselden, space-perception, ii. 473 ; 505.

Chesterfield's, Lord, Letters, quoted from, i. 105.

Chevalier, Aug., Galois's letter to, ii. 686.

Chevenix, not member of any university, i. 238 .

Chevreul, 'Recherches sur les Corps gras d'origine animale,' i. 454 ; ii. 406.

'Chimie, Annales de,' issued by Berthollet, i. 41.

"Chirality" discovered by Pasteur, i. 431 ; origin and meaning of the word, ii. $22 ; 437$.

Chladni,' 'Aknstik,' i. 83; theory of elasticity, ii. 31 .

Chloral discovered by Liebig, i. 93.

Chloroform discovered by Liebig, i. 93.

Christiansen and Kundt, discovery of anomalous dispersion of wave-motion, ii. 53,54 .

Christie, not member of any university, i. 239 .

Christison of Edinburgh University, i. 272.

Chronometers, i. 329.

Chrystal, G., Pliicker, and Faraday, i. 242; 'John Napier, Baron of Merchiston,' quoted, '269; on David Gregory, 270 ; "Maguetism," ii. 75 .

Church on the spiral theory, ii. 224.

Cicero, ii. 523.

"Cinématique," the word introduced by Ampère, ii. 5 .
Circle, squaring of the, ii. 124 ; division of the, 728 .

Clairanlt followed Newton, i. 96; his 'Théorie de la Figure de la Terre,' 99 ; referred to by Voltaire, 106, 107; mathematics made fashionable in France, 237; Laplace and, 319; lunar theory, 329 ; attempt to correct Newton's law, 334; capillary attraction, 356,378 .

Clapeyron, i. 379; suggesterl earlier researches of Clausius and Thomson, ii. 117 ; Carnot's 'Puissance Motrice,' 118 ; heat and work, 123 ; biographical, $i b$.

Clark, J. W., and T. M'K. Hughes, 'Life and Letters of Adam Sedgwick,' i. 267.

Clark, Latimer, "Weber" nuit, i. 369.

Clarke, Newton's "descriptive and calculating" philosophy, i. 337 ; letter to Leibniz on gravitation quoted, 340.

Classics, foreign, superiority in number and quality of German trinslations of, i. 213.

Classification, ii. 231.

Clausins, Rudolf, on atoms, i. 313 ; "Entropy," 316, ii. 169, 181, 184, 594 ; the kinetic theory of gases, i. 43.3 , ii. 34,162 ; 'Die mechanische Wärmetheorie,' i. 434, ii. 163, 167 ; "on the average mean path of a par. ticle," i. 438; theoretical thermodynamies, ii. 62 ; independence of Mlayer's writings, 97 ; "work" and "energy," 115 ; unifies the views of" Mayer and the measurements of Joule, 116; "conservation of energy," 128 ; "dissipation of energy," 131 ; labours of, 133,173 ; researches of, 133; Prof. Unwin's account of theories of, 135 ; elaboration of Joule's and Regnault's experiments, 137 ; physical view of nature, 141 ; dynanical theory of heat, 148; dissociation, 163; "free energy," 175 ; heat, 178; theory of probabilities, 590 ; thermo-dynamics, 603.

Clavius quoted, ii. 287.

Clebsch, A., on Julins Plücker, i. 242, ii. $75,76,677$.

Clifford, W. K., "axioms of geometry," i. 352 ; reflex action, ii. 520 ; " mindstuft" theory, 546 ; criticism of ClerkMaxwell, 606, 608, 656 ; on Riemann, 704.

Colın, quoted, ii. 559.

Colbert recognised the practical value 
of science, i. 98 : 134 ; first statistical bureau, ii. 561 .

Colding, ii. 107, 109; indestructibility of force, 111, 125; heat, 112 .

Coleridge imports philosophy of Kant and schelling into England, i. 17 ; healthy spirit of, 78 ; 'Christabel,' 84 ; intluence on metaphysical studies of, 91 ; lectured at Royal Institution, $219,-64$.

College de France, i. 107.

Collegge et Ecole de Chirurgie, i. 107.

Collignon (see Combes), ii. 101.

Collins, invention of the calculus by Leibniz communicated to, i. 101.

Colour, ii. 484 et seq.

Combe, Geo., phrenology, ii. 477.

Combes, Phillips et Collignon, 'Exposé de la Situation de la llécanique appliquée,'ii. 101 ; quoted by Valson on Canchy, 637.

Combinatorial school in Germany, ii. 642 ; analysis, Leibniz, 679 ; MacMahon on, $i b$.

Combustion, theory of, i. 389.

Commutative principle, ii. 717 .

Compayré, educationalist, on Ronsseau, i. $259,260$.

Complex quantity, ii. 643 ; interpretation of, 653 .

Comte, Auguste, philosophy of, i. 18, 61 , ii. 105; his three stages of thought, i. 73 ; positivist theory of, 85 ; 306 ; 'Philosophie Positive,' 307 , 308 , ii. 37,239 ; scientific errors of, i. 310 ; opposed to undulatory theory of light, ii. 37 ; and De Blainville, $247, \therefore 66$; theory of probabilities, 569 , $608 ; 749$.

Comtism, failure of, i. 72 .

Condanine, La, astronomical constants, i. 322 .

Condillac, 'Essai sur les Origines des Connaissances humaines,' i. '144; neglect of, by Napoleon, 149; his ignorance of physiology, ii. 471; langliage, $530^{\circ}$.

Condorcet, importance in French literature of, i. 105; quoted, 110; educational work of, 112; the theory of probabilities, 120; alliance with medicine, 126; Académie des Sciences morales et politiques, 145 ; suicide of, 147 ; neglect of, by Napoleon, 149 ; distinguishes education and instruction, 259,260 ; statistics, i. 570,573 .

Contlict between the scientific and the philosophical views, i. 205.

Conformal representation, Gauss and
Riemanı on, ii. 700 ; Holtzmïller ol1, 701 .

Congruences, theory of, ii. 723 ; calculus of, 724 .

Conrad, Prof., 'The German Universities for the last Fifty Years,' i. 159; quoted on German universities, 160 ; 'Die Deutschen Universitäten,' 197, 198.

Conring, Hermann, statisties, i. 121, ii. 555 ; political statistics, 562 .

Consciousness, ii. 516.

Conservation of force, i. 218.

Constable, his influence on painting in France, i. 19.

Constant, Benj., visits Germany with Mme. de Staèl, i. 17.

Continuity, of living forms, ii. 453 ; in geometry, 660 .

Continnous, the, ii. 643.

Convention, decree on Academy of, $\mathrm{i}$. 148.

Convergency of series, ii. 646 .

Conybeare, W. D., report on the progress of geological science, ii. 281.

Cook, Captain, i. 52, 179; royages, ii. 222 ; Ton Baer on, 304.

Cooper, Astley, English medical science, i. 208 ; no connection with the English universities, 272

Co-operation, ii. 566.

Cope, E. D., ii. 271 ; neo-Lamarclian, 351.

Copernicus, i. 118 ; precursor of Kepler, 317 ; stimulated star - gazing, 327 ; astronomical theory of, ii. 13 .

Coriolis, St Venant quoted on, i. 369 ; practical school of, ii. 100.

Cornu, "Association Française," i. 298.

Correspondence in mathematics, ii. 736.

'Correspondenz, Monatliche,' Zach's, i. 41.

Corti, arcades of, ii. 372.

Cosmical view, ii. 369.

Cosmos, genesis of the, ii. 360 .

Cossar Ewart on Jameson, i. 283.

"Cost" as factor in industry, ii. 155 .

Coste, study of food fishes, ii. 232.

Cotes, Roger, 'Aestimatio errorum in mixta nathesi,'i. 324; " description and explanation of phenomena," 337 ; second edition of 'Principia,' 351 ; preface to 'Principia' misleading, 355.

Cotton, M. A., "Le Phénomène de Zeemann," ii. 197.

Coulomb, measurements of, i. 343 , $362,369,369$; founded exact science 
of electricity, 347 ; torsion balance, 360 ; attraction and repulsion of electrified bodies, 361 ; 370 ; $t$ wofluid theory of electricity, $i b$.; electro-static formula of, 371 ; Young and, is. 30 ; modern view of electrical phenomena, $67 ; 72$; referred to, 78 , 92 ; laws of, 79 ; practical school of, 100 ; electrical theory of, 153 ; the atomic view of nature, 188, 191, $193 ; 698$.

Counting and measuring, ii. 732 .

Couper, chemical researches of, i. 447.

Courcier, geometrical work of, i. 114.

Cournot, testimony to work of German universities, i. 225 .

Cousin guillotined, i. 147 .

Cousin, Victor, testimony to work of German universities, i. 225.

Couturat, L., ii. 734.

Cowley, Ode on Bacon, i. 96.

Cowper, 'The Task,' i. '285; Letters, $2 \times 6$.

Cramer, 'Analyse des lignes courbes,' \&c., ii. 682.

Crawford, Dr, intiuenced by Black's lectures, ii. $10 \%$.

Crell's 'C'remische Annalen,' i. 41.

Crelle's 'Journal für clie reine und angewandte Mathematik,' i. 41, 186, ii. 58; corresponclence with Gauss, 185.

Cremona, i. 1s8; quoted, ii. 665 ; proves Steiner's theorens, 681.

Critical methods, ii. 626.

Crotton, M. W., "Probabilities," ii. 569.

Crome, Prof., statistics, ii. 579.

Cronsted, inventor of blow-pipe, i. 117.

Crookes, sir William, quoted on Prout's hypothesis, i. 403; sodium vapour in the sun's atmosphere, ii. 48; experiments and discoveries, 190 ; "corpuscular" theory of cathode rays, 192 ; (see Sir Norman Lockyer), 361.

Cruveillier, French melical science, i. 208.

Crystallographic and atomic laws, analogy between, i. 444.

Crystallography, i. 116, 441.

Crystals, laws of formation of, Haiiy's, i. 117 ; ii. 222 .

Cullen, metaphysical leaning in medicine, i. $126 ; 272$.

Culverwell, ii. 595.

Curie, geometrical treatment of crystallography, i. 443.

Currie, first use of thermometer at bedside, ii. 388.
Curtius, Ernst, 'Alterthum und Gegenwart,' i. 215; on English archeologists, 294; quoted, 295 ; on M. IV. Leake, 296.

Curves, degree, class, genus of, ii, 641 . Cuvier, Georges, scientific report of, i. 42, 152, 154; "Tableau" and 'Leçons,' 82; 112; on P'riestley as chemist, 115; on Han̈y, 118; advance in stuly of organic life, 119 ; services of, to practical science, 125 ; 126 ; Eloge of Hallé, I27 ; 'Le Règne animal,' 128 ; quotel, 129, 132, 141, $146,147,150$, ii. 249 ; makes nervous system of animals the basis of classification, i. 130; training of, 133 ; description of the "Larlschule," 134 ; the greatest representative of the academic system, 136; first great historian of science, 137 ; quoted on science and revolution 138; palæontological work of, 139 ; Éloge of Fourrroy, 140 ; elementary scientific textbooks, 143; report of French Institute, 149; ellucational institutions, $155 ; 163,17 \mathrm{I}$; mistrusted speculative spirit in science, $178 ;$ his ideas triumph over those of Geoffroy St Hilaire, $179 ; 200$; in praise of French science, 231: quoted on seience in England, 235; 264; and Brongniart, founders of palsentology, 291 ; 306; depreciated by Comte, 310: zoological labours, ii. 222; study of fossil remains, 225 : anatomical clissection, 232 ; zoological work, 235 ; murplological and anatomical study of animal life, 237 ; classifications, 238, 239, 254: fossils, 240 ; rejects idea of "Échelle les êtres," 243 ; controversy with Geoftiroy, 246, 253; paleontology, 247 ; "catastrophism," 250,251 ; and "theory of analogies," 254; the question of the fixity of species, 256 ; combats influence of Oken, 259 ; extension of morphological view, 260,266 ; influence of, 276 ; 'Ossemens fossiles,' 277 ; exploration of Paris basin, 294; one-silled influence of, 300, 301; and Buffon, 309 ; Éloge lle Lamarck, 316 ; views of Lamarck and Geofiroy, 320 ; and Newton, contrasted with Darwin, 34I; a founder of comparative anatomy, 386, 406; "vortex," 422; 751.

"Cyclical" view, ii. 286.

Cyclopæedia, Nichol's, i. 330, ii. 133. 
Cyclopredias, i. 273.

Cyriacus of Ancona, archæological pioneer, i. 295.

Czapski, 'Theorie der optischen Instrumente nach Abbé,'ii. 14, 229.

Czermak, language, ii. 538.

Czuber, Emmanuel, theory of probabilities, ii. 568 ; method of least squares, 576.

Dacier, Report on the progress of History and Classical Literature, i. 149.

Daguerre, photography, ii. 506.

Dahlmann, "theoretical politician," $i$. 311.

D'Alembert, contributions to the Encyclopédie, i. 34,144 ; his importance in French literature, 105 ; theory of probabilities, $120 ; 215,234$, 237 ; the cure of smallpox, $284 ; 319$; mathematical study of vibrations, ii. 16 ; "measure of force," "Traité de Dynamique,' 100 ; statistics, 571 ; on functions, 694 .

Dallas, ii. 349.

Dalton, John, "New System of Chemical Philosophy,'i. 83 ; atomic theory, $189,266,385,394,415-417,419,425$, 426,428 , ii. 180 ; scientific discoveries of, i. 229 ; not member of any university, 238, 272; neglect of, in England, 245; arithmetical mind of, 246 ; furnished tests for lectures in German universities, 251; 265; science of meteorology, 286; 293, 311,313 ; heat a material substance, 433 ; formulæ of, 436 ; analogy between erystallographic and atomic laws, 444 ; his atomic theory insufficient, 451 ; atomic theory referred to, ii. $19,20,37,95,153,154$; colour blindness, 505 .

Dannecker educated with Cuvier, i. 133.

Dante, i. 261.

Danton, i. 107.

Darwin, Charles, constructive ideas of, i. 81 ; eminence of writings of, 105; 179 ; letter from Sir Charles Lyell on British Association, 240; theory of descent, 201, ii. 321,406 ; furnished texts for lectures in German universities, i. 251, 310 ; 'Cirripedia' monograph, 283 ; 'Autobiography,' ib.; nature-lover, 287 ; and Gilbert White, $290 ; 297,312$; referred to, ii. 136; value of his visits to distant countries, 207; studies of organic life, 209; law of descent, 214 ; con- ceptions of, 246 ; and Owen, 267 ; theory of pangenesis, 271, 454 ; writings of, 301, 306 ; 309; on Lamarck, 318 ; 'Origin of Species,' 326, 329; 'Life and Letters,' 328; and Malthus, 331 ; 'Origin of Species' quoted, 336 ; Bates's "Mimetic Butterflies," 339 ; and Newton compared, 341 et seq. ; "natural selection," 351 , 354 ; 434, 437 ; hybridisation, 373 ; "final causes," 403; 408; struggle for existence, 418 ; 421 ; environment, 430 ; conflict in uature, 431 ; $435,436,451$; quoted, 457; and Weismann, 460; 467, 470;' 'Expression of Emotions,' 477; 511, 514 ; evolution, 530; and Herder's evolutionism, 533; language, 540 ; 587,607 ; variation in nature, 608 ; on mental phenomena, 609 ; on "pangenesis," 610 ; 621 ; two novel points of view of, 624 .

Darwin, Erasmus, anticipated Lamarck, i. $201 ; 285$; colour sensations, ii. 482 .

Darwin, Francis, 'Life and Letters of Charles Darwin,' ii. 329.

Darwin, G. H., 'The 'Tides,' ii, 282.

Darwin, Robert W., colour sensation, ii. 482 .

Darwinism, i. 251, ii. 386 ; and final causes, 411 ; in Germany, 436.

Daubenton at the Collegge de France, i. 107 ; natural history at the Écoles normales, 112 ; 113 ; collection of fossil remains, ii. 248.

Daunou, Académie des Sciences morales et politiques, i. $145 ; 152$.

Davy, Sir Humphry, electro-chemical discoveries of, i. $83,189,363$; scientific work of, 229 ; science in England, 234 ; not member of any university, 238, 272; opposed Dalton's atomic theory, 245, 246 ; studied in laboratory of Royal Institution, 249, 264 ; educated Faraday, 265; unconnected with Cambridge mathematical school, 266; electric action iu chemical processes, 366 ; decomposition of soda and potash, 391, 404; electro-chemical theory, 405, 452 ; salts and acids, 410 ; attitude to Dalton's theory, 417; attitude towards the atomic theory, 418 ; 428 ; chemical application of electricity, ii. 92 ; electro-chemistry, 93 ; heat and chemical change, $10 \%$; attitude to science that of a medical man, 103 ; vibratory view of heat, 
104 ; indestructibility of force, 111 ; the dynamical theory of heat, 128; 154 ; agricultural chemistry, 391.

Dawson, John, i. 267.

De Bary, embryological studies of plant life, ii. 228.

De Blainville, indebtedness of Cuvier to, i. 130 ; organisation, ii. $236 ; 239$; 'Cuvier et Geoftroy Saint Hilaire,' 247,255 ; 'Ostéographie,' 257; 266; unity of organisation, 267 ; "composition et décomposition," 421 ; school of, 431 .

Décade philosophique ridiculed the fall of meteors, i. 327.

De Candolle, A. P., botanist, ii. 222 ; theories of symmetry, 223 ; "Organographie végétale' quoted, 230,236 , 261, 265, 266 ; Théorie élémeutaire de la Botanique' quoterl, 235 ; morphological view, 239; quoted, 240, 242,269 ; regularity and symmetry in organic nature, 241 ; symmetry of form, 243 ; appreciation of Goethe's work, quoted, -244 ; influence of, 276.

Decher (see Clausius), ii. 135.

Decimal fractions, ii. 645,731 .

Dedekind, R., biographical notice of Riemann, i. 352 ; and Dirichlet, ii. 721 ; 726,729 ; on irrational numbers, $733,734,737$.

De Gérando, i. 149.

De Haen, i. 208.

Delage, Yres, history of the study of organic life, ii. 232 ; 'L'Hérédité et les grands problèmes de la Biologie,' $265,364,371,372,444,455,458,459$; 'L'Hérédité' quoted, 271, 298, 348, $349,406,421,427,447,461$; structure of protoplasm, 370; school of "organicism," 436 .

De la Hire, ii, 664,667 .

Delambre, i. 113; report of French Institute, 149; quoted on statistical methors in France, 153.

Delambre and Cuvier, scientific reports of, i. 42 .

Delaunay, lunar theory, i. 329.

De Luc, attacks on Hutton, ii. 291.

Democritus of Abdera, founder of atomistic theory, i. 385; animation of all matter, ii. 369 .

De Moivre, doctrine of chances, ii. $67 \mathrm{~S}$.

Derand, geometrical work of, i. 111.

Derbam, Dr Wm., 'Physical Theology,' ii. 565 .

Descartes, constructive system of, i. 75 ; and Bacon, $84 ; 123,137$; and the philosophy of Kant, 222; Order of Jesus, 256; Harvey's discovery, 282 ; discovery of reflex action, 292 ; 'Les Passions de l'Âme,' 293; 311,313 ; his philosophy and New. ton's contrasted, 338; qualitates occulte, 351 ; Snell's experiments in deflection of light rays, 356 ; levelopment of kinetic view, ii. 6; Euler's opposition to, 8 ; theoretical hydro. dynamics, 58; older vortex theory and, 62 ; the measure of iorce, 100 ; influeuce on German philosophy, 205 ; theory of rortices, 360 ; a fonnder of modern physiology, 378; study of biology, 379, 380 ; illea of life, 409, 410 ; school of "organicisme," 436 , $455 ; 470,519,638,641,697$.

Descent, theory of, i. 201.

Descriptive geometry, ii. 658 et seq.

Deshayes, history of invertebrates, ii. 239 ; Lamarek, 310.

Destructive spirit in writings of eighteenth century, i. 78 .

Destutt de 'Tracy, 'Idéologie,' i. 83; alliance with medicine, $126 ; 152$; icieologist, ii. 472 .

Determinants, ii. 682 ; history of, $i b$.

Development, study of, ii. 264.

Deville, Sainte Claire, ii. 162.

De Wette, theologian, influenced by school of Fries, i. 209, 273.

Diamagnetism, ii. 74 .

Dickson, J. D. H., quoted by Galton, ii. 619 .

Diderot on the genesis of new words, $i$. 21 ; his Encyclopedie, 34, 144, 215.

"Dielectric," ii. 68.

Differential equations, general theory of, ii. 692 ; Sophus Lie on, ib.

"Diffraction," Fresnel's memoir on, ii. $25,27$.

Dilthey, 'Schleiermacher,' i. 279.

Dingeldey, 'Topologische studien,' ii. 64.

Dingler's 'Polytechnic Jonrnal,' ii. 134.

Dini, Ulisse, on theory of functions, ii. 704.

Dionis du Séjour, death of, i. 147.

Dirichlet, Lejemne, lectures on mathematical physics, i. 44 ; discourse on Jacobi, 185; quoted, 186, 188, 189 ; Fourier's series, 241 ; on Steiner, ii. $670 ; 680$; and Fourier, 694 ; his and Thomson's principle, 700, 704, 708; 721, 726, 728.

Dissociation, ii. 163.

Distribution, ii. 566.

Döbereiner, i. 190. 
Dohrn, Anton, scaside laboratory fonnder at Naples, ii. 232.

Düllinger, Jgnaz, evolutionist, and the Naturphilosophie, i. 207; scientific researches, ii. $299 ; 303$.

Dollond, not member of any university, i. 235 ; astronomical instruments, 32:.).

Domestay-Book, ii. 555.

Douders, on language, ii. 538.

Domner's rendering of the Greek dramatists, i. 213.

Doppler, emunciated the principle of liömer's discovery, ii. 10; his principle of wave-motion, 49.

Dove, meteorology, i. 205.

Downs, 0. G., ii. 579.

Dreyfus-Brisac, testimony to work of German universities, i. 225.

Driesch, Hans, ii. 342 ; "organicisme," 455 ; works of, $456 ; 463,549$.

Drobisch, psychologist, ii. 494, 497; pretensions of statistics, 586 .

Drude, P., ii. 38.

Drummond and Edinburgh University, i. 269 .

Drummond, Hewry, ii. 326.

Drummond, Thomas, spectrum analysis, i. 278 .

Duality, principle of, in geometry, ii. 665.

Dublin school of mathematicians, i. 274 , ii. 673.

Du Bois-Reymond, Emil, on the introduction of new ideas from abroad, i. $16 ; 45$; limits of the knowable, $53 ; 106$; the speculative tendency in science, 179; 'Reden,' 188, 215, ii. 149 et seq.; 'Gedächtnissrede auf Joh. Müller,' i. 198, 293; voltaic electricity, 199; quoted, 216, ii. $270,381,469,478$; mechanical view of biology, i. 219; Bell's doctrine, 293 ; 'Alsademie der dentschen Sprache,' 298 ; 'Ueber die Grenzen des Naturerkennens,' 348 ; objectious to Kirclihoff"s definition of "mechanics," 383 ; researches of ii. 208; Eloge of Johannes Miiller, 384, 419, 482;391, revolution in physiological studies, 396 ; 'Researches in Animal Electricity,' 397 ; 401 ; position in vitalistic controversy, 403; essay on Vital Force, 405̃; 408, 409, 411; on the principle of natural selection, quoted, 414; vitalism, 434: "Darwin versus Galiani," quoted, 435; "Exercise," 436; active nervons system, 438; animal electricity, 475,$476 ; 481$; principle of reflex action, $519 ; 546$, 743.

Du Bois-Reymond, Panl, services to scientific reasoning, i. $45 ; 103$; 'Grundlagen der Erlienntniss in den exacten Wissenschaften,' $341 ; 377$; gravitation " unknowable," 352 ; kinetic theory of gases, 433; works of, ii. 631,705 ; theory of functions, 704 ; on arithmetising, 739 .

Du Châtelet, Madame, letter from Vol. taire to, i. 105.

Duchesne, physiognomy, ii. 477.

Duclos, on education, i. 259.

Ducos quoted, i. 109.

Dufay, controversy on electric fluid, i. $36 \%$.

Duhamel, mechanics, i, 44; taught metallurgy at the Ecole des Mines, 107.

Duhem (see Prof. Ostwald), ii. 159; labours of, Horstmann, 170 ; thermodynamic potential, 173 ; 'Mécanique chimique, '173; chemical equilibrium, 175 .

Diihring, E., 'Kritische Geschichte der allgemeinen Principien der Mechanik,' ii. 97, 101; historical and controversial writings, 107.

Dujardin, Felix, sarcode, ii. 264; definition of a cell, 265 .

Dulong and Petit, specific heat of bodies, i. 428,429 .

Dumas, 'Leçons sur la Philosophie chinique,' i. 114 ; revives Prout's hypothesis, 402, 403; explanation of "isomerism," 406; the "radicle" theory, 409; attack on electrochemical theory, ib. ; 410 ; "type" theory, 411 ; 413 ; attitude towards the atomic theory, 418; quoted, 421, ii. 370,441 ; i. 402,428 ; spectroscopic observations, ii. 361 ; 'Essai de Statique chimique des Êtres organisés,' 392 ; substitution in chemistry, $393 ; 406$.

Duncker, G., statistics of variation, ii. 622 .

Düntzer, ii. 531.

Dupin, Charles, ii. 579 ; 658.

Dutens, 'Leibnitii Opera Omnia,' ii. 280.

Dntrochet, Bell's theorem, i. 293; ii. 230, 261.

Dynamics, ii. 5 ; and statics, 144.

Eckermann quoted, ii. 253.

École centrale des Travaux publics, i. 112. 
École des Ponts et Chaussées, i. 107.

École normale supérieure, i. 112, 113, 237.

École polytechnique of Paris, i. 112; used as morlel for German polytechnic schools, 166 .

École vétérinaire d'Alfort, i. 107.

Ecoles de Santé, i. 113; founder at Paris, Strasbourg, and Montpellier, 142.

Economies and biology, ii. 415 .

Eilgeworth, Prot., "The Law of Error," ii. 576 .

'Edinburgh Magazine and Review' issued, i. 273 .

'Edinburgh Review,' literary criticism of, i. 84: 233; quoted, $234,235,236$; on English nniversities, $254 ; 270$; first issued, 273; Brougham's attack on Young, ii. 19.

Erlison, phonograph, ii. 490.

Ellueation, and instruction, i. 258; liberal, ideal of, 255.

Edncational contlict on discipline, i. 133.

Eincational efforts in different countries, i. 252 et seq.; in Scotland, 253 ; literature of Switzerland, $i b$.

Educational institutions, French, i. 112.

Educational organisations in Eugland, i. 262 .

Edward, Thomas, shoemaker and zoologist, i. 287.

Edwards, George, 'History of Birds,'i. 287.

Edwards, Milne, 'History of Invertebrates,' ii. 239 ; Lamarck, 310 ; Huxley on, 322 ; " physiological division of labour," 396.

Ehrenberg, "Ueber Leibnitzens Methode,' ii. 280.

Eighteenth century, one of revolution, i. 77 .

Eisenstein, and theory of numbers, ii. 681.

Elasticity, theory of, ii. 30, 40 ; 31 ; foundation of theory of, 41 .

Electrical and magnetic action, i. 344.

Electricity, and magnetisn, ii. 64 et seq.; velocities of light and, compared, 81 ; mollern researches, 189 ; electric diseharges, 195 ; animal, 475.

Electro-dynamics, Wilhelm Weber's law of, i. 196 ; ii. 149.

Electro-magnetic theory, ii. 64 ; indefiniteness of, $93 ; 153$.

Electro-maguetism, discovery of, i. 9 ?

Electrolysis, ii. 154 et seq.

Electron, the term, ii. 193.
"Electrotonic" state of matter, ii. 68, 81.

Elizabeth, England uniler, i. 67.

Elliptic functions, history of, ii. 648 et seq.

Ellis, Alex. T., on terminology of sound, ii. 489 .

Ellis, Rolsert Leslie, on Bacon, i. 94, 96 ; his report, ii. 649.

Elphinstone, Bishop, starterl Aberdeen University, i. 268.

Elster and Geitel, vacuum tube experiments, ii. 190.

Enanations, law of, i. 344.

Eubryology, ii. 296.

Empedocles, relation to Galileo and Newton, i. 313; attraction and repulsion, 385 ; recurrent cycles, ii. 287.

Fncke, "calculus of probabilities," i. 325.

'Encyclopädie der Mathematischen Wissenschaften,' ii. 73.

Encyclopädie, lectures on, i. 37.

'Encycloperlia Britamica,' article on Napier, i. 269; first published, 273; article on "Agriculture" quoted, 284: article on F. Molnr, ii. 106; article on Sainte Claire Deville, 163; $232,279,569$.

'Encyclopærlia Metropolitana,' i. 236.

Encyclopiedia of Ersch and Gruber, i. 35.

Encyclopedias, origin of, i. 40.

Encyclopedic treatment of learning, age of, i. 34, 215; view necessary in philosophy and history, 203; treatment of scientific subjects, 214.

Encycloperl ists followerl Newton, i. 96 ; constructive work of school of, 110 ; educational influence of, 112.

Energetics, science of, ii. $141 ; 166$; kineties and, 180 .

Energy, conservation of, i. 199, 201; theory of, ii. 87,96 ; works dealing with, 97 ; dissipation of, 97,364 ; the term first used by Young, 9s; notion of, contained in Newton's 'Principia,' 99; the teru introduced by Thomson, 115: and "Foree," 115 ; availability and dissipation of, 119 ; doctrine of, 121; revolutions brought ahout by idea of, 137 ; "potential" and "actual," 139, 398; influence of doctrine of, 399 ; circnlation of, 420 ; 465 ; availability of, 594.

Engel, F., on taste in mathematics, ii. 632 ; on genesis of Lie's icleas, 692.

Englaud, science and philosopliy in, 
during the early part of the century, i. 75 .

English character, individualism of, i. 279 ; changes during last fifty years, 280 ; love of nature, 284,286 ; Hankel ou, ii. 704,711 .

Enneper, 'Elliptische Functionen,' i. $185,187$.

Eutropy, ii. 169 et seq., 181, 594.

Enumeration, ii. 561.

"Environnent," ii. 314, 430.

Epicurus, "essential and inherent gravity," i. 340 ; uatural philosophy of, ii. 4.

Epigenesis and evolution, ii. 298.

Equations, theory of, Abel, ii. 681; general solution of, 687 et seq.

Equivalents, chemical, i. 399.

Erasmus, i. 163.

Erdmanu, misprint in his 'Grundriss der Geschichte der Philosophie,' j. 50 ; ii. 495,512 .

Erlsberg, ii. 271 .

Ernest Augustus, Elector of Hanover, i. 158.

Ermest II., Duke of Gotha, i. 54, 176 ; patron of the astronomer von Zach, 177 ; system of education of, 256 .

Error, element of, i. 323 ; theory of, ii. $568,574$.

Ersch and Gruber, Encyclopædia of, i. 35.

Eschenburg, representative of encyclopredic teaching, i. 38.

Ether, luminiferous, theory of, ii. 18; properties of, 31 ; nature of, 36 ; hy. pothesis of, 37 ; Sir 0 . Lodge on nature of the, 38 ; nature of, 40 et ser.; mathematical and experimental inrestigation of, 44 ; an "elastic solid," 54; luminiterous, 69,70 .

Etymology, value of, for history of Thought, i. 20.

Eucken, R., on philosophical terminology, i. 21.

Euclid preferred in England to Legendre, i. 44; his works models of scientitic thought, $95 ; 120$, ii. 4 ; Proclus on, 634 ; Klein on, 635 ; 718, 733.

Eudenus of Rhodes, ii. 633.

Eurloxus, Proclus on, ii. 634.

Euler, Leonhard, freed analysis from geometrical fetters, i. 103; 135; competed with T. Mayer, 158; 163; connection of, with modern science, $175 ; 181,183,234$; analytical methorls of, 271 ; mathematics, 44 ;
319 ; lunar theory, 329 ; Newton's gravitation formula, 334 ; "Ursache der Gravitation," 341 ; ether theory of gravitation, $343,346,351$; unfavourable to Boscovich's theory, 358 ; ii. 7 ; 'Anleitung zur Naturlehre,' 8 ; the successor of Huygens, 16, 17 ; studies in elasticity, 30 ; spectrum analysis, 46; psycho-physics, $474 ; 510,637$; introduces conception of "fumction," $639 ; 643,646$, 648 ; on different mathematical interests, 657 ; 669, 680, 692, 694, 695, 721 .

Evelyn, John (see Arundel collection), ii. 564 .

Everett, "character" in music, ii. 489.

Evolution, ii. 210, 278.

Ewald, on Humboldt's geological work, ii. $226 ; 253$.

Ewing, 'The Steam-Engine,' ii. 136.

Exner, 'Repertorium der Physik,' i. 323.

Exploration, the spirit of, ii. 206 et seq. Externalisation, ii. 525.

Fabricius of Acquapendente, teacher of Harvey, i. 282.

Fagnano, Count, Euler on, ii. 657.

Falk, Johames, follower of Pestalozzi, i. 258 .

Faraday, electrical theories of, i. 199 ; electrical researches, 201, ii. 86 ; electrical and other discoveries of, $i$. 230; science in England, 236; not nember of any university, 239, 272; and Pliicker, 242 ; neglected iu Eng. land, 246 ; studied in laboratory of Royal Institution, 249; furnished texts for lectures in German univer. sities, 251; at Royal Institution, 264, ii. 80; educated by Davy, i. 265 ; "lines of force," 266 , ii. 68 , 182 ; not connected with Cambridge mathematical school, i. 266 ; neglect of his writings, $277 ; 279,297$; gravitation, 344 ; electricity, 345 ; sym. bolism, 347 ; nature of matter, 358 ; discovery of electrical induction, 363 ; method of measuring the electric current, 365 ; electrical action in chemical processes, 366 ; discovery of magnetic induction, 368,371 ; his influence, 380 ; discovery of "iso. merism," 406 ; his attitude towards the atomic theory, $418 ; 431$; theory of chemical affinity, 452 ; researches of, ii. 35 ; modern view of electrical phenomena, 66 ; "magnetisation of 
light," 74 ; electro-magnetic radiation, 77; and Thomson, 78; galvanic currents, 79; and Clerk-Maxwell, 80 ; "electrotonic state" of matter, 81; tubes of force, 83 ; electricity in motion, 93; and Poggendorf, 107 ; referred to, 111 ; indestructibility of force, $i b$.; correlation and interchangeability of natural forces, 119 ; "force," 125; "regelation of ice," 127 ; indestructibility of force, 130 ; electricity in space, 145; electromagnetic field, 146; electrolytic law, 154,157 ; results of experimental work of, 161; law of, 165; atomic view, 189; observations of vacuum tube phenomena, 190; 191, 193.

Faudel and Schwoerer, 'Life of Hirn,' ii. 134.

Fay, Du, referred to by Voltaire, i. 106.

Faye, 'Sur l'Origine du Monde,' ii. 282, 357,360 .

Fechner, Gustav Theodor, 'Elements of Psycho-physics,' i. 200 ; and Boscovich's theory, 359 ; Ohm's law, 365 ; electrical theory of, 371 ; 'Atomenlehre,' 433 ; ii. 369 ; psycho-physics, 469, 493; psychical research, 508; 'Psychophysik,' 511 ; 514, 546, 743.

Felbiger, Von, elucational work of, i. 256 .

Fellenberg, Von, follower of Pestalozzi, i. 258 .

Fénelon, i. 253.

Fermat, Pierre, the theory of probabil. ities, i. 120 ; arithmetical discoveries, 181; 187; his theorems, ii. 680 , 721 .

Ferrier, functions of the brain, ii. 479.

Fertilisation of plants, ii. 338 .

Fertilisers, invention of artificial, i. 92.

Fessel, fellow-worker with Plïcker, ii. 76.

Fichte, I. H., and Lotze, i. 49.

Fichte, J. G., the province of philosophy, i. 36 ; influence on academic teaching, 37 , 38 ; idealism of, 60 ; 'Wissenschattslehre,' 83 ; doctrine of, 170; 'Nature of the Scholar,' 171; 172 ; influenced by Spinoza, 212 ; educational significance of his writings, $258 ; 263,264$; system of, ii. 500 ; and Herder, 532.

Fiedler, German translations of Salmon's works, i. 275 , ii. $669 ; 685$; expounds von Staurlt's method, 669.

Fiedler and Salmon, i. 44.

"Field," magnetic, ii. 68.

VOL. II.
Finnie, John, agricultural chemistry, i. 285.

Fischer, Emil, ii. 437.

Fischer, E. C.x., first table of standard equivalents, i. $393 ; 398$.

Fischer, Kuno, 'Geschichte der neueren Philosophie,' i. 67.

Fitton, ii. 294.

Fitzgerald, G. F., ii. 193.

Fizeau, velocity of light, ii. 45,85 .

Flamsteed, Newton's correspondence with, i. 98.

Flemming, ii. 444.

Fletcher, L., 'The Optical Indicatrix,' ii. $14,42,55$.

Flourens, 'Histoire des Travaux de Georges Cuvier,'i. 130, 139; 'Éloges Historiques,' 135; and de Blainville, ii. 247; "Eloge" of Geoftroy, 255; doctrine of descent, 322; quoted on Gall, 477 ; phrenology, 478 .

Fluorescence, ii. 52.

Fluxions, invention of method of, $i$. 101 ; method of, ii. 706 .

Fol, on fertilisation, ii. 228.

Fontanes, conversation of Napoleon with, i. 153.

Fontenelle popularised science, i. 106; literary influence of, $111 ; 123,134$, 135, 142, 144, 279; 'Eloge de Leibniz' quoted, ii. 280.

Forbes, Edward, naturalist, i. 283, 288.

Forbes, J. D., i. 272 ; on radiant heat, ii. 105 .

"Force, lines of," ii. 68; Lord Kelvin on, 71 ; and "energy," 115 .

Force, matter and, mathematically defined, i. 334.

Forces, correlation of, ii. 105.

Forms, theory of, ii. 678,684 .

Forster, Georg, Humboldt's view of nature, i. 52; naturalist, services of, 179 ; the term "phrenology," ii. 477; influences Herder, 532.

Forster, Johann Reinhold, i. 179.

Forsyth, A. R., theory of functions, ii. 704.

'Fortnightly Review,'ii. 558.

'Fortschritte der Physik' started, ii. 58.

Foster, Sir Michael, "Text-Book of Physiology' quoter, ii. 289, 446 ; physiology, 346; 'Text-Book,' 417 ; "Metabolism," 421, 442 ; "General Physiology," 423, 430 ; quoted, 428.

Foucanlt, spectrum analysis, i. 278; speed of light, ii. 36,45 ; prismatic analysis of the voltaic are, 50; "gyroscope" and "gyrostat," 61.

$$
3 \mathrm{C}
$$


Foucher, 'Hypothesis Physica,' ii. 5.

Foundations of science, historical and logical, ii. 671 ; of mathematics revised by Weierstrass, 703 ; examination of, 709 .

Foureroy, 'Annales de Chimie,' i. 41 ; at the Jarlin des Plantes, 107 ; Ecole des 'lravaux pnbliques, 112; 113 ; services of, to the Republic, 148; criticisms of Baumes's essay, ii. 390 .

Fourier, Fr. M. C., and co-operation, ii. 566 .

Fourier, J. B. Jos., i. 187 ; neglected by Paris Institute, 241 : 'Théorie de la Chaleur,' 322 , ii. 175 ; theory of dimensions, i. 323 ; his mathematics employed by Lord Kelvin, 330 ; " dynamic equilibrium," ii. 79; quoterl, 120 ; dedication of "Philosophie Positive,' 239; heat, 487 ; analysis of periodic plienomena, 623 ; on Jacobi and Abel, 657; definition of function, $693 ; 697,699$.

Fox-Talbot, light, ii. 11.

France, home of scientific thouglat in the early part of the century, i. 75 .

Francis I. founded Collège de France, i. 107 .

Francke, A. H., influence of, at Halle University, i. 160; educational work of, $256 ; 257$.

Francour's mathematics introduced into England and Germany, i. 44; influenced German thought, ii. 101.

Frank, i. 208.

Franklind, Sir Edw., ehemical researches of, i. 413,447 ; atomicity of chemical compounds discovered by, 414.

Frauklin, controversy on electric fluicl, i. 362; Dary's speculations on heat and light, ii. 104.

Fraunhofer lines, i. 278: theory and practice of measuring, 322 ; spectroscopic observations, ii. 47.

Frederick, Elector, reconstitutes University of Heidelberg, i. 159.

Frederick the Great, popular education, i. 256 ; population statistics, ii. 563 .

Frederick 1I. of Denmark and Tycho, i. $15 \%$.

Freewill, ii. 583.

Frege, G., ii. 737 .

Freind, John, molecular attraction, i. 355.

French, the, masters in science at the beginning of the century, i. 41 .

Fresenius, text-books of, i. 188 .

Fresnel, Augustin, neglected by Paris
Institute, i. 241 ; and Young, theories of, 244 ; dynamical view of light, 370 revival of kinetic view of nature, ii. 8 ; optical phenomena, 13, 14 ; mudulatory theory of light, 21,36 ; views on "sidedness" of rays of light, 24 ; Memoir on Diffraction, 25, 26 ; transverse vibrations, 28 ; elastic theory of light, 31; nature of the ether, 40 ; theory of elasticity, 41 ; definition of motion of light, 42 ; theory of light, 43 ; vibrations of the ether, 56 ; the dielectric and luminiferous ether, 69 , 70, 89; "elastic medium" in space, 84 ; reference to, 86,$91 ; 344,467$.

Freytag, 'Bilder aus der deutschen Vergangenheit,'i. 256.

Frezier, geometrical work of, i. 114.

Fries, Jacob, i. 195; school of, 208; psychology, ii. 495 .

Fritsch, 'Theorie der Newton'schen Gravitation,'i, 343.

Fröbel, foumler of the Kindergarten, i. 258.

Frost, Scheiner's 'Astronomical Spectroscopy,' ii. $46 ; 362$.

Function, mathematical, introduced by Euler, ii. 639.

Functions of living substance, ii. 429.

Functions, theory of, ii. 693 et seq.; two schools, 693 ; non-differentiable, Hankel and Weierstrass on, 705; oscillating, 706; analytic, 712 .

Fundamentals in mathematics. ii. 649 et seq.; geometrical and logical, 651 et seq.; Gauss on, 652 .

Galen, i. 293 ; ii. 207.

Galileo, Bacon's indebtedness to, i. '94; mechanical laws of, 317 ; 318 ; stimnlated star-gazing, 327 ; formulæ of, 335 ; described phenomeua of falling bodies, 353 ; 389, 424; 'Sidereus Nuncius,' discovered the moons of Jupiter, ii. 10 ; 12 ; inertia, 124; astronomical work of, 227 .

Gall, J. F., i. 136; extolled by Comte, 310 ; phrenology, ii. $477,479$.

Galle and the discovery of Neptune, i. 277.

Galois, Évariste, Theory of Equations, ii. 686 ; his life and works, it.; his letter to Chevalier, $i b$. ; and theory of groups, $687 ; 692$.

Galton, Francis, on heredity, ii. 574, 612 ; on variation, 609 ; his works, $i b$. ; combines Quetelet and Darwin, $i b . ;$ on statistical treatment, 612 ; on pangenesis, 614 ; forestalls Weis- 
mann, $i b$.; on "particulate" inheritance, 615 ; on law of distribution, 617 ; on law of regression, 618 .

Galvani, discoveries of, i. 363 , ii. 150 ; galvanic current, 233 ; animal elec. tricity, 474.

"Gamma" fuuction, ii. 696.

Garnett, R., on Georg Forster, i. 52 ; 179.

Gamett, W., and Campbell, 'Life of Clerk-Maxwell,' ii. 599.

Gärtner, investigations of, ii. 415 .

Gases, liquefaction of, i. 316 ; the kinetic theory of, 425, ii. 34 ; i. 433.

Gaskell, Dr, cerebro-spinal nerves, ii. 429 ; analysis of process of "metabolism," 41.2 .

Gassendi tanght at the College de France, i. $107 ; 385$.

Gassiot, experiments with vacuum tubes, ii. 190.

Gatteres of Güttingen University, i. 165.

Gauss, Carl Fr., i. 44, 45; orbit of Ceres, 54; works of, 82 ; and Weber, the telegraph, 92,367 ; 'Disquisitiones Arithnetice,' 105 , 120, ii. 652; Lobatchevski and Bolyai, i. 161; and Humboldt, 167; and Zach, 177; 178; mathematical researches, 181; 182 ; least squares, $183 ; 184,185$, $185,189,191,200,207,211$; " exact habit of thonght," $222 ; 231,238,247$; measurement of magnetic action, 265 ; 303 ; absolute measurements, 309, 369 : astronomical work of, 314,331 ; measurements of, 322 ; 'Theoria motus corporum ccelestinm,' 324; calculus of probabilities, 325 ; 352 ; Coulomb's methods, 360,$362 ; 365$; importance of his work, 384 ; "Top? ologie," ii. 63 ; researches into electrical phenomena, 67; 76; electromagnetic measurements, 78 ; system of absolute measurements, 117 ; arithmetical discoveries of, 124 ; influences Helmholtz, $150 ; 197,254$; science of ehances, 568 ; theory of error, 574 ; 575 ; method of least squares, 576 ; doctrine of probabilities, 577; law of error, 616 ; and Newton compared, 630 ; rediscovery of Ceres, $i b$. : pioneer of modern mathematics, 636 ; Bessel on, $i b . ;$ his style criticised by Abel, 637; 640: his fundamental theorem, 644,688 ; on convergency, 646 ; his work on higher functions, 615 et seq.; on fundamentals, 652 ; his influence on Bolyai, Lobatcherski, and others, 652 ; anticipates the work of others, ib.; comprared to Goethe, 653 ; on exteniled system of number's, 654 ; reforms theory of numbers, 680 et seq., 720 ; on determinants, 682 ; $686,688,693,695,697,698$; on conformal images, 701 ; on non-Euclidean geometry, 710, 713; measure of curvature, 714; theory of congruences, 723 ; on mathematical calculi, 724 ; on bi-quadratic residues, 725 ; 732 ; not a great teacler, 646,743 .

Gauss and Gerling, ii. 713 .

Gauss and Schumacher, correspondence, ii. 710 .

Gauss and Weber, telegraph, i. 92, 367 ; school of, ii. 702 .

Gay-Lnssac, Memoirs of, i. 83 ; 'Annales de Chymie et de Physique, $189 ; 190$; organic analysis, it. ; chemical discoveries, 398 , 467 ; experiments, 425 ; $426-429$; Fresnel's 'Mémoire sur la Diffraction,' ii. 25 ; visit to England, 27; experiment in heat measurement, $109 ; 155,592$.

Geddes and Thomson, 'The Evolution of Sex,' ii. 2:7, 454, 458, 459; sexual selection, 344; "Reproduction," 348.

Gegenbaur, school of Darwinism in Germany, ii. 436.

Gehlen, 'Allgemeines Journal für Chemie,' i. 41.

Geikie, Sir Archd., quoted on Playfair's 'Hnttonian Theory of the Earth,' i. 283; G. Wilson and, 'Memoir' of E. Forbes,' 288.

Geissler, fellow - worker with Pliicker, ii. 76 ; electrical researches, 189; vacuun tubes, 190.

Geitel (see Elster), ii. 190.

Generalisation, process of, in mathematics, ii. $638 ; 650$.

Generalised co-ordinates, Plïcker, ii. 673.

"Genesis," ii. 279.

Genetic view of nature, ii. 276,290 ; in Germany and France, 321 ; trimmph of, 328: on a large scale, 345 ; strengthened by physics and chemistry, 355 .

Genetics, ii. 213.

Genius, latent thought the material of, i. 8 .

'Gentleman's MIagazine,'ii. 679.

Geograpliy, historical, i. 294.

Geological Society, i. 290.

Geology, ii. 290. 
Geometrical axioms, i. 199, 352 ; ii. 649 , et ser.

Geometry, deficiency of organisation. of research in England, i. 243 ; two schools of, ii. 668 .

Geophysics, ii. 363.

George, Duke of Saxony, reconstituted University of Leipzig, i. 159.

Gergonne, ii. 660 ; Hankel on, 666 ; 673.

Gerlardt, C. F., revives Prout's hypothesis, i. 402 ; attack on electro-chemical theory, 409; "type" theory, 411; 413; on the constitution of substances, 419 ; "types," 423 ; Gmelin's system of equivalents, 426 ; characteristic of livdrogen atoms, 430 .

Gerhardt, C. J., on the invention of the calculns, i. 101 ; edited Leibniz, 'Philosophische Schriften,' ii. 5.

Germ plasma and boly plasma, ii. 457, 458 ; plasma, differentiation of, 459 .

German Association, character and decline of, i. 238.

German language, peculiarity of, i. 22.

German universities, i. 226.

Germany leads in the history of thought, i. 46 .

Gervinus on Herder, i. 51 : connection of political and literary history, 59 ; 'Georg Forster's Werke,' 179; relations of philosophy and history, 206 ; "theoretical politician," 311.

Gesner of Göttingen University, i. 165.

"Gewerbeschulen," i. 166.

Gibbon, i. 47 ; 'Roman Empire,' 169 ; influence of, on German thonght and literature, 212; in German universities, 251.

Gibbs, J. Willard, energetics, ii. 166, 171 ; "free energy," 173 ; chemical equilibriun, 175,177 ; formulæ of, 185; on directional calculus, 655; 656 .

Gibson, George A., "Fourier's series," i. 241 .

Giese, vacunm-tnbe experiments, ii. 190.

Gilbert, Sir J. H., agricultural experiments and publications of, i. 284.

Gilbert, Wm., Bacon's indebtedness to, i. 94 .

Glaciers, Helmholtz's theory of, ii. 127.

Glaisher, Prof., quoted on invention of logaritlıms, i. 269 ; 321 ; law of error, ii. 576.

Glazebrook, Prof., 'Report on Optical 'l'heories,' ii. 54; Lord Kelvin's theory of ether, 55 ; 'James Clerk-
Maxwell and Modern Physics,' 77 ; indefiniteness of Maxwell's electromagnetic theory, 94 .

Gmelin, Chr., chemist, i. 188; handbook of chemistry, 208.

Gmelin, Leopold, 'Handbuch der Chemie,' i. 43 , ii. 158 ; system of equivalents of, i. 426,430 .

Goebel, Prof., on biology, ii. 313.

Goethe quoted on history, i. 7 ; quoted on the sticcess of the few, 9 ; made modern German language, 22 ; attitude of, to national iclealism of Germany, 39 ; style of, 51; his work, 61; influence of, on taste, 67 ; 'Fanst,' 76 ; school of, 84 ; Lewes's Life of, 166 ; 179 ; as a scientist, 180 ; influenced by the Naturphilosophie, 207 ; 212 ; introduced hexameter into German poetry, 213; quoted 251, 286, ii. $3,254,258$; educational significance of his writings, i. $258 ; 261$; correspondence of, 279 ; on Luke Howard, 286; introduction of the term morphology, ii. $210 ; 213$; theory of metamorphosis, 223, 243, 267 ; influence of, 225 ; theories of, 246 ; influence of Linnæus, $252 ; 253$; the genetic view, 317,321 ; subjective colonr sensations, 482; fonndations of the study of langnage, 538 .

Goldstein, vacuum-tube experiments, ii. 190; "ether" theory of cathode rays, 192.

Goltz, experiments on the brain, ii. $478 ; 479$.

Goodsir, cell theory, ii. 265.

Gordon, Lewis, Carnot's 'Puissance motrice,' ii. 118.

Göttingen, prize essays on principles of dynamics, ii. 97.

'Göttinger Gelehrte Anzeigen' of Haller, i. 176.

Gough, John, the blind naturalist, i. 287.

Gonrand quotel, ii. 571.

Grævius, recognition of Bentley, i. 169.

Graff, Prot, L. von, on Haeckel's 'Stammbäume,' ii. 337.

Graham, Thomas, chemistry, i. 44; salts and acids, 410; experimental work of, ii. 161: 161; discoveries of, 224.

Grandi, series of, ii. 646 .

Grant, Sir A., 'Story of the University of Edinburgh,' i. 160, 232, 267, 269, 283 ; on David Gregory, 270; ou Bell, 293.

Grant, Prof., natnral selection, ii. 330. 
Grassmann, Hermann, geometry, i. 44 ; geometrical labours of, neglected in Germany, 243, 247 ; 'Ausdehnungslehre,' 275 ; mathematical labours of, ii. $73 ; 630$; Hankel on his science of forms, 640 et seq.; his comprehensive calculus, 655 ; gradual appreciation of his work, $656 ; 710$.

Graunt, John, statistics, i. 122; "Tables of Mortality," ii. 564.

Graves, R. P., 'Life of Sir W. R. Hamilton' quoted, i. 106, 289; ii. 722.

Gravitation, formula of, i. 319 ; lines of thouglit emanating from it, 321 ; not an nltimate property of matter, 335 ; difficulty of measuring clirectly, 353 .

Gray (the poet), i. 285.

Gray quoted on David Robertson, i. 289.

Gray, Asa, criticism of 'Vestiges,' ii. $319 ; 332$.

Gréari, eilucationalist, i. 260.

Green, George, important generalisation in statics and dyuanics, i. 230; his "potential function," 231 ; 246,272 , 331 ; important papers lost, 277 ; properties of ether, ii. 31, 33; inspired by Cauchy, 43; analytical methor of, 45 ; referred to, 54 ; theory of electric and magnetic phenomena, $74 ; 698$.

Grégoire proposed Bureau des Longitudes, i. 113.

Gregory, David, introduced Newtonian philosophy into the University of Edinburgh, i. 232 ; Professor of Astronomy, Oxford, 270, 272 ; astronomical instruments, 322 .

Gregory, F., Hankel on, ii, 712.

Gren's 'Journal der Physik,' i. 41.

Grew, Neliemiah, used the term "cell," i. 195 ; microscopic investigations in biology, 2S3; embryological researches, ii. 227; mieroscopical studies, 260 ; observations of, 261 .

Griesbach, "Animal and Plant Geography," ii. 226.

Griesinger, Mayer's "right of priority," ii. 115 .

Grimaldi, polarisation of light, ii. 18.

Grimm, Jacob, 'Ueber Schule, Universität, Akademie,' i. 100 ; language, ii. 540,542 .

Groth, 'Pliysikalische Krystallographie,' i. 443 .

Groups, theory of, ii. $632,686,687$; Burkharlt on, 688 ; 689 et seq.; continnous and discontinuous, 691.
Grove, "Correlation of Physical Forces," ii. 111 ; "force," $125,130$.

Gruber, Ersch and, Encycloperlia of, i. 35 ; representative of encyclopedic teaching, 38 .

Guardia quoted, i. 106; 'Histoire de la Medicine,' 126.

Guerry, A. M., statistics, ii. 579.

Guhrater, 'Leibniz, eine Biographie,' i. 158 , ii. 280.

Guizot, education, law of, i. 183, 257.

Guldberg, law of mass-action, ii. 157; ideas of Berthollet, 177.

Guyton cle Norvean, i. 116, 131 ; gunpowiler, iron, steel, I4S.

Gyroscope and gyrostat invented, ii. 61.

Haacke, ii. 271.

Hacker, Dr Val., 'Praxis und Theorie der Zellen- und Befruchtungslehre,'ii. 265,$370 ; 371,447$.

Haeckel, Ernst, i. 179; 'Generelle Morphologie der Organischen Wesen,' ii. $213,214,270,271,349$; Goethe's ideas, 244, 216; "Ontogenesis" and "Phylogenesis," 307; "Natiirliche Schöpfungs - Geschichte,' 313, 323; 'History of Creation,' 332, genealogical trees, 337 ; sexual selection, 343 ; 347 ; evolution, 348, 455 ; Darwin and Lamarck, 350; 351, 361 ; conception of nuiversal animation, 369 ; biological theories of, 371 ; 414 ; school of Darwinism in Germany, 436 ; "germinal" element, 457 ; and Weismann, 460 ; and Herder's evolutionisin, 533; man and brute, 541; 546,608 ; kinetic hypothesis, 611.

Haeser, 'Geschichte der Medicin,' i. 126,308, ii. $388,390,401$; on homceopathy, i. 210 ; on Kant, 219.

Hahn, "Cuvier" in "Grande Encyclopédie,' i. 130.

Hahnemann's homceopathy i. 210.

Hales, inprovements in microscopy, ii. 230.

Hall, Marshall, ii. 519.

Halle, University of, i. 165.

Haller, Albrecht von, i. 163; of Göttin. gen University, 165; connection of, with modern science, 175 ; ' Güttinger' Gelehrte Anzeigen,' 176; 'Elementa,'193; 194; zoological labours of, ii. 220,230 ; study of separate organs, 233 ; "evolutionist," 278 ; 279 ; epigenesis, 298 ; 299 , $30 \mathrm{~s}$; vitalistic conceptions, 384 ; discovery of irritability, 429 ; psycho-physical view, 471 ; inftuences Herder, 532 ; 533. 
Halley, Edmund, "reciprocal duplicate" ratio, i. 98; 270 ; Newton's 'Principia,' 283; orbits of comets, 324 ; calculates return of comet, 327 ; Newton to, 342 ; pendulum experiments of, 354 ; statistician, ii. 565 .

Halsted, G. B., on non - Euclidean geometry, ii. $652 ; 714$.

Hamann, Jollann Georg, ii. 535, 536.

Hamilton, Sir W., 'Discussions,' i. 203 ; '1)ugald Stewart's Works,' 359; "Philosophy of the Unconditioned," ii. 326 .

Hamilton, Sir W. R., used the notation of Newton, i. 101; Life of, quoted from, 106; paper on caustics, 230 ; important generalisation in statics and dynamics, 231; Dublin Mathematical School, 274; originality of, ib. ; "characteristic function," 316 ; theory of optical phenomena, ii. 13, 42 ; mathematical labours of, 73 ; dynamies, $139 ; 195$; his quaternions, $654 ; 656,709$; introduces term "associative," 711; 722.

Hank, Theodore, suggested idea of the Royal Society, i. 227.

Hankel, Hermann, generalising aspects of the sciences, i. 46 ; quoted on the establishment of analysis as a science, 103 ; 'Die Entwickelung der IIathematik,' 175 ; 'Theorie der complexen Zahlensysteme,' 185 ; ii. 710 ; 'Die Elemente der Projectivischen Geometrie,' i. 188; ii. 632; on the two processes of algebra, 640 ; on Grassmann, ib., 656; on Peacock and de Ilorgan, 641; on Gauss's theorem, 645; on imaginaries, 653 , 664 ; Poncelet's principle, 661 ; on Gergonne's principle of duality, 666 ; on Steiner, 668; compares von Staudt with Chasles, 669 ; on Möbius, 682 ; on fundamentals, 703 et seq.; on English mathematics, 704, 711; on oscillating functions, 706 ; on Bolzano and Cauchy, 709; principles of arithmetic, 711 ; on principle of permanence, 712 ; on quaternions, ib., $717 ; 726$.

Hänle's 'Nlagazin,' i. 43.

Hänselmann, 'K. F. Gauss,' i. 181.

Hansen, lunar theory, i. 329.

Harcourt, Vernon, i. 236.

Harling, discovery of planets, i. 182.

Harkness and Morley, theory of functions, ii. 704 .

Harmonic functions, ii. 696.

Harriot, a forerunner of Bacon, i. 94.
Harris, James, language, ii. 536.

Harris, Snow, referred to by Faraday, ii. 69 .

Harrison, received prize of Board of Longitude for his chronometers, i. 158 ; astronomical instruments, 322.

Hart, J. M., testimony to work of German universities, i. 225.

Hartmann, ii. 470,608 .

Hartnack and Nachet, improvement in immersion system, ii, 228.

Harvey, contemporary with Bacon, i. 94 ; discovery of the circulation of the blood, $193 ; 272$; contributions to biology, 282; 292 ; study of separate organs, ii, 233; "metamolphosis," 278 ; embryology, 297 ; 349 , 44.4 .

Hatchett, not member of any university, i. 238.

Haukesbee, Francis, capillary phenomena, i. 346 ; experiments of, 355,356 .

Hauptmann, C., 'Die Metaphysik in der modernen Physiologie,' ii. 401, 438; quoted, 407,444 .

Häusser, L., i. 59.

Haüy, Abbé, physics at the École normale, i. 112; crystallography of, 116,117 ; services of, to mineralogy, $118 ; 136$; created the science of crystallography, 441; labours of, ii. 222 ; founder of crystallography, 240 ; 241; crystallography, 264; building up of erystals, 270 .

Haym, Rudolf, 'Leben W. v. Humboldts,' i. 38 ; ehief authority on Herder, 51; biographies of Hegel and others, 279; "Herder nach" seinem Leben und seinen Werken,' ii. $531,533,537$.

Hayward, algebra of 'Coplanar Vec. tors,' ii. $656 \mathbf{b}^{\circ}$.

Heat, Tyndall's dynamical theory of, ii. 57 ; dynamical theory of, 73 ; Black, Rumford, and Davy, 102 ; the non-mechanical nature of heat-phenomena, 120 et seq.; and perpetual motion, 126 et seq. ; of the sun, 357.

Heavisicle, Oliver, popularisation of Maxwell's electro-magnetic theory, ii. 72 ; 193 ; his directional calculus, 655,656 .

Hecker, J.J., established "Realschule" at Berlin, i. 166.

Heeren of Göttingen University, i. 165 ; and Ukert, collections of Histories of all countries, 167.

Hegel, G. W. F, on the province of philosophy, i. 36 ; treated science 
from a metaphysical standpoint, 43 ; philosophy of, intluenced by Herder, 51 ; ridicnled search for new planets, $54 ;$ on status of philosophy, $60 ;$ his definition of philosophy, 61; relation of philosophy to religion, 73 ; 'Phänomenologie des Geistes,' 83 ; spontaneous development of thought, 85: 'Geschichte der Philosophie,' $145 ; 162$; speculative tendency of, 178 ; philosophy of, 204, ii. 279,346 , 500 ; i. 207,208 ; encyclopædic lectures on philosophy, 214; benefactions to historical sciences, 215; Schelling's scheme of evolution, ii. 354 ; 495 ; dialectics, 530 ; 608,751 .

Hegelianism, failure of, i. 72 .

Heideuhain, Prof., function of glandcells, ii. 429.

Heine, E., ii. 704, 733.

Helm, Dr Georg, 'Die Jehre von der Energie,' ii. 97, 14:, 185, 186; 'Die Energetik nach ihrer geschichtlichen Entwickelung,' 97, 106, 108.111, 125, 127, 133, 138; controversies as to priority of discovery in theory of energy, 97, 9s; influence of Poncelet on practical mechanics, 101 ; heat unit, 109; labours of Horstmann, 170; methods of W. Gibbs, 171; criticisn of mechanical view, 183; 188.

Helmholtz, metaphysical foundations of geometry and dyuamics, i. 45 ; 'Reden' quoted, 175 ; on speculative tendency in science, 179; on Goethe as a naturalist, 180 ; 'Vorträge,' 193 ; 198, 199; doctrine of the conservation of energy, 21]; on the relations of mathematical and experimental science, 205; 'Wissenschaftliche Abhandlungen,' $i b$. ; 'Vorträge und Reden' qroted, 209; 'Ueber das Denken in der Medicin,' 210 ; revival of doctrine of conservation of force, 218; on Kant, 219; 220; 'Journal fuir Mathematik,' 231 ; Fourier's series, 241 ; "sense perceptions," 243 ; on Young, 244 ; 'Ueber die Erhaltung der liraft,' 265, 309; on Faraday's ideas, 266 ; vortex motion, 313 , ii. 35,$60 ;$ on the gravitation theory, $i$. 352 ; 375 ; objection against Weber's law, 376,377 ; "action at a distance," 380 ; on the electro-chemical theory, 405 ; investigations of fluid motion, ii. 58 ; articles on aconstics, $i b$.; "vortex filaments," 61 ; influence of his speculations in England, 62; illus- trations of his theories, 63 ; suggested vortex-atom theory, 66; 'Faraday Lecture' quoted, $i b_{.}$; adopted views of English scientists, 93; inclepenılence of Mayer's writings, 97 ; his work theoretical, 99 ; "physical nıchanics," 101 ; scientific services of, 106 ; memoirs refused by Poggentorf, 107 ; classical character of his investigations into the nature of heat, 112; 'Gesammelte Ablandlungen,' 113 ; his recognition of the clains of Mayer, 114 ; 117 ; and Sadi Carnot, 123 ; perpetmal motion, 124 ; conservation of energy, 125, 127, 130, 142, 438; "death" of the universe, 131 ; mathematical treatment of power and work, 137; on tension, 138; 141; energetics, 143; electro-(lynamics, 149 ; theories of electro-dynamic phen. omena, 152; Faraday Lecture, 154; dissociation, 163; thermal measurements, 172; "free energy," 173 ; chemical equilibrium, 175 ; quoted, 182 ; atomic view, 189 ; atom of eleetricity, 193; memoir of, 195; ether theory, 196; imperfections of the eye as an optical instrument, 215 ; microscopic work, 2:29; Goethe's theory of colours, 245; Kant's theory, 282; appreciation of Kant, 284 ; "energy," 355 ; pliysical laws, 356; cosmical origin of life, $369^{\circ}$; on vitali $* m$, 388; 391 ; 'Physiological Optics'' 397 , 450, 508; 'Physiological Acoustics,' 397 ; nature of living forces, 398; $403,421,467$; animal magnetism, 476 ; quoted on "specific energies," 482 ; optics, 483 , 506; psycho-physi. cal science, 485; "Timbre," 4๖8; arrangement of tones, 490 ; and Kant, 491 ; psycho-1hysical phenomena, 496 ; space perception, 504; "UeJer das Sehen des Menschen," 506 ; hearing and seeing, 512; language, 535; on harmonics, 623 ; on foundations of geometry, 7]0; letter to Schering, ib.; on axioms of geometry, 711; and Riemaun on geometry, 7 i3.

Helvetius, ignorance of physiology, ii. 471.

Henle, Jacob, reconstruction of "general anatomy," i. 195 ; 198 ; anthropological lectures of, 215 ; mechanical views in biology of, 219 ; on demonstration of Bell's doctrine, 293; 'Allgemeine Alratomie,' ii. 401.

Henrici, ii. 656 .

Henry, Dr, not member of any univer- 
sity, i. 239 ; 'Life of Dalton,' 246 ; on Charles Bell, 292.

Heraclitus of Ephesus, i. 314 ; the "kinetic theory," 355 ; conception of eternal motion, ii. 3 ; conception of clianging world-perious, 286.

Herapath, "mechanical theory of gases," i. 310 ; 434.

Herbart repudiated by Lotze, i. 49 ; 20s; educational influence of in Gernany, 257 ; phrenology, ii. 478 ; anticipated Helmholtz, 491 ; influence of his philosophy, 494 ; on "faculty"-psychology," 495 ; psychological research, 496 ; mathematical psychology, 498; 500; psychical mechanism of, 504; space perception, 506 ; $507,512,515$; introspective methorl, 527; "Völkerpsychologie" and "Sprachwissenschaft," 530 .

Herbert, Dean, natural selection, ii. 330.

Herder, i. 50 ; History of Humanity, 51 ; 'Ideen,' 53 ; 'Metakritik,' 83'; indebtedness to Gibbon, $169 ; 171$; cited on Georg Forster, 179; scientific ideal of, 211; 212; Alcaic and Sapphic metres, 213; educational influence of, in Germany, $257 ; 258$; scientific work of, ii. 210; influence of, 225 ; 2s0; philosophy of, 346 ; psycho-physical view of nature, 531 ; quoted, 533 ; 'History of Mankind,' $534 ; 538,563$.

Heredity, problem of, ii. 343,613 .

Hering, ii. 442 ; 'Uelser das Gedächtniss als eine allgemeine Funktion der organischen Materie,' 544.

Hermann, Gottfried, indebtedness to Bentley, i. $169 ; 162,172$; science for its own sake, $211 ; 212,214$; classical learning of, 222.

Hermann, Jac., Leibniz's letter to, quoted, ii. 646 .

Hermite, researches of, ii. $124 ; 649$; on determinants, 683 ; on transcendent numbers, 731 .

Herodotus referrerl to on division of History into centuries, i. $13 ; 296$.

Herrmann, Cr., quoted, ii. 266.

Herschel, Caroline, discovers her eight comets, i. 229 ; 285 .

Herschel, Sir John, i. 177; quoted on Laplace, 123 ; astronomical work of, 230 ; introduction of knowledge of Continental mathematics to Cambridge by, 233 ; science in England, 234 ; 236 ; and Airy, article in ' En. cyclopædia Metropolitana,' 236 ; quoted on Fresnel, 241; educational movement promoted by, 261; 'A Preliminary Disconrse on the Study of Natural Philosophy, 263, 306; founded Analytical Society, 271; spectrum analysis, 278 ; stands on Bacon's philosophy, 307 ; 376 ; phenomenon of fluorescence observed by, ii. 52 ; criticism of the term "potential energy," $140 ; 295$; 'Introduction to the Study of Natural Philosophy,' 328 ; experiments at the Cape, 357 ; " sound," $4 \mathrm{SS}$; theory of probabilities, $569 ; 606$.

Herschel, Sir William, 'On the Proper Motion of the Sun and Solar System,' i. 176 ; astronomical discoveries of, 229 ; 238, 285 ; discovery of Uranus, 324 ; 'Observations of Nebula,' ii. 283 ; nebular theory, 295.

Hertwig, O., 'The Cell,' ii. 224, 265, $297,370,371,373,420,427,444,461$; embryological researches, 222 ; "The Biological Problem of To-day', 29s, 459 ; 'Zeit und Streitfragen zur Biologie,' 401 ; quoted, 409 ; 'The Cell,' quoted, 425, 446, 448 ; "idioplasma," 418 ; "organicisme," 455.

Hertz, H., electric theory, i. 344 ; electrical ware-motion, ii. $7 \mathbf{7}$; electrical view of light, 88, 92; "physical mechanics," 101 ; electro-magnetic wave-motion, $148 ; 193$.

Hess, a founder of physical chemistry, ii. $152 ; 157$.

Hesse, Otto, his elegant work, ii. 677 ; introduces determinants, 682 et seq.; and invariants, 684 .

Hessel, 'Krystallometrie,'i. 443.

Hettner, history of the idea of humanity, $i .50$; literary history of the eighteenth century, 59 ; cited on Georg Forster, 179.

Heun, 'Jahresbericht der dentschen Nathematiker-Vereinigung,' ii. 101.

Heussler, Hans, on Bacon, i. 94.

Heyne of Göttingen University, i. 165 ; indebtedness to Bentley, 169.

Hicks, 'Report on Hydrodynamies,' ii. 58 ; contribution to vortex theory, 63.

Higgins, theory of, i. 398.

Hilbert on algebraic numbers, ii. 729.

Hildebrand, Bruno, statistics, ii. 561.

Hillebrand, Karl, 'Zeiten, Völker, und Menschen,' quoted, i. 311.

Hippean, C., 'Public Education during the Revolution in France,' quoted, i. 
108; 109; quotes Condorcet, 111 ; 'L'Instruction publique eu France pendant la Révolution,' 259.

Hippocrates, ii. 470.

Hirn, the steam-engine, i. 331 , ii. 133 ; indestructibility of force, 111 ; controversy with Zeuner, $135 ; 179$.

Hirsch, Dr A., 'Gesch. d. medicinischen Wissenschaften in Deutschland,' $i$. 210 , ii. $390,401$.

Hirzel, Sal., i. 167.

His, W., ii. 271.

Histology, Huxley on, i. 196.

Historians, supposed objectivity of, i. 7.

Historical geography, i. 294.

History, contemporary, to what extent possible and valuable, i. 6; Goethe quoted on re-writing of, 7 ; periods of, 13; philosophy of, tue to Continental thinkers, 25 ; periods of, take their name from some great event or movement, 5s; and science, relations of, 206 .

Hittorf, W., on attraction in chemical phenomena, i. 380; fellow - worker with Plicker, ii. 76 ; electrolysis, 164 ; vacuum-tube experiments, 190.

Hobbes, philosophy of, i. 48 ; 'De Corpore' quoted on Harrey, 282 ; 385, ii. 473.

Hobsou, on the infinite, ii. 736.

Hotf, Prof. van't, i. 431, 450; 'Journal für physicalische Chemie,' ii. 158; (see Ostwald), 159; researches of, 164 ; discovery of, 165 ; carbon tetrahedron of, 424 .

Hoffmann, F., animist, i. 126.

Hotmann, A. W. von, on Liebig, i. 18, 1S8; scientific experiments uuder, 92 ; chemical researches of, 412; "Faraday "lecture, ii. 391 ; 393.

Hofneister, Wilhelm, the genetic conception of plant life, ii. 224 ; inductive school of, 321.

Hogg, 'The Microscope,' ii. 228.

Holbacll, 'Système de la Nature,' i. 144.

Holger, von (see Baumgartner), ii. 107.

Holman, Prof. S. W., 'Matter, Energy, Force, and Work,'ii. 182.

Holtzmann, investigations into nature of heat, ii. 112 ; and Clausius, 135.

Holtzmüller on isogonal relations, ii. 701.

Homer, i. 261, 296.

Homøopathy, i. 210.

Homogeneous formulæ, ii. 681 ; co. ordinates, Möbius, 681.
Homology, study of, ii. 258; in geometry, 663 .

Hooke, Dr Robert, "reciprocal duplicate" ratio, i. 98; used the term "cell," $195 ; 283,434$; referrerl to by Young, ii. 18; theory of elasticity, 30 ; compound microserpe, 228.

Hooker, Sir J. D. (see Darwin), ii. 329 ; Darwin to, 406.

Hopital, Marquis de l', adopited the calculus, i. 101.

'Horen' of Schiller, i. 84.

Horner, 'Edinburgh Review,' i. 273.

Horsley, edition of "Newton's Works," i. 355 .

Horstmann, labours of, ii. 170; free energy, 173.

Houle referred to, ii. 653 ; on nonEuclidean geonetry, 714.

Hovelacque, Abel, 'La Linguistique,' ii. 540 .

Howard, Luke, classification of clouds, i. 286 .

Huber, investigations of, ii. 415.

Huggins, Sir William, light, ii. 11.

Hngo, Prof., of Göttingen, translated 44th chapter of Gibbou's 'Roman Empire,' i. 169.

Humboldt, A. von, on scientific state of Paris at the close of the eighteenth century, i. 17 ; 'Kosmos,' 51 , 53, ii. $277,284,328,329,532$; 'Life' by Bruhns, i. 207, 253, 263; travels in America, i. 83; eminence in seientific literature of, 105 ; his influence as populariser of the study of natural history, 106 ; 133, 155; and Gauss's scheme for a network of magnetic observations, $167 ; 171,175,176$; uninfluencerl by speculative spirit in German science, 178 ; cited on Georg Forster, 179 ; 183, 190; supported scientific institutious at Berlin, 238; Bell's theorem, 293 ; founded, with Oken, "Naturforscher - Versamm lung," 298 ; and Gay-Lussac, 425 ; popular work of, ii. 149; explorations, 206 ; travels, 222, 247 ; morphology, 225,226 ; 252 ; extension of morphological view, 260; and Robert Brown, 265; 266; influence of, 276 ; 293,$300 ; 341,390,467$; inimal electricity, 475,$476 ; 514,607$.

Humboldt, W. von, ereator of Berliu University, i. $38 ; 203,206,212,253$, 263 ; comparative philology, ii. 538; 542.

Hume, David, transition from the logical to the historical view, i. 46 ; 
opposel metaphysics, 75 ; influence of, on German thought and literature, 212 ; sceptical philosophy of, replied to by Kiant, $i b$. ; and Kiant, 219 ; intercourse with French thought, 268 ; intluence of, 273 ; ii. 279 ; and German criticism, 323 ; 326 ; psychology, 497 ; genetic view, 506 ; the study of mankind, 529; quoted, 555.

Hunter, John, English niedical science, i. 208 ; anatomist, 283 ; ii. 217.

Hunter, John and William, no connection with the English universities, i. 272.

Hutton, James, a follower of Boscovich, i. 359 ; study of fossil remains, ii. 2.25 ; Cuvier's "catastrophism," 250 ; school of geology, 291 ; genetic view in geology, $330 ; 364$; and Jameson, services to the study of natural his. tory, i. 283 ; 290.

Huxley, 'T. H., 'Lay Sermons' and other writings, i. 193, 201; quoted, 193, 292, ii. $252,256,257,348,376$, 405, 448; 'American Addresses,' i. 194, ii. 364; on individuality of English scientists, i. 250; 'Science and Culture,' 282; 'Essay on Geological Reform,' 283 ; 'Geological Reform' quoted, 291 ; 'Critiques and Addresses,' 298; 'Life of Charles Darwin,' 310 ; on Whewell and the mechanical equivalent of heat, $i b$.; 'Scientific Aspects of Positivism,' 310; on Comte, 'Lay Sermons' quoted, ii. 37 ; extract from "Lecture on the Study of Biology," 217; quotation from 'Life of Richard Owen,' 222 ; Goethe's illeas, 244, 246; Cuvier's work, 248; quoter on vertebral theory of the skull, 251; on Humboldt, 253 ; the term "homology," 259; on Cuvier and Oken, 260; 268; "Evolution in Biology," 278, 297, 347 ; controversy with Kelvin, 284; on Hutton, 291, 292; and Ton Baer, 299, 302 ; 305 ; historical connection of Lamarck's ideas, 309 ; "Biology," 313 ; 321 ; theory of descent in France and Germany, 322 ; "Agnosticism," 326 ; "Reception of the 'Origin of' Species," "32\%; 329 ; address to the Geological Society, 363; '0n Descartes,' 378 ; "vitalism," 406 ; 411 ; "On the Cell Theory," 423 ; history of Biogenesis, 451 ; the ubiquity of life, 452 ; psycho-physical parallelism, 519 ; theory of reflex action, 520.
Huygens, Chr., variation of gravity in different latitudes, i. $99 ; 103$; the theory of probabilities, 120 ; mechanical laws established by, 317 ; Newton and, $i b . ;$ formulæ of, 335 ; mechanical explanation of gravitation ; 342,351 ; phenomena of gravitation, 35.3 ; 389 ; kinetic view of nature, ii. 6 ; 8 ; followed by Young, 9 ; the theory of light, 13, 14, 17; periodic wave-motion, 21 ; 'Traité de' la Lumière,' 22 ; motion of light, 42 ; conservation of energy, 99,100 ; on probability, 565, 568 .

Hyatt, A., neo-Lamarckian, ii. 351.

Ideal elements, ii. 664; Poncelet on 674 ; numbers, 727 ; Kummer's, 728.

Ideals of life during nineteenth cen. tury, i. 32.

Ideas, migration of, i. 29.

Idéologues, Napoleon and the, i. 152 ; ii. 323.

Imaginary, the, Cayley on, ii. 716.

'Index Lectionum' of Göttingen University, i. 165.

Individualism of English character, i. 279.

Individuality the centre of interest of the sciences, i. 125 ; ii. 746 .

Individuation, ii. 415.

Inductive reasoning in England, i. 103.

Infinite, the, ii. 643, 735 ; Hobson on, 736.

Infinitesimal methods, necessity of developing, i. 373 .

Infinitesimals, method of, ii. 706 .

Inheritance, particulate, ii. 615.

Inquiry, scientific method of, i. 30 .

Institute, French, reports of', i. 149.

Institution, Royal, i. 264.

Interests, human, unity of, i. 33.

Introspective method, ii. 527.

"Invariants," doctrine of, ii. 140, 676; MacMahon on, 676 ; history of, 677 ; unknown to Plücker, 677; Sylvester on, 684 ; different methods in, $i b$.

Inventions, accidental, in sixteenth, seventeenth, and eighteenth centuries, i. 91 .

Inverse operations, ii. $639,727$.

"Ions, migration of," ii. $164 ; 198$

Ireland, Alexander, on authorship of the 'Vestiges,' ii. 318.

Irvine, Dr, the term "capacity" first used by, ii. 102.

Isenkrahe, C., "Das Räthsel von der Schwerkraft,' i. $341,342,343,377$; refers to Euler's ether theory, ii. 8 . 
Isherwood, researches of, ii. 135.

Isomerism, discovery of, ii. 405 .

Isomorphism, ii. $44 \dot{4}$.

Ivory, scientific work of, i. 229 ; well known among Continental mathematicians, 232; not member of any nniversity, 238; maintainel reputation of British mathematicians, 270 .

Jacobi, C. G. I., i. 44 ; 'Werke,' 185 ; 187, 189; influence on Helmholtz, $199 ; 200,205$, ii. 637 ; his relation to Legendre and Abel, 648; on determinants, 683, 686; Theta function, 696,728 .

Jacobi, F. H., 'Offener Brief an Fichte,' i. 83 ; 162 ; influenced by Spinoza, 212 ; psychology, ii. 495.

Jaeger, Dr, "germinal" element, ii. 457.

'Jahresberichte' of Berzelius, i. 167.

James, Alex., process of cellular livision, ii. 445.

James, King, eharter to Edinburgh University, i. 268.

James, Prof. W.., 'Principles of Psychology,' ii. 479, 513, 519; quoted, 522,539 .

Jamieson founded Wernerian Society, i. $118 ; 288$.

Jainin, speed of light, ii. 45.

Januschke, Hans, 'Das Prineip der Erhaltung der Energie, 'ii. 152.

Japp, Prof., "Stereo-chemistry and Vitalism," ii. 437; selective action of certain organisms, 598 .

Jardin des Plantes, i. 107.

Jeffrey, 'Edinburgh Review,' i. 273.

Jenner, Edward, no connection with the English universities, i. 272; 284.

Jevons, Stanley, 'Principles of Science,' i. 37,308 ; on theory of probabilities, 120 ; 325 ; Bacon's " method of instances," ii. 558, 559; "Principles of Science' quoted, 560, $569 ; 737$.

Joachin of Brandenburg, founds University of Königsberg, i. 159.

Joln Frederick, Duke of Hanover, i. 158; founds University of Jena, 159.

John, V., 'Gesch. d. Statistik,' ii. 555, 587 ; statistics, 563 ; 564 ; quoted, 579 .

Jones, Bence, 'The Royal Institntion,' i. 90 .

Jordan, Camille, his 'Théorie des Sulsstitutions,' ii. $686,692$.

Joseph II., i. 256.

Joule, James Prescott, the mechanical equivalent of heat, i. 93 ; doctrine of the conservation of energy, 201;
"J" or Joule's equivalent of heat, 265 ; and Dalton, $i b$; not connecteil with Cambridge Mathematieal School, 266 ; not member of any university, $27 \%$; deternination of the equivalent of heat, 309 ; " mechanical theory of gases," 310 ; 313 ; paper on moleenlar action, 433; calculations of, $434 ; 435,437$; ii. 111 ; kinetic theory of gases, 3t, 162; dynanical theory of heat, 73 ; independence of Nayer's writings, 97; and Tyndall, 107; leat unit, 109 ; scientitic work of, 110 et seq. ; a pupil of Dalton, 111; inclestructibility of force, $i b$.; revival of interest in the ideas of "Energy," 11t; his measurements utiliserl by Clausius and Thomson, 116 ; practical foundation of his researches, 117 ; perpetual motiou, 124; two laws of thermo-dynamics, 128 ; force, 130 ; subjection of physical phenomena to dyuamical laws, 132; measurements of, 133; and experiments, 137 ; "Thermal Unit," 139 ; conservation of energy, 142 ; electrical phenomena, 146; law of, 147 ; electrical measurements, 156 ; heat, 178 ; "energy," 355 ; statistics in physies, 590,592 .

Jousse, geometrical work of, i. 114.

Julius of Brunswick founds University of Helinstädt, i. 160.

Jungfleisch, ii. 437.

Jurin, Dr, experiments in capillary attraction, i. 356.

Jussieu, Ant. Laurent de, anthor of 'Genera Plantarum,' ii. 222, 235, 265.

Jussien, Bernard de, contributions to the study of natural history, i. 116; 119 ; botanical work of, $126^{\circ}$; referred to, 265 .

Justi, 'Winckelmann,' i. 279.

Kane, his work overlooked, i. 414.

Kant, scientific methouls insufticient by themselves, i. 36 ; influenced popu. larity of lectures on "Encyclopädie," 37; a century before his time, 45 ; style of, 51; decadence of philosophical thought after, 78; radicalism of thonght of, 81 ; ideas of, developed by Schiller and others, 83; Helmholtz and the philosoplhy of, 199 ; influenced by political movements in France and America, 203; influence on development of German schools of medicine, 208 ; 211,212 ; mathemati- 
cal and physical sciences affected by, 216 ; influence of, on the development of modern German science, 219; and Hume and Descartes, 222; influence of, on education in Germany, 257 ; was inspired by Rousseau, 259; influenced by Hume, 273; philosophy of, dispelled Cartesian philosophy in Germany; 433 ; cosmological genesis of planetary system, ii. 209 ; nebular theory, 27i, 282; late development of, 309 ; 'Critique of Pure Reason,' 326 ; plilosophical theories, 346; metaplysics, 354; "specific energies," 452 ; science of sensation, 484 ; time and space, 491, 492; the mind, 497 ; space perception, 506; and Heriler, 532, 535; freewill, 584; $634 ; 751$.

Kästner of Göttingen University, i. 165.

Kater, scientific work of, i. 230.

Kaufmann, W., Hamburg Address, ii. $190,197$.

Kaup, Jacob, 'Skizzirte Entwickelungsgeschichte und natürliches System der Europäischen 'Thierwelt,' ii. 317.

Kayser, spectroscopic observations, ii. 361,362 .

Keill, John, molecular attraction, i. 355.

Kekulé, chemical researches of, i. 412 ; 'Lelırbuch der organischen Chemie' quoted, 421, 448; explains phenomenon of multiple proportions, 447 ; theory of aromatic compounds, 449 ; benzine ring, ii. 424.

Kelland's edition of Young's writings quoted, ii. 98, 104.

Kelvin, Lord. See Sir William Thomson.

Kepler, Bacon's indebtedness to, i. 94 ; 118; three laws, 157, 318; received logarithms with enthusiasm, 269 ; Newton and, 317 ; 374; fatber of modern astronomy, 386 ; astronomical work of, ii. $227 ; 634$.

Kerner von Marilaun, "The Natnral History of Plants' quoted, ii. 376.

Kerry, B., on G. Cantor and mathematics, ii. $634 ; 734$.

Ketteler, 'Theoretische Optik,' ii, 54.

Kielmeyer and the Naturphilosophie, i. 207 ; ii. 349 .

Kieser, D. G., and the Naturphilosophie, i. 207 ; ij. 230 ; phytotomic researches in Germany, 261.

Kinetic, view of nature, ii. 3 ; the word introduced by Ampère, 5; revival of kinetic view in nineteenth century, 7 ; theories, 34 ; theory of gases, $i b$.; view of nature, insufficiency of, 96 ; the term substituted for "actual," 139; "kinetics" and "energetics," $180 ; 465,574$.

Kirchhoff, Gustav, 'Mechanik,' i. 45 ; 'Vorlesungen iiber Mathematische Physik,' 23l ; discovery of spectrum analysis, 277 ; coincidence between electrical wave-motion and light, 372 ; Weber's law, 380; definition of "meclianics," 382; Fraunhofer's lines, ii. 48; 'Gesammelte Abhandlungen,' $i b$.; cæsium and rubidium, 49 ; emission and absorption of light rays, 50 ; 51 ; spectrum analysis, 56 ; "physical mechanics," 101.

Kirwan, i. 117 , ii. 291.

Klaproth, i. 117; forerunner of Berzelius, 391 ; 393.

Klein, 'G. Forster in Nainz,' i, 179.

Klein, Felix, pupil of Plïcker, ii. 76 ; his geometrical tract, 632 ; on the period of Euclid, 635; 'Evanston Colloquinm' quoted, $i b . ;$ on abridged mathematics, 636 ; 686 ; his 'Erlangen Programme,' 690; and Lie, 691, 692, 718,720 ; his tract on Riemann's theory, 698, 699; on Riemann's influence, 700 et seq.; on Riemann and Weierstrass, 707 ; on Dirichlet's principle, 708 ; on won-metrical relations, 713; on non-Euclidean geom. etry, 715 ; on Cayley and von Standt, 718; on generalised notion of distance, $i b . ;$ on famous problems, 721 , 731 ; ou arithmetising tendency, 738 , 740.

Klopstock, Alcaic and Sapphic metres of, i. 213.

Knapp, statistics, ii. 563, 566 .

Knott on directional calculus, ii. 656 .

Knowledge, accumulation of, in nineteenth century, i. 28; method and unity of, 29.

Knox, John, creator of Scotch edncational system, i. 253; 'First Book of Discipline,' 255.

Kobell, 'Geschichte der Mineralogie,'i. 117.

Köchly, i. 162 ; 'Gottfried Hermann,' 169.

Kohlrausch, F., electrolysis, ii. 164.

Kohlrausch, R., electrical measurements, i. 369 ; ii. 84 .

Kolbe, chemical researches of, i. 412 ; attacks of, on 'Modern Chemistry, 455. 
Kölliker, von, quoted, ii. 401 ; "idioplasma," 448.

König, Ed., on Wundt, ii. 513.

König, H., 'G. Forster in Hans und Welt,' i, 179.

Königsberger, L., 'Zur Geschichte der Theorie der elliptischen Transcendenten,'i. 185, ii. 648.

Köpke, Rudolf, 'Die Gründung der Königlichen-Wilhelms-Universität zu Berlin,'i. '263.

Kopp, Hermann, on the reports of Berzelius, i. 42 ; 'Die Entwickelung der Chemie,' $115,246,418,419$, ii. 154 ; 'Geschichte der Chemie,' i. 175, 188, 191, 308; quoted on Lavoisier, 386, 387; quoted, 391, 393, 398, 407, 421,422 ; electro-chemical theory, 405; 408 et seq., 413; Avogadro's hypothesis, 428 ; on J. Black, ii. 102 ; founded physical chemistry, $153 ; 157$.

Kossak, E., on Weierstrass, ii. $712 ; 734$.

Kötter, E., on Poncelet's principle of continuity, ii. 660 ; on von Staudt, 661.

"Kreislauf des Lebens," ii, 395.

Kronecker, ii. 727,729 ; on arithmetising, 738 .

Kröiig, A., 'Grundzüge eimer Theorie der Gase,' i. 433 ; ii. $162 ; 179$.

Krug, representative of encyclopædic teaching, i. 38.

Knmmer, ii, 680,726 ; ideal numbers, 728.

Kundt (see Christiansen), 'Die nenere Entwicklung der Electricitätslehre,' i. 380 .

Kuntze, quoted in reference to the brothers Weber, i. 197; biography of G. T. Fechner, 200 ; ii. 508.

La Bêche, de, palæontological work of, i. 139 .

Lacépèàe, i. 119.

Lacroix, geometry, i. 44; 'Differential and, lntegral Calculns,' 233 ; student at Ecole normale, 237 ; ii. $643,686$.

Ladenburg, "Vorträge iber die Entwicklungsgeschichte der Chemie,' ii. 158.

'Ladies' Diary,' i. 236, 238, ii. 679.

Lä̈mnec, French medical science, i. 208.

Lagrange, mechanics, i. 44; general methods of, 45 ; adapts the calculus to the problems of the 'Principia,' 102; 'Mécanique analytique,' 105, ii. 100; mathematics at the "École normale," i. 112; 113, 148, 181, 200, 233 ; 237 ; analytical methods of,
271 ; " potential function," $316 ; 319$;

theories elaboraterl loy Gauss, 331; ii. 5 ; mathematical stuly of vibrations, 16 ; analytical school of, 100 ; dynamies, 138; his system mathematical, $144 ; 467,510,572$; theory of error, 575 ; 637 ; on fundamental questions, 656 ; 669, 680, 690; and Weierstrass, 693-695, 706 .

Laguerre, ii. 715 .

Lakanal on the F́cole normale, i. 109, 112 ; qnoted, 111; 113; obtained a decree from Convention to continue sittings of the Acarlemy during suspension, 148: “"luseum," ii. 311.

Lalande at the College de France, i. $107 ; 113,167,177$; Clairault's attempt to alter gravitation formula, 334.

Lamarck, 'Philosophie Zoologique,' i. 83, ii. 309 et seq.; beginnings of Darwinian theory, i. 137; temporary neglect of suggestions of, 179 ; 'Hydrogéologie,' 194; and the 'Origin of Sipecies,' 201; 'Hydrogéologie' quotel, ii, 217; natural history of vertebrates, $239 ; 247$; and Geoffroy Saint-Hilaire, 255; and Von Baer, 316 et sel.; 321, 322, 327; natural selection, 330,351 ; adaptation, 353 ; "environment," 394; his school, 431; 460, 470, 607, 621.

Lambert, J. H., i. 175: 'Photometry,' 'Pyronetry,'176; 319; cosmological letters, ii. 282.

Lamé, treatises on mathematics and physies, i. 45 ; theories of, $360 ; 379$; synthetic method, ii. 100 ; influenced German thought, 101.

La Mettrie, 'L'Homme Nachine,' i. 144; 'Histoire naturelle de l'Âme,' ib.; ii. 699 .

Landen, scientific services of, i. 229 ; well known among Continental mathematicians, 232; maintained reputation of British mathematicians, 270.

Lange, F. A., 'History of Materialism,' i. 145,385 , ii. $323,513,584$; " psy. chology without a soul, " 523 .

Langley, function of gland cells, ii. 4:29.

Language portrays changes of thonght, i. 11 ; conventional, inadequate for original thought, 12; the problem of, ii. 536 .

Lankester, Fay, "Zoology," ii. 232; the term "homology," 259 .

Lapeyronie founded Acalémie de Chirurgie, i. 10\%. 
Laplace, works of, i. 82,97 ; Newton's ideas elaborated by, 96 ; mathematics at the Ecole normale, 112, 237; 113, 115; crystallograpliy, 116; 'Système du Monde,' 119, 319; 'Théorie analytique des Probabilités,' 120, 325; his own populariser, 122 ; statistics, 124 ; 126 ; and Cuvier contrasted, 132; 148, $154,177,181,187,200$; "exact habit of thought," 222 ; potential function, 231, 316; 241; Dalton's atomic theory, $246^{2}$; 264 ; researches of, 281 ; 306, 311 ; 'Mlécanique céleste,' 319 ; 358 ; gravitation, 321 ; least squares, $324 ; 326$; the Tides, 330 ; Gauss, 331; mathematical expression of astrouomy, 333; emanation theory of light, $344 ; 346$; moleenles, 347 ; gravitation theory, 349 ; molecular attraction, 354 ; 'Théorie de l'Action eapillaire,' 355 : quoted, 356 ; St Venant quoted, 359; 362; corpuscular theory of light, 370 ; measurement of electrical action, 371 ; value of Newton's formula, 373; Newton's law, 375; astronomical view of nature, 380 ; opposed to undulatory theory, ii. 16 ; on Newton's emission theory, 17 ; theory of light, 20; opposed undulatory theory of light, 24 ; on the commission which crowned Fresnel's 'Mémoire sur la Diffraction,' 25 ; extension of gravitation into molecular physics, 29; theory of capillarity, 33 ; researches into electrical phenomena, 67 ; methods of, 70 ; school of, referred to, 93, 100, 101; the material and dynamical conceptions of heat, 118 ; cosmological genesis of planetary system, 209 ; 215 ; astronomical work of, 227 ; 228; nebular theory; 277,284 ; quoted, 285; 290 ; genesis of the cosmos, 320 ; genetic view anticipated by, 330 ; theory of, $35 \%$; hypothesis of, 360 ; stability of solar system, 3S6; animal heat, 390, 433 ; analysis of phenomena of nature, $399 ; 474,457$; science of chances, $568 ; 569,571,572,575$; method of least square, 576 ; doctrine of probabilities, 578; influence of, 581 ; statistical method in social questions, 599 ; curve of elror, 616 ; 634, 637; his 'Mécanique céleste' and 'Theorie des Probabilités,' 642 ; functions of, $696 ; 751$.

Larmor, Jos., vortex theory, ii. 63, 64; 'Ather and Matter,' 89, 195 ; mathe- matical theory of electricity, 193 ; his position, 195 ; 197 ; atomic and euergetic views, 198 ; 595 ; on vectors, 656.

Lasswitz, 'Geschichte der Atomistik, i. 433 , ii. 5 ; 'G. T. Fechner,' 369 , 508 ; Fechner's philosophy, 513.

Laurent, revives Prout's hypothesis, i. 402 ; attack on electro-chemical theory, 409; "type theory," 411 ; 413 ; quoted, 419; "substitution" in chemical combination, 429.

Laurillart, Bell's theorem, i. 293.

Lavater, Caspar, 'Physiognomische Fragmente,' ii. 477 .

Lavoisier, i. 114, 147 ; services to France, 148; 170, 188, 200; scientific method of, 306,365 ; influenced by Laplace, 380 ; theory of combustion, 386,393 ; chemical researches, 391 ; $392,399,400$; organic analysis, 407 ; chemical balance, ii. 152; atomic view, 153 ; 379 ; and his school, 382 ; animal heat, 390,433 ; chemical elements, 398.

Lawes, Sir J. B., experiments and publications in agriculture, i. 284.

Layard, i. 294.

Lazarus, psychologist, ii. 497; the objective mind in history, 530 .

Leake, M. W., explorations of, i. 296.

Learning, apparent disintegratiou of, $i$. 30.

Least squares, method of, i. $120 ; 183$; ii. 576 .

Le Bel, the carbon tetrahedron, i. 450.

Leblanc invents soda process, i. 92.

Le Breton, report on Fine Arts, i. 149.

Le Chatelier, 'Journal de Physique,' ii. $169,173$.

Lecoq de Boisbauriran, discovery of gallium, i. 315, 423.

Legallois, ii. 519.

Legendre reforms geometry, i. 44 ; 'Théorie des Nombres,' 82 ; method of least squares, 120,183 , ii. $576 ; \mathrm{i}$. 181 ; "Traité des Nombres," 182; 'Nouvelles methodes pour la détermination des orbites des comètes,' 183 ; 'Traité des fonctions elliptiques,' 185 ; 187 ; potential function, 231; on elliptic integrals, ii. 648 ; his relation to Abel and Jacobi, ib.; K Königsberger on, $i b$. ; ou foundations of geometry, 656 ; on synthetic method, 670 ; functions of, $696 ; 721$.

Lehmann, 'Molecularphysik' quoted, i. 443.

Leibniz, i. 49; essay on, by the 
author, 50; on thought, 66 ; organises scientific effort, 100 ; "calculus," 101 ; modern analytical spirit of, 102; letter to Huygens on calculus, 103; letter to Bodenhausen, 104; 105 ; 'Schriften,' 122; 137 ; at the court of Brunswick, 158; the University of Halle, 160; encyclopædic view of 'Wissenschaft,' 171; modern science, 175 ; reaction against his plilosophy, 212; notation of, 233 ; 247, 283, 311 ; "energy," 312; $3: 37$; gravitation, 340 ; 358 ; letter to Foucher, ii. 5 ; Euler's opposition to, 8 ; "vis viva," 100 ; indestructibility of force, 111; inthences German philosophy, 205; scientific work of, 210 ; 'Protogæa,' 277, 280, 293; "evolutionist," 278 ; 'Protogrea' quoted, 281; 285; epigenesis, 298; genetic view anticipated by, 380 ; 364 , 365; animation of all nature, 369 ; 403 ; illea of life, 409 ; monalology, 500; 507 ; doctrine of preestablished harmony, 519; (see Herder), 535 ; the theory of language, 537 ; statistical information, 546; 555; Neumanu's statistical tables, 565 ; science of chances, 568 ; theory of probabilities, $573 ; 638,643$; his dyadic system, 645 ; on convergency, 646 ; letter to Huygens, 659 ; on determinants, 682 ; 706; science and religion, 742 .

Leitch, 'Miscellaneous Works' of Dr Young cited, i. 244.

Lelièvre, i. 136.

Lemonnier at the Jardin des Plantes, i. 107.

Lenard, discoveries of light rays, ii. 92; observation of cathode rays, 192.

Lenz, electrical phenomena, ii. 146.

Le Sage, "ultramundane corpuscles," i. 342 ; 344 ; quoted on Epicurns, ii. 4 .

Leslie, scientific work of, i. 229, 230 ; Scoteh university professor, 272.

Lessing, moralising style of, i. 51; and Gibbon, $169 ; 171$; the scientific ideal of, $211 ; 212$.

Leuckart, Rudolf, ii. 322 ; law of linit of growth, 445 .

Leuwenhoek, perfection of simple microscope, ii. 228 ; reference to, 281 .

Leverrier and the discovery of Neptune, i. 277 ; "Association scientifique," 298 ; astronomical achievements of, 314 ; meteoric hypothesis, ii. 357 .
Lewes, G. 11., on Herbert Spencer, i. 48; 'Life of Goethe,' 166; ii. 470 ; plurenology, 478; "specifie energies," 483 ; 512 ; spinal chord, $519 ; 608$.

Lexis, Prof., 'Die dentschen Universitäten,' i. 226 ; statisties, ii. 566.

Lhmilier referred to by Steiner, ii. 669.

Lichtenberg of Göttingen University, i. 165; electricity and the Geissler tubes, ii. 191 ; physiognomy, 477.

Lichton, John, Louvain University, i. 268.

Lie, Sophus, ii. 686; and theory of groups, 690; and Klein, 691, 692, 718 ; on diflerential equations, $696^{\circ}$; on funlamental problem of geometry, $718 ; 7: 0$.

Liebig, J. von, laboratory at Giessen, i. 18 ; 'Jahresbericht der Chemie,' 42 ; works on chemistry, 43; chemical predictions of, 92; on Bacon, 93; 115 ; 162,174 ; temporalily influenced by speculative spirit in German science, 178; establishment of chemical laboratories, 188 ; quoted, 190; his organic analysis, 191; anit Wöhler, 192; 194; metaphysical leanings of, $196 ; 200$; intluenced by the Naturphilosophie, 207; freed under the intluence of French science, 208; underlying idea in founding chemical laboratory, 214; "vital force," 218 ; Dalton's atomic theory, 246 ; agricultural experiments, 285 ; 'Familiar Letters on Chemistry' quoted, 389; discovery of "isomerism," 406 ; the "radicle" theory, 409 ; the hydrogen and the oxygen theory of acils, $410 ; 412$; quoted on chemical research in England, 414; his attitude towaris the atomic theory, 418; scientific work of, ii. 105 ; 'Annalen der Pharmacie,' $10 \bar{\gamma}$, I63, 170; Mohr's and Helm's first papers published, 109; appreciation of Molir and Mayer, 114; 'Die Organische Chemie,' 115; organic chemistry, 117, 391; dynamical theory of heat, 128; popnlar work of, 149 ; 152 ; (see Thos. Graham), 161 ; biological stuties, 208; physiological processes, $390 ; 393$; his influence, 394 ; 396 ; attempt to extend the idea of "Stoffwechsel," 397 ; "chemical Letters,' 398 ; practical study of nature, 404 ; "vitalism" 405 ; 406 , 411,420 ; Bacon's "method of instances," 558. 
Leibisch, 'Plyysikalisehe Krystallographie,' i. 443.

Liebreich, Oscar, discovered action of chloral, i. 93.

Life and mind, ii. 216 ; what are they ? 462 ; mental, 496.

Life, problem of, ii. 352 ; what is it? 381 ; Bichat's definition of, 383 ; 394 ; and mind, 548.

Light, the undulatory theory of, i. 241, ii. 153 ; i. 229,236 ; theories of, ii. 8 ; undulatory and emission theories, 11 ; undulatory theory prepared by acoustics, 12 ; and sound, mechanica! difterence between, 30 ; speed of, 36 ; corpuscular theory of, $i b$. ; speed, 45 ; magnetisation of (Faraday), 74 .

Limits, method of, ii. 706 ; Hankel on, $i b$.

Lindemann, researches of, ii. 124; on transcendency of number $\pi, 731$.

Link, ii. 230 ; observations of, 261.

'Linnæan Society, Transactions of,' i. 41.

Linneus, contributions to study of natural history, i. 116 ; beginning of geometrical crystallography, 117 ; 119 ; system and nomenclature of, $126 ; 145$; classification of living beings, 288 ; system of classification, ii. 220,221 , 232 ; basis of classification of vegetable and animal kingdom, 234; first four classes of, $238 ; 243,251$; classifications, 254,$336 ; 311$.

Lionardo da Vinci, rules of perspective, ii. 663 .

Liouville recognised merits of Green's work, i. 247; publishes Galois' works, ii. $686 ; 726,727$.

Lister, improvements in microscope, ii. 228.

Listing, J. B., 'Vorstudien zur Topologie, 'ii. 63.

Literature, French, influence of science on, i. 104.

Lloyd, Humphrey, experiments in refraction, ii. 43 .

Lobatchevsky, Vasiliev on, i. 161 ; ii. 635 ; and Gauss, 652 ; pupil of Bartels, $653 ; 710,713,718$.

Lacke, David Hume and, i. 47 ; 144 ; influence of, on German thought and literature, 212 ; and Kant, 219 ; school of, 250 ; influence on educational views in England, 253; influence on French philosophy, 273 ; new line of thonglit adopted by, 311 ; sensualistic philosophy, ii. 323 ; psycho-physical view, 471 ; genesis of space perception, 473 ; 497 ; genetic view, 506 ; 516 ; language, $536 ; 751$.

Lockyer, Sir Norman, nature of elements, ii. $192 ; 282$; genesis of the cosmos, 360; 'Inorganic Evolution,' 369.

Lodge, Sir Ol., "The Second Law of Thermodynamies," i. 331 ; 370 ; on "action at a distance," 380 ; on the ether, 'Modern Views of Electricity,' ii. 33, 90, 163; popularisation of Maxwell's electro-magnetic theory, 73 ; illustrations of Maxwell's theory, 90,94 .

Lommel, Ohm's 'Gesammelte Abhandlungen,' i. 365 .

Longet, BeIl's theorem, i. 293.

Longitude, Board of, i. 113; prize offered by, 158 .

Longitudes, Bureau des, i. 113.

Lorentz, H. A., mathematical theories of electricity, ii. 193 ; 195 ; quoted, $195,197$.

Lorenz, O., quoted on division of history into centuries, i. 13; 'Die Geschichts. wissenschaft,' 206.

Loria, Gino, i. 275.

Lotze, Hermann, definition of "reality," i. 32 ; contrasted with Herbert Spencer, 48; quotation from 'Microcosmus,' 52; definition of philosophy, 65 ; constructive ideas of, 81 ; and Fechner, 200; lectures on "encyclo. pædia" of philosophy, 215; mechanical view in biology of, $219 ; 220$; philosophy of, ii. 288; 401; "Leben und Lebenskraft," 401 ; 405; vitalism aud animism, 407 ; purpose and will, 408, 409 ; vitalism, 434 ; anticipater Helm. holtz, 491 ; 492 ; influence of Herbart on, 494 ; physiology of the soul, 500 ; psycho-physics of vision, 504 ; theory of" "local signs," 508; mertical psychology, 512; psycho-pleysics, 517 ; 'Microcosmus,' 532; 549; quoted, 585 ; on non-Euclidean geometry, 716 . Louis XV., i. 107 ; and botany, ii. 235.

Love, A. E. H., 'Dynamies,' ii. 183.

Lowth, 'Lectures on Hebrew Poetry,' ii. 537 .

Lubbock, Sir Jolnn, ii. 415; anthropologist, 497 .

Lucretius, scientific speculations of, i. 313 ; the "atomic theory," 385 ; quoted, ii. 4.

Ludwig, F., mathematical botany, ii 622.

Ludwig, K. F. W., Éloge of Weber, ii. 396 ; "automatic curve-plotting," 403. 
Luminiferous ether, theory of, ii. 18; 69,70 .

Limar theory, i. 329.

Liiroth, on von Standt, ii. 669; and Shepp, trauslation of Dini's work, 704.

Luther, educational work of, i. 255.

Lyell, Sir Chas., i. 229; quoted on British Association, 240; "Travels in North America,' 263; 'Principles of Geology,'291, ii. 277, 317; on Cuvier and the fixity of species, $256 ; 291$; "uniformitarian" school of geology, 292 ; beginnings of the genetic view, 293 ; quoted, 296, 559 ; genesis of the cosmos, 320 ; 327 ; genetic view in geology, $330 ; 335,608$.

M'Aulay, A., on directional calculus, ii. 656.

Macaulay eulogises Bacon, i. 93.

M'Cormack, Thomas, translation of Prof. E. Mach's Works, i. 318; ii. 183.

$\mathrm{M}^{6} \mathrm{Cosh}$, James, ii. 513.

M'Cullagh, James, i. 274 ; properties of ether, ii. 31 ; analytical methoul of, 45 ; referred to, 54 ; contribution to vortex theory, $63 ; 195$.

MacCulloch, J. R., 'Statistical Account of the British Empire,' ii. 563.

Macfarlane on directional calculus, ii. 656.

Mach, Prof. Ernst, 'Mechanik in ihrer Entwickelung' qroted, i. 318, 383, ii. 97, 100; 'Die Geschichte und die Wurzel des Satzes von der Erhaltung der Arbeit,' 97 ; 'Principien der Wärmelehre,' 102, 106, $109,111,175$; popularisation of Fourier's heat theory, 121 ; eriticism of mechanical view, $183 ; 185,737$.

Machiavelli, a model historian, i. 7.

I' 'Kendrick on Helmholtz, ii. 396, 485; quoted, 490.

Maclaurin, Colin, tribute by Playfair to, i. 232 ; 'Treatise on Fluxions,' se., $270 ; 272$; series of, ii. 646; theorem of, 670 .

MacMahon, Major, Address to Mathematical Section of British Association, Glasgow, ii. 140 ; on combinational analysis, $643 ; 679$.

Madrin despaired of Newton's theory of gravitation, i. 334.

Magendie, Bell's theorem, i. 293 ; experimental school of, ii. $384 ; 385$; experimental or vivisectional school, 406 ; experiments, 481.

VOI. II.
Magnus, Gustav, chemist, i. 188; 205 ; chemical researches of, 208.

Mairan, referred to by Voltaire, i. 106.

Malpighi used the term "cell," i. 195; embryological work of, ii. 227,260 ; (see De Candolle), $20^{\circ} 1$; "epigenesis," 278.

Malthıs, 'Principles of Population,' i. 84 , ii. 331 et seq.; conflict in nature, 431.

Malus, polarisation of light aiscovered, i. 83 ; introduced the word "polarity," ii. 22 ; "polarity" acquired by light by reflexion, 23 ; on polarisation, $i b$.; referred to by Young, $2 \overline{7}$.

Man, and brute, the dividing line, ii. 541 ; the "mean," 580.

Manchester Literary and Philosophical Society, i. 265.

Manifold, ii. 713.

Mansel, Dean, 'On the Limits of Religious Thought,' ii. 326 .

Mantegazza, physiognomy, ii. 477 .

Nantell, G., ii. 318.

Marat, i. 107.

Maria Theresa, i. 256.

Marine laboratories, ii. 232.

Marinini, animal electricity, ii. 475.

Marion, 'Grande Encyclopédie' quoted, ii. 495 .

Mariotte, Boyle's law of prescures, i. $425 ; 427$; experimental formule of, 436.

Markgraf, Andreas Sigismund, i. 175.

Martin, Charles, Lamarck's views, ii. 310 ; "Introduction Biographique" of Lamarck, 311.

Maser, H., edition of Abel and Galois, ii. 686 .

Maskelyne, N., i. 177 ; scientific work of, 229 ; not member of any university, 238; measurement of force of gravitation, 320 ; personal equation unkmown to, 325 ; discoveries of, 354 .

Maskelyne, Story, "The Morphology of Crystals,' ii. 222.

Mass, weight and, i. 336.

Massieu, mathematical formulæ of "free energy," ii. 173.

Mathematical methods, Continental, introduced into England by Babbage and others, i. 18.

Nathematical, spirit, i. 314 ; first introduced into science, 317 ; formulæ, focalising effect of, 332 ; definition of matter and force, 334 .

Mathematicians, Kijnigsberg school of, i. 186 ; ancient, catalogue of', ii. 633 .

Mathematies, Continental, methods in, 
i. 100; modern changes in conception of, 221 ; impetus to study of, given by French Revolution, 237 ; prejudices against, ii. 628 ; Sylvester on, 629,631 ; use of, 630 ; Huxley on, $i b$.; Lord Kelvin on, $i b$. ; Gauss on, 631 ; Cayley on, ib.; twofold interest in, 632 ; origin of, 634 ; Euler on, 657; Abel and Jacobi's school of, $i b$.

Mathurin, geometrical work of, i. 114.

Matter and force mathematically defined, i. 334.

Matter, circulation of, ii. 420 ; living, mobility of, 438 .

Natteucci, animal magnetism, ii. 475.

Natthew, Patrick, 'Naval 'Timber and Arboriculture,' ii. 334 ; 347.

Naudsley, Dr H., 'Physiology and Pathology of Mind,' ii. 512.

Maupertuis followed Newton, i. 96; referred to by Voltaire, 105 ; principle of least (or stationary) action, 231 ; astronomical constants, 322.

Maury, Alfred, 'Les Académies d'autrefois, i. 90, 99, 105; quoted on Vol. taire and scientific progress, 106; quoted, 127, 135, 147, 148; 143; 226.

Mauvein, i. 92.

Maxwell, Transactions of Society of Agriculture, i. 284.

Maxwell, James Clerk-, on probabilities, i. 120; 'Science and Freewill,' 124; his theories followed up in Germany and France, 251; and Faraday's "lines of force," 266 ; contributions to study of natural philosophy, 274 ; 'Heat,' 315, ii. 173; 'Electricity and Magnetism,' i. 323; electric theory, 344; "the astronomical method," 347 ; "Action at a Distance,' 348; 'Electrical Researches of Cavendish,' 363; 'Physical Lines of Force,' 372 ; 'Equilibrium of Elas. tic Solids,'379; Weber's theory, 380 : " energy" a substance, 388 ; "Dynamical Evidence of the Molecular Constitution of Bodies' quoted, 424; kinetic theory of gases, 433 , ii. 34 ; the statistical view of nature, i. 438; 'Kinetics,' ii. 5; 'Scientific Papers' quoted, 33,175 ; treatise on electricity and magnetism, 35; followed on the lines of Stokes, 55 ; quoted on Rankine's theory of molecular vortices, 62; "Atom," "Encyclopædia Britannica,' 66 ; electro-magnetic theory, 73, 153; labours of, 76 ; theory of electricity, 78; "tubes of force," 80 ; electrotonic state of matter, 81 ; "On Physical Lines of Force," 82,83 ; "elastic medium" in space, 84; "elastic disturbances" of that medium, 85,86 ; theory of energy, $87,88,89$; indefiniteness of electromagnetic theory, 93 ; physical view of nature, 141, 144; and Faraday's views, 145 ; electro-magnetic field, 147 ; 148 ; theory of electro-dynamical phenomena, 151; 'Theory of Heat,' 167; Willard Gibbs, 172 ; "available energy," $174 ; 179,182$; triumphs of atomic view, 188; 191, 193 ; difficulties of his theories, 194 ; Ampère, 341 ; statistical view, 574, 603 ; theory of probabilities, 590; statistical methods, 592, 593 ; "Sorting Demon," 594 ; quoted, 605, $606 ;$ on historical and statistical methods, $613 ; 624$ et seq., 630 ; on vector analysis, 655 .

Nayer, A. M., Young's colour theory, ii. 480 .

Nayer, Julius Robert, i. 218, 265, 309 ; theory of energy, ii. 97 ; his work theoretical, 99 ; scientific services of, 106 ; memoirs refused by Poggendorf, 107 ; measurement of "energy," 108 ; indestructibility of force, 111 ; neglect of earlier writings of, 113 , 114 ; his views extended and elaborated by Thomson and Clausius, 116 ; 117 ; correlation and interchangeability of natural force, 119; perpetual motion, 124; the dynamical theory of heat, 128, 130; first philosophical generalisations on power and work, 137; "Kraft," 169 ; 207 ; "energy," 355 ; meteoric theory of the sun's heat, 357,358 ; conservation of energy, $397 ; 398$.

Mayer, Tobias, Professor of Mathematics and Economics at Göttingen, i. 158 ; connection of, with modern science, $175 ; 176 ;$ method of least squares, 183 ; astronomical calculatious of, 324 ; lunar theory, 329 ; 368.

Measurements, Weber's fundamental, i. 368 .

Méchain, i. 113.

Mechanical view of nature, ii. 183.

Mechanism, ii. 399.

Meckel, anatomist, ii. 248 ; morphological analogies, 250 ; 308 ; quoted by Huxley, 348 ; law of "biogenesis," 349. 
Medical faculty, \&c., in German universities, i. 197; science and philosophy of nature, 209; medical interest, the, ii. 207 ; thermometry, 389.

Nedicine, i. 126; Austrian school of, 198 ; German schools of, 208 ; influence of, ii. 379 .

Medium, internal, ii. 432.

Melanchthon, and the first Protestant universities, i. 159; educational work of, 255 .

Meldola, R., analytical and synthetical methods in chemical research, i. 457.

Nelloni, radiant heat, ii. 105.

Mendeleffi, D., classification of the elements, i. 315 ; periodic laws of, $403,422,423,448$; ii. 36 .

Mental life of mankind, i. 55 .

Mentelle, geography at the École normale, i. 112.

Mercator, i. 157; his projection, ii. 701.

Merck, 'Annalen der Pharmacie,' ii. 107.

Méré, Chevalier de, i, 120.

Merey, C. H., on foundation of analysis, ii. 704,734 .

Meridian, measurements of arcs of, $i$. 99.

Merkel, 'Jacob Henle,' i. 215, 293.

Mersenue, original member of Paris "Académie des Sciences," i. 228.

Nesmer, animal magnetism, ii. 476 .

Metabolism, ii. 421, 422, 442.

Metaphysical treatment of science in Germany, i. 43 .

Methods have their day and are discarded, i. 56.

Metrical and projective geometry, ii. 668.

Neusnier, i. 115.

Meyer, E. von, 'History of Chemistry,' i. $405,406,413$; quoted, 411; memoirs of, ii. 257 .

Meyer, Franz, his history of Invariants, i. 247,308 ; ii. 677 ; 684 ; on Lie and 'Theory of Groups,' 691 ; on potential theory, $69 \mathrm{~s}$.

Meyer, Lothar, classification of chemical elements, i. 315; "Modern Theories of Chemistry,' 393 ; periodic laws of, 403, 422, 423; 427; "Die Atome und ihre Eigenschaften,' 429, 445; 456 ; 'Molerne 'Theorien der Chemie,' ii. 65.

Meyer, 0. E., 'Die Kinetische Theorie der Gase,' i. 434, 435, 437; quoted on Maxwell, 438; ii. 593.
Meyer, Victor, on cliange of chemical views, ii. 165 .

Michaelis of Göttingen University, i. 165.

Michell, apparatus to measure force of gravitation, i. 320.

'Microcosmus' of Lotze, i. 52.

Microscope, ii. 228.

Miething, E., 'L. Euler's Lehre vom Aether,' i. 343,352 , ii. 8.

Mill, John Stuart, reintrodnces philosopliy of Comte to France, i. 18; 'Logic,' 37 , ii. 307,308 ; on theory of probabilities, i. 120 , ii. 569 ; i. 306 ; 'Autobiography,' 307; opposed to undulatory theory of light, ii. 37 ; on A. Bain, $511 ; 513,571,608$.

Millar, W. J., Pankine's 'Miscellaneous Scientific Papers,'ii. 133, 139.

Miller, Hugh, stonemason and geologist, i. 288 .

Miller, W. A., spectrum analysis, i. 278 ; ii. 47, 48; 'Chemical Physics,' i. 316 .

Milnes-Marshall, ii. 349.

Milton, influence on German thought and literature, i. 212 ; influence of, on educational views in England, 253.

"Mimicry," ii. 338.

Mind, ii. 216, 455 et seq.; the objective, $529 ; 5$ ts

Mines, Ecole des, i. 107.

Mimnigerode, geometrical treatment of crystallograpliy, i. 413.

Nirabeau, higher aims of, not realised, i. 112.

Mirbel, ii. 230; observations of, 261 ; cellular theory, 262.

Mitchell, P. C., ii, 459.

Mitchelson, speed of light, ii. 36.

Mitscherlich, E., i. 174; chenist, 188 ; 190 ; discovery of isomorphism, 19l, 444 ; services of, to chemistry, 208; Dalton's a tomic theory, 246 ; discovers polymorphism, 446 .

Mivart, St George, ii. 546.

Mobility of living matter, ii. 438.

IIobius, A. F., his geometry, i. 44; a pupil of Gauss, 181, 187; his writings unknown to Pliicker, ii. 76 ; and Ganss, 652; his barycentric calculus, 655,724 ; introduces homogeneous co-ordinates, 681 .

Hohl, Hugo von, "protoplasm," i. 309 ; improvements in micrometric processes, ii. 229 ; cellular theory, 262 , 299 ; protoplasm, 264, 265, 422, 443 ; inductive school of, 321 .

Mohr, Karl Friedrich, i. 413 ; scientific 
work of, ii. 106; "On the Nature of Heat," 107 ; indestructibility of force, 111; neglect of early writings of, 113,114 ; referred to, 117 ; correlation and interchangeability of natural forces, 119, 124; "force," 125 , 130 ; first philosophical generalisations on power and work, 137 ; 'Gesch. der Erde,' 289; heat and animal energy, 398.

Moivre, De, the theory of probabilities, i. 120 ; ii. $568 ; 572$.

Molar dimensions, special interest attached to, i. 350 .

Molecular action, i. 346 ; phenomena, astronomical view of, 354 .

Molecules, internal energy of, i. 436.

Moleschott, materialistic worlis of, i. 60 ; Life of Georg Forster, 179; ' Kreislauf des Lebens,' ii. 289, 323.

Moll, Prof., of Utrecht, favourable criticism of science in England, i. 236 ; ignorance of foreign languages in Eugland and France, 237.

Molyneux, space perception, ii. 473.

Monadology, ii. 500.

Monboddo, Lord (James Burnett), ii. 531 ; 'On the Origin and Progress of Language,' 536, 537.

Mlonge, Gaspard, descriptive geometry, i. 44 , ii. $658,664,675,685$; geometry at the École normale, i. 112, 237 ; 'Descriptive Geometry,' 114; 115, 147 ; brass and iron cannons, 148 ; 152,$187 ; 306$; practical school of, ii. 100.

Monro, Alexander, Edinburgh University, i. 268 ; ii. 247.

Monro, John, at Edinburgh University, i. 268 .

Montagu, Lady Mary W., inoculation, i. 284.

Montesquieu reflects the thought of the eighteenth century, i. $61 ; 107$; study of human culture, ii. 529 .

Montgolfier, indestructibility of force, ii. 111.

Moutgomery, Edmund, 'Space and Tonch' ii. 472; article in 'Mind' quoted, 484.

Montmort, Remont de, letter to Brook Taylor, i. 101 ; original member of Paris "Académie des Sciences," 228.

Montucla, 'Histoire des Mathematiques' quoted, i. 114, 307, 334, 358.

'Monumenta Germanix,' i. 167.

Moore, Thomas, on an English characteristic, i. 240.

Morgan, A. de, theory of probabilities, i. 120 ; calculus of probabilities, 325 ; essay on probabilities, ii. $569 ; 641$, $650,709,711$.

Morley, John, 'Diderot,' i. 34.

Norphogenesis, ii. 549.

Morphological view of nature, ii. 200 ; insufficiency of, 270 ; period, 274 ; structural analysis of elements, 423.

Morphology, ii. 212 ; defined, 219; of crystals, 223 ; on a large scale, 224 ; on a minute scale, 227 ; and classificatiou, $231 ; 549$.

Morveau, Guyton de, 'Annales de Chimie,' i. 41.

Mosander, pupil of Berzelius, i. 188.

Moser, perfection of stereoscope, ii. 506.

Mosheim, "libertas docendi," i. 164.

Motion, atomic and molecular, i. 437; in ancient philosophy, ii. 3 ; perpetual, impossible, 124.

Motivity, thermodynamic, ii. 168, 594.

Muir, Thomas, ii. 643.

Müller, Fritz, 'Facts and Arguments for Darwin,' ii. 349.

Müller, Johames, physiology at Berlin, i. 174 ; temporarily influenced by speculative spirit in German science, 178 ; 'Handbuch,' 193 ; 195 ; metaphysical leanings of, 196 ; school of, 197 , ii. 397,403 ; i. $198,200,201$; influenced by the Naturphilosophie, 207 ; freed under influence of French science, $208 ; 211$; upheld the method of historical survey in science, 215 ; his achievements in physiology, 217; "reflex action," 263; 292; Bell's theorem, 293, 294; scientific resear'ches of, ii. $106 ; 117$; influences Du Bois-Reymond and Helmholtz, 150 ; physiological studies, 208; the cellular theory, 263 ; "vital force," 269 ; 301 ; 'Physiology,' 308, 417, $420,443,491$; 381,384 ; chemical processes in the living body, 391; 396 ; cellular theory, \&c., 418; animal magnetism, 475,$476 ; 481$; "specific energies," 482, 483; 519; Herder's 'Werke,' 537; study of language, 538; on Steiner, 670.

Miiller, K. O., i. 215.

Miiller, Max, quoted on definition of thought, i. 4 ; 'Science of Language,' 23 , ii. $540 ; 608$.

Miinchausen, von, founded University of Göttingen, with "libertas docendi," i. 164 .

Munk, experiments on the brain, ii. $478 ; 479$. 
Munro, 'Lueretius,' ii. 4.

Münsterberg, Dr Hugo, psycho-physics, ii. 518 ; experiments, 521 .

Murdoch, W., not member of any uni. versity, i. 239.

'Mlusenalmanach' of Schiller and Goethe, i. 84.

Muséum d'Histoire naturelle, i. 112.

Nägeli, C. von, co-editor with Schleiden of 'Zeitschrift für wissenschaftliche Botanik,' i. 195; mechanical theory of organic structures, ii. 224 ; per. fection of micrometric processes, 229 ; 271 ; inductive school of, $321 ; 351$; ' Micellar Theory,' 425, 427, 611; Weismanu on, 435 ; process of intus. susception, 443; "idioplasma," 448; 613.

Nansen, Fridjof, arctic exploration, ii. 207 ; quoted on the ubiquity of organic germs, 453 .

Napier, John, logarithms, i. 94, 269 ; $272,282$.

Napoleon I., relation to science, i. 42 ; offered prize for discovery of a process of manufacturing carbonate of soda, $92 ; 107$; his influence on science, 149 ; quoted from Thibandeau, 150; founded Université Impériale, 151; favoured mathematical sciences, $i b$.; 152 ; his scientific glory derivative, 154 ; statistical methods employed by, 153; 206 ; animal magnetism, ii. 476.

Napoleon I11., scientific reports, i. 42.

Narbonne, i. 151.

Nasse, Chr. Fried., physiological method in medicine, ii. 388.

Nations, work of the three, compared, i. 298 ; disappearance of national differences, 305.

Natural history, first public course in Paris, i. 143.

Naturalistic school in France, i. 75.

Nature, history of, how to be understood, i. 2; philosophy of, 204; philosophy of, and medical science, 209 ; English love of, 284 ; statistical view of, 438 ; kinetic view of, ii. 1 et ser.; physical view of, 95 et seq.; mystery of the actual processes of, 366 .

Vaturphilosophie of Schelling and Hegel, i. 178,207 ; ii. 315 .

Naumann, C. F., "morphology of the surface of the earth," ii. 212.

Navier, mécanique moléculaire, i. 359 ; 360,379 ; theory of elasticity, ii. 31 , 41 ; properties of the ether, 33 ; synthetic method, 100.
Nees von Esenbeck, ii. 265.

Neptune, discovery of, i. 277 .

Neptunists and Plutonists, i. 283, 290.

Nernst, "Theoretical C'lemistry, i. 448 , ii. 186.

Neumann, Carl, development of astronomical view of nature, i. 366 ; quoted on provisional character of electrical formulæ, 375; 'Die Principien der Electrodynamik,' 376 ; ii. $186^{\circ}$; on potential, 698; and Dirichlet's principle, 708.

Nenmann, Franz, the elder, mathematical physics, i. 44 ; 199 ; experiments in chemistry of, 429 ; properties of ether, ii. 31 ; analytical method of, 45 ; "elastic" theory of ether, 54 ; influences Helmholtz, 150; theory of electro-dynamic phenomena, $151 ; 193$.

Neunamn, Kaspar, statistical tables of, ii. 565 .

Newlands, periodic law of, i. 422,423 .

Newport, his discovery, ii. 227.

Newton, value of work of, i. 93 ; cor. rected the thought of Bacon, 95 ; his work completed and amplified by Laplace, 97 ; mathematical reasonings of, substantiated, 99 ; invention of "fluxions," 100 ; influence on the popular mind inappreciable, $105 ; 118$, 119, 123; contrasted with Cuvier, 132; 137; Cuvier on the gravitation theory of, 146; Gauss's appreciation of, 181 ; discoveries of, frequently forestalled by others, 184; 'Principia,' 188, 189 , 227 , ii. 6 ; pre-eminent as an exact thinker, i. 222; indebtedness of French seience to, 226 ; notation of, 233 ; and Young, 244, ii. 9 ; Flamsteed's observations, i. $250: 267,279$, 282, 311; "energy," 312 ; 317 ; astronomical instruments, 322 ; 323 , 325 ; lunar theory, 329 ; 332 ; mathematical expression of astronomy, 333; matter and force, 334; "deseription and explanation" of phen. omena, 337 ; gravity not "essential and inherent," 340 ; mechanical explamation of gravitation, 342 ; emanation hypothesis of light, 344 ; actio in distans, 345 ; gravitation, 351, 353; molecular attrac. tion, 354 ; Horsley's edition of his works, 355 ; correspondence with Cotes on molecular attraction, ib.; Hauksbee's experiments, 356 ; 358 ; St Venant on, and Boseovich, 359 ; idea of mass, 362 ; 370,372 , 
374: universality and accuracy of his law, 377, 380, 382, 384; 385 , $389,394,424$; calculation of molar and cosnical phenomena, 439 ; "mechanical cause" of gravitation, ii. $4 ; 5$; and Huygens, 6 ; method of, 8 ; Euler's opposition to, $i b$; insufficiency of ellission theory, 14, 15 ; suggested both theories of light, 17; recognisetl "polarity" of light rays, 22 ; general laws of motion, 28 ; formula of attraction, 44 ; referred to, 62 ; and the French school of physical astronomy, 79 ; scientitic terms, 95 ; 'Principia' and the modern notioll of energy, 99,100 , 140 ; vibratory view of heat, 104 ; laws of motion, 143; astronomical researches, 227: Darwin and, compared, 341 et seq.; 344 ; universal gravitation, $351 ; 364,467$; optics, 480 ; and Gauss compared, 630 ; 634, 638, 643 ; his theorem on equations proved by Sylvester, $681 ; 706,733$; science and religion, $742 ; 751$.

Newtonian formula the basis of physical astronomy, i. 375 ; unique as to universality and correctness, 377 ; is it a miversal law? 378 .

Newtonianism created by Voltaire, i. 250, 25l ; dispelled Cartesian physical philosophy in France, 433.

Nichol, Johu, on Francis Bacon and his forerunners, i. 94.

Nichol's 'Cyclopedia,'ii. 133.

Nicholas V., Pope, and the University of Glasgow, i. 268.

Nicholson and Carlisle, scientific dis. covery of, i. 229.

'Nicholson's Journal,' i. 41, ii. 104.

Nicol, 'Crystallography,' i. 117.

Nicomachus, ii. 207 .

Niebuhr, B. G., his indebtedness to Gibbon, i. 169 ; 212.

Niebuhr, Karsten, on Tobias Mayer, $\mathrm{i}$. 158.

Niepce, photograpby, ii. 506.

Nietzsche, illea of recurrent cycles, ii. $28 \pi$.

Nilson, discovery of scandium, i. 423.

Nineteenth century not one of revolution, i. 77 .

Nobili, animal electricity, ii. 475.

Nomenclature, importance of, in science, i. 131 .

Non-Euclidean geometry, ii. 652 et seq.; Klein on, $653 ; 712$, 715 ; Halsted and Schlegel on, 714; criticised by Lotze, 716 .
Nordenskiöld, pupil of Berzelius, i. 188.

'North British Review' quoted on Scotch educational movement, i. 254.

Norwood, determined length of a de. gree, i. 97.

Nöther, M1., on Sophus Lie, ii. 690, 691 ; and Klein, 720. See Brill.

Number $\pi$, ii, 721 ; and $e$, transcendent nature of, 731 .

Numbers, theory of, ii. 680 ; revived by Legendre, and Gauss, $i b$, ; generalised, 726 ; transcendental, 727,730 ; corpus of, 728 ; algebraic, 729 .

Objective mind, ii. 529 .

Observation, insufficiency of mere, i. 328.

Ohservatory, Greenwich, built, i. 98; Pulkowa, i. 99.

Odling, chemical researches of, i. 414.

Oersted referred to, i. 238; discovery of electro-magnetism, $92,207,370$, 371 ; discoveries of, 366 ; electric cur. rents, 367; importance of his discoveries, 372 ; indestructibility of force, ii. 111, 125 ; electrical phenomena, 146.

Oettingen, von, ii. 185 ; statistician, $557,562,585$.

O'Comnell, Daniel, i. 240.

Ohm, G. S., Fourier's series, i. 241 ; anticipated by Cavendish, 363 ; accuracy of his law, 365 ; electro-nagnetic measurements, ii. 78 ; galvanic currents, 79 ; electrical phenomena, 146 ; law of, 147 ; resonance, 487 ; 508; on harmonics, 623.

Oken, originated scientific associations in Germany, i. 42 ; exponent of the Naturphilosophie, 207'; 238; 'Elements of Physio-philosophy,' 283; founded "Naturforscher-Versamm. lung," 298; anatomical aualogies, ii. 251 ; development of Goethe's riews, 255 ; influences Owen, 308 ; natural philosophy, 315 ; the genetic view, 317,321 ; evolution, 354 ; 508.

Olbers, Heinr. Wilh. Mlat., rediscovers Ceres, i. 54, 82 ; astronomical work of, 176 ; biographical, 177 ; calculates orbit of Ceres, 182 ; correspondence with Gauss, 185, 304 .

Oldenburg, i. 293.

Oltramare on Abel, i. 187.

Operations, inverse, ii. 639 ; different kinds of mathematical, 640 ; calculus of, $i b ., 655,684$; Hankel on, 640 ; Peacock on, ib. 
Operator, ii. 655 .

Oppolzer, Viemna school of mediciue, i. $198 ; 208$.

Opthalmoscope, Helmboltz's invention of, i. 200.

Optics, ii. 484.

Order, ii. 556 ; theory of, $6 \% 8$; and unity, 742 et ser.; 745 .

Organic substance, first, produced artiticially, i. 92 ; compound, preparation of, by Wöhler, 191 ; substances, synthesis of, ii. 425 .

Organisation, problem of, ii. $236 ; 415$.

Organs, study of separate, ii. 233.

Ossian, i. 212.

Ostwald, "Die Energie und ihre Wandlungen,' i. 380 ; "energy" a substance, 388 ; on Berthollet's views, 393 ; 'Classiker der exacten Wissenschaften,' 427 ; 'Allgemeine Chemie,' 443, ii. 176; 'Allgemeine Chemie' quoted, i. 444, 445 ; "Physikalische Chemie," 457 , ii. 158,160 ; principle of energetics, 125,142 ; physical chemistry, 153; chemical aftinity, 157,159 ; 165 ; menoirs of W. Gibbs, 171 ; second law of thermo-dynamies, 175 ; criticism of mechanical view, 183 ; quoted, 187.

Otto, translation into German of Thos. Graham's 'Elements of Chemistry, ii. 161 .

Owen, Robert, co-operation, ii. 566.

Owen, Sir Pichard, i. 42; palæontological work, ii. 257 ; the term "homology," 258; influenced by Oken, 259 ; extension of morphological view, 260; Cuvier's position untenable, 266; quoted, 268; morphological view of nature, 276 ; parthenogenesis, 456 .

Packard, A. S., 'Lamarck, his Life and Work,' ii. 312, 351.

Page, 'Text-Book,' ii. 363.

Paine, 'Thomas, 'Age of Reason,' i. 84.

Palæontology, science of, created by Cnvier, i. 131 ; Cuvier's work in, ii. 247 : 363.

Paley, philosophy in English universities represented by, i. 254.

Pallas, travels of, ii. $247,337$.

Pambour, de (see Zeuner), ii. 133.

Pander, ii. 299, 303.

Pangenesis, ii. 271, 454, 610 et seq.

Paper duties, i. 237.

Paradoxes in mathematics, ii. 732.

Parallel lines, axiom of, ii. 518, 717.
Paris, the focus of scientific thought, i. 17.

Paris Academy ridiculed the fall of meteors, i. 327; competition on "Diffraction," ii. 25.

Paris Institute, i. 226.

Parker, Prof., quoted, ii. 345.

Parmenides, unity of all existence, ii. 3.

Parthenogenesis, ii. 456.

Pascal, Blaise, his contributions to science beyond those of Bacon, i. 94 ; the theory of probabilities, 120 , ii. $568 ; 667$.

Pasteur, discoveries of, i. 431 ; the carbon tetrahedron, 451; "redintegration," ii. 387 ; 414 ; bacteriological investigations, 415 ; discovery of " chirality," 437 .

Pathology pre-eminently a German science, i. 216.

Pattison, Mark, meaning of "thought," i. 25 ; on Bentley, quoted, 169.

Panlmier, first majs of Greece, i. 295.

Paulsen, F., 'Geschichte des gelelırten Unterrichts anf den deutschen Schulen und Universitäten,' i. 159, 160, $163,164,166$; on Lotze and Fechner, 200 ; 'Die deutschen Universitäten," 214.

Peabody, C. H., "Thermodynamics of the Steam-Engine,' ii. 136.

Peacock, G., i. 18; introduction of Continental mathematics to Camsbridge by, 233; 'Life of Dr Young' quoted, 245,417 , ii. $20,21,23,26$; educational movement promoted by, i. 261: and the Analytical Society, 271 ; Young's 'Miscellaneous Works,' ii. 9; his "report" quoted, 640, 645 ; referred to by Hankel, 641 ; his history of arithmetic referred to, $645 ; 654 ; 709,711$.

Peano, G., ii. 656, 734, 737.

Pearson, Prof. Karl, i. 398, ii. 30 ; 'Todhunter's 'History of Elasticity, 33 ; 'History of Elasticity' quoted, 43 ; quoted on labours of Neumann, 54 ; modern theory of elasticity, 56 ; 'Grammar of Science,' 183 ; phenomena of heredity, 574; mathematical theory of evolution, 621 et seq. ; and Bateson, 623 ; 737.

Pearson, William, i. 289.

Peel, Sir Robert, ii. 265.

Pelletan, a founder of comparative anatomy, ii. $3 S 6$.

Peltier, phenomenon, ii. 143.

Percival, A. S., 'Optics' quoted, ii. 53.

Percy, Ballads, i. 212 ; ii. 537. 
Périer, Edmond, 'La Philosophie Zoologique avant Darwin' quoted, ii. 309, 32.2 .

Periodic law of Meudeléeff, i. 315, 422.

Periodicals, scientific, the oldest, i. 41.

Permanence of formal rules, principle of, Hankel's, ii. 712 .

Perrault, plan of co-operation proposed by, i. 99.

Perry, calculus for engineers, ii. 636.

Perthes, C. T., 'Politische Zustände und Personen in Deutschlaud zur Zeit der französischen Herrschaft,' i. 133, 256.

Perthes, Frederick, Memoirs of, i. 39, 279.

Pertz, first editor of 'Monumenta Germaniæ,' i. 158.

Peschel, O. F., 'Geschichte der Erdkunde,'i. 291.

Pestalozzi, i. 163, 253; his educational influence in Germany, 257 ; began the purely educational movement, 258 ; inspired by Rousseau, 259.

Peter the Great, i. 153.

Petermann, geographical establishment at Gotha, i. 167.

Petit, i. 107.

Petty, Sir William, statistics, i. 122; (see Arundel) collection of relics, 295; 'Political Arithmetic,' ii. 562 ; 564.

Pfeffer, IV.. labours of, ii. 165 ; cellular substances, 373 .

Pfleiderer, E., 'Philosophie des Heraklit vou Ephesus,' ii. 3.

Pflüger, E., "proteid" theory, ii. 426; "laws of reflex action," 519 ; on compound organic molecule, 611 .

Phalaris, Epistles of, Bentley's controversy about the, i. 169.

"Philanthropinism" of Basedow, i. 166.

Philip of Hesse, first Protestant university founded by, i. 159.

Phillips. See Combes.

Philosophical faculty, development of, in German universities, i. 164, 197.

'Philosophical Magazine and Journal of Sciences,' i. 41 , ii. $48,50,55,58,69$, $75,85,97,109$; on Caruot the elder, $139 ; 480$.

Philosophical theories, ii. 346 ; problems, 352,743 ; thought, geographical centre of, 750 .

Philosophy, definition of, i. 62,65 ; intermediate between science and religion, 71,73; and science, conflict between, 205; and science, 311 .

Phlogiston, i. 388 , ii. 153.

Phonetics, ii. 539.
"Phoronomie," ii. 5.

Phrenology, ii. 476 .

Phylotaxy and phylogenesis, ii. 308.

Physical aud chemical reasoning contrasted, i. 424.

Physical view of nature, ii. 95.

"Physical" method, ii. 428.

Physies and statistics, ii. 589.

'Physik, Annalen der,' Gilbert's, i. 41.

'Physik, Journal der,' Gren's, i. 41.

'Physikalische Gesellschaft' of Berlin, i. 42 .

Physiocrats, so-called, referred to, i. 16 ; ii. 529 .

Physiological, units, ii. 272 ; division of labour, 396 ; psychology, 512.

Physiology pre-eminently a German science, i. :216.

'Physique, Journal de,'i. 41.

'Physique, Observations sur la,' i. 41.

Phytotomy, ii. 260.

Piazzi discovers Ceres, i. 54, 82, 177, $182,423$.

Picard, Ch. E., 'Traité d'Analyse,' ii. 690.

Picard, Jean, calculations of, i. 97 ; astronomical constants, 322 ; "methods of dealing with astronomical errors of observation," 324 .

Picavet, F., 'Les ldéologues,' i. 149, 152, ii. 470 ; quoted, 47.2 .

Pictet, condensation of permanent gases, i. 316.

Piderit, Ph., mimicry and physiognomy, ii. $47 \pi$.

Pinel, medical nomenclature of, i. 131.

Pitcairu, mediciue in alliance with mechanics, i. 126.

Plana, luuar theory, i. 329.

Planck, Max, 'Das Princip der Erhaltung der Energie,' ii. 97, 99, 106, 197 ; 'Thermodynamik,' 142, 186; 159 ; labours of, 165 ; works of, 181 .

Planta, Martin, the forerunner of Pestalozzi, i. 258.

Platen, i. 213.

Plato, constructive system of, i. 75 ; views of Heraclitus, ii. $3 ; 4,246$; archetypes, 259; his mathematics, 633.

Playfair, John, scieutific work of, i. 229 ; criticisms of, on science in England, 231; review of Laplace's 'Mécanique céleste' quoted, 232 ; biographical, $i b$.; tribute to Colin Maclaurin, ib.; 234; quoted, 236 ; 270,272 ; 'Huttonian Theory of the Earth,'283, ii. 292, 356; 579.

Pliicker, Julius, geometry, i. $44 ; 187$; 
geometrical labours of, neglected in Germany, 242; spectrum analysis, 278 ; researches of, ii. 75 ; electrical researches, 189 ; on "singularities of curves," 641; 670 ; new geometry, 671 ; 672 ; deficient in elegance, 677 , 682 ; and Sophus Lie, 692 ; on higher curves, 700 .

Plutonists. See Neptunists.

Poggendorf, 'Annalen,' i. 43, ii. 128, 133, 169, 487 ; refused Helmholtz's 'Ueber die Erhaltung der Kraft,' i. 205 ; Dictionary of, silent about Avogadro, 428; refused Mohr's 'Ueber die Natur der Wärme,' ii. 107.

Poincaré, H., lectures on Maxwell's theories, i. 251 ; on indefiniteness of electro-magnetic theory, ii. 93 ; astronomical mechanies, 101 ; Paris Address, 1900, 188; discourse of, 199 ; quoted, 635; quoted on Weierstrass, 638 et seq.; 703, 705; on "function," 639 ; 686, 690 ; on Piemann and Weierstrass, 707, 708; 737.

Poinsot, ii. 5 ; "geometrical mechanics," 101 ; on synthetic method, 670.

Poisson, mechanies, i. $44 ; 188,345$; electricity, 347 ; "mécanique moléculaire," 359 ; 360 ; analysis of, 362 ; 370 ; Newton's law, 379; Fresnel's calculations, ii. 25 ; retired from commission on Fresnel's theory of transverse vibrations, 26 ; theory of elasticity, 31,$41 ; 32$; properties of ether, 33 ; referred to by Faraday, 69 ; formula of, 72 ; theory of electric and magnetic phenomena, 74 ; "Mémoire sur la Théorie lu Magnétisme" quoted, 75 ; referred to, $76 ; 474$; science of chances, 568 ; on convergency, 646 ; on Jacobi, 657 ; on synthetic metlood, $670 ; 686$.

Polarisation of light, ii. 22.

"Polarity," origin of the word, ii. 22 .

Polymorphism, i. 446.

'Polytechnic Journal,' Dingler's, ii. 134.

'Polytechnique, l'École, Journal de,'i. 41.

Poncelet, J. V., mathematics, i. 45 ; new science of geometry, 114; 187; definitions of horse-power and work, 310 ; 360, ii. 5; 'Traité,' 76, 660; 'Mécanique industrielle,' 100 ; practi. cal school of, $i t . ;$ his influence on practical mechanics, 101 ; thermotics, 118 ; first definite use of new conceptions of power and work, I37;
658 et seq.; his principle of continuity criticised, 660 ; quoted, $66^{\circ} 2$; on "homology" and "reciprocity," 663 ; 673 ; on ideal elements, 674 ; $684,685,692$.

Pond, not member of any university, i. 238.

Poole, 'Index to Periodical Literature,' i. 40 .

Pope, influence of, on German thought and literature, i. $21 \%$.

Popper, Jos., ii. 185.

Positivism, i. 307.

Potential, ii. 698.

Pouillet, Ohm's law, i. 365 ; influenced German thought, ii. 101 ; heat experiments, 357 .

Poulton, Weismann's Essays, ii. 372.

Power Series, Infinite, ii. 707.

"Power," the term, .introluced by Watt, ii. 99.

Poynting, Prof., contributions to Maxwell's electro-magnetic theory, ii. 72; 193; and 'Thomson's 'Text-book of Physies,' Sound, 489.

Practical problens, solidarity of, i. 32.

Preston, T., ii. 361 .

Prévost, theory of exchanges, ii. 46.

Preyer, Prof. W., theory of "Panspermia," ii. 369 ; school of Darwinism in Germany, 436 ; 470.

Priestley, chemical discoveries of, i. 115 ; 155 ; scientific discoveries of, 229 ; not member of any university, 238, 272 ; 'History of Optics,' 358 , ii. 9 ; follower of Boscovich, i. 359; and Lavoisier, 386, 387 ; effect of plants oll air, ii. 391 .

Prime numbers, ii. $72^{\circ}$ et seq.

Pringle-Pattison. See Seth.

Pringsheim, A., on theory of functions, ii. $693 ; 734,739$.

Priugsheim, N., observatious, ii. 447.

Pritchard, "immersion" system in microscope, ii. 228.

Probability, theory of, i. 118, ii. 566.

Prochaska, "reflex action," i. 292 ; ii. 519.

Proclus on Greek mathematicians, ii. 634.

Progress, intellectual, two factors of, $i$. 27.

Projection, method of, ii. 663 .

Projective and metrical geometry, ii. 668 ; properties, 717.

Proportions, fixed, rule of, i. 392 ; multiple, rule of, 398.

'Protogra' of Leibniz, ii. 277, 280. 
Protoplasm, i. 309, ii. 264; theory of, 444.

Proust, theory of fixed proportions, $\mathrm{i}$. 393 ; defeated Berthollet's doctrine of chemical affinity, 394; 398, 416.

Prout, organic analysis, i. 190; on hydrogen, 230; hypothesis of, 402 ; theory of nature of elements, ii. 192 ; Bridgewater 'T'reatise, 325.

Psychology, ii. 465 et seq.; mathematical, 498.

Psycho-physical aspect of nature, ii. 218, 465.

Psycho-physics, E. H. Weber's law of, i. 196 ; 198 , ii. 465 et seq., 469 ; of vision, 504; three facts impressed by, 545 .

Purkinje, founded first physiological laboratory, i. 1S3; 198, 208; follower of Baer, ii. 300 .

Pusey, E. B., quoterl on English and German writers, i. 261.

Puitter of Güttingen University, i. 165.

Pythagoras, unity of all existence, ii. 3 ; school of, 286 ; the octave, 490 ; his mathematical ideas, 633 .

Quantics and " tactics" in mathematics, ii. 683 .

'Quarterly Review,' literary criticism of, i. 84 ; 236,239 ; quoted on educational matters in England, 255; Young quoted, ii. 20.

Quaternions, ii. 654; introduced into Germany by Hankel, $712 ; 717$.

Quatrefages, de, of the "Association Française," quoted, i. 298.

Quesnay, economic system of, i. 16, 107.

Quet, experiments with vacuum tubes, ii. 190 .

Quetelet, statistics, i. 122 , ii. 563,588 ; $555,556,557$; theory of error, 574 ; theory of probabilities, 579 ; quoted, $580,581,587,607,609$; the "'mean man," 617.

Quincke, foam theory of, ii. 427 .

Rademacher, his empiricism in medical science, i, 210.

Rammelsberg, i. 174.

Ramsay, Prof., discovery of argon, i. 423.

Ramsden, i. 177 ; astronomical instruments, 322.

Rankine, Macquorn, improvement in steam-engines, i. 93; "thermodynamic function," 316 , ii. 169 ; the stean-engine, i. 331, ii. 133 ; theor- etical thermo-dynamics, 62 ; molecular vortices, 63,82 ; technical mechanics, 101 ; revival of interest in the ineas of "energy," 114 ; on the mechanical equivalent of heat, 128 ; Prof. Unwin's account of theories of, 135 ; elaboration of Joule's and Reg. nault's experiments, 137; energy, "potential" and "actual," 139, 140, 174 ; reply to Sir J. Herschel, 139 ; physical view of nature, 141 ; theory of energy, 166; 168, 173; heat engines, 175; mechanical analogies of heat, 178 ; entropy, 169,180 ; thermodynamics, 603 .

Raoult, researches of, ii. 164,165 .

Rathtke, ii. 300.

Piau, A., "Theorien der modernen Chemie,' i. 406, 414, 430, 455.

Rauber, 'Formbildung und Formstörung in der Entwickelung von Wirbelthieren,' ii. 401.

Ray, John, botanist, i. 282 ; classification of living beiugs, 288 .

Rayleigh, Lord, discovery of argon, i. 423 ; quoted, ii. 170 ; "free energy," 173 ; optical researches, 229 ; 'Sound,' $488,490$.

"Realschule," i. 166.

Réaumur, referred to by Voltaire, i. 105.

Reciprocity of figures, ii. 663; Gergonne on, 666 .

Records, contemporary, value of, i. 8 .

Redtenbacher, 'Dyuamiden System,' i. 433 ; influenced by Poncelet, ii. 101; heat, 178 .

Registration, ii. 561.

Regnaud, i. 150.

Reguault, chemistry, i. 44 ; 245 ; investigated specific heat of chemical compounds, 429: influenced German thought, ii. 101; experimental work of, 137; "Observations on Steam," 139 ; a founder of physical chemistry, 152.

Rehnisch, statisties, ii. 587.

'Reid, Thomas, Life and Writings of,' by Dugald Stewart, i. 84 .

Reiff, $R_{\text {. }}$, his history of series, ii. 646 .

Reiz, indebtedness to Bentley, i. 169.

Renaissance, period of the, i. 67 .

Renan, testimony to work of German universities, i. 225.

Rendu, Ambroise, 'Code Universitaire:' quoted, i. 150.

wi 14 enc.

Reports, annual, on scientific progress, i. 42.

Reproduction, ii. 443. 
Repsold, measurenents of, i. 322 .

Retrospect and prospect, ii. 741 et seq.

Reuchlin, i. 163.

Revett. See Stuart.

Pevolution, French, added the modern practical popularisation of science, $i$. 145.

Revolutionary theories not practical, i. 79.

Reye, 'Geometrie der Lage,' ii. 669.

Ribbeck, 'Frieclr. Wilh. Ritschl.,' i. 169,172 .

Ribot, 'Modern German Psychology,' ii. 495; 'Psychologie Allemande Contemporaine,' $511 ; 513$.

Richelien, his "metallic" interest in science, i. 105; first statistical bureat, ii. 561.

Richelot at Königsberg with Neumann and Bessel, ii. 54.

Richer, astronomical constants, i. 322 ; pendulum experiments of, 354 .

Richet, Ch., 'Physiologie des MIuscles et des Nerfs,' i. 293, ii. 519.

Richter, J. B., chemical equivalents, i. $189 ; 313$; theory of tixed proportions, 393 ; 398 ; atomic theory, 416 ; the "equivalent" of an element, 419.

Richter, W., theory of "Panspermia," ii. 369 .

Riecke, memoir of Plïcker, ii. 75 ; Éloge of Weber, 197.

Riemann, B., i. 45; 'Hypothesen ler Geometrie, 200; Fourier's series, 241 ; celebrated dissertation of, 243 ; views on ideas of space, 352 ; 'Werke,' ii. 63: researches into electrical phenomena, 67: 254, 635 ; and Cauchy, 693, 699; on Abelian functions, 699 ; his work, 700 ; his surface, 701; 704, 706; and Weierstrass compared, 707 ; on hypotheses of geometry, $710 ; 717,718$.

Riess, frictional electricity, i. 205 ; statical electricity and the Geissler tubes, ii. 191.

Rindfleisch, Ed. von, 'Arztliche Philosophie,' ii. 379,437 .

Ritschl, Friedr. Wilh., inrlebtedness of, to Bentley, i. 169 ; quoted, 172 ; conducted philological seminaries, 214; language, ii. 540 .

Ritter, Karl, comparative geography, ii. 226 ; extension of morphological view, $260 ; 300$.

Rober, construction of the heptagon, ii. 722 .

Robertson, Croom, calls Hobbes's the first English system of philosophy, i.
18; 282 ; 'Mind,' ii. 512 ; on Mün. sterberg's work, 522 .

Robertson, David, naturalist, i. $2 \$ 8$.

Roberval, referred to by Voltaire, 105 ; tanght at the Collège de France, 107.

Pobespierre, i. $10 \%$.

Robin, 'Iraité d'Anatomie générale,' ii. 266.

Robison, John, on Boscovich's theory, i. 358,359 ; publisher of Black's lectures, ii. 102 .

"Rochdale Pioneers," ii. 566.

Rochow, von, educational work of, i. 256.

Rogers, W. G., illustrations of Helmlooltz's theories, ii. 63 .

Rokitansky, Vienna school of nedicine, i. 198,208 .

Roman system of registration, ii. 561.

Romanes, 'Darwin and after Darwin," ii. $346 ; 436$.

Romanticism, reactionary movement of, i. 82 .

Romberg, merlical school of, i. 208.

Romé de l'lsle, contributions to crystal lography, i. 117,118 , ii. 241.

Römer, Claus, motion of light, ii. 10.

Fomme, Gilbert, quoted, i. 110.

Röntgen, discovery of $\mathrm{X}$ rays, ii. 92.

Roscher, 'Gesch. d. National-Oekonomik, 'ii. 555 ; statistics, 563.

Roschlaub inthencel by the Naturphilosophie, i. 207.

Roscoe, Sir H., 'John Dalton,' i. 417.

Rose, H., i. 174 ; the greatest analytical chemist of the century, 399.

Fose, H. aud G., chemists, i. 188.

Posenberger, 'Geschichte der Physik,'i. $308,359,433$, ii. $8,11,178,506$; 'Die moderne Entwickelung der elektrischen Principien,' 90 ; physical nature and "perpetual motion," 124 .

Rosenkranz on the encycloperdists, i. 34.

Ross, Sir James, confirms calculations of Gauss as to south magnetic pole, $i$. 331.

Pothmann, i. 157.

Rousseau, inthence on Herder, i. 50 ; gospel of Nature, 51; and the "Auf. klärung" period, 60 ; 107 ; destruc. tive revolutionary work of, 110 ; popularised botanising, 127 ; centre of reaction against school of Voltaire, Bufton, \&c., 145 ; 163 ; influence of, on German thought aud literature, 212 ; 253,257 ; valuable side of his ideas developed outside of France, 259 ; 285 , ii. 415 ; language, 536 . 
Roux, Wilhelm, 'Entwickelungsmechanik des Embryo,' ii. 401; 'Struggle of the Parts in the Organism,' 436; quoted, 444 ; "organicisme," 455.

Rowland, spectroscopic observatious, ii. 361 .

Royal lnstitution founded, i. 89, 264 . ii. 139.

Royal Society of Edinburgh, i. 269.

Royal Society Catalogue of Scientific Papers, i. 40 ; 'Trausactions' of, 41 ; founded, $89 ; 227,228$; unfavourably criticised by Babbage, 233 ; favourably criticised by Cuvier, 235 ; by Prof. Holl of Utrecht, 236 ; ii. 69 ; Kaspar Neumaun's statistical tables, 565.

Rubidium found by Kirchhoff and Bunserl, ii. 49.

Rückert, imitation of oriental poetry, i. 213 ; "Chidher" quoted, ii. 289.

Rudolf II., Emperor, and Tycho, i. 157 .

Rudolph, 'Grundriss der Physiologie, ii. 499 .

Rudolphi, ii. 230, 261.

Ruffini, Paolo, and theory of gromps, ii. 688.

Rühlmann influenced by Poncelet, ii. 101.

Rumford, Count (Beujamin Thompson), mechanical theory of heat, i. 83 ; 155 ; experiments of, 229 ; not mem. ber of any university, 238; 246 ; founded Royal Institution, 248, 264 ; the steam-engine, 331; the kinetic view of nature, ii. 7 ; investigations of the nature of heat, 102 ; "Inquiry concerning the Source of the Heat which is excited by Friction," 103 ; Dary's speculations on light and heat, 104 ; experiments utilised by Helm in his 'Energetik,' 109.

Runge, C., spectroscopic observations, ii. 361,362 .

Russell, Hon. Bertrand, his writings, ii. $653 ; 718,720,734,737$.

Russell, Lord John, Royal Commission of Inquiry into University Reform, i. 254.

Rutherford, spectroscopic observations, ii. 361.

Rydberg, ii. 362.

Sabine, magnetic experiments, i. 230 .

Sachs, Julius, the effect on biological science of the discovery of the cell, $i$. 195; 'Geschichte der Botanik,' 209, ii. $212,223,227,230,231,246,260$,
265,269 ; importance of the spiral theory, 224; cellular theory, 262; of Hofmeister, 321; quoted, 338 ; 'Lectures on Plant Physiology,' 408. Sacro Bosco, Joamues, ii. 287.

Saint-Hilaire, A uguste de, "Morphologie végétale," ii. 2224.

Saint-Hilaire, Etieune Geoffroy, germ of Darwinian theory, i. $137 ; 200$; and the "Origin of Species," 201; and Cuvier, ii. 239 ; appreciation of Goethe's work, 244 ; controversy with Cuvier, 246 ; morphological analogies, 251 ; labours of, 253 ; quoted, 258 ; unity of orgauisation, $267 ; 301 ;$ and Buffon, 309; 321, 322 ; natural selection, $330 ; 364$.

Saint-Hilaire, Isidore Geoffroy, ii. 322.

Saint Pierre, Bernardin de, taught morals at the École normale, i. 112.

Saint Simon, co-operation, ii. 566 .

Saint-Venant, Barré de, quoted on Boscovich's theory, i. 359 ; properties of ether, ii. 33; "elastic solid" theory of ether, 54 ; synthetic method, 100.

Salisbury, Lord, Oxford Address, ii. 347.

Salmon, George, text-hooks on geometry translated by Fiedler, i. 44 ; scientific work of, and Pluicker, 242; Dublin mathematical school, 275; German edition of his works, ii. 669,685 ; introduces Chasles's work, 673 ; great merit of his text-books, 685; Mieyer on, $i b$.; Italian edition of his works by Brioschi, $i b$.

Sameness and variation, ii. 607.

Sampson, R. A., 'Proceedings of the Society of Antiquaries,' ii. 282.

Sandersou, Sir J. Burdon, quoted, ii. 428, 429, 439 ; "Elementary Problems of Physiology" quoted, 442; 565 .

Sanskrit, discovery of, ii. 538 .

Santi-Linari, aniual maguetism, ii. 475.

Sarcode, ii. 264.

Sartorius von Waltershausen on Gauss, i. 181,183 , ii. 631 .

Saussure, de, ii. 247 ; experiments, 391.

Sauveur, referred to by Voltaire, i. 105.

Savage tribes, history of, i. 3 .

'Savants, Journal des,' i. 41.

Savart, theory of elasticity, ii. $31 ; 193$.

Savigny, i. 162; indebtedness of, to Gibbon, 169.

Sayce, 'Iutroduction to the Science of Language' quoted, ii. 539, 540.

Scaliger, Joseph J., influence of, on German thought and literature, $\mathrm{i}$. 
212,226 ; services to classical learning and criticism, $222 ; 295$.

Scheele, forerunner of Berzelins, i. 391.

Scheidt, edition of 'Protogæa,' ii. 280.

Scheiner, J., 'Astronomical Spectroscopy;' ii. 46, 362; quoted, 49; 'Der Bau des Weltalls,' 282.

Schelling, F. W. J. von, on the province of philosophy, i. 36 ; on position of philosophy, 38; treated science from a metaphysical standpoint, 43 ; philosophy of, influenced by Herder, 51 ; philosophical writings of, $83 ; 162$; speculative tendency of, 178 ; 'Ileen zu einer Philosophie der Natur,' 179 ; philosophy of, 204; 207; influenced by Spinoza, 212; benefactions to historical sciences, 215 ; intluence of, ii. $225,494,500$; and Goethe's views, 245, 255; 'Natur-philosophie,' 304, 315 ; evolution, 354 ; 508 .

Schenstone, IT. A., 'Justus vou Liebig, his Life and Work,' ii. 391, 393.

Schering, E., 'C. F. Gauss und die Erforschung des Erdmagnetismus,' i. 181, 331; address on Gauss's cen. tenary, 304; correspondence with Helmholtz, ii. 710 et seq.

Scheuchzer, correspondence with Leibniz quoted, ii. 281 .

Schiller, style of, i. 51; writings of, 83, 84; educated with Cuvier, 133 ; "The German Muse" quoted, 157; Kant's æsthetical philosophy, ii. 535; 'Wallenstein's Tod' quoted, 586.

Schimper, K. F., "spiral theory," ii. 223.

Schlegel, A. W. von, Berlin lectures, i. 84; on Georg Forster, 179; 263; researches of, ii. 542 .

Schlegel, Fr., on Goethe's school, i. 84; made Shakespeare familiar to German readers, 212.

Schlegel, Victor, 'Hermann Grass. mann,' i. 243; on Grassmanu, ii. $656^{\circ}$; on non-Euclidean geometry, 714 .

Schleicher, August, 'Morphology of Language,' ii. 540, 541.

Schleiden, Mathias, cellular theory of, i. 194,309 , ii. $262,263,299$; i. 200 ; 'Botany as an Inductive Science,' 209 ; biological discoveries of, 217 ; mechanical view in biology, $218 ; 220$; refers to Brown's discovery, ii. 264; theory of cell formation, 265 ; ultimate identity of structure of animals and plants, 267 ; definition of a cell, $370 ; 402,403,408$.
Schleiermacher, F., new era of education in Germany, i. 38 ; philosophical writings of, 83 ; religious revival preached by, 203; scientific ideal of, 211 ; educational significance of his writings, 258 ; 263 ; psychology, ii. 495.

Schlomilch, 0., i. 209 .

Schlosser, F. Chr., 'History of the Eighteenth Century,' i. 5.9.

Schlözer, Ludwig August, of Göttingen University, i. 165 ; statistics, ii. 555.

Schmidt, F., and P. Stäckel publish Bolyai's correspondence, ii. $65^{2}$.

Schnidt, Joliannes, on August Schleicher, ii. 540.

Schmidt, Karl, 'Geschichte der Paidagogik,' i. 166, 256.

Schönflies, A., ii. 734; on G. Cantor's work, $730^{\circ}$.

Schönlein, Lucas, metaphysical leanings of, i. $196 ; 198$; intluenced by the N'aturphilosophie, 207; freed under the influence of French science, 208.

School literature, reform in, i. 44.

School of Oriental Languages in France, i. 113.

School of philology, modern German, i. 172.

School, polytechnic, German, first established at Vienna, i. 166.

Schools, German, i. 166.

Schools of thought in Germany, i. 167.

Schopenhauer, A., animation of all nature, ii. $369: 470$.

Schrüder, E., ii. 737.

Schubert, H., ii. 734

Schultze, Max, protoplasmic theory, ii. $371,443$.

Schumacher, H. C., i. 45; 'Astronomische Nachrichten,' 167 ; correspondence with Gauss, 185, ii. 652; letter from Gauss on telegraph, i. 304.

Schiitte, German translation of Gino Loria's work on geometry, i. 275.

Schwann, Theodor, extended cell theory to animals, i. $195 ; 198,200$; the head of the modern physiological school, 217 ; mechanical view in biology, 320 ; cellular theory, 309, ii. 263 ; identity of all living structure, 209; discovery of the micleus referred to, 264 ; theory of cell formation, 265 ; ultimate identity of structure of auimals and plants, 267; definition of a cell, $371 ; 402,403$; microscopical researches, 418; 'Microscopical Researches,' $419,420,423$; conception of the cell, 422 ; "Metabolism," 442. 
Schwarz, H. A., on Dirichlet's principle, ii. 703 ; Weierstrass's letter to, $i b_{.}$; on Bolzano, 709.

Schweikart, ii. 713.

Schwerd, 'Die Beugungserscheinungen aus den Fundamentalgesetzen der Undulationstheorie analytisch entwickelt ' quoted, ii. 26.

Schwoerer (see Faudel), ii. 134.

Science now international, i. 19, 303; and life, 31; and poetry, ib.; as opposed to other thought, 69 ; the meaniug and use of the word, 89,90 ; Englisl and Continental notions of, 91 ; schools of, in France, 106 ; schools of, promoted by Governments of Revolution, 108; during the Revolution and under the First Empire, 138; popularised by France, 142; German, not patronised by royalty, 157 ; and "Wissenschaft," 168 ; and exact science, 171 ; Gernian, cosmopolitan, 189; in Gernany, 202; and philosophy, conflict between, 205 ; and history, relations of, $2 \cup 6$; for its own sake, 211 ; thoroughness of German men of, 213; and teaching, 214; and philosophy, 215, 311; organisation of, abroad, 226; English, in the early part of nineteenth century, 229; alleged decline of, in England, 230; French, praised by Cuvier, 231 ; English, eriticisms of Playfair, $i b$.; criticisms of Babbage, 233; decline of, in Eugland, 'Edinburgh Review' quoted ou, 234; in England favourably criticised by Cuvier, $i b$.; by Prof. Moll of Utrecht, 235; Prof. Moll on difference between eulture of, in France and England, 237; English, indivilual character and practical teudency of, 251 ; Euglish, peculiarities more marked in early part of century, 252; importance of British contributions to, 276 ; diffusion of scientific knowledge on the Continent, 276 ; isolation of English men of science, 277 ; philosophy of, 306 ; interests which promote, 326 : practical interest in, 328; physical, applied to medicine, ii. 208; abstract, 550 ; of large numbers, 555 .

Science, exact, reception of, in Germany, i. 175 ; absent from German universities in the eighteenth cen. tury, 178.

Sciences, the descriptive, ii. 203 ; natural and mental, separation of the, 534.
Scientific, reasoning, i. 45 ; periodicals, 180: associations, dates of, 227 ; spirit in the first and second half of the century, 302 ; ideas, special, 306 ; antiquity of leading ideas, 312 ; spirit in business, ii. 553 .

Scoteh school of natural philosophy, ii. 141 ; activity of, 148 .

Scott, Sir Walter, i. 82 ; romantic school of, 84; 'Edinburgh Review,' 273.

Secchi, spectroseopic observations, ii. 361.

Sedgwick, A., "A Discourse on the Studies of the University of Cambridge,' i. 263 ; 267 ; worked in harmony with Analytical Society, 271 ; criticism of 'Vestiges,' ii. 319.

Seebeck, electricity and heat, i. 363 ; thermo-electricity, ii. 143 ; the siren, 487.

Seeley, J., 'Life of Stein,'i. 38.

Séguin, heat units, ii. 109 ; indestructibility of force, 111; physiological processes, 390.

Selborne, White's 'Natural History of,' i. 237 .

Selection, "natural" and "sexual," ii. 336 ; natural, within the organism, 435; Maxwell's process of, 598 .

Sellmeier, W., anomalous dispersion of wave-motion, ii. 53 ; researches of, 54.

Seminaries in Germany, i. 214.

Semler, Archdeacon, established the first " Realschule" at Halle, i. 166.

Sensation, Johannes Müller's law of specific energies, i. 198; Weber's law of, 200 ; localisation of, ii. 507.

Sense-perception, i. 199.

"Sensualistes," ii. 323.

Serres, 'Anatomie Comparée du Cerveau," ii. 317 ; "law of biogenesis," 349.

Serret, his 'Algèbre Supérieure,' ii. 686.

Servois, ii. 660,711 .

Seth, A., on Fr. Nietzsche, ii. 287.

Shaftesbury, i. 145.

Shakespeare, influence of, in German thought and literature, i. $212 ; 261$, ii. 251 ; the word "statist," 555 .

Shelburne, Lord, quoted, ii. 56:.

Shelley, P. B., freshness of individual thought of, i. 76 .

Siemeus, Werner, submerged cables, i. 329.

Siemens, William, ii. 179.

Silvius, chemistry in alliance with medicine, i. 126. 
"Simplex sigillum veri," i. 401.

Simpson, Sir J. Y., introduced chlor. otorm, i. 93.

Simson, Robert, Scotch nniversity professor, i. 272 ; and Stewart, ii. 658.

Skoda, i. 198, 208.

Sloman on the invention of the calculus, i. 101.

Smellie, William, 'Edinburgh Magazine and Review,' i. 273.

Smiles, 'Life of 'Thomas Elwards,' i. 287.

Smith, Adam, imported ideas from France, i. 16; intercourse with French thought, $268 ; 272$; influence of, 273 ; ii. 415 ; human culture, 529.

Smith, H., translation of Schwann's principal work, ii. 263 ; on congruence, 723 ; his report, $i b$.

Smith, Sydney, lectured at Royal Institution, i. 249, 264; 'Edinburgh Review,' 273.

Smith, William, on 'Strata,' i. 230; father of English geology, 291 ; study of fossil remains, ii. 225 ; tabular view of the British strata, 293.

Snell, deflection of rays of light, i. 356.

Société Philomatique, bulletin of, i. 41.

Society, Royal, i. 227.

Socrates, ethical philosophy of, ii. 4.

Soemmering, ii. 247 ; intluences Herder, 532.

Sohnke, L., 'Entwickelung der Theorie der Krystallstructur,' i. 443.

Sommer, edition of Herschel 'On the Construction of the Heavens,' ii. 283.

Sophocles, i. 261.

Sound and colour, analogy between, ii. 489.

Sonnd and light, mechanical difference between, ii. 30 .

South, not member of any university, i. 239.

Southey, 'Thalaba,' i. 84.

Spanheim, recognition of Bentley, i. 169.

Species, changes of, services of Lamarck and Saint Hilaire to the study of, debatable, i. 201.

Spectrum analysis, i. 277, ii. 45 et seq.; clue to, $47 ; 359$.

Speculation, meaning and scope of the term, i. 64 .

Spedding, James, i. 282.

Spencer, Herbert, first English system of philosophy, i. 48; on the "Un. knowable," 53, ii. 326 ; constructive ideas of, i. 81; system of, ii. 205; works of, 210 ; vocabulary and irleas of evolution, 214; conceptions of, 246 ; 'Principles of 13iology' quotel, 270 ; "physiological units," 272,424 , 610 ; philosophy of, 279,346 ; quoted, 288 ; 'Biology,' 322, 323, 406, 438; 351 ; "survival of the fittest," $i$ \%; "Factors of Organic Evolution," 353 ; dynamical aspect of science, 355 ; "On the Nebular Hypothesis," 358; "direct equilibration," 436; law of limit of growth, 445 ; theory of evolution, 455; and Weismann, 460; anthropological work, 497; 511 ; study of sociology, 530; 607, 608, 749.

Spinoza, influence of, on German thought and literature, i. 212; on German philosophy, ii. 205; 251; animation of all natter, 369 ; psychophysical parallelism, 519 ; 535.

Spix, morphological analogies, ii. 251.

Spon, Jacob, arehæologist, i. 295.

Sprengel, Chr. C., ii. 230,261 ; fertilisation of plants, 338 ; investigations of, 415.

Spurzheim, Joh. Chr., i. 136 ; phrenology, ii. 477,479 .

Squares, method of least, ii. 576.

Stael, Mme. de, and German literature, i. $17 ; 225$; writings of Herder, ii. 531.

Stägemann, i. 45.

Stahl, animist (medicine), i. 126 ; elaborated the phlogistic theory, 387; "Anima," ii. 388, 503.

Stair, Earl of, first agricultural organisation in Scotland, i. 284.

Stas, J. S., nieasurements of, i. 403.

Statics, ii. 5; and dynamics, 144.

Statistical, methods, used largely by Napoleon, i. 153; view of nature, i. 438 , ii. 546,548 ; application in physics, 589; knowledge of natıre, 600 .

Statistics, beginning of science of, $i$. 121 ; ii. 548 et seq. ; in France, Germany, and England, 562; social, 583 ; pretensions of, 586 .

Staudt, C. G. C. von, his geometry, i. $44,181,275$; and Gauss, ii. 652 ; on imagiuary elements, $661 ; 669$; his work expounded by Reye, Liiroth, and Fiedler, $i b . ;$ and Cayley, 718 ; Klein on, $i b$.

Stebbing, Thomas R. R., 'Naturalist of Cumbrae,'i. 289. 
Steffens, H., on Paris at the close of the eighteenth century, i. 17 ; 'Autobiography,'39; development of Goethe's views, ii. 256 ; natural philosophy, 315 ; erolution, $354 ; 508$.

Stein, H. Fr. K. voll, attitude of, to national idealism in Germany, i. 39 ; quoted on Humboldt, 263.

Steiner, Jacob, geometry, i. 44 ; new science of geometry, 114; 163; and Creile, 186, 187 ; neglect of, in Germany, 213 ; against analysis, ii. 632 ; his niethad, 662; Geyser on, ib.; his great work, 667 ; on isoperimetrical problems, $669 ; 672$; his theorems proved by Cremona, 681 .

Steinheil, measurements of, i. 322.

Steinthal, psychologist, ii. 497; the objective mind in history, 530 .

Stephen, Leslie, i. 25 ; on Hume, 47.

Stephenson, George, the "Racket," i. 303.

Stereo-chemistry, i. 447.

Stevin, Simon, 'La Disme,' ii. 645; reconmends decimal system, $i b$.

Stewart, Balfonr, spectrum analysis, i. 278 ; "radiant heat," ii. 46 ; physical view of nature, 141,601 .

Stewart, Dugald, works of, i. 83 ; quoted, 359 ; ii. 287,601 .

Stewart, Matthew, forerunner of Carnot, ii. 658 .

Stieda, L., 'Life' of von Baer, ii. 300.

Stirling, James, ii. 572.

Stirp, theory of the, ii. 614 .

"Stoffwechsel," ii. 395 ; older ideas corrected, 397.

Stoics, "cyclical" view of the, ii. 286.

Stokes, Sir G. G., i. 274 ; spectrum analysis, 277 , ii. 49 ; properties of ether, 31; quoted, 32, 592; 33; 'Burnett Lectures on Light' quoted, 37 ; "double refraction," 43; lines of sodium, 47, 48 ; translation of Foncault's and Kirchhoff's memoirs, 48 ; on emission and absorption of light rays, 50, 51; invented the term fluorescence, 52 ; referred to, 54,55 ; on whirling motion, 58 ; on undulatory theory, 195; optical researches, $229 ; 630$.

Stoll, Max., i. 208.

Stolz, O., 'Grössen und Zahlen,' i. 275 ; and Weierstrass, ii. 703 ; or Bolzano, $709 ; 726$

Stölzle, 'K. E. von Baer und seine Weltanschanung,' ii. 300.

Stoney, Dr Johnstone, introduces the term "electron," ii. 193; use of recent microscopic appliances, 229.

Stout, G. F., "Herbart compared with English Psychologists and with Benelse," ii. 495, 497 ; "Analytic Psychology,' 528.

Stow, Normal School at Glasgow, i. 257.

Strasburger, E., embryological studies of, ii. 227; "idioplasma," $448 ; 459$.

"Struggle for Existence," ii. 332, $33 \dot{3}$.

Struve on methods of the astronomers of Greenwich Observatory, i. 99.

Stuart, Gilbert, 'Edinburgh Magazine and Review,'i. 273.

Stuart and Revett, archæological explorations of, i. 295 .

Study, E., referred to, ii. 654 .

Sturm, J. C. Fr., recognised merits of Green's work, i. 247; appreciated educational work of the "Order of Jesus," 256.

Substitution, chemical, i. 409.

Substitution, principle of, in mathematics, ii. 686 .

Substitutions, Jordan's treatise on, ii. $686,689,692$.

Sully, Duc de, doctrine of averages, ii. 561 ; political statistics, 563 .

Sully, Janies, article "Evolution" in 'Encyclopxdia Britannica,' ii. 279; "Herder," 533.

Sun, heat of, ii. 357.

Süssmilch, Pastor, the divine origin of language, ii. 536; 'On the Divine Order,' 557, 563; political arith. metic, 585 .

Svieten, G. v., i. 208.

Swan, spectrum analysis, i. 278 .

Sybel, H. von, 'historische Zeitschrift,' i. 159.

Sydenham, i. 272.

Sylow, L., on Abel, ii. 649 ; on Abel and Galois, 686.

Sylvester, J. J., developed theories of Boole, i. 247; on mathematics, ii. 629 ; 631 ; on invariants, 676 ; the proper bilsiness of mathematics, 679 ; proves Newton's theorem, 681; on determinants and Hesse, $683 ; 691$.

Symbolism, chemical, i. 417.

Syme of Edinburgh University, i. 272.

Symington built the tug "Charlotte Dundas," i. 303.

Symnetrical formulæ, ii. 681.

Tacitus, a model historian, i. 7.

Tait, P. G., 'Sketch of Thermodynamics,' i. 376 , ii. $167,173,175$; on 
"action at a rlistance," i. 380 ; "Properties of Matter,'388, 425 ; "Kinetic 'Theory of Gases," 438; "kinetics," ii. 5 ; 'Light,' 11, 592 ; 'Light ' quoted, 13,36 ; criticism of Tyndall's theory of heat, 57 ; translation of Helmholtz's memoir on vortex motion, 58 ; memoir of Rankine, 62 ; 'Recent Advances of Physical Science,' 63, 106, 108; 'On Knots'' 64; 'Recent Advances of Physical Science' quoted, 66 ; 'Sketch of Thermodynamics,' controversy regarding, 97 ; 'Dynamics,' 99 ; and 'Tynrlall and others, 107 ; computations of Séguin, 109 ; quoted on the relative values of the terms "force" and "energy," 116 ; perpetual motion defined, 124 ; preface to Rankine's papers, 133; (see Clausius), 135 ; physical view of nature, 141 ; 'Heat' quoted, 591.

Tait and Crum Brown, Memoir of Thomas Andrews, ii. 162.

Tait and Stcele, 'Dynamics of a Particle,' i. 101, ii. 141.

Tait and Thomson. See Thomson and Tait.

Tait's 'Edinburgh Magazine 'published, i. 273 .

Talbot, solar spectrum, i. 278.

Talleyrand, public instruction, i. 109 ; higher aims of, not realised, 112.

Taunery, Jules, his lectures on theory of functions, ii. $704 ; 737$.

Tauchnitz, edition of ancient classics, $i$. 167.

Taylor, Bayard, 'Fanst' quoted, i. 52.

Taylor, Brook, i. 101.

Taylor, Charles, on continuity, ii. 660 .

Taylor, 'Scientific Memoirs,' i. 325, ii. 263 ; series of, 646.

Telegraph, tirst, i. 92.

Tennyson, mature thought of, i. 76 .

Tenon, i. 107.

"Tension," ii. 138.

'Terquem, ii. 660.

'Terrestrial view, ii. 369.

Teubner, editions of the ancient classics, i. 167 .

Theretetns, Proclus on, ii. 634 .

Thénard, practical discoveries of, i. 147 ; organic analysis, 190 ; 'Chemistry,' 200 ; ii. 508 .

Theological faculty in German universities, ii. 197.

Thermodynamics, ii. 62 ; two laws of, 128.

Thermo-elastic phenomena, ii. 142.
Thermo-electric plienomena, ii. 142.

Theta function, Jacohi's, ii. $619 ; 696$.

Thévenot, original member of Paris

"Acarlémie des Sciences," i. 223.

Thibalud, i. 162.

Thibandean quoted, i. 113; 'Le Consulat et l'Empire,' 149, 152.

Thiersch, Fr., i. 162 ; conducted plilological seminaries, 214.

Tholuck, 'Das akademische Leben thes $17^{\text {ten }}$ Jahrhunderts,' i. 163.

Thomasius represents spirit of Bacon and Leibniz at Halle, i. 160.

Thompson, Benjamin. See Count liumford.

Thomsen, I. L. P., a founder of physical chemistry, ii. 152; chemical affinity, 171.

Thomson and 'lait, 'Natural Philosophy,' i. 45, 101, 274. 316, 318, 376 , ii. $61,99,144,152,153,184$, 358 ; the term "kinetics," 5 ; referred to, 62,148 ; influence of, 145 .

Thonison, J. A., 'Science of Life,' ii. $228,27 \mathrm{I}, 337,338,348,349,370,436$, 447 ; the term "homology," 259 : "Cell and Protoplasm," 266; 298; "embryology," 299; quoterl on vou Baer, 303; 'Evolution of Sex'' 344 ; 'Science of Life' quoted, 448, 455, $458 ; 459$; on "stirps," 614 .

Thomson, James, harmonic analysis, i. 330 ; leat and "perpetual motion," ii. 126 ; prediction, 126,170 ; physical view of nature, 141 ; "Crystallization and Liquefaction," 142 ; theory of energy, 166.

Thomson, J. J., on vortex motion, ii. $63,65,183$; Princetown lectures, 190 ; 'Researches,' 191; 'Discharge of Electricity through Gases,' 192 ; electrical researches, 362 .

Thomson (the poet), i. 285.

Thomson, Prof. Thos., i. 18s; and Dalton, 245 ; the atomic theory, 425.

Thomson, Wm. (Lord Kelvin), on chemical laboratories, i. 188; and Helmholtz, 199, ii. 149 ; the conservation of energy, i. 201 , ii. 128,142 ; Fourier's series, i. 241 ; Green's treatise, 246 ; and Joule, 265, 434, ii. 110 ; Faraday's "lines of force," i. 266, ii. 71 ; referred to, i. 272 ; his work, 274 , ii. 133 ; on discovery of spectrum analysis, i. 277 ; telegraphic connection with America, i. 303; absolute scale of temperature, 309, 315; "vortices," 312, 313; absolute measurements, 323 ; submarine tele- 
graplly, 329 ; 'Popular Lectures and Addresses,' 330 , ii. 61 ; improvements in mariner's compass, i. 331 ; mechanical theory of gravitation, 344 ; Boscovich's theory, 358 ; electrical measurements, 366 ; cohesion and capillary attraction, 376 ; on "capillary attraction" quoted, 425; "chirality," 432, ii. 22 ; "On the Size of Atonı," i. 437; "Steps towards a linetic 'Theory of Matter," 456 ; quoted, ii. 39 , I82, 184, 190 ; sodium, 48 ; wave-motion, 53 ; optics, 55 ; vortex theory, $5 \overline{7}, 58,63$; on gyrostat, 61 ; thermodynamics, 62,603 ; diamagnetism, 74; on "permeability," 75; electro-magnetics, 77 ; Faraday and Clerk-Maxwell, 78,79 ; reprints of papers quoted, 803; physical lines of force, 81 ; electrical researches, 86; "vortex filaments," 89 ; vibrations of the ether, 91 ; independence of Mayer's writings, 97 ; and Mayer's hypothesis, 109 ; "energy," 114; "work" and "energy," 115; Mayer, and Joule, 116; absolute measurements in thermotics, 117 ; Carnot's 'Puissance motrice,' 118 ; dissipation of energy, 119, 131, 132, 364, 598; Sacli Carnot's heat theory, 123; perpetnal motion, 124 . 126 ; experiment, 127 ; Sadi Carnot, 130 ; experiments of Jonle and Reg. nault, 137 ; "potential" and "actual" energy, 139; physical view of nature, 141 ; Regnault's measurements, 152 ; 167 ; thermodynamic "motivity," $168,169,594$; "free energy," 173 ; "available energy," and "entropy," 174,$594 ; 175,179,184$; ether theory, 196 ; recognition of Kant, $284 ; 296$; "On Geological Time" 356 ; "Mechanical Energies of the Solar System," 358 ; on the spectroscope, 362 ; Glasgow Address quoted, 363; cosmical origin of life, $369 ;$ on the dissipation of energy, i. 309 ; ii. 52 , 404 ; irreversibility of natural processes, 593; 699; his theorem and Dirichlet, $700 ; 704,708$.

Thomson, William, and Sir G. G. Stokes, contributions to mathematical physics, i. 274; and Tait: 'Natural Philosophy,' $i b$.

Thorpe, 'Essays in Historical Chem. istry,' ii. 158.

Thought, the hidden world, i. 1; the only moving principle, 2; Max Iiuller on definition of, 4 ; many meanings of, 5 ; forgotten and unexpressed, 8 ; value of contemporary records of, 10; unity of, a product of the nineteenth century, 16; equivalents in German and French, 24; conception of, not specifically English, 26 ; definition of, 33 ; not exhausted by science or philosophy, 66 ; unmethodical, 68 ; religious, 69 ; personal or subjective, 70 ; scientific, philosophical, and individual, 72 ; of nineteenth century characterised, 77 ; constructive, not destructive, 80 ; exact, historical, and critical habits of, 222 ; characteristics of higher mental work in England, 239 ; characteristics of English, 249; scientific, absence of schools of, in England, 250 ; history of, ii. 627 ; not history of knowledge, 628 .

Thouin, agriculture at the École normale, i. 112.

Thucydides, a model historian, i. 7 .

Tiedemann, Fr., chemistry of the living body, ii, $391 ; 317$.

'Tilloch, 'Philosoplical Magazine,'i. 41.

"Timbre," ii. 488.

Tisserand, 'Comptes Rendus,' i. 377 ; quoted on Newton's law, 378.

Titchener, E. B., criticism of MIüsterberg's work, ii. 522 .

Titius, Daniel, astronomical formula of, i. 422 .

Tocqueville, A. de, quoted on contemporary records, i. 10.

'Todhunter, Isaac, his 'Histories,' i. 91; 'History of the Theories of Attraction,' 98, 99, 308, ii. 698 ; theory of probabilities, i. 120, ii. 568 ; 'History of the Theory of Probability,' i. 234 ; 'Life of Whewell,' $236,262,306$; theory of elasticity, ii. 30; on Young's style, ib.; on English science, $i b$.; "History of Elasticity,' 33 ; quoted, 43.

Todhunter and Pearson, 'History of the Theory of Elasticity,' i. 376 , ii. 43 , 56.

Tooke, Horne, on words, i. 21 ; the 'Diversions of Purley,' ii. 537.

Tour, Cagniard de la, the siren, ii. 487.

Traube, medical thermometry, ii. 389.

Treitschke, 'Deutsche Geschichte,' i. 312.

Trembly, ii. 418.

Trench, Archbishop, on words, i. 21.

Treviranus, G. R., 'Biologie,' i. 194 ; identity of all sciences of organic life, ii. 217 ; 230, 261; biological 
researches of, 313 ; genetic view, 321 ; evolution, 327.

Treviranus, L. C., botanical labours of, ii. 218.

Truth, the search after, not the end of knowledge, i. 29.

Tschirnhausen, referred to, i. 101.

Tuibingen school of theological criti. cism, i. 162.

Turgot, founded the École des Ponts et Chaussées, i. 107 ; neglect of, by Napoleon, 149 ; statistics, ii. 57I; 573.

Turner disproves Prout's hypothesis, i. 402.

Tycho, a forerunner of Bacon, i. 94 ; of Kepler, 157; 317 ; discovered variable stars, 327 .

Tylor, E. B., anthropologist, ii. 497 .

Tyndall, John, 'Heat,' ii. 57; aur Faraday, 77; on Mohr's and Mayer's, \&c., scientific work, 107 ; computations of Séguin, 109 ; his works translated into German, 148 ; 405 ; ubiquity of life, 452 ; "tone," 488.

Type theory in chemistry, i. 411 .

Ueberweg and Beneke, ii. 495 ; 512.

Ukert (see Heeren), i. 167.

Ulrich, Duke, reconstituted University of Tübingen, i. 159.

Units, living and lifeless, ii. 620.

Unity of human interests, terms for, $i$. 33.

Universities and high schools, relations of, i. 166.

Universities, Belgian, i. 161.

Universities, British, and others, dates of, i. 228.

Universities, Danish, i. 161.

Universities, Dutch, their influence on German culture, i. $160 ; 161$.

Universities, English, unique character of, i. 254.

Universities, German, foundation of, i. $158 ; 162,197$; testimonies to the great work of, 225 .

Universities, Norwegian, i. 161.

Universities, Russian, i. 161.

Universities, Scotch, i. 160, 267, 271.

Universities, Swedish, i. 161.

Universities, Swiss, retarded develop. ment of, i. 163.

University, Johns Hopkins, Lord Kelvin's lectures, ii. 55.

University of Athens, i. 161.

University of Geneva, i. 160.

University of Göttingen, i. 164, 165, 175 ; prize essays on dynamics, ii. 97 .
University of Halle, i. 165.

University of Kasan, i. 161.

University of Maros Vásírhely, i. 161.

"Unknowable," ii. 326 ; or unknown factor, 375 .

Unwin, W. C., "The Development of the Experimental Study of Heat. Engines," i. 331 ; theories of Rankine and Clansius, ii. 135.

Valenciennes, Bell's theorem, i. 293.

Valeucy, i. 447.

Valmont de Bomare, i. 143.

Valson, his Life of Canchy quoted, ii. 637.

Van't Hoff, 'La Chimie dans l'Espace,' i. 397 ; 'Die Lagerung der Atome im Raume,' 431 ; the carbon tetrahedron, $450,451$.

Variation, ii. 331, 343 ; discontinuous, 623.

Variations, calculns of, ii. 670 .

Varnhagen von Ense quotes Kant, i. 45 ; memoirs of, $2 \overline{7} 9$.

Vasiliev, A., Address on Lobatchévsky, i. 161 .

Vauquelin, practical discoveries of, $\mathrm{j}$. 147.

Vector, ii. 655 : analysis, 73,655 .

Venn, Joln, 'The Logic of Chance,' ii. 569.

Verdet, M., 'CEurres de Fresnel,' quoted on Euler, ii. 9; referred to, 14 ; quoted, 25 ; history of undulatory theory, 26 ; 'CEuvres de Fresnel,' 26; quoted, $27,41,42$.

Veronese, G., ii. 737.

Versification, German, catholicity of, i. 213.

Verworn, Max, quoted, ii. 423: quoted on foam theory, 427 ; 'General Physiology' quoted, 445 .

'Vestiges of Creation,' published, ii. $318 ; 323,327$; and natural selection, 330.

Vicq d'Azyr, i. 107; forerunner of Cuvier, 147; 200; pioneer of the mechanical view in biology, 219; auatomist, ii. 218 ; quoted, 255.

Vieweg, publishers, ii. 300.

Villemain, review of eighteenth - century literature, i. 59; quoted on Napoleon's educational projects, 151 .

Villers, 'Coup-d'reil sur les Úniversités d'Allemagne,' i. 225.

Vinci, Liouardo da, mathematics and science, ii. 5 ; vision, 506.

Vines, S. 1I., ii. 459.

Virchow, Rudolf, "cellular pathology," 
i. 195 , ii. 265,376 ; i. 198,208 ; "Autonomy of the Cell," ii. 395; 'Cellular Pathology' quoted, 402; 444 ; progress of biology, 463 ; quoted by Darwin, 610 .

Virey, indebtedness of Cuvier to, i. 130; importance of nervous system, ii. 237 .

Virgil quoted, ii. $28 \pi$.

Vischer, Fr. 'T., i. 162.

Vital force, i. 218.

Vitalism, extreme, ii. $3 s 8$.

Vitalistic, aspect of nature, ii. 217 ; 353 ; view of nature, 368 ; idea of Bichat, $383 ; 386$.

Vogel, A., address on Liebig, ii. 391.

Vogel, H. C., spectrum analysis of the stars, ii. 362.

Vogt, Karl, materialistic works of, i. 60 ; vertebral theory of the skull, ii. 251 ; 'Bilder aus dem Thierleben,' 323; 107 ; 'Physiologische Briefe,' $469 ; 503$.

Volkmann, W., psychologist, ii. 494, 497.

Volney, history at the École normale, i. 112.

Volta, electric pile, i. 83, ii. 104; dis. coreries of, i. 363 , ii. 150 ; animal electricity, 475 .

Voltaire imported new ideas into France froin England, i. 16 ; century of, 59 ; reflects the thought of the eighteenth century, 61 ; an essayist and man of the world, 93 ; popularised the ideas of Newton, 96 ; importance in French literature of, 105 ; on the progress of the philosophical spirit in France, ib.; influenced by Newton and Descartes, 106 ; coustructive work influenced by, 110; philosophical and philanthropic influence of, $111 ; 123$; 'Siècle de Louis XIV.,' 135; 142; 'Élémens de la Philosophie de Newton,' 144; 'Lettres sur les Anglais,' ib.; created Newtonianism, 250 ; correspondence of, 279 ; the cure of smallpox, 2s4; quoted on the Cartesian and Newtonian philosophies, 340 , ii. 324.

Vortex, motion, i. 199, ii. 35 ; earlier researches, 61 ; filaments, $i b$.; theory developed in England, 62; ring theory, difficulties of 64 ; atom theory, Helmholtz and Thomson, $5 \pi$, 66.

Voss, A., on principles of calculus, quoted, ii. 706 .

Voss, J. H., hexameters, i. 213.
Vries, de, labours of, ii. 165 ; "muta. tion," 304.

Waage, Guldberg and law of massaction, ii. $15 \%$; ideas of Berthollet, 177.

Waals, von der, researches of, ii. 164.

Wagner, A., on freewill, ii. 584.

Wagner, Rudolf, 'Physiological Letters,' ii. 323; 'Handwörterbuch der Physiologie,' 401, 501 ; controversy with Karl Yogt, 469.

Waitz, psychology, ii. 497,530 .

Wald, F., 'Die Energie und ihre Entwerthung,' ii. 169.

Wallace, Alfred Pussel, i. 179; 'Introduction of New Species,' 310; ii. 327,329 ; 'Darwinism,' 330, 339 ; "Struggle for Existence," 332, 333 ; Darwin, 341 ; sexual selection, 343 ; 351 ; quoted, 365 ; 546 ; variation in nature, $608 ; 621$.

Wallis, Dr, quoted in 'History of the Royal Society,' i. 227.

Walther, $\mathrm{Ph}$. von, physiological method in medicine, ii. 388 .

Walton, Izaak, i. 285.

Wand (see Clausius), ii. 135.

Wappäus, statistics, ii. 563.

Ward, James, 'Naturalism and Agnosticism,' ii. 18S, 519; modern psychol. ogy, 522, 523; quoted, 606.

Ward, T. H., 'Reign of Queen Victoria,' i. 310 .

Wardlaw, Bishop, founded University of St Andrews, i. 268.

Wardrop, ii. 505.

Waring, Ed., of Cambridge, quoted, i. 234 ; ii. 658.

Warnkönig, Prof., of Liège, translation of Gibbon's 'Poman Empire,' i. 169.

Waterston, J. J., meteoric theory of the sun's heat, ii. 358 .

Watson, Hewett Cottrell, 'Cybele Britannica,' ii. 335 ; 595.

Watt, James, an inventor with scien. titic training, i. 91 ; not member of any university, 238; definitious of horse-power and work, 310 ; use of term "horse - power," ii. 99, 156 ; technical mechanics, 101; (see Zeuner), 134 : heat measurement, 156.

Wattenbach, W., 'Zum Andenken Lessings,'i, 169 .

Weber Brothers, theory of elasticity, ii. 31 ; biological studies, 208 ; experimental research, 396 ; psycho-physical in restigations, 492. 
Weber, Eduard, i. 196, 519.

Weber, Ernst Heinrich, i. 196; school of, 200 ; law of sensation, $i b$.; "science of life," ii. 396; 402; psycho - physical phenomena, 496; 500 ; psycho-physics of vision, 501 ; 508 ; "touch and bodily feeling," 509 ; psycho-physics, 517, 519.

Weber, H., biographical notice of Wilhelm Weber, i. 304.

Weber, Heinrich, his treatise on algebra, ii. 729,730 .

Weber, Wilhelm, of Güttingen and Gauss, telegraph, i. 92; quoted, $171,172,196,199,211$; 'Electrodynamische Maasbestimmungen,' 265, 303: 365; absolute measurements, 309,323 , ii. 117 ; perfected Coulomb's methods, i. 360 ; astronomical view of nature, 366 ; electrical researches of, 367,365 , 369 ; quoted, 370,373 ; measurements of, $37 \mathrm{l}$, ii. 149 ; importance of his labours, i. 384; law of, ii, $67 ; 76$; electro-magnetic measurements, $78 ; 79$; statical and current electricity, 84 ; theory of, 87 ; researches, 92 ; 97 : electric measurements, 143; electrical phenomena, 146; influences Helmholtz, 150; theory of electro-dynamic phenomena, 151 ; electrical theory of, 153 ; atomic view of nature, 188; Helmholtz quoted, 189; 191, 192; electric particles, 197.

Webster, Daniel, the term "statist," ii. 555.

Webster, Thos., palæontological work of, i. 139.

Wegele, 'Gesch. d. deutschen Historiographie,' i. 206 , ii. 555 .

Weidmann, editions of the ancient classics, i. 167.

Weierstrass, ii. 630 ; Poincaré on, 638, 703 ; and Lagrange, 693; his theory of functions, 694 ; his pure analysis, 702 ; genesis of his ideas, 703 ; Lampe on, $i b$. ; on non-differentiable functions, 705; 706; and Piemann compared, 707; on Piemann, 708; his letter to Schwarz, ib.; proves Gauss's statements, $726 ; 733$.

Weight and mass, i. 336 .

Weis, Samuel Christian, mentioned by Verdet, ii. 41.

Weismann, A., 'Essays upon Heredity,' ii. 372 ; idioplasma theory, 448, 611; on heredity, 450 ; on pangenesis, 455 ; theory of evolution, it.; "On the Duration of Life," 457 ; "Essays on
Descent and IIeredity,' 459 ; versus Lamarck, 460.

Weissbach, influenced by Poncelet, ii. 101.

Weisse, Chr. H., influence on Lotze, ii. $500 ; 508$.

Weld, 'History of the Royal Society,' i. $90,127,227,228,253$; quoted on the publication of the 'Principia,' 98.

Weldon, W. F. R., on crabs, ii. 621 ; on Pearson's methods, 623.

Wells, 'Essay on Dew,' i. 230 ; 'Two Essays upon Dew and Single Vision,' ii. $334 ; 347$.

Werner, A. G., Freiberg Hining Academy, i. 17 ; school of geology of, 116; Cuvier on, 118 ; 155 ; connection of, with modern science, 175 ; scientific strife with Hutton, 283; 290 ; study of fossil remains, ii. $225 ; 266$; and Hutton, 291 ; describes mineral character of rocks, 294.

Wernicke, language, ii. 539.

Wessel, Caspar, on imaginaries, ii. 653.

Weyrauch, Jacob J., 'Kleinere Schriften und Briefe von Robert Mayer,' ii. 97, 108.

Wheatstone and Cooke, first telegraph lines, i. 303.

Wheatstone, Ohm's law, i. 365; quoted, 366 ; stereoscope, ii. 456, $505 ; 506$.

Whewell, Wm., on relations of the sciences, i. 37 ; identification of thought with philosophy, 62 ; 'Writings and Correspondence,' 91; crystallography, 117; 236 ; quoted, ib.; his influence, 261; "History of the Inductive Sciences,' $262,277,306,365$; 270 ; Analytical Society, 271 ; 'History of the Inductive Sciences' quoted, 291, 292, ii. 12; influenced by Kant, i. 307 ; origin and variation of suecies, 310 ; Arogadro's hypothesis not mentioned by him, 428; the final establishment of the undulatory theory, ii. 26 ; 'Philosophy of the Inductive Sciences,' 205 ; his divisions abancloned, 210 ; quotation from Linnats, 220 ; account of vertebral theory, 251 ; 268; the study of functions; 269 ; 318 : Bridgewater 'I'reatise, 325 , 327 ; Bacon's "method of instances," 558.

Whiston, on reluctance of Cambridge to accept theories of Newton, i. 270 .

White, Gilbert, of Selborne, i. 179;

'Natural History' of Selborne,' 286; 
nature lover, 287 ; 288; biographical, 289 ; quoterl, 290.

Whitehead, A. N., his 'Universal Algebra,' ii. 641; 656, 737.

Whittaker, Thos, on "cyclical" view, i. 286.

Wichern, J. H., follower of Pestalozzi, ii. 258 .

Wiechert, E., 'Grundlagen der Elektrodynamik,' ii. 193, 197.

Wiedemann, Georg, 'Die Electricität,' i. 370; 'Annalen,' ii. 186; on Helm. holtz, 410 .

Wien, W., electro-dynamic view of etler, ii. 195.

Wigand, A., Darwin, Newton, and Cuvier compared, ii. 341 .

Wilberforce, William, associated with Rumford's philanthropic schemes, i. 249.

Will, H., text-books of, i. 188.

William IV. of Hesse, astronomer, $i$. 157.

William the Conqueror, ii. 555.

Williamson, chemical researches of, $i$. 414; quoted, ii. 163.

Willis, "reflex action," i. 292.

Willoughby and Ray, botanical travels of, i. 283 ; 'Historia Piscium,' 283.

Wilson, E. B., 'The Cell in Develop. ment and lnheritance,' ii. 370,456 , 458.

Wilson, G. (see A. Geikie), i. 288.

Winckelmann, classic style of, i. 51 ; 171 ; founder of archæology in Germany, 295.

Winkler, discovery of germanium, $i$. 315,423 .

Wiuter, W., "astronomical magnitudes," i. 323.

"Wisseuschaft," meaning and scope of the worl, i. 90, 168; evolution of the idea in German literature, 170; 202; combines the exact, historical, and critical methods of thought, 222 ; moral value of, 223.

"Wissenschaftslehre" of Fichte, i. 170.

Witt, John de, tables of mortality, ii. 565.

Wöhler, his works on chemistry, i. 43 ; prepares organic substances, 92, 191 ; ii. 440 ; i. 188 ; 194, 200 ; services to chemistry, 208; "vital force," 218 ; discovery of "isomerism," 406 ; 412,414; uric acid and its derivatives, ii. 393 ; vitalist, 405 .

Wolf, C., 'Les Hypothèses Cosmogoniques,' ii. 282.

Wolf, F. A., indebtedness to Bentley, i. 169 ; 171 ; philology, 203 ; 212, 214 ; evolved the science of antiquity from vaguer beginnings, 220 ; classical learning of, 222 ; educational ideal differs from that of Pestalozzi, 258; 263,261 ; ii. 538.

Wolf, R., 'Geschichte der Astronomie,' i. $54,157,167,171,177,277,328$; 'Handbuch der Astronomie,' 319, 324 , ii. $282,358,362$.

Wolff, Caspar Friedrich, used the term "cell," i. 195; anticipated Goethe, ii. 212 ; metamorphosis, 267 ; "epigenesis," 278, 299 ; 'Theoria generationis,'298; 494.

Wolff, Christian, philosophy of, i. 212 ; astronomical formula of, 422 ; ii. 563 .

Wollaston, scientific discoveries of, $i$. 229,230 ; not member of any university, 238; contributions to the atomic theory, $245 ; 272$; prophecy of, 397,450 ; his attitude towards Dalton's views, 417; experiments supporting undulatory theory of light, ii. 19, 45 ; Fraunhofer's lines, 47 .

Words, new, and new thoughts, i. 23 .

Wordsworth, his visit to Germany, i. 17 ; influence of, on taste, 67 ; freshness of individual thought of, 76 ; healthy spirit of, $78 ; 179,285$; a friend of Wm. Pearson, 289.

Work, the term introduced by Clausius, ii. 115 .

World, outer and inner, how related, i. 5.

Wright, Ed., length of a degree, i. 97.

Wright, Thos., of Durham, cosmical theories, ii. 282.

Wunderiich, medical thermometry, ii. 389.

Wundt, Wilh., Fechner's work continued by, i. $200 ; 220$; animal electricity, ii. 475 ; physiognomy, 477 ; 'Physiologische Psychologie,' 479, 490, 519, 520, 521 ; "specitic energies," 483; influence of Herbart, $494 ; 497,508$, 510, 512 ; 'System der Philosophie,' 513 ; 514, 515; consciousness, 516; 517 ; psychology, 525; 526.

Wurtz, A., quoted, i. 114 ; 'La Théorie atomique' quoted, $394,421,427$, 429 ; on Dalton, 398 ; 413.

'Xenien' of Schiller and Goethe, i. 84.

Young, Dr Thos., the undulatory theory of light, i. 83,229 , ii. 16 , 36 ; light and hieroglyphies, i. 236 ; 
not a member of a nniversity, 238, 272 ; and Fresnel, 241 ; inadequate a)preciation of, $243,244,277 ; 246$; lecturer at the Royal Institution, 249, 264; recognition of, by French scientists, 251 ; quoted on universities, 261; not connected with the Mathematical School of Cambridge, $266 ; 294$; dynamical view of light, 370 ; revival of kinetic view of nature, ii. 8 ; Euler's ether theory, 9; 'Ont. lines of Experiments and Inquiries respecting sound and Light,' 17; quoted, $i b ., 20$; interference of light, 18; accuracy of Newton's experiments, 19 ; methods of Laplace, 20 ; "interference," 21; polarisation of light, 22 ; rejects projectile theory of light, $i b . ;$ quoted on Malus's discovery of polarisation of light by reflection, 23 ; 24 ; memoir of, 26 ; 'Works' quoted, 27 ; trausverse vibrations of light, 28 ; futility of astronomical view of nature, 28 ; theory of elas. ticity, 30 ; theory of capillarity, 33 ; nature of the ether, 40,43 ; analogy of optical and acoustical phenomena, 50 ; "luminiferous ether," 69, 70, 89 ; "elastic medium" in space, 84 ; referred to, $86,91,95$; first used the term "energy," 98,115 ; his work theoretical, 99 ; value of one horsepower, 99; 'Lectures,' 102 ; theory of heat, 103 et seq.; lieat a form of motion, 104; undulatory theory, 180 ; 341, 344; (see Sir Norman Lockyer), 361 ; colour tlicory, 480 ; 'Essay on Music,' 489.

Zach, von, 'Monatliche Correspondenz,' i. 41 ; 54 ; first international organ for astronomical observations, 167 ; astronomical achievements, 175 ; liographical, $177 ; 182 ; 422$.

Zeemann, magnetism and light, ii. 197.

Zeiss, Carl, improvements in the microscope, ii. 229.

Zeller, E., i. 162; 'Philosophie der Griechen,' ii. 3, 207 ; quoted, 286.

Zeno, unity of all existence, ii. 3 ; 286.

Zeuner, the steam-engine, ii. 133 ; controversy with Hirn, 135 ; (see Clansius), $i b$.; lieat engines, $175 ; 185$; statistics, 566 .

Ziegler, 'Doctrine of Descent,' ii. 349.

Zittel, A. von, 'Gesch. der Geologie,' ii. 212.

Zöllner, F., historical and controversial writings, ii. 107; Poggendorf and Mayer's NS., 114; speculations of, 192; 'Wissenschaftliche Abhand. lungen,' 716 .

Zschokke, H., educational influence of, in Germany, i. $25 \bar{i}$.

Zwingli, educational work of, i. 255. 





\section{PLEASE DO NOT REMOVE}

CARDS OR SLIPS FROM THIS POCKET

UNIVERSITY OF TORONTO LIBRARY 
